\title{
Water Resources Data lowa Water Year 1985
}

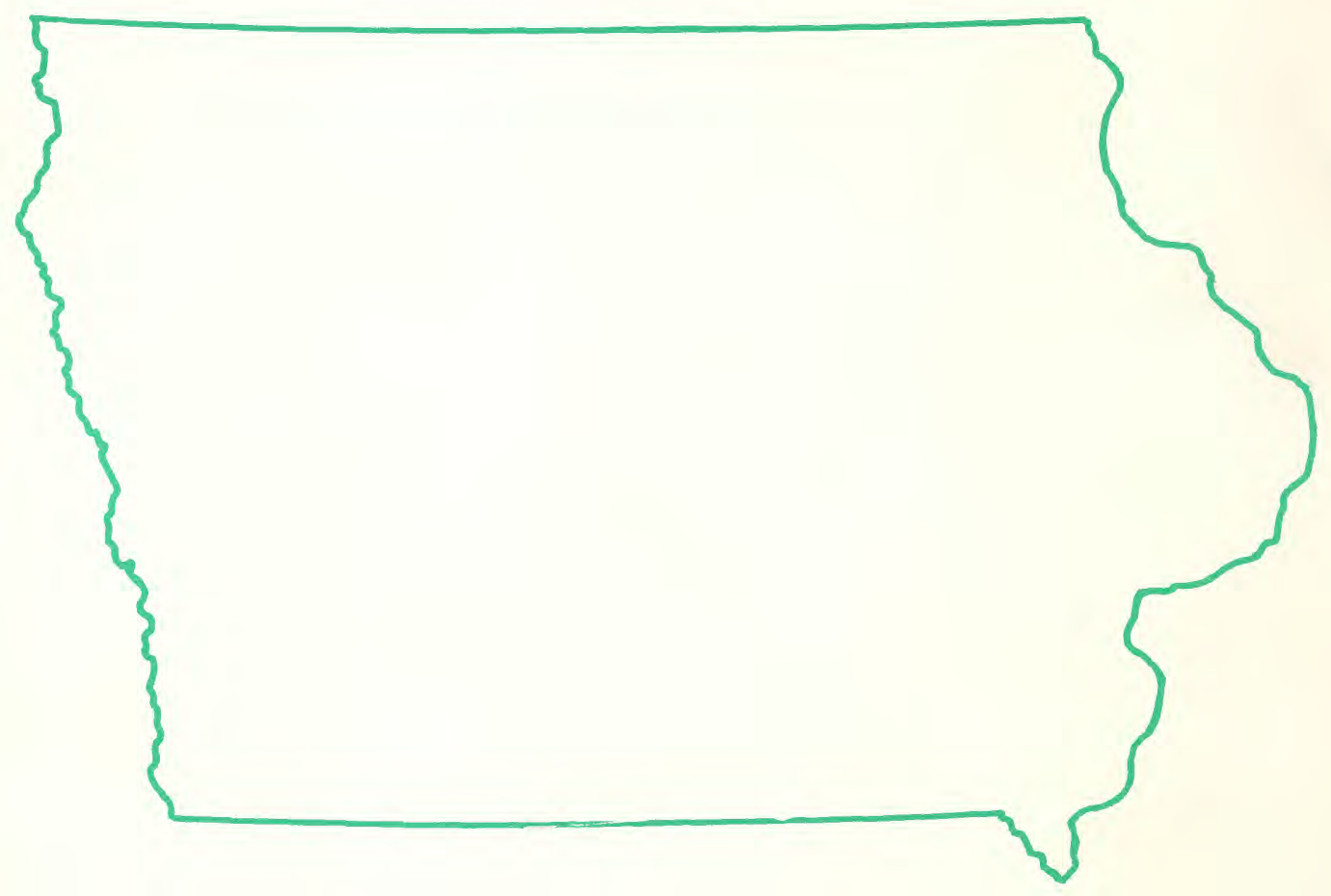

U.S. GEOLOGICAL SURVEY WATER DATA REPORT IA-85-1

Prepared in cooperation with the lowa Geological Survey and with other State and Federal agencies 
CALENDAR FOR WATER YEAR 1985

\begin{tabular}{|c|c|c|c|c|c|c|c|c|c|c|c|c|c|c|c|c|c|c|}
\hline \multicolumn{19}{|c|}{1984} \\
\hline & 0 & C T 0 & $B E R$ & & & NO & $V$ & $E M$ & $B$ & $E R$ & & & $D E$ & $E C$ & $E M$ & $4 B$ & $E R$ & \\
\hline \multirow[t]{2}{*}{$S$} & $M$ & $T W$ & T $F$ & $S$ & $S$ & $M$ & $T$ & W & $T$ & $F$ & $S$ & $S$ & M & $\mathrm{T}$ & $W$ & $\mathrm{~T}$ & $F$ & $S$ \\
\hline & 1 & 23 & 45 & 6 & & & & & & 2 & 3 & & & & & & & 1 \\
\hline 7 & 8 & 910 & 1112 & 13 & 4 & 5 & 6 & 7 & 8 & 9 & 10 & 2 & 3 & 4 & 5 & 6 & 7 & 8 \\
\hline 14 & 15 & 1617 & 1819 & 20 & 11 & 12 & 13 & $14]$ & 15 & 16 & 17 & 9 & 10 & 11 & 12 & 13 & 14 & 15 \\
\hline 21 & 22 & 2324 & 2526 & 27 & 18 & 19 & 20 & 212 & 22 & 23 & 24 & 16 & 17 & 18 & 19 & 20 & 21 & 22 \\
\hline 28 & 29 & 3031 & & & 25 & 26 & 27 & 282 & 29 & 30 & & $\begin{array}{l}23 \\
30\end{array}$ & $\begin{array}{l}24 \\
31\end{array}$ & 25 & 26 & 27 & 28 & 29 \\
\hline
\end{tabular}

1985

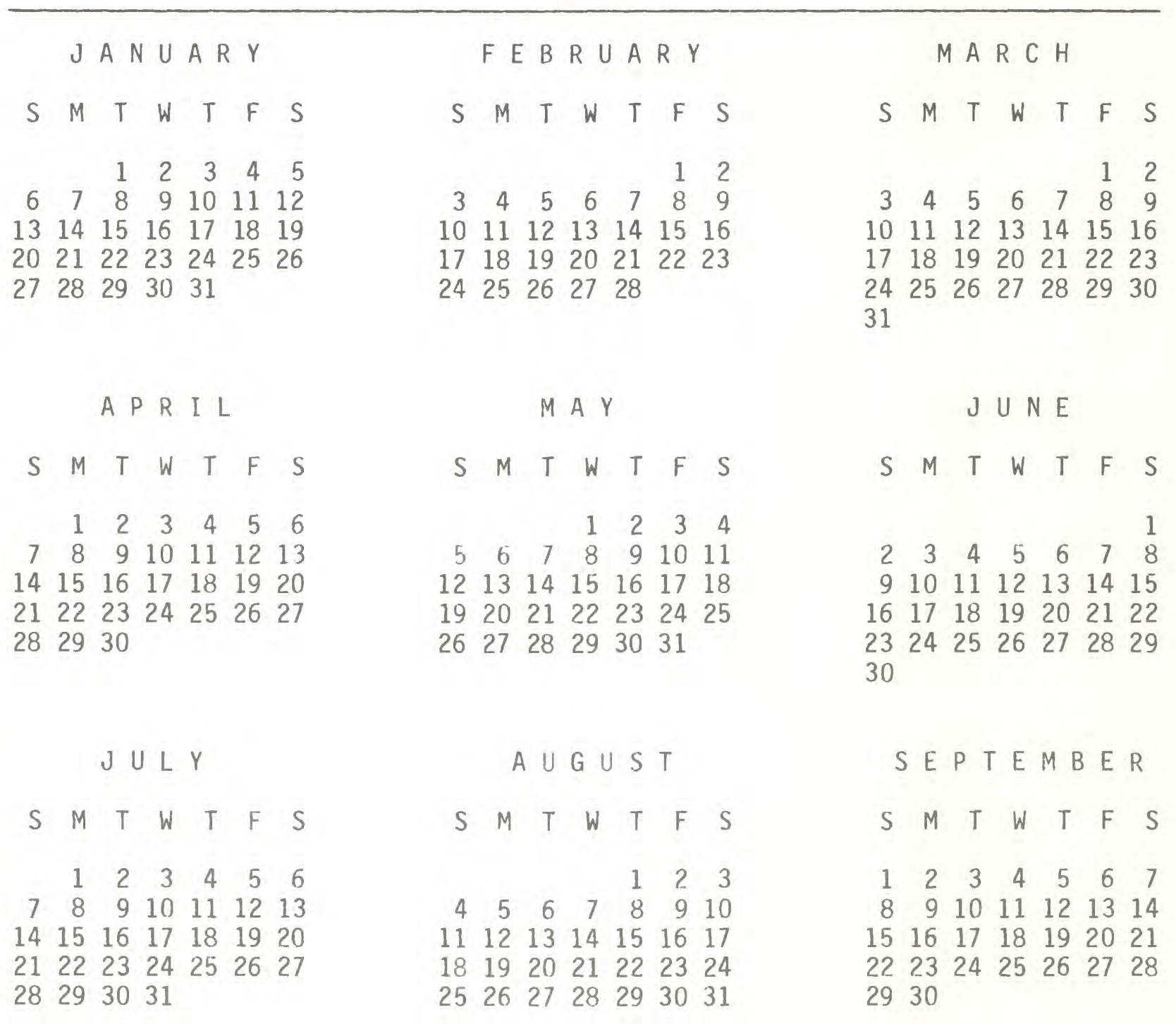




\section{Water Resources Data}

lowa

\section{Water Year 1985}

by N.B. Melcher, M.G. Detroy, W.J. Matthes, and R.E. Hansen

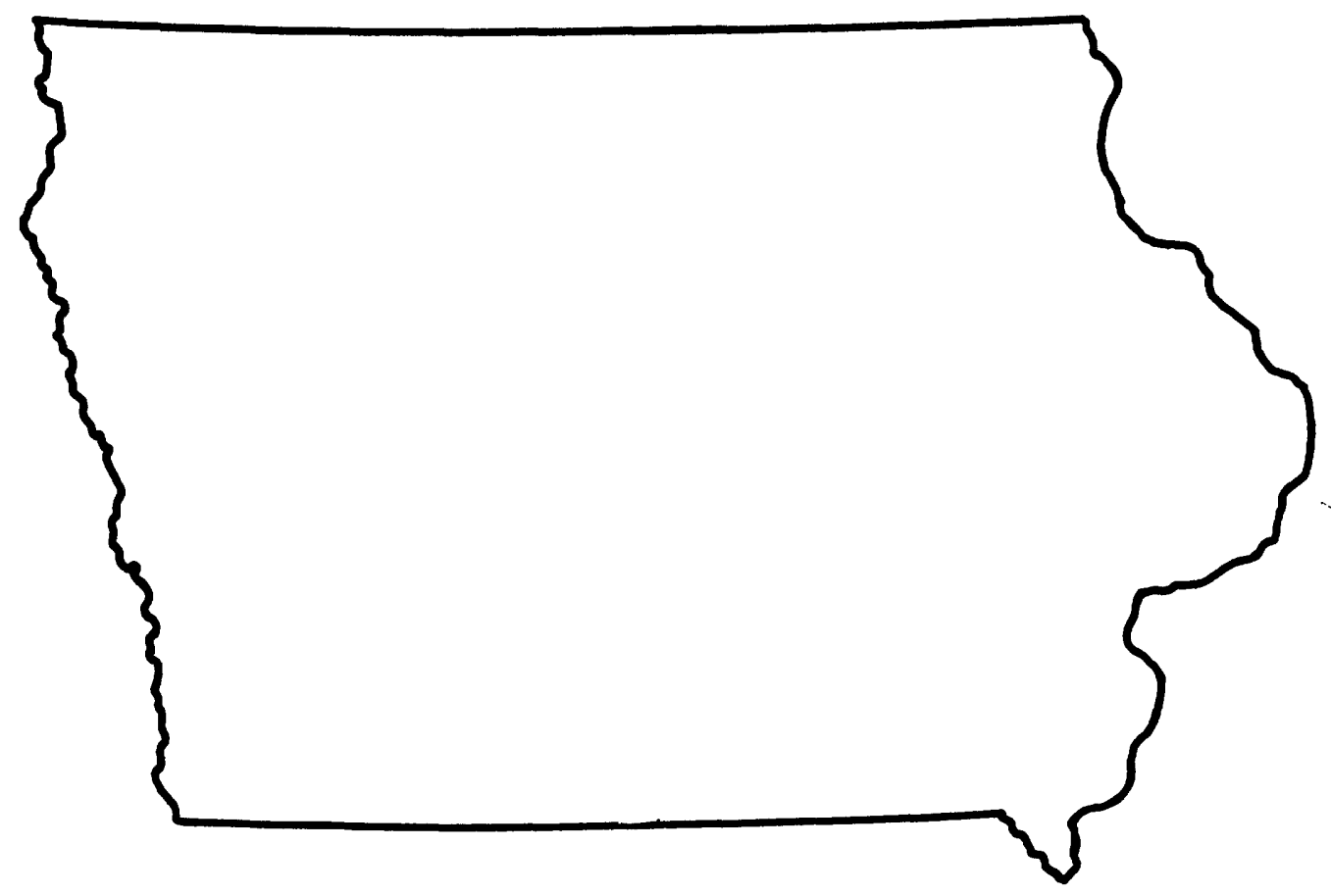

U.S. GEOLOGICAL SURVEY WATER-DATA REPORT IA-85-1

Prepared in cooperation with the lowa Geological

Survey and with other State and Federal agencies 


\author{
UNITED STATES DEPARTMENT OF THE INTERIOR \\ DONALD PAUL HODEL, Secretary \\ GEOLOGICAL SURVEY \\ Dallas L. Peck, Director
}

For information on the water program in Iowa write to

District Chief, Water Resources Division

U.S. Geological Survey

P.O. Box 1230

Iowa City, Iowa 52244 
This report of Iowa is one of a series of annual reports that document hydrologic data gathered from the U.S. Geological survey's surface-water and ground-water data-collection networks in each State, Puerto Rico, and the Trust Territories. These records of streamflow, ground-water levels, and quality of water provide the hydrologic information needed by state, local, and Federal agencies, and the private sector for developing and managing our Nation's land and water resources.

This report is the culmination of a concerted effort by dedicated personnel of the U.S. Geological survey who collected, compiled, analyzed, verified, and organized the data, and who typed, edited, and assembled the report. The authors had primary responsiblity for assuring that the information contained herein is accurate, complete, and adheres to Geological survey policy and established guidelines. Most of the data were collected, computed, and processed from area field offices. Personnel in charge of the field offices are:

Robert W. Baebenroth, Council Bluffs Field Headquarters

Von E. Miller, Iowa City Field Headquarters

Alvin R. Conkling, Ft. Dodge Field Headguarters

The data were collected, computed, and processed by the following personnel:

$\begin{array}{lll}\text { L.R. Amspoker } & \text { C.J. Anderson } & \text { A.R. Conkling } \\ \text { D.T. Conell } & \text { N.F. Fish } & \text { R.D. Goodrich } \\ \text { J.G. Gorman } & \text { L.E Hotka } & \text { R.A. Rarsten } \\ \text { R.L. Kopish } & \text { D.W. Rolpin } & \text { P.D. Lustgraaf } \\ \text { G.D. Lyke } & \text { C.L. Schnell } & \text { J.R. Sondag } \\ \text { J.J. Wellman } & & \end{array}$

This report was prepared in cooperation with the State of Iowa and with other agencies under the general supervision of J.M. Klein, District Chief, Iowa. 


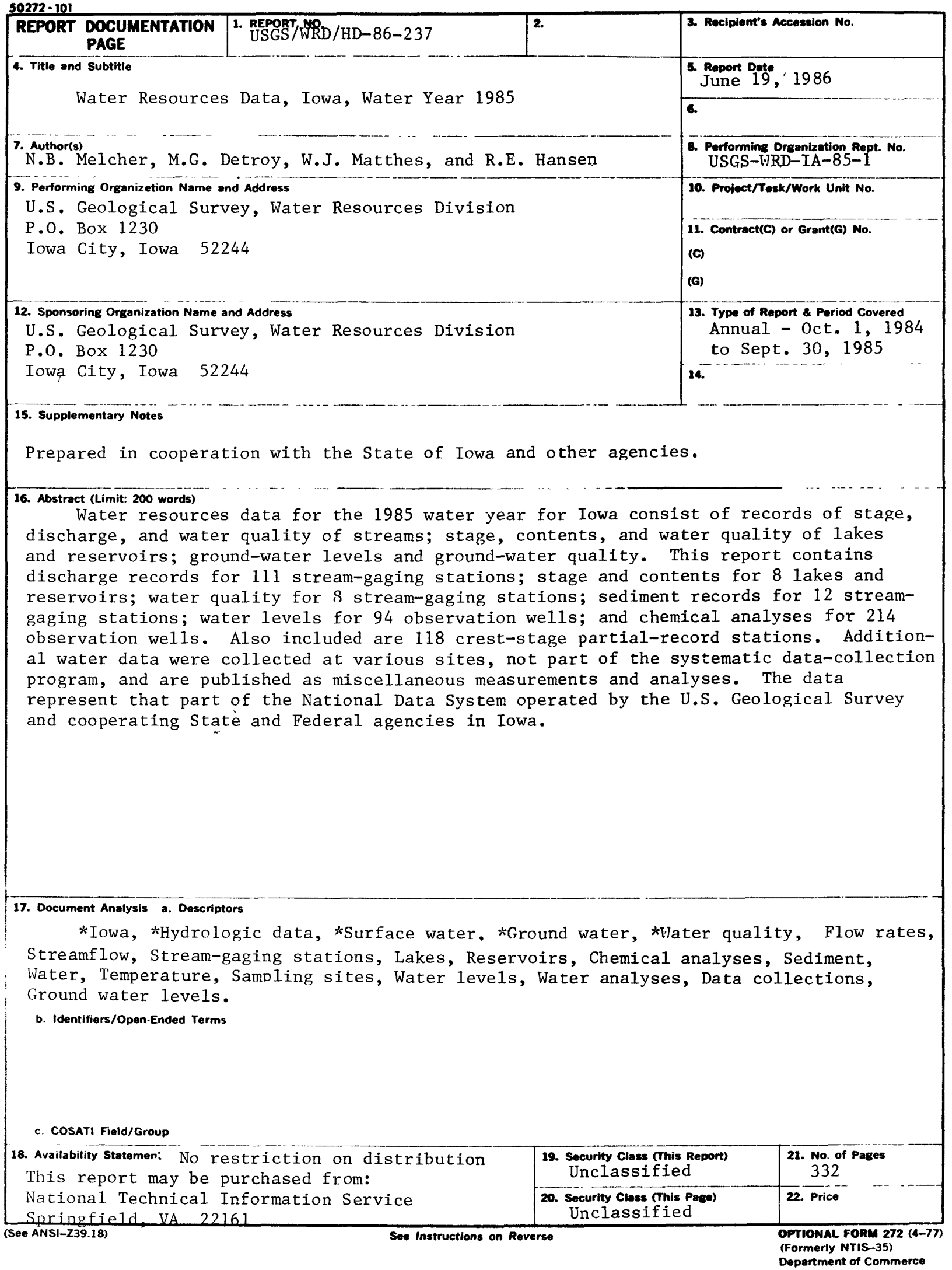


Preface...................................... III

List of gaging stations, in downstream order,

for which records are published.................... VIII

List of ground water wells, by county, for which

records are published........................... XII

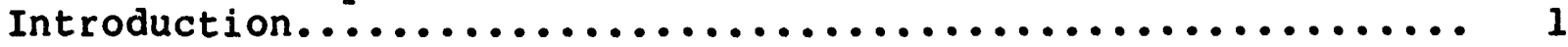

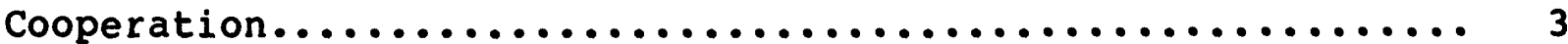

Summary of hydrologic conditions.................... 5

Surface water.................................. 5

Suspended sediment.............................. 6

Surface water-guality............................. 6

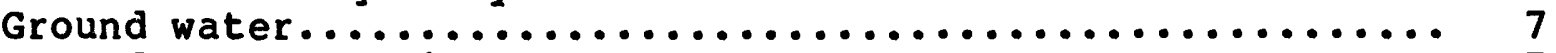

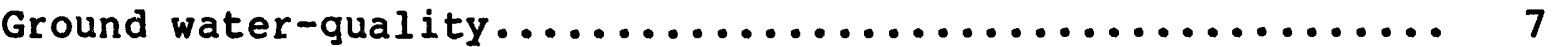

special networks and programs........................ 14

station identification numbers....................... 15

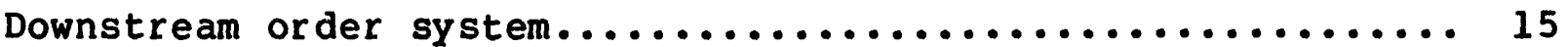

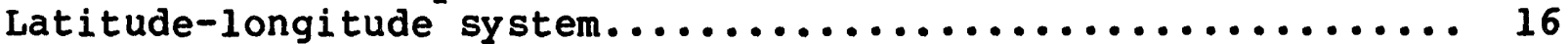

Records of stage and water discharge................... 18

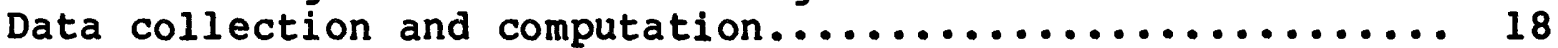

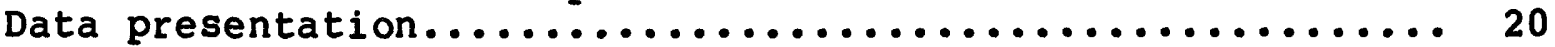

Identifying estimated daily discharge................. 24

Accuracy of the records............................ 24

other records available............................ 25

Records of surface-water quality..................... 26

Classification of records......................... 26

Arrangement of records............................. 26

On-site measurements and sample collection.............. 27

Water temperature and specific conductance.............. 28

Sediment...................................... 28

Laboratory measurements........................... 29

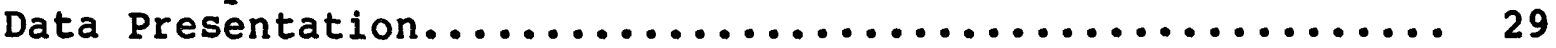

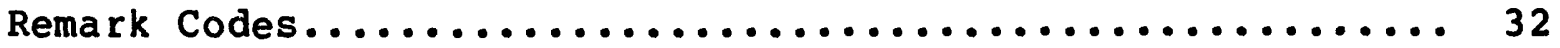

Records of ground-water levels....................... 33

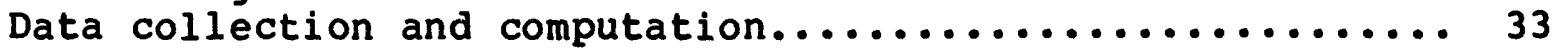

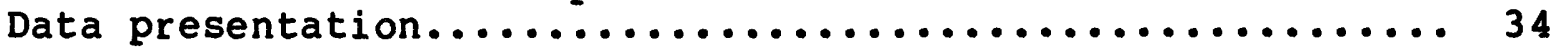

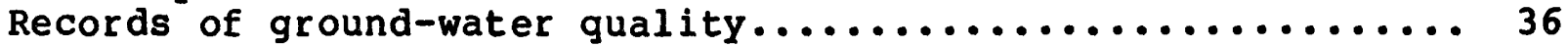

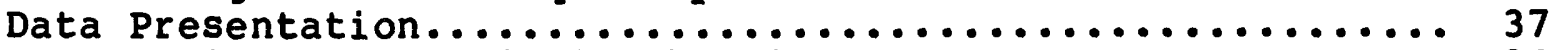

Explanation of descriptive headings................. 38

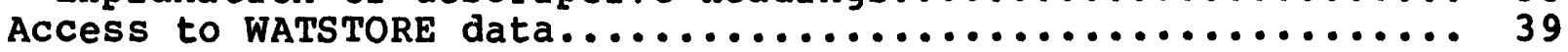

Definition of terms............................. 43

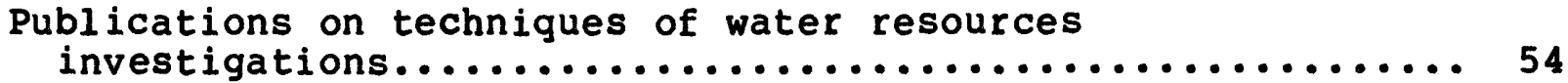

Discontinued gaging stations........................ 55

Discontinued water-quality stations.................. 56

Gaging station records........................... 57

Discharge at partial-record stations and

miscellaneous sites............................. 233 
Crest-stage partial-record stations................... 233

Miscellaneous water-quality data.....................241

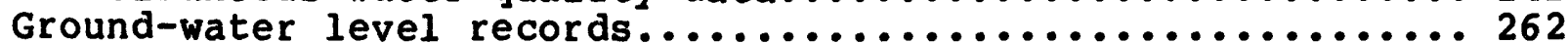

Ground water-quality data........................... 298

Precipitation water-quality data.................... 326

Index........................................... 330 


\section{ILLUSTRATIONS}

Figure 1. Graph showing state average precipitation during the 1985 water year compared to normal annual precipitation

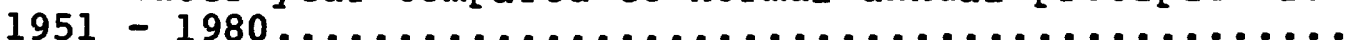

Figure 2. Graph showing daily mean discharge for the 1985 water year compared with mean monthly discharges for water years 1951 - 1980 for three representative stations.... 9

Figure 3. Graph showing comparison of dissolved-solids and nitrate concentrations for the 1985 water year with mean monthly values at the NASQAN station, the Mississippi River

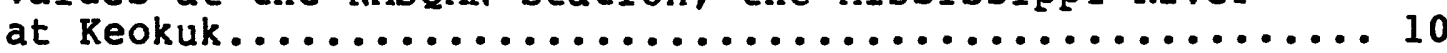

Figure 4. Graph showing comparison of dissolved-solids and nitrate concentrations for the 1985 water year with mean monthly values at the NASQAN station, the Iowa River at wapello................................ 11

Figure 5. Graph showing comparison of dissolved-solids and nitrate concentrations for the 1985 water year with mean monthly values at the NASQAN station, the Missouri River at sioux city............................... 12

Figure 6. Graph showing monthly water levels during the 1985 water year compared to the average monthly level

for the period of record........................13

Figure 7. Latitude-longitude well number.................. 16

Figure 8. Local well-numbering system for well 96-20-3CDBD1...... 17

Figure 9. Map showing location of continuous-record gaging stations in lowa............................ 40

Figure 10. Map showing location of water-quality stations in Iowa.. 41 Figure 11. Map showing location of observation wells in Iowa.....4 42

TABLES

- - - -

Table 1. Runoff at streamflow stations representing all major river basins in Iowa. 
[Letter after station name designates type of data:

(d) discharge, (c) chemical, (m) microbiological,

(t) water temperature (s) sediment]

UPPER MISSISSIPPI RIVER BASIN

Page

Mississippi River:

UPPER IOWA RIVER BASIN

Upper Iowa River near Dorchester (d) .................. 57

Mississippi River at McGregor (dcts)................. 58

TURKEY RIVER BASIN

Turkey River at Spillville (d)..................... 62

Turkey River at Garber (d) ........................ 63

MAQUOKETA RIVER BASIN

Maquoketa River:

North Fork Maquoketa River at Fulton (d)............. 64

Maguoketa River near Maguoketa (d)................. 65

Mississippi River at Clinton (dcmts)................. 66

WAPSIPINICON RIVER BASIN

Wapsipinicon River near Elma $(d) \ldots \ldots \ldots \ldots \ldots \ldots \ldots \ldots \ldots \ldots$

Wapsipinicon River at Independence (d) ............... 71

Wapsipinicon River near De witt (d).................. 72

CROW CREEK BASIN

Crow Creek at Bettendorf (d)..................... 73

IOWA RIVER BASIN

Iowa River:

East Branch Iowa River near Klemme (d).............. 74

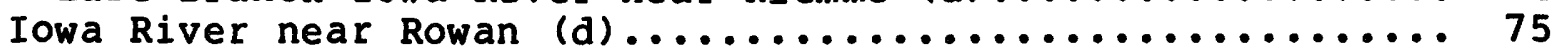

lowa River at Marshalltown (d) .................... 76

Timber Creek near Marshalltown (d)................ 77

Richland Creek near Haven (d) ..................... 78

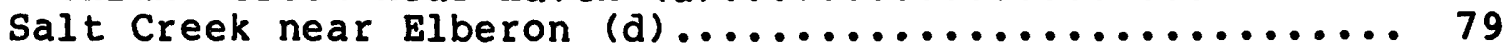

Walnut Creek near Hartwick (d) ...................... 80

Big Bear Creek at Ladora (d) ...................... 81

Iowa River at Marengo (d) ......................... 82

Coralville Lake near Coralville ................... 83

Iowa River:

Rapid Creek near Iowa City (d).................... 84

Clear Creek near Coralville (d).................... 85

Iowa River at Iowa City (dcts).................... 86

Ralston Creek at Iowa City (dcts).................. 91

South Branch Ralston Creek at Iowa City (d) .......... 95

old Mans Creek near Iowa City...................... 96

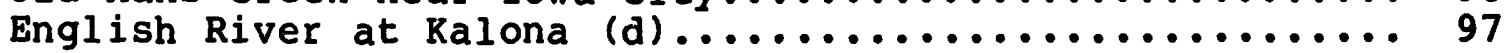

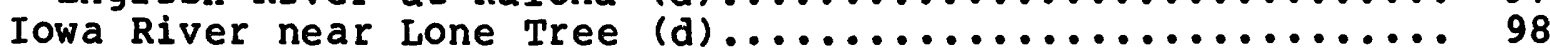

Cedar River at Charles City (d)..................... 99

Little Cedar River near Ionia (d).................. 100 
UPPER MISSISSIPPI RIVER BASIN--Continued IOWA RIVER BASIN--Continued

Cedar River at Janesville (d) ..................... 101

West Fork Cedar River at Finchford (d) .............. 102

Shell Rock River near Northwood (d) ................ 103

Winnebago River at Mason City (d) ................ 104 Willow Creek:

Clear Creek:

Cedar River:

Clear Lake at Clear Lake ................ 105

Shell Rock River at Shell Rock (d).............. 106

Beaver Creek at New Hartford (d)................. 107

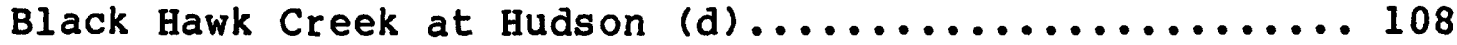

Cedar River at Waterloo (d)........................ 109

Cedar River at Cedar Rapids (d).................... 110

Cedar River near Conesville (d) ......................

Iowa River at Wapello (dcmts) ....................... 112

SKUNK RIVER BASIN

South Skunk River (head of Skunk River) near Ames (d)..... 116

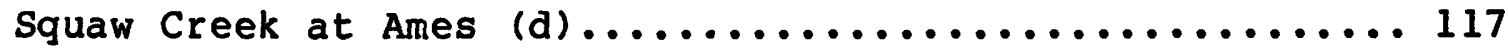

South Skunk River near Oskaloosa (d) ..................... 118

North Skunk River near Sigourney (d) ................... 119

Cedar Creek near Oakland Mills (d) .................. 120

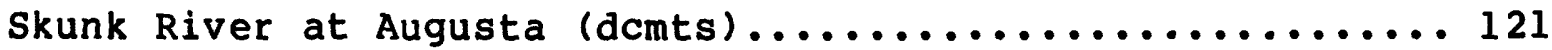

Mississippi River at Keokuk (dcmts)................. 127

DES MOINES RIVER BASIN

Des Moines River at Estherville (d)................. 130

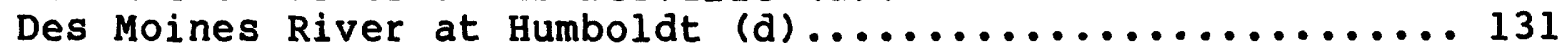

East Fork Des Moines River at Dakota City (d).......... 132

Des Moines River at Fort Dodge (d).................. 133

Boone River near Webster City (d) ................... 134

Des Moines River near stratford (d) ................... 135

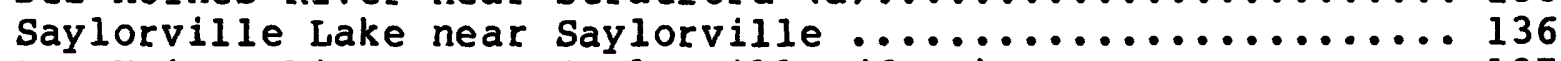

Des Moines River near Saylorville (dcts) .............. 137

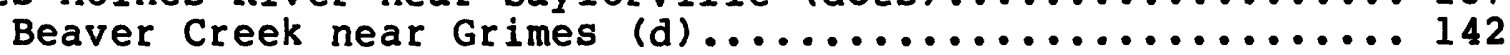

North Raccoon River (head of Raccoon River):

North Raccoon River near Newell (d) ............... 143

Cedar Creek:

Big Cedar Creek near Varina (d)................ 144

North Raccoon River near Sac City (d) ..................... 145

Indian Creek:

Wall Lake outlet:

Blackhawk Lake near Lake view.............. 146 
UPPER MISSISSIPPI RIVER BASIN--Continued

DES MOINES RIVER BASIN--Continued

North Raccoon River near Jefferson (d) ............... 147

Hardin Creek:

East Fork Hardin Creek near Churdan (d)........... 148

South Raccoon River:

Middle Raccoon River near Bayard (dcts)........... 149

Lake Panorama at Panora....................... 154

Middle Raccoon River at Panora (dats)............. 155

South Raccoon River at Redfield (d)................ 160

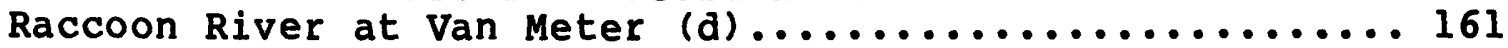

Walnut Creek at Des Moines (d).................... 162

Des Moines River below Raccoon River at Des Moines (d) .... 163

Fourmile Creek at Des Moines (d).................... 164

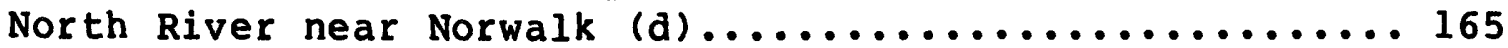

Middle River near Indianola (d).................. 166

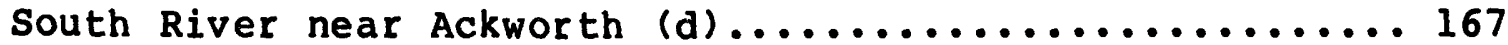

White Breast Creek near Dallas (d).................. 168

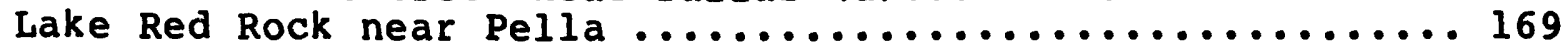

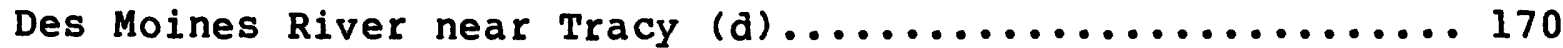

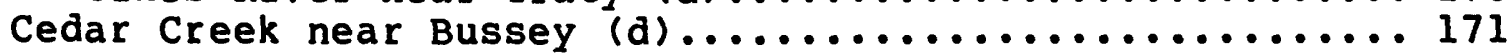

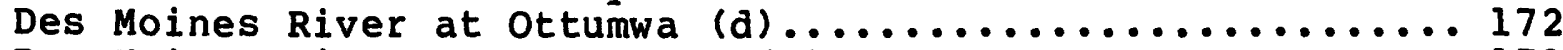

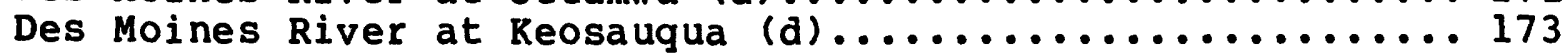

MISSOURI RIVER BASIN

Missouri River:

BIG SIOUX RIVER BASIN

Big Sioux River:

Rock River near Rock valley (d) .................... 174

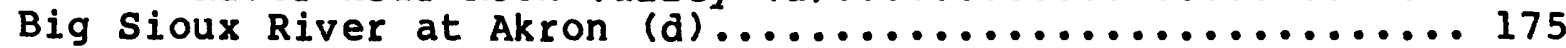

Missouri River at Sioux City (demts).................. 176

PERRY CREEK BASIN

Perry Creek at 38 th street, Sioux City (d)............. 182

FLOYD RIVER BASIN

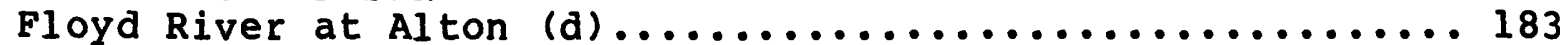

West Branch Floyd River near struble (d) ............. 184

Floyd River at James (d) .......................... 185

MONONA-HARRISON DITCH BASIN

West Fork ditch (head of Monana-Harrison ditch)

at Hornick (d) ............................... 186

Monona-Harrison ditch near Turin (d) ................. 187

LITTLE SIOUX RIVER BASIN

Little Sioux River:

Milfora Creek:

West Okoboji Lake at Lakeside Laboratory near Milford. 188

Ocheyedan River near Spencer (d).................... 189

Little Sioux River at Linn Grove (d).................. 190

Little Sioux River at Correctionville (d).............. 191

Maple River at Mapleton (d) ....................... 192

Little sioux River near Turin (d) ..................... 193

SOLDIER RIVER BASIN

Soldier River at Pisgah (d). 
MISSOURI RIVER BASIN--Continued BOYER RIVER BASIN

Boyer River at Logan (d) ........................... 195

Missouri River at Omaha, Nebraska (dcmts) ................ 196

Missouri River at Nebraska City, Nebraska (ds)............ 202 NISHNABOTNA RIVER BASIN

West Nishnabotna River at Hancock (d) ................. 207

West Nishnabotna River at Randolph (d) .................. 208

East Nishnabotna River near Atlantic (d) .............. 209

East Nishnabotna River at Red Oak (d)................ 210

Nishnabotna River above Hamburg (dcmts) ................. 211 TARKIO RIVER BASIN

Tarkio River at Stanton (d)......................... 214

Missouri River at Rulo, Nebraska (d).................. 215 NODAWAY RIVER BASIN

Nodaway River at Clarinda (dcts).................... 216 PLATTE RIVER BASIN (Iowa-Missouri)

Platte River near Diagonal (d)..................... 221

One Hundred and Two River:

East Fork One Hundred and Two River near Bedford (d) ... 222 GRAND RIVER BASIN

Grand River:

Thompson River:

Elk Creek near Decatur City (dcmts)................ 223

Thompson River at Davis City $(\mathrm{d}) \ldots \ldots \ldots \ldots \ldots \ldots \ldots \ldots \ldots \ldots \ldots \ldots . \ldots 26$

Weldon River near Leon (d) ....................... 227

CHARITON RIVER BASIN

Chariton River near Chariton (d) ...................... 228

South Fork Chariton River near Promise City (d) ........ 229

Rathbun Lake near Rathbun ......................... 230

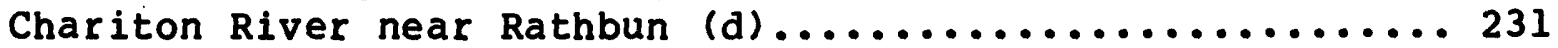

Chariton River near Moulton (d)..................... 232 
BENTON COUNTY

Well 420319N091540102

Well 420731N092083801

Well 420731 N092083802

Well 420731 N092083803

Well 421326 N091522701 BUENA VISTA COUNTY

Well 423646 N095020101

Well 423618N095194511

Well 424023 N095571401

Well 425233N094545001

\section{CALHOUN COUNTY}

Well 422846 N094375601 CARROLL COUNTY

Well 420335N094521501

Well 421058N094582701 CERRO GORDO COUNTY

Well 430806 N093164501

Well 430658N093281001 CHEROKEE COUNTY

Well 423833n095365701

Well 424348N095231601

Well 424348N095231602

Well 424132N095480211

Well 424802 N09531201

CLAYTON COUNTY

Well 424023N091291201

Well 424057N091320001

Well 430156N091182901

Well 425940N091194701 CRAWFORD COUNTY

We11 421031N095225611 DELAWARE COUNTY

Well 422029N091144302 DES MOINES COUNTY

Well 404844N09114270I

Well 404753N091142501 EMMET COUNTY

Well 432927 N09434550I GREENE COUNTY

Well 415449N094161501

Well 415449N094173201 GRUNDY COUNTY

Well $422605 \mathrm{N0} 92560001$ HARRISON COUNTY

Well 413838N095462001

Well 4l4955N096000601 HENRY COUNTY

Well 405810N091330502

Well 410848N091394801
Local number

Local number

Local number

Local number

Local number

Local number

Local number

Local number

Local number

Local number

Local number

Local number

Local number

Local number

Local number

Local number

Local number

Local number

Local number

Local number

Local number

Local number

Local number

Local number

Local number

Local number

Local number

Local number

Local number Local number

Local number

Local number Local number

Local number Local number
84-09-28 DBCC $2 \ldots \ldots \ldots \ldots \ldots 262$

85-11-33 CCBC1......... 263

85-11-33 СCBC2......... 264

85-11-33 ССВC3......... 265

86-09-34 AAADI......... 266

90-36-13 ADDA1 ......... 266

90-38-16 DDDDIl ........ 266

$91-35-26$ BCCC1.......... 267

$93-35-13$ ADAAI .......... 267

89-32-33 CABCl_....... 268

84-35-25 BDADI ......... 268

85-35-07 CCCCl........ 268

96-21-13 BCCB1......... 268

96-22-20 CADCl......... 269

90-40-06 BDCD1......... 269

91-39-01 ADADl......... 269

91-39-01 ADAD2......... 270

91-42-16 DDDD 11......... 270

92-40-10 BDDDl......... 270

$91-05-30$ BBBBl ......... 271

91-06-22 ACACl.......... 271

95-04-22 BCBD1.......... 271

95-04-32 DDDDl......... 272

85-39-16 ADDD $11 \ldots \ldots \ldots \ldots 272$

87-03-18 CBCD2........ 272

69-03-06 AABAI ......... 273

69-03-06 DDCDI......... 273

100-32-11 DDDD1........ 273

82-29-18 CAAAl ......... 274

82-30-13 CABAl......... 274

88-18-15 DBBBl ......... 274

79-42-19 AADB $\ldots \ldots \ldots \ldots . . .275$

81-44-18 AADAl......... 275

71-06-09 ABAC2......... 275

73-07-09 AABD1........ 276 
IDA COUNTY

We11 422115N095390811

Well 423107N095383201 JACKSON COUNTY

Well 420842N090165701

Well 420842N090165703

Well 420842 N090165704 JASPER COUNTY

Well 414205N092592001

Well 414147N093035401 IOHNSON COUNTY

Well 414107N091322901

Well 413925N091324001

Well 413955N091320303

Well 413844 N091323201

Well 414315N091252001

Well 414315N091252002

Well 414853N091425101 JONES COUNTY

Wel1 41580 8N091160501 LINN COUNTY

Well 415422N091422601

Well 415509N091461801

Well 415816N091393401

Well 415725N091410101

Well 420526N091370701

Well 421149N091403301 LYON COUNTY

Well 431812N096302701

Well 432140N095595301

Well 432553N096105701

Well 432601 N096335511 MADISON COUNTY

Well 411727N093483001 MARION COUNTY

Well $411323 N 093142601$ MARSHALL COUNTY

Well 420355n092534701 MONTGOMERY COUNTY

Well 405841N09501270I MUSCATINE COUNTY

Well 412120N091080401 Q'BRIEN COUNTY

Well 425610 N095250611

Well 425808N095480311

Well 430930N095350401 OSCEOLA COUNTY

Well 431620N095250501

Well 431620N095250511

Well 431613N095251801

Well 431620N095482402

Well 432828N095283611
Local number

Local number

Local number

Local number

Local number

Local number

Local number

Local number

Local number

Local number

Local number

Local number

Local number

Local number

Local number

Local number

Local number

Local number

Local number

Local number

Local number

Local number

Local number

Local number

Local number

Local number

Local number

Local number

Local number

Local number

Local number

Local number

Local number

Local number

Local number

Local number

Local number

Local number
87-41-05 CCCC11........ 276

$89-41-13 \operatorname{CCCCl} \ldots \ldots \ldots \ldots . . .276$

85-6E-29 ACADI.......... 277

85-6E-29 ACAD3 .......... 277

85-6E-29 ACAD4 ......... 277

80-18-31 ABBBl ......... 278

80-19-33 ACACl......... 278

79-06-04 AAAAI ......... 278

79-06-09 DDBCl......... 279

79-06-10 BDBC3.......... 279

79-06-16 DDADl.......... 279

80-05-22 CBCB1 .......... 280

80-05-22 CBCB2 ......... 280

81-07-19 BCBB1......... 280

83-04-25 CBBBI......... 281

82-07-18 CDCD1.......... 281

$82-08-20$ ACBBl .......... 281

83-07-28 ADDAl ......... 282

83-07032 ACDCl......... 282

84-07-13 BCBBI ......... 283

85-07-04 CCCC1......... 283

98-48-16 DDADI.......... 284

99-44-26 DDDDl.......... 284

99-45-05 ABAC1.......... 284

$100-48-31$ CCCC11......... 285

75-26-23 AAACl ........ 285

$74-21-11$ BBCD1......... 285

84-18-24 CDCAI ......... 286

71-36-06 DADAl ........ 286

76-02-30 CBAAl ....... 287

94-39-26 BADB11......... 287

94-42-09 DDDD11......... 288

96-40-05 DDDAI......... 288

98-39-26 CDADI......... 288

98-39-26 CDAD11......... 289

98-39-26 CDDC1.......... 289

$98-42-33$ AABB2 ......... 289

$100-39-17$ DCCB11........ 289 
PAGE COUNTY

Well 404257N09515080 l Local number PLYMOUTH COUNTY

Well 424850 N096074801

Well 424850N096074802

Well 424833N096324701

Well 425249N096125001 SAC COUNTY

Well 422500N095084801

Well 423013N095175301

Well 422850N095171501 SCOTT COUNTY

Well 413544N090212901 SIOUX COUNTY

Well 430140N095573101

Well 430913N096033201 WASHINGTON COUNTY

Well 421829N091304701

Well 412037N091564701

Well 412754 N091494701 WEBSTER COUNTY

Well 421550N094041001

Well 421837N094083601

Well 423018N094214701 WOODBURY COUNTY

Well 422058n095573701

Well 422830N096000511

Well 423015N096034601

Well 422910N096135811
Local number

Local number

Local number

Local number

Local number

Local number

Local number

Local number

Local number

Local number

Local number

Local number

Local number

Local number

Local number

Local number

Local number

Local number

Local number

Local number
68-38-07 CCAAL......... 290

92-45-02 СВCB1......... 290

$92-45-02$ СBCB $2 \ldots \ldots \ldots \ldots .290$

92-48-06 DDDAl..........291

93-46-12 DDDD1......... 291

88-37-22 $\operatorname{cccc} 1 . \ldots \ldots \ldots \ldots 291$

89-38-26 ABAAl......... 291

89-38-36 СВCC1.......... 292

78-5E-03 AADA1......... 292

95-43-07 AAAAl.......... 293

96-44-08 ADAAl.......... 293

75-06-14 ABBBl..........293

76-09-31 CBBCl.......... 294

77-09-24 AADAL......... 294

86-28-14 ADABL......... 295

87-28-29 CCCD1......... 295

89-30-23 ССВВ1......... 296

87-44-15 CBBB1......... 296

88-44-06 BAABI1......... 296

89-44-20 DCDCl.......... 296

89-46-36 BвDC11......... 297 
WATER RESOURCES DATA - IOWA, 1985

INTRODUCTION

The Water Resources Division of the U.S. Geological Survey, in cooperation with State agencies, obtains a large amount of data pertaining to the water resources of Iowa each water year. These data, accumulated during many water years, constitute a valuable data base for developing an improved understanding of the water resources of the state. To make these data readily available to interested parties outside of the Geological Survey, the data are published annually in this report series entitled "Water Resources Data - Iowa."

This report contains records for water discharge at 111 gaging stations; stage or contents for 8 lakes and reservoirs; water quality records for 8 gaging stations, sediment records for 12 gaging stations and water levels for 94 observation wells. Also included are data for 118 crest-stage partial-record stations. Additional water data were collected at various sites not involved in the systematic data-collection program and are published as miscellaneous measurements and analyses. These data represent that part of the National Water Data System operated by the U.S. Geological Survey and cooperating state, local, and Federal agencies in Iowa.

Records of discharge and stage of streams, and contents or stage of lakes and reservoirs were first published in a series of U.S. Geological Survey water-supply papers entitled, "Surface Water Supply of the United States." Through September 30, 1960, these water-supply papers were in an annual series and then in a 5-year series for 1961-65 and 1966-70. Records of chemical quality, water temperatures, and suspended sediment were published from 1941 to 1970 in an annual series of water-supply papers entitled, "Quality of Surface waters of the United states." Records of ground-water levels were published from 1935 to 1974 in a series of water-supply papers entitled, "Ground-water Levels in the United States." Water-supply papers may be consulted in the libraries of the principal cities in the United States or may be purchased from Branch of Distribution, U.S. Geological Survey, 604 South Pickett Street, Alexandria, Virginia, 22304.

For water years 1961 through 1970 , streamflow data were released by the Geological survey in annual reports on a State-boundary basis. Water-quality records for water years 1964 through 1970 were similarly released either in separate reports of in conjunction with streamflow records. 
Beginning with the 1971 water year, water data for streamflow, water quality, and ground water are published in official survey reports on a state-boundary basis. These official Survey reports carry an identification number consisting of the two-letter state abbreviation, the last two digits of the water year, and the volume number. For example, this report is identified as "U.S. Geological survey Water-Data Report IA-85-1." These water-data reports are for sale, in paper copy or in microfiche, by the National Technical Information Service, U.S. Department of Commerce, Springfield, Virginia 22161.

Additional information, including current prices, for ordering specific reports may be obtained from the District Chief at the address given on the back of the title page or by telephone, (319) 337-4191. 


\section{COOPERATION}

The U.S. Geological Survey and organizations in the state of Iowa have had cooperative agreements for the systematic collection of streamflow records since 1914, for ground water levels since 1935, and for water-quality records since 1943. Organizations that assisted in collecting data through cooperative agreement with the Survey in 1985 are:

Iowa Geological Survey, Donald L. Koch, Director and State Geologist

University of Iowa, Institute of Hydraulic Research, Robert G. Hering, Dean of College of Engineering and John F. Kennedy, Director

University of Iowa, Hygienic Laboratory, W.J. Hausler, Jr., Director

Iowa Department of Transportation, Highway Division, Robert H. Given, Director, and Vernon J. Marks, Research Engineer

Iowa State University, Richard E. Hasbrook, Contracts and Grants Officer, and E. Robert Bauman, Professor-in-charge; and Engineering Research Institute, T. Al. Austin, Director.

City of Cedar Rapids, Donald Canney, Mayor

City of Des Moines, Pete Creivaro, Mayor

City of Fort Dodge, Michael D. McCarville, General Manager, Department of Municipal Utilities

Assistance in the form of funds or services was given by the Corps of Engineers, U.S. Army, in collecting flow records for 77 gaging stations. Assistance was also furnished by NOAA-National Weather Service, U.S. Department of Commerce.

The following organizations aided in collecting records:

Union Electric Co.; Des Moines Water Works; Waterloo Sewage Treatment Plant; University of Iowa; West Central Iowa Rural Water Association; and cities of, Charles City, Clear Lake, Denison, Iowa city, Marshalltown, Sioux City, and Waterloo.

Organizations that supplied data are acknowledged in station descriptions. 
Table 1.--Runoff at streamflow stations for 1985 compared with long-term average for all major river basins in Iowa. [Average runoff for station based on period of record. Previous maximum runoff value, and the year of occurrence are shown.]

\begin{tabular}{|c|c|c|c|c|c|c|}
\hline \multirow{2}{*}{\multicolumn{2}{|c|}{ Station number and name }} & \multirow{2}{*}{$\begin{array}{l}\text { Drainage } \\
\text { area } \\
\text { square } \\
\text { miles }\end{array}$} & \multicolumn{2}{|c|}{ Runoff, (inches) } & \multicolumn{2}{|c|}{ Previous maximum } \\
\hline & & & $\begin{array}{l}1985 \\
\text { water year }\end{array}$ & Average & (Inches) & $\begin{array}{r}\text { Water } \\
\text { Year }\end{array}$ \\
\hline $\begin{array}{l}05388250 \\
05412500 \\
05418500 \\
05422000 \\
05451500 \\
05455700 \\
05464000 \\
05465000 \\
05465500 \\
05474000 \\
05480500 \\
05484500 \\
05485500 \\
05490500 \\
06483500 \\
06600500 \\
06607500 \\
06609500 \\
06810000 \\
06811840 \\
06817000 \\
06818750 \\
06898000 \\
06898400 \\
06903400 \\
06903700\end{array}$ & $\begin{array}{l}0 \text { Upper Iowa } R \text { nr Dorchester } \\
10 \text { Turkey } R \text { at Garber } \\
10 \text { Maguoketa } R \text { at Maguoketa } \\
0 \text { Wapsipinicon } R \text { nr Dewitt } \\
0 \text { Iowa } R \text { at Marshalltown } \\
0 \text { Iowa } R \text { nr Lone Tree } \\
0 \text { Cedar } R \text { at Waterloo } \\
0 \text { Cedar } R \text { nr Conesville } \\
0 \text { Iowa } R \text { at Wapello } \\
0 \text { Skunk } R \text { at Augusta } \\
0 \text { Des Moines } R \text { at Ft. Dodge } \\
0 \text { Raccoon } R \text { at Van Meter } \\
0 \text { Des Moines } R \text { at Des Moines } \\
0 \text { Des Moines } R \text { Reosaqua } \\
0 \text { Rock } R \text { at Rock Valley } \\
0 \text { Floyd } R \text { at James } \\
0 \text { Little Sioux } R \text { nr Turin } \\
0 \text { Boyer } R \text { at Logan } \\
0 \text { Nishnabotna } R \text { above Hamburg } \\
\text { Tarkio } R \text { at Stanton } \\
\text { Nodaway } R \text { at Clarinda } \\
\text { Platte } R \text { nr Diagonal } \\
\text { Thompson } R \text { at Davis City } \\
\text { Weldon } R \text { nr Leon } \\
\text { Chariton } R \text { nr Chariton } \\
\text { SF Chariton } R \text { nr Promise City }\end{array}$ & $\begin{array}{c}770 \\
1,545 \\
1,553 \\
2,330 \\
1,564^{\star} \\
4,293^{\star} \\
5,460^{\star} \\
7,785^{\star} \\
12,499 \\
4,303 \\
4,190 * \\
4,303^{*} \\
9,879 * \\
14.038 \\
1,592 \\
882 \\
3,526 \\
871 \\
2,806 \\
49.3 \\
762 \\
217 \\
701 \\
104 \\
182 \\
168\end{array}$ & $\begin{array}{l}8.2 \\
6.8 \\
8.9 \\
7.7 \\
4.5 \\
6.0 \\
5.8 \\
6.4 \\
6.2 \\
7.3 \\
5.2 \\
4.0 \\
4.0 \\
4.5 \\
6.7 \\
7.8 \\
7.1 \\
5.1 \\
4.6 \\
1.6 \\
3.0 \\
2.5 \\
2.5 \\
2.5 \\
5.2 \\
9.6\end{array}$ & $\begin{array}{r}10.6 \\
8.4 \\
9.0 \\
9.0 \\
7.1 \\
9.0 \\
8.0 \\
8.3 \\
7.6 \\
7.7 \\
5.0 \\
5.4 \\
6.1 \\
5.6 \\
3.4 \\
3.3 \\
5.2 \\
5.1 \\
5.2 \\
7.8 \\
6.1 \\
8.2 \\
7.2 \\
9.2 \\
8.4 \\
9.4\end{array}$ & $\begin{array}{l}22.6 \\
19.6 \\
20.3 \\
20.3 \\
19.8 \\
19.0 \\
20.2 \\
18.0 \\
18.6 \\
20.6 \\
18.0 \\
19.2 \\
18.1 \\
18.1 \\
14.0 \\
14.7 \\
18.4 \\
13.9 \\
17.4 \\
19.5 \\
20.4 \\
18.2 \\
20.8 \\
23.3 \\
19.3 \\
18.7\end{array}$ & $\begin{array}{l}1983 \\
1983 \\
1973 \\
1973 \\
1983 \\
1973 \\
1983 \\
1983 \\
1973 \\
1973 \\
1983 \\
1973 \\
1983 \\
1983 \\
1983 \\
1983 \\
1983 \\
1983 \\
1973 \\
1973 \\
1973 \\
1973 \\
1973 \\
1959 \\
1973 \\
1973\end{array}$ \\
\hline . & 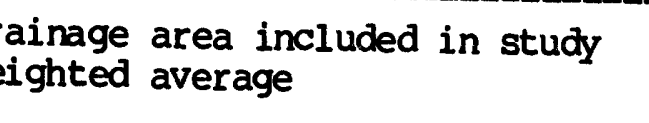 & 8 , & $-\overline{5.9}$ & $\overline{6.4}$ & 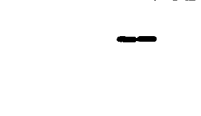 & - \\
\hline
\end{tabular}

* Not included in areal averaging of river basin runoff 


\section{SUMMARY OF HYDROLOGIC CONDITIONS}

\section{Surface Water}

Average annual precipitation in Iowa during the 1985 water year (October 1,1984 to september 30,1985 ) ranged from 30.9 inches in the central area to 37.4 in the southeast area of the State. The 1985 state-wide average was 34.2 inches or 107 percent of the long term average. Winter snowfall was substantially greater in the northern part of the state. Total snowfall from November to April ranged from 16.7 inches in the southcentral area to 33.3 inches in the northcentral area of the state.

Monthly precipitation from October through December (fig. 1) was above average in all areas of Iowa. The runoff from the three index stations (fig. 2) generally reflected the effects of this precipitation. Streamflow at the index station on the Cedar River at Cedar Rapids was in the normal range (25 to 758 quartile of 1951-80 mean daily discharges for specified month) during this period. Streamflow in the Des Moines River at Fort Dodge was in the normal range during october, but responded to the greater than average fall precipitation, and was in the excess range (75\% quartile of 1951-80 mean daily discharges for specified month), in November and December. The discharge of the Nishnabotna River at Hamburg was in the excess range the entire period.

Streamflow throughout Iowa receded normally during the winter. The index stations were all in the excess range in January, due to recharge from the greater than average fall precipitation, but generally receded into their normal range in February and March. Air temperatures in mid-February moderated and the winter ice-cover broke in many streams throughout the state. This condition was accompanied by rainfall accumulations of more than 1 inch in the eastern two-thirds of the state on February 20-21. Because the ground remained frozen, this precipitation caused substantial runoff and severe ice jamming in many streams. Normal winter temperatures in late February and March caused streams to recede for the remainder of the winter.

During April and May precipitation was near normal and discharge at the index stations was in the normal range. During June, precipitation was less than average in all parts of the state. This dry weather continued through July and precipitation throughout the northern two-thirds of Iowa was about one-half of the normal precipitation. Streamflow in the Cedar River at Cedar Rapids receded to the deficient range (25\% quartile of 1951-80 mean daily discharge for specified month) during June and July. Both the Des Moines River at Fort Dodge, and the Nishnabotna River above Hamburg remained in their normal ranges, primarily due to recharge from normal precipitation in April and May. 
Normal precipitation occurred throughout the state in August, and september precipitation was substantially greater than normal. Streamflow at the index stations were all in the normal range during August, except the Cedar River at Cedar Rapids which remained in the deficient range. Streamflow increased at all index stations in response to the greater than normal september precipitation, and all the index stations were in the normal or excess range at the end of the 1985 water year. A summary of runoff at streamflow stations in 1985 is shown in table 1 .

\section{Suspended-sediment}

Sediment transport for the nine daily sediment stations during 1985 was less than one-half the normal accumulated mean load at all sites. The minimum daily load for the Middle Raccoon River at Panora was the minimum for the period of record. Due to the lack of normal seasonal storms and floods during spring and summer, the maximum sediment transport at all sites occurred during the spring ice breakup.

\section{Surface Water-Ouality}

The chemical quality of surface water in Iowa, by samples collected on major rivers, was not table for public water supply and most analysed had concentratioperly treated. None of the samples environmental standards. near or Dissolved-oxygen concentrations were near or greater than saturation at all stations. This generally indicates that, with respect to dissolved oxygen, stream quality has not been significantly affected by oxygen demands such as nutrients, organic matter and suspended sediment to the streams.

A comparison between selected water-quality data for the 1985 water year and historical data for the period of record is shown in figures 3-5. Monthly means of stream discharge for the 1985 water year also are shown to generally relate flow conditions to water-quality measurements obtained during the 1985 water year. Dissolved-solids and nitrate data collected at selected National Stream-Quality Accounting Network (NASQAN) stations were used to demonstrate temporal variability of water quality for the Mississippi, Iowa, and Missouri Rivers. Concentrations of dissolved-solids for the Mississippi River at Keokuk (fig. 3) and the Iowa River at Wapello (fig. 4) were normal for the 1985 water year when compared to historical monthly means for the period of record. Dissolved-solids concentration for the Missouri River station at Sioux City (fig. 5) exceeded the historical monthly mean for four of six samples analysed. 
Nitrate concentrations reported as nitrogen (analysis for nitrate plus nitrite as nitrogen, but nitrite concentration assumed to be negligible) for the Mississippi River at Keokuk (fig. 4) were much less than the historical monthly mean for two measurements. These 2 measurements were near or less than the detection limit of $0.1 \mathrm{mg} / \mathrm{L}$. All nitrate measurements at the Iowa River station (fig. 5) were less than monthly means. Nitrate concentrations at the Missouri River station (fig. 6) exceeded historical monthly means 3 times, however all concentrations were equal to or less than $1.2 \mathrm{mg} / \mathrm{L}$.

\section{Ground Water}

Normally, water levels at the water table rise later in the spring or early summer than what was observed in 1985. After the growing season begins, precipitation normally is lost to runoff and evapotranspiration so that recharge to the aquifers is decreased. The water-level rises in water-table aquifers result, in part, from recharge by direct infiltration of precipitation. The water levels shown in figure 6 are from three shallow, water-table wells completed in Pleistocene glacial drift in Linn, Webster, and Marion Counties. The water-levels reflect the precipitation pattern for 1985 shown in figure 1. Precipitation during April through August was less than the normal annual precipitation (1951-80) for those months. The well in Linn County had water. levels below the average monthly levels for May, June, August, and September. Another well in Johnson County, completed in the same aquifer, had water levels below the average monthly levels during April through September. The well in webster County had water levels below the average monthly levels for May through July. Water levels in a water-table well in Montgomery County were below the average monthly level the entire water year. The well in Marion County in south-central Iowa had water levels below the average monthly levels during April and May. Water levels in a shallow, water-table well completed in Holocene alluvium, in Pottawattamie county, were above the average monthly levels for all months except september.

\section{Ground water-ouality}

The water-quality data obtained from analysis of ground-water samples indicate that nitrate, numerous pesticides and radiochemical constituents are present in concentrations that may be considered undesirable and in many cases exceed publicdrinking water standards. Two-hundred fourteen water-quality analyses of raw water (untreated and obtained directly from the respective aquifer) from municipal wells throughout the state are listed in this report. 
Fifty-six percent of the wells sampled are less than 150 feet deep and are completed in shallow aquifers of Quaternary age. Samples from this category of wells were analysed for a comprehensive list of pesticides in addition to common mineral, metal, nutrient and radiochemical constituents. of particular interest for this category of shallow wells are the concentrations of nitrate and selected pesticides in shallow ground water. of the 120 shallow wells sampled, 7 samples ( 6 percent) had nitrate concentrations greater than the maximum contaminant limit (MCL) for public drinking water of $10 \mathrm{mg} / \mathrm{L}$ nitrate as nitrogen. Samples from 15 or these shallow wells had detectable concentrations of at least 1 pesticide; either atrazine, cyanazine, metribuzin, alachlor, metolachlor, or dicamba. Atrazine was the most prevalent, appearing in 14 of 94 comprehensive pesticide analyses. Analyses are listed for 12 pesticides that commonly are used in Iowa. Analyses for 18 organochlorine pesticides which were also analysed for are not listed in the table, however no organochlorine pesticide was detected in any ground-water sample.

The remainder of the samples collected represent ground-water-quality of deeper aquifers. These analyses describe the quality of ground-water from wells more than 150 feet deep which derive water from deeper bedrock aquifers. These samples indicate that few chemical constituents are present in concentrations that exceed environmental standards. The only significant exception are radiochemical constituents. Eight samples had gross alpha activities greater than the MCL of 15 $\mathrm{pCi} / \mathrm{L}$ and 24 samples had combined radium 226 and 228 greater than the MCL of $5 \mathrm{pCi} / \mathrm{L}$.

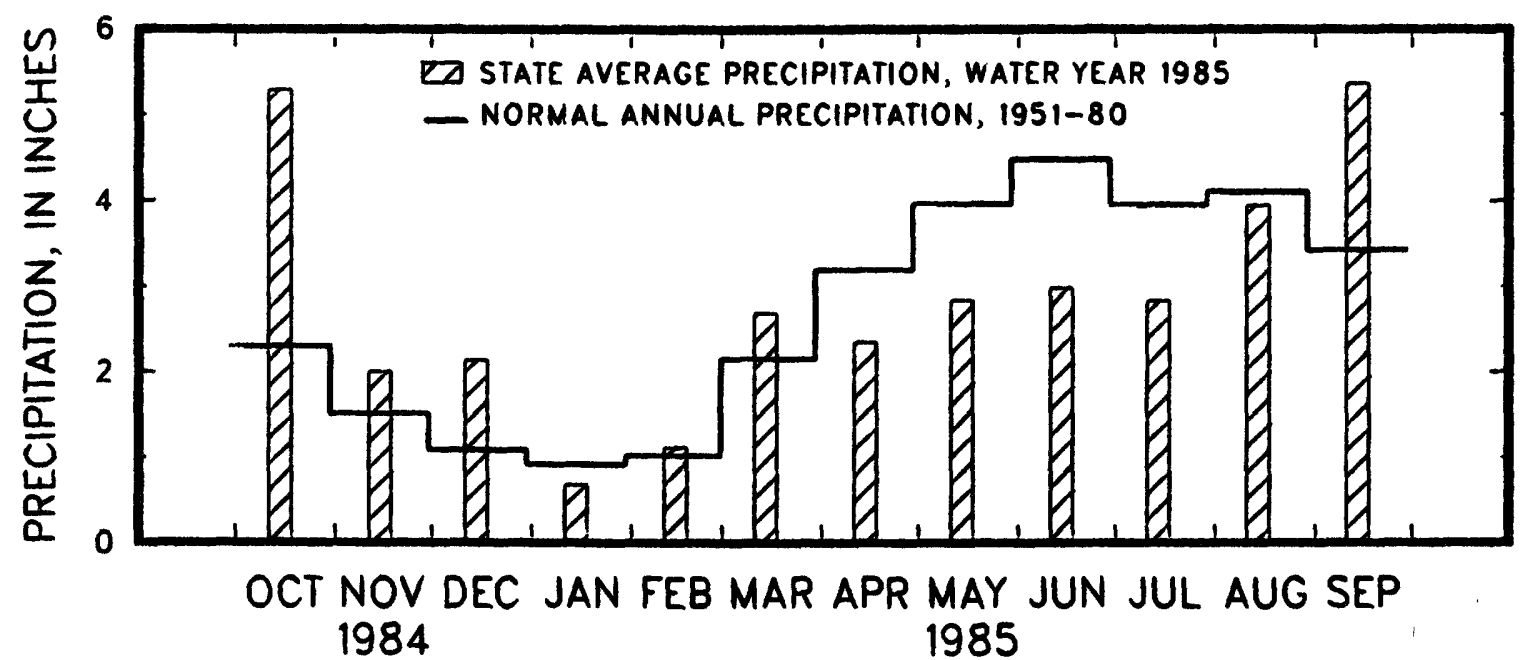

Figure 1.--State average precipitation, during the 1985 water year compared to normal annual precipitation, 1951-80 [Source: P.J. Waite, State Climatologist, oral commun., 1986]. 


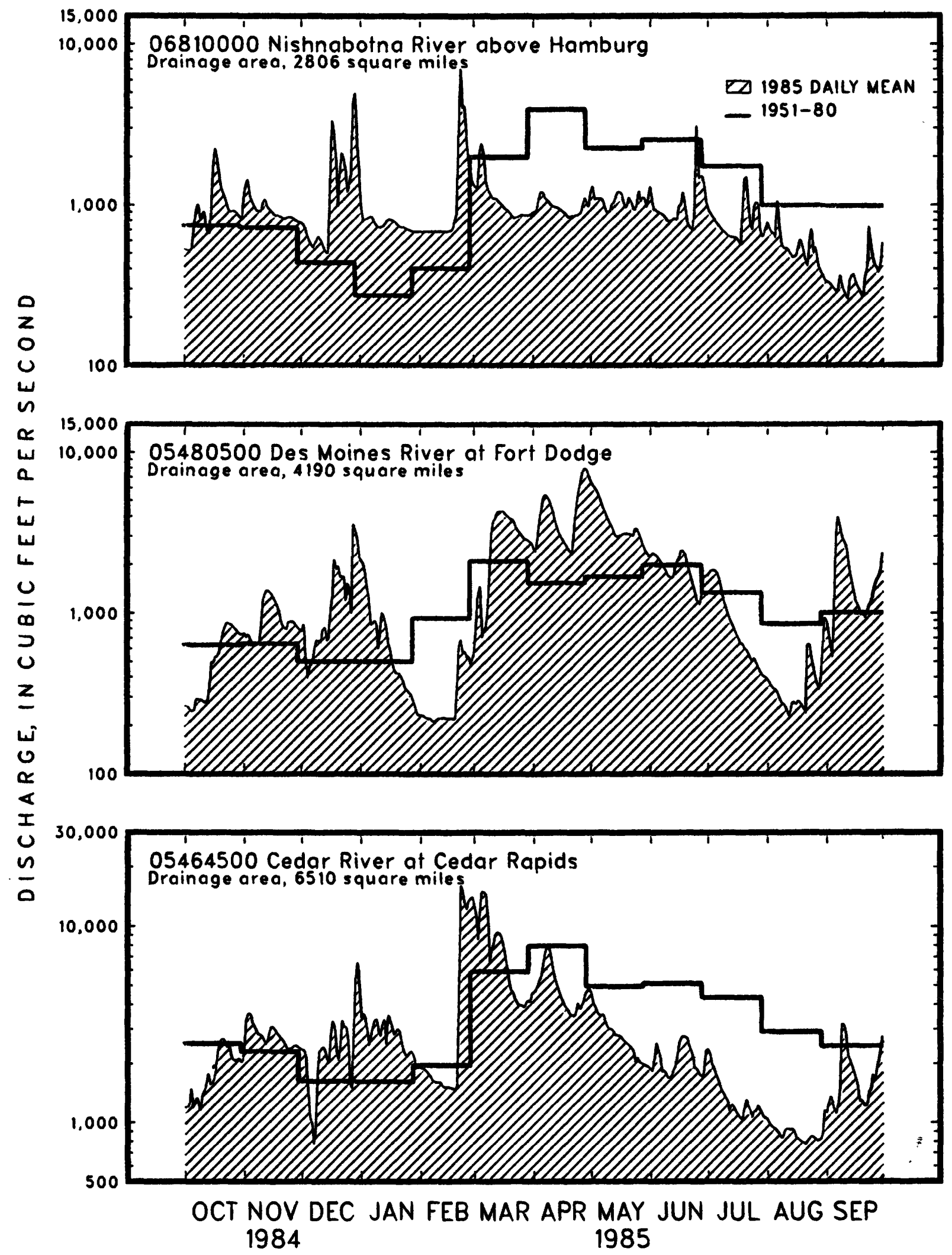

Figure 2. Daily mean discharge for the 1985 water year compared with mean monthly discharges for water years 1951-80 for three representative stations. 

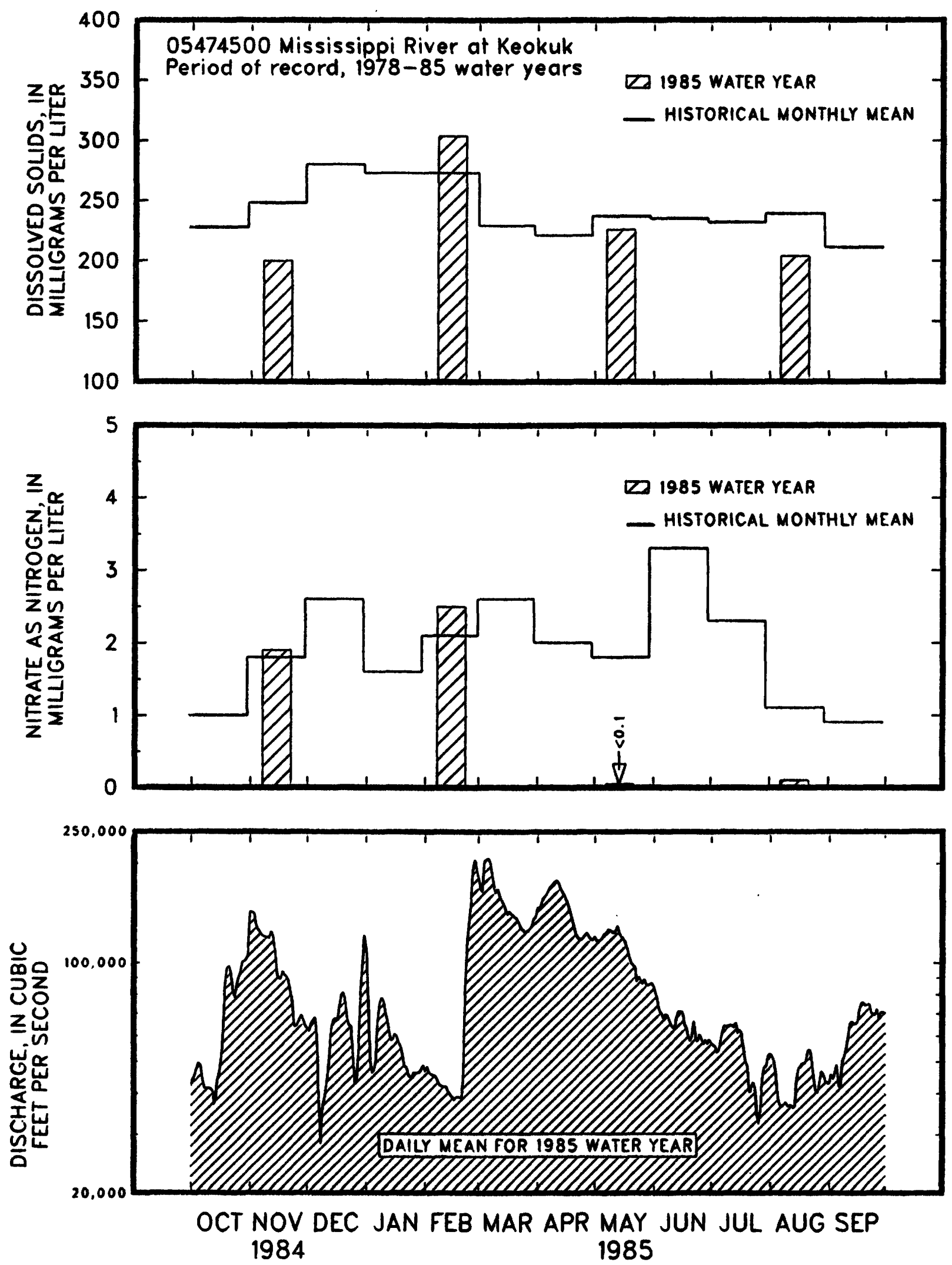

Figure 3. Comparison of dissolved solids and nitrate concentrations for the 1985 water year with mean monthly values at the NASQAN station on the Mississippi River at Keokuk. 

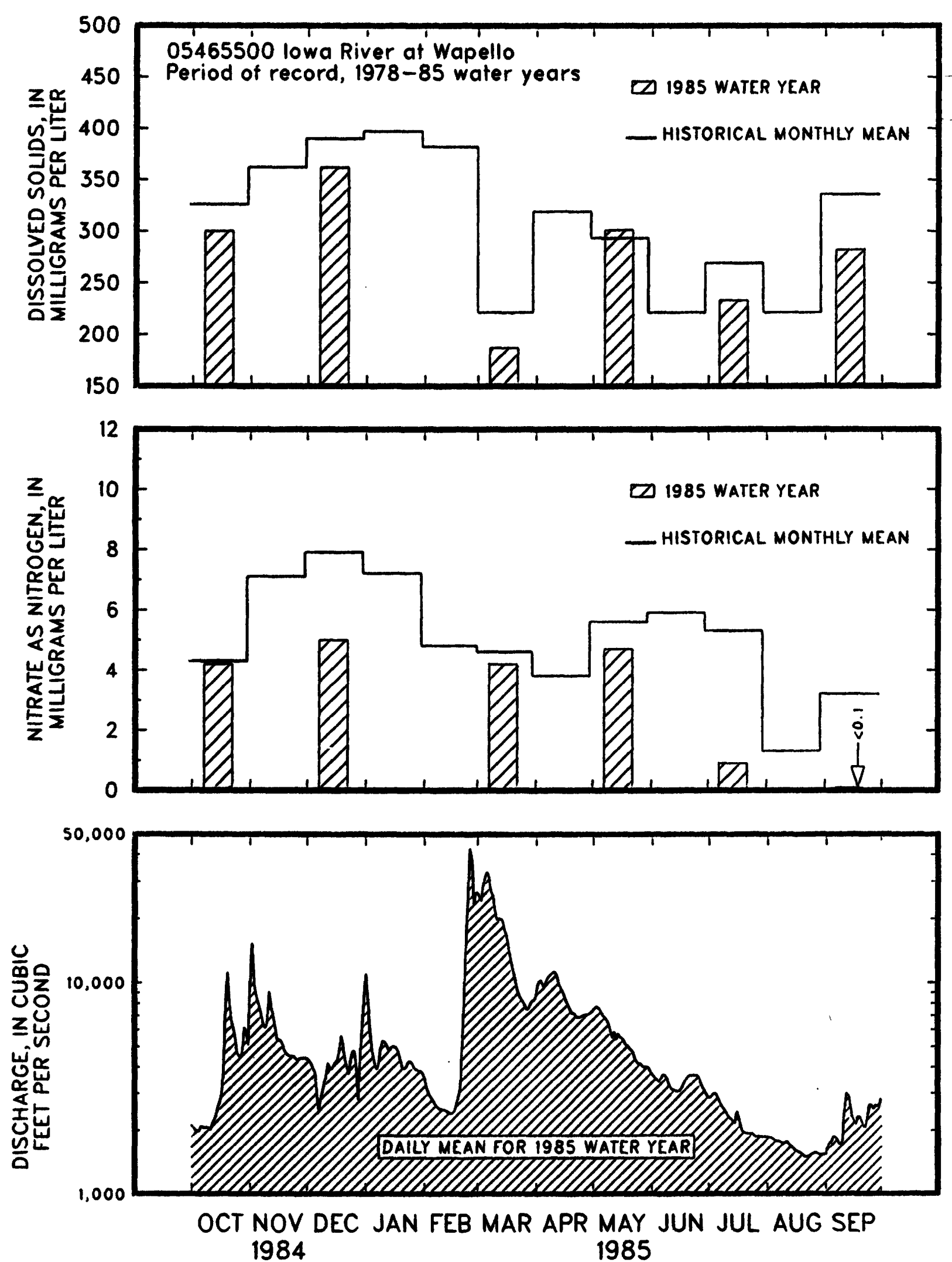

Figure 4. Comparison of dissolved solids and nitrate concentrations for the 1985 water year with mean monthly values at the NASQAN station on the lowa River at Wapello. 


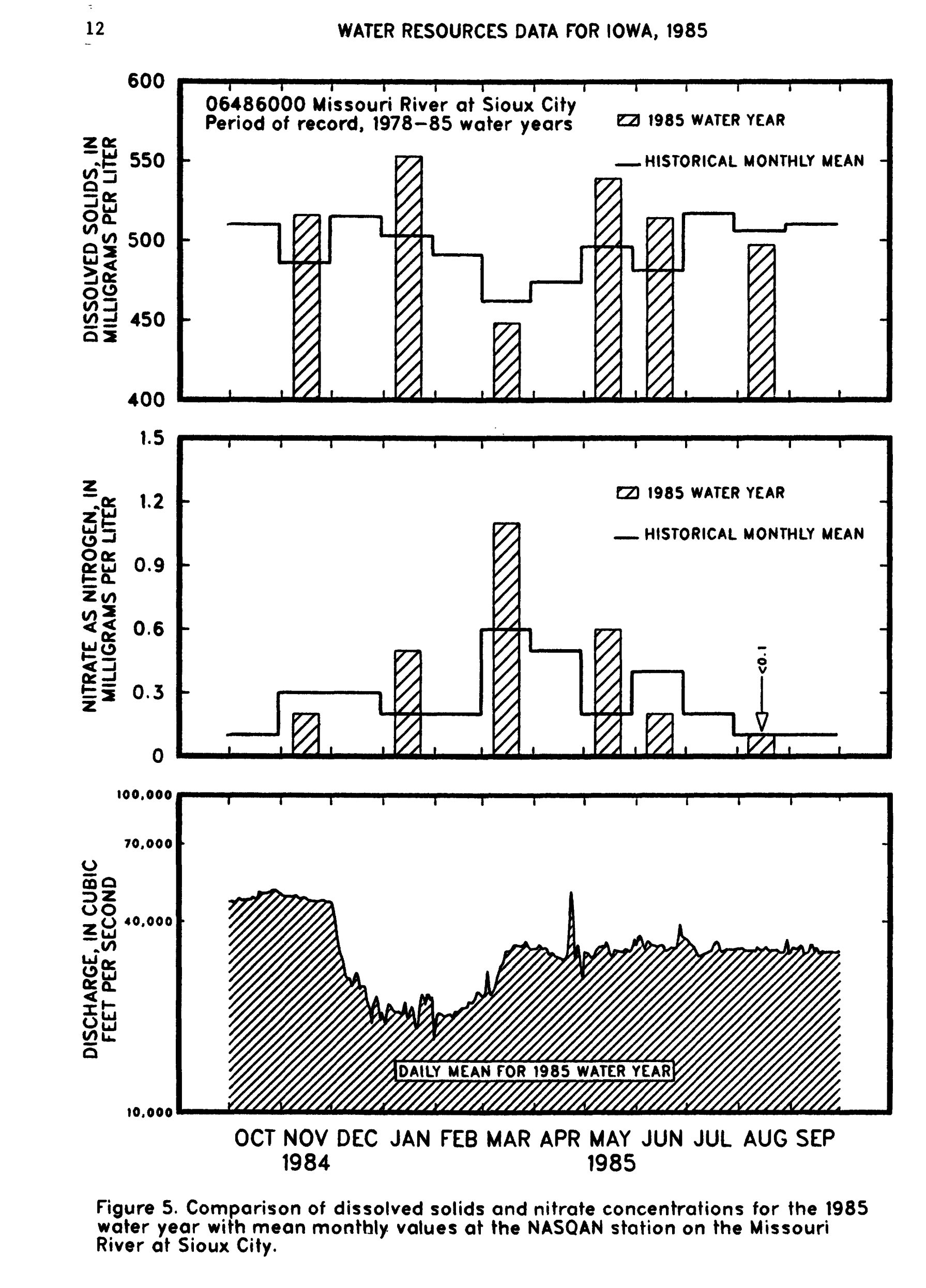




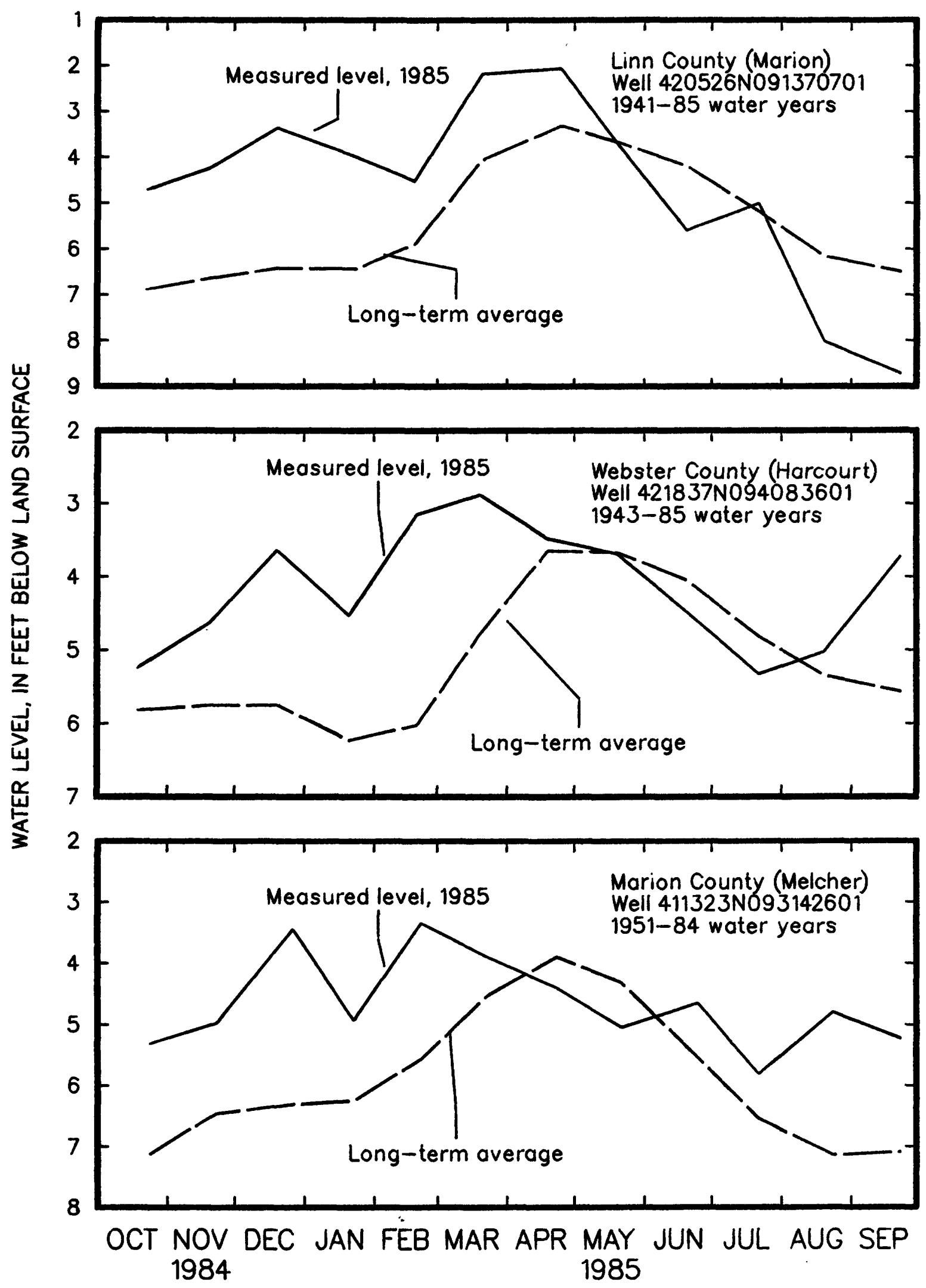

Figure 6. Monthly water levels during the 1985 water year compared to the average monthly level for the period of record 


\section{SPECIAL NETWORKS AND PROGRAMS}

Hydrologic Bench-Mark Network is a network of 57 sites in small drainage basins around the country whose purpose is to provide consistent data on the hydrology, including water quality, and related factors in representative undeveloped watersheds nationwide, and to provide analyses on a continuing basis to compare and contrast conditions observed in basins more obviously affected by the activities of man.

National stream Quality Accounting Network (NASQAN) is a nationwide data-collection network designed by the U.S. Geological survey to meet many of the information needs of government agencies and other groups involved in natural or regional water-quality planning and management. The 500 or so sites in NASQAN are generally located at the downstream ends of hydrologic accounting units designated by the U.S. Geological Survey office of Water Data Coordination in consultation with the Water Resources Council. The objectives of NASQAN are (1) to obtain information on the quality and quantity of water moving within and from the United states through a systematic and uniform process of data collection, summarization, analysis, and reporting such that the data may be used for, (2) description of the areal variability of water quality in the Nation's rivers through analysis of data from this and other programs, (3) detection of changes or trends with time in the pattern of occurrence of water-quality characteristics, and (4) providing a nationally consistent data base useful for water-quality assessment and hydrologic research.

The National Trends Network (NTN) is a 150-station network for sampling atmospheric deposition in the United States. The purpose of the network is to determine the variability, both in location and in time, of the composition of atmospheric deposition, which includes snow, rain, dust particles, aerosols, and gases. The core from which the NTN was built was the alreadyexisting deposition-monitoring network of the National Atmospheric Deposition Program (NADP).

Radiechemical Program is a network of regularly sampled water-quality stations where samples are collected to be analyzed for radioisotopes. The streams that are sampled represent major drainage basins in the conterminous United states.

Tritium Network is a network of stations which has been established to provide baseline information on the occurrence of tritium in the Nation's surface waters. In addition to the surface-water stations in the network, tritium data are also obtained at a number of precipitation stations. The purpose of the precipitation stations is to provide an estimate sufficient for hydrologic studies of the tritium input to the united states. 


\section{EXPLANATION OF THE RECORDS}

The surface-water and ground-water records published in this report are for the 1985 water year that began October 1, 1984, and ended september 30, 1985. A calendar of the water year is provided on the inside of the front cover. The records contain streamflow data, stage and content data for lakes and reservoirs, water-quality data for surface and ground water, and ground-water-level data. The locations of the stations and wells where the data were collected are shown in figures 9-11. The following sections of the introductory text are presented to provide users with a more detailed explanation of how the hydrologic data published in this report were collected, analyzed, computed, and arranged for presentation.

\section{Station Identification Numbers}

Each data station, whether streamsite or well, in this report is assigned a unique identification number. This number is unique in that it applies specifically to a given station and to no other. The number usually is assigned when a station is first established and is retained for that station indefinitely. The systems used by the U.S. Geological survey to assign identification numbers for surface-water stations and for ground-water well sites differ, but both are based on geographic location. The "downstream order" system is used for regular surface-water stations and the "latitude-longitude" system is used for wells.

\section{Downstream Order system}

Since October 1 , 1950, the order of listing hydrologic-station records in survey reports is in a downstream direction along the main stream. All stations on a tributary entering upstream from a mainstream station are listed before that station. A station on a tributary that enters between two mainstream stations is listed between them. A similar order is followed in listing stations on first rank, second rank, and other ranks of tributaries. The rank of any tributary with respect to the stream to which it is immediately tributary is indicated by an indention in the "List of stations" in the front of this report. Each indention represents one rank. This downstream order and system of indention shows which stations are on tributaries between any two stations and the rank of the tributary on which each station is situated. 
The station-identification number is assigned according to downstream order. In assigning station numbers, no distinction is made between partial-record stations and other stations; therefore, the station number for a partial-record station indicates downstream-order position in a list made up of both types of stations. Gaps are left in the series of numbers to allow for new stations that may be established; hence, the numbers are not consecutive. The complete eight-digit number for each station, such as 05388250, which appears just to the left of the station name, includes the two-digit part number "05" plus the six-digit downstream-order number "388250." The Part number designates the major river basin; for example, Part "05" is the Mississippi River Basin.

\section{Latitude-Longitude System}

The identification numbers for wells and miscellaneous surface-water sites are assigned according to the grid system of latitude and longitude. The number consists of 15 digits. The first six digits denote the degrees, minutes, and seconds of latitude, the next seven digits denote degrees, minutes, and seconds of longitude, and the last two digits (assigned sequentially) identify the wells or other sites within a 1-second grid. This site-identification number, once assigned, is a pure number and has no locational significance. In the rare instance where the initial determination of latitude and longitude are found to be in error, the station will retain its initial identification number; however, its true latitude and longitude will be listed in the LOCATION paragraph of the station description. (See figure below.)

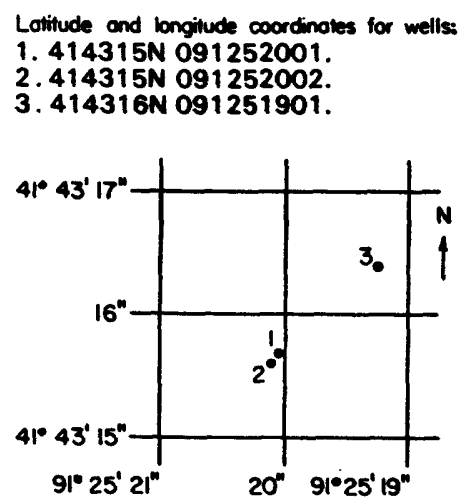

Figure 7.--Latitude-longitude well number. 


\section{NUMBERING SYSTEM FOR WELLS}

Each well is identified by means of (1) a 15-digit number that is based on the grid system of latitude and longitude, and (2) a local number that is provided for continuity with older reports and for other use as dictated by local needs. The former number serves not only to identify the well but also to locate it as a point on a map (fig. 7). For maximum utility, latitude and longitude code numbers are determined to seconds in order that each well may have a unique number. The first six digits denote degrees, minutes, and seconds of latitude; "N" refers to north latitude and is used to break the string of numbers; the next seven digits are degrees, minutes, and seconds of west longitude; and the last two numbers are a sequential number assigned in the order in which the wells are located in a 1-second quadrangle.

The local well numbers are in accordance with the Bureau of Land Management's system of land subdivision. Each well number is made up of three segments. The first segment indicates the township, the second the range, and the third the section in which the well is located (fig. 8). The letters after the section number which are assigned in a counter-clockwise direction (beginning with "A" in the northeast quarter), represent subdivisions of the section. The first letter denotes a 160-acre tract, the second a 40-acre tract, the third a 10-acre tract, and the fourth a 2.5 acre tract. Numbers are added as suffixes to distinguish wells in the same tract. Thus, the number 96-20-3CDBD1 designates the well in the SE $1 / 4 \mathrm{NW} 1 / 4 \mathrm{SE} 1 / 4 \mathrm{SW}$ $1 / 4$ sec.3, T.96 N., R. 20 W.

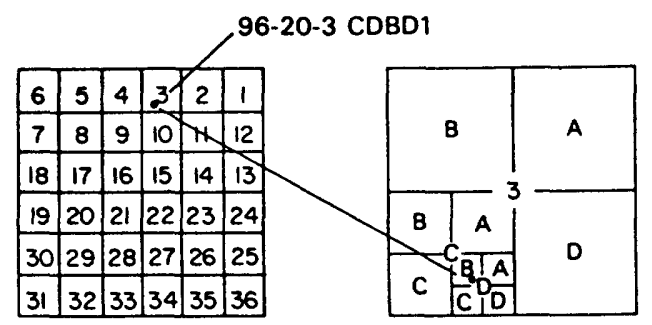

Figure 8.--Local well-numbering system for well 96-20-3CDBD1. 


\section{Records of stage and Water Discharge}

Records of stage and water discharge may be complete or partial. Complete records of discharge are those obtained using a continuous stage-recording device through which either instantaneous or mean daily discharges may be computed for any time, or any period of time, during the period of record. Complete records of lake or reservoir content, similarly, are those for which stage or content may be computed or estimated with reasonable accuracy for any time, or period of time. They may be obtained using a continuous stage-recording device, but need not be. Because daily mean discharges and end-of-day contents commonly are published for such stations, they are referred to as "daily stations." Location of all complete-record surface water stations which are given in this report are shown in figure 9.

Partial records are obtained through discrete measurements without using a continuous stage-recording device and generally pertain only to a characteristic of either high, medium or low flow.

\section{Data Collection and Computation}

The data obtained at a complete-record gaging station on a stream or canal consist of a continuous record of stage, individual measurements of discharge throughout a range of stages, and notations regarding factors that may affect the relationships between stage and discharge. These data, together with supplemental information, such as weather records, are used to compute daily discharges. The data obtained at a complete-record gaging station on a lake or reservoir consist of a record of stage and of notations regarding factors that may affect the relationship between stage and lake content. These data are used with stage-capacity curves or tables to compute lake storage.

Continuous records of stage are obtained with analog recorders that trace continuous graphs of stage or with digital recorders that punch stage values on paper tapes at selected time intervals. Measurements of discharge are made with current meters using methods adopted by the Geological survey as a result of experience accumulated since 1880. These methods are described in standard textbooks, in Water-Supply Paper 2175, and in U.S. Geological survey Techniques of Water-Resources Investigations, Book 3, Chapter A6. 
In computing discharge records, results of individual measurements are plotted against the corresponding stages, and stage-discharge relation curves are then constructed. From these curves, rating tables indicating the approximate discharge for any stage within the range of the measurements are prepared. If it is necessary to define extremes of discharge outside the range of the current-meter measurements, the curves are extended using: (1) logarithmic plotting; (2) velocity-area studies; (3) results of indirect measurements of peak discharge, such as slope- area or contracted-opening measurements, and computations of flow over dams or weirs; or (4) step-backwater techniques.

Daily mean discharges are computed by applying the daily mean stages (gage heights) to the stage-discharge curves or tables. If the stage-discharge relation is subject to change because of frequent or continual change in the physical features that form the control, the daily mean discharge is determined by the shifting-control method, in which correction factors based on the individual discharge measurements and notes of the personnel making the measurements are applied to the gage heights before the discharges are determined from the curves or tables. This shifting-control method also is used if the stage-discharge relation is changed temporarily because of aguatic growth or debris on the control. For some stations, formation of ice in the winter may so obscure the stage-discharge relations that daily mean discharges must be estimated from other information such as temperature and precipitation records, notes of observations, and records for other stations in the same or nearby basins for comparable periods.

At some stream-gaging stations, the stage-discharge relation is affected by the backwater from reservoirs, tributary streams, or other sources. This necessitates the use of the slope method in which the slope or fall in a reach of the stream is a factor in computing discharge. The slope or fall is obtained by means of an auxiliary gage set at some distance from the base gage. At some stations the stage-discharge relation is affected by changing stage; at these stations the rate of change in stage is used as a factor in computing discharge. 
In computing records of lake or reservoir contents, it is necessary to have available from surveys, curves or tables defining the relationship of stage and content. The application of stage to the stage-content curves or tables gives the contents from which daily, monthly, or yearly changes then are determined. If the stage-content relation changes because of deposition of sediment in a lake or reservoir, periodic resurveys may be necessary to redefine the relation. Even when this is done, the contents computed may become increasingly in error as the lapsed time since the last survey increases. Discharges over lake or reservoir spillways are computed using stage-discharge relations.

For some gaging stations, there are periods when no gage-height record is obtained, or the recorded gage height is so faulty that it cannot be used to compute daily discharge or contents. This happens when the recorder stops or otherwise fails to operate properly, intakes are plugged, the float is frozen in the well, or for various other reasons. For these periods, the daily discharges are estimated from the recorded range in stage, discharge computed before and after the missing record, discharge measurements, weather records, and comparison with other station records from the same or nearby basins. Likewise, daily contents may be estimated from operator's logs, previous or following record, inflow-outflow studies, and other information. Information explaining how estimated daily-discharge values are identified in station records is included in the next two sections, "Data Presentation" (REMARKS paragraph) and "Identifying Estimated Daily Discharge."

\section{Data Presentation}

The records published for each gaging station consist of two parts, the manuscript or station description and the data table for the current water year. The manuscript provides, under various headings, descriptive information, such as station location; period of record; average discharge; historical extremes; record accuracy; and other remarks pertinent to station operation and regulation. The following information, as appropriate, is provided with each continuous record of discharge or lake content. Comments to follow clarify information presented under the various headings of the station description. 
LOCATION.--Information on locations is obtained from the most accurate maps available. The location of the gage with respect to the cultural and physical features in the vicinity and with respect to the reference place mentioned in the station name is given. River mileages were determined by methods given in "River Mileage Measurement," Bulletin 14, Revision of October 1968, prepared by the Water Resources Council or were provided by the U.S. Army Corps of Engineers.

DRAINAGE AREA.--Drainage areas are measured using the most accurate maps available. Because the type of maps available varies from one drainage basin to another, the accuracy of drainage areas likewise varies. Drainage areas are updated as better maps become available.

PERIOD OF RECORD.--This indicates the period for which there are published records for the station or for an equivalent station. An equivalent station is one that was in operation at a time that the present station was not, and whose location was such that records from it can reasonably be considered equivalent with records from the present station.

REVISED RECORDS.--Published records, because of new information, occasionally are found to be incorrect, and revisions are printed in later reports. Listed under this heading are all the reports in which revisions have been published for the station and the water years to which the revisions apply. If a revision did not include daily, monthly, or annual figures of discharge, that fact is noted after the year dates as follows: "(M)" means that only the instantaneous maximum discharge was revised; "(m)" that only the instantaneous minimum was revised; and "(P)" that only peak discharges were revised. If the drainage area has been revised, the report in which the most recently revised figure was first published is given.

GAGE.--The type of gage in current use, the datum of the current gage referred to National Geodetic Vertical Datum of 1929 (see glossary), and a condensed history of the types, locations, and datums of previous gages are given under this heading. 
REMARKS.--All periods of estimated daily-discharge record will either be identified by date in this paragraph of the station description for water-discharge stations or flagged in the daily-discharge table. (See next section, "Identifying Estimated Daily Discharge.") If a remarks statement is used to identify estimated record, the paragraph will begin with this information presented as the first entry. The paragraph is also used to present information relative to the accuracy of the records, to special methods of computation, to conditions that affect natural flow at the station and, possibly, to other pertinent items. For reservoir stations, information is given on the dam forming the reservoir, the capacity, outlet works and spillway, and purpose and use of the reservoir.

COOPERATION.--Records provided by a cooperating organization or obtained for the Geological survey by a cooperating organization are identified here.

AVERAGE DISCHARGE.--The discharge value given is the arithmetic mean of the water-year mean discharges. It is computed only for stations having at least 5 water years of complete record, and only water years of complete record are included in the computation. It is not computed for stations where diversions, storage, or other water-use practices cause the value to be meaningless. If water developments significantly altering flow at a station are put into use after the station has been in operation for a period of years, a new average is computed as soon as 5 water years of record have accumulated following the development. The median of yearly mean discharges also is given under this heading for stations having 10 or more water years of record, if the median differs from the average given by more than 10 percent.

EXTREMES FOR PERIOD OF RECORD.--Extremes may include maximum and minimum stages and maximum and minimum discharges or content. Unless otherwise qualified, the maximum discharge or content is the instantaneous maximum corresponding to the highest stage that occurred. The highest stage may have been obtained from a graphic or digital recorder, a crest-stage gage, or by direct observation of a nonrecording gage. If the maximum stage did not occur on the same day as the maximum discharge or content, it is given separately. Similarly, the minimum is the instantaneous minimum discharge, unless otherwise qualified, and was determined and is reported in the same manner as the maximum.

EXTREMES OUTSIDE PERIOD OF RECORD.--Included here is information concerning major floods or unusually low flows that occurred outside the stated period of record. The information may or may not have been obtained by the U.S. Geological survey. 
EXTREMES FOR CURRENT YEAR.--Extremes given here are similar to those for the period of record, except the peak discharge listing may include secondary peaks. For stations meeting certain criteria, all peak discharges and stages occurring during the water year and greater than a selected base discharge are presented under this heading. The peaks greater than the base discharge, excluding the highest one, are referred to as secondary peaks. Peak discharges are not published for canals, ditches, drains, or streams for which the peaks are subject to substantial control by man. The time of occurrence for peaks is expressed in 24-hour local standard time. For example, 12:30 a.m. is 0030, and $1: 30$ p.m. is 1330. The minimum for the current water year appears below the table of peak data.

REVISIONS.--If a critical error in published records is discovered, a revision is included in the first report published following discovery of the error.

Although rare, occasionally the records of a discontinued gaging station may need revision. Because, for these stations, there would be no current or, possibly, future station manuscript published to document the revision in a "Revised Records" entry, users of data for these stations who obtained the record from previously published data reports may wish to contact the offices whose addresses are given on the back of the title page of this report to determine if the published records were ever revised after the station was discontinued. Of course, if the data were obtained by computer retrieval, the data would be current and there would be no need to check because any published revision of data is always accompanied by revision of the corresponding data in computer storage.

Manuscript information for lake or reservoir stations differs from that for stream stations in the nature of the "Remarks" and in the inclusion of a skeleton stage-capacity table when daily contents are given. 
The daily table for stream-gaging stations gives mean discharge for each day and is followed by monthly and yearly summaries. In the monthly summary below the daily table, the line headed "TOTAL" gives the sum of the daily figures. The line headed "MEAN" gives the average flow in cubic feet per second during the month. The lines headed "MAX" and "MIN" give the maximum and minimum daily discharges, respectively, for the month. Discharge for the month also is usually expressed in cubic feet per second per square mile (line headed "CFSM"), or in inches (line headed "IN."), or in acre-feet (line headed "AC-FT"). Figures for cubic feet per second per square mile and runoff in inches are omitted if there is extensive regulation or diversion or if the drainage area includes large noncontributing areas. In the yearly summary below the monthly summary, the figures shown are the appropriate discharges for the calendar and water years. At some stations monthly and (or) yearly observed discharges are adjusted for reservoir storage or diversion, or diversions or reservoir contents are given. These figures are identified by a symbol and corresponding footnote.

Data collected at partial-record information for continuous-record sites. This section consists of

stations follow the stations.

\section{Identifying Estimated Daily Discharge}

Estimated daily-discharge values published in the water-discharge tables of annual state data reports are identified by listing the dates of the estimated record in the REMARKS paragraph of the station description.

Accuracy of the Records

The accuracy of streamflow records depends primarily on: (1) The stability of the stage-discharge relation or, if the control is unstable, the frequency of discharge measurements; and (2) the accuracy of measurements of stage, measurements of discharge, and interpretation of records.

The accuracy attributed to the records is indicated under "REMARKS." "Excellent" means that about 95 percent of the daily discharges are within 5 percent of their true values; "good," within 10 percent; and "fair," within 15 percent. Records that do not meet the criteria mentioned are rated "poor." Different accuracies may be attributed to different parts of a given record. 
Daily mean discharges in this report are given to the nearest hundredth of a cubic foot per second for values less than 1 $\mathrm{ft}^{3} / \mathrm{s}$ the nearest tenth between 1.0 and $10 \mathrm{ft}^{3} / \mathrm{s}$; to whole numbers between 10 and $1,000 \mathrm{ft}^{3} / \mathrm{s} ;$ and to 3 significant figures for more than $1,000 \mathrm{ft}^{3} / \mathrm{s}$. The number of significant figures used is based solely on the magnitude of the discharge value. The same rounding rules apply to discharges listed for partial-record stations and miscellaneous sites.

Discharge at many stations, as indicated by the monthly mean, may not reflect natural runoff due to the effects of diversion, consumption, regulation by storage, increase or decrease in evaporation due to artificial causes, or to other factors. For such stations, figures of cubic feet per second per square mile and of runoff, in inches, are not published.

\section{Other Records Available}

Information used in the preparation of the records in this publication, such as discharge-measurement notes, gage-height records, temperature measurements, and rating tables is on file in various field offices of the lowa District. Also, most of the daily mean discharges are in computer-readable form and have been analyzed statistically. Information on the availability of the unpublished information or on the results of statistical analyses of the published records may be obtained from the offices whose addresses are given on the back of the title page of this report. 


\section{Records of Surface-Water Quality}

Records of surface-water quality ordinarily are obtained at or near stream-gaging stations because interpretation of records of surface-water quality nearly always requires corresponding discharge data. Records of surface-water quality in this report may involve a variety of types of data and measurement frequencies.

\section{Classification of records}

Water-quality data for surface-water sites are grouped into one of three classifications. A continuing-record station is a site where data are collected on a regularly scheduled basis. Frequency may be once or more times daily, weekly, monthly, or quarterly. A partial-record station is a site where limited water-quality data are collected systematically over a period of years. Frequency of sampling is usually less than quarterly. A miscellaneous sampling site is a location other than a continuing or partial-record station, where random samples are collected to give better areal coverage to define water-quality conditions in the river basin.

A careful distinction needs to be made between "continuing records" as used in this report and "continuous recordings," which refers to a continuous graph or a series of discrete values punched at short intervals on a paper tape. Some records of water quality, such as temperature and specific conductance, may be obtained through continuous recordings; however, because of costs, most data are obtained only monthly or less frequently. Locations of stations for which records on the quality of surface water appear in this report are shown in figure 10 .

\section{Arrangement of Records}

Water-quality records collected at a surface-water daily record station are published immediately following that record, regardless of the frequency of sample collection. Station number and name are the same for both records. Where a surface-water daily record station is not available or where the water quality differs significantly from that at the nearby surface-water station, the continuing water-quality record is published with its own station number and name in the regular downstream-order sequence. Water-quality data for partial-record stations and for miscellaneous sampling sites appear in separate tables following the table of discharge measurements at miscellaneous sites. 
On-site measurements and sample collection

In obtaining water-quality data, a major concern needs to be assuring that the data obtained represent the in situ quality of the water. To assure this, certain measurements, such as water temperature, pH, alkalinity and dissolved oxygen, are made onsite when the samples are taken. To assure that measurements made in the laboratory also represent the in situ water, carefully prescribed procedures are followed in collecting the samples, in treating the samples to prevent changes in quality pending analysis, and in shipping the samples to the laboratory. Procedures of onsite measurements and for collecting, treating, and shipping samples are given in publications on "Techniques of Water-Resources Investigations," Book 1, Chap. C2; Book 3, Chap. C2; Book 5, Chap. Al, A3, and A4. All of these references are listed on p. 22 of this report. Also, detailed information on collecting, treating, and shipping samples may be obtained from the Geological Survey District office.

One sample can define adequately the water quality at a given time if the mixture of solutes throughout the stream cross section is homogeneous. However, the concentration of solutes at different locations in the cross section may vary widely with different rates of water discharge, depending on the source of material and the turbulence and mixing of the stream. Some streams must be sampled through several vertical sections to obtain the representative sample needed for an accurate mean concentration and for use in calculating load. All samples obtained for the National stream Quality Accounting Network are obtained from at least several verticals. Whether samples are obtained from the centroid of flow or from several verticals, depends on flow conditions and other factors which must be evaluated by the collector.

Chemical-quality data published in this report are considered to be the most representative values available for stations listed. The values reported represent water-quality conditions at the time of sampling as much as possible, consistent with available sampling techniques and methods of analysis. 


\section{Water temperature and specific conductance}

Water temperatures are measured at most of the water-quality stations. The measurement of temperature and specific conductance is performed during each regular site visit (usually at a six week interval) to stream-gaging stations. Records of stream temperature indicate significant thermal characteristics of the stream when analysed over a long period of record. A summary of monthly maximum, minimum, and mean temperatures were published in the 1974 water data report for gaging stations with 10 or more years of record. Large streams have small daily temperature variations while shallow streams may have a daily range of several degrees and may closely follow the changes in air temperature. Furthermore, some streams may be affected by waste-heat discharge.

Specific conductance can be used as a general indicator of stream quality. This determination is easily made in the field with a portable meter, and the results are very useful as general indicators of dissolved-solids concentration or as a base for extrapolating other analytical data. Records for temperature and specific conductance appear in the section "Analyses of samples collected at miscellaneous sites".

A continuous recording thermograph is located on the Mississippi River at Lock and Dam 13 at Clinton. Daily maximum and minimum temperatures are published for this station.

\section{Sediment}

Suspended-sediment concentrations are determined from samples collected by using depth-integrating samples. Samples usually are obtained at several verticals in the cross section, or a single sample may be obtained at a fixed point and a coefficient applied to determine the mean concentration in the cross sections.

During periods of rapidly changing flow or rapidly changing concentration, samples may have been collected more frequently ( $t$ wice daily or, in some instances, hourly). The published sediment discharges for days of rapidly changing flow or concentration were computed by the subdivided-day method (time-discharge weighted average). Therefore, for those days when the published sediment discharge value differs from the value computed as the product of discharge times mean concentration times 0.0027 , the reader can assume that the sediment discharge for that day was computed by the subdivided-day method. For periods when no samples were collected, daily discharges of suspended sediment were estimated on the basis of water discharge, sediment concentrations observed immediately before and after the periods, and suspended-sediment loads for other periods of similar discharge. 
At other stations, suspended-sediment samples were collected periodically at many verticals in the stream cross section. Although data collected periodically may represent conditions only at the time of observations, such data are useful in establishing seasonal relations between quality and streamflow and in predicting long-term sediment-discharge characteristics of the stream.

In addition to the records of the quantities of suspended-sediment, records of the periodic measurements of the particle-size distribution of the suspended-sediment and bed material are included. Miscellaneous suspended-sediment samples were collected during flood events have been included with the station's water quality data or in the section "Analyses of samples at miscellaneous sites".

\section{Laboratory measurements}

Sediment samples, samples for indicator bacteria, and daily samples for specific conductance are analyzed locally. All other samples are analyzed in the Geological survey laboratories in Arvada, Colorado. Methods used in analyzing sediment samples and computing sediment records are given in TWRI, Book 5, Chap. Cl. Methods used by the Geological Survey laboratories are given in TWRI, Book 1, Chap. D2, Book 3, Chap. C2; Book 5, Chap. Al, $A 3$, and A4.

\section{Data Presentation}

For continuing-record stations, information pertinent to the history of station operation is provided in descriptive headings preceding the tabular data. These descriptive headings give details regarding location, drainage area, period of record, type of data available, instrumentation, general remarks, cooperation, and extremes for parameters currently measured daily. Tables of chemical, physical, biological, radiochemical data, and so forth, obtained at a frequency less than daily are presented first. Tables of "daily values" of specific conductance, $\mathrm{pH}$, water temperature, dissolved oxygen, and suspended sediment then follow in sequence. 
In the descriptive headings, if the location is identical to that of the discharge gaging station, neither the LOCATION nor the DRAINAGE AREA statements are repeated. The following information, as appropriate, is provided with each continuous-record station. Comments that follow clarify information presented under the various headings of the station description.

LOCATION.--See Data Presentation under "Records of Stage and Water Discharge;" same comments apply.

DRAINAGE AREA.--See Data Presentation under "Records of stage and Water Discharge;" same comments apply.

PERIOD OF RECORD.--This indicates the periods for which there are published water-quality records for the station. The periods are shown separately for records of parameters measured daily or continuously and those measured less than daily. For those measured daily or continuously, periods of record are given for the parameters individually.

INSTRUMENTATION. -- Inf ormation on instrumentation is given only if a water-quality monitor temperature record, sediment pumping sampler, or other sampling device is in operation at a station.

REMARKS.--Remarks provide added information pertinent to the collection, analysis, or computation of the records.

COOPERATION.--Records provided by a cooperating organization or obtained for the Geological survey by a cooperating organization are identified here.

EXTREMES.--Maximums and minimums are given only for parameters measured daily or more frequently. None are given for parameters measured weekly or less frequently, because the true maximums or minimums may not have been sampled. Extremes, when given, are provided for both the period of record and for the current water year. 
REVISIONS.--If errors in published water-quality records are discovered after publication, appropriate updates are made to the Water-Quality File in the U.S. Geological Survey's computerized data system, WATSTORE, and subsequently by monthly transfer of update transactions to the U.S. Environmental Protection Agency's STORET system. Because the usual volume of updates makes it impractical to document individual changes in the state data-report series or elsewhere, potential users of U.S. Geological Survey water-quality data are encouraged to obtain all required data from the appropriate computer file to insure the most recent updates.

The surface-water-quality records for partial-record stations and miscellaneous sampling sites are published in separate tables following the table of discharge measurements at miscellaneous sites. No descriptive statements are given for these records. Each station is published with its own station number and name in the regular downstream-order sequence. 


\section{Remark Codes}

The following remark codes may appear with the water-quality data in this report:

PRINTED OUTPUT

$\mathbf{E}$

$>$

$<$

$\mathbf{K}$

L

D

$\&$

\section{REMARK}

Estimated value

Actual value is known to be greater than the value shown

Actual value is known to be less than the value shown

Results based on colony count outside the acceptance range (non-ideal colony count)

Biological organism count less than 0.5 percent (organism may be observed rather than counted)

Biological organism count equal to or greater than 15 percent (dominant)

Biological organism estimated as dominant 


\section{Records of Ground-Water Levels}

Ground-water level data from a network of observation wells in Iowa are published in this report. These data provide a limited historical record of water-level changes in the state's most important aquifers. Locations of the observation wells in this network in lowa are shown in figure 11. Information about the availability of the data in the water-level files of the U.S. Geological Survey may be obtained from the District Chief, Iowa District (see adaress on back of title page page).

Data Collection and Computation

Measurements of water levels are made in many types of wells under varying conditions, but the methods of measurement are standardized to the extent possible. The equipment and measuring techniques used at each observation well ensure that measurements at each well are of consistent accuracy and reliability.

Tables of water-level data are arranged alphabetically by counties. The site identification number, based on latitude and longitude, for a given well is the 15-digit alphanumeric value that appears in the upper left corner of the station description. The secondary identification number is the local well number, an alphanumeric value, derived from the township and range location of the well (fig. 8).

Water-level records are obtained from direct measurements with a chalked steel tape, electric line, airline, or from the graph of a water-level recorder. The water-level measurements in this report are in feet with reference to land-surface datum. Land-surface datum is a plane that is approximately at land surface at each well. The elevation of the land-surface datum is given in the well description. The height of the measuring point above or below land-surface datum is given in each well description. Water levels in wells equipped with recording gages are reported for every fifth day and the end of each month (EOM).

Water-level measurements are reported to the nearest hundreth

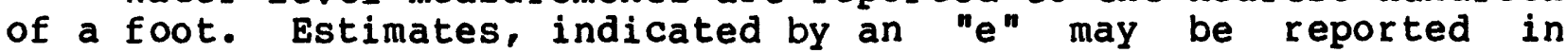
tenths of a foot. The error of water-level measurements may be, at most, a few hundreths of a foot. 


\section{Data Presentation}

Each well record consists of two parts, the station description and the table of water levels observed during the water year. The description of the well is presented by headings preceding the tabular data. The following explains the information presented under each heading.

LOCATION.--This paragraph follows the well identification number and includes the latitude and longitude (given in degrees, minutes, and seconds), the hydrologic unit number, the distance and direction from a geographic point of reference, and the well owner's name.

AQUIFER.--This entry is the aquifer(s) name (if one exists) and geologic age of the strata open to the well.

WELL CHARACTERISTICS.--This entry describes the well depth, casing diameter, casing depth, opening or screened interval(s), method of construction, and use of water from the well.

INSTRUMENTATION.--This paragraph provides information on the frequency of measurement and the collection method used.

DATUM.--This entry includes the measuring point and the land-surface elevation at the well. The measuring point is described physically and in relation to land surface. The elevation of the land-surface datum is in feet above National Geodetic Vertical Datum of 1929 and its precision is dependent on the method of determination.

REMARKS.--This entry describes factors that may influence the water level in a well or the measurement of the water level and any information not presented in the other parts of the station description but considered useful.

PERIOD OF RECORD.--This entry indicates the period for which there are published records for the well. It reports the month and year of the begining of publication of water-level records by the U.S. Geological survey. 
REVISED RECORDS.--If any revisions of previously published data were made for water-levels, the water Data Report in which they appeared and year published would appear here.

EXTREMES FOR PERIOD OF RECORD.--This entry contains the highest and lowest water levels for the period of record, below land-surface datum, and the dates of their occurrence.

A table of water levels follows the station description for each well. Water levels are reported in feet below land-surface datum. For wells equipped with recorders, only abbreviated tables are published. The highest and lowest water levels of the water year and the dates of occurence are shown on a line below the abbreviated table. Because all values are not published for wells with recorders, the extremes may be values that are not listed in the table. Missing records are indicated by dashes in place of the water level.

Hydrographs are included for nine wells which are representative of hydrologic conditions in the important aquifers in Iowa.

Only water-level data from a national network of observation wells are given in this report. These data are intended to provide a sampling and historical record of water-level changes in the Nation's most important aquifers. Locations of the observation wells in this network in lowa are shown in figure 11. 


\section{Records of Ground-Water Quality}

Records of ground-water quality in this report differ from other types of records in that for most sampling sites they consist of only one set of measurements for the water year. The quality of ground water ordinarily changes only slowly; therefore, for most general puposes one annual sampling, or only a few samples taken at infrequent intervals during the year, is sufficient. Frequent measurement of the same constituents is not necessary unless one is concerned with a particular problem, such as monitoring for trends in nitrate concentration. In the special cases where the quality of ground water may change more rapidly, more frequent measurements are made to identify the nature of the changes.

The records of ground-water quality in this report were obtained as a part a statewide ground-water quality monitoring network operated by the Iowa District. All samples were obtained from municipal wells throughout Iowa. This program is conducted in cooperation with the University of Iowa Hygienic Laboratory (UHL) and the Iowa Geological survey. All samples are collected by USGS personnel, field-preserved and submitted to UHL for analysis. Chemical analyses include common constituents (major ions), nutrients, trace metals, radionuclides and pesticides. Approximately 10 percent of the samples receive additional analyses for about 90 organic priority pollutants, however these analyses are not presented in this report but are on file in the District office.

Most methods for collecting and analyzing water samples are described in the "U.S. Geological Survey Techniques of Water-Resources Investigations" manuals listed on a following page. The values reported in this report represent water-quality conditions at the time of sampling as much as possible, consistent with available sampling techniques and methods of analysis. All samples were obtained by trained personnel. The wells sampled were pumped long enough to assure that the water collected came directly from the aquifer and had not stood for a long time in the well casing where it would have been exposed to the atmosphere and to the material, possible metal, comprising the casings. The samples collected represent raw water 


\section{Data Presentation}

The records of ground-water quality are published in a section titled GROUND-WATER QUALITY DATA immediately following the ground-water-level records. Data for quality of ground water are listed alphabetically by County, and are identified by station number. The prime identification number for wells sampled is the 15-digit station number derived from the latitude-longitude locations. No descriptive statements are given for ground-water-quality records; however, the station number, date and time of sampling, depth of well, and other pertinent data are given in the table containing the chemical analyses of the ground water. The REMARK codes 1 isted for surface-water-quality records are also applicable to ground-water-quality records. 
Explanation of descriptive headings

STATION NAME: Descriptive identifier for each well which contains four elements that are explained below.

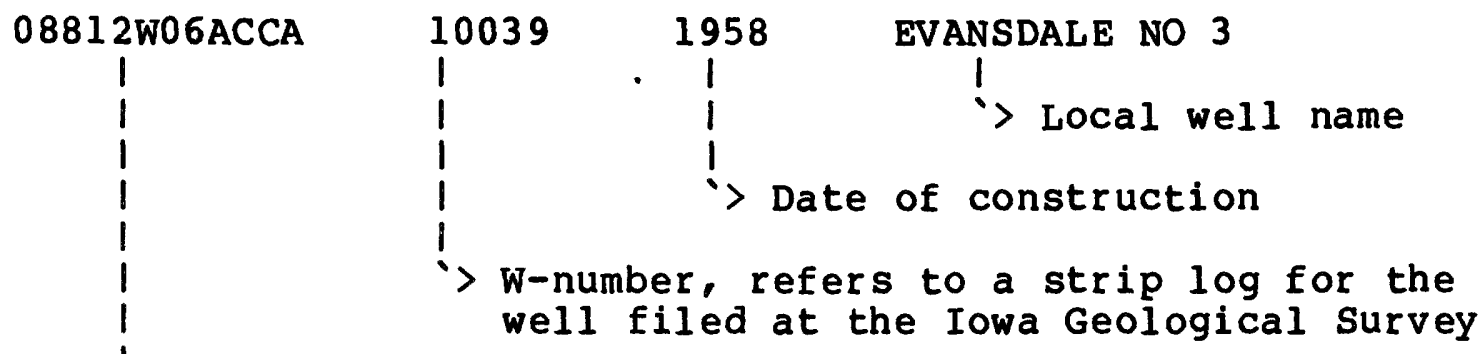

Local well number, refers to the Bureau of Land Management System of land subdivision

GEOLOGIC UNIT: Refers to the lithologic unit in which the well is completed. First two digits of the code refer to the principal unit which is providing the majority of water to the well.

$11=$ Quaternary
$21=$ Cretaceous
$32=$ Pennsylvanian
$33=$ Mississippian

$34=$ Devonian

$35=$ Silurian

$36=$ ordivician

$37=$ Cambrian

Third digit and remaining alphabetic characters refer to the more specific lithologic unit which the well is tapping. The following examples are commonly used units.

CODE General--

112 PLSC--Quaternary

217DKDT--Cretaceous

371 JRDN--Cambrian

325DSMS--Pennsyl vanian

333 STLS--Mississippian

344 CDVL--Devonian

$335 \mathrm{HPKN}--$ Silurian

364STPR--Ordovician
(Pleistocene)

(Dakota sandstone)

(Jordan sandstone)

(Des Moinesian sandstone)

(St. Louis limestone)

(Cedar Valley limestone)

(Hopkinton dolomite)

(st. Peter sandstone) 


\section{ACCESS TO WATSTORE DATA}

The National WATer Data STOrage and REtrieval System (WATSTORE) was established for handling water data collected through the activities of the U.S. Geological survey and to provide for more effective and efficient means of releasing the data to the public. The system is operated and maintained on the central computer facilities of the survey at its National Center in Reston, Virginia.

WATSTORE can provide a variety of useful products ranging from simple data tables to complex statistical analyses. A minimal fee, plus the actual computer cost incurred in producing a desired product, is charged to the requester. Information about the availability of specific types of data, the acquisition of data or products, and user charges can be obtained locally from the offices whose addresses are given on the back of the title page.

General inquiries about WATSTORE may be directed to:

Chief Hydrologist

U.S. Geological Survey

437 National Center

Reston, Virginia 22092 


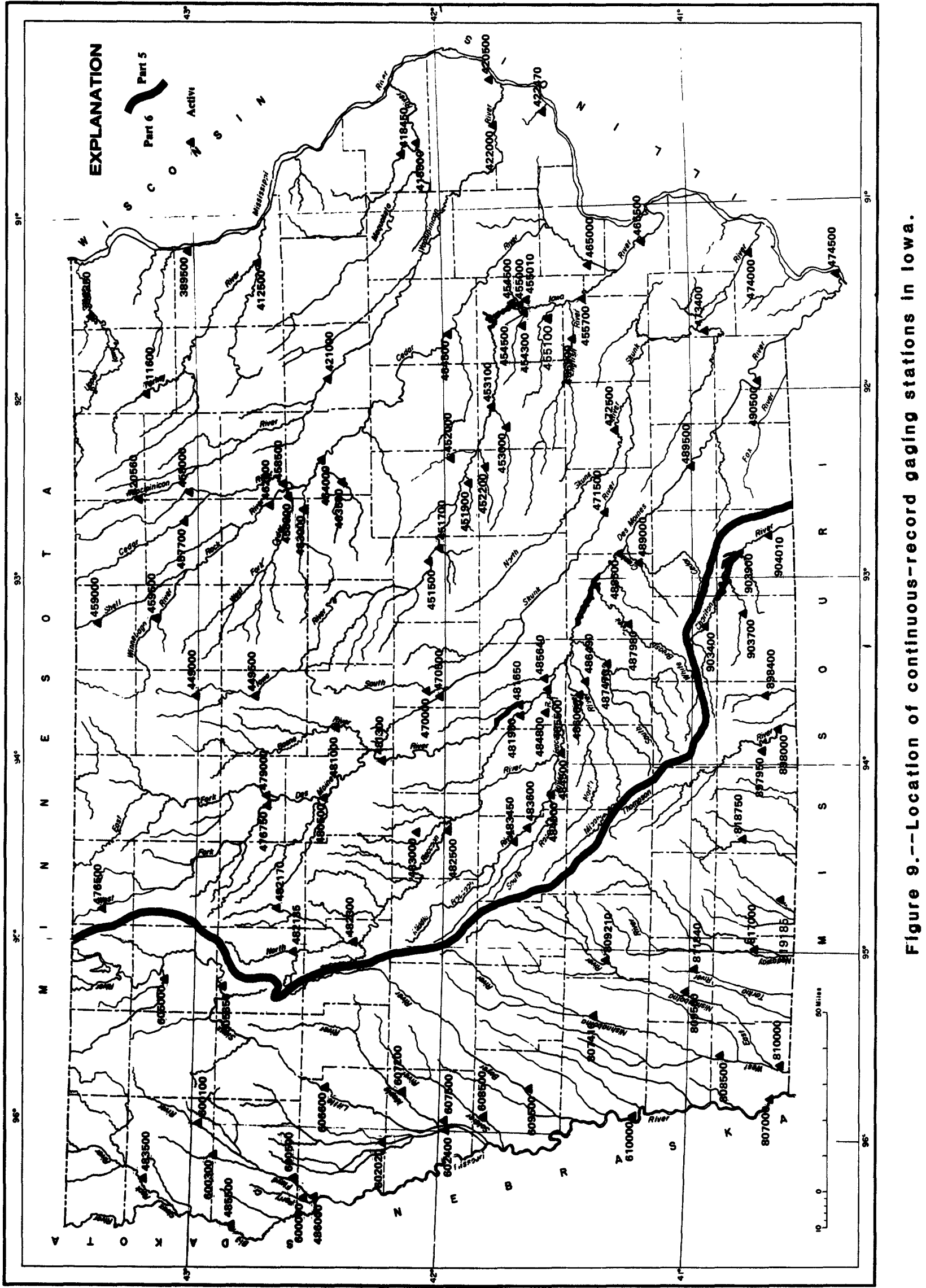




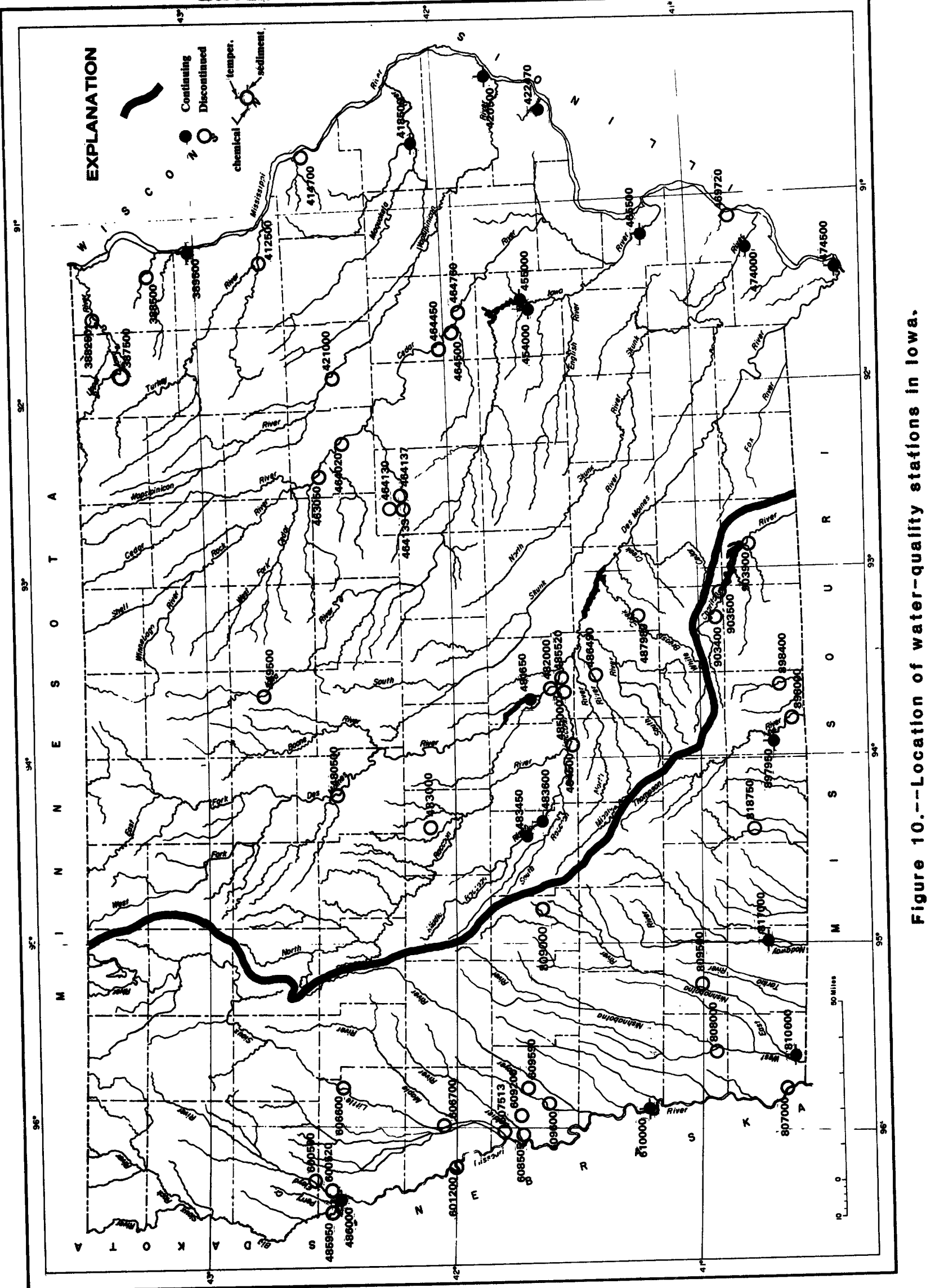




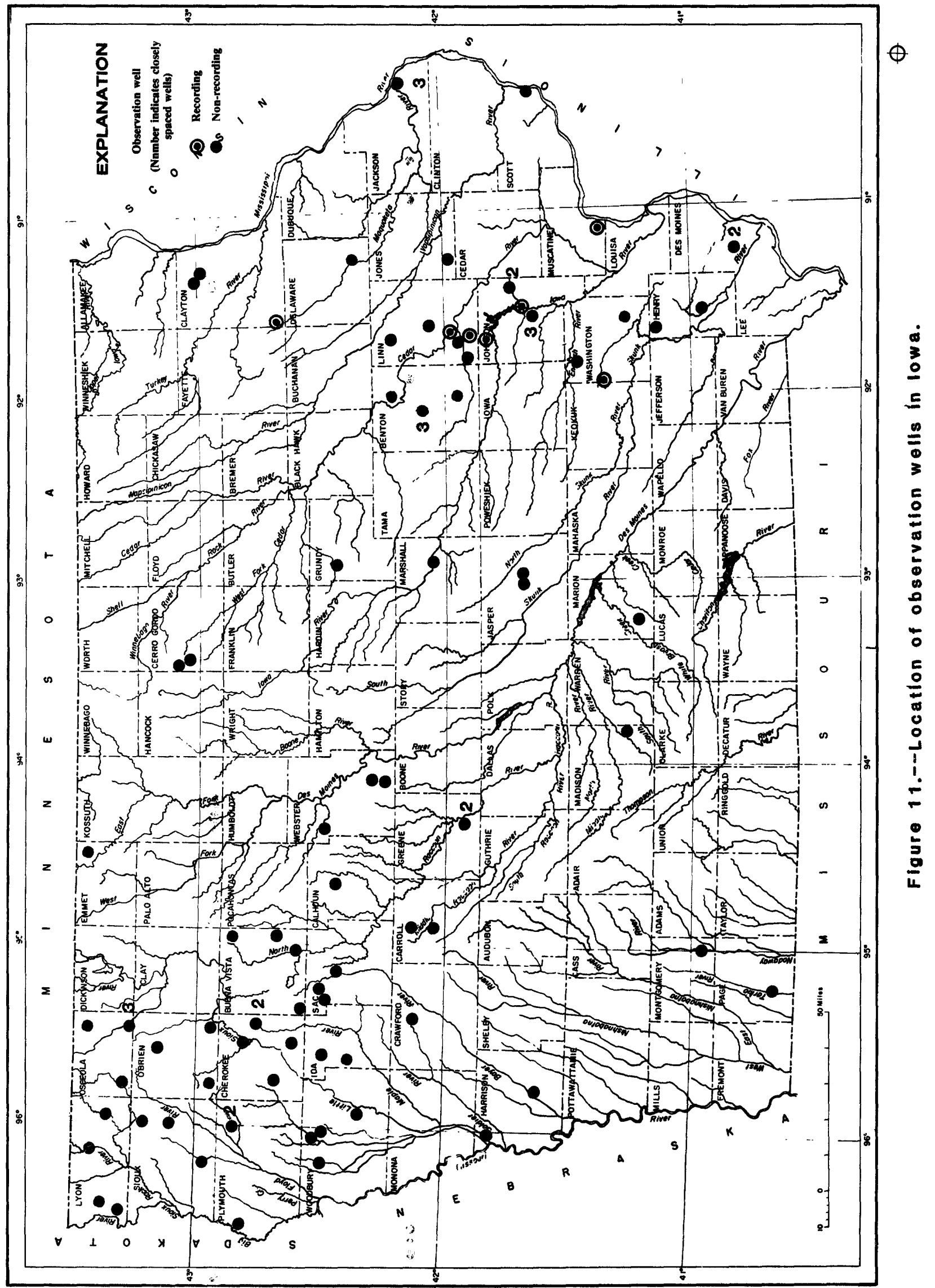




\section{DEFINITION OF TERMS}

Terms related to streamflow, water-quality, and other hydrologic data, as used in this report, are defined below. See also table for converting English units to International system (SI) Units on the inside of the back cover.

Acre-foot (AC-FT, acre-ft) is the quantity of water reguired to cover 1 acre to a depth of 1 foot and is equivalent to 43,560 cubic feet or about 326,000 gallons or 1,233 cubic meters.

Aquifer is a geologic formation, group of formations, or part of a formation that contains sufficient saturated permeable material to yield significant quantities of water to wells and springs.

Artesian means confined and is used to describe a well in which the water level stands above the top of the aquifer tapped by the well. A flowing artesian well is one in which the water level is above the land surface.

Bacteria are microscopic unicellular organisms, typically spherical, rodlike, or spiral and threadlike in shape, often clumped into colonies. Some bacteria cause disease, while others perform an essential role in nature in the recycling of materials; for example, by decomposing organic matter into a form available for reuse by plants.

Fecal coliform bacteria are bacteria that are present in the intestine or feces of warm-blooded animals. They are often used as indicators of the sanitary quality of the water. In the laboratory they are defined as all organisms that produce blue colonies within 24 hours when incubated at $44.5^{\circ} \mathrm{C}$ plus or minus $0.2^{\circ} \mathrm{C}$ on $\mathrm{M}-\mathrm{FC}$ medium (nutrient medium for bacterial growth). Their concentrations are expressed as number of colonies per 100 $\mathrm{mL}$ of sample.

Fecal streptococcal bacteria are bacteria "found also in the intestine of warm-blooded animals. Their presence in water is considered to verify fecal pollution. They are characterized as Gram-positive, cocci bacteria which are capable of growth in brain-heart infusion broth. In the laboratory they are defined as all the organisms which produce red or pink colonies within 48 hours at $35^{\circ} \mathrm{C}$ plus or minus $1.0^{\circ} \mathrm{C}$ on $\mathrm{KF}-$ streptococcus medium (nutrient medium for bacterial growth). Their concentrations are expressed as number of colonies per $100 \mathrm{~mL}$ of sample. 
Bed material is the sediment mixture of which a streambed, lake, pond, reservoir, or estuary bottom is composed.

Bottom material: see Bed material.

Cubic-foot-per-second day is the volume of water represented by a flow of 1 cubic foot per second for 24 hours. It is equivalent to 86,400 cubic feet, approximately 1.9835 acre-feet, about 646,000 gallons, or 2,445 cubic meters.

Contents is the volume of water in a reservoir or lake. Unless otherwise indicated, volume is computed on the basis of a level pool and does not include bank storage.

Control designates a feature downstream from the gage that determines the stage-discharge relation at the gage. This feature may be a natural constriction of the channel, an artificial structure, or a uniform cross section over a long reach of the channel.

Control structure as used in this report is a structure on a stream or canal that is used to regulate the flow or stage of the stream or to prevent the intrusion of salt water.

Cubic foot per second $\left(\mathrm{ft}^{3} / \mathrm{s}\right)$ is the rate of discharge representing a volume of 1 cubic foot passing a given point during 1 second and is equivalent to 7.48 gallons per second or 448.8 gallons per minute or 0.02832 cubic meters per second.

Cubic feet per second per square mile (CFSM) is the average number of cubic feet of water flowing per second from each square mile of area drained, assuming that the runoff is distributed uniformly in time and area.

Discharge is the volume of water (or more broadly, volume of fluid plus suspended sediment) that passes a given point within a given period of time.

Mean discharge (MEAN) is the arithmetic mean of individual daily mean discharges during a specific period.

Instantaneous discharge is the discharge at a particular instant of time.

Dissolved refers to that material in a representative water sample which passes through a 0.45 um membrane filter. This is a convenient operational definition used by Federal agencies that collect water data. Determinations of "dissolved" constituents are made on subsamples of the filtrate. 
Dissolved-solids concentration of water is determined either analytically by the "residue-on-evaporation" method, or mathematically by totaling the concentrations of individual constituents reported in a comprehensive chemical analysis. During the analytical determination of dissolved solids, the bicarbonate (generally a major dissolved component of water) is converted to carbonate. Therefore, in the mathematical calculation of dissolved-solids concentration, the bicarbonate value, in milligrams per liter, is multiplied by 0.492 to reflect the change.

Drainage area of a stream at a specified location is that area, measured in a horizontal plane, enclosed by a topographic divide from which direct surface runoff from precipitation normally drains by gravity into the stream above the specified point. Figures of drainage area given herein include all closed basins, or noncontributing areas, within the area unless otherwise specified.

Drainage basin is a part of the surface of the earth that is occupied by a drainage system, which consists of a surface stream or a body of impounded surface water together with all tributary surface streams and bodies of impounded surface water.

Gage height (G.H.) is the water-surface elevation referred to some arbitrary gage datum. Gage height is often used interchangeably with the more general term "stage," although gage height is more appropriate when used with a reading on a gage.

Gaging station is a particular site on a stream, canal, lake, or reservoir where systematic observations of hydrologic data are obtained.

Hardness of water is a physical-chemical characteristic that is commonly recognized by the increased quantity of soap required to produce lather. It is computed as the sum of equivalents of polyvalent cations and is expressed as the equivalent concentration of calcium carbonate (CaCO).

Hydrologic Bench-Mark Network is a network of 57 sites in small drainage basins around the country whose purpose is to provide consistent data on the hydrology, including water quality, and related factors in representative undeveloped watersheds nationwide, and to provide analyses on a continuing basis to compare and contrast conditions observed in basins more obviously affected by the activities of man. 
Hydrelegic unit is a geographic area representing part or all of a surface drainage basin or distinct hydrologic feature as delineated by the Office of Water Data Coordination on the state Hydrologic Unit Maps; each hydrologic unit is identified by an eight-digit number.

Land-surface datum (lsd) is a datum plane that is approximately at land surface at each ground-water observation well.

Measuring point (MP) is an arbitrary permanent reference point from which the distance to the water surface in a well is measured to obtain the water level.

Micrograms per gram $(u g / g)$ is a unit expressing the concentration of a chemical constituent as the mass (micrograms) of the element per unit mass (gram) of material analyzed.

Micregrams per liter (UG/L, $u g / L$ ) is a unit expressing the concentration of chemical constituents in solution as mass (micrograms) of solute per unit volume (liter) of water. One thousand micrograms per liter is equivalent to one milligram per liter.

Milligrams per liter (MG/L, $\mathrm{mg} / L$ ) is a unit for expressing the concentration of chemical constituents in solution. Milligrams per liter represents the mass of solute per unit volume (liter) of water. Concentration of suspended sediment also is expressed in $\mathrm{mg} / \mathrm{L}$ and is based on the mass of dry sediment per liter of water-sediment mixture.

National Geodetic Vertical Datum of 1929 (NGVD of 1929) is a geodetic datum derived from a general adjustment of the first order level nets of both the United States and Canada. It was formerly called "Sea Level Datum of 1929 " or "mean sea level" in this series of reports. Although the datum was derived from the average sea level over a period of many years at 26 tide stations along the Atlantic, Gulf of Mexico, and Pacific Coasts, it does not necessarily represent local mean sea level at any particular place. 
National stream Quality Accounting Network (NASQAN) is a nationwide data-collection network designed by the U.S. Geological survey to meet many of the information needs of government agencies and other groups involved in natural or regional water-quality planning and management. The 500 or so sites in NASQAN are generally located at the downstream ends of hydrologic accounting units designated by the U.S. Geological Survey Office of Water Data Coordination in consultation with the Water Resources Council. The objectives of NASQAN are (1) to obtain information on the quality and quantity of water moving within and from the United states through a systematic and uniform process of data collection, summarization, analysis, and reporting such that the data may be used for, (2) description of the areal variability of water quality in the Nation's rivers through analysis of data from this and other programs, (3) detection of changes or trends with time in the pattern of occurrence of water-quality characteristics, and (4) providing a nationally consistent data base useful for water-quality assessment and hydrologic research.

The National Trends Network (NTN) is a 150-station network for sampling atmospheric deposition in the United states. The purpose of the network is to determine the variability, both in location and in time, of the composition of atmospheric deposition, which includes snow, rain, dust particles, aerosols, and gases. The core from which the NTN was built was the already-existing deposition-monitoring network of the National Atmospheric Deposition Program (NADP).

Parameter code is a 5-digit number used in the U.S. Geological Survey computerized data system, WATSTORE, to uniquely identify a specific constituent. The codes used in WATSTORE are the same as those used in the U.S. Environmental protection Agency data system, STORET. The Environmental Protection Agency assigns and approves all requests for new codes.

Partial-record station is a particular site where limited streamflow and/or water-quality data are collected systematically over a period of years for use in hydrologic analyses.

Particle size is the diameter, in millimeters (mm), of a particle determined by either sieve or sedimentaiton methods. Sedimentation methods (pipet, bottom-withdrawal tube, visualaccumulation tube) determine fall diameter of particles in either distilled water (chemically dispersed) or in native water (the river water at the time and point of sampling). 
Particle-size classification used in this report agrees with the recommendation made by the American Geophysical Union subcommittee on Sediment Terminology. The classification is as follows :

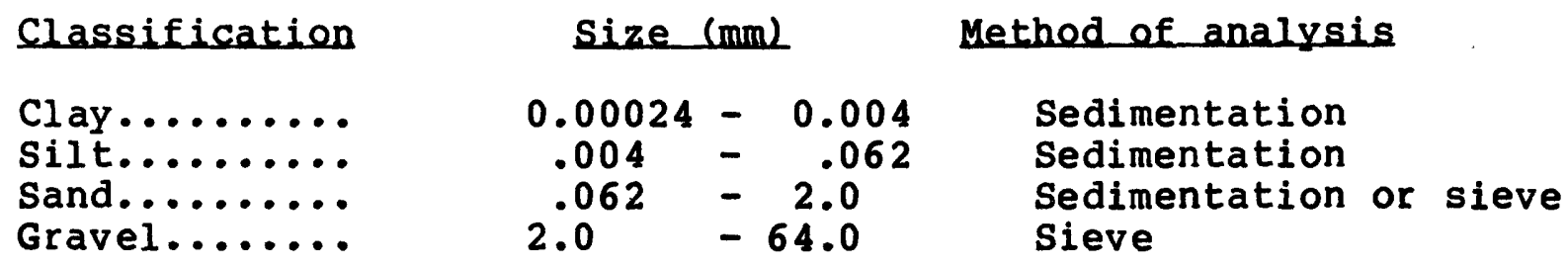

The particle-size distributions given in this report are not necessarily representative of all particles in transport in the stream. Most of the organic matter is removed, and the sample is subjected to mechanical and chemical dispersion before analysis in distilled water. Chemical dispersion is not used for native-water analysis.

Pesticides are chemical compounds used to control undesirable organisms. Major categories of pesticides include insecticides, miticides, fungicides, herbicides, and rodenticides.

Picecurie (PC, $\mathrm{pCi}$ ) is one trillionth ( $1 \times 10$ ) of the amount of radioactivity represented by a curie (Ci). A curie is the amount of radioactivity that yields $3.7 \times 10$ radioactive disintegrations per second. A picocurie yields 2.22 dpm (disintegrations per minute).

Radiochemical program is a network of regularly sampled water-quality stations where samples are collected to be analyzed for radioisotopes. The streams that are sampled represent major drainage basins in the conterminous United States.

Recoverable from bottom material is the amount of a given constituent that is in solution after a representative sample of bottom material has been digested by a method (usually using an acid or mixture of acids) that results in dissolution of readily soluble substances. Complete dissolution of all bottom material is not achieved by the digestion treatment and thus the determination represents less than the total amount (that is, less than 95 percent) of the constituent in the sample. To achieve comparability of analytical data, equivalent digestion procedures would be required of all laboratories performing such analyses because different digestion procedures are likely to produce different analytical results. 
Return peried is the average time interval between occurrences of a hydrological event of a given or greater magnitude, usually expressed in years. May also be called recurrence interval.

Bunoff in inches (IN., in.) shows the depth to which the drainage area would be covered if all the runoff for a given time period were uniformly distributed on it.

Sediment is solid material that originates mostly from disintegrated rocks and is transported by, suspended in, or deposited from water: it includes chemical and biochemical precipitates and decomposed organic material, such as humus. The quantity, characteristics, and cause of the occurrence of sediment in streams are influenced by environmental factors. Some major factors are degree of slope, length of slope, soil characteristics, land usage, and quantity and intensity of precipitation.

Bed load is the sediment that is transported in a stream by rolling, sliding, or skipping along the bed and very close to it. In this report, bed load is considered to consist of particles in transit within $0.25 \mathrm{ft}$ of the streambed.

Bed load discharge (tons per day) is the quantity of bed load measured by dry weight that moves past a section as bed load in a given time.

Suspended sediment is the sediment that at any given time is maintained in suspension by the upward components of turbulent currents or that exists in suspension as a colloid.

Suspended-sediment concentration is the velocity-weighted concentration of suspended sediment in the sampled zone (from the water surface to a point approximately $0.3 \mathrm{ft}$ above the bed) expressed as milligrams of dry sediment per liter of water-sediment mixture (mg/L).

Mean concentration is the time-weighted concentration of suspended sediment passing a stream section during a 24. hour day.

Suspended-sediment discharge (tons/day) is the rate at which dry mass of sediment passes a section of a stream or is the quantity of sediment, as measured by dry mass or volume, that passes a section in a given time. It is calculated in units of tons per day as follows: concentration $(\mathrm{mg} / \mathrm{L}) \times$ discharge $\mathrm{ft}^{3} / \mathrm{s} \times 0.0027$. 
Suspended-sediment load is a general term that refers to material in suspension. It is not synonymous with either discharge or concentration.

Total sediment discharge (tons/day) is the sum of the suspended-sediment discharge and the bed-load discharge. It is the total quantity of sediment, as measured by dry mass or volume, that passes a section during a given time.

Total-sediment load or total load is a term which refers to the total sediment (bed load plus suspended-sediment load) that is in transport. It is not synonymous with total-sediment discharge.

7-day 10-year low flow (7 $Q$ ) is the discharge at the 10-year recurrence interval taken from a frequency curve of annual values of the lowest mean discharge for 7 consecutive days (the 7-day low flow).

Sodium-adsorption-ratio (SAR) is the expression of relative activity of sodium ions in exchange reactions within soil and is an index of sodium or alkali hazard to the soil. Waters range in respect to sodium hazard from those which can be used for irrigation on almost all soils to those which are generally unsatisfactory for irrigation.

solute is any substance that is dissolved in water.

Specific conductance is a measure of the ability of a water to conduct an electrical current. It is expressed in microsiemens per centimeter at $25^{\prime} \mathrm{C}$. Specific conductance is related to the type and concentration of ions in solution and can be used for approximating the dissolved-solids content of the water. Commonly, the concentration of dissolved solids (in milligrams per liter) is about 65 percent of the specific conductance (in microsiemens). This relation is not constant from stream to stream, and it may vary in the same source with changes in the composition of the water.

Stage-discharge relation is the relation between gage height (stage) and volume of water, per unit of time, flowing in a channel. 
Streamflow is the discharge that occurs in a natural channel. Although the term "discharge" can be applied to the flow of a canal, the word "streamflow" uniquely describes the discharge in a surface stream course. The term "streamflow" is more general than "runoff" as streamflow may be applied to discharge whether or not it is affected by diversion or regulation.

Surface area of a lake is that area outlined on the latest U.S.G.S. topographic map as the boundary of the lake and measured by a planimeter in acres. In localities not covered by topographic maps, the areas are computed from the best maps available at the time planimetered. All areas shown are those for the stage when the planimetered map was made.

Surficial bed material is the part $(0.1$ to $0.2 \mathrm{ft})$ of the bed material that is sampled using U.S. Series Bed-Material Samplers.

Suspended (as used in tables of chemical analyses) refers to the amount (concentration) of undissolved material in a water-sediment mixture. It is associated with the material retained on a $0.45-m i c r o m e t e r$ filter.

Suspended, recoverable is the amount of a given constituent that is in solution after the part of a representative water-suspended sediment sample that is retained on a 0.45 um membrane filter has been digested by a method (usually using a dilute acid solution) that results in dissolution of only readily soluble substances. Complete dissolution of all the particulate matter is not achieved by the digestion treatment and thus the determination represents something less than the "total" amount (that is, less than 95 percent) of the constituent present in the sample. To achieve comparability of analytical data, equivalent digestion procedures are required of all laboratories performing such analyses because different digestion procedures are likely to produce different analytical results.

Determinations of "suspended, recoverable" constituents are made either by analyzing portions of the material collected on the filter or, more commonly, by difference, based on determinations of (1) dissolved and (2) total recoverable concentrations of the consti tuent.

Suspended, total is the total amount of a given constituent in the part of a represen-tative water-suspended sediment sample that is retained on a 0.45 um membrane filter. This term is used only when the analytical procedure assures measurement of at least 95 percent of the constituent determined. A knowledge of the expected form of the constituent in the sample, as well as the analytical methodology used, is required to determine when the results should be reported as "suspended, total." 
Determinations of "suspended, total" constituents are made either by analyzing portions of the material collected on the filter or, more commonly, by difference, based on determinations of (1) dissolved and (2) total concentrations of the constituent.

Thermograph is an instrument that continuously records variations of temperature on a chart. The more general term "temperature recorder" is used in the table headings and refers to any instrument that records temperature whether on a chart, a tape, or any other medium.

Time-weighted average is computed by multiplying the number of days in the sampling period by the concentrations of individual constituents for the corresponding period and dividing the sum of the products by the total number of days. A time-weighted average represents the composition of water that would be contained in a vessel or reservoir that had received equal quantities of water from the stream each day for the year.

Tons per acre-foot indicates the dry mass of dissolved solids in 1 acre-foot of water. It is computed by multiplying the concentration of the constituent, in milligrams per liter, by 0.00136 .

Tons per day (T/DAY) is the quantity of a substance in solution or suspension that passes a stream section during a 24-hour period.

Total is the total amount of a given constituent in a representative water-suspended sediment sample, regardless of the constituent's physical or chemical form. This term is used only when the analytical procedure assures measurement of at least 95 percent of the constituent present in both the dissolved and suspended phases of the sample. A knowledge of the expected form of the constituent in the sample, as well as the analytical methodology used, is required to judge when the results should be reported as "total." (Note that the word "total" does double duty here, indicating both that the sample consists of a water-suspended sediment mixture and that the analytical method determined all of the constituent in the sample.)

Total discharge is the total quantity of any individual constituent, as measured by dry mass or volume, that passes through a stream cross-section per unit of time. This term needs to be qualified, such as "total sediment discharge," "total chloride discharge," and so on. 
Total, recoverable is the amount of a given constituent that is in solution after a representative water-suspended sediment sample has been digested by a method (usually using a dilute acid solution) that results in dissolution of only readily soluble substances. Complete dissolution of all particulate matter is not achieved by the digestion treatment, and thus the determination represents something less than the "total" amount (that is, less than 95 percent) of the constituent present in the dissolved and suspended phases of the sample. To achieve comparability of analytical data, equivalent digestion procedures are required of all laboratories performing such analyses because different digestion procedures are likely to produce different analytical results.

Tritium Network is a network of stations which has been established to provide baseline information on the occurrence of tritium in the Nation's surface waters. In addition to the surface-water stations in the network, tritium data are also obtained at a number of precipita- tion stations. The purpose of the precipitation stations is to provide an estimate sufficient for hydrologic studies of the tritium input to the United states.

Water year in Geological survey reports dealing with surface-water supply is the 12-month period October 1 through september 30 . The water year is designated by the calendar year in which it ends and which includes 9 of the 12 months. Thus, the year ending September 30,1985 , is called the "1985 water year."

WDB is used as an abbreviation for "Water-Data Report" in the REVISED RECORDS paragraph to refer to state annual hydrologic-data reports (WRD was used as an abbreviation for "water-Resources Data" in reports published prior to 1976).

Weighted average is used in this report to indicate discharge-weighted average. It is computed by multiplying the discharge for a sampling period by the concentrations of individual constituents for the corresponding period and dividing the sum of the products by the sum of the discharges. A discharge-weighted average approximates the composition of water that would be found in a reservoir containing all the water passing a given location during the water year after thorough mixing in the reservoir.

WSP is used as an abbreviaton for "Water-supply Paper" in reference to previously published reports. 
Forty-one manuals by the U.S. Geological survey have been published to date in the series on techniques describing procedures for planning and executing specialized work in water-resources investigations. The material is grouped under major subject headings called books and is further divided into sections and chapters. For example, Section A of Book 3 (Applications of Hydraulics) is on surface water, The chapter, the unit of publication, is limited to a narrow $f i e l d$ of subject matter. This format permits flexibility in revision and publication as the need arises. The reports listed below are for sale by the U.S. Geological Survey, Branch of Distribution, 604 South Pickett street, Alexandria, VA 22304 (authorized agent of the Superintendent of Documents, Government Printing Office).

NOTE: When ordering any of these publications, please give the title, book number, chapter number and "U.S. Geological Survey Techniques of Water-Resources Investigations".

1-Dl. Water temperature--influential factors, field measurements, and data presentation, by H. H. Stevens, Jr., J. F. Ficke, and G. F. Smoot: USGS--TWRI Book 1, Chapter Dl. 1975.65 pages.

1-D2. Guidelines for collection and field analysis of ground-water samples for selected unstable constituents, by W. W. Wood: USGS--TWRI Book 1, Chapter D2. 1976.24 pages.

2-D1. Application of surface geophysics to ground-water resources investigations, by A. A. R. Zohdy, G. P. Eaton, and D. R. Mabey: USGS--TWRI Book 2, Chapter D1. 1974. 116 pages.

2-El. Application of borehole geophysics to water-resources investigations, by W. S. Keys and L. M. MacCary: USGS--TWRI Book 2, Chapter El. 1971. 126 pages.

3-Al. General field and office procedures for indirect discharge measurements, by M. A. Benson and Tate Dalrymple: USGS-TWRI Book 3, Chapter Al. 1967. 30 pages.

3-A2. Measurement of peak discharge by the slope-area method, by Tate Dalrymple and M. A. Benson: USGS--TWRI Book 3, Chapter A2. 1967 . 12 pages.

3-A3. Measurement of peak discharge at culverts by indirect methods, by G. L. Bodhaine: UsGs-TWRI Book 3, Chapter A3. 1968. 60 pages.

3-A4. Measurement of peak discharge at width contractions by indirect methods, by H. F. Matthai: USGS-TWRI Book 3, Chapter A4. 1967. 44 pages.

3-A5. Measurement of peak discharge at dams by indirect methods, by Harry Hulsing: UsGs--TwRI Book 3, Chapter A5. 1967. 29 pages.

3-A6. General procedure for gaging streams, by R. W. Carter and Jacob Davidian: USGS--TWRI Book 3, Chapter A6. 1968 . 13 pages.3-A

3-A7. State measurements at gaging stations, by T. J. Buchanan and W. P. Somers: USGS--TWRI Book 3 , Chapter A7. 1968 . 29 pages.

3-A8. Discharge measurements at gaging stations, by T. J. Buchanan and W. P. Somers: USGS--TWRI Book 3, Chapter A8. 1969. 65 pages.

3-A9. Measurement of time of travel and dispersion in streams by dye tracing, by E. F. Hubbard, F. A. Kilpatrick, L. A. Martens, and J. F. Wilson, Jr.: USGS-TWRI Book 3, Chapter A9. 1982 . 44 pages.

3-All. Measurements of discharge by moving-boat method, by G. F. Smoot and C. E. Novak: USGS--TWRI Book 3, Chapter All. 1969. 22 pages.

3-A13. Computation of continuous records of streamflow, by E.J. Kennedy: USGS--TWRI Book 3, Chapter A13. 1983. 53 pages.

3-Al4. Use of flumes in measuring discharge, by F.A. Kilpatrick and V.R. Schneider: USGS--TWRI Book 3, Chapter Al4. 1983. 46 pages.

3-Bl. Aquifer-test design, observation, and data analysis, by R. W. Stallman: USGS--TWRI Book 3, Chapter Bl. 1971. 26 pages.

3-B2. Introduction to ground-water hydraulics, a programed text for self-instruction, by G. D. Bennet: USGS--TWRI Book 3, Chapter B2. 1976. 172 pages.

3-B3. Type curves for selected problems of flow to wells in confined aquifers, by J. E. Reed: USGS--TWRI Book 3, Chapter B3. 1980. 106 pages.

3-Cl. Fluvial sediment concepts, by H. P. Guy: USGS--TWRI Book 3, Chapter Cl. 1970.55 pages.

3-C2. Field methods for measurement of fluvial sediment, by $H$. P. Guy and V. W. Norman: usGs-TWRI Book 3, Chapter C2. 1970. 59 pages.

3-C3. Computation of fluvial-sediment discharge, by George Porterfield: USGS--TWRI Book 3, Chapter C3. 1972. 66 pages.

4-Al. Some statistical tools in hydrology, by H. C. Riggs: USGS--TWRI Book 4, Chapter Al. 1968. 39 pages.

4-A2. Frequency curves, by H. C. Riggs: USGS--TWRI Book 4, Chapter A2. 1968. 15 pages.

4-Bl. Low-flow investigations, by H. C. Riggs: USGS--TWRI Book 4, Chapter Bl. 1972 . 18 pages.

4-B2. Storage analyses for water supply, by H. C. Riggs and C. H. Hardison: USGS--TWRI Book 44, Chapter B2. 1973. 20 pages.

4-B3. Regional analyses of streamflow characteristics, by H. C. Riggs: USGS--TWRI Book 4, Chapter B3, 1973 . 15 pages.

4-DI. Computation of rate and volume of stream depletion by wells, by C. T. Jenkins: USGS--TWRI Book 4, Chapter Dl, 1970 . 17 pages.

5-Al. Methods for determination of inorganic substances in water and fluvial sediments, by $M$. W. Skougstad and others, editors: USGS-TWRI Book 5, Chapter Al. 1979, 626 pages.

5-A2. Determination of minor elements in water by emission spectroscopy, by P. R. Barnett and E. C. Mallory, Jr.: USGS--TWRI Book 5, Chapter A2. 1971. 31 pages.

5-A3. Methods for analysis or organic substances in water, by D. F. Goerlitz and Eugene Brown: USGS--TWRI Book 5, Chapter A3. 1972. 40 pages.

5-A4. Methods for collection and analysis of aquatic biological and microbiological samples, edited by P. E. Greeson, T. A. Ehlke, G. A. Irwin, B. W. Lium, and R. V. Slack: USGSTWRI Book 5, Chapter A4, 1977. 332 pages.

5-A5. Methods for determination of radioactive substances in water and fluvial sediments, by L. L. Thatcher, V. J. Janzer, and K. W. Edwards: USGS--TWRI Book 5, Chapter A5. 1977. 95 pages.

5-A6. Quality assurance practices for the chemical and biological analyses of water and fluvial sediments, by L.C. Friedman and D. E. Erdmann: UsGS-TWRI Book 5, Chapter A6. 1982. 181 pages.

5-Cl. Laboratory theory and methods for sediment analysis, by H. P. Guy: USGS--TWRI Book 5, Chapter Cl. 1969.58 pages.

7-Cl. Finite difference model for aquifer simulation in two dimensions with results of numerical experiments, by P. C. Trescott, G. F. Pinder, and S. P. Larson: USGS--TWRI Book 7, Chapter Cl. 1976 . 116 pages.

7-C2. Computer model of two-dimensional solute transport and dispersion in ground water, by L. F. Konikow and J. D. Bredenhoeft: USGS--TWRI Book 7, Chapter C2. 1978. 90 pages.

7-C3. A model for simulation of flow in singular and interconnected channels, by R. W. Schaffranek, R. A. Baltzer, and D. E. Goldberg: USGS-TWRI Book 7, Chapter C3. 1981. 110 pages.

8-Al. Methods of measuring water levels in deep wells, by M. S. Garber and F. C. Koopman: UsGs-TWRI Book 8 , Chapter Al. 1968,23 pages.

8-A2. Installation and service manual for U.S. Geological Survey manometers, by J.D. Craig: UsGs-TWRI Book 8, Chapter A2. 1983. 57 pages.

8-B2. Calibration and maintenance of vertical-axis type current meters, by G. F. Smoot and C. E. Novak: USGS--TWRI Book 8, Chapter B2. 1968 . 15 pages. 
The following stream-gaging stations have been discontinued in Iowa. Continuous daily streamflow records were collected and published for the period of record shown for each station.

Discontinued gaging stations

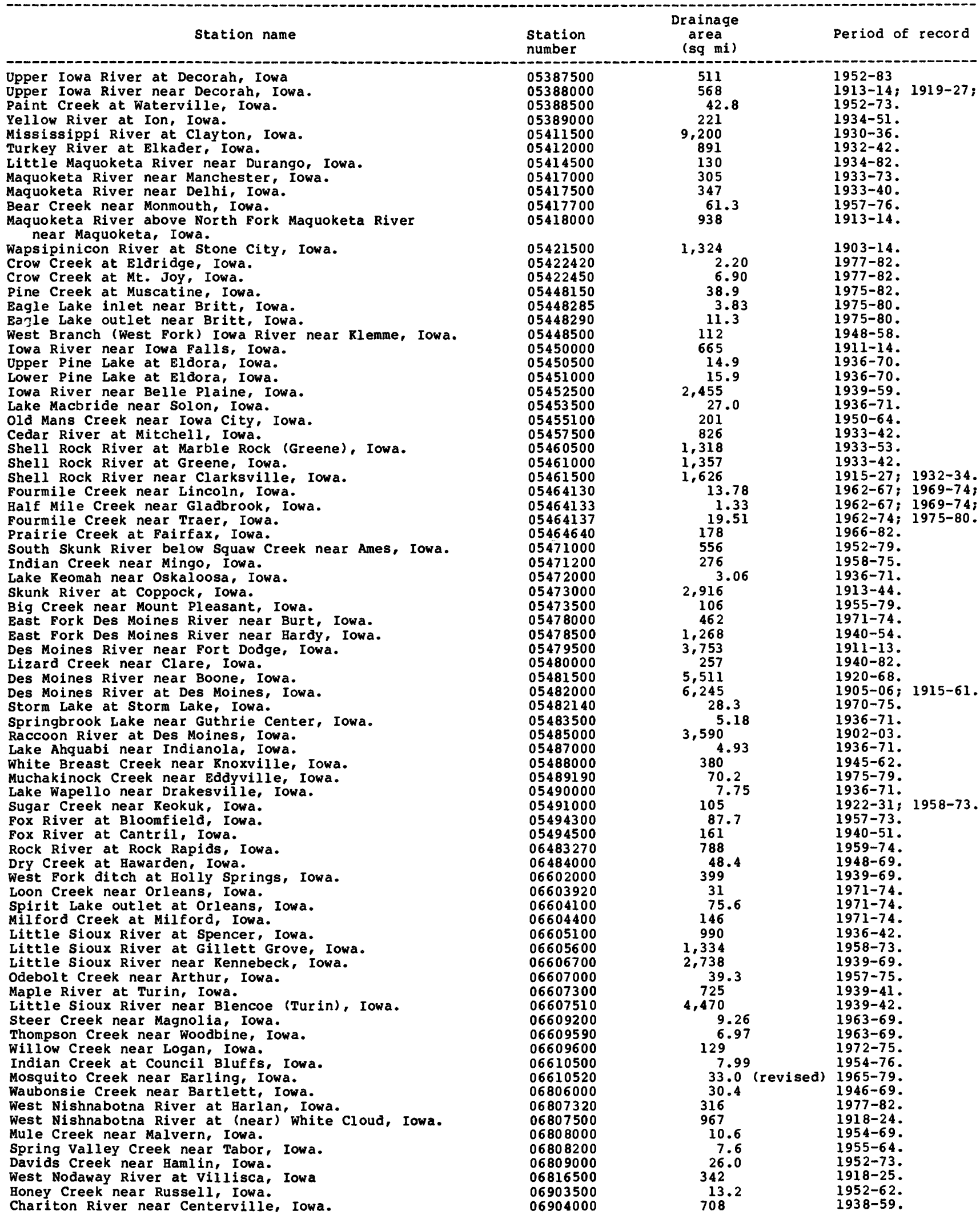


The following water-quality stations have been discontinued in Iowa. Continuous daily records of water temperature or sediment and monthly or periodic samples of chemical quality were collected and published for the period of record shown for each station. An asterisk (*) in the type of record column indicates that periodic data is available for that parameter subsequent to the period of daily record.

Discontinued water-quality stations

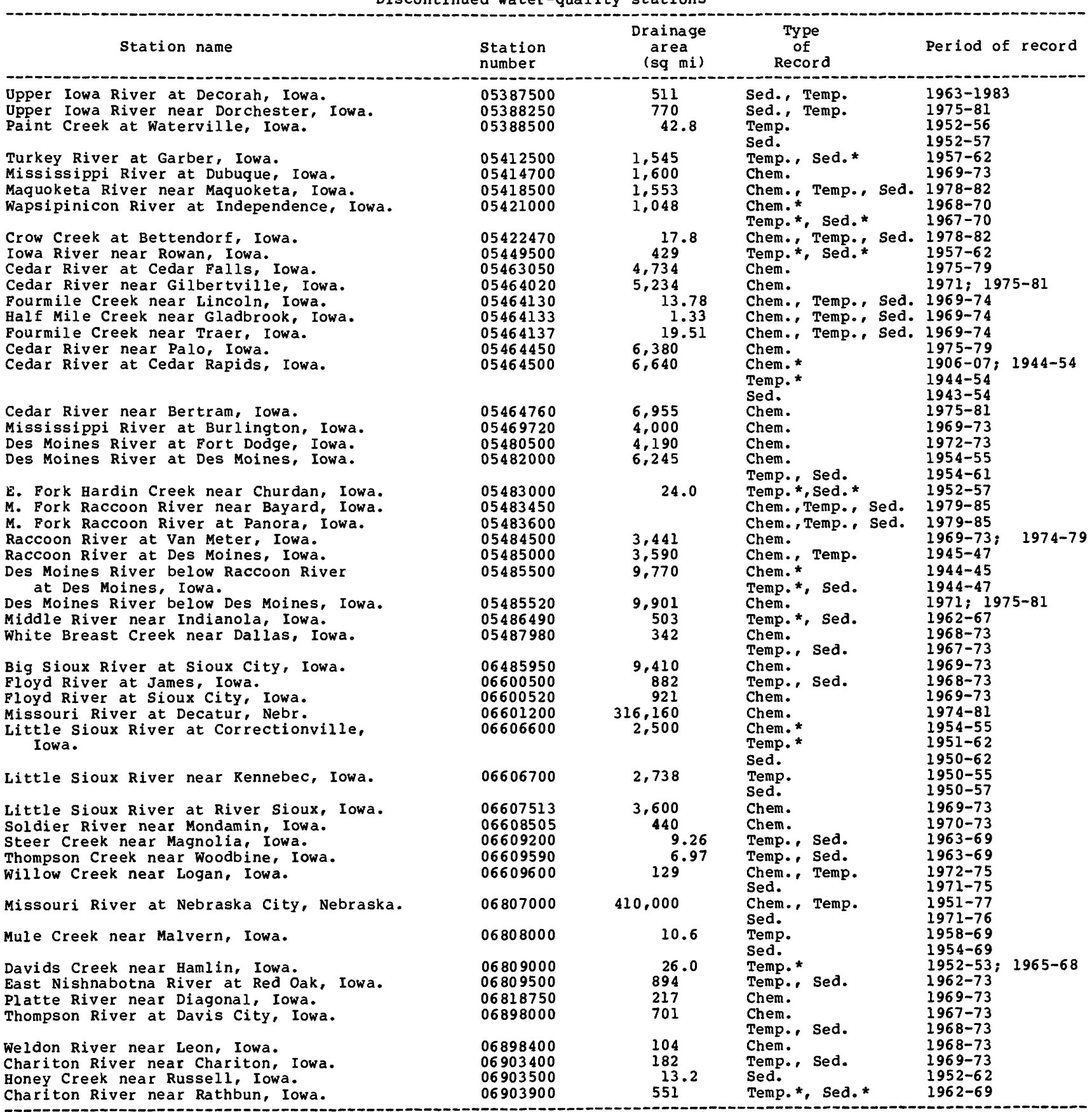

Type of record: Chem. (chemical quality); Temp. (water temperature); Sed. (sediment). 
LOCATION.--Lat $43^{\circ} 25^{\prime} 16^{\prime \prime}$, long $91^{\circ} 30^{\prime} 31^{\prime \prime}$, in SWl/4 NW1/4 sec.1, T.99 N., R.6 W., Allamakee County, Hydrologic Unit 07060002 , on right bank at upstream side of bridge on state Highway 76 , 650 ft upstream from Mineral Creek, $0.5 \mathrm{mi}$ upstream from Bear Creek, $3.5 \mathrm{mi}$ south of Dorchester, and $18.1 \mathrm{mi}$ upstream from mouth.

DRAINAGE AREA. $--770 \mathrm{mi}^{2}$.

PERIOD OF RECORD.--September 1936 to June 1975 (gage heights and discharge measurements only), July 1975 to current year.

GAGE.--Water-stage recorder. Datum of gage is $660.00 \mathrm{ft}$ above NGvD. Prior to Jan. 6, 1938, nonrecording gage on old bridge at site $0.2 \mathrm{mi}$ upstream at datum $5.91 \mathrm{ft}$ higher. Jan. 6 , 1938, to Apr. 26, 1948, nonrecording gage at datum $60.00 \mathrm{ft}$ lower, Apr. 27, 1948 to August 1963 , nonrecording gage on old bridge and August 1963 to June 1975 nonrecording gage on new bridge at same datum.

REMARKS.--Estimated daily discharges: Dec. 3, 5-26, Dec. 31 to Feb. 22. Records good except for periods of estimated daily discharges, which are poor. U.S. Geological survey gage-height telemeter at station.

AVERAGE DISCHARGE.--10 years, $600 \mathrm{ft} / \mathrm{s}, 10.58 \mathrm{in} / \mathrm{yr}, 434,700 \mathrm{acre}-\mathrm{ft} / \mathrm{yr}$.

EXTREMES FOR PERIOD OF RECORD.--Maximum discharge, 14,000 ft3/s Mar. 12, 1976, gage height, 17.67 ft; minimum daily, $79 \mathrm{ft}^{3} / \mathrm{s}$ Dec. $31,1976$.

EXTREMES OUTSIDE PERIOD OF RECORD.--Flood of May 30, 1941, reached a stage of 21.8 ft, from flood profile, file, discharge, $30,400 \mathrm{ft} / \mathrm{s}$ on basis of slope-area determination of peak flow.

EXTREMES FOR CURRENT YEAR.--Peak discharge greater than base of 4,000 $\mathrm{ft}^{3} / \mathrm{s}^{2}$ and maximum (*):

\begin{tabular}{|c|c|c|c|c|c|}
\hline $\begin{array}{l}\text { ate } \\
\text { ec. } 28 \\
\text { eb. } 21\end{array}$ & $\begin{array}{l}\text { Time } \\
0945 \\
1745\end{array}$ & $\begin{array}{c}\text { Discharge } \\
\left(f t^{3} / \mathrm{s}\right) \\
4,210 \\
* 6,630\end{array}$ & $\begin{array}{c}\text { Gage height } \\
\text { (ft) } \\
11.92 \\
\star_{a} 16.03\end{array}$ & & $\begin{array}{c}\text { Gage height } \\
\text { (ft) } \\
13.27\end{array}$ \\
\hline
\end{tabular}

a Ice jam.

Minimum discharge, $113 \mathrm{ft}^{3} / \mathrm{s}$ Dec. 4, result of freeze up.

DISCHARGE, IN CUBIC FEET PER SECOND, WATER YEAR OCTOBER 1984 TO SEPTEMBER 1985 MEAN VALUES

\begin{tabular}{|c|c|c|c|c|c|c|c|c|c|c|c|c|}
\hline DAY & OCT & NOV & DEC & JAN & FEB & MAR & APR & MAY & JUN & JUL & AUG & SEP \\
\hline $\begin{array}{l}1 \\
2 \\
3 \\
4 \\
5\end{array}$ & $\begin{array}{l}242 \\
241 \\
242 \\
242 \\
242\end{array}$ & $\begin{array}{l}427 \\
589 \\
425 \\
407 \\
370\end{array}$ & $\begin{array}{l}288 \\
286 \\
230 \\
169 \\
190\end{array}$ & $\begin{array}{l}580 \\
450 \\
370 \\
390 \\
420\end{array}$ & $\begin{array}{l}245 \\
245 \\
240 \\
240 \\
235\end{array}$ & $\begin{array}{r}1700 \\
1470 \\
1120 \\
876 \\
569\end{array}$ & $\begin{array}{r}525 \\
495 \\
508 \\
729 \\
1350\end{array}$ & $\begin{array}{l}564 \\
538 \\
519 \\
495 \\
477\end{array}$ & $\begin{array}{l}329 \\
309 \\
291 \\
281 \\
268\end{array}$ & $\begin{array}{l}244 \\
239 \\
238 \\
234 \\
231\end{array}$ & $\begin{array}{l}169 \\
166 \\
160 \\
157 \\
157\end{array}$ & $\begin{array}{l}144 \\
148 \\
146 \\
149 \\
607\end{array}$ \\
\hline $\begin{array}{r}6 \\
7 \\
8 \\
9 \\
10\end{array}$ & $\begin{array}{l}243 \\
247 \\
265 \\
255 \\
250\end{array}$ & $\begin{array}{l}348 \\
330 \\
318 \\
309 \\
326\end{array}$ & $\begin{array}{l}180 \\
270 \\
430 \\
480 \\
410\end{array}$ & $\begin{array}{l}435 \\
450 \\
400 \\
370 \\
340\end{array}$ & $\begin{array}{l}235 \\
230 \\
230 \\
230 \\
230\end{array}$ & $\begin{array}{r}555 \\
569 \\
733 \\
2290 \\
5180\end{array}$ & $\begin{array}{r}1560 \\
1340 \\
1120 \\
982 \\
886\end{array}$ & $\begin{array}{l}457 \\
439 \\
430 \\
414 \\
397\end{array}$ & $\begin{array}{l}264 \\
257 \\
257 \\
256 \\
242\end{array}$ & $\begin{array}{l}231 \\
231 \\
231 \\
228 \\
232\end{array}$ & $\begin{array}{l}156 \\
154 \\
153 \\
150 \\
274\end{array}$ & $\begin{array}{l}873 \\
420 \\
339 \\
476 \\
501\end{array}$ \\
\hline $\begin{array}{l}11 \\
12 \\
13 \\
14 \\
15\end{array}$ & $\begin{array}{l}250 \\
250 \\
250 \\
250 \\
265\end{array}$ & $\begin{array}{l}336 \\
342 \\
336 \\
336 \\
336\end{array}$ & $\begin{array}{l}355 \\
390 \\
380 \\
360 \\
360\end{array}$ & $\begin{array}{l}310 \\
300 \\
300 \\
295 \\
290\end{array}$ & $\begin{array}{l}225 \\
225 \\
225 \\
220 \\
220\end{array}$ & $\begin{array}{l}4650 \\
2710 \\
1720 \\
1420 \\
1190\end{array}$ & $\begin{array}{l}821 \\
774 \\
732 \\
696 \\
670\end{array}$ & $\begin{array}{l}388 \\
389 \\
381 \\
377 \\
381\end{array}$ & $\begin{array}{l}246 \\
253 \\
249 \\
242 \\
242\end{array}$ & $\begin{array}{l}236 \\
219 \\
224 \\
220 \\
228\end{array}$ & $\begin{array}{l}214 \\
179 \\
204 \\
183 \\
166\end{array}$ & $\begin{array}{l}383 \\
331 \\
300 \\
278 \\
262\end{array}$ \\
\hline $\begin{array}{l}16 \\
17 \\
18 \\
19 \\
20\end{array}$ & $\begin{array}{l}282 \\
322 \\
315 \\
311 \\
300\end{array}$ & $\begin{array}{l}336 \\
331 \\
320 \\
317 \\
308\end{array}$ & $\begin{array}{l}400 \\
520 \\
450 \\
410 \\
400\end{array}$ & $\begin{array}{l}280 \\
270 \\
260 \\
250 \\
240\end{array}$ & $\begin{array}{l}220 \\
230 \\
230 \\
240 \\
250\end{array}$ & $\begin{array}{r}1020 \\
894 \\
735 \\
663 \\
601\end{array}$ & $\begin{array}{l}649 \\
611 \\
585 \\
562 \\
536\end{array}$ & $\begin{array}{l}369 \\
369 \\
368 \\
368 \\
361\end{array}$ & $\begin{array}{l}242 \\
241 \\
243 \\
242 \\
237\end{array}$ & $\begin{array}{l}245 \\
226 \\
234 \\
235 \\
235\end{array}$ & $\begin{array}{l}157 \\
153 \\
152 \\
143 \\
141\end{array}$ & $\begin{array}{l}250 \\
241 \\
230 \\
220 \\
212\end{array}$ \\
\hline $\begin{array}{l}21 \\
22 \\
23 \\
24 \\
25\end{array}$ & $\begin{array}{l}289 \\
273 \\
262 \\
255 \\
252\end{array}$ & $\begin{array}{l}318 \\
299 \\
323 \\
308 \\
299\end{array}$ & $\begin{array}{l}425 \\
450 \\
420 \\
350 \\
280\end{array}$ & $\begin{array}{l}240 \\
250 \\
255 \\
260 \\
265\end{array}$ & $\begin{array}{l}2000 \\
4200 \\
3300 \\
4100 \\
2910\end{array}$ & $\begin{array}{l}556 \\
528 \\
511 \\
510 \\
501\end{array}$ & $\begin{array}{l}550 \\
543 \\
566 \\
635 \\
625\end{array}$ & $\begin{array}{l}344 \\
335 \\
321 \\
313 \\
320\end{array}$ & $\begin{array}{l}227 \\
230 \\
225 \\
218 \\
216\end{array}$ & $\begin{array}{l}235 \\
214 \\
181 \\
184 \\
192\end{array}$ & $\begin{array}{l}136 \\
125 \\
125 \\
125 \\
132\end{array}$ & $\begin{array}{l}208 \\
206 \\
253 \\
297 \\
289\end{array}$ \\
\hline $\begin{array}{l}26 \\
27 \\
28 \\
29 \\
30 \\
31\end{array}$ & $\begin{array}{l}260 \\
263 \\
280 \\
274 \\
268 \\
261\end{array}$ & $\begin{array}{l}288 \\
298 \\
291 \\
289 \\
289 \\
---\end{array}$ & $\begin{array}{r}300 \\
432 \\
2630 \\
1810 \\
1020 \\
720\end{array}$ & $\begin{array}{l}265 \\
260 \\
255 \\
250 \\
250 \\
250\end{array}$ & $\begin{array}{r}1860 \\
1470 \\
1100 \\
-\ldots \\
- \\
-\end{array}$ & $\begin{array}{l}489 \\
488 \\
504 \\
524 \\
523 \\
543\end{array}$ & $\begin{array}{l}634 \\
659 \\
653 \\
630 \\
592 \\
---\end{array}$ & $\begin{array}{l}312 \\
305 \\
304 \\
300 \\
293 \\
330\end{array}$ & $\begin{array}{l}220 \\
294 \\
270 \\
272 \\
252 \\
---\end{array}$ & $\begin{array}{l}180 \\
174 \\
173 \\
169 \\
165 \\
163\end{array}$ & $\begin{array}{l}135 \\
128 \\
126 \\
141 \\
165 \\
152\end{array}$ & $\begin{array}{l}310 \\
336 \\
330 \\
327 \\
457 \\
---\end{array}$ \\
\hline $\begin{array}{l}\text { TOTAL } \\
\text { MEAN } \\
\text { MAX } \\
\text { MIN } \\
\text { CFSM } \\
\text { IN. } \\
\text { AC-FT }\end{array}$ & $\begin{array}{r}8201 \\
265 \\
322 \\
241 \\
.34 \\
.40 \\
16270\end{array}$ & $\begin{array}{r}10149 \\
338 \\
589 \\
288 \\
.44 \\
.49 \\
20130\end{array}$ & $\begin{array}{r}15795 \\
510 \\
2630 \\
169 \\
.66 \\
.76 \\
31330\end{array}$ & $\begin{array}{r}9800 \\
316 \\
580 \\
240 \\
.41 \\
.47 \\
19440\end{array}$ & $\begin{array}{r}25585 \\
914 \\
4200 \\
220 \\
1.19 \\
1.24 \\
50750\end{array}$ & $\begin{array}{r}36342 \\
1172 \\
5180 \\
488 \\
1.52 \\
1.76 \\
72080\end{array}$ & $\begin{array}{r}22218 \\
741 \\
1560 \\
495 \\
.96 \\
1.07 \\
44070\end{array}$ & $\begin{array}{r}11958 \\
386 \\
564 \\
293 \\
.50 \\
.58 \\
23720\end{array}$ & $\begin{array}{r}7615 \\
254 \\
329 \\
216 \\
.33 \\
.37 \\
15100\end{array}$ & $\begin{array}{r}6671 \\
215 \\
245 \\
163 \\
.28 \\
.32 \\
13230\end{array}$ & $\begin{array}{r}4878 \\
157 \\
274 \\
125 \\
.20 \\
.24 \\
9680\end{array}$ & $\begin{array}{r}9523 \\
317 \\
873 \\
144 \\
.41 \\
.46 \\
18890\end{array}$ \\
\hline $\begin{array}{ll}\text { CAL } & \text { YR } \\
\text { WTR } & \text { YR }\end{array}$ & TC & $\begin{array}{l}277 \\
168\end{array}$ & $\begin{array}{l}\text { ME } \\
\text { ME }\end{array}$ & $\begin{array}{l}759 \\
462\end{array}$ & $\begin{array}{l}\text { MAX } \\
\text { MAX }\end{array}$ & $\begin{array}{l}4800 \\
5180\end{array}$ & $\begin{array}{ll}\text { MIN } & 169 \\
\text { MIN } & 125\end{array}$ & $\begin{array}{l}\text { CFSM } \\
\text { CFSM }\end{array}$ & $\begin{array}{l}.99 \\
.60\end{array}$ & $\begin{array}{r}13.43 \\
8.15\end{array}$ & $\begin{array}{l}A C-F T \\
A C-E T\end{array}$ & $\begin{array}{l}551200 \\
334700\end{array}$ \\
\hline
\end{tabular}


LOCATION, --Lat $43^{\circ} 01^{\prime} 29^{\prime \prime}$, long $91^{\circ} 10^{\prime} 21^{\prime \prime}$, in SEl/4 SEl/4 sec.22, T.95 N. R. 3 W., Clayton County, Hydrologic Unit 07060001 , on right bank in city park at east end of Main street in Mccregor. 2.6 mi upstream from wisconsin River, $4.3 \mathrm{mi}$ downstream from Yellow River, and at mile 633.4 upstream from Ohio River.

DRAINAGE AREA. $--67,500 \mathrm{mi}^{2}$, approximately.

WATER-DISCHARGE RECORDS

PERIOD OF RECORD.--August 1936 to current year.

REVISED RECORDS.--WDR IA-75-1: 1974 .

GAGE.--Water-stage recorder. Datum of gage is $604.84 \mathrm{ft}$ above NGVD. Prior to June 1 , 1937 , and since June 2 , 1939, auxiliary water-stage recorder; June 1 , 1937 to June 1 , 1939 , auxiliary nonrecording gage 14.1 mi upstream in tailwater of dam 9 , at datum $5.30 \mathrm{ft}$ lower.

REMARKS.--Estimated daily discharge: Dec. 6 to Feb. 25, Mar. 3-10, Records good except those for periods of estimated daily discharge, which are fair. Stage-discharge relation affected by backwater from wisconsin River and Lock and Dam No. 10. Minor flow regulation caused by navigation dams.

COOPERATION.--Auxillary gage-height and discharge data at Lock and Dam No, 9 furnished by U.s. Army Corps of Engineers.

AVERAGE DISCHARGE. -49 years, $35,110 \mathrm{ft} / \mathrm{s}, 7.06 \mathrm{in} / \mathrm{yr}, 25,440,000 \mathrm{acre}-\mathrm{ft} / \mathrm{yr}$.

EXTREMES FOR PERIOD OF RECORD.--Maximum daily discharge, 276,000 ft'/s Apr. 24, 1965 ; maximum gage height, 25.38 ft Apr. 24, 1965, minimum daily discharge, 6,200 ft'/s Dec, 9, 1936, minimum gage height, -0.86 ft Aug. 18, 1936.

EXTREMES OUTSIDE PERIOD OF RECORD.--Maximum stage since at least 1828, that of Apr. $24,1965$.

EXTREMES FOR CURRENT YEAR.--Maximum daily discharge, $110,000 \mathrm{ft} / \mathrm{s}$ Apr. 4-5, maximum gage height, 15.71 ft Apr. 5; minimum daily discharge, $17,300 \mathrm{ft} / \mathrm{s}$ Dec. 8; minimum gage height, 6.76 ft $0 \mathrm{ct}$. 10 .

DISCHARGE, IN CUBIC FEET PER SECOND, WATER YEAR OCTOBER 1984 TO SEPTEMBER 1985 MEAN VALUES

\begin{tabular}{|c|c|c|c|c|c|c|c|c|c|c|c|c|}
\hline$A Y$ & $\mathrm{OCT}$ & NOV & DEC & JAN & FEB & MAR & APR & MAY & JUN & JUL & AUG & SEP \\
\hline $\begin{array}{l}1 \\
2 \\
3 \\
4 \\
5\end{array}$ & $\begin{array}{l}32100 \\
31700 \\
31200 \\
30700 \\
29800\end{array}$ & $\begin{array}{l}75300 \\
76300 \\
76800 \\
77900 \\
78000\end{array}$ & $\begin{array}{l}38900 \\
40100 \\
39900 \\
33500 \\
28100\end{array}$ & $\begin{array}{l}40500 \\
40000 \\
37500 \\
35000 \\
33500\end{array}$ & $\begin{array}{l}22600 \\
22600 \\
22500 \\
22500 \\
22500\end{array}$ & $\begin{array}{l}63400 \\
57800 \\
54000 \\
49000 \\
45000\end{array}$ & $\begin{array}{l}105000 \\
108000 \\
109000 \\
110000 \\
110000\end{array}$ & $\begin{array}{l}90400 \\
94500 \\
97400 \\
98500 \\
99800\end{array}$ & $\begin{array}{l}49600 \\
51300 \\
51500 \\
49800 \\
46300\end{array}$ & $\begin{array}{l}39000 \\
40000 \\
42600 \\
46200 \\
49600\end{array}$ & $\begin{array}{l}32800 \\
31000 \\
30300 \\
29800 \\
28300\end{array}$ & $\begin{array}{l}36100 \\
33700 \\
28800 \\
29700 \\
34400\end{array}$ \\
\hline $\begin{array}{r}6 \\
7 \\
8 \\
9 \\
10\end{array}$ & $\begin{array}{l}28500 \\
27200 \\
25800 \\
23500 \\
23300\end{array}$ & $\begin{array}{l}75700 \\
72500 \\
71000 \\
68700 \\
65800\end{array}$ & $\begin{array}{l}22500 \\
18000 \\
17300 \\
18000 \\
19500\end{array}$ & $\begin{array}{l}33500 \\
32500 \\
32500 \\
32500 \\
32300\end{array}$ & $\begin{array}{l}21300 \\
21300 \\
21000 \\
20200 \\
19400\end{array}$ & $\begin{array}{l}40000 \\
38000 \\
38500 \\
40000 \\
45000\end{array}$ & $\begin{array}{l}109000 \\
106000 \\
104000 \\
102000 \\
101000\end{array}$ & $\begin{array}{r}100000 \\
98900 \\
97000 \\
94000 \\
92400\end{array}$ & $\begin{array}{l}45300 \\
45300 \\
46700 \\
50000 \\
51900\end{array}$ & $\begin{array}{l}51700 \\
52800 \\
53200 \\
52100 \\
51300\end{array}$ & $\begin{array}{l}26700 \\
26300 \\
26700 \\
26400 \\
25600\end{array}$ & $\begin{array}{l}38100 \\
39700 \\
41000 \\
42300 \\
43600\end{array}$ \\
\hline $\begin{array}{l}2 \\
3 \\
4\end{array}$ & $\begin{array}{l}23800 \\
25000 \\
27700 \\
27800 \\
27900\end{array}$ & $\begin{array}{l}59300 \\
54200 \\
52200 \\
52100 \\
55500\end{array}$ & $\begin{array}{l}25000 \\
31000 \\
33500 \\
35000 \\
34300\end{array}$ & $\begin{array}{l}31000 \\
31000 \\
30000 \\
29000 \\
27000\end{array}$ & $\begin{array}{l}19400 \\
19700 \\
19900 \\
20000 \\
19500\end{array}$ & $\begin{array}{l}54000 \\
61000 \\
70700 \\
76300 \\
81500\end{array}$ & $\begin{array}{l}99700 \\
97400 \\
94100 \\
90500 \\
87200\end{array}$ & $\begin{array}{l}89600 \\
87700 \\
83900 \\
80200 \\
77400\end{array}$ & $\begin{array}{l}53400 \\
51800 \\
47200 \\
43900 \\
43400\end{array}$ & $\begin{array}{l}50100 \\
48700 \\
46900 \\
44700 \\
42300\end{array}$ & $\begin{array}{l}25600 \\
25300 \\
26400 \\
29900 \\
34200\end{array}$ & $\begin{array}{l}45000 \\
46600 \\
48400 \\
52000 \\
56800\end{array}$ \\
\hline $\begin{array}{l}7 \\
8 \\
9\end{array}$ & $\begin{array}{l}29100 \\
32100 \\
33800 \\
36600 \\
38700\end{array}$ & $\begin{array}{l}57500 \\
57000 \\
55800 \\
51200 \\
46000\end{array}$ & $\begin{array}{l}35000 \\
36200 \\
37000 \\
35000 \\
36000\end{array}$ & $\begin{array}{l}24000 \\
24000 \\
23000 \\
22800 \\
22500\end{array}$ & $\begin{array}{l}19600 \\
19700 \\
19700 \\
19600 \\
19500\end{array}$ & $\begin{array}{l}81100 \\
80700 \\
79000 \\
76700 \\
75000\end{array}$ & $\begin{array}{l}84200 \\
81600 \\
82200 \\
83400 \\
84700\end{array}$ & $\begin{array}{l}75300 \\
73300 \\
70200 \\
67200 \\
65400\end{array}$ & $\begin{array}{l}43500 \\
44000 \\
43900 \\
42400 \\
41100\end{array}$ & $\begin{array}{l}38700 \\
35100 \\
31800 \\
31400 \\
31800\end{array}$ & $\begin{array}{l}36100 \\
36700 \\
36800 \\
36500 \\
35500\end{array}$ & $\begin{array}{l}60200 \\
60100 \\
58800 \\
56500 \\
54000\end{array}$ \\
\hline $\begin{array}{l}22 \\
23 \\
24\end{array}$ & $\begin{array}{l}43000 \\
48900 \\
54500 \\
58400 \\
60200\end{array}$ & $\begin{array}{l}41600 \\
37400 \\
36600 \\
37100 \\
38000\end{array}$ & $\begin{array}{l}35000 \\
34500 \\
35000 \\
36500 \\
36800\end{array}$ & $\begin{array}{l}22800 \\
22800 \\
22700 \\
22700 \\
22700\end{array}$ & $\begin{array}{l}19700 \\
22000 \\
31000 \\
43000 \\
58000\end{array}$ & $\begin{array}{l}75000 \\
77000 \\
80300 \\
83700 \\
87000\end{array}$ & $\begin{array}{l}85200 \\
84900 \\
83300 \\
81400 \\
79300\end{array}$ & $\begin{array}{l}64400 \\
64600 \\
65500 \\
66300 \\
66100\end{array}$ & $\begin{array}{l}40600 \\
40600 \\
40500 \\
40400 \\
40500\end{array}$ & $\begin{array}{l}32100 \\
31600 \\
30000 \\
27500 \\
27700\end{array}$ & $\begin{array}{l}33400 \\
32500 \\
32000 \\
32500 \\
33100\end{array}$ & $\begin{array}{l}51500 \\
50600 \\
51300 \\
51400 \\
50200\end{array}$ \\
\hline $\begin{array}{l}26 \\
27 \\
28 \\
29 \\
30\end{array}$ & $\begin{array}{l}62600 \\
64200 \\
67000 \\
69100 \\
71000 \\
71700\end{array}$ & $\begin{array}{c}37800 \\
36200 \\
34500 \\
34100 \\
36400 \\
\end{array}$ & $\begin{array}{l}37800 \\
38300 \\
39800 \\
41000 \\
41000 \\
41000\end{array}$ & $\begin{array}{l}22800 \\
22500 \\
22700 \\
22500 \\
22500 \\
22500\end{array}$ & $\begin{array}{r}72500 \\
71300 \\
68600 \\
- \\
- \\
\ldots-\end{array}$ & $\begin{array}{r}90600 \\
94800 \\
97700 \\
99900 \\
99900 \\
102000\end{array}$ & $\begin{array}{r}77800 \\
77900 \\
79800 \\
82500 \\
86400 \\
-\end{array}$ & $\begin{array}{l}65900 \\
65000 \\
62100 \\
57900 \\
53900 \\
51200\end{array}$ & $\begin{array}{r}40300 \\
39600 \\
38500 \\
38500 \\
38700 \\
\end{array}$ & $\begin{array}{l}30400 \\
32200 \\
33700 \\
34800 \\
34800 \\
33800\end{array}$ & $\begin{array}{l}32900 \\
28500 \\
27200 \\
28800 \\
31300 \\
34700\end{array}$ & $\begin{array}{l}50200 \\
50800 \\
51700 \\
54900 \\
61600 \\
\end{array}$ \\
\hline $\begin{array}{l}\text { OTAL } \\
\text { EAN } \\
\text { AX } \\
\text { IN } \\
\text { FSM } \\
\text { N. } \\
\text { C-ET }\end{array}$ & $\begin{array}{r}1256900 \\
40550 \\
71700 \\
23300 \\
.60 \\
.69 \\
2493000\end{array}$ & $\begin{array}{r}1648500 \\
54950 \\
78000 \\
34100 \\
.81 \\
.91 \\
3270000\end{array}$ & $\begin{array}{r}1030500 \\
33240 \\
41000 \\
17300 \\
.49 \\
.57 \\
2044000\end{array}$ & $\begin{array}{r}863300 \\
27850 \\
40500 \\
22500 \\
.41 \\
.48 \\
1712000\end{array}$ & $\begin{array}{r}798600 \\
28520 \\
72500 \\
19400 \\
.42 \\
.44 \\
1584000\end{array}$ & $\begin{array}{r}2194600 \\
70790 \\
102000 \\
38000 \\
1.05 \\
1.21 \\
4353000\end{array}$ & $\begin{array}{r}2767500 \\
92250 \\
110000 \\
77800 \\
1.37 \\
1.53 \\
5489000\end{array}$ & $\begin{array}{r}2416000 \\
77940 \\
100000 \\
51200 \\
1.15 \\
1.33 \\
4792000\end{array}$ & $\begin{array}{r}1340500 \\
44680 \\
53400 \\
38500 \\
.66 \\
.74 \\
2659000\end{array}$ & $\begin{array}{r}1228600 \\
39630 \\
53200 \\
27500 \\
.59 \\
.68 \\
2437000\end{array}$ & $\begin{array}{r}953800 \\
30770 \\
36800 \\
25300 \\
.46 \\
.53 \\
1892000\end{array}$ & $\begin{array}{r}1430000 \\
47670 \\
61600 \\
28800 \\
.71 \\
.79 \\
2836000\end{array}$ \\
\hline
\end{tabular}

WTR YR 1985
TOTAL 17928800
MEAN $54150 \quad \operatorname{MAX} 117000$ MEAN 49120

MAX 110000
MIN 17300
CPSM .80

$\begin{array}{ll}\text { CPSM } & .80 \\ \text { CFSM } & .73\end{array}$
IN. 10.92

IN. 9.88
AC-FT 39307000 AC-FT 35562000 
LOCATION.--Samples collected by boat $1.5 \mathrm{mi}$ downstream from discharge station. Prior to April 1981 , at bridge on U.S. Highway $18,1.2 \mathrm{mi}$ upstream from gage.

PERIOD OF RECORD.--Water years 1975 to current year.

PERIOD OF DAILY RECORD. -

SPECIFIC CONDUCTANCE: JuIY 1975 to current year.

WATER TEMPERATURES: July 1975 to current year.

SUSPENDED-SEDIMENT DISCHARGE: July 1975 to current year.

REMARKS.--Records of specific conductance are obtained from suspended-sediment samples at time of analysis.

EXTREMES FOR PERIOD OF DAILY RECORD.--

SEDIMENT CONCENTRATIONS: Maximum dally mean, 882 mg/L Mar. 21, 1982; minimum daily mean, 1 mg/L Dec. 23-25, 1976, Dec. $20,28,1977$

SEDIMENT LOADS: Maximum daily, 166,000 tons Mar. 31, 1979; minimum daily, 31 tons Dec. $25,1976$.

EXTREMES FOR CURRENT YEAR.--

SEDIMENT CONCENTRATIONS: Maximum daily mean, $409 \mathrm{mg} / \mathrm{L}$ Feb, 24; minimum daily mean, $3 \mathrm{mg} / \mathrm{L}$ Feb. 8-12.

SEDIMENT LOADS: Maximum daily, 55,700 tons Feb. 25; minimum daily, 157 tons Feb. 10 , 11 .

SPECIFIC CONDUCTANCE (MICROSEIMENS/CM AT 25 DEG. C.)，WATER YEAR OCTOBER 1984 TO SEPTEMBER 1985 RANDOM VALUES

\begin{tabular}{|c|c|c|c|c|c|c|c|c|c|c|c|c|}
\hline DAY & OCT & NOV & DEC & JAN & FEB & MAR & APR & MAY & JUN & JUL & AUG & SEP \\
\hline 1 & $\cdots$ & -- & -- & -- & 390 & $-\cdots$ & -- & --- & -- & - & - & $-\cdots$ \\
\hline 2 & -- & - & -- & 495 & $\ldots$ & 350 & 305 & 340 & --- & -- & 380 & $-\cdots$ \\
\hline 3 & $m$ & 375 & 450 & $=$ & -- & $-\infty$ & - & $-\infty$ & 390 & -- & $\ldots$ & $\cdots$ \\
\hline 4 & $-\infty$ & - & $\ldots$ & -- & $-\infty$ & -- & -- & -- & - & 410 & -- & - \\
\hline 5 & -- & -- & -- & 380 & 410 & -- & 290 & 0 & $-\cdots$ & $-\infty$ & $m$ & \\
\hline 6 & 370 & 355 & -- & -- & $-\infty$ & 345 & -- & 360 & -- & 405 & 380 & - \\
\hline 7 & $-\infty$ & -- & 455 & $-\infty$ & -- & --- & --- & $-\infty$ & 410 & -- & -- & 330 \\
\hline 8 & --- & --- & -- & $-\infty$ & 460 & $-\infty$ & --- & 380 & -- & -- & -- & -- \\
\hline 9 & -- & -- & --- & 380 & $-\infty$ & 375 & $-\infty$ & 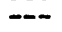 & --- & 420 & 380 & $-\infty$ \\
\hline 10 & 415 & 350 & 450 & $=-$ & $m$ & $-\infty$ & 315 & 340 & --- & --- & -- & - \\
\hline 11 & -- & -- & --- & -- & -- & -- & -- & -- & 395 & -- & -- & 340 \\
\hline 12 & -- & -- & --- & 405 & 460 & -- & 305 & -- & $\cdots$ & 395 & -- & --- \\
\hline 13 & -- & 370 & 430 & $-\infty$ & 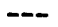 & 370 & $-\infty$ & -- & 420 & -- & -- & 340 \\
\hline 14 & --- & --- & -- & $m$ & $-\infty$ & $-\infty$ & $=-$ & 335 & -- & -- & 360 & -- \\
\hline 15 & -- & -- & --- & 470 & -- & -- & 340 & --- & --- & -- & --- & \\
\hline 16 & -- & 380 & -- & -- & 375 & 300 & -- & 385 & -- & $-\infty$ & -- & $-\infty$ \\
\hline 17 & $-\cdots$ & $-\infty$ & 430 & -- & -- & $-\infty$ & $-\infty$ & $-\infty$ & 425 & 360 & 360 & \\
\hline 18 & $-\infty$ & $m$ & -- & 390 & -- & $-\infty$ & 360 & $\cdots$ & $-\infty$ & $-\infty$ & -- & 350 \\
\hline 19 & -- & --- & --- & -- & $-\infty$ & 300 & -- & $-\infty$ & 410 & 380 & -- & \\
\hline 20 & -- & 380 & --- & 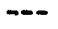 & 375 & $\cdots$ & $-\infty$ & 385 & -- & $-\infty$ & $\cdots$ & \\
\hline 21 & -- & -- & 480 & $-\infty$ & $-\infty$ & $-\infty$ & --- & -- & -- & 380 & 320 & \\
\hline 22 & -- & 400 & -- & 385 & -- & 340 & 310 & $-\infty$ & -- & -- & -- & \\
\hline 23 & $-\infty$ & $m$ & -- & 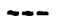 & 245 & - & $-\infty$ & -- & $\cdots$ & -- & -- & \\
\hline 24 & -- & 405 & --- & --- & $-\infty$ & -- & -- & 385 & --- & -- & 320 & \\
\hline 25 & -- & -- & $-\infty$ & -- & 240 & 350 & -- & -- & -- & $-\infty$ & -- & \\
\hline 26 & - & -- & 425 & 400 & -- & $-\infty$ & 325 & -- & --- & 340 & --- & \\
\hline 27 & -- & --- & - & $-\infty$ & -- & $-\infty$ & -- & $-\cdots$ & 375 & -- & -- & \\
\hline 28 & $-\infty$ & 400 & 420 & $-\infty$ & 240 & 325 & --- & 400 & -- & --- & 340 & \\
\hline 29 & -- & $-\infty$ & -- & 400 & $-\infty$ & $-\infty$ & 340 & -- & $\cdots$ & 380 & $m$ & \\
\hline 30 & 380 & 420 & 480 & -- & $-\infty$ & $m$ & $-\infty$ & -- & 430 & -- & -- & \\
\hline 31 & $-\infty$ & -- & -- & $-\infty$ & $m$ & -- & & 400 & $\cdots$ & $-\infty$ & 370 & \\
\hline
\end{tabular}


TEMPERATURE, WATER (DEG. C.) WATER YEAR OCTOBER 1984 TO SEPTEMBER 1985 RANDOM VALUES

\begin{tabular}{|c|c|c|c|c|c|c|c|c|c|c|c|c|}
\hline DAY & OCT & Nov & $\mathrm{DEC}$ & JAN & FEB & MAR & APR & MAY & JUN & JUL & AUG & SEP \\
\hline 1 & --- & -- & & & & -.- & $-\ldots$ & $-\cdots$ & -- & --- & --- & --- \\
\hline 2 & 15.0 & -- & & & & -- & 7.0 & 12.0 & -- & -- & 26.0 & -- \\
\hline 3 & $\cdots$ & 6.0 & & & & $\cdots$ & -- & -- & 20.5 & -- & -- & -- \\
\hline 4 & -- & --- & & & & -- & --- & 21.0 & -- & 26.0 & -- & 24.0 \\
\hline 5 & -- & --- & & & & -- & 10.0 & -- & --- & --- & -- & --- \\
\hline 6 & 20.0 & 5.0 & & & & --- & --- & 14.0 & --- & 27.0 & 26.0 & - \\
\hline 7 & $\cdots$ & $-\cdots$ & & & & --- & -- & 14.0 & 21.0 & -- & -- & 21.0 \\
\hline 8 & $-\infty$ & -- & & & & $\cdots$ & -- & 19.0 & -- & -- & -- & $-\cdots$ \\
\hline 10 & $\overline{7}$ & $\because-$ & & & & $\cdots$ & $-\overline{0}$ & 16.0 & -- & 26.5 & 26.0 & -- \\
\hline & 17.0 & 4.0 & & & & 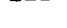 & 8.0 & $-\infty$ & th & - & $\cdots$ & 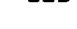 \\
\hline 11 & 14.0 & -- & & & & -- & -- & --- & 20.5 & -- & --- & 22.0 \\
\hline 12 & -- & -- & & & & -- & 10.0 & -- & -- & 28.0 & -- & -- \\
\hline 13 & 14.0 & 4.0 & & & & --- & $\cdots$ & --- & 20.0 & $\cdots$ & -- & 21.0 \\
\hline 14 & -- & -- & & & & -- & -- & 20.0 & $\cdots$ & -- & 24.0 & -- \\
\hline 15 & -- & -- & & & & $\cdots$ & 14.0 & $\cdots$ & $\cdots$ & -- & -- & $\cdots$ \\
\hline 16 & 10.0 & 3.0 & & & & $\ldots$ & -- & 18.0 & --- & -- & --- & -- \\
\hline 17 & $\cdots$ & $\cdots$ & & & & -- & -- & $\ldots$ & 21.0 & 27.0 & 26.0 & - \\
\hline 18 & -- & $-\cdots$ & & & & --- & 14.0 & $-\cdots$ & -- & $\cdots$ & - & 21.0 \\
\hline 19 & 10.0 & --- & & & & -- & $\cdots$ & $-\cdots$ & 21.0 & 27.0 & -- & $\cdots$ \\
\hline 20 & -- & 1.0 & & & & 8.5 & -- & 18.0 & $\cdots$ & -- & -- & $-\infty$ \\
\hline 21 & -- & $\cdots$ & & & & --- & --- & -- & -- & 27.0 & 25.0 & 21.0 \\
\hline 22 & 10.0 & .0 & & & & 6.0 & 18.0 & $\cdots$ & $\cdots$ & -- & -- & $\cdots$ \\
\hline 23 & & -- & & & & $\cdots$ & -- & $\overline{0}$ & $\cdots$ & $\cdots$ & $\cdots$ & -- \\
\hline 24 & -- & 1.0 & & & & --- & $-\cdots$ & 19.0 & $\ldots$ & -- & 24.0 & $\cdots$ \\
\hline 25 & $\cdots$ & $\cdots$ & & & & 6.0 & -- & -- & -- & -- & $-\cdots$ & $-\cdots$ \\
\hline 26 & 10.0 & -- & & & & $\ldots$ & 12.0 & --- & --- & 27.0 & -- & -- \\
\hline 27 & -- & -- & & & & -- & -- & -- & 21.0 & -- & --- & -- \\
\hline 28 & -- & .0 & & & & 8.0 & -- & 23.0 & & -- & 26.0 & 16.0 \\
\hline 29 & -- & -- & & & & -- & 16.5 & -- & $=-$ & 26.0 & $\cdots$ & $\cdots$ \\
\hline 30 & 9.0 & .0 & & & & $\cdots$ & -- & -- & 26.0 & -- & --- & -- \\
\hline 31 & & $\cdots$ & & & & $-\cdots$ & -- & 24.0 & & -- & 22.0 & --- \\
\hline
\end{tabular}

SUSPENDED-SEDIMENT, WATER YEAR OCTOBER 1984 TO SEPTEMBER 1985

\begin{tabular}{|c|c|c|c|c|c|c|c|c|c|c|c|c|}
\hline \multirow[t]{2}{*}{ DAY } & $\begin{array}{c}\text { MEAN } \\
\text { CONCEN- } \\
\text { TRATION } \\
(M G / L)\end{array}$ & $\begin{array}{l}\text { LOADS } \\
\text { (T/DAY) }\end{array}$ & $\begin{array}{c}\text { MEAN } \\
\text { CONCEN- } \\
\text { TRATION } \\
(M G / L)\end{array}$ & $\begin{array}{l}\text { LOADS } \\
\text { (T/DAY) }\end{array}$ & $\begin{array}{c}\text { MEAN } \\
\text { CONCEN- } \\
\text { TRATION } \\
(\text { MG/L) }\end{array}$ & $\begin{array}{l}\text { LOADS } \\
\text { (T/DAY) }\end{array}$ & $\begin{array}{c}\text { MEAN } \\
\text { CONCEN- } \\
\text { TRATION } \\
(\text { MG/L) }\end{array}$ & $\begin{array}{l}\text { LOADS } \\
\text { (T/DAY) }\end{array}$ & $\begin{array}{c}\text { MEAN } \\
\text { CONCEN- } \\
\text { TRATION } \\
\text { (MG/L) }\end{array}$ & $\begin{array}{l}\text { LOADS } \\
\text { (T/DAY) }\end{array}$ & $\begin{array}{c}\text { MEAN } \\
\text { CONCEN- } \\
\text { TRATION } \\
\text { (MG/L) }\end{array}$ & $\begin{array}{l}\text { LOADS } \\
\text { (T/DAY) }\end{array}$ \\
\hline & \multicolumn{2}{|c|}{ OCTOBER } & \multicolumn{2}{|c|}{ NOVEMBER } & \multicolumn{2}{|c|}{ DECEMBER } & \multicolumn{2}{|c|}{ JANUARY } & \multicolumn{2}{|c|}{ FEBRUARY } & \multicolumn{2}{|r|}{ MARCH } \\
\hline $\begin{array}{l}1 \\
2 \\
3 \\
4 \\
5\end{array}$ & $\begin{array}{l}60 \\
23 \\
18 \\
17 \\
20\end{array}$ & $\begin{array}{l}5200 \\
1970 \\
1520 \\
1410 \\
1610\end{array}$ & $\begin{array}{l}65 \\
64 \\
55 \\
50 \\
49\end{array}$ & $\begin{array}{l}13200 \\
13200 \\
11400 \\
10500 \\
10300\end{array}$ & $\begin{array}{r}10 \\
8 \\
5 \\
5 \\
6\end{array}$ & $\begin{array}{r}1050 \\
866 \\
539 \\
452 \\
455\end{array}$ & $\begin{array}{l}21 \\
21 \\
22 \\
22 \\
22\end{array}$ & $\begin{array}{l}2300 \\
2270 \\
2230 \\
2080 \\
1990\end{array}$ & $\begin{array}{r}11 \\
10 \\
9 \\
8 \\
7\end{array}$ & $\begin{array}{l}671 \\
610 \\
547 \\
486 \\
425\end{array}$ & $\begin{array}{l}20 \\
19 \\
18 \\
21 \\
56\end{array}$ & $\begin{array}{l}3420 \\
2970 \\
2620 \\
2780 \\
6800\end{array}$ \\
\hline $\begin{array}{r}6 \\
7 \\
8 \\
9 \\
10\end{array}$ & $\begin{array}{l}22 \\
30 \\
26 \\
21 \\
21\end{array}$ & $\begin{array}{l}1690 \\
2200 \\
1810 \\
1330 \\
1320\end{array}$ & $\begin{array}{l}49 \\
49 \\
49 \\
49 \\
48\end{array}$ & $\begin{array}{r}10000 \\
9590 \\
9390 \\
9090 \\
8530\end{array}$ & $\begin{array}{l}7 \\
7 \\
7 \\
7 \\
7\end{array}$ & $\begin{array}{l}425 \\
340 \\
327 \\
340 \\
369\end{array}$ & $\begin{array}{l}24 \\
26 \\
28 \\
30 \\
31\end{array}$ & $\begin{array}{l}2170 \\
2280 \\
2460 \\
2630 \\
2700\end{array}$ & $\begin{array}{l}5 \\
4 \\
3 \\
3 \\
3\end{array}$ & $\begin{array}{l}288 \\
230 \\
170 \\
164 \\
157\end{array}$ & $\begin{array}{l}69 \\
67 \\
50 \\
41 \\
34\end{array}$ & $\begin{array}{l}7450 \\
6870 \\
5200 \\
4430 \\
4130\end{array}$ \\
\hline $\begin{array}{l}11 \\
12 \\
13 \\
14 \\
15\end{array}$ & $\begin{array}{l}17 \\
20 \\
24 \\
26 \\
29\end{array}$ & $\begin{array}{l}1090 \\
1350 \\
1790 \\
1950 \\
2180\end{array}$ & $\begin{array}{l}39 \\
31 \\
26 \\
44 \\
74\end{array}$ & $\begin{array}{r}6240 \\
4540 \\
3660 \\
6190 \\
11100\end{array}$ & $\begin{array}{r}8 \\
10 \\
12 \\
14 \\
14\end{array}$ & $\begin{array}{r}540 \\
837 \\
1090 \\
1320 \\
1300\end{array}$ & $\begin{array}{l}41 \\
51 \\
53 \\
53 \\
54\end{array}$ & $\begin{array}{l}3430 \\
4270 \\
4290 \\
4150 \\
3940\end{array}$ & $\begin{array}{r}3 \\
3 \\
5 \\
11 \\
17\end{array}$ & $\begin{array}{l}157 \\
160 \\
269 \\
594 \\
895\end{array}$ & $\begin{array}{l}37 \\
46 \\
59 \\
64 \\
69\end{array}$ & $\begin{array}{r}5490 \\
7580 \\
11300 \\
13200 \\
15200\end{array}$ \\
\hline $\begin{array}{l}16 \\
17 \\
18 \\
19 \\
20\end{array}$ & $\begin{array}{l}32 \\
35 \\
44 \\
54 \\
53\end{array}$ & $\begin{array}{l}2510 \\
3030 \\
4020 \\
5340 \\
5540\end{array}$ & $\begin{array}{l}86 \\
80 \\
66 \\
47 \\
29\end{array}$ & $\begin{array}{r}13400 \\
12300 \\
9940 \\
6500 \\
3600\end{array}$ & $\begin{array}{r}11 \\
9 \\
7 \\
6 \\
19\end{array}$ & $\begin{array}{r}1040 \\
880 \\
699 \\
567 \\
1850\end{array}$ & $\begin{array}{l}50 \\
38 \\
28 \\
28 \\
28\end{array}$ & $\begin{array}{l}3240 \\
2460 \\
1740 \\
1720 \\
1700\end{array}$ & $\begin{array}{l}24 \\
27 \\
30 \\
34 \\
37\end{array}$ & $\begin{array}{l}1270 \\
1440 \\
1600 \\
1800 \\
1950\end{array}$ & $\begin{array}{r}82 \\
110 \\
108 \\
90 \\
55\end{array}$ & $\begin{array}{l}18000 \\
24000 \\
23000 \\
18600 \\
11100\end{array}$ \\
\hline $\begin{array}{l}21 \\
22 \\
23 \\
24 \\
25\end{array}$ & $\begin{array}{l}43 \\
30 \\
24 \\
23 \\
26\end{array}$ & $\begin{array}{l}4990 \\
3960 \\
3530 \\
3630 \\
4230\end{array}$ & $\begin{array}{l}28 \\
31 \\
31 \\
26 \\
22\end{array}$ & $\begin{array}{l}3140 \\
3130 \\
3060 \\
2600 \\
2260\end{array}$ & $\begin{array}{l}47 \\
59 \\
60 \\
54 \\
45\end{array}$ & $\begin{array}{l}4440 \\
5500 \\
5670 \\
5320 \\
4470\end{array}$ & $\begin{array}{l}28 \\
27 \\
24 \\
22 \\
18\end{array}$ & $\begin{array}{l}1720 \\
1660 \\
1470 \\
1350 \\
1100\end{array}$ & $\begin{array}{r}50 \\
108 \\
215 \\
409 \\
356\end{array}$ & $\begin{array}{r}2660 \\
6420 \\
18000 \\
47500 \\
55700\end{array}$ & $\begin{array}{l}43 \\
37 \\
37 \\
37 \\
36\end{array}$ & $\begin{array}{l}8710 \\
7690 \\
8020 \\
8360 \\
8460\end{array}$ \\
\hline $\begin{array}{l}26 \\
27 \\
28 \\
29 \\
30 \\
31\end{array}$ & $\begin{array}{l}34 \\
38 \\
39 \\
46 \\
56 \\
62\end{array}$ & $\begin{array}{r}5750 \\
6590 \\
7060 \\
8580 \\
10700 \\
12000\end{array}$ & $\begin{array}{l}19 \\
16 \\
12 \\
12 \\
13 \\
--\end{array}$ & $\begin{array}{c}1940 \\
1560 \\
1120 \\
1100 \\
1280 \\
--\end{array}$ & $\begin{array}{l}34 \\
30 \\
28 \\
24 \\
22 \\
22\end{array}$ & $\begin{array}{l}3470 \\
3100 \\
3010 \\
2660 \\
2440 \\
2440\end{array}$ & $\begin{array}{l}15 \\
14 \\
14 \\
14 \\
13 \\
12\end{array}$ & $\begin{array}{l}923 \\
850 \\
858 \\
850 \\
790 \\
729\end{array}$ & $\begin{array}{r}207 \\
90 \\
31 \\
--- \\
--- \\
---\end{array}$ & $\begin{array}{r}40500 \\
17300 \\
5740 \\
- \\
- \\
-\end{array}$ & $\begin{array}{l}37 \\
46 \\
57 \\
66 \\
67 \\
64\end{array}$ & $\begin{array}{r}9050 \\
11800 \\
15000 \\
17800 \\
18100 \\
17600\end{array}$ \\
\hline$T$ & - & 19880 & --- & 13860 & --- & 57806 & -- & 66350 & -- & 207703 & -- & 324730 \\
\hline
\end{tabular}


05389500 MISSISSIPPI RIVER AT MCGREGOR, IA--Continued

WATER-QUALITY RECORDS

SUSPENDED-SEDIMENT, WATER YEAR OCTOBER 1984 TO SEPTEMBER 1985

\begin{tabular}{|c|c|c|c|c|c|c|c|c|c|c|c|c|}
\hline \multirow[t]{2}{*}{ DAY } & $\begin{array}{c}\text { MEAN } \\
\text { CONCEN- } \\
\text { TRATION } \\
\text { (MG/L) }\end{array}$ & $\begin{array}{l}\text { LOADS } \\
\text { (T/DAY) }\end{array}$ & $\begin{array}{c}\text { MEAN } \\
\text { CONCEN- } \\
\text { TRATION } \\
\text { (MG/L) }\end{array}$ & $\begin{array}{l}\text { LOADS } \\
\text { (T/DAY) }\end{array}$ & $\begin{array}{c}\text { MEAN } \\
\text { CONCEN- } \\
\text { TRATION } \\
\text { (MG/L) }\end{array}$ & $\begin{array}{l}\text { LOADS } \\
(\mathrm{T} / \mathrm{DAY})\end{array}$ & $\begin{array}{l}\text { MEAN } \\
\text { CONCEN- } \\
\text { TRATION } \\
(\text { MG /L) }\end{array}$ & $\begin{array}{l}\text { LOADS } \\
(\mathrm{T} / \mathrm{DAY})\end{array}$ & $\begin{array}{l}\text { MEAN } \\
\text { CONCEN- } \\
\text { TRATION } \\
\text { (MG/L) }\end{array}$ & $\begin{array}{l}\text { LOADS } \\
\text { (T/DAY) }\end{array}$ & $\begin{array}{c}\text { MEAN } \\
\text { CONCEN- } \\
\text { TRATION } \\
(M G / L)\end{array}$ & $\begin{array}{l}\text { LOADS } \\
\text { (T/DAY) }\end{array}$ \\
\hline & \multicolumn{2}{|c|}{ APRIL } & \multicolumn{2}{|c|}{ MAY } & \multicolumn{2}{|c|}{ JUNE } & \multicolumn{2}{|c|}{ JULY } & \multicolumn{2}{|c|}{ AUGUST } & \multicolumn{2}{|c|}{ SEPTEMBER } \\
\hline $\begin{array}{l}1 \\
2 \\
3 \\
4 \\
5\end{array}$ & $\begin{array}{l}55 \\
40 \\
37 \\
35 \\
32\end{array}$ & $\begin{array}{r}15600 \\
11700 \\
10900 \\
10400 \\
9500\end{array}$ & $\begin{array}{l}36 \\
43 \\
49 \\
47 \\
45\end{array}$ & $\begin{array}{r}8790 \\
11000 \\
12900 \\
12500 \\
12100\end{array}$ & $\begin{array}{l}57 \\
60 \\
83 \\
98 \\
87\end{array}$ & $\begin{array}{r}7630 \\
8310 \\
11500 \\
13200 \\
10900\end{array}$ & $\begin{array}{l}30 \\
28 \\
26 \\
23 \\
24\end{array}$ & $\begin{array}{l}3160 \\
3020 \\
2990 \\
2870 \\
3210\end{array}$ & $\begin{array}{l}19 \\
17 \\
20 \\
38 \\
36\end{array}$ & $\begin{array}{l}1680 \\
1420 \\
1640 \\
3060 \\
2750\end{array}$ & $\begin{array}{l}23 \\
23 \\
30 \\
43 \\
41\end{array}$ & $\begin{array}{l}2240 \\
2090 \\
2330 \\
3450 \\
3810\end{array}$ \\
\hline $\begin{array}{r}6 \\
7 \\
8 \\
9 \\
10\end{array}$ & $\begin{array}{l}30 \\
28 \\
27 \\
25 \\
23\end{array}$ & $\begin{array}{l}8830 \\
8010 \\
7580 \\
6880 \\
6270\end{array}$ & $\begin{array}{l}43 \\
49 \\
64 \\
44 \\
37\end{array}$ & $\begin{array}{r}11600 \\
13100 \\
16800 \\
11200 \\
9230\end{array}$ & $\begin{array}{l}76 \\
66 \\
67 \\
68 \\
69\end{array}$ & $\begin{array}{l}9300 \\
8070 \\
8450 \\
9180 \\
9670\end{array}$ & $\begin{array}{l}27 \\
27 \\
28 \\
28 \\
28\end{array}$ & $\begin{array}{l}3770 \\
3850 \\
4020 \\
3940 \\
3880\end{array}$ & $\begin{array}{l}26 \\
23 \\
29 \\
38 \\
40\end{array}$ & $\begin{array}{l}1870 \\
1630 \\
2090 \\
2710 \\
2760\end{array}$ & $\begin{array}{l}39 \\
37 \\
35 \\
32 \\
30\end{array}$ & $\begin{array}{l}4010 \\
3970 \\
3870 \\
3650 \\
3530\end{array}$ \\
\hline $\begin{array}{l}11 \\
12 \\
13 \\
14 \\
15\end{array}$ & $\begin{array}{l}23 \\
23 \\
26 \\
32 \\
38\end{array}$ & $\begin{array}{l}6190 \\
6050 \\
6610 \\
7820 \\
8950\end{array}$ & $\begin{array}{l}40 \\
48 \\
53 \\
56 \\
60\end{array}$ & $\begin{array}{r}9680 \\
11400 \\
12000 \\
12100 \\
12500\end{array}$ & $\begin{array}{l}69 \\
67 \\
64 \\
64 \\
65\end{array}$ & $\begin{array}{l}9950 \\
9370 \\
8160 \\
7590 \\
7620\end{array}$ & $\begin{array}{l}27 \\
27 \\
26 \\
25 \\
24\end{array}$ & $\begin{array}{l}3650 \\
3550 \\
3290 \\
3020 \\
2740\end{array}$ & $\begin{array}{l}46 \\
37 \\
24 \\
23 \\
60\end{array}$ & $\begin{array}{l}3180 \\
2530 \\
1710 \\
1860 \\
5540\end{array}$ & $\begin{array}{l}27 \\
27 \\
25 \\
27 \\
29\end{array}$ & $\begin{array}{l}3280 \\
3400 \\
3270 \\
3790 \\
4450\end{array}$ \\
\hline $\begin{array}{l}16 \\
17 \\
18 \\
19 \\
20\end{array}$ & $\begin{array}{l}42 \\
45 \\
49 \\
48 \\
44\end{array}$ & $\begin{array}{r}9550 \\
9910 \\
10900 \\
10800 \\
10100\end{array}$ & $\begin{array}{l}63 \\
64 \\
66 \\
67 \\
69\end{array}$ & $\begin{array}{l}12800 \\
12700 \\
12500 \\
12200 \\
12200\end{array}$ & $\begin{array}{l}67 \\
67 \\
63 \\
58 \\
52\end{array}$ & $\begin{array}{l}7870 \\
7960 \\
7470 \\
6640 \\
5770\end{array}$ & $\begin{array}{l}23 \\
22 \\
20 \\
19 \\
19\end{array}$ & $\begin{array}{l}2400 \\
2080 \\
1720 \\
1610 \\
1630\end{array}$ & $\begin{array}{l}48 \\
30 \\
26 \\
27 \\
25\end{array}$ & $\begin{array}{l}4680 \\
2970 \\
2580 \\
2660 \\
2400\end{array}$ & $\begin{array}{l}30 \\
31 \\
32 \\
30 \\
30\end{array}$ & $\begin{array}{l}4880 \\
5030 \\
5080 \\
4580 \\
4370\end{array}$ \\
\hline $\begin{array}{l}21 \\
22 \\
23 \\
24 \\
25\end{array}$ & $\begin{array}{l}40 \\
37 \\
41 \\
52 \\
61\end{array}$ & $\begin{array}{r}9200 \\
8480 \\
9220 \\
11400 \\
13100\end{array}$ & $\begin{array}{r}69 \\
68 \\
87 \\
113 \\
120\end{array}$ & $\begin{array}{l}12000 \\
11900 \\
15400 \\
20200 \\
21400\end{array}$ & $\begin{array}{l}47 \\
42 \\
36 \\
41 \\
53\end{array}$ & $\begin{array}{l}5150 \\
4600 \\
3940 \\
4470 \\
5800\end{array}$ & $\begin{array}{l}18 \\
18 \\
18 \\
17 \\
23\end{array}$ & $\begin{array}{l}1560 \\
1540 \\
1460 \\
1260 \\
1720\end{array}$ & $\begin{array}{l}22 \\
17 \\
20 \\
25 \\
29\end{array}$ & $\begin{array}{l}1980 \\
1490 \\
1730 \\
2190 \\
2590\end{array}$ & $\begin{array}{l}30 \\
29 \\
27 \\
25 \\
25\end{array}$ & $\begin{array}{l}4170 \\
3960 \\
3740 \\
3470 \\
3390\end{array}$ \\
\hline $\begin{array}{l}26 \\
27 \\
28 \\
29 \\
30 \\
31\end{array}$ & $\begin{array}{r}71 \\
77 \\
60 \\
32 \\
30 \\
---\end{array}$ & $\begin{array}{r}14900 \\
16200 \\
12900 \\
7130 \\
7000 \\
-\end{array}$ & $\begin{array}{r}111 \\
92 \\
73 \\
68 \\
69 \\
75\end{array}$ & $\begin{array}{l}19800 \\
16100 \\
12200 \\
10600 \\
10000 \\
10600\end{array}$ & $\begin{array}{r}51 \\
38 \\
29 \\
28 \\
30 \\
---\end{array}$ & $\begin{array}{l}5550 \\
4060 \\
3010 \\
2910 \\
3130 \\
-\end{array}$ & $\begin{array}{l}43 \\
66 \\
69 \\
37 \\
22 \\
21\end{array}$ & $\begin{array}{l}3530 \\
5740 \\
6280 \\
3480 \\
2070 \\
1920\end{array}$ & $\begin{array}{l}33 \\
34 \\
20 \\
17 \\
18 \\
20\end{array}$ & $\begin{array}{l}2930 \\
2620 \\
1470 \\
1320 \\
1520 \\
1870\end{array}$ & $\begin{array}{r}24 \\
28 \\
44 \\
58 \\
45 \\
--\end{array}$ & $\begin{array}{r}3250 \\
3840 \\
6140 \\
8600 \\
7480 \\
---\end{array}$ \\
\hline TOTAL & $-\infty$ & 292080 & -- & 399500 & --- & 217230 & -- & 90960 & -- & 73430 & -- & 123120 \\
\hline TOTAL & $A D E O R$ & $\mathbf{R}:$ & 2176649 & TONS. & & & & & & & & \\
\hline
\end{tabular}

WATER QUALITY DATA, WATER YEAR OCTOBER 1984 TO SEPTEMBER 1985

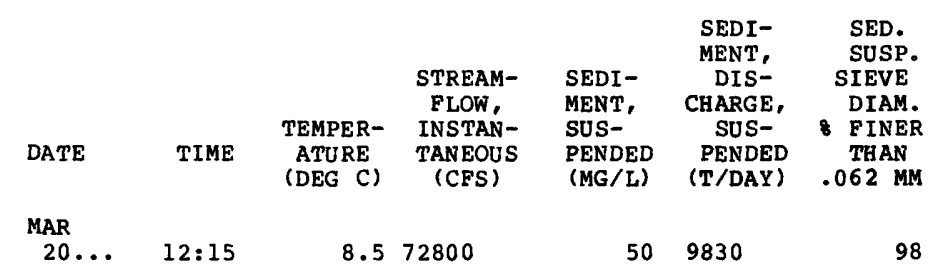

WATER QUALITY DATA, WATER YEAR OCTOBER 1984 TO SEPTEMBER 1985

\begin{tabular}{|c|c|c|c|c|c|c|c|c|c|c|c|}
\hline DATE & TIME & $\begin{array}{l}\text { STREAM- } \\
\text { FLOW, } \\
\text { INSTAN- } \\
\text { TANEOUS } \\
\text { (CFS) }\end{array}$ & $\begin{array}{c}\text { NUMBER } \\
\text { OF } \\
\text { SAM- } \\
\text { PLING } \\
\text { POINTS }\end{array}$ & $\begin{array}{c}\text { BED } \\
\text { MAT. } \\
\text { SIEVE } \\
\text { DIAM. } \\
8 \text { FINER } \\
\text { THAN } \\
.062 \mathrm{MM}\end{array}$ & $\begin{array}{c}\text { BED } \\
\text { MAT. } \\
\text { SIEVE } \\
\text { DIAM. } \\
\text { \&INER } \\
\text { THAN } \\
.125 \mathrm{MM}\end{array}$ & $\begin{array}{c}\text { BED } \\
\text { MAT. } \\
\text { SIEVE } \\
\text { DIAM. } \\
\text { FINER } \\
\text { THAN } \\
.250 \mathrm{MM}\end{array}$ & $\begin{array}{c}\text { BED } \\
\text { MAT. } \\
\text { SIEVE } \\
\text { DIAM. } \\
8 \text { FINER } \\
\text { THAN } \\
.500 \mathrm{MM}\end{array}$ & $\begin{array}{l}\text { BED } \\
\text { MAT. } \\
\text { SIEVE } \\
\text { DIAM. } \\
\text { FINER } \\
\text { THAN } \\
1.00 \mathrm{MM}\end{array}$ & $\begin{array}{c}\text { BED } \\
\text { MAT. } \\
\text { SIEVE } \\
\text { DIAM. } \\
\text { FINER } \\
\text { THAN } \\
2.00 \mathrm{MM}\end{array}$ & $\begin{array}{c}\text { BED } \\
\text { MAT. } \\
\text { SIEVE } \\
\text { DIAM. } \\
\text { FINER } \\
\text { THAN } \\
4.00 \mathrm{MM}\end{array}$ & $\begin{array}{c}\text { BED } \\
\text { MAT. } \\
\text { SIEVE } \\
\text { DIAM. } \\
\text { FINER } \\
\text { THAN } \\
8.00 \mathrm{MM}\end{array}$ \\
\hline MAR & & & & & & & & & & & \\
\hline$\underset{M A Y}{20} \cdots$ & $13: 10$ & 72800 & 6 & 3 & 6 & 38 & 94 & 99 & 99 & 99 & 100 \\
\hline $01 \ldots$ & $12: 30$ & 85900 & 6 & 2 & 5 & 36 & 91 & 97 & 98 & 99 & 100 \\
\hline
\end{tabular}


LOCATION.--Lat $43^{\circ} 12^{\prime} 28^{\prime \prime}$, long $91^{\circ} 56^{\prime} 56^{\prime \prime}$, in SWl/4 NEl/4 sec.19, T.97 N., R.9 W., Winneshiek County, on right bank $60 \mathrm{ft}$ downstream from bridge on county highway wl4 at north edge of Spiliville, l50 ft downstream from old mill dam, $0.6 \mathrm{mi}$ upstream from Wonder Creek and at mile 98.5 .

DRAINAGE AREA. $--177 \mathrm{mi}^{2}$.

PERIOD OF RECORD,--June 1956 to September 1973, October 1977 to current year. Monthly discharge only for some periods, published in WSP 1728 .

REVISED RECORDS.--WDR IA-75-1: 1974.

GAGE.--Water-stage recorder. Datum of gage is $1,034.92 \mathrm{ft}$ above NGVD.

REMARKS.--Estimated daily discharges: Nov. 12-13, 16-23, Dec. 3-9, 11, Dec. 17 to Feb. 25 and Mar. 7-8, 13-20. Records good except for estimated daily discharges, which are poor.

AVERAGE DISCHARGE. --25 years, $126 \mathrm{ft} / \mathrm{s}, 9.67 \mathrm{in} / \mathrm{yr}^{2}, 91,290 \mathrm{acre}-\mathrm{ft} / \mathrm{yr}$.

EXTREMES FOR PERIOD OF RECORD.-Maximum discharge, 8,600 ft3/s July 12, 1972, gage height, 16.73 ft; minimum daily, $4.4 \mathrm{ft}^{3} / \mathrm{s}$ Feb. 1-3, 1959 .

EXTREMES OUTSIDE PERIOD OF RECORD.--Flood in June 1947 reached a stage of 18.4 ft, from floodmark, discharge, about $10,000 \mathrm{ft} / \mathrm{s}$.

EXTREMES FOR CURRENT YEAR.--Peak discharges greater than base of $1,200 \mathrm{ft}^{3} / \mathrm{s}$ and maximum (*):

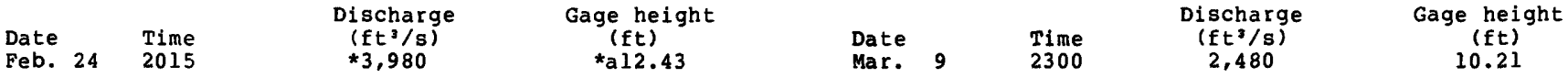

(a) Ice jam.

Minimum discharge, $16 \mathrm{ft}^{3} / \mathrm{s}$ Aug. 8,9 .

DISCHARGE, IN CUBIC FEET PER SECOND, WATER YEAR OCTOBER 1984 TO SEPTEMBER 1985 MEAN VALUES

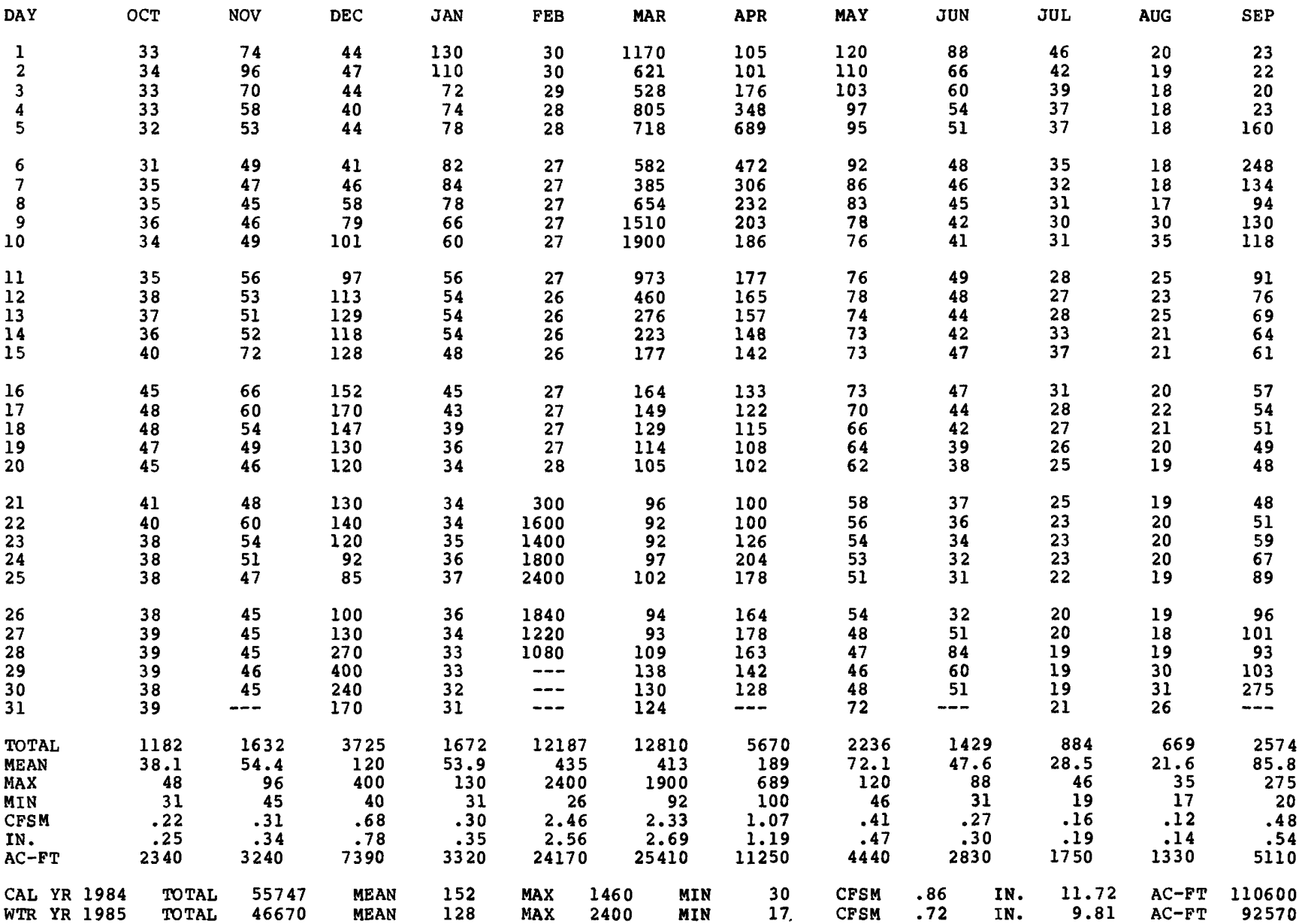


LOCATION, - Lat $42^{\circ} 44^{\prime} 24^{\prime \prime}$, Iong $91^{\circ} 1^{\prime} \mathbf{\prime}^{\prime \prime}$, in SEl/4 NWl/4 sec.36, T.92 N., R. 4 W., Clayton County, Hydrologic Unit 07060004 , on left bank $10 \mathrm{ft}$ downstream from bridge on county highway C43, $800 \mathrm{ft}$ upstream from Wayman Creek, $1,000 \mathrm{ft}$ southeast of Garber, 2,000 ft downstream from Elk Creek, $1 \mathrm{mi}$ downstream from Volga River, and $19.8 \mathrm{mi}$ upstream from mouth.

DRAINAGE AREA. $--1,545 \mathrm{mi}^{2}$.

PERIOD OF RECORD.--August 1913 to November 1916, May 1919 to September 1927 , April 1929 to September 1930 , October 1932 to current year. Monthly discharge only for some periods, published in WSP 1308.

REVISED RECORDS.--WSP 1308: 1922-25 (M), 1927 (M). WSP 1438: Drainage area.

GAGE.--Water-stage recorder. Datum of gage is $634.46 \mathrm{ft}$ above NGVD. Prior to Feb. 7 , 1935 , nonrecording gage at same site and datum.

REMARKS.--Estimated daily discharges: Dec. 3-8, Dec. 17 to Feb. 21, Mar. 18, July 1-15. Records fair except for periods of estimated record, Dec. 3-8, Dec. 17 to Feb. 21, which are poor. U.S. Army Corps of Engineers operate a Data Collection Platform at station.

COOPERATION.--Four discharge measurements provided by U.S. Army Corps of Engineers.

AVERAGE DISCHARGE.--65 years (1913-16, 1919-27, 1929-30, 1932-85), 953 ft $3 / \mathrm{s}, 8.38 \mathrm{in} / \mathrm{yr}^{\mathrm{r}}, 690,400 \mathrm{acre-ft/yr}$.

EXTREMES FOR PERIOD OF RECORD.--Maximum discharge, 32,300 ft $3 / \mathrm{s}$ Feb. 23, 1922, gage height, $28.06 \mathrm{ft}$, from floodmark; minimum daily, $49 \mathrm{ft}^{3} / \mathrm{s}$ Jan. 28, 29, 1940.

EXTREMES OUTSIDE PERIOD OF RECORD.--Maximum stage since at least 1890, that of Feb. 23 , 1922.

EXTREMES FOR CURRENT YEAR.--Peak discharges greater than base of $8,000 \mathrm{ft}^{3} / \mathrm{s}$ and maximum (*):

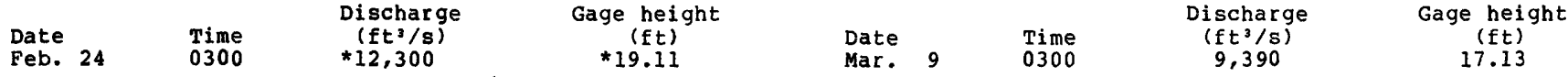

Minimum discharge, $206 \mathrm{ft}^{3} / \mathrm{s}$ Aug. 8-9.

DISCHARGE, IN CUBIC FEET PER SECOND, WATER YEAR OCTOBER 1984 TO SEPTEMBER 1985 MEAN VALUES

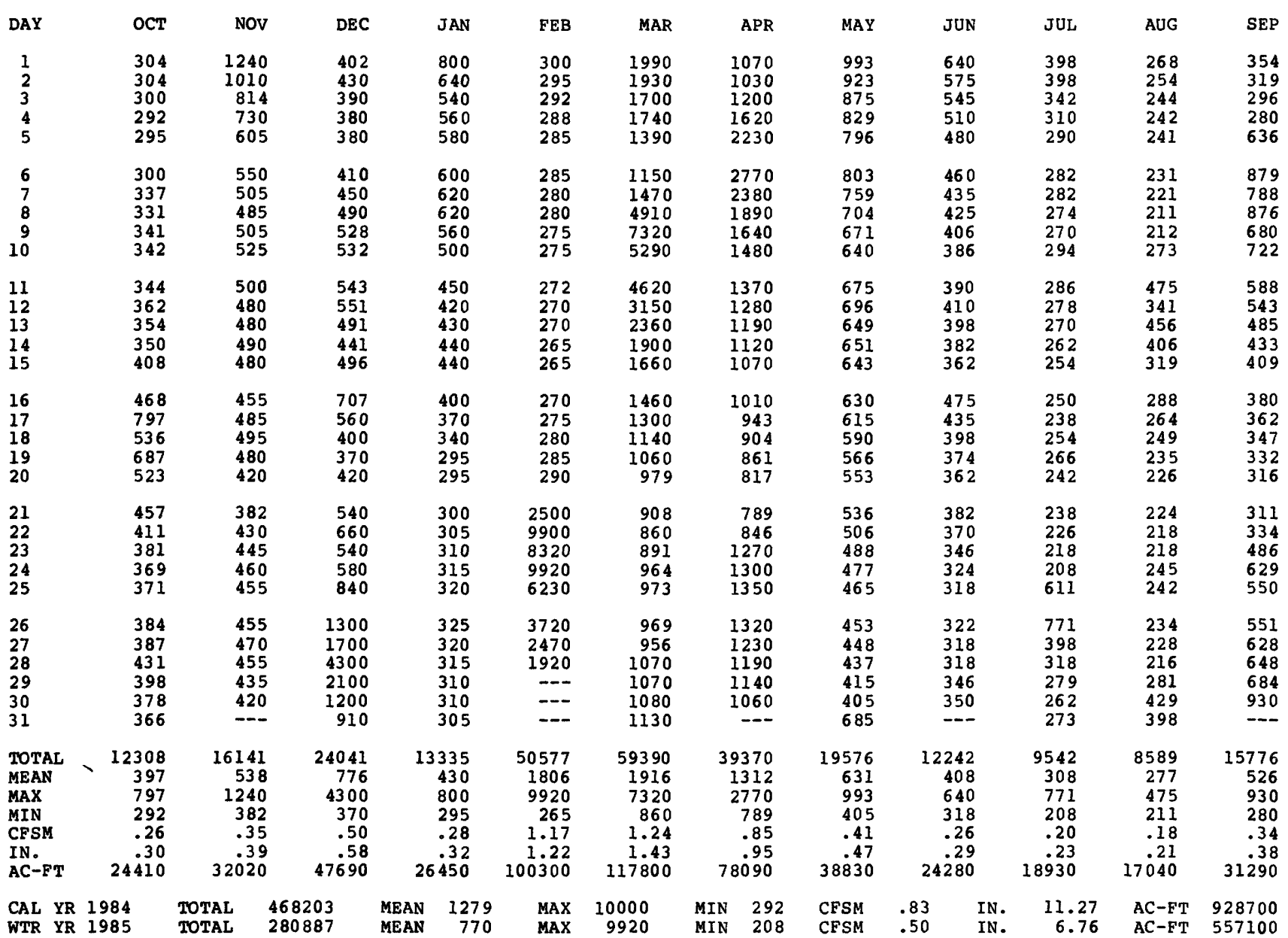




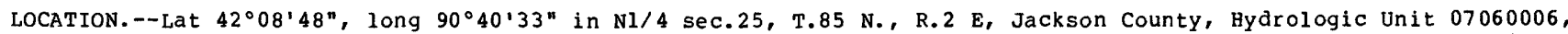
on right downstream bank at bridge on State Highway $61,7.8 \mathrm{mi}$ upstream from mouth, and 5.5 mi north of junction of State Highway 64 and 61 and $0.5 \mathrm{mi}$ south of Fulton.

DRAINAGE AREA. $--516 \mathrm{mi}^{2}$.

PERIOD OF RECORD.--JULY 1977 to current year.

GAGE.--Water-stage recorder. Datum of gage is $666.19 \mathrm{ft}$ above NGVD. Nonrecording gage July 7 to September 22 , 1977 .

REMARKS.-Estimated daily discharges: Oct. 1-16, Oct. 21 to Nov. 14, Nov. 18-22, Dec. 2-28, Jan. 1 to Feb. 22,

April 8-29, Aug. 31 to Sept. 8. Records good except those for Oct. 1-16, Oct. 21 to Nov.14 and April 8-29,

which are fair and Nov. 18-22, Dec. 2-28, Jan. 1 to Feb. 22, and Aug. 31 to Sept. 8, which are poor.

AVERAGE DISCHARGE. --8 years, $368 \mathrm{ft}^{3} / \mathrm{s}, 9.68 \mathrm{in} / \mathrm{yr}, 266,600 \mathrm{acre-ft} / \mathrm{yr}$.

EXTREMES FOR PERIOD OF RECORD.--Maximum discharge, 10,700 ft ${ }^{3} / \mathrm{s}$ Aug. 31, 1981, gage height, $17.26 \mathrm{ft}$; minimum daily, $70 \mathrm{ft}^{3} / \mathrm{s}$ July $11,1977$.

EXTREMES OUTSIDE PERIOD OF RECORD.--Flood of May 18, 1974 reached a stage of 16.0 ft., from floodmark, discharge $10,000 \mathrm{ft}^{3} / \mathrm{s}$.

EXTREMES FOR CURRENT YEAR.--Peak discharges greater than base of $2,500 \mathrm{ft}^{3} / \mathrm{s}$ and maximum (*):

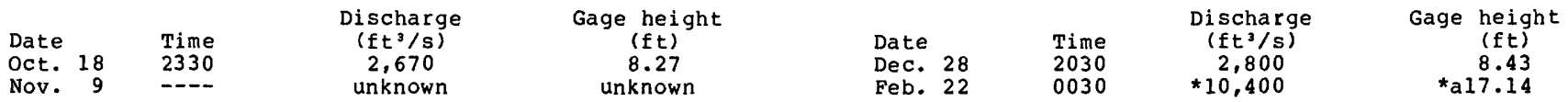

(a) Ice jam

Minimum discharge, $127 \mathrm{ft}^{3} / \mathrm{s}$ sept. 15 .

DISCHARGE, IN CUBIC FEET PER SECOND, WATER YEAR OCTOBER 1984 TO SEPTEMBER 1985 MEAN VALUES

\begin{tabular}{|c|c|c|c|c|c|c|c|c|c|c|c|c|}
\hline DAY & OCT & NOV & DEC & JAN & FEB & MAR & APR & MAY & JUN & JUL & AUG & SEP \\
\hline $\begin{array}{l}1 \\
2 \\
3 \\
4 \\
5\end{array}$ & $\begin{array}{l}164 \\
162 \\
162 \\
160 \\
164\end{array}$ & $\begin{array}{l}969 \\
707 \\
506 \\
419 \\
349\end{array}$ & $\begin{array}{l}247 \\
240 \\
195 \\
172 \\
180\end{array}$ & $\begin{array}{l}250 \\
230 \\
200 \\
190 \\
230\end{array}$ & $\begin{array}{l}190 \\
190 \\
185 \\
185 \\
185\end{array}$ & $\begin{array}{r}541 \\
557 \\
474 \\
710 \\
1290\end{array}$ & $\begin{array}{l}580 \\
521 \\
533 \\
605 \\
595\end{array}$ & $\begin{array}{l}304 \\
281 \\
274 \\
276 \\
285\end{array}$ & $\begin{array}{l}244 \\
240 \\
232 \\
224 \\
223\end{array}$ & $\begin{array}{l}156 \\
160 \\
155 \\
156 \\
154\end{array}$ & $\begin{array}{l}155 \\
147 \\
149 \\
142 \\
146\end{array}$ & $\begin{array}{l}185 \\
171 \\
163 \\
163 \\
420\end{array}$ \\
\hline $\begin{array}{r}6 \\
7 \\
8 \\
9 \\
10\end{array}$ & $\begin{array}{l}166 \\
219 \\
229 \\
200 \\
182\end{array}$ & $\begin{array}{r}304 \\
289 \\
301 \\
2270 \\
783\end{array}$ & $\begin{array}{l}162 \\
200 \\
310 \\
300 \\
270\end{array}$ & $\begin{array}{l}300 \\
368 \\
327 \\
270 \\
230\end{array}$ & $\begin{array}{l}180 \\
180 \\
175 \\
175 \\
175\end{array}$ & $\begin{array}{r}689 \\
547 \\
772 \\
1180 \\
778\end{array}$ & $\begin{array}{l}588 \\
567 \\
498 \\
447 \\
416\end{array}$ & $\begin{array}{l}339 \\
348 \\
313 \\
291 \\
278\end{array}$ & $\begin{array}{l}222 \\
215 \\
215 \\
214 \\
210\end{array}$ & $\begin{array}{l}151 \\
150 \\
149 \\
146 \\
145\end{array}$ & $\begin{array}{l}156 \\
145 \\
136 \\
140 \\
291\end{array}$ & $\begin{array}{l}409 \\
247 \\
188 \\
166 \\
155\end{array}$ \\
\hline $\begin{array}{l}11 \\
12 \\
13 \\
14 \\
15\end{array}$ & $\begin{array}{l}173 \\
171 \\
175 \\
178 \\
180\end{array}$ & $\begin{array}{l}376 \\
310 \\
295 \\
272 \\
280\end{array}$ & $\begin{array}{l}248 \\
260 \\
260 \\
233 \\
259\end{array}$ & $\begin{array}{l}210 \\
190 \\
200 \\
260 \\
235\end{array}$ & $\begin{array}{l}170 \\
170 \\
170 \\
170 \\
170\end{array}$ & $\begin{array}{l}634 \\
562 \\
516 \\
502 \\
486\end{array}$ & $\begin{array}{l}401 \\
387 \\
372 \\
365 \\
354\end{array}$ & $\begin{array}{l}291 \\
316 \\
347 \\
365 \\
694\end{array}$ & $\begin{array}{l}223 \\
218 \\
207 \\
203 \\
221\end{array}$ & $\begin{array}{l}147 \\
152 \\
152 \\
154 \\
194\end{array}$ & $\begin{array}{l}204 \\
162 \\
196 \\
217 \\
185\end{array}$ & $\begin{array}{l}147 \\
139 \\
134 \\
132 \\
132\end{array}$ \\
\hline $\begin{array}{l}16 \\
17 \\
18 \\
19 \\
20\end{array}$ & $\begin{array}{r}239 \\
1390 \\
697 \\
1540 \\
732\end{array}$ & $\begin{array}{l}264 \\
249 \\
240 \\
235 \\
230\end{array}$ & $\begin{array}{l}415 \\
510 \\
320 \\
280 \\
270\end{array}$ & $\begin{array}{l}215 \\
205 \\
200 \\
180 \\
180\end{array}$ & $\begin{array}{l}175 \\
180 \\
185 \\
190 \\
200\end{array}$ & $\begin{array}{l}447 \\
424 \\
404 \\
390 \\
378\end{array}$ & $\begin{array}{l}344 \\
323 \\
316 \\
309 \\
309\end{array}$ & $\begin{array}{l}412 \\
362 \\
331 \\
312 \\
301\end{array}$ & $\begin{array}{l}210 \\
206 \\
200 \\
197 \\
190\end{array}$ & $\begin{array}{l}150 \\
146 \\
145 \\
159 \\
171\end{array}$ & $\begin{array}{l}169 \\
158 \\
153 \\
147 \\
142\end{array}$ & $\begin{array}{l}132 \\
140 \\
140 \\
140 \\
134\end{array}$ \\
\hline $\begin{array}{l}21 \\
22 \\
23 \\
24 \\
25\end{array}$ & $\begin{array}{l}422 \\
328 \\
258 \\
222 \\
227\end{array}$ & $\begin{array}{l}240 \\
240 \\
242 \\
233 \\
233\end{array}$ & $\begin{array}{l}290 \\
506 \\
433 \\
285 \\
230\end{array}$ & $\begin{array}{l}185 \\
190 \\
210 \\
230 \\
240\end{array}$ & $\begin{array}{l}3000 \\
8000 \\
3610 \\
3400 \\
1380\end{array}$ & $\begin{array}{l}360 \\
350 \\
352 \\
382 \\
407\end{array}$ & $\begin{array}{l}302 \\
299 \\
320 \\
323 \\
313\end{array}$ & $\begin{array}{l}286 \\
274 \\
265 \\
264 \\
261\end{array}$ & $\begin{array}{l}192 \\
228 \\
205 \\
181 \\
178\end{array}$ & $\begin{array}{l}163 \\
156 \\
154 \\
145 \\
160\end{array}$ & $\begin{array}{l}144 \\
144 \\
146 \\
153 \\
176\end{array}$ & $\begin{array}{l}135 \\
152 \\
256 \\
286 \\
211\end{array}$ \\
\hline $\begin{array}{l}26 \\
27 \\
28 \\
29 \\
30 \\
31\end{array}$ & $\begin{array}{l}227 \\
250 \\
660 \\
364 \\
286 \\
292\end{array}$ & $\begin{array}{l}234 \\
328 \\
280 \\
259 \\
254 \\
---\end{array}$ & $\begin{array}{r}240 \\
290 \\
900 \\
1670 \\
691 \\
447\end{array}$ & $\begin{array}{l}220 \\
210 \\
205 \\
200 \\
200 \\
195\end{array}$ & $\begin{array}{l}819 \\
617 \\
517 \\
--- \\
--\end{array}$ & $\begin{array}{l}385 \\
378 \\
437 \\
493 \\
473 \\
513\end{array}$ & $\begin{array}{l}306 \\
302 \\
299 \\
313 \\
303 \\
---\end{array}$ & $\begin{array}{l}260 \\
287 \\
263 \\
253 \\
252 \\
251\end{array}$ & $\begin{array}{l}181 \\
181 \\
172 \\
169 \\
164 \\
-\end{array}$ & $\begin{array}{l}179 \\
175 \\
158 \\
152 \\
150 \\
159\end{array}$ & $\begin{array}{l}173 \\
160 \\
152 \\
150 \\
152 \\
226\end{array}$ & $\begin{array}{l}199 \\
186 \\
175 \\
172 \\
189 \\
-\end{array}$ \\
\hline $\begin{array}{l}\text { TOTAL } \\
\text { MEAN } \\
\text { MAX } \\
\text { MIN } \\
\text { CFSM } \\
\text { IN. } \\
\text { AC-FT }\end{array}$ & $\begin{array}{r}10819 \\
349 \\
1540 \\
160 \\
.68 \\
.78 \\
21460\end{array}$ & $\begin{array}{r}12191 \\
406 \\
2270 \\
230 \\
.79 \\
.88 \\
24180\end{array}$ & $\begin{array}{r}11313 \\
365 \\
1670 \\
162 \\
.71 \\
.82 \\
22440\end{array}$ & $\begin{array}{r}6955 \\
224 \\
368 \\
180 \\
.43 \\
.50 \\
13800\end{array}$ & $\begin{array}{r}24943 \\
891 \\
8000 \\
170 \\
1.73 \\
1.80 \\
49470\end{array}$ & $\begin{array}{r}16811 \\
542 \\
1290 \\
350 \\
1.05 \\
1.21 \\
33340\end{array}$ & $\begin{array}{r}11910 \\
397 \\
605 \\
299 \\
.77 \\
.86 \\
23620\end{array}$ & $\begin{array}{r}9636 \\
311 \\
694 \\
251 \\
.60 \\
19110\end{array}$ & $\begin{array}{r}6165 \\
206 \\
244 \\
164 \\
.40 \\
12230\end{array}$ & $\begin{array}{r}4843 \\
156 \\
194 \\
145 \\
.30 \\
.35 \\
9610\end{array}$ & $\begin{array}{r}5116 \\
165 \\
291 \\
136 \\
.32 \\
.37 \\
10150\end{array}$ & $\begin{array}{r}5598 \\
187 \\
420 \\
132 \\
.36 \\
.40 \\
11100\end{array}$ \\
\hline
\end{tabular}

$\begin{array}{lllllllllllllll}\text { CAL YR } 1984 & \text { TOTAL } & 145101 & \text { MEAN } & 396 & \text { MAX } & 5220 & \text { MIN } & 148 & \text { CFSM } & .77 & \text { IN. } & 10.46 & \text { AC-FT } & 287800\end{array}$

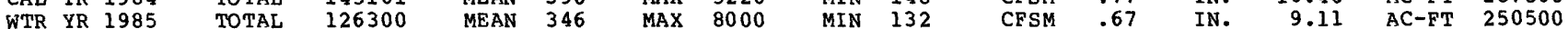


LOCATION.--Lat $42^{\circ} 05^{\prime} 05^{\prime \prime}$, long $90^{\circ} 38^{\prime} 04^{\prime \prime}$, in Swl/4 NEl/4 sec.17, T.84 N., R.3 E., Jackson County, Hydrologic Unit 07060006 , on right bank 300 upstream from bridge on state Highway $62,1,200$ ft upstream from Prairie Creek, 2.0 mi northeast of Maquoketa, $2.2 \mathrm{mi}$ downstream from North Fork, and $26.7 \mathrm{mi}$ upstream $\mathrm{from}$ mouth.

DRAINAGE AREA. $--1,553 \mathrm{mi}^{2}$.

PERIOD OF RECORD.--September 1913 to current year. Prior to October 1939, published as "below North Fork near Maquoketa". Monthly discharge only for some periods, published in wSP 1308.

REVISED RECORDS.--WSP 405: 1914. WSP 1438: Drainage area. WSP 1508: 1914-17, 1919-25, 1926 (M), 1929, 1933-34 (M). 1943 .

GAGE.--Water-stage recorder. Datum of gage is $625.96 \mathrm{ft}$ above NGVD. Prior to July 14 , 1924 , nonrecording gage and July 15, 1924 to Sept. 30, 1972, recording gage at same site at datum $10.00 \mathrm{ft}$ higher.

REMARKS--Estimated daily dicharges: Dec. 4-6, 18-26, Jan. 1 to Feb.22. Records good except those for estimated discharges, which are poor. Diurnal fluctuation caused by powerplant $4 \mathrm{mi}$ upstream of station. U.S. Army Corps of Engineers Data Collection Platform at station.

COOPERATION. --Three discharge measurements provided by U.S. Army Corps of Engineers.

AVERAGE DISCHARGE. -72 years, $1,028 \mathrm{ft}^{3} / \mathrm{s}, 8.99 \mathrm{in} / \mathrm{yr}, 744,800 \mathrm{acre}-\mathrm{ft} / \mathrm{yr}$.

EXTREMES FOR PERIOD OF RECORD.--Maximum discharge, 48,000 ft/s June 27, 1944, gage height, 24.70 ft, at datum then in use; minimum daily, $105 \mathrm{ft}^{3} / \mathrm{s}$ Feb. 11-20, 1936.

EXTREMES OUTSIDE PERIOD OF RECORD.--A flood, probably in 1903 , reached a stage of 23.5 ft, discharge, 43,000 $\mathrm{ft}^{3} / \mathrm{s}$, at datum in use prior to Oct. 1,1972 .

EXTREMES FOR CURRENT YEAR.--Peak discharges greater than base discharge of $7,500 \mathrm{ft} / \mathrm{s}$ and maximum $(*)$ :

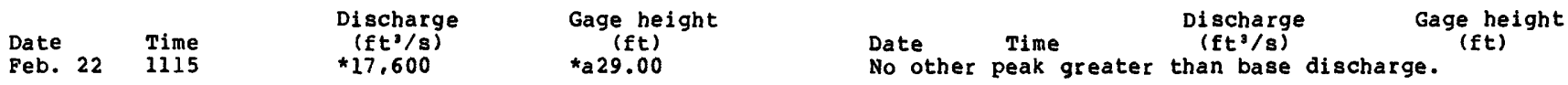

(a) Ice jam.

Minimum discharge, $253 \mathrm{ft}^{3} / \mathrm{s}$ Sept. 4,5 .

DISCHARGE, IN CUBIC FEET PER SECOND, WATER YEAR OCTOBER 1984 TO SEPTEMBER 1985 MEAN VALUES

\begin{tabular}{|c|c|c|c|c|c|c|c|c|c|c|c|c|}
\hline DAY & OCT & NOV & DEC & JAN & FEB & MAR & $A P R$ & MAY & JUN & JUL & AUG & SEP \\
\hline $\begin{array}{l}1 \\
2 \\
3 \\
4 \\
5\end{array}$ & $\begin{array}{l}474 \\
456 \\
456 \\
470 \\
466\end{array}$ & $\begin{array}{l}1930 \\
1710 \\
1770 \\
1480 \\
1180\end{array}$ & $\begin{array}{l}758 \\
812 \\
757 \\
535 \\
540\end{array}$ & $\begin{array}{l}970 \\
860 \\
780 \\
720 \\
740\end{array}$ & $\begin{array}{l}600 \\
590 \\
580 \\
570 \\
560\end{array}$ & $\begin{array}{l}2050 \\
2030 \\
1760 \\
2750 \\
4910\end{array}$ & $\begin{array}{l}1960 \\
1810 \\
1830 \\
1980 \\
2150\end{array}$ & $\begin{array}{l}938 \\
905 \\
874 \\
856 \\
823\end{array}$ & $\begin{array}{l}676 \\
669 \\
651 \\
645 \\
591\end{array}$ & $\begin{array}{l}444 \\
489 \\
487 \\
436 \\
436\end{array}$ & $\begin{array}{l}425 \\
425 \\
425 \\
423 \\
441\end{array}$ & $\begin{array}{l}390 \\
377 \\
367 \\
362 \\
388\end{array}$ \\
\hline $\begin{array}{r}6 \\
7 \\
8 \\
9 \\
10\end{array}$ & $\begin{array}{l}463 \\
553 \\
518 \\
503 \\
496\end{array}$ & $\begin{array}{l}1150 \\
1080 \\
1020 \\
2410 \\
2270\end{array}$ & $\begin{array}{l}550 \\
561 \\
641 \\
802 \\
806\end{array}$ & $\begin{array}{r}980 \\
1230 \\
1100 \\
960 \\
820\end{array}$ & $\begin{array}{l}550 \\
550 \\
540 \\
540 \\
535\end{array}$ & $\begin{array}{l}3050 \\
2160 \\
2090 \\
3360 \\
3380\end{array}$ & $\begin{array}{l}2090 \\
2010 \\
1860 \\
1680 \\
1550\end{array}$ & $\begin{array}{r}942 \\
1030 \\
999 \\
942 \\
907\end{array}$ & $\begin{array}{l}597 \\
602 \\
589 \\
586 \\
573\end{array}$ & $\begin{array}{l}444 \\
422 \\
436 \\
411 \\
414\end{array}$ & $\begin{array}{l}446 \\
442 \\
412 \\
418 \\
710\end{array}$ & $\begin{array}{l}659 \\
490 \\
447 \\
387 \\
361\end{array}$ \\
\hline $\begin{array}{l}11 \\
12 \\
13 \\
14 \\
15\end{array}$ & $\begin{array}{l}477 \\
497 \\
531 \\
534 \\
530\end{array}$ & $\begin{array}{r}1230 \\
1020 \\
1000 \\
894 \\
933\end{array}$ & $\begin{array}{l}816 \\
884 \\
870 \\
807 \\
828\end{array}$ & $\begin{array}{l}740 \\
690 \\
670 \\
720 \\
760\end{array}$ & $\begin{array}{l}530 \\
525 \\
520 \\
520 \\
520\end{array}$ & $\begin{array}{l}2560 \\
2140 \\
1850 \\
1730 \\
1680\end{array}$ & $\begin{array}{l}1490 \\
1330 \\
1280 \\
1230 \\
1230\end{array}$ & $\begin{array}{r}912 \\
942 \\
1030 \\
1070 \\
1510\end{array}$ & $\begin{array}{l}621 \\
567 \\
590 \\
566 \\
647\end{array}$ & $\begin{array}{l}399 \\
394 \\
412 \\
396 \\
469\end{array}$ & $\begin{array}{l}617 \\
511 \\
517 \\
548 \\
466\end{array}$ & $\begin{array}{l}361 \\
391 \\
381 \\
377 \\
371\end{array}$ \\
\hline $\begin{array}{l}16 \\
17 \\
18 \\
19 \\
20\end{array}$ & $\begin{array}{r}650 \\
2060 \\
1270 \\
3220 \\
1820\end{array}$ & $\begin{array}{l}848 \\
888 \\
796 \\
717 \\
702\end{array}$ & $\begin{array}{r}1090 \\
1230 \\
1160 \\
980 \\
920\end{array}$ & $\begin{array}{l}740 \\
680 \\
650 \\
620 \\
580\end{array}$ & $\begin{array}{l}540 \\
560 \\
580 \\
600 \\
700\end{array}$ & $\begin{array}{l}1530 \\
1370 \\
1300 \\
1260 \\
1390\end{array}$ & $\begin{array}{l}1140 \\
1100 \\
1060 \\
1020 \\
1010\end{array}$ & $\begin{array}{r}1130 \\
1070 \\
1020 \\
985 \\
949\end{array}$ & $\begin{array}{l}607 \\
611 \\
627 \\
583 \\
581\end{array}$ & $\begin{array}{l}369 \\
374 \\
358 \\
369 \\
378\end{array}$ & $\begin{array}{l}439 \\
435 \\
424 \\
405 \\
391\end{array}$ & $\begin{array}{l}380 \\
400 \\
389 \\
385 \\
375\end{array}$ \\
\hline $\begin{array}{l}21 \\
22 \\
23 \\
24 \\
25\end{array}$ & $\begin{array}{r}1210 \\
969 \\
852 \\
740 \\
773\end{array}$ & $\begin{array}{l}647 \\
711 \\
717 \\
708 \\
718\end{array}$ & $\begin{array}{r}940 \\
1050 \\
1100 \\
870 \\
560\end{array}$ & $\begin{array}{l}560 \\
580 \\
610 \\
650 \\
680\end{array}$ & $\begin{array}{r}4500 \\
15000 \\
13100 \\
9330 \\
6030\end{array}$ & $\begin{array}{r}932 \\
1030 \\
1160 \\
1220 \\
1310\end{array}$ & $\begin{array}{r}989 \\
968 \\
1020 \\
1100 \\
1136\end{array}$ & $\begin{array}{l}928 \\
899 \\
786 \\
808 \\
760\end{array}$ & $\begin{array}{l}580 \\
592 \\
586 \\
561 \\
499\end{array}$ & $\begin{array}{l}396 \\
371 \\
351 \\
353 \\
385\end{array}$ & $\begin{array}{l}385 \\
387 \\
382 \\
485 \\
498\end{array}$ & $\begin{array}{l}390 \\
414 \\
592 \\
643 \\
526\end{array}$ \\
\hline $\begin{array}{l}26 \\
27 \\
28 \\
29 \\
30 \\
31\end{array}$ & $\begin{array}{r}769 \\
790 \\
1070 \\
1160 \\
933 \\
873\end{array}$ & $\begin{array}{l}718 \\
855 \\
851 \\
820 \\
813 \\
--\end{array}$ & $\begin{array}{r}600 \\
676 \\
2620 \\
3540 \\
2790 \\
1880\end{array}$ & $\begin{array}{l}680 \\
660 \\
640 \\
625 \\
615 \\
600\end{array}$ & $\begin{array}{r}4140 \\
2890 \\
2080 \\
-- \\
--- \\
--\end{array}$ & $\begin{array}{l}1360 \\
1360 \\
1430 \\
1560 \\
1690 \\
1810\end{array}$ & $\begin{array}{r}1120 \\
1120 \\
1050 \\
1020 \\
968 \\
---\end{array}$ & $\begin{array}{l}788 \\
770 \\
824 \\
655 \\
789 \\
682\end{array}$ & $\begin{array}{l}520 \\
513 \\
507 \\
473 \\
499 \\
---\end{array}$ & $\begin{array}{l}414 \\
428 \\
431 \\
386 \\
409 \\
446\end{array}$ & $\begin{array}{l}494 \\
478 \\
391 \\
383 \\
383 \\
382\end{array}$ & $\begin{array}{l}534 \\
475 \\
526 \\
469 \\
525 \\
---\end{array}$ \\
\hline $\begin{array}{l}\text { TOTAL } \\
\text { MEAN } \\
\text { MAX } \\
\text { MIN } \\
\text { CFSM } \\
\text { IN. } \\
\text { AC-FT }\end{array}$ & $\begin{array}{r}26583 \\
858 \\
3220 \\
456 \\
.55 \\
.64 \\
52730\end{array}$ & $\begin{array}{r}32586 \\
1086 \\
2410 \\
647 \\
.70 \\
.78 \\
64630\end{array}$ & $\begin{array}{r}32973 \\
1064 \\
3540 \\
535 \\
.69 \\
.79 \\
65400\end{array}$ & $\begin{array}{r}22910 \\
739 \\
1230 \\
560 \\
.48 \\
.55 \\
45440\end{array}$ & $\begin{array}{r}68280 \\
2439 \\
15000 \\
520 \\
1.57 \\
1.64 \\
135400\end{array}$ & $\begin{array}{r}59212 \\
1910 \\
4910 \\
932 \\
1.23 \\
1.42 \\
117400\end{array}$ & $\begin{array}{r}41295 \\
1377 \\
2150 \\
968 \\
.89 \\
899 \\
81910\end{array}$ & $\begin{array}{r}28523 \\
920 \\
1510 \\
655 \\
.59 \\
.68 \\
56580\end{array}$ & $\begin{array}{r}17509 \\
584 \\
676 \\
473 \\
.38 \\
.42 \\
34730\end{array}$ & $\begin{array}{r}12707 \\
410 \\
489 \\
351 \\
.26 \\
.30 \\
25200\end{array}$ & $\begin{array}{r}13968 \\
451 \\
710 \\
382 \\
.29 \\
.33 \\
27710\end{array}$ & $\begin{array}{r}13132 \\
438 \\
659 \\
361 \\
.28 \\
.31 \\
26050\end{array}$ \\
\hline $\begin{array}{ll}\text { CAL } & \text { YR } \\
\text { WTR } & \text { YR }\end{array}$ & 35 & $\begin{array}{l}\text { TOTAL } \\
\text { TOTAL }\end{array}$ & $\begin{array}{l}48 \\
78\end{array}$ & $\begin{array}{ll}\text { MEAN } & 1216 \\
\text { MEAN } & 1013\end{array}$ & $\begin{array}{l}\text { MAX } \\
\text { MAX }\end{array}$ & $\begin{array}{r}7660 \\
15000\end{array}$ & $\begin{array}{ll}\text { MIN } & 380 \\
\text { MIN } & 351\end{array}$ & $\begin{array}{l}\text { CFSM } \\
\text { CFSM }\end{array}$ & $\begin{array}{l}.78 \\
.65\end{array}$ & $\begin{array}{r}10.66 \\
8.86\end{array}$ & $\begin{array}{l}A C-F T \\
A C-F T\end{array}$ & $\begin{array}{l}882800 \\
733300\end{array}$ \\
\hline
\end{tabular}


05420500 MISSISSIPPI RIVER AT CLINTON, IA

(National stream-quality accounting network station)

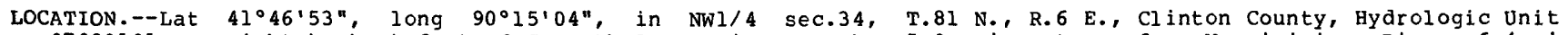
07080101 , on right bank at foot of Seventh Avenue in Camanche, 5.0 mi upstream from Wapsipinicon River, 6.4 mi downstream from Clinton, $10.6 \mathrm{mi}$ downstream from dam 13 , and at mile 511.8 upstream from Ohio River. Prior to June 6,1969 , at site $400 \mathrm{ft}$ downstream.

DRAINAGE AREA.--85,600 $\mathrm{mi}^{2}$, approximately, at Fulton-Lyons Bridge at Clinton.

WATER-DISCHARGE RECORDS

PERIOD OF RECORD.--June to August 1873 (fragmentary), October 1873 to current year (October 1932 to September 1939, published as "at Le (laire").

REVISED RECORDS. - -WDR IA-75-1: 1974 .

GAGE.--Water-stage recorder. Datum of gage is $562.68 \mathrm{ft}$ above NGVD. Oct. 1, 1955 , to June 5 , 1969 , water-stage recorder at site $400 \mathrm{ft}$ downstream at same datum. Auxiliary water-stage recorder at dam 13 since Oct. 1 , 1958 . See WSP 1728 for history of changes prior to Oct. 1, 1955.

REMARKS.--Estimated daily discharge: Oct. 22 to Nov. 20, Jan. 19 to Feb. 21, and Feb. 25. Records good except those for estimated daily discharges, which are fair. Minor flow regulation caused by navigation dams.

COOPERATION.--Discharge data at Lock and Dam No.13 furnished by U.S. Army Corps of Engineers.

AVERAGE DISCHARGE.--112 years, $47,630 \mathrm{ft}^{3} / \mathrm{s}, 7.56 \mathrm{in} / \mathrm{yr}, 34,510,000 \mathrm{acre-ft} / \mathrm{yr}$.

EXTREMES FOR PERIOD OF RECORD.--Maximum daily discharge, 307,000 ft $3 / \mathrm{s} \mathrm{Apr.} \mathrm{28,} \mathrm{1965;} \mathrm{maximum} \mathrm{gage} \mathrm{height,} \mathrm{24.65}$ ft Apr. 28, 1965; minimum daily discharge, 6,500 $\mathrm{ft}^{3} / \mathrm{s} \mathrm{Dec,} \mathrm{25-27,} 1933$.

EXTREMES OUTS IDE PERIOD OF RECORD,--Maximum stage known since at least 1828, that of Apr. 28 , 1965.

EXTREMES FOR CURRENT YEAR.--Maximum daily discharge, 139,000 $\mathrm{ft}^{3} / \mathrm{s}$ Apr. 8; maximum gage height, 16.52 ft Apr. 8, minimum daily discharge, $18,500 \mathrm{ft}^{3} / \mathrm{s}$ Dec. 9, minimum gage height, 8.82 ft. Aug. 13.

DISCHARGE, IN CUBIC FEET PER SECOND, WATER YEAR OCTOBER 1984 TO SEPTEMBER 1985 MEAN VALUES

\begin{tabular}{|c|c|c|c|c|c|c|c|c|c|c|c|c|}
\hline DAY & OCT & NOV & $\mathrm{DEC}$ & JAN & FEB & MAR & APR & MAY & JUN & JUL & AUG & SEP \\
\hline $\begin{array}{l}1 \\
2 \\
3 \\
4 \\
5\end{array}$ & $\begin{array}{l}37600 \\
39300 \\
42000 \\
42600 \\
38700\end{array}$ & $\begin{array}{l}83000 \\
86000 \\
86000 \\
87500 \\
88000\end{array}$ & $\begin{array}{l}41600 \\
42800 \\
48200 \\
50000 \\
42000\end{array}$ & $\begin{array}{l}51000 \\
41000 \\
34500 \\
35600 \\
41100\end{array}$ & $\begin{array}{l}30100 \\
29900 \\
29600 \\
29200 \\
29000\end{array}$ & $\begin{array}{l}66200 \\
62900 \\
67500 \\
81300 \\
82500\end{array}$ & $\begin{array}{l}117000 \\
121000 \\
122000 \\
124000 \\
128000\end{array}$ & $\begin{array}{r}93300 \\
95600 \\
97600 \\
101000 \\
105000\end{array}$ & $\begin{array}{l}61700 \\
58400 \\
56800 \\
57300 \\
57500\end{array}$ & $\begin{array}{l}45000 \\
44600 \\
44500 \\
45900 \\
49700\end{array}$ & $\begin{array}{l}43900 \\
41200 \\
36400 \\
33400 \\
31800\end{array}$ & $\begin{array}{l}38900 \\
41600 \\
41800 \\
39800 \\
35600\end{array}$ \\
\hline $\begin{array}{r}6 \\
7 \\
8 \\
9 \\
10\end{array}$ & $\begin{array}{l}36200 \\
35000 \\
36200 \\
36100 \\
33100\end{array}$ & $\begin{array}{l}87500 \\
87500 \\
88000 \\
85000 \\
82000\end{array}$ & $\begin{array}{l}27100 \\
19700 \\
19500 \\
18500 \\
22400\end{array}$ & $\begin{array}{l}48100 \\
48900 \\
48700 \\
47700 \\
46000\end{array}$ & $\begin{array}{l}28900 \\
28700 \\
27800 \\
27300 \\
27000\end{array}$ & $\begin{array}{l}66500 \\
63500 \\
66800 \\
76300 \\
78300\end{array}$ & $\begin{array}{l}133000 \\
138000 \\
139000 \\
138000 \\
133000\end{array}$ & $\begin{array}{l}109000 \\
107000 \\
106000 \\
105000 \\
104000\end{array}$ & $\begin{array}{l}57700 \\
56600 \\
53900 \\
53300 \\
53000\end{array}$ & $\begin{array}{l}52300 \\
55200 \\
56100 \\
56200 \\
56100\end{array}$ & $\begin{array}{l}31600 \\
31000 \\
30900 \\
29900 \\
30600\end{array}$ & $\begin{array}{l}37300 \\
41200 \\
44400 \\
48700 \\
52700\end{array}$ \\
\hline $\begin{array}{l}11 \\
12 \\
13 \\
14 \\
15\end{array}$ & $\begin{array}{l}30900 \\
29800 \\
32400 \\
35700 \\
35700\end{array}$ & $\begin{array}{l}82000 \\
82500 \\
75000 \\
71000 \\
71000\end{array}$ & $\begin{array}{l}27600 \\
31400 \\
36700 \\
41200 \\
41700\end{array}$ & $\begin{array}{l}46000 \\
46700 \\
48200 \\
43300 \\
41700\end{array}$ & $\begin{array}{l}26800 \\
26300 \\
25900 \\
25600 \\
25200\end{array}$ & $\begin{array}{l}80000 \\
80100 \\
77400 \\
80600 \\
87200\end{array}$ & $\begin{array}{l}129000 \\
125000 \\
123000 \\
121000 \\
115000\end{array}$ & $\begin{array}{r}101000 \\
99400 \\
96400 \\
93100 \\
91500\end{array}$ & $\begin{array}{l}54800 \\
58600 \\
60800 \\
57800 \\
55000\end{array}$ & $\begin{array}{l}56000 \\
55500 \\
54200 \\
52500 \\
52700\end{array}$ & $\begin{array}{l}29500 \\
30100 \\
30700 \\
36900 \\
38600\end{array}$ & $\begin{array}{l}53500 \\
53500 \\
53000 \\
54100 \\
56800\end{array}$ \\
\hline $\begin{array}{l}16 \\
17 \\
18 \\
19 \\
20\end{array}$ & $\begin{array}{l}38200 \\
44100 \\
47600 \\
54000 \\
62800\end{array}$ & $\begin{array}{l}73000 \\
74000 \\
74000 \\
70000 \\
65000\end{array}$ & $\begin{array}{l}44300 \\
50800 \\
52800 \\
51000 \\
47100\end{array}$ & $\begin{array}{l}38600 \\
36700 \\
34900 \\
33400 \\
30000\end{array}$ & $\begin{array}{l}25200 \\
25500 \\
25800 \\
25900 \\
26000\end{array}$ & $\begin{array}{l}87600 \\
88700 \\
90200 \\
90900 \\
90000\end{array}$ & $\begin{array}{r}109000 \\
103000 \\
97000 \\
93300 \\
91200\end{array}$ & $\begin{array}{l}89600 \\
83700 \\
80600 \\
76400 \\
75900\end{array}$ & $\begin{array}{l}53900 \\
51100 \\
49200 \\
49100 \\
48900\end{array}$ & $\begin{array}{l}50600 \\
45500 \\
42000 \\
35800 \\
33300\end{array}$ & $\begin{array}{l}37700 \\
36600 \\
41300 \\
45600 \\
45900\end{array}$ & $\begin{array}{l}60300 \\
63700 \\
65100 \\
63600 \\
62900\end{array}$ \\
\hline $\begin{array}{l}21 \\
22 \\
23 \\
24 \\
25\end{array}$ & $\begin{array}{l}58700 \\
57000 \\
61500 \\
66000 \\
72000\end{array}$ & $\begin{array}{l}59100 \\
49100 \\
44200 \\
45100 \\
44900\end{array}$ & $\begin{array}{l}43900 \\
42300 \\
40100 \\
39000 \\
30700\end{array}$ & $\begin{array}{l}29000 \\
28500 \\
28800 \\
29300 \\
29600\end{array}$ & $\begin{array}{l}29800 \\
59700 \\
84800 \\
98900 \\
96000\end{array}$ & $\begin{array}{l}87900 \\
84800 \\
86600 \\
88800 \\
89100\end{array}$ & $\begin{array}{l}91800 \\
92400 \\
93300 \\
98700 \\
99400\end{array}$ & $\begin{array}{l}73600 \\
71500 \\
70100 \\
70000 \\
69900\end{array}$ & $\begin{array}{l}48000 \\
46800 \\
47100 \\
47900 \\
47000\end{array}$ & $\begin{array}{l}36500 \\
36500 \\
34600 \\
31700 \\
29400\end{array}$ & $\begin{array}{l}44500 \\
39400 \\
35600 \\
32800 \\
35200\end{array}$ & $\begin{array}{l}61700 \\
58700 \\
58300 \\
59100 \\
59000\end{array}$ \\
\hline $\begin{array}{l}26 \\
27 \\
28 \\
29 \\
30 \\
31\end{array}$ & $\begin{array}{l}77000 \\
78500 \\
80000 \\
82000 \\
82500 \\
81000\end{array}$ & $\begin{array}{c}45400 \\
45100 \\
44600 \\
42600 \\
40600 \\
\\
--\end{array}$ & $\begin{array}{l}24400 \\
28900 \\
39600 \\
68100 \\
60700 \\
51700\end{array}$ & $\begin{array}{l}29800 \\
29900 \\
30000 \\
30000 \\
30200 \\
30200\end{array}$ & $\begin{array}{r}81300 \\
72700 \\
70400 \\
- \\
- \\
--\end{array}$ & $\begin{array}{r}90700 \\
94300 \\
99800 \\
104000 \\
106000 \\
108000\end{array}$ & $\begin{array}{r}95500 \\
94000 \\
92600 \\
91200 \\
90700 \\
-\end{array}$ & $\begin{array}{l}69500 \\
69600 \\
69800 \\
69300 \\
67400 \\
65400\end{array}$ & $\begin{array}{r}46900 \\
47300 \\
47400 \\
46700 \\
45300 \\
---\end{array}$ & $\begin{array}{l}35200 \\
40800 \\
41200 \\
40800 \\
42100 \\
44100\end{array}$ & $\begin{array}{l}38800 \\
38300 \\
37000 \\
34900 \\
36200 \\
38600\end{array}$ & $\begin{array}{r}57400 \\
58600 \\
58500 \\
59200 \\
62000 \\
---\end{array}$ \\
\hline $\begin{array}{l}\text { TOTAL } \\
\text { MEAN } \\
\text { MAX } \\
\text { MIN } \\
\text { CFSM } \\
\text { IN. } \\
\text { AC-FT }\end{array}$ & $\begin{array}{r}1584200 \\
51100 \\
82500 \\
29800 \\
.60 \\
.69 \\
3142000\end{array}$ & $\begin{array}{r}2058700 \\
68620 \\
88000 \\
40600 \\
.80 \\
.89 \\
4083000\end{array}$ & $\begin{array}{r}1225800 \\
39540 \\
68100 \\
18500 \\
.46 \\
.53 \\
2431000\end{array}$ & $\begin{array}{r}1167400 \\
37660 \\
51000 \\
28500 \\
.44 \\
.51 \\
2316000\end{array}$ & $\begin{array}{r}1139300 \\
40690 \\
98900 \\
25200 \\
.48 \\
.50 \\
2260000\end{array}$ & $\begin{array}{r}2604500 \\
84020 \\
108000 \\
62900 \\
.98 \\
1.13 \\
5166000\end{array}$ & $\begin{array}{r}3339100 \\
111300 \\
139000 \\
90700 \\
1.30 \\
1.45 \\
6623000\end{array}$ & $\begin{array}{r}2677200 \\
86360 \\
109000 \\
65400 \\
1.01 \\
1.16 \\
5310000\end{array}$ & $\begin{array}{r}1575800 \\
52530 \\
61700 \\
45300 \\
.61 \\
.68 \\
3126000\end{array}$ & $\begin{array}{r}1396600 \\
45050 \\
56200 \\
29400 \\
.53 \\
.61 \\
2770000\end{array}$ & $\begin{array}{r}1124900 \\
36290 \\
45900 \\
29500 \\
.42 \\
.49 \\
2231000\end{array}$ & $\begin{array}{r}1601000 \\
53370 \\
65100 \\
35600 \\
.62 \\
.70 \\
3176000\end{array}$ \\
\hline
\end{tabular}

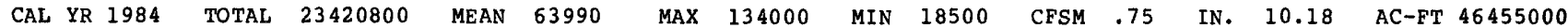

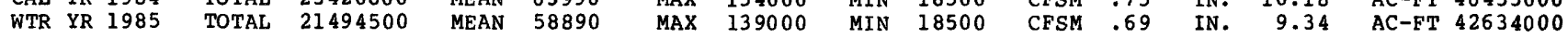


05420500 MISSISSIPPI RIVER AT CLINTON, IA--Continued (National stream-quality accounting network station)

WATER-QUALITY RECORDS

LOCATION.--Samples collected near bridge on state Highway 136 in clinton, 6.4 mi upstream from discharge station. PERIOD OF RECORD.--Water years 1974 to current year.

PERIOD OF DAILY RECORD.--

SPECIFIC CONDUCTANCE: October 1974 to September 1976; October 1978 to september 1981.

WATER TEMPERATURES: October 1974 to current year.

REMARKS.--Temperature data were collected at Dam 13 (Sta. 05420400). No temperature data collected October 1-30 while recorder was being repaired. Recorder clock stopped June 15 to June 24.

COOPERATION.--Temperature record was collected in cooperation with U.s. Army Corps of Engineers.

EXTREMES FOR PERIOD OF DAILY RECORD.--

SPECIFIC CONDUCTANCE: Maximum daily, 560 microsiemens Nov. 24 to Dec. 3, 1979; minimum daily, 220 microsiemens Apr. 19,20, 1976; Nov. 8-18, 1980

WATER TEMPERATURES: Maximum, $31.5^{\circ} \mathrm{C}$ July $21-23,1983$; minumum, $0.0^{\circ} \mathrm{C}$ on many days during winter periods each year.

EXTREMES FOR CURRENT YEAR.--

WATER TEMPERATURE: Maximum, $25.5^{\circ} \mathrm{C}$ July $14-15,27-30$; minimum, $0.0^{\circ} \mathrm{C}$ on many days during winter period.

TEMPERATURE, WATER (DEG. C), WATER YEAR OCTOBER 1984 TO SEPTEMBER 1985

\begin{tabular}{|c|c|c|c|c|c|c|c|c|c|c|c|c|}
\hline \multirow[t]{2}{*}{ DAY } & MAX & MIN & MAX & MIN & MAX & MIN & MAX & MIN & MAX & MIN & MAX & MIN \\
\hline & \multicolumn{2}{|c|}{ OCTOBER } & \multicolumn{2}{|c|}{ NOVEMBER } & \multicolumn{2}{|c|}{ DECEMBER } & \multicolumn{2}{|c|}{ JANUARY } & \multicolumn{2}{|c|}{ FEBRUARY } & \multicolumn{2}{|c|}{ MARCH } \\
\hline $\begin{array}{l}1 \\
2 \\
3 \\
4 \\
5\end{array}$ & $\begin{array}{l}--- \\
--- \\
--- \\
---\end{array}$ & $\begin{array}{l}-- \\
-- \\
-- \\
-- \\
--\end{array}$ & $\begin{array}{l}9.5 \\
7.5 \\
5.5 \\
6.0 \\
6.5\end{array}$ & $\begin{array}{l}7.5 \\
6.5 \\
5.0 \\
5.5 \\
4.5\end{array}$ & $\begin{array}{r}3.0 \\
2.0 \\
2.0 \\
1.0 \\
.5\end{array}$ & $\begin{array}{r}2.5 \\
2.0 \\
1.5 \\
.5 \\
.5\end{array}$ & $\begin{array}{l}.0 \\
.0 \\
.0 \\
.0 \\
.0\end{array}$ & $\begin{array}{l}.0 \\
.0 \\
.0 \\
.0 \\
.0\end{array}$ & $\begin{array}{l}.0 \\
.0 \\
.0 \\
.0 \\
.0\end{array}$ & $\begin{array}{l}.0 \\
.0 \\
.0 \\
.0 \\
.0\end{array}$ & $\begin{array}{l}.0 \\
.0 \\
.0 \\
.0 \\
.0\end{array}$ & $\begin{array}{l}.0 \\
.0 \\
.0 \\
.0 \\
.0\end{array}$ \\
\hline $\begin{array}{r}6 \\
7 \\
8 \\
9 \\
10\end{array}$ & $\begin{array}{l}--- \\
--- \\
--- \\
---\end{array}$ & $\begin{array}{l}-- \\
--- \\
-- \\
-- \\
--\end{array}$ & $\begin{array}{l}4.0 \\
4.0 \\
6.0 \\
5.5 \\
5.0\end{array}$ & $\begin{array}{l}4.0 \\
4.0 \\
5.0 \\
5.0 \\
4.5\end{array}$ & $\begin{array}{l}.5 \\
.5 \\
.5 \\
.5 \\
.5\end{array}$ & $\begin{array}{l}.5 \\
.5 \\
.5 \\
.5 \\
.5\end{array}$ & $\begin{array}{l}.0 \\
.0 \\
.0 \\
.0 \\
.0\end{array}$ & $\begin{array}{l}.0 \\
.0 \\
.0 \\
.0 \\
.0\end{array}$ & $\begin{array}{l}.0 \\
.0 \\
.0 \\
.0 \\
.0\end{array}$ & $\begin{array}{l}.0 \\
.0 \\
.0 \\
.0 \\
.0\end{array}$ & $\begin{array}{r}.0 \\
.0 \\
.5 \\
.5 \\
1.0\end{array}$ & $\begin{array}{r}.0 \\
.0 \\
.0 \\
.0 \\
.0\end{array}$ \\
\hline $\begin{array}{l}11 \\
12 \\
13 \\
14 \\
15\end{array}$ & $\begin{array}{l}--- \\
--- \\
--- \\
---\end{array}$ & $\begin{array}{l}-- \\
-- \\
-- \\
-- \\
--\end{array}$ & $\begin{array}{l}4.5 \\
3.5 \\
3.5 \\
3.5 \\
3.5\end{array}$ & $\begin{array}{l}4.0 \\
3.5 \\
3.5 \\
3.5 \\
3.0\end{array}$ & $\begin{array}{r}.5 \\
.5 \\
.5 \\
.5 \\
1.5\end{array}$ & $\begin{array}{l}.5 \\
.5 \\
.5 \\
.5 \\
.5\end{array}$ & $\begin{array}{l}.0 \\
.0 \\
.0 \\
.0 \\
.0\end{array}$ & $\begin{array}{l}.0 \\
.0 \\
.0 \\
.0 \\
.0\end{array}$ & $\begin{array}{l}.0 \\
.0 \\
.0 \\
.0 \\
.0\end{array}$ & $\begin{array}{l}.0 \\
.0 \\
.0 \\
.0 \\
.0\end{array}$ & $\begin{array}{l}1.5 \\
2.0 \\
2.0 \\
2.0 \\
3.0\end{array}$ & $\begin{array}{l}1.0 \\
1.5 \\
2.0 \\
1.5 \\
2.0\end{array}$ \\
\hline $\begin{array}{l}16 \\
17 \\
18 \\
19 \\
20\end{array}$ & 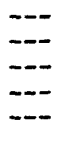 & $\begin{array}{l}--- \\
-m- \\
--- \\
-- \\
--\end{array}$ & $\begin{array}{l}3.0 \\
2.5 \\
2.5 \\
2.5 \\
1.5\end{array}$ & $\begin{array}{l}2.0 \\
2.0 \\
2.5 \\
2.0 \\
1.5\end{array}$ & $\begin{array}{r}1.5 \\
1.5 \\
.5 \\
.5 \\
.5\end{array}$ & $\begin{array}{r}1.0 \\
.5 \\
.5 \\
.5 \\
.5\end{array}$ & $\begin{array}{l}.0 \\
.0 \\
.0 \\
.0 \\
.0\end{array}$ & $\begin{array}{l}.0 \\
.0 \\
.0 \\
.0 \\
.0\end{array}$ & $\begin{array}{l}.0 \\
.0 \\
.0 \\
.0 \\
.0\end{array}$ & $\begin{array}{l}.0 \\
.0 \\
.0 \\
.0 \\
.0\end{array}$ & $\begin{array}{l}3.0 \\
3.0 \\
3.0 \\
4.5 \\
5.0\end{array}$ & $\begin{array}{l}2.5 \\
2.5 \\
2.5 \\
3.0 \\
4.0\end{array}$ \\
\hline $\begin{array}{l}21 \\
22 \\
23 \\
24 \\
25\end{array}$ & $\begin{array}{l}--- \\
--- \\
--- \\
---\end{array}$ & $\begin{array}{l}-- \\
--- \\
--- \\
--- \\
---\end{array}$ & $\begin{array}{l}1.5 \\
1.5 \\
2.0 \\
2.0 \\
2.0\end{array}$ & $\begin{array}{l}1.5 \\
1.5 \\
1.5 \\
2.0 \\
2.0\end{array}$ & $\begin{array}{l}.5 \\
.0 \\
.0 \\
.0 \\
.0\end{array}$ & $\begin{array}{l}.5 \\
.0 \\
.0 \\
.0 \\
.0\end{array}$ & $\begin{array}{l}.0 \\
.0 \\
.0 \\
.0 \\
.0\end{array}$ & $\begin{array}{l}.0 \\
.0 \\
.0 \\
.0 \\
.0\end{array}$ & $\begin{array}{l}.0 \\
.0 \\
.0 \\
.0 \\
.0\end{array}$ & $\begin{array}{l}.0 \\
.0 \\
.0 \\
.0 \\
.0\end{array}$ & $\begin{array}{l}5.0 \\
5.0 \\
4.5 \\
4.0 \\
3.5\end{array}$ & $\begin{array}{l}4.0 \\
4.0 \\
4.0 \\
3.5 \\
3.5\end{array}$ \\
\hline $\begin{array}{l}26 \\
27 \\
28 \\
29 \\
30 \\
31\end{array}$ & $\begin{array}{l}--- \\
--- \\
--- \\
9.5\end{array}$ & $\begin{array}{l}--- \\
-\cdots \\
\cdots-- \\
-\cdots \\
9.0\end{array}$ & $\begin{array}{l}3.5 \\
4.0 \\
4.0 \\
3.0 \\
3.0 \\
---\end{array}$ & $\begin{array}{l}2.0 \\
3.5 \\
3.0 \\
2.5 \\
3.0 \\
-.-\end{array}$ & $\begin{array}{l}.0 \\
.0 \\
.0 \\
.0 \\
.0 \\
.0\end{array}$ & $\begin{array}{l}.0 \\
.0 \\
.0 \\
.0 \\
.0 \\
.0\end{array}$ & $\begin{array}{l}.0 \\
.0 \\
.0 \\
.0 \\
.0 \\
.0\end{array}$ & $\begin{array}{l}.0 \\
.0 \\
.0 \\
.0 \\
.0 \\
.0\end{array}$ & $\begin{array}{r}.0 \\
.0 \\
.0 \\
\hdashline- \\
\hdashline--\end{array}$ & $\begin{array}{r}.0 \\
.0 \\
.0 \\
-- \\
--\end{array}$ & $\begin{array}{l}5.5 \\
7.5 \\
7.5 \\
6.5 \\
6.0 \\
4.0\end{array}$ & $\begin{array}{l}3.5 \\
5.5 \\
6.5 \\
6.5 \\
4.0 \\
3.5\end{array}$ \\
\hline MONTH & 9.5 & 9.0 & 9.5 & 1.5 & 3.0 & .0 & .0 & .0 & .0 & .0 & 7.5 & .0 \\
\hline
\end{tabular}


05420500 MISSISSIPPI RIVER AT CLINTON, IA--Continued

WATER-QUAL ITY RECORDS

TEMPERATURE, WATER (DEG. C), WATER YEAR OCTOBER 1984 TO SEPTEMBER 1985

\begin{tabular}{|c|c|c|c|c|c|c|c|c|c|c|c|c|}
\hline \multirow[t]{2}{*}{ DAY } & MAX & MIN & MAX & MIN & $\operatorname{MAX}$ & MIN & $\operatorname{MAX}$ & MIN & $\operatorname{MAX}$ & MIN & MAX & MIN \\
\hline & \multicolumn{2}{|c|}{ APRIL } & \multicolumn{2}{|c|}{ MAY } & \multicolumn{2}{|c|}{ JUNE } & \multicolumn{2}{|c|}{ JULY } & \multicolumn{2}{|c|}{ AUGUST } & \multicolumn{2}{|c|}{ SEPTEMBER } \\
\hline $\begin{array}{l}1 \\
2 \\
3 \\
4 \\
5\end{array}$ & $\begin{array}{l}3.5 \\
4.5 \\
6.0 \\
6.0 \\
5.0\end{array}$ & $\begin{array}{l}3.0 \\
3.5 \\
4.0 \\
5.0 \\
4.0\end{array}$ & $\begin{array}{l}15.0 \\
14.5 \\
16.0 \\
16.0 \\
16.0\end{array}$ & $\begin{array}{l}13.5 \\
12.5 \\
14.0 \\
15.0 \\
15.0\end{array}$ & $\begin{array}{l}19.0 \\
19.5 \\
19.5 \\
19.0 \\
18.0\end{array}$ & $\begin{array}{l}18.0 \\
18.5 \\
17.0 \\
17.5 \\
17.0\end{array}$ & $\begin{array}{l}23.5 \\
23.5 \\
24.0 \\
24.5 \\
24.0\end{array}$ & $\begin{array}{l}22.0 \\
23.0 \\
22.5 \\
23.0 \\
22.5\end{array}$ & $\begin{array}{l}23.0 \\
23.5 \\
23.5 \\
23.0 \\
22.5\end{array}$ & $\begin{array}{l}22.0 \\
22.0 \\
22.5 \\
22.0 \\
21.5\end{array}$ & $\begin{array}{l}21.5 \\
21.5 \\
22.5 \\
23.0 \\
23.5\end{array}$ & $\begin{array}{l}21.0 \\
21.0 \\
21.5 \\
21.5 \\
23.0\end{array}$ \\
\hline $\begin{array}{r}6 \\
7 \\
8 \\
9 \\
10\end{array}$ & $\begin{array}{l}4.0 \\
4.5 \\
4.0 \\
4.5 \\
5.0\end{array}$ & $\begin{array}{l}3.5 \\
3.5 \\
3.5 \\
3.5 \\
4.0\end{array}$ & $\begin{array}{l}16.5 \\
17.0 \\
18.0 \\
18.0 \\
18.5\end{array}$ & $\begin{array}{l}15.0 \\
15.5 \\
16.0 \\
16.5 \\
17.0\end{array}$ & $\begin{array}{l}19.5 \\
21.0 \\
22.0 \\
20.5 \\
19.5\end{array}$ & $\begin{array}{l}17.5 \\
19.0 \\
20.0 \\
19.5 \\
18.0\end{array}$ & $\begin{array}{l}24.0 \\
24.0 \\
24.0 \\
24.5 \\
24.5\end{array}$ & $\begin{array}{l}22.0 \\
23.0 \\
22.5 \\
23.5 \\
23.0\end{array}$ & $\begin{array}{l}23.5 \\
24.0 \\
24.0 \\
24.5 \\
25.0\end{array}$ & $\begin{array}{l}22.5 \\
23.5 \\
23.5 \\
23.5 \\
24.0\end{array}$ & $\begin{array}{l}24.0 \\
25.0 \\
25.0 \\
25.0 \\
23.5\end{array}$ & $\begin{array}{l}23.5 \\
24.0 \\
24.5 \\
23.5 \\
22.0\end{array}$ \\
\hline $\begin{array}{l}11 \\
12 \\
13 \\
14 \\
15\end{array}$ & $\begin{array}{r}6.5 \\
8.5 \\
9.5 \\
10.0 \\
11.5\end{array}$ & $\begin{array}{l}5.0 \\
6.5 \\
8.5 \\
9.0 \\
9.5\end{array}$ & $\begin{array}{l}18.5 \\
18.0 \\
18.0 \\
18.0 \\
17.5\end{array}$ & $\begin{array}{l}18.0 \\
17.0 \\
17.0 \\
16.0 \\
15.5\end{array}$ & $\begin{array}{r}18.5 \\
18.5 \\
18.5 \\
19.5 \\
\ldots . .\end{array}$ & $\begin{array}{r}18.0 \\
17.5 \\
18.0 \\
17.5 \\
-\ldots\end{array}$ & $\begin{array}{l}24.5 \\
24.5 \\
24.0 \\
25.5 \\
25.5\end{array}$ & $\begin{array}{l}23.0 \\
23.5 \\
23.0 \\
24.0 \\
24.0\end{array}$ & $\begin{array}{l}24.5 \\
24.5 \\
24.5 \\
24.5 \\
24.0\end{array}$ & $\begin{array}{l}24.0 \\
23.5 \\
24.0 \\
24.0 \\
23.0\end{array}$ & $\begin{array}{l}22.0 \\
21.5 \\
20.0 \\
19.0 \\
18.5\end{array}$ & $\begin{array}{l}21.0 \\
20.0 \\
19.0 \\
18.0 \\
17.5\end{array}$ \\
\hline $\begin{array}{l}16 \\
17 \\
18 \\
19 \\
20\end{array}$ & $\begin{array}{l}12.0 \\
12.5 \\
14.0 \\
15.5 \\
16.0\end{array}$ & $\begin{array}{l}11.0 \\
10.5 \\
12.5 \\
13.5 \\
14.0\end{array}$ & $\begin{array}{l}15.5 \\
16.0 \\
17.0 \\
18.0 \\
18.0\end{array}$ & $\begin{array}{l}14.5 \\
14.0 \\
15.0 \\
16.0 \\
16.5\end{array}$ & $\begin{array}{l}-\infty \\
-\infty \\
-\infty \\
-\infty\end{array}$ & $\begin{array}{l}-\infty \\
-- \\
-\infty \\
-\infty\end{array}$ & $\begin{array}{l}25.0 \\
25.0 \\
24.0 \\
24.5 \\
24.5\end{array}$ & $\begin{array}{l}23.5 \\
23.5 \\
23.0 \\
24.0 \\
24.0\end{array}$ & $\begin{array}{l}24.5 \\
24.5 \\
24.0 \\
23.5 \\
22.5\end{array}$ & $\begin{array}{l}23.5 \\
23.5 \\
23.0 \\
22.0 \\
21.5\end{array}$ & $\begin{array}{l}18.5 \\
18.0 \\
19.5 \\
20.0 \\
20.0\end{array}$ & $\begin{array}{l}17.5 \\
17.5 \\
18.0 \\
19.0 \\
19.5\end{array}$ \\
\hline $\begin{array}{l}21 \\
22 \\
23 \\
24 \\
25\end{array}$ & $\begin{array}{l}17.0 \\
17.0 \\
17.0 \\
16.5 \\
15.5\end{array}$ & $\begin{array}{l}15.0 \\
16.0 \\
16.0 \\
15.5 \\
14.5\end{array}$ & $\begin{array}{l}18.0 \\
18.0 \\
19.0 \\
20.0 \\
20.5\end{array}$ & $\begin{array}{l}16.0 \\
16.5 \\
17.0 \\
18.0 \\
19.0\end{array}$ & $\frac{\ldots}{22.0}$ & 20.5 & $\begin{array}{l}24.5 \\
25.0 \\
25.0 \\
24.0 \\
24.0\end{array}$ & $\begin{array}{l}24.0 \\
23.5 \\
24.0 \\
23.5 \\
24.0\end{array}$ & $\begin{array}{l}22.0 \\
22.0 \\
20.5 \\
21.0 \\
20.5\end{array}$ & $\begin{array}{l}21.0 \\
20.5 \\
20.5 \\
20.5 \\
19.5\end{array}$ & $\begin{array}{l}19.5 \\
18.5 \\
18.5 \\
17.5 \\
15.5\end{array}$ & $\begin{array}{l}17.5 \\
17.5 \\
17.5 \\
15.5 \\
14.5\end{array}$ \\
\hline $\begin{array}{l}26 \\
27 \\
28 \\
29 \\
30 \\
31\end{array}$ & $\begin{array}{r}16.0 \\
16.0 \\
15.5 \\
15.5 \\
15.5 \\
-\end{array}$ & $\begin{array}{r}14.5 \\
14.0 \\
13.5 \\
14.0 \\
14.5 \\
-\end{array}$ & $\begin{array}{l}21.5 \\
21.5 \\
19.5 \\
19.5 \\
20.0 \\
20.0\end{array}$ & $\begin{array}{l}19.5 \\
18.5 \\
17.5 \\
18.0 \\
18.0 \\
19.0\end{array}$ & $\begin{array}{r}23.0 \\
23.0 \\
23.0 \\
22.0 \\
22.5 \\
- \\
-\end{array}$ & $\begin{array}{r}21.5 \\
22.0 \\
21.0 \\
21.0 \\
21.5 \\
-\end{array}$ & $\begin{array}{l}25.0 \\
25.5 \\
25.5 \\
25.5 \\
25.5 \\
24.0\end{array}$ & $\begin{array}{l}23.5 \\
24.5 \\
24.5 \\
25.0 \\
24.0 \\
22.5\end{array}$ & $\begin{array}{l}20.0 \\
21.0 \\
21.0 \\
21.0 \\
21.5 \\
21.5\end{array}$ & $\begin{array}{l}19.5 \\
20.0 \\
20.5 \\
20.5 \\
20.5 \\
21.0\end{array}$ & $\begin{array}{r}14.5 \\
14.0 \\
14.5 \\
14.5 \\
14.5 \\
-.-\end{array}$ & $\begin{array}{r}14.0 \\
13.0 \\
13.5 \\
14.0 \\
12.5 \\
\\
\end{array}$ \\
\hline MONTH & 17.0 & 3.0 & 21.5 & 12.5 & 23.0 & 17.0 & 25.5 & 22.0 & 25.0 & 19.5 & 25.0 & 12.5 \\
\hline
\end{tabular}

MATER QUALITY DATA, WATER YEAR OCTOBER 1984 TO SEPTEMBER 1985

\begin{tabular}{|c|c|c|c|c|c|c|c|c|c|c|c|c|}
\hline ATE & TIME & $\begin{array}{l}\text { STREAM- } \\
\text { FLOW, } \\
\text { INSTAN- } \\
\text { TANEOUS } \\
\text { (CFS) } \\
\text { (00061) }\end{array}$ & $\begin{array}{l}\text { SPE- } \\
\text { CIFIC } \\
\text { CON- } \\
\text { DUCT- } \\
\text { ANCE } \\
\text { (US/CM) } \\
\text { (00095) }\end{array}$ & $\begin{array}{c}\text { PH } \\
\text { (STAND- } \\
\text { ARD } \\
\text { UNITS } \\
(00400)\end{array}$ & $\begin{array}{l}\text { TEMPER- } \\
\text { ATURE } \\
\text { (DEG C) } \\
\text { (00010) }\end{array}$ & $\begin{array}{c}\text { TUR- } \\
\text { BID- } \\
\text { ITY } \\
\text { (NTU) } \\
(00076)\end{array}$ & $\begin{array}{c}\text { OXYGEN, } \\
\text { DIS- } \\
\text { SOLVED } \\
(\text { MG } / L) \\
(00300)\end{array}$ & $\begin{array}{c}\text { OXYGEN, } \\
\text { DIS- } \\
\text { SOLVED } \\
\text { (PER- } \\
\text { CENT } \\
\text { SATUR- } \\
\text { ATION) } \\
\text { (00301) }\end{array}$ & $\begin{array}{l}\text { BARO- } \\
\text { METRIC } \\
\text { PRES- } \\
\text { SURE } \\
\text { (MM } \\
\text { OF } \\
\text { HG) } \\
(00025)\end{array}$ & $\begin{array}{l}\text { COLI- } \\
\text { FORM, } \\
\text { FECAL, } \\
0.7 \\
\text { UM-MF } \\
\text { (COLS. } \\
100 \mathrm{ML}) \\
(31625)\end{array}$ & $\begin{array}{c}\text { STREP- } \\
\text { TOCOCCI } \\
\text { FECAL, } \\
\text { KF AGAR } \\
\text { (COLS. } \\
\text { PER } \\
100 \mathrm{ML}) \\
(31673)\end{array}$ & $\begin{array}{c}\text { HARD- } \\
\text { NESS, } \\
\text { NONCAR- } \\
\text { BONATE } \\
\text { (MG/L } \\
\text { CACO3) } \\
(00902)\end{array}$ \\
\hline
\end{tabular}

$\begin{array}{ccc}\text { NOV } 1984 & & \\ \text { MAR } 1985 \ldots & 11: 45 & 40000 \\ 12 \ldots \ldots & 11: 00 & 88600 \\ \text { JUN } & & \\ \text { O4... } & 12: 30 & 57800 \\ \text { AUG } & & \\ 28 \ldots & 10: 30 & 35900\end{array}$

$28 \ldots 10: 30 \quad 35900$

$\begin{array}{rrrr}335 & 8.7 & 2.0 & 20 \\ 336 & 7.9 & 2.0 & 54 \\ 365 & 7.5 & 18.0 & 21 \\ 305 & 8.4 & 21.5 & 9.5\end{array}$

MAGNE-

SIUM, SODIUM, DIS- DIS-

SOLVED SOLVED

DATE

\begin{tabular}{|c|c|c|c|}
\hline $\begin{array}{l}\text { HARD- } \\
\text { NBSS } \\
\text { (MG/L } \\
\text { AS } \\
\text { CACO3) } \\
(00900)\end{array}$ & $\begin{array}{l}\text { CALCIUM } \\
\text { DIS- } \\
\text { SOLVED } \\
\text { (MG/L } \\
\text { AS CA) } \\
(00915)\end{array}$ & $\begin{array}{c}\text { MAGNE- } \\
\text { SIUM, } \\
\text { DIS- } \\
\text { SOLVED } \\
\text { (MG/L } \\
\text { AS MG) } \\
\text { (00925) }\end{array}$ & $\begin{array}{c}\text { SODIUM, } \\
\text { DIS- } \\
\text { SOLVED } \\
\text { (MG/L } \\
\text { AS NA) } \\
(00930)\end{array}$ \\
\hline
\end{tabular}

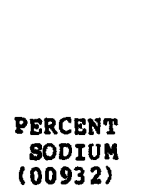

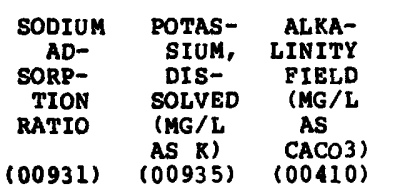

\begin{tabular}{|c|c|}
\hline 12.6 & 93 \\
\hline 12.7 & 93 \\
\hline 6.6 & 71 \\
\hline 8.4 & 97 \\
\hline $\begin{array}{l}\text { OTAS- } \\
\text { SIUM, } \\
\text { DIS- } \\
\text { OLVED } \\
\text { MG/L } \\
\text { S K) } \\
0935)\end{array}$ & $\begin{array}{c}\text { ALKA- } \\
\text { LINITY } \\
\text { FIELD } \\
\text { (MG/L } \\
\text { AS } \\
\text { CACO3) } \\
(00410)\end{array}$ \\
\hline
\end{tabular}

751
753
750
750

LFATE
IS-
MGVD
SO4)
O945)

$\begin{array}{rrr}76 & 12 & 34 \\ K 200 & K 1400 & 23 \\ K 67 & 290 & 62 \\ \text { K36 } & K 68 & 6\end{array}$

CHLO- FLUO- SILICA, RIDE, RIDE, DISDIS- DIS- SOLVED SOLVED (MG/L AS CL)
$(00940)$
SOLVED (MG/

(MG/L AS $\begin{array}{cc}\text { AS F) } & \text { SIO2) } \\ (00950) & (00955)\end{array}$

Nov 1984

\begin{tabular}{|c|c|c|c|c|c|c|c|c|c|c|c|c|c|}
\hline & $\begin{array}{r}1984 \\
20 \ldots\end{array}$ & 160 & 39 & 15 & 6.5 & 8 & 0.2 & 2.5 & - & 34 & 12 & 0.1 & 9.9 \\
\hline MAR & $\begin{array}{c}1985 \\
12 \ldots\end{array}$ & 150 & 37 & 14 & 7.5 & 10 & 0.3 & 4.3 & 127 & 21 & 10 & 0.1 & 11 \\
\hline & $\begin{array}{l}\text { JUN } \\
04 \ldots\end{array}$ & 190 & 45 & 18 & 7.8 & 8 & 0.3 & 2.7 & 125 & 35 & 11 & 0.1 & 6.5 \\
\hline & 28 & 140 & 32 & 14 & 7.1 & 10 & 0.3 & 1.9 & 132 & 22 & 9.4 & 0.1 & 4.2 \\
\hline
\end{tabular}

$K$ Results based on colony count outside ideal range. 
05420500 MISSISSIPPI RIVER AT CLINTON, IA--Continued

WATER-QUALITY RECORDS

WATER QUALITY DATA, WATER YEAR OCTOBER 1984 TO SEPTEMBER 1985

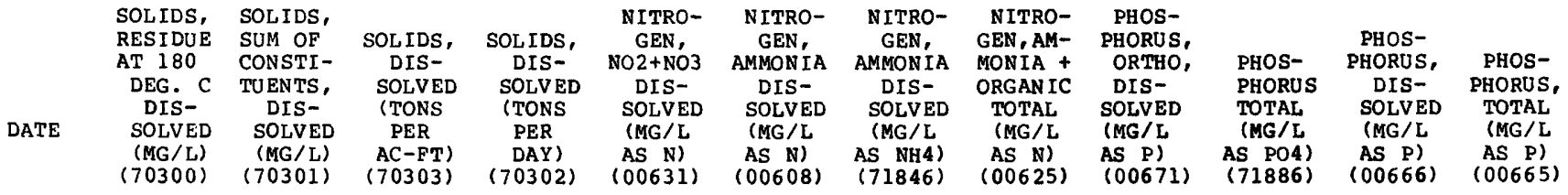

NOV 1984

\begin{tabular}{|c|c|c|c|c|c|c|c|c|c|c|c|c|c|}
\hline - & $\begin{array}{l}20 \ldots \\
1985\end{array}$ & 204 & 190 & 0.28 & 22000 & 1.30 & 0.11 & 0.14 & 1.2 & 0.07 & - & 0.08 & 0.13 \\
\hline & & 175 & 180 & 0.24 & 41900 & 1.60 & 0.54 & 0.7 & 2.2 & 0.12 & -- & 0.13 & 0.38 \\
\hline & $04 \ldots$ & 225 & 200 & 0.31 & 35100 & 0.87 & 0.06 & 0.08 & 1.2 & 0.05 & 0.49 & 0.07 & 0.16 \\
\hline & $\begin{array}{l}\text { AUG } \\
28 \ldots\end{array}$ & 186 & 170 & 0.25 & 18000 & 0.15 & 0.02 & 0.03 & 0.9 & 0.07 & 0.37 & 0.09 & 0.12 \\
\hline & DATE & $\begin{array}{l}\text { SEDI- } \\
\text { MENT, } \\
\text { SUS- } \\
\text { PENDED } \\
\text { (MG/L) } \\
(80154)\end{array}$ & $\begin{array}{c}\text { SEDI- } \\
\text { MENT, } \\
\text { DIS- } \\
\text { CHARGE, } \\
\text { SUS- } \\
\text { PENDED } \\
\text { (T/DAY) } \\
\text { (80155) }\end{array}$ & $\begin{array}{l}\text { SED. } \\
\text { SUSP. } \\
\text { SIEVE } \\
\text { DIAM. } \\
\text { \& FINER } \\
\text { THAN } \\
.062 \text { MM } \\
(70331)\end{array}$ & $\begin{array}{c}\text { ARSEN IC } \\
\text { DIS- } \\
\text { SOLVED } \\
\text { (UG/L } \\
\text { AS AS) } \\
(01000)\end{array}$ & $\begin{array}{l}\text { ALUM- } \\
\text { INUM, } \\
\text { DIS- } \\
\text { SOLVED } \\
\text { (UG/L } \\
\text { AS AL) } \\
(01106)\end{array}$ & $\begin{array}{l}\text { BARIUM, } \\
\text { DIS- } \\
\text { SOLVED } \\
\text { (UG/L } \\
\text { AS BA) } \\
(01005)\end{array}$ & $\begin{array}{l}\text { BERYL- } \\
\text { LIUM, } \\
\text { DIS- } \\
\text { SOLVED } \\
\text { (UG/L } \\
\text { AS BE) } \\
(01010)\end{array}$ & $\begin{array}{c}\text { CADMIUM } \\
\text { DIS- } \\
\text { SOLVED } \\
\text { (UG/L } \\
\text { AS CD) } \\
(01025)\end{array}$ & $\begin{array}{l}\text { CHRO- } \\
\text { MIUM, } \\
\text { DIS- } \\
\text { SOLVED } \\
\text { (UG/L } \\
\text { AS CR) } \\
(01030)\end{array}$ & $\begin{array}{l}\text { COBALT, } \\
\text { DIS- } \\
\text { SOLVED } \\
\text { (UG/L } \\
\text { AS CO) } \\
(01035)\end{array}$ & $\begin{array}{l}\text { COPPER, } \\
\text { DIS- } \\
\text { SOLVED } \\
\text { (UG/L } \\
\text { AS CU) } \\
(01040)\end{array}$ & $\begin{array}{l}\text { IRON, } \\
\text { DIS- } \\
\text { SOLVED } \\
\text { (UG/L } \\
\text { AS FE) } \\
(01046)\end{array}$ \\
\hline
\end{tabular}

NOV 1984

$20 \ldots$

96

20

(01010) (01025)

01030)

(01040) (01046)

MAR 1985

\begin{tabular}{|c|c|c|}
\hline $12 \ldots$ & 188 & 45000 \\
\hline JUN & & \\
\hline $\begin{array}{c}04 \ldots \\
\text { AUG }\end{array}$ & 66 & 10300 \\
\hline
\end{tabular}

$99<1 \quad 100$

$\begin{array}{rrrr}43 & <0.5 & <1 & <1 \\ 65 & <0.5 & 2 & <1 \\ 50 & <0.5 & <1 & <1 \\ 31 & <0.5 & <1 & <1\end{array}$

$\begin{array}{rrr}<3 & 2 & 110 \\ <3 & 2 & 110 \\ <3 & 11 & 16 \\ <3 & 5 & 13\end{array}$

\begin{tabular}{|c|c|c|c|c|c|c|c|c|c|c|c|}
\hline DATE & $\begin{array}{c}\text { LEAD, } \\
\text { DIS- } \\
\text { SOLVED } \\
\text { (UG/L } \\
\text { AS PB) } \\
(01049)\end{array}$ & $\begin{array}{c}\text { LITH IUM } \\
\text { DIS- } \\
\text { SOLVED } \\
\text { (UG/L } \\
\text { AS LI) } \\
(0 I 130)\end{array}$ & $\begin{array}{l}\text { MANGA- } \\
\text { NESE, } \\
\text { DIS- } \\
\text { SOLVED } \\
\text { (UG/L } \\
\text { AS MN) } \\
(01056)\end{array}$ & $\begin{array}{c}\text { MERCURY } \\
\text { DIS- } \\
\text { SOLVED } \\
\text { (UG/L } \\
\text { AS HG) } \\
(71890)\end{array}$ & $\begin{array}{c}\text { MOL YB- } \\
\text { DENUM, } \\
\text { DIS- } \\
\text { SOLVED } \\
\text { (UG/L } \\
\text { AS MO) } \\
(01060)\end{array}$ & $\begin{array}{l}\text { NICKEL, } \\
\text { DIS- } \\
\text { SOLVED } \\
\text { (UG/L } \\
\text { AS NI) } \\
(01065)\end{array}$ & $\begin{array}{c}\text { SELE- } \\
\text { NIUM, } \\
\text { DIS- } \\
\text { SOLVED } \\
\text { (UG/L } \\
\text { AS SE) } \\
(01145)\end{array}$ & $\begin{array}{c}\text { SILVER, } \\
\text { DIS- } \\
\text { SOLVED } \\
\text { (UG/L } \\
\text { AS AG) } \\
(01075)\end{array}$ & $\begin{array}{c}\text { STRON- } \\
\text { TIUM, } \\
\text { DIS- } \\
\text { SOLVED } \\
\text { (UG/L } \\
\text { AS SR) } \\
(01080)\end{array}$ & $\begin{array}{l}\text { VANA- } \\
\text { DIUM, } \\
\text { DIS- } \\
\text { SOLVED } \\
\text { (UG/L } \\
\text { AS V) } \\
(01085)\end{array}$ & $\begin{array}{l}\text { ZINC, } \\
\text { DIS- } \\
\text { SOLVED } \\
\text { (DG/L } \\
\text { AS ZN) } \\
(01090)\end{array}$ \\
\hline
\end{tabular}

NOV 1984

$\begin{array}{cc}1984 & \\ 20 \ldots & <1 \\ \text { MAR } 1985 & <1 \\ 12 \ldots & \\ \text { JUN } & 4 \\ 04 \ldots & \\ \text { AUG } & 4 \\ 28 \ldots & 1\end{array}$

$\begin{array}{rrrr}7 & 12 & <0.1 & <10 \\ 4 & 21 & <0.1 & <10 \\ 9 & 5 & <0.1 & <10 \\ 7 & 3 & <0.1 & <10\end{array}$

$\begin{array}{ll}3 & <1 \\ 4 & <1 \\ <1 & <1 \\ <1 & <1\end{array}$

$<1$
1
$<1$
$<1$

$\begin{array}{rll}76 & <6 & 15 \\ 61 & <6 & 27 \\ 100 & <6 & 16 \\ 70 & <6 & 16\end{array}$




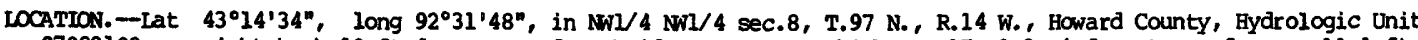
07080102 , on right bank $10 \mathrm{ft}$ downstream from bridge on county highway B17, 0.2 mi downstream from small leftbank tributary, $4.8 \mathrm{mi}$ west of Elma, and at mile 217.9.

DRAINAGE AREA. $--95.2 \mathrm{mi}^{2}$.

PERTOD OF RECORD.--october 1958 to current year.

GAGE. - hater-stage recorder. Datum of gage is 1,130.05 ft above NGVD.

RESARRS. - Estimated daily discharge during water year: Oct.1, Dec. 1-5, Dec. 13 to March 11. Records good, except. for periods of estimated record, which are poor.

AVERAGE DISCHARGE.--27 years, $68.1 \mathrm{ft} / \mathrm{s}, 9.71 \mathrm{in} / \mathrm{yg}^{2}, 49,340 \mathrm{acre}-\mathrm{ft} / \mathrm{ys}$.

EXIREUES FOR PERIOD OF RECORD.-Naximm discharge, 10,100 ft'/s June 4, 1974, gage height, $14.94 \mathrm{ft}$, from highwater mark in well; maximm gage height, $15.38 \mathrm{ft}$, fron high-water mark in well, probably occurred Aug. 22 , 1979 (backwater from vegetation); minimm daily discharge, $1.9 \mathrm{ft} / \mathrm{s}$ Feb. 4-8, 1959 .

EXIRBYES FOR OURREN YEAR.--Peak discharges greater than base $600 \mathrm{ft}^{2} / \mathrm{s}$ and maximum (*):

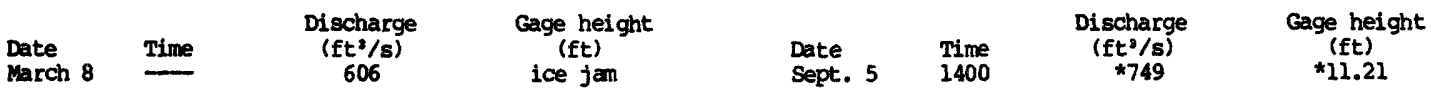

Minimum discharge, $2.6 \mathrm{ft} / \mathrm{s}$ Aug. 3,4 .

DISCHARGE, IN OBIC FEET PER SEDOND, WATER YEAR OCTOBER 1984 TO SEPTEMBER 1985 MEAN VALUES

\begin{tabular}{|c|c|c|c|c|c|c|c|c|c|c|c|c|}
\hline DAY & $\infty C r$ & NOV & DEC & JAN & FEBB & MAR & APR & MAY & JUN & JUL & AUG & SEP \\
\hline $\begin{array}{l}1 \\
2 \\
3 \\
4 \\
5\end{array}$ & $\begin{array}{r}11 \\
7.6 \\
7.4 \\
8.0 \\
9.8\end{array}$ & $\begin{array}{l}54 \\
49 \\
33 \\
28 \\
25\end{array}$ & $\begin{array}{l}19 \\
17 \\
23 \\
22 \\
21\end{array}$ & $\begin{array}{l}41 \\
31 \\
26 \\
20 \\
16\end{array}$ & $\begin{array}{l}8.4 \\
8.4 \\
8.3 \\
8.2 \\
8.2\end{array}$ & $\begin{array}{r}140 \\
145 \\
110 \\
90 \\
83\end{array}$ & $\begin{array}{r}47 \\
61 \\
139 \\
316 \\
338\end{array}$ & $\begin{array}{l}48 \\
42 \\
37 \\
34 \\
32\end{array}$ & $\begin{array}{l}24 \\
19 \\
17 \\
16 \\
15\end{array}$ & $\begin{array}{l}15 \\
13 \\
11 \\
9.2 \\
8.4\end{array}$ & $\begin{array}{l}4.5 \\
3.5 \\
2.9 \\
3.0 \\
3.6\end{array}$ & $\begin{array}{r}6.5 \\
6.1 \\
5.8 \\
7.7 \\
386\end{array}$ \\
\hline $\begin{array}{r}6 \\
7 \\
8 \\
9 \\
10\end{array}$ & $\begin{array}{l}12 \\
14 \\
16 \\
17 \\
15\end{array}$ & $\begin{array}{l}22 \\
20 \\
19 \\
22 \\
41\end{array}$ & $\begin{array}{l}21 \\
21 \\
25 \\
26 \\
26\end{array}$ & $\begin{array}{l}15 \\
15 \\
14 \\
13 \\
13\end{array}$ & $\begin{array}{l}8.2 \\
8.4 \\
8.6 \\
8.8 \\
9.0\end{array}$ & $\begin{array}{r}90 \\
82 \\
190 \\
430 \\
350\end{array}$ & $\begin{array}{r}208 \\
139 \\
106 \\
87 \\
78\end{array}$ & $\begin{array}{l}30 \\
27 \\
25 \\
23 \\
22\end{array}$ & $\begin{array}{c}14 \\
12 \\
12 \\
10 \\
9.8\end{array}$ & $\begin{array}{l}7.8 \\
7.3 \\
6.8 \\
6.4 \\
6.1\end{array}$ & $\begin{array}{l}3.5 \\
3.6 \\
3.8 \\
4.3 \\
7.0\end{array}$ & $\begin{array}{r}178 \\
52 \\
27 \\
81 \\
62\end{array}$ \\
\hline $\begin{array}{l}11 \\
12 \\
13 \\
14 \\
15\end{array}$ & $\begin{array}{l}17 \\
17 \\
17 \\
15 \\
17\end{array}$ & $\begin{array}{l}48 \\
38 \\
35 \\
54 \\
41\end{array}$ & $\begin{array}{l}25 \\
25 \\
23 \\
21 \\
19\end{array}$ & $\begin{array}{l}12 \\
12 \\
11 \\
11 \\
11\end{array}$ & $\begin{array}{l}10 \\
12 \\
14 \\
16 \\
18\end{array}$ & $\begin{array}{r}290 \\
222 \\
177 \\
140 \\
92\end{array}$ & $\begin{array}{l}74 \\
69 \\
64 \\
60 \\
57\end{array}$ & $\begin{array}{l}22 \\
23 \\
22 \\
24 \\
24\end{array}$ & $\begin{array}{l}13 \\
14 \\
14 \\
12 \\
14\end{array}$ & $\begin{array}{l}5.5 \\
7.0 \\
6.9 \\
7.0 \\
5.8\end{array}$ & $\begin{array}{l}6.6 \\
6.6 \\
7.4 \\
8.1 \\
8.3\end{array}$ & $\begin{array}{l}33 \\
23 \\
17 \\
14 \\
12\end{array}$ \\
\hline $\begin{array}{l}16 \\
17 \\
18 \\
19 \\
20\end{array}$ & $\begin{array}{l}23 \\
32 \\
27 \\
23 \\
20\end{array}$ & $\begin{array}{c}28 \\
32 \\
26 \\
19 \\
35\end{array}$ & $\begin{array}{c}29 \\
54 \\
100 \\
56 \\
38\end{array}$ & $\begin{array}{l}10 \\
10 \\
9.8 \\
9.4 \\
9.2\end{array}$ & $\begin{array}{c}20 \\
21 \\
23 \\
25 \\
27\end{array}$ & $\begin{array}{c}76 \\
66 \\
55 \\
49 \\
46\end{array}$ & $\begin{array}{l}52 \\
47 \\
43 \\
40 \\
38\end{array}$ & $\begin{array}{l}24 \\
24 \\
22 \\
20 \\
19\end{array}$ & $\begin{array}{l}14 \\
12 \\
11 \\
10 \\
9.1\end{array}$ & $\begin{array}{l}5.9 \\
6.4 \\
5.5 \\
5.8 \\
5.3\end{array}$ & $\begin{array}{c}9.2 \\
7.5 \\
7.1 \\
7.1 \\
6.9\end{array}$ & $\begin{array}{l}11 \\
11 \\
9.6 \\
8.6 \\
12\end{array}$ \\
\hline $\begin{array}{l}21 \\
22 \\
23 \\
24 \\
25\end{array}$ & $\begin{array}{l}18 \\
16 \\
15 \\
15 \\
17\end{array}$ & $\begin{array}{l}26 \\
21 \\
21 \\
22 \\
22\end{array}$ & $\begin{array}{l}34 \\
31 \\
28 \\
25 \\
22\end{array}$ & $\begin{array}{l}9.2 \\
9.0 \\
9.0 \\
9.0 \\
8.9\end{array}$ & $\begin{array}{l}100 \\
260 \\
215 \\
250 \\
210\end{array}$ & $\begin{array}{l}42 \\
39 \\
41 \\
53 \\
47\end{array}$ & $\begin{array}{l}36 \\
36 \\
45 \\
60 \\
66\end{array}$ & $\begin{array}{l}18 \\
16 \\
16 \\
16 \\
15\end{array}$ & $\begin{array}{l}9.1 \\
8.9 \\
8.2 \\
7.5 \\
7.0\end{array}$ & $\begin{array}{l}5.2 \\
4.9 \\
4.6 \\
5.1 \\
7.2\end{array}$ & $\begin{array}{l}6.8 \\
6.9 \\
8.5 \\
9.0 \\
7.1\end{array}$ & $\begin{array}{r}13 \\
12 \\
92 \\
162 \\
103\end{array}$ \\
\hline $\begin{array}{l}26 \\
27 \\
28 \\
29 \\
30 \\
31\end{array}$ & $\begin{array}{l}21 \\
20 \\
21 \\
23 \\
20 \\
19\end{array}$ & $\begin{array}{l}22 \\
22 \\
22 \\
21 \\
21 \\
\end{array}$ & $\begin{array}{r}20 \\
19 \\
100 \\
97 \\
72 \\
48\end{array}$ & $\begin{array}{l}8.8 \\
8.8 \\
8.7 \\
8.6 \\
8.6 \\
8.5\end{array}$ & $\begin{array}{l}180 \\
160 \\
135 \\
- \\
-\end{array}$ & $\begin{array}{l}43 \\
49 \\
72 \\
68 \\
57 \\
51\end{array}$ & $\begin{array}{r}82 \\
99 \\
79 \\
65 \\
55 \\
\end{array}$ & $\begin{array}{l}15 \\
14 \\
13 \\
12 \\
22 \\
71\end{array}$ & $\begin{array}{l}32 \\
67 \\
30 \\
22 \\
18 \\
\end{array}$ & $\begin{array}{l}5.2 \\
4.3 \\
3.8 \\
3.6 \\
3.4 \\
4.2\end{array}$ & $\begin{array}{c}6.5 \\
6.3 \\
7.4 \\
27 \\
15 \\
8.5\end{array}$ & $\begin{array}{r}90 \\
67 \\
50 \\
125 \\
348 \\
\end{array}$ \\
\hline $\begin{array}{l}\text { TOLAL } \\
\text { MEAN } \\
\text { MAX } \\
\text { MIN } \\
\text { CFSM } \\
\text { IN. } \\
\text { AC-FT }\end{array}$ & $\begin{array}{r}530.8 \\
17.1 \\
32 \\
7.4 \\
.18 \\
.21 \\
1050\end{array}$ & $\begin{array}{r}889 \\
29.6 \\
54 \\
19 \\
.31 \\
.35 \\
1760\end{array}$ & $\begin{array}{r}1107 \\
35.7 \\
100 \\
17 \\
.37 \\
.43 \\
2200\end{array}$ & $\begin{array}{r}406.5 \\
13.1 \\
41 \\
8.5 \\
.14 \\
.16 \\
806\end{array}$ & $\begin{array}{r}1780.5 \\
63.6 \\
260 \\
8.2 \\
.67 \\
.70 \\
3530\end{array}$ & $\begin{array}{r}3485 \\
112 \\
430 \\
39 \\
1.18 \\
1.36 \\
6910\end{array}$ & $\begin{array}{r}2686 \\
89.5 \\
338 \\
36 \\
.94 \\
1.05 \\
5330\end{array}$ & $\begin{array}{r}772 \\
24.9 \\
71 \\
12 \\
.26 \\
.30 \\
1530\end{array}$ & $\begin{array}{r}481.6 \\
16.1 \\
67 \\
7.0 \\
.17 \\
.19 \\
955\end{array}$ & $\begin{array}{r}203.6 \\
6.57 \\
15 \\
3.4 \\
.07 \\
.08 \\
404\end{array}$ & $\begin{array}{r}223.5 \\
7.21 \\
27 \\
2.9 \\
.08 \\
.09 \\
443\end{array}$ & $\begin{array}{r}2025.3 \\
67.5 \\
386 \\
5.8 \\
.71 \\
.79 \\
4020\end{array}$ \\
\hline $\begin{array}{l}\text { CAL Y } \\
\text { WIR Y }\end{array}$ & 84 & $\begin{array}{l}\text { TAL } \\
\text { TAL }\end{array}$ & $\begin{array}{r}.8 \\
.8\end{array}$ & SAN & $\begin{array}{l}\operatorname{MAX} \\
\operatorname{MAX}\end{array}$ & $\begin{array}{r}3340 \\
430\end{array}$ & $\begin{array}{l}7.4 \\
2.9\end{array}$ & $\begin{array}{l}\text { CFSM } \\
\text { CFSM }\end{array}$ & $\begin{array}{r}1.22 \\
.42\end{array}$ & $\begin{array}{lr}\text { IN. } & 16.6 \\
\text { IN. } & 5.7\end{array}$ & $\begin{array}{l}A C-F T \\
A C-F T\end{array}$ & $\begin{array}{l}84360 \\
28940\end{array}$ \\
\hline
\end{tabular}


LOCATION.--Lat $42^{\circ} 27^{\prime} 49^{\prime \prime}$, long $91^{\circ} 53^{\prime} 42^{\prime \prime}$, in SEl/4 sec.4, T.88 N., R, $\mathcal{N}$., Buchanan County, Hydrologic Unit 07080102, on right bank at Sixth street in Independence, 1,800 ft downstream from dam at abandoned hydroelectric plant, 4.9 mi downstream from Otter Creek, $9.7 \mathrm{mi}$ upstream from Pine Creek, and at mile 142.5 .

DRAINAGE AREA. $--1,048 \mathrm{mi}^{2}$.

PERIOD OF RECORD.--July 1933 to current year.

REVISED RECORDS.--WSP 1438: Drainage area. WSP 1508: 1938-39, 1940 (M), 1947.

GAGE.--Water-stage recorder and concrete control. Datum of gage is $882.85 \mathrm{ft}$ above NGVD. Prior to May 24 , 1941 nonrecording gage in tailrace of powerplant $1,800 \mathrm{ft}$ upstream at datum $80.00 \mathrm{ft} 10 \mathrm{wer}$.

REMARKS.--Estimated daily discharges: Dec, 18-20, 24-26, Dec. 31 to Jan. 6, Jan. 10-13, 15-22, 26, 27, Jan. 29 to Feb. 3, Feb. 21-22. Records are excellent except for period of estimated daily discharges, which are fair. U.S. Army Corps of Engineers Data Collection Platform at station.

AVERAGE DISCHARGE. - -52 years, $622 \mathrm{ft} / \mathrm{s}, 8.06 \mathrm{in} / \mathrm{yr}, 450,600 \mathrm{acre}-\mathrm{ft} / \mathrm{yr}$.

EXTREMES FOR PERIOD OF RECORD.--Maximum discharge, 26,800 ft ${ }^{3 / s} \mathrm{July} 18,1968$, gage height, 21.11 ft; minimum daily, $7.0 \mathrm{ft} / \mathrm{s}$ for several days in 1934 and 1977 .

EXTREMES OUTSIDE PERIOD OF RECORD.--Maximum stage since at least 1901, that of July 18 , 1968.

EXTREMES FOR CURRENT YEAR.--Peak discharges greater than base of 4,000 $\mathrm{ft} / \mathrm{s}$ and maximum (*):

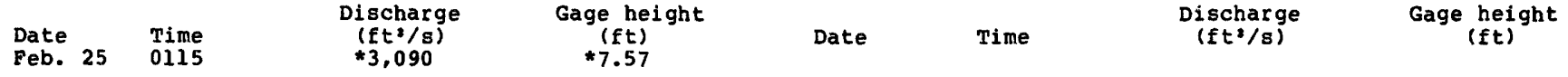

Minimum discharge, $35 \mathrm{ft}^{3 / \mathrm{s}}$ Aug. 8-9, 20-21.

DISCHARGE, IN CUBIC FEET PER SECOND, WATER YEAR OCTOBER 1984 TO SEPTEMBER 1985

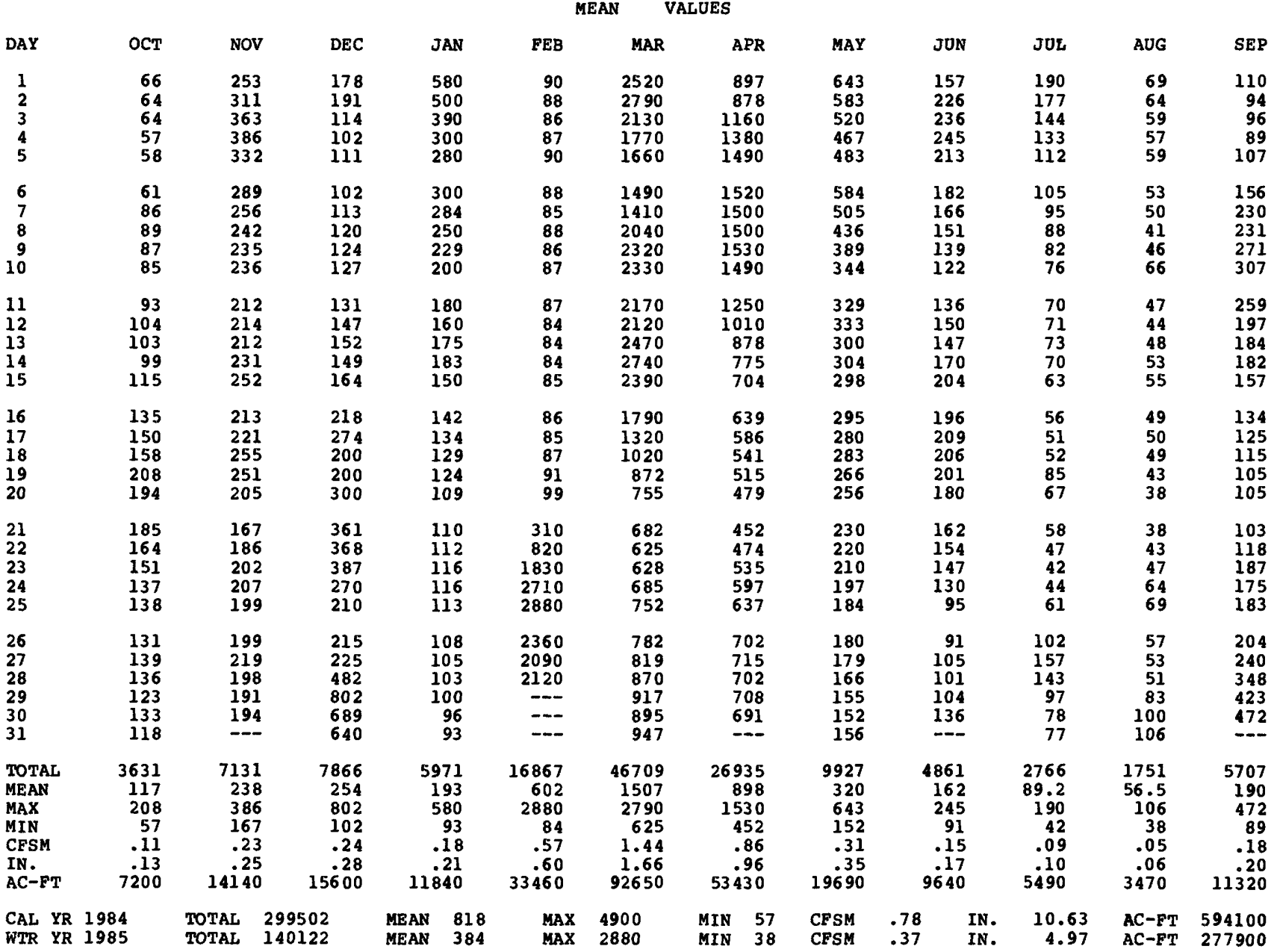


LOCATION.--Lat $41^{\circ} 46^{\prime} 01^{\prime \prime}$, long $90^{\circ} 32^{\prime} 05^{\prime \prime}$, in SWl/4 NE1/4 sec.6, T.80 N., R.4 E., Clinton County, Hydrologic Unit 07080103 , on left bank 5 ft upstream from bridge on U.S. Highway $61,0.9 \mathrm{mi}$ downstream from Silver Creek, 4.0 $\mathrm{mi}$ south of water tower in De Witt, $6.2 \mathrm{mi}$ upstream from Brophy Creek, and $18.2 \mathrm{mi}$ upstream from mouth.

DRAINAGE AREA. $--2,330 \mathrm{mi}^{2}$.

PERIOD OF RECORD.--June 1934 to current year.

REVISED RECORDS.--WSP 1308: 1937 (M). WSP 1438: Drainage area. WSP 1708: 1951.

GAGE.--Water-stage recorder. Datum of gage is $598.81 \mathrm{ft}$ above NGVD.

REMARKS.--Estimated daily discharges: oct. 20-22, Dec. 18-20, 24-27, Jan. 1 to Mar. 1, Apr. 15-16, June 27-28,

July 4, 6-8, 11-22. Records good except Oct. 20-22, Feb. 24-25, Apr. 15-16, June 27-28, July 4, 6-8, 11-22,

which are fair and Dec. 18-20, 24-27, Jan. 1 to Feb. 23, Feb. 26 to Mar. 1, which are poor. U.S. Army Corps of

Engineers gage-height telemeter and Data Collection Platform at station.

COOPERATION.--Four discharge measurements provided by U.S. Army Corps of Engineers.

AVERAGE DISCHARGE. - -51 years, $1,542 \mathrm{ft} / \mathrm{s}, 8.99 \mathrm{in} / \mathrm{yr}, 1,117,000 \mathrm{acre}-\mathrm{ft} / \mathrm{yr}$.

EXTREMES FOR PERIOD OF RECORD.--Maximum discharge, 29,900 $\mathrm{ft}^{3} / \mathrm{s}$ May 17, 1974, gage height, $13.07 \mathrm{ft}$; minimum daily, $46 \mathrm{ft}^{3} / \mathrm{s}$ Jan. $22,23,1977$.

EXTREMES FOR CURRENT YEAR.--Peak discharges greater than base of $6,000 \mathrm{ft}^{3} / \mathrm{s}$ and maximum (*):

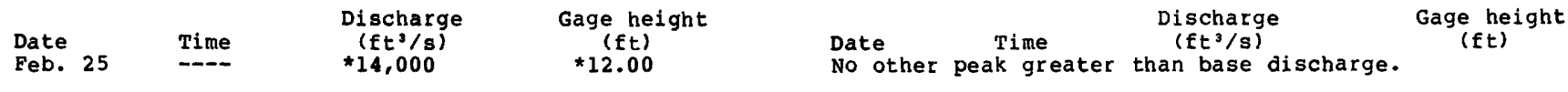

Minimum discharge, $215 \mathrm{ft}^{3} / \mathrm{s}$ sept. 10 .

DISCHARGE, IN CUBIC FEET PER SECOND, WATER YEAR OCTOBER 1984 TO SEPTEMBER 1985 MEAN VALUES

\begin{tabular}{|c|c|c|c|c|c|c|c|c|c|c|c|c|}
\hline DAY & $\mathrm{OCT}$ & NOV & DEC & JAN & FEB & MAR & APR & MAY & JUN & JUL & AUG & SEP \\
\hline $\begin{array}{l}1 \\
2 \\
3 \\
4 \\
5\end{array}$ & $\begin{array}{l}303 \\
295 \\
288 \\
282 \\
274\end{array}$ & $\begin{array}{l}2180 \\
3090 \\
2250 \\
1960 \\
1650\end{array}$ & $\begin{array}{l}903 \\
874 \\
844 \\
718 \\
6: 2\end{array}$ & $\begin{array}{r}1700 \\
1300 \\
1000 \\
940 \\
930\end{array}$ & $\begin{array}{l}515 \\
510 \\
500 \\
495 \\
495\end{array}$ & $\begin{array}{r}6820 \\
8290 \\
6340 \\
8110 \\
10000\end{array}$ & $\begin{array}{l}3020 \\
2940 \\
2780 \\
2670 \\
2770\end{array}$ & $\begin{array}{l}1620 \\
1550 \\
1490 \\
1420 \\
1360\end{array}$ & $\begin{array}{l}752 \\
694 \\
647 \\
618 \\
606\end{array}$ & $\begin{array}{l}402 \\
394 \\
387 \\
380 \\
381\end{array}$ & $\begin{array}{l}325 \\
323 \\
305 \\
290 \\
287\end{array}$ & $\begin{array}{l}220 \\
222 \\
222 \\
221 \\
222\end{array}$ \\
\hline $\begin{array}{r}6 \\
7 \\
8 \\
9 \\
10\end{array}$ & $\begin{array}{l}274 \\
285 \\
296 \\
299 \\
299\end{array}$ & $\begin{array}{l}1450 \\
1340 \\
1260 \\
1200 \\
1590\end{array}$ & $\begin{array}{l}462 \\
550 \\
697 \\
828 \\
843\end{array}$ & $\begin{array}{r}960 \\
1010 \\
1060 \\
1000 \\
850\end{array}$ & $\begin{array}{l}490 \\
480 \\
475 \\
475 \\
480\end{array}$ & $\begin{array}{l}9880 \\
8960 \\
6170 \\
4220 \\
4020\end{array}$ & $\begin{array}{l}3030 \\
3130 \\
3120 \\
3020 \\
2910\end{array}$ & $\begin{array}{l}1330 \\
1290 \\
1240 \\
1270 \\
1230\end{array}$ & $\begin{array}{l}615 \\
606 \\
592 \\
555 \\
549\end{array}$ & $\begin{array}{l}380 \\
374 \\
368 \\
346 \\
333\end{array}$ & $\begin{array}{l}284 \\
276 \\
264 \\
257 \\
270\end{array}$ & $\begin{array}{l}225 \\
224 \\
217 \\
217 \\
217\end{array}$ \\
\hline $\begin{array}{l}11 \\
12 \\
13 \\
14 \\
15\end{array}$ & $\begin{array}{l}305 \\
316 \\
315 \\
315 \\
316\end{array}$ & $\begin{array}{l}2060 \\
1490 \\
1300 \\
1200 \\
1130\end{array}$ & $\begin{array}{l}804 \\
870 \\
858 \\
835 \\
871\end{array}$ & $\begin{array}{l}760 \\
700 \\
660 \\
620 \\
600\end{array}$ & $\begin{array}{l}480 \\
480 \\
490 \\
495 \\
500\end{array}$ & $\begin{array}{l}4270 \\
4430 \\
4240 \\
4120 \\
3870\end{array}$ & $\begin{array}{l}2830 \\
2790 \\
2720 \\
2560 \\
2310\end{array}$ & $\begin{array}{l}1180 \\
1450 \\
1280 \\
1210 \\
1490\end{array}$ & $\begin{array}{l}555 \\
557 \\
565 \\
544 \\
570\end{array}$ & $\begin{array}{l}356 \\
356 \\
334 \\
314 \\
401\end{array}$ & $\begin{array}{l}294 \\
310 \\
305 \\
310 \\
288\end{array}$ & $\begin{array}{l}231 \\
261 \\
279 \\
293 \\
302\end{array}$ \\
\hline $\begin{array}{l}16 \\
17 \\
18 \\
19 \\
20\end{array}$ & $\begin{array}{r}339 \\
546 \\
602 \\
2320 \\
2180\end{array}$ & $\begin{array}{r}1050 \\
1000 \\
979 \\
951 \\
909\end{array}$ & $\begin{array}{r}905 \\
1010 \\
900 \\
880 \\
930\end{array}$ & $\begin{array}{l}595 \\
590 \\
580 \\
560 \\
550\end{array}$ & $\begin{array}{l}510 \\
520 \\
530 \\
550 \\
600\end{array}$ & $\begin{array}{l}3910 \\
4060 \\
4030 \\
3520 \\
2920\end{array}$ & $\begin{array}{l}2110 \\
1950 \\
1840 \\
1740 \\
1660\end{array}$ & $\begin{array}{l}1350 \\
1240 \\
1170 \\
1110 \\
1070\end{array}$ & $\begin{array}{l}576 \\
556 \\
537 \\
551 \\
538\end{array}$ & $\begin{array}{l}325 \\
289 \\
279 \\
272 \\
268\end{array}$ & $\begin{array}{l}267 \\
247 \\
244 \\
240 \\
233\end{array}$ & $\begin{array}{l}297 \\
280 \\
273 \\
264 \\
251\end{array}$ \\
\hline $\begin{array}{l}21 \\
22 \\
23 \\
24 \\
25\end{array}$ & $\begin{array}{r}1440 \\
1160 \\
983 \\
861 \\
791\end{array}$ & $\begin{array}{l}883 \\
870 \\
849 \\
849 \\
829\end{array}$ & $\begin{array}{r}1000 \\
1030 \\
1070 \\
930 \\
850\end{array}$ & $\begin{array}{l}535 \\
530 \\
530 \\
540 \\
550\end{array}$ & $\begin{array}{r}1600 \\
5000 \\
10000 \\
11200 \\
13800\end{array}$ & $\begin{array}{l}2510 \\
2260 \\
2090 \\
1980 \\
1890\end{array}$ & $\begin{array}{l}1570 \\
1500 \\
1480 \\
1480 \\
1570\end{array}$ & $\begin{array}{r}1020 \\
965 \\
928 \\
896 \\
858\end{array}$ & $\begin{array}{l}541 \\
619 \\
567 \\
556 \\
505\end{array}$ & $\begin{array}{l}260 \\
255 \\
253 \\
255 \\
255\end{array}$ & $\begin{array}{l}230 \\
227 \\
225 \\
223 \\
228\end{array}$ & $\begin{array}{l}251 \\
256 \\
284 \\
311 \\
320\end{array}$ \\
\hline $\begin{array}{l}26 \\
27 \\
28 \\
29 \\
30 \\
31\end{array}$ & $\begin{array}{r}749 \\
730 \\
1050 \\
1140 \\
1050 \\
925\end{array}$ & $\begin{array}{r}819 \\
887 \\
1000 \\
982 \\
941 \\
---\end{array}$ & $\begin{array}{l}1000 \\
1200 \\
1570 \\
2500 \\
2940 \\
2490\end{array}$ & $\begin{array}{l}555 \\
560 \\
555 \\
550 \\
540 \\
525\end{array}$ & $\begin{array}{r}11400 \\
8990 \\
7370 \\
- \\
- \\
--\end{array}$ & $\begin{array}{l}1880 \\
1920 \\
2160 \\
2270 \\
2250 \\
2540\end{array}$ & $\begin{array}{l}1800 \\
1820 \\
1730 \\
1680 \\
1640 \\
---\end{array}$ & $\begin{array}{l}843 \\
877 \\
840 \\
812 \\
819 \\
796\end{array}$ & $\begin{array}{l}481 \\
472 \\
451 \\
431 \\
409 \\
--7\end{array}$ & $\begin{array}{l}260 \\
262 \\
262 \\
261 \\
259 \\
304\end{array}$ & $\begin{array}{l}231 \\
227 \\
223 \\
224 \\
232 \\
227\end{array}$ & $\begin{array}{l}316 \\
317 \\
325 \\
323 \\
326 \\
-\end{array}$ \\
\hline $\begin{array}{l}\text { TOTAL } \\
\text { MEAN } \\
\text { MAX } \\
\text { MIN } \\
\text { CFSM } \\
\text { IN. } \\
\text { AC-FT }\end{array}$ & $\begin{array}{r}21328 \\
688 \\
2320 \\
274 \\
.30 \\
.34 \\
42300\end{array}$ & $\begin{array}{r}38948 \\
1298 \\
3090 \\
819 \\
.56 \\
.62 \\
77250\end{array}$ & $\begin{array}{r}32894 \\
1061 \\
2940 \\
462 \\
.46 \\
.53 \\
65250\end{array}$ & $\begin{array}{r}22935 \\
740 \\
1700 \\
525 \\
.32 \\
.37 \\
45490\end{array}$ & $\begin{array}{r}79430 \\
2837 \\
13800 \\
475 \\
1.22 \\
1.27 \\
157500\end{array}$ & $\begin{array}{r}135930 \\
4385 \\
10000 \\
1880 \\
1.88 \\
2.17 \\
269600\end{array}$ & $\begin{array}{r}68170 \\
2272 \\
3130 \\
1480 \\
.98 \\
1.09 \\
135200\end{array}$ & $\begin{array}{r}36004 \\
1161 \\
1620 \\
796 \\
.50 \\
.57 \\
71410\end{array}$ & $\begin{array}{r}16815 \\
561 \\
752 \\
409 \\
.24 \\
.27 \\
33350\end{array}$ & $\begin{array}{r}9825 \\
317 \\
402 \\
253 \\
.14 \\
19490\end{array}$ & $\begin{array}{r}8116 \\
262 \\
325 \\
223 \\
.11 \\
16100\end{array}$ & $\begin{array}{r}7967 \\
266 \\
326 \\
217 \\
.11 \\
.13 \\
15800\end{array}$ \\
\hline
\end{tabular}

$\begin{array}{lllllllllllllll}\text { CAL YR } 1984 & \text { TOTAL } & 742081 & \text { MEAN } & 2028 & \text { MAX } & 9240 & \text { MIN } & 274 & \text { CFSM } & .87 & \text { IN. } & 11.85 & \text { AC-FT } & 1472000\end{array}$

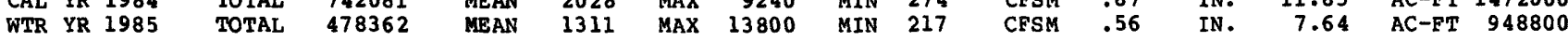


LOCATION.--Lat $41^{\circ} 33^{\prime} 03^{\prime \prime}$, long $90^{\circ} 27^{\prime} 15^{\prime \prime}$, in NW1/4 NW1/4 sec.24, T.78 N., R.4 E., Scott County, Bydrologic Unit 07080101 , on left bank $200 \mathrm{ft}$ upstream from bridge on Valley Road (0ld 0.8. Highway 67$)$, 3.5 mi east of 0.8. Highway 6 , and $0.7 \mathrm{mi}$ upstream from mouth.

DRAINAGE AREA. $--17.8 \mathrm{mi}^{2}$.

PERIOD OF RECORD.--October 1977 to current year.

GAGE.--Water-stage recorder. Datum of gage is $576.23 \mathrm{ft}$ above NGVD.

REMARRS. --Estimated daily discharges: Nov. 20-22, Dec, 6, 20-25, Jan. 1 to Feb. 19. Records fair except those for estimated discharge, which are poor.

AVERAGE DISCHARGE. --8 years, $16.1 \mathrm{ft}^{3} / \mathrm{s}, 12.28 \mathrm{in} / \mathrm{yr}, 11,660 \mathrm{acre}-\mathrm{ft} / \mathrm{yr}$.

EXTREMES FOR PERIOD OF RECORD.--Maximum discharge, 2,490 ft'/s June 15, 1982, gage height, 10.24 ft, minimum daily, $0.23 \mathrm{ft}^{3} / \mathrm{s}$ (corrected) sept. 10, 11, 26-28, 1978 .

EXTREMES FOR CURRENT YEAR.--Peak discharges greater than base discharge of 250 ft'/s and maximum (*):

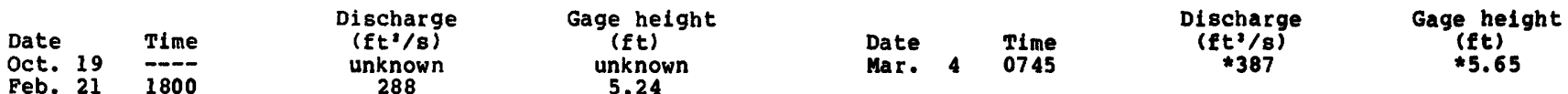

Minimum discharge, $0.10 \mathrm{ft}^{2} / \mathrm{s}$ sept. 12.

DISCHARGE, IN CUBIC FEET PER SECOND, WATER YEAR OCTOBER 1984 TO SEPTEMBER 1985 MEAN VALUES

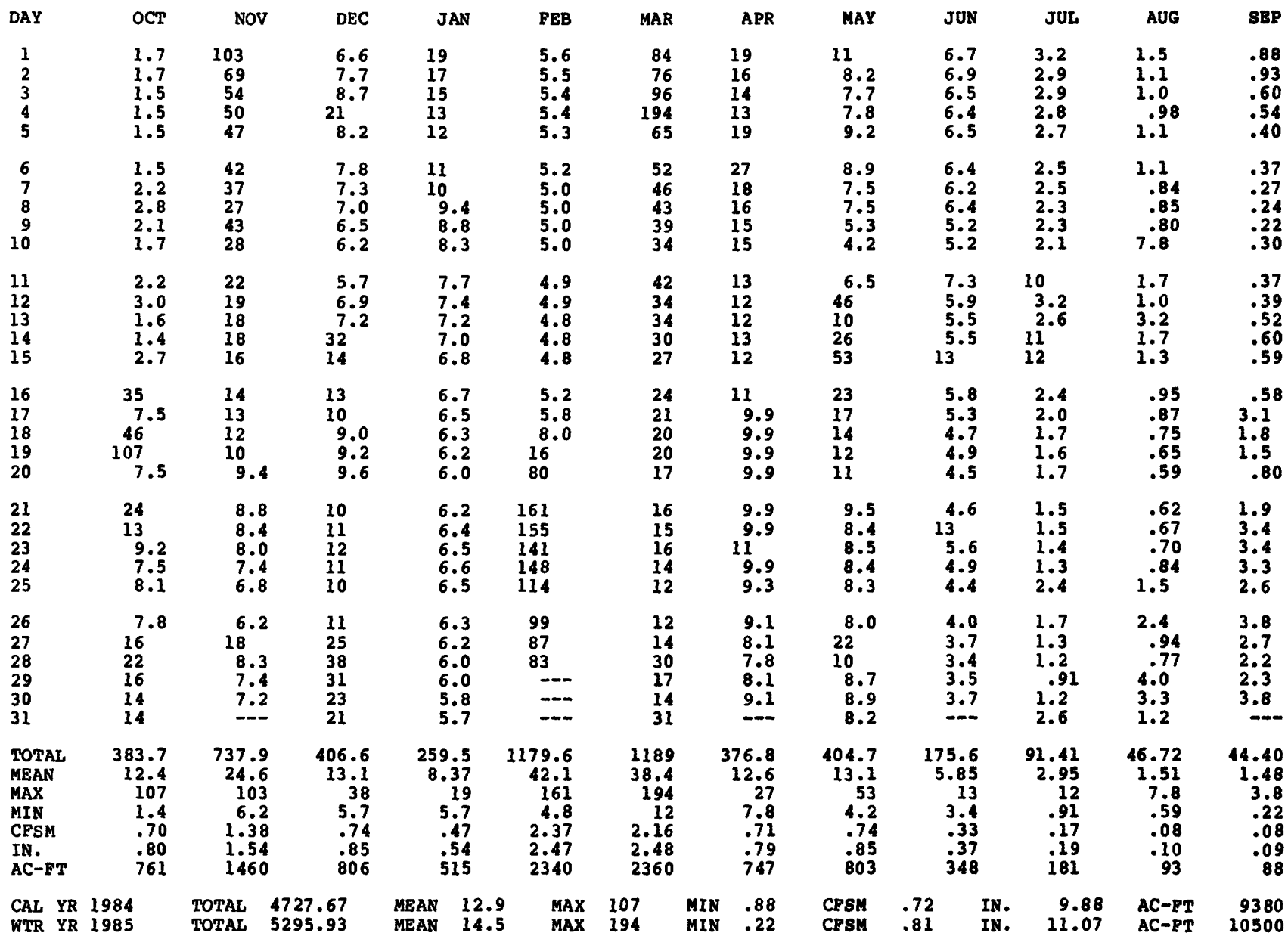


LOCATION.--Lat $43^{\circ} 00^{\prime} 31^{\prime \prime}$, long $93^{\circ} 37^{\prime} 42^{\prime \prime}$, in NEl/4 N1/4 sec.36, T.95 N.. R.24 W., Bancock County, Bydrologic Unit 07080207 , on left bank $15 \mathrm{ft}$ upstream from bridge on county highway B55, 1.2 mi west of Chicago, Rock Island and Pacific Railroad crossing in Klemme, $1.5 \mathrm{mi}$ upstream Erom Drainage ditch 9 , 18.2 mi upstream from confluence with West Branch Iowa River, and at mile 341.0 .

DRAINAGE AREA. $--133 \mathrm{mi}^{2}$.

PERIOD OF RECORD.--April 1948 to September 1976, June 1977 to current year. Prior to October 1958, published as East Fork Iowa River near Klemme.

REVISED RECORDS.-WSP 1438: Drainage area. WDR IA-80-1: 1978 .

GAGE.--Water-8tage recorder. Datum of gage is $1,179.33 \mathrm{ft}$ above NGVD. Apr. 1 , 1948 , to Sept. 30 , 1955, nonrecording gage at site $0.6 \mathrm{mi}$ upstream at datum $0.80 \mathrm{ft}$ higher. Oct. 1, i955, to Sept. 30, i969, at present site at datum $0.31 \mathrm{Et}$ lower.

REMARKS.--Estimated daily discharge during water year: Nov. 14 - 22, Dec. 9 to March 9. Records good, except for periods of estimated record, which are poor.

AVERAGE DISCHARGE.--36 years. (water years 1948-76, 1978-85), 66.7 ft: $/ 8$, 6.81 in/yr, 48,320 acre-ft/yr, median of yearly mean discharges, $54 \mathrm{ft} / \mathrm{s}, 5.5 \mathrm{in} / \mathrm{yr}, 39,100 \mathrm{acre}-\mathrm{ft} / \mathrm{yr}$.

EXTREMES FOR PERIOD OF RECORD.--Maximum discharge, 5,960 ft/s June 19, 1954, gage height, 11.2 ft, from floodmark, site and datum then in use; maximum gage height, $10.67 \mathrm{ft}$ Apr. 6, 1965 (corrected), backwater from ice; minimum daily discharge, $0.2 \mathrm{ft} / \mathrm{s}$ Feb. 22-26, 1959 .

EXTREMES OUTSIDE PERIOD OF RECORD.--Flood in June 1944 reached a stage of about 10 ft, from information by local residents, former site and datum.

EXTREMES FOR CURRENT YEAR.--Peak discharges greater than base of $700 \mathrm{ft} / \mathrm{s}$ and maximum (*):

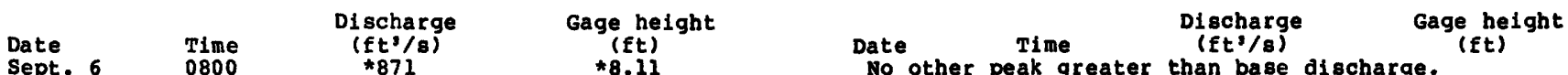

Minimum daily discharge, $3.3 \mathrm{ft} / \mathrm{s}$ Jan. 25 to Feb. 4, Feb 7-12.

DISCHARGE, IN CUBIC FEET PER SECOND, WATER YEAR OCTOBER 1984 TO SEPTEMBER 1985 MEAN VALUES

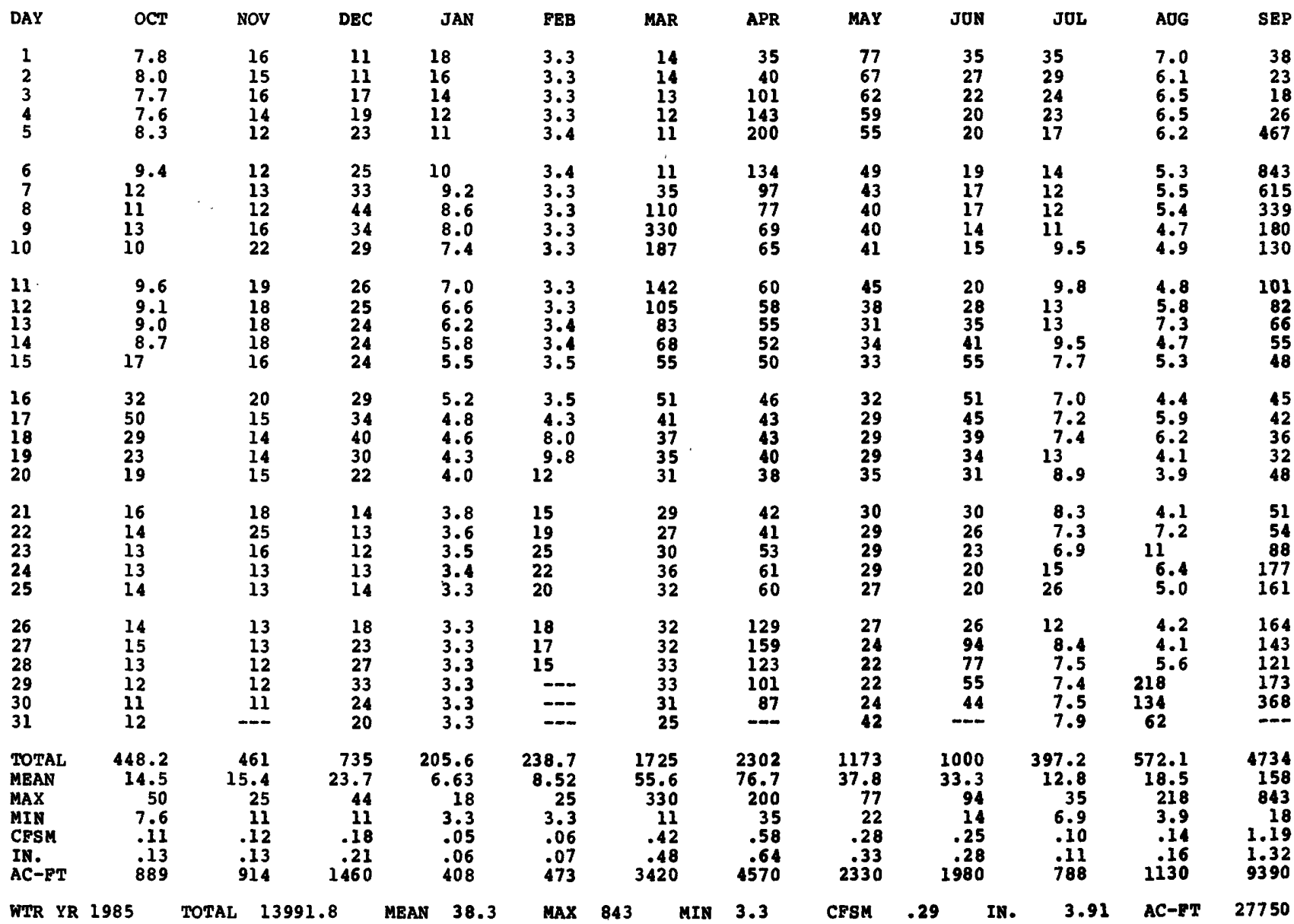


LOCATION,--Lat $42^{\circ} 45^{\prime} 36^{\prime \prime}$, long $93^{\circ} 37^{\prime} 2^{\prime \prime}$, in Nw1/4 NEl/4 sec.25, T.92 N., R.24 w., Wright County, Hydrologic Unit 07080207 , on left bank $10 \mathrm{ft}$ downstream from bridge on county highway C38, $0.9 \mathrm{mi}$ downstream from Drainage ditch $123,3.8 \mathrm{ml}$ northwest of Rowan, $10.7 \mathrm{ml}$ downstream from confluence of East and west Branches, and at mile 316.4 .

DRAINAGE AREA. $--429 \mathrm{ml}^{2}$.

PERIOD OP RECORD.--October 1940 to september 1976, June 1977 to current year.

REVISED RECORDS.--WSP 1308; 1942-43 (M). WSP 1438; Dralnage area. WDR IA-80-1: 1978.

GAGE.--Water-gtage recorder. Datum of gage 18 1,143.35 ft above NGVD. Pr1or to Oct. 14, 1948 , nonrecording gage at same site and datum.

REMARRs.--Estimated dally discharge, Oct. 5-15, Nov. 18 to March 12, July 4 - July 9, July 11 - July 16, July 18 - July 22. Records good, except for perlods of estimated record, which are poor.

AVERAGE DISCHARGE.--44 years (water years 1941-76, 1978-85), 216 ft/s, 6.84 In/yr, 156,500 acre-ft/yr; median of yearly mean discharges, $200 \mathrm{ft} / \mathrm{s}, 6.3 \mathrm{In} / \mathrm{yr}, 145,000$ acre-ft/yr.

EXTREMES FOR PERIOD OF RECORD,--haximum discharge, $8,460 \mathrm{ft} / \mathrm{s}$ June 21, 1954, gage helght, $14.88 \mathrm{ft}$, minimum dally $2.9 \mathrm{ft} / \mathrm{s}$ Jan. $21-23,1959$.

EXTREMES FOR CORREXT YEAR,--Peak discharges greater than base of 1,200 ft $\%$ and maximum (*):

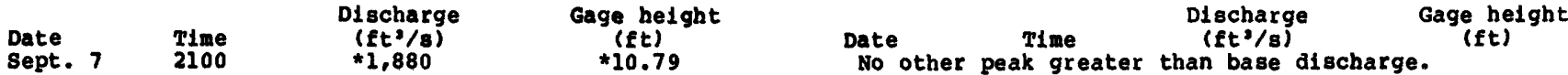

MInlmum dally discharge, $23 \mathrm{ft} / \mathrm{s}$ Jan. 29 to Feb. 17.

DISCHARGE, IN CUBIC FEET PER SECOND, WATER YEAR OCTOBER 1984 TO SEPTEMBER 1985 MEAN VALOES

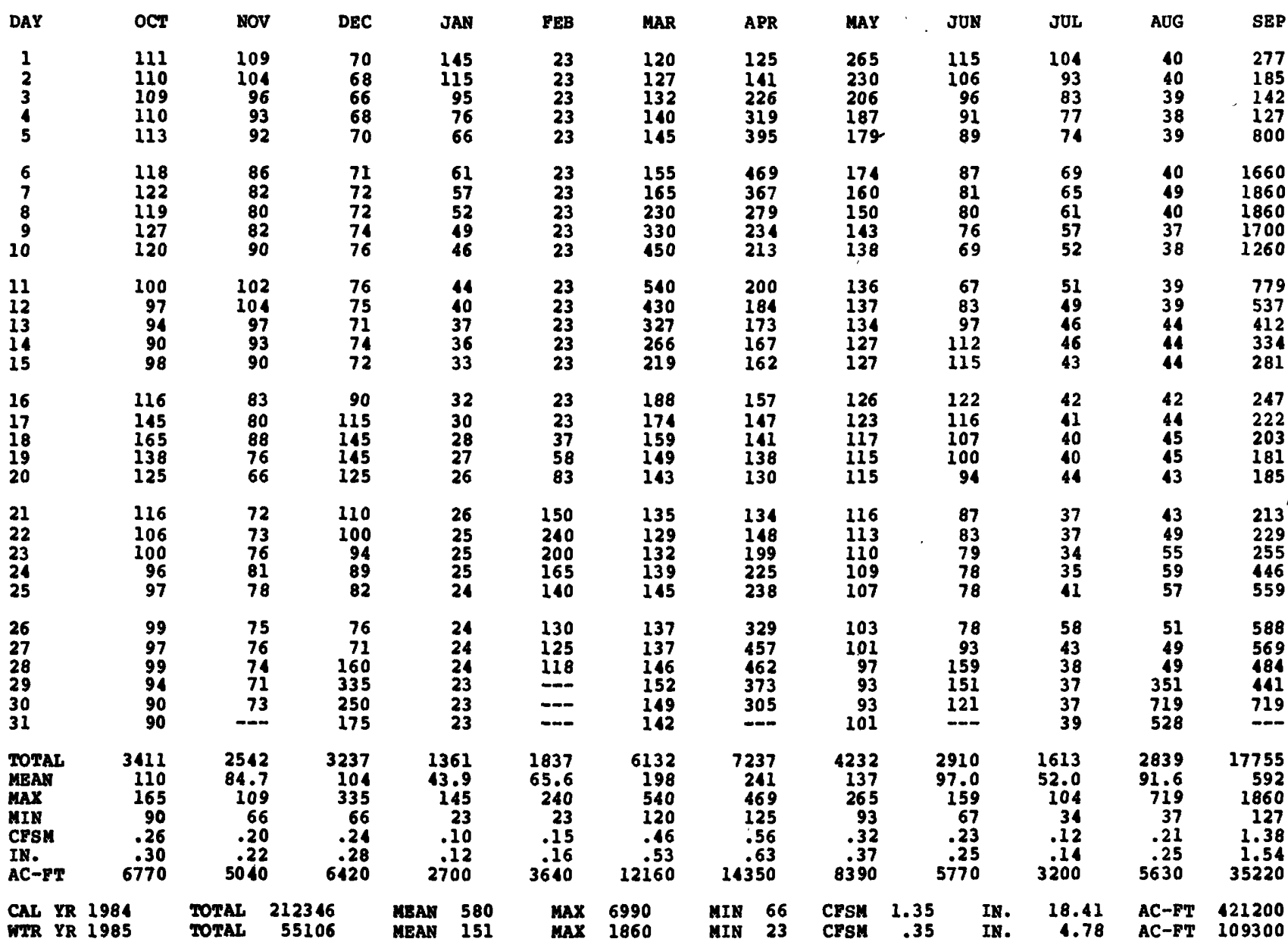


LOCATrow.--lat $42^{\circ} 03^{\prime} 57^{\prime \prime}$, long $92^{\circ} 54^{\prime} 2^{\prime \prime}$, in SEl/4 SEl/4 sec.23, T.84 N., R.18 W., Marshall County, Bydrologic Unit 07080208 , on right bank 10 ft downstrean from bridge on state Highway i4, i,500 ft upstream from Burnett Creek, $2.2 \mathrm{mi}$ upstream from Limn Creek and at mile 222.8 .

DRAINAG ARBA.--1,564 $\mathrm{mi}^{2}$, including that of Burnett Creek.

PERIOD OF RECORD.--October 1902 to september 1903, October 1914 to september 1927 , October 1932 to current year. Monthiy discharge only for sone perlods, published in WSP 1308.

REVI8ED RECORDS.--WSP 1438: Drainage area. WSP 1558, 1915-18, 1919 (M), 1920, 1921-23 (M), 1924-27, 1933, 1934 (H). $1936,1938,1947$ (H).

GAGB.--Nater-stage recorder. Datum of gage is 853.10 ft above NGVD. See wsp 1728 for history of changes prior to sept. 21, 1934.

RBuARRs.--Bgtimated daily discharges: Dec. 5, Dec. 31 to Feb. 22 and Mar. 1 . Records are good except those for estimated daily discharges, which are fair. D.S. Army Corps of Engineers data collection platform at station.

COOPBRATIOA.--mo discharge measurements provided by 0.s. Army Corp of Bngineers.

AVERAGB DI8CHARGB.--67 years (water years 1903, 1915-27, 1933-85), 815 ft/s 7.08 in/yr, 590,500 acre-ft/yr, medIan of yearly mean discharges, $690 \mathrm{ft} / \mathrm{g}, 6.0 \mathrm{in} / \mathrm{yr}, 500,000 \mathrm{acre}-\mathrm{ft} / \mathrm{yr}$.

EXTRENES FOR PERIOD OF RECORD.--Maximum discharge, $42,000 \mathrm{ft} / \mathrm{g}$ June 4, 1918, gage height, 17.74 ft, from floodmark, from rating curve extended above $19,000 \mathrm{ft} / \mathrm{s}$ on basis of velocity-area study; maximum gage height, 19.77 ft March 19,1979, minimum dally discharge, $4.7 \mathrm{ft} / \mathrm{s}$ Jan. $25,1977$.

EXTREABs FOR CURREAT YBAR.--Peak discharges greater than base of $5,000 \mathrm{ft} / \mathrm{s}$ and maximum (*):

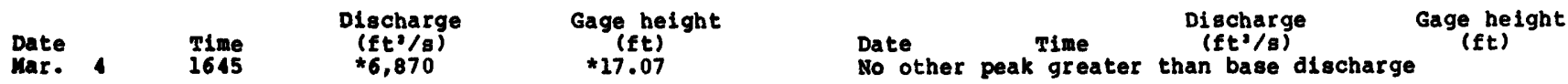

Minimum discharge, $65 \mathrm{ft} / \mathrm{s}$ Aug. 19.

DI8CaARGB, IN CUBIC FEBT PER SECOND, MATER YEAR OCTOBER 1984 TO SEPTEMBER 1985 MBAN VALUES

\begin{tabular}{|c|c|c|c|c|c|c|c|c|c|c|c|c|}
\hline DAY & OCP & MOV & DEC & $\mathbf{J A N}$ & FEB & MAR & APR & MAY & JON & JUL & AUG & SEP \\
\hline $\begin{array}{l}1 \\
2 \\
3 \\
4 \\
5\end{array}$ & $\begin{array}{l}163 \\
163 \\
163 \\
163 \\
163\end{array}$ & $\begin{array}{l}593 \\
725 \\
613 \\
497 \\
443\end{array}$ & $\begin{array}{l}282 \\
273 \\
185 \\
234 \\
265\end{array}$ & $\begin{array}{l}718 \\
700 \\
620 \\
580 \\
505\end{array}$ & $\begin{array}{l}198 \\
194 \\
197 \\
200 \\
204\end{array}$ & $\begin{array}{r}1100 \\
933 \\
1110 \\
6010 \\
5320\end{array}$ & $\begin{array}{r}814 \\
836 \\
1160 \\
1450 \\
1500\end{array}$ & $\begin{array}{l}968 \\
823 \\
778 \\
712 \\
687\end{array}$ & $\begin{array}{l}294 \\
288 \\
288 \\
293 \\
287\end{array}$ & $\begin{array}{l}319 \\
304 \\
271 \\
247 \\
227\end{array}$ & $\begin{array}{l}122 \\
113 \\
108 \\
111 \\
120\end{array}$ & $\begin{array}{l}297 \\
425 \\
420 \\
315 \\
260\end{array}$ \\
\hline $\begin{array}{r}6 \\
7 \\
8 \\
9 \\
10\end{array}$ & $\begin{array}{l}172 \\
185 \\
184 \\
187 \\
180\end{array}$ & $\begin{array}{l}412 \\
392 \\
382 \\
368 \\
368\end{array}$ & $\begin{array}{l}288 \\
294 \\
288 \\
303 \\
306\end{array}$ & $\begin{array}{l}495 \\
450 \\
405 \\
360 \\
325\end{array}$ & $\begin{array}{l}205 \\
203 \\
226 \\
232 \\
240\end{array}$ & $\begin{array}{l}2010 \\
1620 \\
1480 \\
1400 \\
1510\end{array}$ & $\begin{array}{l}1420 \\
1310 \\
1260 \\
1180 \\
1080\end{array}$ & $\begin{array}{l}738 \\
721 \\
683 \\
641 \\
597\end{array}$ & $\begin{array}{l}270 \\
256 \\
246 \\
235 \\
224\end{array}$ & $\begin{array}{l}213 \\
196 \\
178 \\
173 \\
174\end{array}$ & $\begin{array}{l}116 \\
108 \\
104 \\
107 \\
127\end{array}$ & $\begin{array}{l}303 \\
299 \\
518 \\
689 \\
978\end{array}$ \\
\hline $\begin{array}{l}11 \\
12 \\
13 \\
14 \\
15\end{array}$ & $\begin{array}{l}190 \\
203 \\
194 \\
192 \\
218\end{array}$ & $\begin{array}{l}372 \\
372 \\
375 \\
388 \\
392\end{array}$ & $\begin{array}{l}305 \\
310 \\
334 \\
294 \\
301\end{array}$ & $\begin{array}{l}290 \\
278 \\
280 \\
282 \\
278\end{array}$ & $\begin{array}{l}261 \\
270 \\
286 \\
300 \\
312\end{array}$ & $\begin{array}{l}1520 \\
1550 \\
1530 \\
1470 \\
1270\end{array}$ & $\begin{array}{l}978 \\
892 \\
841 \\
809 \\
764\end{array}$ & $\begin{array}{l}\mathbf{5 7 7} \\
\mathbf{5 7 7} \\
538 \\
516 \\
501\end{array}$ & $\begin{array}{l}248 \\
313 \\
346 \\
398 \\
538\end{array}$ & $\begin{array}{l}166 \\
161 \\
159 \\
158 \\
158\end{array}$ & $\begin{array}{l}130 \\
124 \\
109 \\
106 \\
114\end{array}$ & $\begin{array}{r}1250 \\
1320 \\
1220 \\
993 \\
732\end{array}$ \\
\hline $\begin{array}{l}16 \\
17 \\
18 \\
19 \\
20\end{array}$ & $\begin{array}{l}282 \\
344 \\
314 \\
317 \\
318\end{array}$ & $\begin{array}{l}368 \\
359 \\
359 \\
346 \\
306\end{array}$ & $\begin{array}{l}416 \\
525 \\
466 \\
565 \\
516\end{array}$ & $\begin{array}{l}277 \\
262 \\
250 \\
244 \\
240\end{array}$ & $\begin{array}{l}320 \\
330 \\
392 \\
480 \\
585\end{array}$ & $\begin{array}{r}1150 \\
959 \\
930 \\
901 \\
855\end{array}$ & $\begin{array}{l}734 \\
704 \\
670 \\
653 \\
621\end{array}$ & $\begin{array}{l}490 \\
479 \\
464 \\
447 \\
413\end{array}$ & $\begin{array}{l}500 \\
474 \\
436 \\
416 \\
387\end{array}$ & $\begin{array}{l}151 \\
146 \\
140 \\
149 \\
203\end{array}$ & $\begin{array}{r}105 \\
97 \\
101 \\
92 \\
80\end{array}$ & $\begin{array}{l}548 \\
496 \\
454 \\
421 \\
397\end{array}$ \\
\hline $\begin{array}{l}21 \\
22 \\
23 \\
24 \\
25\end{array}$ & $\begin{array}{l}312 \\
294 \\
271 \\
261 \\
259\end{array}$ & $\begin{array}{l}297 \\
297 \\
312 \\
309 \\
312\end{array}$ & $\begin{array}{l}613 \\
704 \\
557 \\
490 \\
501\end{array}$ & $\begin{array}{l}230 \\
226 \\
221 \\
222 \\
220\end{array}$ & $\begin{array}{l}1070 \\
1800 \\
2230 \\
3210 \\
2420\end{array}$ & $\begin{array}{l}809 \\
769 \\
756 \\
751 \\
747\end{array}$ & $\begin{array}{l}597 \\
621 \\
658 \\
641 \\
658\end{array}$ & $\begin{array}{l}350 \\
400 \\
395 \\
393 \\
384\end{array}$ & $\begin{array}{l}359 \\
338 \\
315 \\
299 \\
282\end{array}$ & $\begin{array}{l}183 \\
154 \\
142 \\
130 \\
156\end{array}$ & $\begin{array}{r}76 \\
95 \\
115 \\
117 \\
102\end{array}$ & $\begin{array}{l}390 \\
354 \\
430 \\
478 \\
486\end{array}$ \\
\hline $\begin{array}{l}26 \\
27 \\
28 \\
29 \\
30 \\
31\end{array}$ & $\begin{array}{r}259 \\
254 \\
252 \\
247 \\
248 \\
245\end{array}$ & $\begin{array}{l}306 \\
306 \\
303 \\
300 \\
288 \\
-\infty-\end{array}$ & $\begin{array}{r}527 \\
538 \\
1990 \\
1790 \\
1140 \\
860\end{array}$ & $\begin{array}{l}210 \\
208 \\
205 \\
203 \\
200 \\
198\end{array}$ & $\begin{array}{r}2130 \\
1810 \\
1320 \\
-\ldots \\
- \\
-\end{array}$ & $\begin{array}{l}747 \\
782 \\
804 \\
850 \\
864 \\
859\end{array}$ & $\begin{array}{r}712 \\
738 \\
897 \\
988 \\
1010 \\
-\end{array}$ & $\begin{array}{l}373 \\
363 \\
347 \\
327 \\
319 \\
313\end{array}$ & $\begin{array}{l}278 \\
288 \\
295 \\
282 \\
283 \\
---\end{array}$ & $\begin{array}{l}183 \\
142 \\
121 \\
116 \\
123 \\
123\end{array}$ & $\begin{array}{r}91 \\
87 \\
85 \\
97 \\
119 \\
146\end{array}$ & $\begin{array}{l}551 \\
651 \\
707 \\
775 \\
970 \\
--\end{array}$ \\
\hline $\begin{array}{l}\text { TOTAL } \\
\text { MIAN } \\
\text { MNX } \\
\text { MIN } \\
\text { CPSH } \\
\text { IN. } \\
\text { AC-FT }\end{array}$ & $\begin{array}{r}7197 \\
232 \\
344 \\
163 \\
.15 \\
14280\end{array}$ & $\begin{array}{r}11460 \\
382 \\
725 \\
288 \\
.24 \\
.27 \\
22730\end{array}$ & $\begin{array}{r}16460 \\
531 \\
1990 \\
185 \\
.34 \\
32650\end{array}$ & $\begin{array}{r}10182 \\
328 \\
718 \\
198 \\
.21 \\
.24 \\
20200\end{array}$ & $\begin{array}{r}21625 \\
772 \\
3210 \\
194 \\
.49 \\
.51 \\
42890\end{array}$ & $\begin{array}{r}43366 \\
1399 \\
6010 \\
747 \\
.89 \\
1.03 \\
86020\end{array}$ & $\begin{array}{r}27196 \\
907 \\
1500 \\
597 \\
.58 \\
.65 \\
53940\end{array}$ & $\begin{array}{r}16314 \\
526 \\
968 \\
313 \\
.34 \\
.39 \\
32360\end{array}$ & $\begin{array}{r}9756 \\
325 \\
538 \\
224 \\
.21 \\
.23 \\
19350\end{array}$ & $\begin{array}{r}5466 \\
176 \\
319 \\
116 \\
.11 \\
.13 \\
10840\end{array}$ & $\begin{array}{r}3324 \\
107 \\
146 \\
76 \\
.07 \\
.08 \\
6590\end{array}$ & $\begin{array}{r}18127 \\
604 \\
1320 \\
260 \\
.39 \\
35950\end{array}$ \\
\hline
\end{tabular}

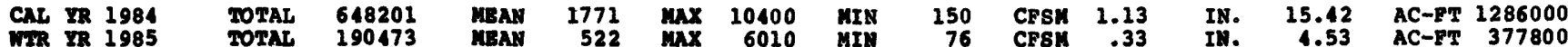


05451700 TIMBER CREER NEAR MARSHALLTOKN, IA

LOCATION.--Lat $42^{\circ} 00^{\prime} 25^{\prime \prime}$, long $92^{\circ} 51^{\prime} 15^{\prime \prime}$, in SEl/4 Swl/4 sec.8, T.83 N., R.17 W., Marshall County, Hydrologic Unit 07080208 , on left bank 20 ft downstream from bridge on U.s. Highway 30 , 3.5 mi upstream from mouth, and 4.1 mi southeast of court house in Marshalltown.

DRAINAGE AREA. $--118 \mathrm{mi}^{2}$.

PERIOD OF RECORD.--October 1949 to current year.

REVISED RECORDS.--WSP 1708: 1950-55, $1957-59$.

GAGE.--Water-stage recorder. Datum of gage is $849.44 \mathrm{ft}$ above NGVD.

REMARRS.--Estimated daily discharges: Oct. 1-14, Dec. 3-4, 8-10, Jan. 1 to Feb. 22, and Sept 6-7, 21-30. Records fair except those for estimated daily discharges, which are poor. U.s. Army Corps of Engineers data collection platform at station.

COOPERATION.--Two discharge measurements provided by U.s. Army Corps of Engineers.

AVERAGE DISCHARGE. -36 years, $73.0 \mathrm{ft} / \mathrm{s}, 8.40 \mathrm{in} / \mathrm{yr}, 52,890 \mathrm{acre}-\mathrm{ft} / \mathrm{yr}$.

EXTREMES FOR PERIOD OF RECORD.--Maximum discharge, 12,000 ft's Aug. 16, 1977, gage height, $17.69 \mathrm{ft}$, no flow for a few days in 1956 and 1977 .

EXTREMES OUTSIDE PERIOD OF RECORD.--Flood in June 1947 reached a stage of $16.8 \mathrm{ft}$, discharge, $5,700 \mathrm{ft} \% \mathrm{~s}$.

EXTREMES FOR CURRENT YEAR.--Peak discharges greater than base of 1,000 ft/s and maximum (*):

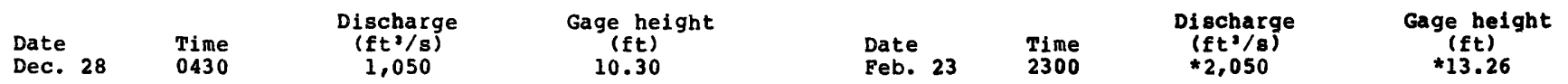

Minimum discharge, $1.5 \mathrm{ft}^{2} / \mathrm{s}$ Sept. 15 .

DISCAARGE, IN CUBIC FEET PER SECOND, WATER YEAR OCTOBER 1984 TO SEPTEMBER 1985

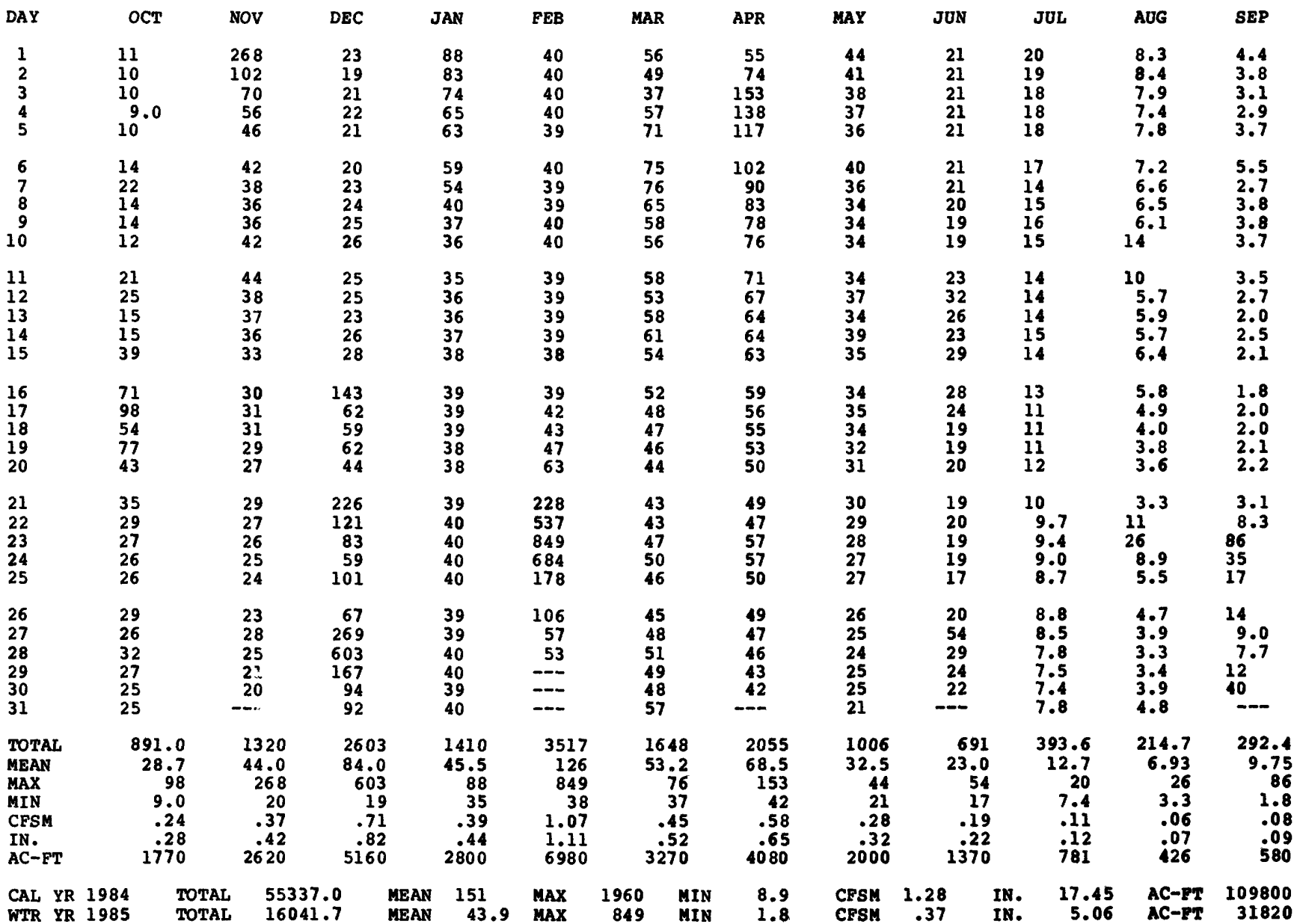


LOCATION,--Lat $41^{\circ} 53^{\prime} 58^{\prime \prime}$, long $92^{\circ} 28^{\prime} 27^{\circ}$, in SEI/4 NEl/4 sec.21, T.82 N., R.14 w., Tama County, Hydrologic Onit 07080208 , on right bank 5 ft upstream from bridge on county highway, $0.6 \mathrm{mi}$ northeast of Haven, and $2.8 \mathrm{mi}$ upstream from mouth.

DRAINAGE AREA. $--56.1 \mathrm{mi}^{2}$.

PERIOD OF RECORD.--October 1949 to current year.

REVISED RECORDS.--WSP 1708: 1950-55, 1956 (M), 1957, 1958 (M), 1959.

GAGE.--Water-stage recorder. Datum of gage is $788.69 \mathrm{ft}$ above NGVD. Prior to Oct. 1 , 1971 , at datum $10.00 \mathrm{ft}$ higher.

REMARKS.--Estimated daily discharge: Dec. 2, Dec. 6-14, and Jan.1 to Feb. 21. Records are good except those for estimated daily discharges, which are poor.

AVERAGE DISCHARGE, -36 years, $36.0 \mathrm{ft}^{3} / \mathrm{s}, 8.71 \mathrm{in} / \mathrm{yr}^{2}, 26,080$ acre-ft/yr; median of yearly mean discharges, $31 \mathrm{ft} / \mathrm{s}, 7.5 \mathrm{in} / \mathrm{yr}, 22,500$ acre-ft/yr.

EXTREMES FOR PERIOD OF RECORD.--Maximum discharge, 7,000 ft3/s May 28, 1974, gage height, 24.00 ft; no flow Jan. 22 to Feb. 2, 1977 .

EXTREMES OOTSIDE PERIOD OF RECORD.--Flood in June 1918 reached a stage of $24.3 \mathrm{ft}$, discharge not determined.

EXTREMES FOR CURRENT YEAR.--Peak discharges greater than base of $1,000 \mathrm{ft}^{3} / \mathrm{s}$ and maximum (*):

\begin{tabular}{|c|c|c|c|c|c|c|c|c|}
\hline $\begin{array}{l}\text { Date } \\
\text { Feb. } 21 \\
\text { Feb. } 23\end{array}$ & $\begin{array}{l}\text { Time } \\
1415 \\
1730\end{array}$ & $\begin{array}{c}\text { Discharge } \\
\left(\mathrm{ft}^{3} / \mathrm{s}\right) \\
1.400 \\
1.570\end{array}$ & $\begin{array}{c}\text { Gage height } \\
\text { (ft) } \\
\star a 20.50 \\
18.75\end{array}$ & $\begin{array}{l}\text { Date } \\
\text { Mar. }\end{array}$ & 4 & $\begin{array}{l}\text { Time } \\
1015\end{array}$ & $\begin{array}{c}\text { Discha rge } \\
\left(\mathrm{ft}^{3} / \mathrm{s}\right) \\
* 1,890\end{array}$ & $\begin{array}{c}\text { Gage helght } \\
\text { (ft) } \\
19.50\end{array}$ \\
\hline
\end{tabular}

(a) ice jam

Minimum daily discharge, $0.63 \mathrm{ft}^{3} / \mathrm{s}$ Aug. 27.

DISCHARGE, IN CUBIC FEET PER SECOND, WATER YEAR OCTOBER 1984 TO SEPTEMBER 1985

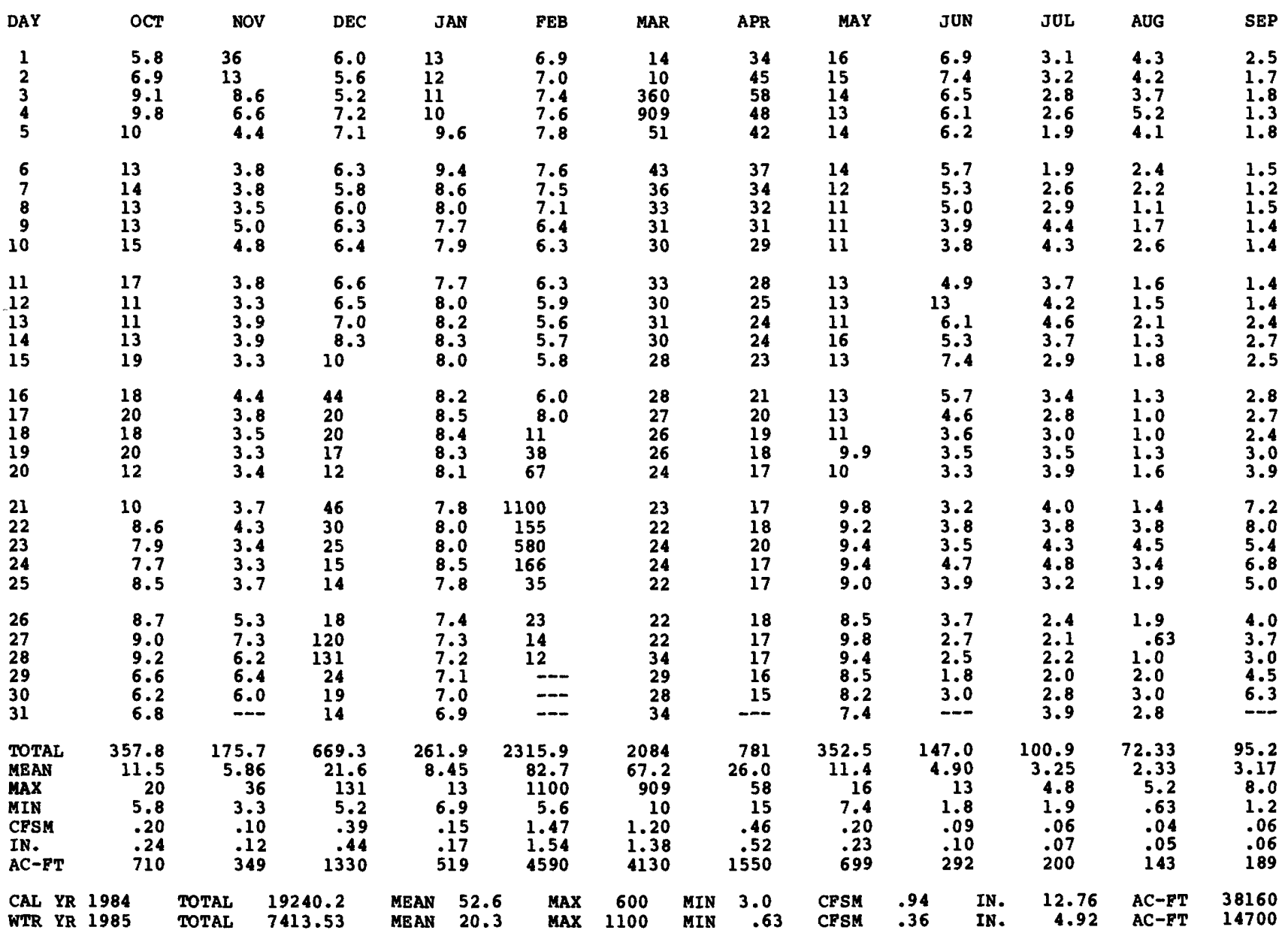


LOCATION,--Lat $41^{\circ} 57^{\prime} 51^{\prime}$, long 92 18'47\%, in NW1/4 NW1/4 sec.36, T.83 N., R.13 W., Tama County, Hydrologic Unit 07080208 , near center of span on downstream side of bridge on 0.5 . Highway 30 , 2.0 mi upstream from tog Run, $3.0 \mathrm{mi}$ south of Elberon, and $9.0 \mathrm{mi}$ upstream from mouth.

DRAINAGE AREA. $--201 \mathrm{mi}^{2}$.

PERIOD OF RECORD.--October 1945 to current year.

REVISED RECORDS.--WSP 1438: Drainage area. WSP 1558: 1946.

GAGE.--Water-stage recorder. Datum of gage is $781.58 \mathrm{ft}$ above NGVD (Iowa Highway Commission bench mark). Prior to Oct. 15, 1945 and June 14, 1947 to Feb. 10, 1949, nonrecording gage on upstream side of bridge at present datum.

REMARRS.--Estimated daily discharges: Dec. 2-6, Dec.13 to Feb. 21, March 5-7 and Aug. 2-19. Records good except those for periods of estimated daily discharges, which are poor. 0. S. Army Corps of Engineers rain-gage telemeter and data collection platform at station.

COOPERATION.-- Pwo discharge measurements provided by o.s. Army Corps of Engineers.

AVERAGE DISCHARGE. - 40 years, $133 \mathrm{ft} / \mathrm{s}, 8.98 \mathrm{in} / \mathrm{yr}^{3}, 96,360$ acre-ft/yr; median of yearly mean discharges, 110 $\mathrm{ft}^{2} / \mathrm{s}, 7.4 \mathrm{in} / \mathrm{yr}, 79,700$ acre-ft/yr.

EXTREMES FOR PERIOD OF RECORD.--Maximum discharge observed, 35,000 ft/s June 13, 1947 , gage height, $17.6 \mathrm{ft}$ from rating curve extended above $17,000 \mathrm{ft} / \mathrm{s}$; maximum gage height, $20.00 \mathrm{ft}$ June 15, 1982; minimum daily dis$0.85 \mathrm{ft}^{3 / \mathrm{s}} \mathrm{Jan} .31,1977$

EXTREMES OOTSIDE PERIOD OF RECORD.--Flood of June 16, 1944, reached a stage of 19.9 ft, from floodmark at downstream side of bridge, discharge, about $30,000 \mathrm{ft}^{3 / \mathrm{s}}$.

EXTREMES FOR CURRENT YEAR.--Peak discharges greater than base of $1,500 \mathrm{ft}^{2} / \mathrm{s}$ and maximum (*):

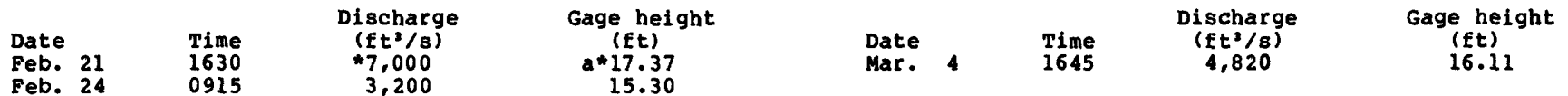

(a) ice jam

Minimum discharge, $6.3 \mathrm{ft}^{3} / \mathrm{s}$ sept. $18-20$.

DISCHARGE, IN CUBIC FEET PER SECOND, MATER YEAR OCTOBER 1984 TO SEPTEMBER 1985 MEAN VALOES

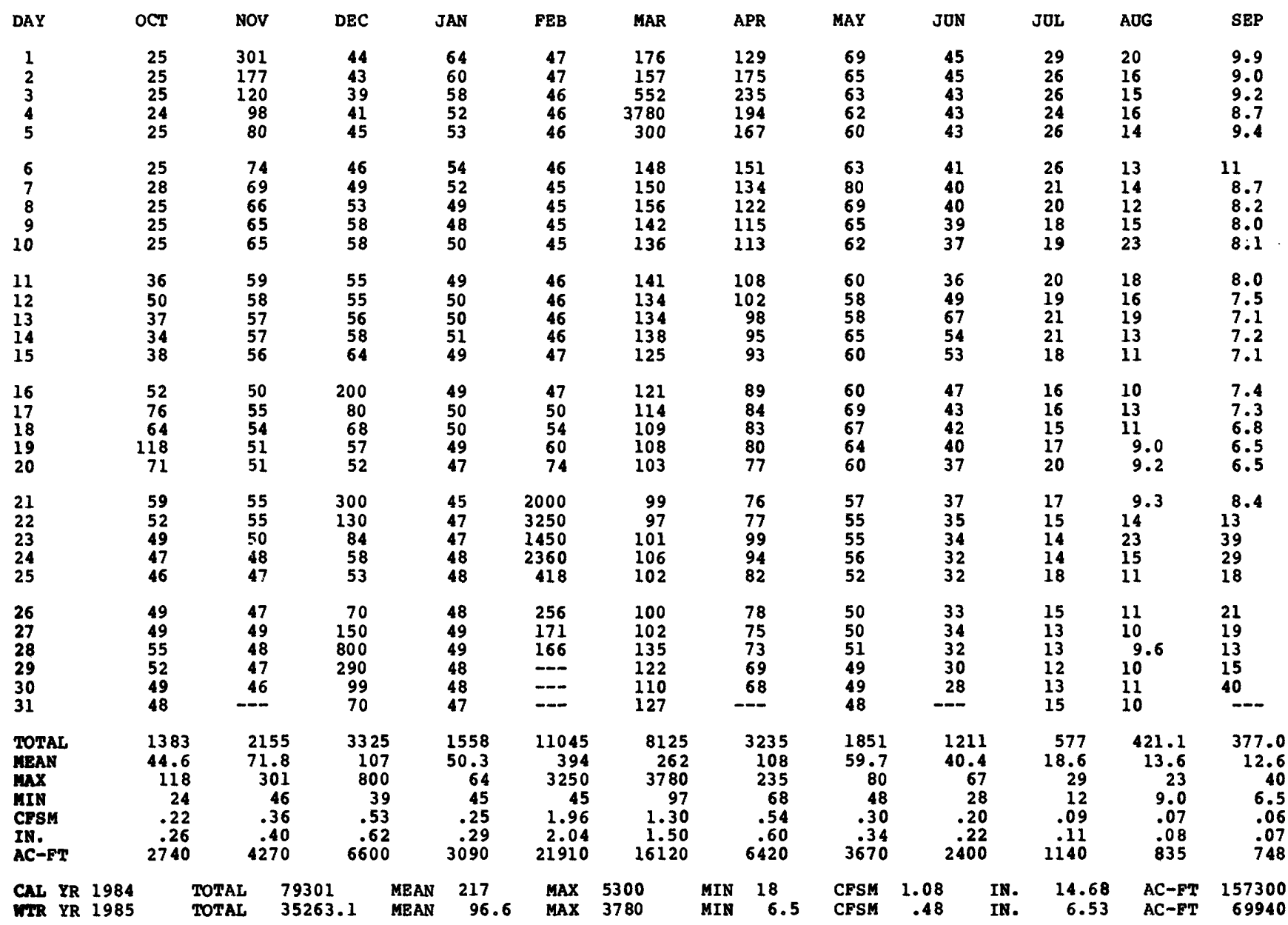


LOCATION.--Lat $41^{\circ} 50^{\prime} 06^{*}$, long $92^{\circ} 23^{\prime} 10^{\circ}$, in SEl/4 SH1/4 sec.8, T.81 N, R.13 w., Poweshiek County, Hydrologic Unit 07080208 , on right bank 5 ft downstream from bridge on county highway v2l, 1.2 mi downstream from North Walnut Creek, $4.0 \mathrm{mi}$ northwest of Hartwick, and $6.5 \mathrm{mi}$ upstream from mouth.

DRAINAGE AREA. $--70.9 \mathrm{mi}^{2}$.

PERIOD OF RECORD.--October 1949 to current year.

REVISED RECORDS.--WSP 1558: 1950 (P), 1951-57.

GAGE.-Water-stage recorder. Datum of gage is $786.59 \mathrm{ft}$ above NGVD.

REMARKS.--Estimated daily discharges: Oct. 16, Nov. 18-19, Dec. 6, 12, 14, 23-26, Jan. 2 to Feb. 23, and Mar. 412. Records are good, except for periods of estimated discharge, which are poor.

COOPERATION.--Two discharge measurements provided by U.s. Army Corps of Engineers.

AVERAGE DISCHARGE. -36 years, $45.0 \mathrm{ft} \% \mathrm{~s}, 8.62 \mathrm{in} / \mathrm{yr}, 32,600 \mathrm{acre}-\mathrm{ft} / \mathrm{yr}$.

EXTREMES FOR PERIOD OF RECORD,--Maximum discharge, 7,100 ft/s July 2 , 1983, gage height, $16.65 \mathrm{ft}$, from rating curve extended above $2,600 \mathrm{ft}^{2} / \mathrm{s}$ on basis of contracted-opening and flow-over-embankment measurement of peak flow; no flow at times for most years.

EXTREMES OOTSIDE PERIOD OF RECORD.--FIood in June 1947 reached a stage of $17.7 \mathrm{ft}$, from information by $10 \mathrm{cal}$ residents, discharge not determined.

EXTREMES FOR CURRENT YEAR.--Peak discharges greater than base of $1,000 \mathrm{ft}^{3} / \mathrm{s}$ and maximum (*):

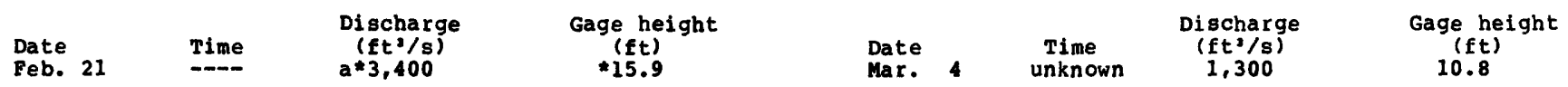

(a) Ice jam, gage height and discharge are estimated.

Minimum discharge, $0.68 \mathrm{ft} / \mathrm{s}$ Sept. 14-15.

DISCHARGE, IN CUBIC FEET PER SECOND, WATER YEAR OCTOBER 1984 TO SEPTEMBER 1985

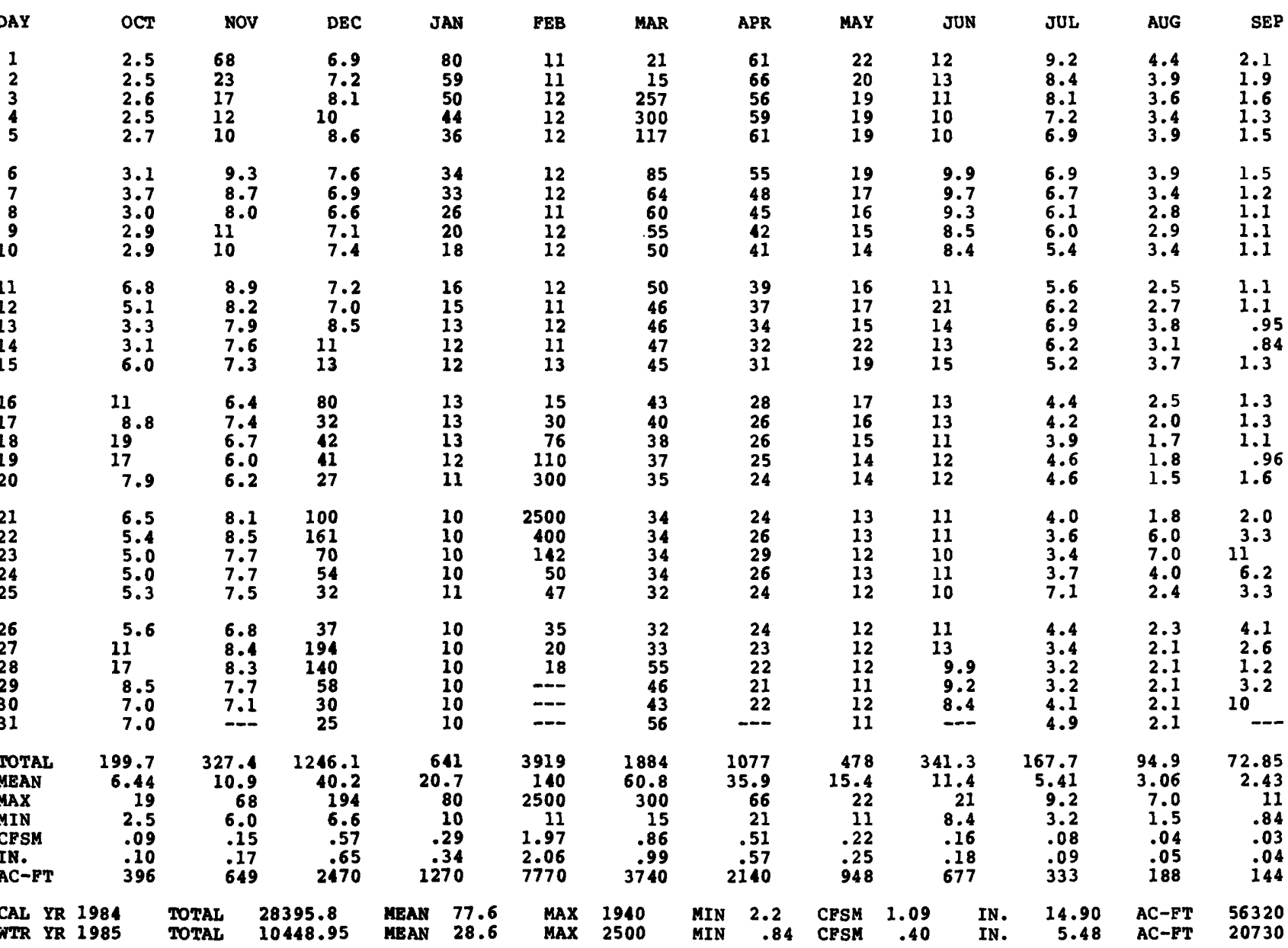


05453000 BIG BEAR CREEX AT LADORA, IA

LOCATION.--Lat $41^{\circ} 44^{\prime} 58^{\prime \prime}$, long $92^{\circ} 10^{\prime} 55^{\prime \prime}$, in sw1/4 sw1/4 sec.7, T.80 H., R.11 W., Iowa County, Bydrologic Onit 07080208 , on left bank $10 \mathrm{ft}$ downstream from bridge on county highway v52, 0.4 mi south of Ladora, $1.2 \mathrm{mi}$ downstream from Coats Creek, $2.8 \mathrm{mi}$ upstream from Little Bear Creek, and 8.1 mi upstream from mouth.

DRAINAGE AREA. $-189 \mathrm{mi}^{2}$.

PERIOD OF RECORD.--October 1945 to current year. Prior to October 1966 , pub1ished as Bear Creek at Ladora.

REVISED RECORDS.--WSP 1308: 1947 (M). WSP 1438: Drainage area.

GAGE.--Water-stage recorder. Datum of gage 18 $744.94 \mathrm{ft}$ above weVD, Oct. 1945 to June 26 , 1946 , non-recording gage and June 27,1946 to sept. 30,1980 , water atage recorder at datum $10.00 \mathrm{ft}$ higher.

REMARKS.--Estimated daily discharges: Nov. 9, Dec. 4-15, 24-26, Jan. 2 to Peb. 19, and Mar. 9-12. Records good except those for Nov. 9 and Mar 9-12, which are fair, and those for per 1ods of ice effect, Dec. 4-15, 24-26, and Jan. 2 to Peb. 19, which are poor. O.S. Army Corps of Engineers data collection plateorm at station.

COOPERATION.--Pour discharge measurements provided by 0.8. Army Corps of Engineers.

AVERAGE DISCHARGE. -40 years, $122 \mathrm{ft}^{2} / 8,8.76 \mathrm{in} / \mathrm{yr}, 88,390 \mathrm{acre}-\mathrm{Et} / \mathrm{yr}$.

EXTREMES FOR PERIOD OP RECORD.--haximum discharge, 10,500 ft\%/8 Mar. 30, 1960, gage helght, 14.60 ft, datum then in use; maximum gage height, $15.32 \mathrm{ft}$, datum then in use, sept. 18,1977 , no Elow for several day in 1956 and 1977.

EXTREMES FOR CURRENT YEAR.--Peak discharges greater than base of $2,000 \mathrm{ft} \% \mathrm{~s}$ and maximum (*),

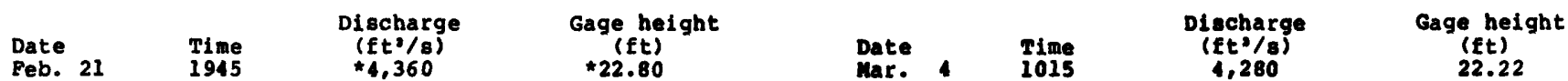

Minimum daily discharge, $2.9 \mathrm{ft} / \mathrm{s}$ sept. 19.

DISCEARGE, IN CUBIC PEET PER SECOND, WATER YEAR OCTOBER 1984 TO BEPFEABER 1985 MEAN VACOES

\begin{tabular}{|c|c|c|c|c|c|c|c|c|c|c|c|c|}
\hline DAY & OCT & NOV & DEC & JAN & FEB & MAR & APR & $\operatorname{Mn} Y$ & JoN & JOL & AOG & SEP \\
\hline $\begin{array}{l}1 \\
2 \\
3 \\
4 \\
5\end{array}$ & $\begin{array}{l}12 \\
12 \\
12 \\
11 \\
11\end{array}$ & $\begin{array}{r}74 \\
110 \\
74 \\
62 \\
51\end{array}$ & $\begin{array}{l}37 \\
38 \\
36 \\
35 \\
35\end{array}$ & $\begin{array}{l}82 \\
78 \\
79 \\
80 \\
79\end{array}$ & $\begin{array}{l}36 \\
37 \\
37 \\
39 \\
40\end{array}$ & $\begin{array}{r}196 \\
187 \\
789 \\
2830 \\
451\end{array}$ & $\begin{array}{l}216 \\
250 \\
266 \\
231 \\
199\end{array}$ & $\begin{array}{l}75 \\
60 \\
55 \\
53 \\
54\end{array}$ & $\begin{array}{l}35 \\
37 \\
37 \\
33 \\
34\end{array}$ & $\begin{array}{l}28 \\
28 \\
25 \\
24 \\
22\end{array}$ & $\begin{array}{l}16 \\
12 \\
10 \\
9.8 \\
9.8\end{array}$ & $\begin{array}{l}7.8 \\
7.1 \\
6.9 \\
5.9 \\
6.4\end{array}$ \\
\hline $\begin{array}{r}6 \\
7 \\
8 \\
9 \\
10\end{array}$ & $\begin{array}{l}13 \\
17 \\
17 \\
17 \\
15\end{array}$ & $\begin{array}{r}47 \\
45 \\
43 \\
158 \\
117\end{array}$ & $\begin{array}{l}36 \\
38 \\
38 \\
38 \\
39\end{array}$ & $\begin{array}{l}78 \\
74 \\
68 \\
60 \\
62\end{array}$ & $\begin{array}{l}41 \\
41 \\
40 \\
41 \\
41\end{array}$ & $\begin{array}{l}278 \\
239 \\
204 \\
187 \\
184\end{array}$ & $\begin{array}{l}175 \\
151 \\
137 \\
129 \\
126\end{array}$ & $\begin{array}{l}61 \\
53 \\
49 \\
49 \\
44\end{array}$ & $\begin{array}{l}33 \\
31 \\
30 \\
27 \\
25\end{array}$ & $\begin{array}{l}21 \\
20 \\
19 \\
19 \\
19\end{array}$ & $\begin{array}{l}9.9 \\
8.8 \\
7.5 \\
6.7 \\
9.3\end{array}$ & $\begin{array}{l}6.8 \\
5.7 \\
5.1 \\
4.8 \\
7.7\end{array}$ \\
\hline $\begin{array}{l}11 \\
12 \\
13 \\
14 \\
15\end{array}$ & $\begin{array}{l}22 \\
28 \\
18 \\
15 \\
28\end{array}$ & $\begin{array}{l}74 \\
61 \\
56 \\
54 \\
48\end{array}$ & $\begin{array}{l}40 \\
48 \\
50 \\
51 \\
52\end{array}$ & $\begin{array}{l}54 \\
49 \\
43 \\
41 \\
35\end{array}$ & $\begin{array}{l}42 \\
42 \\
42 \\
12 \\
41\end{array}$ & $\begin{array}{l}170 \\
146 \\
143 \\
139 \\
125\end{array}$ & $\begin{array}{r}117 \\
109 \\
103 \\
97 \\
93\end{array}$ & $\begin{array}{l}52 \\
68 \\
49 \\
74 \\
71\end{array}$ & $\begin{array}{l}32 \\
60 \\
49 \\
37 \\
57\end{array}$ & $\begin{array}{l}19 \\
19 \\
21 \\
21 \\
20\end{array}$ & $\begin{array}{l}7.1 \\
7.8 \\
9.1 \\
8.1 \\
6.7\end{array}$ & $\begin{array}{l}6.4 \\
6.0 \\
5.1 \\
5.2 \\
7.2\end{array}$ \\
\hline $\begin{array}{l}16 \\
17 \\
18 \\
19 \\
20\end{array}$ & $\begin{array}{r}58 \\
69 \\
56 \\
158 \\
64\end{array}$ & $\begin{array}{l}41 \\
46 \\
46 \\
42 \\
33\end{array}$ & $\begin{array}{r}93 \\
128 \\
98 \\
90 \\
80\end{array}$ & $\begin{array}{l}36 \\
37 \\
38 \\
37 \\
33\end{array}$ & $\begin{array}{r}53 \\
70 \\
120 \\
210 \\
109\end{array}$ & $\begin{array}{r}119 \\
107 \\
101 \\
99 \\
91\end{array}$ & $\begin{array}{l}89 \\
82 \\
80 \\
77 \\
73\end{array}$ & $\begin{array}{l}\mathbf{5 9} \\
57 \\
53 \\
51 \\
55\end{array}$ & $\begin{array}{l}62 \\
45 \\
39 \\
37 \\
36\end{array}$ & $\begin{array}{l}16 \\
15 \\
13 \\
14 \\
15\end{array}$ & $\begin{array}{c}5.9 \\
6.1 \\
10 \\
7.4 \\
6.6\end{array}$ & $\begin{array}{l}5.1 \\
3.6 \\
3.8 \\
2.9 \\
4.1\end{array}$ \\
\hline $\begin{array}{l}21 \\
22 \\
23 \\
24 \\
25\end{array}$ & $\begin{array}{l}49 \\
39 \\
34 \\
31 \\
32\end{array}$ & $\begin{array}{l}40 \\
46 \\
47 \\
42 \\
40\end{array}$ & $\begin{array}{r}135 \\
171 \\
89 \\
82 \\
87\end{array}$ & $\begin{array}{l}33 \\
35 \\
37 \\
39 \\
38\end{array}$ & $\begin{array}{r}3780 \\
1210 \\
983 \\
843 \\
373\end{array}$ & $\begin{array}{l}86 \\
82 \\
84 \\
85 \\
77\end{array}$ & $\begin{array}{l}72 \\
78 \\
91 \\
83 \\
71\end{array}$ & $\begin{array}{l}52 \\
46 \\
44 \\
45 \\
44\end{array}$ & $\begin{array}{l}34 \\
36 \\
32 \\
36 \\
32\end{array}$ & $\begin{array}{l}13 \\
12 \\
11 \\
10 \\
23\end{array}$ & $\begin{array}{l}6.4 \\
13 \\
27 \\
21 \\
13\end{array}$ & $\begin{array}{l}5.7 \\
9.5 \\
33 \\
43 \\
18\end{array}$ \\
\hline $\begin{array}{l}26 \\
27 \\
28 \\
29 \\
30 \\
31\end{array}$ & $\begin{array}{l}34 \\
31 \\
67 \\
52 \\
42 \\
38\end{array}$ & $\begin{array}{r}39 \\
45 \\
45 \\
41 \\
39 \\
-\end{array}$ & $\begin{array}{r}99 \\
186 \\
538 \\
234 \\
156 \\
141\end{array}$ & $\begin{array}{l}37 \\
38 \\
37 \\
37 \\
37 \\
37\end{array}$ & $\begin{array}{l}262 \\
189 \\
185 \\
-\square- \\
--\end{array}$ & $\begin{array}{r}76 \\
79 \\
127 \\
130 \\
109 \\
191\end{array}$ & $\begin{array}{r}68 \\
65 \\
63 \\
60 \\
60 \\
- \\
\end{array}$ & $\begin{array}{l}42 \\
41 \\
42 \\
40 \\
11 \\
37\end{array}$ & $\begin{array}{r}28 \\
47 \\
36 \\
29 \\
27 \\
-\end{array}$ & $\begin{array}{r}18 \\
11 \\
9.3 \\
7.7 \\
8.6 \\
14\end{array}$ & $\begin{array}{l}9.8 \\
8.7 \\
8.2 \\
8.1 \\
8.1 \\
7.8\end{array}$ & $\begin{array}{r}12 \\
12 \\
5.3 \\
6.9 \\
47 \\
-\end{array}$ \\
\hline $\begin{array}{l}\text { TOTAL } \\
\text { MEAN } \\
\text { MAX } \\
\text { MIN } \\
\text { CFSH } \\
\text { IN. } \\
\text { AC-ET }\end{array}$ & $\begin{array}{r}1102 \\
35.5 \\
158 \\
11 \\
.19 \\
.22 \\
2190\end{array}$ & $\begin{array}{r}1709 \\
57.0 \\
158 \\
33 \\
.30 \\
.34 \\
3390\end{array}$ & $\begin{array}{r}3018 \\
97.4 \\
538 \\
35 \\
.52 \\
.59 \\
5990\end{array}$ & $\begin{array}{r}1548 \\
49.9 \\
82 \\
33 \\
.26 \\
.30 \\
3070\end{array}$ & $\begin{array}{r}9289 \\
332 \\
3780 \\
36 \\
1.76 \\
1.83 \\
18420\end{array}$ & $\begin{array}{r}7911 \\
255 \\
2830 \\
76 \\
1.35 \\
1.56 \\
15690\end{array}$ & $\begin{array}{r}3511 \\
117 \\
266 \\
60 \\
.62 \\
.69 \\
6960\end{array}$ & $\begin{array}{r}1616 \\
52.1 \\
75 \\
37 \\
.28 \\
.32 \\
3210\end{array}$ & $\begin{array}{r}1113 \\
37.1 \\
62 \\
25 \\
.20 \\
.22 \\
2210\end{array}$ & $\begin{array}{r}535.6 \\
17.3 \\
28 \\
7.7 \\
.09 \\
.11 \\
1060\end{array}$ & $\begin{array}{r}306.0 \\
9.87 \\
27 \\
5.9 \\
.05 \\
.06 \\
607\end{array}$ & $\begin{array}{r}306.0 \\
10.2 \\
47 \\
2.9 \\
.05 \\
.06 \\
.607\end{array}$ \\
\hline $\begin{array}{ll}\text { CAL } & \text { YR } \\
\text { WTR } & \text { YR }\end{array}$ & & $\begin{array}{l}67 \\
31\end{array}$ & & $\begin{array}{r}183 \\
87.6\end{array}$ & $\begin{array}{l}\operatorname{MAX} \\
\operatorname{MAX}\end{array}$ & $\begin{array}{l}3190 \\
3780\end{array}$ & $\begin{array}{ll}\operatorname{mrn} & 9 \\
\operatorname{Mrn} & 2\end{array}$ & $\begin{array}{l}\text { Cr8M } \\
\text { Cr8M }\end{array}$ & $\begin{array}{l}.97 \\
.46\end{array}$ & $\begin{array}{r}13.19 \\
6.29\end{array}$ & $\begin{array}{l}A C-P T \\
A C-P Y\end{array}$ & $\begin{array}{r}132900 \\
63400\end{array}$ \\
\hline
\end{tabular}


05453100 IOWA RIVER AT MARENGO, IA

LOCATION.-- Lat $41^{\circ} 48^{\prime} 48^{\prime \prime}$ long $92^{\circ} 03^{\prime} 51^{\prime \prime}$, in SEl/4 NEl/4 sec.24, T.81 N., R.11 W., Iowa County, Hydrologic Unit 007080208 , on left bank $5 \mathrm{ft}$ upstream from bridge on State Bighway $411,1.0 \mathrm{mi}$ downstream from Big Bear Creek, $0.8 \mathrm{mi}$ north of Marengo, $4.6 \mathrm{mi}$ upstream from Hilton Creek, and at mile 139.1 .

DRAINAGE AREA. $-\infty 2,794 \mathrm{mi}{ }^{2}$.

PERIOD OR RECORD.--October 1956 to current year. Monthly discharge only for some periods, published in wSP 1728. REVISED RECORDS.--WSP 1558: 1957.

GAGE.--Water-stage recorder. Datum of gage is $720.52 \mathrm{ft}$ above NGVD.

REMARKS.--Estimated daily discharges: Dec. 3-5, 23-24, Dec. 31 to Mar. 6, Aug. 16-21, and sept. 10-30. Records good except for periods of estimated discharge, which are poor.

COOPERATION.--Eight discharge measurements provided by U.S. Army Corps of Engineers.

AVERAGE DISCHARGE. -29 years, $1,827 \mathrm{ft} / \mathrm{s}, 8.88 \mathrm{in} / \mathrm{yr}, 1,324,000 \mathrm{acre}-\mathrm{ft} / \mathrm{yr}$.

EXTREMES FOR PERIOD OF RECORD.--Maximum discharge, 30,800 ft'/s Mar, 31, 1960, gage height, 19.21 ft; maximum gage height, $19.79 \mathrm{ft} J u l y ~ 12,1969$; minimum dally discharge, $24 \mathrm{ft} / \mathrm{s}$ Jan. $29 \mathrm{to}$ Feb. $1,1977$.

EXTREMES FOR CURRENT YEAR.--Peak discharges greater than base of $6,000 \mathrm{ft}^{3} / \mathrm{s}$ and maximum (*):

\begin{tabular}{|c|c|c|c|c|c|c|c|}
\hline $\begin{array}{l}\text { Date } \\
\text { Dec. } 28 \\
\text { Feb. } 21\end{array}$ & $\begin{array}{l}\text { Time } \\
1245 \\
2000\end{array}$ & $\begin{array}{c}\text { Di scharge } \\
\text { (ft } / \mathrm{s}) \\
7,190 \\
\text { ice jam }\end{array}$ & $\begin{array}{c}\text { Gage height } \\
\text { (ft) } \\
14.42 \\
\star 17.62\end{array}$ & $\begin{array}{l}\text { Date } \\
\text { Feb. } 24 \\
\text { Mar. } 4\end{array}$ & $\begin{array}{c}\text { Time } \\
\text { unknown }\end{array}$ & $\begin{array}{c}\text { Discharge } \\
\left(f t^{\prime} / \mathrm{s}\right) \\
7,000 \\
\star 16,200\end{array}$ & $\begin{array}{c}\text { Gage height } \\
\text { (ft) } \\
\text { 1ce jam } \\
17.50\end{array}$ \\
\hline
\end{tabular}

Minimum discharge, $168 \mathrm{ft}^{*} / \mathrm{s}$ Aug. 21 .

DISCHARGE, IN CUBIC FEET PER SECOND, WATER YEAR OCTOBER 1984 TO SEPTEMBER 1985 MEAN VALUES

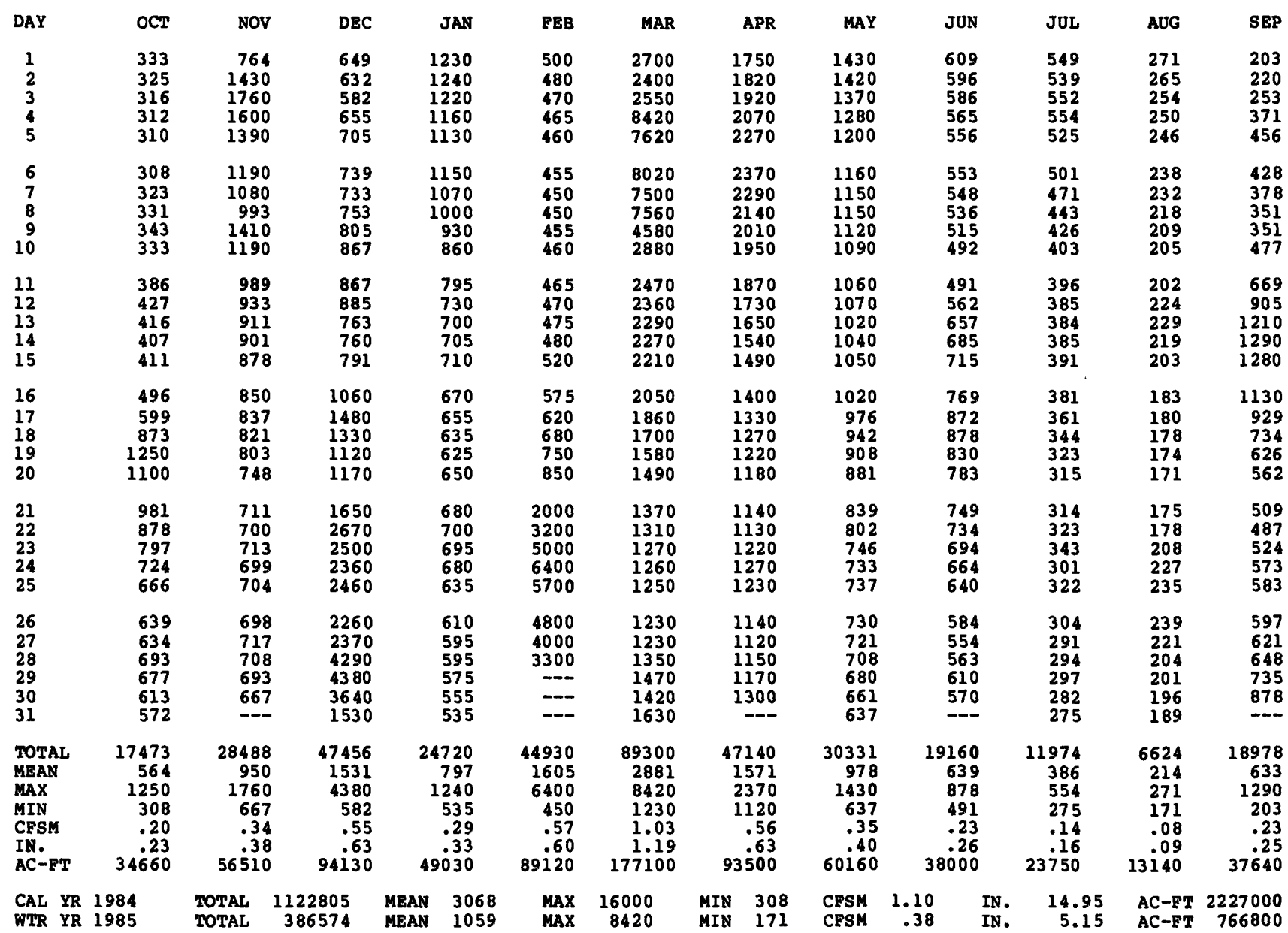


05453510 CORALVILLE LARE NEAR CORALVILLE, IA

LOCATION.--Lat $41^{\circ} 43^{\prime} 29^{\prime \prime}$, long $91^{\circ} 31^{\prime} 40^{\prime \prime}$, in SWl/4 NEl/4 sec.22, T.80 N., R. 6 พ., Johnson County, Hydrologic Unit 07080208 , at outlet works at left end of Coralville Dam on Iowa River, $2.3 \mathrm{mi}$ upstream from Rapid Creek, $4.3 \mathrm{mi}$ northeast of Coralvilie Post office and at mile 83.3 .

DRAINAGE AREA. $--3,115 \mathrm{mi}^{2}$.

PERIOD OF RECORD.--October 1958 to current year.

GAGE.--Water-stage recorder. Datum of gage is at NGVD (levels by U.S. Army Corps of Engineers).

REMARKS.--Reservoir is formed by earthfill dam completed in 1957 . Storage began in September 1958. Releases controlled by three gates, $8.33 \mathrm{ft}$ wide and $20 \mathrm{ft}$ high, into forechamber of $23-\mathrm{ft}$ diameter concrete condult through dam. Inlet invert elevation at $646.0 \mathrm{ft}$. No dead storage. Maximum design discharge through gates is $20,000 \mathrm{ft} / \mathrm{s}$. Ungated spillway is concrete overflow section $500 \mathrm{ft}$ in length at elevation $712 \mathrm{ft}$ above NGVD, contents, 469,000 acre-ft, surface area, 24,800 acres. Reservoir is used for flood control, low-flow augumentation, conservation and recreation. Normal operation will maintain an elevation of $670 \mathrm{ft}$ Feb. 15 to June 15 , surface area, 1,820 acres, $680 \mathrm{ft} J u n e ~ 15$ to sept. 25 , surface area, 4,900 acres, $683 \mathrm{ft}$ Sep. $25 \mathrm{to}$ Dec. 15 , and $680 \mathrm{ft}$ December 15 to Feb. I with a minimum release of $150 \mathrm{ft} / \mathrm{s}$ and maximum release of 10 , $000 \mathrm{ft} / \mathrm{s}$ Dec. 15 to May 1 and $6,000 \mathrm{ft} / \mathrm{s}$ May 1 to Dec. 15 .

COOPERATION.--Records provided by U.S. Army Corps of Engineers.

EXTREMES FOR PERIOD OF RECORD.--Maximum contents, 472,000 acre-ft July 21, 1969, elevation, 711.85 ft; minimum daily contents, 456 acre-ft Jan. 15, 1975; minimum elevation, 658.77 ft Mar. 10, 1959 .

EXTREMES FOR CURRENT YEAR.--Maximum daily contents, 62,500 acre-ft Feb. 28; maximum elevation, 692.26 ft Feb. 28; minimum daily contents, 9,540 acre-ft Apr. 28; minimum elevation, 675.05 ft Apr.29.

Capacity table (elevation, in feet, and contents, in acre-ft)

$\begin{array}{rrrrrr}655 & 5,000 & 683 & 55,000 & 700 & 232,000 \\ 670 & 10,600 & 685 & 69,000 & 705 & 327,000 \\ 675 & 21,000 & 690 & 108,000 & 710 & 427,000 \\ 680 & 40,300 & 695 & 162,000 & 712 & 469,000\end{array}$

RESERVOIR STORAGE (AC-ET), WATER YEAR OCTOBER 1984 TO SEPTEMBER 1985 INSTANTANEOUS OBSERVATIONS AT 2400

\begin{tabular}{|c|c|c|c|c|c|c|c|c|c|c|c|c|}
\hline DAY & OCT & NOV & DEC & JAN & FEB & MAR & APR & MAY & JUN & JUL & AUG & SEP \\
\hline $\begin{array}{l}1 \\
2 \\
3 \\
4 \\
5\end{array}$ & $\begin{array}{l}29700 \\
29700 \\
29700 \\
29600 \\
29500\end{array}$ & $\begin{array}{l}31100 \\
30800 \\
31000 \\
31100 \\
30900\end{array}$ & $\begin{array}{l}27300 \\
27600 \\
27500 \\
27400 \\
27200\end{array}$ & $\begin{array}{l}18000 \\
16700 \\
17200 \\
17800 \\
18600\end{array}$ & $\begin{array}{l}19400 \\
19400 \\
19100 \\
19200 \\
19300\end{array}$ & $\begin{array}{l}57300 \\
50300 \\
44700 \\
46700 \\
49200\end{array}$ & $\begin{array}{l}11000 \\
10700 \\
11000 \\
11200 \\
10900\end{array}$ & $\begin{array}{r}9940 \\
11000 \\
11600 \\
11000 \\
10000\end{array}$ & $\begin{array}{l}18200 \\
18300 \\
18200 \\
18200 \\
1.8100\end{array}$ & $\begin{array}{l}17900 \\
17800 \\
17800 \\
18000 \\
18000\end{array}$ & $\begin{array}{l}18300 \\
18300 \\
18300 \\
18300 \\
18400\end{array}$ & $\begin{array}{l}19100 \\
19000 \\
19000 \\
19000 \\
19100\end{array}$ \\
\hline $\begin{array}{r}6 \\
7 \\
8 \\
9 \\
10\end{array}$ & $\begin{array}{l}29500 \\
29500 \\
29500 \\
29500 \\
29400\end{array}$ & $\begin{array}{l}30200 \\
29700 \\
29300 \\
29900 \\
30100\end{array}$ & $\begin{array}{l}26800 \\
26700 \\
26700 \\
26400 \\
25800\end{array}$ & $\begin{array}{l}19700 \\
20500 \\
20600 \\
20200 \\
20000\end{array}$ & $\begin{array}{l}19400 \\
19400 \\
19600 \\
19700 \\
19800\end{array}$ & $\begin{array}{l}51300 \\
51600 \\
50100 \\
48000 \\
44600\end{array}$ & $\begin{array}{l}10500 \\
10400 \\
10400 \\
10400 \\
10400\end{array}$ & $\begin{array}{r}9860 \\
9940 \\
10300 \\
11100 \\
11800\end{array}$ & $\begin{array}{l}18000 \\
18000 \\
18000 \\
17800 \\
17800\end{array}$ & $\begin{array}{l}18100 \\
18100 \\
18000 \\
18200 \\
18100\end{array}$ & $\begin{array}{l}18400 \\
18400 \\
18400 \\
18500 \\
18700\end{array}$ & $\begin{array}{l}19300 \\
19600 \\
19900 \\
20000 \\
20200\end{array}$ \\
\hline $\begin{array}{l}11 \\
12 \\
13 \\
14 \\
15\end{array}$ & $\begin{array}{l}29800 \\
29800 \\
29700 \\
29700 \\
29900\end{array}$ & $\begin{array}{l}29200 \\
27700 \\
27100 \\
27000 \\
26900\end{array}$ & $\begin{array}{l}25300 \\
24400 \\
23400 \\
22600 \\
21700\end{array}$ & $\begin{array}{l}19700 \\
19200 \\
19100 \\
19200 \\
19500\end{array}$ & $\begin{array}{l}19700 \\
19500 \\
19400 \\
19000 \\
18500\end{array}$ & $\begin{array}{l}38400 \\
30900 \\
25800 \\
22000 \\
18900\end{array}$ & $\begin{array}{l}10500 \\
10500 \\
10300 \\
10200 \\
10100\end{array}$ & $\begin{array}{l}12600 \\
13300 \\
14000 \\
14600 \\
15300\end{array}$ & $\begin{array}{l}17800 \\
17900 \\
18000 \\
18100 \\
18200\end{array}$ & $\begin{array}{l}18200 \\
18200 \\
18300 \\
18500 \\
18400\end{array}$ & $\begin{array}{l}18700 \\
18800 \\
18900 \\
19000 \\
18900\end{array}$ & $\begin{array}{l}20400 \\
20800 \\
21700 \\
22600 \\
23500\end{array}$ \\
\hline $\begin{array}{l}16 \\
17 \\
18 \\
19 \\
20\end{array}$ & $\begin{array}{l}30100 \\
30000 \\
31700 \\
32900 \\
32500\end{array}$ & $\begin{array}{l}26900 \\
27100 \\
27300 \\
27600 \\
27800\end{array}$ & $\begin{array}{l}21300 \\
21100 \\
20800 \\
20300 \\
19800\end{array}$ & $\begin{array}{l}19500 \\
19400 \\
19400 \\
19800 \\
19700\end{array}$ & $\begin{array}{l}18000 \\
17500 \\
17000 \\
16600 \\
16600\end{array}$ & $\begin{array}{l}16900 \\
15300 \\
13900 \\
12800 \\
11600\end{array}$ & $\begin{array}{r}9910 \\
10100 \\
10300 \\
10100 \\
10000\end{array}$ & $\begin{array}{l}16000 \\
16400 \\
16600 \\
16800 \\
16900\end{array}$ & $\begin{array}{l}18200 \\
18200 \\
18300 \\
18400 \\
18400\end{array}$ & $\begin{array}{l}18200 \\
18100 \\
18000 \\
18000 \\
17800\end{array}$ & $\begin{array}{l}18900 \\
18900 \\
19000 \\
18900 \\
18800\end{array}$ & $\begin{array}{l}23900 \\
24300 \\
24500 \\
24500 \\
24700\end{array}$ \\
\hline $\begin{array}{l}21 \\
22 \\
23 \\
24 \\
25\end{array}$ & $\begin{array}{l}31600 \\
30500 \\
29900 \\
29800 \\
30000\end{array}$ & $\begin{array}{l}27700 \\
27600 \\
27500 \\
27400 \\
27100\end{array}$ & $\begin{array}{l}20000 \\
20100 \\
20400 \\
19900 \\
18900\end{array}$ & $\begin{array}{l}19500 \\
19400 \\
19400 \\
19200 \\
19100\end{array}$ & $\begin{array}{l}18200 \\
21800 \\
27300 \\
38200 \\
49100\end{array}$ & $\begin{array}{l}11200 \\
10900 \\
10900 \\
10300 \\
10200\end{array}$ & $\begin{array}{r}10000 \\
10000 \\
10000 \\
10000 \\
9990\end{array}$ & $\begin{array}{l}17100 \\
17400 \\
17600 \\
17800 \\
17800\end{array}$ & $\begin{array}{l}18400 \\
18500 \\
18600 \\
18400 \\
18300\end{array}$ & $\begin{array}{l}17700 \\
17700 \\
17700 \\
17700 \\
17900\end{array}$ & $\begin{array}{l}18700 \\
18800 \\
18800 \\
18800 \\
19000\end{array}$ & $\begin{array}{l}25000 \\
25200 \\
25200 \\
25200 \\
25200\end{array}$ \\
\hline $\begin{array}{l}26 \\
27 \\
28 \\
29 \\
30 \\
31\end{array}$ & $\begin{array}{l}29800 \\
30200 \\
29900 \\
29600 \\
29100 \\
31100\end{array}$ & $\begin{array}{c}27400 \\
27900 \\
27800 \\
27700 \\
27600 \\
---\end{array}$ & $\begin{array}{l}18600 \\
19200 \\
20200 \\
22200 \\
22200 \\
20800\end{array}$ & $\begin{array}{l}19200 \\
19400 \\
19500 \\
19700 \\
19600 \\
19500\end{array}$ & $\begin{array}{r}59400 \\
62200 \\
62500 \\
- \\
-\end{array}$ & $\begin{array}{l}10400 \\
10500 \\
10300 \\
10200 \\
10200 \\
10900\end{array}$ & $\begin{array}{l}9810 \\
9670 \\
9540 \\
9660 \\
9850 \\
---\end{array}$ & $\begin{array}{l}18100 \\
18000 \\
18000 \\
18000 \\
18200 \\
18200\end{array}$ & $\begin{array}{c}18200 \\
18200 \\
18100 \\
18000 \\
18000 \\
-\cdots\end{array}$ & $\begin{array}{l}17900 \\
18000 \\
18000 \\
18000 \\
18200 \\
18300\end{array}$ & $\begin{array}{l}19000 \\
19000 \\
19000 \\
19100 \\
19100 \\
19100\end{array}$ & $\begin{array}{r}25200 \\
25200 \\
25200 \\
25400 \\
25400 \\
\end{array}$ \\
\hline $\begin{array}{l}\text { MEAN } \\
\text { MAX } \\
\text { MIN }\end{array}$ & $\begin{array}{l}30100 \\
32900 \\
29100\end{array}$ & $\begin{array}{l}28500 \\
31100 \\
26900\end{array}$ & $\begin{array}{l}23000 \\
27600 \\
18600\end{array}$ & $\begin{array}{l}19300 \\
20600 \\
16700\end{array}$ & $\begin{array}{l}25500 \\
62500 \\
16600\end{array}$ & $\begin{array}{l}26300 \\
57300 \\
10200\end{array}$ & $\begin{array}{r}10200 \\
11200 \\
9540\end{array}$ & $\begin{array}{r}14700 \\
18200 \\
9860\end{array}$ & $\begin{array}{l}18200 \\
18600 \\
17800\end{array}$ & $\begin{array}{l}18000 \\
18500 \\
17700\end{array}$ & $\begin{array}{l}18700 \\
19100 \\
18300\end{array}$ & $\begin{array}{l}22600 \\
25400 \\
19000\end{array}$ \\
\hline
\end{tabular}

$\begin{array}{lllllll}\text { CAL YR } 1984 & \text { MEAN } & 115000 & \text { MAX } & 464000 & \text { MIN } & 18600\end{array}$ 
LOCATION, --Lat $41^{\circ} 41^{\prime} 19^{\prime \prime}$, long $91^{\circ} 29^{\prime} 15^{\prime \prime}$, in NEl/4 NEl/4 sec.36. T.80 N. R. 6 W. Johnson County, Hydrologic Unit 07080209 , on left bank $80 \mathrm{ft}$ upstream from bridge on state Bighway 1 , $3.5 \mathrm{mi}$ northeast of Iowa $\mathrm{City,} \mathrm{and} 4.7 \mathrm{mi}$ upstream from mouth.

DRAINAGE AREA. $--25.3 \mathrm{mi}^{2}$.

PERIOD OF RECORD.--October 1937 to current year. Monthly discharge only for some periods, published in wSP 1308 .

REVISED RECORDS.--WSP 1558: 1941 (M), 1943 (P), 1944 (M), 1946. WSP 1708: 1951 (P), 1952. WDR IOWA 1967: Drainage area.

GAGE.--Water-stage recorder and concrete control with sharp-crested weir. Datum of gage is 673.72 ft above NGVD.

REMARKS.--Estimated daily discharges: Nov.21, Dec. 2-8, 18-20, 23-25, Dec. 31 to Feb. 21 . Records good except for estimated discharge, which are poor.

AVERAGE DISCHARGE. -48 year, $15.9 \mathrm{ft} / 8,8.53 \mathrm{in} / \mathrm{yr}^{3}, 11,520 \mathrm{acre}-\mathrm{ft} / \mathrm{yr}$.

EXTREMES FOR PERIOD OF RECORD.--Maximum discharge, 6,100 ft2/s May 23, 1965, gage height, $14.10 \mathrm{ft}$, from contracted-opening measurement of peak flow, maximum gage height, 14.93 ft July 17 , ig72; no flow at times most years.

EXTREMES FOR CURRENT YEAR.--Peak discharges greater than base discharge of $600 \mathrm{ft} / \mathrm{s}$ and maximum ( $*$ ):

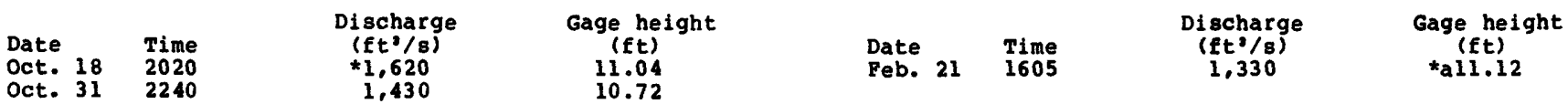

(a) Ice jam

No flow Aug. 21, Sept. 7-21.

DISCHARgE, IN CUBIC FEET PER SECOND, WATER YEAR OCTOBER 1984 TO SEPTEYBER 1985 MEAN VALUES

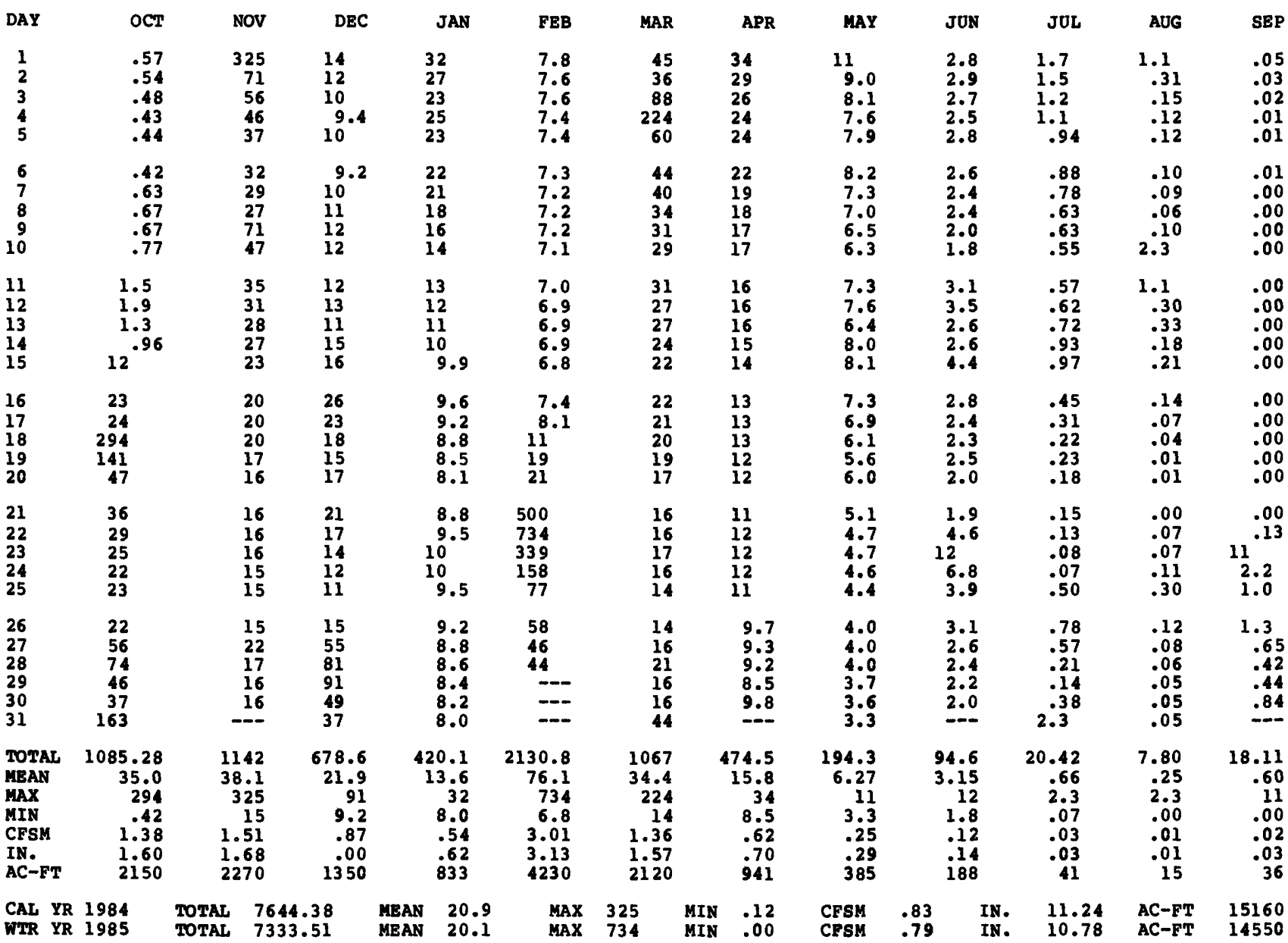


LOCATION.--Lat $41^{\circ} 40^{\prime} 36^{\prime \prime}$, long $91^{\circ} 35^{\prime} 55^{\prime \prime}$, in NEl/4 sEl/4 sec.1, T.79 N., R. 7 w. Johnson County, Bydrologic Unit 07080209 , on left bank about $50 \mathrm{ft}$ upstream from bridge on county highway, 1.1 mi west of post office in Coralvilie, $1.5 \mathrm{mi}$ downstream from Deer Creek and $2.7 \mathrm{mi}$ upstream from mouth.

DRAINAGE AREA. $--98.1 \mathrm{mi}^{2}$.

PERIOD OF RECORD.--October 1952 to current year. Monthly discharge only for some periods, published in wSP 1728.

GAGE.--Water-stage recorder. Datum of gage is $647.48 \mathrm{ft}$ above NGVD (levels by 0.5 . Army Corps of Engineers). Prior to Jan. 7, 1957, nonrecording gage at same site and datum.

REMARKS.--Estimated daily discharge: Dec. 4-7, 12,17-26, Dec. 31 to Feb. 21 . Records good except for periods of estimated discharge, which are fair. U.S. Army Corps of Engineers operate a Data Coliection platform at gage.

COOPERATION.--Three discharge measurements provided by U.S. Army Corps of Engineers.

AVERAGE DISCHARGE. - -33 years, $66.3 \mathrm{ft}^{3} / \mathrm{s}, 9.18$ in/yr, 48,030 acre-ft/yr; median of yearly mean discharges, $52 \mathrm{ft} / \mathrm{s} 7.2 \mathrm{in} / \mathrm{yr}, 37,700$ acre-ft/yr.

EXTREMES FOR PERIOD OF RECORD.--Maximum discharge, 13,000 ft's June 15, 1982, gage height, 14.61 ft; no flow Jan. 18 to Eeb. 4, 1977.

EXTREMES FOR CURRENT YEAR.--Peak discharges greater than base discharge of $1000 \mathrm{ft} / \mathrm{s}$ and maximum (*):

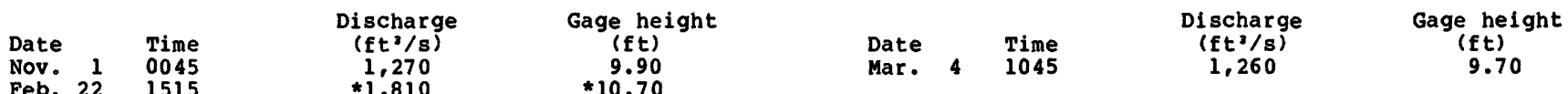

Minimum daily discharge, $2.4 \mathrm{ft}^{3 / \mathrm{s}}$ sept. $8,13-17$.

DISCHARGE, IN CUBIC FEET PER SECOND, WATER YEAR OCTOBER 1984 TO SEPTEMBER 1985 MEAN VALUES

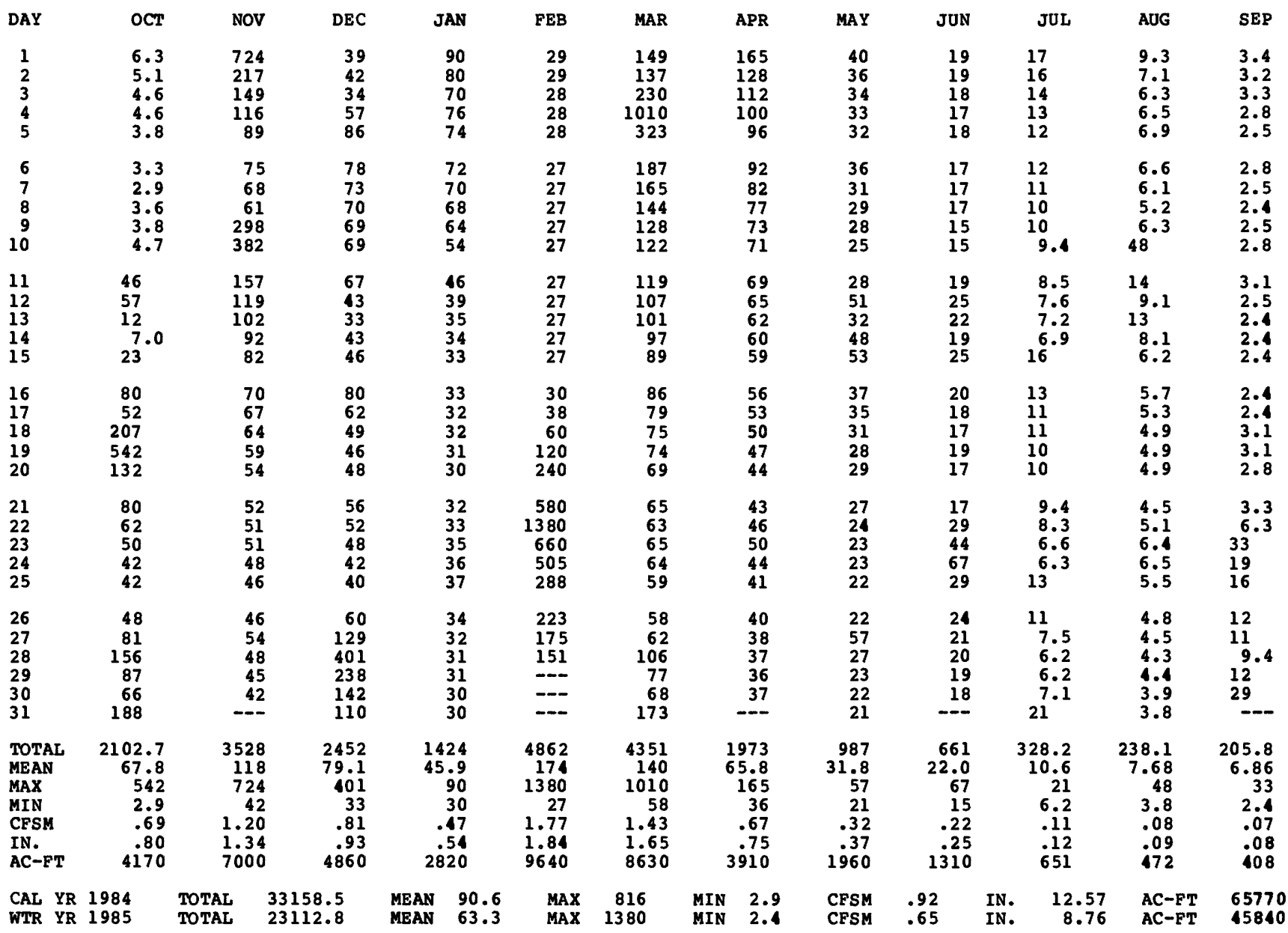




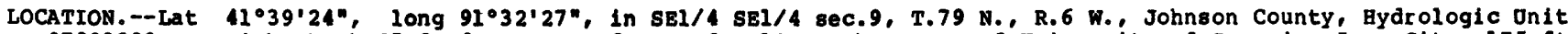
07080209 , on right bank $25 \mathrm{ft}$ downstream from Hydraulics Laboratory of University of Iowa in Iowa City. 175 ft downstream from University Dam, $0.8 \mathrm{mi}$ upstream from Ralston Creek, $3.6 \mathrm{mi}$ downstream from Clear Creek, and at mile 74.2 .

DRAINAGE AREA. $--3,271 \mathrm{mi}^{2}$.

\section{MATER-DISCHARGE RECORDS}

PERIOD OF RECORD.--June 1903 to current year. Wonthly discharge only for some periods, published in wSP 1308.

GAGE.--Water-stage recorder. Datum of gage is $29.00 \mathrm{ft}$ above Iowa City datum, and $617.27 \mathrm{ft}$ above NGVD. Oct. 1 , 1934 to Sept. 30,1972 , at datum 10.00 ft higher. See wSP 1708 for history of changes prior to oct. 1 , 1984.

REMARKS.--Estimated daily discharges: Jan. 20 to Feb. 13, 15-17. Records excellent except for periods of estimated daily discharge, which are fair. slight fluctuation at low stages caused by powerplant above station. Flow regulated by Coralvilie lake (station 05453510) 9.1 mi upstream, since sept. 17, 1958. 0.s. Army Corps of Engineers Data Collection platform at station.

COOPERATION.--Four discharge measurements provided by U.s. Army Corps of Engineers.

AVERAGE DISCHARGE. --82 years, $1,714 \mathrm{ft} / \mathrm{s}, 7.12 \mathrm{in} / \mathrm{yr}, 1,242,000$ acre-ft/yr; median of yearly mean discharges, $1,460 \mathrm{ft} / \mathrm{s}, 6.1 \mathrm{in} / \mathrm{yr}, 1,060,000$ acre-ft/yr.

EXTREMES FOR PERIOD OF RECORD,--Haximum discharge, $42,500 \mathrm{ft} / 8$ June 8 , 1918, gage height, 19.6 ft from graph based on gage readings, site and datum then in use, minimum daily, 29 ft/8 0ct. 21, 22 , 1916 , regulated.

EXTREKES OUTSIDE PERIOD OF RECORD.--Plood of July 17, 1881, reached a stage of 21.1 ft, from floodmarks at site and datum in use 1913-21, from information by local resident, discharge, 51,000 ft'/8. Maximum 8tage known since at least 1850 , about 3 ft higher than that of July 17,1881 , occurred in June 1851 , discharge, 70,000 $\mathrm{ft}^{3 / 8}$, estimated.

EXTREMES FOR CURRENT YEAR.--Waximum discharge, 10,500 ft"/s March 4, gage height, $21.50 \mathrm{ft}$; minimum discharge, $149 \mathrm{ft} / \mathrm{s}$ sept. 13 and 15 .

DISCHARGE, IN CUBIC PEET PER SECOND, MATER YEAR OCTOBER 1984 TO SEPTEMBER 1985

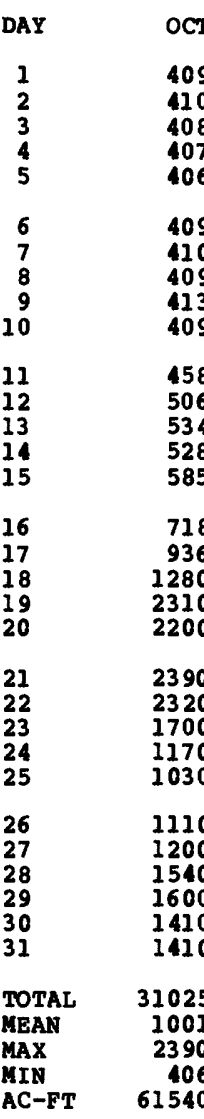

CAL YR 1984 WTR YR 1985

\begin{tabular}{|c|c|c|}
\hline Nov & DEC & JAN \\
\hline $\begin{array}{l}3060 \\
2190 \\
2200 \\
2100 \\
2150\end{array}$ & $\begin{array}{r}1090 \\
938 \\
838 \\
819 \\
836\end{array}$ & $\begin{array}{r}1150 \\
2920 \\
615 \\
597 \\
590\end{array}$ \\
\hline $\begin{array}{l}1990 \\
1820 \\
1800 \\
1950 \\
2250\end{array}$ & $\begin{array}{r}819 \\
701 \\
603 \\
936 \\
1390\end{array}$ & $\begin{array}{r}586 \\
863 \\
1570 \\
1880 \\
1790\end{array}$ \\
\hline $\begin{array}{l}2630 \\
2880 \\
2150 \\
1480 \\
1450\end{array}$ & $\begin{array}{l}1660 \\
1740 \\
1730 \\
1750 \\
1740\end{array}$ & $\begin{array}{r}1630 \\
1640 \\
1460 \\
1140 \\
936\end{array}$ \\
\hline $\begin{array}{r}1300 \\
1070 \\
951 \\
937 \\
988\end{array}$ & $\begin{array}{l}1790 \\
1760 \\
1720 \\
1720 \\
1560\end{array}$ & $\begin{array}{r}1060 \\
1180 \\
1060 \\
836 \\
960\end{array}$ \\
\hline $\begin{array}{l}1130 \\
1220 \\
1210 \\
1190 \\
1180\end{array}$ & $\begin{array}{l}1260 \\
1240 \\
1430 \\
1710 \\
2120\end{array}$ & $\begin{array}{l}940 \\
845 \\
855 \\
880 \\
900\end{array}$ \\
\hline $\begin{array}{r}1000 \\
842 \\
1010 \\
1190 \\
1170 \\
-0\end{array}$ & $\begin{array}{r}1510 \\
710 \\
1990 \\
3310 \\
4320 \\
4860\end{array}$ & $\begin{array}{l}720 \\
660 \\
640 \\
640 \\
700 \\
760\end{array}$ \\
\hline $\begin{array}{r}48488 \\
1616 \\
3060 \\
842 \\
96180\end{array}$ & $\begin{array}{r}50600 \\
1632 \\
4860 \\
603 \\
100400\end{array}$ & $\begin{array}{r}36003 \\
1161 \\
4150 \\
586 \\
71410\end{array}$ \\
\hline
\end{tabular}

$\begin{array}{ll}\text { FEB } & \\ 740 & 89 \\ 660 & 89 \\ 560 & 89 \\ 475 & 86 \\ 450 & 49 \\ 440 & 62 \\ 440 & 73 \\ 440 & 88 \\ 450 & 92 \\ 480 & 91\end{array}$

$450 \quad 9240$

480

614

640

680

775

960

970
990

983
1090

1420

3170

4710
4070

4070
3870

3040

2760

5980
8080

10

$-$

49937
1783

1783
8080

440

99050

3436

TOTAL 1257726

MEA

MAX VALUES

$\begin{array}{rrrrrrr}\text { MAR } & \text { APR } & \text { MAY } & \text { JUN } & \text { JUL } & \text { AUG } & \text { SEP } \\ 8930 & 2580 & 1500 & 671 & 630 & 240 & 199 \\ 8900 & 2840 & 1490 & 670 & 628 & 231 & 197 \\ 8900 & 2380 & 1540 & 660 & 538 & 232 & 196 \\ 8660 & 2150 & 1590 & 660 & 452 & 231 & 203 \\ 4920 & 2700 & 1600 & 662 & 452 & 217 & 208 \\ 6210 & 2980 & 1590 & 661 & 455 & 198 & 207 \\ 7380 & 2800 & 1400 & 659 & 452 & 205 & 193 \\ 8810 & 2610 & 1070 & 613 & 453 & 204 & 189 \\ 9240 & 2610 & 668 & 558 & 414 & 220 & 189 \\ 9170 & 2410 & 669 & 565 & 371 & 304 & 179 \\ 9040 & 2230 & 695 & 575 & 380 & 227 & 153 \\ 8780 & 2230 & 721 & 589 & 375 & 213 & 150 \\ 7830 & 2220 & 701 & 577 & 374 & 231 & 149 \\ 6160 & 2020 & 737 & 573 & 423 & 232 & 150 \\ 5780 & 1840 & 749 & 694 & 456 & 237 & 149 \\ & & & & & & \\ 4520 & 1840 & 727 & 796 & 462 & 250 & 376 \\ 3770 & 1630 & 801 & 784 & 366 & 253 & 659 \\ 3390 & 1450 & 970 & 783 & 369 & 220 & 679 \\ 3020 & 1560 & 963 & 786 & 368 & 213 & 599 \\ 2740 & 1580 & 966 & 785 & 366 & 203 & 478 \\ 2200 & 1440 & 782 & 793 & 364 & 203 & 435 \\ 1870 & 1460 & 617 & 819 & 305 & 212 & \mathbf{1 5 0} \\ 1870 & 1450 & 616 & 868 & 244 & 208 & 731 \\ 1860 & 1440 & 792 & 866 & 278 & 210 & 724 \\ 1680 & 1430 & 803 & 812 & 304 & 204 & 685 \\ 1510 & 1420 & 631 & 726 & 237 & 201 & 663 \\ 1610 & 1420 & 827 & 641 & 228 & 201 & 650 \\ 2060 & 1420 & 866 & 637 & 229 & 200 & 639 \\ 2090 & 1300 & 689 & 637 & 229 & 201 & 655 \\ 1850 & 1280 & 685 & 634 & 247 & 196 & 778 \\ 2180 & -0 & 677 & -50 & 254 & 200 & -5 \\ 56930 & 58720 & 29132 & 20754 & 11703 & 6797 & 11912 \\ 5062 & 1957 & 940 & 692 & 378 & 219 & 397 \\ 9240 & 2980 & 1600 & 868 & 630 & 304 & 778 \\ 1510 & 1280 & 616 & 558 & 228 & 196 & 149 \\ 1300 & 116500 & 57780 & 41170 & 23210 & 13480 & 23630\end{array}$

9390

MIN

377

AC-FT 2495000

AC-FT 1016000 
LOCATION.--Samples collected at Benton street bridge at Iowa City, 0.5 mi downstream from gaging station. PERIOD OF RECORD.--September 1906 to September 1907 , water years 1944 to current year.

PERIOD OF DAILY RECORD.--

CHEMICAL ANALYSIS: September 1906 to September 1907 , October 1943 to september 1954.

SPECIFIC CONDUCTANCE: October 1968 to current year.

WATER TEMPERATURES: January 1944 to current year.

SUSPENDED-SEDIMENT DISCHARGE: October 1943 to current year.

REMARKS.--Records of specific conductance are obtained from suspended-sediment samples at times of analysis. During periods of partial ice cover, sediment samples are collected in open water channel.

EXTREMES FOR PERIOD OF DAILY RECORD. -

SPECIFIC CONDUCTANCE: Maximum daily, 760 microsiemens Jan. 4, 1984; minimum daily, 150 microsiemens May 17, 1974.

WATER TEuPERATURES: Maximum daily, 32.0 July 19, 1957, Aug. 24, 25, 1959, June 27, 1971; minimum daily, $0.0^{\circ} \mathrm{C}$ on many days during winter period.

SEDIMENT CONCENTRATIONS: Maximum daily mean, 7,800 mg/L June 13, 1953, minimum daily mean, 1 mg/L Feb. 4, 1979 , Jan. 14, 15, 29, 1984.

SEDIMENT LOADS: Maximum daily, 177,000 tons May 23, 1944, minimum daily, 0.82 ton Jan. $21,22,1977$.

EXTREMES FOR CURRENT YEAR.--

SPECIFIC CONDUCTANCE: Maximum daily, 660 microsiemens Feb. 19; minimum daily, 250 microsiemens Feb. 28. WATER TEMPERATURES: Maximum daily, $28.0^{\circ} \mathrm{C}$ Sep. 19 ; minimum daily, $0.0^{\circ} \mathrm{C}$ on many days during winter period. SEDIMENT CONCENTRATIONS: Maximum daily mean, 1,400 mg/L Dec. 29; minimum daily mean, $4 \mathrm{mg} / \mathrm{L}$ Feb. 15 . SEDIMENT LOADS: Maximum daily, 25,000 tons Mar. 4, minimum daily, 8.3 tons Feb. 8.

SPECIFIC CONDUCTANCE, LABORATORY (MICROSIEMENS/CK DEG. C), WATER YEAR OCTOBER 1984 TO SEPTEMBER 1985 RANDOM VALUES

\begin{tabular}{|c|c|c|c|c|c|c|c|c|c|c|c|c|}
\hline DAY & $O C T$ & Nov & DEC & JAN & FEB & MAR & APR & MAY & JUN & JUL & AUG & SEP \\
\hline $\begin{array}{l}1 \\
2 \\
3 \\
4 \\
5\end{array}$ & $\begin{array}{l}480 \\
490 \\
540 \\
500 \\
480\end{array}$ & $\begin{array}{l}295 \\
420 \\
-2 \\
-245\end{array}$ & $\begin{array}{l}-\infty \\
-\infty \\
-\infty \\
-\infty\end{array}$ & $\begin{array}{l}-- \\
440 \\
460 \\
-\end{array}$ & $\begin{array}{l}630 \\
630 \\
-630 \\
600\end{array}$ & $\begin{array}{l}--- \\
--- \\
270 \\
290\end{array}$ & $\begin{array}{l}--- \\
--- \\
530 \\
540 \\
535\end{array}$ & $\begin{array}{l}560 \\
560 \\
-- \\
-\infty \\
--\end{array}$ & $\begin{array}{l}--\infty \\
--\infty \\
560 \\
560 \\
560\end{array}$ & $\begin{array}{l}470 \\
480 \\
--- \\
--\end{array}$ & $\begin{array}{r}480 \\
500 \\
--- \\
475\end{array}$ & $\begin{array}{l}--- \\
--- \\
470 \\
480 \\
480\end{array}$ \\
\hline $\begin{array}{r}6 \\
7 \\
8 \\
9 \\
10\end{array}$ & $\begin{array}{l}480 \\
480 \\
480 \\
480\end{array}$ & $\begin{array}{l}460 \\
450 \\
480 \\
500 \\
-\cdots\end{array}$ & $\begin{array}{r}50 \\
560 \\
560 \\
560\end{array}$ & $\begin{array}{l}-- \\
430 \\
410 \\
400 \\
410\end{array}$ & $\begin{array}{r}50 \\
590 \\
640 \\
--- \\
---\end{array}$ & $\begin{array}{l}300 \\
320 \\
330 \\
310 \\
--\end{array}$ & \begin{tabular}{l}
540 \\
\hdashline 530 \\
540 \\
540
\end{tabular} & $\begin{array}{l}560 \\
570 \\
580 \\
595 \\
580\end{array}$ & $\begin{array}{l}545 \\
530 \\
-0 \\
540\end{array}$ & $\begin{array}{l}-- \\
-2 \\
510 \\
510 \\
505\end{array}$ & $\begin{array}{l}480 \\
480 \\
500 \\
460 \\
450\end{array}$ & $\begin{array}{l}480 \\
480 \\
480 \\
480\end{array}$ \\
\hline $\begin{array}{l}11 \\
12 \\
13 \\
14 \\
15\end{array}$ & $\begin{array}{l}480 \\
480 \\
--0 \\
460\end{array}$ & $\begin{array}{l}-- \\
520 \\
520 \\
520 \\
520\end{array}$ & $\begin{array}{l}580 \\
580 \\
620 \\
620 \\
600\end{array}$ & $\begin{array}{l}420 \\
460 \\
-2- \\
520 \\
540\end{array}$ & $\begin{array}{l}630 \\
560 \\
630 \\
620 \\
660\end{array}$ & $\begin{array}{l}270 \\
270 \\
320 \\
330 \\
360\end{array}$ & $\begin{array}{l}550 \\
560 \\
560 \\
550\end{array}$ & $\begin{array}{l}570 \\
=610 \\
620 \\
600\end{array}$ & $\begin{array}{l}530 \\
540 \\
540 \\
540 \\
-\end{array}$ & $\begin{array}{l}505 \\
505 \\
520 \\
480\end{array}$ & $\begin{array}{l}--- \\
460 \\
460 \\
450 \\
480\end{array}$ & $\begin{array}{l}480 \\
500 \\
500 \\
- \\
-\end{array}$ \\
\hline $\begin{array}{l}16 \\
17 \\
18 \\
19 \\
20\end{array}$ & $\begin{array}{l}470 \\
465 \\
2280 \\
--\end{array}$ & $\begin{array}{l}520 \\
520 \\
520 \\
-\square\end{array}$ & $\begin{array}{l}-500 \\
560 \\
580 \\
540\end{array}$ & $\begin{array}{r}580 \\
580 \\
-- \\
--\end{array}$ & $\begin{array}{l}--- \\
\overline{630} \\
660 \\
650\end{array}$ & $\begin{array}{l}400 \\
450 \\
460 \\
470\end{array}$ & $\begin{array}{l}580 \\
-55 \\
555 \\
560 \\
570\end{array}$ & $\begin{array}{l}590 \\
600 \\
600 \\
--- \\
---\end{array}$ & $\begin{array}{l}- \\
520 \\
530 \\
520 \\
520\end{array}$ & $\begin{array}{l}500 \\
520 \\
520 \\
500 \\
520\end{array}$ & $\begin{array}{l}460 \\
450 \\
-20 \\
460 \\
480\end{array}$ & $\begin{array}{l}460 \\
480 \\
460 \\
460 \\
450\end{array}$ \\
\hline $\begin{array}{l}21 \\
22 \\
23 \\
24 \\
25\end{array}$ & $\begin{array}{l}--5 \\
460 \\
465 \\
470\end{array}$ & $\begin{array}{l}510 \\
-- \\
-\infty\end{array}$ & $\begin{array}{l}560 \\
500 \\
-560 \\
-\end{array}$ & $\begin{array}{l}600 \\
600 \\
600 \\
620\end{array}$ & $\begin{array}{l}630 \\
440 \\
-- \\
370\end{array}$ & $\begin{array}{l}--\overline{480} \\
500 \\
--520\end{array}$ & $\begin{array}{l}---0 \\
580 \\
560 \\
--- \\
570\end{array}$ & $\begin{array}{l}605 \\
585 \\
580 \\
600 \\
---\end{array}$ & $\begin{array}{l}500 \\
500 \\
-170 \\
480\end{array}$ & $\begin{array}{l}-- \\
500 \\
470 \\
460 \\
470\end{array}$ & $\begin{array}{l}480 \\
440 \\
440 \\
460 \\
-\end{array}$ & $\begin{array}{l}--- \\
440 \\
460 \\
460\end{array}$ \\
\hline $\begin{array}{l}26 \\
27 \\
28 \\
29 \\
30 \\
31\end{array}$ & $\begin{array}{l}480 \\
460 \\
450 \\
460 \\
465\end{array}$ & $\begin{array}{l}500 \\
-210 \\
-2\end{array}$ & $\begin{array}{l}--- \\
560 \\
480 \\
480 \\
--- \\
480\end{array}$ & $\begin{array}{l}-- \\
--- \\
570 \\
620 \\
580 \\
610\end{array}$ & $\begin{array}{l}340 \\
270 \\
250 \\
-- \\
-- \\
--\end{array}$ & $\begin{array}{l}550 \\
540 \\
550 \\
550 \\
-\square \\
-\end{array}$ & $\begin{array}{l}-20 \\
560 \\
-270 \\
560\end{array}$ & $\begin{array}{l}-- \\
--- \\
580 \\
580 \\
580 \\
575\end{array}$ & $\begin{array}{l}470 \\
460 \\
460 \\
470 \\
--\end{array}$ & $\begin{array}{l}490 \\
500 \\
480 \\
440 \\
440\end{array}$ & $\begin{array}{l}450 \\
440 \\
440 \\
460 \\
480 \\
460\end{array}$ & $\begin{array}{l}460 \\
460 \\
480 \\
-480\end{array}$ \\
\hline
\end{tabular}


05454500 IOWA RIVER AT IOWA CITY, IA--Continued

WATER-QUALITY RECORDS

TEMPERATURE, WATER (DEG. C), WATER YEAR OCTOBER 1984 TO SEPTEMBER 1985

\begin{tabular}{|c|c|c|c|c|c|c|c|c|c|c|c|c|}
\hline DAY & OCT & NOV & DEC & JAN & FEB & MAR & APR & MAY & JUN & JUL & AUG & SEP \\
\hline $\begin{array}{l}1 \\
2 \\
3 \\
4 \\
5\end{array}$ & $\begin{array}{l}13.0 \\
13.0 \\
16.0 \\
16.0 \\
16.0\end{array}$ & $\begin{array}{r}11.0 \\
8.0 \\
8.0\end{array}$ & $\overline{0}$ & \begin{tabular}{l}
$\cdots$ \\
\hdashline-0 \\
1.0 \\
$\cdots$
\end{tabular} & $\begin{array}{r}.0 \\
.0 \\
.0 \\
2.0\end{array}$ & $\begin{array}{r}--- \\
2.0 \\
.0\end{array}$ & $\begin{array}{r}-10 \\
10.0 \\
14.0 \\
7.0\end{array}$ & \begin{tabular}{r}
16.0 \\
14.0 \\
\hdashline \\
\end{tabular} & $\begin{array}{r}--- \\
18.0 \\
18.0 \\
18.0\end{array}$ & 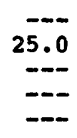 & $\begin{array}{r}20.0 \\
22.0 \\
\hdashline 22.0\end{array}$ & $\begin{array}{r}\ddot{25.0} \\
23.0 \\
24.0\end{array}$ \\
\hline $\begin{array}{r}6 \\
7 \\
8 \\
9 \\
10\end{array}$ & $\begin{array}{r}17.0 \\
16.0 \\
17.0 \\
17.0\end{array}$ & $\begin{array}{r}6.0 \\
14.0 \\
15.0 \\
12.0 \\
\end{array}$ & $\begin{array}{r}.0 \\
.0 \\
.0 \\
3.0\end{array}$ & $\begin{array}{r}--0 \\
1.0 \\
1.0 \\
1.0\end{array}$ & $\begin{array}{r}1.0 \\
.0 \\
.0 \\
-0 \\
-\end{array}$ & $\begin{array}{l}2.0 \\
3.0 \\
2.0 \\
3.0 \\
-\end{array}$ & $\begin{array}{r}15.0 \\
4.0 \\
7.0\end{array}$ & $\begin{array}{l}16.0 \\
22.0 \\
17.0 \\
18.0 \\
18.0\end{array}$ & $\begin{array}{r}21.0 \\
22.0 \\
\hdashline \overline{19.0}\end{array}$ & $\begin{array}{l}\square- \\
\square-- \\
\square-\end{array}$ & $\begin{array}{l}24.0 \\
24.0 \\
22.0 \\
23.0 \\
23.0\end{array}$ & $\begin{array}{r}25.0 \\
25.0 \\
25.0 \\
22.0\end{array}$ \\
\hline $\begin{array}{l}11 \\
12 \\
13 \\
14 \\
15\end{array}$ & $\begin{array}{r}17.0 \\
17.0 \\
18.0\end{array}$ & $\begin{array}{r}11.0 \\
11.0 \\
10.0 \\
7.0\end{array}$ & $\begin{array}{l}7.0 \\
6.0 \\
2.0 \\
6.0 \\
3.0\end{array}$ & $\begin{array}{r}.0 \\
.0 \\
-.0 \\
.0\end{array}$ & $\begin{array}{r}2.0 \\
.0 \\
.0 \\
.0 \\
.0\end{array}$ & $\begin{array}{l}5.0 \\
2.0 \\
5.0 \\
4.0 \\
4.0\end{array}$ & $\begin{array}{r}7.0 \\
8.0 \\
14.0 \\
13.0\end{array}$ & $\begin{array}{r}19.0 \\
17.0 \\
17.0 \\
17.0\end{array}$ & $\begin{array}{r}18.0 \\
17.0 \\
20.0 \\
18.0 \\
\end{array}$ & $\begin{array}{l}=- \\
=- \\
=-\end{array}$ & $\begin{array}{r}23.0 \\
24.0 \\
24.0 \\
22.0\end{array}$ & $\begin{array}{r}20.0 \\
19.0 \\
19.0 \\
ב\end{array}$ \\
\hline $\begin{array}{l}16 \\
17 \\
18 \\
19 \\
20\end{array}$ & $\begin{array}{r}15.0 \\
15.0 \\
16.0 \\
-\end{array}$ & $\begin{array}{r}6.0 \\
6.0 \\
6.0 \\
\end{array}$ & $\begin{array}{r}2.0 \\
.0 \\
.0 \\
.0\end{array}$ & $\begin{array}{r}.0 \\
-3.0 \\
.0 \\
--\end{array}$ & \begin{tabular}{l}
--- \\
\hdashline 2.0 \\
1.0 \\
1.0
\end{tabular} & $\begin{array}{l}6.0 \\
5.0 \\
8.0 \\
7.0\end{array}$ & $\begin{array}{r}14.0 \\
15.0 \\
15.0 \\
17.0\end{array}$ & $\begin{array}{r}15.0 \\
14.0 \\
16.0 \\
-0\end{array}$ & $\begin{array}{r}20.0 \\
\hdashline- \\
\hdashline-\end{array}$ & $\begin{array}{l}20.0 \\
23.0 \\
24.0 \\
24.0 \\
23.0\end{array}$ & $\begin{array}{r}22.0 \\
22.0 \\
-12.0 \\
21.0\end{array}$ & $\begin{array}{l}19.0 \\
19.0 \\
20.0 \\
28.0 \\
22.0\end{array}$ \\
\hline $\begin{array}{l}21 \\
22 \\
23 \\
24 \\
25\end{array}$ & $\begin{array}{r}1 \overline{16.0} \\
10.0 \\
16.0 \\
14.0\end{array}$ & 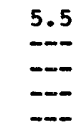 & $\begin{array}{r}4.0 \\
5.0 \\
-.0 \\
-2\end{array}$ & $\begin{array}{r}.0 \\
2.0 \\
1.0 \\
1.0\end{array}$ & $\begin{array}{r}1.0 \\
1.0 \\
.0\end{array}$ & $\begin{array}{l}\overline{7.0} \\
8.0 \\
\overline{6.0}\end{array}$ & $\begin{array}{r}21.0 \\
18.0 \\
16.0\end{array}$ & $\begin{array}{r}18.0 \\
16.0 \\
21.0 \\
16.0 \\
-\end{array}$ & $\begin{array}{l}=- \\
\overline{--} \\
\overline{--} \\
\square-\end{array}$ & $\begin{array}{r}--- \\
23.0 \\
21.0 \\
23.0 \\
24.0\end{array}$ & $\begin{array}{r}20.0 \\
21.0 \\
22.0 \\
20.0 \\
-\end{array}$ & $\frac{\overline{16.0}}{\overline{14.0}} \overline{15.0}$ \\
\hline $\begin{array}{l}26 \\
27 \\
28 \\
29 \\
30 \\
31\end{array}$ & $\begin{array}{r}15.0 \\
15.0 \\
8.0 \\
15.0 \\
15.0\end{array}$ & \begin{tabular}{l}
8.5 \\
\hdashline.- \\
\hdashline 4.5 \\
---
\end{tabular} & $\begin{array}{l}\overline{2.0} \\
5.0 \\
4.0 \\
2.0\end{array}$ & $\begin{array}{r}--- \\
.0 \\
.0 \\
1.0 \\
.0\end{array}$ & $\begin{array}{r}1.0 \\
.00 \\
1.0 \\
\hdashline-0\end{array}$ & \begin{tabular}{l}
0.0 \\
0.0 \\
9.0 \\
8.0 \\
\hdashline- \\
-
\end{tabular} & $\begin{array}{r}16.0 \\
14.0 \\
16.0 \\
\end{array}$ & $\begin{array}{r}-\overline{14.0} \\
18.0 \\
2 \overline{22.0}\end{array}$ & $\begin{array}{l}=- \\
=- \\
=- \\
=- \\
--\end{array}$ & \begin{tabular}{r}
24.0 \\
23.0 \\
\hdashline 24.0 \\
22.0
\end{tabular} & $\begin{array}{l}21.0 \\
19.0 \\
21.0 \\
22.0 \\
21.0 \\
21.0\end{array}$ & $\begin{array}{r}15.0 \\
13.0 \\
15.0 \\
15.0 \\
-\end{array}$ \\
\hline
\end{tabular}

SUSPENDED-SEDIMENT, WATER YEAR OCTOBER 1984 TO SEPTEMBER 1985

\begin{tabular}{|c|c|c|c|c|c|c|c|c|c|c|c|c|}
\hline \multirow[t]{2}{*}{ DAY } & $\begin{array}{c}\text { MEAN } \\
\text { CONCEN- } \\
\text { TRATION } \\
\text { (MG/L) }\end{array}$ & $\begin{array}{l}\text { LOADS } \\
\text { (T/DAY) }\end{array}$ & $\begin{array}{c}\text { MEAN } \\
\text { CONCEN- } \\
\text { TRATION } \\
\text { (MG/L) }\end{array}$ & $\begin{array}{l}\text { LOADS } \\
\text { (T/DAY) }\end{array}$ & $\begin{array}{c}\text { MEAN } \\
\text { CONCEN- } \\
\text { TRATION } \\
\text { (MG/L) }\end{array}$ & $\begin{array}{l}\text { LOADS } \\
\text { (T/DAY) }\end{array}$ & $\begin{array}{l}\text { MEAN } \\
\text { CONCEN- } \\
\text { TRATION } \\
\text { (MG/L) }\end{array}$ & $\begin{array}{l}\text { LOADS } \\
\text { (T/DAY) }\end{array}$ & $\begin{array}{c}\text { MEAN } \\
\text { CONCEN- } \\
\text { TRATION } \\
\text { (MG/L) }\end{array}$ & $\begin{array}{l}\text { LOADS } \\
\text { (T/DAY) }\end{array}$ & $\begin{array}{c}\text { MEAN } \\
\text { CONCEN- } \\
\text { TRATION } \\
(\text { MG/L) }\end{array}$ & $\begin{array}{l}\text { LOADS } \\
\text { (T/DAY) }\end{array}$ \\
\hline & \multicolumn{2}{|c|}{ OCTOBER } & \multicolumn{2}{|c|}{ NOVEMBER } & \multicolumn{2}{|c|}{ DECEMBER } & \multicolumn{2}{|c|}{ JANUARY } & \multicolumn{2}{|c|}{ FEBRUARY } & \multicolumn{2}{|c|}{ MARCB } \\
\hline $\begin{array}{l}1 \\
2 \\
3 \\
4 \\
5\end{array}$ & $\begin{array}{l}35 \\
31 \\
29 \\
28 \\
28\end{array}$ & $\begin{array}{l}39 \\
34 \\
32 \\
31 \\
31\end{array}$ & $\begin{array}{r}916 \\
178 \\
87 \\
70 \\
54\end{array}$ & $\begin{array}{r}8230 \\
1050 \\
517 \\
397 \\
313\end{array}$ & $\begin{array}{l}11 \\
10 \\
10 \\
11 \\
14\end{array}$ & $\begin{array}{l}32 \\
25 \\
23 \\
24 \\
32\end{array}$ & $\begin{array}{r}218 \\
147 \\
99 \\
85 \\
81\end{array}$ & $\begin{array}{r}2440 \\
1160 \\
164 \\
137 \\
129\end{array}$ & $\begin{array}{r}5 \\
8 \\
11 \\
12 \\
16\end{array}$ & $\begin{array}{l}10 \\
14 \\
17 \\
15 \\
19\end{array}$ & $\begin{array}{r}608 \\
465 \\
445 \\
1070 \\
400\end{array}$ & $\begin{array}{r}14700 \\
11200 \\
10700 \\
25000 \\
5310\end{array}$ \\
\hline $\begin{array}{r}6 \\
7 \\
8 \\
9 \\
10\end{array}$ & $\begin{array}{l}31 \\
30 \\
30 \\
30 \\
30\end{array}$ & $\begin{array}{l}34 \\
33 \\
33 \\
33 \\
33\end{array}$ & $\begin{array}{r}42 \\
35 \\
30 \\
64 \\
110\end{array}$ & $\begin{array}{l}226 \\
172 \\
146 \\
337 \\
668\end{array}$ & $\begin{array}{l}13 \\
12 \\
10 \\
19 \\
38\end{array}$ & $\begin{array}{r}29 \\
23 \\
16 \\
48 \\
143\end{array}$ & $\begin{array}{l}76 \\
75 \\
75 \\
70 \\
54\end{array}$ & $\begin{array}{l}120 \\
175 \\
318 \\
355 \\
261\end{array}$ & $\begin{array}{r}16 \\
15 \\
7 \\
7 \\
7\end{array}$ & $\begin{array}{l}19 \\
18 \\
8.3 \\
8.5 \\
9.1\end{array}$ & $\begin{array}{l}245 \\
172 \\
239 \\
338 \\
402\end{array}$ & $\begin{array}{l}4110 \\
3430 \\
5690 \\
8430 \\
9950\end{array}$ \\
\hline $\begin{array}{l}11 \\
12 \\
13 \\
14 \\
15\end{array}$ & $\begin{array}{l}51 \\
53 \\
42 \\
37 \\
46\end{array}$ & $\begin{array}{l}63 \\
72 \\
61 \\
53 \\
73\end{array}$ & $\begin{array}{r}115 \\
85 \\
54 \\
34 \\
33\end{array}$ & $\begin{array}{l}817 \\
661 \\
313 \\
136 \\
129\end{array}$ & $\begin{array}{l}10 \\
23 \\
12 \\
11 \\
13\end{array}$ & $\begin{array}{r}45 \\
108 \\
56 \\
52 \\
61\end{array}$ & $\begin{array}{r}33 \\
38 \\
31 \\
12 \\
8\end{array}$ & $\begin{array}{r}145 \\
168 \\
122 \\
37 \\
20\end{array}$ & $\begin{array}{r}17 \\
39 \\
9 \\
8 \\
4\end{array}$ & $\begin{array}{l}28 \\
67 \\
17 \\
17 \\
10\end{array}$ & $\begin{array}{l}379 \\
320 \\
259 \\
202 \\
148\end{array}$ & $\begin{array}{l}9250 \\
7590 \\
5480 \\
3360 \\
2310\end{array}$ \\
\hline $\begin{array}{l}16 \\
17 \\
18 \\
19 \\
20\end{array}$ & $\begin{array}{r}63 \\
80 \\
264 \\
738 \\
402\end{array}$ & $\begin{array}{r}122 \\
202 \\
1280 \\
4750 \\
2390\end{array}$ & $\begin{array}{l}31 \\
25 \\
22 \\
19 \\
34\end{array}$ & $\begin{array}{r}109 \\
72 \\
56 \\
48 \\
91\end{array}$ & $\begin{array}{l}13 \\
28 \\
15 \\
16 \\
15\end{array}$ & $\begin{array}{r}63 \\
133 \\
70 \\
74 \\
63\end{array}$ & $\begin{array}{l}7 \\
7 \\
7 \\
7 \\
7\end{array}$ & $\begin{array}{l}20 \\
22 \\
20 \\
16 \\
18\end{array}$ & $\begin{array}{r}5 \\
7 \\
8 \\
8 \\
34\end{array}$ & $\begin{array}{r}13 \\
19 \\
21 \\
24 \\
130\end{array}$ & $\begin{array}{r}105 \\
68 \\
69 \\
88 \\
72\end{array}$ & $\begin{array}{r}1280 \\
692 \\
632 \\
718 \\
533\end{array}$ \\
\hline $\begin{array}{l}21 \\
22 \\
23 \\
24 \\
25\end{array}$ & $\begin{array}{r}220 \\
90 \\
59 \\
52 \\
61\end{array}$ & $\begin{array}{r}1420 \\
564 \\
271 \\
164 \\
170\end{array}$ & $\begin{array}{l}39 \\
29 \\
25 \\
22 \\
22\end{array}$ & $\begin{array}{r}119 \\
96 \\
82 \\
71 \\
70\end{array}$ & $\begin{array}{l}17 \\
21 \\
16 \\
13 \\
14\end{array}$ & $\begin{array}{l}58 \\
70 \\
62 \\
60 \\
80\end{array}$ & $\begin{array}{l}6 \\
6 \\
5 \\
6 \\
6\end{array}$ & $\begin{array}{l}15 \\
14 \\
12 \\
14 \\
15\end{array}$ & $\begin{array}{l}347 \\
620 \\
488 \\
356 \\
270\end{array}$ & $\begin{array}{l}3950 \\
7950 \\
5360 \\
3720 \\
2220\end{array}$ & $\begin{array}{l}83 \\
88 \\
74 \\
73 \\
78\end{array}$ & $\begin{array}{l}493 \\
444 \\
374 \\
367 \\
354\end{array}$ \\
\hline $\begin{array}{l}26 \\
27 \\
28 \\
29 \\
30 \\
31\end{array}$ & $\begin{array}{r}62 \\
73 \\
142 \\
81 \\
42 \\
88\end{array}$ & $\begin{array}{l}186 \\
237 \\
590 \\
350 \\
160 \\
507\end{array}$ & $\begin{array}{l}21 \\
19 \\
18 \\
17 \\
13 \\
--\end{array}$ & $\begin{array}{r}57 \\
43 \\
49 \\
55 \\
41 \\
---\end{array}$ & $\begin{array}{r}14 \\
14 \\
420 \\
1400 \\
875 \\
280\end{array}$ & $\begin{array}{r}57 \\
27 \\
2260 \\
12500 \\
10200 \\
3670\end{array}$ & $\begin{array}{r}25 \\
39 \\
21 \\
7 \\
20 \\
7\end{array}$ & $\begin{array}{l}49 \\
69 \\
36 \\
12 \\
38 \\
14\end{array}$ & $\begin{array}{l}220 \\
349 \\
557 \\
--- \\
---\end{array}$ & $\begin{array}{r}1640 \\
5630 \\
12200 \\
-\end{array}$ & $\begin{array}{r}110 \\
121 \\
147 \\
97 \\
80 \\
142\end{array}$ & $\begin{array}{l}448 \\
526 \\
818 \\
547 \\
400 \\
836\end{array}$ \\
\hline TOTAL & $\cdots$ & 14018 & -- & 15171 & -- & 30164 & -- & 6135 & -- & 43153.9 & --- & 135972 \\
\hline
\end{tabular}


IOWA RIVER BASIN

05454500 IOWA RIVER AT IOWA CITY, IA--Continued

WATER-QUALITY RECORDS

SUSPENDED-SEDIKENT, WATER YEAR OCTOBER 1984 TO SEPTENBER 1985

\begin{tabular}{|c|c|c|c|c|c|c|c|c|c|c|c|c|}
\hline \multirow[t]{2}{*}{ DAY } & $\begin{array}{l}\text { MEAN } \\
\text { CONCEN- } \\
\text { TRATION } \\
\text { (MG/L) }\end{array}$ & $\begin{array}{l}\text { LOADS } \\
\text { (T/DAY) }\end{array}$ & $\begin{array}{l}\text { MEAN } \\
\text { CONCEN- } \\
\text { TRATION } \\
\text { (MG/L) }\end{array}$ & $\begin{array}{l}\text { LOADS } \\
\text { (T/DAY) }\end{array}$ & $\begin{array}{l}\text { MEAN } \\
\text { CONCEN- } \\
\text { TRATION } \\
\text { (MG/L) }\end{array}$ & $\begin{array}{l}\text { LOADS } \\
\text { (T/DAY) }\end{array}$ & $\begin{array}{l}\text { MEAN } \\
\text { CONCEN- } \\
\text { TRATION } \\
\text { (MG/L) }\end{array}$ & $\begin{array}{l}\text { LOADS } \\
\text { (T/DAY) }\end{array}$ & $\begin{array}{l}\text { MEAN } \\
\text { CONCEN- } \\
\text { TRATION } \\
\text { (MG/L) }\end{array}$ & $\begin{array}{l}\text { LOADS } \\
\text { (T/DAY) }\end{array}$ & $\begin{array}{l}\text { MEAN } \\
\text { CONCEN- } \\
\text { TRATION } \\
\text { (MG/L) }\end{array}$ & $\begin{array}{l}\text { LOADS } \\
\text { (T/DAY) }\end{array}$ \\
\hline & \multicolumn{2}{|c|}{ APRIL } & \multicolumn{2}{|c|}{ MAY } & \multicolumn{2}{|c|}{ JUNE } & \multicolumn{2}{|c|}{ JULY } & \multicolumn{2}{|c|}{ AUGUST } & \multicolumn{2}{|c|}{ SEPTEMBER } \\
\hline $\begin{array}{l}1 \\
2 \\
3 \\
4 \\
5\end{array}$ & $\begin{array}{r}184 \\
132 \\
80 \\
82 \\
85\end{array}$ & $\begin{array}{r}1280 \\
1010 \\
514 \\
476 \\
620\end{array}$ & $\begin{array}{l}70 \\
57 \\
67 \\
86 \\
79\end{array}$ & $\begin{array}{l}283 \\
229 \\
279 \\
369 \\
341\end{array}$ & $\begin{array}{l}98 \\
87 \\
78 \\
76 \\
76\end{array}$ & $\begin{array}{l}178 \\
157 \\
139 \\
135 \\
136\end{array}$ & $\begin{array}{l}71 \\
69 \\
58 \\
51 \\
75\end{array}$ & $\begin{array}{r}121 \\
117 \\
84 \\
62 \\
92\end{array}$ & $\begin{array}{l}42 \\
35 \\
33 \\
35 \\
35\end{array}$ & $\begin{array}{l}27 \\
22 \\
21 \\
22 \\
21\end{array}$ & $\begin{array}{l}27 \\
33 \\
35 \\
33 \\
30\end{array}$ & $\begin{array}{l}15 \\
18 \\
19 \\
18 \\
17\end{array}$ \\
\hline $\begin{array}{r}6 \\
7 \\
8 \\
9 \\
10\end{array}$ & $\begin{array}{l}81 \\
68 \\
72 \\
82 \\
65\end{array}$ & $\begin{array}{l}652 \\
514 \\
507 \\
578 \\
423\end{array}$ & $\begin{array}{l}72 \\
75 \\
60 \\
48 \\
43\end{array}$ & $\begin{array}{r}309 \\
283 \\
173 \\
87 \\
78\end{array}$ & $\begin{array}{l}85 \\
90 \\
91 \\
88 \\
86\end{array}$ & $\begin{array}{l}152 \\
160 \\
151 \\
133 \\
131\end{array}$ & $\begin{array}{l}85 \\
80 \\
68 \\
50 \\
54\end{array}$ & $\begin{array}{r}104 \\
98 \\
83 \\
56 \\
54\end{array}$ & $\begin{array}{l}34 \\
48 \\
38 \\
37 \\
42\end{array}$ & $\begin{array}{l}18 \\
27 \\
21 \\
22 \\
34\end{array}$ & $\begin{array}{l}28 \\
25 \\
24 \\
24 \\
34\end{array}$ & $\begin{array}{l}16 \\
13 \\
12 \\
12 \\
16\end{array}$ \\
\hline $\begin{array}{l}11 \\
12 \\
13 \\
14 \\
15\end{array}$ & $\begin{array}{l}60 \\
68 \\
75 \\
76 \\
77\end{array}$ & $\begin{array}{l}361 \\
409 \\
450 \\
415 \\
383\end{array}$ & $\begin{array}{l}76 \\
82 \\
76 \\
75 \\
75\end{array}$ & $\begin{array}{l}143 \\
160 \\
144 \\
149 \\
152\end{array}$ & $\begin{array}{r}103 \\
86 \\
85 \\
89 \\
87\end{array}$ & $\begin{array}{l}160 \\
137 \\
132 \\
138 \\
163\end{array}$ & $\begin{array}{l}61 \\
52 \\
50 \\
65 \\
64\end{array}$ & $\begin{array}{l}63 \\
53 \\
50 \\
74 \\
79\end{array}$ & $\begin{array}{l}29 \\
46 \\
38 \\
77 \\
57\end{array}$ & $\begin{array}{l}18 \\
26 \\
24 \\
48 \\
36\end{array}$ & $\begin{array}{l}32 \\
40 \\
42 \\
34 \\
29\end{array}$ & $\begin{array}{l}13 \\
16 \\
17 \\
14 \\
12\end{array}$ \\
\hline $\begin{array}{l}16 \\
17 \\
18 \\
19 \\
20\end{array}$ & $\begin{array}{r}77 \\
85 \\
94 \\
106 \\
105\end{array}$ & $\begin{array}{l}383 \\
374 \\
368 \\
446 \\
448\end{array}$ & $\begin{array}{l}80 \\
74 \\
70 \\
70 \\
72\end{array}$ & $\begin{array}{l}157 \\
160 \\
183 \\
182 \\
188\end{array}$ & $\begin{array}{l}82 \\
80 \\
79 \\
82 \\
82\end{array}$ & $\begin{array}{l}176 \\
169 \\
167 \\
174 \\
174\end{array}$ & $\begin{array}{r}73 \\
110 \\
67 \\
55 \\
72\end{array}$ & $\begin{array}{r}91 \\
109 \\
67 \\
55 \\
71\end{array}$ & $\begin{array}{l}44 \\
60 \\
49 \\
41 \\
45\end{array}$ & $\begin{array}{l}30 \\
41 \\
29 \\
24 \\
25\end{array}$ & $\begin{array}{l}37 \\
33 \\
32 \\
38 \\
33\end{array}$ & $\begin{array}{l}38 \\
59 \\
59 \\
61 \\
43\end{array}$ \\
\hline $\begin{array}{l}21 \\
22 \\
23 \\
24 \\
25\end{array}$ & $\begin{array}{r}102 \\
117 \\
124 \\
105 \\
90\end{array}$ & $\begin{array}{l}397 \\
461 \\
485 \\
408 \\
347\end{array}$ & $\begin{array}{r}72 \\
77 \\
82 \\
88 \\
114\end{array}$ & $\begin{array}{l}152 \\
128 \\
136 \\
188 \\
247\end{array}$ & $\begin{array}{r}80 \\
95 \\
105 \\
109 \\
94\end{array}$ & $\begin{array}{l}171 \\
210 \\
246 \\
255 \\
206\end{array}$ & $\begin{array}{l}70 \\
64 \\
64 \\
78 \\
73\end{array}$ & $\begin{array}{l}69 \\
53 \\
42 \\
59 \\
60\end{array}$ & $\begin{array}{l}38 \\
35 \\
45 \\
65 \\
54\end{array}$ & $\begin{array}{l}21 \\
20 \\
25 \\
37 \\
30\end{array}$ & $\begin{array}{l}31 \\
49 \\
70 \\
55 \\
43\end{array}$ & $\begin{array}{r}36 \\
60 \\
138 \\
108 \\
80\end{array}$ \\
\hline $\begin{array}{l}26 \\
27 \\
28 \\
29 \\
30 \\
31\end{array}$ & $\begin{array}{r}90 \\
92 \\
82 \\
70 \\
71 \\
-\end{array}$ & $\begin{array}{l}345 \\
353 \\
314 \\
246 \\
245 \\
-\end{array}$ & $\begin{array}{l}90 \\
78 \\
94 \\
78 \\
77 \\
89\end{array}$ & $\begin{array}{l}153 \\
174 \\
220 \\
145 \\
142 \\
163\end{array}$ & $\begin{array}{r}85 \\
81 \\
86 \\
92 \\
83 \\
-\end{array}$ & $\begin{array}{l}167 \\
140 \\
148 \\
158 \\
142 \\
-\end{array}$ & $\begin{array}{l}58 \\
63 \\
58 \\
55 \\
65 \\
56\end{array}$ & $\begin{array}{l}37 \\
39 \\
36 \\
34 \\
43 \\
38\end{array}$ & $\begin{array}{l}43 \\
35 \\
26 \\
30 \\
47 \\
28\end{array}$ & $\begin{array}{l}23 \\
19 \\
14 \\
16 \\
25 \\
15\end{array}$ & $\begin{array}{r}33 \\
25 \\
27 \\
23 \\
30 \\
---\end{array}$ & $\begin{array}{r}59 \\
44 \\
47 \\
41 \\
63 \\
-\end{array}$ \\
\hline TOTAL & -- & 14212 & -- & 5897 & -- & 4905 & $-\infty$ & 2093 & $-\infty$ & 781 & -- & 1164 \\
\hline
\end{tabular}

TOTAL LOAD FOR YEAR: 273665.9 TONS.

WATER QUALITY DATA, WATER YEAR OCTOBER 1984 TO SEPTEMBER 1985

\begin{tabular}{|c|c|c|c|c|c|c|c|c|c|c|}
\hline DATE & TIME & $\begin{array}{l}\text { TEKPER- } \\
\text { ATURE } \\
\text { (DEG C) }\end{array}$ & $\begin{array}{l}\text { STREAN- } \\
\text { FLOW, } \\
\text { INSTAN- } \\
\text { TANEOUS } \\
\text { (CES) }\end{array}$ & $\begin{array}{l}\text { SEDI- } \\
\text { MENT, } \\
\text { SUS- } \\
\text { PENDED } \\
\text { (MG/L) }\end{array}$ & $\begin{array}{c}\text { SEDI- } \\
\text { MENT., } \\
\text { DIS- } \\
\text { CEARGE, } \\
\text { SUS- } \\
\text { PENDED } \\
\text { (T/DAY) }\end{array}$ & $\begin{array}{l}\text { SED. } \\
\text { SUSP. } \\
\text { FALL } \\
\text { DIAM. } \\
\text { FINER } \\
\text { THAN } \\
.002\end{array}$ & $\begin{array}{l}\text { SED. } \\
\text { SUSP } \\
\text { FALL } \\
\text { DIAM. } \\
\text { FINER } \\
\text { THAN } \\
.004 \text { iIS }\end{array}$ & $\begin{array}{l}\text { SED. } \\
\text { SUSP. } \\
\text { FALL } \\
\text { DIAY. } \\
\text { FINER } \\
\text { THAN } \\
.008\end{array}$ & $\begin{array}{l}\text { SED. } \\
\text { SUSP. } \\
\text { FALL } \\
\text { DIAM. } \\
\text { FINER } \\
\text { THAN } \\
.016 \text { VIY }\end{array}$ & $\begin{array}{c}\text { SED. } \\
\text { SUSP. } \\
\text { SIEVE } \\
\text { DIAY. } \\
\text { PINER } \\
\text { THAN } \\
.062 \mathrm{MM}\end{array}$ \\
\hline OCT & & & & & & & & & & \\
\hline $\operatorname{NOV}^{03} \ldots$ & $10: 45$ & 16.0 & 410 & 29 & 32 & -- & -- & $-\infty$ & -- & 99 \\
\hline$\underset{A P R}{06 \ldots}$ & $10: 55$ & 10.0 & 2120 & 40 & 229 & -- & -- & -- & -- & 99 \\
\hline $\begin{array}{l}05 \ldots \\
\text { MAY }\end{array}$ & $11: 00$ & 7.5 & 2720 & 78 & 573 & -- & -- & -- & -- & 99 \\
\hline $\begin{array}{l}09 \ldots \\
23 \ldots \\
\text { JUN }\end{array}$ & $\begin{array}{l}09: 30 \\
14: 45\end{array}$ & $\begin{array}{l}20.5 \\
21.0\end{array}$ & $\begin{array}{l}665 \\
616\end{array}$ & $\begin{array}{l}66 \\
68\end{array}$ & $\begin{array}{l}119 \\
113\end{array}$ & --55 & -71 & -84 & ${ }^{--} 92$ & $\begin{array}{l}95 \\
99\end{array}$ \\
\hline$\underset{\text { JUL }}{20}$ & $14: 30$ & 22.0 & 800 & 66 & 143 & 55 & 67 & 78 & 90 & 99 \\
\hline $\begin{array}{l}02 \ldots \\
26 \ldots \\
\text { AUG }\end{array}$ & $\begin{array}{l}09: 30 \\
09: 15\end{array}$ & $\begin{array}{l}25.0 \\
25.0\end{array}$ & $\begin{array}{l}639 \\
216\end{array}$ & $\begin{array}{l}79 \\
52\end{array}$ & $\begin{array}{r}136 \\
30\end{array}$ & $=$ & -- & $=$ & $\overline{--}$ & $\begin{array}{l}99 \\
97\end{array}$ \\
\hline $\begin{array}{r}02 \ldots \\
23 \ldots \\
\text { SEP }\end{array}$ & $\begin{array}{l}09: 15 \\
09: 00\end{array}$ & $\begin{array}{l}23.5 \\
22.0\end{array}$ & $\begin{array}{l}228 \\
195\end{array}$ & $\begin{array}{l}33 \\
37\end{array}$ & $\begin{array}{l}20 \\
19\end{array}$ & - & $\ddot{--}$ & -- & $=$ & $\begin{array}{l}99 \\
98\end{array}$ \\
\hline $\begin{array}{l}03 \ldots \\
26 \ldots\end{array}$ & $\begin{array}{l}14: 15 \\
14: 15\end{array}$ & $\begin{array}{l}26.5 \\
17.0\end{array}$ & $\begin{array}{l}196 \\
650\end{array}$ & $\begin{array}{l}36 \\
33\end{array}$ & $\begin{array}{l}19 \\
58\end{array}$ & -- & -- & -- & -- & $\begin{array}{l}99 \\
99\end{array}$ \\
\hline
\end{tabular}


IOWA RIVER BASIN

05454500 IOWA RIVER AT IOWA CITY, IA--Continued

WATER-QUALITY RECORDS

WATER QUALITY DATA, WATER YEAR OCTOBER 1984 TO SEPTELBER 1985

\begin{tabular}{|c|c|c|c|c|c|c|c|}
\hline DATE & TIME & $\begin{array}{l}\text { STREAM- } \\
\text { FLOW, } \\
\text { INSTAN- } \\
\text { TANEOUS } \\
\text { (CFS) }\end{array}$ & $\begin{array}{c}\text { NOMBER } \\
\text { OF } \\
\text { SAM- } \\
\text { PLING } \\
\text { POINTS }\end{array}$ & $\begin{array}{c}\text { BED } \\
\text { MAT. } \\
\text { SIEVE } \\
\text { DIAM. } \\
\text { FINER } \\
\text { THAN } \\
.062 \mathrm{MH}\end{array}$ & $\begin{array}{c}\text { BED } \\
\text { MAT. } \\
\text { SIEVE } \\
\text { DIAM. } \\
\text { FINER } \\
\text { TEAN } \\
.125 \mathrm{NM}\end{array}$ & $\begin{array}{c}\text { BED } \\
\text { MAT. } \\
\text { SIEVE } \\
\text { DIAM. } \\
\text { FINER } \\
\text { THAN } \\
.250 \mathrm{MH}\end{array}$ & $\begin{array}{c}\text { BED } \\
\text { MAT. } \\
\text { SIEVE } \\
\text { DIAM. } \\
\text { FINER } \\
\text { THAN } \\
.500 \mathrm{MM}\end{array}$ \\
\hline $\begin{array}{l}\text { NOV } \\
06 \ldots \\
\text { MAY }\end{array}$ & $11: 20$ & 2120 & 7 & 1 & 1 & 6 & 48 \\
\hline JUL & $10: 00$ & 665 & 6 & $-\infty$ & 0 & 7 & 55 \\
\hline & $13: 15$ & 639 & 7 & - & 0 & 6 & 56 \\
\hline
\end{tabular}

\begin{tabular}{|c|c|c|c|c|c|c|}
\hline DATE & $\begin{array}{c}\text { BED } \\
\text { MAT. } \\
\text { SIEVE } \\
\text { DIAM. } \\
\text { EINER } \\
\text { THAN } \\
1.00 \mathrm{MM}\end{array}$ & $\begin{array}{c}\text { BED } \\
\text { HAT. } \\
\text { SIEVE } \\
\text { DIAY. } \\
\text { 8 FINER } \\
\text { THAN } \\
2.00 \mathrm{MM}\end{array}$ & $\begin{array}{l}\text { BED } \\
\text { MAT. } \\
\text { SIEVE } \\
\text { DIAY. } \\
\text { FINER } \\
\text { THAN } \\
\text { 4.00 MM }\end{array}$ & $\begin{array}{c}\text { BED } \\
\text { MAT. } \\
\text { SIEVE } \\
\text { DIAM. } \\
\text { 8 FINER } \\
\text { THAN } \\
8.00 \mathrm{MM}\end{array}$ & $\begin{array}{c}\text { BED } \\
\text { MAT. } \\
\text { SIEVE } \\
\text { DIAM. } \\
8 \text { FINER } \\
\text { THAN } \\
16.0 \text { MA }\end{array}$ & $\begin{array}{c}\text { BED } \\
\text { MAT. } \\
\text { SIEVE } \\
\text { DIAM. } \\
\text { EINER } \\
\text { THAN } \\
32.0 \mathrm{dM}\end{array}$ \\
\hline $\begin{array}{l}\text { NOV } \\
06 \ldots \\
\text { MAY }\end{array}$ & 82 & 94 & 98 & 99 & 100 & - \\
\hline $\begin{array}{c}09 . \ldots \\
\text { JUL } \\
02 \ldots . .\end{array}$ & 84 & 91 & 93 & 96 & 100 & 100 \\
\hline
\end{tabular}


LOCATION.--Lat $41^{\circ} 39^{\prime} 50^{\prime \prime}$, long $91^{\circ} 30^{\prime} 48^{\prime \prime}$, in SEl/4 N1/4 sec. 11, T.79 N., R.6 W., Johnson County, Hydrologic Unit 07080209 , on left bank 10 ft upstream from bridge on Rochester Avenue, $1.0 \mathrm{mi}$ northeast of post office in Iowa City and $2.2 \mathrm{mi}$ upstream from mouth.

DRAINAGE AREA. $--3.01 \mathrm{~m}^{2}$.

\section{WATER-DISCHARGE RECORDS}

PER IOD OF RECORD.--September 1924 to current year.

REVISED RECORDS.--WSP 1508: 1933, 1935-37, 1940-41 (M), 1942, 1943 (M), 1948-51, 1952 (P), 1953, 1954 (M), 1955, WDR IOWA 1967: 1965-66; WDR IA-80-1: 1965(M).

GAGE.-Water-8tage recorder and V-notch sharp-crested weir. Datum of gage is 663.27 ft above NGVD (University of Iowa bench mark).

REMARKS.--Estimated daily discharge: Dec, 18-26, Jan. 1-4, 9-13, Jan. 16 to Feb. 14. Records fair except for periods of estimated daily discharge, which are poor.

AVERAGE DISCHARGE. -61 years, $1.72 \mathrm{ft} / 8,7.76 \mathrm{in} / \mathrm{yr}, 1,250 \mathrm{acre}-\mathrm{ft} / \mathrm{yr}$.

EXTREMES FOR PERIOD OF RECORD,--Maximum discharge, 1,760 ft'/8 July 17, 1972, gage height, 9.01 ft; maximum gage gage height, $9.06 \mathrm{ft} J u l y 18,1956$, no flow at times most years.

BXTREMES FOR CURRENT YEAR.--Peak discharges greater than base discharge of $200 \mathrm{ft} \% \mathrm{~s}$ and maximum (*):

$\begin{array}{llcccc}\text { Date } & \text { Time } & \text { Discharge } & \text { Gage height } & \text { Discharge } \\ \text { (ft) } & \text { Gage height } \\ \text { Oct. } 18 & 2040 & * 175 & * 3.99 & \text { Date } & \text { Time }\end{array}$

No flow sept. $12-20$.

DISCHARGE, IN CUBIC FEET PER SECOND, MATER YEAR OCTOBER 1984 TO SEPTEMBER 1985 MEAN VALUES

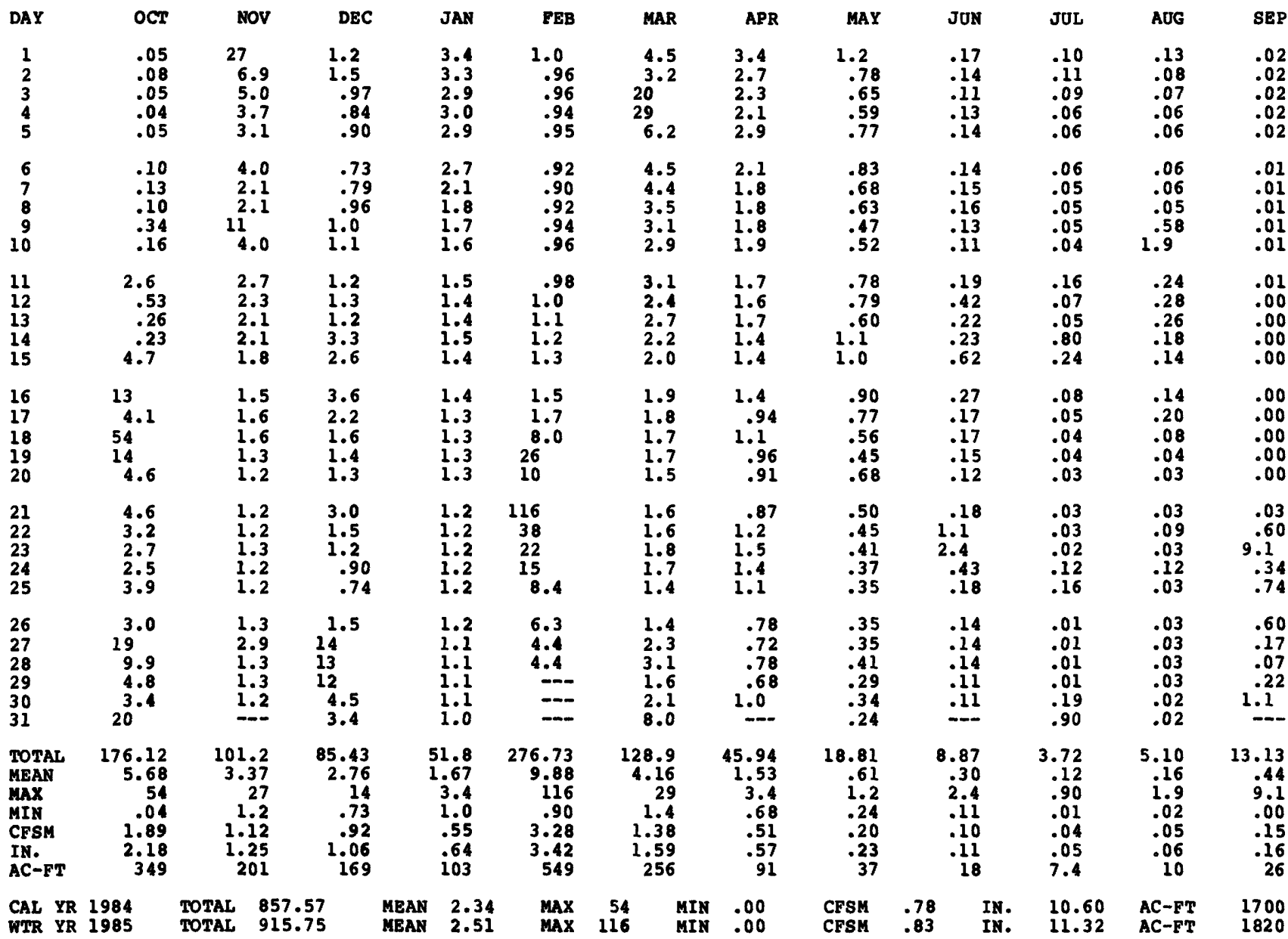


PERIOD OF RECORD.--Water years 1952 to current year.

PERIOD OF DAILY RECORD.--

SPECIFIC CONDUCTANCE: April 1968 to current year.

WATER TEMPERATURES: October 1960 to current year.

SUSPENDED-SEDIMENT DISCHARGE: April 1952 to current year.

REMARKS.--Records of specific conductance are obtained from suspended-sediment samples at time of analysis.

EXTREMES FOR PERIOD OF DAILY RECORD.--

SPECIRIC CONDUCTANCE: Maximum daily, 8,000 microsiemens Dec. 24, 1973, minimum daily, 120 microsiemens May $19,20,1977$

WATER TEMPERATURes: Maximum daily, $31.0^{\circ} \mathrm{C}$ July 21,1968 , minimum daily, $0.0^{\circ} \mathrm{C}$ on many days during winter periods.

SEDIMENT CONCENTRATIONS: Maximum daily mean, $9,300 \mathrm{mg} / \mathrm{L}$ Aug, 20,1975 , minimum daily mean, 0 mg/L on many days in 1953-59, 1963-68, 1971, 1975-77, 1980-81, 1983,1984, 1985.

SEDIMENT LOADS: Maximum daily, 4,300 tons May 23, 1966 ; minimum daily, 0 ton on many days most years.

EXTREMES FOR CURRENT YEAR.--

SPECIFIC CONDUCTANCE: Maximum daily, 1600 microsiemens Feb, 18, minimum daily, 220 microsiemens Sept. $22,23$. WATER TEMPERATURES: Maximum daily, $25.0^{\circ} \mathrm{C}$ July 24 , Aug. 13, Sep. 5,6 , minimum daily, $0.0^{\circ} \mathrm{C}$ on many days during winter period.

SEDIMENT CONCENTRATIONS: Maximum daily mean, $685 \mathrm{mg} / \mathrm{L}$ Feb. 21, Mar. 4, minimum dally mean, 0 mg/L on several days during september.

SEDIMENT LOADS: Maximum daily, 215 tons Feb. 21, minimum daily, 0 ton on many days during October, June, July August, and september.

SPECIFIC CONDUCTANCE, LABORATORY (MICROSIEMENS/CM AT 25 DEG. C), WATER YEAR OCTOBER 1984 TO SEPTEMBER 1985 RANDOM VALUES

\begin{tabular}{|c|c|c|c|c|c|c|c|c|c|c|c|c|}
\hline DAY & OCT & NOV & DEC & JAN & FEB & MAR & APR & MAY & JUN & JUL & AUG & SEP \\
\hline $\begin{array}{l}1 \\
2 \\
3 \\
4 \\
5\end{array}$ & $\begin{array}{l}600 \\
590 \\
610 \\
580 \\
540\end{array}$ & $\begin{array}{l}--- \\
-- \\
--\end{array}$ & $\begin{array}{l}480 \\
480 \\
480 \\
480 \\
520\end{array}$ & $\begin{array}{l}--- \\
--0 \\
500 \\
490 \\
500\end{array}$ & $\begin{array}{l}510 \\
610 \\
510 \\
660\end{array}$ & $\begin{array}{l}520 \\
520 \\
440 \\
400 \\
485\end{array}$ & $\begin{array}{l}600 \\
520 \\
480 \\
540 \\
510\end{array}$ & $\begin{array}{l}480 \\
490 \\
450 \\
440 \\
370\end{array}$ & $\begin{array}{l}420 \\
440 \\
420 \\
420 \\
400\end{array}$ & $\begin{array}{l}400 \\
400 \\
490 \\
420 \\
460\end{array}$ & $\begin{array}{l}540 \\
510 \\
560 \\
540 \\
500\end{array}$ & $\begin{array}{l}520 \\
580 \\
440 \\
580 \\
540\end{array}$ \\
\hline $\begin{array}{r}6 \\
7 \\
8 \\
9 \\
10\end{array}$ & $\begin{array}{l}-\infty \\
-- \\
-- \\
--\end{array}$ & $\begin{array}{l}\mathbf{5 0 0} \\
\mathbf{5 0 0} \\
\mathbf{5 2 0} \\
\mathbf{5 2 0} \\
\mathbf{5 2 0}\end{array}$ & $\begin{array}{l}500 \\
-510 \\
480 \\
480\end{array}$ & $\begin{array}{l}500 \\
-480 \\
520\end{array}$ & $\begin{array}{l}--0 \\
560 \\
600 \\
610 \\
--\infty\end{array}$ & $\begin{array}{l}520 \\
540 \\
510 \\
525 \\
560\end{array}$ & $\begin{array}{l}460 \\
520 \\
540 \\
440 \\
440\end{array}$ & $\begin{array}{l}440 \\
430 \\
440 \\
550 \\
440\end{array}$ & $\begin{array}{l}480 \\
405 \\
420 \\
410 \\
560\end{array}$ & $\begin{array}{l}380 \\
410 \\
380 \\
390 \\
380\end{array}$ & $\begin{array}{l}420 \\
500 \\
540 \\
440 \\
420\end{array}$ & $\begin{array}{l}540 \\
505 \\
580 \\
550 \\
560\end{array}$ \\
\hline $\begin{array}{l}11 \\
12 \\
13 \\
14 \\
15\end{array}$ & $\begin{array}{l}-- \\
470 \\
-- \\
--\end{array}$ & $\begin{array}{l}\mathbf{5 2 0} \\
\mathbf{5 2 0} \\
\mathbf{5 2 0} \\
\mathbf{5 2 0} \\
\mathbf{5 2 0}\end{array}$ & $\begin{array}{l}510 \\
450 \\
510 \\
-\end{array}$ & $\begin{array}{l}890 \\
580 \\
580 \\
510 \\
510\end{array}$ & $\begin{array}{l}940 \\
590 \\
540 \\
500 \\
460\end{array}$ & $\begin{array}{l}480 \\
580 \\
550 \\
540 \\
520\end{array}$ & $\begin{array}{l}480 \\
460 \\
500 \\
450 \\
480\end{array}$ & $\begin{array}{l}550 \\
480 \\
460 \\
480 \\
585\end{array}$ & $\begin{array}{r}405 \\
430 \\
440 \\
420 \\
520\end{array}$ & $\begin{array}{l}320 \\
390 \\
370 \\
480 \\
390\end{array}$ & $\begin{array}{l}460 \\
480 \\
470 \\
540 \\
480\end{array}$ & 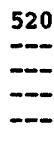 \\
\hline $\begin{array}{l}16 \\
17 \\
18 \\
19 \\
20\end{array}$ & $\begin{array}{l}-\infty \\
-- \\
-- \\
--\end{array}$ & $\begin{array}{l}450 \\
450 \\
450 \\
460 \\
460\end{array}$ & \begin{tabular}{l}
540 \\
-- \\
\hdashline 760 \\
590
\end{tabular} & $\begin{array}{l}520 \\
510 \\
610 \\
660 \\
560\end{array}$ & $\begin{array}{r}530 \\
700 \\
1600 \\
700 \\
660\end{array}$ & $\begin{array}{l}490 \\
640 \\
540 \\
530 \\
500\end{array}$ & $\begin{array}{l}510 \\
500 \\
510 \\
450 \\
490\end{array}$ & $\begin{array}{l}460 \\
440 \\
560 \\
450 \\
400\end{array}$ & $\begin{array}{l}520 \\
440 \\
440 \\
410 \\
620\end{array}$ & $\begin{array}{l}500 \\
440 \\
430 \\
440 \\
460\end{array}$ & $\begin{array}{l}440 \\
510 \\
500 \\
540 \\
460\end{array}$ & $\begin{array}{l}-- \\
-- \\
--\end{array}$ \\
\hline $\begin{array}{l}21 \\
22 \\
23 \\
24 \\
25\end{array}$ & $\begin{array}{l}-- \\
-- \\
--0 \\
510\end{array}$ & $\begin{array}{l}460 \\
460 \\
460 \\
460 \\
460\end{array}$ & $\begin{array}{l}--10 \\
610 \\
620 \\
--\end{array}$ & $\begin{array}{l}560 \\
480 \\
560 \\
840 \\
560\end{array}$ & $\begin{array}{l}340 \\
380 \\
410 \\
500 \\
540\end{array}$ & $\begin{array}{l}500 \\
520 \\
520 \\
580 \\
540\end{array}$ & $\begin{array}{l}530 \\
520 \\
500 \\
520\end{array}$ & $\begin{array}{l}440 \\
440 \\
430 \\
440 \\
440\end{array}$ & $\begin{array}{l}420 \\
520 \\
240 \\
400 \\
500\end{array}$ & $\begin{array}{l}590 \\
520 \\
560 \\
450 \\
480\end{array}$ & $\begin{array}{l}460 \\
580 \\
460 \\
420 \\
450\end{array}$ & $\begin{array}{l}-220 \\
220 \\
320 \\
270\end{array}$ \\
\hline $\begin{array}{l}26 \\
27 \\
28 \\
29 \\
30 \\
31\end{array}$ & $\begin{array}{l}- \\
- \\
560 \\
620 \\
-\end{array}$ & $\begin{array}{l}460 \\
460 \\
460 \\
450 \\
450 \\
-\end{array}$ & $\begin{array}{l}230 \\
400 \\
-\ldots \\
-\end{array}$ & $\begin{array}{l}510 \\
560 \\
480 \\
590 \\
640\end{array}$ & $\begin{array}{l}540 \\
565 \\
520 \\
-- \\
- \\
--\end{array}$ & $\begin{array}{l}535 \\
480 \\
575 \\
600 \\
610 \\
560\end{array}$ & $\begin{array}{l}450 \\
460 \\
540 \\
540 \\
560 \\
-\end{array}$ & $\begin{array}{r}400 \\
440 \\
420 \\
430 \\
660 \\
80\end{array}$ & $\begin{array}{l}420 \\
405 \\
420 \\
420 \\
380 \\
-\end{array}$ & $\begin{array}{l}530 \\
580 \\
580 \\
480 \\
540 \\
520\end{array}$ & $\begin{array}{l}450 \\
520 \\
520 \\
580 \\
500 \\
590\end{array}$ & $\begin{array}{l}360 \\
360 \\
450 \\
430 \\
420 \\
-\end{array}$ \\
\hline
\end{tabular}


05455000 RALSTON CREEK AT IOWA CITY, IA--Continued

WATER-QUALITY RECORDS

TEMPERATURE, WATER (DEG. C), WATER YEAR OCTOBER 1984 TO SEPTEMBER 1985 RANDOM VALUES

\begin{tabular}{|c|c|c|c|c|c|c|c|c|c|c|c|c|}
\hline DAY & OCT & NOV & DEC & JAN & FEB & MAR & APR & MAY & JUN & JUL & AUG & SEP \\
\hline $\begin{array}{l}1 \\
2 \\
3 \\
4 \\
5\end{array}$ & $\begin{array}{r}8.0 \\
7.0 \\
14.0 \\
14.0 \\
15.0\end{array}$ & $\begin{array}{r}10.0 \\
5.0 \\
4.0 \\
10.0 \\
5.0\end{array}$ & $\begin{array}{l}4.0 \\
4.0 \\
.0 \\
.0 \\
.0\end{array}$ & $\begin{array}{r}.0 \\
.0 \\
1.0 \\
1.0 \\
2.0\end{array}$ & $\begin{array}{r}.0 \\
.0 \\
.0 \\
.0\end{array}$ & $\begin{array}{l}7.0 \\
4.0 \\
4.0 \\
4.0 \\
3.0\end{array}$ & $\begin{array}{l}6.0 \\
8.0 \\
5.0 \\
6.0 \\
5.0\end{array}$ & $\begin{array}{r}11.0 \\
10.0 \\
9.0 \\
10.0 \\
15.0\end{array}$ & $\begin{array}{l}16.0 \\
15.0 \\
16.0 \\
13.0 \\
15.0\end{array}$ & $\begin{array}{l}17.0 \\
18.0 \\
18.0 \\
20.0 \\
18.0\end{array}$ & $\begin{array}{l}20.0 \\
20.0 \\
21.0 \\
18.0 \\
20.0\end{array}$ & $\begin{array}{l}21.0 \\
22.0 \\
22.0 \\
23.0 \\
25.0\end{array}$ \\
\hline $\begin{array}{r}6 \\
7 \\
8 \\
9 \\
10\end{array}$ & $\begin{array}{l}16.0 \\
15.0 \\
13.0 \\
17.0 \\
15.0\end{array}$ & $\begin{array}{r}6.0 \\
4.0 \\
7.0 \\
11.0 \\
5.0\end{array}$ & $\begin{array}{r}.0 \\
.0 \\
.0 \\
.0 \\
2.0\end{array}$ & $\begin{array}{r}1.0 \\
1.0 \\
1.0 \\
1.0 \\
.0\end{array}$ & $\begin{array}{r}.0 \\
.0 \\
.0 \\
1.0\end{array}$ & $\begin{array}{l}4.0 \\
5.0 \\
7.0 \\
6.0 \\
8.0\end{array}$ & $\begin{array}{l}3.0 \\
7.0 \\
3.0 \\
1.0 \\
5.0\end{array}$ & $\begin{array}{l}10.0 \\
11.0 \\
20.0 \\
12.0 \\
12.0\end{array}$ & $\begin{array}{l}16.0 \\
20.0 \\
20.0 \\
20.0 \\
16.0\end{array}$ & $\begin{array}{l}20.0 \\
20.0 \\
20.0 \\
20.0 \\
21.0\end{array}$ & $\begin{array}{l}20.0 \\
21.0 \\
22.0 \\
22.0 \\
22.0\end{array}$ & $\begin{array}{l}25.0 \\
22.5 \\
23.0 \\
22.0 \\
21.0\end{array}$ \\
\hline $\begin{array}{l}11 \\
12 \\
13 \\
14 \\
15\end{array}$ & $\begin{array}{l}18.0 \\
18.0 \\
18.0 \\
17.0 \\
15.0\end{array}$ & $\begin{array}{l}5.0 \\
5.0 \\
5.0 \\
5.0 \\
5.0\end{array}$ & $\begin{array}{r}2.0 \\
1.0 \\
1.0 \\
1.0 \\
.0\end{array}$ & $\begin{array}{r}.0 \\
-0 \\
.0 \\
.0\end{array}$ & $\begin{array}{r}1.0 \\
.0 \\
1.0 \\
1.0 \\
.0\end{array}$ & $\begin{array}{l}8.5 \\
8.0 \\
7.0 \\
7.0 \\
9.0\end{array}$ & $\begin{array}{r}5.0 \\
7.0 \\
10.0 \\
9.0 \\
5.0\end{array}$ & $\begin{array}{l}15.0 \\
16.0 \\
18.0 \\
16.0 \\
12.0\end{array}$ & $\begin{array}{l}14.0 \\
14.0 \\
15.0 \\
14.0 \\
20.0\end{array}$ & $\begin{array}{l}20.0 \\
20.0 \\
24.0 \\
21.0 \\
19.0\end{array}$ & $\begin{array}{l}22.0 \\
23.0 \\
25.0 \\
22.0 \\
23.0\end{array}$ & $\begin{array}{r}18.0 \\
- \\
-\end{array}$ \\
\hline $\begin{array}{l}16 \\
17 \\
18 \\
19 \\
20\end{array}$ & $\begin{array}{l}11.0 \\
10.0 \\
11.0 \\
10.0 \\
10.0\end{array}$ & $\begin{array}{l}4.0 \\
6.0 \\
4.0 \\
1.0 \\
1.0\end{array}$ & $\begin{array}{l}4.0 \\
.0 \\
.0 \\
.0 \\
.0\end{array}$ & $\begin{array}{l}.0 \\
.5 \\
.0 \\
.0 \\
.0\end{array}$ & $\begin{array}{l}1.5 \\
1.5 \\
3.0 \\
2.0 \\
2.0\end{array}$ & $\begin{array}{l}8.0 \\
9.0 \\
8.0 \\
0.0 \\
2.0\end{array}$ & $\begin{array}{r}8.0 \\
8.0 \\
14.0 \\
12.0 \\
20.0\end{array}$ & $\begin{array}{l}11.0 \\
10.0 \\
11.0 \\
20.0 \\
15.0\end{array}$ & $\begin{array}{l}15.0 \\
17.0 \\
16.0 \\
15.0 \\
16.0\end{array}$ & $\begin{array}{l}18.0 \\
18.0 \\
24.0 \\
22.5 \\
24.0\end{array}$ & $\begin{array}{l}19.5 \\
23.5 \\
21.0 \\
22.0 \\
18.0\end{array}$ & $\begin{array}{l}-m \\
-- \\
--\end{array}$ \\
\hline $\begin{array}{l}21 \\
22 \\
23 \\
24 \\
25\end{array}$ & $\begin{array}{r}10.0 \\
7.0 \\
5.0 \\
5.0 \\
8.0\end{array}$ & $\begin{array}{r}1.0 \\
.0 \\
.0 \\
.0 \\
1.0\end{array}$ & $\begin{array}{r}0 \\
.0 \\
.0 \\
-- \\
--\end{array}$ & $\begin{array}{r}10 \\
1.0 \\
1.0 \\
.0 \\
1.0\end{array}$ & $\begin{array}{r}10 \\
2.0 \\
3.0 \\
3.0 \\
3.0\end{array}$ & $\begin{array}{r}10.0 \\
8.0 \\
7.0 \\
6.0 \\
6.0\end{array}$ & $\begin{array}{l}20.0 \\
16.0 \\
15.0 \\
12.0 \\
14.0\end{array}$ & $\begin{array}{l}11.0 \\
18.0 \\
15.0 \\
18.0 \\
17.0\end{array}$ & $\begin{array}{l}18.0 \\
19.0 \\
20.0 \\
19.0 \\
19.0\end{array}$ & $\begin{array}{l}23.0 \\
23.0 \\
24.0 \\
25.0 \\
22.5\end{array}$ & $\begin{array}{l}15.0 \\
18.0 \\
18.0 \\
19.0 \\
17.0\end{array}$ & $\begin{array}{l}15.0 \\
15.0 \\
14.0 \\
14.0 \\
13.0\end{array}$ \\
\hline $\begin{array}{l}26 \\
27 \\
28 \\
29 \\
30 \\
31\end{array}$ & $\begin{array}{r}9.0 \\
15.0 \\
8.0 \\
5.0 \\
10.0 \\
8.0\end{array}$ & $\begin{array}{l}3.0 \\
7.0 \\
2.0 \\
4.0 \\
4.0 \\
-\end{array}$ & $\begin{array}{r}2.0 \\
4.0 \\
-.0 \\
.0\end{array}$ & $\begin{array}{r}-0 \\
-0 \\
.0 \\
.0 \\
.0\end{array}$ & $\begin{array}{l}4.0 \\
4.0 \\
5.0 \\
-\ldots \\
-- \\
--\end{array}$ & $\begin{array}{l}1.0 \\
2.0 \\
2.0 \\
9.0 \\
7.0 \\
3.0\end{array}$ & $\begin{array}{l}12.0 \\
10.0 \\
10.0 \\
10.0 \\
12.0 \\
\ldots\end{array}$ & $\begin{array}{l}16.0 \\
18.0 \\
16.0 \\
14.0 \\
15.0 \\
20.0\end{array}$ & $\begin{array}{r}20.0 \\
20.0 \\
16.0 \\
17.0 \\
18.0 \\
-.\end{array}$ & $\begin{array}{l}20.0 \\
23.0 \\
20.0 \\
20.0 \\
20.0 \\
20.0\end{array}$ & $\begin{array}{l}17.0 \\
18.5 \\
19.5 \\
20.0 \\
20.0 \\
18.0\end{array}$ & $\begin{array}{r}12.0 \\
15.0 \\
12.0 \\
11.0 \\
10.0 \\
\end{array}$ \\
\hline
\end{tabular}

SUSPENDED-SEDIMENT, WATER YEAR OCTOBER 1984 TO SEPTEMBER 1985

\begin{tabular}{|c|c|c|c|c|c|c|c|c|c|c|c|c|}
\hline \multirow[t]{2}{*}{ DAY } & $\begin{array}{c}\text { MEAN } \\
\text { CONCEN- } \\
\text { TRATION } \\
\text { (MG/L) }\end{array}$ & $\begin{array}{l}\text { LOADS } \\
\text { (T/DAY) }\end{array}$ & $\begin{array}{c}\text { MEAN } \\
\text { CONCEN- } \\
\text { TRATION } \\
\text { (MG/L) }\end{array}$ & $\begin{array}{l}\text { LOADS } \\
\text { (T/DAY) }\end{array}$ & $\begin{array}{c}\text { MEAN } \\
\text { CONCEN- } \\
\text { TRATION } \\
\text { (MG/L) }\end{array}$ & $\begin{array}{l}\text { LOADS } \\
\text { (T/DAY) }\end{array}$ & $\begin{array}{l}\text { MEAN } \\
\text { CONCEN- } \\
\text { TRATION } \\
\text { (MG/L) }\end{array}$ & $\begin{array}{l}\text { LOADS } \\
\text { (T/DAY) }\end{array}$ & $\begin{array}{l}\text { MEAN } \\
\text { CONCEN- } \\
\text { TRATION } \\
\text { (MG/L) }\end{array}$ & $\begin{array}{l}\text { LOADS } \\
\text { (T/DAY) }\end{array}$ & $\begin{array}{c}\text { MEAN } \\
\text { CONCEN- } \\
\text { TRATION } \\
\text { (MG/L) }\end{array}$ & $\begin{array}{l}\text { LOADS } \\
\text { (T/DAY) }\end{array}$ \\
\hline & \multicolumn{2}{|c|}{ OCTOBER } & \multicolumn{2}{|c|}{ NOV EMBER } & \multicolumn{2}{|c|}{ DECEMBER } & \multicolumn{2}{|c|}{ JANUARY } & \multicolumn{2}{|c|}{ FEBRUARY } & \multicolumn{2}{|c|}{ MARCB } \\
\hline $\begin{array}{l}1 \\
2 \\
3 \\
4 \\
5\end{array}$ & $\begin{array}{l}47 \\
25 \\
15 \\
19 \\
26\end{array}$ & $\begin{array}{l}.00 \\
.00 \\
.00 \\
.00 \\
.00\end{array}$ & $\begin{array}{r}534 \\
64 \\
62 \\
63 \\
50\end{array}$ & $\begin{array}{l}50 \\
1.2 \\
.84 \\
.63 \\
.42\end{array}$ & $\begin{array}{l}62 \\
82 \\
71 \\
70 \\
62\end{array}$ & $\begin{array}{l}.20 \\
.33 \\
.19 \\
.16 \\
.15\end{array}$ & $\begin{array}{r}88 \\
101 \\
66 \\
56 \\
38\end{array}$ & $\begin{array}{l}.81 \\
.90 \\
.52 \\
.45 \\
.30\end{array}$ & $\begin{array}{l}37 \\
35 \\
28 \\
35 \\
48\end{array}$ & $\begin{array}{l}.10 \\
.09 \\
.07 \\
.09 \\
.12\end{array}$ & $\begin{array}{r}74 \\
47 \\
422 \\
685 \\
160\end{array}$ & $\begin{array}{l}.90 \\
23^{.11} \\
54 \\
2.7\end{array}$ \\
\hline $\begin{array}{r}6 \\
7 \\
8 \\
9 \\
10\end{array}$ & $\begin{array}{l}57 \\
15 \\
31 \\
60 \\
28\end{array}$ & $\begin{array}{l}.02 \\
.00 \\
.00 \\
.06 \\
.01\end{array}$ & $\begin{array}{r}46 \\
45 \\
43 \\
69 \\
100\end{array}$ & $\begin{array}{l}.50 \\
.26 \\
.24 \\
2.0 \\
1.1\end{array}$ & $\begin{array}{l}77 \\
57 \\
59 \\
70 \\
43\end{array}$ & $\begin{array}{r}.15 \\
.12 \\
.15 \\
.19 \\
.13\end{array}$ & $\begin{array}{l}43 \\
47 \\
42 \\
50 \\
35\end{array}$ & $\begin{array}{l}.31 \\
.27 \\
.20 \\
.23 \\
.15\end{array}$ & $\begin{array}{l}36 \\
42 \\
58 \\
52 \\
56\end{array}$ & $\begin{array}{l}.09 \\
.10 \\
.14 \\
.13 \\
.15\end{array}$ & $\begin{array}{r}85 \\
105 \\
97 \\
67 \\
63\end{array}$ & $\begin{array}{c}1.0 \\
1.2 \\
.92 \\
.56 \\
.49\end{array}$ \\
\hline $\begin{array}{l}11 \\
12 \\
13 \\
14 \\
15\end{array}$ & $\begin{array}{r}105 \\
108 \\
67 \\
52 \\
280\end{array}$ & $\begin{array}{l}1.2 \\
.15 \\
.05 \\
.03 \\
5.5\end{array}$ & $\begin{array}{l}72 \\
70 \\
69 \\
68 \\
70\end{array}$ & $\begin{array}{l}.52 \\
.43 \\
.39 \\
.39 \\
.34\end{array}$ & $\begin{array}{l}33 \\
29 \\
32 \\
74 \\
66\end{array}$ & $\begin{array}{l}.11 \\
.10 \\
.10 \\
.66 \\
.46\end{array}$ & $\begin{array}{l}28 \\
31 \\
31 \\
28 \\
41\end{array}$ & $\begin{array}{l}.11 \\
.12 \\
.12 \\
.11 \\
.15\end{array}$ & $\begin{array}{l}77 \\
49 \\
54 \\
64 \\
65\end{array}$ & $\begin{array}{l}.20 \\
.13 \\
.16 \\
.21 \\
.23\end{array}$ & $\begin{array}{l}64 \\
48 \\
39 \\
32 \\
42\end{array}$ & $\begin{array}{l}.54 \\
.31 \\
.28 \\
.19 \\
.23\end{array}$ \\
\hline $\begin{array}{l}16 \\
17 \\
18 \\
19 \\
20\end{array}$ & $\begin{array}{r}487 \\
365 \\
671 \\
244 \\
92\end{array}$ & $\begin{array}{c}36 \\
4.0 \\
164 \\
19 \\
1.1\end{array}$ & $\begin{array}{r}72 \\
75 \\
88 \\
107 \\
77\end{array}$ & $\begin{array}{l}.29 \\
.32 \\
.38 \\
.38 \\
.25\end{array}$ & $\begin{array}{l}76 \\
69 \\
69 \\
44 \\
49\end{array}$ & $\begin{array}{l}.74 \\
.41 \\
.30 \\
.17 \\
.17\end{array}$ & $\begin{array}{l}43 \\
25 \\
27 \\
15 \\
37\end{array}$ & $\begin{array}{l}.16 \\
.09 \\
.09 \\
.05 \\
.13\end{array}$ & $\begin{array}{r}74 \\
53 \\
215 \\
110 \\
82\end{array}$ & $\begin{array}{l}.30 \\
.24 \\
4.6 \\
7.7 \\
2.2\end{array}$ & $\begin{array}{l}73 \\
80 \\
67 \\
45 \\
36\end{array}$ & $\begin{array}{l}.37 \\
.39 \\
.31 \\
.21 \\
.15\end{array}$ \\
\hline $\begin{array}{l}21 \\
22 \\
23 \\
24 \\
25\end{array}$ & $\begin{array}{r}110 \\
78 \\
100 \\
122 \\
82\end{array}$ & $\begin{array}{l}1.4 \\
.67 \\
.73 \\
.82 \\
.86\end{array}$ & $\begin{array}{l}59 \\
80 \\
79 \\
83 \\
83\end{array}$ & $\begin{array}{l}.19 \\
.26 \\
.28 \\
.27 \\
.27\end{array}$ & $\begin{array}{l}75 \\
41 \\
22 \\
20 \\
17\end{array}$ & $\begin{array}{l}.61 \\
.17 \\
.07 \\
.05 \\
.03\end{array}$ & $\begin{array}{l}38 \\
39 \\
30 \\
30 \\
23\end{array}$ & $\begin{array}{l}.12 \\
.13 \\
.10 \\
.10 \\
.07\end{array}$ & $\begin{array}{r}685 \\
450 \\
407 \\
220 \\
78\end{array}$ & $\begin{array}{r}215 \\
46 \\
24 \\
8.9 \\
1.8\end{array}$ & $\begin{array}{l}55 \\
53 \\
70 \\
33 \\
24\end{array}$ & $\begin{array}{l}.24 \\
.23 \\
.34 \\
.15 \\
.09\end{array}$ \\
\hline $\begin{array}{l}26 \\
27 \\
28 \\
29 \\
30 \\
31\end{array}$ & $\begin{array}{r}80 \\
153 \\
97 \\
65 \\
91 \\
218\end{array}$ & $\begin{array}{c}15^{.65} \\
3.4 \\
.84 \\
.84\end{array}$ & $\begin{array}{l}94 \\
71 \\
56 \\
60 \\
70 \\
--\end{array}$ & $\begin{array}{l}.33 \\
.56 \\
.20 \\
.21 \\
.23 \\
--.\end{array}$ & $\begin{array}{r}16 \\
442 \\
385 \\
100 \\
75 \\
63\end{array}$ & $\begin{array}{l}43^{.06} \\
14 \\
3.2 \\
.91 \\
.58\end{array}$ & $\begin{array}{l}28 \\
32 \\
33 \\
32 \\
22 \\
18\end{array}$ & $\begin{array}{l}.09 \\
.10 \\
.10 \\
.10 \\
.07 \\
.05\end{array}$ & $\begin{array}{r}62 \\
75 \\
93 \\
-- \\
-- \\
--\end{array}$ & \begin{tabular}{c}
1.1 \\
.89 \\
1.1 \\
\hdashline- \\
\hdashline-
\end{tabular} & $\begin{array}{r}27 \\
40 \\
34 \\
25 \\
90 \\
210\end{array}$ & $\begin{array}{l}.10 \\
.25 \\
.28 \\
.11 \\
.51 \\
4.5\end{array}$ \\
\hline TOTAL & -- & 297.33 & -- & 63.68 & -- & 67.67 & --- & 6.30 & -- & 315.84 & $\cdots$ & 94.96 \\
\hline
\end{tabular}


05455000 RALSTON CREER AT IOWA CITY, IA--Continued

WATER-QUALITY RECORDS

SUSPENDED-SEDIMENT, WATER YEAR OCTOBER 1984 TO SEPTEMBER 1985

\begin{tabular}{|c|c|c|c|c|c|c|c|c|c|c|c|c|}
\hline \multirow[t]{2}{*}{ DAY } & $\begin{array}{c}\text { MEAN } \\
\text { CONCEN- } \\
\text { TRATION } \\
(\text { MG/L) }\end{array}$ & $\begin{array}{l}\text { LOADS } \\
\text { (T/DAY) }\end{array}$ & $\begin{array}{c}\text { MEAN } \\
\text { CONCEN- } \\
\text { TRATION } \\
(\text { MG/L) }\end{array}$ & $\begin{array}{l}\text { LOADS } \\
\text { (T/DAY) }\end{array}$ & $\begin{array}{c}\text { MEAN } \\
\text { CONCEN- } \\
\text { TRATION } \\
\text { (MG/L) }\end{array}$ & $\begin{array}{l}\text { LOADS } \\
\text { (T/DAY) }\end{array}$ & $\begin{array}{c}\text { MEAN } \\
\text { CONCEN- } \\
\text { TRATION } \\
(\text { MG/L) }\end{array}$ & $\begin{array}{l}\text { LOADS } \\
\text { (T/DAY) }\end{array}$ & $\begin{array}{c}\text { MEAN } \\
\text { CONCEN- } \\
\text { TRATION } \\
\text { (MG/L) }\end{array}$ & $\begin{array}{l}\text { LOADS } \\
\text { (T/DAY) }\end{array}$ & $\begin{array}{c}\text { MEAN } \\
\text { CONCEN- } \\
\text { TRATION } \\
\text { (MG/L) }\end{array}$ & $\begin{array}{l}\text { LOADS } \\
\text { (T/DAY) }\end{array}$ \\
\hline & \multicolumn{2}{|c|}{ APRIL } & \multicolumn{2}{|c|}{ MAY } & \multicolumn{2}{|c|}{ JUNE } & \multicolumn{2}{|c|}{ JULY } & \multicolumn{2}{|c|}{ AUGUST } & \multicolumn{2}{|c|}{ SEPTEMBER } \\
\hline $\begin{array}{l}1 \\
2 \\
3 \\
4 \\
5\end{array}$ & $\begin{array}{r}65 \\
67 \\
99 \\
56 \\
106\end{array}$ & $\begin{array}{l}.60 \\
.49 \\
.61 \\
.32 \\
.83\end{array}$ & $\begin{array}{r}88 \\
73 \\
77 \\
82 \\
145\end{array}$ & $\begin{array}{l}.29 \\
.15 \\
.14 \\
.13 \\
.30\end{array}$ & $\begin{array}{l}32 \\
31 \\
30 \\
29 \\
27\end{array}$ & $\begin{array}{l}.01 \\
.01 \\
.00 \\
.01 \\
.01\end{array}$ & $\begin{array}{r}185 \\
94 \\
70 \\
60 \\
53\end{array}$ & $\begin{array}{l}.05 \\
.03 \\
.02 \\
.00 \\
.00\end{array}$ & $\begin{array}{l}52 \\
25 \\
19 \\
37 \\
54\end{array}$ & $\begin{array}{l}.02 \\
.00 \\
.00 \\
.00 \\
.00\end{array}$ & $\begin{array}{l}43 \\
32 \\
27 \\
36 \\
24\end{array}$ & $\begin{array}{l}.00 \\
.00 \\
.00 \\
.00 \\
.00\end{array}$ \\
\hline $\begin{array}{r}6 \\
7 \\
8 \\
9 \\
10\end{array}$ & $\begin{array}{l}98 \\
90 \\
87 \\
72 \\
55\end{array}$ & $\begin{array}{l}.56 \\
.44 \\
.42 \\
.35 \\
.28\end{array}$ & $\begin{array}{r}114 \\
100 \\
74 \\
38 \\
34\end{array}$ & $\begin{array}{l}.26 \\
.18 \\
.13 \\
.05 \\
.05\end{array}$ & $\begin{array}{l}25 \\
24 \\
23 \\
21 \\
91\end{array}$ & $\begin{array}{l}.00 \\
.00 \\
.00 \\
.00 \\
.03\end{array}$ & $\begin{array}{l}48 \\
47 \\
46 \\
44 \\
42\end{array}$ & $\begin{array}{l}.00 \\
.00 \\
.00 \\
.00 \\
.00\end{array}$ & $\begin{array}{r}58 \\
44 \\
40 \\
76 \\
116\end{array}$ & $\begin{array}{l}.00 \\
.00 \\
.00 \\
.12 \\
.60\end{array}$ & $\begin{array}{l}30 \\
46 \\
84 \\
92 \\
59\end{array}$ & $\begin{array}{l}.00 \\
.00 \\
.00 \\
.00 \\
.00\end{array}$ \\
\hline $\begin{array}{l}11 \\
12 \\
13 \\
14 \\
15\end{array}$ & $\begin{array}{l}70 \\
74 \\
71 \\
70 \\
81\end{array}$ & $\begin{array}{l}.32 \\
.32 \\
.33 \\
.26 \\
.31\end{array}$ & $\begin{array}{r}83 \\
46 \\
61 \\
172 \\
64\end{array}$ & $\begin{array}{l}.17 \\
.10 \\
.10 \\
.51 \\
.17\end{array}$ & $\begin{array}{l}66 \\
122 \\
112 \\
129 \\
119\end{array}$ & $\begin{array}{l}.03 \\
.14 \\
.07 \\
.08 \\
.20\end{array}$ & $\begin{array}{l}182 \\
152 \\
129 \\
260 \\
352\end{array}$ & $\begin{array}{l}.08 \\
.03 \\
.02 \\
.56 \\
.23\end{array}$ & $\begin{array}{l}49 \\
42 \\
56 \\
30 \\
36\end{array}$ & $\begin{array}{l}.03 \\
.03 \\
.04 \\
.01 \\
.01\end{array}$ & \begin{tabular}{c}
53 \\
--- \\
\hdashline-- \\
---
\end{tabular} & \begin{tabular}{c}
.00 \\
\hdashline.- \\
\hdashline-0 \\
\hdashline-0
\end{tabular} \\
\hline $\begin{array}{l}16 \\
17 \\
18 \\
19 \\
20\end{array}$ & $\begin{array}{l}61 \\
56 \\
82 \\
68 \\
40\end{array}$ & $\begin{array}{l}.23 \\
.14 \\
.24 \\
.18 \\
.10\end{array}$ & $\begin{array}{r}122 \\
93 \\
33 \\
26 \\
126\end{array}$ & $\begin{array}{l}.30 \\
.19 \\
.05 \\
.03 \\
.23\end{array}$ & $\begin{array}{l}70 \\
65 \\
75 \\
60 \\
50\end{array}$ & $\begin{array}{l}.05 \\
.03 \\
.03 \\
.02 \\
.02\end{array}$ & $\begin{array}{r}118 \\
77 \\
61 \\
55 \\
60\end{array}$ & $\begin{array}{l}.03 \\
.01 \\
.00 \\
.00 \\
.00\end{array}$ & $\begin{array}{l}57 \\
94 \\
25 \\
26 \\
67\end{array}$ & $\begin{array}{l}.02 \\
.05 \\
.00 \\
.00 \\
.00\end{array}$ & 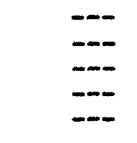 & $\begin{array}{l}=- \\
=- \\
\square- \\
--\end{array}$ \\
\hline $\begin{array}{l}21 \\
22 \\
23 \\
24 \\
25\end{array}$ & $\begin{array}{r}20 \\
45 \\
100 \\
62 \\
75\end{array}$ & $\begin{array}{l}.05 \\
.15 \\
.41 \\
.23 \\
.22\end{array}$ & $\begin{array}{r}166 \\
133 \\
82 \\
58 \\
48\end{array}$ & $\begin{array}{l}.22 \\
.16 \\
.09 \\
.06 \\
.05\end{array}$ & $\begin{array}{l}120 \\
163 \\
270 \\
150 \\
209\end{array}$ & $\begin{array}{r}.06 \\
.48 \\
1.7 \\
.17 \\
.10\end{array}$ & $\begin{array}{l}80 \\
60 \\
57 \\
80 \\
74\end{array}$ & $\begin{array}{l}.00 \\
.00 \\
.00 \\
.03 \\
.03\end{array}$ & $\begin{array}{l}50 \\
81 \\
57 \\
86 \\
98\end{array}$ & $\begin{array}{l}.00 \\
.02 \\
.00 \\
.03 \\
.00\end{array}$ & $\begin{array}{r}39 \\
91 \\
399 \\
225 \\
240\end{array}$ & $\begin{array}{r}.00 \\
.15 \\
.7 \\
.21 \\
.48\end{array}$ \\
\hline $\begin{array}{l}26 \\
27 \\
28 \\
29 \\
30 \\
31\end{array}$ & $\begin{array}{r}99 \\
70 \\
63 \\
60 \\
84 \\
-\end{array}$ & $\begin{array}{l}.21 \\
.14 \\
.13 \\
.11 \\
.23 \\
.\end{array}$ & $\begin{array}{l}46 \\
44 \\
42 \\
39 \\
35 \\
34\end{array}$ & $\begin{array}{l}.04 \\
.04 \\
.05 \\
.03 \\
.03 \\
.02\end{array}$ & $\begin{array}{l}191 \\
177 \\
143 \\
135 \\
180 \\
-\end{array}$ & $\begin{array}{l}.07 \\
.07 \\
.05 \\
.04 \\
.05 \\
.--\end{array}$ & $\begin{array}{r}37 \\
29 \\
39 \\
43 \\
103 \\
119\end{array}$ & $\begin{array}{l}.00 \\
.00 \\
.00 \\
.00 \\
.05 \\
.29\end{array}$ & $\begin{array}{l}60 \\
50 \\
39 \\
32 \\
24 \\
27\end{array}$ & $\begin{array}{l}.00 \\
.00 \\
.00 \\
.00 \\
.00 \\
.00\end{array}$ & $\begin{array}{r}159 \\
40 \\
32 \\
48 \\
60 \\
-\end{array}$ & $\begin{array}{l}.26 \\
.02 \\
.00 \\
.03 \\
.18 \\
\end{array}$ \\
\hline TOTAL & -- & 9.21 & -- & 4.32 & --- & 3.53 & --- & 1.46 & -- & 0.98 & -- & 18.33 \\
\hline
\end{tabular}

TOTAL LOAD FOR YEAR: 883.61 TONS. 
EOCATION.--Lat $41^{\circ} 39^{\prime} 05^{\prime}$, long $91^{\circ} 30^{\prime} 27^{*}$, in SW1/4 NEl/4 sec.14, T.79 N., R.6 w., Johnson County, Hydrologic Unit 07080209, on right bank $60 \mathrm{ft}$ downstream from bridge on Muscatine Avenue in Iowa City, and 1.2 mi upstream from mouth.

DRAINAGE AREA. $--2.94 \mathrm{mi}^{2}$.

PERIOD OF RECORD.--October 1963 to current year.

REVISED RECORDS.--WDR IOWA 1966: Drainage area.

GAGE.--Water-stage recorder and V-notch sharp-crested weir. Datum of gage is 678.03 ft above NGVD.

REMARKs.--Estimated daily discharges: Dec. 5-7, 18-19, 23-25, Jan. 1-4, Jan. 9 to Feb. 19. Records good except for periods of estimated daily discharge, which are poor.

AVERAGE DISCHARGE, -22 years, $2.45 \mathrm{ft} / \mathrm{s}, 11.3 \mathrm{in} / \mathrm{yr}^{\circ}, 1.780 \mathrm{acre}-\mathrm{ft} / \mathrm{yr}$.

EXTREMES FOR PERIOD OF RECORD,--Maximum discharge, 1,070 ft/s July 17, 1972 , gage height, $9.47 \mathrm{ft}$, no flow at times most years.

EXTREMES OUTSIDE PERIOD OF RECORD,--Plood of July 14, 1962, reached a stage of 10.5 ft, from flood profile, discharge not determined.

EXTREMES FOR CURRENT YEAR.-- Peak discharges greater than base discharge of 200 ft'/8, and maximum (*):

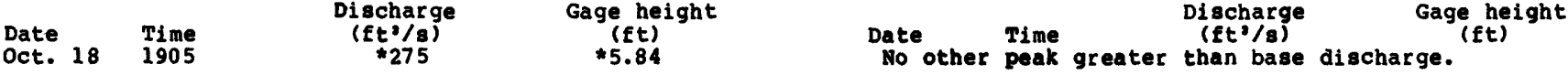

No flow July 29, Sept. 3-20.

DISCHARGE, IN CUBIC FEET PER SECOND, WATER YEAR OCTOBER 1984 TO SEPTEYBER 1985 MEAN VALUES

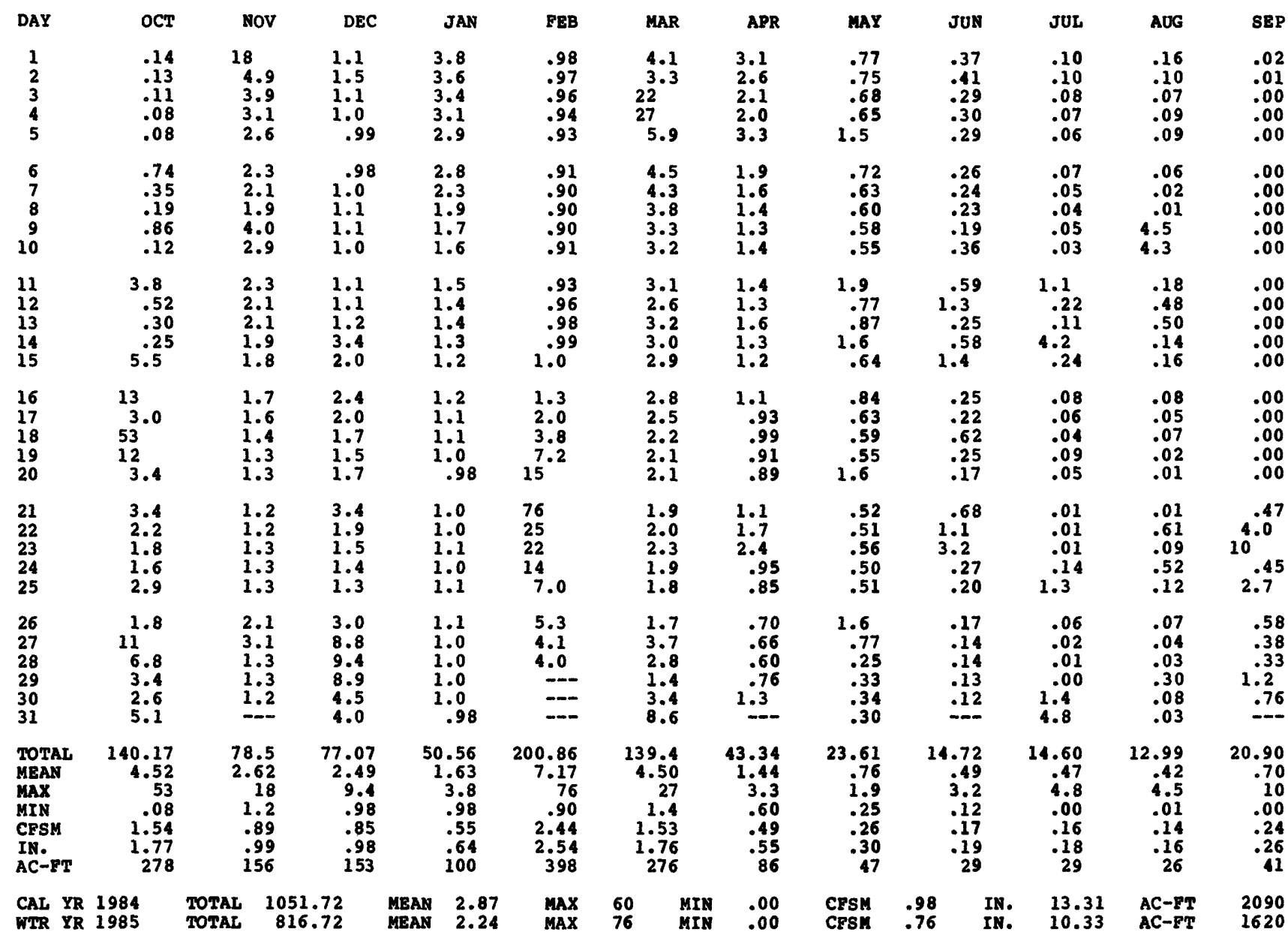


LOCATION.--Lat. $41^{\circ} 36^{\prime} 23^{\prime \prime}$, long. $91^{\circ} 36^{\prime} 56^{\prime \prime}$, in SEl/4 SWl/4 NWl/4 sec. 36 , T.79 N., R. 7 W., Johnson County, Hydrologic Unit 07080209 , on left bank $10 \mathrm{ft}$. downstream from bridge on county highway w62, 5 miles southwest of Iowa City, 5.9 miles upstream of Dirty Face Creek, and 8.6 miles upstream from mouth.

DRAINAGE AREA.- $-201 \mathrm{mi}^{2}$.

PERIOD OF RECORD.--October 1950 to September 1964 , published in wsP 1914. Annual maximum, water years 1965-84. Occasional low-flow measurements, water years $1964-77$, October 1984 to September 1985.

GAGE.-Water-stage recorder. Datum of gage is $639.49 \mathrm{ft}$. above NGVD. Prior to Nov. 16, 1984 , nonrecording gage at same datum.

REMARKS.--Estimated daily discharges: Oct. 1 to Nov, 17, Dec, 6, 17-21, 24-28, Jan. 2 to Feb. 21, 25-27, July 3-14, July 16 to Aug. 18. Records good except those for Oct. 1 to Nov. 17, July $3-14$, July 16 to Aug. 18 , which are fair and those for Dec. 6, 17-21, 24-28, Jan. 2 to Feb. 21, 25-27, which are poor.

COOPERATION.--Two discharge measurements provided by U.S. Army Corps of Engineers.

EXTREMES FOR PERIOD OF RECORD,--Maximum discharge, 2,870 ft3/s Feb. 23, 1985, gage height, 12.22 ft.; minimum discharge $2.6 \mathrm{ft}^{2} / \mathrm{s}$ Sept. 20,1985 .

EXTREMES OUTSIDE PERIOD OF RECORD.-Maximum discharge, 13,500 ft 3 , June 15, 1982, gage height, 15.25 ft.

EXTREMES FOR CURRENT YEAR.--Peak discharges greater than base discharge base of 1,500 ft'/s and maximum (*):

\begin{tabular}{|c|c|c|c|c|c|c|c|}
\hline $\begin{array}{l}\text { Date } \\
\text { Nov. } 1 \\
\text { Feb. } 23\end{array}$ & $\begin{array}{l}\text { Time } \\
0700 \\
1100\end{array}$ & $\begin{array}{c}\text { Discharge } \\
\left(f t^{3} / s\right) \\
1,890 \\
* 2,870\end{array}$ & $\begin{array}{c}\text { Gage height } \\
\text { (ft) } \\
10.28 \\
* 12.22\end{array}$ & $\begin{array}{l}\text { Date } \\
\text { Mar. }\end{array}$ & $\begin{array}{l}\text { Time } \\
0945\end{array}$ & $\begin{array}{c}\text { Discharge } \\
\left(f t^{2} / \mathrm{s}\right) \\
2,150\end{array}$ & $\begin{array}{c}\text { Gage height } \\
(f t) \\
10.90\end{array}$ \\
\hline
\end{tabular}

Minimum daily discharge, $2.6 \mathrm{ft} / \mathrm{s}$ Sept. 20.

DISCHARGE, IN CUBIC FEET PER SECOND, WATER YEAR OCTOBER 1984 TO SEPTEMBER 1985

\begin{tabular}{|c|c|c|c|c|c|c|c|c|c|c|c|c|}
\hline DAY & OCT & NOV & DEC & JAN & FEB & MAR & APR & MAY & JUN & JUL & AUG & SEP \\
\hline $\begin{array}{l}1 \\
2 \\
3 \\
4 \\
5\end{array}$ & $\begin{array}{l}7.0 \\
4.4 \\
4.0 \\
3.7 \\
3.7\end{array}$ & $\begin{array}{r}1510 \\
508 \\
296 \\
224 \\
176\end{array}$ & $\begin{array}{l}68 \\
68 \\
63 \\
59 \\
95\end{array}$ & $\begin{array}{l}131 \\
113 \\
100 \\
105 \\
110\end{array}$ & $\begin{array}{l}48 \\
47 \\
46 \\
46 \\
46\end{array}$ & $\begin{array}{r}271 \\
246 \\
398 \\
1810 \\
1290\end{array}$ & $\begin{array}{l}271 \\
215 \\
188 \\
169 \\
158\end{array}$ & $\begin{array}{l}61 \\
55 \\
48 \\
49 \\
49\end{array}$ & $\begin{array}{l}35 \\
32 \\
31 \\
26 \\
27\end{array}$ & $\begin{array}{l}20 \\
21 \\
20 \\
18 \\
16\end{array}$ & $\begin{array}{r}19 \\
7.5 \\
5.7 \\
4.4 \\
4.4\end{array}$ & $\begin{array}{l}5.8 \\
5.1 \\
4.8 \\
4.0 \\
3.7\end{array}$ \\
\hline $\begin{array}{r}6 \\
7 \\
8 \\
9 \\
10\end{array}$ & $\begin{array}{r}4.0 \\
8.5 \\
12 \\
9.0 \\
4.4\end{array}$ & $\begin{array}{l}150 \\
138 \\
128 \\
175 \\
547\end{array}$ & $\begin{array}{r}110 \\
103 \\
101 \\
91 \\
83\end{array}$ & $\begin{array}{r}120 \\
130 \\
110 \\
90 \\
80\end{array}$ & $\begin{array}{l}46 \\
46 \\
46 \\
46 \\
47\end{array}$ & $\begin{array}{l}419 \\
325 \\
274 \\
240 \\
222\end{array}$ & $\begin{array}{l}149 \\
132 \\
121 \\
116 \\
118\end{array}$ & $\begin{array}{l}54 \\
50 \\
46 \\
42 \\
40\end{array}$ & $\begin{array}{l}27 \\
23 \\
23 \\
21 \\
18\end{array}$ & $\begin{array}{l}15 \\
14 \\
13 \\
11 \\
11\end{array}$ & $\begin{array}{l}4.0 \\
4.0 \\
4.0 \\
4.0 \\
45\end{array}$ & $\begin{array}{l}3.7 \\
3.6 \\
3.6 \\
4.3 \\
3.4\end{array}$ \\
\hline $\begin{array}{l}11 \\
12 \\
13 \\
14 \\
15\end{array}$ & $\begin{array}{l}8.5 \\
16 \\
12 \\
7.0 \\
6.1\end{array}$ & $\begin{array}{l}241 \\
196 \\
170 \\
158 \\
139\end{array}$ & $\begin{array}{l}68 \\
64 \\
51 \\
57 \\
69\end{array}$ & $\begin{array}{l}74 \\
66 \\
62 \\
60 \\
60\end{array}$ & $\begin{array}{l}47 \\
46 \\
46 \\
45 \\
45\end{array}$ & $\begin{array}{l}205 \\
187 \\
176 \\
169 \\
153\end{array}$ & $\begin{array}{r}113 \\
108 \\
102 \\
99 \\
98\end{array}$ & $\begin{array}{l}44 \\
99 \\
75 \\
78 \\
93\end{array}$ & $\begin{array}{l}22 \\
34 \\
44 \\
30 \\
31\end{array}$ & $\begin{array}{l}10 \\
9.5 \\
11 \\
13 \\
82\end{array}$ & $\begin{array}{l}61 \\
12 \\
7.5 \\
6.6 \\
5.3\end{array}$ & $\begin{array}{l}3.5 \\
3.5 \\
3.5 \\
3.4 \\
3.2\end{array}$ \\
\hline $\begin{array}{l}16 \\
17 \\
18 \\
19 \\
20\end{array}$ & $\begin{array}{r}20 \\
70 \\
143 \\
765 \\
270\end{array}$ & $\begin{array}{r}120 \\
115 \\
113 \\
103 \\
94\end{array}$ & $\begin{array}{r}115 \\
125 \\
94 \\
84 \\
82\end{array}$ & $\begin{array}{l}58 \\
56 \\
54 \\
53 \\
49\end{array}$ & $\begin{array}{r}47 \\
52 \\
70 \\
100 \\
220\end{array}$ & $\begin{array}{l}149 \\
135 \\
133 \\
134 \\
127\end{array}$ & $\begin{array}{l}94 \\
88 \\
84 \\
82 \\
77\end{array}$ & $\begin{array}{l}67 \\
65 \\
60 \\
56 \\
57\end{array}$ & $\begin{array}{l}30 \\
25 \\
23 \\
23 \\
22\end{array}$ & $\begin{array}{l}25 \\
10 \\
8.5 \\
8.0 \\
7.5\end{array}$ & $\begin{array}{r}4.9 \\
4.0 \\
4.0 \\
13 \\
3.2\end{array}$ & $\begin{array}{l}3.4 \\
3.5 \\
3.5 \\
3.3 \\
2.8\end{array}$ \\
\hline $\begin{array}{l}21 \\
22 \\
23 \\
24 \\
25\end{array}$ & $\begin{array}{r}161 \\
115 \\
93 \\
79 \\
72\end{array}$ & $\begin{array}{l}89 \\
89 \\
87 \\
83 \\
82\end{array}$ & $\begin{array}{r}100 \\
107 \\
80 \\
62 \\
58\end{array}$ & $\begin{array}{l}48 \\
52 \\
56 \\
54 \\
54\end{array}$ & $\begin{array}{r}700 \\
1550 \\
2350 \\
1180 \\
720\end{array}$ & $\begin{array}{l}114 \\
112 \\
114 \\
113 \\
104\end{array}$ & $\begin{array}{l}75 \\
70 \\
82 \\
71 \\
66\end{array}$ & $\begin{array}{l}56 \\
48 \\
46 \\
44 \\
43\end{array}$ & $\begin{array}{l}21 \\
31 \\
44 \\
81 \\
47\end{array}$ & $\begin{array}{l}6.6 \\
5.3 \\
4.0 \\
4.0 \\
60\end{array}$ & $\begin{array}{r}4.8 \\
3.5 \\
5.0 \\
14 \\
9.0\end{array}$ & $\begin{array}{l}3.7 \\
7.4 \\
27 \\
42 \\
21\end{array}$ \\
\hline $\begin{array}{l}26 \\
27 \\
28 \\
29 \\
30 \\
31\end{array}$ & $\begin{array}{r}77 \\
161 \\
326 \\
168 \\
125 \\
375\end{array}$ & $\begin{array}{r}80 \\
86 \\
85 \\
77 \\
73 \\
-\end{array}$ & $\begin{array}{r}90 \\
228 \\
646 \\
492 \\
271 \\
203\end{array}$ & $\begin{array}{l}52 \\
51 \\
50 \\
49 \\
49 \\
48\end{array}$ & $\begin{array}{l}410 \\
300 \\
262 \\
\ldots- \\
\ldots-\end{array}$ & $\begin{array}{l}102 \\
103 \\
143 \\
129 \\
109 \\
233\end{array}$ & $\begin{array}{r}64 \\
60 \\
60 \\
57 \\
58 \\
---\end{array}$ & $\begin{array}{l}42 \\
68 \\
57 \\
43 \\
40 \\
38\end{array}$ & $\begin{array}{r}32 \\
26 \\
24 \\
23 \\
21 \\
--\end{array}$ & $\begin{array}{l}46 \\
8.0 \\
4.4 \\
4.0 \\
3.4 \\
8.0\end{array}$ & $\begin{array}{l}6.9 \\
6.4 \\
6.0 \\
5.8 \\
5.9 \\
6.2\end{array}$ & $\begin{array}{c}15 \\
23 \\
8.5 \\
4.8 \\
21 \\
-\end{array}$ \\
\hline $\begin{array}{l}\text { TOTAL } \\
\text { MEAN } \\
\text { MAX } \\
\text { MIN }\end{array}$ & $\begin{array}{r}3130.3 \\
101 \\
765 \\
3.7\end{array}$ & $\begin{array}{r}6132 \\
204 \\
1510 \\
73\end{array}$ & $\begin{array}{r}3987 \\
129 \\
646 \\
51\end{array}$ & $\begin{array}{r}2244 \\
72.4 \\
131 \\
48\end{array}$ & $\begin{array}{r}8654 \\
309 \\
2350 \\
45\end{array}$ & $\begin{array}{r}8439 \\
272 \\
1810 \\
102\end{array}$ & $\begin{array}{r}3245 \\
108 \\
271 \\
57\end{array}$ & $\begin{array}{r}1713 \\
55.3 \\
99 \\
38\end{array}$ & $\begin{array}{r}897 \\
29.9 \\
81 \\
18\end{array}$ & $\begin{array}{r}497.2 \\
16.0 \\
82 \\
3.4\end{array}$ & $\begin{array}{r}297.0 \\
9.58 \\
61 \\
3.2\end{array}$ & $\begin{array}{r}249.0 \\
8.30 \\
42 \\
2.8\end{array}$ \\
\hline WTR YR & 985 & ALL & 4.5 & MEAN & 108 & MAX & 2350 & MIN & & & & \\
\hline
\end{tabular}


05455500 ENGLISH RIVER AT RALONA, IA

LOCATION.--Lat $41^{\circ} 27^{\prime} 59^{\prime \prime}$, long $91^{\circ} 42^{\prime} 56^{\prime \prime}$, in SEl/4 SEl/4 sec.13, T.77 N., R.8 W., Washington County, Bydrologic Unit 07080209 , on right bank $30 \mathrm{ft}$ upgtream from bridge on state Highway 1 , 0.8 mi south of Ralona, $1.1 \mathrm{mi}$ upstream from Camp Creek, $4.5 \mathrm{mi}$ downstream from Smith Creek, and $14.5 \mathrm{mi}$ upstream from mouth.

DRAINAGE AREA. $--573 \mathrm{mi}^{2}$.

PERIOD OF RECORD.--September 1939 to current year.

REVISED RECORDS.--WSP 1438: Drainage area, WSP 1558: 1940 (M), 1941. WSP 1708: 1956, 1957 (P), 1958 (P).

GAGE.-Water-stage recorder. Datum of gage is $633.45 \mathrm{ft}$ above NGVD (levels by 0.5 . Army Corps of Engineers). Prior to Dec. 27, 1939 , nonrecording gage $30 \mathrm{ft}$ downstream at same datum.

REMARKS.--Estimated daily discharges: Dec. 3-14, Dec, 21 to Feb. 24 and Mar. 28 to Apr. 3. Records good except those for estimated daily discharges, which are poor. 0.S. Army Corps of Engineers gage-height telemeter and data collection platform at station.

COOPERATION.--Four discharge measurements provided by 0.S. Army Corps of Engineers.

AVERAGE DISCHARGE. -46 years, $371 \mathrm{ft} / \mathrm{s}, 8.79 \mathrm{in} / \mathrm{yr}, 268,800$ acre-ft/yr; median of yearly mean discharges, 330 $\mathrm{ft}^{2} / \mathrm{s}, 7.8 \mathrm{in} / \mathrm{yr}, 239,000$ acre-ft/yr.

EXTREMES FOR PERIOD OF RECORD.--Maximum discharge, $20,000 \mathrm{ft} / \mathrm{s}$ sept. 21, 1965, gage height, $21.45 \mathrm{ft}$; minimum daily, $0.66 \mathrm{ft} / \mathrm{s}$ Feb. 5-7, 1977 .

EXTREMES OUTSIDE PERIOD OF RECORD,--Flood in June 1930 reached a stage of 19.9 ft, from floodmark, from information by local residents, discharge, $18,500 \mathrm{ft} / \mathrm{s}$.

EXTREMES FOR CURRENT YEAR.--Peak discharges greater than base of 4,000 ft/s and maximum (*):

\begin{tabular}{|c|c|c|c|c|c|}
\hline $\begin{array}{l}\text { ate } \\
\text { eb. } 23\end{array}$ & $\begin{array}{l}\text { Time } \\
1415\end{array}$ & $\begin{array}{c}\text { Discharge } \\
\left(f t^{3} / 8\right) \\
* 6,100\end{array}$ & $\begin{array}{c}\text { Gage height } \\
\text { (ft) } \\
*_{a} 16.23\end{array}$ & $\begin{array}{l}\text { Date } \\
\text { Mar. }\end{array}$ & $\begin{array}{c}\text { Gage height } \\
\text { (ft) } \\
15.58\end{array}$ \\
\hline
\end{tabular}

(a) Ice jam
Minimum daily discharge, $6.2 \mathrm{ft} / \mathrm{s}$ Sept. 20.

DISCHARGE, IN CUBIC FEET PER SECOND, WATER YEAR OCTOBER 1984 TO SEPTEMBER 1985 MEAN VALUES

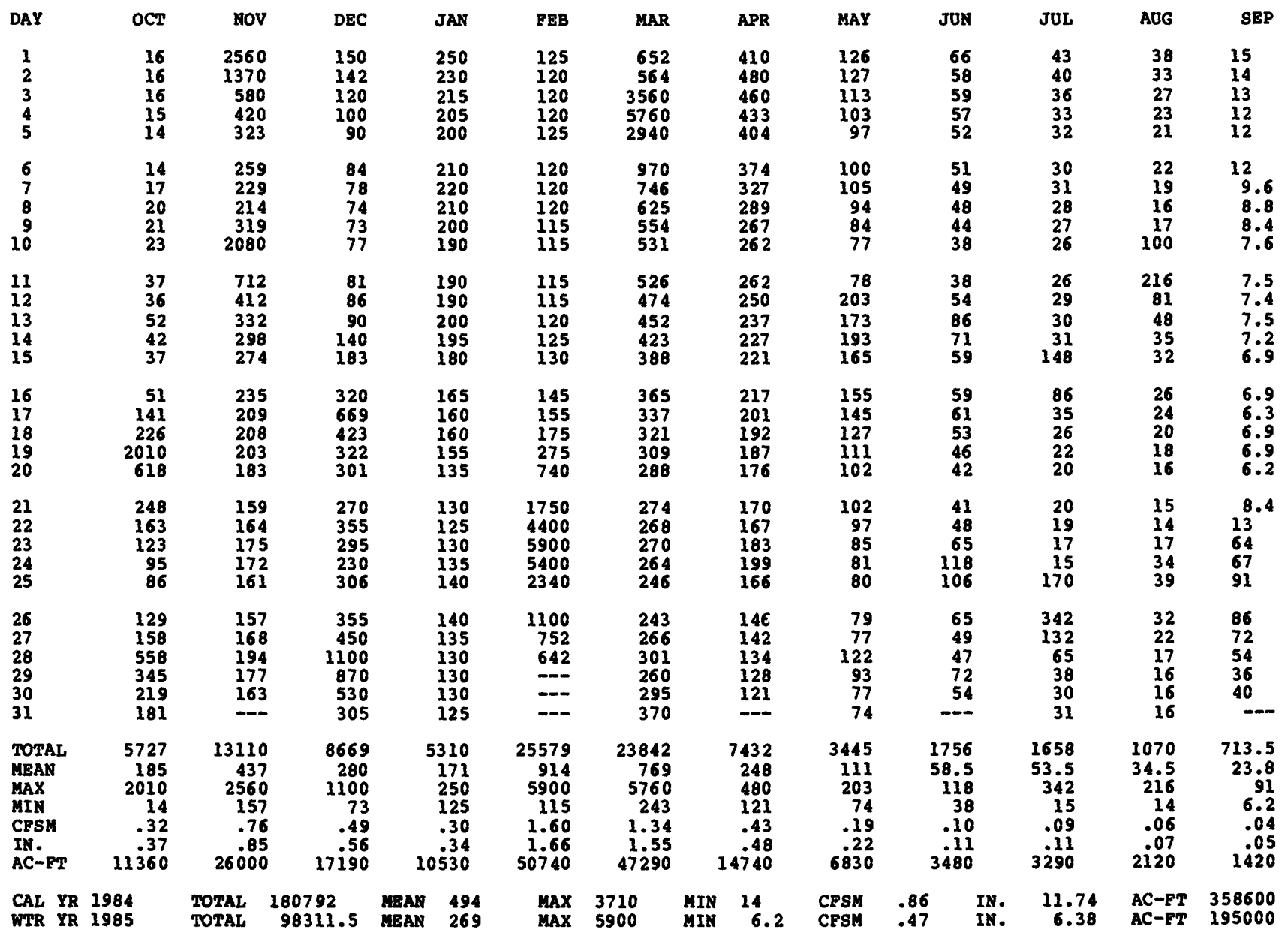


LOCATION.--Lat $41^{\circ} 25^{\prime} 15^{\prime \prime}$, long $91^{\circ} 28^{\prime 2} 5^{\prime \prime}$, in NWI/4 NEl/4 sec.6, T.76 N., R.5 W., LOuisa County, Hydrologic Unit 07080209 , on left bank $2,000 \mathrm{ft}$, downstream from new tri-county bridge on county highway w66, 5 mi southwest of Lone Tree, $6.2 \mathrm{mi}$ downstream from English River, and at mile 47.2 .

DRAINAGE AREA. $--4,293 \mathrm{mi}^{2}$.

PERIOD OF RECORD.--October 1956 to current year.

GAGE.-Water-stage recorder. Datum of gage is $588.16 \mathrm{ft}$ above NGvD. Prior to Dec. 28 , 1956 , nonrecording gage same site and datum.

REMARRS.--Estimated daily discharges: Dec, 5-10, Dec, 22 - Feb.24, April 23 to May 6, June 1-28, July 4-22, 24, Aug. 2-9, Aug. 24-26 and Sept. 17, 19, 21, 22, 28, 29, 30. Records good except those for periods of estimated record, which are poor. Flow regulated by Coralville Lake (station 05453510) $36.1 \mathrm{mi}$ upstream since Sept. 17 , 1958. U.S. Army Corps of Engineers gage-height telemeter and data collection platform at station.

COOPERATION.--Three discharge measurements provided by U.S. Army Corps of Engineers.

AVERAGE DISCHARGE.--29 years, $2,858 \mathrm{ft} / \mathrm{s}, 9.04 \mathrm{in} / \mathrm{yr}, 2,071,000 \mathrm{acre}-\mathrm{ft} / \mathrm{yr}$.

EXTREMES FOR PERIOD OF RECORD.--Maximum discharge, 35,700 ft3/s May 19, 1974, gage height, 18.97 ft; maximum gage height, $20.27 \mathrm{ft}$ Sept. 22, 1965 ; minimum daily discharge, $69 \mathrm{ft} / \mathrm{s} ; \mathrm{Aug}$. 4, 1977 .

EXTREMES OUTSIDE PERIOD OF RECORD.--Flood of May 25, 1944, reached a stage of $19.94 \mathrm{ft}$, discharge not determined, from information by U.S. Army Corps of Engineers.

EXTREMES FOR CURRENT YEAR.--Maximum discharge, 14,800 $\mathrm{ft}^{3} / \mathrm{s}$ Mar. 5 , gage height, $15.02 \mathrm{ft}$; maximum gage height, $16.16 \mathrm{ft}$ Feb.23, backwater from ice; minimum daily discharge, $183 \mathrm{ft} / \mathrm{s}$ Sept. 16 .

DISCHARGE, IN CUBIC FEET PER SECOND, WATER YEAR OCTOBER 1984 TO SEPTEMBER 1985 MEAN VALUES

\begin{tabular}{|c|c|c|c|c|c|c|c|c|c|c|c|c|}
\hline DAY & OCT & NOV & DEC & JAN & FEB & MAR & APR & MAY & JUN & JUL & AUG & SEP \\
\hline $\begin{array}{l}1 \\
2 \\
3 \\
4 \\
5\end{array}$ & $\begin{array}{l}498 \\
498 \\
503 \\
503 \\
503\end{array}$ & $\begin{array}{l}6140 \\
6080 \\
3680 \\
2970 \\
2790\end{array}$ & $\begin{array}{r}1370 \\
1250 \\
1110 \\
1010 \\
950\end{array}$ & $\begin{array}{r}4000 \\
3400 \\
1200 \\
940 \\
860\end{array}$ & $\begin{array}{l}940 \\
960 \\
920 \\
780 \\
700\end{array}$ & $\begin{array}{r}9200 \\
10000 \\
10300 \\
11700 \\
14300\end{array}$ & $\begin{array}{l}3060 \\
3380 \\
3580 \\
3540 \\
3440\end{array}$ & $\begin{array}{l}1850 \\
1830 \\
1810 \\
1830 \\
1850\end{array}$ & $\begin{array}{l}760 \\
740 \\
720 \\
720 \\
710\end{array}$ & $\begin{array}{l}711 \\
702 \\
693 \\
650 \\
550\end{array}$ & $\begin{array}{l}334 \\
310 \\
300 \\
295 \\
285\end{array}$ & $\begin{array}{l}242 \\
238 \\
238 \\
235 \\
230\end{array}$ \\
\hline $\begin{array}{r}6 \\
7 \\
8 \\
9 \\
10\end{array}$ & $\begin{array}{l}514 \\
514 \\
520 \\
520 \\
530\end{array}$ & $\begin{array}{l}2610 \\
2270 \\
2190 \\
2180 \\
4160\end{array}$ & $\begin{array}{l}880 \\
820 \\
750 \\
700 \\
770\end{array}$ & $\begin{array}{r}960 \\
1200 \\
1450 \\
1800 \\
2000\end{array}$ & $\begin{array}{l}680 \\
670 \\
660 \\
660 \\
660\end{array}$ & $\begin{array}{r}14100 \\
10900 \\
9840 \\
10100 \\
10400\end{array}$ & $\begin{array}{l}3520 \\
3600 \\
3390 \\
3350 \\
3310\end{array}$ & $\begin{array}{l}1870 \\
1850 \\
1620 \\
1410 \\
1140\end{array}$ & $\begin{array}{l}700 \\
700 \\
680 \\
640 \\
620\end{array}$ & $\begin{array}{l}530 \\
520 \\
520 \\
510 \\
430\end{array}$ & $\begin{array}{l}260 \\
250 \\
250 \\
250 \\
354\end{array}$ & $\begin{array}{l}230 \\
229 \\
222 \\
218 \\
214\end{array}$ \\
\hline $\begin{array}{l}11 \\
12 \\
13 \\
14 \\
15\end{array}$ & $\begin{array}{l}563 \\
648 \\
689 \\
689 \\
725\end{array}$ & $\begin{array}{l}4000 \\
3590 \\
3320 \\
2130 \\
1930\end{array}$ & $\begin{array}{l}1640 \\
1860 \\
1850 \\
1890 \\
1910\end{array}$ & $\begin{array}{l}1900 \\
1750 \\
1750 \\
1550 \\
1300\end{array}$ & $\begin{array}{l}650 \\
650 \\
660 \\
730 \\
880\end{array}$ & $\begin{array}{r}10600 \\
10600 \\
10500 \\
9760 \\
8460\end{array}$ & $\begin{array}{l}3050 \\
2890 \\
2870 \\
2850 \\
2640\end{array}$ & $\begin{array}{l}1090 \\
1090 \\
1090 \\
1120 \\
1130\end{array}$ & $\begin{array}{l}620 \\
660 \\
700 \\
640 \\
710\end{array}$ & $\begin{array}{l}410 \\
410 \\
440 \\
530 \\
640\end{array}$ & $\begin{array}{l}412 \\
416 \\
395 \\
363 \\
346\end{array}$ & $\begin{array}{l}210 \\
206 \\
200 \\
193 \\
189\end{array}$ \\
\hline $\begin{array}{l}16 \\
17 \\
18 \\
19 \\
20\end{array}$ & $\begin{array}{r}772 \\
1200 \\
1430 \\
5190 \\
3900\end{array}$ & $\begin{array}{l}1850 \\
1630 \\
1400 \\
1320 \\
1270\end{array}$ & $\begin{array}{l}1990 \\
2380 \\
2310 \\
2070 \\
1950\end{array}$ & $\begin{array}{r}1050 \\
1250 \\
1300 \\
1150 \\
940\end{array}$ & $\begin{array}{l}1200 \\
1300 \\
1350 \\
1300 \\
1800\end{array}$ & $\begin{array}{l}7630 \\
6580 \\
5710 \\
5110 \\
4660\end{array}$ & $\begin{array}{l}2490 \\
2440 \\
2250 \\
2110 \\
2110\end{array}$ & $\begin{array}{l}1140 \\
1110 \\
1200 \\
1240 \\
1240\end{array}$ & $\begin{array}{l}820 \\
850 \\
840 \\
820 \\
810\end{array}$ & $\begin{array}{l}680 \\
580 \\
470 \\
420 \\
410\end{array}$ & $\begin{array}{l}329 \\
305 \\
287 \\
280 \\
275\end{array}$ & $\begin{array}{l}183 \\
353 \\
749 \\
631 \\
525\end{array}$ \\
\hline $\begin{array}{l}21 \\
22 \\
23 \\
24 \\
25\end{array}$ & $\begin{array}{l}2930 \\
2670 \\
2440 \\
1570 \\
1310\end{array}$ & $\begin{array}{l}1270 \\
1430 \\
1450 \\
1430 \\
1410\end{array}$ & $\begin{array}{l}1800 \\
1400 \\
1100 \\
1300 \\
1700\end{array}$ & $\begin{array}{l}1250 \\
1200 \\
1150 \\
1150 \\
1100\end{array}$ & $\begin{array}{r}2200 \\
4800 \\
10000 \\
14000 \\
12300\end{array}$ & $\begin{array}{l}4250 \\
3760 \\
3350 \\
3110 \\
2880\end{array}$ & $\begin{array}{l}2100 \\
2030 \\
2010 \\
1990 \\
1970\end{array}$ & $\begin{array}{r}1210 \\
1080 \\
1000 \\
964 \\
1040\end{array}$ & $\begin{array}{r}800 \\
860 \\
900 \\
950 \\
1000\end{array}$ & $\begin{array}{l}400 \\
390 \\
360 \\
320 \\
364\end{array}$ & $\begin{array}{l}270 \\
261 \\
259 \\
280 \\
290\end{array}$ & $\begin{array}{l}498 \\
431 \\
519 \\
718 \\
714\end{array}$ \\
\hline $\begin{array}{l}26 \\
27 \\
28 \\
29 \\
30 \\
31\end{array}$ & $\begin{array}{l}1310 \\
1390 \\
2380 \\
2440 \\
2040 \\
1700\end{array}$ & $\begin{array}{l}1400 \\
1230 \\
1170 \\
1390 \\
1410 \\
-\end{array}$ & $\begin{array}{r}2000 \\
1300 \\
850 \\
1400 \\
3400 \\
4300\end{array}$ & $\begin{array}{r}1050 \\
1000 \\
960 \\
940 \\
930 \\
920\end{array}$ & $\begin{array}{r}5840 \\
5800 \\
7840 \\
--- \\
--- \\
---\end{array}$ & $\begin{array}{l}2710 \\
2570 \\
2530 \\
2640 \\
2720 \\
2740\end{array}$ & $\begin{array}{l}1950 \\
1940 \\
1910 \\
1900 \\
1880 \\
---\end{array}$ & $\begin{array}{r}1040 \\
974 \\
1050 \\
1050 \\
979 \\
910\end{array}$ & $\begin{array}{l}890 \\
800 \\
700 \\
714 \\
716 \\
--2\end{array}$ & $\begin{array}{l}395 \\
476 \\
400 \\
337 \\
312 \\
314\end{array}$ & $\begin{array}{l}280 \\
254 \\
250 \\
250 \\
245 \\
242\end{array}$ & $\begin{array}{l}701 \\
662 \\
650 \\
700 \\
800 \\
-\end{array}$ \\
\hline $\begin{array}{l}\text { TOTAL } \\
\text { MEAN } \\
\text { MAX } \\
\text { MIN } \\
\text { AC-FT }\end{array}$ & $\begin{array}{r}43089 \\
1390 \\
5190 \\
498 \\
85470\end{array}$ & $\begin{array}{r}71100 \\
2370 \\
6140 \\
1170 \\
141000\end{array}$ & $\begin{array}{r}50010 \\
1613 \\
4300 \\
700 \\
99190\end{array}$ & $\begin{array}{r}43400 \\
1400 \\
4000 \\
860 \\
86080\end{array}$ & $\begin{array}{r}80930 \\
2890 \\
14000 \\
650 \\
160500\end{array}$ & $\begin{array}{r}223710 \\
7216 \\
14300 \\
2530 \\
443700\end{array}$ & $\begin{array}{r}79550 \\
2652 \\
3600 \\
1880 \\
157800\end{array}$ & $\begin{array}{r}39807 \\
1284 \\
1870 \\
910 \\
78960\end{array}$ & $\begin{array}{r}22790 \\
760 \\
1000 \\
620 \\
45200\end{array}$ & $\begin{array}{r}14874 \\
480 \\
711 \\
312 \\
29500\end{array}$ & $\begin{array}{r}9177 \\
296 \\
416 \\
242 \\
18200\end{array}$ & $\begin{array}{r}12128 \\
404 \\
800 \\
183 \\
24060\end{array}$ \\
\hline $\begin{array}{ll}\text { CAL YR } \\
\text { WTR YR }\end{array}$ & $\begin{array}{l}84 \\
85\end{array}$ & $\begin{array}{l}\text { TOTAL } \\
\text { TOTAL }\end{array}$ & $\begin{array}{r}1560887 \\
690565\end{array}$ & $\begin{array}{l}\text { MEAN } \\
\text { MEAN }\end{array}$ & $\begin{array}{l}4265 \\
1892\end{array}$ & $\begin{array}{l}\text { MAX } \\
\text { MAX }\end{array}$ & $\begin{array}{l}13100 \\
14300\end{array}$ & $\begin{array}{l}\text { MIN } \\
\text { MIN }\end{array}$ & $\begin{array}{l}463 \\
183\end{array}$ & $\begin{array}{l}\mathbf{T} 309 \\
\mathrm{~T} 137\end{array}$ & & \\
\hline
\end{tabular}


LOCATION.--Lat $43^{\circ} 03^{\prime} 45^{\prime \prime}$, long $92^{\circ} 40^{\prime} 23^{\prime}$, in SEI/4 NEL/4, sec.12, T.95 N., R.16 W., Floyd County, 㫙arologic Unit 07080201 , on right bank $800 \mathrm{ft}$ downstream from bridge on U.S. Highway 18 (Brantingham Street) in Charles City, 10.6 mi upstream from Gizzard Creek, and at mile 252.9 upstream from mouth of Iowa River.

DRATNAGE AREA. $-1,054 \mathrm{mi}^{2}$.

PERTOD OF RECORD,--October 1964 to current year.

GAGE.--Mater-stage recorder. Datum of gage is $973.02 \mathrm{ft}$ above NGVD.

REMARKS.--Estimated daily discharge: Dec, 16 - 27, Jan. 1 to March 10. Records good, except for periods of estimated record, which are poor. Occasional minor regulation by dam 0.2 mi upstream from gage. Daily wireweight gage readings available in district office for period Sept. 13, 1945, to June 30, 1954, at same site and daturm. Discharge not published for this period because of extrene regulation of streanflow by power dam $0.2 \mathrm{mi}$ upstream. National Weather Service gage-height teleneter at station.

AVERAGE DISCHARGE.-21 years, $732 \mathrm{ft} / \mathrm{s}, 9.43 \mathrm{in} / \mathrm{yr}, 530,300 \mathrm{acre}-\mathrm{ft} / \mathrm{yr}$.

EXIREIISS FOR PERIOD OF RECORD.-Waximu discharge, 21,000 ft/s Apr. 7, 1965, gage height, $19.14 \mathrm{ft}$; maximum gage height, $21.64 \mathrm{ft}$ Mar. 2, 1965, backwater from ice, minimu daily discharge, $60 \mathrm{ft} / \mathrm{s}$ Nov. 23, 1977, Jan. 7. 1978.

EXIREMES OUISIDE PERIOD OF REDORD.-Flood of Mar. 27, 1961, reached a stage of $21.6 \mathrm{ft}$, from floodnarks, discharge, 29,200 ft: $/ \mathrm{s}$.

EXIREVES FOR CURRENT YEAR.-Peak discharges greater than base of $3,600 \mathrm{ft} / \mathrm{s}$ and maximm (*):

\begin{tabular}{|c|c|c|c|c|c|c|c|}
\hline $\begin{array}{l}\text { ate } \\
\text { eb. } 24\end{array}$ & Time & $\begin{array}{c}\text { Discharge } \\
\text { (ft'/s) } \\
\text { ice jam }\end{array}$ & $\begin{array}{l}\text { Gage height } \\
\text { (ft) } \\
* 6.24\end{array}$ & $\begin{array}{l}\text { Date } \\
\text { Mar. } 11\end{array}$ & $\begin{array}{l}\text { Time } \\
1530\end{array}$ & $\begin{array}{c}\text { Discharge } \\
\left(\mathrm{ft}^{*} / \mathrm{s}\right) \\
* 2,860\end{array}$ & $\begin{array}{l}\text { Gage height } \\
\text { (ft) } \\
5.88\end{array}$ \\
\hline
\end{tabular}

Minimm discharge, $108 \mathrm{ft} / \mathrm{s}$ Aug. 12.

DISCHARGE, IN OBIC FEET PER SECOND, WATER YEAR OCLOBER 1984 TO SEPTERER 1985 MEAN VALUES

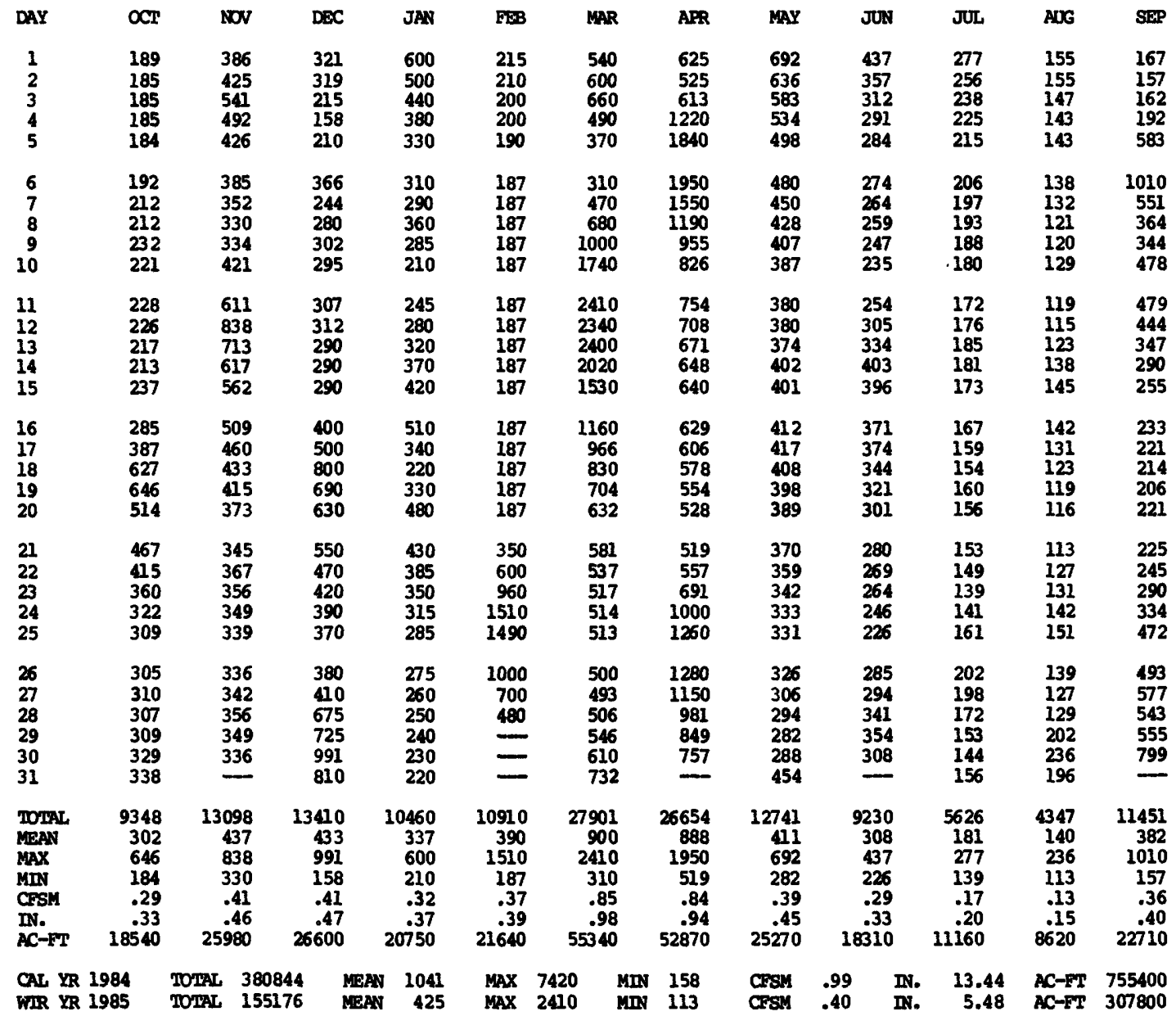


LOCATION.--Lat $43^{\circ} 02^{\prime} 05^{*}$, long $92^{\circ} 30^{\prime} 05^{*}$, in Sw1/4 NEI/4 sec.21, T.95 N., R.14 w., Chickasaw County, Bydrologic Onit 07080201 , on left bank $12 \mathrm{ft}$ downstream from bridge on county highway B57, $2.4 \mathrm{mi}$ west of Ionia, $6.4 \mathrm{mi}$ upstream from mouth, and $7.6 \mathrm{mi}$ downstream from Beaver Creek.

DRAINAGE AREA. $--306 \mathrm{~mL}^{2}$.

PERIOD OP RECORD.--October 2954 to current year.

REVISED RECORDS.--WSP 1438: Drainage area. WSP 1708: 1959.

GAGE.-Water-stage recorder. Datum of gage is $973.35 \mathrm{ft}$ above NGVD.

REMARRs.--Estimated dally discharge: Dec. 28 to Jan. 5 . Records are good except for periods of estimated record, which are poor. National Weather service gage-height telemeter at station.

AVERAGE DISCHARGE.--31 years, $178 \mathrm{ft} / \mathrm{s}, 7.90 \mathrm{in} / \mathrm{yr}, 128,900$ acre-ft/yr; median of yearly mean discharges, 150 $f t^{2} / 8,6.7$ in/yr, 109,000 acre-ft/yr.

EXTREMES FOR PERIOD OF RECORD.--Maximum discharge, 10,800 ft/8 Mar. 27, 1961, gage height, 15.58 ft; minimum da11Y, 3.0 ft/s Feb. $1-9,1959$.

EXTREMES OUTSIDE PERIOD OF RECORD,--F1ood of June 22,1954 , reached a stage of $11.37 \mathrm{ft}$, discharge, 4,600 ft'/s. EXTREMES FOR CURRENT YEAR.--Peak discharges greater than base of $1,200 \mathrm{ft}^{2} / \mathrm{s}$ and maximum (*):

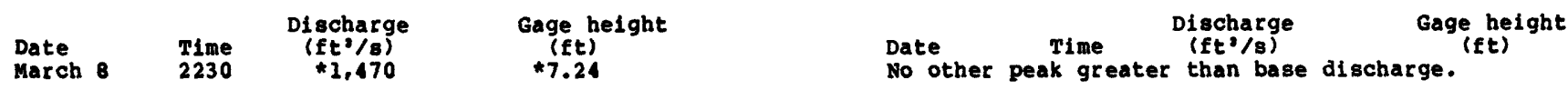

Minimum discharge, $15 \mathrm{ft} / \mathrm{s}$ Aug. $20,21,22$.

DISCAARGE, IN CUBIC FEET PER SBCOND, WATER YEAR OCTOBER 1984 TO SEPTEMBER 1985

MEAN VALUES

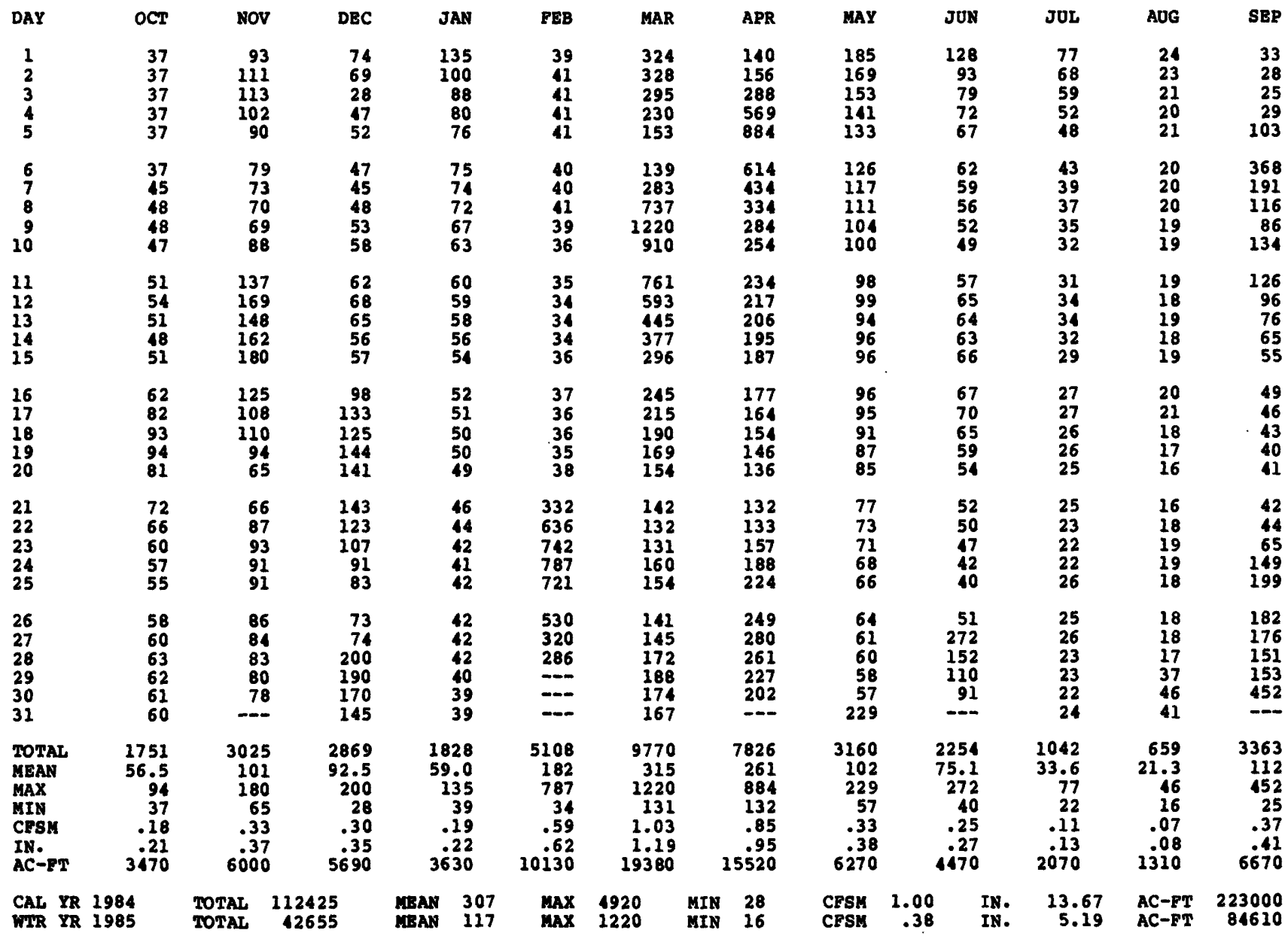


LOCATION.--Lat $42^{\circ} 38^{\prime} 54^{\prime \prime}$, long $92^{\circ} 27^{\prime} 54^{\prime \prime}$, in NEl/4 Swl/4 sec.35, T.91 N., R.14 W., Bremer County, Bydrologic Onit 07080201 , on left bank $300 \mathrm{ft}$ downstream from bridge on county highway at Janesville, 3.6 mi upstream from West Fork Cedar River, and at mile 207.7 upstream from mouth of Iowa River.

DRAINAGE AREA. $--1,661 \mathrm{mi}^{2}$.

PERIOD OF RECORD.--October 1904 to Sept. 1906 , October 1914 to September 1927 , October 1932 to September 1942, October 1945 to current year. Monthiy discharge only for some periods, published in wsp 1308. Published as Red Cedar River at Janesville, 1905-6.

REVISED RECORDS.--WSP 1438: Drainage area. WSP 1558: 1906 (M), 1915-16 (M), 1917, 1918-19 (M), 1920-27, 1933-37 (M) $1940-42$ (M).

GAGE.--Water-stage recorder. Datum of gage is $868.26 \mathrm{ft}$ above NGVD. Prior to July 26 , 1919 , nonrecording gage at site $1,000 \mathrm{ft}$ downstream at datum $4.0 \mathrm{ft}$ lower. July 26, 1919, to sept. 30, 1927, Nov. 14, 1932, to sept 30, 1942, and Apr. 26, 1946, to Nov. 10, 1949, nonrecording gage at county bridge 300 ft upstream at same datum.

REMARRS.--Estimated daily discharges: Nov. 29 to March 9. Records good except for estimated daily discharges, which are poor. Diurnal fluctuation during low water caused by powerplant at Waverly, lo mi upstream. National Weather Service gage-height telemeter at station.

AVERAGE DISCHARGE. --65 years (water years $1905-06,1915-27,1933-42,1946-85$ ), 860 ft3/s, 7.03 in/yr, 623,100 acre $-\mathrm{ft} / \mathrm{yr}$; median of yearly mean discharges, $750 \mathrm{ft}^{2} / \mathrm{s}, 6.1 \mathrm{in} / \mathrm{yr}, 543,400 \mathrm{acre}-\mathrm{ft} / \mathrm{yr}$.

EXTREMES FOR PERIOD OF RECORD.--Maximum discharge, 37,000 ft3/s Mar. 28, 1961, gage height, 16.33 ft; minimum daily, $28 \mathrm{ft}^{2} / \mathrm{s}$ Oct. 21,1922 .

EXTREMES OUTSIDE PERIOD OF RECORD.--Flood of Mar. 17, 1945, reached a stage of 16.2 ft, from floodmark at site $300 \mathrm{ft}$ upstream, discharge, $34,300 \mathrm{ft}^{2} / \mathrm{s}$. Flood of Mar. 16, 1929, reached a stage of about 16 ft, from information by City of waterloo, discharge not determined.

EXTREMES FOR CURRENT YEAR.--Peak discharges greater than base of $4,000 \mathrm{ft}^{3} / \mathrm{s}$ and maximum (*):

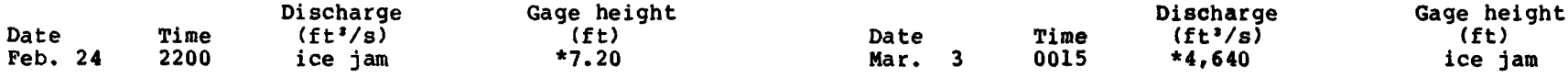

a ice jam

Minimum discharge, $212 \mathrm{ft}^{3} / \mathrm{s}$ Aug. 9.

DISCHARGE, IN CUBIC FEET PER SECOND, WATER YEAR OCTOBER 1984 TO SEPTEMBER 1985 MEAN VALUES

\begin{tabular}{|c|c|c|c|c|c|c|c|c|c|c|c|c|}
\hline DAY & OCT & NOV & DEC & JAN & FEB & MAR & APR & MAY & JUN & JUL & AUG & SEP \\
\hline $\begin{array}{l}1 \\
2 \\
3 \\
4 \\
5\end{array}$ & $\begin{array}{l}389 \\
380 \\
530 \\
379 \\
371\end{array}$ & $\begin{array}{l}706 \\
637 \\
675 \\
795 \\
831\end{array}$ & $\begin{array}{l}550 \\
520 \\
400 \\
355 \\
500\end{array}$ & $\begin{array}{r}1200 \\
1400 \\
1600 \\
1590 \\
780\end{array}$ & $\begin{array}{l}280 \\
280 \\
280 \\
280 \\
285\end{array}$ & $\begin{array}{l}2900 \\
3900 \\
4500 \\
3500 \\
1600\end{array}$ & $\begin{array}{l}1120 \\
1050 \\
1080 \\
1270 \\
1850\end{array}$ & $\begin{array}{r}1240 \\
1120 \\
1020 \\
938 \\
905\end{array}$ & $\begin{array}{l}639 \\
666 \\
606 \\
539 \\
484\end{array}$ & $\begin{array}{l}520 \\
451 \\
429 \\
385 \\
364\end{array}$ & $\begin{array}{l}254 \\
248 \\
244 \\
240 \\
242\end{array}$ & $\begin{array}{l}346 \\
307 \\
286 \\
294 \\
407\end{array}$ \\
\hline $\begin{array}{r}6 \\
7 \\
8 \\
9 \\
10\end{array}$ & $\begin{array}{l}259 \\
388 \\
524 \\
427 \\
421\end{array}$ & $\begin{array}{l}727 \\
644 \\
613 \\
572 \\
612\end{array}$ & $\begin{array}{l}700 \\
620 \\
540 \\
480 \\
470\end{array}$ & $\begin{array}{l}600 \\
570 \\
560 \\
530 \\
500\end{array}$ & $\begin{array}{l}285 \\
285 \\
290 \\
290 \\
290\end{array}$ & $\begin{array}{l}1200 \\
1000 \\
1900 \\
2300 \\
3330\end{array}$ & $\begin{array}{l}2710 \\
2840 \\
2500 \\
1990 \\
1650\end{array}$ & $\begin{array}{l}864 \\
801 \\
751 \\
711 \\
676\end{array}$ & $\begin{array}{l}456 \\
430 \\
403 \\
403 \\
400\end{array}$ & $\begin{array}{l}329 \\
331 \\
307 \\
301 \\
319\end{array}$ & $\begin{array}{l}240 \\
236 \\
230 \\
226 \\
252\end{array}$ & $\begin{array}{r}533 \\
1170 \\
966 \\
699 \\
585\end{array}$ \\
\hline $\begin{array}{l}11 \\
12 \\
13 \\
14 \\
15\end{array}$ & $\begin{array}{l}472 \\
380 \\
470 \\
453 \\
447\end{array}$ & $\begin{array}{r}601 \\
842 \\
1130 \\
1050 \\
909\end{array}$ & $\begin{array}{l}460 \\
485 \\
600 \\
350 \\
560\end{array}$ & $\begin{array}{l}480 \\
470 \\
460 \\
450 \\
440\end{array}$ & $\begin{array}{l}290 \\
290 \\
290 \\
290 \\
290\end{array}$ & $\begin{array}{l}3330 \\
3380 \\
3380 \\
3240 \\
2950\end{array}$ & $\begin{array}{l}1450 \\
1310 \\
1220 \\
1150 \\
1100\end{array}$ & $\begin{array}{l}658 \\
659 \\
641 \\
651 \\
652\end{array}$ & $\begin{array}{l}408 \\
437 \\
473 \\
486 \\
550\end{array}$ & $\begin{array}{l}282 \\
283 \\
271 \\
284 \\
290\end{array}$ & $\begin{array}{l}235 \\
236 \\
240 \\
232 \\
227\end{array}$ & $\begin{array}{l}625 \\
676 \\
649 \\
588 \\
474\end{array}$ \\
\hline $\begin{array}{l}16 \\
17 \\
18 \\
19 \\
20\end{array}$ & $\begin{array}{l}560 \\
526 \\
565 \\
737 \\
703\end{array}$ & $\begin{array}{l}833 \\
822 \\
767 \\
719 \\
665\end{array}$ & $\begin{array}{r}490 \\
540 \\
550 \\
960 \\
1250\end{array}$ & $\begin{array}{l}430 \\
420 \\
400 \\
380 \\
370\end{array}$ & $\begin{array}{l}295 \\
300 \\
300 \\
300 \\
360\end{array}$ & $\begin{array}{l}2410 \\
1920 \\
1600 \\
1420 \\
1270\end{array}$ & $\begin{array}{r}1050 \\
1010 \\
982 \\
1030 \\
813\end{array}$ & $\begin{array}{l}646 \\
643 \\
628 \\
617 \\
610\end{array}$ & $\begin{array}{l}587 \\
551 \\
546 \\
523 \\
487\end{array}$ & $\begin{array}{l}259 \\
261 \\
256 \\
276 \\
256\end{array}$ & $\begin{array}{l}234 \\
247 \\
251 \\
235 \\
222\end{array}$ & $\begin{array}{l}433 \\
404 \\
374 \\
355 \\
327\end{array}$ \\
\hline $\begin{array}{l}21 \\
22 \\
23 \\
24 \\
25\end{array}$ & $\begin{array}{l}782 \\
821 \\
670 \\
617 \\
469\end{array}$ & $\begin{array}{l}618 \\
596 \\
635 \\
635 \\
608\end{array}$ & $\begin{array}{r}940 \\
1000 \\
1070 \\
1100 \\
1350\end{array}$ & $\begin{array}{l}370 \\
360 \\
350 \\
335 \\
320\end{array}$ & $\begin{array}{r}910 \\
2150 \\
2900 \\
3900 \\
3600\end{array}$ & $\begin{array}{r}1110 \\
1010 \\
971 \\
953 \\
936\end{array}$ & $\begin{array}{r}870 \\
1020 \\
953 \\
1060 \\
1170\end{array}$ & $\begin{array}{l}589 \\
589 \\
566 \\
385 \\
498\end{array}$ & $\begin{array}{l}451 \\
441 \\
393 \\
401 \\
382\end{array}$ & $\begin{array}{l}255 \\
247 \\
236 \\
235 \\
295\end{array}$ & $\begin{array}{l}218 \\
229 \\
237 \\
245 \\
238\end{array}$ & $\begin{array}{l}329 \\
339 \\
423 \\
435 \\
482\end{array}$ \\
\hline $\begin{array}{l}26 \\
27 \\
28 \\
29 \\
30 \\
31\end{array}$ & $\begin{array}{l}540 \\
541 \\
536 \\
599 \\
525 \\
538\end{array}$ & $\begin{array}{l}597 \\
594 \\
597 \\
580 \\
560 \\
---\end{array}$ & $\begin{array}{r}1600 \\
580 \\
800 \\
1110 \\
1090 \\
1120\end{array}$ & $\begin{array}{l}310 \\
290 \\
290 \\
285 \\
280 \\
280\end{array}$ & $\begin{array}{r}3400 \\
3050 \\
2700 \\
-\ldots- \\
-\ldots-\end{array}$ & $\begin{array}{r}909 \\
923 \\
923 \\
932 \\
954 \\
1030\end{array}$ & $\begin{array}{l}1650 \\
1800 \\
1730 \\
1510 \\
1370 \\
-\cdots\end{array}$ & $\begin{array}{l}495 \\
485 \\
502 \\
491 \\
461 \\
431\end{array}$ & $\begin{array}{l}367 \\
447 \\
640 \\
568 \\
553 \\
---\end{array}$ & $\begin{array}{l}249 \\
251 \\
271 \\
269 \\
265 \\
264\end{array}$ & $\begin{array}{l}249 \\
243 \\
239 \\
346 \\
320 \\
332\end{array}$ & $\begin{array}{l}640 \\
676 \\
702 \\
775 \\
894 \\
\end{array}$ \\
\hline $\begin{array}{l}\text { TOTAL } \\
\text { MEAN } \\
\text { MAX } \\
\text { MIN } \\
\text { CFSM } \\
\text { IN. } \\
\text { AC-FT }\end{array}$ & $\begin{array}{r}16019 \\
517 \\
821 \\
259 \\
.31 \\
.36 \\
31770\end{array}$ & $\begin{array}{r}21170 \\
706 \\
1130 \\
560 \\
.43 \\
.47 \\
41990\end{array}$ & $\begin{array}{r}23140 \\
746 \\
1600 \\
350 \\
.45 \\
.52 \\
45900\end{array}$ & $\begin{array}{r}17100 \\
552 \\
1600 \\
280 \\
.33 \\
.38 \\
33920\end{array}$ & $\begin{array}{r}28460 \\
1016 \\
3900 \\
280 \\
.61 \\
.64 \\
56450\end{array}$ & $\begin{array}{r}61681 \\
1990 \\
4500 \\
909 \\
1.20 \\
1.38 \\
122300\end{array}$ & $\begin{array}{r}42308 \\
1410 \\
2840 \\
813 \\
.85 \\
.95 \\
83920\end{array}$ & $\begin{array}{r}20923 \\
675 \\
1240 \\
385 \\
.41 \\
.47 \\
41500\end{array}$ & $\begin{array}{r}14717 \\
491 \\
666 \\
367 \\
.30 \\
.33 \\
29190\end{array}$ & $\begin{array}{r}9291 \\
300 \\
520 \\
235 \\
.18 \\
.21 \\
18430\end{array}$ & $\begin{array}{r}7667 \\
247 \\
346 \\
218 \\
.15 \\
15217\end{array}$ & $\begin{array}{r}16193 \\
540 \\
1170 \\
286 \\
.33 \\
32120\end{array}$ \\
\hline $\begin{array}{ll}\text { CAL } & \text { YR } \\
\text { WTR } & \text { YR }\end{array}$ & $\begin{array}{l}84 \\
85\end{array}$ & $\begin{array}{l}\text { TOTAL } \\
\text { TOTAL }\end{array}$ & $\begin{array}{l}3 \\
9\end{array}$ & $\begin{array}{rr}\text { MEAN } & 1727 \\
\text { MEAN } & 763\end{array}$ & $\begin{array}{l}\text { MAX } \\
\text { MAX }\end{array}$ & $\begin{array}{l}1300 \\
4500\end{array}$ & $\begin{array}{ll}\text { MIN } & 259 \\
\text { MIN } & 218\end{array}$ & $\begin{array}{l}\text { CFSM } \\
\text { CPSM }\end{array}$ & $\begin{array}{l}.04 \\
.46\end{array}$ & $\begin{array}{l}\text { IN. } \quad 14.15 \\
\text { IN. } 6.24\end{array}$ & $\begin{array}{l}A C-F T \\
A C-F T\end{array}$ & $\begin{array}{r}1253000 \\
552700\end{array}$ \\
\hline
\end{tabular}


LOCATION.-Lat $42^{\circ} 37^{\prime} 50^{\prime \prime}$, long $92^{\circ} 32^{\prime} 24^{\prime \prime}$, in SWl/4 SEl/4 sec.6, T.90 N., R.14 W., Black Hawk County, Hydrologic Unit 07080204 , on left bank $100 \mathrm{ft}$ downstream from bridge on county highway C55 at Finchford, 3.2 mi upstream upstream from Shell Rock River, and $5.0 \mathrm{mi}$ upstream from mouth.

DRAINAGE AREA. $--846 \mathrm{mi}^{2}$.

PERIOD OF RECORD.--October 1945 to current year. Prior to October 1955, published as West Fork Shel1 Rock River at Finchford.

REVISED RECORDS.--WSP 1438: Drainage area. WSP 1558; 1946 (M), 1947.

GAGE.-Water-stage recorder. Datum of gage is $867.54 \mathrm{ft}$ above NGVD. Prior to June 10 , 1955 , nonrecording gage at same site and datum.

REMARKs.--Estimated daily discharge: Nov. 19 - 21, Nov. 28 to March 10, July 22 - 24 . Records good, except for estimated daily discharges, which are poor. An authorized diversion is made into Big Marsh, 16 m1 upstream from gage, of 2,100 acre-ft each year between September 1 and November 15 . Net effect on daily flows at gage is unknown. National Weather Service gage-height telemeter at station.

AVERAGE DISCHARGE. -40 years, $513 \mathrm{ft} / \mathrm{s}, 8.23 \mathrm{in} / \mathrm{yr}, 371,700$ acre-ft/yr; median of yearly mean discharges, 450 $\mathrm{ft} / \mathrm{s}, 7.2 \mathrm{in} / \mathrm{yr}, 326,000$ acre-ft/yr.

EXTREMES FOR PERIOD OF RECORD.--Maximum discharge, 31,900 ft3/s June 27, 1951 , gage height, 17.28 ft, from floodmarks; minimum daily, $5.9 \mathrm{ft}^{2} / \mathrm{s}$ Feb. 26, 27, 1959 .

EXTREMES OUTSIDE PERIOD OF RECORD.--Flood in March 1929 reached a stage of about $14 \mathrm{ft}$, $f$ rom information by local resident, discharge, about $12,800 \mathrm{ft} / \mathrm{s}$.

EXTREMES FOR CURRENT YEAR.--Peak discharges greater than base of $2,500 \mathrm{ft}^{3} / \mathrm{s}$ and maximum (*):

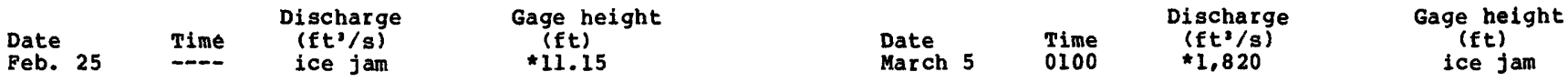

Minimum daily discharge, $62 \mathrm{ft} / \mathrm{s}$ Feb. 17.

DISCHARGE, IN CUBIC FEET PER SECOND, WATER YEAR OCTOBER I984 TO SEPTEMBER 1985 MEAN VALUES

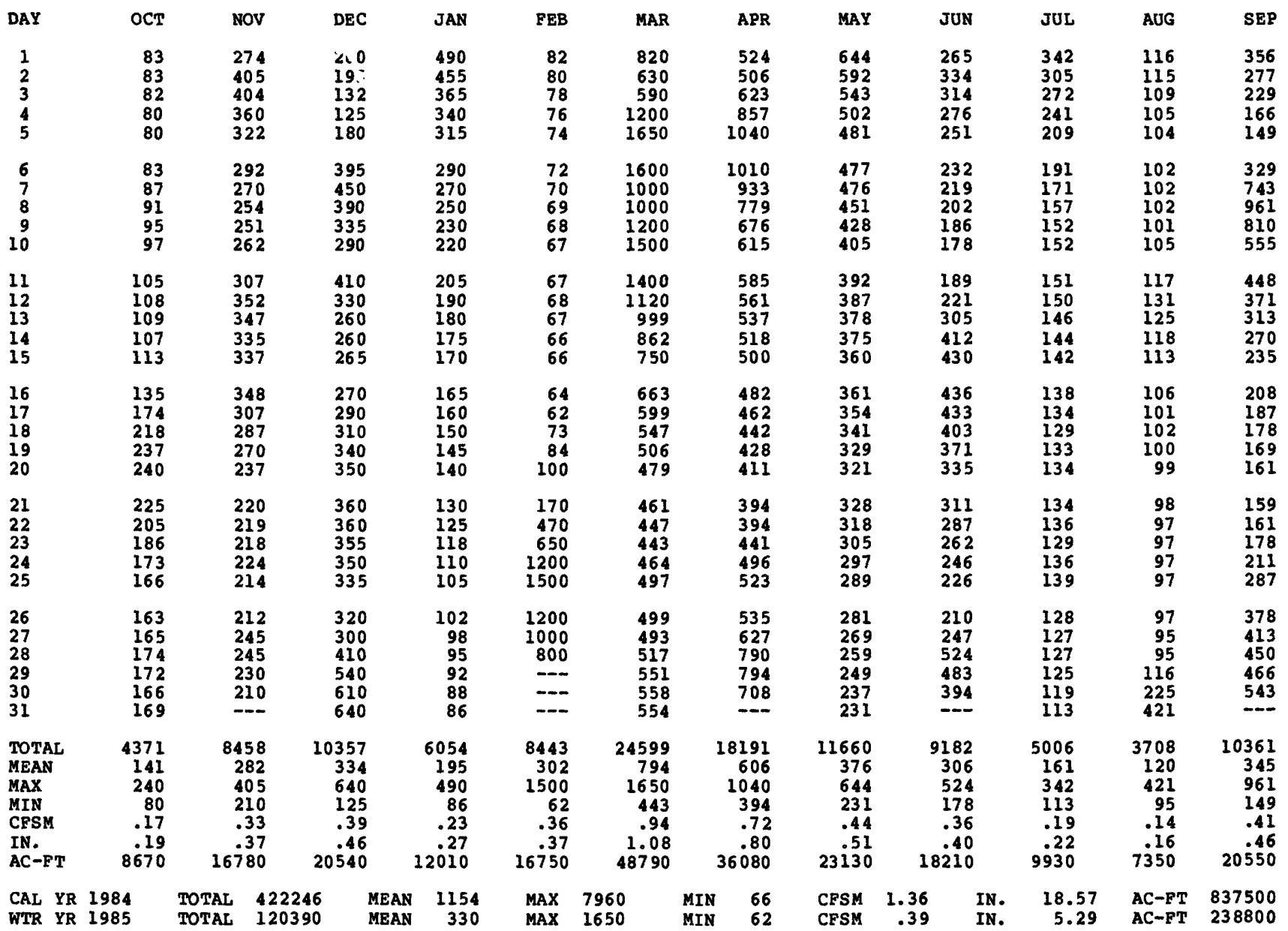


05459000 SHELL ROCK RIVER NEAR NOPTHWOOD, IA

LOCATION.--Lat $43^{\circ} 24^{\prime} 51^{\prime \prime}$, long $93^{\circ} 13^{\prime} 14^{\prime \prime}$, in NWL/4 NW1/4 sec.9, T.99 N., s.<0 W., Worth County, Hydrologic Unit 07080202 , on right bank $50 \mathrm{ft}$ downstream from bridge on snunty highway A27, $1.3 \mathrm{mi}$ downstream from drainage ditch 2, $2.0 \mathrm{mi}$ south of Northwood, $3.7 \mathrm{mi}$ upstream from Elk Creek, and $84.5 \mathrm{mi}$ upstream from mouth.

DRAINAGE AREA. $--300 \mathrm{mi}^{2}$.

PERIOD OF RECORD,--October 1945 to current year. Prior to April 1948 monthly discharge only, published in wSP 1308.

REVISED RECORDS.--WSP 1308: 1948 (M). WSP 1438: Drainage area.

GAGE.--Water-stage recorder. Datum of gage is 1,176.48 ft above NGvD. Prior to May 17 , 1956 , nonrecording gage at same site and datum.

REMARRs.--Estimated daily discharge: Dec. 1-3, Dec. 13 to March 10 . Records good except for periods of estimated record, which are poor.

AVERAGE DISCHARGE. -40 years, $159 \mathrm{ft} / \mathrm{s}, 7.20 \mathrm{in} / \mathrm{yr}, 115,200$ acre-ft/yr; median of yearly mean discharges, 140 $\mathrm{ft}^{3} / \mathrm{s}, 6.3 \mathrm{in} / \mathrm{yr}, 101,000$ acre-ft/yr.

EXTREMES FOR PERIOD OF RECORD,--Maximum discharge, 3,400 fts Apr. 8, 1965, gage height, 12.07 ft, backwater from ice; no flow Jan. 14-19, 26-30, 1977.

EXTREMES FOR CORRENT YEAR.--Peak discharges greater than base of $700 \mathrm{ft} / \mathrm{s}$ and maximum (*):

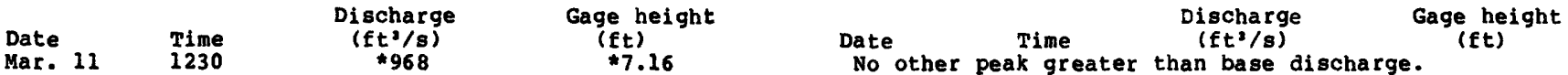

Minimum discharge, $13 \mathrm{ft} / \mathrm{s}$ July 23, 24, Aug. 9, Oct. 2.

DISCHARGE, IN CUBIC FEET PER SECOND, WATER YEAR OCTOBER 1984 TO SEPTEMBER 1985 MEAN VALUES

\begin{tabular}{|c|c|c|c|c|c|c|c|c|c|c|c|c|}
\hline DAY & OCT & NOV & DEC & JAN & FEB & MAR & APR & MAY & JUN & JUL & AUG & SEP \\
\hline $\begin{array}{l}1 \\
2 \\
3 \\
4 \\
5\end{array}$ & $\begin{array}{l}24 \\
14 \\
16 \\
15 \\
17\end{array}$ & $\begin{array}{l}152 \\
167 \\
136 \\
127 \\
133\end{array}$ & $\begin{array}{r}94 \\
93 \\
150 \\
211 \\
183\end{array}$ & $\begin{array}{l}140 \\
135 \\
128 \\
120 \\
112\end{array}$ & $\begin{array}{l}35 \\
34 \\
33 \\
32 \\
31\end{array}$ & $\begin{array}{l}150 \\
170 \\
185 \\
205 \\
230\end{array}$ & $\begin{array}{l}268 \\
273 \\
363 \\
435 \\
557\end{array}$ & $\begin{array}{l}189 \\
178 \\
168 \\
158 \\
144\end{array}$ & $\begin{array}{l}73 \\
63 \\
58 \\
56 \\
55\end{array}$ & $\begin{array}{l}49 \\
45 \\
44 \\
39 \\
36\end{array}$ & $\begin{array}{l}20 \\
18 \\
16 \\
16 \\
17\end{array}$ & $\begin{array}{r}40 \\
38 \\
37 \\
44 \\
129\end{array}$ \\
\hline $\begin{array}{r}6 \\
7 \\
8 \\
9 \\
10\end{array}$ & $\begin{array}{l}20 \\
25 \\
26 \\
31 \\
30\end{array}$ & $\begin{array}{l}129 \\
121 \\
113 \\
125 \\
195\end{array}$ & $\begin{array}{l}173 \\
187 \\
191 \\
185 \\
177\end{array}$ & $\begin{array}{r}105 \\
100 \\
95 \\
90 \\
85\end{array}$ & $\begin{array}{l}31 \\
31 \\
31 \\
31 \\
31\end{array}$ & $\begin{array}{l}260 \\
295 \\
360 \\
485 \\
660\end{array}$ & $\begin{array}{l}510 \\
456 \\
426 \\
397 \\
361\end{array}$ & $\begin{array}{l}139 \\
134 \\
125 \\
116 \\
110\end{array}$ & $\begin{array}{l}51 \\
48 \\
49 \\
45 \\
47\end{array}$ & $\begin{array}{l}34 \\
30 \\
25 \\
24 \\
24\end{array}$ & $\begin{array}{l}15 \\
15 \\
15 \\
14 \\
15\end{array}$ & $\begin{array}{r}121 \\
92 \\
77 \\
92 \\
115\end{array}$ \\
\hline $\begin{array}{l}11 \\
12 \\
13 \\
14 \\
15\end{array}$ & $\begin{array}{l}30 \\
31 \\
31 \\
31 \\
54\end{array}$ & $\begin{array}{l}215 \\
190 \\
191 \\
188 \\
186\end{array}$ & $\begin{array}{l}170 \\
174 \\
140 \\
151 \\
170\end{array}$ & $\begin{array}{l}80 \\
76 \\
72 \\
69 \\
65\end{array}$ & $\begin{array}{l}31 \\
31 \\
31 \\
31 \\
31\end{array}$ & $\begin{array}{l}625 \\
500 \\
476 \\
480 \\
452\end{array}$ & $\begin{array}{l}336 \\
313 \\
301 \\
295 \\
281\end{array}$ & $\begin{array}{l}111 \\
107 \\
107 \\
113 \\
122\end{array}$ & $\begin{array}{r}54 \\
84 \\
132 \\
112 \\
112\end{array}$ & $\begin{array}{l}22 \\
24 \\
25 \\
23 \\
22\end{array}$ & $\begin{array}{l}15 \\
17 \\
22 \\
21 \\
19\end{array}$ & $\begin{array}{r}101 \\
88 \\
76 \\
66 \\
61\end{array}$ \\
\hline $\begin{array}{l}16 \\
17 \\
18 \\
19 \\
20\end{array}$ & $\begin{array}{r}80 \\
167 \\
150 \\
131 \\
141\end{array}$ & $\begin{array}{l}189 \\
182 \\
166 \\
159 \\
157\end{array}$ & $\begin{array}{l}193 \\
250 \\
240 \\
228 \\
215\end{array}$ & $\begin{array}{l}62 \\
59 \\
56 \\
53 \\
50\end{array}$ & $\begin{array}{l}31 \\
31 \\
32 \\
34 \\
38\end{array}$ & $\begin{array}{l}445 \\
418 \\
386 \\
361 \\
335\end{array}$ & $\begin{array}{l}267 \\
256 \\
234 \\
226 \\
210\end{array}$ & $\begin{array}{l}130 \\
139 \\
125 \\
113 \\
105\end{array}$ & $\begin{array}{r}114 \\
106 \\
108 \\
100 \\
88\end{array}$ & $\begin{array}{l}22 \\
21 \\
21 \\
21 \\
19\end{array}$ & $\begin{array}{l}18 \\
19 \\
19 \\
17 \\
16\end{array}$ & $\begin{array}{l}51 \\
48\end{array}$ \\
\hline $\begin{array}{l}22 \\
22 \\
23 \\
24 \\
25\end{array}$ & $\begin{array}{l}131 \\
123 \\
119 \\
111 \\
107\end{array}$ & $\begin{array}{l}160 \\
153 \\
134 \\
130 \\
127\end{array}$ & $\begin{array}{l}205 \\
195 \\
185 \\
180 \\
173\end{array}$ & $\begin{array}{l}49 \\
48 \\
47 \\
46 \\
45\end{array}$ & $\begin{array}{l}45 \\
54 \\
64 \\
74 \\
89\end{array}$ & $\begin{array}{l}316 \\
298 \\
287 \\
288 \\
277\end{array}$ & $\begin{array}{l}223 \\
226 \\
255 \\
268 \\
258\end{array}$ & $\begin{array}{r}103 \\
97 \\
97 \\
99 \\
94\end{array}$ & $\begin{array}{l}78 \\
77 \\
70 \\
61 \\
56\end{array}$ & $\begin{array}{l}18 \\
16 \\
15 \\
20 \\
30\end{array}$ & $\begin{array}{l}17 \\
24 \\
32 \\
28 \\
25\end{array}$ & $\begin{array}{r}66 \\
58 \\
71 \\
127 \\
127\end{array}$ \\
\hline $\begin{array}{l}26 \\
27 \\
28 \\
29 \\
30 \\
31\end{array}$ & $\begin{array}{l}108 \\
105 \\
124 \\
120 \\
104 \\
111\end{array}$ & $\begin{array}{l}123 \\
124 \\
127 \\
124 \\
120 \\
-\end{array}$ & $\begin{array}{l}170 \\
165 \\
160 \\
158 \\
155 \\
150\end{array}$ & $\begin{array}{l}44 \\
42 \\
41 \\
39 \\
38 \\
37\end{array}$ & $\begin{array}{l}105 \\
115 \\
130 \\
--- \\
---\end{array}$ & $\begin{array}{l}264 \\
257 \\
266 \\
271 \\
268 \\
259\end{array}$ & $\begin{array}{l}250 \\
239 \\
223 \\
201 \\
194 \\
---\end{array}$ & $\begin{array}{l}86 \\
82 \\
77 \\
70 \\
69 \\
72\end{array}$ & $\begin{array}{r}53 \\
65 \\
64 \\
59 \\
53 \\
-\end{array}$ & $\begin{array}{l}22 \\
1.9 \\
17 \\
16 \\
17 \\
20\end{array}$ & $\begin{array}{l}23 \\
21 \\
28 \\
76 \\
56 \\
47\end{array}$ & $\begin{array}{l}136 \\
137 \\
122 \\
170 \\
315 \\
--\end{array}$ \\
\hline $\begin{array}{l}\text { TOTAL } \\
\text { MEAN } \\
\text { MAX } \\
\text { MIN } \\
\text { CESH } \\
\text { IN. } \\
\text { AC-FT }\end{array}$ & $\begin{array}{r}2327 \\
75.1 \\
167 \\
14 \\
.25 \\
.29 \\
4620\end{array}$ & $\begin{array}{r}4543 \\
151 \\
215 \\
113 \\
.50 \\
.56 \\
9010\end{array}$ & $\begin{array}{r}5471 \\
176 \\
250 \\
93 \\
.59 \\
.68 \\
10850\end{array}$ & $\begin{array}{r}2228 \\
71.9 \\
140 \\
37 \\
.24 \\
.28 \\
4420\end{array}$ & $\begin{array}{r}1317 \\
47.0 \\
130 \\
31 \\
.16 \\
.16 \\
2610\end{array}$ & $\begin{array}{r}10529 \\
340 \\
660 \\
150 \\
1.13 \\
1.31 \\
20880\end{array}$ & $\begin{array}{r}9102 \\
303 \\
557 \\
194 \\
1.01 \\
1.13 \\
18050\end{array}$ & $\begin{array}{r}3579 \\
115 \\
189 \\
69 \\
.38 \\
7104\end{array}$ & $\begin{array}{r}2291 \\
73.0 \\
132 \\
45 \\
.24 \\
.27 \\
4350\end{array}$ & $\begin{array}{r}780 \\
25.2 \\
49 \\
15 \\
.08 \\
.10 \\
1550\end{array}$ & $\begin{array}{r}721 \\
23.3 \\
76 \\
14 \\
.08 \\
.09 \\
1.430\end{array}$ & $\begin{array}{r}2764 \\
92.1 \\
315 \\
37 \\
.31 \\
.34 \\
5480\end{array}$ \\
\hline $\begin{array}{ll}\text { CAL } & \text { YR } \\
\text { WTR } & \text { YR }\end{array}$ & & TAL & $\begin{array}{l}72 \\
52\end{array}$ & $\begin{array}{ll}\text { MEAN } & 346 \\
\text { MEAN } & 125\end{array}$ & $\begin{array}{l}\text { MAX } \\
\text { MAX }\end{array}$ & $\begin{array}{r}1760 \\
660\end{array}$ & $\begin{array}{ll}\text { MIN } & 14 \\
\text { MIN } & 14\end{array}$ & $\begin{array}{l}\text { CFSM } \\
\text { CFSM }\end{array}$ & $\begin{array}{r}1.15 \\
.42\end{array}$ & $\begin{array}{r}15.71 \\
5.65\end{array}$ & $\begin{array}{l}\text { AC-FT } \\
\text { AC-FT }\end{array}$ & $\begin{array}{r}251300 \\
90350\end{array}$ \\
\hline
\end{tabular}


05459500 WINNEBAGO RIVER AT MASON CITY, IA

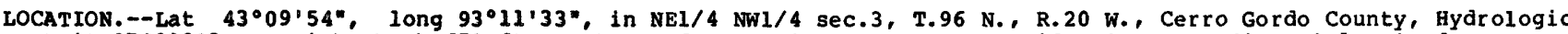
Onit 07080203 , on $r i g h t$ bank $650 \mathrm{ft}$ upstream from Thirteenth street Bridge in Mason City, 0.1 mi downstream from Calmus Creek, and 1.0 mi upstream from willow Creek, and at mile 275.8 upstream from mouth of Iowa River.

DRAINAGE AREA. $--526 \mathrm{mi}^{2}$.

PERIOD OF RECORD.-- October 1932 to current year. Prior to December 1932, monthly discharge only, published in wSP 1308. Prior to October 1959, published as Lime Creek at Mason City.

REVISED RECORDS.--WSP 825: 1935-36. WSP 1438: Drainage area. WSP 1558: 1933-37, 1943 (M), 1945,1948 .

GAGE.--Water-stage recorder and concrete control. Datum of gage is $1,069.59 \mathrm{ft}$ above NGVD. Prior to Oct. 15, 1934, nonrecording gage at datum $6.47 \mathrm{ft}$ lower. Oct. 15 to Nov. 6 , 1934, nonrecording gage at different datum, and Nov. 7, 1934, to Mar. 22, 1935, nonrecording gage at present datum.

REMARKS.--Estimated daily discharge: Dec. 28 - March 12. Records good, except for periods of estimated record, which are poor. National Weather service gage-height telemeter at station.

AVERAGE DISCHARGE. -53 years, $264 \mathrm{ft}^{2} / \mathrm{s}, 6.82 \mathrm{in} / \mathrm{yr}, 191,300$ acre-ft/yr; median of yearly mean discharges, 220 $\mathrm{ft}^{2} / \mathrm{s}, 5.7$ in/yr, 159,000 acre-ft/yr.

EXTREMES FOR PERIOD OF RECORD.--Maximum discharge, $10,800 \mathrm{ft}^{3} / \mathrm{s}$ Mar. 30,1933 , gage height, 15.7 ft, present datum; minimum dally, $2.5 \mathrm{ft} / \mathrm{s}$ Dec. 29-31, 1933, Aug. 5, 1934.

EXTREMES FOR CURRENT YEAR.--Peak discharges greater than base of $2,000 \mathrm{ft}^{3} / \mathrm{s}$ and maximum ( $*$ ):

\begin{tabular}{|c|c|c|c|c|c|c|c|}
\hline $\begin{array}{l}\text { Date } \\
\text { Mar. } 11\end{array}$ & $\begin{array}{l}\text { Time } \\
2030 .\end{array}$ & $\begin{array}{c}\text { Discharge } \\
(\mathrm{ft} / \mathrm{s}) \\
* 1,700\end{array}$ & $\begin{array}{c}\text { Gage height } \\
(f t) \\
a * 6.48\end{array}$ & Date & Time & $\begin{array}{c}\text { Discharge } \\
\left(\mathrm{ft}^{3} / \mathrm{s}\right)\end{array}$ & $\begin{array}{l}\text { Gage height } \\
(\mathrm{ft})\end{array}$ \\
\hline
\end{tabular}

a ice jam

Minimum discharge, $20 \mathrm{ft}^{3} / \mathrm{s}$ Aug. 11.

DISCHARGE, IN CUBIC FEET PER SECOND, WATER YEAR OCTOBER 1984 TO SEPTEMBER 1985 MEAN VALUES

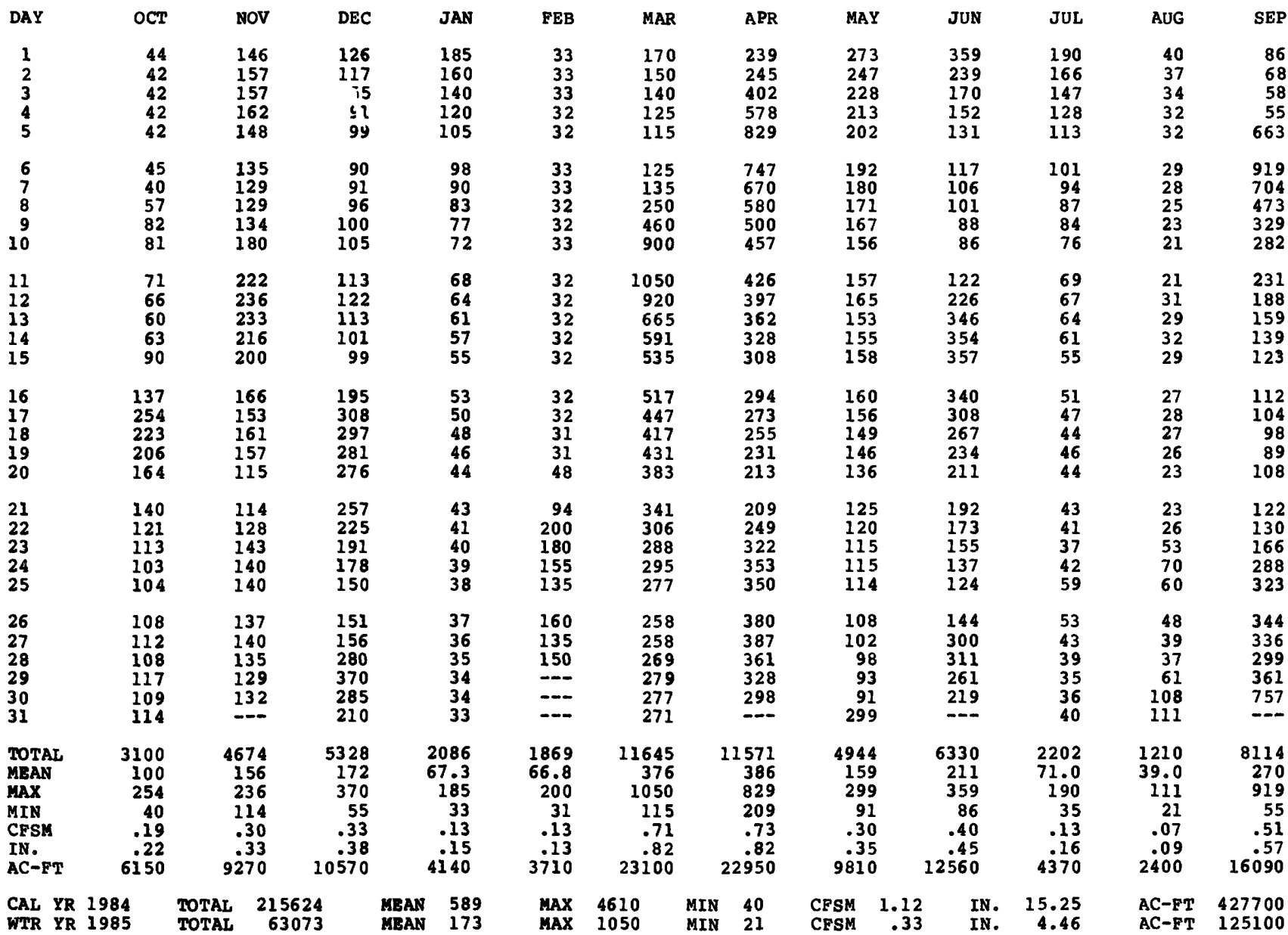


LOCATION.--Lat $43^{\circ} 08^{\prime} 01^{\prime \prime}$, long $93^{\circ} 22^{\prime} 57^{\prime \prime}$, in SEl/4 NEl/4 sec.13, T.96 N., R.22 w., Cerro Gordo County, Hydrologic Unit 07080203 , at the public bathing beach in the town of Clear Lake near dam across Clear Creek,

DRAINAGE AREA. $--22.6 \mathrm{mi}^{2}$.

PERIOD OF RECORD.--May 1933 to current year. No winter records 1933-52. Record fragmentary November 1952 to June 1959.

GAGE.--Water-stage recorder. Datum of gage is $1,222.24 \mathrm{ft}$ above NGVD, and $4.60 \mathrm{ft}$ below crest of spillway of dam at outlet. See WSP 1708 for history of changes prior to June 25, 1959.

REMARKS.--Lake is formed by concrete dam on clear Creek with ungated overflow spillway 50 ft long at elevation $1,226.84 \mathrm{ft}$ above NGVD. Dam constructed in 1903 . A previous outlet works had been constructed in 1887 . Lake is used for conservation and recreation. Area of lake is approximately 3,600 acres.

EXTREMES FOR PERIOD OF RECORD.--Maximum gage height observed, $5.94 \mathrm{ft}$ July 3 , 1951 , minimum observed, 1.16 ft DeC. $20,22-24,1958$.

EXTREMES FOR CURRENT YEAR.--Maximum gage height, $4.88 \mathrm{ft}$ Apr. 20 , minimum, $3.68 \mathrm{ft}$ Aug. 21.

GAGE HEIGHT (FEET ABOVE DATUM) NATER YEAR OCTOBER 1984 TO SEPTEMBER 1985

\begin{tabular}{|c|c|c|c|c|c|c|c|c|c|c|c|c|}
\hline DAY & OCT & Nov & DEC & JAN & FEB & MAR & APR & MAY & JUN & JUL & AUG & SEP \\
\hline $\begin{array}{l}1 \\
2 \\
3 \\
4 \\
5\end{array}$ & $\begin{array}{r}3.95 \\
3.94 \\
3.93 \\
-2.88\end{array}$ & $\begin{array}{c}4.13 \\
\ldots \\
\cdots\end{array}$ & $\begin{array}{r}4.09 \\
4.12 \\
4.13 \\
- \\
-\end{array}$ & $\begin{array}{l}4.29 \\
4.29 \\
4.29 \\
4.29 \\
4.29\end{array}$ & $\begin{array}{l}--- \\
--- \\
4.34 \\
4.35\end{array}$ & $\begin{array}{l}-- \\
-- \\
-\infty \\
-\infty\end{array}$ & 4.78 & $\begin{array}{l}4.75 \\
4.75 \\
4.76 \\
4.76 \\
4.70\end{array}$ & $\begin{array}{l}4.51 \\
4.47 \\
4.45 \\
4.44 \\
4.42\end{array}$ & $\begin{array}{l}4.35 \\
4.35 \\
4.33 \\
4.32 \\
4.26\end{array}$ & $\begin{array}{l}3.97 \\
3.96 \\
3.94 \\
3.93 \\
3.93\end{array}$ & $\begin{array}{l}3.82 \\
3.83 \\
3.84 \\
3.83 \\
4.04\end{array}$ \\
\hline $\begin{array}{r}6 \\
7 \\
8 \\
9 \\
10\end{array}$ & $\begin{array}{l}-- \\
-- \\
--- \\
--- \\
--\end{array}$ & $\begin{array}{r}4.07 \\
-- \\
-- \\
---\end{array}$ & $\begin{array}{l}--- \\
-- \\
--\end{array}$ & $\begin{array}{l}4.30 \\
4.30 \\
4.29 \\
4.29 \\
4.30\end{array}$ & $\begin{array}{c}4.35 \\
-- \\
-- \\
--\end{array}$ & $\begin{array}{l}-\infty \\
-\infty \\
-\infty \\
-\infty \\
--\infty\end{array}$ & $\ddot{--}$ & $\begin{array}{l}4.68 \\
4.66 \\
4.66 \\
4.68 \\
4.66\end{array}$ & $\begin{array}{l}4.42 \\
4.41 \\
4.43 \\
4.39 \\
4.34\end{array}$ & $\begin{array}{l}4.24 \\
4.23 \\
4.20 \\
4.19 \\
4.18\end{array}$ & $\begin{array}{l}3.93 \\
3.91 \\
3.90 \\
3.87 \\
3.85\end{array}$ & $\begin{array}{r}4.10 \\
4.12 \\
4.10 \\
4.10 \\
4.06\end{array}$ \\
\hline $\begin{array}{l}11 \\
12 \\
13 \\
14 \\
15\end{array}$ & $\begin{array}{r}3.99 \\
- \\
-\end{array}$ & $\begin{array}{l}-.- \\
-1.13 \\
4.14 \\
4.20\end{array}$ & $\begin{array}{l}--- \\
-- \\
-- \\
--\end{array}$ & $\begin{array}{l}4.31 \\
4.31 \\
4.32 \\
4.31 \\
4.31\end{array}$ & $\begin{array}{l}-- \\
-- \\
-- \\
--\end{array}$ & $\begin{array}{c}4.59 \\
-.- \\
-.-\end{array}$ & $\frac{-}{--}$ & $\begin{array}{l}4.63 \\
4.67 \\
4.59 \\
4.59 \\
4.63\end{array}$ & $\begin{array}{l}4.37 \\
4.40 \\
4.40 \\
4.42 \\
4.46\end{array}$ & $\begin{array}{l}4.15 \\
4.13 \\
4.13 \\
4.11 \\
4.10\end{array}$ & $\begin{array}{l}3.81 \\
3.82 \\
3.83 \\
3.81 \\
3.79\end{array}$ & $\begin{array}{l}4.04 \\
4.03 \\
4.00 \\
4.00 \\
3.98\end{array}$ \\
\hline $\begin{array}{l}16 \\
17 \\
18 \\
19 \\
20\end{array}$ & $\begin{array}{l}-- \\
-- \\
-- \\
--\infty \\
--\end{array}$ & $\begin{array}{l}4.13 \\
4.12 \\
4.10 \\
4.09 \\
4.09\end{array}$ & $\begin{array}{r}-1 \overline{-} \\
4.18 \\
4.18 \\
4.18 \\
4.17\end{array}$ & $\begin{array}{l}4.31 \\
4.32 \\
4.34 \\
4.33 \\
4.33\end{array}$ & $\begin{array}{l}-- \\
-- \\
-- \\
--\end{array}$ & $\begin{array}{r}--- \\
--65 \\
4.65 \\
4.65\end{array}$ & $\begin{array}{r}--2 \\
4.73 \\
4.73 \\
4.70\end{array}$ & $\begin{array}{l}4.60 \\
4.57 \\
4.58 \\
4.60 \\
4.60\end{array}$ & $\begin{array}{l}4.45 \\
4.48 \\
4.41 \\
4.39 \\
4.38\end{array}$ & $\begin{array}{l}4.07 \\
4.06 \\
4.05 \\
4.10 \\
4.08\end{array}$ & $\begin{array}{l}3.77 \\
3.79 \\
3.77 \\
3.73 \\
3.73\end{array}$ & $\begin{array}{l}3.98 \\
3.98 \\
3.97 \\
3.99 \\
4.03\end{array}$ \\
\hline $\begin{array}{l}21 \\
22 \\
23 \\
24 \\
25\end{array}$ & $\begin{array}{l}--- \\
-\infty- \\
--- \\
---\end{array}$ & $\begin{array}{l}4.09 \\
4.09 \\
4.08 \\
4.08 \\
4.07\end{array}$ & $\begin{array}{l}4.22 \\
4.23 \\
4.23 \\
4.23 \\
4.23\end{array}$ & $\begin{array}{l}4.33 \\
4.32 \\
4.32 \\
4.32 \\
4.32\end{array}$ & $\frac{--}{--}$ & $\begin{array}{r}4.65 \\
-0.69 \\
4.69\end{array}$ & $\begin{array}{r}4.68 \\
4.69 \\
4.74 \\
4.74 \\
4.71\end{array}$ & $\begin{array}{l}4.57 \\
4.56 \\
4.56 \\
4.54 \\
4.55\end{array}$ & $\begin{array}{l}4.37 \\
4.38 \\
4.33 \\
4.28 \\
4.28\end{array}$ & $\begin{array}{l}4.08 \\
4.05 \\
4.02 \\
4.04 \\
4.07\end{array}$ & $\begin{array}{l}3.71 \\
3.74 \\
3.78 \\
3.78 \\
3.74\end{array}$ & $\begin{array}{l}4.00 \\
4.01 \\
4.09 \\
4.10 \\
4.08\end{array}$ \\
\hline $\begin{array}{l}26 \\
27 \\
28 \\
29 \\
30 \\
31\end{array}$ & 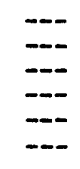 & $\begin{array}{r}4.10 \\
4.13 \\
4.13 \\
4.10 \\
4.11 \\
. .-1\end{array}$ & $\begin{array}{l}4.24 \\
4.25 \\
4.26 \\
4.27 \\
4.27 \\
4.28\end{array}$ & $\begin{array}{r}4.31 \\
-ב \\
-2 . \\
-25\end{array}$ & $\ddot{m}$ & $=$ & $\begin{array}{r}4.75 \\
4.75 \\
4.74 \\
4.78 \\
4.77 \\
-\ldots\end{array}$ & $\begin{array}{l}4.53 \\
4.49 \\
4.47 \\
4.46 \\
4.48 \\
4.58\end{array}$ & $\begin{array}{r}4.30 \\
4.40 \\
4.38 \\
4.37 \\
4.36 \\
-\end{array}$ & $\begin{array}{l}4.05 \\
4.05 \\
4.03 \\
4.00 \\
3.97 \\
3.97\end{array}$ & $\begin{array}{l}3.74 \\
3.74 \\
3.73 \\
3.85 \\
3.84 \\
3.83\end{array}$ & $\begin{array}{r}4.10 \\
4.08 \\
4.08 \\
4.13 \\
4.18 \\
\end{array}$ \\
\hline $\begin{array}{l}\text { MEAN } \\
\text { MAX } \\
\text { MIN }\end{array}$ & 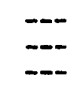 & $\overline{-}$ & - & $\begin{array}{l}-- \\
--\end{array}$ & $\overline{-}$ & -- & 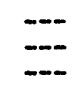 & $\begin{array}{l}4.61 \\
4.76 \\
4.46\end{array}$ & $\begin{array}{l}4.40 \\
4.51 \\
4.28\end{array}$ & $\begin{array}{l}4.13 \\
4.35 \\
3.97\end{array}$ & $\begin{array}{l}3.82 \\
3.97 \\
3.71\end{array}$ & $\begin{array}{l}4.02 \\
4.18 \\
3.82\end{array}$ \\
\hline
\end{tabular}


05462000 SHELL ROCK RIVER AT SHELL ROCK, IA

LOCATAION,-Lat $42^{\circ} 39^{\prime} I^{\prime \prime}$, long $92^{\circ} 35^{\prime} 45^{\prime \prime}$, in NEI/4 NWl/4 sec.11, T.91 N. R.I5 W., Butler County, Hydrologic Unit 07080202 on right bank $400 \mathrm{ft}$ upstream from bridge on county highway C45 in shell Rock, 2.2 mi downstream from

Curry Creek, and $10.4 \mathrm{mi}$ upstream from mouth.

DRAINAGE AREA. $--1,746 \mathrm{mi}^{2}$.

PERIOD OF RECORD.--June 1953 to current year. Prior to July 1953, monthly discharge only, published in wsP 1728.

REVISED RECORDS,--WSP 1438: Drainage area.

GAGE.--Water-stage recorder. Rockfill dan since Oct. 19, 1957 . Datum of gage is 885.34 ft above NGVD.

REMARKS.--No estimated daily discharges. Records good. Diurnal fluctuation at low stages caused by power plant upstream at Greene. National Weather Service gage-height telemeter at station.

AVERAGE DISCHARGE. -32 years, $995 \mathrm{ft} / \mathrm{s}, 7.74 \mathrm{in} / \mathrm{yr}, 720,900$ acre-ft/yr, median of yearly mean discharges, $830 \mathrm{ft}^{3} / \mathrm{s}, 6.5 \mathrm{in} / \mathrm{yr}, 601,000$ acre-ft/yr.

EXTREMES FOR PERIOD OF RECORD.--Maximum discharge, 33,500 ft/s Max. 28, 1961, gage height, 16.26 ft, minimum daily, $38 \mathrm{ft} / \mathrm{s}$ Feb. 9, 1977.

EXTREMES OUTSIDE PERIOD OF RECORD.--FIood in 1856 reached a stage of $17.7 \mathrm{ft}$ at bridge 400 ft downstream, from information provided by U.S. Army Corps of Engineers, discharge, about $45,000 \mathrm{ft} / 8$.

EXTREMES FOR CURRENT YEAR.--Peak discharges greater than base of 4,000 ft'/s and maximum (*):

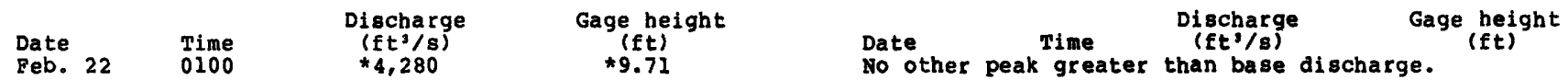

Minimum discharge, $185 \mathrm{ft}^{3} / \mathrm{s}$ Aug. $21,22$.

DISCHARGE, IN CUBIC FEET PER SECOND, WATER YEAR OCTOBER I984 TO SEPTEMBER I985

MEAN VALUES

\begin{tabular}{|c|c|c|c|c|c|c|c|c|c|c|c|c|}
\hline DAY & OCT & NOV & DEC & JAN & FEB & MAR & APR & MAY & JUN & JUL & AUG & SEP \\
\hline $\begin{array}{l}1 \\
2 \\
3 \\
4 \\
5\end{array}$ & $\begin{array}{l}302 \\
299 \\
298 \\
290 \\
289\end{array}$ & $\begin{array}{l}597 \\
604 \\
630 \\
621 \\
585\end{array}$ & $\begin{array}{l}499 \\
500 \\
371 \\
302 \\
313\end{array}$ & $\begin{array}{l}648 \\
552 \\
535 \\
584 \\
617\end{array}$ & $\begin{array}{l}278 \\
271 \\
264 \\
262 \\
258\end{array}$ & $\begin{array}{r}865 \\
902 \\
888 \\
1610 \\
866\end{array}$ & $\begin{array}{r}921 \\
862 \\
1060 \\
1590 \\
2320\end{array}$ & $\begin{array}{r}1050 \\
957 \\
861 \\
795 \\
755\end{array}$ & $\begin{array}{l}888 \\
875 \\
662 \\
543 \\
478\end{array}$ & $\begin{array}{l}661 \\
579 \\
524 \\
484 \\
454\end{array}$ & $\begin{array}{l}239 \\
239 \\
234 \\
227 \\
224\end{array}$ & $\begin{array}{l}308 \\
280 \\
254 \\
249 \\
354\end{array}$ \\
\hline $\begin{array}{r}6 \\
7 \\
8 \\
9 \\
10\end{array}$ & $\begin{array}{l}295 \\
316 \\
345 \\
338 \\
354\end{array}$ & $\begin{array}{l}554 \\
535 \\
525 \\
520 \\
577\end{array}$ & $\begin{array}{l}300 \\
399 \\
447 \\
441 \\
451\end{array}$ & $\begin{array}{l}598 \\
578 \\
539 \\
498 \\
475\end{array}$ & $\begin{array}{l}257 \\
258 \\
252 \\
252 \\
251\end{array}$ & $\begin{array}{r}761 \\
2060 \\
2330 \\
2890 \\
2730\end{array}$ & $\begin{array}{l}2700 \\
2350 \\
2030 \\
1780 \\
1610\end{array}$ & $\begin{array}{l}716 \\
664 \\
625 \\
591 \\
562\end{array}$ & $\begin{array}{l}443 \\
413 \\
395 \\
375 \\
358\end{array}$ & $\begin{array}{l}422 \\
388 \\
349 \\
334 \\
320\end{array}$ & $\begin{array}{l}218 \\
218 \\
212 \\
213 \\
240\end{array}$ & $\begin{array}{r}1420 \\
1820 \\
1350 \\
967 \\
731\end{array}$ \\
\hline $\begin{array}{l}11 \\
12 \\
13 \\
14 \\
15\end{array}$ & $\begin{array}{l}386 \\
381 \\
357 \\
337 \\
349\end{array}$ & $\begin{array}{l}748 \\
809 \\
781 \\
761 \\
797\end{array}$ & $\begin{array}{l}458 \\
456 \\
429 \\
383 \\
432\end{array}$ & $\begin{array}{l}445 \\
390 \\
407 \\
418 \\
382\end{array}$ & $\begin{array}{l}251 \\
251 \\
251 \\
249 \\
242\end{array}$ & $\begin{array}{l}2810 \\
2580 \\
2240 \\
1940 \\
1750\end{array}$ & $\begin{array}{l}1470 \\
1350 \\
1240 \\
1160 \\
1100\end{array}$ & $\begin{array}{l}540 \\
547 \\
545 \\
545 \\
546\end{array}$ & $\begin{array}{l}371 \\
402 \\
612 \\
910 \\
983\end{array}$ & $\begin{array}{l}310 \\
300 \\
293 \\
297 \\
285\end{array}$ & $\begin{array}{l}213 \\
193 \\
199 \\
217 \\
217\end{array}$ & $\begin{array}{l}654 \\
574 \\
492 \\
442 \\
403\end{array}$ \\
\hline $\begin{array}{l}16 \\
17 \\
18 \\
19 \\
20\end{array}$ & $\begin{array}{l}416 \\
523 \\
674 \\
737 \\
676\end{array}$ & $\begin{array}{l}722 \\
628 \\
655 \\
601 \\
568\end{array}$ & $\begin{array}{l}494 \\
615 \\
718 \\
787 \\
787\end{array}$ & $\begin{array}{l}378 \\
386 \\
389 \\
324 \\
283\end{array}$ & $\begin{array}{l}242 \\
250 \\
260 \\
270 \\
293\end{array}$ & $\begin{array}{l}1640 \\
1510 \\
1370 \\
1260 \\
1150\end{array}$ & $\begin{array}{r}1040 \\
966 \\
916 \\
856 \\
804\end{array}$ & $\begin{array}{l}557 \\
561 \\
561 \\
561 \\
545\end{array}$ & $\begin{array}{r}1010 \\
952 \\
870 \\
775 \\
698\end{array}$ & $\begin{array}{l}274 \\
266 \\
260 \\
285 \\
267\end{array}$ & $\begin{array}{l}210 \\
213 \\
207 \\
198 \\
191\end{array}$ & $\begin{array}{l}369 \\
344 \\
325 \\
306 \\
294\end{array}$ \\
\hline $\begin{array}{l}21 \\
22 \\
23 \\
24 \\
25\end{array}$ & $\begin{array}{l}612 \\
577 \\
531 \\
501 \\
489\end{array}$ & $\begin{array}{l}515 \\
498 \\
512 \\
547 \\
536\end{array}$ & $\begin{array}{l}836 \\
798 \\
639 \\
463 \\
412\end{array}$ & $\begin{array}{l}322 \\
342 \\
334 \\
330 \\
324\end{array}$ & $\begin{array}{l}1230 \\
3170 \\
2020 \\
2300 \\
1840\end{array}$ & $\begin{array}{r}1070 \\
1020 \\
999 \\
1000 \\
998\end{array}$ & $\begin{array}{r}754 \\
750 \\
857 \\
1060 \\
1150\end{array}$ & $\begin{array}{l}523 \\
490 \\
480 \\
467 \\
461\end{array}$ & $\begin{array}{l}630 \\
586 \\
545 \\
502 \\
470\end{array}$ & $\begin{array}{l}266 \\
258 \\
247 \\
242 \\
256\end{array}$ & $\begin{array}{l}187 \\
198 \\
202 \\
208 \\
244\end{array}$ & $\begin{array}{l}309 \\
342 \\
408 \\
431 \\
620\end{array}$ \\
\hline $\begin{array}{l}26 \\
27 \\
28 \\
29 \\
30 \\
31\end{array}$ & $\begin{array}{l}490 \\
491 \\
492 \\
496 \\
496 \\
488\end{array}$ & $\begin{array}{l}527 \\
523 \\
521 \\
518 \\
507 \\
---\end{array}$ & $\begin{array}{r}474 \\
576 \\
964 \\
1250 \\
1310 \\
948\end{array}$ & $\begin{array}{l}313 \\
311 \\
307 \\
295 \\
296 \\
291\end{array}$ & $\begin{array}{r}1330 \\
968 \\
830 \\
-\ldots- \\
---\end{array}$ & $\begin{array}{l}948 \\
922 \\
911 \\
975 \\
959 \\
991\end{array}$ & $\begin{array}{l}1220 \\
1450 \\
1480 \\
1310 \\
1170 \\
-0\end{array}$ & $\begin{array}{l}445 \\
426 \\
409 \\
395 \\
387 \\
466\end{array}$ & $\begin{array}{l}449 \\
810 \\
882 \\
913 \\
766 \\
---\end{array}$ & $\begin{array}{l}264 \\
273 \\
264 \\
246 \\
244 \\
243\end{array}$ & $\begin{array}{l}237 \\
220 \\
206 \\
273 \\
240 \\
286\end{array}$ & $\begin{array}{r}753 \\
804 \\
822 \\
804 \\
1060 \\
--\end{array}$ \\
\hline $\begin{array}{l}\text { TOTAL } \\
\text { MEAN } \\
\text { MAX } \\
\text { MIN } \\
\text { CFSM } \\
\text { IN. } \\
\text { AC-ET }\end{array}$ & $\begin{array}{r}13625 \\
440 \\
737 \\
289 \\
.25 \\
.29 \\
27030\end{array}$ & $\begin{array}{r}18022 \\
601 \\
809 \\
498 \\
.34 \\
.38 \\
35750\end{array}$ & $\begin{array}{r}18252 \\
589 \\
1310 \\
300 \\
.34 \\
.39 \\
36200\end{array}$ & $\begin{array}{r}12891 \\
416 \\
648 \\
283 \\
.24 \\
.27 \\
25570\end{array}$ & $\begin{array}{r}18850 \\
673 \\
3170 \\
242 \\
.39 \\
.40 \\
37390\end{array}$ & $\begin{array}{r}44945 \\
1450 \\
2890 \\
761 \\
.83 \\
.96 \\
89150\end{array}$ & $\begin{array}{r}39326 \\
1311 \\
2700 \\
750 \\
.75 \\
.84 \\
78000\end{array}$ & $\begin{array}{r}18033 \\
582 \\
1050 \\
387 \\
.33 \\
.38 \\
35770\end{array}$ & $\begin{array}{r}19566 \\
652 \\
1010 \\
358 \\
.37 \\
.42 \\
38810\end{array}$ & $\begin{array}{r}10155 \\
328 \\
661 \\
242 \\
.19 \\
.22 \\
20140\end{array}$ & $\begin{array}{r}6823 \\
220 \\
286 \\
187 \\
.13 \\
.15 \\
13530\end{array}$ & $\begin{array}{r}18289 \\
610 \\
1820 \\
249 \\
.35 \\
.39 \\
36280\end{array}$ \\
\hline
\end{tabular}

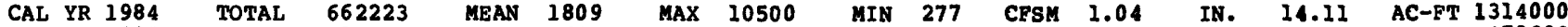

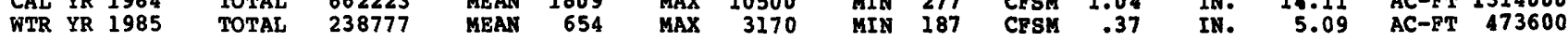


05463000 BEAVER CREER AT NEW HARTEORD, IA

LOCATION.--Lat $42^{\circ} 30^{\prime} 50^{\prime \prime}$, long $92^{\circ} 37^{\prime} 55^{\prime \prime}$, in SEl/4 sEl/4 sec.28, T.90 N., R.15 W., Butler County, Eydrologic Unit 07080205 , on downstream side of center bridge pier of bridge on county highway T55, 0.2 mi north of New Hartford, and $8 \mathrm{mi}$ upstream from mouth.

DRAINAGE AREA. $--347 \mathrm{mi}^{2}$.

PERIOD OF RECORD.--October 1945 to current year. Prior to April 1948, monthly discharge only, published in wSP 1308 .

REVISED RECORDS.--WSP 1438: Drainage area. WSP 1558: 1948-49. WSP 1708: 1947 (M).

GAGE.--Water-stage recorder. Datum of gage is $882.44 \mathrm{ft}$ above NGVD. Prior to July 14 , 1959 , nonrecording gage at same site and datum.

REMARRS.--Estimated daily discharge: Oct. 1-2, 6-10, 13-17, 24-28, Nov. 29 to March 8. Records good except for estimated daily discharges, which are poor. National Weather Service gage-height telemeter at station.

AVERAGE DISCHARGE. --40 years, $200 \mathrm{ft} / \mathrm{s}, 7.83 \mathrm{in} / \mathrm{yr}, 144,900 \mathrm{acre}-\mathrm{ft} / \mathrm{yr}$.

EXTREMES FOR PERIOD OF RECORD,--Waximum discharge, 18,000 ft3/s June 13, 1947, gage height, 13.5 ft, from graph

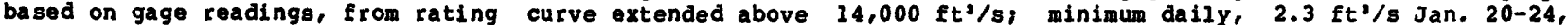
1956, Jan. 24, 1977 . r. SR

EXTREMES FOR CURRENT YEAR.--Peak discharges greater than base of 1,400 ft's and maximum ( $*$ ):

$\begin{array}{lcccc}\text { Date } & \text { Time } & \begin{array}{c}\text { Discharge } \\ (f t / 8)\end{array} & \begin{array}{c}\text { Gage height } \\ \text { (ft) }\end{array} & \text { Date harge height } \\ \text { March } 5 & -\cdots & * 3,930 & a * 10.56 & \text { No other peak greater than base discharge. }\end{array}$

a ice jam

Minimum daily discharge, $27 \mathrm{ft} / \mathrm{s}$ sept. 21.

DISCHARGE, IN CUBIC FEET PER SECOND, WATER YEAR OCTOBER 1984 TO SEPTEMBER 1985 MEAN VALUES

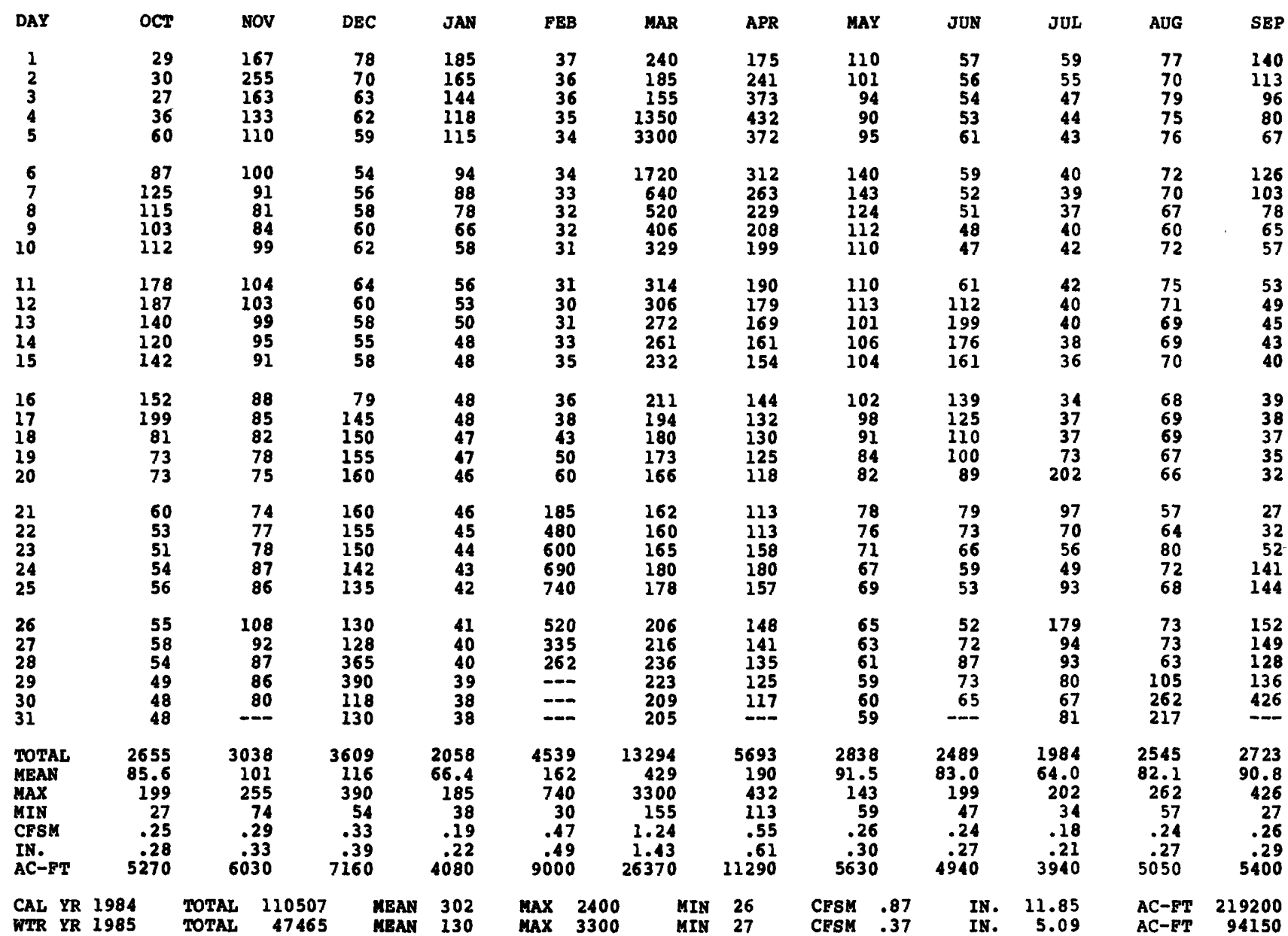


LOCATION.--Lat $42^{\circ} 24^{\prime} 28^{\prime \prime}$, long $92^{\circ} 27^{\prime} 47^{\prime \prime}$, in Sw1/4 NE1/4 sec.27, T.88 N., R.14 W., Black Hawk County, Hydrologic Unit 07080205 , on left bank $35 \mathrm{ft}$ downstream from bridge on state Highway 58 , $0.2 \mathrm{mi}$ northwest of Chicago and Great Western Railway tracks at the west edge of Hudson, $4.5 \mathrm{mi}$ upstream from Prescotts Creek, and $9.6 \mathrm{mi}$ upstream from mouth.

DRAINAGE AREA. $--303 \mathrm{mi}^{2}$.

PERIOD OF RECORD.--April 1952 to current year.

REVISED RECORDS.--WSP 1438: Drainage area.

GAGE.--Water-stage recorder. Datum of gage is $865.03 \mathrm{ft}$ above NGVD.

REMARRS.--Estimated daily discharges: Nov. 29 to March 8. Records good, except for estimated daily discharges, which are poor. National Weather Service gage-height telemeter at station.

AVERAGE DISCHARGE.--33 years, $172 \mathrm{ft} / \mathrm{s}, 7.71 \mathrm{in} / \mathrm{yr}, 124,600 \mathrm{acre-ft/yr}$ median of yearly mean discharges, 150 $\mathrm{ft}^{\mathrm{O}} / \mathrm{s}, 6.7 \mathrm{in} / \mathrm{yr}, 109,000$ acre-ft/yr.

EXTRENES FOR PERIOD OF RECORD,--Maximum discharge, $19,300 \mathrm{ft} / \mathrm{s}$ July 9, 1969 , gage height, 18.23 ft; minimum daily, $0.12 \mathrm{ft} / \mathrm{s}$ Jan. 26,1977

EXTREMES POR CURRENT YEAR.--Peak discharge greater than base discharge of $1,200 \mathrm{ft} / \mathrm{s}$ and maximum (*):

$\begin{array}{lcccc}\text { Discharge } & \text { Gage height } & \text { Discharge } & \text { Gage height } \\ \text { Date } & \text { Time } & (\mathrm{ft} / \mathrm{s}) & (\mathrm{ft}) & \text { Date } \\ \text { March } 4 & -2,300 & \mathrm{a} * 14.80 & \text { No other peak greater than base discharge. }\end{array}$

a ice jam

Minimum daily discharge, $17 \mathrm{ft} / \mathrm{s}$ sept. 20.

DISCHARGE, IN CUBIC FEET PER SECOND, WATER YEAR OCTOBER 1984 TO SEPTEMBER 1985 MEAN VALUES

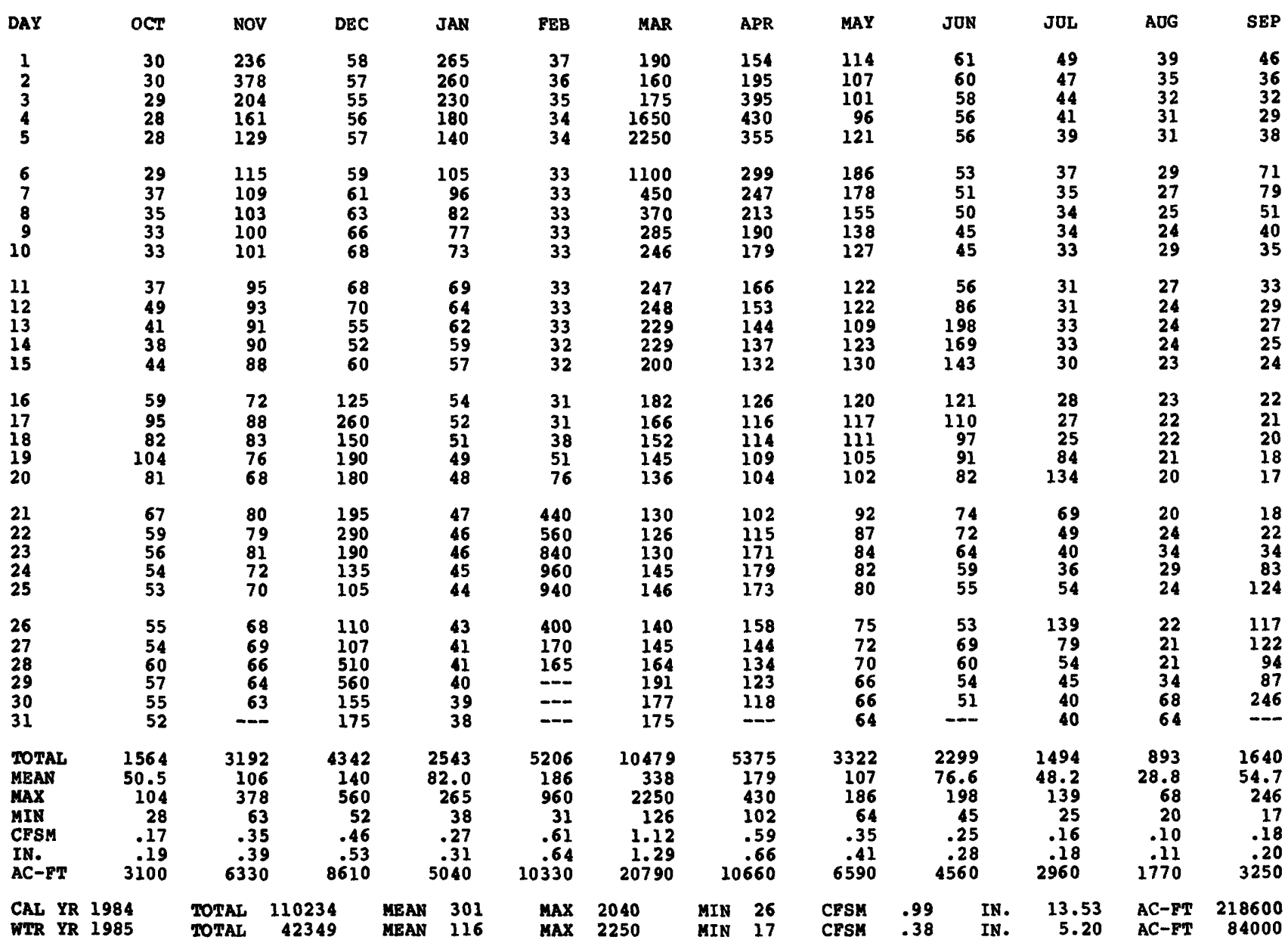


LOCATION.--Lat $42^{\circ} 29^{\prime} 44^{\prime \prime}$, long $92^{\circ} 20^{\prime} 03^{\prime \prime}$, in NWl/4 NWI/4 sec.25, T.89 N., R.13 W., Black Hawk County, Hydrologic Unit 07080205 , on left bank at foot of East Seventh Street, 0.3 mi upstream from Eleventh Avenue bridge in Waterloo, $1.1 \mathrm{mi}$ downstream from Black Hawk Creek, and at mile 187.9 upstream from mouth of Iowa River.

DRAINAGE AREA. $--5,146 \mathrm{mi}^{2}$.

PERIOD OF RECORD.--October 1940 to current year. Prior to April 194l, monthly discharge only, published in wSP 1308.

REVISED RECORDS.--WSP 1438: Drainage area. WSP 1558: 1950.

GAGE.--Water-stage recorder. Datum of gage is $824.14 \mathrm{ft}$ above NGVD.

REMARKS.--Estimated daily discharges: Dec. 2 to March 2. Records good, except for estimated daily discharges, which are poor. slight diurnal fluctuation during low flow caused by powerplant upstream from station. National Weather Service gage-height telemeter and U.S. Army Corps of Engineers Data Collection Platform at station.

AVERAGE DISCHARGE--45 years $3,036 \mathrm{ft}^{3} / \mathrm{s} 8.01 \mathrm{in} / \mathrm{yr}, 2,200,000 \mathrm{acre}-\mathrm{ft} / \mathrm{yr}$.

EXTREMES FOR PERIOD OF RECORD.--Maximum discharge, $76,700 \mathrm{ft}^{3} / \mathrm{s}$ Mar. 29, $1961, \mathrm{gage}$ height, $21.86 \mathrm{ft}$; minimum daily, $152 \mathrm{ft}^{3} / \mathrm{s}$ Jan. 28, 1959.

EXTREMES OUTSIDE PERIOD OF RECORD.--Fiood of Mar. 16, 1929, reached a stage of about $20 \mathrm{ft}$, determined by U. S. Army Corps of Engineers, from information by City of Water 100 , discharge, 65,000 ft\%/s. Flood of Apr. 2, 1933, reached a stage of about $19.5 \mathrm{ft}$ from information by City of waterloo, discharge, 61,000 ft'/8.

EXTREMES FOR CURRENT YEAR.--Peak discharges greater than base of $13,000 \mathrm{ft} / \mathrm{s}$ and maximum (*):

\begin{tabular}{|c|c|c|c|c|c|c|c|}
\hline $\begin{array}{l}\text { ate } \\
\text { eb. } 25\end{array}$ & Time & $\begin{array}{c}\text { Discharge } \\
(\mathrm{ft} / \mathrm{s}) \\
\text { ice jam }\end{array}$ & $\begin{array}{c}\text { Gage height } \\
\text { (ft) } \\
* 8.75\end{array}$ & $\begin{array}{l}\text { Date } \\
\text { March } 5\end{array}$ & $\begin{array}{l}\text { Time } \\
1200\end{array}$ & $\begin{array}{c}\text { Discharge } \\
\left(f t^{2} / \mathrm{s}\right) \\
* 10,400\end{array}$ & $\begin{array}{c}\text { Gage height } \\
(f t) \\
8.42\end{array}$ \\
\hline
\end{tabular}

Minimum daily discharge, $590 \mathrm{ft}^{2} / \mathrm{s}$ Feb. 19.

DISCHARGE, IN CUBIC FEET PER SECOND, WATER YEAR OCTOBER 1984 TO SEPTEMBER 1985 MEAN VALUES

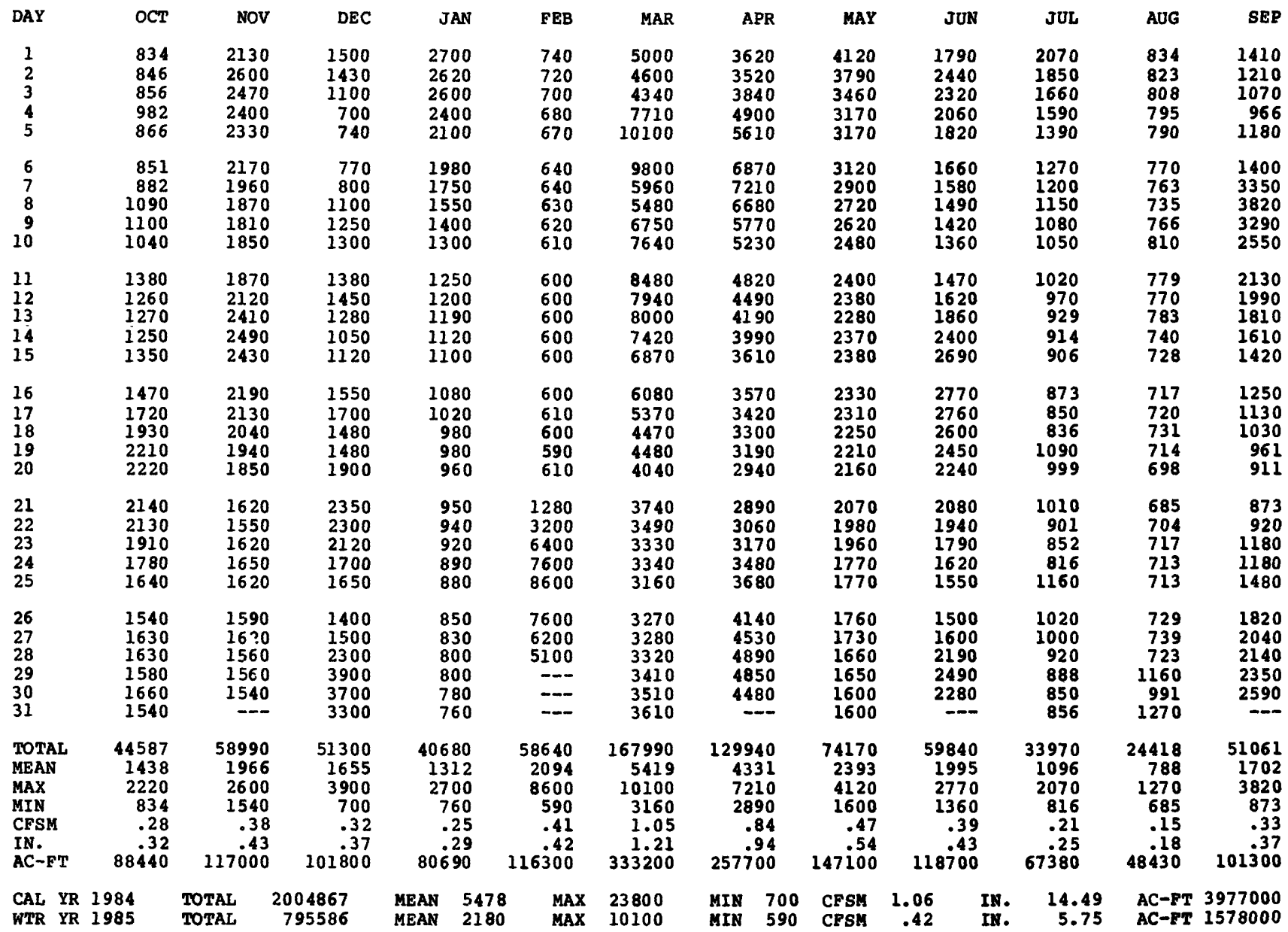


LOCATION.--Lat $41^{\circ} 58^{\prime} 1^{\prime \prime}$, long $91^{\circ} 40^{\prime} 01^{\prime \prime}$, in SEl/4 Nw1/4 sec.28, T.83 N., R.7 w., Linn County, Bydrologic Unit 07080205 , on right bank $400 \mathrm{ft}$ upstream from bridge on Eighth Avenue in Cedar Rapids, 2.7 mi upstream from Prairie Creek, and at mile 112.7 upstream from mouth of Iowa River.

DRAINAGE AREA. $--6,510 \mathrm{mi}^{2}$.

PERIOD OF RECORD.--October 1902 to current year. Monthly discharge only for some periods, published in wSP 1308.

REVISED RECORDS.--WSP 955: 1924. WSP 1308: 1904, 1906-13, 1915, 1917, 1919-24, 1928, 1930,. WSP 1438: Drainage area. WSP 1558: 1915-18 (M), 1920 (M), 1922 (M), 1929, $1933,1943$.

GAGE.--Water-stage recorder. Datum of gage is $700.47 \mathrm{ft}$ above NGVD. Prior to Aug. 20, 1920 , nonrecording gage at same site and datum.

REMARKS.--Estimated daily discharges: Jan. 2-3, Jan. 16 to Feb. 27. Records good except those for estimated discharge, which are fair. U.S.G.S. gage-height telemeter and U.S. Army Corps of Engineers data collection platform at station.

AVERAGE DISCHARGE. -83 years, 3,467 ft'/s, $7.23 \mathrm{in} / \mathrm{yr}, 2,512,000 \mathrm{acre}-\mathrm{ft} / \mathrm{yr}$.

EXTREMES FOR PERIOD OF RECORD.--Maximum discharge, 73,000 ft3/s Mar. 31, 1961, gage height, 19.66 ft; maximum gage height, $20.0 \mathrm{ft}$ Mar. 18, 1929; minimum discharge $53 \mathrm{ft} / \mathrm{s} J a n$. 6, 1950, caused by construction operations upstream; minimum daily, $212 \mathrm{ft}^{3} / \mathrm{s}$ Dec. $10,1949$.

EXTREMES OUTSIDE PERIOD OF RECORD.--Flood in June 1851 reached a stage of about $20 \mathrm{ft}$, discharge, $65,000 \mathrm{~b} f{ }^{3} / \mathrm{s}$, estimated.

EXTREMES FOR CURRENT YEAR.--Peak discharges greater than base of $12,000 \mathrm{ft}^{3} / \mathrm{s}$ and maximum (*):

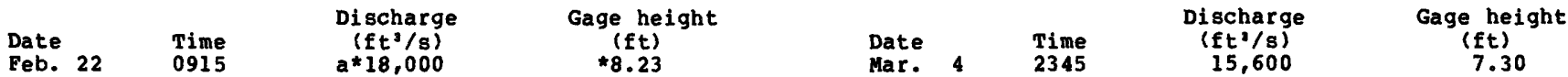

(a) Ice jam

Minimum discharge, $730 \mathrm{ft}^{3} / \mathrm{s}$ Dec. 7 .

DISCHARGE, IN CUBIC FEET PER SECOND, WATER YEAR OCTOBER 1984 TO SEPTEMBER 1985 MEAN VALUES

\begin{tabular}{|c|c|c|c|c|c|c|c|c|c|c|c|c|}
\hline DAY & OCT & NOV & DEC & JAN & FEB & MAR & APR & MAY & JUN & JUL & AUG & SEP \\
\hline $\begin{array}{l}1 \\
2 \\
3 \\
4 \\
5\end{array}$ & $\begin{array}{l}1190 \\
1210 \\
1210 \\
1480 \\
1190\end{array}$ & $\begin{array}{l}2400 \\
3420 \\
3610 \\
3560 \\
3260\end{array}$ & $\begin{array}{l}2340 \\
2320 \\
2100 \\
1450 \\
1050\end{array}$ & $\begin{array}{l}3410 \\
3600 \\
3400 \\
2980 \\
2430\end{array}$ & $\begin{array}{l}1900 \\
1880 \\
1860 \\
1810 \\
1760\end{array}$ & $\begin{array}{r}12500 \\
11100 \\
8590 \\
12100 \\
14900\end{array}$ & $\begin{array}{l}4610 \\
4710 \\
4950 \\
5300 \\
5620\end{array}$ & $\begin{array}{l}4580 \\
4060 \\
3910 \\
3640 \\
3540\end{array}$ & $\begin{array}{l}1860 \\
1830 \\
2110 \\
2540 \\
2310\end{array}$ & $\begin{array}{l}2360 \\
2220 \\
1970 \\
1900 \\
1770\end{array}$ & $\begin{array}{r}1030 \\
985 \\
953 \\
936 \\
928\end{array}$ & $\begin{array}{l}1110 \\
1250 \\
1350 \\
1240 \\
1150\end{array}$ \\
\hline $\begin{array}{r}6 \\
7 \\
8 \\
9 \\
10\end{array}$ & $\begin{array}{l}1280 \\
1330 \\
1240 \\
1160 \\
1400\end{array}$ & $\begin{array}{l}3100 \\
2960 \\
2810 \\
2820 \\
2740\end{array}$ & $\begin{array}{r}995 \\
778 \\
893 \\
1570 \\
2310\end{array}$ & $\begin{array}{l}2720 \\
3030 \\
3290 \\
3360 \\
2900\end{array}$ & $\begin{array}{l}1700 \\
1630 \\
1610 \\
1590 \\
1600\end{array}$ & $\begin{array}{r}14900 \\
14300 \\
10700 \\
6620 \\
7640\end{array}$ & $\begin{array}{l}6550 \\
7390 \\
8010 \\
7680 \\
6900\end{array}$ & $\begin{array}{l}3510 \\
3570 \\
3340 \\
3150 \\
3010\end{array}$ & $\begin{array}{l}2130 \\
1810 \\
1850 \\
1770 \\
1690\end{array}$ & $\begin{array}{l}1670 \\
1550 \\
1450 \\
1400 \\
1330\end{array}$ & $\begin{array}{l}902 \\
877 \\
837 \\
833 \\
904\end{array}$ & $\begin{array}{l}1110 \\
1230 \\
1530 \\
3170 \\
3140\end{array}$ \\
\hline $\begin{array}{l}11 \\
12 \\
13 \\
14 \\
15\end{array}$ & $\begin{array}{l}1440 \\
1570 \\
1770 \\
1560 \\
1590\end{array}$ & $\begin{array}{l}2620 \\
2500 \\
2620 \\
2850 \\
3070\end{array}$ & $\begin{array}{l}2350 \\
2420 \\
2290 \\
2100 \\
2010\end{array}$ & $\begin{array}{l}2750 \\
3150 \\
3330 \\
2500 \\
3520\end{array}$ & $\begin{array}{l}1610 \\
1530 \\
1510 \\
1510 \\
1520\end{array}$ & $\begin{array}{l}8100 \\
9110 \\
9310 \\
9110 \\
8810\end{array}$ & $\begin{array}{l}5880 \\
5380 \\
5010 \\
4700 \\
4330\end{array}$ & $\begin{array}{l}3010 \\
2980 \\
2820 \\
2800 \\
2770\end{array}$ & $\begin{array}{l}1680 \\
1740 \\
1840 \\
1920 \\
2230\end{array}$ & $\begin{array}{l}1290 \\
1150 \\
1220 \\
1220 \\
1170\end{array}$ & $\begin{array}{l}926 \\
921 \\
916 \\
926 \\
892\end{array}$ & $\begin{array}{l}2800 \\
2180 \\
2070 \\
1950 \\
1830\end{array}$ \\
\hline $\begin{array}{l}16 \\
17 \\
18 \\
19 \\
20\end{array}$ & $\begin{array}{l}1650 \\
1830 \\
2320 \\
2560 \\
2650\end{array}$ & $\begin{array}{l}3050 \\
2940 \\
2830 \\
2770 \\
2690\end{array}$ & $\begin{array}{l}2720 \\
3280 \\
3060 \\
2320 \\
2080\end{array}$ & $\begin{array}{l}3300 \\
3050 \\
2800 \\
2900 \\
3000\end{array}$ & $\begin{array}{l}1500 \\
1490 \\
1480 \\
1470 \\
1550\end{array}$ & $\begin{array}{l}8010 \\
7020 \\
6060 \\
5340 \\
4730\end{array}$ & $\begin{array}{l}4170 \\
3940 \\
3830 \\
3680 \\
3530\end{array}$ & $\begin{array}{l}2760 \\
2680 \\
2610 \\
2550 \\
2500\end{array}$ & $\begin{array}{l}2550 \\
2700 \\
2760 \\
2720 \\
2700\end{array}$ & $\begin{array}{l}1110 \\
1080 \\
1040 \\
1050 \\
1170\end{array}$ & $\begin{array}{l}830 \\
823 \\
801 \\
789 \\
783\end{array}$ & $\begin{array}{l}1680 \\
1550 \\
1290 \\
1300 \\
1240\end{array}$ \\
\hline $\begin{array}{l}21 \\
22 \\
23 \\
24 \\
25\end{array}$ & $\begin{array}{l}2660 \\
2520 \\
2420 \\
2480 \\
2180\end{array}$ & $\begin{array}{l}2610 \\
2510 \\
2380 \\
2360 \\
2390\end{array}$ & $\begin{array}{l}2400 \\
3310 \\
3070 \\
3070 \\
2620\end{array}$ & $\begin{array}{l}2900 \\
2500 \\
2300 \\
2200 \\
2210\end{array}$ & $\begin{array}{r}4500 \\
16000 \\
14600 \\
13000 \\
12200\end{array}$ & $\begin{array}{l}4630 \\
4290 \\
4110 \\
3950 \\
3990\end{array}$ & $\begin{array}{l}3540 \\
3480 \\
3610 \\
4060 \\
3790\end{array}$ & $\begin{array}{l}2450 \\
2380 \\
2300 \\
2020 \\
2150\end{array}$ & $\begin{array}{l}2470 \\
2330 \\
2180 \\
1890 \\
1900\end{array}$ & $\begin{array}{l}1300 \\
1210 \\
1150 \\
1060 \\
1140\end{array}$ & $\begin{array}{l}770 \\
805 \\
823 \\
848 \\
837\end{array}$ & $\begin{array}{l}1220 \\
1240 \\
1440 \\
1480 \\
1750\end{array}$ \\
\hline $\begin{array}{l}26 \\
27 \\
28 \\
29 \\
30 \\
31\end{array}$ & $\begin{array}{l}2090 \\
2070 \\
2080 \\
2120 \\
2040 \\
2040\end{array}$ & $\begin{array}{l}2410 \\
2470 \\
2460 \\
2410 \\
2360 \\
---\end{array}$ & $\begin{array}{l}1570 \\
1490 \\
2630 \\
5310 \\
6530 \\
4950\end{array}$ & $\begin{array}{l}2290 \\
2300 \\
2200 \\
2000 \\
1900 \\
1910\end{array}$ & $\begin{array}{r}13300 \\
13800 \\
14000 \\
- \\
-- \\
-\end{array}$ & $\begin{array}{l}3930 \\
3880 \\
4090 \\
4190 \\
4100 \\
4530\end{array}$ & $\begin{array}{l}3960 \\
4120 \\
4530 \\
4690 \\
4800 \\
---\end{array}$ & $\begin{array}{l}2020 \\
2010 \\
1980 \\
1950 \\
1930 \\
1910\end{array}$ & $\begin{array}{l}1800 \\
1730 \\
1710 \\
1810 \\
2340 \\
---\end{array}$ & $\begin{array}{l}1130 \\
1210 \\
1160 \\
1120 \\
1060 \\
1060\end{array}$ & $\begin{array}{r}817 \\
802 \\
815 \\
818 \\
878 \\
1150\end{array}$ & $\begin{array}{l}1660 \\
1850 \\
2070 \\
2350 \\
2750 \\
--\end{array}$ \\
\hline $\begin{array}{l}\text { TOTAL } \\
\text { MEAN } \\
\text { MAX } \\
\text { MIN } \\
\text { CESM } \\
\text { IN. } \\
\text { AC-FT }\end{array}$ & $\begin{array}{r}56330 \\
1817 \\
2660 \\
1160 \\
.28 \\
.32 \\
111700\end{array}$ & $\begin{array}{r}82980 \\
2766 \\
3610 \\
2360 \\
.42 \\
.47 \\
164600\end{array}$ & $\begin{array}{r}77386 \\
2496 \\
6530 \\
778 \\
.38 \\
.44 \\
153500\end{array}$ & $\begin{array}{r}86130 \\
2778 \\
3600 \\
1900 \\
.43 \\
.49 \\
170800\end{array}$ & $\begin{array}{r}133910 \\
4783 \\
16000 \\
1470 \\
.73 \\
.77 \\
265600\end{array}$ & $\begin{array}{r}234640 \\
7569 \\
14900 \\
3880 \\
1.16 \\
1.34 \\
465400\end{array}$ & $\begin{array}{r}146750 \\
4892 \\
8010 \\
3480 \\
.75 \\
.84 \\
291100\end{array}$ & $\begin{array}{r}86890 \\
2803 \\
4580 \\
1910 \\
.43 \\
.50 \\
172300\end{array}$ & $\begin{array}{r}62900 \\
2097 \\
2760 \\
1680 \\
.32 \\
.36 \\
124800\end{array}$ & $\begin{array}{r}41720 \\
1346 \\
2360 \\
1040 \\
.21 \\
.24 \\
82750\end{array}$ & $\begin{array}{r}27155 \\
876 \\
1150 \\
770 \\
.13 \\
.16 \\
53860\end{array}$ & $\begin{array}{r}51980 \\
1733 \\
3170 \\
1110 \\
.27 \\
.30 \\
103100\end{array}$ \\
\hline
\end{tabular}

$\begin{array}{llllllllllllll}\text { CAL YR 1984 TOTAL } & 2712326 & \text { MEAN } & 7411 & \text { MAX } & 30800 & \text { MIN } & 778 & \text { CFSM } & 1.14 & \text { IN. } & 15.50 & \text { AC-FT } & 5380000\end{array}$ WTR YR 1985 TOTAL 1088771 MEAN $2983 \quad$ MAX 16000 MIN 770 CFSM .46 
LOCATION.--Lat $41^{\circ} 24^{\prime} 36^{\prime \prime}$, long $91^{\circ} 17^{\prime} 06^{\prime \prime}$, in Sw1/4 SW1/4 sec.2, T.76 N., R.4 W., Muscatine County, Hydrologic Unit 07080206 , on right bank $10 \mathrm{ft}$ downstream from bridge on county highway G28, 3.4 mi northeast of Conesville, 5.2 mi downstream from Wapsinonoc Creek, $10.7 \mathrm{mi}$ upstream from mouth, and at mile 39.8 upstream from mouth of Iowa River.

DRAINAGE AREA. $--7,785 \mathrm{mi}^{2}$.

PERIOD OF RECORD.--September 1939 to current year.

REVISED RECORDS.--WSP 1438: Drainage area. WSP 1708: 1956.

GAGE.--Water-stage recorder. Datum of gage is $581.95 \mathrm{ft}$ above NGVD. Prior to Feb. 2, 1940 , and Apr. 11, 1952 , to July 1, 1954, nonrecording gage, Feb. 2, 1940, to Apr, 10, 1952, and July 2, 1954, to Sept. 16, 1963, waterstage recorder, at site $150 \mathrm{ft}$ downstream on left bank at same datum.

REMARKS.-- Estimated daily discharges during water year: Dec. 6 to Feb. 28 . Records good except those for estimated daily discharge, which are poor. U.s. Army Corps of Engineers data collection platform at gage.

COOPERATION.--Four discharge measurements provided by U.S. Army Corps of Engineers.

AVERAGE DISCHARGE. - 46 years, $4.738 \mathrm{ft} / \mathrm{s}, 8.26 \mathrm{in} / \mathrm{yr}^{\mathrm{r}}, 3,433,000 \mathrm{acre-ft} / \mathrm{yr}$.

EXTREMES FOR PERIOD OF RECORD.--Kaximum discharge, $70,800 \mathrm{ft} / \mathrm{s}$ Apr. 2, 1961, gage height, 16.62 ft; maximum gage height, $16.85 \mathrm{ft}$ Apr. 12, 1965; minimum daily discharge, $250 \mathrm{ft} / \mathrm{s}$ Nov. 28, 1955, result of freezeup.

EXTREMES OOTSIDE PERIOD OF RECORD.--Flood in March 1929 reached a stage of 15.8 ft, from information by local residents to $0 . S$. Army Corps of Engineers.

EXTREMES FOR CURRENT YEAR.--Peak discharges above base of $12,000 \mathrm{ft}^{3} / \mathrm{s}$ and maximum (*):

\begin{tabular}{|c|c|c|c|c|c|c|}
\hline $\begin{array}{l}\text { Date } \\
\text { Peb. } 25\end{array}$ & Time & $\begin{array}{l}\text { Discharge } \\
\left(f t^{*} / \mathrm{s}\right) \\
\star 28,000\end{array}$ & $\begin{array}{c}\text { Gage height } \\
(f t) \\
a * 16.56\end{array}$ & $\begin{array}{l}\text { Date } \\
\text { Mar. } 6\end{array}$ & $\begin{array}{l}\text { Time } \\
1500\end{array}$ & $\begin{array}{c}\text { Gage height } \\
\text { (ft) } \\
12.67\end{array}$ \\
\hline
\end{tabular}

a Ice jam

Minimum daily discharge, $1,040 \mathrm{ft} / \mathrm{s}$ Aug. 22.

DISCHARGE, IN CUBIC FEET PER SECOND, WATER YEAR OCTOBER 1984 TO SEPTEMBER 1985 MEAN VALUES

\begin{tabular}{|c|c|c|c|c|c|c|c|c|c|c|c|c|}
\hline DAY & OCT & Nov & DEC & JAN & FEB & MAR & APR & MAY & JUN & JUL & AUG & SEP \\
\hline $\begin{array}{l}1 \\
2 \\
3 \\
4 \\
5\end{array}$ & $\begin{array}{l}1480 \\
1430 \\
1440 \\
1430 \\
1440\end{array}$ & $\begin{array}{l}5550 \\
6610 \\
5010 \\
5000 \\
4730\end{array}$ & $\begin{array}{l}2880 \\
2840 \\
2810 \\
2630 \\
2330\end{array}$ & $\begin{array}{l}5100 \\
3600 \\
3800 \\
3200 \\
2900\end{array}$ & $\begin{array}{l}2150 \\
2000 \\
2000 \\
1950 \\
1850\end{array}$ & $\begin{array}{l}16500 \\
14800 \\
13300 \\
15500 \\
17900\end{array}$ & $\begin{array}{l}6170 \\
6370 \\
6280 \\
6380 \\
6610\end{array}$ & $\begin{array}{l}5510 \\
5380 \\
5000 \\
4570 \\
4440\end{array}$ & $\begin{array}{l}2580 \\
2510 \\
2450 \\
2430 \\
2710\end{array}$ & $\begin{array}{l}2110 \\
2400 \\
2370 \\
2230 \\
2060\end{array}$ & $\begin{array}{l}1380 \\
1310 \\
1270 \\
1250 \\
1230\end{array}$ & $\begin{array}{l}1100 \\
1230 \\
1230 \\
1310 \\
1360\end{array}$ \\
\hline $\begin{array}{r}6 \\
7 \\
8 \\
9 \\
10\end{array}$ & $\begin{array}{l}1600 \\
1460 \\
1520 \\
1530 \\
1440\end{array}$ & $\begin{array}{l}4270 \\
3900 \\
3710 \\
3580 \\
4210\end{array}$ & $\begin{array}{l}1600 \\
1150 \\
1500 \\
1650 \\
1700\end{array}$ & $\begin{array}{l}2700 \\
2900 \\
3100 \\
3150 \\
3000\end{array}$ & $\begin{array}{l}1800 \\
1750 \\
1700 \\
1700 \\
1650\end{array}$ & $\begin{array}{r}18900 \\
17800 \\
16800 \\
14100 \\
9630\end{array}$ & $\begin{array}{l}6940 \\
7450 \\
7940 \\
8250 \\
8360\end{array}$ & $\begin{array}{l}4310 \\
4300 \\
4270 \\
4120 \\
3910\end{array}$ & $\begin{array}{l}2880 \\
2710 \\
2530 \\
2320 \\
2300\end{array}$ & $\begin{array}{l}1980 \\
1920 \\
1840 \\
1760 \\
1700\end{array}$ & $\begin{array}{l}1220 \\
1200 \\
1180 \\
1150 \\
1350\end{array}$ & $\begin{array}{l}1310 \\
1260 \\
1220 \\
1240 \\
1670\end{array}$ \\
\hline $\begin{array}{l}11 \\
12 \\
13 \\
14 \\
15\end{array}$ & $\begin{array}{l}1440 \\
1590 \\
1650 \\
1730 \\
1820\end{array}$ & $\begin{array}{l}4180 \\
3600 \\
3320 \\
3170 \\
3320\end{array}$ & $\begin{array}{l}2150 \\
2500 \\
2300 \\
2350 \\
2200\end{array}$ & $\begin{array}{l}2850 \\
3000 \\
3200 \\
2400 \\
3500\end{array}$ & $\begin{array}{l}1550 \\
1550 \\
1500 \\
1500 \\
1500\end{array}$ & $\begin{array}{r}9390 \\
9780 \\
10400 \\
10900 \\
10600\end{array}$ & $\begin{array}{l}8040 \\
7230 \\
6610 \\
6260 \\
5860\end{array}$ & $\begin{array}{l}3760 \\
3740 \\
4050 \\
3800 \\
3850\end{array}$ & $\begin{array}{l}2250 \\
2230 \\
2190 \\
2210 \\
2300\end{array}$ & $\begin{array}{l}1660 \\
1650 \\
1640 \\
1530 \\
1760\end{array}$ & $\begin{array}{l}1370 \\
1210 \\
1230 \\
1250 \\
1200\end{array}$ & $\begin{array}{l}2610 \\
2650 \\
2380 \\
2030 \\
1950\end{array}$ \\
\hline $\begin{array}{l}16 \\
17 \\
18 \\
19 \\
20\end{array}$ & $\begin{array}{l}1820 \\
1990 \\
2300 \\
5260 \\
5420\end{array}$ & $\begin{array}{l}3490 \\
3500 \\
3410 \\
3300 \\
3200\end{array}$ & $\begin{array}{l}2100 \\
2550 \\
3000 \\
3500 \\
3000\end{array}$ & $\begin{array}{l}3400 \\
3250 \\
3050 \\
2900 \\
2600\end{array}$ & $\begin{array}{l}1600 \\
1650 \\
1700 \\
1800 \\
2050\end{array}$ & $\begin{array}{r}10300 \\
9560 \\
8690 \\
7780 \\
7080\end{array}$ & $\begin{array}{l}5490 \\
5150 \\
4970 \\
4840 \\
4660\end{array}$ & $\begin{array}{l}3830 \\
3640 \\
3540 \\
3410 \\
3320\end{array}$ & $\begin{array}{l}2390 \\
2650 \\
2850 \\
2950 \\
2970\end{array}$ & $\begin{array}{l}1660 \\
1480 \\
1410 \\
1390 \\
1360\end{array}$ & $\begin{array}{l}1180 \\
1140 \\
1100 \\
1090 \\
1070\end{array}$ & $\begin{array}{l}1860 \\
1770 \\
1670 \\
1580 \\
1430\end{array}$ \\
\hline $\begin{array}{l}21 \\
22 \\
23 \\
24 \\
25\end{array}$ & $\begin{array}{l}3790 \\
3420 \\
3190 \\
2930 \\
2870\end{array}$ & $\begin{array}{l}3090 \\
3010 \\
2950 \\
2860 \\
2790\end{array}$ & $\begin{array}{l}2600 \\
2300 \\
2850 \\
3400 \\
2500\end{array}$ & $\begin{array}{l}2500 \\
2400 \\
2700 \\
2600 \\
2600\end{array}$ & $\begin{array}{r}2700 \\
8800 \\
12000 \\
17500 \\
23500\end{array}$ & $\begin{array}{l}6310 \\
6090 \\
5760 \\
5490 \\
5240\end{array}$ & $\begin{array}{l}4480 \\
4410 \\
4430 \\
4520 \\
4770\end{array}$ & $\begin{array}{l}3230 \\
3130 \\
3050 \\
2970 \\
2850\end{array}$ & $\begin{array}{l}2890 \\
2870 \\
2750 \\
2570 \\
2370\end{array}$ & $\begin{array}{l}1360 \\
1440 \\
1440 \\
1400 \\
1390\end{array}$ & $\begin{array}{l}1050 \\
1040 \\
1050 \\
1090 \\
1100\end{array}$ & $\begin{array}{l}1460 \\
1460 \\
1650 \\
1710 \\
1680\end{array}$ \\
\hline $\begin{array}{l}26 \\
27 \\
28 \\
29 \\
30 \\
31\end{array}$ & $\begin{array}{l}2840 \\
2640 \\
3010 \\
3260 \\
2910 \\
2790\end{array}$ & $\begin{array}{c}2800 \\
3010 \\
3150 \\
3020 \\
2960 \\
---\end{array}$ & $\begin{array}{l}1800 \\
1750 \\
2550 \\
3600 \\
5000 \\
6600\end{array}$ & $\begin{array}{l}2550 \\
2400 \\
2450 \\
2500 \\
2450 \\
2300\end{array}$ & $\begin{array}{r}27000 \\
23000 \\
18000 \\
\end{array}$ & $\begin{array}{l}5060 \\
5060 \\
5160 \\
5320 \\
5340 \\
5510\end{array}$ & $\begin{array}{r}4620 \\
4640 \\
4710 \\
5010 \\
5240 \\
-2\end{array}$ & $\begin{array}{l}2810 \\
2900 \\
2810 \\
2730 \\
2690 \\
2620\end{array}$ & $\begin{array}{c}2180 \\
2130 \\
2030 \\
1970 \\
1950 \\
-0-\end{array}$ & $\begin{array}{l}1380 \\
1370 \\
1370 \\
1380 \\
1380 \\
1460\end{array}$ & $\begin{array}{l}1100 \\
1080 \\
1050 \\
1050 \\
1060 \\
1050\end{array}$ & $\begin{array}{l}1720 \\
1830 \\
1760 \\
1890 \\
2120 \\
---\end{array}$ \\
\hline $\begin{array}{l}\text { TOTAL } \\
\text { MEAN } \\
\text { MAX } \\
\text { MIN } \\
\text { CFSH } \\
\text { IN. } \\
\text { AC-FT }\end{array}$ & $\begin{array}{r}73440 \\
2369 \\
5420 \\
1430 \\
.30 \\
.35 \\
145700\end{array}$ & $\begin{array}{r}110700 \\
3690 \\
6610 \\
2790 \\
.47 \\
.53 \\
219600\end{array}$ & $\begin{array}{r}81690 \\
2635 \\
6600 \\
1150 \\
.34 \\
.39 \\
162000\end{array}$ & $\begin{array}{r}91050 \\
2937 \\
5100 \\
2300 \\
.38 \\
.44 \\
180600\end{array}$ & $\begin{array}{r}167450 \\
5980 \\
27000 \\
1500 \\
.77 \\
.80 \\
332100\end{array}$ & $\begin{array}{r}310050 \\
10000 \\
18900 \\
5060 \\
1.28 \\
1.48 \\
615000\end{array}$ & $\begin{array}{r}176690 \\
5890 \\
8360 \\
4410 \\
.76 \\
.84 \\
350500\end{array}$ & $\begin{array}{r}114540 \\
3695 \\
5510 \\
2620 \\
.47 \\
.55 \\
227200\end{array}$ & $\begin{array}{r}74120 \\
2471 \\
2970 \\
1950 \\
.32 \\
.35 \\
147000\end{array}$ & $\begin{array}{r}51280 \\
1654 \\
2400 \\
1360 \\
.21 \\
.25 \\
101700\end{array}$ & $\begin{array}{r}36100 \\
1165 \\
1380 \\
1040 \\
.15 \\
.17 \\
71600\end{array}$ & $\begin{array}{r}50140 \\
1671 \\
2650 \\
1100 \\
.21 \\
924 \\
99450\end{array}$ \\
\hline
\end{tabular}

CAL IR 1984 TOTAL $2987790 \quad$ MEAN $8163 \quad$ MAX $29000 \quad$ MIN 1150 CFSM $1.05 \quad$ IN. $14.28 \quad$ AC-FT 5926000

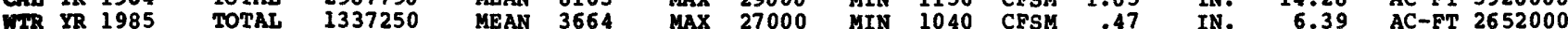


05465500 IOWA RIVER AT WAPELLO, IA

(National stream-quality accounting network station)

LOCATION.--Lat $41^{\circ} 10^{\prime} 48^{\prime \prime}$, long $91^{\circ} 10^{\prime} 57^{\prime \prime}$, in NW1/4 SE1/4 sec.27, T.74 N., R.3 W., Louisa County, Hydrologic Unit 07080209 , on right bank $30 \mathrm{ft}$ downstream from bridge on state Highway 99 at east edge of Wapello, 13.0 mi downstream from Cedar River, and at mile 16.0 .

DRAINAGE AREA. $--12,499 \mathrm{mi}^{2}$.

\section{WATER-DISCHARGE RECORDS}

PERIOD OF RECORD.--October 1914 to current year. Monthly discharge only for some periods, published in WSP 1308.

REVISED RECORDS.--WSP 1308: 1917, 1923-30, 1932. WSP 1438: Drainage area. WSP 1558: 1918, 1923-25 (M), 1929. WSP 1708: $1955(\mathrm{P}), 1956$.

GAGE.--Water-stage recorder. Datum of gage is $538.17 \mathrm{ft}$ above NGVD; Oct. 1, 1914 to Apr. 15 , 1934 , nonrecording gage and Apr. 16, 1934 to Sept. 30, 1972, water-stage recorder at datum $10.00 \mathrm{ft}$ higher.

REMARRS.--Estimated daily discharge: Dec. 6 to Feb. 24. Records good except those for periods of estimated record which are poor. Flow regulated by Coralville Lake (station 05453510) 67.3 mi upstream, since Sept. 17, 1958. U.S. Army Corps of Engineers data collection platform at gage.

COOPERATION.--Four discharge measurements provided by U.S. Army Corps of Engineers.

AVERAGE DISCHARGE, --71 years, $7,001 \mathrm{ft} / \mathrm{s}, 7.61 \mathrm{in} / \mathrm{yr}, 5,072,000 \mathrm{acre}-\mathrm{ft} / \mathrm{yr}$.

EXTREMES FOR PERIOD OF RECORD.--Maximum discharge, $94,000 \mathrm{ft} 3 / \mathrm{s}$ June 18, 1947, gage height, 16.14 ft, datum then in use; maximum gage height, $28.63 \mathrm{ft} \mathrm{Apr.} \mathrm{22,} \mathrm{1973;} \mathrm{minimum} \mathrm{daily} \mathrm{discharge,} 300 \mathrm{ft} / \mathrm{s}$ Nov. 28,1955 , result of freezeup.

EXTREMES FOR CURRENT YEAR,--Maximum discharge, 44,400 ft3/s Feb, 25, gage height, $23.37 \mathrm{ft}$; minimum daily discharge, $1,490 \mathrm{ft}^{3} / \mathrm{s}$ Aug. 22.

DISCHARGE, IN CUBIC FEET PER SECOND, WATER YEAR OCTOBER 1984 TO SEPTEMBER 1985 MEAN VALUES

\begin{tabular}{|c|c|c|c|c|c|c|c|c|c|c|c|c|}
\hline DAY & OCT & NOV & DEC & JAN & FEB & MAR & APR & MAY & JUN & JUL & AUG & SEP \\
\hline $\begin{array}{l}1 \\
2 \\
3 \\
4 \\
5\end{array}$ & $\begin{array}{l}2110 \\
2050 \\
1990 \\
1980 \\
1980\end{array}$ & $\begin{array}{r}9430 \\
15200 \\
9990 \\
8690 \\
7980\end{array}$ & $\begin{array}{l}4360 \\
4270 \\
4130 \\
3910 \\
3770\end{array}$ & $\begin{array}{r}11000 \\
8300 \\
6000 \\
4950 \\
4400\end{array}$ & $\begin{array}{l}3500 \\
3200 \\
3000 \\
2900 \\
2800\end{array}$ & $\begin{array}{l}26300 \\
25200 \\
24300 \\
28600 \\
31300\end{array}$ & $\begin{array}{r}8880 \\
9870 \\
10200 \\
9930 \\
9510\end{array}$ & $\begin{array}{l}7390 \\
7620 \\
7700 \\
7530 \\
7250\end{array}$ & $\begin{array}{l}3650 \\
3590 \\
3510 \\
3430 \\
3410\end{array}$ & $\begin{array}{l}2850 \\
2850 \\
2940 \\
2990 \\
2960\end{array}$ & $\begin{array}{l}1850 \\
1840 \\
1840 \\
1810 \\
1780\end{array}$ & $\begin{array}{l}1520 \\
1650 \\
1740 \\
1750 \\
1860\end{array}$ \\
\hline $\begin{array}{r}6 \\
7 \\
8 \\
9 \\
10\end{array}$ & $\begin{array}{l}2080 \\
2070 \\
2030 \\
2070 \\
2040\end{array}$ & $\begin{array}{l}7490 \\
6850 \\
6310 \\
6120 \\
6440\end{array}$ & $\begin{array}{l}3000 \\
2400 \\
2800 \\
3000 \\
3300\end{array}$ & $\begin{array}{l}4000 \\
3900 \\
4200 \\
4950 \\
5300\end{array}$ & $\begin{array}{l}2700 \\
2600 \\
2550 \\
2500 \\
2500\end{array}$ & $\begin{array}{l}32900 \\
30800 \\
26600 \\
25500 \\
21800\end{array}$ & $\begin{array}{r}9990 \\
10500 \\
10800 \\
11000 \\
11200\end{array}$ & $\begin{array}{l}7020 \\
6820 \\
6690 \\
6410 \\
5910\end{array}$ & $\begin{array}{l}3560 \\
3670 \\
3620 \\
3490 \\
3280\end{array}$ & $\begin{array}{l}2810 \\
2680 \\
2580 \\
2520 \\
2430\end{array}$ & $\begin{array}{l}1770 \\
1770 \\
1750 \\
1720 \\
1730\end{array}$ & $\begin{array}{l}1860 \\
1790 \\
1720 \\
1710 \\
1790\end{array}$ \\
\hline $\begin{array}{l}11 \\
12 \\
13 \\
14 \\
15\end{array}$ & $\begin{array}{l}2000 \\
2110 \\
2220 \\
2330 \\
2570\end{array}$ & $\begin{array}{l}9050 \\
7550 \\
7060 \\
6250 \\
5360\end{array}$ & $\begin{array}{l}3650 \\
4150 \\
3950 \\
3900 \\
4100\end{array}$ & $\begin{array}{l}5200 \\
5000 \\
4800 \\
4900 \\
5000\end{array}$ & $\begin{array}{l}2500 \\
2450 \\
2450 \\
2400 \\
2400\end{array}$ & $\begin{array}{l}19800 \\
20100 \\
19900 \\
19700 \\
17800\end{array}$ & $\begin{array}{r}11100 \\
10400 \\
9770 \\
9370 \\
8960\end{array}$ & $\begin{array}{l}5480 \\
5840 \\
5380 \\
5730 \\
5490\end{array}$ & $\begin{array}{l}3170 \\
3100 \\
3090 \\
3050 \\
3050\end{array}$ & $\begin{array}{l}2360 \\
2290 \\
2250 \\
2180 \\
2150\end{array}$ & $\begin{array}{l}1770 \\
1730 \\
1690 \\
1670 \\
1640\end{array}$ & $\begin{array}{l}2470 \\
2990 \\
2900 \\
2540 \\
2300\end{array}$ \\
\hline $\begin{array}{l}16 \\
17 \\
18 \\
19 \\
20\end{array}$ & $\begin{array}{r}2720 \\
2980 \\
3850 \\
7730 \\
11100\end{array}$ & $\begin{array}{l}5370 \\
5330 \\
5050 \\
4780 \\
4620\end{array}$ & $\begin{array}{l}4200 \\
4300 \\
4700 \\
5600 \\
4900\end{array}$ & $\begin{array}{l}5000 \\
4950 \\
4750 \\
4400 \\
4000\end{array}$ & $\begin{array}{l}2400 \\
2500 \\
2700 \\
2900 \\
3150\end{array}$ & $\begin{array}{l}16800 \\
15000 \\
13400 \\
12000 \\
11000\end{array}$ & $\begin{array}{l}8420 \\
8040 \\
7700 \\
7300 \\
7140\end{array}$ & $\begin{array}{l}5480 \\
5310 \\
5080 \\
5040 \\
4920\end{array}$ & $\begin{array}{l}3080 \\
3200 \\
3340 \\
3480 \\
3580\end{array}$ & $\begin{array}{l}2450 \\
2280 \\
2070 \\
1960 \\
1940\end{array}$ & $\begin{array}{l}1600 \\
1590 \\
1570 \\
1550 \\
1520\end{array}$ & $\begin{array}{l}2200 \\
2130 \\
2300 \\
2320 \\
2180\end{array}$ \\
\hline $\begin{array}{l}21 \\
22 \\
23 \\
24 \\
25\end{array}$ & $\begin{array}{l}7650 \\
6600 \\
6110 \\
5410 \\
4630\end{array}$ & $\begin{array}{l}4520 \\
4480 \\
4500 \\
4450 \\
4350\end{array}$ & $\begin{array}{l}4300 \\
3950 \\
3700 \\
4250 \\
4700\end{array}$ & $\begin{array}{l}3900 \\
3950 \\
4150 \\
4250 \\
4200\end{array}$ & $\begin{array}{r}5200 \\
8600 \\
16000 \\
26000 \\
42600\end{array}$ & $\begin{array}{r}10100 \\
9180 \\
8640 \\
8310 \\
8080\end{array}$ & $\begin{array}{l}7090 \\
6870 \\
6790 \\
6840 \\
6880\end{array}$ & $\begin{array}{l}4830 \\
4680 \\
4350 \\
4210 \\
4120\end{array}$ & $\begin{array}{l}3620 \\
3640 \\
3650 \\
3640 \\
3630\end{array}$ & $\begin{array}{l}1930 \\
1920 \\
1920 \\
1920 \\
1880\end{array}$ & $\begin{array}{l}1500 \\
1490 \\
1500 \\
1530 \\
1540\end{array}$ & $\begin{array}{l}2070 \\
2060 \\
2260 \\
2640 \\
2640\end{array}$ \\
\hline $\begin{array}{l}26 \\
27 \\
28 \\
29 \\
30 \\
31\end{array}$ & $\begin{array}{l}4500 \\
4430 \\
4760 \\
6140 \\
5580 \\
5100\end{array}$ & $\begin{array}{l}4290 \\
4390 \\
4390 \\
4390 \\
4430 \\
---\end{array}$ & $\begin{array}{l}4750 \\
3800 \\
2800 \\
4200 \\
6000 \\
8400\end{array}$ & $\begin{array}{l}4000 \\
3900 \\
3850 \\
3800 \\
3800 \\
3700\end{array}$ & $\begin{array}{r}37500 \\
23300 \\
26400 \\
--- \\
---\end{array}$ & $\begin{array}{l}7750 \\
7450 \\
7590 \\
8010 \\
8260 \\
8220\end{array}$ & $\begin{array}{l}6980 \\
7010 \\
7040 \\
7080 \\
7220 \\
---\end{array}$ & $\begin{array}{l}4130 \\
4000 \\
3950 \\
4000 \\
3960 \\
3790\end{array}$ & $\begin{array}{c}3520 \\
3320 \\
3180 \\
3040 \\
2920 \\
---\end{array}$ & $\begin{array}{l}1850 \\
1880 \\
1870 \\
1860 \\
1850 \\
1860\end{array}$ & $\begin{array}{l}1560 \\
1570 \\
1540 \\
1520 \\
1530 \\
1550\end{array}$ & $\begin{array}{l}2530 \\
2630 \\
2600 \\
2610 \\
2800 \\
---\end{array}$ \\
\hline $\begin{array}{l}\text { TOTAL } \\
\text { MEAN } \\
\text { MAX } \\
\text { MIN } \\
\text { AC-ET }\end{array}$ & $\begin{array}{r}120920 \\
3901 \\
11100 \\
1980 \\
239800\end{array}$ & $\begin{array}{r}189110 \\
6304 \\
15200 \\
4290 \\
375100\end{array}$ & $\begin{array}{r}129240 \\
4169 \\
8400 \\
2400 \\
256300\end{array}$ & $\begin{array}{r}148500 \\
4790 \\
11000 \\
3700 \\
294500\end{array}$ & $\begin{array}{r}239700 \\
8561 \\
42600 \\
2400 \\
475400\end{array}$ & $\begin{array}{r}530390 \\
17110 \\
32900 \\
7450 \\
1052000\end{array}$ & $\begin{array}{r}259880 \\
8663 \\
11200 \\
6790 \\
515500\end{array}$ & $\begin{array}{r}170110 \\
5487 \\
7700 \\
3790 \\
337400\end{array}$ & $\begin{array}{r}101510 \\
3384 \\
3670 \\
2920 \\
201300\end{array}$ & $\begin{array}{r}70280 \\
2267 \\
2990 \\
1850 \\
139400\end{array}$ & $\begin{array}{r}51020 \\
1646 \\
1850 \\
1490 \\
101200\end{array}$ & $\begin{array}{r}66560 \\
2219 \\
2990 \\
1520 \\
132000\end{array}$ \\
\hline $\begin{array}{ll}\text { CAL YR } \\
\text { WTR YR }\end{array}$ & $\begin{array}{l}984 \\
985\end{array}$ & $\begin{array}{l}\text { TOTAL } \\
\text { TOTAL }\end{array}$ & $\begin{array}{l}4446180 \\
2077220\end{array}$ & $\begin{array}{l}\text { MEAN } \\
\text { MEAN }\end{array}$ & $\begin{array}{r}12150 \\
5691\end{array}$ & $\begin{array}{l}\text { MAX } \\
\text { MAX }\end{array}$ & $\begin{array}{l}34900 \\
42600\end{array}$ & $\begin{array}{l}\text { MIN } \\
\text { MIN }\end{array}$ & $\begin{array}{l}80 \\
190\end{array}$ & $\begin{array}{ll}\text { ET } & 881 \\
\text { FT } & 41\end{array}$ & & \\
\hline
\end{tabular}


05465500 IOWA RIVER AT WAPELLO, IA--Continued

(National stream-accounting network station)

WATER-QUALITY RECORDS

PERIOD OR RECORD.--Water years 1978 to current year.

PERIOD OF DAILY RECORD, --

SPECIRIC CONDUCTANCE: January 1978 to current year.

WATER TEMPERATURES: January 1978 to current year.

SUSPENDED-SEDIMENT DISCHARGE: April 1978 to current year.

REMARKS.--During periods of ice effect samples are collected in open water channel or through ice cover. Records of specific conductance are obtained from suspended-sediment samples at time of analysis.

EXTREMES FOR PERIOD OF DAILY RECORD.--

SPECIFIC CONDUCTANCE: Maximum daily, 810 microsiemens Jan. 23, 1978-Jan. 20, 1981, minimum daily, 250 microsiemens sept. 18,1978 , July 20,1982 .

WATER TEMPERATUREs: Maximum daily, $32.0^{\circ} \mathrm{C} J u l y ~ 15,1980$, minimum daily, $0.0^{\circ} \mathrm{C}$ on many days during winter period.

SEDIMENT CONCENTRATIONS: Maximum daily mean, 4,970 mg/L June 25, 1981, minimum daily mean, I mg/L Jan. 21,22, 1981.

SEDIMENT LOADS: Maximum daily, 413,000 tons July 19, 1982, minimum daily, 5.4 tons Jan. $21,1981$.

EXTREMES FOR CORRENT YEAR.--

SEDIHENT CONCENTRATIONS: Maximum daily mean, $1,670 \mathrm{mg} / \mathrm{L}$ Feb, 24, minimum daily mean, $4 \mathrm{mg} / \mathrm{L}$ Jan 22, Feb. 12.

SEDIMENT LOADS: Maximum daily, 183,000 tons Feb. 25, minimum daily, 26 tons Feb. 12.

SUSPENDED-SEDIMENT, MATER YEAR OCTOBER 1984 TO SEPTEMBER 1985

\begin{tabular}{|c|c|c|c|c|c|c|c|c|c|c|c|c|}
\hline \multirow[t]{2}{*}{ DAY } & $\begin{array}{l}\text { MEAN } \\
\text { CONCEN- } \\
\text { TRATION } \\
\text { (MG/L) }\end{array}$ & $\begin{array}{l}\text { LOADS } \\
\text { (T/DAY) }\end{array}$ & $\begin{array}{l}\text { MEAN } \\
\text { CONCEN- } \\
\text { TRATION } \\
\text { (HG/L) }\end{array}$ & $\begin{array}{l}\text { LOADS } \\
\text { (T/DAY) }\end{array}$ & $\begin{array}{c}\text { MEAN } \\
\text { CONCEN- } \\
\text { TRATION } \\
\text { (MG/L) }\end{array}$ & $\begin{array}{l}\text { LOADS } \\
\text { (T/DAY) }\end{array}$ & $\begin{array}{l}\text { MEAN } \\
\text { CONCEN- } \\
\text { TRATION } \\
\text { (MG/L) }\end{array}$ & $\begin{array}{l}\text { LOADS } \\
\text { (T/DAY) }\end{array}$ & $\begin{array}{l}\text { MEAN } \\
\text { CONCEN- } \\
\text { TRATION } \\
\text { (MG/L) }\end{array}$ & $\begin{array}{l}\text { LOADS } \\
\text { (T/DAY) }\end{array}$ & $\begin{array}{c}\text { MEAN } \\
\text { CONCEN- } \\
\text { TRATION } \\
\text { (MG/L) }\end{array}$ & $\begin{array}{l}\text { LOADS } \\
\text { (T/DAY) }\end{array}$ \\
\hline & \multicolumn{2}{|c|}{ OCTOBER } & \multicolumn{2}{|c|}{ NOVEYBER } & \multicolumn{2}{|c|}{ DECEMBER } & \multicolumn{2}{|c|}{ JANUARY } & \multicolumn{2}{|c|}{ FEBRDARY } & \multicolumn{2}{|c|}{ MARCH } \\
\hline $\begin{array}{l}1 \\
2 \\
3 \\
4 \\
5\end{array}$ & $\begin{array}{l}71 \\
67 \\
62 \\
59 \\
58\end{array}$ & $\begin{array}{l}404 \\
371 \\
333 \\
315 \\
310\end{array}$ & $\begin{array}{r}744 \\
1300 \\
584 \\
232 \\
172\end{array}$ & $\begin{array}{r}21900 \\
53400 \\
16300 \\
5440 \\
3710\end{array}$ & $\begin{array}{l}32 \\
31 \\
32 \\
32 \\
29\end{array}$ & $\begin{array}{l}377 \\
357 \\
357 \\
338 \\
295\end{array}$ & $\begin{array}{l}328 \\
297 \\
246 \\
207 \\
193\end{array}$ & $\begin{array}{l}9740 \\
6660 \\
3990 \\
2770 \\
2290\end{array}$ & $\begin{array}{r}13 \\
13 \\
12 \\
10 \\
9\end{array}$ & $\begin{array}{r}123 \\
112 \\
97 \\
78 \\
68\end{array}$ & $\begin{array}{l}520 \\
297 \\
165 \\
240 \\
245\end{array}$ & $\begin{array}{l}36900 \\
20200 \\
10800 \\
18500 \\
20700\end{array}$ \\
\hline $\begin{array}{r}6 \\
7 \\
8 \\
9 \\
10\end{array}$ & $\begin{array}{r}84 \\
101 \\
78 \\
90 \\
84\end{array}$ & $\begin{array}{l}472 \\
564 \\
428 \\
503 \\
463\end{array}$ & $\begin{array}{r}143 \\
119 \\
98 \\
86 \\
204\end{array}$ & $\begin{array}{l}2890 \\
2200 \\
1670 \\
1420 \\
3550\end{array}$ & $\begin{array}{l}25 \\
20 \\
25 \\
39 \\
54\end{array}$ & $\begin{array}{l}202 \\
130 \\
189 \\
316 \\
481\end{array}$ & $\begin{array}{r}168 \\
129 \\
101 \\
85 \\
73\end{array}$ & $\begin{array}{l}1810 \\
1360 \\
1150 \\
1140 \\
1040\end{array}$ & $\begin{array}{l}8 \\
7 \\
6 \\
6 \\
5\end{array}$ & $\begin{array}{l}58 \\
49 \\
41 \\
40 \\
34\end{array}$ & $\begin{array}{r}154 \\
118 \\
104 \\
96 \\
88\end{array}$ & $\begin{array}{r}13700 \\
9810 \\
7470 \\
6610 \\
5180\end{array}$ \\
\hline $\begin{array}{l}11 \\
12 \\
13 \\
14 \\
15\end{array}$ & $\begin{array}{r}76 \\
80 \\
104 \\
139 \\
165\end{array}$ & $\begin{array}{r}410 \\
456 \\
623 \\
874 \\
1140\end{array}$ & $\begin{array}{l}708 \\
390 \\
170 \\
119 \\
115\end{array}$ & $\begin{array}{r}17300 \\
7950 \\
3240 \\
2010 \\
1660\end{array}$ & $\begin{array}{r}69 \\
105 \\
81 \\
66 \\
60\end{array}$ & $\begin{array}{r}680 \\
1180 \\
864 \\
695 \\
664\end{array}$ & $\begin{array}{l}62 \\
50 \\
42 \\
35 \\
30\end{array}$ & $\begin{array}{l}870 \\
675 \\
544 \\
463 \\
405\end{array}$ & $\begin{array}{r}5 \\
4 \\
6 \\
8 \\
11\end{array}$ & $\begin{array}{l}34 \\
26 \\
40 \\
52 \\
71\end{array}$ & $\begin{array}{l}135 \\
229 \\
312 \\
300 \\
257\end{array}$ & $\begin{array}{r}7220 \\
12400 \\
16800 \\
16000 \\
12400\end{array}$ \\
\hline $\begin{array}{l}16 \\
17 \\
18 \\
19 \\
20\end{array}$ & $\begin{array}{r}108 \\
90 \\
225 \\
1100 \\
1490\end{array}$ & $\begin{array}{r}793 \\
724 \\
2340 \\
25000 \\
45300\end{array}$ & $\begin{array}{l}98 \\
92 \\
81 \\
61 \\
45\end{array}$ & $\begin{array}{r}1420 \\
1320 \\
1100 \\
787 \\
561\end{array}$ & $\begin{array}{l}57 \\
55 \\
74 \\
76 \\
60\end{array}$ & $\begin{array}{r}646 \\
639 \\
939 \\
1150 \\
794\end{array}$ & $\begin{array}{l}27 \\
20 \\
17 \\
13 \\
10\end{array}$ & $\begin{array}{l}364 \\
267 \\
218 \\
154 \\
108\end{array}$ & $\begin{array}{l}15 \\
19 \\
19 \\
12 \\
25\end{array}$ & $\begin{array}{r}97 \\
128 \\
139 \\
94 \\
213\end{array}$ & $\begin{array}{l}229 \\
213 \\
197 \\
181 \\
164\end{array}$ & $\begin{array}{r}10400 \\
8630 \\
7130 \\
5860 \\
4870\end{array}$ \\
\hline $\begin{array}{l}21 \\
22 \\
23 \\
24 \\
25\end{array}$ & $\begin{array}{l}555 \\
258 \\
168 \\
130 \\
110\end{array}$ & $\begin{array}{r}11500 \\
4600 \\
2770 \\
1900 \\
1380\end{array}$ & $\begin{array}{l}44 \\
42 \\
41 \\
39 \\
36\end{array}$ & $\begin{array}{l}537 \\
508 \\
498 \\
469 \\
423\end{array}$ & $\begin{array}{l}50 \\
45 \\
40 \\
37 \\
34\end{array}$ & $\begin{array}{l}580 \\
480 \\
400 \\
425 \\
431\end{array}$ & $\begin{array}{r}6 \\
4 \\
24 \\
40 \\
45\end{array}$ & $\begin{array}{r}63 \\
43 \\
269 \\
459 \\
510\end{array}$ & $\begin{array}{r}62 \\
730 \\
1370 \\
1670 \\
1590\end{array}$ & $\begin{array}{r}870 \\
17000 \\
59200 \\
117000 \\
183000\end{array}$ & $\begin{array}{l}149 \\
134 \\
123 \\
115 \\
109\end{array}$ & $\begin{array}{l}4060 \\
3320 \\
2870 \\
2580 \\
2380\end{array}$ \\
\hline $\begin{array}{l}26 \\
27 \\
28 \\
29 \\
30 \\
31\end{array}$ & $\begin{array}{r}103 \\
99 \\
131 \\
359 \\
248 \\
179\end{array}$ & $\begin{array}{l}1250 \\
1180 \\
1680 \\
5950 \\
3740 \\
2460\end{array}$ & $\begin{array}{r}32 \\
52 \\
48 \\
40 \\
35 \\
--\end{array}$ & $\begin{array}{l}371 \\
616 \\
569 \\
474 \\
419 \\
--\end{array}$ & $\begin{array}{r}30 \\
30 \\
40 \\
109 \\
205 \\
275\end{array}$ & $\begin{array}{r}385 \\
308 \\
302 \\
1240 \\
3320 \\
6240\end{array}$ & $\begin{array}{l}11 \\
34 \\
25 \\
23 \\
20 \\
16\end{array}$ & $\begin{array}{l}443 \\
358 \\
260 \\
236 \\
205 \\
160\end{array}$ & $\begin{array}{l}610 \\
212 \\
602 \\
-\ldots \\
-\infty\end{array}$ & $\begin{array}{r}61800 \\
13300 \\
42900 \\
- \\
-\end{array}$ & $\begin{array}{l}105 \\
103 \\
108 \\
126 \\
138 \\
144\end{array}$ & $\begin{array}{l}2200 \\
2070 \\
2210 \\
2730 \\
3080 \\
3200\end{array}$ \\
\hline TOTAL & -- & 120233 & -- & 154712 & -- & 25404 & $-\infty$ & 39024 & $-\infty$ & 496664 & $-\infty$ & 282280 \\
\hline
\end{tabular}


05465500 IOWA RIVER AT WAPELLO, IA--Continued

WATER-QUALITY RECORDS

SUSPENDED-SEDIMENT, WATER YEAR OCTOBER 1984 TO SEPTEMBER 1985

\begin{tabular}{|c|c|c|c|c|c|c|c|c|c|c|c|c|}
\hline \multirow[t]{2}{*}{ DAY } & $\begin{array}{l}\text { MEAN } \\
\text { CONCEN- } \\
\text { TRATION } \\
(M G / L)\end{array}$ & $\begin{array}{l}\text { LOADS } \\
\text { (T/DAY) }\end{array}$ & $\begin{array}{l}\text { MEAN } \\
\text { CONCEN- } \\
\text { TRATION } \\
\text { (MG/L) }\end{array}$ & $\begin{array}{l}\text { LOADS } \\
\text { (T/DAY) }\end{array}$ & $\begin{array}{c}\text { MEAN } \\
\text { CONCEN- } \\
\text { TRATION } \\
\text { (MG/L) }\end{array}$ & $\begin{array}{l}\text { LOADS } \\
\text { (T/DAY) }\end{array}$ & $\begin{array}{c}\text { MEAN } \\
\text { CONCEN- } \\
\text { TRATION } \\
(M G / L)\end{array}$ & $\begin{array}{l}\text { LOADS } \\
\text { (T/DAY) }\end{array}$ & $\begin{array}{c}\text { MEAN } \\
\text { CONCEN- } \\
\text { TRATION } \\
(M G / L)\end{array}$ & $\begin{array}{l}\text { LOADS } \\
\text { (T/DAY) }\end{array}$ & $\begin{array}{l}\text { MEAN } \\
\text { CONCEN- } \\
\text { TRATION } \\
\text { (MG/L) }\end{array}$ & $\begin{array}{l}\text { LOADS } \\
\text { (T/DAY) }\end{array}$ \\
\hline & \multicolumn{2}{|c|}{ APRIL } & \multicolumn{2}{|r|}{ MAY } & \multicolumn{2}{|c|}{ JUNE } & \multicolumn{2}{|c|}{ JULY } & \multicolumn{2}{|c|}{ AUGUST } & \multicolumn{2}{|c|}{ SEPTEMBER } \\
\hline $\begin{array}{l}1 \\
2 \\
3 \\
4 \\
5\end{array}$ & $\begin{array}{l}147 \\
133 \\
119 \\
120 \\
123\end{array}$ & $\begin{array}{l}3520 \\
3540 \\
3280 \\
3220 \\
3160\end{array}$ & $\begin{array}{l}157 \\
163 \\
167 \\
166 \\
160\end{array}$ & $\begin{array}{l}3130 \\
3350 \\
3470 \\
3370 \\
3130\end{array}$ & $\begin{array}{l}165 \\
149 \\
135 \\
122 \\
114\end{array}$ & $\begin{array}{l}1630 \\
1440 \\
1280 \\
1130 \\
1050\end{array}$ & $\begin{array}{l}128 \\
130 \\
143 \\
161 \\
165\end{array}$ & $\begin{array}{r}985 \\
1000 \\
1140 \\
1300 \\
1320\end{array}$ & $\begin{array}{l}89 \\
85 \\
82 \\
79 \\
77\end{array}$ & $\begin{array}{l}445 \\
422 \\
407 \\
386 \\
370\end{array}$ & $\begin{array}{l}112 \\
106 \\
104 \\
102 \\
117\end{array}$ & $\begin{array}{l}460 \\
472 \\
489 \\
482 \\
588\end{array}$ \\
\hline $\begin{array}{r}6 \\
7 \\
8 \\
9 \\
10\end{array}$ & $\begin{array}{l}120 \\
114 \\
139 \\
128 \\
120\end{array}$ & $\begin{array}{l}3240 \\
3230 \\
4050 \\
3800 \\
3630\end{array}$ & $\begin{array}{l}153 \\
142 \\
129 \\
122 \\
118\end{array}$ & $\begin{array}{l}2900 \\
2610 \\
2330 \\
2110 \\
1880\end{array}$ & $\begin{array}{r}124 \\
126 \\
110 \\
85 \\
70\end{array}$ & $\begin{array}{r}1190 \\
1250 \\
1080 \\
801 \\
620\end{array}$ & $\begin{array}{l}163 \\
157 \\
148 \\
139 \\
131\end{array}$ & $\begin{array}{r}1240 \\
1140 \\
1030 \\
946 \\
859\end{array}$ & $\begin{array}{l}74 \\
69 \\
66 \\
65 \\
63\end{array}$ & $\begin{array}{l}354 \\
330 \\
312 \\
302 \\
294\end{array}$ & $\begin{array}{l}108 \\
108 \\
100 \\
105 \\
145\end{array}$ & $\begin{array}{l}542 \\
522 \\
464 \\
485 \\
701\end{array}$ \\
\hline $\begin{array}{l}11 \\
12 \\
13 \\
14 \\
15\end{array}$ & $\begin{array}{l}156 \\
180 \\
173 \\
147 \\
121\end{array}$ & $\begin{array}{l}4680 \\
5050 \\
4560 \\
3720 \\
2930\end{array}$ & $\begin{array}{l}118 \\
292 \\
240 \\
262 \\
178\end{array}$ & $\begin{array}{l}1750 \\
4600 \\
3490 \\
4050 \\
2640\end{array}$ & $\begin{array}{l}59 \\
51 \\
45 \\
41 \\
41\end{array}$ & $\begin{array}{l}505 \\
427 \\
375 \\
338 \\
338\end{array}$ & $\begin{array}{l}127 \\
123 \\
119 \\
115 \\
113\end{array}$ & $\begin{array}{l}809 \\
761 \\
723 \\
677 \\
656\end{array}$ & $\begin{array}{l}65 \\
69 \\
66 \\
65 \\
67\end{array}$ & $\begin{array}{l}311 \\
322 \\
301 \\
293 \\
297\end{array}$ & $\begin{array}{l}161 \\
135 \\
113 \\
110 \\
103\end{array}$ & $\begin{array}{r}1070 \\
1090 \\
885 \\
754 \\
640\end{array}$ \\
\hline $\begin{array}{l}16 \\
17 \\
18 \\
19 \\
20\end{array}$ & $\begin{array}{l}105 \\
112 \\
152 \\
119 \\
119\end{array}$ & $\begin{array}{l}2390 \\
2430 \\
3160 \\
2350 \\
2290\end{array}$ & $\begin{array}{l}188 \\
200 \\
182 \\
185 \\
186\end{array}$ & $\begin{array}{l}2780 \\
2870 \\
2500 \\
2520 \\
2470\end{array}$ & $\begin{array}{r}43 \\
51 \\
69 \\
108 \\
139\end{array}$ & $\begin{array}{r}358 \\
441 \\
622 \\
1010 \\
1340\end{array}$ & $\begin{array}{l}181 \\
154 \\
144 \\
140 \\
134\end{array}$ & $\begin{array}{r}1200 \\
948 \\
805 \\
741 \\
702\end{array}$ & $\begin{array}{l}67 \\
60 \\
64 \\
79 \\
68\end{array}$ & $\begin{array}{l}289 \\
258 \\
271 \\
331 \\
279\end{array}$ & $\begin{array}{r}93 \\
98 \\
122 \\
104 \\
110\end{array}$ & $\begin{array}{l}552 \\
564 \\
758 \\
651 \\
647\end{array}$ \\
\hline $\begin{array}{l}21 \\
22 \\
23 \\
24 \\
25\end{array}$ & $\begin{array}{l}123 \\
119 \\
112 \\
104 \\
104\end{array}$ & $\begin{array}{l}2350 \\
2210 \\
2050 \\
1920 \\
1930\end{array}$ & $\begin{array}{l}175 \\
165 \\
169 \\
185 \\
192\end{array}$ & $\begin{array}{l}2280 \\
2080 \\
1980 \\
2100 \\
2140\end{array}$ & $\begin{array}{l}157 \\
169 \\
174 \\
172 \\
164\end{array}$ & $\begin{array}{l}1530 \\
1660 \\
1710 \\
1690 \\
1610\end{array}$ & $\begin{array}{l}130 \\
127 \\
121 \\
115 \\
110\end{array}$ & $\begin{array}{l}677 \\
658 \\
627 \\
596 \\
558\end{array}$ & $\begin{array}{l}66 \\
67 \\
70 \\
73 \\
70\end{array}$ & $\begin{array}{l}267 \\
270 \\
283 \\
302 \\
291\end{array}$ & $\begin{array}{r}110 \\
89 \\
93 \\
121 \\
120\end{array}$ & $\begin{array}{l}615 \\
495 \\
567 \\
862 \\
855\end{array}$ \\
\hline $\begin{array}{l}26 \\
27 \\
28 \\
29 \\
30 \\
31\end{array}$ & $\begin{array}{l}117 \\
133 \\
142 \\
150 \\
154 \\
---\end{array}$ & $\begin{array}{l}2200 \\
2520 \\
2700 \\
2870 \\
3000 \\
---\end{array}$ & $\begin{array}{l}185 \\
172 \\
171 \\
184 \\
193 \\
184\end{array}$ & $\begin{array}{l}2060 \\
1860 \\
1820 \\
1990 \\
2060 \\
1880\end{array}$ & $\begin{array}{l}157 \\
147 \\
138 \\
132 \\
129 \\
-\cdots\end{array}$ & $\begin{array}{l}1490 \\
1320 \\
1180 \\
1080 \\
1020 \\
-\end{array}$ & $\begin{array}{r}107 \\
104 \\
101 \\
99 \\
94 \\
92\end{array}$ & $\begin{array}{l}534 \\
528 \\
510 \\
497 \\
470 \\
462\end{array}$ & $\begin{array}{r}86 \\
112 \\
107 \\
79 \\
72 \\
106\end{array}$ & $\begin{array}{l}362 \\
475 \\
445 \\
324 \\
297 \\
444\end{array}$ & $\begin{array}{l}116 \\
125 \\
126 \\
118 \\
128 \\
--2\end{array}$ & $\begin{array}{l}792 \\
888 \\
885 \\
832 \\
968 \\
---\end{array}$ \\
\hline TOTAL & $-\infty$ & 91980 & -- & 80200 & -- & 31515 & --- & 25099 & -- & 10334 & $-\infty$ & 20575 \\
\hline
\end{tabular}

TOTAL LOAD FOR YEAR: 1378020 TONS.

WATER QUALITY DATA, WATER YEAR OCTOBER 1984 TO SEPTEMBER 1985

\begin{tabular}{|c|c|c|c|c|c|c|c|c|c|c|c|c|}
\hline DATE & TIME & $\begin{array}{l}\text { STREAK- } \\
\text { FLOW, } \\
\text { INSTAN- } \\
\text { TANEOOS } \\
\text { (CFS) } \\
(00061)\end{array}$ & $\begin{array}{l}\text { SPE- } \\
\text { CIFIC } \\
\text { CON- } \\
\text { DUCT- } \\
\text { ANCE } \\
\text { (US/CM) } \\
\text { (O0095) }\end{array}$ & $\begin{array}{c}\text { PH } \\
\text { (STAND- } \\
\text { ARD } \\
\text { UNITS) } \\
(00400)\end{array}$ & $\begin{array}{l}\text { TEMPER- } \\
\text { ATURE } \\
\text { (DEG C) } \\
(00010)\end{array}$ & $\begin{array}{c}\text { TUR- } \\
\text { BID- } \\
\text { ITY } \\
\text { (NTU) } \\
(00076)\end{array}$ & $\begin{array}{c}\text { OXYGEN, } \\
\text { DIS- } \\
\text { SOLVED } \\
\text { (MG/L) } \\
(00300)\end{array}$ & $\begin{array}{c}\text { OXYGEN, } \\
\text { DIS- } \\
\text { SOLVED } \\
\text { (PER- } \\
\text { CENT } \\
\text { SATUR- } \\
\text { ATION) } \\
\text { (OO301) }\end{array}$ & $\begin{array}{l}\text { BARO- } \\
\text { METRIC } \\
\text { PRES- } \\
\text { SURE } \\
\text { (MM } \\
\text { OF } \\
\text { BG) } \\
(00025)\end{array}$ & $\begin{array}{l}\text { COLI- } \\
\text { FORM, } \\
\text { FECAL, } \\
0.7 \\
\text { UM-ME } \\
\text { (COLS.' } \\
\text { I0O ML) } \\
\text { (31625) }\end{array}$ & $\begin{array}{c}\text { STREP- } \\
\text { TOCOCCI } \\
\text { FECAL, } \\
\text { RF AGAR } \\
\text { (COLS. } \\
\text { PER } \\
100 \mathrm{ML}) \\
(31673)\end{array}$ & $\begin{array}{c}\text { HARD- } \\
\text { NESS, } \\
\text { NONCAR- } \\
\text { BONATE } \\
\text { (MG/L } \\
\text { CACO3) } \\
(00902)\end{array}$ \\
\hline $\begin{array}{c}1984 \\
30 \ldots \\
\text { DEC }\end{array}$ & $10: 30$ & 5640 & 484 & 8.2 & 11.0 & 66 & 8.2 & 76 & 750 & $-\infty$ & R8900 & 56 \\
\hline AR 1985 & $10: 30$ & 3650 & 573 & 8.4 & 0.0 & 12 & 14.2 & 100 & 744 & 180 & 150 & 70 \\
\hline & $12: 00$ & 26300 & 294 & 7.6 & 3.0 & 150 & 13.9 & 106 & 745 & $\mathrm{~K} 800$ & 12000 & 49 \\
\hline JUL & $11: 30$ & 7410 & 494 & 8.6 & 17.0 & 18 & 10.5 & 111 & 750 & $\mathbf{K} 80$ & 130 & 81 \\
\hline & $11: 30$ & 2510 & 408 & 8.9 & 27.0 & 18 & 10.9 & 139 & 750 & R22 & $\mathbf{R} 20$ & 53 \\
\hline - & $10: 30$ & 1530 & 483 & 9.2 & 21.0 & 23 & 10.8 & 123 & 750 & -- & K15 & 49 \\
\hline
\end{tabular}

R Results based on colony count outside ideal range. 
05465500 IOWA RIVER AT WAPELLO, IA--Continued

WATER-QUALITY RECORDS

WATER QUALITY DATA, WATER YEAR OCTOBER 1984 TO SEPTEMBER 1985

$\begin{array}{cc}\text { HARD- } & \text { CALCIOM } \\ \text { NESS } & \text { DIS- } \\ \text { (MG/L } & \text { SOLVED } \\ \text { AS } & \text { (HG/L } \\ \text { CACO3) } & \text { AS CA) } \\ (00900) & (00915)\end{array}$

MAgNe-

SIUM, SODTOM,

DIS- DIS-

SOLVED SOLVED

(MG/L) (MG/L

AS MG) AS NA) SODIUM

$\begin{array}{lll}(00925) & (00930) & (00932)\end{array}$
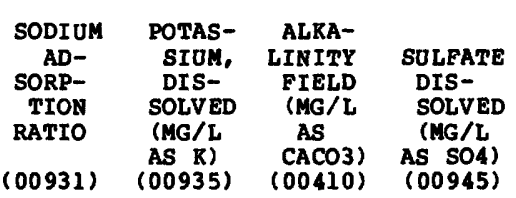

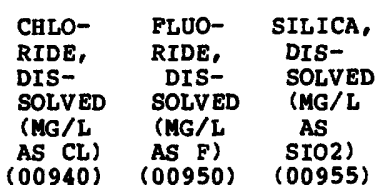

(00940) (00950) (00955)

OCT 198

\begin{tabular}{|c|c|c|c|c|c|c|c|c|c|c|c|c|}
\hline $\begin{array}{c}1984 \\
30 \ldots \\
D E C\end{array}$ & 230 & 58 & 20 & 15 & 12 & 0.4 & 4.6 & 171 & 41 & 25 & 0.2 & 12 \\
\hline 1985 & 270 & 70 & 23 & 19 & 13 & 0.5 & 2.6 & 200 & 44 & 29 & 0.2 & 10 \\
\hline$\underset{\text { MAY }}{01} \cdots$ & 130 & 36 & 10 & 6.6 & 9 & 0.3 & 5.7 & 82 & 22 & 12 & 0.2 & 9.5 \\
\hline$\underset{\text { JOL }}{01 \ldots}$ & 260 & 65 & 23 & 13 & 10 & 0.4 & 2.5 & 176 & 28 & 24 & 0.2 & 2.9 \\
\hline$\underset{A O G}{09} \cdots$ & 170 & 31 & 22 & 19 & 19 & 0.7 & 2.7 & 115 & 51 & 28 & 0.3 & 0.4 \\
\hline 27 & 200 & 43 & 22 & 30 & 24 & 1 & 2.9 & 149 & 47 & 46 & 0.3 & 330 \\
\hline
\end{tabular}

SOLIDS, SOLIDS

RESIDUE SUM OF

AT 180 CONSTI-

DEG. C TUENTS,

SOLIDS, SOLIDS,

NITRO- NITRO- NITRO- NITRO- PHOS-

GEN, GEN, GEN, GEN, AY- PBOROS,

DIS- NO2+NO3 AMWONIA AMWONIA MONIA + ORTHO.

SOLVED SOLVED DIS- DIS- DIS- ORGANIC DIS-

DIS- DIS-

(MG/L) (MG/L)

(TONS (TONS

SOLVED

AC-PT) (MG/L

SOLVED

(70300) (70301)

$\begin{array}{ccc}\text { AC-FT) } & \text { DAY }) & \text { AS N }) \\ (70303) & (70302) & (00631)\end{array}$

(MG/L (MG/L (MG/L

$\begin{array}{ccc}\text { AS N) } & \text { AS NH4) } & \text { AS N) } \\ (00608) & (71846) & (00625)\end{array}$

AS P)

$\begin{array}{ccc} & \text { PHOS- } & \\ \text { PHOS- } & \text { PHORUS, } & \text { PHOS- } \\ \text { PHOROS } & \text { DIS- } & \text { PHORUS, } \\ \text { TOTAL } & \text { SOLVED } & \text { TOTAL } \\ \text { (MG/L } & \text { (MG/L } & \text { (MG/L } \\ \text { AS PO4) } & \text { AS P) } & \text { AS P) } \\ (71886) & (00666) & (00665)\end{array}$

OCT 1984

$30 \ldots 2300 \quad 280$

$0.41 \quad 4570$

$4.20 \quad 0.12$

0.15

2.6

0.18

$-$

0.22

0.54

11... 362

$\begin{array}{lll}320 & 0.49 & 3570\end{array}$

$5.00<0.01$

0.01

1.5

0.09

$-$

0.11

0.23

$\begin{array}{lll}1985 & & \\ 01 . . . & 187 & 150\end{array}$

0.2513300

$4.20 \quad 0.73$

0.94

4.0

0.26

$-$

0.26

0.68

MI... 301

260

4.70

0.02

0.03

1.8

0.02

0.03

0.25

$09 \ldots 233$

220

0.321580

0.92

0.03

0.04

3.5

0.01

1.0

0.01

0.33

$27 \ldots 282$

610

$0.38 \quad 1160$

$<0.10 \quad 0.06$

0.08

1.60 .10

0.86

0.09

0.28

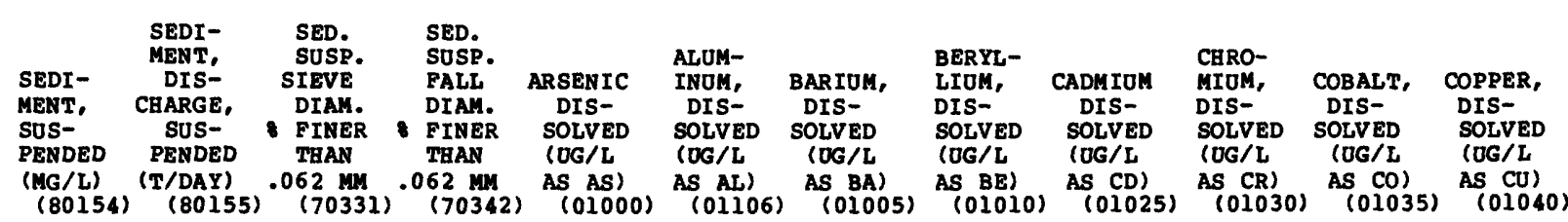

OCT 1984

\begin{tabular}{|c|c|c|c|c|c|c|c|c|c|c|c|c|c|}
\hline \multirow{2}{*}{ MAR } & \multirow{6}{*}{$\begin{array}{c}1984 \\
30 \ldots \\
\text { DEC } \\
11 . . . \\
1985 \\
01 . . . \\
\text { MAY } \\
01 . \ldots \\
\text { JUL } \\
09 . . . \\
\text { AOG } \\
27 \ldots\end{array}$} & 1070 & 16300 & - & 98 & 1 & \multicolumn{2}{|r|}{110} & $<0.5$ & 1 & $<1$ & $<3$ & 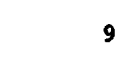 \\
\hline & & - & - & - & - & - & - & -- & - & - & - & -- & - \\
\hline & & 531 & 37700 & - & 74 & $<1$ & 110 & 76 & 2 & 1 & $<1$ & $<3$ & 5 \\
\hline & & 150 & 3000 & 95 & - & 1 & $<10$ & 110 & $<0.5$ & $<1$ & $<1$ & $<3$ & 1 \\
\hline & & 140 & 949 & 98 & - & - & - & - & -- & -- & - & - & - \\
\hline & & 81 & 335 & 96 & - & 2 & $<10$ & 94 & $<0.5$ & $<1$ & $<1$ & $<3$ & 5 \\
\hline & DATE & $\begin{array}{l}\text { IRON, } \\
\text { DIS- } \\
\text { SOLVED } \\
\text { (OG/L } \\
\text { AS RE) } \\
(01046)\end{array}$ & $\begin{array}{l}\text { LEAD, } \\
\text { DIS- } \\
\text { SOLVED } \\
\text { (UG/L } \\
\text { AS PB) } \\
(01049)\end{array}$ & $\begin{array}{c}\text { LITH IUM } \\
\text { DIS- } \\
\text { SOLVED } \\
\text { (OG/L } \\
\text { AS LI) } \\
(01130)\end{array}$ & $\begin{array}{l}\text { MANGA- } \\
\text { NESE, } \\
\text { DIS- } \\
\text { SOLVED } \\
\text { (OG/L } \\
\text { AS MN) } \\
\text { (01056) }\end{array}$ & $\begin{array}{c}\text { MERCURY } \\
\text { DIS- } \\
\text { SOLVED } \\
\text { (DG/L } \\
\text { AS BG) } \\
(71890)\end{array}$ & $\begin{array}{c}\text { MOLYB- } \\
\text { DENUM, } \\
\text { DIS- } \\
\text { SOLVED } \\
\text { (DG/L } \\
\text { AS MO) } \\
(01060)\end{array}$ & $\begin{array}{l}\text { NICKEL, } \\
\text { DIS- } \\
\text { SOLVED } \\
\text { (OG/L } \\
\text { AS NI) } \\
\text { (01065) }\end{array}$ & $\begin{array}{l}\text { SELE- } \\
\text { NIUH, } \\
\text { DIS- } \\
\text { SOLVED } \\
\text { (UG/L } \\
\text { AS SE) } \\
\text { (O1145) }\end{array}$ & $\begin{array}{c}\text { SILVER, } \\
\text { DIS- } \\
\text { SOLVED } \\
\text { (DG/L } \\
\text { AS AG) } \\
(01075)\end{array}$ & $\begin{array}{c}\text { STRON- } \\
\text { TIUM, } \\
\text { DIS- } \\
\text { SOLVED } \\
\text { (OG/L } \\
\text { AS SR) } \\
\text { (01080) }\end{array}$ & $\begin{array}{l}\text { VANA- } \\
\text { DIUM, } \\
\text { DIS- } \\
\text { SOLVED } \\
\text { (UG/L } \\
\text { AS V) } \\
(01085)\end{array}$ & $\begin{array}{c}\text { ZINC, } \\
\text { DIS- } \\
\text { SOLVED } \\
\text { (OG/L } \\
\text { AS ZN) } \\
(01090)\end{array}$ \\
\hline
\end{tabular}

OCT 1984

30 .

DEC

MAR 1985

$01 \ldots$

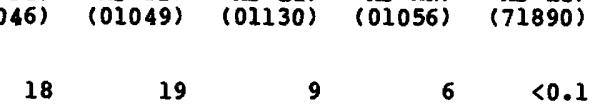

01060)

$01065)$

01145)

01075)

01085)

MAY

JUL

JUL

27 .

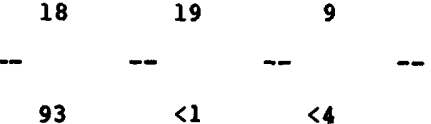

$6<0.1$

$<10$

8

$<1$

$<1$

$150<6 \quad 10$

140

$<0.1<10$

1

$<1$

$<1$

74

$<6$

12

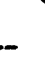

$-$

5

$<1$

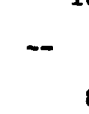

$-$

$-$

$-$

10

3 
LOCATION.--Lat $42^{\circ} 04^{\prime} 05^{\prime \prime}$, long $93^{\circ} 37^{\prime} 02^{\prime \prime}$, in Nw1/4 Sw1/4 sec.23, T.84 N., R.24 w., Story County, Hydrologic Unit 07080105 , on left bank $2.5 \mathrm{mi}$ north of Ames, $3.5 \mathrm{mi}$ downstream from Keigley Branch, 5.2 mi upstream from Squaw Creek, and at mile 228.1 upstream from mouth of skunk River.

DRAINAGE AREA. $--315 \mathrm{mi}^{2}$.

PERIOD OF RECORD.--July 1920 to September 1927 , October 1932 to current year. Monthly discharge only for some periods, published in WSP 1308. Prior to October 1966, published as Skunk River near Ames.

REVISED RECORDS.--WSP 1438: Drainage area. WSP 1308: 1921, 1925-26, 1934-35 (M), 1937 (M), 1939 (M), 1947-50 (H). WDR IOWa 1967: 1965. WDR IA-74-1: 1973 (P)

GAGE.--Water-stage recorder. Concrete control since July 21, 1934. Datum of gage is 893.61 ft above NGVD (Iowa Highway Commission benchmark). Prior to Aug. 25, 1921, nonrecording gage at same site and datum.

REMARKS.--No estimated daily discharges. Records good. National Weather Service gage-height telemeter at station.

AVERAGE DISChARGE--60 years (water years 1921-27, 1933-85), 160 ft: $/ 8,6.90$ in/yr, 115,900 acre-ft/yr; median of yearly mean discharges, $120 \mathrm{ft} / \mathrm{s}, 5.2 \mathrm{in} / \mathrm{yr}, 86,900 \mathrm{acre}-\mathrm{ft} / \mathrm{yr}$.

EXTREMES FOR PERIOD OF RECORD.--Maximum discharge, 8,630 ft/s June 10, 1954, gage height, 13.66 ft; maximum gage height, $13.90 \mathrm{ft}$ May 20,1944; no flow at times in 1934, 1937, 1953-57, 1977.

EXTREMES FOR CURRENT YEAR.--Peak discharge greater than base of $1,500 \mathrm{ft}^{3} / \mathrm{s}$ and maximum (*):

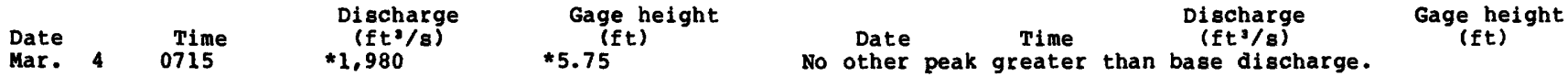

Minimum discharge, $1.2 \mathrm{ft} / \mathrm{s}$ Aug. $11,12$.

DISCHARgE, IN CUBIC FEET PER SECOND, WATER YEAR OCTOBER 1984 TO SEPTEMBER 1985 MEAN VALUES

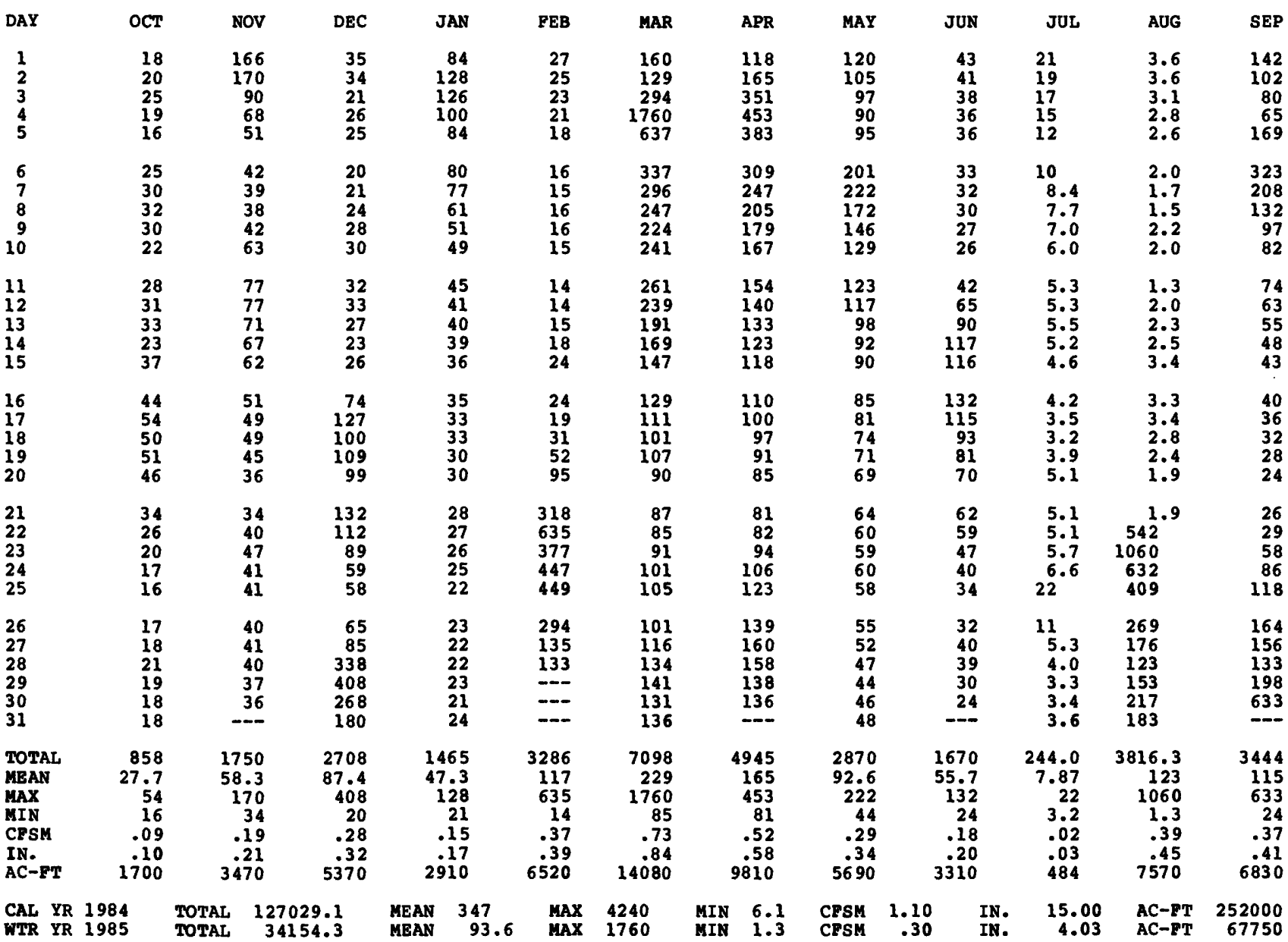


05470500 SQUAW CREEK AT AMES, IA

LOCATION.--Lat $42^{\circ} 01^{\prime} 21^{\prime \prime}$, long $93^{\circ} 37^{\prime} 45^{\prime \prime}$, in NEl/4 NWl/4 sec.10, T.83 N., R.24 W., Story County, Hydrological Unit 07080105 , on left bank $65 \mathrm{ft}$ downstream from Lincoln Way Bridge in Ames, $0.2 \mathrm{mi}$, downstream from College Creek, and $2.4 \mathrm{mi}$, upstream from mouth.

DRAINAGE AREA. $-204 \mathrm{mi}^{2}$.

PERIOD OF REOORD.-- Nay 1919 to September 1927, May 1965 to current year. Monthly discharge only for same periods, published in WSP 1308.

REVISED RECORDS.-WSP 1308: Drainage area, 1920-22 (M), 1923, 1924-25 (M), 1926, 1927 (M), WDR IOwa. 1966: 1965, WDR IA-71-1: 1970 (M).

GAGE.-- Mater-stage recorder and concrete control. Datum of gage is 881.00 ft above NGVD (levels by Iowa State University). Prior to Mar. 11, 1925, nonrecording gage at site 0.6 mi upstrean at different datum. Mar. 11, 1925 to Apr. 30, 1927, nonrecording gage at site $65 \mathrm{ft}$ upstream at datum about $4 \mathrm{ft}$ higher.

REMARKS. - Estimated daily discharges: Jan. 13, 19-22, 25-26, Jan. 30 to Feb. 4, Sept. 25-29. Records good except for estimated daily discharges which are fair. Gage-height telemeter at station.

AVERAGE DISCHARGE. -28 years (water years 1920-27,1966-85), $128 \mathrm{ft}^{3} / \mathrm{s}, 8.52 \mathrm{in} / \mathrm{yr}, 92,740 \mathrm{acre}-\mathrm{ft} / \mathrm{yr} ; \mathrm{median}$ of yearly mean discharges, $98 \mathrm{ft} / \mathrm{s}, 6.5 \mathrm{in} / \mathrm{yr}, 71,000$ acre-ft/yr.

EXIREVES EOR PERIOD OF RECORD.-Waximum discharge, 11,300 ft'/s June 27, 1975, gage height, $14.00 \mathrm{ft}$, on basis of contracted-opening measurement; no flow at times most years.

EXIREMES OUTSIDE PERIOD OF RECORD.--Flood of June 4, 1918, reached a stage of $14.5 \mathrm{ft}$, from floodmarks, site and datum used 1919-25, discharge, $6,900 \mathrm{ft} / \mathrm{s}$. Flood of Mar. 1, 1965, reached a stage of $10.7 \mathrm{ft}$, from graph based on gage readings, at present site and datum, discharge, $4,200 \mathrm{ft}^{3} / \mathrm{s}$.

EXIREYES FOR CURRENT YEAR.--Peak discharges greater than base of $1,600 \mathrm{ft}^{3} / \mathrm{s}$ and maximum (*):

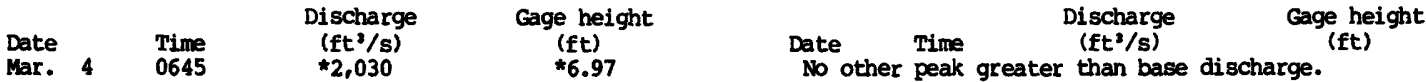

No flow for part of each day Aug. 11-13, 18-21.

DISCHARGE, IN OBIC FEET PER SECOND, WATER YEAR OCTOBER 1984 TO SEPTEYBER 1985

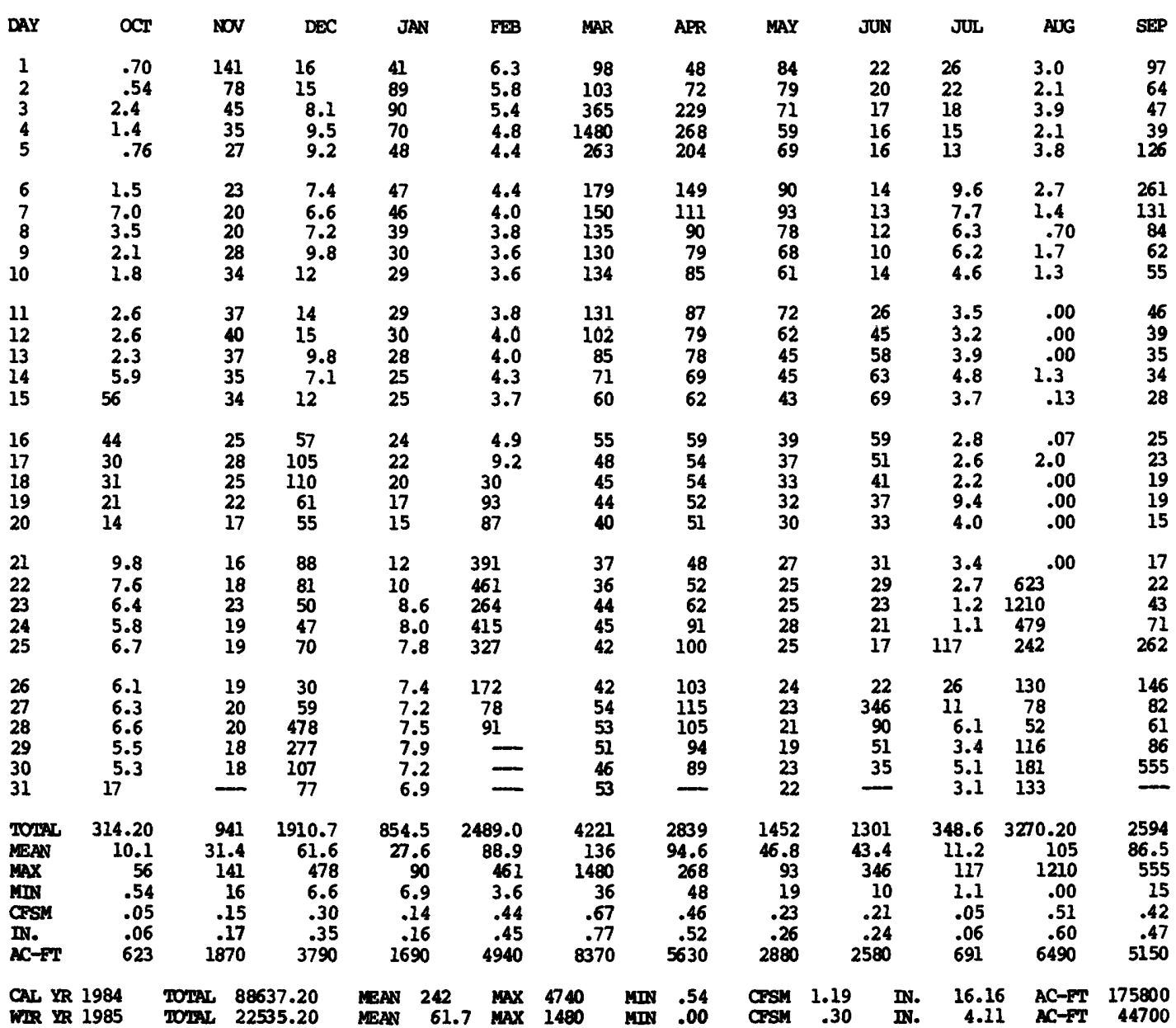


LOCATION.--Lat $41^{\circ} 21^{\prime} 19^{\prime \prime}$, long $92^{\circ} 39^{\prime} 31^{\prime \prime}$, in Nw1/4 Swl/4 sec.25, T.76 N., R.16 w., Mahaska County, Bydrologic Unit 07080105 , on right bank $400 \mathrm{ft}$ upstream from bridge on 0.5 . Highway 63 , 0.3 mi downstream from Painter Creek, $4.0 \mathrm{mi}$ north of Oskaloosa, $52.0 \mathrm{mi}$. upstream from confluence with North Skunk River, and at mile 147.3 upstream from mouth of Skunk River.

DRAINAGE AREA. $--1,635 \mathrm{mi}^{2}$.

PERIOD OF RECORD.--October 1945 to current year. Prior to October 1966, published as Skunk River near Oskaloosa. Prior to October 1948, monthly discharge only, published in wSP 1308.

REVISED RECORDS.--WSP 1438: Drainage area.

GAGE.--Water-stage recorder. Datum of gage $18685.50 \mathrm{ft}$ above NGVD. Prior to Nov. 21 , 1947 , nonrecording gage at site $400 \mathrm{ft}$ downstream at same datum.

REMARKs.--Estimated dally discharges: Dec. 4-16, Dec. 20-28, Jan. 1 to Feb. 22, Mar. 3-4, 6-14, and Sept. 4-8, 11-25. Records good except those for estimated discharges, which are poor. National Weather Service gageheight telemeter and U.S. Army Corps of Engineers Data Collection Platform at station.

AVERAGE DISCHARGE. -40 years, $947 \mathrm{ft}^{\circ} / \mathrm{s}, 7.87 \mathrm{in} / \mathrm{yr}, 686,100 \mathrm{acre}-\mathrm{ft} / \mathrm{yr}^{\mathrm{r}}$.

EXTREMES FOR PERIOD OF RECORD,--Maximum discharge, $20,000 \mathrm{ft}^{2} / \mathrm{s}$ June 15,1947 , gage height, $21.26 \mathrm{ft}$, from floodmark8; maximum gage height, $22.52 \mathrm{ft}$ Feb. 3, 1973, backwater from ice; minimum daily discharge, 1.8 $\mathrm{ft}^{\mathrm{J}} / \mathrm{s}$ Oct. $11-13,1956$

EXTREMES OUTSIDE PERIOD OF RECORD.--Flood in May 1944 reached a stage of 25.8 ft, from floodmarks, discharge, $37,000 \mathrm{ft} / \mathrm{s}$, from rating curve extended above $18,000 \mathrm{ft} / \mathrm{s}$ on basis of velocity-area study.

EXTREMES FOR CURRENT YEAR.--Peak discharges greater than base of $5,000 \mathrm{ft}^{2} / \mathrm{s}$ and maximum ( $*$ ):

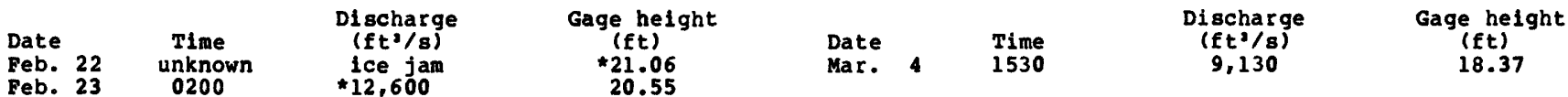

Minimum daily discharge, $52 \mathrm{ft} / \mathrm{s}$ Aug. 22.

DISCHARGE, IN CUBIC FEET PER SECOND, WATER YEAR OCTOBER 1984 TO SEPTEMBER 1985

\begin{tabular}{|c|c|c|c|c|c|c|c|c|c|c|c|c|}
\hline DAY & OCT & NOV & DEC & JAN & FEB & MAR & APR & MAY & JUN & JUL & AUG & SEP \\
\hline $\begin{array}{l}1 \\
2 \\
3 \\
4 \\
5\end{array}$ & $\begin{array}{l}151 \\
147 \\
143 \\
142 \\
163\end{array}$ & $\begin{array}{r}793 \\
1480 \\
1120 \\
897 \\
737\end{array}$ & $\begin{array}{l}384 \\
375 \\
355 \\
350 \\
340\end{array}$ & $\begin{array}{r}1100 \\
940 \\
800 \\
700 \\
620\end{array}$ & $\begin{array}{l}240 \\
240 \\
240 \\
240 \\
240\end{array}$ & $\begin{array}{l}1680 \\
1580 \\
2570 \\
8210 \\
8350\end{array}$ & $\begin{array}{r}996 \\
1040 \\
1090 \\
1250 \\
1540\end{array}$ & $\begin{array}{l}549 \\
540 \\
522 \\
503 \\
482\end{array}$ & $\begin{array}{l}277 \\
269 \\
266 \\
266 \\
263\end{array}$ & $\begin{array}{l}289 \\
263 \\
240 \\
219 \\
197\end{array}$ & $\begin{array}{l}86 \\
85 \\
82 \\
80 \\
78\end{array}$ & $\begin{array}{l}504 \\
480 \\
418 \\
363 \\
331\end{array}$ \\
\hline $\begin{array}{r}6 \\
7 \\
8 \\
9 \\
10\end{array}$ & $\begin{array}{l}161 \\
163 \\
205 \\
204 \\
156\end{array}$ & $\begin{array}{r}634 \\
586 \\
555 \\
1120 \\
803\end{array}$ & $\begin{array}{l}340 \\
335 \\
330 \\
330 \\
330\end{array}$ & $\begin{array}{l}560 \\
520 \\
480 \\
440 \\
410\end{array}$ & $\begin{array}{l}240 \\
240 \\
240 \\
240 \\
240\end{array}$ & $\begin{array}{l}4840 \\
2740 \\
2150 \\
1810 \\
1600\end{array}$ & $\begin{array}{r}1560 \\
1350 \\
1170 \\
1060 \\
985\end{array}$ & $\begin{array}{l}464 \\
461 \\
463 \\
474 \\
482\end{array}$ & $\begin{array}{l}258 \\
249 \\
238 \\
227 \\
218\end{array}$ & $\begin{array}{l}178 \\
160 \\
146 \\
134 \\
123\end{array}$ & $\begin{array}{l}77 \\
75 \\
73 \\
71 \\
70\end{array}$ & $\begin{array}{l}302 \\
352 \\
507 \\
449 \\
371\end{array}$ \\
\hline $\begin{array}{l}11 \\
12 \\
13 \\
14 \\
15\end{array}$ & $\begin{array}{l}228 \\
249 \\
214 \\
249 \\
576\end{array}$ & $\begin{array}{l}656 \\
608 \\
586 \\
581 \\
560\end{array}$ & $\begin{array}{l}330 \\
340 \\
360 \\
380 \\
480\end{array}$ & $\begin{array}{l}380 \\
360 \\
340 \\
320 \\
310\end{array}$ & $\begin{array}{l}240 \\
240 \\
240 \\
240 \\
240\end{array}$ & $\begin{array}{l}1500 \\
1420 \\
1300 \\
1170 \\
1090\end{array}$ & $\begin{array}{l}934 \\
899 \\
855 \\
813 \\
782\end{array}$ & $\begin{array}{l}484 \\
485 \\
470 \\
451 \\
437\end{array}$ & $\begin{array}{l}213 \\
213 \\
216 \\
218 \\
223\end{array}$ & $\begin{array}{l}115 \\
110 \\
107 \\
104 \\
102\end{array}$ & $\begin{array}{l}70 \\
68 \\
67 \\
66 \\
64\end{array}$ & $\begin{array}{l}325 \\
295 \\
278 \\
264 \\
249\end{array}$ \\
\hline $\begin{array}{l}16 \\
17 \\
18 \\
19 \\
20\end{array}$ & $\begin{array}{r}649 \\
972 \\
964 \\
1000 \\
651\end{array}$ & $\begin{array}{l}515 \\
496 \\
497 \\
481 \\
455\end{array}$ & $\begin{array}{l}720 \\
827 \\
658 \\
727 \\
790\end{array}$ & $\begin{array}{l}290 \\
285 \\
280 \\
270 \\
270\end{array}$ & $\begin{array}{r}240 \\
250 \\
300 \\
450 \\
1000\end{array}$ & $\begin{array}{r}1010 \\
942 \\
883 \\
848 \\
840\end{array}$ & $\begin{array}{l}751 \\
714 \\
683 \\
654 \\
629\end{array}$ & $\begin{array}{l}417 \\
399 \\
377 \\
350 \\
339\end{array}$ & $\begin{array}{l}228 \\
235 \\
239 \\
240 \\
237\end{array}$ & $\begin{array}{l}99 \\
95 \\
93 \\
93 \\
91\end{array}$ & $\begin{array}{l}62 \\
60 \\
58 \\
56 \\
55\end{array}$ & $\begin{array}{l}234 \\
219 \\
212 \\
196 \\
184\end{array}$ \\
\hline $\begin{array}{l}21 \\
22 \\
23 \\
24 \\
25\end{array}$ & $\begin{array}{l}553 \\
478 \\
425 \\
394 \\
386\end{array}$ & $\begin{array}{l}433 \\
425 \\
426 \\
425 \\
426\end{array}$ & $\begin{array}{r}1000 \\
1200 \\
1100 \\
1000 \\
950\end{array}$ & $\begin{array}{l}270 \\
270 \\
265 \\
265 \\
260\end{array}$ & $\begin{array}{r}3000 \\
5800 \\
11900 \\
10200 \\
6260\end{array}$ & $\begin{array}{l}826 \\
789 \\
783 \\
804 \\
805\end{array}$ & $\begin{array}{l}606 \\
590 \\
610 \\
608 \\
580\end{array}$ & $\begin{array}{l}338 \\
331 \\
322 \\
312 \\
307\end{array}$ & $\begin{array}{l}231 \\
226 \\
219 \\
212 \\
205\end{array}$ & $\begin{array}{l}91 \\
90 \\
89 \\
86 \\
86\end{array}$ & $\begin{array}{r}53 \\
52 \\
770 \\
1900 \\
1580\end{array}$ & $\begin{array}{l}172 \\
163 \\
280 \\
450 \\
395\end{array}$ \\
\hline $\begin{array}{l}26 \\
27 \\
28 \\
29 \\
30 \\
31\end{array}$ & $\begin{array}{l}394 \\
387 \\
436 \\
383 \\
362 \\
349\end{array}$ & $\begin{array}{l}420 \\
438 \\
421 \\
408 \\
400 \\
---\end{array}$ & $\begin{array}{r}900 \\
1300 \\
2000 \\
2400 \\
2100 \\
1320\end{array}$ & $\begin{array}{l}260 \\
250 \\
250 \\
250 \\
245 \\
245\end{array}$ & $\begin{array}{r}3670 \\
2500 \\
1860 \\
-\ldots \\
-\ldots\end{array}$ & $\begin{array}{l}788 \\
772 \\
882 \\
879 \\
826 \\
929\end{array}$ & $\begin{array}{l}567 \\
566 \\
564 \\
559 \\
554 \\
-\infty-\end{array}$ & $\begin{array}{l}302 \\
298 \\
297 \\
294 \\
290 \\
284\end{array}$ & $\begin{array}{l}197 \\
406 \\
540 \\
396 \\
323 \\
---\end{array}$ & $\begin{array}{l}87 \\
87 \\
86 \\
88 \\
87 \\
86\end{array}$ & $\begin{array}{l}996 \\
720 \\
572 \\
479 \\
412 \\
426\end{array}$ & $\begin{array}{l}429 \\
436 \\
437 \\
486 \\
759 \\
--\end{array}$ \\
\hline $\begin{array}{l}\text { TOTAL } \\
\text { MEAN } \\
\text { MAX } \\
\text { MIN } \\
\text { CFSM } \\
\text { IN. } \\
\text { AC-FT }\end{array}$ & $\begin{array}{r}11934 \\
385 \\
1000 \\
142 \\
.24 \\
.27 \\
23670\end{array}$ & $\begin{array}{r}18382 \\
613 \\
1480 \\
400 \\
.37 \\
.42 \\
36460\end{array}$ & $\begin{array}{r}24351 \\
786 \\
2400 \\
330 \\
.48 \\
.55 \\
48300\end{array}$ & $\begin{array}{r}12505 \\
403 \\
1100 \\
245 \\
.25 \\
.28 \\
24800\end{array}$ & $\begin{array}{r}51030 \\
1823 \\
11900 \\
240 \\
1.11 \\
1.16 \\
101200\end{array}$ & $\begin{array}{r}55616 \\
1794 \\
8350 \\
772 \\
1.10 \\
1.27 \\
110300\end{array}$ & $\begin{array}{r}25559 \\
852 \\
1560 \\
554 \\
.52 \\
.58 \\
50700\end{array}$ & $\begin{array}{r}12524 \\
404 \\
549 \\
284 \\
.25 \\
288 \\
24840\end{array}$ & $\begin{array}{r}7748 \\
258 \\
540 \\
197 \\
.16 \\
15370\end{array}$ & $\begin{array}{r}3921 \\
126 \\
289 \\
86 \\
.08 \\
.09 \\
7780\end{array}$ & $\begin{array}{r}9363 \\
302 \\
1900 \\
52 \\
.18 \\
18121 \\
1850\end{array}$ & $\begin{array}{r}10540 \\
351 \\
759 \\
163 \\
.21 \\
.24 \\
20910\end{array}$ \\
\hline
\end{tabular}

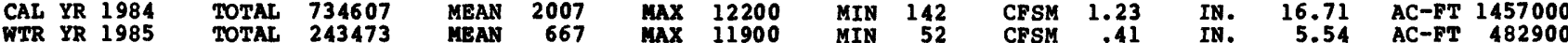


05472500 NORTH SKUNR RIVER NEAR SIGOURNEY, IA

LOCATION,-Lat $41^{\circ} 18^{\prime} 03^{\prime}$, , long $92^{\circ} 12^{\prime} 16^{\prime}$, in NE1/4 SE1/4 sec.14, T.75 N., R.12 W., Reokuk County, Hydrologic Unit 07080106 , on right bank 20 ft downstream from bridge on State Highway 149, 1.2 mi downstream from Cedar Creek, $2.2 \mathrm{mi}$ south of Sigourney, $4.0 \mathrm{mi}$ upstream from Bridge Creek, and $16.2 \mathrm{mi}$ upstream from confluence with South Skunk River.

DRAINAGE AREA. $-730 \mathrm{mi}^{2}$.

PERIOD OF RECORD.--October 1945 to current year.

REVISED RECORDS.--WSP 1438: Drainage area. WSP 1558: 1946-47 (K).

GAGE.--Water-stage recorder. Datum of gage is $651.53 \mathrm{ft}$ above NGVD. Prior to June 10 , 1953 , nonrecording gage at same site and datum.

REMARRS.--Estimated daily discharges during water year: Oct. 20, 21, Dec. 4-12, Dec. 19 to Feb. 26, Mar. 4,5 and Aug. 19-22. Records good except for periods of estimated record, which are poor. National Weather Service gage-height telemeter at station. U.S. Army Corps of Engineers Data Collection Platform at station.

AVERAGE DISCHARGE. -40 years, $443 \mathrm{ft} / \mathrm{s}, 8.24 \mathrm{in} / \mathrm{yr}, 321,000 \mathrm{acre}-\mathrm{ft} / \mathrm{yr}$.

EXTREMES FOR PERIOD OF RECORD,-Maximum discharge, 27,500 ft $3 / \mathrm{s}$ Mar. 31, 1960, gage height, $25.33 \mathrm{ft}$; minimum daily, $0.1 \mathrm{ft}^{3} / \mathrm{s}$ Oct. 7 to Nov. $15,1956$.

EXTREMES OUTSIDE PERIOD OF RECORD.--Flood in May 1944 reached a stage of $22.8 \mathrm{ft}$, from floodmark, discharge, $14,500 \mathrm{ft}^{3} / \mathrm{s}$.

EXTREXES FOR CURRENT YEAR.--Peak discharges greater than base discharge of $3,800 \mathrm{ft} / \mathrm{s}$ and maximum (*):

\begin{tabular}{|c|c|c|c|c|c|c|c|c|}
\hline b. 25 & $\begin{array}{c}\text { Time } \\
\text { unknown }\end{array}$ & $\begin{array}{c}\text { Discharge } \\
(f t / s) \\
4,000\end{array}$ & $\begin{array}{c}\text { Gage height } \\
\text { (ft) } \\
\star a 17.78\end{array}$ & $\begin{array}{l}\text { Date } \\
\text { Mar. }\end{array}$ & 7 & $\begin{array}{l}\text { Time } \\
0200\end{array}$ & $\begin{array}{c}\text { Discharge } \\
\left(f t^{3} / \mathrm{s}\right) \\
\star 4,750\end{array}$ & $\begin{array}{c}\text { Gage height } \\
\text { (ft) } \\
17.56\end{array}$ \\
\hline
\end{tabular}

(a) ice jam

Minimum discharge, $8.7 \mathrm{ft}^{3} / \mathrm{s}$ sept. $20,21$.

DISCHARGE, IN CUBIC FEET PER SECOND, WATER YEAR OCTOBER 1984 TO SEPTEXBER 1985

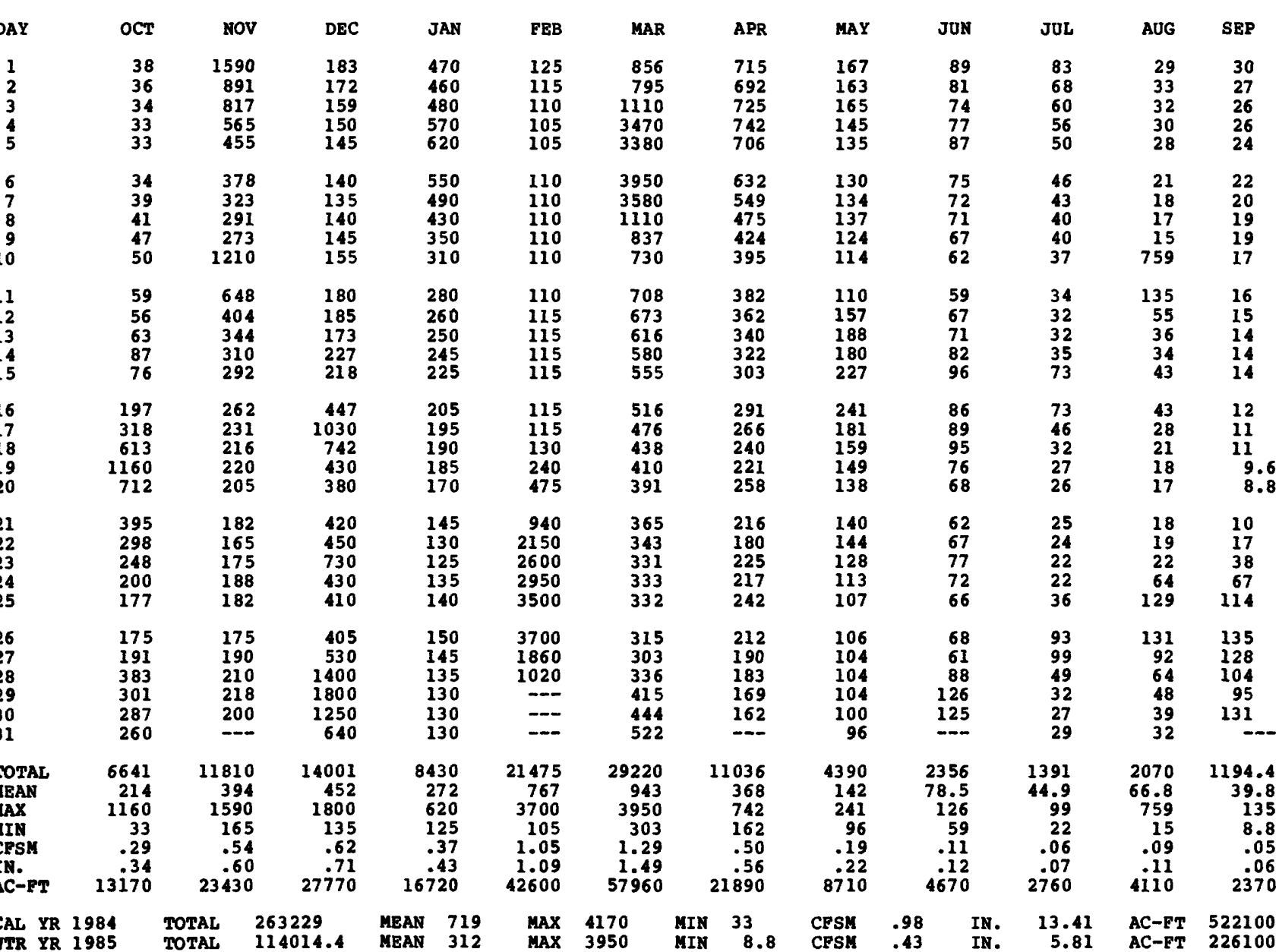


LOCATION.--Lat. $40^{\circ} 55^{\prime} 20^{\prime \prime}$, long $91^{\circ} 40^{\prime} 10^{\prime \prime}$, in SEl/4 NWl/4 sec. 28, T.71 N., R.7 W., Henry County, Hydrologic Unit 07080107 , on left bank $30 \mathrm{ft}$ upstream from bridge on county highway H46, $3.0 \mathrm{mi}$ west of Oakland Mills, $2.9 \mathrm{mi}$ upstream from Wolf Creek, and $4.3 \mathrm{mi}$ upstream from mouth.

DRAINAGE AREA. $--530 \mathrm{mi}^{2}$.

PERIOD OF RECORD.--Occasional low-flow measurements, water years 1957 to 1977. July 1977 to current year.

GAGE.--Water-stage recorder. Datum of gage is 565.07 above NGVD.

REMARKS.--Estimated daily discharges: Dec. 5 to Feb. 22 and Mar. 3 to Apr. 3 . Records good except those for periods of estimated record, which are fair. Occasional high-water measurements were made by 0.5 . Army Corps of Engineers in 1965, 1966, 1970 and 1974 and by U.S. Geological Survey in 1966 and 1967.

AVERAGE DISCHARGE. -8 years, $396 \mathrm{ft}^{3} / \mathrm{s}, 10.1 \mathrm{in} / \mathrm{yr}, 286,900 \mathrm{acre}-\mathrm{ft} / \mathrm{yr}$.

EXTREMES FOR PERIOD OF RECORD.--Maximum discharge, 8,560 fts/s Apr. 3, 1983, gage height, 19.68 ft; minimum daily, $1.0 \mathrm{ft}^{3} / \mathrm{s}$ July 9,1977 and Sept. $14,1983$.

EXTREMES OUTSIDE PERIOD OF RECORD,--Flood of April 22, 1973 reached a stage of 24.09 ft, discharge not determined. Flood of June 1905 reached a stage approximately 2 feet higher from information by local resident.

EXTREMES FOR CURRENT PERIOD.--Peak discharges greater than base of $3,000 \mathrm{ft} / \mathrm{s}$ and maximum ( $*$ ):

\begin{tabular}{|c|c|c|c|c|c|c|c|c|}
\hline $\begin{array}{l}\text { Date } \\
\text { Oct. } 19 \\
\text { Nov. } 2 \\
\text { Feb. } 22\end{array}$ & $\begin{array}{l}\text { Time } \\
0445 \\
0330 \\
1115\end{array}$ & $\begin{array}{c}\text { Discharge } \\
\left(\mathrm{ft}^{3} / \mathrm{s}\right) \\
4,980 \\
7,110 \\
\text { ice jam }\end{array}$ & $\begin{array}{c}\text { Gage height } \\
\text { (ft) } \\
15.71 \\
18.35 \\
\star 18.89\end{array}$ & $\begin{array}{l}\text { Date } \\
\text { Feb. } \\
\text { May }\end{array}$ & $\begin{array}{l}24 \\
12\end{array}$ & $\begin{array}{l}\text { Time } \\
0630 \\
0330\end{array}$ & $\begin{array}{c}\text { Discharge } \\
\left(f t^{3} / \mathrm{s}\right) \\
\star 7,350 \\
3,620\end{array}$ & $\begin{array}{c}\text { Gage height } \\
\text { (ft) } \\
18.58 \\
13.44\end{array}$ \\
\hline
\end{tabular}

Minimum discharge, $1.3 \mathrm{ft}^{3} / \mathrm{s}$ Sept. $18-20$.

DISCHARgE, IN CUBIC FEET PER SECOND, WATER YEAR OCTOBER 1984 TO SEPTEMBER 1985 MEAN VALUES

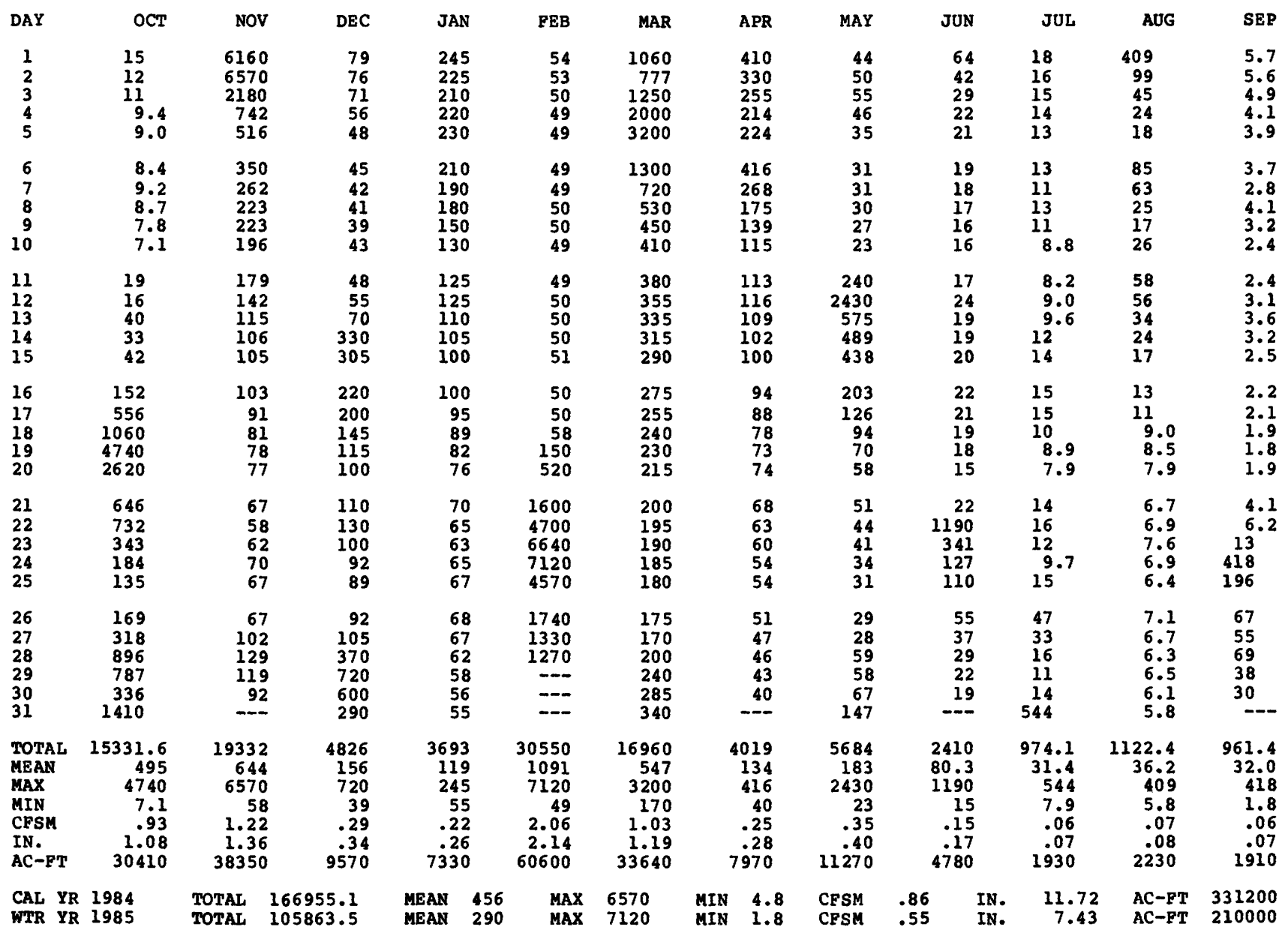


05474000 SKUNK RIVER AT AUGUSTA, IA

(National stream-quality accounting network station)

LOCATION.--Lat $40^{\circ} 45^{\prime} 13^{\prime \prime}$, long $91^{\circ} 16^{\prime} 40^{\prime}$, in NEl/4 NEl/4 sec.26, T.69 N., R.4 W., Des Moines County, Bydrologic Unit 07080107 , on left bank $300 \mathrm{ft}$ upstream from bridge on state Highway 394 at Augusta, $2.0 \mathrm{mi}$ upstream from Long Creek, and at mile 12.5 .

DRAINAGE AREA. $--4,303 \mathrm{mi}^{2}$.

WATER-DISCHARGE RECORDS

PERIOD OF RECORD.--September to November 1913, October 1914 to current year. Monthly discharge only for some periods, published in wSP 1308 .

REVISED RECORDS,--WSP 1308: 1915 (M), 1919-27 (M), 1932-34 (M), 1936, 1937-38 (M), 1942 (M). MSP 1438: Drainage area. WDR IA-71-1: 1966 (M).

GAGE.--Water-stage recorder. Datum of gage is $521.24 \mathrm{ft}$ above NGVD. Prior to Nov. 15 , 1913 , nonrecording gage at site $400 \mathrm{ft}$ upstream at datum about $0.7 \mathrm{ft}$ higher. May 27 , 1915, to Jan. 14, 1935, nonrecording gage at site $400 \mathrm{ft}$ upstream at present datum.

REMARRS.--Estimated dally discharges during water year: Dec. 7-12 and Dec. 22 to Feb. 23. Records good except those for periods of estimated record, which are fair. National Weather service gage-height telemeter and U.S. Army Corps of Engineers data collection platform at station.

COOPERATION.--Two discharge measurements provided by U.S. Army Corps of Engineers.

AVERAGE DISCHARGE.--71 years (water years 1915-85), 2,440 ft'/s, 7.70 in/yr, $1,768,000$ acre-ft/yr.

EXTREMES FOR PERIOD OF RECORD.--Maximum discharge, $66,800 \mathrm{ft} / \mathrm{s}$ Apr. 23, 1973, gage height, $27.05 \mathrm{ft}$, minimum

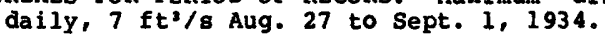

EXTREMES OUTSIDE PERIOD OF RECORD, - Flood of June 1, 1903, reached a stage of about 21 ft, discharge, about 45,000 $\mathrm{ft}^{2} / \mathrm{s}$. Stage and discharge for flood of April 1973 are believed to be the greatest since 1851.

EXTREMES FOR CURRENT YEAR.--Peak discharges greater than base of $15,000 \mathrm{ft}^{3 / \mathrm{s}}$ and maximum (*):

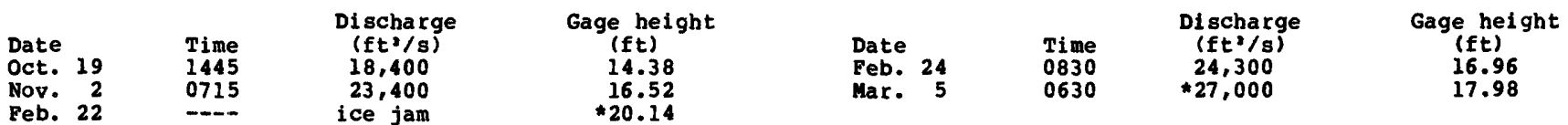

Minimum discharge, $133 \mathrm{ft} / \mathrm{s}$ Aug. $25,26$.

DISCHARGE, IN CUBIC FEET PER SECOND, WATER YEAR OCTOBER 1984 TO SEPTEYBER 1985 MEAN VALUES

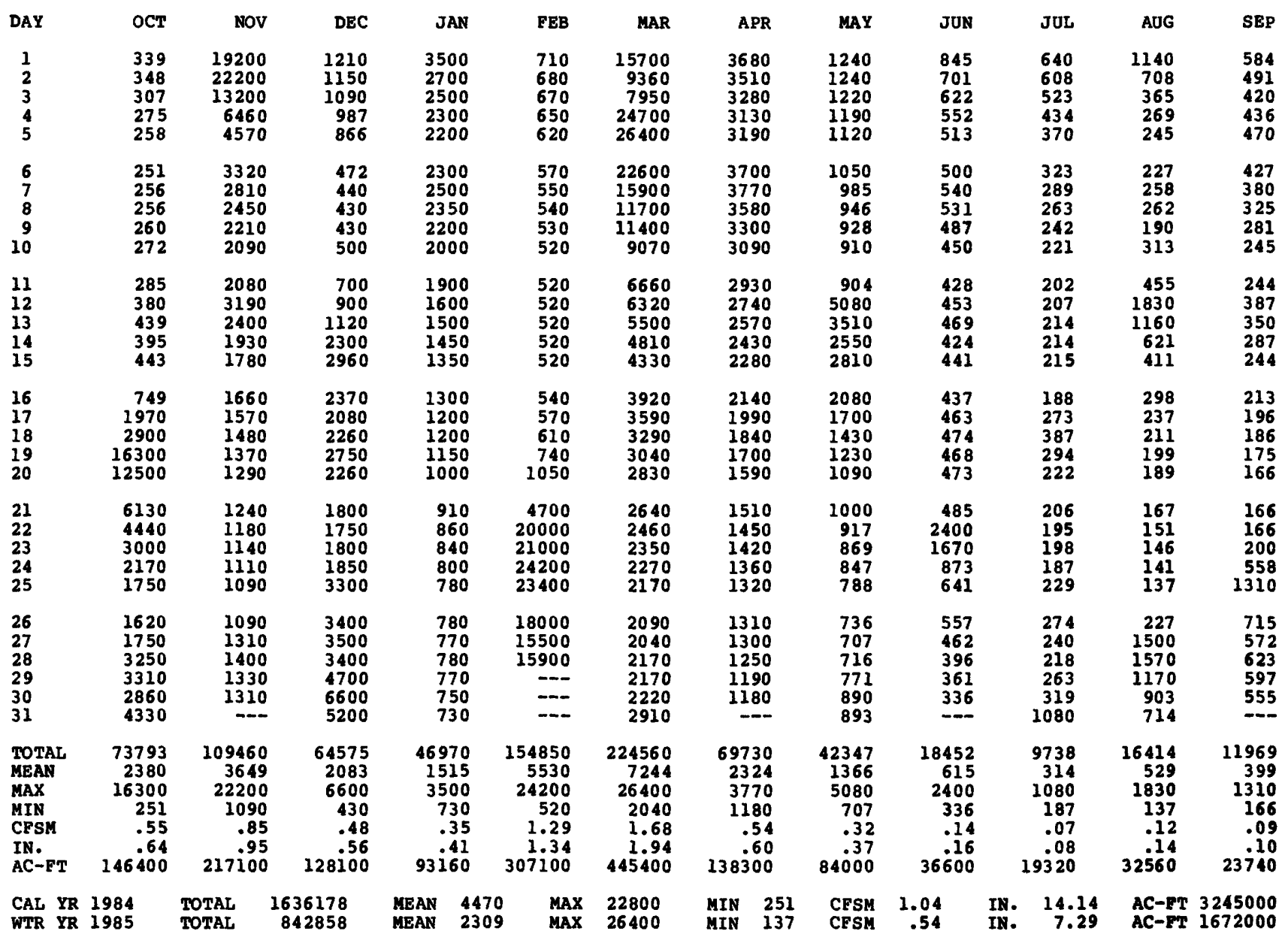


05474000 SRUNR RIVER AT AUGUSTA, IA--Continued

(National stream-quality accounting network station)

WATER-QUALITY RECORDS

LOCATION.--Samples collected at bridge on state Highway 394, 300 ft downstream from gage.

PERIOD OF RECORD.--Water years 1975 to current year.

PERIOD OF DAILY RECORD.--

SPECIFIC CONDUCTANCE: October 1975 to current year.

WATER TEMPERATURES: October 1975 to current year.

SUSPENDED-SEDIMENT DISCHARGE: October 1975 to current year.

REMARKS.--During periods of ice effect, sediment samples are collected in open water channel. Records of specific conductance are obtained from suspended sediment samples at time of analysis.

EXTREMES FOR PERIOD OF DAILY RECORD.--

SPECIFIC CONDUCTANCE: Maximum daily, 950 microsiemens Dec. 20, 1979, Feb. 12, 1980; minimum daily, 190 microsiemens Aug. 10, 1977

WATER TEMPERATURES: Maximum daily, $34.0^{\circ} \mathrm{C}$ July 20,1980 ; minimum daily, $0.0^{\circ} \mathrm{C}$ on many days during winter periods.

SEDIMENT CONCENTRATIONS: Maximum daily mean, 8,550 mg/L June 25, 1981; minimum daily mean, 1 mg/L Mar. 8, 9, 12,1978 , Jan. $5,6,1984$

SEDIMENT LOADS: Maximum daily, 499,000 tons Mar. 21, 1978; minimum daily, 1.5 tons Feb. 8 , 1977.

EXTREMES FOR CURRENT YEAR.--

SPECIFIC CONDUCTANCE: Maximum dally, 640 microsiemens Feb. 9,10; minimum daily, 200 microsiemens Oct. 19, Nov, 1, Mar. 5

TEMPERATURES: Maximum dally, $31.0^{\circ} \mathrm{C}$ sep. 7,8 ; minimum daily, $0.0^{\circ} \mathrm{C}$ on many days during winter periods.

SEDIMENT CONCENTRATIONS: Maximum daily mean, 5,620 mg/L May 12; minimum daily mean, $8 \mathrm{mg} / \mathrm{L}$ Feb. 17.

SEDIMENT LOADS: Maximum daily, 233,000 tons Mar 4; minimum daily, 12 tons Dec. 8, Feb. 17.

SPECIFIC CONDUCTANCE LABORATORY (MICROSIEMENS/CM AT 25 DEG. C), WATER YEAR OCTOBER 1984 TO SEPTEMBER 1985 RANDOM VALUES

\begin{tabular}{|c|c|c|c|c|c|c|c|c|c|c|c|c|}
\hline DAY & OCT & NOV & DEC & JAN & FEB & MAR & APR & MAY & JUN & JUL & AUG & SEP \\
\hline $\begin{array}{l}1 \\
2 \\
3 \\
4 \\
5\end{array}$ & $\begin{array}{l}540 \\
540 \\
490 \\
540 \\
520\end{array}$ & $\begin{array}{l}200 \\
220 \\
240 \\
320 \\
400\end{array}$ & $\begin{array}{l}560 \\
560 \\
550 \\
560 \\
560\end{array}$ & $\begin{array}{l}380 \\
420 \\
-- \\
--\end{array}$ & $\begin{array}{l}570 \\
--- \\
630 \\
630\end{array}$ & $\begin{array}{l}320 \\
360 \\
360 \\
220 \\
200\end{array}$ & $\begin{array}{l}460 \\
480 \\
500 \\
500 \\
500\end{array}$ & $\begin{array}{l}480 \\
460 \\
470 \\
500 \\
500\end{array}$ & $\begin{array}{l}540 \\
530 \\
520 \\
480 \\
480\end{array}$ & $\begin{array}{l}480 \\
480 \\
480 \\
460 \\
420\end{array}$ & $\begin{array}{l}430 \\
340 \\
360 \\
370 \\
390\end{array}$ & $\begin{array}{l}450 \\
480 \\
500 \\
520 \\
520\end{array}$ \\
\hline $\begin{array}{r}6 \\
7 \\
8 \\
9 \\
10\end{array}$ & $\begin{array}{l}540 \\
530 \\
530 \\
510 \\
520\end{array}$ & $\begin{array}{l}410 \\
450 \\
480 \\
500 \\
520\end{array}$ & $\begin{array}{l}580 \\
590 \\
600 \\
580 \\
600\end{array}$ & $\begin{array}{l}520 \\
540 \\
540 \\
560 \\
560\end{array}$ & $\begin{array}{l}-20 \\
600 \\
640 \\
640\end{array}$ & $\begin{array}{l}230 \\
260 \\
270 \\
300 \\
350\end{array}$ & $\begin{array}{l}500 \\
500 \\
520 \\
530 \\
535\end{array}$ & $\begin{array}{l}480 \\
445 \\
450 \\
440 \\
450\end{array}$ & $\begin{array}{l}490 \\
470 \\
420 \\
430 \\
440\end{array}$ & $\begin{array}{l}440 \\
520 \\
490 \\
460 \\
420\end{array}$ & $\begin{array}{l}430 \\
450 \\
470 \\
500 \\
360\end{array}$ & $\begin{array}{l}520 \\
440 \\
500 \\
520 \\
550\end{array}$ \\
\hline $\begin{array}{l}11 \\
12 \\
13 \\
14 \\
15\end{array}$ & $\begin{array}{l}520 \\
520 \\
520 \\
540 \\
500\end{array}$ & $\begin{array}{l}520 \\
540 \\
400 \\
400 \\
460\end{array}$ & $\begin{array}{l}580 \\
520 \\
550 \\
460 \\
410\end{array}$ & $\begin{array}{l}580 \\
600 \\
600 \\
590 \\
600\end{array}$ & $\begin{array}{l}610 \\
600 \\
610 \\
630 \\
600\end{array}$ & $\begin{array}{l}360 \\
340 \\
440 \\
460 \\
480\end{array}$ & $\begin{array}{l}540 \\
540 \\
540 \\
540 \\
550\end{array}$ & $\begin{array}{l}500 \\
240 \\
320 \\
490 \\
420\end{array}$ & $\begin{array}{l}520 \\
520 \\
550 \\
540 \\
520\end{array}$ & $\begin{array}{l}400 \\
440 \\
460 \\
480 \\
440\end{array}$ & $\begin{array}{l}450 \\
400 \\
300 \\
330 \\
320\end{array}$ & $\begin{array}{l}520 \\
520 \\
480 \\
460 \\
450\end{array}$ \\
\hline $\begin{array}{l}16 \\
17 \\
18 \\
19 \\
20\end{array}$ & $\begin{array}{l}540 \\
440 \\
320 \\
200 \\
260\end{array}$ & $\begin{array}{l}500 \\
520 \\
540 \\
540 \\
550\end{array}$ & $\begin{array}{l}440 \\
460 \\
490 \\
480 \\
460\end{array}$ & $\begin{array}{l}600 \\
600 \\
---\end{array}$ & $\begin{array}{l}620 \\
610 \\
480 \\
580 \\
560\end{array}$ & $\begin{array}{l}500 \\
490 \\
--- \\
520 \\
520\end{array}$ & $\begin{array}{l}550 \\
550 \\
550 \\
530 \\
510\end{array}$ & $\begin{array}{l}500 \\
500 \\
540 \\
550 \\
560\end{array}$ & $\begin{array}{l}500 \\
460 \\
460 \\
460 \\
440\end{array}$ & $\begin{array}{l}480 \\
480 \\
520 \\
540 \\
520\end{array}$ & $\begin{array}{l}340 \\
340 \\
360 \\
400 \\
400\end{array}$ & $\begin{array}{l}540 \\
510 \\
500 \\
440 \\
440\end{array}$ \\
\hline $\begin{array}{l}21 \\
22 \\
23 \\
24 \\
25\end{array}$ & $\begin{array}{l}300 \\
310 \\
380 \\
420 \\
460\end{array}$ & $\begin{array}{l}560 \\
570 \\
570 \\
560 \\
570\end{array}$ & $\begin{array}{l}480 \\
480 \\
480 \\
520 \\
550\end{array}$ & $\begin{array}{l}-- \\
610 \\
580 \\
--- \\
---\end{array}$ & $\begin{array}{l}380 \\
240 \\
210 \\
210 \\
220\end{array}$ & $\begin{array}{l}540 \\
520 \\
530 \\
540 \\
540\end{array}$ & $\begin{array}{l}510 \\
520 \\
530 \\
490 \\
480\end{array}$ & $\begin{array}{l}560 \\
560 \\
560 \\
580 \\
600\end{array}$ & $\begin{array}{l}440 \\
340 \\
280 \\
340 \\
460\end{array}$ & $\begin{array}{l}520 \\
460 \\
460 \\
460 \\
440\end{array}$ & $\begin{array}{l}390 \\
410 \\
440 \\
440 \\
450\end{array}$ & $\begin{array}{l}440 \\
420 \\
460 \\
530 \\
440\end{array}$ \\
\hline $\begin{array}{l}26 \\
27 \\
28 \\
29 \\
30 \\
31\end{array}$ & $\begin{array}{l}485 \\
500 \\
440 \\
410 \\
450 \\
340\end{array}$ & $\begin{array}{l}560 \\
560 \\
550 \\
540 \\
560 \\
-\end{array}$ & $\begin{array}{l}560 \\
550 \\
520 \\
410 \\
390 \\
370\end{array}$ & $\begin{array}{l}620 \\
580 \\
-620 \\
580 \\
580\end{array}$ & $\begin{array}{l}250 \\
265 \\
280 \\
-- \\
--\end{array}$ & $\begin{array}{l}550 \\
520 \\
440 \\
530 \\
540 \\
510\end{array}$ & $\begin{array}{l}480 \\
490 \\
460 \\
460 \\
480 \\
-\infty\end{array}$ & $\begin{array}{l}560 \\
560 \\
560 \\
570 \\
540 \\
570\end{array}$ & $\begin{array}{l}460 \\
440 \\
420 \\
440 \\
420 \\
---\end{array}$ & $\begin{array}{l}420 \\
500 \\
500 \\
520 \\
540 \\
320\end{array}$ & $\begin{array}{l}480 \\
560 \\
320 \\
320 \\
400 \\
440\end{array}$ & $\begin{array}{l}410 \\
340 \\
410 \\
460 \\
480 \\
-\end{array}$ \\
\hline
\end{tabular}


05474000 SKUNK RIVER AT AUGUSTA, IA--Continued

WATER-QUALITY RECORDS

TEMPERATORE, WATER (DEG. C), WATER YEAR OCTOBER 1984 TO SEPTEMBER 1985 RANDOM VALUES

\begin{tabular}{|c|c|c|c|c|c|c|c|c|c|c|c|c|}
\hline DAY & OCT & NOV & DEC & JAN & FEB & MAR & APR & MAY & JUN & JUL & AUG & SEP \\
\hline $\begin{array}{l}1 \\
2 \\
3 \\
4 \\
5\end{array}$ & $\begin{array}{l}15.0 \\
16.0 \\
17.0 \\
19.0 \\
19.0\end{array}$ & $\begin{array}{r}10.0 \\
10.0 \\
10.0 \\
10.0 \\
9.0\end{array}$ & $\begin{array}{l}6.0 \\
4.0 \\
4.0 \\
1.0 \\
1.0\end{array}$ & $\begin{array}{l}.0 \\
.0 \\
.0 \\
.0 \\
.0\end{array}$ & $\begin{array}{l}.0 \\
.0 \\
.0 \\
.0 \\
.0\end{array}$ & $\begin{array}{l}6.0 \\
6.0 \\
5.0 \\
4.0 \\
4.0\end{array}$ & $\begin{array}{r}6.0 \\
10.0 \\
12.0 \\
12.0 \\
9.0\end{array}$ & $\begin{array}{l}18.0 \\
19.0 \\
20.0 \\
20.0 \\
20.0\end{array}$ & $\begin{array}{l}25.0 \\
25.0 \\
25.0 \\
25.0 \\
23.0\end{array}$ & $\begin{array}{l}28.0 \\
27.5 \\
29.0 \\
29.0 \\
29.0\end{array}$ & $\begin{array}{l}25.0 \\
25.0 \\
24.0 \\
23.0 \\
23.0\end{array}$ & $\begin{array}{l}26.0 \\
28.0 \\
28.0 \\
27.0 \\
29.0\end{array}$ \\
\hline $\begin{array}{r}6 \\
7 \\
8 \\
9 \\
10\end{array}$ & $\begin{array}{l}19.0 \\
19.0 \\
18.0 \\
20.0 \\
20.0\end{array}$ & $\begin{array}{r}9.0 \\
9.0 \\
9.0 \\
13.0 \\
7.0\end{array}$ & $\begin{array}{l}.0 \\
3.0 \\
3.0 \\
2.0 \\
3.0\end{array}$ & $\begin{array}{l}.0 \\
.0 \\
.0 \\
.0 \\
.0\end{array}$ & $\begin{array}{l}.0 \\
.0 \\
.0 \\
.0 \\
.0\end{array}$ & $\begin{array}{l}4.0 \\
4.0 \\
5.0 \\
6.0 \\
6.0\end{array}$ & $\begin{array}{r}10.0 \\
10.0 \\
9.0 \\
10.0 \\
9.5\end{array}$ & $\begin{array}{l}21.0 \\
22.5 \\
23.0 \\
23.0 \\
24.0\end{array}$ & $\begin{array}{l}23.0 \\
26.0 \\
29.0 \\
28.0 \\
23.0\end{array}$ & $\begin{array}{l}28.0 \\
28.0 \\
30.0 \\
30.0 \\
30.0\end{array}$ & $\begin{array}{l}27.0 \\
29.0 \\
29.0 \\
30.0 \\
27.0\end{array}$ & $\begin{array}{l}29.0 \\
31.0 \\
31.0 \\
27.0 \\
27.0\end{array}$ \\
\hline $\begin{array}{l}11 \\
12 \\
13 \\
14 \\
15\end{array}$ & $\begin{array}{l}18.0 \\
18.0 \\
20.0 \\
20.0 \\
18.0\end{array}$ & $\begin{array}{l}7.0 \\
7.0 \\
8.0 \\
8.0 \\
8.0\end{array}$ & $\begin{array}{l}3.0 \\
3.0 \\
3.0 \\
3.0 \\
3.0\end{array}$ & $\begin{array}{l}.0 \\
.0 \\
.0 \\
.0 \\
.0\end{array}$ & $\begin{array}{r}.0 \\
.0 \\
.0 \\
.0 \\
-.0\end{array}$ & $\begin{array}{l}7.0 \\
8.0 \\
8.0 \\
8.0 \\
8.0\end{array}$ & $\begin{array}{l}13.0 \\
17.0 \\
16.0 \\
14.0 \\
15.0\end{array}$ & $\begin{array}{l}24.0 \\
23.0 \\
18.0 \\
20.0 \\
20.0\end{array}$ & $\begin{array}{l}20.0 \\
20.0 \\
21.0 \\
19.0 \\
24.0\end{array}$ & $\begin{array}{l}30.0 \\
29.0 \\
29.0 \\
29.0 \\
29.0\end{array}$ & $\begin{array}{l}27.0 \\
27.0 \\
27.0 \\
25.0 \\
25.0\end{array}$ & $\begin{array}{l}21.0 \\
21.0 \\
20.0 \\
19.0 \\
19.0\end{array}$ \\
\hline $\begin{array}{l}16 \\
17 \\
18 \\
19 \\
20\end{array}$ & $\begin{array}{l}17.0 \\
15.0 \\
14.0 \\
14.0 \\
12.0\end{array}$ & $\begin{array}{l}6.0 \\
6.0 \\
5.0 \\
4.0 \\
4.0\end{array}$ & $\begin{array}{l}6.0 \\
4.0 \\
3.0 \\
3.0 \\
1.5\end{array}$ & $\begin{array}{l}.0 \\
.0 \\
.0 \\
.0 \\
.0\end{array}$ & $\begin{array}{l}.0 \\
.0 \\
.0 \\
.0\end{array}$ & $\begin{array}{r}8.0 \\
8.0 \\
10.0 \\
10.0 \\
12.0\end{array}$ & $\begin{array}{l}18.0 \\
19.0 \\
21.0 \\
21.0 \\
23.0\end{array}$ & $\begin{array}{l}16.0 \\
18.0 \\
21.0 \\
22.0 \\
21.0\end{array}$ & $\begin{array}{l}25.0 \\
25.0 \\
22.0 \\
24.0 \\
25.0\end{array}$ & $\begin{array}{l}29.0 \\
28.0 \\
29.0 \\
29.0 \\
29.0\end{array}$ & $\begin{array}{l}27.0 \\
29.0 \\
29.0 \\
28.0 \\
25.0\end{array}$ & $\begin{array}{l}22.0 \\
22.0 \\
26.0 \\
26.0 \\
22.0\end{array}$ \\
\hline $\begin{array}{l}21 \\
22 \\
23 \\
24 \\
25\end{array}$ & $\begin{array}{l}12.0 \\
12.0 \\
12.0 \\
11.0 \\
11.0\end{array}$ & $\begin{array}{l}4.0 \\
4.0 \\
5.0 \\
5.0 \\
8.0\end{array}$ & $\begin{array}{r}3.0 \\
3.0 \\
4.0 \\
.0 \\
.0\end{array}$ & $\begin{array}{l}.0 \\
.0 \\
.0 \\
.0 \\
.0\end{array}$ & $\begin{array}{l}2.0 \\
1.0 \\
1.0 \\
1.0 \\
2.0\end{array}$ & $\begin{array}{r}12.0 \\
10.0 \\
9.0 \\
9.0 \\
8.0\end{array}$ & $\begin{array}{l}23.0 \\
22.0 \\
21.0 \\
20.0 \\
20.0\end{array}$ & $\begin{array}{l}23.0 \\
22.0 \\
23.0 \\
24.0 \\
25.0\end{array}$ & $\begin{array}{l}25.0 \\
23.0 \\
24.0 \\
26.0 \\
27.0\end{array}$ & $\begin{array}{l}29.0 \\
29.0 \\
28.0 \\
28.0 \\
28.0\end{array}$ & $\begin{array}{l}26.0 \\
26.0 \\
23.0 \\
23.0 \\
23.0\end{array}$ & $\begin{array}{l}22.0 \\
20.0 \\
20.0 \\
17.0 \\
15.0\end{array}$ \\
\hline $\begin{array}{l}26 \\
27 \\
28 \\
29 \\
30 \\
31\end{array}$ & $\begin{array}{l}13.0 \\
14.0 \\
12.0 \\
12.0 \\
12.0 \\
12.0\end{array}$ & $\begin{array}{l}9.0 \\
6.0 \\
6.0 \\
6.0 \\
6.0 \\
-.-\end{array}$ & $\begin{array}{r}.0 \\
.0 \\
.0 \\
3.0 \\
4.0 \\
4.0\end{array}$ & $\begin{array}{l}.0 \\
.0 \\
.0 \\
.0 \\
.0 \\
.0\end{array}$ & $\begin{array}{l}2.0 \\
2.0 \\
4.0 \\
-\square- \\
--- \\
---\end{array}$ & $\begin{array}{r}12.0 \\
13.0 \\
14.0 \\
11.0 \\
11.0 \\
7.0\end{array}$ & $\begin{array}{l}22.0 \\
22.0 \\
23.0 \\
20.0 \\
19.0 \\
-\end{array}$ & $\begin{array}{l}28.0 \\
22.0 \\
23.0 \\
23.0 \\
25.0 \\
25.0\end{array}$ & $\begin{array}{r}30.0 \\
26.0 \\
26.0 \\
26.0 \\
26.0 \\
-\end{array}$ & $\begin{array}{l}28.0 \\
29.0 \\
29.0 \\
29.0 \\
25.0 \\
23.0\end{array}$ & $\begin{array}{l}23.0 \\
23.0 \\
23.0 \\
23.0 \\
26.0 \\
26.0\end{array}$ & $\begin{array}{r}15.0 \\
15.0 \\
17.0 \\
17.0 \\
13.0 \\
-\end{array}$ \\
\hline
\end{tabular}

SUSPENDED-SEDIMENT, WATER YEAR OCTOBER 1984 TO SEPTEMBER 1985

\begin{tabular}{|c|c|c|c|c|c|c|c|c|c|c|c|c|}
\hline \multirow[t]{2}{*}{ DAY } & $\begin{array}{l}\text { MEAN } \\
\text { CONCEN- } \\
\text { TRATION } \\
\text { (MG/L) }\end{array}$ & $\begin{array}{l}\text { LOADS } \\
\text { ( } \mathrm{T} / \mathrm{DAY})\end{array}$ & $\begin{array}{c}\text { MEAN } \\
\text { CONCEN- } \\
\text { TRATION } \\
\text { (MG/L) }\end{array}$ & $\begin{array}{l}\text { LOADS } \\
\text { (T/DAY) }\end{array}$ & $\begin{array}{l}\text { MEAN } \\
\text { CONCEN- } \\
\text { TRATION } \\
(M G / L)\end{array}$ & $\begin{array}{l}\text { LOADS } \\
(T / D A Y)\end{array}$ & $\begin{array}{l}\text { MEAN } \\
\text { CONCEN- } \\
\text { TRATION } \\
\text { (MG/L) }\end{array}$ & $\begin{array}{l}\text { LOADS } \\
\text { (T/DAY) }\end{array}$ & $\begin{array}{l}\text { MEAN } \\
\text { CONCEN- } \\
\text { TRATION } \\
\text { (MG/L) }\end{array}$ & $\begin{array}{l}\text { LOADS } \\
\text { (T/DAY) }\end{array}$ & $\begin{array}{l}\text { MEAN } \\
\text { CONCEN- } \\
\text { TRATION } \\
(\text { MG/L) }\end{array}$ & $\begin{array}{l}\text { LOADS } \\
\text { (T/DAY) }\end{array}$ \\
\hline & \multicolumn{2}{|c|}{ OCPOBER } & \multicolumn{2}{|c|}{ NOVEMBER } & \multicolumn{2}{|c|}{ DECEMBER } & \multicolumn{2}{|c|}{ JANUARY } & \multicolumn{2}{|c|}{ FEBRUARY } & \multicolumn{2}{|c|}{ MARCH } \\
\hline $\begin{array}{l}1 \\
2 \\
3 \\
4 \\
5\end{array}$ & $\begin{array}{l}35 \\
40 \\
40 \\
42 \\
45\end{array}$ & $\begin{array}{l}32 \\
38 \\
33 \\
31 \\
31\end{array}$ & $\begin{array}{r}3050 \\
1390 \\
2100 \\
730 \\
640\end{array}$ & $\begin{array}{r}151000 \\
83300 \\
74800 \\
12700 \\
7900\end{array}$ & $\begin{array}{l}17 \\
18 \\
16 \\
11 \\
12\end{array}$ & $\begin{array}{l}56 \\
56 \\
47 \\
29 \\
28\end{array}$ & $\begin{array}{r}1190 \\
620 \\
107 \\
25 \\
35\end{array}$ & $\begin{array}{r}11200 \\
4520 \\
722 \\
155 \\
208\end{array}$ & $\begin{array}{l}35 \\
43 \\
38 \\
24 \\
10\end{array}$ & $\begin{array}{l}67 \\
79 \\
69 \\
42 \\
17\end{array}$ & $\begin{array}{r}820 \\
730 \\
1460 \\
3490 \\
2710\end{array}$ & $\begin{array}{r}34800 \\
18400 \\
38700 \\
233000 \\
193000\end{array}$ \\
\hline $\begin{array}{r}6 \\
7 \\
8 \\
9 \\
10\end{array}$ & $\begin{array}{l}40 \\
40 \\
37 \\
37 \\
31\end{array}$ & $\begin{array}{l}27 \\
28 \\
26 \\
26 \\
23\end{array}$ & $\begin{array}{l}585 \\
359 \\
200 \\
154 \\
139\end{array}$ & $\begin{array}{r}5240 \\
2720 \\
1320 \\
919 \\
784\end{array}$ & $\begin{array}{l}10 \\
11 \\
10 \\
13 \\
14\end{array}$ & $\begin{array}{l}13 \\
13 \\
12 \\
15 \\
19\end{array}$ & $\begin{array}{l}47 \\
55 \\
60 \\
66 \\
45\end{array}$ & $\begin{array}{l}292 \\
371 \\
381 \\
392 \\
243\end{array}$ & $\begin{array}{r}17 \\
15 \\
12 \\
9 \\
14\end{array}$ & $\begin{array}{l}26 \\
22 \\
17 \\
13 \\
20\end{array}$ & $\begin{array}{r}1650 \\
1450 \\
1250 \\
940 \\
670\end{array}$ & $\begin{array}{r}101000 \\
62200 \\
39500 \\
28900 \\
16400\end{array}$ \\
\hline $\begin{array}{l}11 \\
12 \\
13 \\
14 \\
15\end{array}$ & $\begin{array}{l}27 \\
30 \\
32 \\
29 \\
51\end{array}$ & $\begin{array}{l}21 \\
31 \\
38 \\
31 \\
61\end{array}$ & $\begin{array}{l}159 \\
840 \\
500 \\
410 \\
319\end{array}$ & $\begin{array}{r}893 \\
7230 \\
3240 \\
2140 \\
1530\end{array}$ & $\begin{array}{r}20 \\
28 \\
24 \\
600 \\
525\end{array}$ & $\begin{array}{r}38 \\
68 \\
73 \\
3730 \\
4200\end{array}$ & $\begin{array}{r}56 \\
75 \\
121 \\
59 \\
43\end{array}$ & $\begin{array}{l}287 \\
324 \\
490 \\
231 \\
157\end{array}$ & $\begin{array}{l}16 \\
16 \\
17 \\
17 \\
17\end{array}$ & $\begin{array}{l}22 \\
22 \\
24 \\
24 \\
24\end{array}$ & $\begin{array}{l}960 \\
820 \\
505 \\
345 \\
279\end{array}$ & $\begin{array}{r}17300 \\
14000 \\
7500 \\
4480 \\
3260\end{array}$ \\
\hline $\begin{array}{l}16 \\
17 \\
18 \\
19 \\
20\end{array}$ & $\begin{array}{r}150 \\
440 \\
645 \\
2420 \\
1770\end{array}$ & $\begin{array}{r}303 \\
2340 \\
5050 \\
108000 \\
59700\end{array}$ & $\begin{array}{r}155 \\
132 \\
63 \\
55 \\
37\end{array}$ & $\begin{array}{l}695 \\
560 \\
252 \\
203 \\
129\end{array}$ & $\begin{array}{l}225 \\
140 \\
125 \\
318 \\
282\end{array}$ & $\begin{array}{r}1440 \\
786 \\
763 \\
2360 \\
1720\end{array}$ & $\begin{array}{l}60 \\
59 \\
54 \\
43 \\
17\end{array}$ & $\begin{array}{r}211 \\
191 \\
175 \\
134 \\
46\end{array}$ & $\begin{array}{r}12 \\
8 \\
44 \\
25 \\
30\end{array}$ & $\begin{array}{l}17 \\
12 \\
72 \\
50 \\
85\end{array}$ & $\begin{array}{l}241 \\
265 \\
193 \\
175 \\
164\end{array}$ & $\begin{array}{l}2550 \\
2570 \\
1710 \\
1440 \\
1250\end{array}$ \\
\hline $\begin{array}{l}21 \\
22 \\
23 \\
24 \\
25\end{array}$ & $\begin{array}{r}1270 \\
760 \\
420 \\
260 \\
160\end{array}$ & $\begin{array}{r}21000 \\
9110 \\
3400 \\
1520 \\
756\end{array}$ & $\begin{array}{l}24 \\
22 \\
19 \\
22 \\
19\end{array}$ & $\begin{array}{l}80 \\
70 \\
58 \\
66 \\
56\end{array}$ & $\begin{array}{r}196 \\
169 \\
130 \\
105 \\
56\end{array}$ & $\begin{array}{l}953 \\
799 \\
632 \\
524 \\
499\end{array}$ & $\begin{array}{l}12 \\
20 \\
29 \\
40 \\
18\end{array}$ & $\begin{array}{l}29 \\
46 \\
66 \\
86 \\
38\end{array}$ & $\begin{array}{r}610 \\
1480 \\
1420 \\
1800 \\
1360\end{array}$ & $\begin{array}{r}7740 \\
79900 \\
84300 \\
109000 \\
78900\end{array}$ & $\begin{array}{r}142 \\
121 \\
117 \\
106 \\
74\end{array}$ & $\begin{array}{r}1010 \\
804 \\
742 \\
650 \\
434\end{array}$ \\
\hline $\begin{array}{l}26 \\
27 \\
28 \\
29 \\
30 \\
31\end{array}$ & $\begin{array}{r}131 \\
158 \\
428 \\
413 \\
320 \\
1490\end{array}$ & $\begin{array}{r}573 \\
747 \\
3760 \\
3690 \\
2470 \\
26900\end{array}$ & $\begin{array}{r}16 \\
40 \\
48 \\
33 \\
20 \\
--\end{array}$ & $\begin{array}{r}47 \\
141 \\
181 \\
119 \\
71 \\
--\end{array}$ & $\begin{array}{r}30 \\
42 \\
280 \\
1460 \\
1850 \\
1750\end{array}$ & $\begin{array}{r}275 \\
397 \\
2570 \\
18500 \\
33000 \\
24600\end{array}$ & $\begin{array}{l}11 \\
18 \\
29 \\
43 \\
35 \\
36\end{array}$ & $\begin{array}{l}23 \\
37 \\
61 \\
89 \\
71 \\
71\end{array}$ & $\begin{array}{r}1260 \\
1030 \\
760 \\
--- \\
---\end{array}$ & $\begin{array}{r}61200 \\
43100 \\
32600 \\
- \\
-\end{array}$ & $\begin{array}{r}72 \\
94 \\
214 \\
142 \\
97 \\
230\end{array}$ & $\begin{array}{r}406 \\
518 \\
1250 \\
832 \\
581 \\
1810\end{array}$ \\
\hline COTAL & $-\infty$ & 249796 & -- & 358444 & -- & 98215 & -- & 21347 & -- & 497464 & -- & 830997 \\
\hline
\end{tabular}


05474000 SKONK RIVER AT AUGUSTA, IA--Continued

WATER-QUALITY RECORDS

SUSPENDED-SEDIMENT, WATER YEAR OCTOBER 1984 TO SEPTEMBER 1985

\begin{tabular}{|c|c|c|c|c|c|c|c|c|c|c|c|c|}
\hline \multirow[t]{2}{*}{ DAY } & $\begin{array}{c}\text { MEAN } \\
\text { CONCEN- } \\
\text { TRATION } \\
\text { (MG/L) }\end{array}$ & $\begin{array}{l}\text { LOADS } \\
(\mathrm{T} / \mathrm{DAY})\end{array}$ & $\begin{array}{c}\text { MEAN } \\
\text { CONCEN- } \\
\text { TRATION } \\
\text { (MG/L) }\end{array}$ & $\begin{array}{l}\text { LOADS } \\
\text { (T/DAY) }\end{array}$ & $\begin{array}{l}\text { MEAN } \\
\text { CONCEN- } \\
\text { TRATION } \\
\text { (MG/L) }\end{array}$ & $\begin{array}{l}\text { LOADS } \\
\text { (T/DAY) }\end{array}$ & $\begin{array}{c}\text { MEAN } \\
\text { CONCEN- } \\
\text { TRATION } \\
\text { (MG/L) }\end{array}$ & $\begin{array}{l}\text { LOADS } \\
\text { (T/DAY) }\end{array}$ & $\begin{array}{l}\text { MEAN } \\
\text { CONCEN- } \\
\text { TRATION } \\
\text { (MG/L) }\end{array}$ & $\begin{array}{l}\text { LOADS } \\
\text { (T/DAY) }\end{array}$ & $\begin{array}{l}\text { MEAN } \\
\text { CONCEN- } \\
\text { TRATION } \\
\text { (MG/L) }\end{array}$ & $\begin{array}{l}\text { LOADS } \\
\text { (T/DAY) }\end{array}$ \\
\hline & \multicolumn{2}{|c|}{ APRIL } & \multicolumn{2}{|r|}{ MAY } & \multicolumn{2}{|c|}{ JUNE } & \multicolumn{2}{|c|}{ JULY } & \multicolumn{2}{|c|}{ AUGUST } & \multicolumn{2}{|c|}{ SEPTEMBER } \\
\hline $\begin{array}{l}1 \\
2 \\
3 \\
4 \\
5\end{array}$ & $\begin{array}{l}478 \\
350 \\
270 \\
225 \\
192\end{array}$ & $\begin{array}{l}4750 \\
3320 \\
2390 \\
1900 \\
1650\end{array}$ & $\begin{array}{l}94 \\
93 \\
95 \\
78 \\
72\end{array}$ & $\begin{array}{l}315 \\
311 \\
313 \\
251 \\
218\end{array}$ & $\begin{array}{l}181 \\
152 \\
145 \\
125 \\
105\end{array}$ & $\begin{array}{l}413 \\
288 \\
244 \\
186 \\
145\end{array}$ & $\begin{array}{r}80 \\
101 \\
96 \\
68 \\
64\end{array}$ & $\begin{array}{r}138 \\
166 \\
136 \\
80 \\
64\end{array}$ & $\begin{array}{l}545 \\
229 \\
185 \\
157 \\
117\end{array}$ & $\begin{array}{r}1490 \\
367 \\
139 \\
84 \\
57\end{array}$ & $\begin{array}{l}77 \\
63 \\
58 \\
59 \\
65\end{array}$ & $\begin{array}{r}114 \\
79 \\
63 \\
68 \\
81\end{array}$ \\
\hline $\begin{array}{r}6 \\
7 \\
8 \\
9 \\
10\end{array}$ & $\begin{array}{l}241 \\
249 \\
260 \\
220 \\
180\end{array}$ & $\begin{array}{l}2410 \\
2530 \\
2510 \\
1960 \\
1500\end{array}$ & $\begin{array}{l}72 \\
77 \\
60 \\
60 \\
65\end{array}$ & $\begin{array}{l}204 \\
205 \\
153 \\
150 \\
160\end{array}$ & $\begin{array}{l}88 \\
95 \\
71 \\
59 \\
75\end{array}$ & $\begin{array}{r}119 \\
139 \\
102 \\
78 \\
91\end{array}$ & $\begin{array}{l}69 \\
59 \\
59 \\
57 \\
42\end{array}$ & $\begin{array}{l}60 \\
46 \\
42 \\
37 \\
25\end{array}$ & $\begin{array}{r}99 \\
98 \\
118 \\
116 \\
247\end{array}$ & $\begin{array}{r}45 \\
51 \\
61 \\
43 \\
161\end{array}$ & $\begin{array}{l}78 \\
91 \\
77 \\
72 \\
91\end{array}$ & $\begin{array}{l}90 \\
93 \\
68 \\
55 \\
60\end{array}$ \\
\hline $\begin{array}{l}11 \\
12 \\
13 \\
14 \\
15\end{array}$ & $\begin{array}{r}135 \\
115 \\
100 \\
82 \\
83\end{array}$ & $\begin{array}{r}1070 \\
851 \\
694 \\
538 \\
511\end{array}$ & $\begin{array}{r}77 \\
5620 \\
3170 \\
1190 \\
820\end{array}$ & $\begin{array}{r}188 \\
98100 \\
33600 \\
8190 \\
6220\end{array}$ & $\begin{array}{r}91 \\
100 \\
103 \\
110 \\
113\end{array}$ & $\begin{array}{l}105 \\
122 \\
130 \\
126 \\
135\end{array}$ & $\begin{array}{l}35 \\
41 \\
45 \\
38 \\
48\end{array}$ & $\begin{array}{l}19 \\
23 \\
26 \\
22 \\
28\end{array}$ & $\begin{array}{l}185 \\
557 \\
249 \\
277 \\
180\end{array}$ & $\begin{array}{r}197 \\
2630 \\
733 \\
417 \\
173\end{array}$ & $\begin{array}{r}99 \\
105 \\
65 \\
77 \\
100\end{array}$ & $\begin{array}{r}65 \\
110 \\
61 \\
60 \\
66\end{array}$ \\
\hline $\begin{array}{l}16 \\
17 \\
18 \\
19 \\
20\end{array}$ & $\begin{array}{l}74 \\
55 \\
47 \\
63 \\
90\end{array}$ & $\begin{array}{l}428 \\
296 \\
233 \\
289 \\
386\end{array}$ & $\begin{array}{l}480 \\
305 \\
231 \\
170 \\
142\end{array}$ & $\begin{array}{r}2700 \\
1400 \\
892 \\
565 \\
418\end{array}$ & $\begin{array}{r}108 \\
102 \\
97 \\
88 \\
93\end{array}$ & $\begin{array}{l}127 \\
128 \\
124 \\
111 \\
119\end{array}$ & $\begin{array}{l}54 \\
58 \\
56 \\
64 \\
64\end{array}$ & $\begin{array}{l}27 \\
43 \\
59 \\
49 \\
35\end{array}$ & $\begin{array}{r}162 \\
138 \\
106 \\
95 \\
84\end{array}$ & $\begin{array}{r}110 \\
74 \\
50 \\
43 \\
36\end{array}$ & $\begin{array}{r}100 \\
89 \\
79 \\
72 \\
81\end{array}$ & $\begin{array}{l}58 \\
47 \\
40 \\
34 \\
36\end{array}$ \\
\hline $\begin{array}{l}21 \\
22 \\
23 \\
24 \\
25\end{array}$ & $\begin{array}{l}89 \\
84 \\
80 \\
85 \\
85\end{array}$ & $\begin{array}{l}363 \\
329 \\
307 \\
312 \\
303\end{array}$ & $\begin{array}{r}126 \\
114 \\
96 \\
71 \\
62\end{array}$ & $\begin{array}{l}340 \\
282 \\
225 \\
162 \\
132\end{array}$ & $\begin{array}{r}210 \\
2450 \\
1870 \\
765 \\
232\end{array}$ & $\begin{array}{r}275 \\
17100 \\
8430 \\
1800 \\
402\end{array}$ & $\begin{array}{l}73 \\
85 \\
84 \\
80 \\
82\end{array}$ & $\begin{array}{l}34 \\
36 \\
34 \\
29 \\
37\end{array}$ & $\begin{array}{l}75 \\
77 \\
70 \\
67 \\
76\end{array}$ & $\begin{array}{l}28 \\
26 \\
23 \\
21 \\
23\end{array}$ & $\begin{array}{r}88 \\
81 \\
74 \\
118 \\
308\end{array}$ & $\begin{array}{r}39 \\
36 \\
40 \\
178 \\
1090\end{array}$ \\
\hline $\begin{array}{l}26 \\
27 \\
28 \\
29 \\
30 \\
31\end{array}$ & $\begin{array}{r}72 \\
63 \\
61 \\
63 \\
74 \\
---\end{array}$ & $\begin{array}{l}255 \\
221 \\
206 \\
202 \\
236 \\
---\end{array}$ & $\begin{array}{l}109 \\
144 \\
127 \\
128 \\
485 \\
385\end{array}$ & $\begin{array}{r}217 \\
275 \\
246 \\
266 \\
1170 \\
928\end{array}$ & $\begin{array}{r}117 \\
91 \\
66 \\
44 \\
39 \\
--\end{array}$ & $\begin{array}{r}176 \\
114 \\
71 \\
43 \\
35 \\
-0\end{array}$ & $\begin{array}{r}83 \\
74 \\
81 \\
79 \\
80 \\
1040\end{array}$ & $\begin{array}{r}45 \\
35 \\
35 \\
41 \\
51 \\
2680\end{array}$ & $\begin{array}{r}84 \\
343 \\
328 \\
260 \\
160 \\
101\end{array}$ & $\begin{array}{r}44 \\
1320 \\
1330 \\
772 \\
367 \\
182\end{array}$ & $\begin{array}{r}205 \\
165 \\
141 \\
109 \\
95 \\
---\end{array}$ & $\begin{array}{l}396 \\
255 \\
237 \\
176 \\
142 \\
-\end{array}$ \\
\hline OTA & -- & 32950 & $-\infty$ & 158796 & $-\infty$ & 31478 & - & 4182 & -- & 11097 & -- & 3937 \\
\hline
\end{tabular}

TOTAL LOAD FOR YEAR: 2298703 TONS. 
05474000 SKUNK RIVER AT AUGUSTA, IA--Continued

WATER-QUALITY RECORDS

WATER QUALITY DATA, WATER YEAR OCTOBER 1984 TO SEPTEMBER 1985

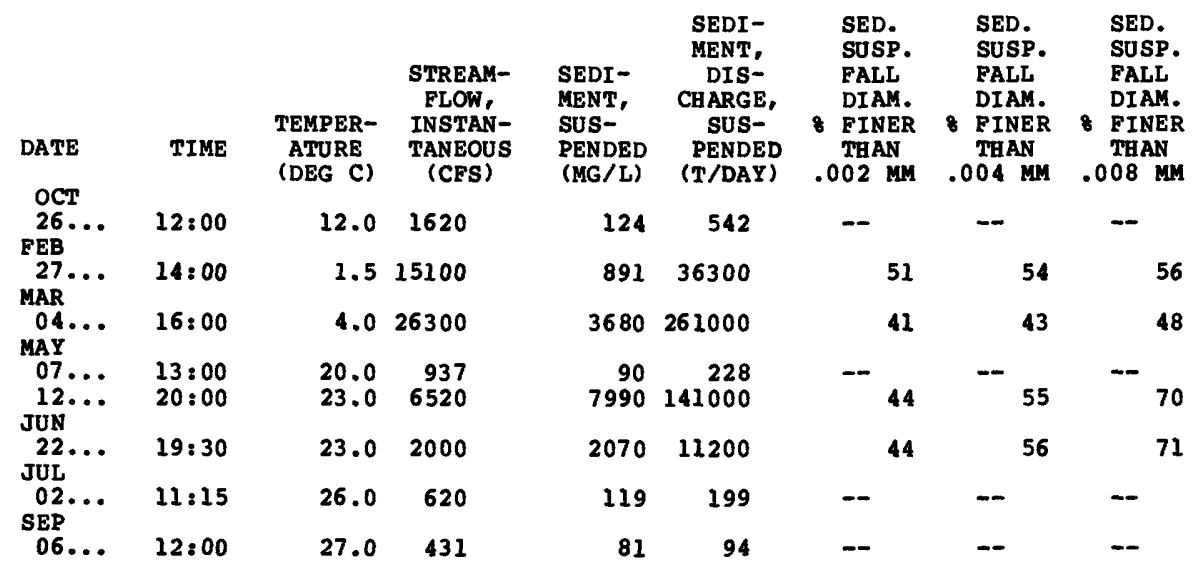
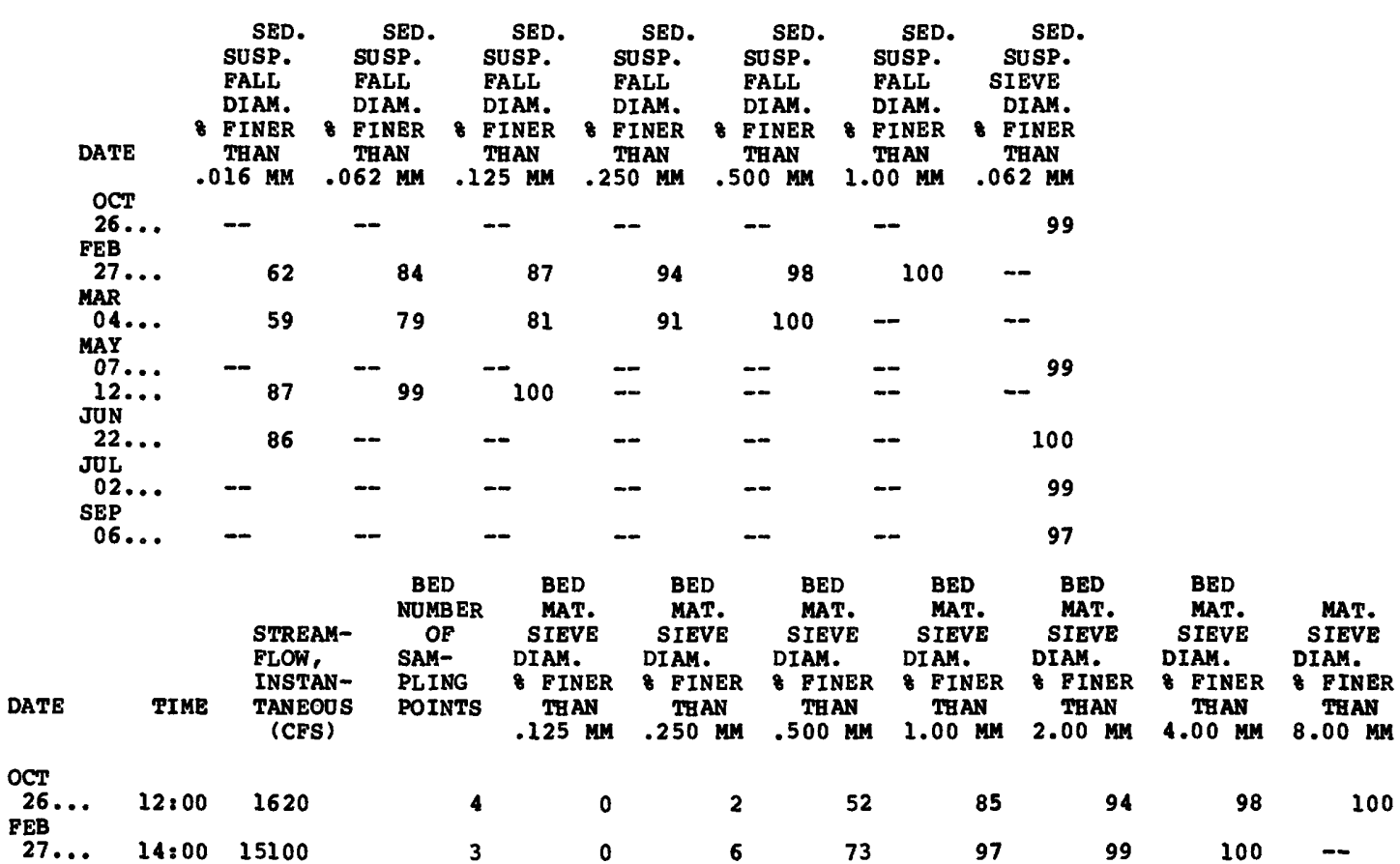

$\begin{array}{llll}4 & 0 & 2 & 52 \\ 3 & 0 & 6 & 73\end{array}$

85
97

94

$98 \quad 100$

73

99

100

$-$

\begin{tabular}{|c|c|c|c|c|c|c|c|c|c|c|c|c|c|}
\hline & DATE & TIRE & $\begin{array}{l}\text { STREAM- } \\
\text { FLOW, } \\
\text { INSTAN- } \\
\text { TANEOOS } \\
\text { (CFS) } \\
(00061) .\end{array}$ & $\begin{array}{l}\text { SPE- } \\
\text { CIFIC } \\
\text { CON- } \\
\text { DUCT- } \\
\text { ANCE } \\
\text { (US/CK) } \\
(00095)\end{array}$ & $\begin{array}{c}\text { PH } \\
\text { (STAND- } \\
\text { ARD } \\
\text { UNITS) } \\
(00400)\end{array}$ & $\begin{array}{l}\text { TEMPER- } \\
\text { ATURE } \\
\text { (DEG C) } \\
(00010)\end{array}$ & $\begin{array}{c}\text { TUR- } \\
\text { BID- } \\
\text { ITY } \\
\text { (NTU) } \\
(00076)\end{array}$ & $\begin{array}{c}\text { OXYGEN, } \\
\text { DIS- } \\
\text { SOLVED } \\
\text { (MG/L) } \\
(00300)\end{array}$ & $\begin{array}{c}\text { OXYGEN, } \\
\text { DIS- } \\
\text { SOLVED } \\
\text { (PER- } \\
\text { CENT } \\
\text { SATUR- } \\
\text { ATION) } \\
\text { (00301) }\end{array}$ & $\begin{array}{l}\text { BARO- } \\
\text { METRIC } \\
\text { PRES- } \\
\text { SURE } \\
\text { (MM } \\
\text { OE } \\
\text { BG) } \\
(00025)\end{array}$ & $\begin{array}{l}\text { COLI- } \\
\text { FORM, } \\
\text { FECAL, } \\
0.7 \\
\text { UM-ME, } \\
\text { (COLS., } \\
100 \text { ML) } \\
(31625)\end{array}$ & $\begin{array}{c}\text { STREP- } \\
\text { TOCOCCI } \\
\text { FECAL, } \\
\text { KF AGAR } \\
\text { (COLS. } \\
\text { PER } \\
100 \mathrm{ML}) \\
(31673)\end{array}$ & $\begin{array}{c}\text { HARD- } \\
\text { NESS, } \\
\text { NONCAR- } \\
\text { BONATE } \\
\text { (MG/L } \\
\text { CACO3) } \\
\text { (00902) }\end{array}$ \\
\hline OC? & $\begin{array}{c}1984 \\
26 . . .\end{array}$ & $12: 00$ & 1620 & 466 & 8.4 & 12.0 & 35 & 9.6 & 90 & 751 & 1400 & 1000 & 65 \\
\hline FEB & $1985 \ldots$ & $12: 30$ & 2180 & 442 & 7.8 & 0.0 & 150 & 14.3 & 100 & 750 & 2600 & $\mathrm{~K} 14000$ & 60 \\
\hline & MAY & $14: 00$ & 15100 & 238 & 7.8 & 1.5 & 290 & 12.9 & 94 & 750 & 1500 & K15000 & 50 \\
\hline & JUL 07. & $13: 00$ & 937 & 474 & 8.9 & 20.0 & 10 & -- & -- & 749 & K15 & K15 & 78 \\
\hline & $\underset{\text { SEP }}{02 \ldots}$ & $11: 15$ & 620 & 505 & 8.9 & 26.0 & 22 & 12.8 & 161 & 751 & $\mathbf{K 7 3}$ & R56 & 52 \\
\hline & & $12: 00$ & 431 & 514 & 8.8 & 27.0 & 30 & 8.3 & 106 & 750 & K48 & 120 & 62 \\
\hline
\end{tabular}

x Results based on colony count outside ideal range. 
WATER-QUALITY RECORDS

WATER QUALITY DATA, WATER YEAR OCTOBER 1984 TO SEPTEMBER 1985

DATE

$\begin{array}{cc}\text { HARD- } & \text { CALCIUM } \\ \text { NESS } & \text { DIS- } \\ \text { (MG/L } & \text { SOLVED } \\ \text { AS } & (\text { KG/L } \\ \text { CACO3) } & \text { AS CA) } \\ (00900) & (00915)\end{array}$

MAGNE-

SIUM, SODIUM,

DIS- DIS-

SOLVED SOLVED

(MG/L (MG/L

AS MG) AS NA
$(00925) \quad(00930)$

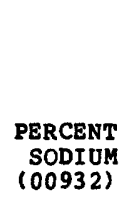

$\begin{array}{ccc}\begin{array}{c}\text { SODIUM } \\ \text { AD- }\end{array} & \begin{array}{c}\text { POTAS- } \\ \text { SIUM, }\end{array} & \begin{array}{c}\text { ALKA- } \\ \text { LINITY }\end{array} \\ \text { SORP- } & \text { DIS- } & \text { FIELD } \\ \text { TION } & \text { SOLVED } & \text { (MG/L } \\ \text { RATIO } & (M G / L & \text { AS } \\ & \text { AS R) } & \text { CACO3) } \\ (00931) & (00935) & (00410)\end{array}$

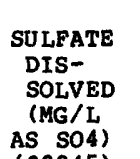

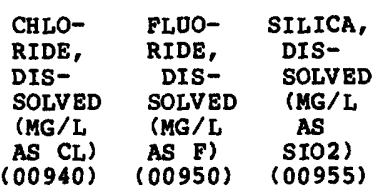

OCT 198

$26 . \ldots \quad 230 \quad 58$

DEC

$20 \ldots$

200

$$
50
$$

20

11
12
5.2
14
16
12

9
11
8
11
13
9

\begin{tabular}{rrrrr}
0.3 & 5.8 & \multicolumn{1}{c}{-} & 47 & 16 \\
0.4 & 3.5 & 139 & 45 & 16 \\
0.2 & 6.0 & 66 & 23 & 11 \\
0.4 & 2.5 & 159 & 58 & 19 \\
0.5 & 3.0 & 183 & 57 & 22 \\
0.3 & 4.5 & 190 & 40 & 20
\end{tabular}

16

$\begin{array}{cc}0.3 & 15 \\ <0.1 & 11 \\ 0.2 & 10 \\ 0.3 & 3.5 \\ 0.3 & 4.3 \\ 0.4 & 15\end{array}$

SOLIDS, SOLIDS, RESIDUE SUM OF AT 180 CONSTIDIS- DIS-

SOLVED SOLVED

(MG/L) (MG/L)

(70300) (70301)

$\begin{array}{cc}\text { SOLIDS, } & \text { SOLIDS, } \\ \text { DIS- } & \text { DIS- } \\ \text { SOLVED } & \text { SOLVED } \\ \text { (TONS } & \text { (TONS } \\ \text { PER } & \text { PER } \\ \text { AC-FT) } & \text { DAY) } \\ (70303) & (70302)\end{array}$

$\begin{array}{ccc}\text { NITRO- } & \text { NITRO- } & \text { NITRO- } \\ \text { GEN, } & \text { GEN, } & \text { GEN, } \\ \text { NO2+NO3 } & \text { AMMONIA } & \text { AMMONIA } \\ \text { DIS- } & \text { DIS- } & \text { DIS- } \\ \text { SOLVED } & \text { SOLVED } & \text { SOLVED } \\ \text { (MG/L } & \text { (MG/L } & \text { (MG/L } \\ \text { AS N) } & \text { AS N) } & \text { AS NH4) } \\ (00631) & (00608) & (71846)\end{array}$

NITRO-
GEN, AM-
MONIA +
ORGANIC
TOTAL
(MG/L
AS N)
$(00625)$

PHOSPHORUS, ORTHO, DISSOLVED (MG/L (70303) (70302)

$(00608)$

OCT 1984

$26 \ldots 281 \quad 270$

(00671)

As

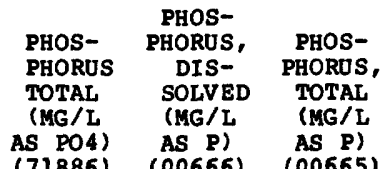

(71886)

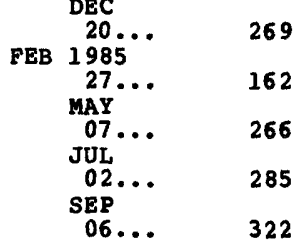

$\begin{array}{rr}0.38 & 1230 \\ 0.37 & 1580 \\ 0.22 & 6600 \\ 0.36 & 673 \\ 0.39 & 477 \\ 0.44 & 375\end{array}$

$\begin{array}{ll}4.90 & 0.09 \\ 5.60 & 0.26 \\ 4.30 & 0.62 \\ 2.60 & 0.03 \\ 0.36 & 0.04 \\ 4.00 & 0.05\end{array}$

0.12
0.33
0.8
0.04
0.05
0.06

2.1

2.1
2.2
2.9
2.1
2.1
2.1

BERYL-
IUM,
DIS-
SOLVED
(UG/L
AS BE)
OIOIO)

\begin{abstract}
0.04
\end{abstract}
0.11

0.13

$<0.01$

0.03

0.13

SEDI- SED. SED.

\begin{tabular}{|c|c|c|c|c|}
\hline $\begin{array}{l}\text { SEDI- } \\
\text { MENT, } \\
\text { SUS- } \\
\text { PENDED } \\
\text { (MG/L) } \\
(80154)\end{array}$ & $\begin{array}{c}\text { DIS- } \\
\text { CHARGE, } \\
\text { SUS- } \\
\text { PENDED } \\
\text { (T/DAY) } \\
\text { (80155) }\end{array}$ & $\begin{array}{c}\text { SIEVE } \\
\text { DIAM. } \\
\text { 8 EINER } \\
\text { THAN } \\
.062 \mathrm{MM} \\
(70331)\end{array}$ & $\begin{array}{l}\text { FALL } \\
\text { DIAM. } \\
\text { FINER } \\
\text { THAN } \\
.062 \mathrm{MM} \\
(70342)\end{array}$ & $\begin{array}{c}\text { ARSENIC } \\
\text { DIS- } \\
\text { SOLVED } \\
\text { (UG/L } \\
\text { AS AS) } \\
(01000)\end{array}$ \\
\hline
\end{tabular}

ALUM-

INUM, BARIUM, BERYL DIS- DISSOLVED SOLVED (UG/L

\section{AS AL) AS BA)} (01106) (01005)
(010)

\section{CADMIUM SOLVED (UG/L) AS $C D$ )} (01025)

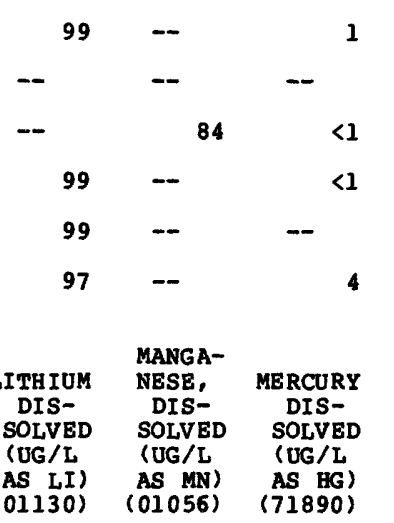

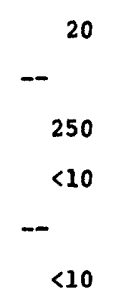

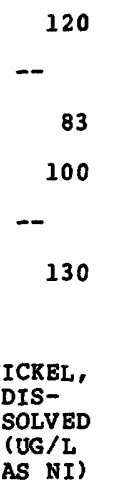

MOLYB-

DENUM, NICR

DIS-

(UG/L

AS NO) AS NI

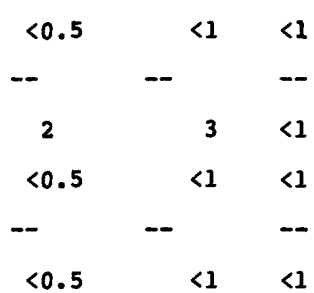

SELENIUM, DIS(UG/L) AS SE) AS SE)
$(01145)$

$\begin{array}{lll}-- & 0.18 & 0.29 \\ -- & 0.13 & 0.52 \\ -- & 0.15 & 0.72 \\ -- & 0.01 & 0.17 \\ 0.77 & 0.04 & 0.25 \\ 0.74 & 0.15 & 0.24\end{array}$

CHROCHRO-
MIUM,
DIS-
DISSOLVED SOLVED SOLVED (UG/L (UG/L (UG/L AS CR) AS CO) AS CU) $\begin{array}{lll}(01030) & (01035) \quad(01040)\end{array}$

OCT 1984

26.

1985

27 .

MAY 07 .

JUL

SEP

DATE

$\begin{array}{ccc}\text { DIS- } & \text { DIS- } & \text { DIS } \\ \text { SOLVED } & \text { SOLVED } & \text { SOLVED } \\ \text { (UG/L } & \text { (UG/L } & \text { (UG/L }\end{array}$

$\begin{array}{cc}\text { AS FE) } & \text { AS PB) } \\ (01046) & (01049)\end{array}$

(01060) (01065)

$<1$
$<-$
$<1$
$<1$
--
$<1$

TRON-
TIUM,
DIS-
SOLVED
UG/L
AS SR)
IO80) (OSO

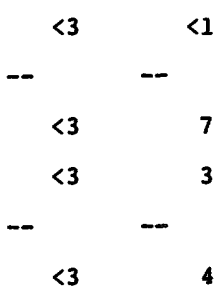

VANA-

DIUH, ZINC, DIS- DIS(UG/L (UG/L $\begin{array}{cccc}(U G / L & (U G / L & (U G / L & (U G / L \\ \text { AS AG) } & \text { AS SR) } & \text { AS V) } & \text { AS ZN }) \\ (01075) & (01080) & (01085) & (01090)\end{array}$

OCT 1984

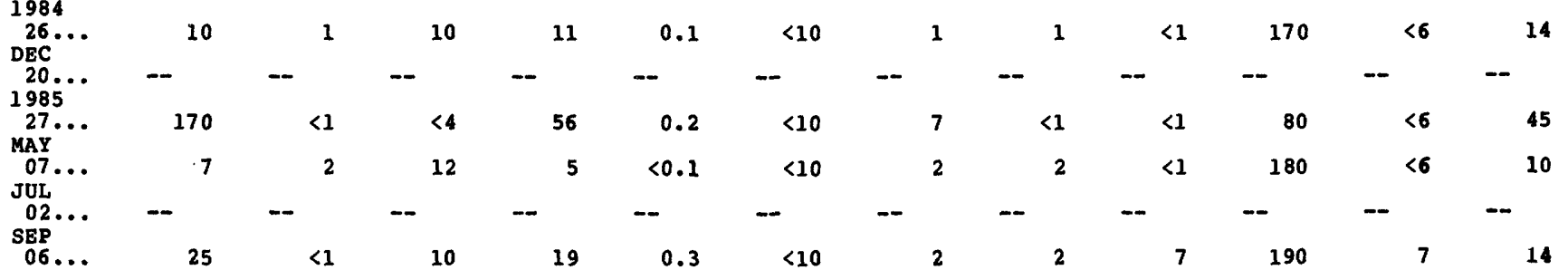


05474500 MISSISSIPPI RIVER AT REOKUK, IA

(National stream-quality accounting network station)

LOCATION,--Lat $40^{\circ} 23^{\prime} 37^{\prime \prime}$, long $91^{\circ} 22^{\prime 2} 27^{\prime \prime}$, in SEI/4 SwL/4 sec.30, T.65 N., R.4 W., Lee County, Hydrologic Onit 07080104 , near right bank in tailwater of dam and powerplant of onion Electric Co. at Reokuk, 0.2 mi upstream from bridge on U.S. Highway $136,2.7 \mathrm{mi}$ upstream from Des Moines River, and at mile 364.2 upstream from Ohio River.

DRAINAGE AREA. $--119,000 \mathrm{mi}^{2}$, approximately.

WATER-DISCHARGE RECORDS

PERIOD OF RECORD.--January 1878 to current year.

GAGE.--Water-stage recorder. Datum of gage is $477.41 \mathrm{ft}$ above NGVD (levels by U.S. Army Corps of Engineers), Jan. 1, 1978, to May 1913, nonrecording gage at Galland (formerly Nashville), $8 \mathrm{mi}$ upstreami zero of gage was set to low-water mark of 1864 , or $496.52 \mathrm{ft}$ above NGVD.

REMARKS.--Discharge computed from records of operation of turbines in powerplant and spillway gates in dam. Minor flow regulation caused by powerplant since 1913 and navigation dams. Records for May 1913 to september 1937 adjusted for change in contents in Keokuk Reservoir, those after September 1937 unadjusted.

COOPERATION.--Records provided by Union Electric Co.

AVERAGE DISCHARGE.-- 107 years, $63,790 \mathrm{ft} / 8,7.28 \mathrm{in} / \mathrm{yr}, 46,220,000 \mathrm{acre}-\mathrm{ft} / \mathrm{yr}$.

EXTREMES FOR PERIOD OF RECORD,--Maximum daily discharge, 344,000 ft/8 Apr. 24, 1973, maximum gage height, $23.35 \mathrm{ft}$ Apr. 24, 1973, minimum daily discharge, 5,000 ft $/ 8$ Dec. $27,1933$.

EXTREMES OOTSIDE PERIOD OF RECORD,--Fiood of June 6, 1851, reached a stage of 21.0 ft, present site and datum, estimated as $13.5 \mathrm{ft}$ at Galland, discharge, $360.000 \mathrm{ft}^{\circ} / \mathrm{s}$.

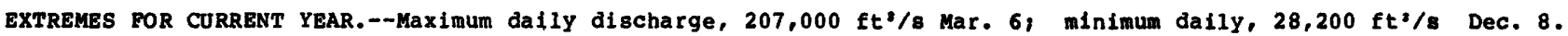

DISCHARGE, IN CUBIC FEET PER SECOND, WATER YEAR OCTOBER 1984 TO SEPTEMBER 1985 MEAN VALOES

\begin{tabular}{|c|c|c|c|c|c|c|c|c|c|c|c|c|}
\hline DAY & OCT & NOV & DEC & JAN & FEB & MAR & APR & MAY & JON & JOL & AOG & SEP \\
\hline $\begin{array}{l}1 \\
2 \\
3 \\
4 \\
5\end{array}$ & $\begin{array}{l}42000 \\
44100 \\
45500 \\
47700 \\
49500\end{array}$ & $\begin{array}{l}143000 \\
142000 \\
141000 \\
130000 \\
126000\end{array}$ & $\begin{array}{l}63200 \\
61900 \\
65200 \\
66700 \\
68000\end{array}$ & $\begin{array}{r}108000 \\
75000 \\
50200 \\
46400 \\
47200\end{array}$ & $\begin{array}{l}46900 \\
48400 \\
46400 \\
46000 \\
45600\end{array}$ & $\begin{array}{l}179000 \\
167000 \\
165000 \\
204000 \\
205000\end{array}$ & $\begin{array}{l}147000 \\
145000 \\
152000 \\
157000 \\
159000\end{array}$ & $\begin{array}{l}120000 \\
116000 \\
117000 \\
117000 \\
119000\end{array}$ & $\begin{array}{l}83900 \\
80500 \\
74700 \\
71100 \\
70100\end{array}$ & $\begin{array}{l}56900 \\
56100 \\
55800 \\
53400 \\
54200\end{array}$ & $\begin{array}{l}53000 \\
51800 \\
50000 \\
45700 \\
38800\end{array}$ & $\begin{array}{l}42900 \\
45700 \\
44400 \\
46400 \\
48900\end{array}$ \\
\hline $\begin{array}{r}6 \\
7 \\
8 \\
9 \\
10\end{array}$ & $\begin{array}{l}48700 \\
44100 \\
41500 \\
41500 \\
41600\end{array}$ & $\begin{array}{l}124000 \\
121000 \\
120000 \\
120000 \\
119000\end{array}$ & $\begin{array}{l}59600 \\
36500 \\
28200 \\
36200 \\
38700\end{array}$ & $\begin{array}{l}49900 \\
65400 \\
75100 \\
78100 \\
76100\end{array}$ & $\begin{array}{l}45500 \\
44500 \\
43000 \\
42300 \\
42300\end{array}$ & $\begin{array}{l}207000 \\
200000 \\
184000 \\
169000 \\
163000\end{array}$ & $\begin{array}{l}162000 \\
167000 \\
171000 \\
173000 \\
176000\end{array}$ & $\begin{array}{l}122000 \\
122000 \\
126000 \\
125000 \\
124000\end{array}$ & $\begin{array}{l}67700 \\
69700 \\
69300 \\
66800 \\
64600\end{array}$ & $\begin{array}{l}57300 \\
61300 \\
64200 \\
64300 \\
64000\end{array}$ & $\begin{array}{l}36800 \\
36500 \\
36800 \\
37600 \\
36500\end{array}$ & $\begin{array}{r}41800 \\
42200 \\
50500 \\
52000 \\
55000\end{array}$ \\
\hline $\begin{array}{l}11 \\
12 \\
13 \\
14\end{array}$ & $\begin{array}{l}41500 \\
41000 \\
37100 \\
38700 \\
44000\end{array}$ & $\begin{array}{r}119000 \\
124000 \\
120000 \\
106000 \\
92400\end{array}$ & $\begin{array}{l}41800 \\
46100 \\
55300 \\
64400 \\
67300\end{array}$ & $\begin{array}{l}70800 \\
67000 \\
61300 \\
58200 \\
58600\end{array}$ & $\begin{array}{l}41800 \\
42200 \\
40400 \\
39900 \\
39000\end{array}$ & $\begin{array}{l}167000 \\
159000 \\
154000 \\
150000 \\
144000\end{array}$ & $\begin{array}{l}178000 \\
174000 \\
168000 \\
164000 \\
160000\end{array}$ & $\begin{array}{l}123000 \\
125000 \\
129000 \\
122000 \\
120000\end{array}$ & $\begin{array}{l}63600 \\
63600 \\
68100 \\
71100 \\
70900\end{array}$ & $\begin{array}{l}64800 \\
64700 \\
63700 \\
65800 \\
61300\end{array}$ & $\begin{array}{l}36800 \\
36800 \\
36100 \\
36500 \\
44000\end{array}$ & $\begin{array}{l}59400 \\
65500 \\
66400 \\
64900 \\
65300\end{array}$ \\
\hline $\begin{array}{l}16 \\
17 \\
18 \\
19\end{array}$ & $\begin{array}{l}46400 \\
51600 \\
59900 \\
84900 \\
96300\end{array}$ & $\begin{array}{l}89600 \\
89500 \\
94100 \\
91800 \\
91000\end{array}$ & $\begin{array}{l}67800 \\
67000 \\
74100 \\
79700 \\
81000\end{array}$ & $\begin{array}{l}60700 \\
59600 \\
57300 \\
55400 \\
52200\end{array}$ & $\begin{array}{l}38300 \\
39100 \\
39100 \\
39000 \\
38600\end{array}$ & $\begin{array}{l}140000 \\
143000 \\
140000 \\
139000 \\
137000\end{array}$ & $\begin{array}{l}154000 \\
149000 \\
142000 \\
135000 \\
128000\end{array}$ & $\begin{array}{r}118000 \\
115000 \\
110000 \\
104000 \\
99400\end{array}$ & $\begin{array}{l}70400 \\
64800 \\
63600 \\
59700 \\
57900\end{array}$ & $\begin{array}{l}62700 \\
61100 \\
54500 \\
50200 \\
48700\end{array}$ & $\begin{array}{l}47600 \\
48500 \\
49600 \\
49000 \\
50900\end{array}$ & $\begin{array}{l}66100 \\
72000 \\
75500 \\
75600 \\
73800\end{array}$ \\
\hline $\begin{array}{l}21 \\
22 \\
23 \\
24 \\
25\end{array}$ & $\begin{array}{l}97500 \\
91800 \\
82100 \\
78200 \\
84500\end{array}$ & $\begin{array}{l}88200 \\
82400 \\
75600 \\
64300 \\
63800\end{array}$ & $\begin{array}{l}74900 \\
67000 \\
64300 \\
64400 \\
51000\end{array}$ & $\begin{array}{l}48400 \\
48500 \\
46000 \\
45000 \\
44800\end{array}$ & $\begin{array}{r}43600 \\
80000 \\
113000 \\
133000 \\
151000\end{array}$ & $\begin{array}{l}136000 \\
132000 \\
128000 \\
126000 \\
124000\end{array}$ & $\begin{array}{l}122000 \\
119000 \\
117000 \\
118000 \\
119000\end{array}$ & $\begin{array}{l}98200 \\
97200 \\
87700 \\
90800 \\
88500\end{array}$ & $\begin{array}{l}59500 \\
66300 \\
58400 \\
57800 \\
60600\end{array}$ & $\begin{array}{l}40400 \\
40800 \\
43300 \\
41800 \\
34600\end{array}$ & $\begin{array}{l}54300 \\
54400 \\
49500 \\
44300 \\
40300\end{array}$ & $\begin{array}{l}74500 \\
75000 \\
70200 \\
70000 \\
69200\end{array}$ \\
\hline $\begin{array}{l}26 \\
27 \\
28 \\
29 \\
30\end{array}$ & $\begin{array}{r}90200 \\
93200 \\
101000 \\
101000 \\
102000 \\
107000\end{array}$ & $\begin{array}{r}65500 \\
67300 \\
69300 \\
66400 \\
64100 \\
-\end{array}$ & $\begin{array}{r}43200 \\
43000 \\
53800 \\
80200 \\
98900 \\
121000\end{array}$ & $\begin{array}{l}46400 \\
46200 \\
46500 \\
46400 \\
47600 \\
48800\end{array}$ & $\begin{array}{r}191000 \\
205000 \\
189000 \\
\ldots- \\
\ldots-\end{array}$ & $\begin{array}{l}124000 \\
125000 \\
127000 \\
129000 \\
136000 \\
137000\end{array}$ & $\begin{array}{r}122000 \\
123000 \\
119000 \\
118000 \\
117000\end{array}$ & $\begin{array}{l}86200 \\
89200 \\
85700 \\
85400 \\
86300 \\
86600\end{array}$ & $\begin{array}{r}58400 \\
56700 \\
58300 \\
56700 \\
58600\end{array}$ & $\begin{array}{l}00 \\
00 \\
00 \\
00 \\
00 \\
00\end{array}$ & $\begin{array}{l}40300 \\
42900 \\
46700 \\
45700 \\
43400 \\
43300\end{array}$ & $\begin{array}{r}71800 \\
67900 \\
70700 \\
70600 \\
70300 \\
-\end{array}$ \\
\hline $\begin{array}{l}\text { TOTAL } \\
\text { MEAN } \\
\text { MAX } \\
\text { MIN } \\
\text { CESM } \\
\text { IN. } \\
\text { AC-FT }\end{array}$ & $\begin{array}{r}2016100 \\
65040 \\
107000 \\
37100 \\
.55 \\
.63 \\
3999000\end{array}$ & $\begin{array}{r}3010300 \\
100300 \\
143000 \\
63800 \\
.84 \\
.94 \\
5971000\end{array}$ & $\begin{array}{r}1930400 \\
62270 \\
121000 \\
28200 \\
.52 \\
.60 \\
3829000\end{array}$ & $\begin{array}{r}1787100 \\
57650 \\
108000 \\
44800 \\
.48 \\
.56 \\
3545000\end{array}$ & $\begin{array}{r}1953900 \\
69780 \\
205000 \\
38300 \\
.59 \\
.61 \\
3876000\end{array}$ & $\begin{array}{r}4740000 \\
152900 \\
207000 \\
124000 \\
1.28 \\
1.48 \\
9402000\end{array}$ & $\begin{array}{r}4355000 \\
145200 \\
178000 \\
117000 \\
1.22 \\
1.36 \\
8638000\end{array}$ & $\begin{array}{r}3355200 \\
108200 \\
129000 \\
85400 \\
.91 \\
1.05 \\
6655000\end{array}$ & $\begin{array}{r}1963400 \\
65450 \\
83900 \\
56700 \\
.55 \\
.61 \\
3894000\end{array}$ & $\begin{array}{r}1647700 \\
53150 \\
65800 \\
32800 \\
.45 \\
.52 \\
3268000\end{array}$ & $\begin{array}{r}1364400 \\
44010 \\
54400 \\
36100 \\
.37 \\
.43 \\
2706000\end{array}$ & $\begin{array}{r}1864500 \\
62150 \\
75600 \\
41800 \\
.52 \\
.58 \\
3698000\end{array}$ \\
\hline
\end{tabular}

CAL YR 1984 TOTAL 35066800 MEAN 95810 MAX 192000 MIN 22700 CESH WTR YR 1985 TOTAL 29988000 MEAN 82160 MAX 207000 MIN 28200 CFS

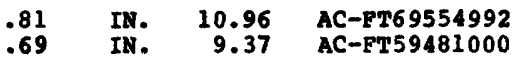


WATER-QUALITY RECORDS

LOCATION.--Samples collected at public access $0.5 \mathrm{mi}$ downstream from discharge station.

PERIOD OF RECORD.--Water years 1975 to current year.

PERIOD OF DAILY RECORD.--

SPECIFIC CONDUCTANCE: December 1977 to September 1981.

WATER TEMPERATURES: December 1977 to September 1981 .

EXTREMES FOR PERIOD OF DAILY RECORD,--

SPECIEIC CONDUCTANCE: Maximum daily, 612 microsiemens Jan. 21, 1980; minimum daily, 310 microsiemens Apr. 7 , 1981. WATER TEMPERATURES: Maximum daily, $28.0^{\circ} \mathrm{C}$ July $13-23$, i980; minimum daily, $0.0^{\circ} \mathrm{C}$ on many days during winter periods.

WATER QUALITY DATA, WATER YEAR OCTOBER 1984 TO SEPTEMBER 1985

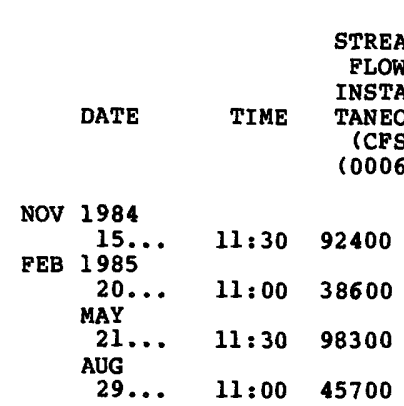

NOV 1984

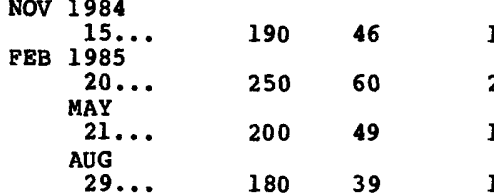
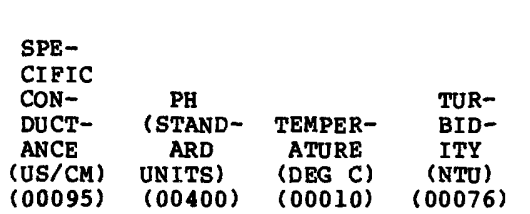

$\begin{array}{cc} & \text { OXYGEN, } \\ & \text { DIS- } \\ & \text { SOLVED } \\ \text { OXYGEN, } & \text { (PER- } \\ \text { DIS- } & \text { CENT } \\ \text { SOLVED } & \text { SATUR- } \\ \text { (MG/L) } & \text { ATION) } \\ (00300) & (00301)\end{array}$
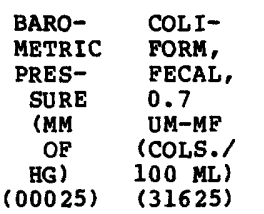

STREPTOCOCCI FECAL, KE AGAR KE AGA (COLS. PER (00025)

(31673)

$\begin{array}{ccc} & \text { HARD- } & \text { CALCIUM } \\ & \text { NESS } & \text { DIS- } \\ \text { (MG/L } & \text { SOLVED } \\ \text { DATE } & \text { AS } & \text { (MG/L } \\ \text { CACO3) } & \text { AS CA) } \\ & (00900) & (00915)\end{array}$

$\begin{array}{ll}364 & 7.9 \\ 472 & 8.0 \\ 358 & 8.0 \\ 348 & 8.2\end{array}$

$\begin{array}{rc}6.5 & 62 \\ 0.0 & 2.6 \\ 19.5 & 28 \\ 23.0 & 3.8\end{array}$

$\begin{array}{rr}11.3 & 93 \\ 13.5 & 93 \\ 9.1 & 100 \\ 7.1 & 84\end{array}$

MAGNE-

SIUM, SODIUM DISSOLVED (MG/L AS MG) (00925)
DIS-

SOLVED
(MG/L

AS NA)

(00930)

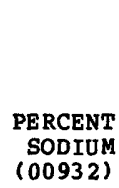
ADSORP-

TION

RATIO

$(00932)$

(00931)

$\begin{array}{lc}\text { POTAS- } & \text { ALRA- } \\ \text { SIUM, } & \text { LINITY } \\ \text { DIS- } & \text { FIELD } \\ \text { SOLVED } & \text { (MG/L } \\ \text { (MG/L } & \text { AS } \\ \text { AS R) } & \text { CACO3) } \\ (00935) & (00410)\end{array}$

751
754
753
750


DLEATE
SOLVED
(MG/L
SO4)
OOS45)

1000
640
$K 54$
$K 15$

CHLO-
RIDE,
DIS-
SOLVED
(MG/L
AS CL)
OO940)

2000

80$$
\text { K43 }
$$$$
\text { K67 }
$$

$\begin{array}{cc}18 & 8.8 \\ 24 & 12 \\ 19 & 7.9 \\ 19 & 9.7\end{array}$

$\begin{array}{ll}0.3 & 3.0 \\ 0.3 & 2.5 \\ 0.3 & 3.0 \\ 0.3 & 2.3\end{array}$

141
194
170
141

30
39
39
25
18
12

15

11
BARDNESS, NONCARBONATE (MG/L

CACO3 (00902)

$$
55
$$$$
31
$$
ELUO- SILICA, RIDE, DIS- DIS- SOLVED SOLVED (MG/L (MG/L AS AS F) STO2) (00950) (00955)

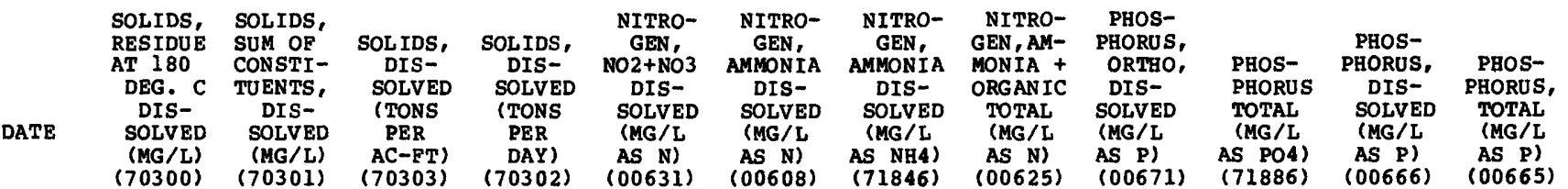

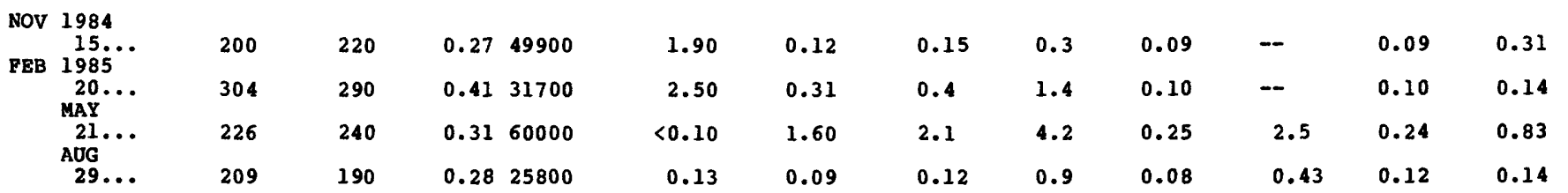

R Results based on colony count outside ideal range. 
05474500 MISSISSIPPI RIVER AT REOKUR, IA--Continued

WATER-QUALITY RECORDS

WATER QUALITY DATA, WATER YEAR OCTOBER 1984 TO SEPTBMBER 1985

\begin{tabular}{|c|c|c|c|c|c|c|c|c|c|c|c|c|}
\hline DATE & $\begin{array}{l}\text { SEDI- } \\
\text { MENT, } \\
\text { SUS- } \\
\text { PENDED } \\
\text { (MG/L) } \\
(80154)\end{array}$ & $\begin{array}{c}\text { SEDI- } \\
\text { MENT, } \\
\text { DIS- } \\
\text { CEARGE, } \\
\text { SUS- } \\
\text { PENDED } \\
\text { (T/DAY) } \\
(80155)\end{array}$ & $\begin{array}{c}\text { SED. } \\
\text { SUSP. } \\
\text { SIEVE } \\
\text { DIAM. } \\
\text { FINER } \\
\text { THAN } \\
.062 \mathrm{MM} \\
(70331)\end{array}$ & $\begin{array}{c}\text { ARSEN IC } \\
\text { DIS- } \\
\text { SOEVED } \\
\text { (UG/L } \\
\text { AS AS) } \\
(01000)\end{array}$ & $\begin{array}{c}\text { ALUM- } \\
\text { INUM, } \\
\text { DIS- } \\
\text { SOLVED } \\
\text { (UG/L } \\
\text { AS AL) } \\
\text { (01106) }\end{array}$ & $\begin{array}{l}\text { BARIUM, } \\
\text { DIS- } \\
\text { SOLVED } \\
\text { (UG/L } \\
\text { AS BA) } \\
(01005)\end{array}$ & $\begin{array}{l}\text { BERYL- } \\
\text { LIUM, } \\
\text { DIS- } \\
\text { SOLVED } \\
\text { (UG/L } \\
\text { AS BE) } \\
(01010)\end{array}$ & $\begin{array}{c}\text { CADMIUM } \\
\text { DIS- } \\
\text { SOLVED } \\
\text { (UG/L } \\
\text { AS CD) } \\
(01025)\end{array}$ & $\begin{array}{l}\text { CHRO- } \\
\text { MIUH, } \\
\text { DIS- } \\
\text { SOLVED } \\
\text { (UG/L } \\
\text { AS CR) } \\
(01030)\end{array}$ & $\begin{array}{l}\text { COBALT, } \\
\text { DIS- } \\
\text { SOLVED } \\
\text { (UG/L } \\
\text { AS CO) } \\
(01035)\end{array}$ & $\begin{array}{l}\text { COPPER, } \\
\text { DIS- } \\
\text { SOLVED } \\
\text { (UG/L } \\
\text { AS CU) } \\
(01040)\end{array}$ & $\begin{array}{l}\text { IRON, } \\
\text { DIS- } \\
\text { SOLVED } \\
\text { (UG/L } \\
\text { AS FE) } \\
(01046)\end{array}$ \\
\hline
\end{tabular}

NOV 1984

\begin{tabular}{|c|c|c|c|c|c|c|c|c|c|c|c|c|}
\hline $15 \ldots$ & 193 & 48100 & 99 & $<1$ & 20 & 56 & $<0.5$ & $<1$ & $<1$ & $<3$ & 2 & 63 \\
\hline & 8 & 834 & 60 & $<1$ & 10 & 57 & $<0.5$ & $<1$ & $<1$ & $<3$ & 2 & 61 \\
\hline AUG & 68 & 18000 & 95 & $<1$ & $<10$ & 59 & 0.5 & 2 & $<1$ & $<3$ & 1 & 9 \\
\hline & 12 & 1480 & 89 & 2 & $<10$ & 42 & $<0.5$ & $<1$ & $<1$ & 3 & 4 & 7 \\
\hline
\end{tabular}

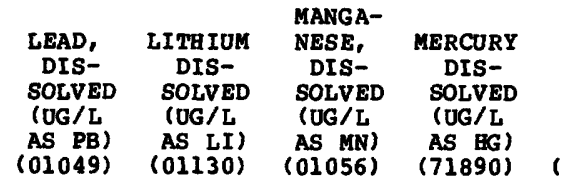

DENOM, NICKEL,

SELE- $\quad$ STRON- VANA-

NIUM, SILVER, TIUM, DIUM, ZINC,

DIS- DIS- DIS- DIS- DIS- DIS- DIS-

SOLVED SOLVED SOLVED SOLVED SOLVED SOLVED SOLVED

(UG/L (UG/L (UG/L (UG/L (UG/L (UG/L (UG/L

AS (10) AS NI) AS SE) AS AG) AS SR) AS V) AS ZN)

$\begin{array}{lllllllllll}(01049) & (01130) & (01056) & (71890) & (01060) & (01065) & (01145) & (01075) & (01080) & (01085) & (01090)\end{array}$

NOV 1984

\begin{tabular}{|c|c|c|c|c|c|c|c|c|c|c|c|c|}
\hline BB & $\begin{array}{l}15 \\
1985\end{array}$ & 3 & 6 & 4 & $<0.1$ & $<10$ & 1 & $<1$ & $<1$ & 87 & $<6$ & 12 \\
\hline & $20 \ldots$ & 2 & 7 & 38 & $<0.1$ & $<10$ & 6 & 1 & $<1$ & 110 & $<6$ & 4 \\
\hline & & 2 & 10 & 8 & $<0.1$ & $<10$ & 5 & 1 & $<1$ & 99 & $<6$ & 16 \\
\hline & $29 \ldots$ & $<1$ & 9 & 3 & $<0.1$ & $<10$ & 2 & $<1$ & $<1$ & 88 & $<6$ & 8 \\
\hline
\end{tabular}


05476500 DES MOINES RIVER AT ESTHERVILLE, IA

LOCATION.--Lat $43^{\circ} 23^{\prime} 51^{\prime \prime}$, long $94^{\circ} 50^{\prime} 38^{\prime}$, in SW $1 / 4$ SE1/4 sec.10, T.99 N., R.34 w., Emmet County, Bydrologic unit 07100002 , on right bank in city park, 1,200 ft downstream from bridge on State Highway 9 at Estherville, $0.1 \mathrm{mi}$ upstream from School Creek, 2.3 mi upstream from Brown Creek, and at mile 404.2.

DRAINAGE AREA. $--1,372 \mathrm{mi}^{2}$.

PERIOD OF RECORD.--October 1951 to current year. Prior to November 1951, monthly discharge only, published in wSP 1728 .

REVISED RECORDS.--WSP 1438: Drainage area.

GAGE.--Water-stage recorder and concrete control. Datum of gage is $1,247.55 \mathrm{ft}$ above NGVD.

REMARKS.--Estimated daily discharges: Jan. 26 to Feb. 19, and June 24 to July 1. Records good except for estimated discharges which are poor.

AVERAGE DISCBARGE. - -34 years, $372 \mathrm{ft} / \mathrm{s}, 3.68 \mathrm{in} / \mathrm{y}^{3}, 269,500$ acre-ft/yr, median of yearly mean discharges, 250 $\mathrm{ft} / \mathrm{s}, 2.5 \mathrm{in} / \mathrm{yr}, 181,000$ acre-ft/yr.

EXTREMES FOR PERIOD OF RECORD.--Maximum discharge, 16,000 ft'/s Apr. 12, 1969, gage height, $17.68 \mathrm{ft}$, from floodmark; no flow Jan. 16-18, 1977.

EXTREMES FOR CURRENT YEAR.--Peak discharges greater than base of $1,500 \mathrm{ft} / \mathrm{s}$ and maximum $(*)$ :

\begin{tabular}{|c|c|c|c|c|c|c|c|c|}
\hline $\begin{array}{l}\text { Date } \\
\text { Mar. } \\
\text { Mar. }\end{array}$ & $\begin{array}{l}13 \\
18\end{array}$ & $\begin{array}{l}\text { Time } \\
1700 \\
2300\end{array}$ & $\begin{array}{c}\text { Discharge } \\
\left(\mathrm{ft}^{3} / \mathrm{s}\right) \\
2,480 \\
2,640\end{array}$ & $\begin{array}{c}\text { Gage height } \\
\text { (ft) } \\
7.88 \\
8.21\end{array}$ & $\begin{array}{l}\text { Date } \\
\text { Apr. } 3\end{array}$ & $\begin{array}{l}\text { Time } \\
0800\end{array}$ & $\begin{array}{l}\text { Di scharge } \\
\left(\mathrm{ft}^{3} / \mathrm{s}\right) \\
* 2,930\end{array}$ & $\begin{array}{c}\text { Gage height } \\
(\mathrm{ft}) \\
* 8.77\end{array}$ \\
\hline
\end{tabular}

Minimum daily discharge, $23 \mathrm{ft}^{3 / \mathrm{s}}$ Feb. 10.

DISCBARGE, IN CUBIC FEET PER SECOND, WATER YEAR OCTOBER 1984 TO SEPTEMBER 1985 MEAN VALUES

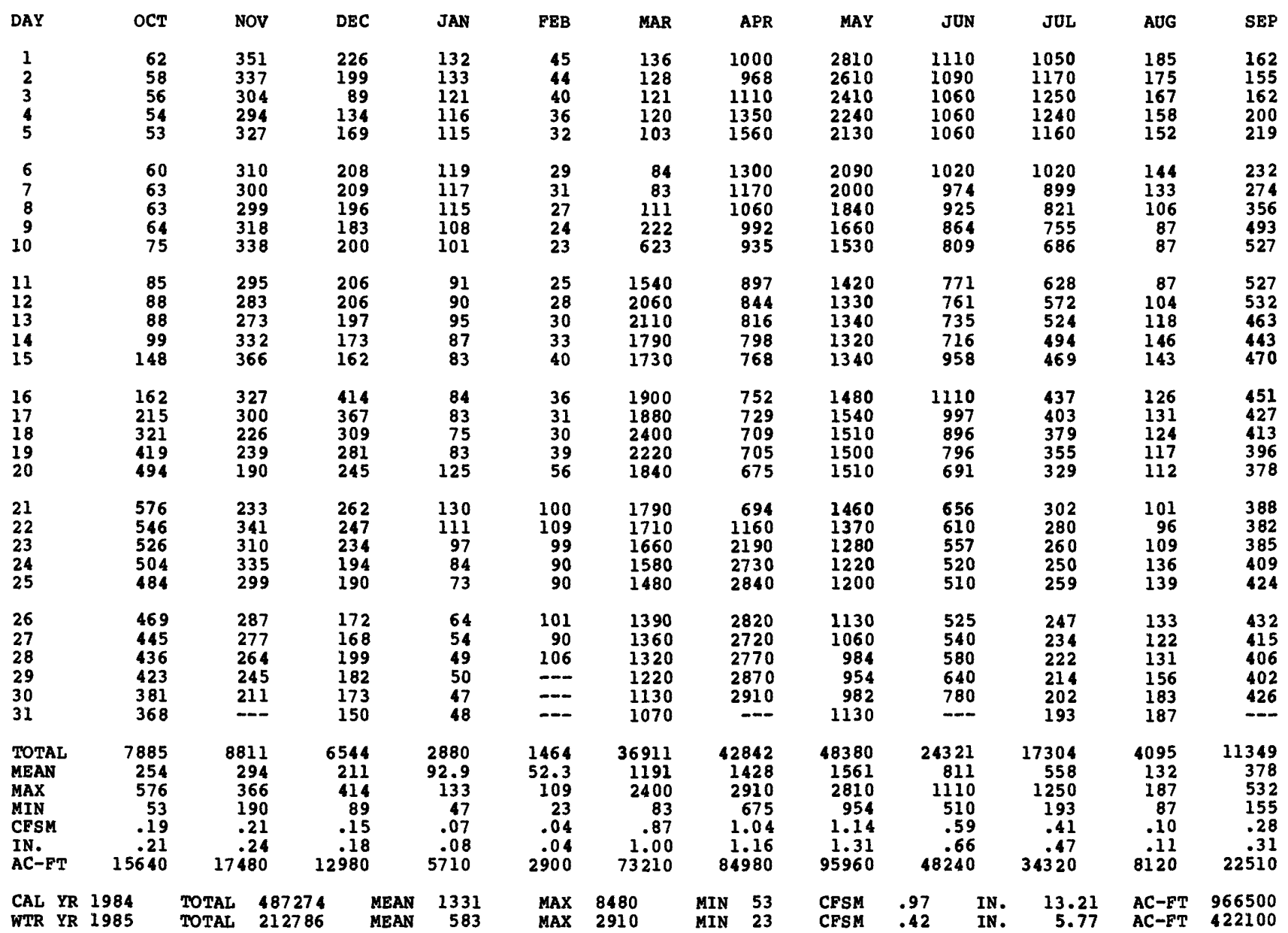


LOCATION.--Lat $42^{\circ} 43^{\prime} 12^{\prime \prime}$, long $94^{\circ} 13^{\prime} 06^{\prime \prime}$, in SE1/4 SW1/4 sec.1, T.91 N., R.29 W., Bumboldt County, Bydrologic Unit 07100002 on left bank $5 \mathrm{ft}$ downstream from First Avenue in city of Humboldt, about $700 \mathrm{ft}$ below dam, $3.2 \mathrm{mi}$ below dam $3.2 \mathrm{mi}$ upstream from Indian Creek, $3.9 \mathrm{mi}$ upstream from East Fork Des Moines River, and at mile 334.3.

DRAINAGE AREA. $--2,256 \mathrm{mi}^{2}$.

PERIOD OF RECORD.--October 1964 to current year. Prior to October 1970, published as West Fork Des Moines River at Humboldt.

GAGE.--Water-stage recorder. Datum of gage is $1,053.54 \mathrm{ft}$ above NGVD. Prior to Oct. 3 , 1966, nonrecording gage at same site and datum.

REMARKS.--Estimated daily discharges: Dec. 31 to Mar. 4. Records good except for estimated daily discharges, which are poor. Daily nonrecording gage readings available in district office for period Mar. 7, 1940, to Sept. 30, 1964. Discharge not published for this period because of extreme regulation at dam $700 \mathrm{ft}$ upstream from gage. Power generation and streamflow regulation discontinued August 1964. Low-flow discharges occasionally affected by minor regulation. U.S. Army Corp of Engineers data collection platform at site.

AVERAGE DISCHARGE.--21 years, $928 \mathrm{ft} / \mathrm{s}, 5.59$ in/yr, 672,300 acre-ft/yr; median of yearly mean discharges, 750 $\mathrm{ft}^{3} / \mathrm{s}, 4.5 \mathrm{in} / \mathrm{yr}, 543,000 \mathrm{acre}-\mathrm{ft} / \mathrm{yr}$.

EXTREMES FOR PERIOD OF RECORD.--Maximum discharge, 18,000 ft/s Apr, 14, 1969, gage height, 15.40 ft, minimum daily, $13 \mathrm{ft}^{3 / \mathrm{s}}$ Nov. 12, 1976, Jan. 12 to Feb. 2, 1977.

EXTREMES OUTSIDE PERIOD OF RECORD, --Flood of June 23, 1947, reached a stage of $12.2 \mathrm{ft}$, discharge, $11,000 \mathrm{ft} / \mathrm{s}$ at present site and datum.

EXTREMES FOR CURRENT YEAR.--Peak discharges greater than base of $2,800 \mathrm{ft}^{2} / \mathrm{s}$ and maximum ( $*$ ):

\begin{tabular}{|c|c|c|c|c|c|c|c|}
\hline $\begin{array}{l}\text { Date } \\
\text { Mar. } 13 \\
\text { Apr. } 7\end{array}$ & $\begin{array}{l}\text { Time } \\
0645 \\
0230\end{array}$ & $\begin{array}{c}\text { Di scharge } \\
\left(\mathrm{ft}^{2} / \mathrm{s}\right) \\
2,830 \\
3,190\end{array}$ & $\begin{array}{c}\text { Gage height } \\
\text { (ft) } \\
6.64 \\
6.96\end{array}$ & $\begin{array}{l}\text { Date } \\
\text { Apr. } 28\end{array}$ & $\begin{array}{l}\text { Time } \\
1745\end{array}$ & $\begin{array}{c}\text { Di scharge } \\
\left(f t^{\prime} / s\right) \\
\star 4,280\end{array}$ & $\begin{array}{c}\text { Gage height } \\
(f t) \\
* 7.84\end{array}$ \\
\hline
\end{tabular}

Minimum daily discharge, $125 \mathrm{ft}^{2} / \mathrm{s}$ Feb. 11,12 .

DISCHARGE, IN CUBIC FEET PER SECOND, WATER YEAR OCTOBER 1984 TO SEPTEMBER 1985 MEAN VALUES

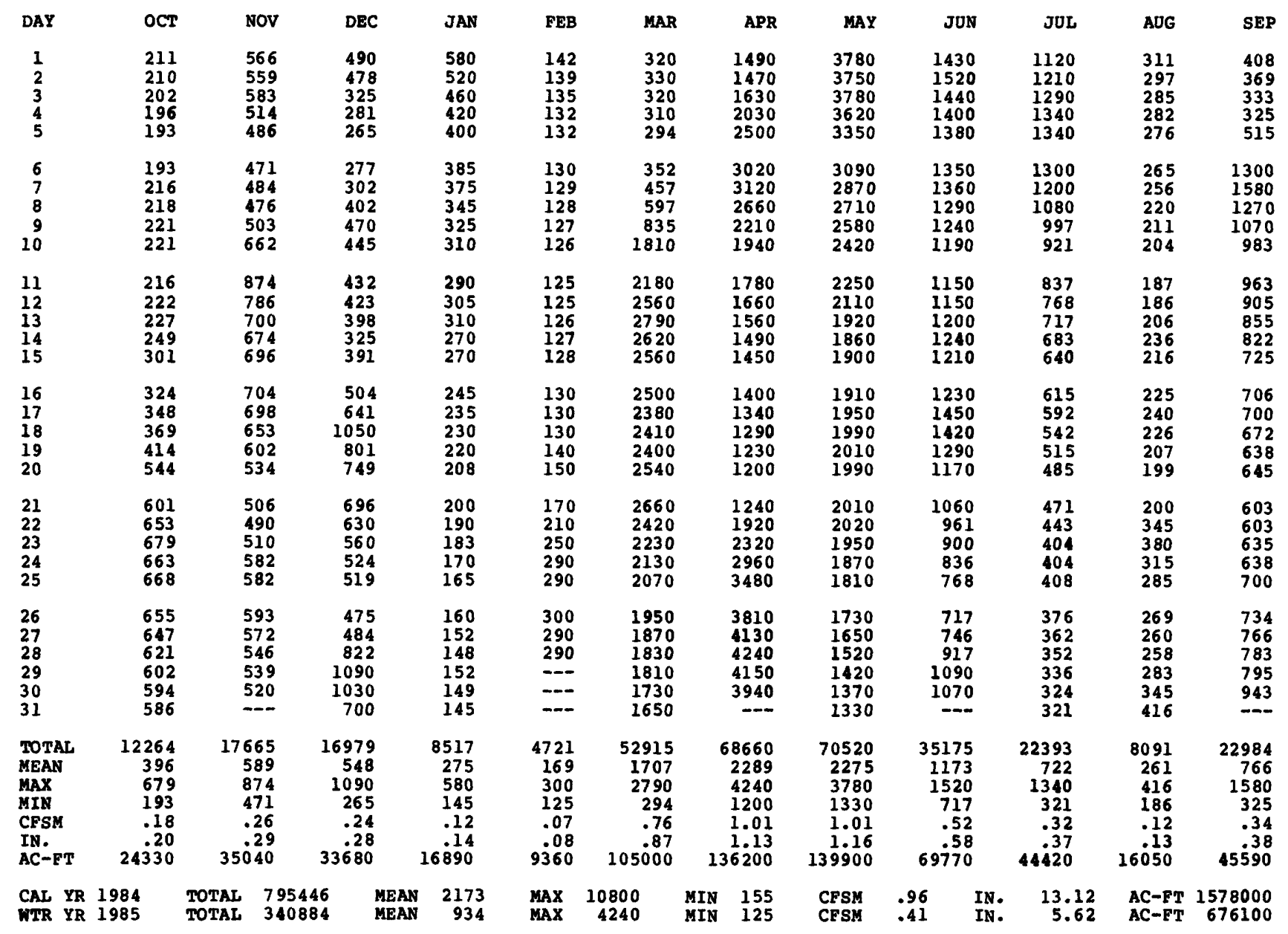


LOCATION.--Lat $42^{\circ} 43^{\prime} 26^{\circ}$, long $94^{\circ} 11^{\prime} 30^{\circ}$, in NWl/4 SEl/4 sec.6, T.91 N., R. 28 w., Humboldt County, Hydrologic Unit 07100003 , on right bank $50 \mathrm{ft}$ upgtream from old mill dam, in city park at east edge of Dakota City, 500 ft upstream from bridge on county highway P56, $0.6 \mathrm{mi}$ downstream from bridge on State Bighway 3 , 3.4 mi upstream from confluence with Des Moines River, and at mile 333.8 upstream from mouth of Des Moines River.

DRAINAGE AREA. $--1,308 \mathrm{mi}^{2}$.

PERIOD OF RECORD.--March 1940 to current year. Prior to October 1954, published as "near Hardy".

REVISED RECORDS.--WSP 1438: Drainage area. WSP 1508: 1944, 1945-47(K).

GAGE.--Water-stage recorder. Datum of gage is 1,038.71 ft above NGvD. Prior to Oct. 1, 1954 , nonrecording gage at site 8 mi upstream at different datum.

REMARKS.--Estimated daily discharges: Dec. 13 to Mar. 8. Records good except for estimated daily discharges, which are poor. U. S. Army Corps of Engineers data collection platform at site.

COOPERATION.--Two discharge measurements were provided by the U.S. Army Corps of Engineers.

AVERAGE DISCHARGE. -45 years, $550 \mathrm{ft} / \mathrm{s}, 5.71 \mathrm{in} / \mathrm{yr}, 398,500 \mathrm{acre}-\mathrm{ft} / \mathrm{yr}$.

EXTREKES POR PERIOD OR RECORD.--Maximum discharge, 18,800 ft'/s June 21, 1954, gage height, $16.95 \mathrm{ft}$, from floodmark, site and datum then in use; minimum daily, $4.8 \mathrm{ft} / \mathrm{s} \mathrm{Jan}$. 11-14, 1977 .

EXTREMES OOTSIDE PERIOD OF RECORD.--Flood of June 21, 1954, reached a stage of $24.02 \mathrm{ft}$, discharge, 17,400 ft/s at present site. Flood of September 1938 reached a stage of $17.4 \mathrm{ft}$, discharge, about $22,000 \mathrm{ft} / \mathrm{s}$, $\mathrm{site}$ and datum in use during the period 1940-54.

EXTREMES FOR CURRENT YEAR.--Peak discharges greater than base of $1,700 \mathrm{ft} / \mathrm{s}$ and maximum ( $*$ )

\begin{tabular}{|c|c|c|c|c|c|c|c|}
\hline $\begin{array}{l}\text { Date } \\
\text { Apr. } 9 \\
\text { Apr. } 27\end{array}$ & $\begin{array}{l}\text { Time } \\
1445 \\
2100\end{array}$ & $\begin{array}{c}\text { Discharge } \\
\left.\text { (ft } t^{2} / \mathrm{s}\right) \\
2,270 \\
* 2,560\end{array}$ & $\begin{array}{c}\text { Gage height } \\
\text { (ft) } \\
11.71 \\
* 12.10\end{array}$ & $\begin{array}{l}\text { Date } \\
\text { Sept. } 7\end{array}$ & $\begin{array}{l}\text { Time } \\
0230\end{array}$ & $\begin{array}{c}\text { Di scharge } \\
(f t: / s) \\
2,280\end{array}$ & $\begin{array}{c}\text { Gage height } \\
(f t) \\
11.73\end{array}$ \\
\hline
\end{tabular}

Minimum discharge, $25 \mathrm{ft}^{\prime} / \mathrm{s}$ Aug. 21.

DISCHARGE, IN CUBIC FEET PER SECOND, WATER YEAR OCTOBER 1984 TO SEPTEMBER 1985 MEAN VALUES

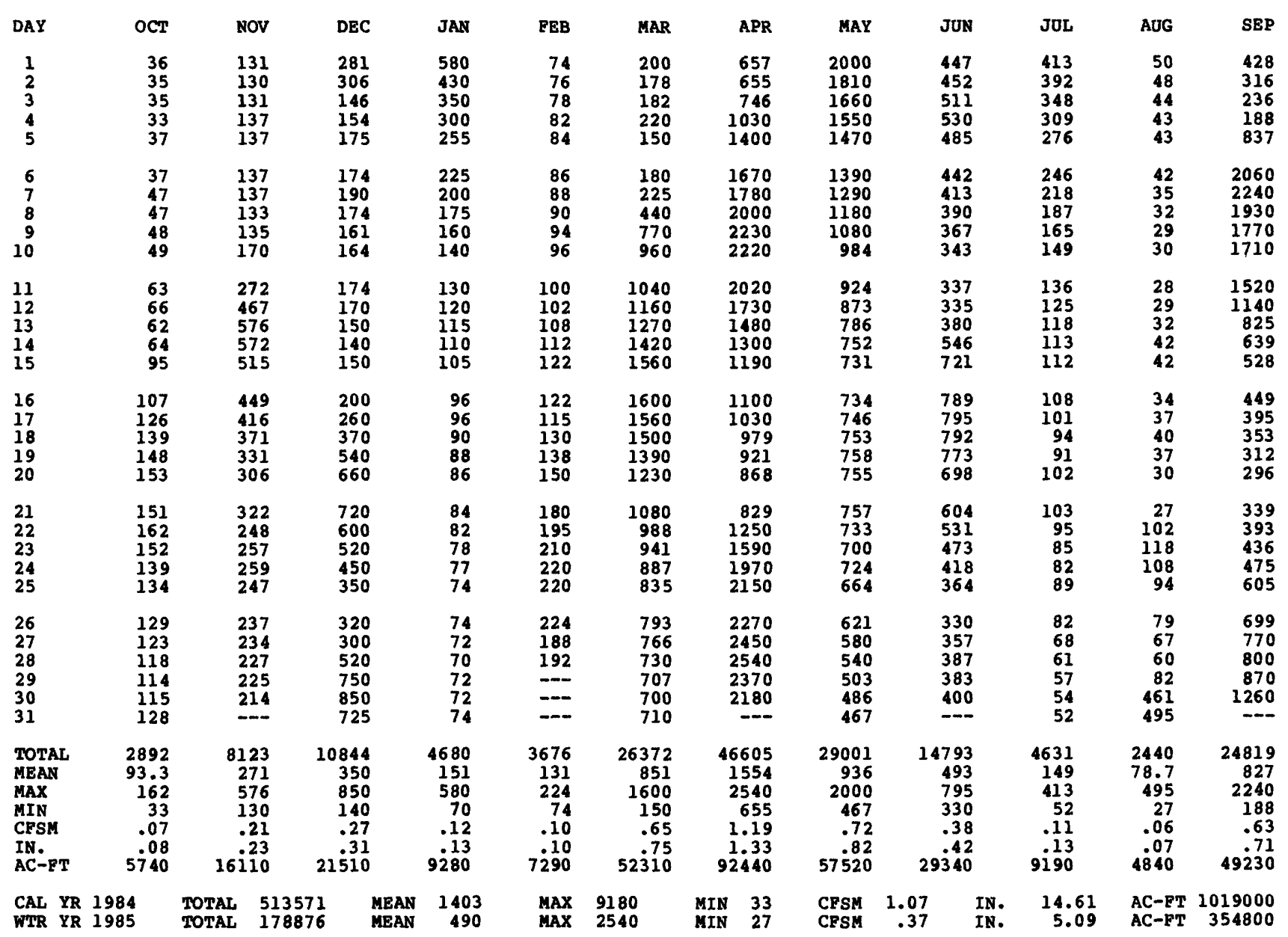


05480500 DES MOINES RIVER AT FORT DODGE, IA

LOCATION.--Lat $42^{\circ} 30^{\prime} 22^{\prime \prime}$, long $94^{\circ} 12^{\prime} 04^{\prime \prime}$, in Nw1/4 Sw1/4 sec,19, T.89 N., R.28 w.., Webster County, Hydrologic Unit 07100004 , on right bank $400 \mathrm{ft}$ upstream from soldier creek, 1,800 ft downstream from Illinois Central Rail road bridge in Fort Dodge, 2,000 ft downstream from Lizard Creek, and at mile 314.6 .

DRAINAGE AREA. $--4,190 \mathrm{mi}^{2}$.

PERIOD OF RECORD.--April 1905 to July 1906 (no winter records), October 1913 to September 1927 (published as "at Kalo"). October 1946 to current year. Monthly discharge only for some periods, published in wsp 1308.

REVISED RECORDS.--WSP 1438: Drainage area. WSP 1308: 1924, 1925 (M).

GAGE.--Water-stage recorder. Datum of gage is $969.38 \mathrm{ft}$ above NGVD. See wSP 1728 for history of changes prior to Dec. 8, 1949.

REMARKS.--Estimated dally discharges: Jan. 11 to Mar. 3 . Records good except for estimated daily discharges, which are poor. Occasional minor regulation caused by dam 0.8 mi upstream from gage. 0 . $s$. Army Corps of Engineers rain-gage and data collection platform and city of Fort Dodge gage-height telemeter at station.

COOPERATION.--One discharge measurement provided by 0 . S. Army Corps of Engineers.

AVERAGE DISCHARGE.--53 years (water years 1914-27, 1947-85), $1,540 \mathrm{ft} / \mathrm{s}, 4.99 \mathrm{in} / \mathrm{yr}, 1,116,000$ acre-ft/yr; median of yearly mean discharges, $1,250 \mathrm{ft} / \mathrm{s}, 4.1 \mathrm{in} / \mathrm{yr}^{3}, 906,000 \mathrm{acre}-\mathrm{ft} / \mathrm{yr}$.

EXTREMES FOR PERIOD OF RECORD.--Maximum discharge, 35,600 ft/s Apr. 8, 1965, gage height, 17.79 ft; maximum gage height, $19.62 \mathrm{ft}$, from floodmark, June 23, 1947, present site and datum; minimum daily discharge, $14 \mathrm{ft}^{\mathrm{O}} / \mathrm{s}$ Nov. 3,1955 .

EXTREMES FOR CURRENT YEAR.--Peak discharges greater than base of $6,000 \mathrm{ft} / \mathrm{s}$ and maximum (*):

\begin{tabular}{|c|c|c|c|c|c|c|}
\hline $\begin{array}{l}\text { Date } \\
\text { Dec. } 28\end{array}$ & $\begin{array}{l}\text { Time } \\
2030\end{array}$ & $\begin{array}{c}\text { Discharge } \\
\left(f t^{3} / 8\right) \\
7,410\end{array}$ & $\begin{array}{c}\text { Gage height } \\
\text { (ft) } \\
7.10\end{array}$ & $\begin{array}{l}\text { Date } \\
\text { Apr. } 27\end{array}$ & $\begin{array}{l}\text { Time } \\
2300\end{array}$ & $\begin{array}{c}\text { Gage height } \\
\text { (ft) } \\
\star 7.26\end{array}$ \\
\hline
\end{tabular}

Minimum daily discharge, $210 \mathrm{ft}^{3 / \mathrm{s}} \mathrm{Feb}, 7,8$.

DISCHARGE, IN CUBIC PEET PER SECOND, WATER YEAR OCTOBER 1984 TO SEPTEMBER 1985 MBAN VALUES

\begin{tabular}{|c|c|c|c|c|c|c|c|c|c|c|c|c|}
\hline DAY & OCT & Hov & DEC & JAN & FEB & MAR & APR & MAY & JUN & JUL & AUG & SEP \\
\hline $\begin{array}{l}1 \\
2 \\
3 \\
4 \\
5\end{array}$ & $\begin{array}{l}263 \\
262 \\
254 \\
245 \\
243\end{array}$ & $\begin{array}{l}748 \\
703 \\
737 \\
681 \\
656\end{array}$ & $\begin{array}{l}767 \\
842 \\
514 \\
393 \\
459\end{array}$ & $\begin{array}{l}2120 \\
2030 \\
1800 \\
1420 \\
1210\end{array}$ & $\begin{array}{l}230 \\
230 \\
225 \\
220 \\
220\end{array}$ & $\begin{array}{r}560 \\
800 \\
1300 \\
1450 \\
707\end{array}$ & $\begin{array}{l}2470 \\
2390 \\
2830 \\
3540 \\
4280\end{array}$ & $\begin{array}{l}6520 \\
6190 \\
6010 \\
5710 \\
5330\end{array}$ & $\begin{array}{l}2230 \\
2330 \\
2300 \\
2250 \\
2190\end{array}$ & $\begin{array}{l}1710 \\
1790 \\
1830 \\
1840 \\
1820\end{array}$ & $\begin{array}{l}383 \\
367 \\
349 \\
338 \\
333\end{array}$ & $\begin{array}{r}878 \\
739 \\
614 \\
535 \\
1080\end{array}$ \\
\hline $\begin{array}{r}6 \\
7 \\
8 \\
9 \\
10\end{array}$ & $\begin{array}{l}251 \\
290 \\
289 \\
287 \\
286\end{array}$ & $\begin{array}{l}625 \\
637 \\
629 \\
658 \\
836\end{array}$ & $\begin{array}{l}479 \\
516 \\
613 \\
672 \\
668\end{array}$ & $\begin{array}{l}847 \\
847 \\
898 \\
842 \\
603\end{array}$ & $\begin{array}{l}220 \\
210 \\
210 \\
215 \\
220\end{array}$ & $\begin{array}{r}786 \\
798 \\
1010 \\
1720 \\
3040\end{array}$ & $\begin{array}{l}5160 \\
5430 \\
5270 \\
4980 \\
4610\end{array}$ & $\begin{array}{l}4910 \\
4530 \\
4250 \\
4000 \\
3760\end{array}$ & $\begin{array}{l}2090 \\
2020 \\
1910 \\
1820 \\
1700\end{array}$ & $\begin{array}{l}1730 \\
1590 \\
1380 \\
1220 \\
1120\end{array}$ & $\begin{array}{l}319 \\
300 \\
281 \\
269 \\
266\end{array}$ & $\begin{array}{l}3050 \\
3920 \\
3370 \\
2950 \\
2770\end{array}$ \\
\hline $\begin{array}{l}11 \\
12 \\
13 \\
14 \\
15\end{array}$ & $\begin{array}{l}274 \\
281 \\
286 \\
343 \\
495\end{array}$ & $\begin{array}{l}1200 \\
1330 \\
1380 \\
1340 \\
1300\end{array}$ & $\begin{array}{l}657 \\
783 \\
813 \\
672 \\
682\end{array}$ & $\begin{array}{r}770 \\
1000 \\
920 \\
820 \\
650\end{array}$ & $\begin{array}{l}220 \\
220 \\
225 \\
220 \\
220\end{array}$ & $\begin{array}{l}3690 \\
3800 \\
4230 \\
4250 \\
4270\end{array}$ & $\begin{array}{l}4220 \\
3750 \\
3430 \\
3160 \\
2960\end{array}$ & $\begin{array}{l}3550 \\
3380 \\
3120 \\
2960 \\
2990\end{array}$ & $\begin{array}{l}1670 \\
1640 \\
1660 \\
1910 \\
2080\end{array}$ & $\begin{array}{r}1020 \\
937 \\
878 \\
826 \\
767\end{array}$ & $\begin{array}{l}246 \\
230 \\
243 \\
275 \\
278\end{array}$ & $\begin{array}{l}2600 \\
2210 \\
1810 \\
1550 \\
1330\end{array}$ \\
\hline $\begin{array}{l}16 \\
17 \\
18 \\
19 \\
20\end{array}$ & $\begin{array}{l}485 \\
532 \\
534 \\
571 \\
662\end{array}$ & $\begin{array}{r}1240 \\
1190 \\
1120 \\
1030 \\
902\end{array}$ & $\begin{array}{r}958 \\
1230 \\
2140 \\
1860 \\
1970\end{array}$ & $\begin{array}{l}600 \\
490 \\
450 \\
420 \\
420\end{array}$ & $\begin{array}{l}220 \\
220 \\
220 \\
220 \\
320\end{array}$ & $\begin{array}{l}4280 \\
4090 \\
4030 \\
3920 \\
3810\end{array}$ & $\begin{array}{l}2840 \\
2700 \\
2590 \\
2460 \\
2380\end{array}$ & $\begin{array}{l}3000 \\
3050 \\
3090 \\
3100 \\
3100\end{array}$ & $\begin{array}{l}2200 \\
2420 \\
2420 \\
2290 \\
2080\end{array}$ & $\begin{array}{l}720 \\
681 \\
646 \\
640 \\
599\end{array}$ & $\begin{array}{l}268 \\
286 \\
277 \\
264 \\
252\end{array}$ & $\begin{array}{r}1180 \\
1120 \\
1050 \\
964 \\
984\end{array}$ \\
\hline $\begin{array}{l}21 \\
22 \\
23 \\
24 \\
25\end{array}$ & $\begin{array}{l}761 \\
820 \\
870 \\
843 \\
846\end{array}$ & $\begin{array}{l}825 \\
807 \\
786 \\
878 \\
873\end{array}$ & $\begin{array}{l}1660 \\
1700 \\
1680 \\
1200 \\
1520\end{array}$ & $\begin{array}{l}415 \\
390 \\
370 \\
340 \\
330\end{array}$ & $\begin{array}{l}600 \\
680 \\
560 \\
580 \\
530\end{array}$ & $\begin{array}{l}3820 \\
3580 \\
3340 \\
3210 \\
3110\end{array}$ & $\begin{array}{l}2310 \\
2980 \\
4100 \\
5150 \\
6040\end{array}$ & $\begin{array}{l}3070 \\
3050 \\
3000 \\
3310 \\
3320\end{array}$ & $\begin{array}{l}1870 \\
1680 \\
1510 \\
1370 \\
1220\end{array}$ & $\begin{array}{l}591 \\
558 \\
522 \\
496 \\
523\end{array}$ & $\begin{array}{l}240 \\
633 \\
645 \\
531 \\
456\end{array}$ & $\begin{array}{r}942 \\
1010 \\
1110 \\
1140 \\
1330\end{array}$ \\
\hline $\begin{array}{l}26 \\
27 \\
28 \\
29 \\
30 \\
31\end{array}$ & $\begin{array}{l}824 \\
796 \\
777 \\
743 \\
726 \\
733\end{array}$ & $\begin{array}{l}891 \\
866 \\
826 \\
803 \\
780 \\
---\end{array}$ & $\begin{array}{l}1400 \\
1000 \\
3550 \\
3220 \\
2860 \\
2220\end{array}$ & $\begin{array}{l}320 \\
310 \\
285 \\
260 \\
235 \\
230\end{array}$ & $\begin{array}{l}540 \\
470 \\
510 \\
-- \\
--\end{array}$ & $\begin{array}{l}2970 \\
2890 \\
2840 \\
2820 \\
2750 \\
2690\end{array}$ & $\begin{array}{r}6870 \\
7800 \\
7950 \\
7530 \\
7020 \\
-\end{array}$ & $\begin{array}{l}3070 \\
2850 \\
2620 \\
2430 \\
2330 \\
2240\end{array}$ & $\begin{array}{r}1150 \\
1130 \\
1360 \\
1690 \\
1670 \\
\end{array}$ & $\begin{array}{l}491 \\
456 \\
433 \\
411 \\
399 \\
396\end{array}$ & $\begin{array}{l}393 \\
358 \\
333 \\
400 \\
610 \\
932\end{array}$ & $\begin{array}{r}1500 \\
1610 \\
1680 \\
1810 \\
2340 \\
-\end{array}$ \\
\hline $\begin{array}{l}\text { TOTAL } \\
\text { MEAN } \\
\text { MAX } \\
\text { MIN } \\
\text { CFSM } \\
\text { IN. } \\
\text { AC-ET }\end{array}$ & $\begin{array}{r}15872 \\
512 \\
870 \\
243 \\
.12 \\
.14 \\
31480\end{array}$ & $\begin{array}{r}27277 \\
909 \\
1380 \\
625 \\
.22 \\
.24 \\
54100\end{array}$ & $\begin{array}{r}39698 \\
1281 \\
3550 \\
393 \\
.31 \\
.35 \\
78740\end{array}$ & $\begin{array}{r}22642 \\
730 \\
2120 \\
230 \\
.17 \\
.20 \\
44910\end{array}$ & $\begin{array}{r}8975 \\
321 \\
680 \\
210 \\
.08 \\
.08 \\
17800\end{array}$ & $\begin{array}{r}86561 \\
2792 \\
4280 \\
560 \\
.67 \\
.77 \\
171700\end{array}$ & $\begin{array}{r}129200 \\
4307 \\
7950 \\
2310 \\
1.03 \\
1.15 \\
256300\end{array}$ & $\begin{array}{r}113840 \\
3672 \\
6520 \\
2240 \\
.88 \\
1.01 \\
225800\end{array}$ & $\begin{array}{r}55860 \\
1862 \\
2420 \\
1130 \\
.44 \\
110800\end{array}$ & $\begin{array}{r}29020 \\
936 \\
1840 \\
396 \\
.22 \\
.26 \\
57560\end{array}$ & $\begin{array}{r}11355 \\
366 \\
932 \\
230 \\
.09 \\
10 \\
22520\end{array}$ & $\begin{array}{r}49176 \\
1639 \\
3920 \\
535 \\
.39 \\
.44 \\
97540\end{array}$ \\
\hline $\begin{array}{l}\text { CAL YE } \\
\text { WTR YE }\end{array}$ & & AL & & $\begin{array}{l}4639 \\
N \quad 1615\end{array}$ & $\begin{array}{l}\text { MAX } \\
\text { MAX }\end{array}$ & $\begin{array}{r}26500 \\
7950\end{array}$ & $\begin{array}{ll}\text { MIN } & 243 \\
\text { MIN } & 210\end{array}$ & $\begin{array}{l}\text { CFSH } \\
\text { CPSH }\end{array}$ & .11 & $\begin{array}{r}15.08 \\
5.23\end{array}$ & $\begin{array}{l}A C-F \\
A C-F\end{array}$ & $\begin{array}{l}3368000 \\
1169000\end{array}$ \\
\hline
\end{tabular}


LOCATION. - - at $42^{\circ} 26^{\prime} 01^{\prime \prime}$, long $93^{\circ} 48^{\prime} 12^{\prime \prime}$, in NWL/4 SEY/4 sec, 18, T.88 N., R. 25 w., Hamilton County, Hydrologic Tnit 07100005 , on right bank $100 \mathrm{ft}$ upstrean from bridge on State Highway 17, 2.5 mi south of Webster City, and 3.2 mi downstream from Brewers Creek.

DRAINAGE AREA. $-844 \mathrm{mi} .^{2}$

PERIOD OR RECORD. - March 1940 to current year.

REVISED RECORDS.--hSP 1438: Drainage area. WSP 1308: 1940 (M), hSP 1708: 1956.

GAGE. - Water-stage recorder. Datum of gage is $989.57 \mathrm{ft}$ above NGVD. Prior to June 26, 1940, nonrecording gage at same site and datum.

RGMaRRs.--Est1mated daily discharges: Oct. 14-18, Dec. 2-27, Jan. 2 to Feb. 27, Mar. 31. Records good except for estimated daily discharges which are poo. U. S. Army Corps of Engineers rain-gage and gage-height telemeters at station.

COOPERATION.--Three discharge measurements provided by U. S. Army Corps of Engineers.

AVBRAGE DISCHARGE, -45 years, $412 \mathrm{ft}^{3} / \mathrm{s}, 6.63 \mathrm{in} / \mathrm{yr}, 298,500$ acre-ft/yr; median of yearly mean discharges, 340 $\mathrm{ft}^{3} / \mathrm{s}, 5.5 \mathrm{in} / \mathrm{yr}^{2}, 246,000 \mathrm{acre}-\mathrm{ft} / \mathrm{yr}$.

EXIREMES FOR PERIOD OR RECORD.--Kaximum discharge, $20,300 \mathrm{ft} / \mathrm{s}$ June 22, 1954, gage helght, $18.55 \mathrm{ft}$, no $\mathrm{flow}$ Feb. 7, 1977

EXIREMES CUISIDE FERIOD OF RECORD,--Kaximum stage since 1896, $19.1 \mathrm{ft}$ about June 10, 1918, frcm floocmarks, fram information by local resident, discharge, $21,500 \mathrm{ft} / \mathrm{s}$. Flood of June 18, 1932, reached a stage of $16.0 \mathrm{ft}$, discharge, $15,000 \mathrm{ft}^{2} / \mathrm{s}$

EXIREYES FOR OURRENT YEAR.-Deak discharges greater than base of $2,200 \mathrm{ft} 1 / \mathrm{s}$ and maximum (*):

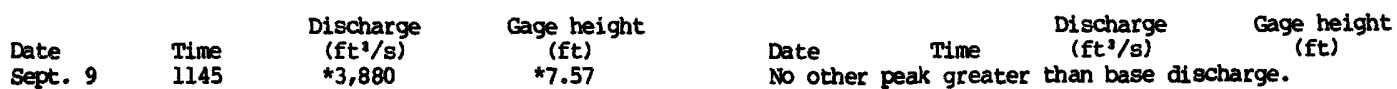

Minimum discharge, $15 \mathrm{ft} / \mathrm{s}$ Aug. 16-18, 21.

DISCHARGE, IN CUBIC FEET PER SECOND, WATER YEAR OCTOBER 1984 TO SEPTEYBER 1985

MEAN VALUES

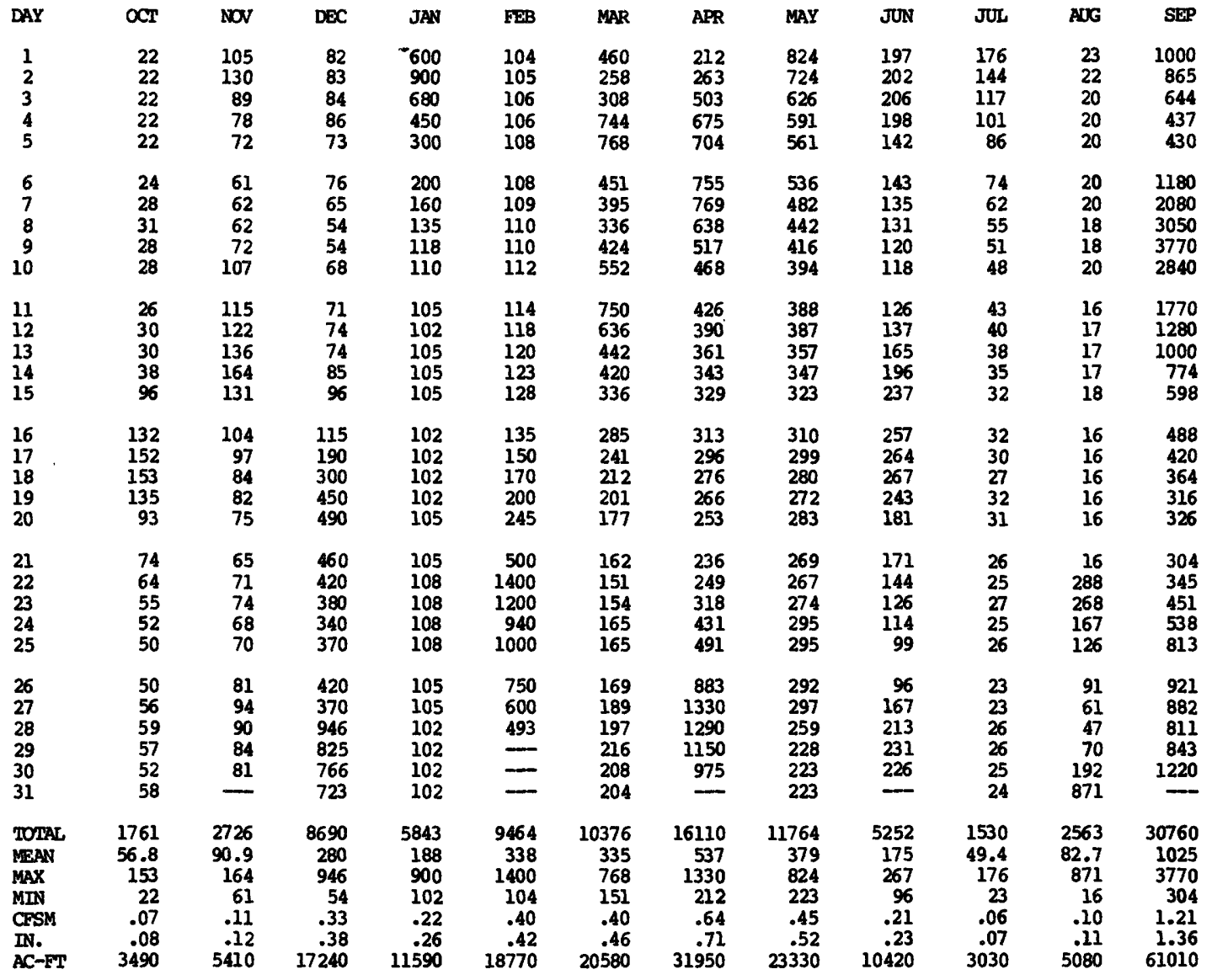

CAL YR 1984 WIR YR 1985
TOTAL 376938 TOTAL 106839
MEAN 1030 MAX 10800

MEAN 293
MAX 3770
MIN $21 \quad$ CFSM 1.22

CFSM .35 
LOCATION.--Lat $42^{\circ} 15^{\prime} 04^{\prime \prime}$, Iong $93^{\circ} 59^{\prime} 52^{\prime \prime}$, in NWI/4 NEl/4 sec.21, T.86 N., R.27 W., Webster County, Hydrologic Unit 07100004 , on right bank $6 \mathrm{ft}$ downstream from bridge on state Highway 175 , 0.1 mi downstream from Skillet Creek, $4.0 \mathrm{mi}$ southwest of stratford, $7.3 \mathrm{mi}$ downstream from Boone River and at $\mathrm{mile} 276.7$.

DRAINAGE AREA. $--5,452 \mathrm{mi}^{2}$.

PERIOD OF RECORD.--April 1920 to current year in reports of Geological Survey. Published as "near Boone" 1920-67. Monthly discharge only for some periods, published in WSP 1308 . December 1904 to April 1920 (fragmentary gage heights during high-water periods only) in reports of U.S. Weather Bureau.

REVISED RECORDS.--WSP 1438: Drainage area. WSP 1508: 1925-27, 1934. WSP 1708: 1955.

GAGE.--Water-stage recorder. Datum of gage is $894.00 \mathrm{ft}$ above NGvD. Prior to May 1.1920 , nonrecording gage 16.6 mi downstream at datum 23.49 ft lower. Oct. 9, 1924, to Jan. 10, 1933, nonrecordinga gage 17.6 mi downstream at datum $28.53 \mathrm{ft}$ lower. Jan. 11, 1933, to sept. 30, 1934, nonrecording gage $17.9 \mathrm{mi}$ downstream at datum $22.25 \mathrm{ft}$ lower. Oct. 1, 1934 to Feb. 6, 1935, nonrecording gage and Feb. 7 , 1935 to sept. 30 , 1967, water-stage recorder $17.9 \mathrm{mi}$ downstream at datum $21.84 \mathrm{ft}$ lower.

REMARKS.--Estimated daily discharges: Dec. 5 to Mar. 9. Records good except for estimated daily discharges, which are poor. Occasional minor regulation caused by dam at Fort Dodge. U. s. Army Corps of Engineers raingage and gage-height telemeters at station.

COOPERATION.--Three discharge measurements provided by U. S. Army Corps of Engineers.

AVERAGE DISCHARGE.--65 years, $1,951 \mathrm{ft} / \mathrm{s}, 4.86 \mathrm{in} / \mathrm{yr}, 1,413,000$ acre-ft/yr; median of yearly mean discharges, $1.630 \mathrm{ft} \% \mathrm{~s}, 4.1 \mathrm{in} / \mathrm{yr}, 1,181,000$ acre-ft/yr.

EXTREMES FOR PERIOD OF RECORD.--Maximum discharge, 57,400 ft'/s June 22, 1954, gage height, 25.35 ft, from graph based on hourly gage readings, site and datum then in use, no flow for a short time on Jan. 9 , 25 , 1938 , caused by manipulation of gates in control dam, site then in use; minimum unregulated daily discharge, i3 ft/s Jan. 23, 24, 1977 .

EXTREMES OUTSIDE PERIOD OP RECORD.--Flood of May 30, 1903, reached a stage of 25.4 ft, from high-water mark, site and datum then in use, discharge, $43,600 \mathrm{ft}^{2} / \mathrm{s}$. Flood of June 22 , 1954, reached a stage of 29.7

ft, from floodmark, present site and datum, discharge, $54,200 \mathrm{ft}^{3} / \mathrm{s}$.

EXTREMES FOR CURRENT YEAR.--Peak discharges greater than base of $7,000 \mathrm{ft} / \mathrm{s}$ and maximum (*):

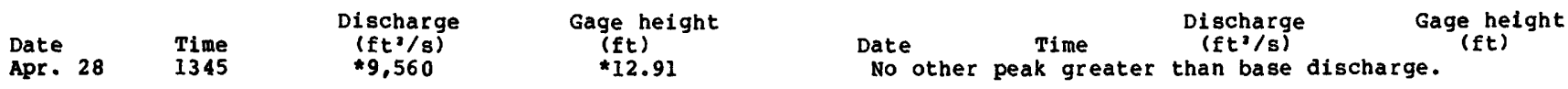

Minimum discharge, $274 \mathrm{ft} / \mathrm{s}$ Oct. 5-7.

DISCHARGE, IN CUBIC FEET PER SECOND, WATER YEAR OCTOBER 1984 TO SEPTEMBER 1985 MEAN VALUES

\begin{tabular}{|c|c|c|c|c|c|c|c|c|c|c|c|c|c|}
\hline DAY & $O C T$ & NOV & DEC & JAN & FEB & MAR & APR & MAY & JUN & & JUL & AUG & SEP \\
\hline $\begin{array}{l}1 \\
2 \\
3 \\
4 \\
5\end{array}$ & $\begin{array}{l}286 \\
286 \\
289 \\
289 \\
278\end{array}$ & $\begin{array}{l}974 \\
987 \\
950 \\
924 \\
859\end{array}$ & $\begin{array}{l}988 \\
974 \\
969 \\
543 \\
600\end{array}$ & $\begin{array}{l}3600 \\
4000 \\
3300 \\
2600 \\
2000\end{array}$ & $\begin{array}{l}650 \\
640 \\
640 \\
640 \\
640\end{array}$ & $\begin{array}{l}1300 \\
1500 \\
1400 \\
2400 \\
2700\end{array}$ & $\begin{array}{l}3000 \\
2880 \\
3420 \\
4240 \\
5050\end{array}$ & $\begin{array}{l}7970 \\
7360 \\
7000 \\
6710 \\
6490\end{array}$ & $\begin{array}{l}2420 \\
2450 \\
2480 \\
2420 \\
2380\end{array}$ & & $\begin{array}{l}2040 \\
2000 \\
1990 \\
1970 \\
1930\end{array}$ & $\begin{array}{l}463 \\
447 \\
430 \\
410 \\
401\end{array}$ & $\begin{array}{l}2160 \\
2060 \\
1730 \\
1380 \\
1330\end{array}$ \\
\hline $\begin{array}{r}6 \\
7 \\
8 \\
9 \\
10\end{array}$ & $\begin{array}{l}274 \\
285 \\
332 \\
327 \\
316\end{array}$ & $\begin{array}{l}818 \\
775 \\
787 \\
812 \\
941\end{array}$ & $\begin{array}{r}980 \\
960 \\
1050 \\
1200 \\
1220\end{array}$ & $\begin{array}{r}1600 \\
1300 \\
1000 \\
900 \\
820\end{array}$ & $\begin{array}{l}640 \\
640 \\
640 \\
640 \\
630\end{array}$ & $\begin{array}{l}1700 \\
1550 \\
1550 \\
1720 \\
2800\end{array}$ & $\begin{array}{l}5870 \\
6470 \\
6400 \\
6020 \\
5670\end{array}$ & $\begin{array}{l}6160 \\
5620 \\
5170 \\
4810 \\
4510\end{array}$ & $\begin{array}{l}2280 \\
2190 \\
2110 \\
2000 \\
1900\end{array}$ & & $\begin{array}{l}1880 \\
1780 \\
1640 \\
1460 \\
1320\end{array}$ & $\begin{array}{l}391 \\
377 \\
355 \\
334 \\
332\end{array}$ & $\begin{array}{l}2620 \\
5560 \\
6580 \\
6870 \\
6440\end{array}$ \\
\hline $\begin{array}{l}11 \\
12 \\
13 \\
14 \\
15\end{array}$ & $\begin{array}{l}314 \\
310 \\
310 \\
321 \\
490\end{array}$ & $\begin{array}{l}1160 \\
1470 \\
1570 \\
1640 \\
1620\end{array}$ & $\begin{array}{l}1180 \\
1110 \\
1120 \\
1220 \\
1180\end{array}$ & $\begin{array}{l}790 \\
760 \\
740 \\
700 \\
690\end{array}$ & $\begin{array}{l}630 \\
630 \\
630 \\
630 \\
625\end{array}$ & $\begin{array}{l}4470 \\
4640 \\
4800 \\
4850 \\
4750\end{array}$ & $\begin{array}{l}5270 \\
4800 \\
4360 \\
3980 \\
3700\end{array}$ & $\begin{array}{l}4220 \\
4000 \\
3690 \\
3400 \\
3270\end{array}$ & $\begin{array}{l}1950 \\
1970 \\
1960 \\
2060 \\
2310\end{array}$ & & $\begin{array}{r}1220 \\
1140 \\
1070 \\
998 \\
940\end{array}$ & $\begin{array}{l}322 \\
308 \\
298 \\
309 \\
335\end{array}$ & $\begin{array}{l}5190 \\
4210 \\
3440 \\
2840 \\
2440\end{array}$ \\
\hline $\begin{array}{l}16 \\
17 \\
18 \\
19 \\
20\end{array}$ & $\begin{array}{l}637 \\
726 \\
744 \\
720 \\
715\end{array}$ & $\begin{array}{l}1560 \\
1480 \\
1420 \\
1340 \\
1240\end{array}$ & $\begin{array}{l}1300 \\
1600 \\
2300 \\
2450 \\
2700\end{array}$ & $\begin{array}{l}680 \\
680 \\
670 \\
660 \\
660\end{array}$ & $\begin{array}{l}625 \\
625 \\
620 \\
620 \\
620\end{array}$ & $\begin{array}{l}4730 \\
4590 \\
4410 \\
4330 \\
4200\end{array}$ & $\begin{array}{l}3510 \\
3330 \\
3170 \\
3060 \\
2920\end{array}$ & $\begin{array}{l}3290 \\
3270 \\
3300 \\
3320 \\
3360\end{array}$ & $\begin{array}{l}2500 \\
2590 \\
2730 \\
2730 \\
2540\end{array}$ & & $\begin{array}{l}866 \\
814 \\
769 \\
786 \\
736\end{array}$ & $\begin{array}{l}333 \\
324 \\
346 \\
322 \\
307\end{array}$ & $\begin{array}{l}2080 \\
1870 \\
1740 \\
1650 \\
1630\end{array}$ \\
\hline $\begin{array}{l}21 \\
22 \\
23 \\
24 \\
25\end{array}$ & $\begin{array}{l}767 \\
828 \\
871 \\
903 \\
893\end{array}$ & $\begin{array}{l}1110 \\
1080 \\
1060 \\
1050 \\
1120\end{array}$ & $\begin{array}{l}2900 \\
2600 \\
2400 \\
2100 \\
2000\end{array}$ & $\begin{array}{l}660 \\
660 \\
660 \\
660 \\
660\end{array}$ & $\begin{array}{r}620 \\
2200 \\
2100 \\
1880 \\
1680\end{array}$ & $\begin{array}{l}4150 \\
4090 \\
3810 \\
3600 \\
3460\end{array}$ & $\begin{array}{l}2820 \\
2930 \\
4220 \\
5180 \\
6340\end{array}$ & $\begin{array}{l}3290 \\
3280 \\
3240 \\
3480 \\
3750\end{array}$ & $\begin{array}{l}2290 \\
2050 \\
1860 \\
1680 \\
1490\end{array}$ & & $\begin{array}{l}692 \\
659 \\
619 \\
584 \\
604\end{array}$ & $\begin{array}{r}298 \\
1790 \\
3130 \\
1950 \\
1400\end{array}$ & $\begin{array}{l}1650 \\
1570 \\
1700 \\
2080 \\
2290\end{array}$ \\
\hline $\begin{array}{l}26 \\
27 \\
28 \\
29 \\
30 \\
31\end{array}$ & $\begin{array}{l}920 \\
895 \\
911 \\
884 \\
853 \\
844\end{array}$ & $\begin{array}{l}1110 \\
1100 \\
1090 \\
1040 \\
1020 \\
\end{array}$ & $\begin{array}{l}2010 \\
2090 \\
2800 \\
3950 \\
3950 \\
3600\end{array}$ & $\begin{array}{l}660 \\
650 \\
650 \\
650 \\
650 \\
650\end{array}$ & $\begin{array}{r}1500 \\
1350 \\
1200 \\
- \\
- \\
-\end{array}$ & $\begin{array}{l}3360 \\
3300 \\
3230 \\
3190 \\
3170 \\
3160\end{array}$ & $\begin{array}{c}7300 \\
8600 \\
9470 \\
9240 \\
8650 \\
-\end{array}$ & $\begin{array}{l}3630 \\
3350 \\
3070 \\
2820 \\
2680 \\
2570\end{array}$ & $\begin{array}{l}1360 \\
2460 \\
1990 \\
2020 \\
2150 \\
-\end{array}$ & & $\begin{array}{l}581 \\
540 \\
502 \\
483 \\
479 \\
480\end{array}$ & $\begin{array}{r}1070 \\
845 \\
698 \\
708 \\
919 \\
1420\end{array}$ & $\begin{array}{r}2710 \\
2760 \\
2730 \\
2900 \\
4080 \\
-\end{array}$ \\
\hline $\begin{array}{l}\text { TOTAE } \\
\text { MEAN } \\
\text { MAX } \\
\text { MIN } \\
\text { CESM } \\
\text { IN. } \\
\text { AC-FT }\end{array}$ & $\begin{array}{r}17818 \\
575 \\
920 \\
274 \\
.11 \\
.12 \\
35340\end{array}$ & $\begin{array}{r}34107 \\
1137 \\
1640 \\
775 \\
.21 \\
.23 \\
67650\end{array}$ & $\begin{array}{r}56044 \\
1808 \\
3950 \\
543 \\
.33 \\
.38 \\
111200\end{array}$ & $\begin{array}{r}35360 \\
1141 \\
4000 \\
650 \\
.21 \\
70144\end{array}$ & $\begin{array}{r}25185 \\
899 \\
2200 \\
620 \\
.16 \\
.17 \\
49950\end{array}$ & $\begin{array}{r}102910 \\
3320 \\
4850 \\
1300 \\
.61 \\
.70 \\
204100\end{array}$ & $\begin{array}{r}151870 \\
5062 \\
9470 \\
2820 \\
.93 \\
1.04 \\
301200\end{array}$ & $\begin{array}{r}132080 \\
4261 \\
7970 \\
2570 \\
.78 \\
.90 \\
262000\end{array}$ & $\begin{array}{r}65320 \\
2177 \\
2730 \\
1360 \\
.40 \\
.45 \\
129600\end{array}$ & & $\begin{array}{r}33572 \\
1083 \\
2040 \\
479 \\
.20 \\
.23 \\
66590\end{array}$ & $\begin{array}{r}21372 \\
689 \\
3130 \\
298 \\
.13 \\
.15 \\
42390\end{array}$ & $\begin{array}{r}88290 \\
2943 \\
6870 \\
1330 \\
.54 \\
.60 \\
175100\end{array}$ \\
\hline $\begin{array}{l}\text { CAL YE } \\
\text { TIY } Y E\end{array}$ & $\begin{array}{l}84 \\
85\end{array}$ & PAL & $\begin{array}{l}344 \\
928\end{array}$ & $\begin{array}{ll}\text { MEAN } & 5986 \\
\text { MEAN } & 2093\end{array}$ & $\begin{array}{l}\text { MAX } \\
\text { MAX }\end{array}$ & $\begin{array}{r}35900 \\
9470\end{array}$ & $\begin{array}{ll}\text { MIN } & 274 \\
\text { MIN } & 274\end{array}$ & $\begin{array}{l}\text { CFSM } \\
\text { CFSM }\end{array}$ & $\begin{array}{r}1.10 \\
.38\end{array}$ & $\begin{array}{l}\text { IN. } \\
\text { IN. }\end{array}$ & $\begin{array}{r}14.95 \\
5.21\end{array}$ & $\begin{array}{l}A C-E T \\
A C-F T\end{array}$ & $\begin{array}{l}4346000 \\
1515000\end{array}$ \\
\hline
\end{tabular}


LOCATION.--Lat $41^{\circ} 42^{\prime} 13^{\prime \prime}$, long $93^{\circ} 41^{\prime} 21^{\prime \prime}$, in SE 1/4, Sw $1 / 4$ sec.30, T.80 N., R.24 w., Polk County, Hydrologic Unit 07100004 , in control tower of Saylorville Dam, $3.2 \mathrm{mi}$ northwest of Saylorville, $4.2 \mathrm{mi}$ upstream from Beaver Creek, and at mile 213.7 .

DRAINAGE AREA. $--5,823 \mathrm{mi} 2$.

PERIOD OF RECORD.--April 1977 to current year.

GAGE.--Water-stage recorder. Datum of gage is at NGVD (levels by U.s. Army Corps of Engineers).

REMARKS.--Reservoir is formed by earthfill dam completed in 1976. Storage began in April 1977. Release controlled at intake structure to forechamber of $22 \mathrm{ft}$ diameter concrete conduit through dam. Ungated chute spiliway $430 \mathrm{ft}$ in length at right end of dam at elevation $884 \mathrm{ft}$, contents, 570,000 acre-ft. Conservation pool at elevation $833 \mathrm{ft}$, contents, 74,000 acre-ft, surface area, 5,400 acres. Flood pool elevation at 890 ft, contents, 676,000 acre-ft, surface area, 16,700 acres. Reservoir is used for flood control, low-flow augmentation, conservation and recreation.

COOPERATION.--Records provided by U.S. Army Corps of Engineers.

EXTREMES FOR PERIOD OF RECORD.--Maximum daily contents, 655,000 acre-ft June 22, 1984, maximum elevation, 889.25 ft June 22, 1984; minimum daily contents, 45,000 acre-ft May 15, 1985; minimum elevation, 832.61 ft Jan.

$19,1979$.

EXTREMES FOR CURRENT YEAR.--Maximum daily contents, 56,000 acre-ft Nov. 13; maximum elevation, 839.39 ft Sept. 9; minimum daily contents, 45,000 acre-ft May 15, minimum elevation, 835.94 ft May 5 .

Capacity table (elevation, in feet, and contents, in acre-feet)

$\begin{array}{rrrrrr}805 & 360 & 833 & 74,000 & 884 & 570,000 \\ 810 & 2,300 & 840 & 116,000 & 890 & 676,000 \\ 815 & 7,700 & 850 & 190,000 & 900 & 938,000 \\ 820 & 19,000 & 860 & 278,000 & 910 & 1,320,000 \\ 830 & 58,600 & 880 & 511,000 & 915 & 1,530,000\end{array}$

RESERVOIR STORAGE (AC-FT), WATER YEAR OCTOBER 1984 TO SEPTEMBER 1985 INSTANTANEOUS OBSERVATIONS AT 2400

\begin{tabular}{|c|c|c|c|c|c|c|c|c|c|c|c|c|}
\hline DAY & OCT & Nov & DEC & JAN & FEB & MAR & APR & MAY & JUN & JUL & AUG & SEP \\
\hline $\begin{array}{l}1 \\
2 \\
3 \\
4 \\
5\end{array}$ & $\begin{array}{l}53600 \\
53600 \\
53700 \\
53800 \\
53900\end{array}$ & $\begin{array}{l}55500 \\
55400 \\
55500 \\
55600 \\
55600\end{array}$ & $\begin{array}{l}54900 \\
546) 0 \\
54840 \\
54300 \\
53600\end{array}$ & $\begin{array}{l}47600 \\
46600 \\
46400 \\
47200 \\
47200\end{array}$ & $\begin{array}{l}47200 \\
47100 \\
47100 \\
47100 \\
47200\end{array}$ & $\begin{array}{l}46500 \\
46500 \\
47100 \\
48200 \\
47700\end{array}$ & $\begin{array}{l}45700 \\
45700 \\
45900 \\
47000 \\
47800\end{array}$ & $\begin{array}{r}45800 \\
45600 \\
45300 \\
45100 \\
45600\end{array}$ & $\begin{array}{l}45500 \\
45200 \\
45100 \\
45400 \\
45500\end{array}$ & $\begin{array}{l}45200 \\
45700 \\
45600 \\
45500 \\
45600\end{array}$ & $\begin{array}{l}46300 \\
46400 \\
46400 \\
46600 \\
46700\end{array}$ & $\begin{array}{l}52400 \\
52500 \\
52300 \\
52200 \\
52500\end{array}$ \\
\hline $\begin{array}{r}6 \\
7 \\
8 \\
9 \\
10\end{array}$ & $\begin{array}{l}54000 \\
54100 \\
54200 \\
54200 \\
54400\end{array}$ & $\begin{array}{l}55500 \\
55500 \\
55400 \\
55300 \\
55400\end{array}$ & $\begin{array}{l}52700 \\
52300 \\
52100 \\
51300 \\
51500\end{array}$ & $\begin{array}{l}47200 \\
47200 \\
47000 \\
46900 \\
47000\end{array}$ & $\begin{array}{r}47200 \\
47300 \\
47400 \\
47400 \\
47400\end{array}$ & $\begin{array}{l}47300 \\
47000 \\
46700 \\
46400 \\
47100\end{array}$ & $\begin{array}{l}47400 \\
47300 \\
47100 \\
46400 \\
46000\end{array}$ & $\begin{array}{l}46100 \\
46200 \\
45900 \\
45700 \\
45800\end{array}$ & $\begin{array}{r}45600 \\
45700 \\
45600 \\
45400 \\
45400\end{array}$ & $\begin{array}{l}45900 \\
46200 \\
46400 \\
46200 \\
46000\end{array}$ & $\begin{array}{l}46800 \\
46900 \\
46900 \\
46900 \\
47000\end{array}$ & $\begin{array}{l}52500 \\
53700 \\
55400 \\
55600 \\
55400\end{array}$ \\
\hline $\begin{array}{l}11 \\
12 \\
13 \\
14 \\
15\end{array}$ & $\begin{array}{l}54500 \\
54500 \\
54500 \\
54600 \\
55000\end{array}$ & $\begin{array}{l}55600 \\
55800 \\
56000 \\
55200 \\
55000\end{array}$ & $\begin{array}{l}50900 \\
50900 \\
50800 \\
50000 \\
48800\end{array}$ & $\begin{array}{l}47000 \\
46800 \\
46700 \\
46800 \\
46700\end{array}$ & $\begin{array}{l}47500 \\
47500 \\
47500 \\
47600 \\
47600\end{array}$ & $\begin{array}{l}47700 \\
49000 \\
48700 \\
47600 \\
46900\end{array}$ & $\begin{array}{l}45600 \\
45800 \\
46200 \\
46100 \\
45900\end{array}$ & $\begin{array}{l}46000 \\
46100 \\
45800 \\
45200 \\
45000\end{array}$ & $\begin{array}{l}45700 \\
45900 \\
46000 \\
46100 \\
46200\end{array}$ & $\begin{array}{l}46000 \\
46000 \\
46100 \\
46100 \\
46000\end{array}$ & $\begin{array}{l}47000 \\
47000 \\
47000 \\
47100 \\
47200\end{array}$ & $\begin{array}{l}54200 \\
52400 \\
51200 \\
51300 \\
51800\end{array}$ \\
\hline $\begin{array}{l}16 \\
17 \\
18 \\
19 \\
20\end{array}$ & $\begin{array}{l}55300 \\
55300 \\
55300 \\
55100 \\
54800\end{array}$ & $\begin{array}{l}54600 \\
54700 \\
54900 \\
55000 \\
55100\end{array}$ & $\begin{array}{l}48200 \\
47200 \\
47100 \\
47700 \\
48300\end{array}$ & $\begin{array}{l}46800 \\
47000 \\
47200 \\
47300 \\
47300\end{array}$ & $\begin{array}{l}47600 \\
47600 \\
47800 \\
48000 \\
48100\end{array}$ & $\begin{array}{l}46500 \\
46300 \\
46400 \\
46300 \\
46100\end{array}$ & $\begin{array}{l}46400 \\
46800 \\
46800 \\
46200 \\
45800\end{array}$ & $\begin{array}{l}45200 \\
45500 \\
45800 \\
46100 \\
46200\end{array}$ & $\begin{array}{l}46500 \\
46500 \\
46200 \\
46100 \\
45900\end{array}$ & $\begin{array}{l}45800 \\
45800 \\
46000 \\
46300 \\
46400\end{array}$ & $\begin{array}{l}47200 \\
47400 \\
47400 \\
47500 \\
47500\end{array}$ & $\begin{array}{l}52000 \\
51700 \\
51500 \\
51400 \\
51700\end{array}$ \\
\hline $\begin{array}{l}21 \\
22 \\
23 \\
24 \\
25\end{array}$ & $\begin{array}{l}54800 \\
54900 \\
55000 \\
54900 \\
54900\end{array}$ & $\begin{array}{l}55100 \\
55000 \\
54800 \\
54600 \\
54400\end{array}$ & $\begin{array}{l}48900 \\
48400 \\
47600 \\
47200 \\
46700\end{array}$ & $\begin{array}{l}47200 \\
47200 \\
47200 \\
47300 \\
47300\end{array}$ & $\begin{array}{l}48100 \\
47400 \\
47400 \\
47800 \\
47600\end{array}$ & $\begin{array}{l}46000 \\
46100 \\
46300 \\
46300 \\
46300\end{array}$ & $\begin{array}{l}45600 \\
45600 \\
46300 \\
46800 \\
47300\end{array}$ & $\begin{array}{l}45900 \\
45700 \\
45700 \\
45800 \\
46300\end{array}$ & $\begin{array}{l}45700 \\
45700 \\
45700 \\
45700 \\
45500\end{array}$ & $\begin{array}{l}46500 \\
46400 \\
46400 \\
46500 \\
46800\end{array}$ & $\begin{array}{l}47700 \\
48200 \\
50300 \\
53100 \\
52900\end{array}$ & $\begin{array}{l}52200 \\
52400 \\
51700 \\
51200 \\
51200\end{array}$ \\
\hline $\begin{array}{l}26 \\
27 \\
28 \\
29 \\
30 \\
31\end{array}$ & $\begin{array}{l}54900 \\
55000 \\
54900 \\
54900 \\
54900 \\
55500\end{array}$ & $\begin{array}{r}54400 \\
54600 \\
54800 \\
54900 \\
55000 \\
-\end{array}$ & $\begin{array}{l}46500 \\
47000 \\
47500 \\
47700 \\
48100 \\
48600\end{array}$ & $\begin{array}{l}47300 \\
47300 \\
47200 \\
47100 \\
47300 \\
47200\end{array}$ & $\begin{array}{r}46900 \\
46000 \\
46500 \\
- \\
\hdashline-\end{array}$ & $\begin{array}{l}46500 \\
46200 \\
46100 \\
46000 \\
46100 \\
46000\end{array}$ & $\begin{array}{r}47600 \\
47600 \\
47600 \\
47400 \\
46600 \\
-\end{array}$ & $\begin{array}{l}46600 \\
46100 \\
45800 \\
45800 \\
45800 \\
45700\end{array}$ & $\begin{array}{r}45700 \\
45600 \\
45800 \\
45500 \\
45300 \\
-\end{array}$ & $\begin{array}{l}46600 \\
46200 \\
45900 \\
45900 \\
46000 \\
46200\end{array}$ & $\begin{array}{l}\mathbf{5 2 1 0 0} \\
\mathbf{5 2 0 0 0} \\
\mathbf{5 2 0 0 0} \\
\mathbf{5 2 2 0 0} \\
\mathbf{5 2 2 0 0} \\
\mathbf{5 2 2 0 0}\end{array}$ & $\begin{array}{r}51500 \\
51800 \\
52300 \\
52900 \\
52300 \\
-\end{array}$ \\
\hline $\begin{array}{l}\text { MEAN } \\
\text { MAX } \\
\text { MIN }\end{array}$ & $\begin{array}{l}54600 \\
55500 \\
53600\end{array}$ & $\begin{array}{l}55100 \\
56000 \\
54400\end{array}$ & $\begin{array}{l}49900 \\
54800 \\
46500\end{array}$ & $\begin{array}{l}47100 \\
47600 \\
46400\end{array}$ & $\begin{array}{l}47400 \\
48100 \\
46000\end{array}$ & $\begin{array}{r}46800 \\
49000 \\
46000\end{array}$ & $\begin{array}{l}46500 \\
47800 \\
45600\end{array}$ & $\begin{array}{l}45800 \\
46600 \\
45000\end{array}$ & $\begin{array}{l}45700 \\
46500 \\
45100\end{array}$ & $\begin{array}{l}46100 \\
46800 \\
45200\end{array}$ & $\begin{array}{l}48500 \\
53100 \\
46300\end{array}$ & $\begin{array}{l}52400 \\
55600 \\
51200\end{array}$ \\
\hline
\end{tabular}


05481650 DES MOINES RIVER hEAR SAYLORVILLE, IA

LOCATION.--Lat $41^{\circ} 40^{\prime} 50^{\prime}$, long $93^{\circ} 40^{\prime} 05^{\prime \prime}$, near center of sec.5, T.79 N., R.24 W., Polk County, Bydrologic Onit 07100004 , on left bank' $5 \mathrm{ft}$ upstream of Fisher bridge on county highway R6E, $2.0 \mathrm{mi}$ west of Saylorvilie, 2.1 mi downstream from Rock Creek, $2.3 \mathrm{mi}$ downstream from Saylorville Dam, $2.3 \mathrm{mi}$ upstream from Beaver Creek, and mile 211.4

DRAINAGE AREA, $--5,841 \mathrm{mi}^{2}$.

\section{WATER-DISCHARGE RECORDS}

PERIOD OF RECORD.--October 1961 to current year.

GAGE.--Water-stage recorder. Datum of gage is $787.42 \mathrm{ft}$ above ngvD (levels by 0 . S. Army Corps of Engineers). Prior to Aug. 6, 1970 , nonrecording gage at same site and datum.

REMARKS.--No estimated dally discharges. Records good. Flow regulated by Saylorville Lake (station 05481630 ) 2.3 mi upstream since Apr. 12, 1977. U. S. Army Corps of Engineers satelite telemeter at station.

COOPERATION.--Four discharge measurements provided by 0 . S. Army Corps of Engineers.

AVERAGE DISCHARGE.- -24 years, $2,863 \mathrm{ft} / \mathrm{s}, 6.66 \mathrm{in} / \mathrm{yr}, 2,074,000$ acre-ft/yr; median of yearly mean discharges, $2,280 \mathrm{ft} / \mathrm{s}, 5.3 \mathrm{in} / \mathrm{Yr}, 1,650,000 \mathrm{acre}-\mathrm{ft} / \mathrm{Yr}$.

EXTREMES FOR PERIOD OF RECORD.--Maximum discharge, $47,400 \mathrm{ft}^{2} / 8$ Apr. 10, 1965, gage height, 24.02 ft; minimum daily, $13 \mathrm{ft}^{3} / \mathrm{s}$ Jan. 25,1977 .

EXTREMES OUTSIDE PERIOD OF RECORD,--Maximum stage since at least 1893, 24.5 ft June 24, 1954, from floodmarks, discharge, $60,000 \mathrm{ft}^{3} / \mathrm{s}$.

EXTREMES FOR CURRENT YEAR.--Maximum discharge, $9,220 \mathrm{ft}^{3 / 8}$ Apr. 29, gage height, $12.80 \mathrm{ft}$, minimum daily discharge, $205 \mathrm{ft}^{2} / \mathrm{s}$ Aug. 15.

DISCEARGE, IN CUBIC PEET PER SECOND, WATER YEAR OCTOBER 1984 TO SEPTEMBER 1985 MEAN VALUES

\begin{tabular}{|c|c|c|c|c|c|c|c|c|c|c|c|c|}
\hline DAY & OCT & NOV & DEC & JAN & FEB & MAR & $\mathbf{A P R}$ & MAY & JUN & JUL & AUG & SEP \\
\hline $\begin{array}{l}1 \\
2 \\
3 \\
4 \\
5\end{array}$ & $\begin{array}{l}272 \\
278 \\
283 \\
296 \\
305\end{array}$ & $\begin{array}{l}1730 \\
1690 \\
1400 \\
1270 \\
1250\end{array}$ & $\begin{array}{r}1100 \\
983 \\
886 \\
876 \\
1070\end{array}$ & $\begin{array}{r}3330 \\
2970 \\
1480 \\
961 \\
1680\end{array}$ & $\begin{array}{l}491 \\
487 \\
484 \\
381 \\
300\end{array}$ & $\begin{array}{l}1230 \\
1140 \\
1160 \\
1900 \\
2680\end{array}$ & $\begin{array}{l}3140 \\
2850 \\
2730 \\
2750 \\
3590\end{array}$ & $\begin{array}{l}8540 \\
7180 \\
6740 \\
6430 \\
5790\end{array}$ & $\begin{array}{l}2660 \\
2650 \\
2390 \\
2190 \\
2190\end{array}$ & $\begin{array}{l}2250 \\
1640 \\
2140 \\
2130 \\
1920\end{array}$ & $\begin{array}{l}352 \\
319 \\
321 \\
319 \\
319\end{array}$ & $\begin{array}{l}1290 \\
1960 \\
2210 \\
1790 \\
1290\end{array}$ \\
\hline $\begin{array}{r}6 \\
7 \\
8 \\
9 \\
10\end{array}$ & $\begin{array}{l}310 \\
316 \\
322 \\
331 \\
338\end{array}$ & $\begin{array}{l}1240 \\
1240 \\
1240 \\
1240 \\
1210\end{array}$ & $\begin{array}{r}1540 \\
1120 \\
849 \\
851 \\
824\end{array}$ & $\begin{array}{l}1680 \\
1670 \\
1660 \\
1350 \\
1130\end{array}$ & $\begin{array}{l}297 \\
308 \\
296 \\
290 \\
290\end{array}$ & $\begin{array}{l}2630 \\
2250 \\
1920 \\
1900 \\
1890\end{array}$ & $\begin{array}{l}5140 \\
5640 \\
5990 \\
6290 \\
5790\end{array}$ & $\begin{array}{l}5520 \\
5520 \\
5330 \\
4870 \\
4280\end{array}$ & $\begin{array}{l}2200 \\
2200 \\
2220 \\
2230 \\
2000\end{array}$ & $\begin{array}{l}1630 \\
1510 \\
1680 \\
1780 \\
1600\end{array}$ & $\begin{array}{l}318 \\
287 \\
256 \\
255 \\
254\end{array}$ & $\begin{array}{l}1560 \\
2230 \\
3730 \\
5780 \\
6220\end{array}$ \\
\hline $\begin{array}{l}11 \\
12 \\
13 \\
14 \\
15\end{array}$ & $\begin{array}{l}344 \\
429 \\
489 \\
494 \\
576\end{array}$ & $\begin{array}{l}1190 \\
1190 \\
1480 \\
1980 \\
2130\end{array}$ & $\begin{array}{r}728 \\
921 \\
1110 \\
1500 \\
1800\end{array}$ & $\begin{array}{r}1120 \\
1130 \\
986 \\
875 \\
875\end{array}$ & $\begin{array}{l}294 \\
291 \\
279 \\
274 \\
270\end{array}$ & $\begin{array}{l}2230 \\
3080 \\
4500 \\
5560 \\
5220\end{array}$ & $\begin{array}{l}5390 \\
4730 \\
3950 \\
3930 \\
3720\end{array}$ & $\begin{array}{l}4010 \\
3980 \\
3950 \\
3950 \\
3500\end{array}$ & $\begin{array}{l}1800 \\
1810 \\
1830 \\
1970 \\
2170\end{array}$ & $\begin{array}{l}1310 \\
1190 \\
1180 \\
1170 \\
1160\end{array}$ & $\begin{array}{l}256 \\
259 \\
259 \\
235 \\
205\end{array}$ & $\begin{array}{l}6170 \\
5810 \\
4870 \\
3180 \\
2350\end{array}$ \\
\hline $\begin{array}{l}16 \\
17 \\
18 \\
19 \\
20\end{array}$ & $\begin{array}{r}766 \\
1030 \\
1160 \\
1270 \\
1360\end{array}$ & $\begin{array}{l}2130 \\
1750 \\
1460 \\
1450 \\
1450\end{array}$ & $\begin{array}{l}1810 \\
1800 \\
1360 \\
1030 \\
1300\end{array}$ & $\begin{array}{r}765 \\
699 \\
690 \\
650 \\
1030\end{array}$ & $\begin{array}{l}269 \\
272 \\
276 \\
285 \\
433\end{array}$ & $\begin{array}{l}4880 \\
4530 \\
4270 \\
4250 \\
4240\end{array}$ & $\begin{array}{l}3060 \\
2600 \\
2900 \\
3230 \\
2930\end{array}$ & $\begin{array}{l}2960 \\
2830 \\
2850 \\
2850 \\
3130\end{array}$ & $\begin{array}{l}2260 \\
2540 \\
2760 \\
2780 \\
2790\end{array}$ & $\begin{array}{l}988 \\
768 \\
699 \\
696 \\
695\end{array}$ & $\begin{array}{l}220 \\
223 \\
227 \\
230 \\
233\end{array}$ & $\begin{array}{l}2350 \\
2360 \\
2270 \\
1930 \\
1670\end{array}$ \\
\hline $\begin{array}{l}21 \\
22 \\
23 \\
24 \\
25\end{array}$ & $\begin{array}{r}1120 \\
917 \\
1050 \\
1190 \\
1200\end{array}$ & $\begin{array}{l}1360 \\
1410 \\
1400 \\
1400 \\
1380\end{array}$ & $\begin{array}{l}1780 \\
2410 \\
2750 \\
2240 \\
1790\end{array}$ & $\begin{array}{r}1060 \\
763 \\
693 \\
676 \\
683\end{array}$ & $\begin{array}{l}1220 \\
2200 \\
2180 \\
2270 \\
2610\end{array}$ & $\begin{array}{l}3960 \\
3720 \\
3710 \\
3690 \\
3510\end{array}$ & $\begin{array}{l}2630 \\
2600 \\
2590 \\
3280 \\
4440\end{array}$ & $\begin{array}{l}3330 \\
3340 \\
3130 \\
2970 \\
2970\end{array}$ & $\begin{array}{l}2540 \\
2370 \\
2160 \\
2000 \\
2000\end{array}$ & $\begin{array}{l}691 \\
690 \\
696 \\
635 \\
507\end{array}$ & $\begin{array}{r}236 \\
248 \\
248 \\
256 \\
1850\end{array}$ & $\begin{array}{l}1430 \\
1750 \\
2540 \\
2670 \\
2390\end{array}$ \\
\hline $\begin{array}{l}26 \\
27 \\
28 \\
29 \\
30 \\
31\end{array}$ & $\begin{array}{l}1210 \\
1230 \\
1300 \\
1390 \\
1400 \\
1410\end{array}$ & $\begin{array}{l}1240 \\
1130 \\
1110 \\
1100 \\
1100 \\
-0-\end{array}$ & $\begin{array}{l}1430 \\
1170 \\
1760 \\
2380 \\
2690 \\
3000\end{array}$ & $\begin{array}{l}672 \\
668 \\
662 \\
560 \\
503 \\
640\end{array}$ & $\begin{array}{r}2330 \\
1670 \\
1390 \\
\square \\
\ldots-\end{array}$ & $\begin{array}{l}3250 \\
3290 \\
3250 \\
3050 \\
3030 \\
3150\end{array}$ & $\begin{array}{l}5510 \\
7010 \\
8440 \\
9010 \\
9180 \\
-0-\end{array}$ & $\begin{array}{l}3340 \\
3710 \\
3360 \\
2830 \\
2660 \\
2660\end{array}$ & $\begin{array}{l}1790 \\
2050 \\
2400 \\
2380 \\
2370 \\
---\end{array}$ & $\begin{array}{l}803 \\
987 \\
775 \\
492 \\
403 \\
401\end{array}$ & $\begin{array}{r}1860 \\
1100 \\
873 \\
798 \\
919 \\
1020\end{array}$ & $\begin{array}{l}2350 \\
2540 \\
2640 \\
2850 \\
3540 \\
-\end{array}$ \\
\hline $\begin{array}{l}\text { TOTAL } \\
\text { MEAN } \\
\text { MAX } \\
\text { MIN } \\
\text { AC-FT }\end{array}$ & $\begin{array}{r}24386 \\
787 \\
1410 \\
272 \\
48370\end{array}$ & $\begin{array}{r}42350 \\
1412 \\
2130 \\
1100 \\
84000\end{array}$ & $\begin{array}{r}46858 \\
1512 \\
3000 \\
728 \\
92940\end{array}$ & $\begin{array}{r}34311 \\
1107 \\
3330 \\
503 \\
68060\end{array}$ & $\begin{array}{r}22437 \\
801 \\
2610 \\
269 \\
44500\end{array}$ & $\begin{array}{r}99070 \\
3196 \\
5560 \\
1140 \\
196500\end{array}$ & $\begin{array}{r}135040 \\
4501 \\
9180 \\
2590 \\
267900\end{array}$ & $\begin{array}{r}128510 \\
4145 \\
8540 \\
2660 \\
254900\end{array}$ & $\begin{array}{r}67700 \\
2257 \\
2790 \\
1790 \\
134300\end{array}$ & $\begin{array}{r}35216 \\
1136 \\
2250 \\
401 \\
69850\end{array}$ & $\begin{array}{r}14755 \\
476 \\
1860 \\
205 \\
29270\end{array}$ & $\begin{array}{r}85720 \\
2857 \\
6220 \\
1290 \\
170000\end{array}$ \\
\hline $\begin{array}{ll}\text { CAL YR } \\
\text { WIR YR }\end{array}$ & $\begin{array}{l}84 \\
85\end{array}$ & $\begin{array}{l}\text { TOTAL } \\
\text { TOTAL }\end{array}$ & $\begin{array}{r}2365471 \\
736353\end{array}$ & $\begin{array}{l}\text { MEAN } \\
\text { MEAN }\end{array}$ & $\begin{array}{l}6463 \\
2017\end{array}$ & $\begin{array}{l}\text { MAX } \\
\text { MAX }\end{array}$ & $\begin{array}{r}29600 \\
9180\end{array}$ & $\begin{array}{l}\text { MIN } \\
\text { MIN }\end{array}$ & $\begin{array}{l}191 \\
205\end{array}$ & $\begin{array}{l}\text { PT } 469 \\
\text { FT } 146\end{array}$ & & ! \\
\hline
\end{tabular}


PERIOD OF RECORD: Water years 1962 to current year.

PERIOD OF DAILY RECORD.--

SPECIFIC CONDUCTANCE: December 1967 to september 1971, October 1971 to september 1980 (partial record station), October 1980 to current year.

WATER TEMPERATURES: October 1961 to September 1971, October 1971 to september 1980 (partial record station). October 1980 to current year.

SUSPENDED-SEDIMENT DISCAARGE: October 1961 to current year.

REMARKS.--Records of specific conductance are obtained from suspended-sediment samples at time of analysis. During periods of partial ice cover, sediment samples are collected in open water channel.

EXTREMES FOR PERIOD OF DAILY RECORD.-

SPECIFIC CONDUCTANCE: Maximun daily, 1,400 microsiemens Feb, 18, 1977, minimum daily, 90 microsiemens Feb. 19 , 1971 .

WATER TEMPERATUREs: Maximum daily, $36.0^{\circ} \mathrm{C}$ June 29,1971 ; minimum daily, $0.0^{\circ} \mathrm{C}$ on many days during winter periods.

SEDIMENT CONCENTRATIONS: Maximum dally mean, 5,400 mg/L May 14, 1970; minimum daily mean, 1 mg/L Jan. 8 , 1965. SEDIMENT LOADS: Maximum da11Y, 148,000 tons June 12, 1966; minimum daily, 1 ton Jan. 8, 1965, Feb. 8-12, 23, 1967 .

EXTREMES FOR CURRENT YEAR:

SPECIFIC CONDUCTANCE: Maximum daily, 1050 microsiemens Jan. 31, minimum daily, 185 microsiemens Feb. 10.

WATER TEMPERATURES: Maximum daily, $28.0^{\circ} \mathrm{C}$ July 22 minimum daily, $0.0^{\circ} \mathrm{C}$ several days during winter period. SEDIMENT CONCENTRATIONS: Maximum daily mean, $166 \mathrm{mg} / \mathrm{L}$ June 21 , minimum daily mean, $7 \mathrm{mg} / \mathrm{L}$ Mar. 9 , Sept. 19. SEDIMENT LOADS: Maximum daily, 3,530 tons Apt, 28, minimum daily, 6.9 tons Feb. 19.

SPECIFIC CONDUCTANCE (MICROSIEMENS/CM AT 25 DEG. C.) WATER YEAR OCTOBER 1984 TO SEPTEMBER 1985 RANDOM VALUES

\begin{tabular}{|c|c|c|c|c|c|c|c|c|c|c|c|c|}
\hline DAY & $O C T$ & NOV & DEC & JAN & FEB & MAR & APR & MAY & JUN & JUL & AUG & SEP \\
\hline $\begin{array}{l}1 \\
2 \\
3 \\
4 \\
5\end{array}$ & $\frac{610}{-210}$ & $\begin{array}{c}--- \\
620 \\
-510 \\
---\end{array}$ & $\begin{array}{l}680 \\
--0 \\
-740\end{array}$ & $\begin{array}{l}-- \\
-- \\
-- \\
-- \\
--\end{array}$ & $\begin{array}{l}-\ldots 25 \\
\ldots- \\
\ldots-\end{array}$ & $\begin{array}{r}830 \\
780 \\
--\end{array}$ & $\begin{array}{l}--- \\
--- \\
480 \\
480\end{array}$ & $\begin{array}{r}605 \\
620 \\
--0 \\
640\end{array}$ & $\begin{array}{l}700 \\
640 \\
620 \\
-100 \\
700\end{array}$ & $\begin{array}{l}600 \\
--2 \\
-570 \\
670\end{array}$ & $\begin{array}{l}-\infty \\
-270 \\
670 \\
670\end{array}$ & $\begin{array}{l}700 \\
680 \\
680 \\
680 \\
680\end{array}$ \\
\hline $\begin{array}{r}6 \\
7 \\
8 \\
9 \\
10\end{array}$ & $\begin{array}{l}605 \\
590 \\
-605\end{array}$ & $\begin{array}{l}--- \\
--- \\
--- \\
---\end{array}$ & $\frac{740}{-20}$ & $\begin{array}{l}750 \\
--\infty \\
640 \\
--\end{array}$ & $\begin{array}{l}240 \\
--- \\
--2 \\
185\end{array}$ & $\frac{--}{620}$ & $\begin{array}{l}-\infty \\
-\infty \\
--\infty \\
480\end{array}$ & $\begin{array}{l}--1 \\
--150 \\
680 \\
680\end{array}$ & $\begin{array}{l}660 \\
620 \\
630 \\
-\end{array}$ & $\begin{array}{l}660 \\
630 \\
680 \\
660\end{array}$ & $\begin{array}{l}670 \\
660 \\
670 \\
660\end{array}$ & \begin{tabular}{l}
680 \\
\hdashline 690 \\
690
\end{tabular} \\
\hline $\begin{array}{l}11 \\
12 \\
13 \\
14 \\
15\end{array}$ & $\begin{array}{l}600 \\
600 \\
--- \\
---\end{array}$ & $\begin{array}{l}660 \\
--- \\
--\infty \\
--\infty\end{array}$ & $\begin{array}{l}--- \\
680 \\
-- \\
--\end{array}$ & $\begin{array}{l}640 \\
780 \\
740 \\
--- \\
---\end{array}$ & $\frac{-2-}{810}$ & $\overline{-}$ & $\begin{array}{r}580 \\
560 \\
-0- \\
480 \\
--0\end{array}$ & $\begin{array}{l}695 \\
680 \\
620 \\
680 \\
685\end{array}$ & $\begin{array}{l}-540 \\
640 \\
640\end{array}$ & $\begin{array}{l}640 \\
-620 \\
600 \\
580\end{array}$ & $\begin{array}{l}660 \\
660 \\
700 \\
700\end{array}$ & $\begin{array}{l}--- \\
560 \\
560 \\
560 \\
560\end{array}$ \\
\hline $\begin{array}{l}16 \\
17 \\
18 \\
19 \\
20\end{array}$ & $\begin{array}{r}600 \\
620 \\
-\cdots\end{array}$ & $\begin{array}{l}--- \\
--- \\
680 \\
---\end{array}$ & $\begin{array}{l}--- \\
660 \\
--\infty \\
--\infty\end{array}$ & $\begin{array}{l}-- \\
--\infty \\
-\infty \\
-\infty\end{array}$ & $\begin{array}{l}--- \\
260 \\
--2 \\
-230\end{array}$ & $\overline{-}$ & $\begin{array}{l}--1 \\
580 \\
595 \\
580 \\
--\end{array}$ & $\begin{array}{l}680 \\
680 \\
--0 \\
700 \\
700\end{array}$ & $\begin{array}{l}580 \\
680 \\
650 \\
660 \\
620\end{array}$ & $\begin{array}{l}580 \\
560 \\
600 \\
560 \\
560\end{array}$ & $\begin{array}{l}700 \\
700 \\
700 \\
700 \\
700\end{array}$ & $\begin{array}{l}- \\
570 \\
580 \\
5-10\end{array}$ \\
\hline $\begin{array}{l}21 \\
22 \\
23 \\
24 \\
25\end{array}$ & 610 & $\begin{array}{l}680 \\
--0 \\
--- \\
-\infty- \\
---\end{array}$ & $\begin{array}{l}-- \\
-- \\
-- \\
-\infty 80\end{array}$ & $\begin{array}{l}650 \\
-620 \\
-560\end{array}$ & $\begin{array}{l}840 \\
740 \\
--\infty\end{array}$ & $\overline{-}$ & $\begin{array}{l}580 \\
580 \\
580 \\
-- \\
--\end{array}$ & $\begin{array}{l}-- \\
520 \\
630 \\
-\end{array}$ & $\begin{array}{l}-530 \\
-- \\
640\end{array}$ & $\begin{array}{l}660 \\
595 \\
670 \\
680 \\
--\end{array}$ & $\begin{array}{l}700 \\
700 \\
700\end{array}$ & $\begin{array}{l}560 \\
580 \\
680 \\
680\end{array}$ \\
\hline $\begin{array}{l}26 \\
27 \\
28 \\
29 \\
30 \\
31\end{array}$ & 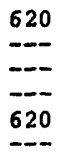 & $\begin{array}{l}640 \\
--- \\
630 \\
645 \\
---\end{array}$ & $\begin{array}{l}--- \\
--- \\
630 \\
-- \\
-- \\
630\end{array}$ & $\begin{array}{c}710 \\
-- \\
--0 \\
050\end{array}$ & $\begin{array}{l}710 \\
-\ldots \\
\cdots-\end{array}$ & \begin{tabular}{l}
-- \\
$\cdots-$ \\
\hdashline- \\
490 \\
480
\end{tabular} & $\begin{array}{l}600 \\
620 \\
620 \\
-00 \\
640 \\
-\end{array}$ & $\begin{array}{l}640 \\
-20 \\
680 \\
600 \\
700 \\
680\end{array}$ & $\begin{array}{c}620 \\
680 \\
\ldots \ldots \\
\ldots\end{array}$ & $\begin{array}{l}--- \\
670 \\
660 \\
680 \\
670 \\
---\end{array}$ & 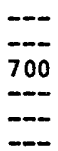 & $\begin{array}{c}-- \\
650 \\
-- \\
- \\
-\end{array}$ \\
\hline
\end{tabular}


05481650 DES WOINES RIVER NEAR SAYLORVILLE, IA--Continued

WATER-QUAL ITY RECORDS

TEMPERATURE, WATER (DEG. C.) WATER YEAR OCTOBER 1984 TO SEPTEMBER 1985 RANDOH VALUES

\begin{tabular}{|c|c|c|c|c|c|c|c|c|c|c|c|c|}
\hline DAY & OCI & nov & DEC & JAN & FEB & MAR & APR & MAY & JUA & JUL & AUG & SEP \\
\hline $\begin{array}{l}1 \\
2 \\
3 \\
4 \\
5\end{array}$ & $\begin{array}{r}16.0 \\
16.0 \\
16.0\end{array}$ & $\begin{array}{r}7.0 \\
10.0 \\
10.0 \\
-0 .\end{array}$ & \begin{tabular}{l}
5.0 \\
\hdashline 6.0 \\
\hdashline- \\
-0
\end{tabular} & $=$ & $\begin{array}{c}2.0 \\
\ldots- \\
\ldots-\end{array}$ & $\begin{array}{l}-0 \\
3.0 \\
3.0 \\
--\infty\end{array}$ & $\begin{array}{l}7.0 \\
7.0 \\
7.0\end{array}$ & $\begin{array}{r}13.0 \\
13.0 \\
13.0 \\
13.0\end{array}$ & $\begin{array}{r}23.0 \\
23.0 \\
23.0 \\
23.0\end{array}$ & $\begin{array}{r}24.0 \\
- \\
24.0 \\
25.0\end{array}$ & $\begin{array}{r}--- \\
--- \\
24.0 \\
24.0\end{array}$ & $\begin{array}{l}26.0 \\
26.0 \\
26.0 \\
26.0 \\
26.0\end{array}$ \\
\hline $\begin{array}{r}6 \\
7 \\
8 \\
9 \\
10\end{array}$ & $\begin{array}{r}15.0 \\
15.0 \\
16.0\end{array}$ & $\begin{array}{r}-.0 \\
7.0 \\
0.0\end{array}$ & $\begin{array}{l}7.0 \\
10.0\end{array}$ & $\begin{array}{r}2.0 \\
2.0 \\
-\end{array}$ & $\begin{array}{l}2.0 \\
2.0 \\
2.0\end{array}$ & $\begin{array}{r}--0 \\
6.0 \\
6.0\end{array}$ & $\begin{array}{l}--0 \\
-- \\
-- \\
7.0\end{array}$ & $\begin{array}{l}--0 \\
14.0 \\
14.0 \\
14.0\end{array}$ & $\begin{array}{r}23.0 \\
23.0 \\
23.0 \\
-\end{array}$ & $\begin{array}{r}25.0 \\
25.0 \\
26.0 \\
23.0\end{array}$ & $\begin{array}{r}24.0 \\
25.0 \\
25.0 \\
25.0\end{array}$ & $\begin{array}{r}26.0 \\
25.0 \\
25.0\end{array}$ \\
\hline $\begin{array}{l}11 \\
12 \\
13 \\
14 \\
15\end{array}$ & $\begin{array}{r}15.0 \\
15.0 \\
- \\
-\end{array}$ & $\begin{array}{r}10.0 \\
- \\
-\end{array}$ & $\begin{array}{l}2.0 \\
-- \\
--\end{array}$ & $\begin{array}{r}2.0 \\
1.0 \\
2.0 \\
-.0\end{array}$ & $\begin{array}{l}-.0 \\
5.0 \\
5.0\end{array}$ & $\begin{array}{l}-\infty \\
-\infty .0 \\
-\infty\end{array}$ & $\begin{array}{r}4.0 \\
10.0 \\
10.0 \\
10.0 \\
\end{array}$ & $\begin{array}{r}14.0 \\
14.0 \\
14.0 \\
17.0\end{array}$ & $\begin{array}{r}23.0 \\
23.0 \\
22.0\end{array}$ & $\begin{array}{r}26.0 \\
26.0 \\
27.0 \\
27.0\end{array}$ & $\begin{array}{r}25.0 \\
25.0 \\
25.0 \\
25.0\end{array}$ & $\begin{array}{l}22.0 \\
22.0 \\
22.0\end{array}$ \\
\hline $\begin{array}{l}16 \\
17 \\
18 \\
19 \\
20\end{array}$ & $\begin{array}{r}15.0 \\
14.0 \\
\ldots\end{array}$ & $\begin{array}{l}-- \\
--0 \\
5.0 \\
--\infty\end{array}$ & 2.0 & $=$ & $\begin{array}{l}--5 \\
5.0 \\
--5\end{array}$ & $\begin{array}{l}--0 \\
6.0 \\
6.0 \\
6.0 \\
6.0\end{array}$ & $\begin{array}{r}10.0 \\
10.0 \\
10.0 \\
-\end{array}$ & $\begin{array}{r}19.0 \\
22.0 \\
22.0 \\
20.0\end{array}$ & $\begin{array}{l}22.0 \\
22.0 \\
22.0 \\
22.0 \\
22.0\end{array}$ & $\begin{array}{l}27.0 \\
27.0 \\
25.0 \\
27.0 \\
27.0\end{array}$ & $\begin{array}{l}25.0 \\
25.0 \\
25.0 \\
25.0 \\
25.0\end{array}$ & $\begin{array}{r}20.0 \\
22.0 \\
20.0\end{array}$ \\
\hline $\begin{array}{l}21 \\
22 \\
23 \\
24 \\
25\end{array}$ & $\begin{array}{r}14.0 \\
14.0 \\
\hdashline-0\end{array}$ & $\begin{array}{l}6.0 \\
-- \\
-- \\
-- \\
--\end{array}$ & $\begin{array}{l}-\infty \\
-\cdots \\
2.0 \\
-\infty-\end{array}$ & $\begin{array}{l}2.0 \\
2.0 \\
2.0\end{array}$ & $\begin{array}{l}5.0 \\
5.0 \\
2.0 \\
--\end{array}$ & $\begin{array}{l}-\infty \\
5.0 \\
-\infty\end{array}$ & $\begin{array}{r}11.0 \\
12.0 \\
12.0 \\
-\ldots \\
-\end{array}$ & $\begin{array}{r}22.0 \\
22.0 \\
\ldots \\
\ldots-\end{array}$ & 23.0 & $\begin{array}{r}27.0 \\
28.0 \\
25.0 \\
25.0 \\
-\end{array}$ & $\begin{array}{r}23.0 \\
22.0 \\
22.0\end{array}$ & $\begin{array}{r}22.0 \\
19.0 \\
19.0\end{array}$ \\
\hline $\begin{array}{l}26 \\
27 \\
28 \\
29 \\
30 \\
31\end{array}$ & $\begin{array}{r}13.0 \\
0.0 \\
11.0\end{array}$ & $\begin{array}{l}5.0 \\
3.0 \\
5.0 \\
-\ldots-\end{array}$ & \begin{tabular}{l}
-- \\
2.0 \\
2.0 \\
\hdashline 2.0
\end{tabular} & $\begin{array}{l}2.0 \\
2.0 \\
2.0\end{array}$ & $\begin{array}{l}3.0 \\
-\infty \\
-\infty\end{array}$ & $\begin{array}{l}5.0 \\
5.0 \\
5.0 \\
5.0 \\
6.0 \\
7.0\end{array}$ & $\begin{array}{r}13.0 \\
13.0 \\
13.0 \\
15.0\end{array}$ & $\begin{array}{r}22.0 \\
22.0 \\
22.0 \\
23.0 \\
23.0\end{array}$ & $\begin{array}{r}24.0 \\
24.0 \\
- \\
-\end{array}$ & $\begin{array}{r}--0 \\
24.0 \\
25.0 \\
24.0 \\
24.0 \\
\end{array}$ & $\begin{array}{r}--- \\
24.0 \\
24.0 \\
-\cdots\end{array}$ & 17.0 \\
\hline
\end{tabular}

SUSPENDED-SEDIMENT, WATER YEAR OCTOBER 1984 TO SEPTEMBER 1985

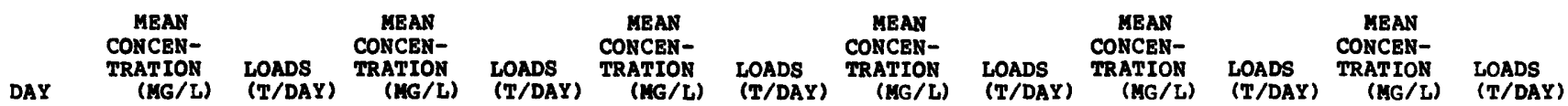
OCTOBER NOVBHBER DECEMBER JANUARY FEBRUARY

MARCH

$\begin{array}{llll}13 & 9.5 & 27 & 126 \\ 17 & 13 & 25 & 11 \\ 23 & 18 & 23 & 87 \\ 24 & 19 & 22 & 75 \\ 22 & 18 & 23 & 78\end{array}$

126
114
87
75
78

23
18
17
17
30

$\begin{array}{ll}68 & 36 \\ 48 & 35 \\ 41 & 32 \\ 40 & 18 \\ 87 & 21\end{array}$

$\begin{array}{rr}36 & 324 \\ 35 & 281 \\ 32 & 128 \\ 18 & 47 \\ 21 & 95\end{array}$

324
281
128
47
95

$\begin{array}{ll}18 & 15 \\ 15 & 13 \\ 17 & 15 \\ 17 & 15 \\ 18 & 16\end{array}$

$\begin{array}{rr}26 & 87 \\ 32 & 107 \\ 38 & 127 \\ 42 & 141 \\ 36 & 118\end{array}$

$\begin{array}{rr}65 & 270 \\ 56 & 169 \\ 48 & 110 \\ 44 & 101 \\ 40 & 89\end{array}$

25
28
53
56
58

113
126
23
20
17

113
126
238
204
177

$\begin{array}{ll}36 & 48 \\ 27 & 36 \\ 24 & 31 \\ 22 & 23 \\ 20 & 16\end{array}$

$\begin{array}{ll}18 & 14 \\ 17 & 14 \\ 16 & 13 \\ 17 & 13 \\ 17 & 13\end{array}$

$\begin{array}{ll}22 & 20 \\ 24 & 2 \\ 24 & 3 \\ 24 & 3 \\ 27 & 4\end{array}$

80
71

92
128

39

77
90

161

$$
\begin{aligned}
& 33 \\
& 35
\end{aligned}
$$$$
\begin{aligned}
& 134 \\
& 170
\end{aligned}
$$$$
\begin{aligned}
& 59 \\
& 50 \\
& 31 \\
& 18 \\
& 17
\end{aligned}
$$

178
153

$173 \quad 35 \quad 171$

137

110

106

$\begin{array}{ll}35 & 171 \\ 37 & 180 \\ 39 & 143 \\ 37 & 103\end{array}$

180
143
103

130

118

126
129

129

129
127

$\begin{array}{ll}40 & 192 \\ 40 & 260\end{array}$

$\begin{array}{ll}40 & 260 \\ 40 & 297\end{array}$

37

224

114
64

98
106

106
105

109

106
110

\begin{tabular}{rr}
34 & 114 \\
21 & 64 \\
13 & 39 \\
21 & 62 \\
28 & 83 \\
\hline
\end{tabular}

43
54
52
56
55

166
171
247
360
399
364

3223

$---$

5161

14
13
16
19
98

104

90
82

82
74
64

45

$\begin{array}{ll}26 & 21 \\ 40 & 31 \\ 51 & 38 \\ 45 & 33 \\ 20 & 15\end{array}$

14
14
13
13
13
21
31
38
33
15

29
25
30
33
273

1

13
12
11
9

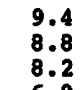

6.9

298

185
153

135

1

1

100

TOTAL

1613.5 
WATER-QUALITY RECORDS

DAY

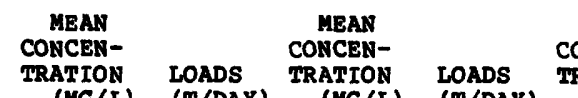
MEAN TRATION MEAN
CONCEN-
LOADS TRATION MEAN
CONCEN(WE/L) (T/DAY)

(MG/L) (T/DAY)

$(M G / L) \quad(T / D A Y) \quad(M G / L)$ (T/DAY)

LOADS TRATION LOADS APRIL MAY JUNE JULY ADGUST SEPTEMBER

1
2
3
4
5
6
7
8
9
10

$\begin{array}{ll}14 & 119 \\ 20 & 154 \\ 22 & 162 \\ 22 & 163 \\ 18 & 17 \\ 25 & 347 \\ 27 & 41 \\ 24 & 388 \\ 19 & 323 \\ 37 & 57\end{array}$

119
154
162
163
174
347

$\begin{array}{lll}26 & 600 & 30 \\ 30 & 582 & 20 \\ 16 & 291 & 36 \\ 12 & 208 & 34 \\ 14 & 219 & 24\end{array}$

$\begin{array}{ll}30 & 2 \\ 20 & 1 \\ 36 & 2 \\ 34 & 2 \\ 24 & 1\end{array}$

215
143
232
201
142

$\begin{array}{rr}93 & 565 \\ 121 & 536 \\ 106 & 612 \\ 80 & 460 \\ 56 & 290\end{array}$

$\begin{array}{rr}29 & 172 \\ 29 & 172 \\ 14 & 84\end{array}$

238

268

374

84
151

$28 \quad 123$

$\begin{array}{rr}28 & 123 \\ 16 & 65 \\ 18 & 82\end{array}$

18
20

20
35

$\begin{array}{ll}43 & 626 \\ 38 & 485\end{array}$

485
267

267
149

161

64693

$\begin{array}{ll}35 & 376 \\ 10 & 107\end{array}$

376
107
245

45

272

313
237

237
223

293

$\begin{array}{ll}25 & 88 \\ 27 & 87\end{array}$

$\begin{array}{lr}27 & 87 \\ 48 & 153\end{array}$

$\begin{array}{ll}48 & 153 \\ 44 & 139\end{array}$

$45 \quad 141$

238

165
246

246

266
262

190

$49 \quad 392$

$\begin{array}{ll}49 & 392 \\ 41 & 313\end{array}$

313
192
192

192
177

39

91
119

119
123

624
887

887
923

1050

$\begin{array}{ll}28 & 75 \\ 12 & 25\end{array}$

12

32

27

1140

216
325

325
262

262
192

166

148

144

1140
947
840

840

745

$\begin{array}{rr}49 & 91 \\ 56 & 104\end{array}$

259
407

407
875

123

664

$\begin{array}{ll}84 & 406 \\ 45 & 249 \\ 49 & 318 \\ 52 & 334 \\ 68 & 435\end{array}$

406
249
318
334
435

--

11334

12893

TOTAL LOAD FOR YEAR: 76217.1 TONS.

82
96

$\begin{array}{ll}12 & 11 \\ 13 & 11 \\ 13 & 11 \\ 17 & 15 \\ 16 & 14\end{array}$

11
11
11
15
14

18
15

15

9.6

10

$16 \quad 11$

12

11

11.9

$\begin{array}{ll}17 & 10 \\ 17 & 10\end{array}$

10

12
12

34

34
34
32

32
37

37
639

472

472
229
130
97

146

-.. 2305.3

4710

169

101

63

$19 \quad 80$

$21 \quad 126$

222

343
588

633

502

342

249
178

165

172

74

36
68

162

180

165

202
187

178

219

235

262

325

6548

WATER QUALITY DATA, WATER YEAR OCTOBER 1984 TO SEPTEWBER 1985

\begin{tabular}{|c|c|c|c|c|c|c|}
\hline DATE & TIME & $\begin{array}{l}\text { TEMPER- } \\
\text { ATORE } \\
\text { (DEG C) }\end{array}$ & $\begin{array}{l}\text { STREAY- } \\
\text { FLOW, } \\
\text { INSTAN- } \\
\text { TANEOOS } \\
\text { (CFS) }\end{array}$ & $\begin{array}{l}\text { SEDI- } \\
\text { MENT, } \\
\text { SUS- } \\
\text { PENDED } \\
\text { (MG/L) }\end{array}$ & $\begin{array}{c}\text { SEDI- } \\
\text { MENT, } \\
\text { DIS- } \\
\text { CHARGE, } \\
\text { SOS- } \\
\text { PENDED } \\
\text { (T/DAY) }\end{array}$ & $\begin{array}{c}\text { SED. } \\
\text { SUSP. } \\
\text { SIEVE } \\
\text { DIAM. } \\
\text { \& FINER } \\
\text { THAN } \\
.062 \mathrm{MM}\end{array}$ \\
\hline $\begin{array}{l}\text { NOV } \\
29 \ldots \\
\text { APR }\end{array}$ & $11: 40$ & 7.0 & 1090 & 15 & 44 & 63 \\
\hline${ }_{\text {JUN }}^{11} \ldots$ & $13: 59$ & 7.0 & 5240 & 82 & 1160 & 91 \\
\hline $\begin{array}{c}25 \\
\text { SEP } \\
17 \ldots\end{array}$ & $\begin{array}{l}10: 35 \\
12: 45\end{array}$ & $\begin{array}{l}26.0 \\
24.0\end{array}$ & $\begin{array}{l}2000 \\
2360\end{array}$ & 90 & 486 & 95 \\
\hline
\end{tabular}


05481650 DES MOINES RIVER NEAR SAYLORVILIE, IA- Continued

WATER QUALITY DATA, WATER YEAR OCTOBER 1984 TO SEPTEMBER 1985

\begin{tabular}{|c|c|c|c|c|c|c|c|}
\hline DATE & TIME & $\begin{array}{l}\text { STREAM- } \\
\text { FLOW, } \\
\text { INSTAN- } \\
\text { TANEOUS } \\
\text { (CFS) }\end{array}$ & $\begin{array}{c}\text { NOMBER } \\
\text { OF } \\
\text { SAY- } \\
\text { PLING } \\
\text { POINTS }\end{array}$ & $\begin{array}{c}\text { BED } \\
\text { MAT. } \\
\text { SIEVE } \\
\text { DIAH. } \\
8 \text { FINER } \\
\text { THAN } \\
.062 \mathrm{MM}\end{array}$ & $\begin{array}{c}\text { BED } \\
\text { MAT. } \\
\text { SIEVE } \\
\text { DIAY. } \\
\text { F FNER } \\
\text { THAN } \\
.125 \mathrm{MM}\end{array}$ & $\begin{array}{c}\text { BED } \\
\text { MAT. } \\
\text { SIEVE } \\
\text { DIAM. } \\
\text { 8 FINER } \\
\text { THAN } \\
.250 \text { MIM }\end{array}$ & $\begin{array}{c}\text { BED } \\
\text { MAT. } \\
\text { SIEVE } \\
\text { DIAM. } \\
\text { FINER } \\
\text { THAN } \\
.500 \mathrm{NM}\end{array}$ \\
\hline $\begin{array}{l}\text { NOV } \\
29 \ldots \\
\text { APR }\end{array}$ & $10: 45$ & 1090 & 5 & 1 & 2 & 6 & 29 \\
\hline${ }_{\text {JON }}^{11} \ldots$ & $14: 20$ & 5240 & 5 & 2 & 7 & 24 & 61 \\
\hline $\operatorname{sep}^{25} \ldots$ & $11: 30$ & 2000 & 5 & 0 & 1 & 7 & 25 \\
\hline $17 \ldots$ & $13: 00$ & 2360 & 5 & 0 & 1 & 8 & 53 \\
\hline
\end{tabular}

\begin{tabular}{|c|c|c|c|c|c|c|}
\hline DATE & $\begin{array}{l}\text { BED } \\
\text { MAT. } \\
\text { SIEVE } \\
\text { DIAM. } \\
\text { \& FINER } \\
\text { THAN } \\
1.00 \mathrm{MM}\end{array}$ & $\begin{array}{c}\text { BED } \\
\text { MAT, } \\
\text { SIEVE } \\
\text { DIAY. } \\
\text { 8INER } \\
\text { THAN } \\
2.00 \mathrm{NM}\end{array}$ & $\begin{array}{c}\text { BED } \\
\text { MAT. } \\
\text { SIEVE } \\
\text { DIAN. } \\
\text { 8 FINER } \\
\text { THAN } \\
4.00 \mathrm{MM}\end{array}$ & $\begin{array}{l}\text { BED } \\
\text { MAT. } \\
\text { SIEVE } \\
\text { DIAY. } \\
\text { 8 FINER } \\
\text { THAN } \\
8.00 \text { MIM }\end{array}$ & $\begin{array}{c}\text { BED } \\
\text { MAT. } \\
\text { SIEVE } \\
\text { DIAN. } \\
\text { FINER } \\
\text { THAN } \\
16.0 \mathrm{MH}\end{array}$ & $\begin{array}{c}\text { BED } \\
\text { MAT. } \\
\text { SIEVE } \\
\text { DIAH. } \\
\text { 8INER } \\
\text { FHAN } \\
32.0 \text { MM }\end{array}$ \\
\hline $\begin{array}{l}\text { NOV } \\
29 . . . \\
\text { APR }\end{array}$ & 49 & 66 & 83 & 93 & 100 & -- \\
\hline JUN & 73 & 80 & 94 & 99 & 100 & -- \\
\hline $\begin{array}{c}25 \ldots \\
\operatorname{sep} \\
17 \ldots\end{array}$ & 32 & 40 & 58 & 77 & 94 & 100 \\
\hline
\end{tabular}


LOATION.-Lat $41^{\circ} 41^{\prime} 18^{\prime \prime}$, long $93^{\circ} 44^{\prime} 08^{\prime \prime}$, in SWl/4 SWl/4 sec.35, T.80 N., R. 25 W., Polk County, Bydrologic unit 07100004, on right bank $6 \mathrm{ft}$ upstrean from bridge on Northwest 70th Avenue, $0.5 \mathrm{mi}$ downstream from Little Beaver Creek, $2.5 \mathrm{mi}$ east of Grimes and $6 \mathrm{mi}$ upstrean from mouth.

DRAINAGE AREA. $-358 \mathrm{mi}^{2}$.

PERIOD OF RECORD.--April 1960 to current year.

REVISED RECORDS. - WDR IA-77-1: 1974 (P).

GAGE.- Water-stage recorder and concrete and steel sheeting broad-crested control. Datum of gage is 806.98 ft above NGVD. Prior to Aug. 31, 1966, nonrecording gage at same site and datum.

REMARKS.--Estimated daily discharges: oct. 6-22, Dec. 3-11, Jan. 2 to Mar. 7. Records good except those for estimated daily discharges, which are poor. U. S. Any Corps of Engineers gage-height telemeter at station.

COOPERATION.--One discharge measurement provided by U. S. Army Corps of Engineers.

AVRRAGE DISCHARGE. -25 years, $209 \mathrm{ft}^{3} / \mathrm{s}, 7.93 \mathrm{in} / \mathrm{Yr}, 151,400 \mathrm{acre}-\mathrm{ft} / \mathrm{Yr}$; median of yearly mean discharges, 200 $\mathrm{ft}^{3} / \mathrm{s}, 7.6 \mathrm{in} / \mathrm{yr}, 145,000 \mathrm{acre}-\mathrm{ft} / \mathrm{yr}$.

EXIREMES FOR PERTOD OF RECORD.--Maximum discharge, 7,340 ft/s May 19, 1974, gage height, $14.69 \mathrm{ft}$; no flow for several days in 1970 and 1971 and many days in 1977.

EXIREVES FOR OURRENT YEAR. - Peak discharges greater than base of $1,500 \mathrm{ft}^{3 / \mathrm{s}}$ and maximum $(*)$ :

\begin{tabular}{|c|c|c|c|c|c|c|}
\hline $\begin{array}{l}\text { Date } \\
\text { Dec. } 28\end{array}$ & $\begin{array}{l}\text { Time } \\
2215\end{array}$ & $\begin{array}{c}\text { Discharge } \\
\left(f t^{3} / \mathrm{s}\right) \\
* 1,120\end{array}$ & $\begin{array}{c}\text { Gage height } \\
\text { (ft) } \\
\star 7.66\end{array}$ & Date & Time & $\begin{array}{l}\text { Discharge } \\
\left(\mathrm{ft}^{3} / \mathrm{s}\right)\end{array}$ \\
\hline
\end{tabular}

Minimum daily discharge, $0.04 \mathrm{ft}^{3} / \mathrm{s}$ Aug. 3 .

DISCHARGE, IN OUBIC FEET PER SECOND, WATER YEAR OCIOBER 1984 TO SEPTEMBER 1985 MEAN VALUES

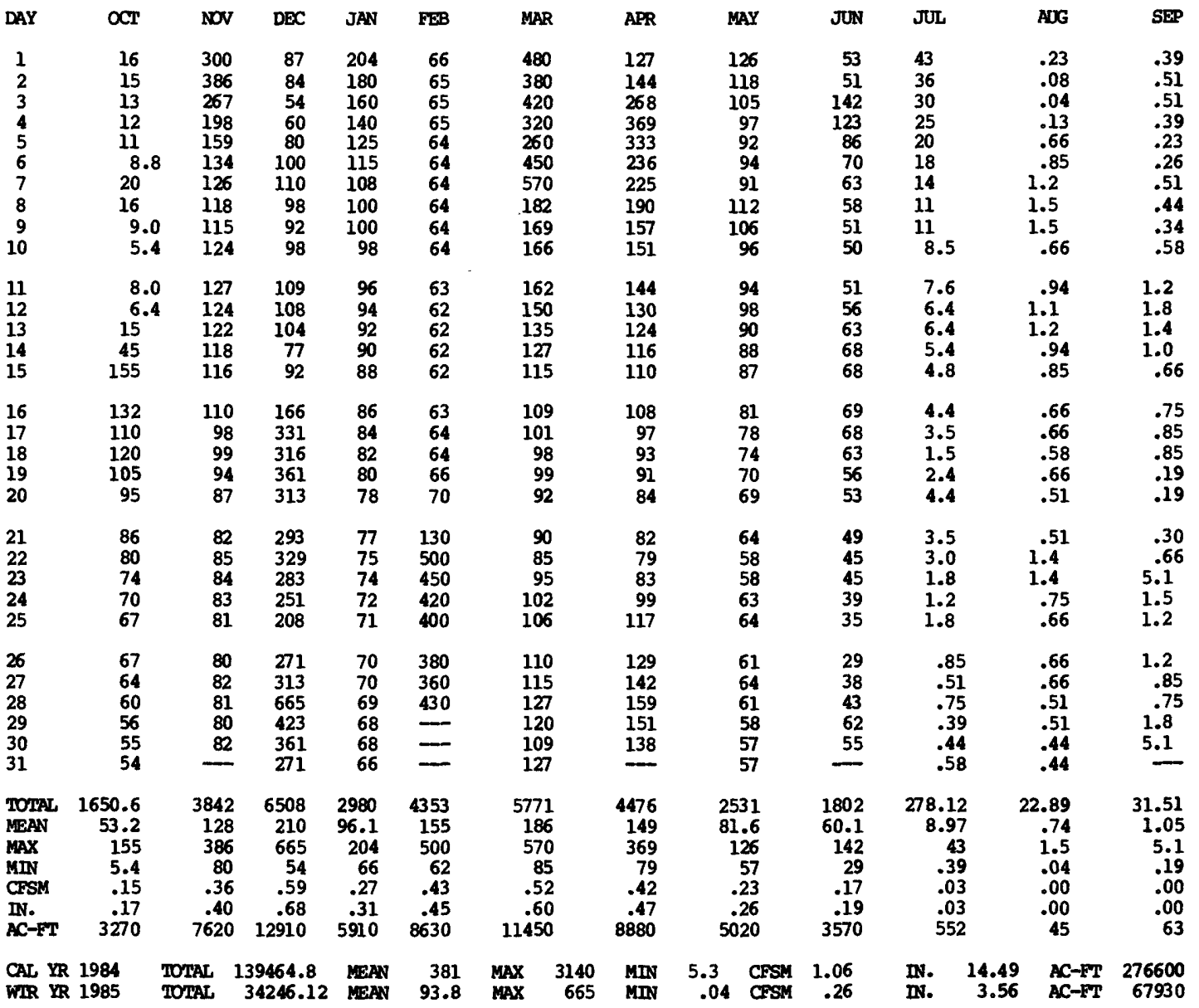


05482135 NORTH RACCOON RIVER NEAR NEWELL, IA

LOCATION.--Lat $42^{\circ} 36^{\prime} 16^{\prime \prime}$, long $95^{\circ} 02^{\prime} 42^{\prime \prime}$, in NEl/4 NW1/4 sec.24, T.90 N., R.36 W., Buena Vista County, Hyarologic Unit 07100005 , on left bank $40 \mathrm{ft}$ downstream from bridge on state Highway 7 , $0.8 \mathrm{mi}$ upstream from Outlet Creek, $2.2 \mathrm{mi}$ west of Newell, and at mile 398.6 upstream from mouth of Des Moines River.

DRAINAGE AREA, $--233 \mathrm{mi}^{2}$.

PERIOD OF RECORD.--October 1982 to current year.

GAGE.-Water-stage recorder. Datum of gage is $1235.50 \mathrm{ft}$ above NGVD.

REMARRS.--Estimated daily discharges: Oct. 7-8, Nov. 16 to Mar. 6. Records good except for estimated daily discharges, which are poor. Gage-height telemeter at station.

EXTREMES FOR CURRENT YEAR.--Peak discharges greater than base of $750 \mathrm{ft} \% / 8$ and maximum $(*)$ :

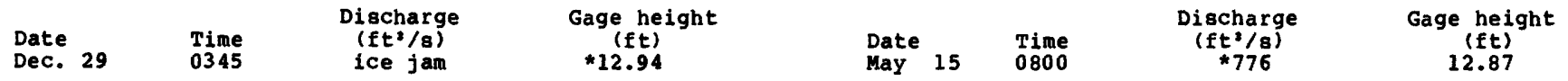

Minimum discharge, $3.3 \mathrm{ft} / \mathrm{s}$ Aug. 28 .

DISCHARGE, IN CUBIC FEET PER SECOND, WATER YEAR OCTOBER 1984 TO SEPTEMBER 1985 MEAN VALUES

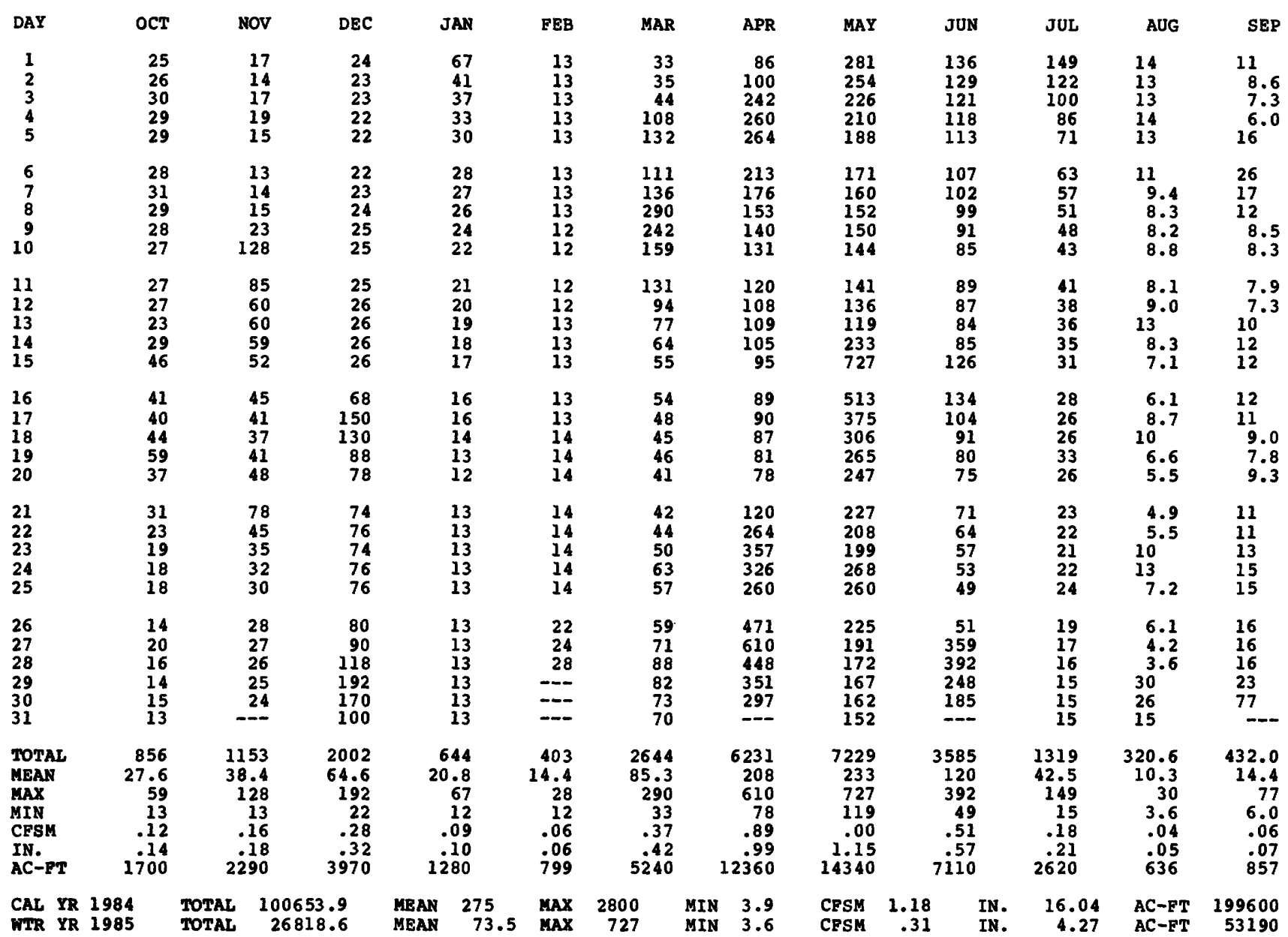


LOCATION.--Lat $42^{\circ} 41^{\prime} 16^{\prime \prime}$, long $94^{\circ} 47^{\prime} 52^{\prime \prime}$, in NEl/4 NEl/4 sec.24, T.91 N., R.34 N., Pocahontas County, Hydrologic Unit 07100006 , on left bank $2 \mathrm{ft}$ downstream from bridge on county highway N33, $2.0 \mathrm{mi}$ downstream from Drainage

ditch $21,3.5 \mathrm{mi}$ upstream from Drainage ditch 74 , and $5.5 \mathrm{mi}$ northeast of varina.

DRAINAGE AREA. $--80.0 \mathrm{mi}^{2}$.

PERIOD OF RECORD.--October 1959 to current year.

GAGE.--Water-stage recorder. Datum of gage is $1,225.12 \mathrm{ft}$ above NGVD.

REMARKS.--Estimated daily discharges: Nov. 16 to Mar. 12 . Records good, except for estimated daily discharges, which are poor.

AVERAGE DISCHARGE.--26 years, $42.0 \mathrm{ft}^{3} / \mathrm{s}, 7.13 \mathrm{in} / \mathrm{yr}, 30,430 \mathrm{acre}-\mathrm{ft} / \mathrm{yr}$; median of yearly mean discharges, 34 $f t^{3} / \mathrm{s}, 5.8 \mathrm{in} / \mathrm{yr}, 24,600 \mathrm{acre}-\mathrm{ft} / \mathrm{yr}$.

EXTREMES FOR PERIOD OF RECORD.--Maximum discharge, 2,080 ft $3 / \mathrm{s}$ Aug, 31, 1962, gage height, $13.68 \mathrm{ft}$, maximum gage height, $16.29 \mathrm{ft}$ Mar. 24, 1979, backwater from ice; no flow at times most years.

EXTREMES FOR CURRENT YEAR.--Peak discharges greater than base of $400 \mathrm{ft}^{\prime} / \mathrm{s}$ and maximum (*):

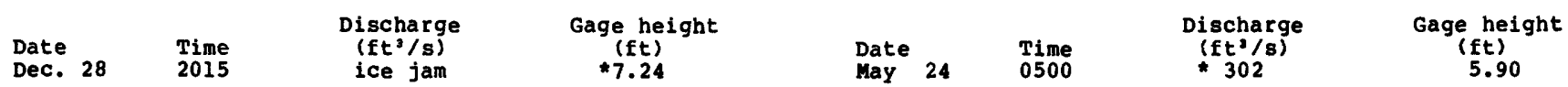

No flow Jan. 16-30.

DISCHARGE, IN CUBIC FEET PER SECOND, WATER YEAR OCTOBER 1984 TO SEPTEMBER 1985 MEAN VALUES

\begin{tabular}{|c|c|c|c|c|c|c|c|c|c|c|c|c|}
\hline DAY & OCT & NOV & DEC & JAN & FEB & MAR & APR & MAY & JUN & JUL & AUG & SEP \\
\hline $\begin{array}{l}1 \\
2 \\
3 \\
4 \\
5\end{array}$ & $\begin{array}{r}.39 \\
.43 \\
1.3 \\
1.1 \\
.41\end{array}$ & $\begin{array}{c}1.4 \\
2.4 \\
.95 \\
1.1 \\
.78\end{array}$ & $\begin{array}{l}1.3 \\
1.2 \\
1.2 \\
1.1 \\
1.2\end{array}$ & $\begin{array}{r}14 \\
9.0 \\
7.6 \\
6.8 \\
6.5\end{array}$ & $\begin{array}{r}.17 \\
.35 \\
.70 \\
1.5 \\
2.6\end{array}$ & $\begin{array}{l}27 \\
26 \\
38 \\
45 \\
72\end{array}$ & $\begin{array}{r}29 \\
30 \\
89 \\
108 \\
113\end{array}$ & $\begin{array}{l}86 \\
78 \\
70 \\
64 \\
56\end{array}$ & $\begin{array}{l}32 \\
30 \\
28 \\
27 \\
26\end{array}$ & $\begin{array}{l}45 \\
37 \\
31 \\
27 \\
22\end{array}$ & $\begin{array}{l}2.9 \\
2.3 \\
2.6 \\
2.9 \\
2.2\end{array}$ & $\begin{array}{l}4.4 \\
3.8 \\
3.2 \\
2.9 \\
12\end{array}$ \\
\hline $\begin{array}{r}6 \\
7 \\
8 \\
9 \\
10\end{array}$ & $\begin{array}{l}.48 \\
.59 \\
.60 \\
.47 \\
.44\end{array}$ & $\begin{array}{r}.72 \\
.70 \\
.70 \\
6.0 \\
30\end{array}$ & $\begin{array}{l}1.3 \\
1.4 \\
5.6 \\
7.6 \\
4.2\end{array}$ & $\begin{array}{l}5.6 \\
4.7 \\
3.9 \\
3.0 \\
2.0\end{array}$ & $\begin{array}{l}5.2 \\
6.2 \\
6.9 \\
7.8 \\
8.8\end{array}$ & $\begin{array}{r}73 \\
98 \\
180 \\
195 \\
70\end{array}$ & $\begin{array}{l}82 \\
65 \\
55 \\
52 \\
51\end{array}$ & $\begin{array}{l}51 \\
49 \\
48 \\
47 \\
46\end{array}$ & $\begin{array}{l}25 \\
24 \\
23 \\
21 \\
21\end{array}$ & $\begin{array}{l}18 \\
16 \\
13 \\
12 \\
10\end{array}$ & $\begin{array}{l}1.8 \\
1.5 \\
1.3 \\
1.3 \\
2.0\end{array}$ & $\begin{array}{r}13 \\
7.5 \\
4.8 \\
3.6 \\
3.2\end{array}$ \\
\hline $\begin{array}{l}11 \\
12 \\
13 \\
14 \\
15\end{array}$ & $\begin{array}{l}.44 \\
.60 \\
.38 \\
.68 \\
6.0\end{array}$ & $\begin{array}{r}14 \\
8.9 \\
7.0 \\
6.4 \\
5.0\end{array}$ & $\begin{array}{l}2.8 \\
1.6 \\
1.6 \\
1.5 \\
2.2\end{array}$ & $\begin{array}{r}1.2 \\
.80 \\
.52 \\
.29 \\
.17\end{array}$ & $\begin{array}{l}9.9 \\
11 \\
11 \\
12 \\
9.6\end{array}$ & $\begin{array}{l}55 \\
43 \\
39 \\
32 \\
28\end{array}$ & $\begin{array}{l}47 \\
44 \\
41 \\
39 \\
39\end{array}$ & $\begin{array}{l}46 \\
45 \\
40 \\
39 \\
41\end{array}$ & $\begin{array}{l}23 \\
23 \\
23 \\
25 \\
41\end{array}$ & $\begin{array}{l}9.6 \\
9.5 \\
8.7 \\
8.0 \\
7.0\end{array}$ & $\begin{array}{l}1.3 \\
2.3 \\
3.0 \\
1.7 \\
1.3\end{array}$ & $\begin{array}{l}3.0 \\
3.1 \\
3.7 \\
3.1 \\
2.5\end{array}$ \\
\hline $\begin{array}{l}16 \\
17 \\
18 \\
19 \\
20\end{array}$ & $\begin{array}{l}3.7 \\
3.6 \\
3.0 \\
7.1 \\
3.8\end{array}$ & $\begin{array}{l}5.6 \\
4.6 \\
3.5 \\
3.6 \\
3.5\end{array}$ & $\begin{array}{l}18 \\
40 \\
47 \\
31 \\
22\end{array}$ & $\begin{array}{l}.00 \\
.00 \\
.00 \\
.00 \\
.00\end{array}$ & $\begin{array}{l}10 \\
11 \\
12 \\
17 \\
21\end{array}$ & $\begin{array}{l}24 \\
20 \\
19 \\
18 \\
15\end{array}$ & $\begin{array}{l}35 \\
33 \\
31 \\
29 \\
29\end{array}$ & $\begin{array}{l}43 \\
43 \\
43 \\
43 \\
43\end{array}$ & $\begin{array}{l}39 \\
30 \\
27 \\
23 \\
21\end{array}$ & $\begin{array}{l}6.2 \\
5.6 \\
5.6 \\
7.3 \\
5.0\end{array}$ & $\begin{array}{l}1.1 \\
2.2 \\
1.7 \\
.99 \\
1.7\end{array}$ & $\begin{array}{r}2.3 \\
2.3 \\
2.0 \\
1.9 \\
15\end{array}$ \\
\hline $\begin{array}{l}21 \\
22 \\
23 \\
24 \\
25\end{array}$ & $\begin{array}{l}2.1 \\
1.5 \\
1.1 \\
.90 \\
1.1\end{array}$ & $\begin{array}{l}3.8 \\
4.2 \\
3.5 \\
3.3 \\
3.7\end{array}$ & $\begin{array}{l}18 \\
15 \\
14 \\
11 \\
10\end{array}$ & $\begin{array}{l}.00 \\
.00 \\
.00 \\
.00 \\
.00\end{array}$ & $\begin{array}{l}23 \\
22 \\
19 \\
18 \\
19\end{array}$ & $\begin{array}{l}14 \\
12 \\
14 \\
17 \\
14\end{array}$ & $\begin{array}{r}75 \\
112 \\
132 \\
112 \\
87\end{array}$ & $\begin{array}{r}44 \\
44 \\
46 \\
204 \\
111\end{array}$ & $\begin{array}{l}20 \\
18 \\
17 \\
15 \\
15\end{array}$ & $\begin{array}{l}4.9 \\
4.7 \\
4.2 \\
7.5 \\
5.3\end{array}$ & $\begin{array}{r}1.8 \\
8.0 \\
12 \\
8.8 \\
4.6\end{array}$ & $\begin{array}{l}7.6 \\
6.8 \\
7.8 \\
8.9 \\
8.7\end{array}$ \\
\hline $\begin{array}{l}26 \\
27 \\
28 \\
29 \\
30 \\
31\end{array}$ & $\begin{array}{l}1.3 \\
1.2 \\
.95 \\
.78 \\
.68 \\
.68\end{array}$ & $\begin{array}{l}3.6 \\
3.1 \\
2.4 \\
1.9 \\
1.4 \\
-. .-\end{array}$ & $\begin{array}{l}9.9 \\
10 \\
56 \\
50 \\
25 \\
16\end{array}$ & $\begin{array}{l}.00 \\
.00 \\
.00 \\
.00 \\
.00 \\
.12\end{array}$ & $\begin{array}{l}22 \\
26 \\
30\end{array}$ & $\begin{array}{l}14 \\
20 \\
23 \\
21 \\
18 \\
13\end{array}$ & $\begin{array}{l}177 \\
210 \\
151 \\
120 \\
101 \\
-\end{array}$ & $\begin{array}{l}90 \\
72 \\
57 \\
50 \\
44 \\
38\end{array}$ & $\begin{array}{r}15 \\
149 \\
133 \\
81 \\
57 \\
\end{array}$ & $\begin{array}{l}3.6 \\
3.2 \\
3.0 \\
2.7 \\
2.9 \\
3.2\end{array}$ & $\begin{array}{c}3.4 \\
2.1 \\
4.4 \\
10 \\
5.5 \\
3.8\end{array}$ & $\begin{array}{c}8.9 \\
8.8 \\
9.4 \\
22 \\
48 \\
-\end{array}$ \\
\hline $\begin{array}{l}\text { TOTAL } \\
\text { MEAN } \\
\text { MAX } \\
\text { MIN } \\
\text { CFSM } \\
\text { IN. } \\
\text { AC-FT }\end{array}$ & $\begin{array}{r}47.80 \\
1.54 \\
7.1 \\
.38 \\
.02 \\
.02 \\
95\end{array}$ & $\begin{array}{r}137.75 \\
4.59 \\
30 \\
.70 \\
.06 \\
.06 \\
273\end{array}$ & $\begin{array}{r}428.7 \\
13.8 \\
56 \\
1.1 \\
.17 \\
.20 \\
850\end{array}$ & $\begin{array}{r}66.20 \\
2.14 \\
14 \\
.00 \\
.03 \\
.03 \\
131\end{array}$ & $\begin{array}{r}343.72 \\
12.3 \\
30 \\
.17 \\
.15 \\
.16 \\
682\end{array}$ & $\begin{array}{r}1297 \\
41.8 \\
195 \\
12 \\
.52 \\
.60 \\
2570\end{array}$ & $\begin{array}{r}2318 \\
77.3 \\
210 \\
29 \\
.97 \\
1.08 \\
4600\end{array}$ & $\begin{array}{r}1821 \\
58.7 \\
204 \\
38 \\
.73 \\
.85 \\
3610\end{array}$ & $\begin{array}{r}1052 \\
35.1 \\
149 \\
15 \\
.44 \\
.49 \\
2090\end{array}$ & $\begin{array}{r}348.7 \\
11.2 \\
45 \\
2.7 \\
.14 \\
.16 \\
692\end{array}$ & $\begin{array}{r}102.49 \\
3.31 \\
12 \\
.99 \\
.04 \\
.05 \\
203\end{array}$ & $\begin{array}{r}234.2 \\
7.81 \\
48 \\
1.9 \\
.10 \\
.11 \\
465\end{array}$ \\
\hline $\begin{array}{ll}\text { CAL } & Y_{F} \\
\text { WTR } & \mathbf{Y}\end{array}$ & 15 & $\begin{array}{l}\text { TAL } \\
\text { TAL }\end{array}$ & $\begin{array}{l}66 \\
56\end{array}$ & $\begin{array}{l}\text { IEAN } \\
\text { IEAN }\end{array}$ & $\begin{array}{l}\text { MAX } \\
\text { MAX }\end{array}$ & $\begin{array}{r}1260 \\
210\end{array}$ & $\begin{array}{ll}\text { MIN } & .38 \\
\text { MIN } & .00\end{array}$ & $\begin{array}{l}\text { CPSM } \\
\text { CFSH }\end{array}$ & $\begin{array}{r}1.34 \\
.28\end{array}$ & $\begin{array}{r}18.13 \\
3.81\end{array}$ & $\begin{array}{l}A C-F T \\
A C-F T\end{array}$ & $\begin{array}{l}77330 \\
16260\end{array}$ \\
\hline
\end{tabular}


LOCATION.--Lat $42^{\circ} 20^{\prime} 28^{\prime \prime}$, long $94^{\circ} 59^{\prime} 05^{\circ}$, in NEl/4 Ww1/4 sec.24, T.87 N., R.36 W., Sac County, Hydrologic Unit 07100006 , on right bank $15 \mathrm{ft}$ downstream from bridge on county highway, $0.2 \mathrm{mi}$ upstream from Indian Creek, 0.9 mi downstream from Drainage ditch $73,5.6$ mi south of Sac City, and at mile 365.9 upstream from mouth of Des Moines River.

DRAINAGE AREA. $--713 \mathrm{mi}^{2}$.

PERIOD OF RECORD.--June 1958 to current year.

GAGE.--Water-stage recorder. Datum of gage is $1,144.60 \mathrm{ft}$ above NGVD (levels by Iowa Natural Resources Council).

REMARKS.--Estimated daily discharges: Nov. 17 to Mar. 9, Apr. 3-16, May 7-16, and June 8-13. Records good except estimated daily discharges, which are poor.

AVERAGE DISCHARGE. - 27 years, $352 \mathrm{ft}^{3} / \mathrm{s}, 6.70 \mathrm{in} / \mathrm{yr}, 255,000$ acre-ft/yr; median of yearly mean discharges, 270 $\mathrm{ft}^{3} / \mathrm{s}, 5.1 \mathrm{in} / \mathrm{yr}, 196,000$ acre-ft/yr.

EXTREMES FOR PERIOD OF RECORD.--Maximum discharge, 13,100 ft/s Mar. 23, 1979, gage height, 18.02 ft, maximum gage height, 18.12 ft Sept. 1 , 1962 ; no flow Jan. 30 to Feb. 4 , 1977.

EXTREMES OUTSIDE PERIOD OF RECORD.--Flood of June 2l, 1954, reached a stage of $15.61 \mathrm{ft}$, $f$ rom floodmark, discharge, $7,000 \mathrm{ft}^{2} / \mathrm{s}$.

EXTREMES FOR CURRENT YEAR.--Peak discharges greater than base of $2,000 \mathrm{ft} / \mathrm{s}$ and maximum (*):

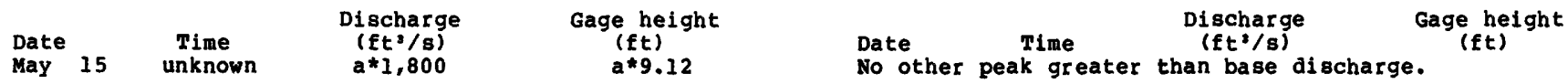

a Estimated.

Minimum discharge, $21 \mathrm{ft} / \mathrm{s}$ Aug. $11,22-23$.

DISCHARGE, IN CUBIC PEET PER SECOND, WATER YEAR OCTOBER 1984 TO SEPTEHBER 1985 MEAN VALUES

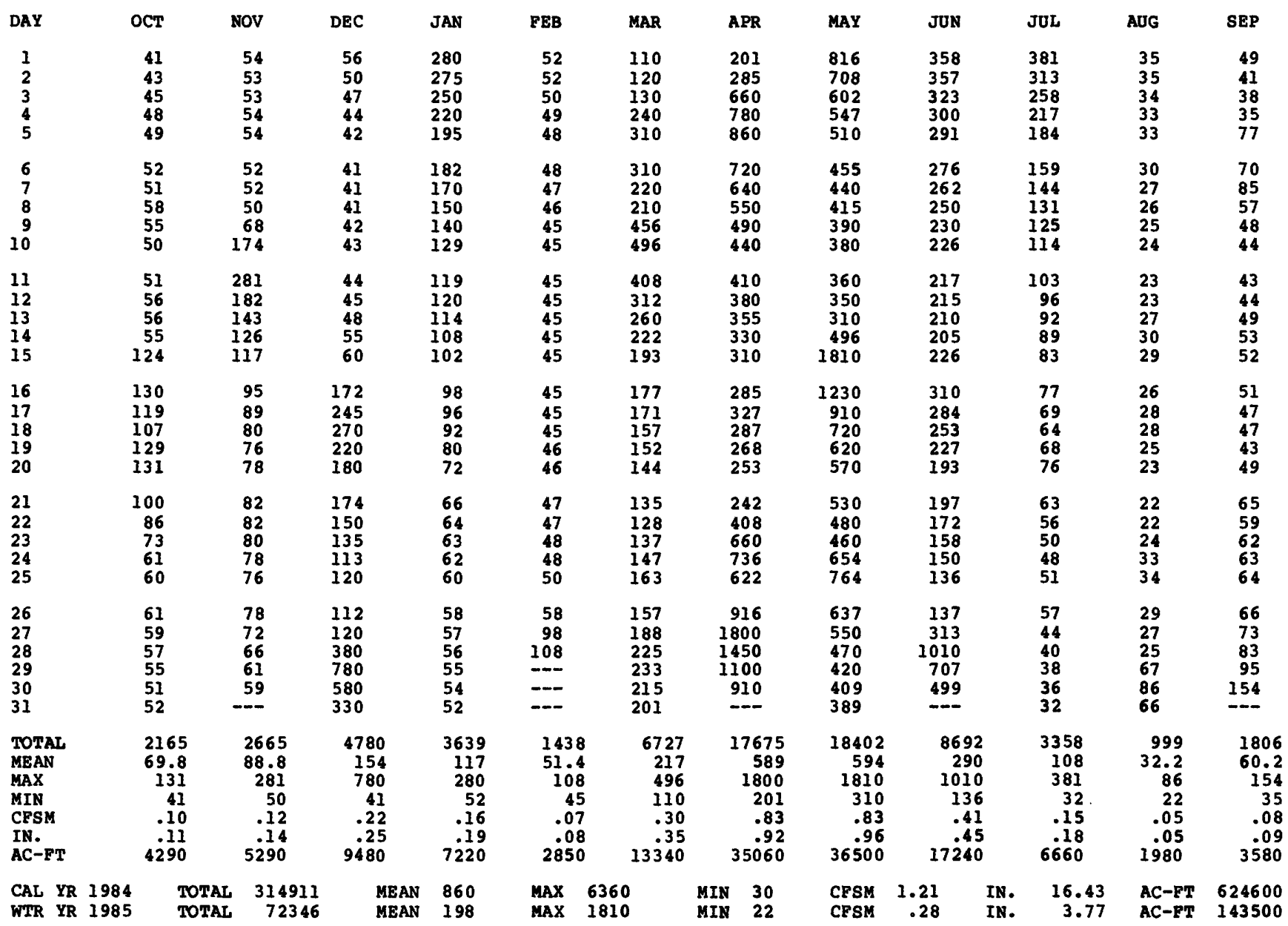


LOCATION.--Lat $42^{\circ} 18^{\prime} 15^{\prime \prime}$, long $95^{\circ} 02^{\prime} 30^{\prime \prime}$, in NW1/4 SEl/4 sec.33, T.87 N., R.36 w., Sac County, Hydrologic Unit 07100006 , on south shore across from swimming beach at Lake view and 2 mi upstream from lake outlet.

DRAINAGE AREA. $-23.3 \mathrm{mi}^{2}$.

PERIOD OF RECORD.--April 1970 to September 1975, April 1978 to current year.

GAGE.--Water-stage reacorder. Datum of gage is $1,218.50 \mathrm{ft}$ above NGVD and $2.00 \mathrm{ft}$ below crest of spillway of dam at outlet. Prior to June 25, 1970, nonrecording gage at lake outlet.

REMARKS.--Lake is formed by concrete dam with ungated overflow spillway at elevation 1,220.50 ft above NGvD. Lake is used for conservation and recreation. Area of lake is approximately 957 acres.

EXTREMES FOR PERIOD OF RECORD.--Maximum gage height, 4.08 ft Mar. 20, 1979; minimum, 0.02 ft Sept. $26,1981$.

EXTREMES FOR CURRENT YEAR.--Maximum gage height, $2.62 \mathrm{ft}$ Dec. 30; minimum, $1.44 \mathrm{ft}$ Aug. 28.

GAGE HEIGHT (FEET ABOVE DATUM), NATER YEAR OCTOBER 1984 TO SEPTEMBER 1985

\begin{tabular}{|c|c|c|c|c|c|c|c|c|c|c|c|c|}
\hline DAY & OCT & NOV & DEC & JAN & FEB & MAR & APR & MAY & JUN & JUL & AUG & SEP \\
\hline $\begin{array}{l}1 \\
2 \\
3 \\
4 \\
5\end{array}$ & $\begin{array}{l}1.52 \\
1.50 \\
1.49 \\
1.50 \\
1.51\end{array}$ & $\begin{array}{l}1.89 \\
1.92 \\
1.92 \\
1.90 \\
1.90\end{array}$ & $\begin{array}{l}2.11 \\
2.09 \\
2.10 \\
2.10 \\
2.11\end{array}$ & $\begin{array}{l}2.52 \\
2.47 \\
2.43 \\
2.39 \\
2.37\end{array}$ & $\begin{array}{l}2.09 \\
2.09 \\
2.08 \\
2.07 \\
2.08\end{array}$ & $\begin{array}{l}2.15 \\
2.15 \\
2.18 \\
2.19 \\
2.20\end{array}$ & $\begin{array}{l}2.26 \\
2.25 \\
2.27 \\
2.31 \\
2.34\end{array}$ & $\begin{array}{l}2.40 \\
2.39 \\
2.37 \\
2.33 \\
2.36\end{array}$ & $\begin{array}{l}2.20 \\
2.20 \\
2.19 \\
2.18 \\
2.18\end{array}$ & $\begin{array}{l}2.09 \\
2.07 \\
2.06 \\
2.02 \\
2.00\end{array}$ & $\begin{array}{l}1.67 \\
1.66 \\
1.66 \\
1.64 \\
1.63\end{array}$ & $\begin{array}{l}1.65 \\
1.65 \\
1.63 \\
1.63 \\
1.67\end{array}$ \\
\hline $\begin{array}{r}6 \\
7 \\
8 \\
9 \\
10\end{array}$ & $\begin{array}{l}1.55 \\
1.55 \\
1.60 \\
1.63 \\
1.64\end{array}$ & $\begin{array}{l}1.90 \\
1.92 \\
1.90 \\
1.98 \\
2.01\end{array}$ & $\begin{array}{l}2.10 \\
2.10 \\
2.09 \\
2.13 \\
2.14\end{array}$ & $\begin{array}{l}2.35 \\
2.34 \\
2.31 \\
2.30 \\
2.30\end{array}$ & $\begin{array}{l}2.07 \\
2.06 \\
2.05 \\
2.05 \\
2.05\end{array}$ & $\begin{array}{l}2.20 \\
2.19 \\
2.19 \\
2.19 \\
2.18\end{array}$ & $\begin{array}{l}2.35 \\
2.33 \\
2.32 \\
2.33 \\
2.31\end{array}$ & $\begin{array}{l}2.37 \\
2.36 \\
2.34 \\
2.32 \\
2.31\end{array}$ & $\begin{array}{l}2.18 \\
2.17 \\
2.15 \\
2.12 \\
2.15\end{array}$ & $\begin{array}{l}1.98 \\
1.95 \\
1.94 \\
1.92 \\
1.90\end{array}$ & $\begin{array}{l}1.62 \\
1.61 \\
1.60 \\
1.57 \\
1.55\end{array}$ & $\begin{array}{l}1.66 \\
1.66 \\
1.65 \\
1.62 \\
1.61\end{array}$ \\
\hline $\begin{array}{l}11 \\
12 \\
13 \\
14 \\
15\end{array}$ & $\begin{array}{l}1.64 \\
1.64 \\
1.64 \\
1.66 \\
1.75\end{array}$ & $\begin{array}{l}2.07 \\
2.10 \\
2.12 \\
2.13 \\
2.06\end{array}$ & $\begin{array}{l}2.14 \\
2.15 \\
2.14 \\
2.20 \\
2.23\end{array}$ & $\begin{array}{l}2.28 \\
2.26 \\
2.25 \\
2.24 \\
2.22\end{array}$ & $\begin{array}{l}2.04 \\
2.04 \\
2.03 \\
2.03 \\
2.02\end{array}$ & $\begin{array}{l}2.18 \\
2.19 \\
2.17 \\
2.16 \\
2.16\end{array}$ & $\begin{array}{l}2.30 \\
2.28 \\
2.25 \\
2.25 \\
2.24\end{array}$ & $\begin{array}{l}2.30 \\
2.24 \\
2.26 \\
2.31 \\
2.32\end{array}$ & $\begin{array}{l}2.18 \\
2.18 \\
2.17 \\
2.18 \\
2.19\end{array}$ & $\begin{array}{l}1.87 \\
1.90 \\
1.88 \\
1.86 \\
1.85\end{array}$ & $\begin{array}{l}1.55 \\
1.54 \\
1.53 \\
1.53 \\
1.53\end{array}$ & $\begin{array}{l}1.61 \\
1.62 \\
1.64 \\
1.65 \\
1.64\end{array}$ \\
\hline $\begin{array}{l}16 \\
17 \\
18 \\
19 \\
20\end{array}$ & $\begin{array}{l}1.82 \\
1.85 \\
1.86 \\
1.86 \\
1.87\end{array}$ & $\begin{array}{l}2.08 \\
2.09 \\
2.09 \\
2.09 \\
2.10\end{array}$ & $\begin{array}{l}2.30 \\
2.34 \\
2.38 \\
2.39 \\
2.38\end{array}$ & $\begin{array}{l}2.21 \\
2.20 \\
2.20 \\
2.19 \\
2.17\end{array}$ & $\begin{array}{l}2.02 \\
2.01 \\
2.01 \\
2.01 \\
2.03\end{array}$ & $\begin{array}{l}2.15 \\
2.15 \\
2.15 \\
2.14 \\
2.14\end{array}$ & $\begin{array}{l}2.25 \\
2.24 \\
2.22 \\
2.22 \\
2.20\end{array}$ & $\begin{array}{l}2.32 \\
2.33 \\
2.32 \\
2.31 \\
2.32\end{array}$ & $\begin{array}{l}2.18 \\
2.14 \\
2.11 \\
2.10 \\
2.11\end{array}$ & $\begin{array}{l}1.83 \\
1.81 \\
1.78 \\
1.79 \\
1.78\end{array}$ & $\begin{array}{l}1.53 \\
1.55 \\
1.54 \\
1.52 \\
1.51\end{array}$ & $\begin{array}{l}1.64 \\
1.63 \\
1.63 \\
1.62 \\
1.62\end{array}$ \\
\hline $\begin{array}{l}21 \\
22 \\
23 \\
24 \\
25\end{array}$ & $\begin{array}{l}1.87 \\
1.87 \\
1.86 \\
1.87 \\
1.89\end{array}$ & $\begin{array}{l}2.10 \\
2.09 \\
2.10 \\
2.10 \\
2.13\end{array}$ & $\begin{array}{l}2.42 \\
2.41 \\
2.38 \\
2.36 \\
2.34\end{array}$ & $\begin{array}{l}2.16 \\
2.15 \\
2.14 \\
2.14 \\
2.13\end{array}$ & $\begin{array}{l}2.05 \\
2.09 \\
2.13 \\
2.14 \\
2.14\end{array}$ & $\begin{array}{l}2.14 \\
2.13 \\
2.14 \\
2.14 \\
2.17\end{array}$ & $\begin{array}{l}2.21 \\
2.20 \\
2.20 \\
2.19 \\
2.24\end{array}$ & $\begin{array}{l}2.31 \\
2.29 \\
2.30 \\
2.32 \\
2.31\end{array}$ & $\begin{array}{l}2.07 \\
2.04 \\
2.04 \\
2.04 \\
2.04\end{array}$ & $\begin{array}{l}1.77 \\
1.75 \\
1.74 \\
1.74 \\
1.75\end{array}$ & $\begin{array}{l}1.51 \\
1.50 \\
1.49 \\
1.48 \\
1.47\end{array}$ & $\begin{array}{l}1.62 \\
1.61 \\
1.60 \\
1.61 \\
1.62\end{array}$ \\
\hline $\begin{array}{l}26 \\
27 \\
28 \\
29 \\
30 \\
31\end{array}$ & $\begin{array}{l}1.91 \\
1.89 \\
1.90 \\
1.90 \\
1.89 \\
1.90\end{array}$ & $\begin{array}{l}2.12 \\
2.10 \\
2.11 \\
2.11 \\
2.11 \\
\end{array}$ & $\begin{array}{l}2.31 \\
2.30 \\
2.42 \\
2.59 \\
2.61 \\
2.57\end{array}$ & $\begin{array}{l}2.12 \\
2.11 \\
2.11 \\
2.10 \\
2.10 \\
2.10\end{array}$ & $\begin{array}{r}2.14 \\
2.14 \\
2.14 \\
-.- \\
.-\end{array}$ & $\begin{array}{l}2.16 \\
2.19 \\
2.20 \\
2.19 \\
2.21 \\
2.27\end{array}$ & $\begin{array}{l}2.32 \\
2.37 \\
2.41 \\
2.42 \\
2.42 \\
\end{array}$ & $\begin{array}{l}2.30 \\
2.28 \\
2.27 \\
2.25 \\
2.23 \\
2.18\end{array}$ & $\begin{array}{l}2.02 \\
2.10 \\
2.11 \\
2.10 \\
2.10 \\
-\end{array}$ & $\begin{array}{l}1.74 \\
1.72 \\
1.70 \\
1.68 \\
1.68 \\
1.68\end{array}$ & $\begin{array}{l}1.46 \\
1.45 \\
1.45 \\
1.63 \\
1.67 \\
1.67\end{array}$ & $\begin{array}{r}1.61 \\
1.61 \\
1.64 \\
1.69 \\
1.71 \\
-\end{array}$ \\
\hline $\begin{array}{l}\text { MEAN } \\
\text { MAX } \\
\text { MIN }\end{array}$ & $\begin{array}{l}1.74 \\
1.91 \\
1.49\end{array}$ & $\begin{array}{l}2.04 \\
2.13 \\
1.89\end{array}$ & $\begin{array}{l}2.27 \\
2.61 \\
2.09\end{array}$ & $\begin{array}{l}2.24 \\
2.52 \\
2.10\end{array}$ & $\begin{array}{l}2.07 \\
2.14 \\
2.01\end{array}$ & $\begin{array}{l}2.17 \\
2.27 \\
2.13\end{array}$ & $\begin{array}{l}2.28 \\
2.42 \\
2.19\end{array}$ & $\begin{array}{l}2.31 \\
2.40 \\
2.18\end{array}$ & $\begin{array}{l}2.13 \\
2.20 \\
2.02\end{array}$ & $\begin{array}{l}1.85 \\
2.09 \\
1.68\end{array}$ & $\begin{array}{l}1.56 \\
1.67 \\
1.45\end{array}$ & $\begin{array}{l}1.63 \\
1.71 \\
1.60\end{array}$ \\
\hline
\end{tabular}

$\begin{array}{lllllll}\text { CAL YR } 1984 & \text { MEAN } & 2.30 & \text { MAX } & 3.31 & \text { MIN } & 1.49 \\ \text { WTR YR } 1985 & \text { MEAN } & 2.02 & \text { MAX } & 2.61 & \text { MIN } & 1.45\end{array}$ 
LOCATION. -Lat $41^{\circ} 59^{\prime} 17^{\prime \prime}$, long $94^{\circ} 22^{\prime} 36^{\prime \prime}$, in SW1/4 N1/4 sec. 20, T.83 N., R.30 W., Greene County, Aydrologic Unit 07100006 , on right bank $5 \mathrm{ft}$ downtream from bridge on State Highway $4,0.1$ mi downstream from Drainage ditch 33 and $40,1.9 \mathrm{mi}$ south of Jefferson, $4.2 \mathrm{mi}$ upstream from Bardin Creek, and at mile 292.5 upstream from mouth of Des Moines River.

DRAMNAGE AREA. $-1,619 \mathrm{mi}^{3}$.

PERTOD OF RECORD. - Warch 1940 to current year. Prior to April 1940, monthly discharge only, published in wSP 1308. Prior to October 1955, published as Raccoon River near Jefferson.

REVISED RECORDS.--nSP 1438: Drainage area. WSP 1508: 1940 (M), 1950-51.

GAGE. - hater-stage recorder. Datum of gage is $967.09 \mathrm{ft}$ above NGVD. Prior to Apr. 22, 1946, nonrecording gage at site $4 \mathrm{mi}$ upstream at different datum. Apr. 22 to June 25, 1946, nonrecording gage, June 26 , 1946 to Sept. 30 , 1955, water-stage recorder, Oct. 1, 1955 to Apr. 30, 1958, nonrecording gage, at present site and daturn.

REYARKS.--Estimated daily discharge: Nov. 23 to March 4, 7-11. Records good except for estimated daily discharges, which are poor. U.S. Army Corps of Engineers data collection platform at station.

COOPERATION. - Two discharge measurements furnished by U.S. Army Corps of Engineers.

AVERAGE DISCHARGE. -45 years, $732 \mathrm{ft}^{3} / \mathrm{s}, 6.14 \mathrm{in} / \mathrm{yr}, 530,300$ acre-ft/yr; median of yearly mean discharges, 600 $\mathrm{ft}^{\mathrm{J}} / \mathrm{s}, 5.0 \mathrm{in} / \mathrm{yr}, 435,000$ acre-ft/yr.

EXIREIES FOR PERIOD OF RBOORD. - Waximum discharge, 29,100 ft'/s June 23, 1947, gage height, $22.3 \mathrm{ft}$; minimm daily, $0.6 \mathrm{ft}^{3} / \mathrm{s}$ Oct. $5,1956$.

EXIREES FOR CURREN YEAR.--Peak discharges greater than base of $4,000 \mathrm{ft} / \mathrm{s}$ and maximu $(*)$ :

\begin{tabular}{|c|c|c|c|c|c|c|c|}
\hline $\begin{array}{l}\text { Date } \\
\text { Dec. } 31\end{array}$ & $\begin{array}{l}\text { Time } \\
0600\end{array}$ & $\begin{array}{c}\text { Discharge } \\
\left(\mathrm{ft}^{2} / \mathrm{s}\right) \\
\star 2,800\end{array}$ & $\begin{array}{c}\text { Gage height } \\
\text { (ft) } \\
a * 13.10\end{array}$ & Date & Time & $\begin{array}{l}\text { Discharge } \\
\left(\mathrm{ft}^{2} / \mathrm{s}\right)\end{array}$ & $\begin{array}{c}\text { Gage height } \\
\text { (ft) }\end{array}$ \\
\hline
\end{tabular}

(a) Ice jam.

Minimin discharge, $68 \mathrm{ft}^{3} / \mathrm{s}$ Aug. 21 .

DISCAARGE, IN OUBIC FEET PER SECOND, WATER YEAR OCTCBER 1984 TO SEPTEMBER 1985 MEAN VALUES

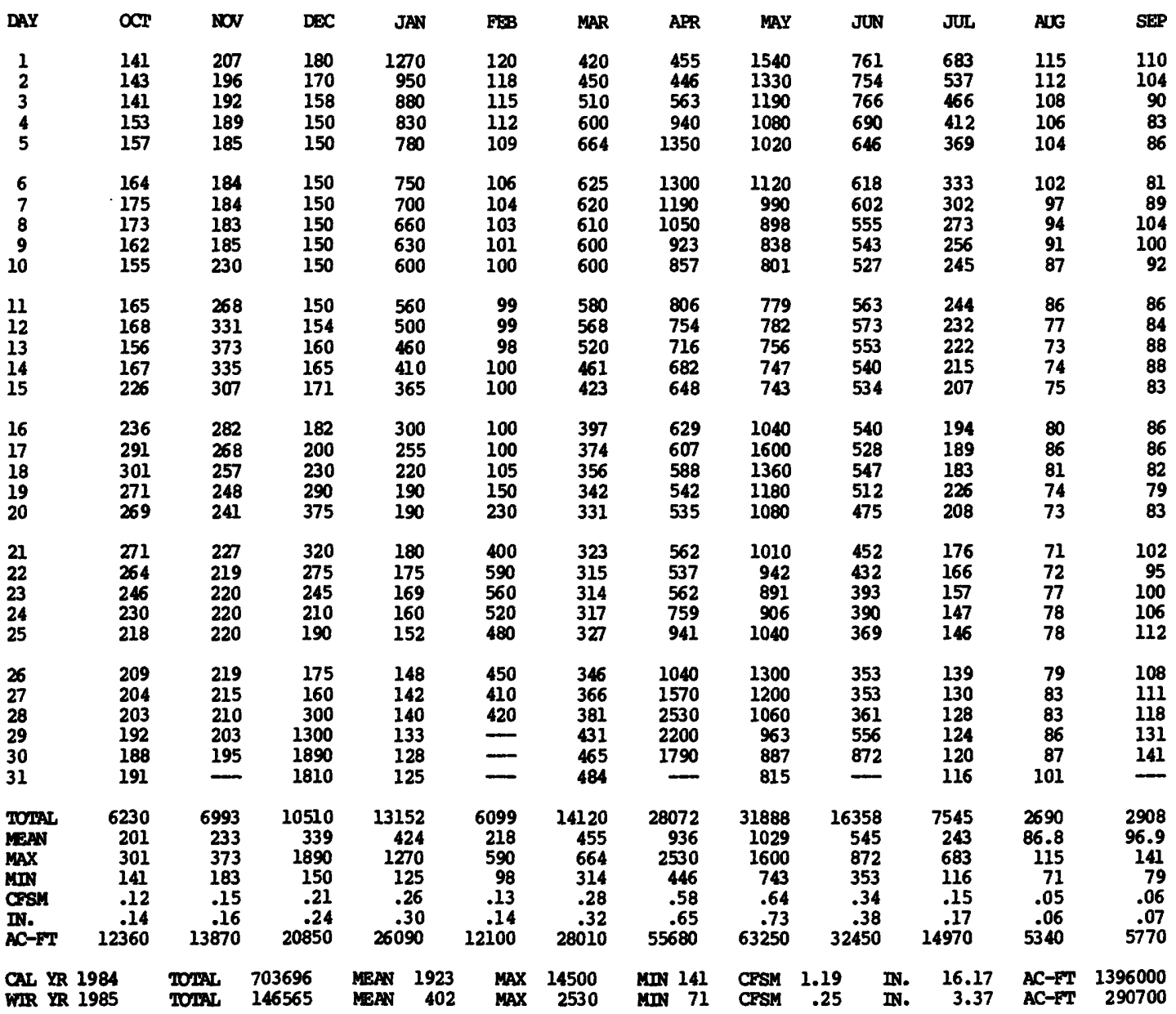


LOCATION.--Lat $42^{\circ} 06^{\prime} 27^{\prime \prime}$, long $94^{\circ} 22^{\prime} 12^{\prime \prime}$, in SEl/4 swl/4 sec. 5, T.84 N., R.30 W., Greene County, Hyarologic unit 07100006 , on left bank $35 \mathrm{ft}$ upstream from bridge on county highway E26, 1.6 mi upstream from small left-bank tributary, $4.4 \mathrm{mi}$ upstrean from mouth, and $6.5 \mathrm{mi}$ southeast of Churdan.

DRAINAGE AREA. $-24.0 \mathrm{mi}^{2}$.

PERIOD OP RECORD.--July 1952 to current year.

REVISED RECORDS.--hSP 1438: Drainage area. WSP 1708: 1954-55, 1957 (M).

GaGE. - Water-stage recorder. Datum of gage is $1,050.90 \mathrm{ft}$ above NGVD.

REMARKS.--Estimated daily discharges: Jan. 18-24, Feb. 17-22 and June 2. Records good except for estimated daily discharges, which are poor. Small diversion for irrigation upstrean from station.

AVERAGE DISCHARGE.--33 years, $10.4 \mathrm{ft}^{3} / \mathrm{s}, 5.88 \mathrm{in} / \mathrm{yr}, 7,535$ acre-ft/yr; median of yearly mean discharges, 7.7 $\mathrm{ft}^{3} / \mathrm{s}, 4.4 \mathrm{in} / \mathrm{yr}, 5,580 \mathrm{acre}-\mathrm{ft} / \mathrm{yr}$.

EXIREYES FOR PERTOD OR RECORD.-Maximm discharge, $413 \mathrm{ft} / \mathrm{s}$ May 5, 1960, gage height, $8.92 \mathrm{ft}$, from rating curve extended above $330 \mathrm{ft}^{3} / \mathrm{s}$; no flow at times most years.

EXIREARS FOR CURRENT YEAR.--Peak discharge greater than base of $150 \mathrm{ft}^{2} / \mathrm{s}$ and maximum (*):

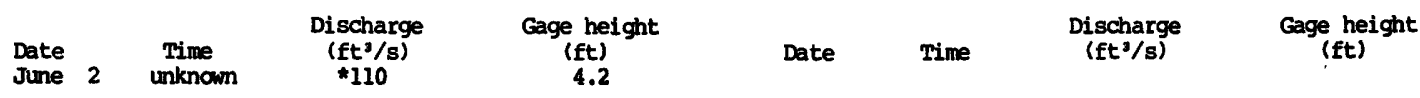

No flow Oct. 1-3, Jan. 18-24, Sept 1-4, 7-13 and 20-22.

DISCHARGE, IN OBIC FEET PER SEOOND, WATER YEAR OCTCBER 1984 TO SEPTEEBER 1985

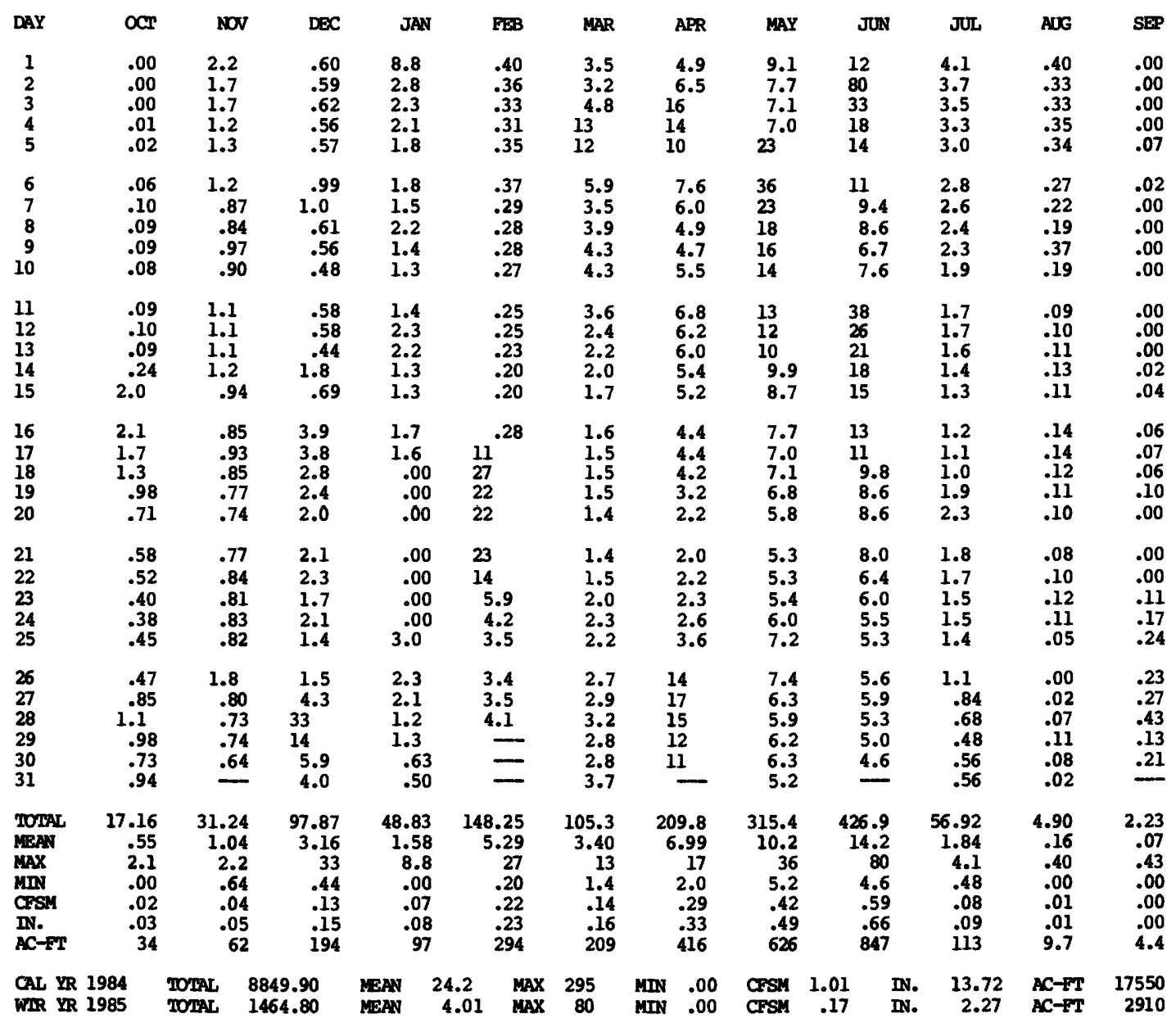


05483450 MIDDLE RACCOON RIVER NEAR BAYARD, IA

LOCATION.--Lat $41^{\circ} 46^{\prime} 43^{\prime}$, long $94^{\circ} 29^{\prime} 33^{\prime}$, in Swl/4 sw1/4 sec. 32 , T.81 N., R.31 w., Guthrie County, Bydrologic Onit 07100007 , on left bank $110 \mathrm{ft}$, downstream from bridge on State Highway $25,0.2 \mathrm{mi}$ downstream $\mathrm{from}$ Battle Run Creek, I.8 mi upstream from Springbrook Creek, $5.8 \mathrm{mi}$ southeast of Bayard, $10.4 \mathrm{mi}$ upstream from dam at Lake Panorama, and at mile $\mathbf{2 7 9 . 2}$ upstream from mouth of Des Moines River.

DRAINAGE AREA. $--375 \mathrm{mi}^{2}$.

\section{WATER-DISCHARGE RECORDS}

PERIOD OF RECORD. - March 1979 to current year. Occasional low-flow measurements, water years I976,77. Contracted opening measurement of July 3,1973 flood.

GAGE.-Water-stage recorder. Datum of gage is 1,040.00 ft above NGVD. Prior to June 23, 1979 , nonrecording gage on downstream side of State Highway 25 bridge.

REMARKS.--Estimated daily discharges: Dec. 3 to Feb. 22, and Feb. 28 to Mar. 8 . Records good, except for estimated daily discharges, which are poor. Gage-height telemeter at station.

AVERAGE DISCHARGE. --6 years, $221 \mathrm{ft} / \mathrm{s}, 8.00 \mathrm{in} / \mathrm{yr} 160,110 \mathrm{acre}-\mathrm{ft} / \mathrm{yr}$.

EXTREMES FOR PERIOD OF RECORD.--Maximum discharge, 5,190 ft $3 / \mathrm{s}$ July 2, 1983, gage height, l9.79 ft, maximum gage height, $19.99 \mathrm{ft}, \mathrm{Apr} .30,1984 \mathrm{minimum}$ daily, $5.5 \mathrm{ft} / \mathrm{s}$, June $13,14,1981$.

EXTREMES OUTSIDE PEIROD OF RECORD.--Flood of July 3, 1973 reached a stage of 21.63 ft, from contracted opening measurement, discharge, $14,600 \mathrm{ft}^{3} / \mathrm{s}$.

EXTREMES FOR CURRENT YEAR.--Peak discharge greater than base of 1,200 $\mathrm{ft}^{3} / \mathrm{s}^{\mathrm{and}} \mathrm{maximum}(*)$ :

\begin{tabular}{|c|c|c|c|c|c|c|c|}
\hline $\begin{array}{l}\text { Date } \\
\text { Feb. } 22\end{array}$ & Time & $\begin{array}{c}\text { Discharge } \\
\left(\mathrm{ft}^{3} / \mathrm{s}\right) \\
* 1,170\end{array}$ & $\begin{array}{l}\text { Gage height } \\
\text { (ft) }\end{array}$ & Date & Time & $\begin{array}{c}\text { Discharge } \\
\left(f t^{2} / s\right)\end{array}$ & $\begin{array}{l}\text { Gage height } \\
(f t)\end{array}$ \\
\hline
\end{tabular}

a ice jam

Minimum discharge, $22 \mathrm{ft}^{3} / \mathrm{s}$ Sept. 18,19 .

DISCHARGE, IN COBIC FEET PER SECOND, WATER YEAR OCTOBER 1984 TO SEPTEMBER 1985 MEAN VALUES

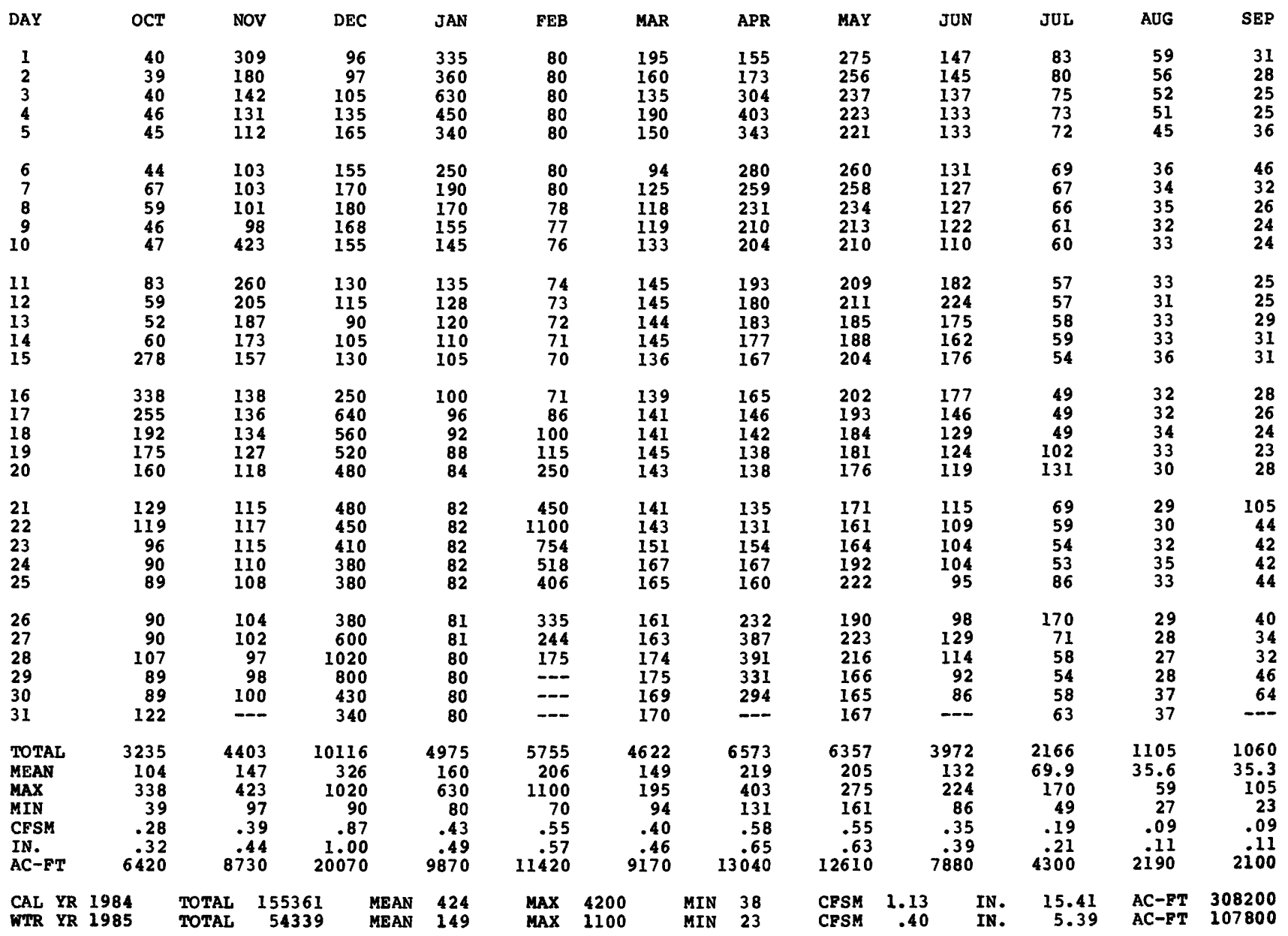


PERIOD OF RECORD.--April 1979 to current year (discontinued).

PERIOD OF DAILY RECORD.--

SPECIFIC CONDUCTANCE: April 1979 to current year (discontinued).

WATER TBMPERATURBS: April 1979 to current year (discontinued).

SUSPENDED-SBDIMBNT DISCHARGB: April 1979 to current year (discontinued).

REMARKs.--Records of specific conductance are obtained from suspended-sediment samples at time of analysis.

BXTREMES FOR PERIOD OF DAIIY RECORD.--

SPECIFIC CONDUCTANCE: Maximum dally, 880 microsiemens Har. 8, 1984; minimum daily, 230 microsiemens Feb. 22, 1982

WATER TEMPERATURES: Maximum daily, 32.0C Aug. 5, 1979 , minimum daily, $0.0^{\circ} \mathrm{C}$ on many days during winter periods.

SEDIMBNT CONCENTRATIONs: Maximum daily mean, 9,440 mg/L June 27, 1979, minimum daily mean, 1 mg/L Jan. 29. 1982 .

SBDIMBNT LOADS: Maximum daily, 62,000 tons July 2, 1983, minimum daily, 0.06 tons Jan. $29,1982$.

EXTREMES FOR CURRENT YEAR:

SPECIFIC CONDUCTANCB: Maximum dally, 840 microsiemens Mar. 8; minimum daily, 280 microsiemens Feb. 21.

WATER TEMPBRATURES: Maximum dally, $32.0^{\circ} \mathrm{C}$ Aug. $6-7$, minimum daily, $0.0^{\circ} \mathrm{C}$ on many days during winter period.

SEDIYBNT CONCENTRATIONS: Maximum daily mean, $2,580 \mathrm{mg} / \mathrm{L}$ Nov. 10 , minimum daily mean, 13 mg/L Fab. 15 .

SEDIMENT LOADS: Maximu daily, 4,630 tons Dec. 28 ; minimum dally, 1.6 tons Sept. 12 .

SPBCIEIC CONDUCTANCE (MICROBIBMEAS/CY AT 25 DBG.), WATER YEAR OCTOBER 1984 TO SEPTEMBER 1985 RAMDOM VARUBS

\begin{tabular}{|c|c|c|c|c|c|c|c|c|c|c|c|c|}
\hline DAY & OCT & MOV & DEC & JAA & PBB & MAR & APR & MAY & JON & JOL & ADG & SEP \\
\hline $\begin{array}{l}1 \\
2 \\
3 \\
4 \\
5\end{array}$ & $\begin{array}{l}640 \\
665 \\
640 \\
630 \\
560\end{array}$ & $\begin{array}{l}480 \\
630 \\
640 \\
610 \\
530\end{array}$ & $\begin{array}{l}510 \\
-0 \\
-510 \\
600\end{array}$ & $\begin{array}{l}-\infty \\
-\infty 70 \\
-\infty \\
-\infty\end{array}$ & $\begin{array}{c}--- \\
550 \\
-2 .\end{array}$ & \begin{tabular}{l}
560 \\
$-ב 40$ \\
\hdashline- \\
-
\end{tabular} & $\begin{array}{l}580 \\
540 \\
605 \\
620 \\
595\end{array}$ & $\begin{array}{l}540 \\
600 \\
600 \\
650 \\
620\end{array}$ & $\begin{array}{l}670 \\
580 \\
550 \\
640 \\
560\end{array}$ & $\begin{array}{l}500 \\
540 \\
510 \\
545 \\
560\end{array}$ & $\begin{array}{l}590 \\
--0 \\
660 \\
650 \\
570\end{array}$ & $\begin{array}{l}\mathbf{5 8 0} \\
\mathbf{5 6 0} \\
\mathbf{5 4 0} \\
560 \\
\mathbf{5 6 0}\end{array}$ \\
\hline $\begin{array}{r}6 \\
7 \\
8 \\
9 \\
10\end{array}$ & $\begin{array}{l}560 \\
620 \\
680 \\
660 \\
660\end{array}$ & $\begin{array}{l}540 \\
560 \\
590 \\
570 \\
440\end{array}$ & $\begin{array}{l}540 \\
600 \\
570 \\
520 \\
---\end{array}$ & $\begin{array}{l}-590 \\
620 \\
--0 \\
540\end{array}$ & $\bar{~}$ & $\begin{array}{l}520 \\
-20 \\
840 \\
560 \\
540\end{array}$ & $\begin{array}{l}560 \\
-540 \\
540 \\
590 \\
600\end{array}$ & $\begin{array}{l}640 \\
660 \\
665 \\
640 \\
640\end{array}$ & $\begin{array}{l}--- \\
530 \\
530 \\
640\end{array}$ & $\begin{array}{l}540 \\
600 \\
420 \\
410 \\
420\end{array}$ & $\begin{array}{l}600 \\
580 \\
540 \\
560 \\
580\end{array}$ & $\begin{array}{l}580 \\
620 \\
630 \\
560 \\
560\end{array}$ \\
\hline $\begin{array}{l}11 \\
12 \\
13 \\
14 \\
15\end{array}$ & $\begin{array}{l}600 \\
600 \\
660 \\
660 \\
540\end{array}$ & $\begin{array}{l}560 \\
670 \\
640 \\
620 \\
660\end{array}$ & $\begin{array}{l}640 \\
-\infty \\
-\infty \\
-\infty\end{array}$ & $\begin{array}{l}-\infty \\
--\infty \\
-\infty \\
660\end{array}$ & \begin{tabular}{c}
660 \\
$-\infty$ \\
\hdashline-
\end{tabular} & $\begin{array}{l}620 \\
620 \\
600 \\
-\end{array}$ & $\begin{array}{l}-120 \\
620 \\
570 \\
600\end{array}$ & $\begin{array}{l}--0 \\
660 \\
--0 \\
660 \\
530\end{array}$ & $\begin{array}{l}650 \\
500 \\
680 \\
670 \\
640\end{array}$ & $\begin{array}{l}540 \\
540 \\
560 \\
620 \\
-\end{array}$ & $\begin{array}{l}610 \\
--\infty \\
-\infty \\
-\infty\end{array}$ & $\begin{array}{l}620 \\
580 \\
560 \\
580 \\
520\end{array}$ \\
\hline $\begin{array}{l}16 \\
17 \\
18 \\
19 \\
20\end{array}$ & $\begin{array}{l}540 \\
570 \\
570 \\
680 \\
680\end{array}$ & $\begin{array}{l}530 \\
565 \\
600 \\
560 \\
580\end{array}$ & $\begin{array}{l}510 \\
-\infty \\
-\infty \\
-\infty \\
-\infty\end{array}$ & $\begin{array}{l}-\infty \\
-\infty \\
660 \\
-\infty\end{array}$ & $\begin{array}{l}630 \\
-260 \\
---\end{array}$ & $\begin{array}{l}540 \\
--- \\
550 \\
630 \\
---\end{array}$ & $\begin{array}{l}620 \\
-0- \\
650 \\
680\end{array}$ & $\begin{array}{l}540 \\
540 \\
600 \\
-640\end{array}$ & $\begin{array}{l}580 \\
630 \\
--0 \\
670 \\
565\end{array}$ & $\begin{array}{l}520 \\
520 \\
600 \\
480 \\
440\end{array}$ & $\begin{array}{l}610 \\
580 \\
520 \\
540 \\
450\end{array}$ & $\begin{array}{l}540 \\
580 \\
615 \\
670 \\
670\end{array}$ \\
\hline $\begin{array}{l}21 \\
22 \\
23 \\
24 \\
25\end{array}$ & $\begin{array}{l}730 \\
730 \\
580 \\
640 \\
620\end{array}$ & $\begin{array}{l}640 \\
540 \\
540 \\
520 \\
565\end{array}$ & $\begin{array}{l}--\infty \\
--\infty \\
-\infty \\
-\infty \\
-\infty\end{array}$ & $\begin{array}{l}660 \\
690 \\
2-0\end{array}$ & \begin{tabular}{l}
280 \\
$=-$ \\
\hdashline- \\
$-\infty$
\end{tabular} & $\begin{array}{l}640 \\
--0 \\
630 \\
520 \\
480\end{array}$ & $\begin{array}{l}660 \\
540 \\
--0 \\
605 \\
530\end{array}$ & $\begin{array}{l}550 \\
690 \\
-50 \\
630 \\
590\end{array}$ & $\begin{array}{l}620 \\
540 \\
610 \\
=-20\end{array}$ & $\begin{array}{l}600 \\
640 \\
620 \\
605 \\
520\end{array}$ & $\begin{array}{l}480 \\
520 \\
490 \\
600 \\
500\end{array}$ & $\begin{array}{l}380 \\
450 \\
590 \\
660\end{array}$ \\
\hline $\begin{array}{l}26 \\
27 \\
28 \\
29 \\
30 \\
31\end{array}$ & $\begin{array}{l}580 \\
605 \\
600 \\
600 \\
530 \\
665\end{array}$ & $\begin{array}{l}555 \\
560 \\
-550 \\
-\ldots-\end{array}$ & $\begin{array}{l}-- \\
420 \\
--\infty \\
-\ldots \\
-\infty\end{array}$ & $\begin{array}{l}--0 \\
665 \\
-\infty \\
-\infty 40 \\
--0\end{array}$ & $\begin{array}{l}450 \\
550 \\
--\infty \\
-\infty\end{array}$ & $\begin{array}{l}600 \\
575 \\
-580 \\
560 \\
-\ldots\end{array}$ & $\begin{array}{l}620 \\
650 \\
660 \\
660 \\
640 \\
-\end{array}$ & $\begin{array}{l}600 \\
620 \\
640 \\
580 \\
630\end{array}$ & $\begin{array}{l}580 \\
600 \\
640 \\
500 \\
- \\
-\end{array}$ & $\begin{array}{l}400 \\
-20 \\
620 \\
660 \\
600 \\
590\end{array}$ & $\begin{array}{l}480 \\
560 \\
600 \\
-20 \\
580 \\
620\end{array}$ & $\begin{array}{l}640 \\
660 \\
-640 \\
610\end{array}$ \\
\hline
\end{tabular}


DES MOINES RIVER BASIN

05483450 MIDDLE RACCOON RIVER NEAR BAYARD--Continued

WATER-QUALITY RECORDS

TEMPERATURE, WATER (DEG. C.), WATER YEAR OCTOBER 1984 TO SEPTEMBER 1985 RANDOM VALUES

\begin{tabular}{|c|c|c|c|c|c|c|c|c|c|c|c|c|}
\hline DAY & OCT & nov & DEC & JAN & FEB & MAR & APR & MAY & JUN & JUL & AUG & SEP \\
\hline $\begin{array}{l}1 \\
2 \\
3 \\
4 \\
5\end{array}$ & $\begin{array}{r}8.0 \\
11.0 \\
11.0 \\
12.0 \\
13.0\end{array}$ & $\begin{array}{l}7.0 \\
5.0 \\
6.0 \\
7.0 \\
6.0\end{array}$ & $\begin{array}{l}2.0 \\
4.0 \\
4.0 \\
4.0 \\
3.0\end{array}$ & $\overline{2.0}$ & \begin{tabular}{l}
$\overline{2.0}$ \\
\hdashline 2.0 \\
2.0
\end{tabular} & $\frac{9.0}{7.0}$ & $\begin{array}{r}6.0 \\
6.0 \\
14.0 \\
14.0 \\
13.0\end{array}$ & $\begin{array}{l}20.0 \\
20.0 \\
21.0 \\
23.0 \\
20.0\end{array}$ & $\begin{array}{l}22.0 \\
14.0 \\
22.0 \\
18.0 \\
24.0\end{array}$ & $\begin{array}{l}29.0 \\
28.0 \\
30.0 \\
29.0 \\
29.0\end{array}$ & $\begin{array}{l}25.0 \\
26.0 \\
21.0 \\
30.0\end{array}$ & $\begin{array}{l}28.0 \\
24.0 \\
28.0 \\
27.0 \\
29.0\end{array}$ \\
\hline $\begin{array}{r}6 \\
7 \\
8 \\
9 \\
10\end{array}$ & $\begin{array}{l}15.0 \\
16.0 \\
15.0 \\
15.0 \\
16.0\end{array}$ & $\begin{array}{r}5.0 \\
8.0 \\
8.0 \\
11.0 \\
7.0\end{array}$ & $\begin{array}{l}3.0 \\
5.0 \\
5.0 \\
4.0 \\
-.-\end{array}$ & $\begin{array}{r}-.0 \\
1.0 \\
2.0\end{array}$ & $\overline{2.0}$ & $\begin{array}{r}6.0 \\
10.0 \\
9.0 \\
8.0\end{array}$ & $\begin{array}{l}10.0 \\
11.0 \\
12.0 \\
15.0\end{array}$ & $\begin{array}{l}21.0 \\
23.0 \\
24.0 \\
23.0 \\
22.0\end{array}$ & $\begin{array}{r}27.0 \\
25.0 \\
20.0\end{array}$ & $\begin{array}{l}29.0 \\
29.0 \\
26.0 \\
31.0 \\
30.0\end{array}$ & $\begin{array}{l}32.0 \\
32.0 \\
30.0 \\
28.0 \\
27.0\end{array}$ & $\begin{array}{l}31.0 \\
30.0 \\
29.0 \\
22.0 \\
22.0\end{array}$ \\
\hline $\begin{array}{l}11 \\
12 \\
13 \\
14 \\
15\end{array}$ & $\begin{array}{l}17.0 \\
17.0 \\
17.0 \\
17.0 \\
17.0\end{array}$ & $\begin{array}{l}6.0 \\
4.0 \\
6.0 \\
9.0 \\
6.0\end{array}$ & $\begin{array}{l}4.0 \\
3.0 \\
1.0 \\
-\cdots \\
-\ldots\end{array}$ & $\begin{array}{l}-- \\
\square-\infty \\
\square-\infty\end{array}$ & \begin{tabular}{c}
2.0 \\
\hdashline- \\
\hdashline- \\
$-\cdots$
\end{tabular} & $\begin{array}{r}9.0 \\
10.0 \\
6.0 \\
-\cdots\end{array}$ & $\begin{array}{l}--- \\
20.0 \\
14.0 \\
11.0 \\
19.0\end{array}$ & $\begin{array}{r}21.0 \\
15.0 \\
14.0\end{array}$ & $\begin{array}{l}18.0 \\
15.0 \\
15.0 \\
17.0 \\
26.0\end{array}$ & $\begin{array}{r}29.0 \\
26.0 \\
26.0 \\
29.0 \\
\ldots\end{array}$ & \begin{tabular}{c}
22.0 \\
\hdashline- \\
\hdashline- \\
-
\end{tabular} & $\begin{array}{l}24.0 \\
18.0 \\
17.0 \\
22.0 \\
22.0\end{array}$ \\
\hline $\begin{array}{l}16 \\
17 \\
18 \\
19 \\
20\end{array}$ & $\begin{array}{r}12.0 \\
9.0 \\
11.0 \\
11.0 \\
8.0\end{array}$ & $\begin{array}{l}4.0 \\
4.0 \\
5.0 \\
4.0 \\
2.0\end{array}$ & $\begin{array}{l}3.0 \\
2.0 \\
-\end{array}$ & $\begin{array}{l}--- \\
\overline{--} \\
\overline{1.0} \\
---\end{array}$ & \begin{tabular}{c}
2.0 \\
\hdashline 1.0 \\
\hdashline-
\end{tabular} & $\begin{array}{r}12.0 \\
12.0 \\
16.0 \\
16.0 \\
-\ldots\end{array}$ & \begin{tabular}{r}
20.0 \\
\hdashline$\overline{19.0}$ \\
23.0
\end{tabular} & $\begin{array}{r}15.0 \\
20.0 \\
22.0 \\
24.0\end{array}$ & $\begin{array}{r}27.0 \\
20.0 \\
25.0 \\
22.0\end{array}$ & $\begin{array}{l}26.0 \\
29.0 \\
27.0 \\
25.0 \\
26.0\end{array}$ & $\begin{array}{l}27.0 \\
26.0 \\
24.0 \\
26.0 \\
17.0\end{array}$ & $\begin{array}{l}21.0 \\
27.0 \\
24.0 \\
27.0 \\
20.0\end{array}$ \\
\hline $\begin{array}{l}21 \\
22 \\
23 \\
24 \\
25\end{array}$ & $\begin{array}{r}9.0 \\
9.0 \\
7.0 \\
7.0 \\
10.0\end{array}$ & $\begin{array}{l}2.0 \\
4.0 \\
4.0 \\
4.0 \\
6.0\end{array}$ & \begin{tabular}{l}
3.0 \\
2.0 \\
\hdashline-0
\end{tabular} & \begin{tabular}{l}
2.0 \\
\hdashline 2.0 \\
\hdashline-0
\end{tabular} & \begin{tabular}{c}
5.0 \\
\hdashline- \\
\hdashline- \\
\hdashline-
\end{tabular} & $\begin{array}{r}9.0 \\
11.0 \\
6.0 \\
10.0\end{array}$ & $\begin{array}{l}20.0 \\
20.0 \\
15.0 \\
13.0\end{array}$ & $\begin{array}{l}24.0 \\
23.0 \\
25.0 \\
26.0\end{array}$ & $\begin{array}{r}26.0 \\
24.0 \\
21.0 \\
29.0\end{array}$ & $\begin{array}{l}30.0 \\
27.0 \\
28.0 \\
26.0 \\
29.0\end{array}$ & $\begin{array}{l}23.0 \\
22.0 \\
26.0 \\
23.0 \\
23.0\end{array}$ & $\begin{array}{l}15.0 \\
21.0 \\
14.0 \\
16.0 \\
16.0\end{array}$ \\
\hline $\begin{array}{l}26 \\
27 \\
28 \\
29 \\
30 \\
31\end{array}$ & $\begin{array}{r}9.0 \\
16.0 \\
9.0 \\
8.0 \\
9.0 \\
8.0\end{array}$ & $\begin{array}{l}7.0 \\
7.0 \\
4.0 \\
6.0 \\
5.0 \\
\end{array}$ & $\begin{array}{r}\overline{4.0} \\
\hdashline-0 \\
\hdashline 1.0\end{array}$ & \begin{tabular}{l}
-1.0 \\
\hdashline 1.0 \\
\hdashline-0
\end{tabular} & \begin{tabular}{c}
3.0 \\
8.0 \\
\hdashline-0 \\
-0
\end{tabular} & $\begin{array}{r}13.0 \\
15.0 \\
9.0 \\
6.0 \\
-\end{array}$ & $\begin{array}{r}13.0 \\
15.0 \\
14.0 \\
19.0 \\
17.0 \\
-\end{array}$ & $\begin{array}{l}26.0 \\
26.0 \\
25.0 \\
27.0 \\
20.0\end{array}$ & $\begin{array}{r}27.0 \\
23.0 \\
25.0 \\
25.0 \\
-.0\end{array}$ & $\begin{array}{l}30.0 \\
25.0 \\
27.0 \\
24.0 \\
21.0\end{array}$ & $\begin{array}{l}25.0 \\
26.0 \\
27.0 \\
23.0 \\
26.0\end{array}$ & $\begin{array}{r}17.0 \\
19.0 \\
8.0 \\
11.0 \\
-\end{array}$ \\
\hline
\end{tabular}

SUSPENDED-SEDIMENT, WATER YEAR OCTOBER 1984 TO SEPTEMBER 1985

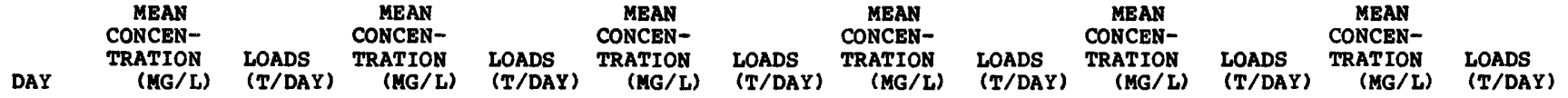
OCTOBER NOVEMBER DECEMBER

JANUARY

FEBRUARY

MARCH

\begin{tabular}{|c|c|c|c|c|c|c|c|c|c|c|c|c|}
\hline $\begin{array}{l}1 \\
2 \\
3 \\
4 \\
5\end{array}$ & $\begin{array}{l}39 \\
36 \\
46 \\
56 \\
76\end{array}$ & $\begin{array}{l}4.2 \\
3.8 \\
5.0 \\
7.0 \\
9.2\end{array}$ & $\begin{array}{l}775 \\
200 \\
115 \\
129 \\
137\end{array}$ & $\begin{array}{r}647 \\
97 \\
44 \\
46 \\
41\end{array}$ & $\begin{array}{r}64 \\
112 \\
123 \\
125 \\
124\end{array}$ & $\begin{array}{l}17 \\
29 \\
35 \\
46 \\
55\end{array}$ & $\begin{array}{l}243 \\
190 \\
141 \\
122 \\
117\end{array}$ & $\begin{array}{l}220 \\
185 \\
240 \\
148 \\
107\end{array}$ & $\begin{array}{l}30 \\
40 \\
49 \\
54 \\
60\end{array}$ & $\begin{array}{l}6.5 \\
8.6 \\
11 \\
12 \\
13\end{array}$ & $\begin{array}{l}505 \\
428 \\
390 \\
402 \\
795\end{array}$ & $\begin{array}{l}266 \\
185 \\
142 \\
206 \\
322\end{array}$ \\
\hline $\begin{array}{r}6 \\
7 \\
8 \\
9 \\
10\end{array}$ & $\begin{array}{r}55 \\
140 \\
114 \\
64 \\
83\end{array}$ & $\begin{array}{l}6.5 \\
25 \\
18 \\
7.9 \\
11\end{array}$ & $\begin{array}{r}118 \\
114 \\
89 \\
88 \\
2580\end{array}$ & $\begin{array}{r}33 \\
32 \\
24 \\
23 \\
2950\end{array}$ & $\begin{array}{l}120 \\
111 \\
115 \\
124 \\
119\end{array}$ & $\begin{array}{l}50 \\
51 \\
56 \\
56 \\
50\end{array}$ & $\begin{array}{l}131 \\
161 \\
134 \\
113 \\
100\end{array}$ & $\begin{array}{l}88 \\
83 \\
62 \\
47 \\
39\end{array}$ & $\begin{array}{l}53 \\
47 \\
38 \\
29 \\
20\end{array}$ & $\begin{array}{l}11 \\
10 \\
8.0 \\
6.0 \\
4.1\end{array}$ & $\begin{array}{l}460 \\
353 \\
277 \\
199 \\
180\end{array}$ & $\begin{array}{r}117 \\
119 \\
88 \\
64 \\
65\end{array}$ \\
\hline $\begin{array}{l}11 \\
12 \\
13 \\
14 \\
15\end{array}$ & $\begin{array}{r}410 \\
105 \\
75 \\
120 \\
1010\end{array}$ & $\begin{array}{r}92 \\
17 \\
11 \\
19 \\
758\end{array}$ & $\begin{array}{l}900 \\
250 \\
200 \\
180 \\
145\end{array}$ & $\begin{array}{r}632 \\
138 \\
101 \\
84 \\
61\end{array}$ & $\begin{array}{r}57 \\
122 \\
98 \\
88 \\
112\end{array}$ & $\begin{array}{l}20 \\
38 \\
24 \\
25 \\
39\end{array}$ & $\begin{array}{l}94 \\
88 \\
83 \\
76 \\
70\end{array}$ & $\begin{array}{l}34 \\
30 \\
27 \\
23 \\
20\end{array}$ & $\begin{array}{l}17 \\
18 \\
17 \\
14 \\
13\end{array}$ & $\begin{array}{l}3.4 \\
3.5 \\
3.3 \\
2.7 \\
2.5\end{array}$ & $\begin{array}{l}218 \\
210 \\
176 \\
169 \\
167\end{array}$ & $\begin{array}{l}85 \\
82 \\
68 \\
66 \\
61\end{array}$ \\
\hline $\begin{array}{l}16 \\
17 \\
18 \\
19 \\
20\end{array}$ & $\begin{array}{l}820 \\
395 \\
235 \\
195 \\
190\end{array}$ & $\begin{array}{r}748 \\
272 \\
122 \\
92 \\
82\end{array}$ & $\begin{array}{r}168 \\
168 \\
136 \\
78 \\
79\end{array}$ & $\begin{array}{l}63 \\
62 \\
49 \\
27 \\
25\end{array}$ & $\begin{array}{l}330 \\
656 \\
272 \\
110 \\
105\end{array}$ & $\begin{array}{r}223 \\
1130 \\
411 \\
154 \\
136\end{array}$ & $\begin{array}{l}64 \\
62 \\
64 \\
66 \\
62\end{array}$ & $\begin{array}{l}17 \\
16 \\
16 \\
16 \\
14\end{array}$ & $\begin{array}{r}17 \\
24 \\
50 \\
304 \\
580\end{array}$ & $\begin{array}{r}3.3 \\
5.6 \\
13 \\
94 \\
391\end{array}$ & $\begin{array}{l}199 \\
129 \\
107 \\
145 \\
141\end{array}$ & $\begin{array}{l}75 \\
49 \\
41 \\
57 \\
54\end{array}$ \\
\hline $\begin{array}{l}21 \\
22 \\
23 \\
24 \\
25\end{array}$ & $\begin{array}{r}130 \\
132 \\
102 \\
90 \\
113\end{array}$ & $\begin{array}{l}45 \\
42 \\
26 \\
22 \\
27\end{array}$ & $\begin{array}{r}85 \\
122 \\
132 \\
123 \\
78\end{array}$ & $\begin{array}{l}26 \\
39 \\
41 \\
37 \\
23\end{array}$ & $\begin{array}{r}202 \\
186 \\
134 \\
108 \\
92\end{array}$ & $\begin{array}{r}262 \\
226 \\
148 \\
111 \\
94\end{array}$ & $\begin{array}{l}75 \\
65 \\
49 \\
37 \\
29\end{array}$ & $\begin{array}{l}17 \\
14 \\
11 \\
8.2 \\
6.4\end{array}$ & $\begin{array}{r}845 \\
1020 \\
825 \\
708 \\
632\end{array}$ & $\begin{array}{r}1030 \\
3030 \\
1680 \\
990 \\
693\end{array}$ & $\begin{array}{l}119 \\
130 \\
163 \\
221 \\
194\end{array}$ & $\begin{array}{r}45 \\
50 \\
66 \\
100 \\
86\end{array}$ \\
\hline $\begin{array}{l}26 \\
27 \\
28 \\
29 \\
30 \\
31\end{array}$ & $\begin{array}{r}136 \\
95 \\
155 \\
138 \\
132 \\
170\end{array}$ & $\begin{array}{l}33 \\
23 \\
45 \\
33 \\
32 \\
56\end{array}$ & $\begin{array}{r}95 \\
94 \\
110 \\
97 \\
86 \\
--\end{array}$ & $\begin{array}{r}27 \\
26 \\
29 \\
26 \\
23 \\
--\end{array}$ & $\begin{array}{r}105 \\
350 \\
1680 \\
1100 \\
415 \\
302\end{array}$ & $\begin{array}{r}108 \\
567 \\
4630 \\
2380 \\
482 \\
277\end{array}$ & $\begin{array}{l}23 \\
23 \\
23 \\
24 \\
25 \\
28\end{array}$ & $\begin{array}{l}5.0 \\
5.0 \\
5.0 \\
5.2 \\
5.4 \\
6.0\end{array}$ & $\begin{array}{l}558 \\
485 \\
448 \\
--- \\
--- \\
---\end{array}$ & $\begin{array}{l}505 \\
320 \\
212 \\
\end{array}$ & $\begin{array}{l}180 \\
270 \\
298 \\
212 \\
165 \\
149\end{array}$ & $\begin{array}{r}78 \\
119 \\
140 \\
100 \\
75 \\
68\end{array}$ \\
\hline TOTAI & -- & 2694.6 & -- & 5476 & -- & 11930 & -- & 1520.2 & $-\cdots$ & 9072.5 & -- & 3139 \\
\hline
\end{tabular}


05483450 MIDDLE RACCOON RIVER NEAR BAYARD--Continued

WATER-QUALITY RECORDS

\begin{tabular}{|c|c|c|c|c|c|c|c|c|c|c|c|c|}
\hline DAY & $\begin{array}{c}\text { MEAN } \\
\text { CONCEN- } \\
\text { TRATION } \\
(\text { MG /L) }\end{array}$ & $\begin{array}{l}\text { LOADS } \\
\text { (T/DAY) } \\
\text { APRIL }\end{array}$ & $\begin{array}{c}\text { MEAN } \\
\text { CONCEN- } \\
\text { TRATION } \\
\text { (MG/L) }\end{array}$ & $\begin{array}{l}\text { LOADS } \\
\text { (T/DAY) } \\
\text { MAY }\end{array}$ & $\begin{array}{c}\text { MEAN } \\
\text { CONCEN- } \\
\text { TRATION } \\
\text { (MG/L) }\end{array}$ & $\begin{array}{l}\text { LOADS } \\
\text { (T/DAY) } \\
\text { UNE }\end{array}$ & $\begin{array}{c}\text { MEAN } \\
\text { CONCEN- } \\
\text { TRATION } \\
(\text { MG/L) }\end{array}$ & $\begin{array}{l}\text { LOADS } \\
\text { (T/DAY) } \\
\text { ULY }\end{array}$ & \multicolumn{2}{|c|}{$\begin{array}{l}\text { MEAN } \\
\text { CONCEN- } \\
\text { TRATION LOADS } \\
\begin{array}{c}\text { (MG/L) (T/DAY) } \\
\text { AUGUST }\end{array}\end{array}$} & $\begin{array}{l}\text { MEAN } \\
\text { CONCEN- } \\
\text { TRATION } \\
\text { (MG/L) } \\
\text { SEP }\end{array}$ & $\begin{array}{l}\text { LOADS } \\
\text { (T/DAY) } \\
\text { TEMBER }\end{array}$ \\
\hline $\begin{array}{l}1 \\
2 \\
3 \\
4 \\
5\end{array}$ & $\begin{array}{r}143 \\
420 \\
1320 \\
1580 \\
1070\end{array}$ & $\begin{array}{r}60 \\
196 \\
1080 \\
1720 \\
991\end{array}$ & $\begin{array}{l}520 \\
485 \\
430 \\
365 \\
350\end{array}$ & $\begin{array}{l}386 \\
335 \\
275 \\
220 \\
209\end{array}$ & $\begin{array}{l}600 \\
340 \\
315 \\
300 \\
288\end{array}$ & $\begin{array}{l}238 \\
133 \\
117 \\
108 \\
103\end{array}$ & $\begin{array}{l}226 \\
205 \\
185 \\
150 \\
130\end{array}$ & $\begin{array}{l}51 \\
44 \\
37 \\
30 \\
25\end{array}$ & $\begin{array}{r}125 \\
105 \\
100 \\
110 \\
99\end{array}$ & $\begin{array}{l}20 \\
16 \\
14 \\
15 \\
12\end{array}$ & $\begin{array}{r}70 \\
62 \\
45 \\
48 \\
190\end{array}$ & $\begin{array}{r}5.9 \\
4.7 \\
3.0 \\
3.2 \\
18\end{array}$ \\
\hline $\begin{array}{r}6 \\
7 \\
8 \\
9 \\
10\end{array}$ & $\begin{array}{l}620 \\
438 \\
370 \\
290 \\
300\end{array}$ & $\begin{array}{l}469 \\
306 \\
231 \\
164 \\
165\end{array}$ & $\begin{array}{l}600 \\
600 \\
405 \\
345 \\
350\end{array}$ & $\begin{array}{l}421 \\
418 \\
256 \\
198 \\
198\end{array}$ & $\begin{array}{l}295 \\
320 \\
318 \\
295 \\
235\end{array}$ & $\begin{array}{r}104 \\
110 \\
109 \\
97 \\
70\end{array}$ & $\begin{array}{l}120 \\
115 \\
160 \\
225 \\
250\end{array}$ & $\begin{array}{l}22 \\
21 \\
29 \\
37 \\
40\end{array}$ & $\begin{array}{r}88 \\
80 \\
89 \\
100 \\
72\end{array}$ & $\begin{array}{l}8.6 \\
7.3 \\
8.4 \\
8.6 \\
6.4\end{array}$ & $\begin{array}{r}200 \\
131 \\
71 \\
50 \\
41\end{array}$ & $\begin{array}{r}25 \\
11 \\
5.0 \\
3.2 \\
2.7\end{array}$ \\
\hline $\begin{array}{l}11 \\
12 \\
13 \\
14 \\
15\end{array}$ & $\begin{array}{l}310 \\
285 \\
270 \\
220 \\
219\end{array}$ & $\begin{array}{r}162 \\
139 \\
133 \\
105 \\
99\end{array}$ & $\begin{array}{l}329 \\
360 \\
360 \\
290 \\
403\end{array}$ & $\begin{array}{l}186 \\
205 \\
180 \\
147 \\
222\end{array}$ & $\begin{array}{r}1000 \\
2330 \\
650 \\
410 \\
472\end{array}$ & $\begin{array}{r}491 \\
1410 \\
307 \\
179 \\
224\end{array}$ & $\begin{array}{l}215 \\
190 \\
160 \\
185 \\
205\end{array}$ & $\begin{array}{l}33 \\
29 \\
25 \\
29 \\
30\end{array}$ & $\begin{array}{l}50 \\
48 \\
42 \\
48 \\
58\end{array}$ & $\begin{array}{l}4.5 \\
4.0 \\
3.7 \\
4.3 \\
5.6\end{array}$ & $\begin{array}{l}28 \\
24 \\
27 \\
49 \\
47\end{array}$ & $\begin{array}{l}1.9 \\
1.6 \\
2.1 \\
4.1 \\
3.9\end{array}$ \\
\hline $\begin{array}{l}16 \\
17 \\
18 \\
19 \\
20\end{array}$ & $\begin{array}{l}228 \\
248 \\
262 \\
274 \\
268\end{array}$ & $\begin{array}{r}102 \\
98 \\
100 \\
102 \\
100\end{array}$ & $\begin{array}{l}400 \\
395 \\
340 \\
325 \\
325\end{array}$ & $\begin{array}{l}218 \\
206 \\
169 \\
159 \\
154\end{array}$ & $\begin{array}{l}865 \\
547 \\
360 \\
265 \\
270\end{array}$ & $\begin{array}{r}413 \\
216 \\
125 \\
89 \\
87\end{array}$ & $\begin{array}{l}185 \\
170 \\
145 \\
458 \\
660\end{array}$ & $\begin{array}{r}24 \\
22 \\
19 \\
126 \\
233\end{array}$ & $\begin{array}{l}70 \\
68 \\
55 \\
70 \\
90\end{array}$ & $\begin{array}{l}6.0 \\
5.9 \\
5.0 \\
6.2 \\
7.3\end{array}$ & $\begin{array}{l}58 \\
32 \\
41 \\
49 \\
37\end{array}$ & $\begin{array}{l}4.4 \\
2.2 \\
2.7 \\
3.0 \\
2.8\end{array}$ \\
\hline $\begin{array}{l}21 \\
22 \\
23 \\
24 \\
25\end{array}$ & $\begin{array}{l}279 \\
300 \\
298 \\
273 \\
270\end{array}$ & $\begin{array}{l}102 \\
106 \\
124 \\
123 \\
117\end{array}$ & $\begin{array}{r}350 \\
300 \\
290 \\
398 \\
1100\end{array}$ & $\begin{array}{l}162 \\
130 \\
128 \\
206 \\
659\end{array}$ & $\begin{array}{l}275 \\
260 \\
295 \\
270 \\
225\end{array}$ & $\begin{array}{l}85 \\
77 \\
83 \\
76 \\
58\end{array}$ & $\begin{array}{l}286 \\
205 \\
145 \\
113 \\
370\end{array}$ & $\begin{array}{l}53 \\
33 \\
21 \\
16 \\
86\end{array}$ & $\begin{array}{r}72 \\
50 \\
79 \\
85 \\
130\end{array}$ & $\begin{array}{r}5.6 \\
4.1 \\
6.8 \\
8.0 \\
12\end{array}$ & $\begin{array}{r}609 \\
272 \\
120 \\
78 \\
66\end{array}$ & $\begin{array}{r}173 \\
32 \\
14 \\
8.8 \\
7.8\end{array}$ \\
\hline $\begin{array}{l}26 \\
27 \\
28 \\
29 \\
30 \\
31\end{array}$ & $\begin{array}{r}362 \\
1140 \\
1140 \\
790 \\
580 \\
--\end{array}$ & $\begin{array}{r}227 \\
1190 \\
1200 \\
706 \\
460 \\
-0-\end{array}$ & $\begin{array}{r}585 \\
751 \\
1760 \\
1240 \\
925 \\
1270\end{array}$ & $\begin{array}{r}300 \\
452 \\
1030 \\
556 \\
412 \\
573\end{array}$ & $\begin{array}{l}224 \\
392 \\
320 \\
247 \\
234 \\
---\end{array}$ & $\begin{array}{r}59 \\
137 \\
98 \\
61 \\
54 \\
---\end{array}$ & $\begin{array}{r}1610 \\
880 \\
302 \\
128 \\
123 \\
130\end{array}$ & $\begin{array}{r}739 \\
169 \\
47 \\
19 \\
19 \\
22\end{array}$ & $\begin{array}{r}107 \\
69 \\
50 \\
59 \\
120 \\
100\end{array}$ & $\begin{array}{l}8.4 \\
5.2 \\
3.6 \\
4.5 \\
12 \\
10\end{array}$ & $\begin{array}{r}59 \\
46 \\
45 \\
48 \\
102 \\
---\end{array}$ & $\begin{array}{c}6.4 \\
4.2 \\
3.9 \\
6.0 \\
18 \\
-\cdots\end{array}$ \\
\hline TOTAL & -- & 10877 & $-\infty$ & 9370 & $-\infty$ & 5518 & -- & 2130 & --- & 249.0 & -- & 384.5 \\
\hline TOTAL & $A D$ & EAR: & 0.0 & & & & & & & & & \\
\hline
\end{tabular}

WATER QUALITY DATA, WATER YEAR OCTOBER 1984 TO SEPTEMBER 1985

\begin{tabular}{|c|c|c|c|c|c|c|}
\hline DATE & TIME & $\begin{array}{l}\text { TEMPER- } \\
\text { ATURE } \\
\text { (DEG C) }\end{array}$ & $\begin{array}{l}\text { STREAM- } \\
\text { FLOW, } \\
\text { INSTAN- } \\
\text { TANEOUS } \\
\text { (CFS) }\end{array}$ & $\begin{array}{l}\text { SEDI- } \\
\text { MENT, } \\
\text { SUS- } \\
\text { PENDED } \\
\text { (MG/L) }\end{array}$ & $\begin{array}{c}\text { SEDI- } \\
\text { MENT, } \\
\text { DIS- } \\
\text { CHARGE, } \\
\text { SUS- } \\
\text { PENDED } \\
\text { (T/DAY) }\end{array}$ & $\begin{array}{c}\text { SED. } \\
\text { SUSP. } \\
\text { SIEVE } \\
\text { DIAM. } \\
8 \text { FINER } \\
\text { THAN } \\
.062 \mathrm{MM}\end{array}$ \\
\hline OCT & & & & & & \\
\hline NOV & $11: 30$ & 7.0 & 99 & 71 & 19 & 86 \\
\hline$\underset{A P R}{29} \cdots$ & $12: 30$ & 6.0 & 98 & 91 & 24 & 84 \\
\hline$\underset{\text { MAY }}{02 \ldots}$ & $11: 10$ & 5.0 & 141 & 205 & 78 & 92 \\
\hline JUN & $15: 05$ & 22.0 & 211 & 351 & 200 & 96 \\
\hline $\begin{array}{l}20 \\
\text { AUG }\end{array}$ & $14: 10$ & 22.0 & 120 & 255 & 83 & 94 \\
\hline $05 \ldots$ & $10: 45$ & 23.0 & 44 & 111 & 13 & 96 \\
\hline
\end{tabular}


05483450 MIDDLE RACCOON RIVER NEAR BAYARD--Continued

WATER-QUALITY RECORDS

WATER QUALITY DATA, WATER YEAR OCTOBER 1984 TO SEPTEMBER 1985

\begin{tabular}{|c|c|c|c|c|c|c|c|c|c|c|c|}
\hline DATE & TIME & $\begin{array}{l}\text { STREAM- } \\
\text { FLOW, } \\
\text { INSTAN- } \\
\text { TANEOUS } \\
\text { (CES) }\end{array}$ & $\begin{array}{c}\text { NUMBER } \\
\text { OF } \\
\text { SAM- } \\
\text { PLING } \\
\text { POINTS }\end{array}$ & $\begin{array}{c}\text { MAT. } \\
\text { SIEVE } \\
\text { DIAM. } \\
\text { EINER } \\
\text { THAN } \\
.062 \text { MM }\end{array}$ & $\begin{array}{l}\text { MAT. } \\
\text { SIEVE } \\
\text { DIAH. } \\
8 \text { FINER } \\
\text { THAN } \\
.125 \mathrm{MM}\end{array}$ & $\begin{array}{l}\text { MAT. } \\
\text { SIEVE } \\
\text { DIAM. } \\
\text { \& FINER } \\
\text { THAN } \\
.250 \mathrm{MM}\end{array}$ & $\begin{array}{l}\text { MAT. } \\
\text { SIEVE } \\
\text { DIAM. } \\
8 \text { FINER } \\
\text { THAN } \\
.500 \text { MM }\end{array}$ & $\begin{array}{l}\text { MAT. } \\
\text { SIEVE } \\
\text { DIAH. } \\
\text { FINER } \\
\text { THAN } \\
1.00 \mathrm{MM}\end{array}$ & $\begin{array}{l}\text { MAT. } \\
\text { SIEVE } \\
\text { DIAM. } \\
\text { FINER } \\
\text { THAN } \\
2.00 \mathrm{MM}\end{array}$ & $\begin{array}{l}\text { MAT. } \\
\text { SIEVE } \\
\text { DIAM. } \\
8 \text { FINER } \\
\text { THAN } \\
4.00 \mathrm{MM}\end{array}$ & $\begin{array}{l}\text { MAT. } \\
\text { SIEVE } \\
\text { DIAM. } \\
8 \text { FINER } \\
\text { THAN } \\
8.00 \mathrm{MM}\end{array}$ \\
\hline$C T$ & & & & & & & & & & & \\
\hline $\operatorname{NOV}^{31} \ldots$ & $11: 30$ & 99 & 5 & 1 & 2 & 17 & 66 & 90 & 97 & 100 & -- \\
\hline$\underset{A P R}{29} \cdots$ & $12: 35$ & 98 & 5 & 1 & 1 & 16 & 68 & 91 & 98 & 100 & -- \\
\hline$\underset{\text { MAY }}{02} \cdots$ & $11: 30$ & 141 & 6 & 1 & 1 & 13 & 69 & 92 & 98 & 99 & 100 \\
\hline$\underset{\text { JUN }}{09} \ldots$ & $15: 00$ & 211 & 5 & 1 & 2 & 11 & 63 & 90 & 96 & 98 & 100 \\
\hline AUG & $14: 00$ & 120 & 5 & 1 & 2 & 11 & 57 & 87 & 95 & 98 & 100 \\
\hline$\underset{\text { SEP }}{05} \cdots$ & $10: 30$ & 44 & 5 & 1 & 1 & 15 & 73 & 92 & 98 & 100 & $-\infty$ \\
\hline $18 \ldots$ & $11: 35$ & 26 & 5 & 1 & 1 & 11 & 63 & 91 & 97 & 99 & 100 \\
\hline
\end{tabular}


LOCATION.--Lat $41^{\circ} 41^{\prime} 44^{\prime \prime}$, long $94^{\circ} 22^{\prime} 53^{\prime \prime}$, in Sw1/4 NE1/4 sec.31, T.80 N., R.30 W., Guthrie County, Hydrologic Unit 07100007 , in gate control building of dam on Middle Raccoon River, $0.5 \mathrm{mi}$ upstream from State Highway 44 , 1.0 mi west of Panora, $4.4 \mathrm{mi}$ upstream from Bay Branch, and at mile 268.8 upstream from mouth of Des Moines River.

DRAINAGE AREA. $--433 \mathrm{mi}^{2}$.

PERIOD OF RECORD.--May 1979 to current year.

GAGE.-Water-stage recorder. Datum of gage is $1,000.00 \mathrm{ft}$ above NGVD.

REMARKS.--Lake is formed by earthfill dam with $100 \mathrm{ft}$ bascule gate and concrete chute spillway, and 300 ft earthen emergency spillway. Low-flow outlet is 30-inch conduit and gate valve through dam. Dam was completed in August 1970 and began filling April 27, 1971. Total storage, 60,000 acre-ft, surface area, 2,9000 acres, at top of dam, elevation $1,068 \mathrm{ft}$. Storage unknown at top of spillway, elevation l,048 ft. Normal storage, 19,700 acre-ft, surface area, 1,270 acres with bascule gate closed, elevation 1,045 ft. Dead storage unknown with bascule gate open, elevation $1,036 \mathrm{ft}$. Present lake classification is utility (industrial) but is also used for recreation. Gage-height telemeter at station.

EXTREMES FOR PERIOD OF RECORD.--Maximum gage height, $47.18 \mathrm{ft}$ Dec. 29, 1984; minimum, $44.05 \mathrm{ft}$ Mar. 11, 1983.

EXTREMES FOR CURRENT YEAR.--Maximum gage height, $47.18 \mathrm{ft}$ Dec. 29; minimum recorded, $44.60 \mathrm{ft}$ Feb. 13 , 16, but may have been less during period of no gage height record Aug. 8 to Sept. 8 .

GAGE HEIGHT (FEET ABOVE DATUM), WATER YEAR OCTOBER 1984 TO SEPTEMBER 1985 MEAN VALUES

\begin{tabular}{|c|c|c|c|c|c|c|c|c|c|c|c|c|}
\hline DAY & OCT & NOV & DEC & JAN & FEB & MAR & APR & MAY & JUN & JUL & AUG & SEP \\
\hline $\begin{array}{l}1 \\
2 \\
3 \\
4 \\
5\end{array}$ & $\begin{array}{l}45.25 \\
45.22 \\
45.23 \\
45.28 \\
45.33\end{array}$ & $\begin{array}{l}45.85 \\
45.54 \\
45.32 \\
45.39 \\
45.46\end{array}$ & $\begin{array}{l}45.35 \\
45.36 \\
45.29 \\
45.23 \\
45.24\end{array}$ & $\begin{array}{l}45.22 \\
45.08 \\
45.14 \\
45.22 \\
45.24\end{array}$ & $\begin{array}{l}44.70 \\
44.67 \\
44.66 \\
44.66 \\
44.65\end{array}$ & $\begin{array}{l}44.91 \\
45.02 \\
45.07 \\
45.23 \\
45.23\end{array}$ & $\begin{array}{l}45.28 \\
45.19 \\
45.27 \\
45.48 \\
45.54\end{array}$ & $\begin{array}{l}45.67 \\
45.53 \\
45.44 \\
45.35 \\
45.32\end{array}$ & $\begin{array}{l}45.07 \\
45.06 \\
45.21 \\
45.33 \\
45.41\end{array}$ & $\begin{array}{l}45.26 \\
45.24 \\
45.20 \\
45.21 \\
45.22\end{array}$ & $\begin{array}{l}45.02 \\
44.97 \\
44.98 \\
45.12 \\
45.15\end{array}$ & $\begin{array}{l}-- \\
-- \\
--\end{array}$ \\
\hline $\begin{array}{r}6 \\
7 \\
8 \\
9 \\
10\end{array}$ & $\begin{array}{l}45.33 \\
45.33 \\
45.24 \\
45.10 \\
44.90\end{array}$ & $\begin{array}{l}45.47 \\
45.47 \\
45.49 \\
45.50 \\
45.69\end{array}$ & $\begin{array}{l}45.23 \\
45.25 \\
45.30 \\
45.36 \\
45.38\end{array}$ & $\begin{array}{l}45.23 \\
45.21 \\
45.17 \\
45.11 \\
45.07\end{array}$ & $\begin{array}{l}44.64 \\
44.64 \\
44.63 \\
44.63 \\
44.64\end{array}$ & $\begin{array}{l}45.12 \\
45.07 \\
45.06 \\
45.01 \\
44.98\end{array}$ & $\begin{array}{l}45.48 \\
45.39 \\
45.35 \\
45.47 \\
45.57\end{array}$ & $\begin{array}{l}45.32 \\
45.35 \\
45.33 \\
45.28 \\
45.28\end{array}$ & $\begin{array}{l}45.47 \\
45.46 \\
45.47 \\
45.48 \\
45.47\end{array}$ & $\begin{array}{l}45.20 \\
45.26 \\
45.28 \\
45.23 \\
45.14\end{array}$ & $\begin{array}{r}45.26 \\
45.26 \\
\ldots- \\
-.- \\
---\end{array}$ & $\begin{array}{r}-- \\
44.94 \\
44.82\end{array}$ \\
\hline $\begin{array}{l}11 \\
12 \\
13 \\
14 \\
15\end{array}$ & $\begin{array}{l}44.94 \\
45.04 \\
45.11 \\
45.23 \\
45.57\end{array}$ & $\begin{array}{l}45.85 \\
45.80 \\
45.72 \\
45.68 \\
45.65\end{array}$ & $\begin{array}{l}45.39 \\
45.43 \\
45.38 \\
45.34 \\
45.30\end{array}$ & $\begin{array}{l}45.04 \\
45.00 \\
44.98 \\
44.98 \\
44.97\end{array}$ & $\begin{array}{l}44.64 \\
44.63 \\
44.62 \\
44.62 \\
44.61\end{array}$ & $\begin{array}{l}45.01 \\
45.12 \\
45.23 \\
45.28 \\
45.29\end{array}$ & $\begin{array}{l}45.60 \\
45.59 \\
45.59 \\
45.55 \\
45.51\end{array}$ & $\begin{array}{l}45.34 \\
45.39 \\
45.35 \\
45.31 \\
45.31\end{array}$ & $\begin{array}{l}45.50 \\
45.62 \\
45.65 \\
45.60 \\
45.55\end{array}$ & $\begin{array}{l}45.21 \\
45.19 \\
45.23 \\
45.35 \\
45.23\end{array}$ & $\begin{array}{l}-- \\
-- \\
-\cdots \\
-\cdots\end{array}$ & $\begin{array}{l}44.81 \\
44.74 \\
44.76 \\
44.83 \\
44.89\end{array}$ \\
\hline $\begin{array}{l}16 \\
17 \\
18 \\
19 \\
20\end{array}$ & $\begin{array}{l}45.53 \\
45.20 \\
45.18 \\
45.26 \\
45.27\end{array}$ & $\begin{array}{l}45.58 \\
45.53 \\
45.53 \\
45.51 \\
45.48\end{array}$ & $\begin{array}{l}45.43 \\
45.91 \\
45.89 \\
45.25 \\
45.22\end{array}$ & $\begin{array}{l}44.95 \\
44.92 \\
44.92 \\
44.89 \\
44.82\end{array}$ & $\begin{array}{l}44.61 \\
44.62 \\
44.66 \\
44.74 \\
44.87\end{array}$ & $\begin{array}{l}45.30 \\
45.29 \\
45.27 \\
45.27 \\
45.26\end{array}$ & $\begin{array}{l}45.48 \\
45.44 \\
45.41 \\
45.38 \\
45.38\end{array}$ & $\begin{array}{l}45.31 \\
45.28 \\
45.24 \\
45.23 \\
45.21\end{array}$ & $\begin{array}{l}45.56 \\
45.54 \\
45.49 \\
45.40 \\
45.39\end{array}$ & $\begin{array}{l}45.27 \\
45.34 \\
45.35 \\
45.35 \\
45.36\end{array}$ & $\begin{array}{l}--- \\
--- \\
--- \\
---\end{array}$ & $\begin{array}{l}44.83 \\
44.87 \\
44.98 \\
45.05 \\
45.13\end{array}$ \\
\hline $\begin{array}{l}21 \\
22 \\
23 \\
24 \\
25\end{array}$ & $\begin{array}{l}45.23 \\
45.18 \\
45.15 \\
45.26 \\
45.36\end{array}$ & $\begin{array}{l}45.44 \\
45.42 \\
45.43 \\
45.43 \\
45.42\end{array}$ & $\begin{array}{l}45.33 \\
45.39 \\
45.35 \\
45.21 \\
45.09\end{array}$ & $\begin{array}{l}44.76 \\
44.74 \\
44.73 \\
44.74 \\
44.75\end{array}$ & $\begin{array}{r}45.24 \\
45.71 \\
- \\
-\end{array}$ & $\begin{array}{l}45.26 \\
45.25 \\
45.28 \\
45.29 \\
45.27\end{array}$ & $\begin{array}{l}45.37 \\
45.36 \\
45.38 \\
45.40 \\
45.39\end{array}$ & $\begin{array}{l}45.20 \\
45.19 \\
45.28 \\
45.39 \\
45.47\end{array}$ & $\begin{array}{l}45.44 \\
45.41 \\
45.46 \\
45.55 \\
45.53\end{array}$ & $\begin{array}{l}45.37 \\
45.37 \\
45.38 \\
45.39 \\
45.40\end{array}$ & $\begin{array}{l}--- \\
-\cdots \\
--\end{array}$ & $\begin{array}{l}--- \\
--- \\
--- \\
--- \\
---\end{array}$ \\
\hline $\begin{array}{l}26 \\
27 \\
28 \\
29 \\
30 \\
31\end{array}$ & $\begin{array}{l}45.24 \\
45.21 \\
45.35 \\
45.43 \\
45.49 \\
45.52\end{array}$ & $\begin{array}{r}45.42 \\
45.43 \\
45.41 \\
45.40 \\
45.40 \\
-\end{array}$ & $\begin{array}{l}45.08 \\
45.21 \\
46.07 \\
46.86 \\
45.63 \\
45.46\end{array}$ & $\begin{array}{l}44.75 \\
44.75 \\
44.75 \\
44.73 \\
44.74 \\
44.72\end{array}$ & $\begin{array}{r}--- \\
44.95 \\
44.88 \\
--- \\
---\end{array}$ & $\begin{array}{l}45.25 \\
45.31 \\
45.32 \\
45.32 \\
45.29 \\
45.33\end{array}$ & $\begin{array}{r}45.41 \\
45.58 \\
45.75 \\
45.76 \\
45.74 \\
-\end{array}$ & $\begin{array}{l}45.53 \\
45.54 \\
45.56 \\
45.55 \\
45.54 \\
45.29\end{array}$ & $\begin{array}{r}45.32 \\
45.27 \\
45.25 \\
45.27 \\
45.29 \\
-\end{array}$ & $\begin{array}{r}45.40 \\
- \\
45.19 \\
45.09 \\
45.10\end{array}$ & $\begin{array}{l}--- \\
--- \\
-- \\
--\end{array}$ & $\begin{array}{l}--- \\
-- \\
-- \\
--\end{array}$ \\
\hline $\begin{array}{l}\text { MEAN } \\
\text { MAX } \\
\text { MIN }\end{array}$ & $\begin{array}{l}45.26 \\
45.57 \\
44.90\end{array}$ & $\begin{array}{l}45.52 \\
45.85 \\
45.32\end{array}$ & $\begin{array}{l}45.43 \\
46.86 \\
45.08\end{array}$ & $\begin{array}{l}44.95 \\
45.24 \\
44.72\end{array}$ & $\overline{--}$ & $\begin{array}{l}45.20 \\
45.33 \\
44.91\end{array}$ & $\begin{array}{l}45.47 \\
45.76 \\
45.19\end{array}$ & $\begin{array}{l}45.37 \\
45.67 \\
45.19\end{array}$ & $\begin{array}{l}45.42 \\
45.65 \\
45.06\end{array}$ & $\begin{array}{l}--- \\
--- \\
---\end{array}$ & $-\infty$ & $=-$ \\
\hline
\end{tabular}


LOCATION.--Lat $41^{\circ} 41^{\prime} 14^{\prime \prime}$, long $94^{\circ} 22^{\prime} 15^{\prime \prime}$, in NEl/4 NWl/4 sec.5, T.79 N., R.30 w., Guthrie County, Bydrologic Unit 07100007 , on left bank $15 \mathrm{ft}$ downstream from bridge on county highway, 0.2 mi southwest of Panora, $1.5 \mathrm{mi}$ upstream from Andy's Branch, $1.6 \mathrm{mi}$ downstream from Lake Panorama, $18.2 \mathrm{mi}$ upstream from mouth, and at mile 267.2 upstream from mouth of Des Moines River.

DRAINAGE AREA. $--440 \mathrm{mi}^{2}$.

\section{WATER-DISCHARGE RECORDS}

PERIOD OF RECORD.--June 1958 to current year.

REVISED RECORDS.--WDR IOWA 1974: 1973 (P).

GAGE.--Water-stage recorder and concrete control. Datum of gage is $991.20 \mathrm{ft}$ above NGVD.

REMARKS.--Estimated daily discharges: oct. 1-30. Records good except for periods of estimated record, which are poor. City of Panora diverts approximately 100 acre $\mathrm{ft} / \mathrm{yr}$ above station. Flow regulated by dam on Lake Panorama since August 1970.

AVERAGE DISCHARGE. - - 27 years, $217 \mathrm{ft} / \mathrm{s}, 6.70 \mathrm{in} / \mathrm{yr} 157,200$ acre-ft/yr; median of yearly mean discharges, 170 $\mathrm{ft}^{3} / \mathrm{s}, 5.2 \mathrm{in} / \mathrm{yr}, 123,000$ acre-ft/yr.

EXTREMES FOR PERIOD OF RECORD.--Maximum discharge, 14,000 ft $3 / \mathrm{s}$ May 19, 1974, gage height, $14.80 \mathrm{ft}$, from rating curve extended above $5,200 \mathrm{ft} / \mathrm{s}$ by step-backwater analysis; no flow June 9, 10, 1977, result of gate operation at Lake Panorama; minimum daily discharge excluding regulation at Lake Panorama, 3.0 ft $/ \mathrm{s}$ July 9, 14, $22-23,1977$

EXTREMES OUTSIDE PERIOD OF RECORD.--Flood of June 10, 1953, reached a stage of 14.3 ft, from floodmark, discharge, about $14,000 \mathrm{ft} / \mathrm{s}$.

EXTREMES FOR CURRENT YEAR.--Peak discharges greater than base of $2,500 \mathrm{ft} / \mathrm{s}$ and maximum (*):

\begin{tabular}{|c|c|c|c|c|c|c|}
\hline $\begin{array}{l}\text { Date } \\
\text { Dec. } 29\end{array}$ & $\begin{array}{l}\text { Time } \\
1100\end{array}$ & $\begin{array}{c}\text { Discharge } \\
(\mathrm{ft} / \mathrm{s}) \\
* 2,350\end{array}$ & $\begin{array}{c}\text { Gage height } \\
(f t) \\
* 7.43\end{array}$ & Date & Time & Gage height \\
\hline
\end{tabular}

Minimum discharge, $18 \mathrm{ft}^{\circ} / \mathrm{s} \mathrm{July} 11,18$

DISCHARGE, IN CUBIC FEET PER SECOND, WATER YEAR OCTOBER 1984 TO SEPTEMBER 1985 MEAN VALUES

\begin{tabular}{|c|c|c|c|c|c|c|c|c|c|c|c|c|}
\hline DAY & OCT & NOV & DEC & JAN & FEB & MAR & APR & MAY & JUN & JUL & AUG & SEP \\
\hline $\begin{array}{l}1 \\
2 \\
3 \\
4 \\
5\end{array}$ & $\begin{array}{l}68 \\
54 \\
51 \\
61 \\
70\end{array}$ & $\begin{array}{r}371 \\
328 \\
199 \\
80 \\
97\end{array}$ & $\begin{array}{l}94 \\
97 \\
83 \\
69 \\
75\end{array}$ & $\begin{array}{l}264 \\
186 \\
187 \\
219 \\
226\end{array}$ & $\begin{array}{l}86 \\
84 \\
82 \\
81 \\
81\end{array}$ & $\begin{array}{l}131 \\
127 \\
156 \\
221 \\
204\end{array}$ & $\begin{array}{l}169 \\
197 \\
228 \\
316 \\
353\end{array}$ & $\begin{array}{l}297 \\
267 \\
240 \\
212 \\
202\end{array}$ & $\begin{array}{r}161 \\
82 \\
42 \\
62 \\
84\end{array}$ & $\begin{array}{l}97 \\
93 \\
87 \\
87 \\
84\end{array}$ & $\begin{array}{l}72 \\
66 \\
52 \\
22 \\
23\end{array}$ & $\begin{array}{l}33 \\
33 \\
33 \\
29 \\
31\end{array}$ \\
\hline $\begin{array}{r}6 \\
7 \\
8 \\
9 \\
10\end{array}$ & $\begin{array}{r}75 \\
98 \\
120 \\
110 \\
125\end{array}$ & $\begin{array}{l}100 \\
103 \\
108 \\
109 \\
180\end{array}$ & $\begin{array}{r}77 \\
78 \\
88 \\
102 \\
110\end{array}$ & $\begin{array}{l}219 \\
212 \\
197 \\
176 \\
162\end{array}$ & $\begin{array}{l}81 \\
81 \\
81 \\
81 \\
81\end{array}$ & $\begin{array}{l}176 \\
161 \\
156 \\
142 \\
134\end{array}$ & $\begin{array}{l}328 \\
294 \\
174 \\
132 \\
165\end{array}$ & $\begin{array}{l}204 \\
219 \\
212 \\
200 \\
158\end{array}$ & $\begin{array}{r}97 \\
100 \\
99 \\
99 \\
102\end{array}$ & $\begin{array}{l}77 \\
75 \\
73 \\
50 \\
20\end{array}$ & $\begin{array}{l}26 \\
24 \\
28 \\
36 \\
41\end{array}$ & $\begin{array}{l}33 \\
29 \\
32 \\
31 \\
29\end{array}$ \\
\hline $\begin{array}{l}11 \\
12 \\
13 \\
14 \\
15\end{array}$ & $\begin{array}{r}100 \\
82 \\
68 \\
58 \\
120\end{array}$ & $\begin{array}{l}234 \\
218 \\
194 \\
180 \\
173\end{array}$ & $\begin{array}{r}117 \\
129 \\
113 \\
106 \\
94\end{array}$ & $\begin{array}{l}156 \\
145 \\
137 \\
139 \\
138\end{array}$ & $\begin{array}{l}81 \\
78 \\
78 \\
78 \\
78\end{array}$ & $\begin{array}{r}89 \\
64 \\
88 \\
103 \\
109\end{array}$ & $\begin{array}{l}184 \\
189 \\
190 \\
182 \\
174\end{array}$ & $\begin{array}{l}145 \\
180 \\
177 \\
175 \\
183\end{array}$ & $\begin{array}{l}115 \\
156 \\
162 \\
160 \\
162\end{array}$ & $\begin{array}{l}19 \\
20 \\
23 \\
32 \\
38\end{array}$ & $\begin{array}{l}40 \\
37 \\
33 \\
33 \\
36\end{array}$ & $\begin{array}{l}29 \\
29 \\
30 \\
27 \\
27\end{array}$ \\
\hline $\begin{array}{l}16 \\
17 \\
18 \\
19 \\
20\end{array}$ & $\begin{array}{l}250 \\
500 \\
390 \\
300 \\
235\end{array}$ & $\begin{array}{l}147 \\
136 \\
134 \\
131 \\
124\end{array}$ & $\begin{array}{l}146 \\
315 \\
598 \\
334 \\
190\end{array}$ & $\begin{array}{l}134 \\
130 \\
129 \\
127 \\
114\end{array}$ & $\begin{array}{r}76 \\
76 \\
87 \\
108 \\
148\end{array}$ & $\begin{array}{l}117 \\
112 \\
111 \\
114 \\
111\end{array}$ & $\begin{array}{l}166 \\
160 \\
150 \\
141 \\
139\end{array}$ & $\begin{array}{l}191 \\
183 \\
168 \\
164 \\
170\end{array}$ & $\begin{array}{l}164 \\
163 \\
144 \\
128 \\
119\end{array}$ & $\begin{array}{l}32 \\
20 \\
19 \\
37 \\
62\end{array}$ & $\begin{array}{l}35 \\
35 \\
38 \\
39 \\
38\end{array}$ & $\begin{array}{l}27 \\
27 \\
28 \\
27 \\
26\end{array}$ \\
\hline $\begin{array}{l}21 \\
22 \\
23 \\
24 \\
25\end{array}$ & $\begin{array}{l}180 \\
145 \\
130 \\
115 \\
100\end{array}$ & $\begin{array}{l}117 \\
115 \\
114 \\
114 \\
112\end{array}$ & $\begin{array}{l}239 \\
258 \\
237 \\
192 \\
156\end{array}$ & $\begin{array}{r}101 \\
92 \\
89 \\
90 \\
94\end{array}$ & $\begin{array}{l}326 \\
781 \\
509 \\
405 \\
311\end{array}$ & $\begin{array}{l}110 \\
108 \\
120 \\
125 \\
122\end{array}$ & $\begin{array}{l}135 \\
133 \\
139 \\
150 \\
15 ?\end{array}$ & $\begin{array}{r}157 \\
91 \\
87 \\
131 \\
159\end{array}$ & $\begin{array}{l}118 \\
110 \\
124 \\
141 \\
124\end{array}$ & $\begin{array}{l}74 \\
73 \\
65 \\
63 \\
71\end{array}$ & $\begin{array}{l}33 \\
35 \\
39 \\
40 \\
34\end{array}$ & $\begin{array}{l}28 \\
35 \\
47 \\
46 \\
51\end{array}$ \\
\hline $\begin{array}{l}26 \\
27 \\
28 \\
29 \\
30 \\
31\end{array}$ & $\begin{array}{l}90 \\
78 \\
74 \\
73 \\
77 \\
91\end{array}$ & $\begin{array}{l}113 \\
114 \\
107 \\
104 \\
103 \\
-\end{array}$ & $\begin{array}{r}156 \\
225 \\
682 \\
1750 \\
754 \\
369\end{array}$ & $\begin{array}{l}94 \\
92 \\
92 \\
92 \\
94 \\
89\end{array}$ & $\begin{array}{l}264 \\
213 \\
186 \\
-- \\
---\end{array}$ & $\begin{array}{l}122 \\
132 \\
137 \\
142 \\
140 \\
160\end{array}$ & $\begin{array}{l}166 \\
233 \\
305 \\
319 \\
307 \\
--\end{array}$ & $\begin{array}{l}174 \\
181 \\
233 \\
243 \\
201 \\
182\end{array}$ & $\begin{array}{r}114 \\
116 \\
115 \\
106 \\
99 \\
-\end{array}$ & $\begin{array}{r}95 \\
100 \\
88 \\
78 \\
76 \\
77\end{array}$ & $\begin{array}{l}34 \\
34 \\
34 \\
30 \\
33 \\
34\end{array}$ & $\begin{array}{r}50 \\
48 \\
53 \\
68 \\
74 \\
--\end{array}$ \\
\hline $\begin{array}{l}\text { TOTAL } \\
\text { MEAN } \\
\text { MAX } \\
\text { MIN } \\
\text { CFSK } \\
\text { IN. } \\
\text { AC-FT }\end{array}$ & $\begin{array}{r}4088 \\
132 \\
500 \\
51 \\
.30 \\
835 \\
8110\end{array}$ & $\begin{array}{r}4459 \\
149 \\
371 \\
80 \\
.34 \\
.38 \\
8840\end{array}$ & $\begin{array}{r}8033 \\
259 \\
1750 \\
69 \\
.59 \\
.68 \\
15930\end{array}$ & $\begin{array}{r}4416 \\
142 \\
264 \\
89 \\
.32 \\
.37 \\
8760\end{array}$ & $\begin{array}{r}4702 \\
168 \\
781 \\
76 \\
.38 \\
.40 \\
9330\end{array}$ & $\begin{array}{r}4044 \\
130 \\
221 \\
64 \\
.30 \\
.34 \\
8020\end{array}$ & $\begin{array}{r}6071 \\
202 \\
353 \\
132 \\
.46 \\
.51 \\
12040\end{array}$ & $\begin{array}{r}5786 \\
187 \\
297 \\
87 \\
.42 \\
11480\end{array}$ & $\begin{array}{r}3568 \\
119 \\
164 \\
42 \\
.27 \\
.30 \\
7080\end{array}$ & $\begin{array}{r}1905 \\
61.5 \\
100 \\
19 \\
.14 \\
.16 \\
3780\end{array}$ & $\begin{array}{r}1134 \\
36.6 \\
72 \\
22 \\
.08 \\
110 \\
2250\end{array}$ & $\begin{array}{r}1090 \\
36.3 \\
74 \\
26 \\
.08 \\
.09 \\
2160\end{array}$ \\
\hline $\begin{array}{ll}\text { CAL } & \text { YR } \\
\text { WTR } & \text { YR }\end{array}$ & 4 & $\begin{array}{ll}L & 16 \\
L & \end{array}$ & & $\begin{array}{l}443 \\
135\end{array}$ & $\begin{array}{l}\text { MAX } \\
\text { MAX }\end{array}$ & & $\begin{array}{l}28 \\
19\end{array}$ & $\begin{array}{l}\text { CFSH } \\
\text { CFSK }\end{array}$ & Is & $\begin{array}{r}13.70 \\
4.17\end{array}$ & $\begin{array}{l}\mathrm{AC}-\mathrm{FT} \\
\mathrm{AC}-\mathrm{FT}\end{array}$ & $\begin{array}{r}321400 \\
97780\end{array}$ \\
\hline
\end{tabular}


PERIOD OF RECORD.--April 1979 to current year (discontinued).

PERIOD OF DAILY RECORD.--

SPECIFIC CONDUCTANCE: April 1979 to current year (discontinued).

WATER TEMPERATURES: April 1979 to current year (discontinued)

SUSPENDED SEDIMENT DISCHARGE: April 1979 to current year (discontinued).

REMARRS.--Records of specific conductance are obtained from suspended-sediment samples at time of analysis.

EXTREMES FOR PERIOD OF DAILY RECORD.--

SPECIFIC CONDUCTANCE: Maximum daily, 800 microsiemens oct. 29, 1979, Dec. 26, 28, 1983, minimum daily, 280 microsiemens reb. $25,26,1982$.

MATER TEMPERATURES: Maximum daily, $32.0^{\circ} \mathrm{C}$ July 15,1979, minimum daily, $0.0^{\circ} \mathrm{C}$ on many days during winter period.

SEDIMENT CONCENTRATIONS: Maximum daily mean, 1,600 mg/L April 20, 1976; minimum daily mean, 3 mg/L Dec. 10, 1983 , Mar. 15, 1984, Jan. 25, 1985

SEDIMENT LOADS: Maximum daily, 6,300 tons June 15, 1982, minimum daily, 0.43 ton July $12,1985$.

EXTREMES EOR CURRENT YEAR.-

SEDIMENT CONCENTRATIONS: Maximum daily mean, $258 \mathrm{mg} / \mathrm{L}$ Feb. 23; minimum daily mean, 3 mg/L Jan. 25.

SEDIMENT LOADS: Maximum daily, 502 tons Feb. 22; minimum daily, 0.43 tons July 12 .

SPECIFIC CONDUCTANCE (MICROSIEMENS/CM AT 25 DEG.C.) WATER YEAR OCTOBER 1984 TO SEPTEMBER 1985 RANDOM VALUES

\begin{tabular}{|c|c|c|c|c|c|c|c|c|c|c|c|c|}
\hline DAY & OCT & Nov & DEC & JAN & FEB & MAR & APR & MAY & JUN & JUL & AUG & SEP \\
\hline $\begin{array}{l}1 \\
2 \\
3 \\
4 \\
5\end{array}$ & $\begin{array}{c}-- \\
530 \\
-- \\
-230\end{array}$ & \begin{tabular}{c}
--- \\
560 \\
\hdashline 590
\end{tabular} & $\begin{array}{l}-- \\
-- \\
-\infty \\
500\end{array}$ & $\begin{array}{l}520 \\
-- \\
--\end{array}$ & $\begin{array}{r}540 \\
620 \\
---\end{array}$ & $\frac{650}{---}$ & $\begin{array}{l}520 \\
540 \\
520 \\
-\ldots- \\
--\end{array}$ & $\begin{array}{l}-- \\
-- \\
-- \\
--\end{array}$ & $\begin{array}{l}-- \\
-- \\
--\end{array}$ & \begin{tabular}{l}
540 \\
510 \\
\hdashline 480
\end{tabular} & $\begin{array}{l}-- \\
-- \\
-- \\
470\end{array}$ & $\overline{-}$ \\
\hline $\begin{array}{r}6 \\
7 \\
8 \\
9 \\
10\end{array}$ & $\begin{array}{l}520 \\
-20 \\
520 \\
-500\end{array}$ & $\overline{--}$ & $\begin{array}{l}-- \\
-- \\
-- \\
-- \\
--\end{array}$ & $\begin{array}{l}- \\
460 \\
560 \\
-580\end{array}$ & $\begin{array}{l}640 \\
--0 \\
600 \\
--- \\
--\end{array}$ & $\begin{array}{l}430 \\
- \\
-2 \\
530\end{array}$ & - & $\begin{array}{l}-- \\
--- \\
-- \\
-- \\
--\end{array}$ & $\begin{array}{l}540 \\
--- \\
-- \\
-210\end{array}$ & $\begin{array}{c}-- \\
440 \\
-210\end{array}$ & $\begin{array}{l}-- \\
-- \\
-- \\
-- \\
--\end{array}$ & 510 \\
\hline $\begin{array}{l}11 \\
12 \\
13 \\
14 \\
15\end{array}$ & 500 & $\overline{--}$ & $\begin{array}{l}-20 \\
510 \\
500 \\
--\end{array}$ & $\frac{-}{--}$ & \begin{tabular}{c}
600 \\
\hdashline 620 \\
600
\end{tabular} & $\begin{array}{r}530 \\
540 \\
--\end{array}$ & $\begin{array}{l}--10 \\
540 \\
520 \\
--- \\
520\end{array}$ & $\begin{array}{l}--- \\
--00 \\
570 \\
570\end{array}$ & $\begin{array}{l}-- \\
-- \\
--\end{array}$ & $\frac{510}{\overline{510}}$ & $\begin{array}{l}-- \\
-- \\
-- \\
-- \\
--\end{array}$ & 520 \\
\hline $\begin{array}{l}16 \\
17 \\
18 \\
19 \\
20\end{array}$ & & \begin{tabular}{l}
570 \\
\hdashline$-\overline{-0}$ \\
\hdashline 560
\end{tabular} & $\overline{-\infty}$ & $\begin{array}{l}-- \\
560 \\
--- \\
---\end{array}$ & $\begin{array}{l}-- \\
-20 \\
615 \\
540\end{array}$ & $\begin{array}{l}-- \\
-- \\
540 \\
540\end{array}$ & $\begin{array}{l}580 \\
520 \\
530 \\
--- \\
---\end{array}$ & $\begin{array}{l}-- \\
-- \\
-- \\
540\end{array}$ & $\begin{array}{l}-\overline{510} \\
520 \\
\overline{530}\end{array}$ & $\overline{-}$ & $\begin{array}{l}-200 \\
520 \\
--2\end{array}$ & $\begin{array}{l}480 \\
-520 \\
-\end{array}$ \\
\hline $\begin{array}{l}21 \\
22 \\
23 \\
24 \\
25\end{array}$ & $\begin{array}{l}540 \\
540 \\
-- \\
-- \\
-\end{array}$ & $\begin{array}{c}-- \\
-- \\
-- \\
--\end{array}$ & $\begin{array}{l}510 \\
--0 \\
--0 \\
-\end{array}$ & $\begin{array}{l}560 \\
-560 \\
-560\end{array}$ & 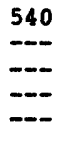 & -- & $\begin{array}{r}--- \\
490 \\
---\end{array}$ & $\begin{array}{l}--- \\
480 \\
--- \\
--\end{array}$ & $\begin{array}{l}-- \\
-- \\
-- \\
--\end{array}$ & $\overline{510}$ & - & 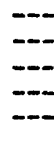 \\
\hline $\begin{array}{l}26 \\
27 \\
28 \\
29 \\
30 \\
31\end{array}$ & $\begin{array}{c}-0 \\
-0 \\
-0 \\
540\end{array}$ & $\begin{array}{l}510 \\
-20 \\
495 \\
500 \\
-\end{array}$ & $\begin{array}{l}--- \\
--0 \\
550 \\
--0 \\
520\end{array}$ & $\begin{array}{l}--- \\
\overline{550} \\
\overline{560}\end{array}$ & $\begin{array}{l}450 \\
425 \\
-- \\
--\end{array}$ & \begin{tabular}{l}
530 \\
-2 \\
\hdashline 530 \\
-
\end{tabular} & $\begin{array}{l}445 \\
-20 \\
460 \\
480\end{array}$ & $\overline{-}$ & 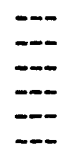 & $\overline{-}$ & $\begin{array}{l}500 \\
500 \\
-\square \\
--0\end{array}$ & $\overline{-}$ \\
\hline
\end{tabular}


DES MOINES RIVER BASIN

05483600 MIDDLE RACCOON RIVER AT PANORA, IA--Continued

WATER-QUALITY RECORDS

TEMPERATURE, WATER (DEG. C.) WATER YEAR OCTOBER 1984 TO SEPTEMBER 1985 RANDOM VALUES

\begin{tabular}{|c|c|c|c|c|c|c|c|c|c|c|c|c|}
\hline DAY & OCT & Nov & DEC & JAN & FEB & MAR & APR & MAY & JUN & JUL & AUG & SEP \\
\hline $\begin{array}{l}1 \\
2\end{array}$ & 16.0 & 10.0 & $=-$ & 2.0 & $\overline{1.0}$ & $\overline{6.0}$ & $\begin{array}{l}5.0 \\
6.0\end{array}$ & $\because$ & $\overline{---}$ & 17.0 & $\overline{-r}$ & $\because-$ \\
\hline $\begin{array}{l}3 \\
4\end{array}$ & $\cdots$ & $\cdots$ & $\cdots$ & -.- & .0 & 1.0 & 5.0 & $=-$ & 16.0 & 17.0 & $\overline{-}$ & $=$ \\
\hline 5 & 16.0 & 10.0 & 4.0 & -- & $\cdots$ & $\cdots$ & -- & $\cdots$ & --- & 17.0 & 21.0 & -- \\
\hline 6 & 15.0 & -- & $\because-$ & $\because-$ & .0 & 1.0 & -- & -- & 16.0 & -- & -- & -- \\
\hline 8 & 16.0 & - & 3.0 & 1.0 & .0 & $\cdots$ & 5.0 & - & - & 17.0 & -- & 14.0 \\
\hline 10 & 160 & 10.0 & 30 & 20 & $\because$ & $=0$ & -- & $\because-$ & $\pi 0$ & $\overline{0}$ & $=$ & - \\
\hline & & & & & & & & & & & & \\
\hline 11 & 30 & -- & 30 & -- & $\therefore$ & 3.0 & 5.0 & $\overline{-}$ & -- & 17.0 & $\overline{-}$ & $\cdots$ \\
\hline 13 & $\cdots$ & 9.0 & 2.0 & -- & .0 & $\because-$ & 14.0 & 15.0 & -- & $\cdots$ & -- & 14.0 \\
\hline 15 & 16.0 & $\cdots$ & 2.0 & 2.0 & 1.0 & $\because$ & 6.0 & 15.0 & -- & 18.0 & -- & -- \\
\hline 16 & -- & 8.0 & -- & --- & -- & -- & 14.0 & -- & -- & --- & --- & 15.0 \\
\hline $\begin{array}{l}17 \\
18\end{array}$ & $\overline{---}$ & $\because-$ & 2.0 & 2.0 & $\overline{1}$ & 30 & 6.0 & $=$ & 16.0 & 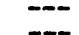 & 16.0 & $2 ? 0$ \\
\hline 19 & 13.0 & - & 1.0 & $=-$ & 1.0 & 3.0 & 14.0 & $=-$ & 10.0 & -- & 16.0 & 22.0 \\
\hline 20 & & 7.0 & $\cdots$ & --- & 1.0 & 3.0 & -- & 14.0 & 20.0 & 20.0 & -- & -- \\
\hline 21 & 14.0 & -- & 2.0 & --- & 1.0 & -- & --- & --- & --- & -- & -- & $\cdots$ \\
\hline 23 & 13.0 & 70 & $=$ & 30 & $=$ & $=$ & 10.0 & 14.0 & $=$ & 18.0 & $=$ & $=-$ \\
\hline 24 & -- & $-\cdots$ & 2.0 & $\cdots$ &.-- & - & 10.0 & -- & --- & $\ldots$ & 16.0 & - \\
\hline 25 & $\cdots$ & -- & $\ldots$ & 1.0 & -.- & 4.0 & 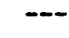 & $\cdots$ & -- & -- & -- & -- \\
\hline 26 & -- & 7.0 & -- & --- & 1.0 & 5.0 & 10.0 & $\cdots$ & $\cdots$ & -- & 15.0 & $\cdots$ \\
\hline 27 & $\because-$ & $\because-$ & $\overline{-}$ & $=$ & $\overline{3}$ & $=-$ & $\bar{\cdots}$ & $\because-$ & $=-$ & $=$ & 15,0 & $\ldots$ \\
\hline 29 & $\cdots$ & 5.0 & 2.0 & 1.0 & $=-$ & 5.0 & 11.0 & -- & -- & -- & $-\cdots$ & $=$ \\
\hline 31 & 11.0 & $\begin{array}{l}4.0 \\
---\end{array}$ & 2.0 & $=-$ & $=-$ & $\cdots$ & 11.0 & $\because$ & $=$ & -- & - & 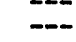 \\
\hline
\end{tabular}

SUSPENDED-SEDIMENT, WATER YEAR OCTOBER 1984 TO SEPTEMBER 1985

\begin{tabular}{|c|c|c|c|c|c|c|c|c|c|c|c|c|}
\hline \multirow[t]{2}{*}{ DAY } & $\begin{array}{c}\text { MEAN } \\
\text { CONCEN- } \\
\text { TRATION } \\
\text { (MG/L) }\end{array}$ & $\begin{array}{l}\text { LOADS } \\
\text { (T/DAY) }\end{array}$ & $\begin{array}{c}\text { MEAN } \\
\text { CONCEN- } \\
\text { TRATION } \\
\text { (MG/L) }\end{array}$ & $\begin{array}{l}\text { LOADS } \\
\text { (T/DAY) }\end{array}$ & $\begin{array}{c}\text { MEAN } \\
\text { CONCEN- } \\
\text { TRATION } \\
\text { (MG/L) }\end{array}$ & $\begin{array}{l}\text { LOADS } \\
\text { (T/DAY) }\end{array}$ & $\begin{array}{c}\text { MEAN } \\
\text { CONCEN- } \\
\text { TRATION } \\
\text { (MG } / \mathrm{L} \text { ) }\end{array}$ & $\begin{array}{l}\text { LOADS } \\
\text { (T/DAY) }\end{array}$ & $\begin{array}{c}\text { MEAN } \\
\text { CONCEN- } \\
\text { TRATION } \\
\text { (MG/L) }\end{array}$ & $\begin{array}{l}\text { LOADS } \\
\text { (T/DAY) }\end{array}$ & $\begin{array}{l}\text { MEAN } \\
\text { CONCEN- } \\
\text { TRATION } \\
\text { (MG/L) }\end{array}$ & $\begin{array}{l}\text { LOADS } \\
\text { (T/DAY) }\end{array}$ \\
\hline & \multicolumn{2}{|c|}{ OCTOBER } & \multicolumn{2}{|c|}{ NOVEMBER } & \multicolumn{2}{|c|}{ DECEMBER } & \multicolumn{2}{|c|}{ JANUARY } & \multicolumn{2}{|c|}{ FEBRUARY } & \multicolumn{2}{|c|}{ MARCB } \\
\hline $\begin{array}{l}1 \\
2 \\
3 \\
4 \\
5\end{array}$ & $\begin{array}{l}24 \\
24 \\
23 \\
23 \\
25\end{array}$ & $\begin{array}{l}4.4 \\
3.5 \\
3.2 \\
3.8 \\
4.7\end{array}$ & $\begin{array}{l}62 \\
17 \\
13 \\
13 \\
13\end{array}$ & $\begin{array}{c}62 \\
15 \\
7.0 \\
2.8 \\
3.4\end{array}$ & $\begin{array}{l}16 \\
11 \\
10 \\
11 \\
11\end{array}$ & $\begin{array}{l}4.1 \\
2.9 \\
2.2 \\
2.0 \\
2.2\end{array}$ & $\begin{array}{r}17 \\
11 \\
10 \\
8 \\
7\end{array}$ & $\begin{array}{r}12 \\
5.5 \\
5.0 \\
4.7 \\
4.3\end{array}$ & $\begin{array}{r}15 \\
10 \\
7 \\
7 \\
5\end{array}$ & $\begin{array}{l}3.5 \\
2.3 \\
1.5 \\
1.5 \\
1.1\end{array}$ & $\begin{array}{r}95 \\
69 \\
71 \\
99 \\
103\end{array}$ & $\begin{array}{l}34 \\
24 \\
30 \\
59 \\
57\end{array}$ \\
\hline $\begin{array}{r}6 \\
7 \\
8 \\
9 \\
10\end{array}$ & $\begin{array}{l}24 \\
20 \\
20 \\
25 \\
36\end{array}$ & $\begin{array}{r}4.9 \\
5.3 \\
6.5 \\
7.4 \\
12\end{array}$ & $\begin{array}{l}11 \\
10 \\
8 \\
10 \\
25\end{array}$ & $\begin{array}{r}3.0 \\
2.8 \\
2.3 \\
2.9 \\
12\end{array}$ & $\begin{array}{r}9 \\
12 \\
16 \\
21 \\
24\end{array}$ & $\begin{array}{l}1.9 \\
2.5 \\
3.8 \\
5.8 \\
7.1\end{array}$ & $\begin{array}{l}7 \\
7 \\
8 \\
9 \\
8\end{array}$ & $\begin{array}{l}4.1 \\
4.0 \\
4.3 \\
4.3 \\
3.5\end{array}$ & $\begin{array}{l}5 \\
7 \\
8 \\
9 \\
9\end{array}$ & $\begin{array}{l}1.1 \\
1.5 \\
1.7 \\
2.0 \\
2.0\end{array}$ & $\begin{array}{r}102 \\
98 \\
68 \\
40 \\
25\end{array}$ & $\begin{array}{c}48 \\
43 \\
29 \\
15 \\
9.0\end{array}$ \\
\hline $\begin{array}{l}11 \\
12 \\
13 \\
14 \\
15\end{array}$ & $\begin{array}{l}57 \\
72 \\
75 \\
78 \\
73\end{array}$ & $\begin{array}{l}15 \\
16 \\
14 \\
12 \\
24\end{array}$ & $\begin{array}{r}36 \\
28 \\
16 \\
13 \\
8\end{array}$ & $\begin{array}{l}23 \\
16 \\
8.4 \\
6.3 \\
3.7\end{array}$ & $\begin{array}{l}27 \\
25 \\
16 \\
20 \\
10\end{array}$ & $\begin{array}{l}8.5 \\
8.7 \\
4.9 \\
5.7 \\
2.5\end{array}$ & $\begin{array}{l}8 \\
8 \\
8 \\
8 \\
7\end{array}$ & $\begin{array}{l}3.4 \\
3.1 \\
3.0 \\
3.0 \\
2.6\end{array}$ & $\begin{array}{l}8 \\
6 \\
4 \\
5 \\
8\end{array}$ & $\begin{array}{l}1.7 \\
1.3 \\
.84 \\
1.1 \\
1.7\end{array}$ & $\begin{array}{l}16 \\
13 \\
13 \\
13 \\
15\end{array}$ & $\begin{array}{l}3.8 \\
2.2 \\
3.1 \\
3.6 \\
4.4\end{array}$ \\
\hline $\begin{array}{l}16 \\
17 \\
18 \\
19 \\
20\end{array}$ & $\begin{array}{l}58 \\
49 \\
42 \\
30 \\
30\end{array}$ & $\begin{array}{l}39 \\
66 \\
44 \\
24 \\
19\end{array}$ & $\begin{array}{r}8 \\
8 \\
9 \\
7 \\
11\end{array}$ & $\begin{array}{l}3.2 \\
2.9 \\
3.3 \\
2.5 \\
3.7\end{array}$ & $\begin{array}{r}8 \\
8 \\
9 \\
9 \\
17\end{array}$ & $\begin{array}{r}3.2 \\
6.8 \\
15 \\
8.1 \\
8.7\end{array}$ & $\begin{array}{l}7 \\
7 \\
7 \\
8 \\
8\end{array}$ & $\begin{array}{l}2.5 \\
2.5 \\
2.4 \\
2.7 \\
2.5\end{array}$ & $\begin{array}{r}9 \\
10 \\
12 \\
19 \\
153\end{array}$ & $\begin{array}{l}1.8 \\
2.1 \\
2.8 \\
5.5 \\
61\end{array}$ & $\begin{array}{l}15 \\
14 \\
16 \\
16 \\
17\end{array}$ & $\begin{array}{l}4.7 \\
4.2 \\
4.8 \\
4.9 \\
5.1\end{array}$ \\
\hline $\begin{array}{l}21 \\
22 \\
23 \\
24 \\
25\end{array}$ & $\begin{array}{l}78 \\
27 \\
28 \\
17 \\
27\end{array}$ & $\begin{array}{l}38 \\
11 \\
9.8 \\
5.3 \\
7.3\end{array}$ & $\begin{array}{l}14 \\
16 \\
22 \\
29 \\
40\end{array}$ & $\begin{array}{r}4.4 \\
5.0 \\
6.8 \\
8.9 \\
12\end{array}$ & $\begin{array}{l}40 \\
53 \\
36 \\
19 \\
15\end{array}$ & $\begin{array}{l}26 \\
37 \\
23 \\
9.8 \\
6.3\end{array}$ & $\begin{array}{r}8 \\
12 \\
12 \\
7 \\
3\end{array}$ & $\begin{array}{l}2.2 \\
3.0 \\
2.9 \\
1.7 \\
.76\end{array}$ & $\begin{array}{l}164 \\
238 \\
258 \\
223 \\
197\end{array}$ & $\begin{array}{l}144 \\
502 \\
355 \\
244 \\
165\end{array}$ & $\begin{array}{r}15 \\
14 \\
13 \\
9 \\
6\end{array}$ & $\begin{array}{l}4.5 \\
4.1 \\
4.2 \\
3.0 \\
2.0\end{array}$ \\
\hline $\begin{array}{l}26 \\
27 \\
28 \\
29 \\
30 \\
31\end{array}$ & $\begin{array}{r}129 \\
37 \\
35 \\
32 \\
30 \\
34\end{array}$ & $\begin{array}{l}31 \\
7.8 \\
7.0 \\
6.3 \\
6.2 \\
8.4\end{array}$ & $\begin{array}{l}50 \\
44 \\
35 \\
27 \\
21\end{array}$ & $\begin{array}{c}15 \\
14 \\
10 \\
7.6 \\
5.8 \\
--.\end{array}$ & $\begin{array}{l}13 \\
15 \\
70 \\
56 \\
24 \\
20\end{array}$ & $\begin{array}{r}5.5 \\
9.1 \\
129 \\
265 \\
49 \\
20\end{array}$ & $\begin{array}{r}5 \\
8 \\
10 \\
14 \\
15 \\
17\end{array}$ & $\begin{array}{l}1.3 \\
2.0 \\
2.5 \\
3.5 \\
3.8 \\
4.1\end{array}$ & $\begin{array}{l}172 \\
146 \\
122 \\
--- \\
---\end{array}$ & $\begin{array}{r}123 \\
84 \\
61 \\
- \\
-ב- \\
--\end{array}$ & $\begin{array}{r}7 \\
6 \\
5 \\
5 \\
6 \\
34\end{array}$ & $\begin{array}{r}2.3 \\
2.1 \\
1.8 \\
1.9 \\
2.3 \\
15\end{array}$ \\
\hline TOTAL & -- & 466.8 & --- & 275.7 & --- & 686.3 & --- & 107.16 & -.. & 1776.04 & --- & 432.0 \\
\hline
\end{tabular}


05483600 MIDDLE RACCOON RIVER AT PANORA, IA--Continued

WATER-QUALITY RECORDS

SUSPENDED-SEDIHENT, WATER YEAR OCTOBER 1984 TO SEPTEMBER 1985

\begin{tabular}{|c|c|c|c|c|c|c|c|c|c|c|c|c|}
\hline \multirow[t]{2}{*}{ DAY } & $\begin{array}{l}\text { MEAN } \\
\text { CONCEN- } \\
\text { TRATION } \\
\text { (MG/L) }\end{array}$ & $\begin{array}{l}\text { LOADS } \\
\text { (T/DAY) }\end{array}$ & $\begin{array}{l}\text { HEAN } \\
\text { CONCEN- } \\
\text { TRATION } \\
\text { (HG/L) }\end{array}$ & $\begin{array}{l}\text { LOADS } \\
\text { (T/DAY) }\end{array}$ & $\begin{array}{l}\text { MEAN } \\
\text { CONCEN- } \\
\text { TRATION } \\
\text { (MG/L) }\end{array}$ & $\begin{array}{l}\text { LOADS } \\
\text { (T/DAY) }\end{array}$ & $\begin{array}{l}\text { MEAN } \\
\text { CONCEN- } \\
\text { TRATION } \\
(\text { HG/L) }\end{array}$ & $\begin{array}{l}\text { LOADS } \\
\text { (T/DAY) }\end{array}$ & $\begin{array}{l}\text { MEAN } \\
\text { CONCEN- } \\
\text { TRATION } \\
\text { (HG/L) }\end{array}$ & $\begin{array}{l}\text { LOADS } \\
\text { (T/DAY) }\end{array}$ & $\begin{array}{l}\text { MEAN } \\
\text { CONCEN- } \\
\text { TRATION } \\
\text { (MG/L) }\end{array}$ & $\begin{array}{l}\text { LOADS } \\
\text { (T/DAY) }\end{array}$ \\
\hline & \multicolumn{2}{|c|}{ APRIL } & \multicolumn{2}{|r|}{ MAY } & \multicolumn{2}{|c|}{ JUNE } & \multicolumn{2}{|c|}{ JULY } & \multicolumn{2}{|c|}{ AUGUST } & \multicolumn{2}{|c|}{ SEPTEMBER } \\
\hline $\begin{array}{l}1 \\
2 \\
3 \\
4 \\
5\end{array}$ & $\begin{array}{l}27 \\
12 \\
12 \\
23 \\
23\end{array}$ & $\begin{array}{c}12 \\
6.4 \\
7.4 \\
20 \\
22\end{array}$ & $\begin{array}{l}70 \\
58 \\
48 \\
29 \\
18\end{array}$ & $\begin{array}{c}56 \\
42 \\
31 \\
17 \\
9.8\end{array}$ & $\begin{array}{l}39 \\
26 \\
19 \\
11 \\
13\end{array}$ & $\begin{array}{r}17 \\
5.8 \\
2.2 \\
1.8 \\
2.9\end{array}$ & $\begin{array}{l}50 \\
40 \\
32 \\
31 \\
32\end{array}$ & $\begin{array}{c}13 \\
10 \\
7.5 \\
7.3 \\
7.3\end{array}$ & $\begin{array}{l}40 \\
39 \\
37 \\
23 \\
16\end{array}$ & $\begin{array}{c}7.8 \\
6.9 \\
5.2 \\
1.4 \\
.99\end{array}$ & $\begin{array}{l}15 \\
15 \\
17 \\
17 \\
17\end{array}$ & $\begin{array}{l}1.3 \\
1.3 \\
1.5 \\
1.3 \\
1.4\end{array}$ \\
\hline $\begin{array}{r}6 \\
7 \\
8 \\
9 \\
10\end{array}$ & $\begin{array}{r}20 \\
16 \\
7 \\
14 \\
12\end{array}$ & $\begin{array}{c}18 \\
13 \\
3.3 \\
5.0 \\
5.3\end{array}$ & $\begin{array}{l}15 \\
14 \\
19 \\
24 \\
23\end{array}$ & $\begin{array}{c}8.3 \\
8.3 \\
11 \\
13 \\
9.8\end{array}$ & $\begin{array}{l}13 \\
14 \\
16 \\
19 \\
23\end{array}$ & $\begin{array}{l}3.4 \\
3.8 \\
4.3 \\
5.1 \\
6.3\end{array}$ & $\begin{array}{l}35 \\
41 \\
43 \\
35 \\
28\end{array}$ & $\begin{array}{l}7.3 \\
8.3 \\
8.5 \\
4.7 \\
1.5\end{array}$ & $\begin{array}{l}18 \\
12 \\
17 \\
22 \\
29\end{array}$ & $\begin{array}{l}1.3 \\
.78 \\
1.3 \\
2.1 \\
3.2\end{array}$ & $\begin{array}{l}17 \\
17 \\
16 \\
15 \\
15\end{array}$ & $\begin{array}{l}1.5 \\
1.3 \\
1.4 \\
1.3 \\
1.2\end{array}$ \\
\hline $\begin{array}{l}11 \\
12 \\
13 \\
14 \\
15\end{array}$ & $\begin{array}{r}7 \\
6 \\
14 \\
14 \\
6\end{array}$ & $\begin{array}{l}3.5 \\
3.1 \\
7.2 \\
6.9 \\
2.8\end{array}$ & $\begin{array}{l}39 \\
63 \\
50 \\
32 \\
25\end{array}$ & $\begin{array}{l}15 \\
31 \\
24 \\
15 \\
12\end{array}$ & $\begin{array}{l}20 \\
20 \\
20 \\
23 \\
24\end{array}$ & $\begin{array}{r}6.2 \\
8.4 \\
8.7 \\
9.9 \\
10\end{array}$ & $\begin{array}{r}17 \\
8 \\
10 \\
11 \\
14\end{array}$ & $\begin{array}{l}.87 \\
.43 \\
.62 \\
.95 \\
1.4\end{array}$ & $\begin{array}{l}26 \\
24 \\
19 \\
26 \\
36\end{array}$ & $\begin{array}{l}2.8 \\
2.4 \\
1.7 \\
2.3 \\
3.5\end{array}$ & $\begin{array}{r}16 \\
16 \\
13 \\
9 \\
6\end{array}$ & $\begin{array}{r}1.3 \\
1.3 \\
1.1 \\
.66 \\
.44\end{array}$ \\
\hline $\begin{array}{l}16 \\
17 \\
18 \\
19 \\
20\end{array}$ & $\begin{array}{l}28 \\
53 \\
44 \\
43 \\
47\end{array}$ & $\begin{array}{l}13 \\
23 \\
18 \\
16 \\
18\end{array}$ & $\begin{array}{l}24 \\
27 \\
34 \\
43 \\
47\end{array}$ & $\begin{array}{l}12 \\
13 \\
15 \\
19 \\
22\end{array}$ & $\begin{array}{l}21 \\
21 \\
26 \\
24 \\
20\end{array}$ & $\begin{array}{c}9.3 \\
9.2 \\
10 \\
8.3 \\
6.4\end{array}$ & $\begin{array}{l}10 \\
10 \\
12 \\
24 \\
27\end{array}$ & $\begin{array}{l}.86 \\
.54 \\
.62 \\
2.4 \\
4.5\end{array}$ & $\begin{array}{l}46 \\
55 \\
51 \\
45 \\
38\end{array}$ & $\begin{array}{l}4.3 \\
5.2 \\
5.2 \\
4.7 \\
3.9\end{array}$ & $\begin{array}{r}6 \\
12 \\
19 \\
19 \\
18\end{array}$ & $\begin{array}{l}.44 \\
.87 \\
1.4 \\
1.4 \\
1.3\end{array}$ \\
\hline $\begin{array}{l}21 \\
22 \\
23 \\
24 \\
25\end{array}$ & $\begin{array}{l}59 \\
67 \\
66 \\
64 \\
65\end{array}$ & $\begin{array}{l}22 \\
24 \\
25 \\
26 \\
27\end{array}$ & $\begin{array}{l}63 \\
79 \\
82 \\
84 \\
81\end{array}$ & $\begin{array}{l}27 \\
19 \\
19 \\
30 \\
35\end{array}$ & $\begin{array}{l}19 \\
16 \\
28 \\
51 \\
44\end{array}$ & $\begin{array}{c}6.1 \\
4.8 \\
9.4 \\
19 \\
15\end{array}$ & $\begin{array}{l}28 \\
32 \\
35 \\
37 \\
36\end{array}$ & $\begin{array}{l}5.6 \\
6.3 \\
6.1 \\
6.3 \\
6.9\end{array}$ & $\begin{array}{l}34 \\
26 \\
22 \\
19 \\
21\end{array}$ & $\begin{array}{l}3.0 \\
2.5 \\
2.3 \\
2.1 \\
1.9\end{array}$ & $\begin{array}{l}18 \\
35 \\
40 \\
43 \\
41\end{array}$ & $\begin{array}{l}1.4 \\
3.3 \\
5.1 \\
5.3 \\
5.6\end{array}$ \\
\hline $\begin{array}{l}26 \\
27 \\
28 \\
29 \\
30 \\
31\end{array}$ & $\begin{array}{r}79 \\
78 \\
79 \\
69 \\
75 \\
---\end{array}$ & $\begin{array}{l}35 \\
49 \\
65 \\
59 \\
62 \\
---\end{array}$ & $\begin{array}{l}73 \\
65 \\
80 \\
75 \\
60 \\
53\end{array}$ & $\begin{array}{l}34 \\
32 \\
50 \\
49 \\
33 \\
26\end{array}$ & $\begin{array}{r}38 \\
42 \\
45 \\
50 \\
53 \\
---\end{array}$ & $\begin{array}{l}12 \\
13 \\
14 \\
14 \\
14 \\
---\end{array}$ & $\begin{array}{l}34 \\
33 \\
34 \\
37 \\
38 \\
38\end{array}$ & $\begin{array}{l}8.7 \\
8.9 \\
8.1 \\
7.8 \\
7.8 \\
7.9\end{array}$ & $\begin{array}{l}24 \\
22 \\
20 \\
18 \\
16 \\
16\end{array}$ & $\begin{array}{l}2.2 \\
2.0 \\
1.8 \\
1.5 \\
1.4 \\
1.5\end{array}$ & $\begin{array}{r}38 \\
36 \\
45 \\
54 \\
55 \\
--\end{array}$ & $\begin{array}{r}5.1 \\
4.7 \\
6.4 \\
9.9 \\
11\end{array}$ \\
\hline TOTAL & -- & 617.9 & -- & 738.2 & -- & 260.3 & $-\infty$ & 168.99 & -- & 89.17 & -- & 81.51 \\
\hline TOTAL & LOAD FOR & AR: & 5700.07 & rons. & & & & & & & & \\
\hline
\end{tabular}

WATER QUALITY DATA, WATER YEAR OCTOBER 1984 TO SEPTEMBER 1985

\begin{tabular}{|c|c|c|c|c|c|c|}
\hline DATE & TIME & $\begin{array}{l}\text { TEKPER- } \\
\text { ATURE } \\
\text { (DEG C) }\end{array}$ & $\begin{array}{l}\text { STREAM- } \\
\text { FLOW, } \\
\text { INSTAN- } \\
\text { TANEOUS } \\
\text { (CFS) }\end{array}$ & $\begin{array}{l}\text { SEDI- } \\
\text { MENT, } \\
\text { SUS- } \\
\text { PENDED } \\
\text { (MG/L) }\end{array}$ & $\begin{array}{c}\text { SEDI- } \\
\text { HENT, } \\
\text { DIS- } \\
\text { CHARGE, } \\
\text { SUS- } \\
\text { PENDED } \\
\text { (T/DAY) }\end{array}$ & $\begin{array}{l}\text { SED. } \\
\text { SUSP. } \\
\text { SIEVE } \\
\text { DIAM. } \\
\text { FINER } \\
\text { THAN } \\
\text {. } 62 \mathrm{MH}\end{array}$ \\
\hline $\begin{array}{l}\text { OCT } \\
31 \ldots . . . \\
\text { NOV }\end{array}$ & $14: 15$ & 11.0 & 81 & 39 & 8.5 & 86 \\
\hline & $10: 15$ & 5.0 & 104 & 26 & 7.3 & 67 \\
\hline & $14: 00$ & 6.0 & 189 & 11 & 5.6 & 81 \\
\hline $20 \ldots$ & $11: 15$ & 20.0 & 128 & 30 & 10 & 94 \\
\hline
\end{tabular}


05483600 MIDDLE RACCOON RIVER AT PANORA, IA--Continued

WATER-QUALITY RECORDS

WATER QUALITY DATA, WATER YEAR OCTOBER 1984 TO SEPTEABER

\begin{tabular}{|c|c|c|c|c|c|c|c|}
\hline DATE & TIME & $\begin{array}{l}\text { STREAY- } \\
\text { FLOW, } \\
\text { INBTAN- } \\
\text { TANEOOS } \\
\text { (CFS) }\end{array}$ & $\begin{array}{c}\text { MUMBER } \\
\text { OF } \\
\text { SAM- } \\
\text { PLING } \\
\text { POINTS }\end{array}$ & $\begin{array}{c}\text { BED } \\
\text { MAT. } \\
\text { SIEVE } \\
\text { DINA. } \\
\text { PINER } \\
\text { PIAAN } \\
.062 \mathrm{~m}\end{array}$ & $\begin{array}{c}\text { BED } \\
\text { MAT. } \\
\text { SIENB } \\
\text { DIAM. } \\
\text { PINBR } \\
\text { PTHAM } \\
.125 \mathrm{~mm}\end{array}$ & $\begin{array}{c}\text { BBD } \\
\text { MAT. } \\
\text { SIEVE } \\
\text { DIMH. } \\
\text { PINER } \\
\text { PINAM } \\
.250 \mathrm{~m}\end{array}$ & $\begin{array}{c}\text { BED } \\
\text { MAT. } \\
\text { SIEVE } \\
\text { DIAN. } \\
\text { FINER } \\
\text { THAN } \\
.500\end{array}$ \\
\hline $\begin{array}{l}\text { OCT } \\
31 . . . \\
\text { Nov }\end{array}$ & $14: 25$ & 81 & 5 & 1 & 3 & 13 & 48 \\
\hline$\underset{A P R}{29 . . .}$ & $10: 45$ & 104 & 5 & 1 & 1 & 7 & 29 \\
\hline MAY & $14: 40$ & 189 & 6 & 1 & 2 & 7 & 26 \\
\hline JUN & $12: 10$ & 181 & 5 & 1 & 2 & 6 & 27 \\
\hline SEP & $11: 35$ & 128 & 3 & 3 & 6 & 18 & 45 \\
\hline 18. & $14: 20$ & 28 & 4 & 0 & 1 & 3 & 23 \\
\hline
\end{tabular}

WATER QUALITY DATA, WATER YEAR OCTOBER 1984 TO 8EPTEMBER 2985

\begin{tabular}{|c|c|c|c|c|c|c|c|}
\hline DATE & $\begin{array}{c}\text { BED } \\
\text { MAT. } \\
\text { SIEVE } \\
\text { DINH. } \\
\text { PINER } \\
\text { THAN } \\
\text { THA } \\
1.00 \mathrm{kM}\end{array}$ & $\begin{array}{c}\text { BED } \\
\text { MAT. } \\
\text { BIEVE } \\
\text { DINA. } \\
\text { PINER } \\
\text { PINEN } \\
2.00 \mathrm{THA}\end{array}$ & $\begin{array}{c}\text { BED } \\
\text { MAT. } \\
\text { SIEVE } \\
\text { DIAN. } \\
\text { PINER } \\
\text { THAN } \\
4.00 \mathrm{mM}\end{array}$ & $\begin{array}{c}\text { BED } \\
\text { MAT. } \\
\text { BIEVE } \\
\text { DINH. } \\
\text { FINBR } \\
\text { FRN } \\
\text { 8.00 m }\end{array}$ & $\begin{array}{c}\text { BED } \\
\text { MAT. } \\
\text { SIEVE } \\
\text { DIAM. } \\
\text { PINER } \\
\text { TIRM } \\
16.0 \mathrm{mM}\end{array}$ & $\begin{array}{c}\text { BED } \\
\text { MAT. } \\
\text { 8IBVE } \\
\text { DIMA. } \\
\text { FINER } \\
\text { FIAM } \\
32.0 \mathrm{~mm}\end{array}$ & $\begin{array}{c}\text { BED } \\
\text { MAT. } \\
\text { SIEVE } \\
\text { DIAY. } \\
\text { PINER } \\
\text { THAN } \\
64.0 \mathrm{MN}\end{array}$ \\
\hline 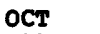 & & & & & & & \\
\hline $\operatorname{mov}^{31} \ldots$ & 71 & 83 & 89 & 93 & 97 & 100 & - \\
\hline & 50 & 60 & 69 & 79 & 87 & 100 & - \\
\hline MAY & 50 & 65 & 75 & 85 & 92 & 100 & -- \\
\hline JUN & 46 & 57 & 63 & 68 & 74 & 81 & 100 \\
\hline SEP & 63 & 75 & 83 & 90 & 100 & - & - \\
\hline & 46 & 59 & 68 & 76 & 78 & 100 & -- \\
\hline
\end{tabular}


LOCATION.--Lat $41^{\circ} 34^{\prime} 48^{\prime \prime}$, long $94^{\circ} 10^{\prime} 58^{\prime \prime}$, in SW1/4 SW1/4 sec. 3, T.78 N., R.29 w., Dallas County, Hydrologic Unit 07100007 , on left bank $35 \mathrm{ft}$ (revised) downstream from bridge on county highway at Redfield, $0.8 \mathrm{mi}$ downstream from bridge on U.S. Highway $6,1.0 \mathrm{mi}$ downstream from Middle Raccoon River, $16.4 \mathrm{mi}$ upstream from mouth, and

at mile 248.0 upstream from mouth of Des Moines River.

DRAINAGE AREA. $--988 \mathrm{mi}^{2}$.

PERIOD OF RECORD.--March 1940 to current year.

REVISED RECORDS.--WSP 1438: Drainage area. WSP 1508: 1940.

GAGE.--water-stage recorder. Datum of gage is $896.43 \mathrm{ft}$ above NGVD. Prior to June 12, 1946, nonrecording gage, and June 12, 1946, to Sept. 30, 1966, water-stage recorder at site $20 \mathrm{ft}$ upstream at same datum.

REMARKS.--Estimated daily discharges: oct. 23 to Nov. 8, Dec. 5 to Feb. 24 . Records good except for periods of National Weather Service gage-height telemeter at station.

COOPERATION. - Three discharge measurements provided by U.S. Army Corps of Engineers.

AVERAGE DISCHARGE. -45 years, $457 \mathrm{ft} / \mathrm{s}, 6.28 \mathrm{in} / \mathrm{yr}, 331,100$ acre- $\mathrm{ft} / \mathrm{yr}$; median of yearly mean discharges $400 \mathrm{ft}^{3} / \mathrm{s}, 5.5 \mathrm{in} / \mathrm{yr}, 290,000$ acre-ft/yr.

EXTREMES FOR PERIOD OF RECORD.--Maximum discharge, 35,000 ft3/s July 2, 1958, gage height, $29.04 \mathrm{ft}$, from floodmark; minimum daily, $17 \mathrm{ft}^{3} / \mathrm{s}$ Aug. 4,1977 .

EXTREMES FOR CURRENT YEAR.--Peak discharges greater than base of $5,000 \mathrm{ft}^{3} / \mathrm{s}$ and maximum $(*)$ :

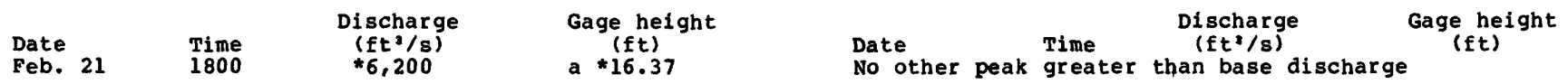

a ice jam

Minimum discharge, $55 \mathrm{ft}^{3} / \mathrm{s}$ Sept. $3,10,18$.

DISCHARGE, IN CUBIC FEET PER SECOND, WATER YEAR OCTOBER 1984 TO SEPTEMBER 1985 MEAN VALUES

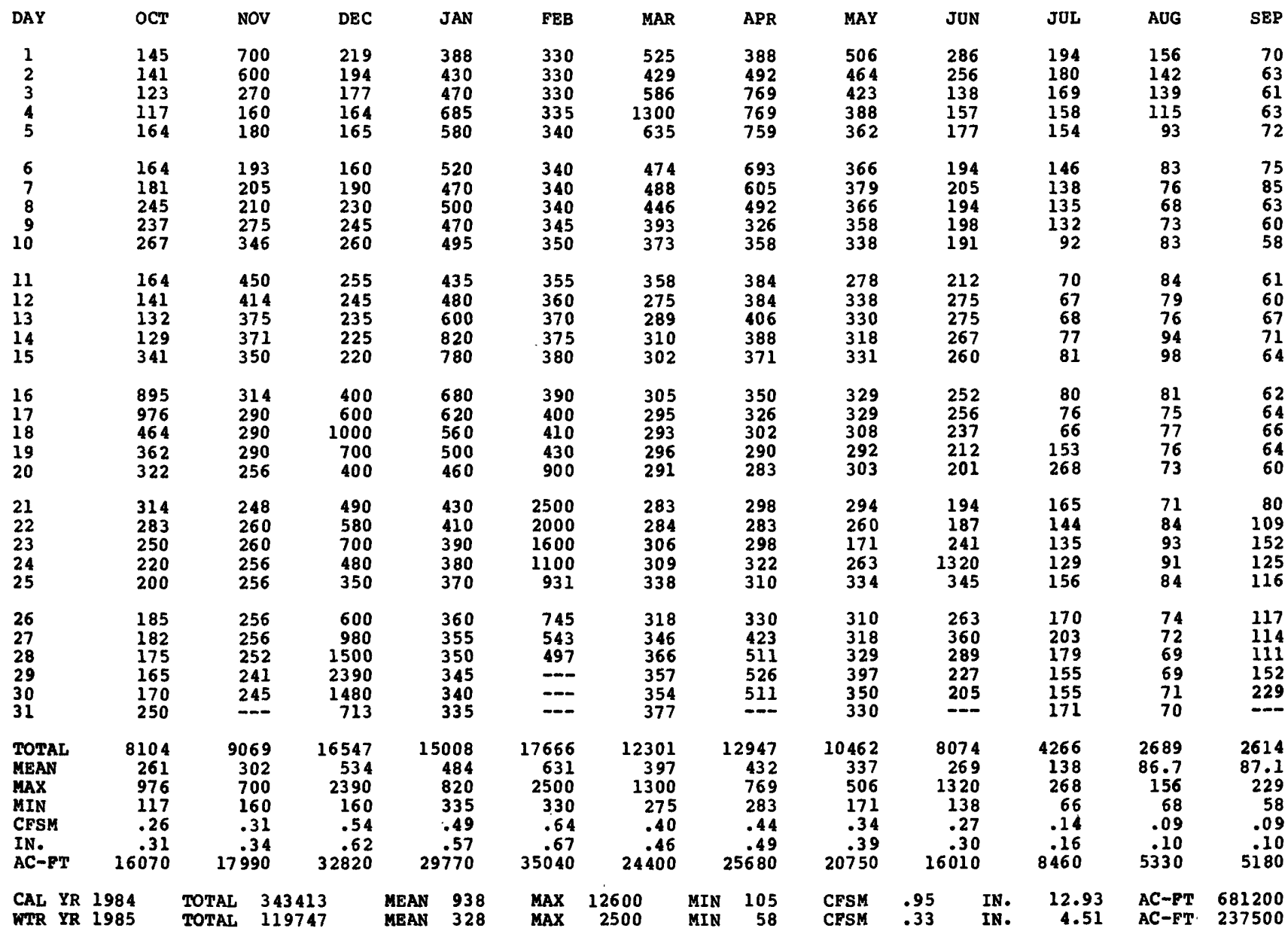


LOCATION.--Lat $41^{\circ} 32^{\prime} 02^{\prime \prime}$, long $93^{\circ} 56^{\prime} 59^{\prime \prime}$, in Swl/4 Sw1/4 sec.22, T.78 N., R.27 W., Dallas County, Hydrologic Unit 07100007 , on right bank $10 \mathrm{ft}$ downstream from bridge on county highway Rl6, 0.3 mi northeast of Van Meter, 0.7 mi upstream from small left bank tributary, l. i mi downstream from confluence of North and South Raccoon Rivers, $29.0 \mathrm{mi}$ upstream from mouth, and at mile 230.5 upstream from mouth of Des Moines River.

DRAINAGE AREA, $--3,441 \mathrm{mi}^{2}$.

PERIOD OF RECORD.--April 1915 to current year. Prior to October 1934, monthly discharge only, published in wSP 1308 .

REVISED RECORDS.--WSP 1308: 1927 (M), WSP 1438: Drainage area, WSP 1508: 1915 (M), 1925 (M), 1926, 1933 (M), 1939 (M), 1947 (M), 1949 (M).

GAGE.- Water-stage recorder. Datum of gage is $841.16 \mathrm{ft}$ above NGVD. See wSP 1308 for history of changes prior to Aug. 8, 1934 .

REMARKS.--Estimated daily discharges: Dec. 4-12, Dec. 14 to Mar. 3 . Records good except for estimated daily discharges, which are poor. U.S. Army Corps of Engineers rain-gage and gage-height telemeters and data collection platform at station.

COOPERATION.--Two discharge measurements provided by U.S. Army Corps of Engineers.

AVERAGE DISCHARGE.--70 years, $1,379 \mathrm{ft} / \mathrm{s}, 5.44 \mathrm{in} / \mathrm{yr}, 999,100$ acre-ft/yr; median of yearly mean discharges, $1,150 \mathrm{ft} / 8,4.5 \mathrm{in} / \mathrm{yr}, 833,000$ acre-ft/yr.

EXTREMES FOR PERIOD OF RECORD.--Maximum discharge, 41,200 ft/s June 13, 1947, gage height, 21.37 ft, from floodmark; maximum gage height, $21.77 \mathrm{ft}$ July 3 , 1958; minimum daily discharge, 10 ft/s Jan. 22-31, 1940.

EXTREMES FOR CURRENT YEAR.--Peak discharges greater than base of $8,500 \mathrm{ft}^{\mathrm{J}} / \mathrm{s}$ and maximum (*):

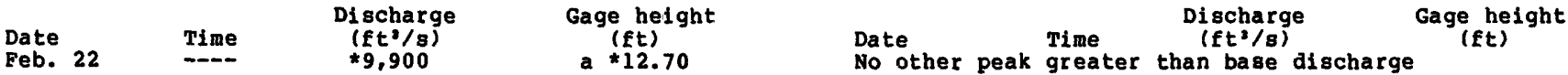

a ice jam

Minimum daily discharge, $145 \mathrm{ft} / \mathrm{s}$ Sept. 20.

DISCHARGE, IN CUBIC FEET PER SECOND, WATER YEAR OCTOBER 1984 TO SEPTEMBER 1985 MEAN VALUES

\begin{tabular}{|c|c|c|c|c|c|c|c|c|c|c|c|c|}
\hline DAY & OCT & NOV & DEC & JAN & FEB & MAR & APR & MAY & JUN & JUL & AUG & SEP \\
\hline $\begin{array}{l}1 \\
2 \\
3 \\
4 \\
5\end{array}$ & $\begin{array}{l}261 \\
253 \\
245 \\
252 \\
269\end{array}$ & $\begin{array}{r}1090 \\
1760 \\
1230 \\
976 \\
741\end{array}$ & $\begin{array}{l}543 \\
508 \\
417 \\
270 \\
240\end{array}$ & $\begin{array}{l}2300 \\
2200 \\
2380 \\
2700 \\
3200\end{array}$ & $\begin{array}{l}500 \\
490 \\
490 \\
485 \\
480\end{array}$ & $\begin{array}{l}1260 \\
1200 \\
1390 \\
2860 \\
1720\end{array}$ & $\begin{array}{l}1330 \\
1410 \\
1750 \\
2000 \\
2380\end{array}$ & $\begin{array}{l}2960 \\
2640 \\
2370 \\
2160 \\
2020\end{array}$ & $\begin{array}{l}1470 \\
1360 \\
1400 \\
1410 \\
1270\end{array}$ & $\begin{array}{r}1160 \\
1090 \\
937 \\
821 \\
733\end{array}$ & $\begin{array}{l}327 \\
287 \\
276 \\
271 \\
200\end{array}$ & $\begin{array}{l}167 \\
177 \\
229 \\
224 \\
210\end{array}$ \\
\hline $\begin{array}{r}6 \\
7 \\
8 \\
9 \\
10\end{array}$ & $\begin{array}{l}287 \\
315 \\
344 \\
448 \\
354\end{array}$ & $\begin{array}{l}698 \\
677 \\
664 \\
666 \\
653\end{array}$ & $\begin{array}{l}450 \\
680 \\
660 \\
660 \\
560\end{array}$ & $\begin{array}{l}2900 \\
2650 \\
3000 \\
2600 \\
2100\end{array}$ & $\begin{array}{l}480 \\
480 \\
475 \\
475 \\
470\end{array}$ & $\begin{array}{l}1520 \\
1560 \\
1610 \\
1500 \\
1390\end{array}$ & $\begin{array}{l}2730 \\
2630 \\
2430 \\
2050 \\
1890\end{array}$ & $\begin{array}{l}1930 \\
2330 \\
2220 \\
1970 \\
1810\end{array}$ & $\begin{array}{r}1180 \\
1120 \\
1060 \\
990 \\
938\end{array}$ & $\begin{array}{l}662 \\
598 \\
560 \\
526 \\
469\end{array}$ & $\begin{array}{l}205 \\
200 \\
177 \\
172 \\
181\end{array}$ & $\begin{array}{l}200 \\
220 \\
186 \\
177 \\
186\end{array}$ \\
\hline $\begin{array}{l}11 \\
12 \\
13 \\
14 \\
15\end{array}$ & $\begin{array}{l}394 \\
288 \\
285 \\
279 \\
409\end{array}$ & $\begin{array}{l}819 \\
850 \\
892 \\
972 \\
934\end{array}$ & $\begin{array}{l}530 \\
520 \\
627 \\
495 \\
400\end{array}$ & $\begin{array}{l}1800 \\
1600 \\
1430 \\
1230 \\
1120\end{array}$ & $\begin{array}{l}470 \\
470 \\
470 \\
475 \\
480\end{array}$ & $\begin{array}{l}1350 \\
1440 \\
1420 \\
1380 \\
1260\end{array}$ & $\begin{array}{l}1800 \\
1720 \\
1690 \\
1610 \\
1550\end{array}$ & $\begin{array}{l}1700 \\
1660 \\
1630 \\
1550 \\
1530\end{array}$ & $\begin{array}{r}936 \\
1050 \\
1170 \\
1160 \\
1130\end{array}$ & $\begin{array}{l}401 \\
371 \\
354 \\
343 \\
330\end{array}$ & $\begin{array}{l}177 \\
167 \\
172 \\
181 \\
200\end{array}$ & $\begin{array}{l}210 \\
220 \\
190 \\
186 \\
177\end{array}$ \\
\hline $\begin{array}{l}16 \\
17 \\
18 \\
19 \\
20\end{array}$ & $\begin{array}{r}1080 \\
1650 \\
1250 \\
1040 \\
951\end{array}$ & $\begin{array}{l}850 \\
772 \\
743 \\
717 \\
655\end{array}$ & $\begin{array}{r}500 \\
700 \\
920 \\
1300 \\
1200\end{array}$ & $\begin{array}{l}990 \\
900 \\
810 \\
740 \\
680\end{array}$ & $\begin{array}{r}485 \\
495 \\
510 \\
520 \\
1300\end{array}$ & $\begin{array}{l}1190 \\
1120 \\
1070 \\
1050 \\
1000\end{array}$ & $\begin{array}{l}1490 \\
1410 \\
1350 \\
1270 \\
1210\end{array}$ & $\begin{array}{l}1530 \\
1720 \\
2300 \\
2100 \\
1930\end{array}$ & $\begin{array}{r}1090 \\
1060 \\
984 \\
953 \\
890\end{array}$ & $\begin{array}{l}312 \\
287 \\
260 \\
298 \\
495\end{array}$ & $\begin{array}{l}190 \\
172 \\
172 \\
172 \\
167\end{array}$ & $\begin{array}{l}163 \\
158 \\
150 \\
150 \\
145\end{array}$ \\
\hline $\begin{array}{l}21 \\
22 \\
23 \\
24 \\
25\end{array}$ & $\begin{array}{l}866 \\
773 \\
711 \\
597 \\
527\end{array}$ & $\begin{array}{l}612 \\
606 \\
596 \\
584 \\
588\end{array}$ & $\begin{array}{l}1330 \\
1480 \\
1400 \\
1300 \\
1480\end{array}$ & $\begin{array}{l}620 \\
580 \\
560 \\
550 \\
540\end{array}$ & $\begin{array}{l}3200 \\
8200 \\
5400 \\
3300 \\
2000\end{array}$ & $\begin{array}{l}968 \\
929 \\
959 \\
998 \\
997\end{array}$ & $\begin{array}{l}1200 \\
1160 \\
1160 \\
1220 \\
1350\end{array}$ & $\begin{array}{l}1770 \\
1640 \\
1560 \\
1550 \\
1550\end{array}$ & $\begin{array}{r}827 \\
766 \\
951 \\
1990 \\
1030\end{array}$ & $\begin{array}{l}489 \\
411 \\
344 \\
315 \\
368\end{array}$ & $\begin{array}{l}158 \\
167 \\
200 \\
195 \\
177\end{array}$ & $\begin{array}{l}150 \\
215 \\
350 \\
321 \\
276\end{array}$ \\
\hline $\begin{array}{l}26 \\
27 \\
28 \\
29 \\
30 \\
31\end{array}$ & $\begin{array}{l}535 \\
734 \\
492 \\
467 \\
477 \\
458\end{array}$ & $\begin{array}{l}596 \\
603 \\
594 \\
572 \\
564 \\
-\cdots\end{array}$ & $\begin{array}{l}1750 \\
2100 \\
2500 \\
3000 \\
3500 \\
2900\end{array}$ & $\begin{array}{l}520 \\
520 \\
510 \\
510 \\
500 \\
500\end{array}$ & $\begin{array}{r}1500 \\
1300 \\
1240 \\
-0 \\
\ldots-\end{array}$ & $\begin{array}{r}996 \\
1040 \\
1100 \\
1120 \\
1140 \\
1280\end{array}$ & $\begin{array}{l}1640 \\
1860 \\
2470 \\
3590 \\
3350 \\
---\end{array}$ & $\begin{array}{l}1680 \\
2030 \\
1930 \\
1840 \\
1700 \\
1580\end{array}$ & $\begin{array}{l}761 \\
835 \\
820 \\
688 \\
688 \\
---\end{array}$ & $\begin{array}{l}350 \\
368 \\
344 \\
315 \\
332 \\
338\end{array}$ & $\begin{array}{l}158 \\
154 \\
150 \\
163 \\
177 \\
172\end{array}$ & $\begin{array}{l}292 \\
321 \\
255 \\
321 \\
456 \\
---\end{array}$ \\
\hline $\begin{array}{l}\text { TOTAL } \\
\text { MEAN } \\
\text { MAX } \\
\text { MIN } \\
\text { CESH } \\
\text { IN. } \\
\text { AC-FT }\end{array}$ & $\begin{array}{r}17291 \\
558 \\
1650 \\
245 \\
.16 \\
.19 \\
34300\end{array}$ & $\begin{array}{r}23274 \\
776 \\
1760 \\
564 \\
.23 \\
.25 \\
46160\end{array}$ & $\begin{array}{r}34920 \\
1126 \\
3500 \\
240 \\
.33 \\
.38 \\
69260\end{array}$ & $\begin{array}{r}43240 \\
1395 \\
3200 \\
500 \\
.41 \\
.47 \\
85770\end{array}$ & $\begin{array}{r}36640 \\
1309 \\
8200 \\
470 \\
.38 \\
.40 \\
72680\end{array}$ & $\begin{array}{r}39817 \\
1284 \\
2860 \\
929 \\
.37 \\
.43 \\
78980\end{array}$ & $\begin{array}{r}54700 \\
1823 \\
3590 \\
1160 \\
.53 \\
.59 \\
108500\end{array}$ & $\begin{array}{r}58890 \\
1900 \\
2960 \\
1530 \\
.55 \\
.64 \\
116800\end{array}$ & $\begin{array}{r}31977 \\
1066 \\
1990 \\
688 \\
.31 \\
.35 \\
63430\end{array}$ & $\begin{array}{r}14981 \\
483 \\
1160 \\
260 \\
.14 \\
.16 \\
29710\end{array}$ & $\begin{array}{r}5937 \\
192 \\
327 \\
150 \\
.06 \\
.06 \\
11780\end{array}$ & $\begin{array}{r}6682 \\
223 \\
456 \\
145 \\
.06 \\
.07 \\
13250\end{array}$ \\
\hline
\end{tabular}

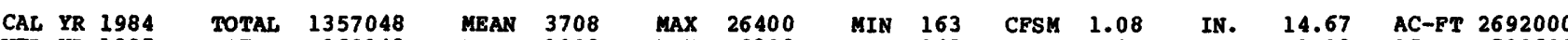
WTR YR 1985 TOTAL 368349 MEAN 1009 MAX $8200 \quad$ MIN $145 \quad$ CFSM $.29 \quad$ IN. 3.98 AC-FT 730600 
LOCATION.--Lat $41^{\circ} 35^{\prime} 14^{\prime \prime}$, long $93^{\circ} 42^{\prime} 11^{\prime \prime}$, in SWl/4 SEl/4 sec.2, T.78 N., R.25 W., Polk County, Hyarologic Unit 07100006 , on left bank, $25 \mathrm{ft}$ downstream from bridge on $63 \mathrm{rd}$ street in Des Moines, and 2.2 mi upstream from

Raccoon River.

DRAINAGE AREA. $--78.4 \mathrm{mi}^{2}$.

PERIOD OF RECORD.--October 1971 to current year.

REVISED RECORDS.--WDR IOWa 1973: 1972. WDR IA-75-1: 1973-74.

GAGE.--Water-stage recorder. Datum of gage is $801.04 \mathrm{ft}$ above NGVD (levels by Iowa Natural Resources Council).

REMARKS.--Estimated daily discharges: Oct. 1-2, Nov, 30 to Dec. 6, 9-11, 15-19, Jan. 1 to Feb. 21, Mar. 4-6. Records good except those for estimated discharges, which are poor. National Weather Service gage-height telemeter at station.

AVERAGE DISCHARGE. - -14 years, $62.7 \mathrm{ft}^{2} / \mathrm{s}, 10.5 \mathrm{in} / \mathrm{yr}^{2}, 45,430 \mathrm{acre}-\mathrm{ft} / \mathrm{yr}^{\mathrm{r}}$.

EXTREMES FOR PERIOD OF RECORD.--Maximum discharge, 9,000 $\mathrm{ft} 3 / \mathrm{s} \mathrm{July} 1,1973$, gage height, $17.72 \mathrm{ft}$, no flow for many days in 1977 .

EXTREMES FOR CURRENT YEAR.--Peak discharges greater than base of $600 \mathrm{ft}^{2} / \mathrm{s}$ and maximum (*):

\begin{tabular}{|c|c|c|c|c|c|c|c|c|}
\hline Nov. & 1 & $\begin{array}{l}\text { Time } \\
0145\end{array}$ & $\begin{array}{c}\text { Discharge } \\
\left(\mathrm{ft}^{3} / \mathrm{s}\right) \\
\star 946\end{array}$ & $\begin{array}{c}\text { Gage height } \\
\text { (ft) } \\
\star 9.69\end{array}$ & $\begin{array}{l}\text { Date } \\
\text { Sep. } 22\end{array}$ & $\begin{array}{l}\text { Time } \\
2145\end{array}$ & $\begin{array}{c}\text { Discharge } \\
\text { (ft } 3 / \mathrm{s}) \\
776\end{array}$ & $\begin{array}{c}\text { Gage height } \\
\text { (ft) } \\
9.02\end{array}$ \\
\hline
\end{tabular}

Minimum daily discharge, $0.14 \mathrm{ft}^{2} / \mathrm{s}$ Aug. 19.

DISCHARGE, IN CUBIC FEET PER SECOND, WATER YEAR OCTOBER 1984 TO SEPTEMBER 1985 MEAN VALUES

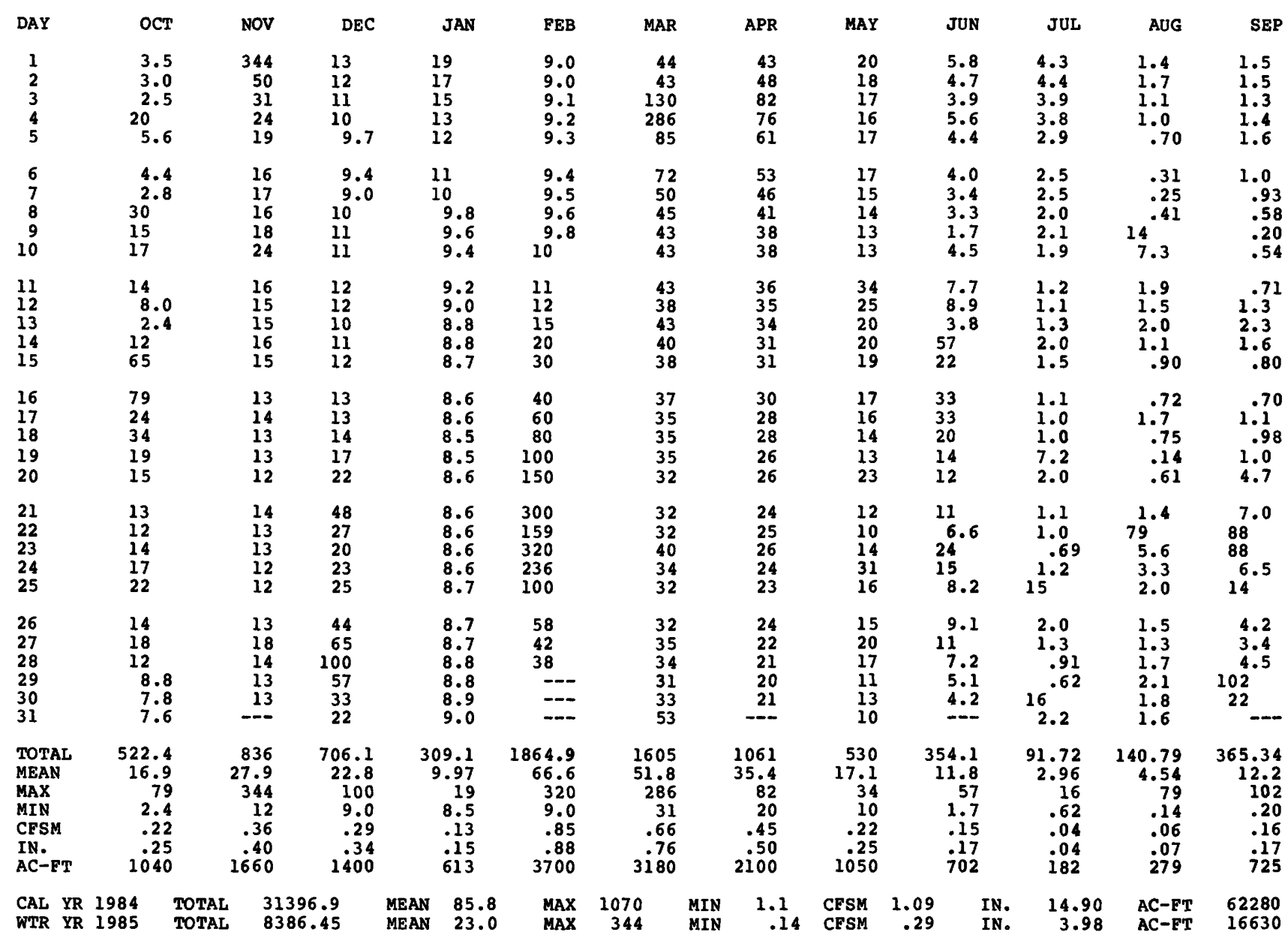




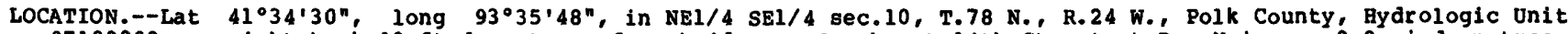
07100008 , on $r i g h t$ bank $10 \mathrm{ft}$ downstream from bridge on southeast 14 th street at Des Moines, $0.8 \mathrm{mi}$ downstream from Raccoon River and scott street Dam, and at mile 200.7.

DRAINAGE AREA. $--9,879 \mathrm{mi}^{2}$.

PERIOD OF RECORD.--April 1940 to current year.

REVISED RECORDS.--WSP 1438: Drainage area. WSP 1508: 1943 (P).

GAGE.--Water-stage recorder. Datum of gage is $762.52 \mathrm{ft}$ above NGVD. Prior to Oct. 1, 1951, and Oct. 1, 1953, to Sept. 30 , 1959, water-stage recorder upstream of scott street Dam, $0.8 \mathrm{mi}$ upstream at datum $11.16 \mathrm{ft}$ higher. Oct. 1, 1951, to sept. 30, 1953, and Oct. 1, 1959 to sept. 30, 1961, nonrecording gage at present site and datum.

REMARKS.--Estimated daily discharges: Dec. 6-7, 14, 18-26, Dec. 31 to Feb. 23 . Records good except those for estimated discharges, which are poor. Des Moines municipal water supply is taken from infiltration galleries on Raccoon River, $3.5 \mathrm{mi}$ upstream from station. Average daily pumpage was about $58 \mathrm{ft} / \mathrm{s}$. At times, water is pumped from Raccoon River into recharge basins, or into waterworks Reservoir, capacity, 4,800 acre-ft. Effluent from sewage treatment plant enters the river $2.3 \mathrm{mi}$ downstream from station. Net effect diversions not known. Flow regulated by Saylorville Lake (station 05481630) $13.0 \mathrm{mi}$ upstream, since Apr. 12, 1977 . U.S. Army Corps of Engineers Data Collection Platform at station.

COOPERATION.--Two discharge measurements provided by U.s. Army Corps of Engineers. Average monthly pumpage from galleries provided by Des Molnes Water Works.

AVERAGE DISCHARGE.--45 years, $4,422 \mathrm{ft} / \mathrm{s}, 6.08 \mathrm{in} / \mathrm{yr}, 3,204,000$ acre-ft/yr; median of yearly mean discharges $3,580 \mathrm{ft} / \mathrm{s}, 4.9 \mathrm{in} / \mathrm{yr}, 2,590,000$ acre-ft/yr.

EXTREMES FOR PERIOD OF RECORD,--Maximum discharge, 77,000 ftº June 26, 1947, gage height, 20.8 ft in gage well, $21.6 \mathrm{ft}$ from outside floodmark, site and datum then in use; minimum daily, 26 ft:s Jan. $16-29,1977$.

EXTREMES OUTSIDE PERIOD OF RECORD.--Maximum stage since at least 1893, that of June 26, 1947, site and datum then in use. Flood of May 31, 1903, reached a stage of $20.9 \mathrm{ft}$, from flood profile, at scott street site and datum, by office of Des Moines City Engineer.

EXTREMES FOR CURRENT YEAR.--Maximum discharge, 13,900 fts Apr. 30, gage height, 17.71 ft; minimum daily discharge, $340 \mathrm{ft} / \mathrm{s}$ Aug. 21 .

DISCBARGE, IN CUBIC FEET PER SECOND, WATER YEAR OCTOBER 1984 TO SEPTEMBER 1985 MEAN VALDES

\begin{tabular}{|c|c|c|c|c|c|c|c|c|c|c|c|c|}
\hline DAY & OCT & NOV & DEC & JAN & FEB & MAR & APR & MAY & JUN & JUL & AUG & SEP \\
\hline $\begin{array}{l}1 \\
2 \\
3 \\
4 \\
5\end{array}$ & $\begin{array}{l}694 \\
569 \\
533 \\
634 \\
568\end{array}$ & $\begin{array}{l}2870 \\
3150 \\
2740 \\
2150 \\
1810\end{array}$ & $\begin{array}{l}1350 \\
1270 \\
1130 \\
1040 \\
1040\end{array}$ & $\begin{array}{l}5860 \\
4220 \\
2730 \\
1620 \\
2900\end{array}$ & $\begin{array}{l}660 \\
640 \\
620 \\
600 \\
580\end{array}$ & $\begin{array}{l}2460 \\
2350 \\
2530 \\
4890 \\
5260\end{array}$ & $\begin{array}{l}4340 \\
4100 \\
4190 \\
4720 \\
5590\end{array}$ & $\begin{array}{r}13000 \\
11100 \\
10100 \\
9590 \\
8730\end{array}$ & $\begin{array}{l}4500 \\
4380 \\
4130 \\
4020 \\
3880\end{array}$ & $\begin{array}{l}3270 \\
2810 \\
3130 \\
3140 \\
2870\end{array}$ & $\begin{array}{l}527 \\
394 \\
590 \\
598 \\
579\end{array}$ & $\begin{array}{l}1190 \\
1830 \\
2330 \\
1920 \\
1360\end{array}$ \\
\hline $\begin{array}{r}6 \\
7 \\
8 \\
9 \\
10\end{array}$ & $\begin{array}{l}578 \\
578 \\
599 \\
714 \\
655\end{array}$ & $\begin{array}{l}1670 \\
1610 \\
1570 \\
1570 \\
1560\end{array}$ & $\begin{array}{l}2600 \\
1550 \\
1120 \\
1130 \\
1170\end{array}$ & $\begin{array}{l}3180 \\
3110 \\
3020 \\
2890 \\
1920\end{array}$ & $\begin{array}{l}570 \\
560 \\
540 \\
540 \\
530\end{array}$ & $\begin{array}{l}4170 \\
3780 \\
3330 \\
3300 \\
3160\end{array}$ & $\begin{array}{l}7930 \\
8840 \\
8910 \\
9080 \\
8410\end{array}$ & $\begin{array}{l}8130 \\
8200 \\
8380 \\
7640 \\
6800\end{array}$ & $\begin{array}{l}3740 \\
3650 \\
3590 \\
3520 \\
3320\end{array}$ & $\begin{array}{l}2480 \\
2230 \\
2290 \\
2430 \\
2250\end{array}$ & $\begin{array}{l}529 \\
509 \\
443 \\
463 \\
500\end{array}$ & $\begin{array}{l}1380 \\
2090 \\
3390 \\
5820 \\
6500\end{array}$ \\
\hline $\begin{array}{l}11 \\
12 \\
13 \\
14 \\
15\end{array}$ & $\begin{array}{l}677 \\
636 \\
640 \\
665 \\
994\end{array}$ & $\begin{array}{l}1590 \\
1660 \\
1890 \\
2390 \\
2580\end{array}$ & $\begin{array}{l}1090 \\
1200 \\
1300 \\
1550 \\
1880\end{array}$ & $\begin{array}{l}1580 \\
2000 \\
1500 \\
1300 \\
1200\end{array}$ & $\begin{array}{l}530 \\
530 \\
530 \\
530 \\
530\end{array}$ & $\begin{array}{l}3310 \\
4040 \\
5450 \\
6880 \\
6570\end{array}$ & $\begin{array}{l}7710 \\
7100 \\
5860 \\
5770 \\
5550\end{array}$ & $\begin{array}{l}6360 \\
6220 \\
6140 \\
6080 \\
5680\end{array}$ & $\begin{array}{l}3030 \\
3030 \\
3140 \\
3430 \\
3540\end{array}$ & $\begin{array}{l}1870 \\
1590 \\
1600 \\
1580 \\
1540\end{array}$ & $\begin{array}{l}439 \\
445 \\
435 \\
442 \\
378\end{array}$ & $\begin{array}{l}6510 \\
6120 \\
5210 \\
3520 \\
2360\end{array}$ \\
\hline $\begin{array}{l}16 \\
17 \\
18 \\
19 \\
20\end{array}$ & $\begin{array}{l}1330 \\
2160 \\
2480 \\
2110 \\
2050\end{array}$ & $\begin{array}{l}2520 \\
2200 \\
1810 \\
1780 \\
1920\end{array}$ & $\begin{array}{l}2210 \\
2260 \\
1900 \\
1770 \\
2160\end{array}$ & $\begin{array}{l}1100 \\
1050 \\
1000 \\
1050 \\
1100\end{array}$ & $\begin{array}{r}530 \\
540 \\
540 \\
560 \\
1000\end{array}$ & $\begin{array}{l}6010 \\
5690 \\
5200 \\
5130 \\
5090\end{array}$ & $\begin{array}{l}4780 \\
4120 \\
4190 \\
4550 \\
4290\end{array}$ & $\begin{array}{l}5050 \\
4840 \\
5190 \\
5530 \\
5530\end{array}$ & $\begin{array}{l}3680 \\
3830 \\
4030 \\
3950 \\
3920\end{array}$ & $\begin{array}{l}1410 \\
1140 \\
1020 \\
1070 \\
1050\end{array}$ & $\begin{array}{l}375 \\
375 \\
364 \\
350 \\
344\end{array}$ & $\begin{array}{l}2320 \\
2310 \\
2260 \\
1920 \\
1680\end{array}$ \\
\hline $\begin{array}{l}21 \\
22 \\
23 \\
24 \\
25\end{array}$ & $\begin{array}{l}1770 \\
1440 \\
1430 \\
1500 \\
1450\end{array}$ & $\begin{array}{l}1630 \\
1630 \\
1620 \\
1610 \\
1580\end{array}$ & $\begin{array}{l}2890 \\
3540 \\
4030 \\
3420 \\
2420\end{array}$ & $\begin{array}{r}1100 \\
1000 \\
960 \\
940 \\
940\end{array}$ & $\begin{array}{l}1900 \\
2800 \\
5000 \\
8930 \\
5810\end{array}$ & $\begin{array}{l}4850 \\
4490 \\
4520 \\
4530 \\
4390\end{array}$ & $\begin{array}{l}3850 \\
3820 \\
3780 \\
4250 \\
5660\end{array}$ & $\begin{array}{l}5610 \\
5460 \\
5170 \\
4880 \\
4860\end{array}$ & $\begin{array}{l}3670 \\
3310 \\
3180 \\
3560 \\
3640\end{array}$ & $\begin{array}{r}1180 \\
1120 \\
1050 \\
1000 \\
925\end{array}$ & $\begin{array}{r}340 \\
650 \\
407 \\
384 \\
1520\end{array}$ & $\begin{array}{l}1400 \\
1700 \\
2840 \\
2880 \\
2510\end{array}$ \\
\hline $\begin{array}{l}26 \\
27 \\
28 \\
29 \\
30 \\
31\end{array}$ & $\begin{array}{l}1380 \\
1470 \\
1480 \\
1420 \\
1410 \\
1440\end{array}$ & $\begin{array}{c}1530 \\
1420 \\
1400 \\
1380 \\
1360 \\
---\end{array}$ & $\begin{array}{l}1990 \\
1820 \\
4470 \\
6010 \\
7230 \\
6990\end{array}$ & $\begin{array}{l}900 \\
900 \\
860 \\
760 \\
700 \\
680\end{array}$ & $\begin{array}{r}4570 \\
3260 \\
2650 \\
--- \\
--- \\
---\end{array}$ & $\begin{array}{l}4120 \\
4080 \\
4290 \\
4000 \\
3990 \\
4210\end{array}$ & $\begin{array}{r}7080 \\
8990 \\
11000 \\
12900 \\
13800 \\
---\end{array}$ & $\begin{array}{l}5150 \\
5890 \\
5800 \\
5090 \\
4780 \\
4600\end{array}$ & $\begin{array}{l}2870 \\
2890 \\
3390 \\
3300 \\
3220 \\
----\end{array}$ & $\begin{array}{r}1010 \\
1330 \\
1200 \\
1310 \\
850 \\
766\end{array}$ & $\begin{array}{r}2260 \\
1200 \\
930 \\
797 \\
850 \\
991\end{array}$ & $\begin{array}{l}2350 \\
2470 \\
2660 \\
3150 \\
3610 \\
---\end{array}$ \\
\hline $\begin{array}{l}\text { TOTAL } \\
\text { MEAN } \\
\text { MAX } \\
\text { MIN } \\
\text { AC-FT }\end{array}$ & $\begin{array}{r}36054 \\
1163 \\
2480 \\
533 \\
71510\end{array}$ & $\begin{array}{r}56200 \\
1873 \\
3150 \\
1360 \\
111500\end{array}$ & $\begin{array}{r}75520 \\
2436 \\
7230 \\
1040 \\
149800\end{array}$ & $\begin{array}{r}54070 \\
1744 \\
5860 \\
680 \\
107200\end{array}$ & $\begin{array}{r}46580 \\
1664 \\
8930 \\
530 \\
92390\end{array}$ & $\begin{array}{r}136070 \\
4389 \\
6880 \\
2350 \\
269900\end{array}$ & $\begin{array}{r}195160 \\
6505 \\
13800 \\
3780 \\
387100\end{array}$ & $\begin{array}{r}205580 \\
6632 \\
13000 \\
4600 \\
407800\end{array}$ & $\begin{array}{r}107340 \\
3578 \\
4500 \\
2870 \\
212900\end{array}$ & $\begin{array}{r}52511 \\
1694 \\
3270 \\
766 \\
104200\end{array}$ & $\begin{array}{r}19408 \\
626 \\
2260 \\
340 \\
38500\end{array}$ & $\begin{array}{r}87590 \\
2920 \\
6510 \\
1190 \\
173700\end{array}$ \\
\hline $\begin{array}{ll}\text { CAL YR } \\
\text { WMR YR }\end{array}$ & $\begin{array}{l}84 \\
85\end{array}$ & $\begin{array}{l}\text { TOTAL } \\
\text { TOTAL }\end{array}$ & $\begin{array}{l}4193534 \\
1072083\end{array}$ & $\begin{array}{l}\text { MEAN } \\
\text { MEAN }\end{array}$ & $\begin{array}{r}11460 \\
2937\end{array}$ & $\begin{array}{l}\text { MAX } \\
\text { MAX }\end{array}$ & $\begin{array}{l}56700 \\
13800\end{array}$ & $\begin{array}{l}\text { MIN } \\
\text { MIN }\end{array}$ & $\begin{array}{l}533 \\
340\end{array}$ & $\begin{array}{l}\text { ET } 831 \\
\text { PT } 212\end{array}$ & & \\
\hline
\end{tabular}


LOCATION.--Lat $41^{\circ} 36^{\prime} 50^{\prime \prime}$, long $93^{\circ} 32^{\prime} 43^{\prime \prime}$, in NEl/4 NEl/4 sec.32, T.79 N., R.23 W., Polk County, Hydrologic Onit 07100008 , on right bank $20 \mathrm{ft}$ downstream from bridge on Baston Blvd., 4.4 mi downstream from Muchikinock Creek and $5.0 \mathrm{mi}$ upstream from Des Moines River.

DRAINAGE AREA. $--92.7 \mathrm{mi}^{2}$.

PERIOD OF RECORD,--October 1971 to current year.

REVISED RECORDS. - WDR IA-75-1: 1974 (P).

GAGE.--Water-stage recorder. Datum of gage is $795.87 \mathrm{ft}$ above NGVD.

REMARKS.--Estimated daily discharges: Oct, 15-16, Dec, 4-26, Jan. 2 to Feb. 21, Aug. 20, Sept. 16. Records good except those for estimated discharge, which are poor. National Weather service gage-height telemeter at station.

AVERAGE DISCHARGE. - 14 years, $74.8 \mathrm{ft}^{2} / \mathrm{s}, 11.0 \mathrm{in} / \mathrm{yr}^{2}, 54,190 \mathrm{acre}-\mathrm{ft} / \mathrm{yr}$.

EXTREMES FOR PERIOD OF RECORD, - Maximum discharge, $5,340 \mathrm{ft} / \mathrm{s}$ June 9 , 1974, gage height, 14.84 ft; no flow for many days in 1977 .

EXTREMES FOR CURRENT YEAR.--Peak discharges greater than base of $500 \mathrm{ft}^{3 / \mathrm{s}}$ and maximum (*):

\begin{tabular}{|c|c|c|c|c|c|c|c|c|}
\hline $\begin{array}{l}\text { Date } \\
\text { Nov. } 1 \\
\text { Feb. } 23\end{array}$ & $\begin{array}{l}\text { Time } \\
0630 \\
2015\end{array}$ & $\begin{array}{c}\text { Discharge } \\
\left(\mathrm{ft}^{\prime} / \mathrm{s}\right) \\
662 \\
1,010\end{array}$ & $\begin{array}{c}\text { Gage height } \\
\text { (ft) } \\
7.54 \\
8.71\end{array}$ & $\begin{array}{l}\text { Date } \\
\text { Mar. }\end{array}$ & 4 & $\begin{array}{l}\text { Time } \\
0415\end{array}$ & $\begin{array}{c}\text { Di scharge } \\
\left(\mathrm{ft}^{3} / \mathrm{s}\right) \\
* 1,160\end{array}$ & $\begin{array}{c}\text { Gage height } \\
(\mathrm{ft}) \\
* 9.10\end{array}$ \\
\hline
\end{tabular}

Minimum daily discharge, $0.27 \mathrm{ft} / \mathrm{s}$ Aug. 12 .

DISCHARGE, IN CUBIC FEET PER SECOND, WATER YEAR OCTOBER 1984 TO SEPTEMBER 1985 MEAN VALUES

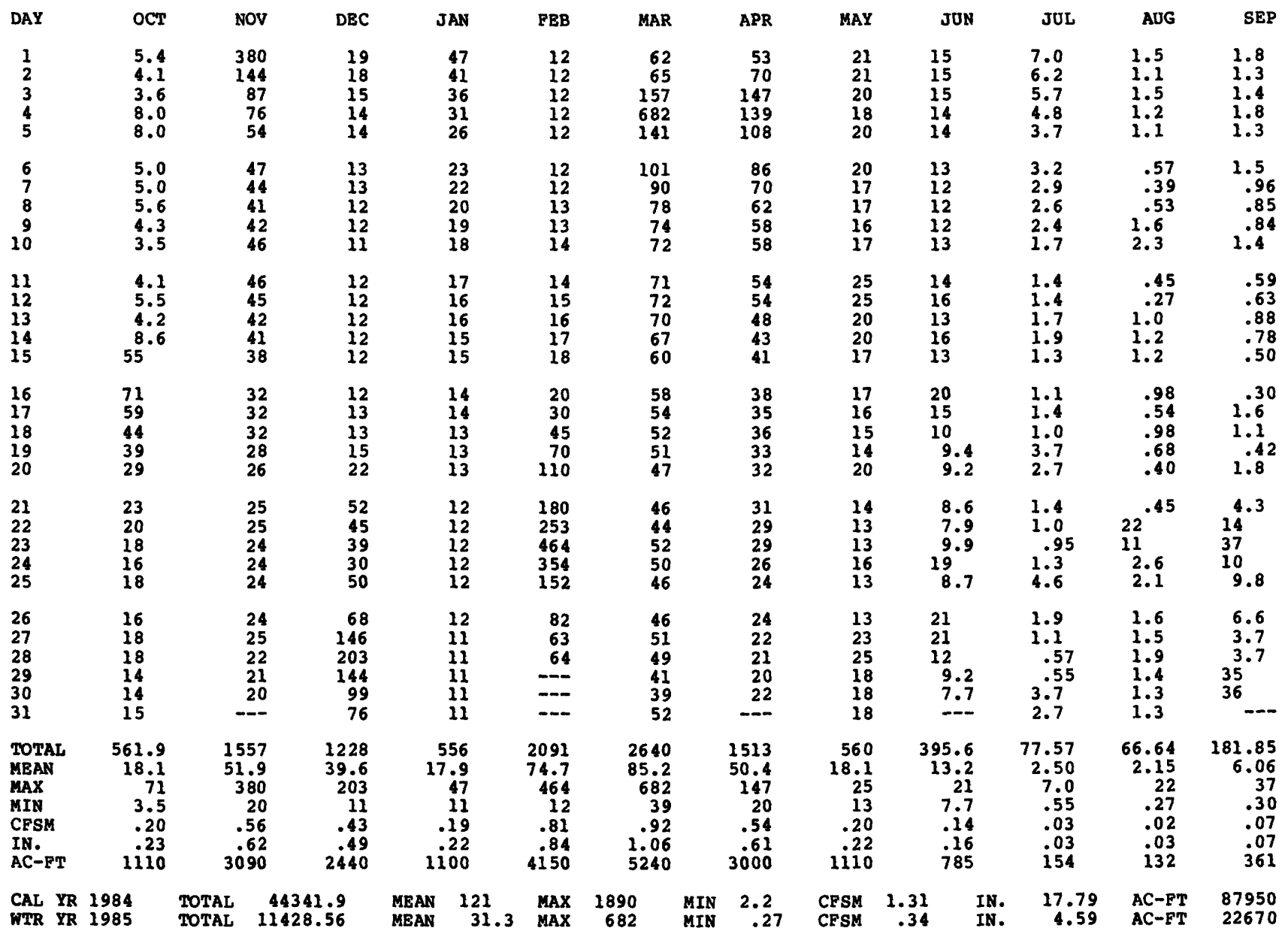


LOCATION.--Lat $41^{\circ} 27^{\prime} 25^{\prime \prime}$, long $93^{\circ} 39^{\prime} 10^{\prime \prime}$, in NWl/4 SWl/4 sec.20, T.77 N., R.24 W., Warren County, Hydrologic Unit 07100008 , on left bank $10 \mathrm{ft}$ downstream from bridge on county highway R57, 1.7 mi southeast of Norwalk, 5.2 mi upstream from Middle Creek, and $6.2 \mathrm{mi}$ downstream from Badger Creek.

DRAINAGE AREA. $--349 \mathrm{mi}^{2}$.

PERIOD OF RECORD.--February 1940 to current year.

REVISED RECORDS.--WSP 1438: Drainage area. WSP 1508: 1946. WDR IA-76-1: 1975 (P).

GAGE.-Water-stage recorder. Datum of gage is $788.45 \mathrm{ft}$ above NGVD (levels by U.S. Army Corps of Engineers). Prior to June 12, 1946, nonrecording gage at same site and datum. Jan. 7 to Oct. 11, 1960 , nonrecording gage at site $2.1 \mathrm{mi}$ upstream at different datum.

REMARKS.--Estimated daily discharges: Oct. 31, Dec, 22-24, Jan. 1 to Feb. 23, June 22, and Sept. 18-21. Records fair except those for estimated discharges, which are poor. U.s. Army Corps of Engineers Data Collection Platform at station.

COOPERATION.--One discharge measurement provided by U.S. Army Corps of Engineers.

AVERAGE DISCHARGE. -45 years, $186 \mathrm{ft} / \mathrm{s}, 7.24 \mathrm{in} / \mathrm{yr}, 134,800 \mathrm{acre-ft} / \mathrm{yr}$; median of yearly mean discharges, $170 \mathrm{ft}^{3} / \mathrm{s}, 6.6 \mathrm{in} / \mathrm{yr}, 123,000$ acre-ft/yr.

EXTREMES FOR PERIOD OF RECORD.-Maximum discharge, $32,000 \mathrm{ft} / \mathrm{s}$ June 13,1947, gage height, $25.3 \mathrm{ft}, \mathrm{from}$ floodmark, from rating curve extended above $9,100 \mathrm{ft} / \mathrm{s}$ on basis of velocity-area studies. No flow at times during period 1954-58.

EXTREMES FOR CURRENT YEAR.--Peak discharges greater than base of $1,700 \mathrm{ft}^{3} / \mathrm{s}$ and maximum (*):

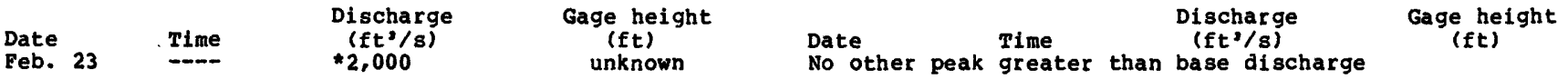

Minimum daily discharge, $0.25 \mathrm{ft}^{3} / \mathrm{s}$ sept. $20-21$.

DISCHARGE, IN CUBIC FEET PER SECOND, WATER YEAR OCTOBER 1984 TO SEPTEMBER 1985

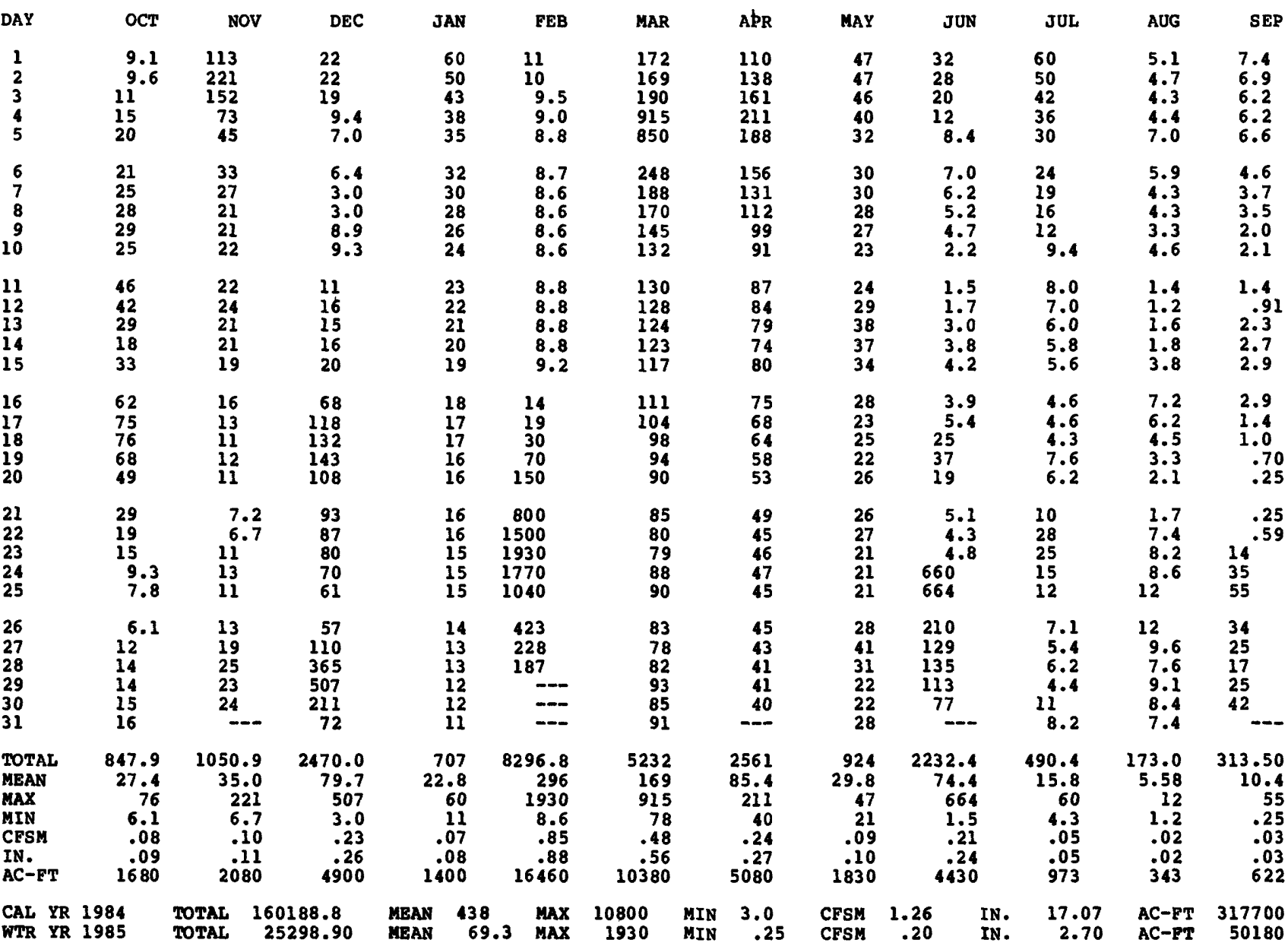


LOCATION,--Lat $41^{\circ} 25^{\prime} 27^{\prime \prime}$, long $93^{\circ} 35^{\prime} 09^{\prime \prime}$, in Sw1/4 SE1/4 sec.35, T.77 N., R.24 w., Warren County, Hydrologic Onit 07100008 , on right bank $10 \mathrm{ft}$ downstream from bridge on county highway, $0.4 \mathrm{mi}$ upstream from Cavitt Creek, 1.5 $\mathrm{mi}$ upstream from bridge on U.S. Highway 69 , and $4.6 \mathrm{mi}$ northwest of Indianola.

DRAINAGE AREA. $--503 \mathrm{mi}^{2}$.

PERIOD OF RECORD.--March 1940 to current year.

REVISED RECORDS.--WSP 1438: Drainage area. WSP 1508: 1940 (M), 1941, 1944, 1946, 1949 (M).

GAGE.--Water-stage recorder. Datum of gage is $776.15 \mathrm{ft}$ above NGvD (0.S. Army Corps of Engineers bench mark). Prior to June 11, 1946, June 9, 1947, to Nov, 23, 1948, and Sept. 8, 1951, to Oct. 30, 1952, nonrecording gage and June 11 , 1946 , to June 8,1947 (destroyed by flood), Nov, 24, 1948, to Sept. 7 , 1951, Sept. 1 , 1952, to Sept. 30, 1962, water-stage recorder at site $1.6 \mathrm{mi}$ downstream at datum $2.81 \mathrm{ft} 10 \mathrm{wer}$.

REMARKS.--Estimated daily discharges: Dec. 5-28, Jan. 1 to Feb. 23 and July 4-8. Records good except those for estimated discharges, which are poor. U.S. Army Corps of Engineers Data Collection Platform at station.

AVERAGE DISCHARGE, --45 years, $260 \mathrm{ft} / \mathrm{s}, 7.02 \mathrm{in} / \mathrm{yr}, 188,400 \mathrm{acre}-\mathrm{ft} / \mathrm{yr}$.

EXTREMES FOR PERIOD OF RECORD.--Maximum discharge, $34,000 \mathrm{ft} / \mathrm{s}$ June 13,1947 , gage heights: $26.40 \mathrm{ft}$, from floodmark, former site and datum; $28.27 \mathrm{ft}$, from floodmark, present site and datum; minimum daily, 0.11 ft/s JuIy 2, 1977.

EXTREMES FOR CURRENT YEAR.--Peak discharges greater than base of 4,500 $\mathrm{ft}^{2} / \mathrm{s}$ and maximum (*):

\begin{tabular}{|c|c|c|c|c|c|c|}
\hline $\begin{array}{l}\text { Date } \\
\text { Feb. } 21\end{array}$ & $\begin{array}{l}\text { Time } \\
\text { I430 }\end{array}$ & $\begin{array}{l}\text { Discharge } \\
\left(\mathrm{ft}^{3} / \mathrm{s}\right) \\
\text { ice jam }\end{array}$ & $\begin{array}{c}\text { Gage height } \\
(\mathrm{ft}) \\
* 15.97\end{array}$ & $\begin{array}{l}\text { Date } \\
\text { June } 24\end{array}$ & $\begin{array}{l}\text { Time } \\
0330\end{array}$ & $\begin{array}{c}\text { Gage height } \\
(f t) \\
15.09\end{array}$ \\
\hline
\end{tabular}

Minimum discharge, $5.0 \mathrm{ft} / \mathrm{s}$ sept. 20 .

DISCHARGE, IN CUBIC FEET PER SECOND, WATER YEAR OCTOBER 1984 TO SEPTEMBER 1985 MEAN VALUES

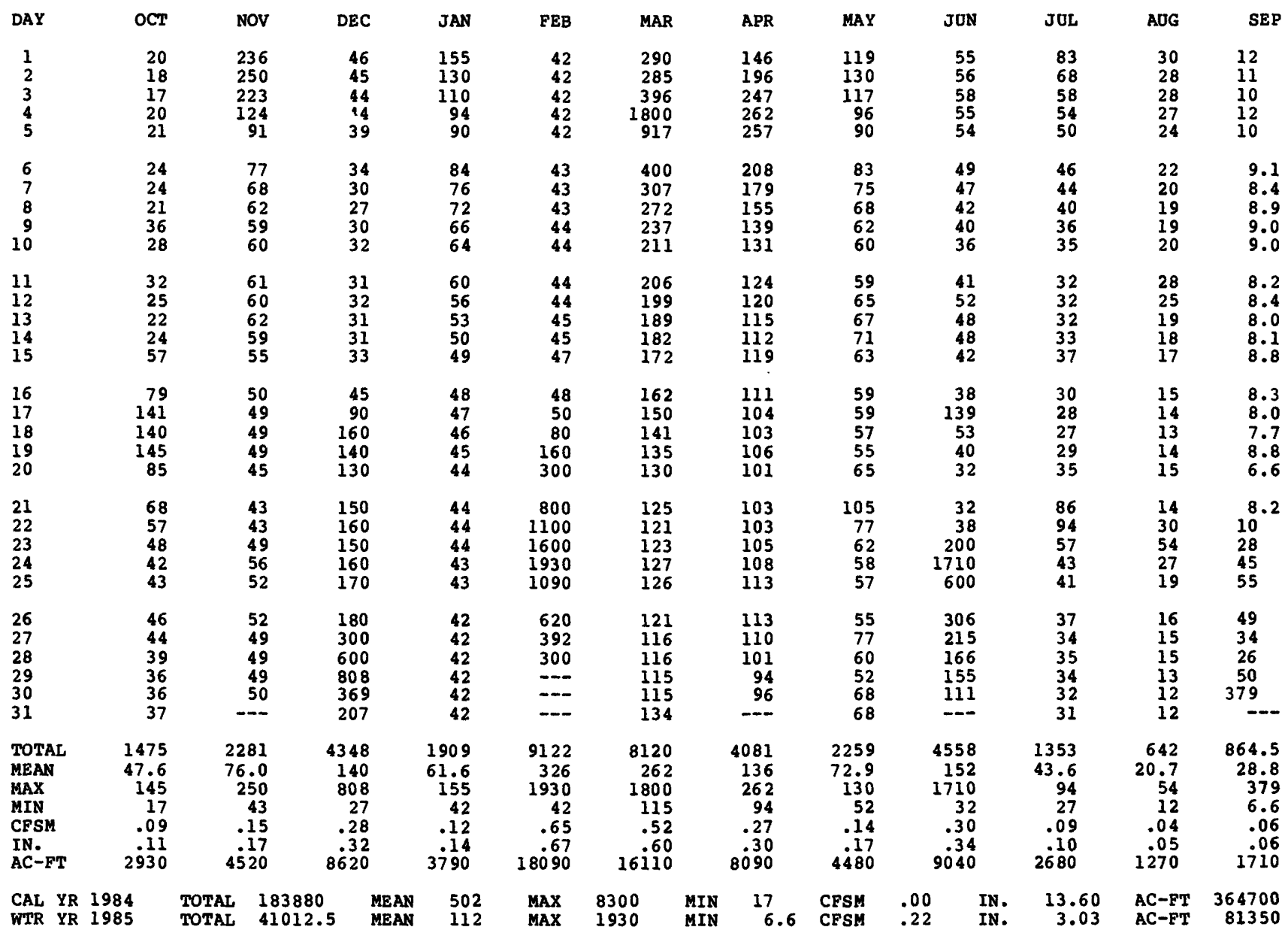


05487470 SOUTH RIVER NEAR ACKWORTH, TA

LOCATION.--Lat $41^{\circ} 20^{\prime} 14^{\prime \prime}$, long $93^{\circ} 29^{\prime} 10^{\prime}$, in SEl/4 SEl/4 sec.34, T. 76 N., R.23 W., Warren County, Hyarologic Unit 07100008 , on right bank $15 \mathrm{ft}$ downstream from bridge on county highway, $0.5 \mathrm{mi}$ downstream from Otter Creek, and $2.2 \mathrm{mi}$ southwest of Ackworth.

DRAINAGE AREA. $--460 \mathrm{mi}$.

PERIOD OF RECORD.--February 1940 to current year.

REVISED RECORDS.--WSP 1438: Drainage area. WSP 1508: 1941, 1945 (M), 1946.

GAGE.-Water-stage recorder. Datum of gage is $769.97 \mathrm{ft}$ above NGVD. Prior to June 12 , 1946 , nonrecording gage, June 13, 1946, to Apr. 13, 1960, water-stage recorder, and Apr. 14, 1960, to Sept. 30, 1961, gage, all at site $4.0 \mathrm{mi}$ downstream at datum $8.06 \mathrm{ft}$ lower.

REMARRs.--Estimated daily discharges: Nov, 8-19, Dec. 3, 7-28, Jan. 1 to Feb. 28, June 1-18. Records good except those for estimated discharges, which are poor. U.s. Army Corps of Engineers Data Collection platform at station.

AVERAGE DISCHARGE. --45 years, $246 \mathrm{ft} / \mathrm{s}, 7.26 \mathrm{in} / \mathrm{yr}^{\prime}, 178,200 \mathrm{acre}-\mathrm{ft} / \mathrm{yr}$.

EXTREMES FOR PERIOD OF RECORD.--Maximum discharge, 34,000 ft'/s June 5, 1947, gage height, 24.60 ft, site and datum then in use; maximum gage height, $32.85 \mathrm{ft}$ July 5, 1981; no flow Sept. ig to Oct. i3, 1956.

EXTREMES OUTSIDE PERIOD OF RECORD.--Flood in June 1930 reached a stage of $24.5 \mathrm{ft}$, from information by local residents, discharge, about $30,000 \mathrm{ft} / \mathrm{s}$, at site $4.0 \mathrm{mi}$ downstream.

EXTREMES FOR CURRENT YEAR.--Peak discharges greater than base of $5,000 \mathrm{ft} / \mathrm{s}$ and maximum (*):

\begin{tabular}{|c|c|c|c|}
\hline ate 24 & $\begin{array}{l}\text { Time } \\
0045\end{array}$ & $\begin{array}{c}\text { Discharge } \\
\left(f t^{2} / \mathrm{s}\right) \\
* 5,700\end{array}$ & $\begin{array}{c}\text { Gage height } \\
\text { (ft) } \\
\star 18.08\end{array}$ \\
\hline
\end{tabular}

Minimum daily discharge, $2.7 \mathrm{ft} / \mathrm{s}$ June 13.

DISCBARGE, IN CUBIC FEET PER SECOND, WATER YEAR OCTOBER 1984 TO SEPTEMBER 1985

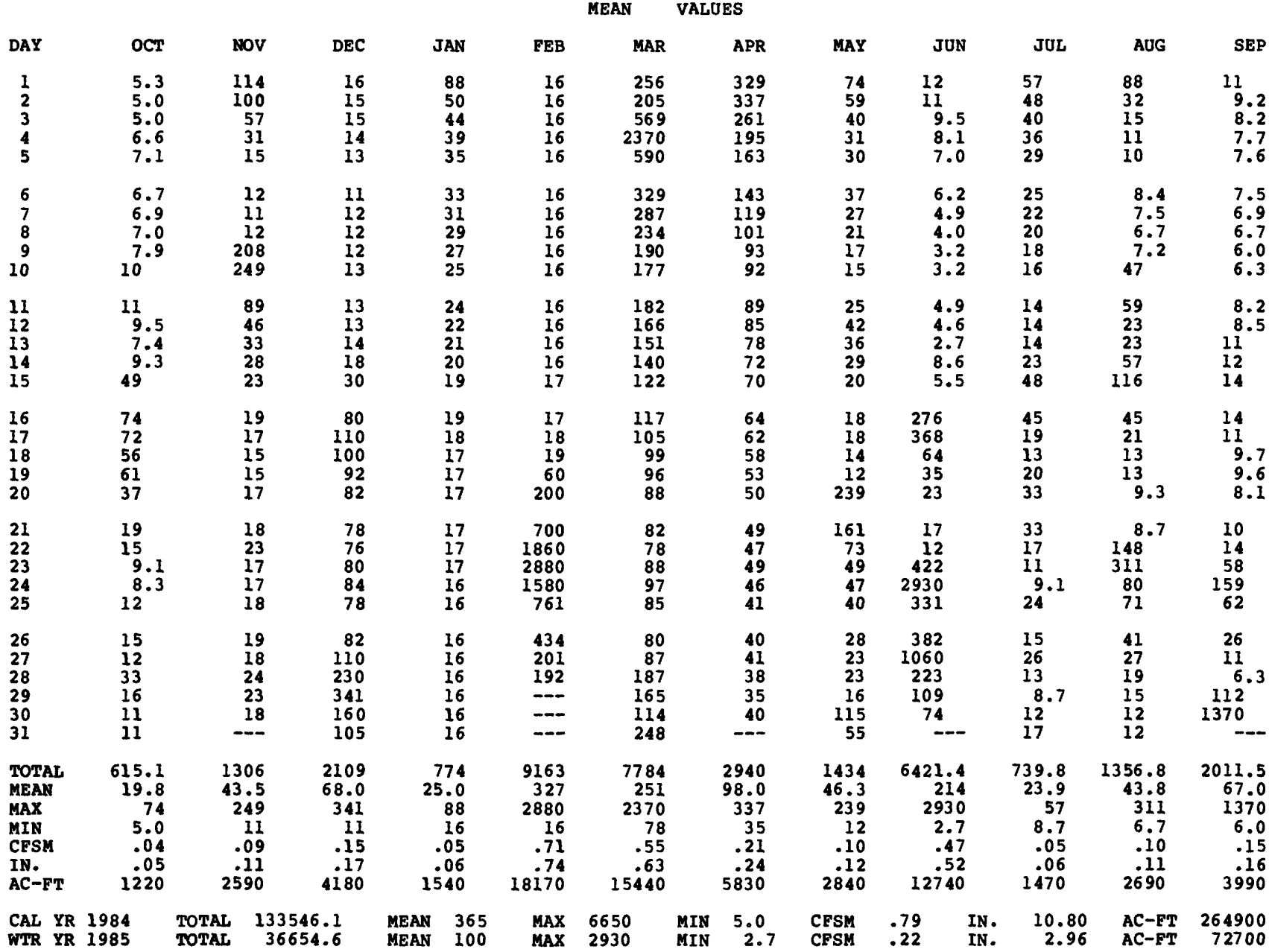


LOCATION.-- Lat $41^{\circ} 14^{\prime} 41^{\prime \prime}$, long $93^{\circ} 16^{\prime} 08^{\prime \prime}$, in Nw1/4 Nwl/4 sec.3, T.74 N., R.21 W., Marion County, Hydrologic Unit 07100008 , on left bank $15 \mathrm{ft}$ downstream from bridge on county highway, 0.5 mi downstream from Kirk Branch, and $1.7 \mathrm{mi}$ nor thwest of Dallas.

DRAINAGE AREA. $--342 \mathrm{mi}^{2}$.

PERIOD OF RECORD.--October 1962 to current year.

GAGE.--Water-stage recorder. Datum of gage is $759.21 \mathrm{ft}$ above NGVD.

REMARKs.--Estimated daily discharges: Oct. 1-7, Dec, 3-10, 13, 19, 22, Jan. 1 to Feb. 23, and Mar. 4. Records good except those for estimated discharges, which are poor. U.s. Army Corps of Engineers Data Collection Platform at station.

COOPERATION.--One discharge measurement provided by U.S. Army Corps of Engineers.

AVERAGE DISCHARGE. - -23 years, $203 \mathrm{ft} / \mathrm{s}, 8.06 \mathrm{in} / \mathrm{yr}, 147,100$ acre-ft/yr; median of yearly mean discharges, 160 $\mathrm{ft}^{2} / \mathrm{s}, 6.4 \mathrm{in} / \mathrm{yr}, 116,000$ acre-ft/yr.

EXTREMES FOR PERIOD OF RECORD.--Maximum discharge, 37,300 ft/s July 16, 1982, gage height, 33.45 ft; minimum daily, $0.07 \mathrm{ft}^{\prime} / \mathrm{s}$ Sept. $29,1968$.

EXTREMES OUTSIDE PERIOD OF RECORD.--Flood of June 11, 1962, reached a stage of 28.87 ft, from floodmark, discharge, about $12,000 \mathrm{ft} / \mathrm{s}$. Flood of June 6,1947 , may have been slightly higher.

EXTREMES FOR CURRENT YEAR.--Peak discharges greater than base of $3,000 \mathrm{ft}^{2} / \mathrm{s}$ and maximum ( $*$ ):

\begin{tabular}{|c|c|c|c|c|c|c|c|}
\hline $\begin{array}{l}\text { Date } \\
\text { Feb. } 21 \\
\text { Mar. } 4\end{array}$ & $\begin{array}{l}\text { Time } \\
1745 \\
1000\end{array}$ & $\begin{array}{c}\text { Discharge } \\
\left(\mathrm{ft} \mathrm{t}^{2} / \mathrm{s}\right) \\
\text { ice jam } \\
* 3,720\end{array}$ & $\begin{array}{c}\text { Gage height } \\
\text { (ft) } \\
* 17.53 \\
15.99\end{array}$ & $\begin{array}{l}\text { Date } \\
\text { June } 24\end{array}$ & $\begin{array}{l}\text { Time } \\
0215\end{array}$ & $\begin{array}{c}\text { Discharge } \\
\left(f t^{2} / s\right) \\
3,150\end{array}$ & $\begin{array}{c}\text { Gage height } \\
\text { (ft) } \\
14.91\end{array}$ \\
\hline
\end{tabular}

Minimum daily discharge, $1.2 \mathrm{ft}^{2} / \mathrm{s}$ sept. 17-19.

DISCHARGE, IN CUBIC FEET PER SECOND, WATER YEAR OCTOBER 1984 TO SEPTEMBER 1985 MEAN VALUES

\begin{tabular}{|c|c|c|c|c|c|c|c|c|c|c|c|c|c|c|}
\hline DAY & OCT & NOV & DEC & JAN & FEB & MAR & & APR & MAY & JUN & & JUL & AUG & SEP \\
\hline $\begin{array}{l}1 \\
2 \\
3 \\
4 \\
5\end{array}$ & $\begin{array}{l}20 \\
15 \\
11 \\
10 \\
11\end{array}$ & $\begin{array}{r}185 \\
132 \\
68 \\
47 \\
26\end{array}$ & $\begin{array}{l}6.1 \\
5.9 \\
5.0 \\
4.0 \\
3.5\end{array}$ & $\begin{array}{l}54 \\
40 \\
30 \\
21 \\
19\end{array}$ & $\begin{array}{l}8.9 \\
8.9 \\
9.0 \\
9.0 \\
9.0\end{array}$ & $\begin{array}{r}236 \\
193 \\
880 \\
3280 \\
1240\end{array}$ & & $\begin{array}{l}398 \\
319 \\
222 \\
162 \\
132\end{array}$ & $\begin{array}{l}39 \\
35 \\
29 \\
22 \\
17\end{array}$ & $\begin{array}{l}7.9 \\
5.7 \\
4.2 \\
3.6 \\
4.4\end{array}$ & & $\begin{array}{l}16 \\
12 \\
10 \\
8.0 \\
6.0\end{array}$ & $\begin{array}{r}843 \\
112 \\
47 \\
27 \\
19\end{array}$ & $\begin{array}{r}10 \\
8.6 \\
7.6 \\
6.6 \\
5.2\end{array}$ \\
\hline $\begin{array}{r}6 \\
7 \\
8 \\
9 \\
10\end{array}$ & $\begin{array}{l}10 \\
9.6 \\
9.4 \\
9.5 \\
12\end{array}$ & $\begin{array}{c}17 \\
12 \\
7.8 \\
250 \\
105\end{array}$ & $\begin{array}{l}3.2 \\
3.5 \\
3.6 \\
3.9 \\
4.1\end{array}$ & $\begin{array}{l}17 \\
16 \\
15 \\
14 \\
13\end{array}$ & $\begin{array}{l}9.0 \\
9.0 \\
9.0 \\
9.0 \\
9.0\end{array}$ & $\begin{array}{l}356 \\
262 \\
210 \\
163 \\
144\end{array}$ & & $\begin{array}{r}118 \\
95 \\
78 \\
68 \\
66\end{array}$ & $\begin{array}{c}17 \\
14 \\
12 \\
9.0 \\
7.6\end{array}$ & $\begin{array}{l}4.1 \\
3.8 \\
3.2 \\
2.3 \\
2.7\end{array}$ & & $\begin{array}{l}4.8 \\
4.3 \\
3.9 \\
3.9 \\
3.5\end{array}$ & $\begin{array}{l}15 \\
11 \\
7.5 \\
6.4 \\
54\end{array}$ & $\begin{array}{l}4.9 \\
3.7 \\
2.6 \\
2.1 \\
2.0\end{array}$ \\
\hline $\begin{array}{l}11 \\
12 \\
13 \\
14 \\
15\end{array}$ & $\begin{array}{r}25 \\
11 \\
7.2 \\
24 \\
103\end{array}$ & $\begin{array}{l}56 \\
33 \\
25 \\
25 \\
19\end{array}$ & $\begin{array}{l}4.3 \\
18 \\
19 \\
20 \\
53\end{array}$ & $\begin{array}{l}12 \\
12 \\
11 \\
11 \\
10\end{array}$ & $\begin{array}{l}9.0 \\
9.0 \\
9.0 \\
9.2 \\
9.6\end{array}$ & $\begin{array}{r}147 \\
136 \\
119 \\
103 \\
87\end{array}$ & & $\begin{array}{l}66 \\
63 \\
58 \\
56 \\
55\end{array}$ & $\begin{array}{l}21 \\
50 \\
29 \\
22 \\
20\end{array}$ & $\begin{array}{l}5.3 \\
6.2 \\
3.0 \\
73 \\
24\end{array}$ & & $\begin{array}{l}3.2 \\
2.9 \\
3.4 \\
12 \\
23\end{array}$ & $\begin{array}{r}187 \\
65 \\
91 \\
54 \\
138\end{array}$ & $\begin{array}{l}2.0 \\
1.8 \\
1.8 \\
1.7 \\
1.5\end{array}$ \\
\hline $\begin{array}{l}16 \\
17 \\
18 \\
19 \\
20\end{array}$ & $\begin{array}{r}155 \\
115 \\
239 \\
167 \\
78\end{array}$ & $\begin{array}{l}11 \\
11 \\
13 \\
11 \\
8.2\end{array}$ & $\begin{array}{r}421 \\
202 \\
103 \\
94 \\
82\end{array}$ & $\begin{array}{l}10 \\
9.8 \\
9.6 \\
9.4 \\
9.2\end{array}$ & $\begin{array}{r}11 \\
13 \\
25 \\
100 \\
200\end{array}$ & $\begin{array}{l}82 \\
71 \\
66 \\
65 \\
58\end{array}$ & & $\begin{array}{l}51 \\
49 \\
52 \\
39 \\
36\end{array}$ & $\begin{array}{c}15 \\
14 \\
13 \\
9.7 \\
143\end{array}$ & $\begin{array}{r}271 \\
727 \\
59 \\
26 \\
16\end{array}$ & & $\begin{array}{l}35 \\
30 \\
13 \\
10 \\
11\end{array}$ & $\begin{array}{r}117 \\
36 \\
18 \\
12 \\
7.5\end{array}$ & $\begin{array}{l}1.4 \\
1.2 \\
1.2 \\
1.2 \\
1.4\end{array}$ \\
\hline $\begin{array}{l}21 \\
22 \\
23 \\
24 \\
25\end{array}$ & $\begin{array}{l}37 \\
22 \\
15 \\
7.1 \\
8.9\end{array}$ & $\begin{array}{r}5.5 \\
5.6 \\
7.6 \\
8.2 \\
10\end{array}$ & $\begin{array}{l}75 \\
68 \\
62 \\
49 \\
41\end{array}$ & $\begin{array}{l}9.2 \\
9.2 \\
8.8 \\
8.7 \\
8.8\end{array}$ & $\begin{array}{r}600 \\
900 \\
1300 \\
1840 \\
1210\end{array}$ & $\begin{array}{l}54 \\
51 \\
56 \\
59 \\
53\end{array}$ & & $\begin{array}{l}34 \\
34 \\
39 \\
35 \\
29\end{array}$ & $\begin{array}{l}50 \\
26 \\
18 \\
21 \\
17\end{array}$ & $\begin{array}{r}12 \\
44 \\
159 \\
1910 \\
320\end{array}$ & & $\begin{array}{l}18 \\
20 \\
10 \\
5.7 \\
38\end{array}$ & $\begin{array}{r}5.2 \\
115 \\
838 \\
259 \\
85\end{array}$ & $\begin{array}{r}2.0 \\
2.9 \\
648 \\
706 \\
155\end{array}$ \\
\hline $\begin{array}{l}26 \\
27 \\
28 \\
29 \\
30 \\
31\end{array}$ & $\begin{array}{l}13 \\
11 \\
24 \\
9.0 \\
7.2 \\
4.8\end{array}$ & $\begin{array}{l}11 \\
11 \\
12 \\
11 \\
9.5 \\
--0\end{array}$ & $\begin{array}{r}135 \\
342 \\
368 \\
353 \\
159 \\
76\end{array}$ & $\begin{array}{l}8.8 \\
8.7 \\
8.8 \\
8.8 \\
8.7 \\
8.8\end{array}$ & $\begin{array}{r}734 \\
337 \\
213 \\
- \\
-\end{array}$ & $\begin{array}{r}50 \\
57 \\
116 \\
92 \\
87 \\
261\end{array}$ & & $\begin{array}{r}27 \\
26 \\
25 \\
24 \\
24 \\
--\end{array}$ & $\begin{array}{l}13 \\
11 \\
10 \\
7.9 \\
53 \\
19\end{array}$ & $\begin{array}{r}95 \\
114 \\
56 \\
33 \\
22 \\
-\end{array}$ & & $\begin{array}{c}42 \\
42 \\
17 \\
8.3 \\
8.7 \\
506\end{array}$ & $\begin{array}{l}47 \\
30 \\
21 \\
16 \\
13 \\
12\end{array}$ & $\begin{array}{r}74 \\
41 \\
26 \\
199 \\
2420 \\
\end{array}$ \\
\hline $\begin{array}{l}\text { TOTAL } \\
\text { MEAN } \\
\text { MAX } \\
\text { MIN } \\
\text { CFSM } \\
\text { IN. } \\
\text { AC-FT }\end{array}$ & $\begin{array}{r}1200.7 \\
38.7 \\
239 \\
4.8 \\
.11 \\
.13 \\
2380\end{array}$ & $\begin{array}{r}1153.4 \\
38.4 \\
250 \\
5.5 \\
.11 \\
.13 \\
2290\end{array}$ & $\begin{array}{r}2787.1 \\
89.9 \\
421 \\
3.2 \\
.26 \\
.30 \\
5530\end{array}$ & $\begin{array}{r}440.3 \\
14.2 \\
54 \\
8.7 \\
.04 \\
.05 \\
873\end{array}$ & $\begin{array}{r}7618.6 \\
272 \\
1840 \\
8.9 \\
.80 \\
.83 \\
15110\end{array}$ & $\begin{array}{r}8834 \\
285 \\
3280 \\
50 \\
.83 \\
.96 \\
17520\end{array}$ & & $\begin{array}{r}2480 \\
82.7 \\
398 \\
24 \\
.24 \\
.27 \\
4920\end{array}$ & $\begin{array}{r}784.2 \\
25.3 \\
143 \\
7.6 \\
.07 \\
.09 \\
1560\end{array}$ & $\begin{array}{r}4017.4 \\
134 \\
1910 \\
2.3 \\
.39 \\
.44 \\
7970\end{array}$ & & $\begin{array}{r}931.6 \\
30.1 \\
506 \\
2.9 \\
.09 \\
180 \\
1850\end{array}$ & $\begin{array}{r}3308.6 \\
107 \\
843 \\
5.2 \\
.31 \\
.36 \\
6560\end{array}$ & $\begin{array}{r}4342.4 \\
145 \\
2420 \\
1.2 \\
.42 \\
.47 \\
8610\end{array}$ \\
\hline $\begin{array}{ll}\text { CAL } & \text { YR } \\
\text { WYR } & \text { YR }\end{array}$ & $\begin{array}{l}1984 \\
1985\end{array}$ & $\begin{array}{rr}\text { OOTAL } & 10 \\
\text { OTAL } & 3\end{array}$ & $\begin{array}{l}30.7 \\
98.3\end{array}$ & $\begin{array}{ll}\text { MEAN } & 294 \\
\text { MEAN } & 104\end{array}$ & $\begin{array}{l}\text { MAX } \\
\text { MAX }\end{array}$ & $\begin{array}{l}4420 \\
3280\end{array}$ & $\begin{array}{l}\text { MIN } \\
\text { MIN }\end{array}$ & $\begin{array}{l}2.3 \\
1.2\end{array}$ & $\begin{array}{l}\text { CEsM } \\
\text { CPSM }\end{array}$ & $\begin{array}{l}.86 \\
.30\end{array}$ & $\begin{array}{l}\text { IN. } \\
\text { IN. }\end{array}$ & $\begin{array}{r}11.69 \\
4.12\end{array}$ & $\begin{array}{l}A C-E T \\
A C-F T\end{array}$ & $\begin{array}{r}213100 \\
75170\end{array}$ \\
\hline
\end{tabular}


LOCATION.--Lat $41^{\circ} 22^{\prime} 11^{\prime \prime}$, Iong $92^{\circ} 58^{\prime} 48^{\prime \prime}$, in NEl/4 NWl/4 sec.19, T.76 N., R.18 W., Marion County, Hydrologic Unit 07100008 , at outlet works near right end of Red Rock Dam on Des Moines River, $1.4 \mathrm{mi}$ upstream from Lake Creek, $4.5 \mathrm{mi}$ southwest of Pella and at mile 142.3 .

DRAINAGE AREA. $--12,323 \mathrm{mi}^{2}$.

PERIOD OF RECORD.--March 1969 to current year.

GAGE.--Water-stage recorder. Datum of gage is at NGVD (levels by U.S. Army Corps of Engineers).

REMARKS.--Reservoir is formed by earthfill dam completed in 1969. Storage began in March 1969. Releases controlled through 14 concrete conduits extending through the concrete ogee spillway section into the stilling basin. Inlet invert elevation at $690 \mathrm{ft}$ above NGVD. Maximum design discharge through the conduits is 37,500 $\mathrm{ft}^{3 / \mathrm{s}}$ but normal flood control operation limits maximum outflow to $30,000 \mathrm{ft} / \mathrm{s}$. Spillway section consists of 5 tainter gates, $41 \mathrm{ft}$ wide and $46 \mathrm{ft}$ high, on concrete ogee crest at elevation $736 \mathrm{ft}$. The storage capacity of the reservoir at full flood-control pool level, $780 \mathrm{ft}$, is $1,790,000$ acre-ft, surface are, 65,500 acres and that of conservation pool level, 728 feet, is 89,000 acre-feet, surface area, 9,980 acres. Reservoir is used for flood control, low-flow augmentation, conservation and recreation. Normal operation will maintain an elevation of $728 \mathrm{ft}$ with minimum release of $300 \mathrm{ft}^{3} / \mathrm{s}$ and maximum release of $30,000 \mathrm{ft} / \mathrm{s}$ during the nongrowing season, providing discharges at Ottumwa and Keosauqua do not exceed $30,000 \mathrm{ft}^{3 / \mathrm{s}}$ and $35,000 \mathrm{ft} / \mathrm{s}$ respectively.

COOPERATION.--Records provided by U.S. Army Corps of Engineers.

EXTREMES FOR PERIOD OF RECORD.--Maximum daily contents, 1,765,000 acre-ft June 25, 1984; maximum elevation, $779.61 \mathrm{ft}$ June 25, $1984 ;$ minimum daily contents, 43,900 acre-ft May 24, 1985 , minimum elevation, 719.68 ft Feb. 17, 1977 .

EXTREMES FOR CURRENT YEAR.-Maximum daily contents, 82,600 acre-ft Mar. 6; maximum elevation, 733.89 ft Mar. 7, minimum daily contents, 43,900 acre-ft May 24; minimum elevation, 727.18 ft Jan. 2 .

Capacity table (elevation, in feet, and contents, in acre-feet)

$\begin{array}{rrrrrrr}722 & 45,600 & 740 & 256,000 & 760 & 789,000 \\ 725 & 63,400 & 745 & 357,000 & 765 & 983,000 \\ 730 & 110,000 & 750 & 479,000 & 770 & 1,213,000 \\ 735 & 174,000 & 755 & 623,000 & & \end{array}$

RESERVOIR STORAGE (AC-FT), WATER YEAR OCTOBER 1984 TO SEPTEMBER 1985 INSTANTANEOUS OBSERVATIONS AT 2400

\begin{tabular}{|c|c|c|c|c|c|c|c|c|c|c|c|c|}
\hline DAY & OCT & NOV & DEC & JAN & FEB & MAR & APR & MAY & JUN & JUL & AUG & SEP \\
\hline $\begin{array}{l}1 \\
2 \\
3 \\
4 \\
5\end{array}$ & $\begin{array}{l}66200 \\
66600 \\
66700 \\
67000 \\
67100\end{array}$ & $\begin{array}{l}64300 \\
64600 \\
65200 \\
65400 \\
64900\end{array}$ & $\begin{array}{l}64500 \\
64800 \\
64600 \\
64500 \\
64500\end{array}$ & $\begin{array}{l}48300 \\
46500 \\
48400 \\
48800 \\
47400\end{array}$ & $\begin{array}{l}49000 \\
49500 \\
49400 \\
48900 \\
48800\end{array}$ & $\begin{array}{l}49400 \\
48800 \\
51000 \\
70000 \\
79700\end{array}$ & $\begin{array}{l}48100 \\
48000 \\
47600 \\
47200 \\
46900\end{array}$ & $\begin{array}{l}47100 \\
47700 \\
46300 \\
46400 \\
46900\end{array}$ & $\begin{array}{l}45800 \\
45800 \\
45800 \\
45700 \\
45800\end{array}$ & $\begin{array}{l}47500 \\
47000 \\
46100 \\
46500 \\
47400\end{array}$ & $\begin{array}{l}48200 \\
47800 \\
47000 \\
46700 \\
46700\end{array}$ & $\begin{array}{l}58000 \\
58400 \\
58700 \\
58500 \\
58600\end{array}$ \\
\hline $\begin{array}{r}6 \\
7 \\
8 \\
9 \\
10\end{array}$ & $\begin{array}{l}67500 \\
67600 \\
67100 \\
66600 \\
66200\end{array}$ & $\begin{array}{l}64900 \\
65300 \\
65600 \\
66200 \\
66200\end{array}$ & $\begin{array}{l}64300 \\
64900 \\
66000 \\
66000 \\
64400\end{array}$ & $\begin{array}{l}49300 \\
51000 \\
50800 \\
49500 \\
49700\end{array}$ & $\begin{array}{l}48900 \\
48900 \\
48900 \\
48900 \\
48900\end{array}$ & $\begin{array}{l}82600 \\
79100 \\
69000 \\
59700 \\
54600\end{array}$ & $\begin{array}{l}46400 \\
47100 \\
46200 \\
44900 \\
45300\end{array}$ & $\begin{array}{l}45400 \\
45400 \\
45800 \\
47000 \\
47600\end{array}$ & $\begin{array}{l}45900 \\
46200 \\
46400 \\
46200 \\
46200\end{array}$ & $\begin{array}{l}47600 \\
47600 \\
47200 \\
47400 \\
47600\end{array}$ & $\begin{array}{l}46700 \\
46600 \\
46700 \\
47000 \\
47000\end{array}$ & $\begin{array}{l}58800 \\
58300 \\
58400 \\
58000 \\
57700\end{array}$ \\
\hline $\begin{array}{l}11 \\
12 \\
13 \\
14 \\
15\end{array}$ & $\begin{array}{l}66200 \\
66000 \\
65600 \\
65200 \\
66100\end{array}$ & $\begin{array}{l}65700 \\
65300 \\
64800 \\
65000 \\
65000\end{array}$ & $\begin{array}{l}62400 \\
60300 \\
57900 \\
56200 \\
54700\end{array}$ & $\begin{array}{l}50800 \\
51100 \\
51000 \\
50700 \\
50200\end{array}$ & $\begin{array}{l}49000 \\
49000 \\
49000 \\
48900 \\
48800\end{array}$ & $\begin{array}{l}52200 \\
51900 \\
51300 \\
49900 \\
50200\end{array}$ & $\begin{array}{l}45300 \\
45800 \\
46400 \\
46200 \\
45900\end{array}$ & $\begin{array}{l}47600 \\
47000 \\
46400 \\
46800 \\
47100\end{array}$ & $\begin{array}{l}46500 \\
46500 \\
46300 \\
46500 \\
47100\end{array}$ & $\begin{array}{l}47800 \\
47800 \\
47800 \\
48100 \\
48300\end{array}$ & $\begin{array}{l}47200 \\
47800 \\
48000 \\
47800 \\
47600\end{array}$ & $\begin{array}{l}58000 \\
58400 \\
58000 \\
58100 \\
58200\end{array}$ \\
\hline $\begin{array}{l}16 \\
17 \\
18 \\
19 \\
20\end{array}$ & $\begin{array}{l}67100 \\
66900 \\
69000 \\
69100 \\
68000\end{array}$ & $\begin{array}{l}64700 \\
64700 \\
64800 \\
64700 \\
64400\end{array}$ & $\begin{array}{l}55300 \\
56300 \\
55200 \\
54000 \\
53400\end{array}$ & $\begin{array}{l}49600 \\
49400 \\
49400 \\
49900 \\
50100\end{array}$ & $\begin{array}{l}48900 \\
48800 \\
49100 \\
49600 \\
49700\end{array}$ & $\begin{array}{l}50700 \\
50200 \\
49200 \\
48700 \\
48400\end{array}$ & $\begin{array}{l}45600 \\
46300 \\
46500 \\
46300 \\
46200\end{array}$ & $\begin{array}{l}45900 \\
45500 \\
46600 \\
47600 \\
46900\end{array}$ & $\begin{array}{l}47300 \\
47600 \\
47400 \\
46900 \\
46600\end{array}$ & $\begin{array}{l}48400 \\
48400 \\
48200 \\
48100 \\
47700\end{array}$ & $\begin{array}{l}47600 \\
47600 \\
47500 \\
47500 \\
47400\end{array}$ & $\begin{array}{l}58000 \\
57600 \\
57300 \\
57700 \\
58200\end{array}$ \\
\hline $\begin{array}{l}21 \\
22 \\
23 \\
24 \\
25\end{array}$ & $\begin{array}{l}66500 \\
64500 \\
64100 \\
63800 \\
64300\end{array}$ & $\begin{array}{l}64600 \\
65000 \\
65200 \\
65400 \\
65600\end{array}$ & $\begin{array}{l}55400 \\
55600 \\
55500 \\
53600 \\
49800\end{array}$ & $\begin{array}{l}50100 \\
50100 \\
50100 \\
50200 \\
50200\end{array}$ & $\begin{array}{l}57800 \\
67400 \\
69500 \\
71600 \\
64600\end{array}$ & $\begin{array}{l}48000 \\
47700 \\
47500 \\
47300 \\
47800\end{array}$ & $\begin{array}{l}45900 \\
46100 \\
46400 \\
45600 \\
45900\end{array}$ & $\begin{array}{l}46000 \\
45000 \\
44100 \\
43900 \\
45200\end{array}$ & $\begin{array}{l}47100 \\
47300 \\
48100 \\
50700 \\
48600\end{array}$ & $\begin{array}{l}47400 \\
47300 \\
47400 \\
48000 \\
49000\end{array}$ & $\begin{array}{l}47400 \\
48300 \\
49700 \\
51300 \\
53000\end{array}$ & $\begin{array}{l}57800 \\
57500 \\
58300 \\
59500 \\
60100\end{array}$ \\
\hline $\begin{array}{l}26 \\
27 \\
28 \\
29 \\
30 \\
31\end{array}$ & $\begin{array}{l}64300 \\
64500 \\
64300 \\
63700 \\
63500 \\
64200\end{array}$ & $\begin{array}{r}65800 \\
65600 \\
65100 \\
64900 \\
64800 \\
-\end{array}$ & $\begin{array}{l}49600 \\
52600 \\
56400 \\
56200 \\
54500 \\
52900\end{array}$ & $\begin{array}{l}50100 \\
50100 \\
50100 \\
50000 \\
50000 \\
49000\end{array}$ & $\begin{array}{r}59400 \\
54700 \\
50700 \\
- \\
-\end{array}$ & $\begin{array}{l}49000 \\
48400 \\
48400 \\
47700 \\
47500 \\
47800\end{array}$ & $\begin{array}{l}47100 \\
46200 \\
45200 \\
46800 \\
47500 \\
---\end{array}$ & $\begin{array}{l}47200 \\
47500 \\
47200 \\
46900 \\
46500 \\
45900\end{array}$ & $\begin{array}{r}48500 \\
48400 \\
46500 \\
46700 \\
47500 \\
--\end{array}$ & $\begin{array}{l}48500 \\
48100 \\
47800 \\
47600 \\
47900 \\
47800\end{array}$ & $\begin{array}{l}54600 \\
55800 \\
56600 \\
57400 \\
57800 \\
57800\end{array}$ & $\begin{array}{r}59000 \\
57600 \\
57200 \\
58800 \\
60800 \\
-0-\end{array}$ \\
\hline $\begin{array}{l}\text { MEAN } \\
\text { MAX } \\
\text { MIN }\end{array}$ & $\begin{array}{l}66000 \\
69100 \\
63500\end{array}$ & $\begin{array}{l}65100 \\
66200 \\
64300\end{array}$ & $\begin{array}{l}58300 \\
66000 \\
49600\end{array}$ & $\begin{array}{l}49700 \\
51100 \\
46500\end{array}$ & $\begin{array}{l}52700 \\
71600 \\
48800\end{array}$ & $\begin{array}{l}54000 \\
82600 \\
47300\end{array}$ & $\begin{array}{l}46400 \\
48100 \\
44900\end{array}$ & $\begin{array}{l}46400 \\
47700 \\
43900\end{array}$ & $\begin{array}{l}46900 \\
50700 \\
45700\end{array}$ & $\begin{array}{l}47700 \\
49000 \\
46100\end{array}$ & $\begin{array}{l}49600 \\
57800 \\
46600\end{array}$ & $\begin{array}{l}58300 \\
60800 \\
57200\end{array}$ \\
\hline
\end{tabular}

CAL YR $1984 \quad$ MEAN $436000 \quad$ MAX $1765000 \quad$ MIN 49600

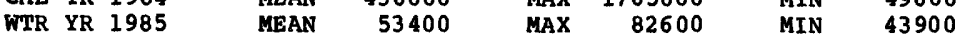


LOCATION.--Lat $41^{\circ} 16^{\prime} 53^{\prime \prime}$, long $92^{\circ} 51^{\prime} 34^{\prime \prime}$, in NW1/4 SEl/4 sec.19, T.75 N., R.17 W., Mahaska County, Hydrologic Unit 07100009 , on $r$ ight bank $250 \mathrm{ft}$ upstream from abandoned Bellefountaine Bridge, $0.5 \mathrm{mi}$ downstream from bridge on old State Highway 92 (now relocated), $0.8 \mathrm{mi}$ east of $T r a c y, 3.1 \mathrm{mi}$ upstream from Cedar Creek, $3.8 \mathrm{mi}$ downstream from bridge on newly located State Highway 92, 6.4 mi downstream from English Creek, and at mile 130.4 .

DRAINAGE AREA. $--12,479 \mathrm{mi}^{2}$.

PERIOD OF RECORD.--March 1920 to current year. Monthly discharge only for some periods, published in wSp 1308 .

REVISED RECORDS.--WSP 1438: Drainage area. WSP 1508: 1920 (M), 1922 (M), 1933.

GAGE.--Water-stage recorder. Datum of gage is $670.91 \mathrm{ft}$ above NGVD. Prior to June 26, 1940 , and June 30 , 1952 , to Nov. 4, 1960, nonrecording gage, and June 27, 1940 , to June 29, 1952, water-8tage recorder, at site 250 ft downstream at same datum.

REMARKS,--Estimated daily discharges: Jan. 12 to Feb. 18. Records good except those for estimated discharges, which are fair. Flow regulated by Lake Red Rock (station 05488100) 11.9 mi upstream, since March 12 . 1969. U.S. Army Corps of Engineers gage-height telemeter and Data Collection platform at station.

COOPERATION.--Five discharge measurements provided by U.s. Army Corps of Englneers.

AVERAGE DISCHARGE. - -65 years, 5,010 $\mathrm{ft}^{2} / \mathrm{s}, 5.45 \mathrm{in} / \mathrm{yr}, 3,630,000$ acre-ft/yr; median of yearly mean discharges $4,160 \mathrm{ft} / \mathrm{s}, 4.5 \mathrm{in} / \mathrm{yr}, 3,010,000 \mathrm{acre}-\mathrm{ft} / \mathrm{yr}$.

EXTREMES FOR PERIOD OF RECORD.- Maximum discharge, 155,000 ft/s, June 14, 1947, gage height, 26.5 ft; minimum daily, $40 \mathrm{ft}^{3} / \mathrm{s}$ Jan. 29 to Feb. $1,1940$.

EXTREMES OUTSIDE PERIOD OF RECORD.--Maximum stage since 1851, that of June 14, 1947. Flood of May 31, 1903, reached a stage of about $25 \mathrm{ft}$, discharge, about $130,000 \mathrm{ft} / \mathrm{s}$. Minimum daily discharge since at least 1910 , that of Jan. 29 to Feb. $1,1940$.

EXTREMES FOR CURRENT YEAR.--Maximum discharge, $19,400 \mathrm{ft} / \mathrm{s}$ Feb. 25, gage height, $11.80 \mathrm{ft}$; minimum daily discharge, $351 \mathrm{ft} / \mathrm{s}$ Aug. 29.

DISCHARGE, IN CUBIC FEET PER SECOND, WATER YEAR OCTOBER 1984 TO SEPTEMBER 1985 MEAN VALUES

\begin{tabular}{|c|c|c|c|c|c|c|c|c|c|c|c|c|}
\hline DAY & OCT & Nov & DEC & JAN & FEB & MAR & APR & MAY & JUN & JUL & AUG & SEP \\
\hline $\begin{array}{l}1 \\
2 \\
3 \\
4 \\
5\end{array}$ & $\begin{array}{l}516 \\
516 \\
555 \\
696 \\
698\end{array}$ & $\begin{array}{l}2830 \\
4090 \\
4110 \\
4150 \\
4200\end{array}$ & $\begin{array}{l}2400 \\
2120 \\
1860 \\
1880 \\
1980\end{array}$ & $\begin{array}{l}8360 \\
7180 \\
3270 \\
3250 \\
4310\end{array}$ & $\begin{array}{l}1800 \\
1500 \\
1700 \\
2000 \\
1800\end{array}$ & $\begin{array}{l}7220 \\
5650 \\
5010 \\
6350 \\
5540\end{array}$ & $\begin{array}{l}5670 \\
6420 \\
6720 \\
6910 \\
7010\end{array}$ & $\begin{array}{r}13300 \\
12500 \\
11400 \\
10400 \\
9200\end{array}$ & $\begin{array}{l}4960 \\
4640 \\
4630 \\
4570 \\
4290\end{array}$ & $\begin{array}{l}3460 \\
3870 \\
3640 \\
3110 \\
2740\end{array}$ & $\begin{array}{r}1280 \\
1280 \\
1270 \\
1180 \\
893\end{array}$ & $\begin{array}{r}795 \\
790 \\
1310 \\
2370 \\
2110\end{array}$ \\
\hline $\begin{array}{r}6 \\
7 \\
8 \\
9 \\
10\end{array}$ & $\begin{array}{r}692 \\
784 \\
1140 \\
1320 \\
1310\end{array}$ & $\begin{array}{l}3750 \\
2780 \\
2760 \\
2990 \\
3050\end{array}$ & $\begin{array}{l}2200 \\
1740 \\
1400 \\
1820 \\
3040\end{array}$ & $\begin{array}{l}3120 \\
2160 \\
4560 \\
5370 \\
4410\end{array}$ & $\begin{array}{l}1500 \\
1400 \\
1400 \\
1350 \\
1300\end{array}$ & $\begin{array}{r}5470 \\
8200 \\
13700 \\
12600 \\
9640\end{array}$ & $\begin{array}{r}7740 \\
8390 \\
9600 \\
10300 \\
9350\end{array}$ & $\begin{array}{l}9180 \\
8740 \\
8170 \\
7790 \\
7220\end{array}$ & $\begin{array}{l}4040 \\
3560 \\
3540 \\
3820 \\
3940\end{array}$ & $\begin{array}{l}2710 \\
2710 \\
2700 \\
2530 \\
2250\end{array}$ & $\begin{array}{l}764 \\
748 \\
691 \\
554 \\
509\end{array}$ & $\begin{array}{l}1520 \\
1740 \\
2400 \\
2920 \\
5380\end{array}$ \\
\hline $\begin{array}{l}11 \\
12 \\
13 \\
14 \\
15\end{array}$ & $\begin{array}{l}1350 \\
1320 \\
1310 \\
1370 \\
1410\end{array}$ & $\begin{array}{l}3430 \\
3420 \\
3400 \\
3260 \\
3290\end{array}$ & $\begin{array}{l}3570 \\
3570 \\
3640 \\
3560 \\
3580\end{array}$ & $\begin{array}{l}2750 \\
2700 \\
2600 \\
2600 \\
2700\end{array}$ & $\begin{array}{l}1300 \\
1300 \\
1300 \\
1300 \\
1300\end{array}$ & $\begin{array}{l}7420 \\
5350 \\
6110 \\
8430 \\
8230\end{array}$ & $\begin{array}{l}9020 \\
8060 \\
7550 \\
6800 \\
6790\end{array}$ & $\begin{array}{l}7260 \\
7210 \\
6920 \\
6510 \\
6470\end{array}$ & $\begin{array}{l}3330 \\
3340 \\
3320 \\
3340 \\
3340\end{array}$ & $\begin{array}{l}2230 \\
2210 \\
2010 \\
1680 \\
1660\end{array}$ & $\begin{array}{l}622 \\
394 \\
453 \\
654 \\
669\end{array}$ & $\begin{array}{l}5550 \\
5710 \\
5940 \\
5080 \\
3470\end{array}$ \\
\hline $\begin{array}{l}16 \\
17 \\
18 \\
19 \\
20\end{array}$ & $\begin{array}{l}1710 \\
2710 \\
3250 \\
3480 \\
4020\end{array}$ & $\begin{array}{l}3750 \\
3550 \\
3170 \\
3150 \\
3150\end{array}$ & $\begin{array}{l}3780 \\
3690 \\
3930 \\
3730 \\
3650\end{array}$ & $\begin{array}{l}2600 \\
2400 \\
2200 \\
2100 \\
2100\end{array}$ & $\begin{array}{l}1300 \\
1300 \\
1300 \\
1330 \\
1930\end{array}$ & $\begin{array}{l}7680 \\
7670 \\
7650 \\
7170 \\
6480\end{array}$ & $\begin{array}{l}6480 \\
5520 \\
4790 \\
5330 \\
5340\end{array}$ & $\begin{array}{l}6460 \\
5800 \\
4510 \\
4820 \\
5820\end{array}$ & $\begin{array}{l}3720 \\
4620 \\
4740 \\
4760 \\
4440\end{array}$ & $\begin{array}{l}1650 \\
1640 \\
1630 \\
1620 \\
1590\end{array}$ & $\begin{array}{l}630 \\
516 \\
507 \\
508 \\
502\end{array}$ & $\begin{array}{l}2670 \\
2670 \\
2670 \\
2510 \\
2250\end{array}$ \\
\hline $\begin{array}{l}21 \\
22 \\
23 \\
24 \\
25\end{array}$ & $\begin{array}{l}4030 \\
3400 \\
2500 \\
2340 \\
2110\end{array}$ & $\begin{array}{l}2910 \\
2500 \\
2490 \\
2490 \\
2490\end{array}$ & $\begin{array}{l}2720 \\
3390 \\
4780 \\
5470 \\
6140\end{array}$ & $\begin{array}{l}2100 \\
2100 \\
2100 \\
2100 \\
2100\end{array}$ & $\begin{array}{r}4310 \\
9670 \\
15800 \\
17400 \\
19300\end{array}$ & $\begin{array}{l}6480 \\
6360 \\
5990 \\
5970 \\
5560\end{array}$ & $\begin{array}{l}5340 \\
4920 \\
4390 \\
5130 \\
5130\end{array}$ & $\begin{array}{l}6460 \\
6450 \\
6330 \\
5810 \\
4700\end{array}$ & $\begin{array}{l}3700 \\
3320 \\
3450 \\
4980 \\
9060\end{array}$ & $\begin{array}{l}1580 \\
1470 \\
1210 \\
1210 \\
1310\end{array}$ & $\begin{array}{l}464 \\
359 \\
361 \\
381 \\
357\end{array}$ & $\begin{array}{l}2250 \\
2270 \\
2500 \\
3040 \\
3330\end{array}$ \\
\hline $\begin{array}{l}26 \\
27 \\
28 \\
29 \\
30 \\
31\end{array}$ & $\begin{array}{l}2090 \\
2100 \\
2220 \\
2590 \\
2400 \\
2060\end{array}$ & $\begin{array}{l}2490 \\
2700 \\
3090 \\
2870 \\
2470 \\
---\end{array}$ & $\begin{array}{l}4460 \\
2110 \\
4480 \\
8430 \\
9540 \\
9690\end{array}$ & $\begin{array}{l}2100 \\
2100 \\
2100 \\
2100 \\
2100 \\
2100\end{array}$ & $\begin{array}{r}17900 \\
13600 \\
10600 \\
- \\
-\end{array}$ & $\begin{array}{l}4950 \\
5490 \\
6270 \\
6200 \\
5640 \\
5190\end{array}$ & $\begin{array}{r}4870 \\
7790 \\
9790 \\
9850 \\
11400 \\
---\end{array}$ & $\begin{array}{l}4180 \\
4710 \\
6100 \\
6120 \\
6130 \\
5770\end{array}$ & $\begin{array}{l}5820 \\
5230 \\
5810 \\
4020 \\
3270 \\
---\end{array}$ & $\begin{array}{l}1540 \\
1540 \\
1520 \\
1500 \\
1460 \\
1310\end{array}$ & $\begin{array}{l}352 \\
352 \\
354 \\
351 \\
432 \\
787\end{array}$ & $\begin{array}{c}3550 \\
3860 \\
3360 \\
3410 \\
4210 \\
-\end{array}$ \\
\hline $\begin{array}{l}\text { TOTAL } \\
\text { MEAN } \\
\text { MAX } \\
\text { MIN } \\
\text { AC-FT }\end{array}$ & $\begin{array}{r}57997 \\
1871 \\
4030 \\
516 \\
115000\end{array}$ & $\begin{array}{r}94780 \\
3159 \\
4200 \\
2470 \\
188000\end{array}$ & $\begin{array}{r}118350 \\
3818 \\
9690 \\
1400 \\
234700\end{array}$ & $\begin{array}{r}93840 \\
3027 \\
8360 \\
2100 \\
186100\end{array}$ & $\begin{array}{r}137990 \\
4928 \\
19300 \\
1300 \\
273700\end{array}$ & $\begin{array}{r}215670 \\
6957 \\
13700 \\
4950 \\
427800\end{array}$ & $\begin{array}{r}212400 \\
7080 \\
11400 \\
4390 \\
421300\end{array}$ & $\begin{array}{r}222440 \\
7175 \\
13300 \\
4180 \\
441200\end{array}$ & $\begin{array}{r}129600 \\
4320 \\
9060 \\
3270 \\
257100\end{array}$ & $\begin{array}{r}63290 \\
2042 \\
3870 \\
1210 \\
125500\end{array}$ & $\begin{array}{r}19174 \\
619 \\
1280 \\
351 \\
38030\end{array}$ & $\begin{array}{r}91635 \\
3055 \\
5940 \\
790 \\
181800\end{array}$ \\
\hline $\begin{array}{ll}\text { CAL YR } \\
\text { WTR } \\
\text { YR }\end{array}$ & $\begin{array}{l}984 \\
985\end{array}$ & $\begin{array}{l}\text { TOTAL } \\
\text { TOTAL }\end{array}$ & $\begin{array}{l}4836837 \\
1457166\end{array}$ & $\begin{array}{l}\text { MEAN } \\
\text { MEAN }\end{array}$ & $\begin{array}{r}13220 \\
3992\end{array}$ & $\begin{array}{l}\text { MAX } \\
\text { MAX }\end{array}$ & $\begin{array}{l}42400 \\
19300\end{array}$ & $\begin{array}{l}\text { MIN } \\
\text { MIN }\end{array}$ & $\begin{array}{l}516 \\
351\end{array}$ & $\begin{array}{ll}\mathrm{FT} & 95 \\
\mathrm{FT} & \mathbf{2 8}\end{array}$ & & \\
\hline
\end{tabular}


05489000 CEDAR CREER NEAR BUSSEY, IA

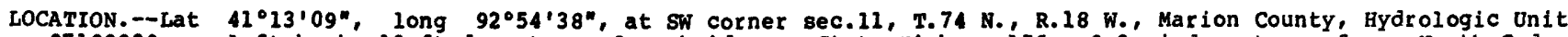
07100009 , on left bank $10 \mathrm{ft}$ downstream from bridge on state Highway 156 , $0.8 \mathrm{mi}$ downstream from North Cedar Creek, $1.6 \mathrm{mi}$ northwest of Bussey, $3.0 \mathrm{mi}$ upstream from Honey Creek, and $8.9 \mathrm{mi}$ upstream from mouth.

DRAINAGE AREA. $--374 \mathrm{mi}$.

PERIOD OF RECORD. --October 1947 to current year.

REVISED RECORDS. --WSP 1438: Drainage area.

GAGE.--Water-stage recorder. Datum of gage is $682.15 \mathrm{ft}$ above NGVD (levels by 0.5 . Army Corps of Engineers). Prior to Feb. 21, 1949, nonrecording gage at same site and datum.

REMARRs,--Estimated daily discharges: Dec, 19 to Feb, 23, Feb. 26 to Mar. 5, Apr. 3-10. Records good except those for periods of estimated record, which are poor. U.s. Army Corps of Engineers Data Collection Platform at station.

COOPERATION. --Two discharge measurements provided by U.S. Army Corps of Engineers.

AVERAGE DISCHARGE, - -38 years, $215 \mathrm{ft} / 8,7.81$ in/yr, 155,800 acre-ft/yr; median of yearly mean discharges, $180 \mathrm{ft} / \mathrm{s}, 6.5 \mathrm{in} / \mathrm{yr}, 130,000 \mathrm{acre}-\mathrm{ft} / \mathrm{yr}$.

EXTREMES FOR PERIOD OF RECORD.--Maximum discharge, $96,000 \mathrm{ft} / \mathrm{s}$ July 3 , 1982 , gage height, 34.61 ft; no flow Sept. 6-20, 1955, Oct. 11, 12, 1956.

EXTREMES OUTSIDE PERIOD OF RECORD.--FIood in June 1946 reached a stage of $28.45 \mathrm{ft}$ on upstream side and $28.05 \mathrm{ft}$ on downstream side of bridge, levels to floodmarks by $0 . S$. Army Corps of Engineers, discharge, $31,500 \mathrm{ft} / \mathrm{s}$.

EXTREMES FOR CURRENT YEAR.--Peak discharges greater than base of $4,000 \mathrm{ft} \% \mathrm{~s}$ and maximum $(*)$ :

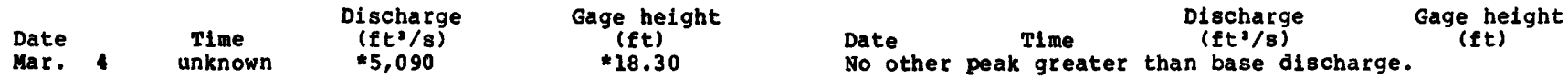

Minimum discharge, $3.5 \mathrm{ft}^{2} / \mathrm{s}$ Sept. 13.

DISCBARGE, IN CUBIC FEET PER SECOND, WATER YEAR OCTOBER 1984 TO SEPTEMBER 1985 MEAN VALUES

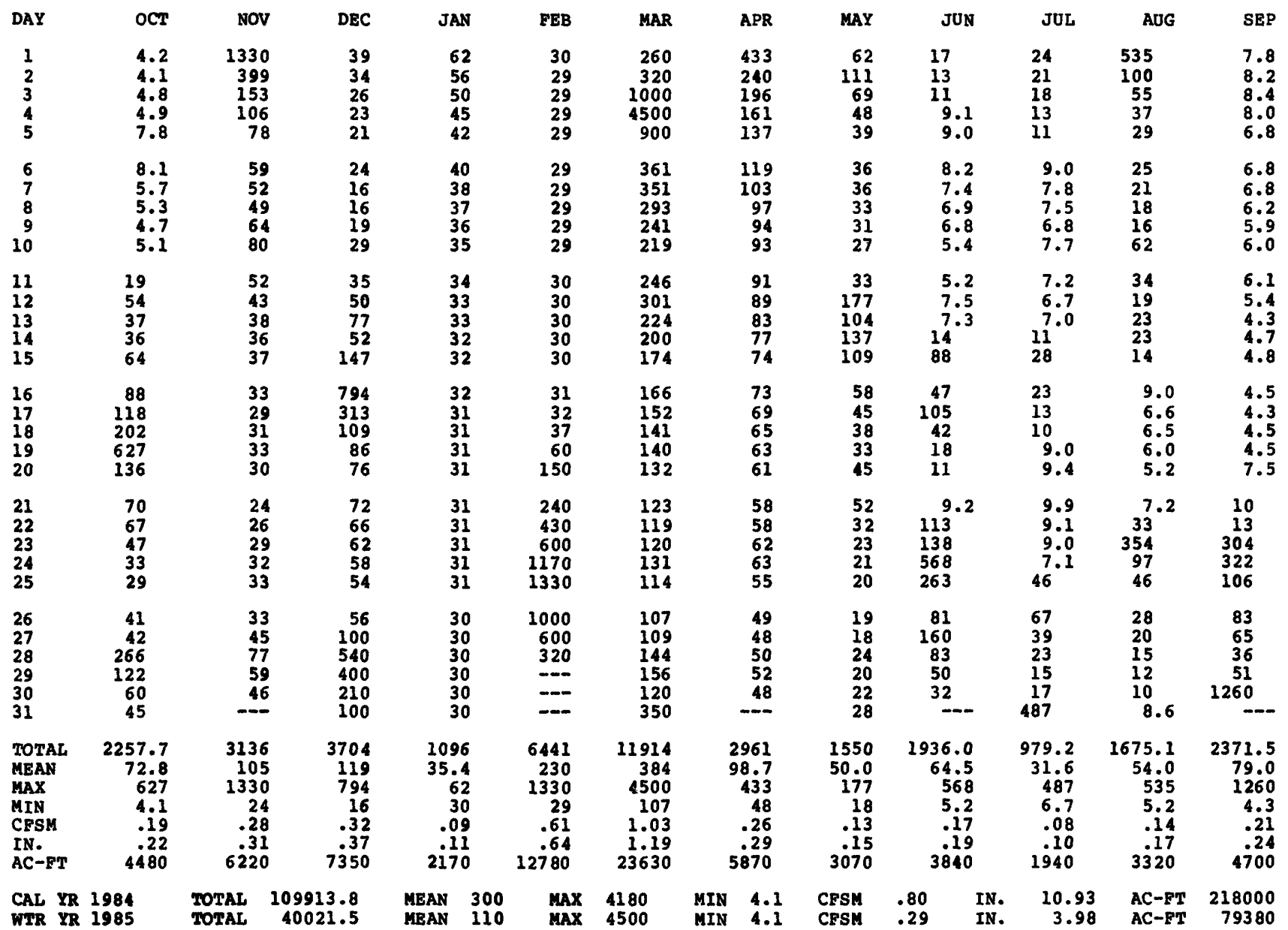


LOCATION.--Lat $41^{\circ} 00^{\prime} 39^{\prime \prime}$, long $92^{\circ} 24^{\prime} 40^{\prime \prime}$, in SEl/4 NEl/4 sec.25, T.72 N., R.14 W., Wapello County, Hydrologic Unit 07100009 , on right bank $15 \mathrm{ft}$ downstream from Wabash Railroad Bridge at Ottumwa, 0.4 mi downstream from Ottumwa powerplant, $6.5 \mathrm{mi}$ upstream from Village Creek, $9.5 \mathrm{mi}$ downstream from South Avery Creek, and at mile 94.1 .

DRAINAGE AREA. $--13,374 \mathrm{mi}^{2}$.

PERIOD OF RECORD.--March 1917 to current year (published as "at Eldon" October 1930 to March 1935). Monthly discharge only for some periods, published in wSP 1308 .

REVISED RECORDS,--WSP 525: 1917-20. WSP 1308: 1917-23 (M), 1925-27 (M), 1931. WSP 1438: Drainage area.

GAGE.-Water-stage recorder. Datum of gage is $622.00 \mathrm{ft}$ above NGVD. Prior to Sept. 30 , 1930 , nonrecording gages at Market Street Bridge $1,700 \mathrm{ft}$ upstream at datum $0.83 \mathrm{ft}$ higher. 0ct. 1, 1930 , to Mar. 31 , 1935 , nonrecording Mar. 31, 1935, nonrecording gage at Eldon $15 \mathrm{mi}$ downstream at different datum. Apr. 1 , 1935 , to Oct. 25, 1963, water-stage recorder at site $1,100 \mathrm{ft}$ downstream at vine street Bridge at datum 0.77 ft higher.

REMARKS.--Estimated daily discharge: Dec. 29 to Jan. 1, Jan. 4 to Feb. 21, Aug. 14-17, Sept. 1-15, 17-30. Records good except those for periods of estimated record, which are poor. Prior to Dec. 12, 1958 , and since Nov. 30 , 1960, diurnal fluctuation at low flow caused by powerplant above station. Flow regulated by Lake Red Rock (station 05488100) 48.2 mi upstream, since March 12, 1969. U.S. Army Corps of Engineers gage-height telemeter and data collection platform at station.

COOPERATION.--Two discharge measurements provided by U.S. Army Corps of Engineers.

AVERAGE DISCHARGE. -68 years, $5,431 \mathrm{ft}^{3} / \mathrm{s}, 5.51 / \mathrm{yr}, 3,935,000$ acre-ft/yr; median of yearly mean discharges, 4,610 $\mathrm{ft}^{2} / \mathrm{s}, 4.7 \mathrm{in} / \mathrm{yr}, 3,340,000$ acre-ft/yr.

EXTREMES FOR PERIOD OF RECORD.--Maximum discharge, 135,000 ft $3 / \mathrm{s}$ June 7, 1947, gage height, 20.2 ft, site and datum then in use; minimum daily, $30 \mathrm{ft} / \mathrm{s} \mathrm{Jan.} \mathrm{27-29,} \mathrm{31,} \mathrm{Feb.} \mathrm{2,} \mathrm{3,} \mathrm{5-7,} 1940$.

EXTREMES OUTSIDE PERIOD OF RECORD.--Maximum stage since at least 1850, that of June 7, 1947. Flood of May 31, 1903, reached a stage of $19.4 \mathrm{ft}$, former site and datum at Vine street Bridge or about $22 \mathrm{ft}$ at Market street Bridge, from information by U.S. Army Corps of Engineers and National Weather Service, discharge, about 140,000 $\mathrm{ft} / \mathrm{s}$.

EXTREMES FOR CURRENT YEAR.--Maximum discharge, 22,300 ft3/s Feb. 26, gage height, $9.79 \mathrm{ft}$; minimum daily, 250 $f t^{2} / \mathrm{s}$ Sept. 2

DISCHARGE, IN CUBIC FEET PER SECOND, WATER YEAR OCTOBER 1984 TO SEPTEMBER 1985 MEAN VALUES

\begin{tabular}{|c|c|c|c|c|c|c|c|c|c|c|c|c|}
\hline DAY & OCT & NOV & $\mathrm{DEC}$ & JAN & FEB & MAR & $A P R$ & MAY & JUN & JUL & AUG & SEP \\
\hline $\begin{array}{l}1 \\
2 \\
3 \\
4 \\
5\end{array}$ & $\begin{array}{l}731 \\
744 \\
680 \\
757 \\
837\end{array}$ & $\begin{array}{l}7170 \\
6380 \\
5220 \\
5050 \\
4890\end{array}$ & $\begin{array}{l}2210 \\
2220 \\
1590 \\
1550 \\
1690\end{array}$ & $\begin{array}{l}9800 \\
8660 \\
7940 \\
5310 \\
3620\end{array}$ & $\begin{array}{l}2100 \\
1850 \\
1650 \\
2200 \\
2000\end{array}$ & $\begin{array}{r}9890 \\
7390 \\
7510 \\
15600 \\
11400\end{array}$ & $\begin{array}{l}6130 \\
6670 \\
6860 \\
7080 \\
7140\end{array}$ & $\begin{array}{l}11200 \\
13100 \\
13700 \\
13400 \\
12500\end{array}$ & $\begin{array}{l}5600 \\
4960 \\
4830 \\
4830 \\
4630\end{array}$ & $\begin{array}{l}4430 \\
4000 \\
4050 \\
4040 \\
3450\end{array}$ & $\begin{array}{l}1410 \\
1530 \\
1410 \\
1320 \\
1230\end{array}$ & $\begin{array}{r}330 \\
250 \\
600 \\
1150 \\
2700\end{array}$ \\
\hline $\begin{array}{r}6 \\
7 \\
8 \\
9 \\
10\end{array}$ & $\begin{array}{r}921 \\
950 \\
979 \\
1360 \\
1680\end{array}$ & $\begin{array}{l}4840 \\
3490 \\
3120 \\
2750 \\
3900\end{array}$ & $\begin{array}{r}880 \\
1280 \\
1570 \\
1520 \\
3460\end{array}$ & $\begin{array}{l}4780 \\
4380 \\
3970 \\
4700 \\
5900\end{array}$ & $\begin{array}{l}1800 \\
1600 \\
1500 \\
1450 \\
1450\end{array}$ & $\begin{array}{r}6400 \\
7130 \\
13600 \\
14700 \\
12000\end{array}$ & $\begin{array}{r}7510 \\
8040 \\
8800 \\
9970 \\
10600\end{array}$ & $\begin{array}{r}11500 \\
10800 \\
10100 \\
9450 \\
8800\end{array}$ & $\begin{array}{l}4380 \\
3970 \\
3570 \\
3640 \\
4070\end{array}$ & $\begin{array}{l}2900 \\
2770 \\
2670 \\
2690 \\
2480\end{array}$ & $\begin{array}{r}1100 \\
963 \\
863 \\
842 \\
833\end{array}$ & $\begin{array}{l}2100 \\
1600 \\
1900 \\
2400 \\
3600\end{array}$ \\
\hline $\begin{array}{l}11 \\
12 \\
13 \\
14 \\
15\end{array}$ & $\begin{array}{l}1840 \\
2020 \\
1800 \\
1720 \\
2080\end{array}$ & $\begin{array}{l}3630 \\
3710 \\
3800 \\
3630 \\
3480\end{array}$ & $\begin{array}{l}3990 \\
3900 \\
4090 \\
4330 \\
5220\end{array}$ & $\begin{array}{l}3800 \\
3100 \\
3000 \\
2900 \\
3000\end{array}$ & $\begin{array}{l}1400 \\
1400 \\
1400 \\
1450 \\
1400\end{array}$ & $\begin{array}{l}8970 \\
6800 \\
5790 \\
8070 \\
8830\end{array}$ & $\begin{array}{r}10200 \\
9620 \\
8830 \\
7930 \\
7240\end{array}$ & $\begin{array}{l}7970 \\
7840 \\
7660 \\
7460 \\
7180\end{array}$ & $\begin{array}{l}3800 \\
3100 \\
3250 \\
3280 \\
3280\end{array}$ & $\begin{array}{l}2270 \\
2140 \\
2100 \\
2030 \\
1730\end{array}$ & $\begin{array}{l}825 \\
805 \\
764 \\
370 \\
360\end{array}$ & $\begin{array}{l}6000 \\
6100 \\
6200 \\
6400 \\
4000\end{array}$ \\
\hline $\begin{array}{l}16 \\
17 \\
18 \\
19 \\
20\end{array}$ & $\begin{array}{l}2160 \\
2940 \\
4730 \\
7540 \\
5270\end{array}$ & $\begin{array}{l}3750 \\
4170 \\
3660 \\
3230 \\
3300\end{array}$ & $\begin{array}{l}5940 \\
4400 \\
4560 \\
4180 \\
4010\end{array}$ & $\begin{array}{l}2900 \\
2700 \\
2500 \\
2350 \\
2300\end{array}$ & $\begin{array}{l}1400 \\
1400 \\
1450 \\
1650 \\
2500\end{array}$ & $\begin{array}{l}8070 \\
7870 \\
7780 \\
7660 \\
6680\end{array}$ & $\begin{array}{l}7040 \\
6720 \\
5940 \\
5250 \\
5200\end{array}$ & $\begin{array}{l}6950 \\
6770 \\
6320 \\
5680 \\
5440\end{array}$ & $\begin{array}{l}3480 \\
4260 \\
4960 \\
5030 \\
4960\end{array}$ & $\begin{array}{l}1600 \\
1480 \\
1440 \\
1420 \\
1390\end{array}$ & $\begin{array}{l}540 \\
680 \\
771 \\
705 \\
682\end{array}$ & $\begin{array}{l}2390 \\
2500 \\
2750 \\
2900 \\
2900\end{array}$ \\
\hline $\begin{array}{l}21 \\
22 \\
23 \\
24 \\
25\end{array}$ & $\begin{array}{l}5090 \\
4910 \\
3330 \\
2910 \\
2460\end{array}$ & $\begin{array}{l}3280 \\
2660 \\
2370 \\
2290 \\
2360\end{array}$ & $\begin{array}{l}3030 \\
3840 \\
5590 \\
5390 \\
5870\end{array}$ & $\begin{array}{l}2250 \\
2250 \\
2250 \\
2250 \\
2300\end{array}$ & $\begin{array}{r}4600 \\
9200 \\
12300 \\
15200 \\
17600\end{array}$ & $\begin{array}{l}6460 \\
6430 \\
6080 \\
5940 \\
5870\end{array}$ & $\begin{array}{l}5190 \\
5190 \\
4910 \\
4550 \\
4830\end{array}$ & $\begin{array}{l}5670 \\
6070 \\
6340 \\
6460 \\
6220\end{array}$ & $\begin{array}{l}4200 \\
3750 \\
3620 \\
3910 \\
9980\end{array}$ & $\begin{array}{l}1340 \\
1420 \\
1310 \\
1100 \\
1060\end{array}$ & $\begin{array}{l}648 \\
615 \\
578 \\
577 \\
564\end{array}$ & $\begin{array}{l}2500 \\
2450 \\
2500 \\
3000 \\
3350\end{array}$ \\
\hline $\begin{array}{l}26 \\
27 \\
28 \\
29 \\
30 \\
31\end{array}$ & $\begin{array}{l}2410 \\
2320 \\
3550 \\
3120 \\
2900 \\
2520\end{array}$ & $\begin{array}{l}2410 \\
2570 \\
3310 \\
3220 \\
2610 \\
---\end{array}$ & $\begin{array}{r}5190 \\
7470 \\
7080 \\
8600 \\
9900 \\
10000\end{array}$ & $\begin{array}{l}2300 \\
2300 \\
2200 \\
2200 \\
2200 \\
2200\end{array}$ & $\begin{array}{r}19400 \\
17300 \\
14000 \\
- \\
- \\
--\end{array}$ & $\begin{array}{l}5010 \\
4930 \\
6300 \\
6370 \\
6110 \\
6550\end{array}$ & $\begin{array}{l}4900 \\
5010 \\
6020 \\
7860 \\
9480 \\
---\end{array}$ & $\begin{array}{l}4760 \\
4390 \\
5920 \\
6310 \\
6460 \\
6410\end{array}$ & $\begin{array}{r}10100 \\
7810 \\
6860 \\
6450 \\
5330 \\
--\end{array}$ & $\begin{array}{l}1070 \\
1220 \\
1320 \\
1300 \\
1340 \\
1400\end{array}$ & $\begin{array}{l}520 \\
486 \\
655 \\
632 \\
581 \\
459\end{array}$ & $\begin{array}{l}3750 \\
4100 \\
4400 \\
3700 \\
4700 \\
-\end{array}$ \\
\hline $\begin{array}{l}\text { TOTAC } \\
\text { MEAN } \\
\text { MAX } \\
\text { MIN }\end{array}$ & $\begin{array}{r}77259 \\
2492 \\
7540 \\
680\end{array}$ & $\begin{array}{r}110250 \\
3675 \\
7170 \\
2290\end{array}$ & $\begin{array}{r}134550 \\
4340 \\
10000 \\
880\end{array}$ & $\begin{array}{r}112310 \\
3623 \\
9800 \\
2200\end{array}$ & $\begin{array}{r}142650 \\
5095 \\
19400 \\
1400\end{array}$ & $\begin{array}{r}248190 \\
8006 \\
15600 \\
4930\end{array}$ & $\begin{array}{r}210710 \\
7024 \\
10600 \\
4550\end{array}$ & $\begin{array}{r}248830 \\
8027 \\
13700 \\
4390\end{array}$ & $\begin{array}{r}145890 \\
4863 \\
10100 \\
3100\end{array}$ & $\begin{array}{r}64960 \\
2095 \\
4430 \\
1060\end{array}$ & $\begin{array}{r}24318 \\
784 \\
1530 \\
360\end{array}$ & $\begin{array}{r}93220 \\
3107 \\
6400 \\
250\end{array}$ \\
\hline $\begin{array}{l}\text { CAL YR } \\
\text { WHR YE }\end{array}$ & $\begin{array}{l}1984 \\
1985\end{array}$ & $\begin{array}{l}\text { TOTAL, } \\
\text { TOTAL }\end{array}$ & $\begin{array}{l}5181692 \\
1613137\end{array}$ & $\begin{array}{l}\text { MEAN } \\
\text { MEAN }\end{array}$ & $\begin{array}{r}14160 \\
4420\end{array}$ & $\begin{array}{l}\text { MAX } \\
\text { MAX }\end{array}$ & $\begin{array}{l}46800 \\
19400\end{array}$ & $\begin{array}{l}\text { MIN } \\
\text { MIN }\end{array}$ & $\begin{array}{l}680 \\
250\end{array}$ & & & \\
\hline
\end{tabular}


LOCATION,--Lat $40^{\circ} 43^{\prime} 40^{\prime \prime}$, long $91^{\circ} 57^{\prime} 34^{\prime \prime}$, in SEI/4 SWl/4 sec.36, T.69 N., R.10 W., Van Buren County, Hydrologic Unit 07100009 , on right bank $10 \mathrm{ft}$ upstream from bridge on state Bighway 1 at keosaugua, 4.0 mi downstream from Cheguest Creek, and at mile 51.3 .

DRAINAGE AREA. $--14,038 \mathrm{mi}^{2}$.

PERIOD OF RECORD.--May 1903 to July 1906, April to December 1910, August 1911 to current year. Monthly discharge only for some periods, published in wSP 1308 .

REVISED RECORDS.--WSP 525: 1913-20. WSP 1438: Drainage area. WSP 1508: 1903, 1905-6, 1915-18 (M), 1922 (K), $1924-26(M), 1932-34(M), 1937,1942(M)$.

GAGE.--Water-stage recorder. Datum of gage is $547.36 \mathrm{ft}$ above NGVD. Prior to Dec. 24 , 1933 , nonrecording gage, and Dec. 25, 1933, to Sept. 30, 1972, water-8tage recorder, at same site at datum 10.00 ft higher.

REMARKS.--Estimated daily discharges during water year: Jan. 14 to Feb. 25, March 15-22, April 20-24, April 30 to May 15, May 28 to June 25 and Sept. 30. Records good except those for periods of estimated record, which are poor. Prior to Dec. 21, 1958, and since Nov. 30, 1960, some diurnal fluctuation at medium and 10w stages caused by power plant at ottumwa. Flow regulated by Lake Red Rock (8tation 05488100 ) 91.0 mi upstream, since March 12, 1969 . National Weather Service gage-height telemeter and U.S. Army Corps of Engineers data collection platform at station.

COOPERATION.--Four discharge measurements provided by U.s. Army Corps of Engineers.

AVERAGE DISCHARGE.--76 years (water years 1904-05, 19l2-85), 5,818 ft3/8, 5.63 in/yr, 4,215,000 acre-ft/yr; median of yearly mean discharges, $4,990 \mathrm{ft} / \mathrm{s}, 4.8 \mathrm{in} / \mathrm{yr}, 3,620,000 \mathrm{acre}-\mathrm{ft} / \mathrm{yr}$.

EXTREMES FOR PERIOD OF RECORD.--Maximum discharge, 146,000 ft:s June I, 1903, gage height, 27.85 ft, from floodmark, datum then in use; minimum daily, $40 \mathrm{ft}^{2} / \mathrm{s} \mathrm{Jan} .30,1940$.

EXTREMES OUTSIDE PERIOD OF RECORD.--FIOOd of June 1, 1851, reached a stage of 24 ft, discharge not determined.

EXTREMES FOR CURRENT YEAR.--Maximum discharge, $27,200 \mathrm{ft} / \mathrm{s}$ March 4, gage height, $18.95 \mathrm{ft}$; maximum gage height, $22.83 \mathrm{ft}$. Feb. 22, backwater from ice; minimum discharge, $222 \mathrm{ft}^{3} / \mathrm{s}$ Aug. I4.

DISCHARGE, IN CUBIC FEET PER SECOND, WATER YEAR OCTOBER 1984 TO SEPTEMBER 1985

\begin{tabular}{|c|c|}
\hline DAY & OCT \\
\hline $\begin{array}{l}1 \\
2 \\
3 \\
4 \\
5\end{array}$ & $\begin{array}{r}970 \\
1040 \\
1070 \\
877 \\
969\end{array}$ \\
\hline $\begin{array}{r}6 \\
7 \\
8 \\
9 \\
10\end{array}$ & $\begin{array}{l}1060 \\
1180 \\
1240 \\
1290 \\
1460\end{array}$ \\
\hline $\begin{array}{l}11 \\
12 \\
13 \\
14 \\
15\end{array}$ & $\begin{array}{l}2000 \\
2220 \\
2210 \\
2010 \\
2160\end{array}$ \\
\hline $\begin{array}{l}16 \\
17 \\
18 \\
19 \\
20\end{array}$ & $\begin{array}{l}2610 \\
2270 \\
3910 \\
9580 \\
5770\end{array}$ \\
\hline $\begin{array}{l}21 \\
22 \\
23 \\
24 \\
25\end{array}$ & $\begin{array}{l}5050 \\
4870 \\
4240 \\
2840 \\
2740\end{array}$ \\
\hline $\begin{array}{l}26 \\
27 \\
28 \\
29 \\
30 \\
31\end{array}$ & $\begin{array}{l}2420 \\
2560 \\
3100 \\
3420 \\
3180 \\
4200\end{array}$ \\
\hline $\begin{array}{l}\text { TOTAL } \\
\text { MEAN } \\
\text { MAX } \\
\text { MIN } \\
\text { AC-FT }\end{array}$ & $\begin{array}{r}84516 \\
2726 \\
9580 \\
877 \\
167600\end{array}$ \\
\hline
\end{tabular}

\begin{tabular}{|c|c|}
\hline NOV & DEC \\
\hline $\begin{array}{r}14300 \\
8960 \\
5810 \\
4700 \\
4520\end{array}$ & $\begin{array}{l}2600 \\
2350 \\
2310 \\
1790 \\
1770\end{array}$ \\
\hline $\begin{array}{l}4270 \\
4100 \\
2820 \\
2600 \\
2680\end{array}$ & $\begin{array}{l}1180 \\
1220 \\
1490 \\
1850 \\
1730\end{array}$ \\
\hline $\begin{array}{l}2960 \\
3300 \\
3270 \\
3270 \\
3250\end{array}$ & $\begin{array}{l}2830 \\
3770 \\
3720 \\
4380 \\
4820\end{array}$ \\
\hline $\begin{array}{l}2960 \\
3510 \\
3600 \\
3120 \\
2930\end{array}$ & $\begin{array}{l}4760 \\
5710 \\
4640 \\
4100 \\
4040\end{array}$ \\
\hline $\begin{array}{l}2940 \\
2930 \\
2350 \\
2240 \\
2250\end{array}$ & $\begin{array}{l}4110 \\
3450 \\
3340 \\
4660 \\
4690\end{array}$ \\
\hline $\begin{array}{l}2530 \\
2920 \\
3220 \\
3340 \\
3160 \\
-\cdots\end{array}$ & $\begin{array}{r}4880 \\
5790 \\
5520 \\
7640 \\
10200 \\
10100\end{array}$ \\
\hline $\begin{array}{r}14810 \\
3827 \\
14300 \\
2240 \\
227700\end{array}$ & $\begin{array}{r}125440 \\
4046 \\
10200 \\
1180 \\
248800\end{array}$ \\
\hline
\end{tabular}
MEAN VALUES

CAL YR 1984

TOTAL $\quad 5100646$ WTR YR 1985 TOTAL $\quad 1695459$

JAN
9780
8770
6170
3600
2470
3900
4570

2960

5370

4700

2710

2910

3050

3100

3050

2800

2600

2500

2400

2300

2300

2300

2300

2350

2350

2300
2300

2300

2250

106850
3447

9780

2250
211900

FEB
2200
2100
1900
2200
2250
1900
1700
1600
1550

1500

1500

1500

1500

1500

1500

1500

1550

1950
3400

8000

11500

14500

17000

19500

22000

18800

14700

---

$-$

162300

5796
22000

22000
1500
321900

266340

$\begin{array}{rr}\text { MEAN } & 13940 \\ \text { MEAN } & 4645\end{array}$
12300

9000

7170

20000

15800

8610

6690

9470

12800

11200
8880

8880

6480

6130

8100

9200

8800

8200

8100

7800

7000

6600

6240

6010

6010
5920

5630

5070

5570

6390

6320
6760

8592

8592
20000

5070
528300

$\begin{array}{r}A P R \\ 6920 \\ 6450 \\ 6730 \\ 6930 \\ 7240 \\ 7510 \\ 7860 \\ 8400 \\ 9550 \\ 10200 \\ 9330 \\ 9060 \\ 8100 \\ 7690 \\ 6870 \\ 6730 \\ 6590 \\ 5970 \\ 6070 \\ 5790 \\ 5500 \\ 5230 \\ 4960 \\ 4710 \\ 5110 \\ 5500 \\ 5040 \\ 9240 \\ 10700 \\ 12500 \\ -9 \\ 218480 \\ 7283 \\ 12500 \\ 4710 \\ 433400 \\ \hline 50 \\ \hline\end{array}$

MAY

14000

15000

15500

15000

23500

12000

10500

9700

8500

8200

7900

7600

7400

6720

6580

6120

4800

4820

5750

6430

6450

6430

6060

5140

4440

5600

6600

7000
7100

$\operatorname{mx}$
$\max$
22000

8575

16000

4440
527300

\begin{tabular}{rr} 
JUN & JUL \\
& \\
6800 & 3730 \\
5900 & 3440 \\
5200 & 3790 \\
5000 & 3910 \\
4900 & 3420 \\
4700 & 2830 \\
4300 & 2750 \\
3800 & 2550 \\
3600 & 2830 \\
4100 & 2740 \\
4000 & 2710 \\
3500 & 2640 \\
3300 & 2720 \\
3400 & 2550 \\
3500 & 1890 \\
4000 & 1680 \\
4600 & 1410 \\
5100 & 1500 \\
5300 & 1490 \\
5400 & 1500 \\
4900 & 1380 \\
4250 & 1540 \\
4000 & 1580 \\
5700 & 1270 \\
9700 & 1290 \\
& \\
10100 & 1370 \\
5990 & 1420 \\
5360 & 1860 \\
5980 & 1620 \\
4610 & 1840 \\
-90 & 10400 \\
150990 & 77650 \\
5033 & 2505 \\
10100 & 10400 \\
3300 & 1270 \\
299500 & 154000 \\
& \\
\hline
\end{tabular}

AUG SEP

$3210 \quad 510$

$\begin{array}{ll}2230 & 432 \\ 1680 & 705\end{array}$

$1140 \quad 873$

$1360 \quad 1680$

1460

976
857

$909 \quad 1990$

$805 \quad 2410$

$929 \quad 4800$

956
927 5470

$382 \quad 5480$

630

$\begin{array}{ll}712 & 4340\end{array}$

$798 \quad 2760$

$765 \quad 2790$

416

2730

$564 \quad 2620$

$590 \quad 2590$

$597 \quad 3260$

$563 \quad 3180$

742

570

1230

1540

631

3290

1020

3500

4500

\section{0}

299500

29993

968

3210

92250

3075

5910

432
83000 $\begin{array}{llll}\text { MIN } & 877 & \text { AC-FT } & 10117000\end{array}$ 
LOCATION.--Lat $43^{\circ} 12^{\prime} 52^{\prime \prime}$, long $96^{\circ} 17^{\prime 3} 39^{\prime \prime}$, in SWl/4 SWl/4 sec.16, T.97 N., R.46 W., Sioux County, Hydrologic Unit 10170204 , on left bank $3 \mathrm{ft}$ upstream from bridge on county highway $\mathrm{x} 30$, $0.3 \mathrm{mi}$ north of Rock Valley and at mile 19.1 .

DRAINAGE AREA. $--1,592 \mathrm{mi}^{2}$.

PERIOD OF RECORD.--June 1948 to current year.

REVISED RECORDS.--WSP 1439: Drainage area.

GAGE. - Water-stage recorder. Datum of gage is 1,222.54 ft above NGvD. Prior to Aug. 13, 1952, nonrecording gage with supplementary water-stage recorder operating above $6.2 \mathrm{ft}$ gage height June 4, 1949 , to Aug. 12, 1952 , and Aug. 13, 1952, to May 4, 1976, water-stage recorder, at site 3.2 mi downstream at datum 10.73 ft $10 w e r$.

REMARKS.--Estimated daily discharges: Dec. 3 to Mar. 6 , Mar. 8-18, Apr. 3-5, 21-23, May 14 to June 5 and Aug. 1 to Sept. 10. Records good except estimated daily discharges, which are poor. U.S. Army Corps of Engineers rain-gage and gage-height satellite data collection platform at station.

AVERAGE DISCHARGE. - -37 years, $399 \mathrm{ft}^{3} / \mathrm{s}, 3.40 \mathrm{in} / \mathrm{yr}, 289,100$ acre-ft/yr; median of yearly mean discharges, 300 $\mathrm{ft}^{3} / \mathrm{s}, 2.6 \mathrm{in} / \mathrm{yr}, 217,000$ acre-ft/yr.

EXTREMES FOR PERIOD OF RECORD,--Maximum discharge, $40,400 \mathrm{ft} / \mathrm{s}$ Apr. 7, 1969, gage height, 17.32 ft, site and datum then in use, no flow for many days during winter period in ig59 and 1977.

EXTREMES OUTSIDE PERIOD OF RECORD.--Flood in 1897 reached a stage of $17.0 \mathrm{ft}$, former site and datum, discharge not determined, from information by state Highway commission.

EXTREMES FOR CURRENT YEAR.--Peak discharges greater than base of $3,000 \mathrm{ft}^{3} / \mathrm{s}$ and maximum (*):

$\begin{array}{lccc}\text { Date } & \text { Time } & \begin{array}{c}\text { Discharge } \\ \left(\mathrm{ft}^{3} / \mathrm{s}\right)\end{array} & \begin{array}{c}\text { Gage height } \\ \text { (ft) }\end{array} \\ \text { Mar. } 12 & \text { unknown } & 6,800 & 13.20 \\ \text { Apr. } 24 & 1415 & * 12,500 & * 16.07\end{array}$

Minimum daily discharge, $50 \mathrm{ft}^{3} / \mathrm{s}$ Feb. 5-16.

DISCHARGE, IN CUBIC FEET PER SECOND, WATER YEAR OCTOBER 1984 TO SEPTEMBER 1985

\begin{tabular}{|c|c|c|}
\hline DAY & OCT & NOV \\
\hline $\begin{array}{l}1 \\
2 \\
3 \\
4 \\
5\end{array}$ & $\begin{array}{l}159 \\
158 \\
156 \\
155 \\
161\end{array}$ & $\begin{array}{l}493 \\
467 \\
460 \\
469 \\
461\end{array}$ \\
\hline $\begin{array}{r}6 \\
7 \\
8 \\
9 \\
10\end{array}$ & $\begin{array}{l}186 \\
211 \\
237 \\
242 \\
241\end{array}$ & $\begin{array}{l}442 \\
431 \\
425 \\
422 \\
415\end{array}$ \\
\hline $\begin{array}{l}11 \\
12 \\
13 \\
14 \\
15\end{array}$ & $\begin{array}{l}240 \\
253 \\
307 \\
322 \\
416\end{array}$ & $\begin{array}{l}396 \\
386 \\
389 \\
395 \\
392\end{array}$ \\
\hline $\begin{array}{l}16 \\
17 \\
18 \\
19 \\
20\end{array}$ & $\begin{array}{l}1110 \\
1530 \\
1330 \\
1340 \\
1380\end{array}$ & $\begin{array}{l}344 \\
360 \\
364 \\
326 \\
305\end{array}$ \\
\hline $\begin{array}{l}21 \\
22 \\
23 \\
24 \\
25\end{array}$ & $\begin{array}{r}1280 \\
1000 \\
830 \\
733 \\
679\end{array}$ & $\begin{array}{l}297 \\
380 \\
381 \\
365 \\
361\end{array}$ \\
\hline $\begin{array}{l}26 \\
27 \\
28 \\
29 \\
30 \\
31\end{array}$ & $\begin{array}{l}648 \\
626 \\
590 \\
556 \\
527 \\
505\end{array}$ & $\begin{array}{l}366 \\
361 \\
328 \\
327 \\
342 \\
--\end{array}$ \\
\hline $\begin{array}{l}\text { TOTAL } \\
\text { MEAN } \\
\text { MAX } \\
\text { MIN } \\
\text { CESM } \\
\text { IN. } \\
\text { AC-ET }\end{array}$ & $\begin{array}{r}18108 \\
584 \\
1530 \\
155 \\
.37 \\
.42 \\
35920\end{array}$ & $\begin{array}{r}11650 \\
388 \\
493 \\
297 \\
.24 \\
23110\end{array}$ \\
\hline
\end{tabular}

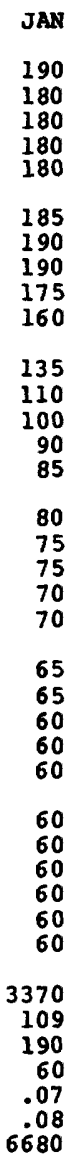

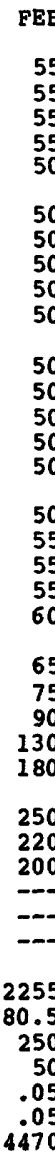
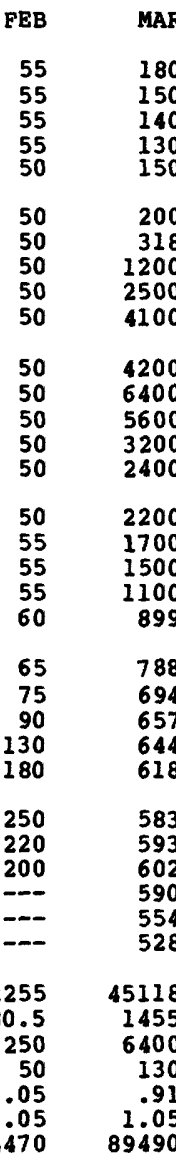

TOTAL 589671 TOTAL 286196 $\begin{array}{rr}\text { MEAN } & 1611 \\ \text { MEAN } & 784\end{array}$
MAX 14700 MAX 11700

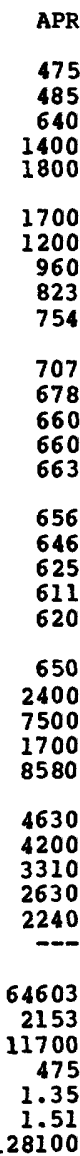

APR
475
485
640
400
800

MAY
1980
1750
1550
1410

1410
1270

$$
1180
$$

$$
\begin{aligned}
& 1110 \\
& 1050
\end{aligned}
$$

1050

980
921

904

1410

1140
1100

1100
2400

2700

2300

1900

1650

1500

1350

1200

1100

1050

1050

1050
900

900
820
880

880
1130

1130
3500

44235

1427
3500

3500
820

.90
1.03

\begin{tabular}{|c|c|c|c|}
\hline JUN & JUL & AUG & SEP \\
\hline $\begin{array}{l}3100 \\
1700 \\
1600 \\
1350 \\
1200\end{array}$ & $\begin{array}{r}1110 \\
969 \\
858 \\
768 \\
691\end{array}$ & $\begin{array}{l}160 \\
150 \\
135 \\
130 \\
125\end{array}$ & $\begin{array}{r}440 \\
355 \\
330 \\
380 \\
2400\end{array}$ \\
\hline $\begin{array}{r}1090 \\
999 \\
927 \\
854 \\
804\end{array}$ & $\begin{array}{l}624 \\
556 \\
501 \\
465 \\
422\end{array}$ & $\begin{array}{l}120 \\
115 \\
115 \\
110 \\
115\end{array}$ & $\begin{array}{l}5100 \\
2900 \\
1900 \\
1450 \\
1150\end{array}$ \\
\hline $\begin{array}{l}818 \\
813 \\
774 \\
746 \\
730\end{array}$ & $\begin{array}{l}388 \\
361 \\
342 \\
337 \\
323\end{array}$ & $\begin{array}{l}110 \\
145 \\
225 \\
245 \\
210\end{array}$ & $\begin{array}{r}998 \\
904 \\
1020 \\
1590 \\
1900\end{array}$ \\
\hline $\begin{array}{l}687 \\
654 \\
613 \\
588 \\
563\end{array}$ & $\begin{array}{l}302 \\
279 \\
260 \\
241 \\
224\end{array}$ & $\begin{array}{l}190 \\
175 \\
175 \\
165 \\
155\end{array}$ & $\begin{array}{r}1610 \\
1380 \\
1220 \\
1080 \\
970\end{array}$ \\
\hline $\begin{array}{l}540 \\
517 \\
490 \\
463 \\
446\end{array}$ & $\begin{array}{l}214 \\
204 \\
193 \\
186 \\
193\end{array}$ & $\begin{array}{l}150 \\
150 \\
170 \\
190 \\
190\end{array}$ & $\begin{array}{r}902 \\
890 \\
961 \\
1020 \\
1050\end{array}$ \\
\hline $\begin{array}{r}812 \\
1550 \\
1990 \\
1680 \\
1340 \\
-\end{array}$ & $\begin{array}{l}206 \\
194 \\
166 \\
153 \\
149 \\
149\end{array}$ & $\begin{array}{l}180 \\
165 \\
175 \\
410 \\
695 \\
780\end{array}$ & $\begin{array}{r}1010 \\
966 \\
914 \\
902 \\
1020\end{array}$ \\
\hline $\begin{array}{r}30438 \\
1015 \\
3100 \\
446 \\
.64 \\
.71 \\
60370\end{array}$ & $\begin{array}{r}12028 \\
388 \\
1110 \\
149 \\
.24 \\
.28 \\
23860\end{array}$ & $\begin{array}{r}6325 \\
204 \\
780 \\
110 \\
.13 \\
.15 \\
12550\end{array}$ & $\begin{array}{r}38712 \\
1290 \\
5100 \\
330 \\
.81 \\
.90 \\
76790\end{array}$ \\
\hline
\end{tabular}

1.03
87740

MIN 149 CFSM 1.01 IN. 13.78 AC-FT 1170000

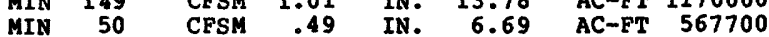

Gage height
(ft)
11.42
12.53 
LOCATION.--Lat $42^{\circ} 49^{\prime} 42^{\prime}$, long $96^{\circ} 33^{\prime} 45^{\prime \prime}$, in NWl/4 Swl/4 sec.31, T.93 N., R.48 W., Plymouth County, Bydrologic Onit 10170203, on left bank at west edge of Akron, $0.6 \mathrm{mi}$ downstream from bridge on state $8 i$ hway 48 , and $2.3 \mathrm{mi}$ upstream from Union Creek.

DRAINAGE AREA. $-8,424 \mathrm{mi}^{2}$, approximately, of which about $1,487 \mathrm{mi} 2$ is probably noncontributing.

\section{WATER-DISCHARGE RECORDS}

PERIOD OF RECORD.--October 1928 to current year.

REVISED RECORDS.--WSP 1309: 1929 (M), 1931-33 (M), 1936 (M), 1938 (M), 1940 (M). WSP 1389: Drainage area. WDR SD-84-1: Drainage area.

GAGE.-Water-stage recorder. Datum of gage is 1,118.90 ft above National Geodetic Vertical Datum of 1929. Prior to Dec. 3, 1934, nonrecording gage at bridge $300 \mathrm{ft}$ upstream at same datum.

REMARKS.--Records good except those for the winter period, Dec. 13 to Mar. 8, which are poor, and May 30 to July 17. which are fair. U.S. Army Corps of Engineers satellite data-collection platform at station.

AVERAGE DISCBARgE.--57 years, $982 \mathrm{ft} / \mathrm{s}$, (711,500 acre-ft/yr); median of yearly mean discharges, $750 \mathrm{ft} / \mathrm{s}$, $(543,000$ acre-ft/yr).

EXTREKES FOR PERIOD OF RECORD.--Maximum discharge, $80,800 \mathrm{ft}^{3 / s}$ Apr. 9, 1969, (gage height, 22.99 ft); minimum daily, $4.0 \mathrm{ft}^{2} / \mathrm{s}$ Jan. $17,1977$.

EXTREMES FOR CURRENT YEAR.--Peak discharges greater than base of $3,500 \mathrm{ft}^{3} / \mathrm{s}$ and maximum $(*)$ :

\begin{tabular}{|c|c|c|c|c|c|c|c|c|}
\hline $\begin{array}{l}\text { Date } \\
\text { Mar. } \\
\text { Apr. } \\
\text { Apr. } \\
\text { May }\end{array}$ & $\begin{array}{r}14 \\
6 \\
26 \\
18\end{array}$ & $\begin{array}{l}\text { Time } \\
0800 \\
1800 \\
0630 \\
1400\end{array}$ & $\begin{array}{c}\text { Discharge } \\
\left(f t^{3} / \mathrm{s}\right) \\
10,100 \\
5,400 \\
* 21,000 \\
3,720\end{array}$ & $\begin{array}{c}\text { Gage helght } \\
\text { (m) } \\
17.03 \\
14.48 \\
* 20.29 \\
12.56\end{array}$ & $\begin{array}{l}\text { Date } \\
\text { June } 1 \\
\text { Aug. } 29 \\
\text { Sept. } 7\end{array}$ & $\begin{array}{l}\text { Time } \\
1900 \\
1100 \\
1845\end{array}$ & $\begin{array}{c}\text { Discharge } \\
\left(f t^{3} / s\right) \\
5,180 \\
4,120 \\
3,880\end{array}$ & $\begin{array}{c}\text { Gage height } \\
\text { (m) } \\
14.13 \\
12.98 \\
12.71\end{array}$ \\
\hline
\end{tabular}

Minimum daily discharge, $290 \mathrm{ft}^{3} / \mathrm{s}$ Feb. 6-17

DISCHARGE, IN CUBIC FEET PER SECOND, WATER YEAR OCTOBER 1984 TO SEPTEMBER 1985 MEAN VALUES

\begin{tabular}{|c|c|c|c|c|c|c|c|c|c|c|c|c|}
\hline DAY & $O C T$ & NOV & DEC & JAN & FEB & MAR & $\mathbf{A P R}$ & MAY & JUN & JUL & AUG & SEP \\
\hline $\begin{array}{l}1 \\
2 \\
3 \\
4 \\
5\end{array}$ & $\begin{array}{l}620 \\
640 \\
660 \\
652 \\
646\end{array}$ & $\begin{array}{l}2090 \\
1940 \\
1850 \\
1770 \\
1700\end{array}$ & $\begin{array}{r}1090 \\
1070 \\
963 \\
672 \\
700\end{array}$ & $\begin{array}{r}1100 \\
1000 \\
960 \\
900 \\
800\end{array}$ & $\begin{array}{l}330 \\
320 \\
310 \\
310 \\
300\end{array}$ & $\begin{array}{l}1400 \\
1500 \\
1600 \\
1700 \\
1300\end{array}$ & $\begin{array}{l}4310 \\
3890 \\
3670 \\
3590 \\
3700\end{array}$ & $\begin{array}{l}6480 \\
5910 \\
5120 \\
4440 \\
3920\end{array}$ & $\begin{array}{l}4850 \\
5050 \\
4680 \\
3870 \\
3370\end{array}$ & $\begin{array}{l}2210 \\
1930 \\
1740 \\
1580 \\
1450\end{array}$ & $\begin{array}{l}701 \\
689 \\
677 \\
671 \\
652\end{array}$ & $\begin{array}{r}1310 \\
1150 \\
1050 \\
983 \\
1090\end{array}$ \\
\hline $\begin{array}{r}6 \\
7 \\
8 \\
9 \\
10\end{array}$ & $\begin{array}{l}669 \\
714 \\
733 \\
764 \\
751\end{array}$ & $\begin{array}{l}1650 \\
1600 \\
1550 \\
1530 \\
1520\end{array}$ & $\begin{array}{l}699 \\
903 \\
983 \\
955 \\
996\end{array}$ & $\begin{array}{l}760 \\
730 \\
700 \\
650 \\
620\end{array}$ & $\begin{array}{l}290 \\
290 \\
290 \\
290 \\
290\end{array}$ & $\begin{array}{l}1200 \\
1200 \\
1400 \\
2460 \\
3080\end{array}$ & $\begin{array}{l}4830 \\
4830 \\
4560 \\
3800 \\
3380\end{array}$ & $\begin{array}{l}3530 \\
3310 \\
3150 \\
3000 \\
2870\end{array}$ & $\begin{array}{l}3110 \\
2910 \\
2700 \\
2490 \\
2300\end{array}$ & $\begin{array}{r}1340 \\
1230 \\
1140 \\
1070 \\
996\end{array}$ & $\begin{array}{l}631 \\
610 \\
589 \\
569 \\
558\end{array}$ & $\begin{array}{l}2410 \\
3640 \\
3140 \\
2630 \\
2490\end{array}$ \\
\hline $\begin{array}{l}11 \\
12 \\
13 \\
14 \\
15\end{array}$ & $\begin{array}{l}774 \\
792 \\
815 \\
869 \\
958\end{array}$ & $\begin{array}{l}1470 \\
1410 \\
1360 \\
1330 \\
1320\end{array}$ & $\begin{array}{l}1020 \\
1040 \\
1050 \\
1040 \\
1020\end{array}$ & $\begin{array}{l}600 \\
570 \\
540 \\
520 \\
500\end{array}$ & $\begin{array}{l}290 \\
290 \\
290 \\
290 \\
290\end{array}$ & $\begin{array}{l}3540 \\
4640 \\
8480 \\
9810 \\
8290\end{array}$ & $\begin{array}{l}3180 \\
3060 \\
2950 \\
2880 \\
2820\end{array}$ & $\begin{array}{l}2770 \\
2740 \\
2870 \\
2820 \\
2900\end{array}$ & $\begin{array}{l}2180 \\
2110 \\
2040 \\
1910 \\
1810\end{array}$ & $\begin{array}{l}927 \\
869 \\
828 \\
793 \\
769\end{array}$ & $\begin{array}{l}550 \\
591 \\
680 \\
776 \\
833\end{array}$ & $\begin{array}{l}2300 \\
2140 \\
2310 \\
2480 \\
2760\end{array}$ \\
\hline $\begin{array}{l}16 \\
17 \\
18 \\
19 \\
20\end{array}$ & $\begin{array}{l}1050 \\
1560 \\
2170 \\
2270 \\
2480\end{array}$ & $\begin{array}{l}1300 \\
1250 \\
1210 \\
1190 \\
1160\end{array}$ & $\begin{array}{l}1000 \\
1100 \\
1200 \\
1300 \\
1300\end{array}$ & $\begin{array}{l}490 \\
480 \\
470 \\
470 \\
460\end{array}$ & $\begin{array}{l}290 \\
290 \\
295 \\
300 \\
330\end{array}$ & $\begin{array}{l}7860 \\
7640 \\
8240 \\
8670 \\
7960\end{array}$ & $\begin{array}{l}2770 \\
2710 \\
2660 \\
2600 \\
2580\end{array}$ & $\begin{array}{l}3230 \\
3530 \\
3700 \\
3540 \\
3430\end{array}$ & $\begin{array}{l}1730 \\
1660 \\
1580 \\
1510 \\
1430\end{array}$ & $\begin{array}{l}766 \\
752 \\
728 \\
756 \\
764\end{array}$ & $\begin{array}{l}798 \\
766 \\
765 \\
780 \\
767\end{array}$ & $\begin{array}{l}2960 \\
2850 \\
2710 \\
2610 \\
2510\end{array}$ \\
\hline $\begin{array}{l}21 \\
22 \\
23 \\
24 \\
25\end{array}$ & $\begin{array}{l}3120 \\
3300 \\
3140 \\
3080 \\
3150\end{array}$ & $\begin{array}{r}1080 \\
999 \\
1060 \\
1090 \\
1130\end{array}$ & $\begin{array}{l}1300 \\
1300 \\
1300 \\
1300 \\
1270\end{array}$ & $\begin{array}{l}450 \\
440 \\
440 \\
440 \\
430\end{array}$ & $\begin{array}{l}360 \\
400 \\
490 \\
600 \\
750\end{array}$ & $\begin{array}{l}7660 \\
7220 \\
7740 \\
8800 \\
9090\end{array}$ & $\begin{array}{r}2580 \\
4780 \\
7190 \\
9630 \\
16200\end{array}$ & $\begin{array}{l}3200 \\
3020 \\
2860 \\
2700 \\
2600\end{array}$ & $\begin{array}{l}1360 \\
1310 \\
1250 \\
1170 \\
1100\end{array}$ & $\begin{array}{l}745 \\
719 \\
698 \\
686 \\
681\end{array}$ & $\begin{array}{l}735 \\
708 \\
699 \\
702 \\
765\end{array}$ & $\begin{array}{l}2390 \\
2310 \\
2300 \\
2320 \\
2330\end{array}$ \\
\hline $\begin{array}{l}26 \\
27 \\
28 \\
29 \\
30 \\
31\end{array}$ & $\begin{array}{l}3270 \\
3350 \\
3190 \\
2820 \\
2470 \\
2240\end{array}$ & $\begin{array}{l}11: 0 \\
1140 \\
1150 \\
1150 \\
1110 \\
-\end{array}$ & $\begin{array}{l}1250 \\
1200 \\
1170 \\
1150 \\
1150 \\
1150\end{array}$ & $\begin{array}{l}420 \\
410 \\
390 \\
370 \\
350 \\
340\end{array}$ & $\begin{array}{c}1100 \\
1500 \\
1400 \\
- \\
--- \\
--\end{array}$ & $\begin{array}{l}8570 \\
7440 \\
6370 \\
5870 \\
5340 \\
4820\end{array}$ & $\begin{array}{r}18800 \\
13700 \\
10100 \\
8500 \\
7340 \\
-0-\end{array}$ & $\begin{array}{l}2520 \\
2390 \\
2260 \\
2190 \\
2370 \\
3250\end{array}$ & $\begin{array}{l}1170 \\
1490 \\
2100 \\
2450 \\
2480 \\
-0-\end{array}$ & $\begin{array}{l}695 \\
764 \\
768 \\
735 \\
701 \\
702\end{array}$ & $\begin{array}{r}800 \\
716 \\
679 \\
2520 \\
1460 \\
1530\end{array}$ & $\begin{array}{l}2280 \\
2180 \\
2070 \\
2000 \\
2010 \\
-\end{array}$ \\
\hline $\begin{array}{l}\text { TOTAL } \\
\text { MEAN } \\
\text { MAX } \\
\text { MIN } \\
\text { AC-FT }\end{array}$ & $\begin{array}{r}53717 \\
1733 \\
3350 \\
620 \\
10650\end{array}$ & $\begin{array}{r}41249 \\
1375 \\
2090 \\
999 \\
81820\end{array}$ & $\begin{array}{r}33641 \\
1085 \\
1300 \\
672 \\
66730\end{array}$ & $\begin{array}{r}17800 \\
574 \\
1100 \\
340 \\
35310\end{array}$ & $\begin{array}{r}12575 \\
449 \\
1500 \\
290 \\
24940\end{array}$ & $\begin{array}{r}170890 \\
5513 \\
9810 \\
1200 \\
339000\end{array}$ & $\begin{array}{r}167590 \\
5586 \\
18800 \\
2580 \\
332400\end{array}$ & $\begin{array}{r}102620 \\
3310 \\
6480 \\
2190 \\
203500\end{array}$ & $\begin{array}{r}69170 \\
2306 \\
5050 \\
1100 \\
137200\end{array}$ & $\begin{array}{r}30532 \\
985 \\
2210 \\
681 \\
60560\end{array}$ & $\begin{array}{r}24967 \\
805 \\
2520 \\
550 \\
49520\end{array}$ & $\begin{array}{r}67713 \\
2257 \\
3640 \\
983 \\
134300\end{array}$ \\
\hline $\begin{array}{ll}\text { CAL } & \text { YR } \\
\text { WPR } & \text { YR }\end{array}$ & $\begin{array}{l}984 \\
985\end{array}$ & 1 & $\begin{array}{l}900 \\
464\end{array}$ & $\begin{array}{l}\text { MEAN } \\
\text { MEAN }\end{array}$ & $\begin{array}{l}4459 \\
2171\end{array}$ & $\begin{array}{l}\text { MAX } \\
\text { MAX }\end{array}$ & $\begin{array}{l}49000 \\
18800\end{array}$ & $\begin{array}{l}\text { MIN } \\
\text { MIN }\end{array}$ & $\begin{array}{l}440 \\
290\end{array}$ & $\begin{array}{ll}\text { C-FT } & 32 \\
\text { C-FT } & 15\end{array}$ & $\begin{array}{l}00 \\
00\end{array}$ & \\
\hline
\end{tabular}


06486000 MISSOURI RIVER AT SIOUX CITY, IA

(National stream-quality accounting network station)

LOCATION,--Lat. $42^{\circ} 29^{\prime} 09^{\prime \prime}$, long $96^{\circ} 24^{\prime} 49^{\prime \prime}$, in NWl/4 sEl/4 sec.16 T.29 N., R.9 E. sixth prinicipal meridian, Dakota County, Nebraska, Hydrologic Unit 10230001 , on right bank on upstream side of bridge on U.S. Highway 20 and 77 at South Sioux City, Nebraska, $1.9 \mathrm{mi}$ downstream from Big Sioux River, and at mile 732.2 .

DRAINAGE. $-314,600 \mathrm{mi}^{2}$, approximately.

\section{WATER-DISCHARGE RECORDS}

PERIOD OF RECORD.--October 1897 to current year in reports of Geological survey. Prior to October 1928 and october 1931 to September 1938, monthly discharges only, published in wSP 1310. January 1879 to December 1890 (monthly discharges only) in House Document 238, 73rd Congress, 2d session, Missouri River. Gage-height records collected in this vicinity September 1878 to December 1899 are contained in reports of Missouri River Commission and since July 1889 are contained in reports of $U . S$. Weather Bureau.

REVISED RECORDS.--WSP 716: 1929-30. WSP 876: Drainage area.

GAGE.-Water-stage recorder, Datum of gage is $1,056.98 \mathrm{ft}$ above NGVD. Sept. 2 , 1878, to Dec, 31 , 1905, nonrecording gauges at various locations within $1.7 \mathrm{mi}$ of present site and at various datums. Jan. 1 , 1906 to Feb. 14, 1935, nonrecording gage, and Feb. 15, 1935 to sept. 30, 1969 , water-stage recorder at site 227 ft downstream at datum $19.98 \mathrm{ft}$ higher, and oct. 1,1969 to sept. 30,1970 at datum $20.00 \mathrm{ft}$ higher. Oct. 1 , 1970 to Jan. 30, 1981, water-stage recorder at site $227 \mathrm{ft}$ dwonstream at present datum.

REMARKS.--Estimated daily discharges: Dec. 25,30 , Jan. $1,2,11,12,15,16,20-22,25$, Jan. 28 to Feb. 5 and Feb. 9, 10. Records good except for estimated daily discharges, which are poor. Flow regulated by upstream main-stem reservoirs. U.S. National Weather Service gage-height telemeter at station. U.S. Army Corps of Engineers rain-gage and gage-height satellite data collection platform at station.

AVERAGE DISCHARGE. --88 years $32,050 \mathrm{ft}^{2} / \mathrm{s}, 23,220,000$ acre- $\mathrm{ft} / \mathrm{yr}$.

EXTREMES FOR PERIOD OF RECORD.--Maximum discharge, 441,000 ft/s Apr. 14, 1952, gage height, 24.28 ft, datum then in use; minimum, 2,500 $\mathrm{ft}^{2} / \mathrm{s}$ Dec. 29, 1941; minimum gage height, $9.00 \mathrm{ft}$ Jan. 8 , 1980, based on gage readings at site $14 \mathrm{mi}$ downstream.

EXTREMES FOR CURRENT YEAR,--Maximum discharges, $56,600 \mathrm{ft}^{2} / \mathrm{s}$ Apr, 23 gage height, $23.94 \mathrm{ft}$; minimum daily discharge, $17,000 \mathrm{ft} / \mathrm{s}$ Jan. 31 ; minimum gage height not determind, occurred during period of no gage-height record Jan. 31 .

DISCHARGE, IN CUBIC FEET PER SECOND, WATER YEAR OCTOBER 1984 TO SEPTEMBER 1985 MEAN VALUES

\begin{tabular}{|c|c|c|c|c|c|c|c|c|c|c|c|c|}
\hline DAY & OCT & NOV & DEC & JAN & FEB & MAR & APR & MAY & JUN & JUL & AOG & SEP \\
\hline $\begin{array}{l}1 \\
2 \\
3 \\
4 \\
5\end{array}$ & $\begin{array}{l}46200 \\
46400 \\
46100 \\
45600 \\
46000\end{array}$ & $\begin{array}{l}48700 \\
48000 \\
47800 \\
47800 \\
47800\end{array}$ & $\begin{array}{l}45800 \\
44000 \\
40500 \\
36700 \\
33800\end{array}$ & $\begin{array}{l}19600 \\
19000 \\
20600 \\
21900 \\
21700\end{array}$ & $\begin{array}{l}18600 \\
20300 \\
20600 \\
20400 \\
20300\end{array}$ & $\begin{array}{l}23200 \\
23300 \\
24000 \\
27900 \\
24400\end{array}$ & $\begin{array}{l}32800 \\
32800 \\
33000 \\
33800 \\
33000\end{array}$ & $\begin{array}{l}32100 \\
31800 \\
31800 \\
31200 \\
30800\end{array}$ & $\begin{array}{l}33600 \\
35700 \\
36100 \\
35300 \\
33600\end{array}$ & $\begin{array}{l}35000 \\
34500 \\
33900 \\
33700 \\
33300\end{array}$ & $\begin{array}{l}32900 \\
32700 \\
33000 \\
32600 \\
32300\end{array}$ & $\begin{array}{l}31900 \\
32900 \\
33000 \\
32600 \\
32800\end{array}$ \\
\hline $\begin{array}{r}6 \\
7 \\
8 \\
9 \\
10\end{array}$ & $\begin{array}{l}46500 \\
47200 \\
46600 \\
46500 \\
46700\end{array}$ & $\begin{array}{l}47800 \\
47700 \\
47600 \\
48000 \\
48200\end{array}$ & $\begin{array}{l}31700 \\
31000 \\
29800 \\
27100 \\
26500\end{array}$ & $\begin{array}{l}21200 \\
20800 \\
20700 \\
20600 \\
20800\end{array}$ & $\begin{array}{l}20000 \\
20100 \\
20300 \\
20300 \\
20400\end{array}$ & $\begin{array}{l}23400 \\
23900 \\
24300 \\
25200 \\
26800\end{array}$ & $\begin{array}{l}32700 \\
32900 \\
33000 \\
32000 \\
31400\end{array}$ & $\begin{array}{l}30800 \\
31400 \\
32400 \\
32800 \\
33300\end{array}$ & $\begin{array}{l}32700 \\
34000 \\
34600 \\
34000 \\
33600\end{array}$ & $\begin{array}{l}32500 \\
31700 \\
31000 \\
31200 \\
31200\end{array}$ & $\begin{array}{l}32200 \\
32300 \\
32300 \\
32300 \\
32400\end{array}$ & $\begin{array}{l}33000 \\
33500 \\
33000 \\
31400 \\
31800\end{array}$ \\
\hline $\begin{array}{l}11 \\
12 \\
13 \\
14 \\
15\end{array}$ & $\begin{array}{l}46600 \\
46800 \\
46700 \\
46700 \\
47700\end{array}$ & $\begin{array}{l}47300 \\
47000 \\
47100 \\
47500 \\
47600\end{array}$ & $\begin{array}{l}26300 \\
26300 \\
24900 \\
25400 \\
26700\end{array}$ & $\begin{array}{l}20500 \\
20300 \\
21100 \\
22200 \\
19800\end{array}$ & $\begin{array}{l}19900 \\
20400 \\
20800 \\
20600 \\
20800\end{array}$ & $\begin{array}{l}27800 \\
28900 \\
29200 \\
30200 \\
32200\end{array}$ & $\begin{array}{l}31700 \\
31800 \\
31200 \\
30900 \\
30800\end{array}$ & $\begin{array}{l}33100 \\
33500 \\
33100 \\
34400 \\
33400\end{array}$ & $\begin{array}{l}33700 \\
33500 \\
33200 \\
33300 \\
33600\end{array}$ & $\begin{array}{l}31500 \\
31600 \\
31800 \\
32000 \\
32200\end{array}$ & $\begin{array}{l}32000 \\
33000 \\
32700 \\
32400 \\
32400\end{array}$ & $\begin{array}{l}31800 \\
32000 \\
33700 \\
33600 \\
32200\end{array}$ \\
\hline $\begin{array}{l}16 \\
17 \\
18 \\
19\end{array}$ & $\begin{array}{l}47200 \\
46800 \\
47200 \\
49400 \\
49000\end{array}$ & $\begin{array}{l}46900 \\
46500 \\
46400 \\
46300 \\
46300\end{array}$ & $\begin{array}{l}27100 \\
25800 \\
24200 \\
25000 \\
24900\end{array}$ & $\begin{array}{l}19900 \\
20900 \\
21500 \\
20500 \\
18500\end{array}$ & $\begin{array}{l}21100 \\
21300 \\
21300 \\
21400 \\
21400\end{array}$ & $\begin{array}{l}32200 \\
32100 \\
32400 \\
33000 \\
33700\end{array}$ & $\begin{array}{l}30600 \\
30600 \\
30100 \\
30400 \\
30600\end{array}$ & $\begin{array}{l}31800 \\
31100 \\
31300 \\
32500 \\
32200\end{array}$ & $\begin{array}{l}33700 \\
33400 \\
32300 \\
32400 \\
32500\end{array}$ & $\begin{array}{l}32400 \\
33500 \\
34300 \\
34500 \\
34000\end{array}$ & $\begin{array}{l}32500 \\
33200 \\
32600 \\
32400 \\
32200\end{array}$ & $\begin{array}{l}32900 \\
32800 \\
31600 \\
31900 \\
32200\end{array}$ \\
\hline $\begin{array}{l}21 \\
22 \\
23 \\
24\end{array}$ & $\begin{array}{l}48800 \\
49000 \\
48900 \\
49200 \\
49400\end{array}$ & $\begin{array}{l}46200 \\
46100 \\
46000 \\
46300 \\
46500\end{array}$ & $\begin{array}{l}24800 \\
22600 \\
21700 \\
21200 \\
19100\end{array}$ & $\begin{array}{l}18400 \\
19700 \\
22000 \\
23500 \\
22900\end{array}$ & $\begin{array}{l}22300 \\
22100 \\
22100 \\
22400 \\
23000\end{array}$ & $\begin{array}{l}33600 \\
33500 \\
33500 \\
33300 \\
33600\end{array}$ & $\begin{array}{l}31700 \\
37900 \\
49500 \\
43200 \\
30600\end{array}$ & $\begin{array}{l}32200 \\
32100 \\
32100 \\
31900 \\
32600\end{array}$ & $\begin{array}{l}32900 \\
33100 \\
32900 \\
32800 \\
33000\end{array}$ & $\begin{array}{l}32400 \\
32000 \\
32200 \\
32500 \\
32700\end{array}$ & $\begin{array}{l}32500 \\
32300 \\
32500 \\
32500 \\
32000\end{array}$ & $\begin{array}{l}31900 \\
31800 \\
32100 \\
32000 \\
32000\end{array}$ \\
\hline $\begin{array}{l}26 \\
27 \\
28 \\
29 \\
30\end{array}$ & $\begin{array}{l}49700 \\
50200 \\
50000 \\
49800 \\
49300 \\
48900\end{array}$ & $\begin{array}{c}46600 \\
46300 \\
46000 \\
46000 \\
46000 \\
-\end{array}$ & $\begin{array}{l}21800 \\
22400 \\
23200 \\
21600 \\
19500 \\
20700\end{array}$ & $\begin{array}{l}21900 \\
23500 \\
23500 \\
22600 \\
23100 \\
17000\end{array}$ & $\begin{array}{r}23900 \\
23900 \\
23400 \\
- \\
-- \\
--\end{array}$ & $\begin{array}{l}33900 \\
34600 \\
33600 \\
33000 \\
32600 \\
32800\end{array}$ & $\begin{array}{r}31300 \\
33700 \\
31000 \\
27400 \\
26400 \\
\end{array}$ & $\begin{array}{l}32700 \\
32400 \\
32100 \\
32300 \\
32700 \\
33200\end{array}$ & $\begin{array}{r}35400 \\
39100 \\
36000 \\
35500 \\
35300 \\
-\ldots\end{array}$ & $\begin{array}{l}32600 \\
32600 \\
32600 \\
32500 \\
32600 \\
32800\end{array}$ & $\begin{array}{l}31800 \\
31900 \\
31800 \\
33400 \\
34900 \\
31600\end{array}$ & $\begin{array}{r}32000 \\
31800 \\
31800 \\
32000 \\
32200\end{array}$ \\
\hline $\begin{array}{l}\text { TOTAL } \\
\text { MEAN } \\
\text { MAX } \\
\text { MIN } \\
\text { AC-ET }\end{array}$ & $\begin{array}{r}1481100 \\
47780 \\
50200 \\
45600 \\
2938000\end{array}$ & $\begin{array}{r}1410300 \\
47010 \\
48700 \\
46000 \\
2797000\end{array}$ & $\begin{array}{r}842100 \\
27160 \\
45800 \\
19100 \\
1670000\end{array}$ & $\begin{array}{r}650200 \\
20970 \\
23500 \\
17000 \\
1290000\end{array}$ & $\begin{array}{r}593400 \\
21190 \\
23900 \\
18600 \\
1177000\end{array}$ & $\begin{array}{r}926100 \\
29870 \\
34600 \\
23200 \\
1837000\end{array}$ & $\begin{array}{r}978800 \\
32630 \\
49500 \\
26400 \\
1941000\end{array}$ & $\begin{array}{r}1001100 \\
32290 \\
34400 \\
30800 \\
1986000\end{array}$ & $\begin{array}{r}1020800 \\
34030 \\
39100 \\
32300 \\
2025000\end{array}$ & $\begin{array}{r}1013300 \\
32690 \\
35000 \\
31000 \\
2010000\end{array}$ & $\begin{array}{r}1007600 \\
32500 \\
34900 \\
31600 \\
1999000\end{array}$ & $\begin{array}{r}970200 \\
32340 \\
33700 \\
31400 \\
1924000\end{array}$ \\
\hline $\begin{array}{ll}\text { CAL YR } \\
\text { WIR YR }\end{array}$ & $\begin{array}{l}1984 \\
1985\end{array}$ & $\begin{array}{l}\text { TOTAL } \\
\text { TOTAL }\end{array}$ & $\begin{array}{l}184800 \\
895000\end{array}$ & $\begin{array}{l}\text { MEAN } \\
\text { MEAN }\end{array}$ & $\begin{array}{l}38760 \\
32590\end{array}$ & $\begin{array}{l}\text { MAX } \\
\text { MAX }\end{array}$ & $\begin{array}{r}103000 \\
50200\end{array}$ & MIN & $\begin{array}{l}100 \\
00\end{array}$ & 223 & & \\
\hline
\end{tabular}


PERIOD OF RECORD.--Water years 1972 to current year. Daily sediment loads october 1954 to september 1971 in reports of Corps of Engineers. Samples for particle-size distribution were collected from boat cross-section 0.2 mile downstream from gage.

PERIOD OF DAILY RECORD.--

SPECIFIC CONDUCTANCE: October 1972 to September 1976, November 1977 to September 1981.

WATER TEMPERATURES: October 1971 to September 1976, November 1977 to September 1981.

SUSPENDED-SEDIMENT DISCHARGE: October 1971 to September 1976.

EXTREMES FOR PERIOD OF DAILY RECORD -

SPECIFIC CONDUCTANCE: Maximum daily, 950 microsiemens June 17, 19, 1981; minimum daily, 410 microsiemens Mar. 22,1978

WATER TEMPERATURES: Maximum daily, $28.0^{\circ} \mathrm{C} \mathrm{July} 30,1976$ and Aug. 7,$1979 ; \mathrm{minimum}$ daily, $0.0^{\circ} \mathrm{C}$ on many days during the winter periods.

SEDIMENT CONCENTRATIONS: Maximum da11y mean, 1,620 mg/L Nov. 20, 1972; minimum daily mean, $42 \mathrm{mg} / \mathrm{L}$ Dec. 29 , 1975. SEDIMENT LOADS: Maximum daily, 222,000 tons Nov. 20, 1972; minimum daily, 2,970 tons Dec. $29,1975$.

WATER QUALITY DATA, WATER YEAR OCTOBER 1984 TO SEPTEMBER 1985

\begin{tabular}{|c|c|c|}
\hline DATE & TIME & $\begin{array}{r}\text { STREA } \\
\text { FLOW } \\
\text { INSTA } \\
\text { TANEO } \\
\text { (CFS } \\
10006\end{array}$ \\
\hline $\begin{array}{c}1984 \\
15 \ldots \\
1985\end{array}$ & $13: 00$ & 46100 \\
\hline $\begin{array}{l}08 \ldots \\
\text { MAR }\end{array}$ & $12: 30$ & 21300 \\
\hline${ }_{\operatorname{MAY}}^{12} \ldots$ & $12: 00$ & 28900 \\
\hline$\underset{\text { JUN }}{07} \cdots$ & $13: 00$ & 30900 \\
\hline AUG & $14: 10$ & 31100 \\
\hline $26 \ldots$ & $14: 45$ & 31700 \\
\hline
\end{tabular}

$\begin{array}{cc}\text { HARD- } & \text { CALCIUM } \\ \text { NESS } & \text { DIS- } \\ \text { (MG/L } & \text { SOLVED } \\ \text { AS } & \text { (MG/L } \\ \text { CACO3) } & \text { AS CA) } \\ (00900) & (00915)\end{array}$

CIFIC

CON-

DUCT-

ANCE

(00095)
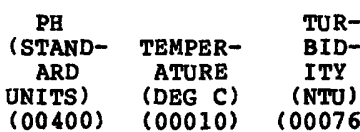

(00400)

(00010)
(00076)

$\begin{array}{ccc} & \text { OXYGEN, } & \text { BARO- } \\ & \text { DIS- } & \text { METRIC } \\ & \text { SOLVED } & \text { PRES- } \\ \text { OXYGEN, } & \text { (PER- } & \text { SURE } \\ \text { DIS- } & \text { CENT } & \text { (MM } \\ \text { SOLVED } & \text { SATUR- } & \text { OF } \\ (M G / L) & \text { ATION) } & \text { HG) } \\ (00300) & (00301) & (00025)\end{array}$

$$
\begin{aligned}
& \text { COLI- } \\
& \text { FORM, } \\
& \text { FECAL, } \\
& 0.7 \\
& \text { UM-MF, } \\
& \text { (COLS.' } \\
& 100 \text { ML) } \\
& (31625)
\end{aligned}
$$

STREPOCOCCI FECAL, KF AGAR (COLS. PER $100 \mathrm{ML})$ (31673)

BONATE

(MG/L

\begin{tabular}{|c|c|c|}
\hline 825 & 8.0 & 5.5 \\
\hline 810 & 8.5 & 0.0 \\
\hline 681 & 8.1 & 2.0 \\
\hline 830 & 7.8 & 17.0 \\
\hline 760 & 8.1 & 24.5 \\
\hline 755 & 8.4 & 22.0 \\
\hline $\begin{array}{l}\text { AGNE- } \\
\text { IUM, } \\
\text { OIS- } \\
\text { LVED } \\
\text { IG/L } \\
\text { MG) } \\
925 \text { ) }\end{array}$ & $\begin{array}{c}\text { SODIUM, } \\
\text { DIS- } \\
\text { SOLVED } \\
\text { (MG/L } \\
\text { AS NA) } \\
(00930)\end{array}$ & $\begin{array}{r}\text { PERCENT } \\
\text { SODIUU } \\
(00932)\end{array}$ \\
\hline
\end{tabular}

18
9.1
57
32
21
18

\begin{tabular}{|c|c|}
\hline 11.6 & 96 \\
\hline 15.2 & 107 \\
\hline 13.2 & 100 \\
\hline 9.8 & 106 \\
\hline 7.6 & 96 \\
\hline 8.3 & 99 \\
\hline $\begin{array}{l}\text { OTAS- } \\
\text { SIUM, } \\
\text { DIS- } \\
\text { OLVED } \\
\text { MG/L } \\
\text { S R) } \\
0935 \text { ) }\end{array}$ & $\begin{array}{c}\text { ALKA- } \\
\text { LINITY } \\
\text { FIELD } \\
\text { (MG/L } \\
\text { AS } \\
\text { CACO3) } \\
(00410)\end{array}$ \\
\hline
\end{tabular}

$\begin{array}{ccc}\text { SODIUM } & \text { POTAS- } & \text { ALKA- } \\ \text { AD- } & \text { SIUM, } & \text { LINITY } \\ \text { SORP- } & \text { DIS- } & \text { FIELD } \\ \text { TION } & \text { SOLVED } & \text { (MG/L } \\ \text { RATIO } & (M G / L & \text { AS } \\ & \text { AS R) } & \text { CACO3) } \\ (00931) & (00935) & (00410)\end{array}$

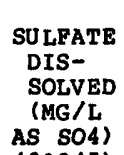

$$
\begin{aligned}
& \text { CHLO- } \\
& \text { RIDE, } \\
& \text { DIS- } \\
& \text { SOLVED } \\
& \text { (MG/L } \\
& \text { AS CL) }
\end{aligned}
$$

\begin{tabular}{|c|c|c|c|c|c|}
\hline 5.2 & 180 & 240 & 13 & 0.5 & 7.7 \\
\hline 5.1 & 210 & 230 & 13 & 0.5 & 8.8 \\
\hline 5.9 & 155 & 200 & 11 & 0.4 & 10 \\
\hline 6.5 & 180 & 230 & 11 & 0.5 & 9.9 \\
\hline 5.5 & 183 & 220 & 11 & 0.4 & 6.2 \\
\hline 5.5 & 185 & 220 & 10 & 0.5 & 7.3 \\
\hline $\begin{array}{l}\text { ITRO- } \\
\text { GEN, } \\
\text { IMONIA } \\
\text { DIS- } \\
\text { SOLVED } \\
\text { MG/L } \\
\text { NB4) } \\
(1846)\end{array}$ & $\begin{array}{c}\text { NITRO- } \\
\text { GEN, AY- } \\
\text { MONIA + } \\
\text { ORGANIC } \\
\text { TOTAL } \\
\text { (MG/L } \\
\text { AS N) } \\
(00625)\end{array}$ & $\begin{array}{l}\text { PHOS- } \\
\text { PHORUS, } \\
\text { ORTHO, } \\
\text { DIS- } \\
\text { SOLVED } \\
\text { (MG/L } \\
\text { AS P) } \\
\text { (00671) }\end{array}$ & $\begin{array}{l}\text { PHOS- } \\
\text { PHORUS } \\
\text { TOTAL } \\
\text { (MG/L } \\
\text { AS PO4) } \\
(71886)\end{array}$ & $\begin{array}{l}\text { PHOS- } \\
\text { PHORUS, } \\
\text { DIS- } \\
\text { SOLVED } \\
\text { (MG/L } \\
\text { AS P) } \\
(00666)\end{array}$ & $\begin{array}{c}\text { PHOS- } \\
\text { PHORUS, } \\
\text { TOTAL } \\
\text { (MG/L } \\
\text { AS P) } \\
(00665)\end{array}$ \\
\hline
\end{tabular}
$(00945) \quad(00940)$

NOV 1984

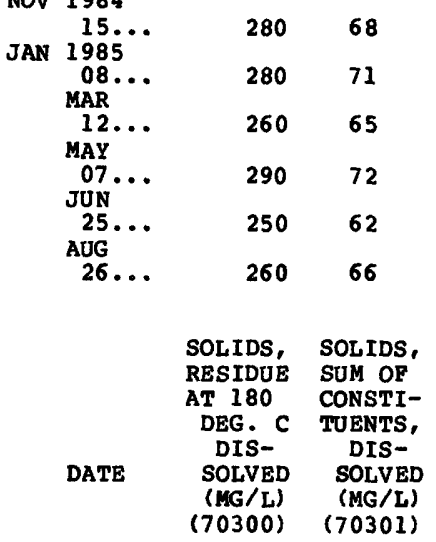

$\begin{array}{ll}26 & 68 \\ 26 & 71 \\ 23 & 51 \\ 27 & 59 \\ 24 & 69 \\ 24 & 67\end{array}$

$\begin{array}{ll}34 & 2 \\ 35 & 2 \\ 30 & 1 \\ 30 & 2 \\ 37 & 2 \\ 35 & 2\end{array}$

$\begin{array}{ccc}\text { SOLIDS, } & \text { SOLIDS, } & \text { NITRO- } \\ \text { GEN, } \\ \text { DIS- } & \text { DIS- } & \text { NO2+NO3 } \\ \text { SOLVED } & \text { SOLVED } & \text { DIS- } \\ \text { (TONS } & \text { (TONS } & \text { SOLVED } \\ \text { PER } & \text { PER } & \text { (MG/L } \\ \text { AC-FT) } & \text { DAY) } & \text { AS N) } \\ (70303) & (70302) & (00631)\end{array}$

NITRO-
GEN,
AMMONIA
DIS-
SOLVED
(MG/L
AS N)
$(00608)$

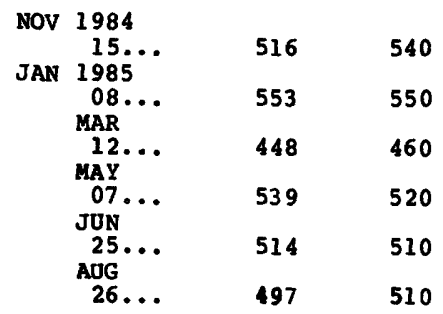

0.28

0.48

1.10

0.56

0.24

$<0.10$
0.05

\begin{abstract}
1.4
\end{abstract}
0.02

0.06

0.8

0.19

1.7

0.02

0.08

0.03

0.02

0.06

5.3

0.6

0.02

0.01

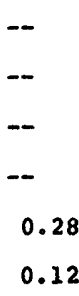

0.01

0.09

0.01

0.07

0.11

0.47

0.04

0.09

0.01

0.09

$x$ Results based on colony count outside ideal range. 


$\begin{array}{lccc} & \text { SEDI- } & \text { SED. } & \\ & \text { MENT, } & \text { SUSP. } & \\ \text { SEDI- } & \text { DIS- } & \text { SIEVE } & \text { ARSENIC } \\ \text { MENT, } & \text { CHARGE, } & \text { DIAM. } & \text { DIS- } \\ \text { SUS- } & \text { SUS- } & \text { FINER } & \text { SOLVED } \\ \text { PENDED } & \text { PENDED } & \text { THAN } & \text { (UG/L } \\ (M G / L) & (\text { T /DAY) } & .062 M M & \text { AS AS) } \\ (80154) & (80155) & (70331) & (01000)\end{array}$

$\begin{array}{cc}\text { ALUM- } & \\ \text { INUM, } & \text { BARIUM, } \\ \text { DIS- } & \text { DIS- } \\ \text { SOLVED } & \text { SOLVED } \\ \text { (UG/L } & \text { (UG/L } \\ \text { AS AL) } & \text { AS BA) } \\ (01106) & (01005)\end{array}$

$\begin{array}{lc}\text { BERYL- } & \\ \text { LIUM, } & \text { CADMIUM } \\ \text { DIS- } & \text { DIS- } \\ \text { SOLVED } & \text { SOLVED } \\ \text { (UG/L } & \text { (UG/L } \\ \text { AS BE) } & \text { AS CD) } \\ (01010) & (01025)\end{array}$

CHRO-

MIUM, COBALT, COPPER, IRON, DIS- DIS- DIS- DISSOLVED SOLVED SOLVED SOLVED (UG/L (UG/L (UG/L (UG/L

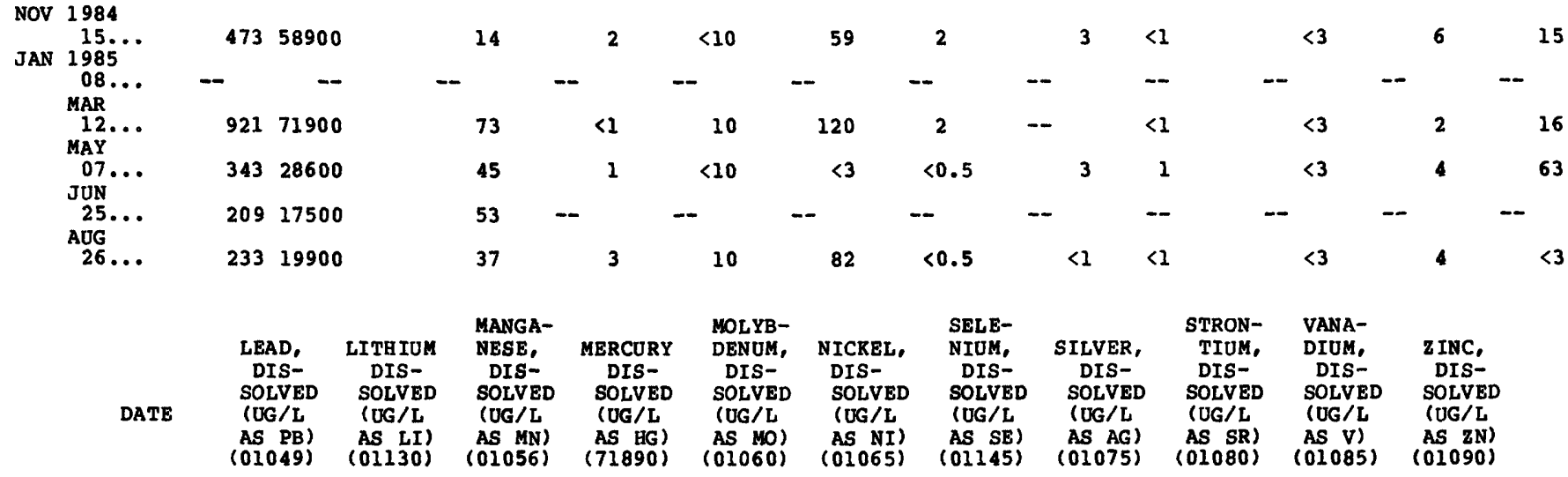

NOV 1984

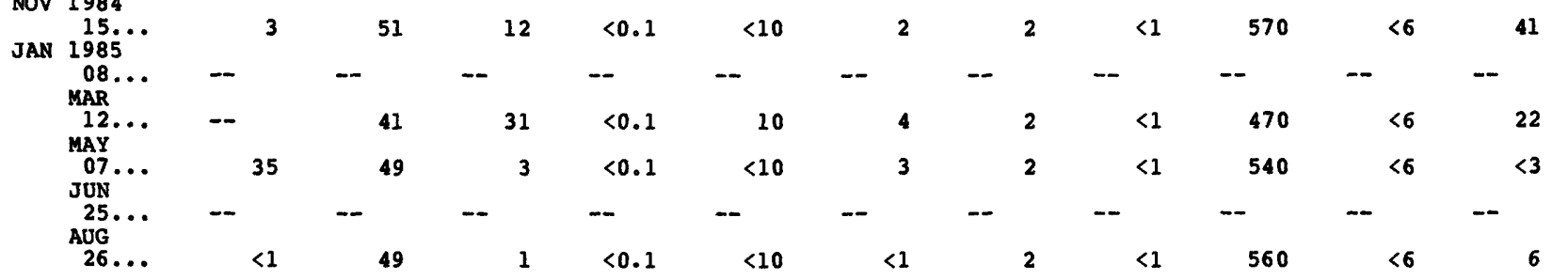


WATER-QUALITY RECORDS

PARTICLE SIZE DISTRIBUTION OF SUSPENDED-SEDIMENT, WATER YEAR OCTOBER 1984 TO SEPTEMBER 1985

\begin{tabular}{|c|c|c|c|c|c|c|c|c|c|c|c|c|c|c|c|c|}
\hline TE & TIME & $\begin{array}{l}\text { SAMPLE } \\
\text { LOC- } \\
\text { ATION, } \\
\text { CROSS } \\
\text { SECTION } \\
\text { (FT FM } \\
\text { L BANK) }\end{array}$ & $\begin{array}{l}\text { DEPTH } \\
\text { AT } \\
\text { SAMPLE } \\
\text { LOC- } \\
\text { ATION, } \\
\text { TOTAL } \\
\text { (EEET) }\end{array}$ & $\begin{array}{l}\text { SAM- } \\
\text { PLING } \\
\text { DEPTH } \\
\text { (FEET) }\end{array}$ & $\begin{array}{l}\text { STREAM } \\
\text { VELOC- } \\
\text { ITY, } \\
\text { POINT) } \\
\text { (FPS) }\end{array}$ & $\begin{array}{l}\text { SEDI- } \\
\text { MENT, } \\
\text { SUS- } \\
\text { PENDED } \\
(M G / L)\end{array}$ & $\begin{array}{l}\text { SED. } \\
\text { SUSP. } \\
\text { FALL } \\
\text { DIAM. } \\
\text { FINER } \\
\text { THAN } \\
.004 \text { MM }\end{array}$ & $\begin{array}{l}\text { SED. } \\
\text { SUSP. } \\
\text { FALL } \\
\text { DIAM. } \\
\text { FINER } \\
\text { THAN } \\
.062 \text { MM }\end{array}$ & 8 & $\begin{array}{l}\text { SED. } \\
\text { SUSP. } \\
\text { FALL } \\
\text { DIAM. } \\
\text { FINER } \\
\text { THAN } \\
25 \text { MM }\end{array}$ & $\begin{array}{l}8 \\
.2\end{array}$ & $\begin{array}{l}\text { SED. } \\
\text { SUSP. } \\
\text { FALL } \\
\text { DIAM. } \\
\text { FINER } \\
\text { THAN } \\
50 \text { MM }\end{array}$ & 8 & $\begin{array}{l}\text { SED. } \\
\text { SUSP. } \\
\text { FALL } \\
\text { DIAM. } \\
\text { FINER } \\
\text { THAN } \\
500 \mathrm{MM}\end{array}$ & $B$ & $\begin{array}{l}\text { SED. } \\
\text { SUSP. } \\
\text { FALL } \\
\text { DIAM. } \\
\text { FINER } \\
\text { THAN } \\
.00 \mathrm{MM}\end{array}$ \\
\hline
\end{tabular}

OCT 1984

$11 . .$. WATER TEMPERATURE, $16.0^{\circ} \mathrm{C}$ (1005-1300 HOURS); DISCHARGE, $45,000 \mathrm{ft} / \mathrm{s}$.

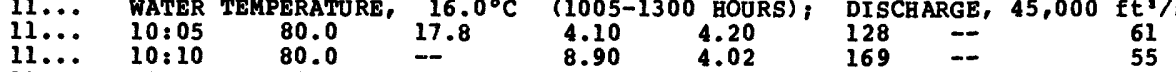

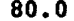

11.0

11.0

80.0

$\begin{array}{rr}8.90 & 4.02 \\ 12.7 & 3.59\end{array}$

$11 \cdots \quad 10: 25$

$11 \ldots \quad 10: 30$

80.0
80.0

-- $\quad 12.7$

80.0

$\overline{-1}$

$11 \ldots .10: 40$

$11 \ldots 10: 45$

$11 \ldots 10: 50$

180

180
180

$11 \ldots .010: 55$

180
180

18.0

16.0

2.81

$\begin{array}{ll}128 & - \\ 169 & -\end{array}$

16.8

2.76

4230
$303 \quad--$

$\begin{array}{cc}- & 9.10 \\ - & 13.0\end{array}$

1.76
5.32

$\begin{array}{ll}377 & - \\ 218 & -\end{array}$

180

$11 \ldots 11: 05 \quad 180$

$11 \ldots \quad 11: 10$

305
305

$\begin{array}{lll}11 \ldots \ldots & 11: 15 & 305 \\ 11 \ldots . & 11: 20 & 305\end{array}$

$11 \ldots \ldots \quad 11: 22$

305
305

$11 \ldots 11: 25$

305

$\begin{array}{lll}11 \ldots . . & 11: 30 & 305 \\ 11 \ldots & 11: 35 & 305\end{array}$

$\begin{array}{lll}11 \ldots . . & 11: 35 & 305 \\ 11 \ldots & 11: 40 & 390\end{array}$

$11 \ldots . . \quad 11: 45 \quad 390$

$\begin{array}{lll}11 \ldots . & 11: 50 & 390 \\ 11 \ldots & 11: 55 & 390\end{array}$

$11 \ldots . .12: 00 \quad 390$

$11 \ldots . . \quad 12: 04 \quad 390$

$11 \ldots . .12: 08$

$11 \ldots .12: 10$

$11 \ldots .12: 15$

$11 \ldots .12: 20$

$11 \ldots .12: 25$

$11 \ldots . \quad 12: 30$

$\begin{array}{lll}13.0 & 3.42 \\ - & 15.2 & 3.42\end{array}$

$\begin{array}{lll}1 & 15.2 & 3.42 \\ -\quad 16.4 & 3.57\end{array}$

$\overline{17.6} \quad 4.10$

$\begin{array}{ll}17.6 & 4.10 \\ - & 8.80\end{array}$

17.6

12.6

$\begin{array}{ll}- & 14.7 \\ - & 15.8\end{array}$

$\overline{21.2} \quad 16.6$

$\begin{array}{ll}- & 10.6 \\ - & 15.1\end{array}$

- $\quad 17.7$

3.28

322
465

$\begin{array}{ll}465 & -- \\ 638 & -- \\ 536 & --\end{array}$

5367
767

3.28
5.85

$\ldots$

$11 \ldots 12: 40$

390
470

470
470

470
470

470
470
470

-- $\quad 19.1$

$-20.4$

$21.2 \quad 4.90$

5.89
4.59

$-4.59 \quad 486$

486

$\ldots \quad 10.6$

15.1

4.80
4.72

$4.65=$

40

61
55
54
96
27
28
48
28
19
16
15
13
$-\quad$
$-\quad$
-10
-10
--16
-1
40
33
24
17
16
14
13
52
47
23
16
11
13
9

\begin{tabular}{r}
78 \\
75 \\
67 \\
97 \\
47 \\
42 \\
63 \\
46 \\
30 \\
28 \\
25 \\
26 \\
$-\quad$ \\
$-\quad$ \\
-- \\
$-\quad$ \\
\hline- \\
-56 \\
\\
\\
\hline 30 \\
39 \\
27 \\
27 \\
24 \\
23 \\
69 \\
61 \\
30 \\
22 \\
15 \\
18 \\
16
\end{tabular}

100
98
98
100
96
93
100
97
89
86
80
89

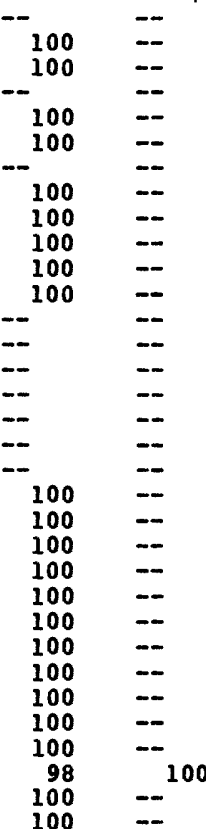

MAY 1985

02... WATER TEMPERATURE,

02... 09:45

MPERATURE,
80.0
80.0
80.0
80.0
80.0
190
190
190
190
190
290
290
290
290
290
290
290
385
385
385
385
385
385
475
475
475
475
475
475

$16.0^{\circ} \mathrm{C}$

(0945-1330 HOURS);

DISCHARGE, $31,700 \mathrm{ft} / \mathrm{s}$.

2... $09: 55$

9.70

$2.10 \quad 3.55$

, DISCHARG

$02 \ldots 10: 15$

$\begin{array}{ll}02 \ldots & 10: 15 \\ 02 \ldots & 10: 25\end{array}$

$02 \ldots 10: 30$

$02 \ldots 10: 35$

$02 \ldots 10: 40$

$02 \ldots 10: 45$

$02 \ldots \quad 10: 50$

$02 \ldots \ldots \quad 11: 05$

$02 \ldots \quad 11: 10$

$02 \ldots \quad 11: 15$

$02 \ldots \quad 11: 20$

$02 \ldots .11: 25$

$02 \ldots \quad 11: 30$

$02 \ldots \quad 11: 45$

$02 \ldots \quad 11: 50$

$02 \ldots \ldots 12: 10$

$02 \ldots \ldots 12: 15$

$02 \ldots . .12: 25$

$02 \ldots 12: 30$

$02 \ldots 12: 35$

$02 \ldots \quad 12: 40$

$02 \ldots 12: 45$

$\begin{array}{ll}02 \ldots & 12: 50 \\ 02 \ldots & 12: 55\end{array}$

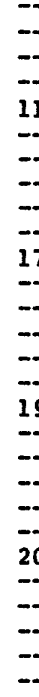

4.60
$-\quad 6.60$

3.55
3.22

3.02

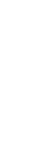

$\begin{array}{ll}11.8 & 8.30 \\ & 2.70\end{array}$

$\begin{array}{ll}- & 5.90 \\ - & 8.40\end{array}$

$\begin{array}{ccc}- & 8.40 & 3.42 \\ - & 9.80 & 3.24\end{array}$

$\overline{17.2}$

$\begin{array}{r}4.00 \\ --\quad 8.60 \\ \hline\end{array}$

$-\quad 12.3$

$\begin{array}{ll}-- & 14.3 \\ - & 15.5 \\ 19.6 & 16.2\end{array}$

$19.6 \quad 4.50$

$=\quad 9.80$

- 16.3

- 17.6

$20.8 \quad 4.80$

$-\quad 10.4$

$\begin{array}{ll}- & 17.3 \\ - & 18.7\end{array}$

18.7
19.6

2.61

4.9

4.96
3.76

3.76

2.50
3.17

3.17
3.00

3.00
5.39
5.15

5.15

4.20
4.09

4.09
3.68

3.68

5.39

4.63

4.46

3.85
3.39

3.39
3.24

$\begin{array}{rr}536 & - \\ 569 & - \\ 600 & - \\ 657 & - \\ 687 & - \\ 561 & - \\ 647 & - \\ 656 & - \\ 773 & - \\ 809 & - \\ 663 & \\ - & - \\ - & - \\ - & - \\ - & - \\ - & - \\ - & - \\ 435 & - \\ 479 & - \\ 611 & - \\ 678 & - \\ 847 & - \\ 958 & - \\ 339 & - \\ 394 & - \\ 350 & - \\ 531 & - \\ 432 & - \\ 801 & -\end{array}$

\begin{tabular}{r}
94 \\
91 \\
89 \\
83 \\
80 \\
87 \\
82 \\
79 \\
69 \\
69 \\
61 \\
\hline- \\
- \\
- \\
\hline- \\
- \\
- \\
- \\
72 \\
66 \\
62 \\
53 \\
45 \\
42 \\
77 \\
70 \\
80 \\
60 \\
59 \\
38
\end{tabular}

98
95
92
88
85
92
88
84
75
74
-
-
-
$-\quad$
--
-
-
-
92
82
80
72
59
57
91
85
92
74
69
48

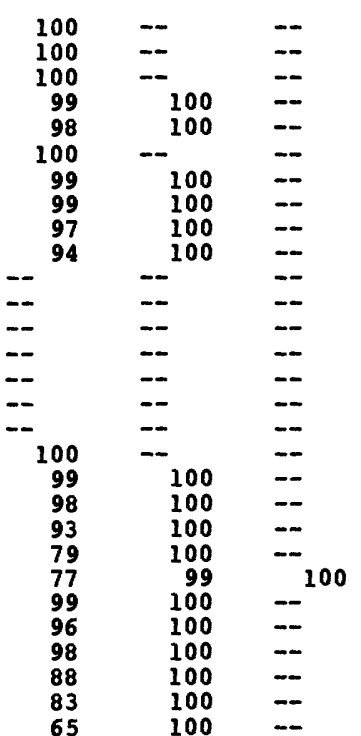


WATER-QUALITY RECORDS

PARTICLE SIZE DISTRIBUTION OF SUPSENDED-SEDIMENT, WATER YEAR OCTOBER 1984 TO SEPTEMBER 1985

\begin{tabular}{|c|c|c|c|c|c|c|c|c|c|c|c|c|}
\hline 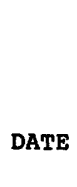 & IME & $\begin{array}{l}\text { SAMPLE } \\
\text { LOC- } \\
\text { ATION, } \\
\text { CROSS } \\
\text { SECTION } \\
\text { (FT FM } \\
\text { L BANK) }\end{array}$ & $\begin{array}{l}\text { DEPTH } \\
\text { AT } \\
\text { SAMPLE } \\
\text { LOC- } \\
\text { ATION, } \\
\text { TOTAL } \\
\text { (FEET) }\end{array}$ & $\begin{array}{l}\text { SAY- } \\
\text { PLING } \\
\text { DEPTH } \\
\text { (EEET) }\end{array}$ & $\begin{array}{l}\text { STREAM } \\
\text { VELOC- } \\
\text { ITY, } \\
\text { POINT) } \\
\text { (FPS) }\end{array}$ & $\begin{array}{l}\text { SEDI- } \\
\text { MENT, } \\
\text { SUS- } \\
\text { PENDED } \\
\text { (MG/L) }\end{array}$ & $\begin{array}{l}\text { SED. } \\
\text { SUSP. } \\
\text { FALL } \\
\text { DIAM. } \\
\text { FINER } \\
\text { THAN } \\
.004 \text { MM }\end{array}$ & $\begin{array}{l}\text { SED. } \\
\text { SUSP. } \\
\text { FALL } \\
\text { DIAM. } \\
\text { FINER } \\
\text { THAN } \\
.062 \mathrm{MM}\end{array}$ & $\begin{array}{l}\text { SED. } \\
\text { SUSP. } \\
\text { PALL } \\
\text { DIAM. } \\
\text { FINER } \\
\text { THAN } \\
.125 \text { MIM }\end{array}$ & $\begin{array}{l}\text { SED. } \\
\text { SUSP. } \\
\text { FALE } \\
\text { DIAN. } \\
\text { \& FINER } \\
\text { THAN } \\
.250 \text { MM }\end{array}$ & $\begin{array}{c}\text { SED. } \\
\text { SUSP. } \\
\text { FALL } \\
\text { DIAM. } \\
8 \text { FINER } \\
\text { THAN } \\
.500 \text { MM }\end{array}$ & $\begin{array}{l}\text { SED. } \\
\text { SUSP. } \\
\text { FALL } \\
\text { DIAM. } \\
\text { 8 FINER } \\
\text { THAN } \\
1.00 \mathrm{MM}\end{array}$ \\
\hline
\end{tabular}
JUN 1985

$06 .$. WATER TEMPERATURE, $20.0^{\circ} \mathrm{C} \quad\left(0915-1245\right.$ HOURS); DISCHARGE, $31,500 \mathrm{ft}^{3} / \mathrm{s}$.

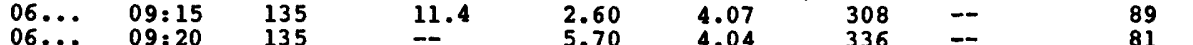

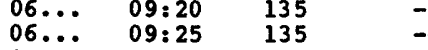

$06 \ldots . .09: 30 \quad 135$

$06 \ldots .09: 35 \quad 135$

$06 \ldots 09: 55 \quad 260$

$06 \ldots 10: 00 \quad 260$

$06 \ldots . .10: 05 \quad 260$

$06 \ldots 10: 10 \quad 260$

$\begin{array}{lll}06 \ldots & 10: 15 & 260 \\ 06 \ldots & 10: 20 & 260\end{array}$

$06 \ldots . .10: 30 \quad 355$

$06 \ldots . .10: 35 \quad 355$

$\begin{array}{lll}06 \ldots . . & 10: 40 & 355 \\ 06 \ldots & 10: 43 & 355\end{array}$

$06 \ldots . .10: 45 \quad 355$

$06 \ldots \quad 10: 50 \quad 355$

$06 \ldots . .10: 55 \quad 355$

$\begin{array}{lll}06 \ldots . . & 11: 00 & 415 \\ 06 \ldots & 11: 05 & 415\end{array}$

$\begin{array}{lll}06 \ldots . . & 11: 05 & 415 \\ 06 \ldots & 11: 10 & 415\end{array}$

$06 \ldots \quad 11: 15 \quad 415$

$06 \ldots \quad 11: 20 \quad 415$

$06 \ldots . . . \quad 11: 25 \quad 415$

$\begin{array}{lll}06 \ldots . . & 11: 30 & 475 \\ 06 & 11: 35 & 475\end{array}$

$06.011: 40 \quad 475$

06.11 .45

$06 \ldots . . \quad 11: 45$

$\begin{array}{ll}06 \ldots . . & 11: 50 \\ 06 \ldots & 11: 55\end{array}$

475
475

475
475
475

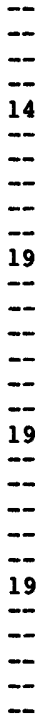

14.

$=$

5.70
8.10

10.4

3.35
2.33

433

7.00

10.0

11.7

4.37

4.37
4.07
3.94

4.07
3.94
3.72

$12.6 \quad 3.09$

$\overline{19} \quad 13.8 \quad 1.00$

4.60
9.90

$\begin{array}{rrr}14.90 & 4.37 \\ - & 14.1 & 3.72\end{array}$

$\overline{-} \quad \overline{16.5}$

-- $\quad 17.8$

$\overline{19.8}$

$--$

18.6

14.1

16.5

-- $\quad 17.8$

19.8

18.6

$\begin{array}{ll}19.8 & 4.60 \\ -- & 9.90\end{array}$

$-\quad 16.5$

16.5
17.8
18.6

2.85
5.00
4.37
3.72
--

247

247
289

289
307
460

506

$--$

$\overline{-}$

3.50

2.70
2.16

2.16
5.76

4.96

4.11

4.11

3.81

3.33

5.50

5.17

4.48
4.35

4.35
4.24

3.89

$-^{-514}$

-

$-$

147
189
191

242

331

526
128

122

160 --

247 --

251
364

$\overline{-}$

$\because$

$\overline{-}$

$\Xi$

$\bar{\Xi}$

JUL 1985

$18 .$. WATER TEMPERATURE, $25.0^{\circ} \mathrm{C}$

$18 \ldots$ 09:21

$18 \ldots \quad 09: 21$

$\begin{array}{ll}18 \ldots . . & 09: 24 \\ 18 . . & 09: 28\end{array}$

$18 \ldots .09: 32$

$18 \ldots .09: 36$

$18 \ldots .09: 40$

$18 \ldots \quad 10: 05$

$18 \ldots . .10: 10$

$18 \ldots 10: 15$

$18 \ldots \quad 10: 20$

$18 \ldots .10: 25$

$18 \ldots . .10: 45$

$18 \ldots .10: 46$

$18 \ldots . .10: 50$

$18 \ldots . \quad 10: 55$

$18 \ldots . \quad 11: 00$

$18 \ldots . .11: 05$

$18 \ldots . .11: 10$

$18 \ldots$... $11: 35$

$18 \ldots . .11: 39$

$18 \ldots .11: 43$

$18 . . . \quad 11: 47$

$18 . . . \quad 11: 51$

$18 \ldots . \quad 11: 55$

$18 \ldots \quad 12: 10$

$18 . . . \quad 12: 15$

$18 \ldots .12: 20$

$18 \ldots . .12: 25$

$18 \ldots \quad 12.30$

$18 \ldots .12: 35$

$18 . . . \quad 12: 40$

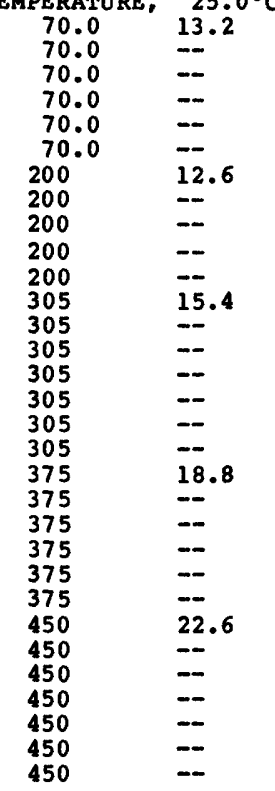

(0921-1245 HOURS)

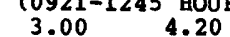

$\begin{array}{ll}3.00 & 4.20\end{array}$

$\begin{array}{rr}6.50 & 3.72 \\ 9.30 & 3.15\end{array}$

10.8

10.8
11.7

12.2

2.90

6.30
9.00

10.5

11.3

3.50

7.60

10.9

12.9

13.7

14.3

4.30
9.40

13.4

15.7

16.9

17.7

5.20

11.3

16.1

18.8

20.3

21.3

3.15
2.68

2.68
2.57

2.24
4.37

4.37
3.98
3.52

3.52

3.37

3.20
4.26

377
3.20

$-4.39$

4.11

3.94

3.72

3.57

4.30

4.26
4.33

4.28

3.68

3.50

5.04

4.26
3.96

3.83

3.07

3.22

DISCHARGE, 34,200 $\mathrm{ft}^{3 / \mathrm{s}}$.

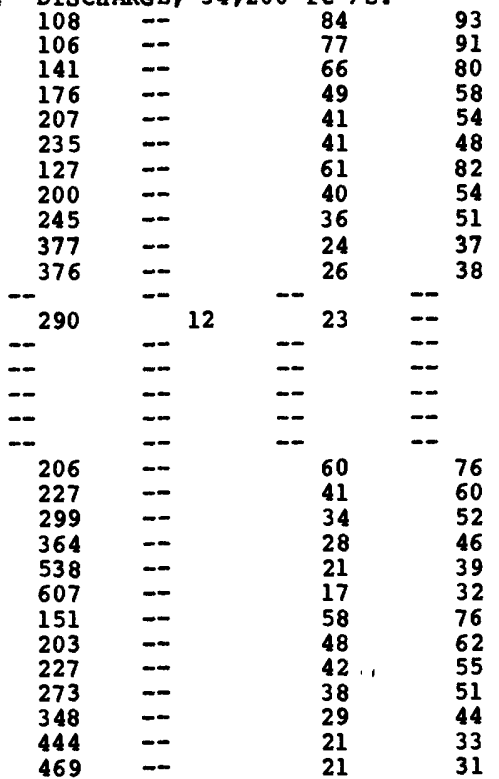

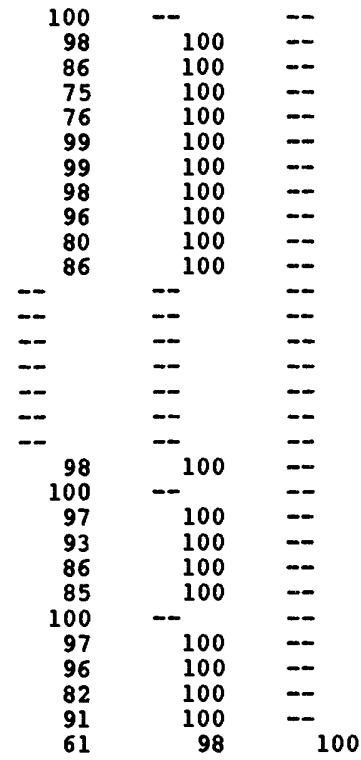

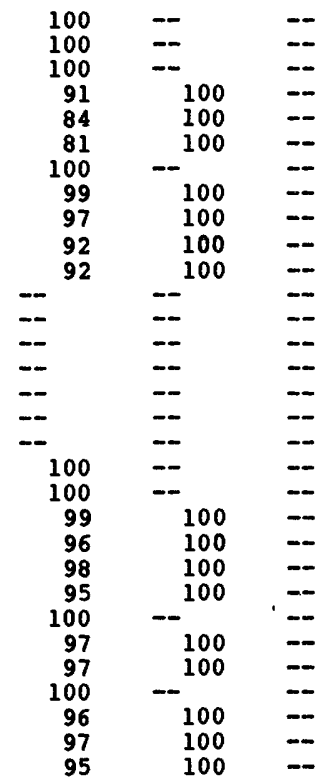


06486000 MISSOURI RIVER AT SIOUX CITY, IA--Continued

WATER-QUALITY RECORDS

PARTICLE SIZE DISTRIBUTION OF SUSPENDED-SEDIMENT, WATER YEAR OCTOBER 1984 TO SEPTEMBER 1985

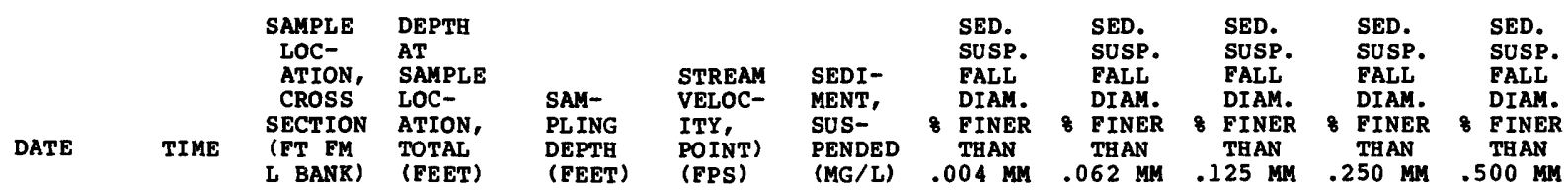

AUG 1985

$22.0^{\circ} \mathrm{C}$ (1105-1255 HOURS); DISCHARGE, $32,700 \mathrm{ft}^{3} / \mathrm{s}$

29. WATER TEMPERATURE

29... 11.05

DISCHARG
353
360

95.0 -

95.0

$--$

$-$

$\overline{15.2}$

15.2

95.0

275

$29 \ldots \quad 11.30$

29... 11:45

29... $11: 50$

$29 \ldots \quad 11: 52$

$29 \ldots \quad 11: 55$

29... 12:00

29... 12:05

$29 \ldots . \quad 12: 10$

$29 \ldots . \quad 12: 25$

$29 \ldots \ldots 12: 30$

$29 \ldots \quad 12: 35$

29... 12:40

$29 \ldots .12: 45$

$29 \ldots 12: 50$

275
275

275
275

275

275

415
415

415

415

415

$--$

$=\overline{10.9}$

-- 13.7

$-16.3$

16.8

$-$

$-$

$\overline{-}$

7.00

10.0

4.37

4.07
3.83

360
434

12.6

2.96

496

518
707

- 707

4.59 --

3.50

7.60

3.94

$-$

$-389$

3.50

3.15

2.89
2.63

3.90

3.90
12.0

2.63
4.59

4.59
4.20

4.20
4.04

14.0

3.72

15.1

15.1
15.8

3.94

$\overline{--}$

$--$

178
227

294

424

349

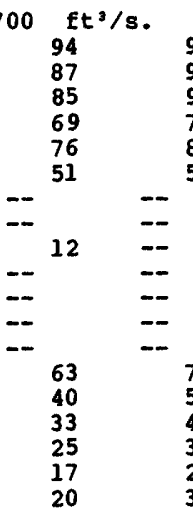

PARTICLE SIZE DISTRIBUTION OF BED MATERIAL, WATER YEAR OCTOBER 1984 TO SEPTEMBER 1985

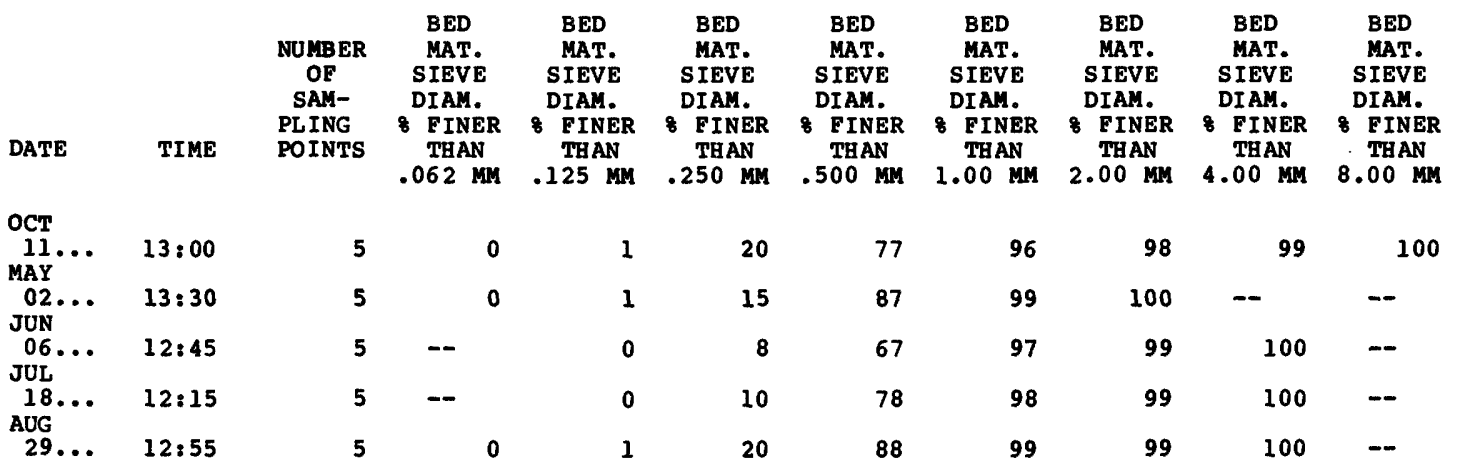


LOCATION.--Lat $42^{\circ} 32^{\prime} 08^{\prime \prime}$, long $96^{\circ} 24^{\prime} 39^{\prime \prime}$, woodbury County, Hydrologic Unit 1023000l, on left bank at downstream side of bridge on $38 \mathrm{th}$ street in sioux City, $1.9 \mathrm{mi}$ downstream from West Branch, and $3.6 \mathrm{mi}$ upstream from mouth.

DRAINAGE AREA. $--65.1 \mathrm{mi}^{2}$.

PERIOD OF RECORD.--October 1945 to September 1969, June 1981 to current year.

REVISED RECORDS.--WSP 1440: Drainage area.

GAGE.-Water-stage recorder. Datum of gage is 1,112.04 ft above NGVD (city of Sioux City benchmark). Prior to May 20, 1954, nonrecording gage with supplementary water-stage recorder in operation above 5.0 ft gage height and May 20, 1954 to Sept. 30, 1969, water-stage recorder at present site at datum 5.0 ft higher.

REMARKS.--Estimated daily discharges: Oct. $1-15$ and Dec. 9 to Feb. 10 . Records good except those for Dec. 9 to Feb. 10, which are poor. National Weather service gage-height telemeter at station.

AVERAGE DISCHARGE.--28 years (water years 1946-69, 1982-85), $16.5 \mathrm{ft}^{3} / \mathrm{s}, 3.44$ in/yr, 11,950 acre-ft/yr; median of yearly mean discharges, $12 \mathrm{ft} / \mathrm{s}, 2.5 \mathrm{in} / \mathrm{yr}, 8,700$ acre-ft/yr.

EXTREMES FOR PERIOD OF RECORD.--Maximum discharge, 7,780 ft/s Sept. 10, 1949, gage height, 26.80 ft, present datum, from rating curve extended above $1,700 \mathrm{ft} / \mathrm{s}$ on basis of slope-area measurement of peak flow; no flow at times in $1946,1958-60$.

EXTREMES OUTSIDE PERIOD OF RECORD.--Flood of July 7, 1944, reached a stage of about 30.5 ft, from floodmarks, present datum, discharge, $9,600 \mathrm{ft} / \mathrm{s}$, on basis of contracted-opening measurement of peak flow by Corps of Engineers.

EXTREMES FOR CURRENT PERIOD,--Peak discharges greater than base of $800 \mathrm{ft} / \mathrm{s}$ and maximum (*):

\begin{tabular}{|c|c|c|c|c|c|c|c|}
\hline $\begin{array}{l}\text { Date } \\
\text { Mar. } 4 \\
\text { Apr. } 22\end{array}$ & $\begin{array}{l}\text { Time } \\
0200 \\
0415\end{array}$ & $\begin{array}{c}\text { Discharge } \\
\text { (ft: } / \mathrm{s} \text { ) } \\
1,470 \\
1,470\end{array}$ & $\begin{array}{c}\text { Gage height } \\
\text { (ft) } \\
13.26 \\
13.28\end{array}$ & $\begin{array}{l}\text { Date } \\
\text { Apr. } 23\end{array}$ & $\begin{array}{l}\text { Time } \\
1145\end{array}$ & $\begin{array}{c}\text { Discharge } \\
\left.\text { (ft } t^{3} / \mathrm{s}\right) \\
* 3,940\end{array}$ & $\begin{array}{c}\text { Gage height } \\
\text { (ft) } \\
\star 19.20\end{array}$ \\
\hline
\end{tabular}

Minimum daily discharge $6.0 \mathrm{ft} \% \mathrm{~s}$ Oct. 7.

DISCHARGE, IN CUBIC FEET PER SECOND, WATER YEAR OCTOBER 1984 TO SEPTEMBER 1985 MEAN VALUES

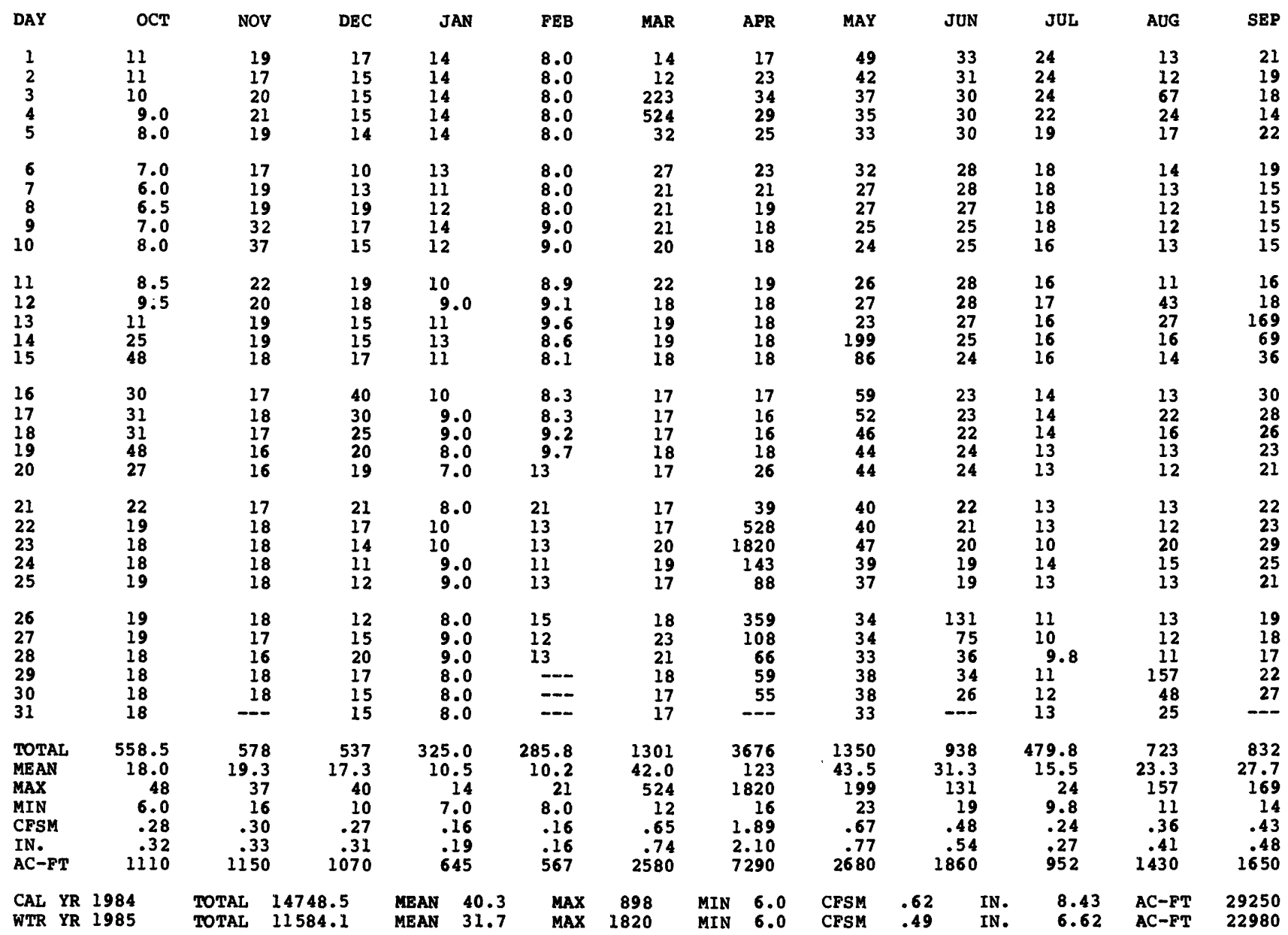


LOCATION.--Lat $42^{\circ} 58^{\prime} 55^{\prime}$, , long $96^{\circ} 00^{\prime} 03^{\prime}$, , in NEl/4 NEl/4 sec.11, T.94 N., R.44 W., Sioux County, Bydrologic Unit 10230002 , on left bank $270 \mathrm{ft}$. downstream from South County Road at east edge of Alton, 34.3 mi upstream from West Branch Floyd River, and at mile 58.1 .

DRAINAGE AREA. $--268 \mathrm{mi}^{2}$.

PERIOD OF RECORD,--October 1955 to current year. Prior to December 1955, monthly discharge only, published in wSP 1730 .

REVISED RECORDS.--WDR IA-82-1: Drainage area.

GAGE.--Water-stage recorder. Datum of gage is $1.269 .55 \mathrm{ft}$ above NGVD.

REMARKS.--Estimated daily discharges: Nov. 6-19, Dec. 4 to Mar. 2, Mar. 8-11, 28-31. Records good except those for estimated daily discharges, which are poor. U. S. Army Corps of Engineers rain-gage and gage-height satellite data collection platform at station.

AVERAGE DISCHARGE. -30 years, $68.6 \mathrm{ft} / \mathrm{s}, 3.48 \mathrm{in} / \mathrm{yr}, 49.700$ acre-ft/yr; median of yearly mean discharges, 53 $\mathrm{ft}^{3} / \mathrm{s}, 2.7 \mathrm{in} / \mathrm{yr}, 38,400$ acre-ft/yr.

EXTREMES FOR PERIOD OF RECORD.--Maximum discharge, 16,300 ft/s June 20, 1983, gage height 18.54 ft, from floodmark, from rating curve extended above $8,500 \mathrm{ft} / \mathrm{s}$; no flow at times in $1956,1958-59,1965$, 1968 , 1977 .

EXTREMES OUTSIDE PERIOD OF RECORD. --Flood in June 1953 reached a discharge of about 45,500 ft $3 / 8$, from information by U. S. Army Corps of Engineers.

EXIREMES FOR CURRENT YEAR.--Peak discharges greater than base of $800 \mathrm{ft} / \mathrm{s}$ and maximum $(*)$

\begin{tabular}{|c|c|c|c|c|c|c|c|}
\hline 23 & $\begin{array}{c}\text { Time } \\
\text { unknown }\end{array}$ & $\begin{array}{c}\text { Discharge } \\
\left(\mathrm{ft}^{3} / \mathrm{s}\right) \\
* 5,660\end{array}$ & $\begin{array}{c}\text { Gage height } \\
\text { (ft }) \\
* 16.93\end{array}$ & $\begin{array}{l}\text { Date } \\
\text { Apr. } 27\end{array}$ & $\begin{array}{c}\text { Time } \\
\text { unknown }\end{array}$ & $\begin{array}{c}\text { Discharge } \\
(\mathrm{ft} / \mathrm{s}) \\
1,090\end{array}$ & $\begin{array}{c}\text { Gage height } \\
\text { (ft }) \\
11.01\end{array}$ \\
\hline
\end{tabular}

Minimum daily discharge, $10 \mathrm{ft} / \mathrm{s}$ Feb. $1-9$.

DISCHARGE, IN CUBIC FEET PER SECOND, WATER YEAR OCTOBER 1984 TO SEPTEMBER 1985 MEAN VALUES

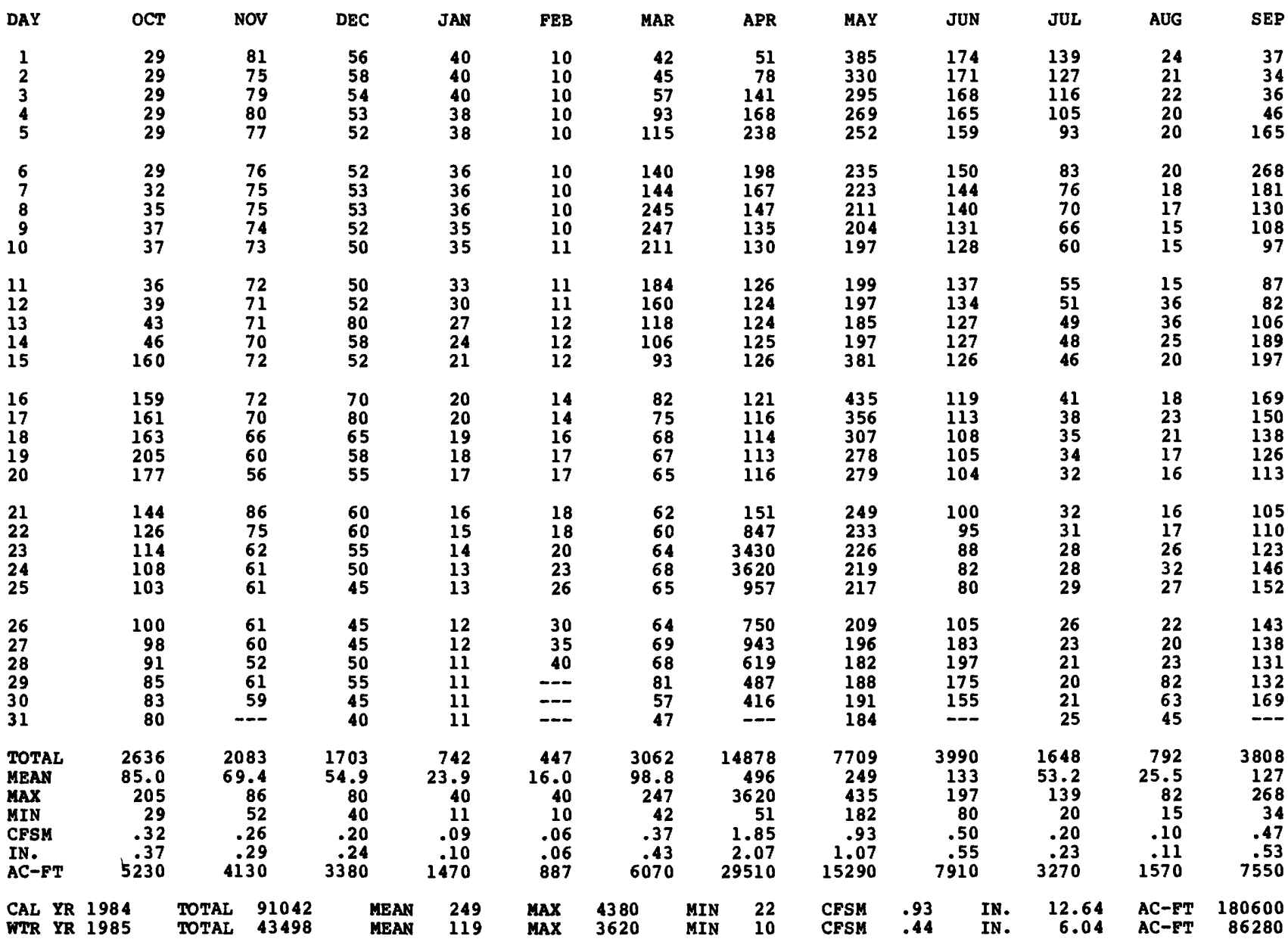


LOCATION.--Lat $42^{\circ} 55^{\prime} 25^{\prime \prime}$, long $96^{\circ} 10^{\prime} 34^{\prime \prime}$, in NEl/4 NEl/4 sec. 32, T.94 N., R.45 W., Sioux County, Hydrologic Unit 10230002 , on left bank near wingwall at downstream side of bridge on county highway $B 62$, 0.1 mi west of U.S. Highway $75,0.8 \mathrm{mi}$ downstream from Orange City slough, $2.2 \mathrm{mi}$ northeast of struble, $21.4 \mathrm{mi}$ upstream from Floyd River, and at mile 45.2, upstream from mouth of Floyd River.

DRAINAGE AREA. $--180 \mathrm{mi}^{2}$.

PERIOD OF RECORD.--October 1955 to current year. Prior to December 1955, monthly discharge only, published in wSP 1730 .

REVISED RECORDS.--WDR IA-82-1: Drainage area, 1978-81 (P).

GAGE.--Water-stage recorder. Datum of gage is 1,239.40 ft above NGVD (State Highway Commission bench mark). Prior to Jan. 5, 1978, at site $721 \mathrm{ft}$ right at old channel at same datum.

REMARKS.--Estimated daily discharges: Dec. 3 to Feb. 28, Apr. 22, 24-28 and June 27 to July 1. Records good except those for estimated daily discharge, which are poor. U.S. National weather Service gage-height telemeter at station.

AVERAGE DISCHARGE. -30 years, $45.1 \mathrm{ft} / \mathrm{s}, 3.40 \mathrm{in} / \mathrm{yr}, 32.670$ acre-ft/yr; median of yearly mean discharges, 32 $\mathrm{ft}^{3} / \mathrm{yr}, 2.4 \mathrm{in} / \mathrm{yr}, 23,200$ acre-ft/yr.

EXTREMES FOR PERIOD OF RECORD.--Maximum discharge, 8.060 ft'/s Mar. 28, 1962, gage height, 15.63 ft; maximum gage height, $15.86 \mathrm{ft}$ June 20, 1983 ; no flow at times most years.

EXTREMES FOR CURRENT YEAR.--Peak discharges greater than base of $400 \mathrm{ft} / \mathrm{s}$ and maximum $(*)$ :

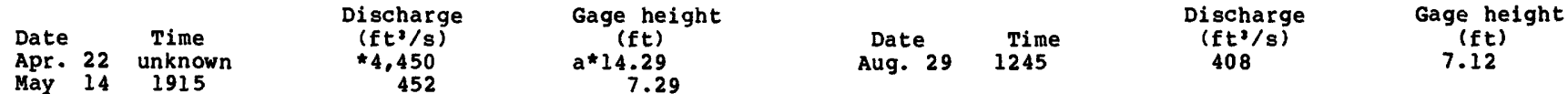

a From floodmark.

Minimum daily discharge, $9.0 \mathrm{ft} / \mathrm{s}$ Feb. $13,14$.

DISCHARGE, IN CUBIC FEET PER SECOND, WATER YEAR OCTOBER 1984 TO SEPTEMBER 1985 MEAN VALUES

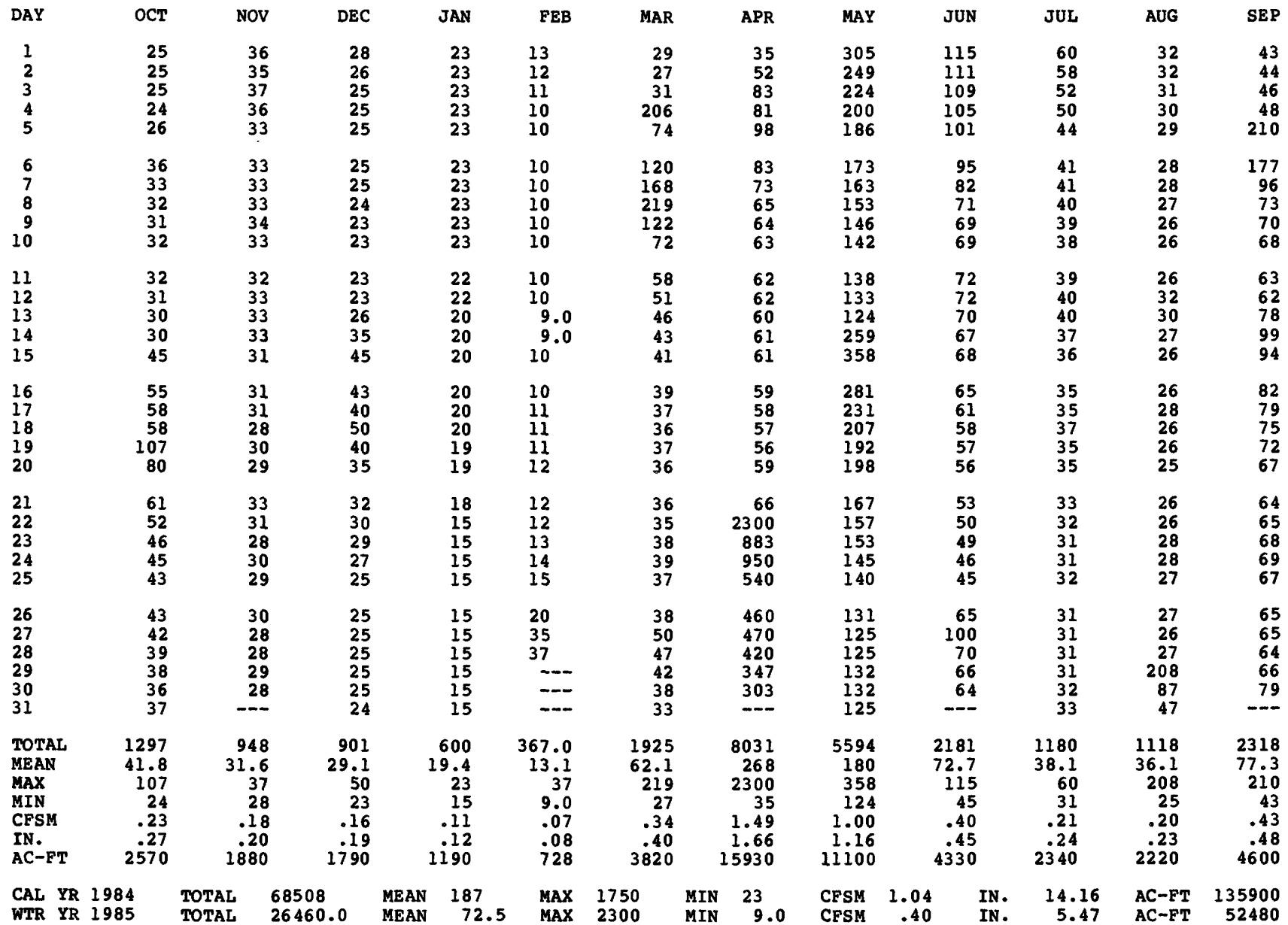


LOCATION.--Lat $42^{\circ} 34^{\prime} 36^{\prime \prime}$, long $96^{\circ} 18^{\prime} 43^{\prime \prime}$, in SEl/4 SEl/4 sec.30, T.90 N., R.46 W., P1Ymouth County, HYdrologic Unit 10230002, on right bank at downstream side of bridge on county highway C70, $0.2 \mathrm{mi}$ east of James, $14.3 \mathrm{mi}$ downstream from West Branch Floyd River, and at mile 7.5.

DRAINAGE AREA.--886 $\mathrm{mi}^{*}$.

PERIOD OF RECORD.--December 1934 to current year.

REVISED RECORDS.-WWP 1240: 1935 (M), 1936, 1937-38 (M), 1942, 1945. wSP 1440: Drainage area.

GAGE.-Water-stage recorder. Datum of gage is 1,092.59 ft above ngvD. Prior to Sept. 11, 1938 , June 9 to Nov. 5, 1953, and Oct. 1, 1955, to May 22, 1957, nonrecording gage and May 23, 1957, to Sept. 30, 1970, water-stage recorder at same site at datum $10.0 \mathrm{ft}$ higher.

REMARKS.--Estimated daily discharges: Dec. 4 to Mar. 2 and Mar. 5-7. Records good except for estimated daily discharges, which are poor. U. S. Army Corps of Engineers rain-gage and gage-height satellite telemeter at station.

AVERAGE DISCaARGE, - -50 years (water years 1936-85), $217 \mathrm{ft}^{3} / \mathrm{s}, 3.33$ in/yr, 157,200 acre-ft/yr, median of yearly mean discharges, $160 \mathrm{ft} / 8,2.5 \mathrm{in} / \mathrm{Yr}, 116,000$ acre-ft/yr.

EXTREMES FOR PERIOD OF RECORD.--Maximum discharge, 71,500 ft:/s June 8 , 1953, gage height, $25.3 \mathrm{ft}$, from floodmarks, datum then in use, from rating curve extended above $16,000 \mathrm{ft}^{3} / \mathrm{s}$ on basis of contracted-opening and flow-over-embankment measurement of peak flow; minimum daily, $0.90 \mathrm{ft}^{2} / \mathrm{s} \mathrm{Jan} .10-22,1977$.

EXTREMES OUTSIDE PERIOD OF RECORD.--Maximum stage and discharge since 1892, that of June 8, 1953, from information by U. S. Army Corps of Engineers.

EXTREMES POR CURRENT YEAR.--Peak discharges greater than base of $2,500 \mathrm{ft}^{2} / \mathrm{s}$ and maximum (*):

\begin{tabular}{|c|c|c|c|c|c|c|c|}
\hline $\begin{array}{l}\text { ate } \\
\text { lar. } 4 \\
\text { por. } 23\end{array}$ & $\begin{array}{l}\text { Time } \\
0900 \\
1115\end{array}$ & $\begin{array}{c}\text { Discharge } \\
(\mathrm{ft} / \mathrm{s}) \\
3,730 \\
* 11,100\end{array}$ & $\begin{array}{c}\text { Gage height } \\
\text { (ft) } \\
15.78 \\
* 22.84\end{array}$ & $\begin{array}{l}\text { Date } \\
\text { Aug. } 29\end{array}$ & $\begin{array}{l}\text { Time } \\
1745\end{array}$ & $\begin{array}{c}\text { Discharge } \\
\left(f t^{2} / \mathrm{s}\right) \\
4,760\end{array}$ & $\begin{array}{c}\text { Gage height } \\
\text { (ft) } \\
17.13\end{array}$ \\
\hline
\end{tabular}

Minimum daily discharge, $75 \mathrm{ft}^{3} / \mathrm{s}$ Jan. 30 to Feb. 10.

DISCHARGE, IN CUBIC FEET PER SECOND, WATER YEAR OCTOBER 1984 TO SEPTEMBER 1985 MEAN VALUES

\begin{tabular}{|c|c|c|c|c|c|c|c|c|c|c|c|c|}
\hline DAY & OCT & NOV & $\mathrm{DEC}$ & JAN & FEB & MAR & APR & MAY & JUN & JUL & AUG & SEP \\
\hline $\begin{array}{l}1 \\
2 \\
3 \\
4 \\
5\end{array}$ & $\begin{array}{l}167 \\
162 \\
160 \\
157 \\
159\end{array}$ & $\begin{array}{l}327 \\
317 \\
317 \\
324 \\
315\end{array}$ & $\begin{array}{l}253 \\
251 \\
175 \\
320 \\
250\end{array}$ & $\begin{array}{l}250 \\
200 \\
180 \\
160 \\
140\end{array}$ & $\begin{array}{l}75 \\
75 \\
75 \\
75 \\
75\end{array}$ & $\begin{array}{r}250 \\
350 \\
607 \\
2710 \\
2200\end{array}$ & $\begin{array}{l}203 \\
237 \\
363 \\
478 \\
531\end{array}$ & $\begin{array}{l}1790 \\
1570 \\
1380 \\
1230 \\
1140\end{array}$ & $\begin{array}{l}680 \\
648 \\
623 \\
607 \\
586\end{array}$ & $\begin{array}{l}559 \\
515 \\
473 \\
428 \\
391\end{array}$ & $\begin{array}{l}152 \\
150 \\
184 \\
158 \\
143\end{array}$ & $\begin{array}{l}424 \\
346 \\
309 \\
279 \\
331\end{array}$ \\
\hline $\begin{array}{r}6 \\
7 \\
8 \\
9 \\
10\end{array}$ & $\begin{array}{l}169 \\
200 \\
207 \\
204 \\
202\end{array}$ & $\begin{array}{l}308 \\
311 \\
303 \\
316 \\
369\end{array}$ & $\begin{array}{l}250 \\
240 \\
240 \\
240 \\
230\end{array}$ & $\begin{array}{l}140 \\
130 \\
130 \\
130 \\
125\end{array}$ & $\begin{array}{l}75 \\
75 \\
75 \\
75 \\
75\end{array}$ & $\begin{array}{l}1900 \\
1750 \\
1620 \\
1410 \\
1130\end{array}$ & $\begin{array}{l}610 \\
520 \\
450 \\
414 \\
399\end{array}$ & $\begin{array}{r}1040 \\
944 \\
884 \\
832 \\
794\end{array}$ & $\begin{array}{l}543 \\
514 \\
494 \\
467 \\
451\end{array}$ & $\begin{array}{l}357 \\
334 \\
311 \\
301 \\
285\end{array}$ & $\begin{array}{l}138 \\
131 \\
123 \\
117 \\
116\end{array}$ & $\begin{array}{l}905 \\
793 \\
565 \\
445 \\
382\end{array}$ \\
\hline $\begin{array}{l}11 \\
12 \\
13 \\
14 \\
15\end{array}$ & $\begin{array}{l}202 \\
209 \\
206 \\
200 \\
266\end{array}$ & $\begin{array}{l}315 \\
302 \\
306 \\
306 \\
298\end{array}$ & $\begin{array}{l}230 \\
230 \\
230 \\
250 \\
350\end{array}$ & $\begin{array}{l}120 \\
120 \\
115 \\
115 \\
115\end{array}$ & $\begin{array}{l}80 \\
80 \\
80 \\
80 \\
85\end{array}$ & $\begin{array}{l}776 \\
602 \\
444 \\
365 \\
330\end{array}$ & $\begin{array}{l}392 \\
378 \\
375 \\
374 \\
377\end{array}$ & $\begin{array}{r}768 \\
762 \\
703 \\
960 \\
1570\end{array}$ & $\begin{array}{l}465 \\
473 \\
454 \\
437 \\
445\end{array}$ & $\begin{array}{l}267 \\
258 \\
250 \\
246 \\
239\end{array}$ & $\begin{array}{l}115 \\
194 \\
233 \\
177 \\
153\end{array}$ & $\begin{array}{l}347 \\
320 \\
461 \\
524 \\
579\end{array}$ \\
\hline $\begin{array}{l}16 \\
17 \\
18 \\
19 \\
20\end{array}$ & $\begin{array}{l}468 \\
549 \\
537 \\
678 \\
751\end{array}$ & $\begin{array}{l}269 \\
277 \\
281 \\
267 \\
259\end{array}$ & $\begin{array}{l}450 \\
700 \\
600 \\
500 \\
480\end{array}$ & $\begin{array}{l}110 \\
110 \\
110 \\
105 \\
100\end{array}$ & $\begin{array}{l}85 \\
85 \\
90 \\
90 \\
90\end{array}$ & $\begin{array}{l}304 \\
277 \\
263 \\
251 \\
240\end{array}$ & $\begin{array}{l}372 \\
358 \\
346 \\
360 \\
385\end{array}$ & $\begin{array}{l}1640 \\
1490 \\
1300 \\
1180 \\
1120\end{array}$ & $\begin{array}{l}432 \\
406 \\
386 \\
378 \\
373\end{array}$ & $\begin{array}{l}230 \\
223 \\
212 \\
210 \\
200\end{array}$ & $\begin{array}{l}138 \\
158 \\
153 \\
134 \\
125\end{array}$ & $\begin{array}{l}586 \\
528 \\
479 \\
436 \\
394\end{array}$ \\
\hline $\begin{array}{l}21 \\
22 \\
23 \\
24 \\
25\end{array}$ & $\begin{array}{l}601 \\
505 \\
449 \\
417 \\
402\end{array}$ & $\begin{array}{l}251 \\
269 \\
283 \\
273 \\
275\end{array}$ & $\begin{array}{l}500 \\
470 \\
420 \\
380 \\
350\end{array}$ & $\begin{array}{l}95 \\
95 \\
95 \\
90 \\
90\end{array}$ & $\begin{array}{r}95 \\
95 \\
100 \\
100 \\
110\end{array}$ & $\begin{array}{l}232 \\
228 \\
237 \\
239 \\
236\end{array}$ & $\begin{array}{r}487 \\
3440 \\
9860 \\
9790 \\
5850\end{array}$ & $\begin{array}{r}1060 \\
974 \\
930 \\
901 \\
843\end{array}$ & $\begin{array}{l}363 \\
349 \\
332 \\
315 \\
309\end{array}$ & $\begin{array}{l}193 \\
189 \\
182 \\
178 \\
179\end{array}$ & $\begin{array}{l}121 \\
119 \\
130 \\
135 \\
134\end{array}$ & $\begin{array}{l}363 \\
356 \\
394 \\
430 \\
437\end{array}$ \\
\hline $\begin{array}{l}26 \\
27 \\
28 \\
29 \\
30 \\
31\end{array}$ & $\begin{array}{l}393 \\
386 \\
365 \\
346 \\
335 \\
331\end{array}$ & $\begin{array}{l}273 \\
267 \\
259 \\
257 \\
273 \\
---\end{array}$ & $\begin{array}{l}400 \\
400 \\
500 \\
600 \\
400 \\
350\end{array}$ & $\begin{array}{l}85 \\
85 \\
80 \\
80 \\
75 \\
75\end{array}$ & $\begin{array}{l}130 \\
150 \\
200 \\
--- \\
---\end{array}$ & $\begin{array}{l}233 \\
248 \\
271 \\
258 \\
242 \\
233\end{array}$ & $\begin{array}{c}3800 \\
3900 \\
2860 \\
2270 \\
1970 \\
--0\end{array}$ & $\begin{array}{l}799 \\
768 \\
719 \\
687 \\
683 \\
682\end{array}$ & $\begin{array}{l}420 \\
824 \\
744 \\
689 \\
613 \\
---\end{array}$ & $\begin{array}{l}181 \\
167 \\
160 \\
154 \\
147 \\
146\end{array}$ & $\begin{array}{r}130 \\
123 \\
118 \\
2240 \\
1330 \\
583\end{array}$ & $\begin{array}{l}440 \\
415 \\
398 \\
409 \\
486 \\
-\end{array}$ \\
\hline $\begin{array}{l}\text { TOTAL } \\
\text { MEAN } \\
\text { MAX } \\
\text { MIN } \\
\text { CESM } \\
\text { IN. } \\
\text { AC-FT }\end{array}$ & $\begin{array}{r}10383 \\
335 \\
751 \\
157 \\
.38 \\
.44 \\
20590\end{array}$ & $\begin{array}{r}8767 \\
292 \\
369 \\
251 \\
.33 \\
1739\end{array}$ & $\begin{array}{r}11239 \\
363 \\
700 \\
175 \\
.41 \\
.47 \\
22290\end{array}$ & $\begin{array}{r}3650 \\
118 \\
250 \\
75 \\
.13 \\
.15 \\
7240\end{array}$ & $\begin{array}{r}2575 \\
92.0 \\
200 \\
75 \\
.10 \\
111 \\
5110\end{array}$ & $\begin{array}{r}20436 \\
659 \\
2710 \\
228 \\
.74 \\
.86 \\
40530\end{array}$ & $\begin{array}{r}52149 \\
1738 \\
9860 \\
203 \\
1.96 \\
2.19 \\
103400\end{array}$ & $\begin{array}{r}32143 \\
1037 \\
1790 \\
682 \\
1.17 \\
1.35 \\
63760\end{array}$ & $\begin{array}{r}14820 \\
494 \\
824 \\
309 \\
.56 \\
.62 \\
29400\end{array}$ & $\begin{array}{r}8165 \\
263 \\
559 \\
146 \\
.30 \\
.34 \\
16200\end{array}$ & $\begin{array}{r}8155 \\
263 \\
2240 \\
115 \\
.30 \\
.34 \\
16180\end{array}$ & $\begin{array}{r}13561 \\
452 \\
905 \\
279 \\
.51 \\
.57 \\
26900\end{array}$ \\
\hline
\end{tabular}

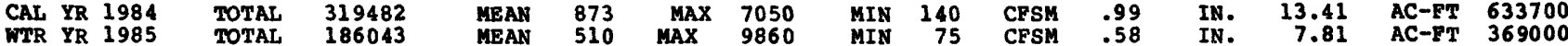


LOCATION.--Lat $42^{\circ} 13^{\prime} 37^{\prime \prime}$, long $96^{\circ} 04^{\prime} 40^{\prime \prime}$, in SWl/4 sec.27, T.86 N., R.45 W., Woodbury County, Hydrologic Unit 10230004 , on left bank' at upstream side of State Highway I4I bridge," $1.0 \mathrm{mi}$ east of Hornick, 9.2 mi upstream from Wolf Creek, and $13.5 \mathrm{mi}$ north of Onawa.

DRAINAGE AREA. $--403 \mathrm{mi}^{2}$.

PERIOD OF RECORD.--Apr 111939 to September 1969 (published as "at Holly Springs"), July 1974 to current year.

REVISED RECORDS.--WSP 1240: 1943, 1945 (M). WSP 1310: 1941 (M) 1944-46 (M). WSP 1440: Drainage area.

GAGE.--Water-stage recorder. Datum of gage is 1,045.82 ft above NGVD. Prior to June 16 , 1959 , nonrecording gage at site $3.0 \mathrm{mi}$ upstream and June 16,1959 to Sept. 30,1969 , recording gage at site 2.2 mi upstream at datum $7.0 \mathrm{ft}$ higher.

REMARKS.--Estimated daily discharge: Dec, 3 to Mar.3. Records good except those for Dec. 3 to Mar. 3 , which are poor. West Fork ditch is a dredged channel which diverts flow of West Fork Little Sioux River at Holly Springs $5.5 \mathrm{mi}$ south, thence southeast $6.5 \mathrm{mi}$ to a point $1.2 \mathrm{mi}$ west of Rennebec, where Wolf creek enters from left. From this point, ditch roughly parallels the Little sioux River and is known as Monona-Harrison ditch.

AVERAGE DISCHARGE.--41 years (water years 1940-69, 1975-85), $108 \mathrm{ft} / \mathrm{s}, 3.64 \mathrm{in} / \mathrm{yr}$, 78,250 acre-ft/yr, median of yearly mean discharges $89 \mathrm{ft} / \mathrm{s}, 3.0 \mathrm{in} / \mathrm{yr}, 64,500$ acre-ft/yr.

EXTREMES FOR PERIOD OF RECORD.-Maximum discharge, 12,400 ft/s Mar. 28, 1962, gage height, 22.46 ft, site and datum then in use; maximum gage height, $25.2 \mathrm{ft}$ Mar. 30, 1960 , from floodmark, site and datum then in use; minimum daily discharge, $0.2 \mathrm{ft} / \mathrm{s}$ July 30 , Aug. $17,1956$.

EXTREMES FOR CURRENT YEAR.--Peak discharges greater than base of $1,800 \mathrm{ft}^{3} / \mathrm{s}$ and maximum (*):

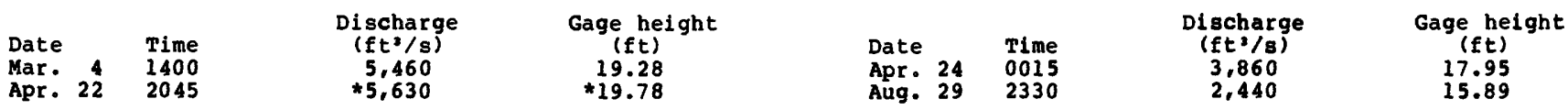

Minimum daily discharge, $60 \mathrm{ft}^{2} / \mathrm{s}$ Feb. 6-14.

DISCHARGE, IN CUBIC FEET PER SECOND, WATER YEAR OCTOBER 1984 TO SEPTEMBER 1985 WAN VALUES

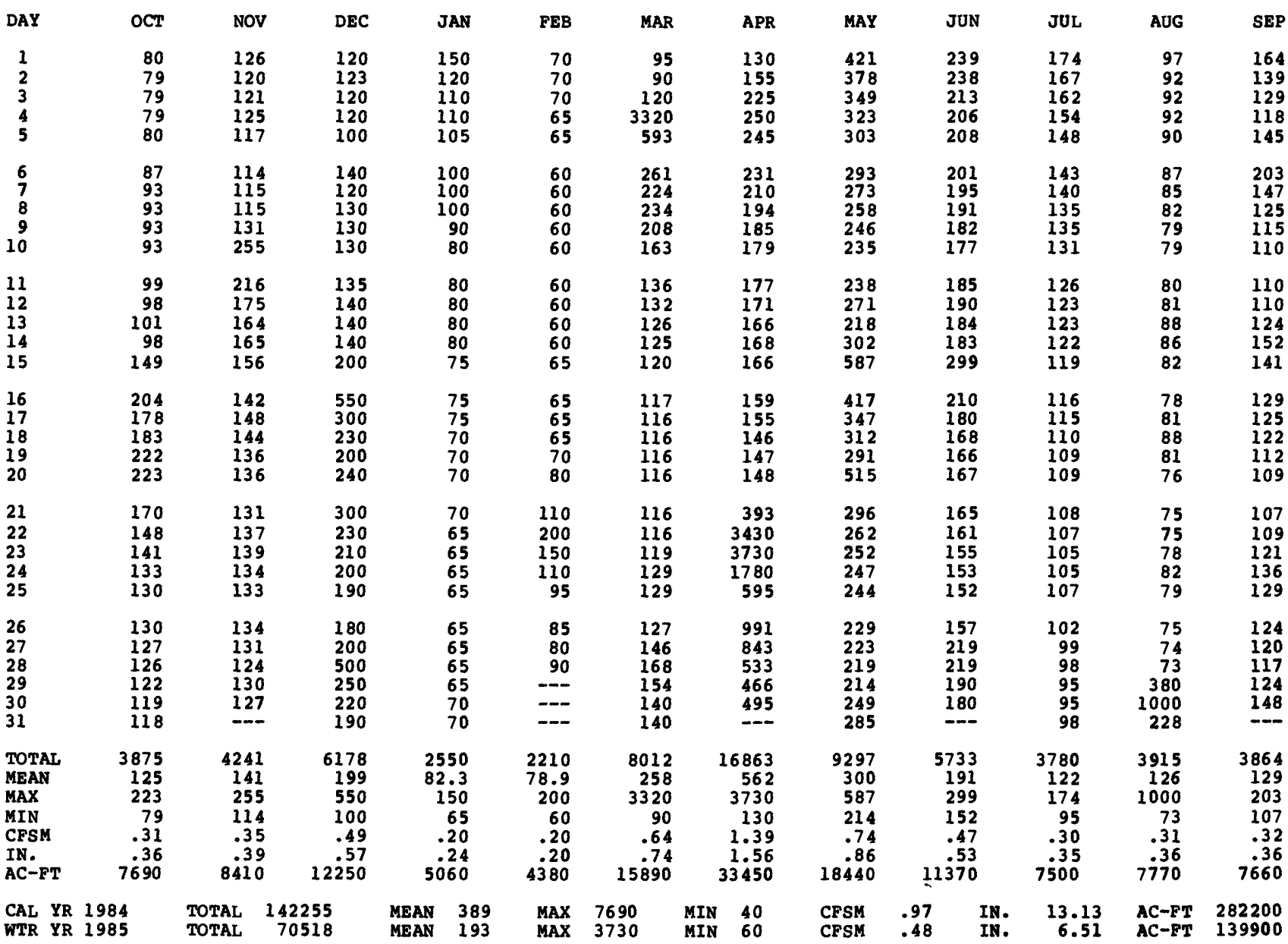




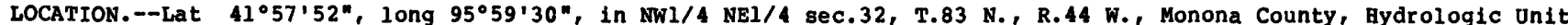
10230004 , on left pier at downstream side of bridge on county highway E54, 1.0 mi west of gaging station on little sioux River near Turin, $4 \mathrm{mi}$ southwest of Turin, $5.2 \mathrm{mi}$ northeast of Blencoe, and $12.5 \mathrm{mi}$ upstream from mouth.

DRAINAGE AREA. $--900 \mathrm{mi}$.

PERIOD OF RECORD.--April 1939 to current year. Records for April 1939 to January 1958 not equivalent owing to diversion from Little sioux River through equalizer ditch $1.5 \mathrm{mi}$ upstream. Prior to May 1942 , published as "near Blencoen.

GAGE.-- Water-stage recorder. Datum of gage is 1,015.00 ft above NGVD (U. S. Army Corps of Engineers bench mark). Prior to May 7, 1942, nonrecording gage at site $4.8 \mathrm{mi}$ downstream at datum $5.40 \mathrm{ft}$ lower. May 7 , 1942 to Oct. 13, 1953, nonrecording gage and oct. 14,1953 to sept. 30, 1975 , recording gage at same site at datum $5.00 \mathrm{ft}$ higher.

REMARRS.--Estimated daily discharges: Dec, 4-7, 13, 14, 17-26, 28-31, Jan, 1 to Feb, 17 , and May 23 to June 18, Records good except those for estimated discharges, which are poor. Monona-Harrison ditch is a dug channel is a continuation of West Fork ditch, paralleling the Little sioux River, and discharging into the Missouri River $1.5 \mathrm{mi}$ upstream from the mouth of the Little sioux River. $U$. S. Army Corps of Engineers rain-gage and gageheight satellite data collection platform at station.

AVERAGE DISCHARGE.--27 years (water years 1959-85), $245 \mathrm{ft} / \mathrm{s}, 3.70 \mathrm{in} / \mathrm{yr}^{\mathrm{r}}, 177,500 \mathrm{acre-ft} / \mathrm{yr}$.

EXTREMES FOR PERIOD OF RECORD.--Maximum discharge, 19,900 ft'/s Feb. 19, 1971, gage height, 28.03 ft, present datum, minimum daily, $8.5 \mathrm{ft} / \mathrm{s}$ Jan. 3-11, 1959 .

EXTREMES FOR CURRENT YEAR.--Peak discharges greater than base of $2,500 \mathrm{ft} / \mathrm{s}$ and maximum (*):

\begin{tabular}{|c|c|c|c|c|c|c|c|}
\hline $\begin{array}{l}\text { Date } \\
\text { Mar. } 4 \\
\text { Apr. } 22\end{array}$ & $\begin{array}{l}\text { Time } \\
1545 \\
1530\end{array}$ & $\begin{array}{c}\text { Discharge } \\
\left(f t^{3} / \mathrm{s}\right) \\
7,730 \\
* 9,860\end{array}$ & $\begin{array}{c}\text { Gage helght } \\
\text { (ft) } \\
19.47 \\
* 21.30\end{array}$ & $\begin{array}{l}\text { Date } \\
\text { Apr. } 23 \\
\text { Apr. } 26\end{array}$ & $\begin{array}{l}\text { Time } \\
1830 \\
2000\end{array}$ & $\begin{array}{c}\text { Discharge } \\
\left(f t^{3} / \mathrm{s}\right) \\
9,720 \\
5,060\end{array}$ & $\begin{array}{c}\text { Gage height } \\
(\mathrm{ft}) \\
21.19 \\
16.70\end{array}$ \\
\hline
\end{tabular}

Minimum daily discharge, $100 \mathrm{ft} / \mathrm{g}$ Feb. 6-14.

DISCHARGE, IN CUBIC FEET PER SECOND, WATER YEAR OCTOBER 1984 TO SEPTEMBER 1985 MEAN VALUES

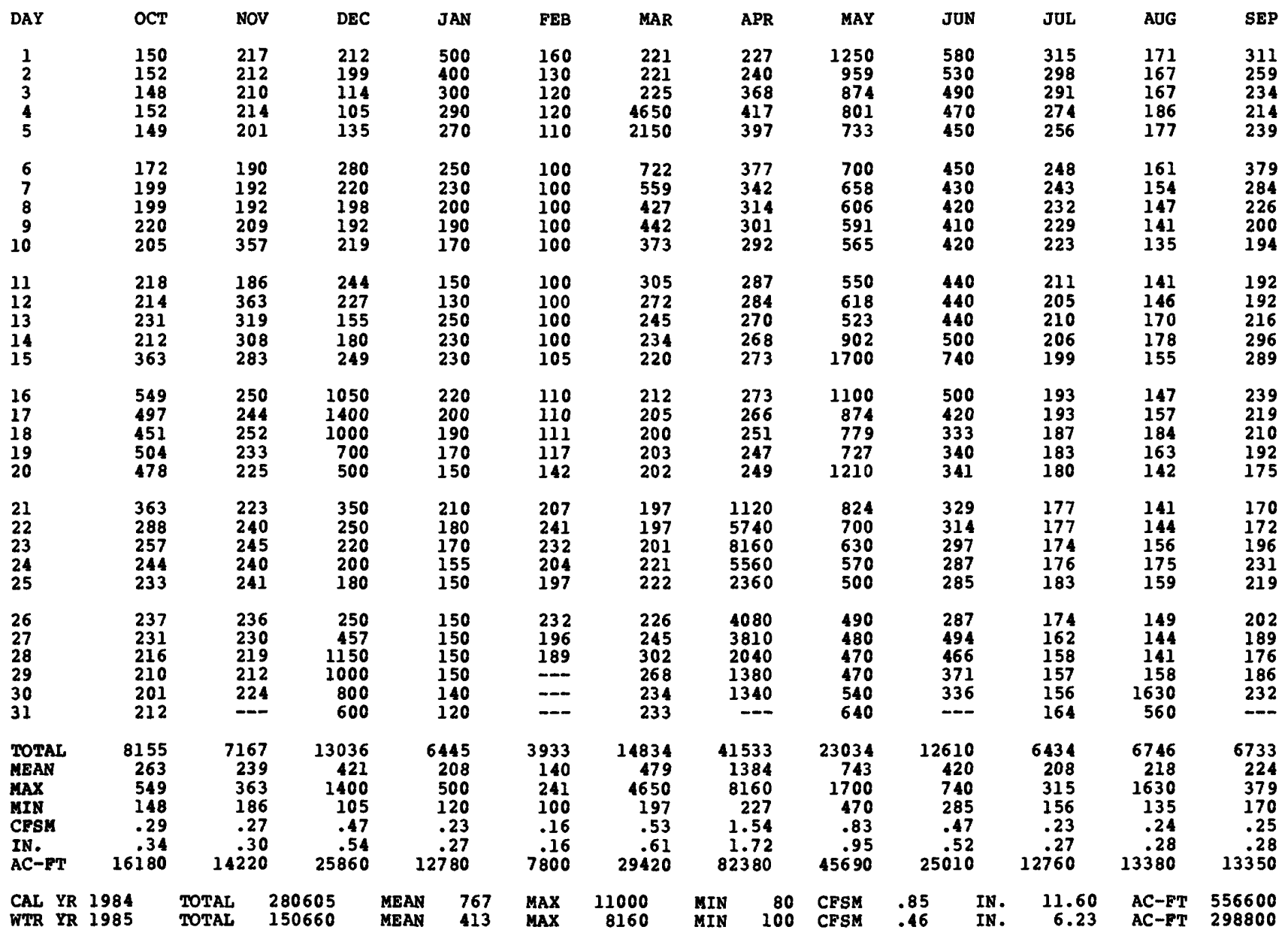


LOCATION, --Lat $43^{\circ} 22^{\prime} 43^{\prime}$, Iong $95^{\circ} 10^{\prime} 52^{*}$, in NEL/4 swl/4 sec.23, T.99N., R.37W., Dickinson County, Bydrologic Onit 10230003 , at pumping station of Lakeside Laboratory on west shore, $2.3 \mathrm{mi}$ upstream from lake outlet and 3.8 mi northwest of Milford.

DRA INAGE AREA. $--125 \mathrm{mi}^{2}$.

PERIOD OF RECORD,--May 1933 to current year. Published as "Okoboji Lake at Arnold's Park" $1933-37$ and as "Okoboji Lake at Lakeside Laboratory near Milford" 1937-66.

GAGE.--Water-stage recorder. Datum of gage is $1,391.76 \mathrm{ft}$ above NGvD, $94.51 \mathrm{ft}$ above Iowa Lake Survey datum, and about $4.0 \mathrm{ft}$ below crest of spillway. Prior to June 17, 1938 , nonrecording gage at State Pier at Arnolds Park at same datum.

REMARKS.--Lake formed by concrete dam with ungated spillway at elevation $1,395.8 \mathrm{ft}$ above NGVD. Lake is used for conservation and recreation. Area of lake is approximately 3,900 acres.

EXTREMES FOR PERIOD OF RECORD.--Maximum gage height, 6.28 ft June 22, 1984; minimum observed, 0.20 ft Sept. 20, 1959.

EXTREMES FOR CURRENT YEAR.--Maximum gage height, $4.92 \mathrm{ft}$ Apr. 26 ; minimum, $3.73 \mathrm{ft}$ Oct. $4,5$.

GAGE HEIGHT (FEET ABOVE DATUM) WATER YEAR OCTOBER 1984 TO SEPTEMBER 1985

MEAN VALOES

\begin{tabular}{|c|c|c|c|c|c|c|c|c|c|c|c|c|}
\hline DAY & $\mathrm{OCT}$ & HOV & DEC & JAN & FEB & MAR & APR & MAY & JON & JOL & AUG & SEP \\
\hline $\begin{array}{l}1 \\
2 \\
3 \\
4 \\
5\end{array}$ & $\begin{array}{l}3.76 \\
3.75 \\
3.74 \\
3.73 \\
3.73\end{array}$ & $\begin{array}{l}3.86 \\
3.84 \\
3.80 \\
3.81 \\
3.80\end{array}$ & $\begin{array}{l}3.85 \\
3.84 \\
3.83 \\
3.82 \\
3.81\end{array}$ & $\begin{array}{l}4.04 \\
4.04 \\
4.04 \\
4.04 \\
4.04\end{array}$ & $\begin{array}{l}4.06 \\
4.06 \\
4.05 \\
4.05 \\
4.06\end{array}$ & $\begin{array}{l}4.10 \\
4.10 \\
4.18 \\
4.27 \\
4.27\end{array}$ & $\begin{array}{l}4.53 \\
4.51 \\
4.52 \\
4.61 \\
4.64\end{array}$ & $\begin{array}{l}4.82 \\
4.79 \\
4.76 \\
4.73 \\
4.73\end{array}$ & $\begin{array}{l}4.49 \\
4.48 \\
4.45 \\
4.43 \\
4.43\end{array}$ & $\begin{array}{l}4.37 \\
4.37 \\
4.35 \\
4.34 \\
4.32\end{array}$ & $\begin{array}{l}3.97 \\
3.95 \\
3.94 \\
3.93 \\
3.92\end{array}$ & $\begin{array}{l}3.92 \\
3.93 \\
3.95 \\
3.98 \\
4.18\end{array}$ \\
\hline $\begin{array}{r}6 \\
7 \\
8 \\
9 \\
10\end{array}$ & $\begin{array}{l}3.75 \\
3.76 \\
3.77 \\
3.77 \\
3.78\end{array}$ & $\begin{array}{l}3.80 \\
3.80 \\
3.80 \\
3.86 \\
3.92\end{array}$ & $\begin{array}{l}3.81 \\
3.80 \\
3.80 \\
3.81 \\
3.81\end{array}$ & $\begin{array}{l}4.04 \\
4.04 \\
4.04 \\
4.04 \\
4.05\end{array}$ & $\begin{array}{l}4.06 \\
4.06 \\
4.05 \\
4.05 \\
4.06\end{array}$ & $\begin{array}{l}4.27 \\
4.28 \\
4.29 \\
4.34 \\
4.43\end{array}$ & $\begin{array}{l}4.63 \\
4.61 \\
4.60 \\
4.57 \\
4.56\end{array}$ & $\begin{array}{l}4.71 \\
4.69 \\
4.66 \\
4.63 \\
4.63\end{array}$ & $\begin{array}{l}4.40 \\
4.39 \\
4.37 \\
4.35 \\
4.35\end{array}$ & $\begin{array}{l}4.30 \\
4.27 \\
4.28 \\
4.28 \\
4.27\end{array}$ & $\begin{array}{l}3.91 \\
3.90 \\
3.88 \\
3.87 \\
3.85\end{array}$ & $\begin{array}{l}4.19 \\
4.18 \\
4.19 \\
4.17 \\
4.15\end{array}$ \\
\hline $\begin{array}{l}11 \\
12 \\
13 \\
14 \\
15\end{array}$ & $\begin{array}{l}3.79 \\
3.79 \\
3.79 \\
3.79 \\
3.88\end{array}$ & $\begin{array}{l}3.90 \\
3.90 \\
3.89 \\
3.89 \\
3.87\end{array}$ & $\begin{array}{l}3.81 \\
3.80 \\
3.81 \\
3.84 \\
3.86\end{array}$ & $\begin{array}{l}4.05 \\
4.05 \\
4.05 \\
4.05 \\
4.05\end{array}$ & $\begin{array}{l}4.06 \\
4.06 \\
4.05 \\
4.05 \\
4.05\end{array}$ & $\begin{array}{l}4.55 \\
4.61 \\
4.63 \\
4.63 \\
4.63\end{array}$ & $\begin{array}{l}4.55 \\
4.55 \\
4.54 \\
4.54 \\
4.54\end{array}$ & $\begin{array}{l}4.64 \\
4.60 \\
4.59 \\
4.64 \\
4.65\end{array}$ & $\begin{array}{l}4.37 \\
4.39 \\
4.36 \\
4.36 \\
4.40\end{array}$ & $\begin{array}{l}4.26 \\
4.24 \\
4.23 \\
4.22 \\
4.20\end{array}$ & $\begin{array}{l}3.83 \\
3.88 \\
3.92 \\
3.90 \\
3.89\end{array}$ & $\begin{array}{l}4.13 \\
4.13 \\
4.13 \\
4.12 \\
4.09\end{array}$ \\
\hline $\begin{array}{l}16 \\
17 \\
18 \\
19 \\
20\end{array}$ & $\begin{array}{l}3.92 \\
3.95 \\
3.96 \\
3.94 \\
3.94\end{array}$ & $\begin{array}{l}3.86 \\
3.86 \\
3.86 \\
3.85 \\
3.85\end{array}$ & $\begin{array}{l}3.96 \\
3.99 \\
4.00 \\
4.00 \\
4.00\end{array}$ & $\begin{array}{l}4.05 \\
4.06 \\
4.06 \\
4.07 \\
4.06\end{array}$ & $\begin{array}{l}4.05 \\
4.05 \\
4.05 \\
4.05 \\
4.06\end{array}$ & $\begin{array}{l}4.61 \\
4.60 \\
4.59 \\
4.58 \\
4.56\end{array}$ & $\begin{array}{l}4.55 \\
4.52 \\
4.52 \\
4.53 \\
4.53\end{array}$ & $\begin{array}{l}4.64 \\
4.63 \\
4.60 \\
4.58 \\
4.59\end{array}$ & $\begin{array}{l}4.40 \\
4.38 \\
4.37 \\
4.35 \\
4.34\end{array}$ & $\begin{array}{l}4.18 \\
4.16 \\
4.14 \\
4.13 \\
4.11\end{array}$ & $\begin{array}{l}3.88 \\
3.89 \\
3.87 \\
3.86 \\
3.84\end{array}$ & $\begin{array}{r}4.08 \\
4.08 \\
4.09 \\
4.09 \\
4.09\end{array}$ \\
\hline $\begin{array}{l}21 \\
22 \\
23 \\
24 \\
25\end{array}$ & $\begin{array}{l}3.94 \\
3.93 \\
3.91 \\
3.89 \\
3.90\end{array}$ & $\begin{array}{l}3.84 \\
3.83 \\
3.84 \\
3.83 \\
3.84\end{array}$ & $\begin{array}{l}4.00 \\
4.00 \\
4.00 \\
4.01 \\
4.01\end{array}$ & $\begin{array}{l}4.06 \\
4.06 \\
4.06 \\
4.06 \\
4.06\end{array}$ & $\begin{array}{l}4.07 \\
4.08 \\
4.09 \\
4.09 \\
4.10\end{array}$ & $\begin{array}{l}4.55 \\
4.53 \\
4.54 \\
4.53 \\
4.52\end{array}$ & $\begin{array}{l}4.57 \\
4.74 \\
4.86 \\
4.89 \\
4.88\end{array}$ & $\begin{array}{l}4.57 \\
4.54 \\
4.53 \\
4.54 \\
4.52\end{array}$ & $\begin{array}{l}4.33 \\
4.31 \\
4.30 \\
4.29 \\
4.27\end{array}$ & $\begin{array}{l}4.10 \\
4.09 \\
4.06 \\
4.07 \\
4.06\end{array}$ & $\begin{array}{l}3.82 \\
3.80 \\
3.86 \\
3.87 \\
3.86\end{array}$ & $\begin{array}{r}4.08 \\
4.09 \\
4.09 \\
4.08 \\
4.08\end{array}$ \\
\hline $\begin{array}{l}26 \\
27 \\
28 \\
29 \\
30 \\
31\end{array}$ & $\begin{array}{l}3.90 \\
3.89 \\
3.90 \\
3.88 \\
3.87 \\
3.86\end{array}$ & $\begin{array}{r}3.85 \\
3.84 \\
3.84 \\
3.85 \\
3.85 \\
-\end{array}$ & $\begin{array}{l}4.00 \\
4.01 \\
4.02 \\
4.02 \\
4.02 \\
4.04\end{array}$ & $\begin{array}{l}4.06 \\
4.06 \\
4.06 \\
4.07 \\
4.07 \\
4.07\end{array}$ & $\begin{array}{r}4.10 \\
4.10 \\
4.10 \\
. .- \\
-.\end{array}$ & $\begin{array}{l}4.53 \\
4.56 \\
4.55 \\
4.54 \\
4.53 \\
4.55\end{array}$ & $\begin{array}{l}4.89 \\
4.87 \\
4.86 \\
4.85 \\
4.84 \\
-\end{array}$ & $\begin{array}{l}4.51 \\
4.49 \\
4.46 \\
4.47 \\
4.48 \\
4.48\end{array}$ & $\begin{array}{r}4.31 \\
4.40 \\
4.40 \\
4.40 \\
4.39 \\
\end{array}$ & $\begin{array}{l}4.05 \\
4.03 \\
4.01 \\
4.00 \\
4.00 \\
3.99\end{array}$ & $\begin{array}{l}3.85 \\
3.84 \\
3.87 \\
3.93 \\
3.93 \\
3.92\end{array}$ & $\begin{array}{l}4.07 \\
4.05 \\
4.06 \\
4.09 \\
4.11 \\
\end{array}$ \\
\hline $\begin{array}{l}\text { MEAN } \\
\text { MAX } \\
\text { MIN }\end{array}$ & $\begin{array}{l}3.84 \\
3.96 \\
3.73\end{array}$ & $\begin{array}{l}3.85 \\
3.92 \\
3.80\end{array}$ & $\begin{array}{l}3.92 \\
4.04 \\
3.80\end{array}$ & $\begin{array}{l}4.05 \\
4.07 \\
4.04\end{array}$ & $\begin{array}{l}4.06 \\
4.10 \\
4.05\end{array}$ & $\begin{array}{l}4.47 \\
4.63 \\
4.10\end{array}$ & $\begin{array}{l}4.65 \\
4.89 \\
4.51\end{array}$ & $\begin{array}{l}4.61 \\
4.82 \\
4.46\end{array}$ & $\begin{array}{r}4.38 \\
4.49 \\
4.27\end{array}$ & $\begin{array}{l}4.18 \\
4.37 \\
3.99\end{array}$ & $\begin{array}{l}3.88 \\
3.97 \\
3.80\end{array}$ & $\begin{array}{l}4.09 \\
4.19 \\
3.92\end{array}$ \\
\hline
\end{tabular}

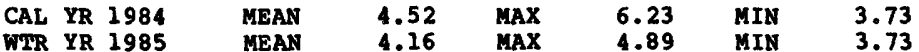

WIR YR 1985 MEAN 4.16 MAX 4.89 MIN 3.73


LOCATION.--Lat $43^{\circ} 07^{\prime} 44^{\prime \prime}$, long $95^{\circ} 12^{\prime} 37^{\prime \prime}$, in SWl/4SWl/4 sec.15, T.96N., R.37w., Clay County, Hydrologic Unit 10230003 , on left bank 3 ft downstream from bridge on county highway M38, $3.4 \mathrm{mi}$ west by southwest of Spencer, and at mile 4.1 .

DRAINAGE AREA. $--426 \mathrm{mi}^{2}$.

PERIOD OF RECORD.--October 1977 to current year. Occasional low-flow measurements, water years 1957-61, 1964, $1966-68,1970,1971,1974-77$.

GAGE.--Water-stage recorder. Datum of gage is $1,311.66 \mathrm{ft}$ above NGVD.

REMARKS.--Estimated dialy discharges: Dec. 4 to Mar. 8, Mar. 30, 31, and Apr. 9-14. Records good except for estimated daily discharges, which are poor.

AVERAGE DISCHARGE. --8 years, $256 \mathrm{ft}^{3} / \mathrm{s}, 8.16 \mathrm{in} / \mathrm{yr}^{2}, 185,500 \mathrm{acre}-\mathrm{ft} / \mathrm{yr}$.

EXTREMES FOR PERIOD OF RECORD.--Maximum discharge, $6,450 \mathrm{ft} / \mathrm{s}$ June 21 , 1983 , gage height, $10.49 \mathrm{ft}$; no flow Jan. 24 to Mar. 9, 1979 .

EXTREMES OUTSIDE PERIOD OF RECORD.--Flood of June 8,1953 reached a stage of $12.89 \mathrm{ft}^{\mathrm{d}} \mathrm{discharge,} 26,000 \mathrm{ft} 3 / \mathrm{s}$ on basis of contracted-opening measurement of peak flow.

EXTREMES FOR CURRENT YEAR.--Peak discharges greater than base of $1,700 \mathrm{ft}^{3} / \mathrm{s}$ and maximum (*):

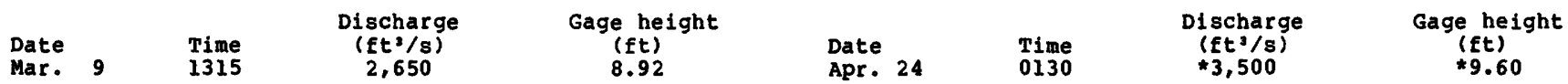

Minimum daily discharge, $17 \mathrm{ft}^{3} / \mathrm{s}$ Jan 30 to Feb. 18.

DISCHARGE, IN CUBIC FEET PER SECOND, WATER YEAR OCTOBER 1984 TO SEPTEMBER 1985 MEAN VALUES

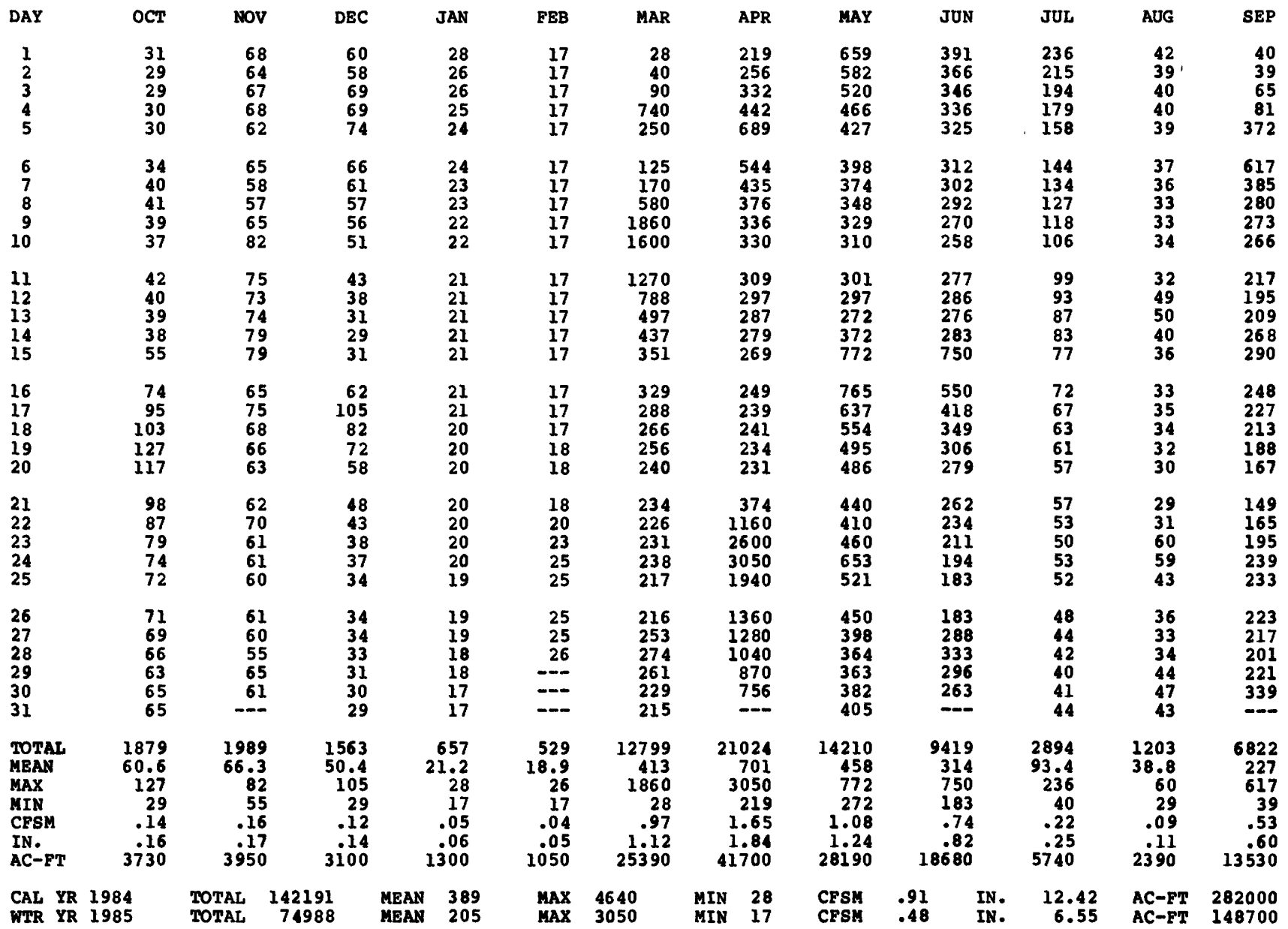


LOCATION,--Lat $42^{\circ} 53^{\prime} 24^{\prime \prime}$, long $95^{\circ} 14^{\prime} 30^{\prime \prime}$, in Sw1/4 Swl/4 sec.5, T.93 N., R.37 W., Buena Vista County, Hydrologic Unit 10230003 , on right bank at downstream side of bridge on state Highway 264 , in Linn Grove, and at mile 123.7 .

DRAINAGE AREA. $--1,548 \mathrm{mi}^{2}$.

PERIOD OF RECORD.--October 1972 to current year.

REVISED RECORDS.--WDR IA-80-1: 1978-79.

GAGE.--Water-stage recorder. Datum of gage is $1,223.60 \mathrm{ft}$ above NGVD.

REMARRS.--Estimated daily discharges: Oct. 21-24, and Dec. 9 to Mar. 5. Records good except for estimated daily discharges which are poor. U. S. Army Corps of Engineers rain-gage and gage-height satellite data collection platform at station.

AVERAGE DISCHARGE, -13 years, $720 \mathrm{ft} / \mathrm{s}, 6.32 \mathrm{in} / \mathrm{yr}, 521,600$ acre-ft/yr; median of yearly mean discharges, 680 $\mathrm{ft}^{2} / \mathrm{s}, 6.0 \mathrm{in} / \mathrm{yr}, 493,000$ acre-ft/yr.

EXTREMES FOR PERIOD OF RECORD.--Kaximum discharge, 13,100 ft'/s June 17, 1984, gage height, $19.58 \mathrm{ft}$; maximum gage height, $19.58 \mathrm{ft}$ June 17, 1984 ; minimum daily discharge, $0.70 \mathrm{ft} / \mathrm{s}$ Feb. 4,1977 .

EXTREMES FOR CURRENT YEAR.--Peak discharges greater than base of $1,500 \mathrm{ft} / \mathrm{s}$ and maximum (*):

\begin{tabular}{|c|c|c|c|c|c|c|c|c|}
\hline $\begin{array}{l}\text { Date } \\
\text { Mar. } 13 \\
\text { Apr. } 7 \\
\text { Apr. } 26\end{array}$ & $\begin{array}{l}\text { Time } \\
1230 \\
2000 \\
0330\end{array}$ & $\begin{array}{c}\text { Discharge } \\
\left(f^{2} / \mathrm{s}\right) \\
3,130 \\
1,980 \\
* 6,000\end{array}$ & $\begin{array}{c}\text { Gage height } \\
\text { (ft) } \\
13.37 \\
10.56 \\
* 16.21\end{array}$ & $\begin{array}{l}\text { Date } \\
\text { May } \\
\text { May } \\
\text { June }\end{array}$ & $\begin{array}{l}18 \\
25 \\
17\end{array}$ & $\begin{array}{l}\text { Time } \\
1000 \\
1530 \\
1215\end{array}$ & $\begin{array}{c}\text { Discharge } \\
\left(f t^{\prime} / \mathrm{s}\right) \\
2,150 \\
2,140 \\
1,630\end{array}$ & $\begin{array}{c}\text { Gage height } \\
(f t) \\
11.07 \\
11.04 \\
9.71\end{array}$ \\
\hline
\end{tabular}

Minimum daily discharge, $67 \mathrm{ft}^{2} / \mathrm{s}$ Feb. 15.

DISCHARGE, IN CUBIC FEET PER SECOND, WATER YEAR OCTOBER 1984 TO SEPTEMBER 1985 MEAN VALUES

\begin{tabular}{|c|c|c|c|c|c|c|c|c|c|c|c|c|}
\hline DAY & OCT & NOV & DEC & JAN & FEB & MAR & APR & MAY & JUN & JUL & AUG & SE \\
\hline $\begin{array}{l}1 \\
2 \\
3 \\
4 \\
5\end{array}$ & $\begin{array}{l}126 \\
130 \\
131 \\
129 \\
126\end{array}$ & $\begin{array}{l}219 \\
210 \\
201 \\
199 \\
195\end{array}$ & $\begin{array}{l}223 \\
198 \\
134 \\
103 \\
131\end{array}$ & $\begin{array}{l}330 \\
280 \\
260 \\
240 \\
230\end{array}$ & $\begin{array}{l}74 \\
73 \\
71 \\
71 \\
71\end{array}$ & $\begin{array}{l}155 \\
162 \\
210 \\
280 \\
305\end{array}$ & $\begin{array}{r}780 \\
779 \\
894 \\
1100 \\
1410\end{array}$ & $\begin{array}{l}3600 \\
3190 \\
2820 \\
2490 \\
2230\end{array}$ & $\begin{array}{l}1180 \\
1190 \\
1150 \\
1130 \\
1090\end{array}$ & $\begin{array}{l}874 \\
780 \\
702 \\
635 \\
569\end{array}$ & $\begin{array}{l}129 \\
128 \\
126 \\
122 \\
123\end{array}$ & $\begin{array}{l}167 \\
157 \\
173 \\
177 \\
312\end{array}$ \\
\hline $\begin{array}{r}6 \\
7 \\
8 \\
9 \\
10\end{array}$ & $\begin{array}{l}130 \\
131 \\
144 \\
156 \\
159\end{array}$ & $\begin{array}{l}189 \\
184 \\
184 \\
207 \\
318\end{array}$ & $\begin{array}{l}156 \\
152 \\
117 \\
118 \\
120\end{array}$ & $\begin{array}{l}208 \\
195 \\
188 \\
177 \\
167\end{array}$ & $\begin{array}{l}70 \\
70 \\
70 \\
70 \\
69\end{array}$ & $\begin{array}{r}340 \\
551 \\
1010 \\
1430 \\
2190\end{array}$ & $\begin{array}{l}1730 \\
1940 \\
1910 \\
1700 \\
1520\end{array}$ & $\begin{array}{l}1960 \\
1720 \\
1550 \\
1420 \\
1300\end{array}$ & $\begin{array}{r}1030 \\
956 \\
883 \\
817 \\
754\end{array}$ & $\begin{array}{l}513 \\
469 \\
427 \\
391 \\
365\end{array}$ & $\begin{array}{l}123 \\
116 \\
111 \\
108 \\
110\end{array}$ & $\begin{array}{r}912 \\
1240 \\
1290 \\
975 \\
766\end{array}$ \\
\hline $\begin{array}{l}11 \\
12 \\
13 \\
14 \\
15\end{array}$ & $\begin{array}{l}154 \\
151 \\
150 \\
149 \\
171\end{array}$ & $\begin{array}{l}371 \\
337 \\
312 \\
307 \\
315\end{array}$ & $\begin{array}{l}130 \\
140 \\
160 \\
180 \\
150\end{array}$ & $\begin{array}{l}158 \\
148 \\
138 \\
127 \\
122\end{array}$ & $\begin{array}{l}69 \\
69 \\
69 \\
68 \\
67\end{array}$ & $\begin{array}{l}2870 \\
3020 \\
3100 \\
2890 \\
2310\end{array}$ & $\begin{array}{l}1370 \\
1240 \\
1160 \\
1110 \\
1090\end{array}$ & $\begin{array}{l}1210 \\
1140 \\
1070 \\
1190 \\
1530\end{array}$ & $\begin{array}{r}731 \\
757 \\
807 \\
812 \\
1100\end{array}$ & $\begin{array}{l}338 \\
315 \\
293 \\
276 \\
259\end{array}$ & $\begin{array}{l}106 \\
111 \\
158 \\
162 \\
136\end{array}$ & $\begin{array}{l}726 \\
682 \\
643 \\
642 \\
678\end{array}$ \\
\hline $\begin{array}{l}16 \\
17 \\
18 \\
19 \\
20\end{array}$ & $\begin{array}{l}218 \\
254 \\
296 \\
339 \\
359\end{array}$ & $\begin{array}{l}307 \\
277 \\
290 \\
278 \\
239\end{array}$ & $\begin{array}{l}250 \\
600 \\
620 \\
570 \\
520\end{array}$ & $\begin{array}{l}121 \\
114 \\
110 \\
103 \\
101\end{array}$ & $\begin{array}{l}68 \\
69 \\
72 \\
76 \\
86\end{array}$ & $\begin{array}{l}2010 \\
1910 \\
1800 \\
1620 \\
1420\end{array}$ & $\begin{array}{r}1060 \\
1010 \\
958 \\
887 \\
847\end{array}$ & $\begin{array}{l}1880 \\
2090 \\
2140 \\
2020 \\
1880\end{array}$ & $\begin{array}{l}1420 \\
1610 \\
1510 \\
1260 \\
1110\end{array}$ & $\begin{array}{l}244 \\
230 \\
215 \\
201 \\
188\end{array}$ & $\begin{array}{l}131 \\
126 \\
116 \\
126 \\
105\end{array}$ & $\begin{array}{l}698 \\
651 \\
599 \\
556 \\
510\end{array}$ \\
\hline $\begin{array}{l}21 \\
22 \\
23 \\
24 \\
25\end{array}$ & $\begin{array}{l}348 \\
329 \\
308 \\
289 \\
251\end{array}$ & $\begin{array}{l}223 \\
243 \\
273 \\
253 \\
245\end{array}$ & $\begin{array}{l}470 \\
430 \\
380 \\
350 \\
310\end{array}$ & $\begin{array}{l}99 \\
96 \\
93 \\
91 \\
88\end{array}$ & $\begin{array}{l}104 \\
130 \\
147 \\
150 \\
150\end{array}$ & $\begin{array}{r}1230 \\
1100 \\
1020 \\
999 \\
981\end{array}$ & $\begin{array}{r}874 \\
1200 \\
1800 \\
2570 \\
4800\end{array}$ & $\begin{array}{l}1770 \\
1630 \\
1500 \\
1650 \\
2070\end{array}$ & $\begin{array}{l}992 \\
880 \\
764 \\
671 \\
601\end{array}$ & $\begin{array}{l}178 \\
169 \\
161 \\
161 \\
167\end{array}$ & $\begin{array}{l}101 \\
104 \\
214 \\
282 \\
249\end{array}$ & $\begin{array}{l}469 \\
453 \\
461 \\
502 \\
589\end{array}$ \\
\hline $\begin{array}{l}26 \\
27 \\
28 \\
29 \\
30 \\
31\end{array}$ & $\begin{array}{l}249 \\
249 \\
241 \\
227 \\
216 \\
214\end{array}$ & $\begin{array}{l}249 \\
251 \\
239 \\
223 \\
233 \\
---\end{array}$ & $\begin{array}{l}280 \\
260 \\
350 \\
450 \\
400 \\
350\end{array}$ & $\begin{array}{l}86 \\
85 \\
83 \\
79 \\
77 \\
76\end{array}$ & $\begin{array}{l}150 \\
148 \\
151 \\
-- \\
-\cdots\end{array}$ & $\begin{array}{l}910 \\
868 \\
896 \\
937 \\
889 \\
844\end{array}$ & $\begin{array}{r}5880 \\
5390 \\
5330 \\
4830 \\
4140 \\
---\end{array}$ & $\begin{array}{l}2010 \\
1670 \\
1420 \\
1280 \\
1200 \\
1180\end{array}$ & $\begin{array}{r}553 \\
617 \\
924 \\
1040 \\
977 \\
-\end{array}$ & $\begin{array}{l}162 \\
152 \\
140 \\
134 \\
130 \\
129\end{array}$ & $\begin{array}{l}194 \\
163 \\
154 \\
161 \\
164 \\
167\end{array}$ & $\begin{array}{l}629 \\
636 \\
633 \\
630 \\
712 \\
---\end{array}$ \\
\hline $\begin{array}{l}\text { TOTAL } \\
\text { MEAN } \\
\text { MAX } \\
\text { MIN } \\
\text { CFSM } \\
\text { IN. } \\
\text { AC-FT }\end{array}$ & $\begin{array}{r}6524 \\
210 \\
359 \\
126 \\
.14 \\
.16 \\
12940\end{array}$ & $\begin{array}{r}7571 \\
252 \\
371 \\
184 \\
.16 \\
.18 \\
15020\end{array}$ & $\begin{array}{r}8802 \\
284 \\
620 \\
103 \\
.18 \\
.21 \\
17460\end{array}$ & $\begin{array}{r}4470 \\
144 \\
330 \\
76 \\
.09 \\
.11 \\
8870\end{array}$ & $\begin{array}{r}2552 \\
91.1 \\
151 \\
67 \\
.06 \\
.06 \\
5060\end{array}$ & $\begin{array}{r}40257 \\
1299 \\
3100 \\
155 \\
.84 \\
.97 \\
79850\end{array}$ & $\begin{array}{r}61309 \\
2044 \\
5880 \\
779 \\
1.32 \\
1.47 \\
121600\end{array}$ & $\begin{array}{r}55810 \\
1800 \\
3600 \\
1070 \\
1.16 \\
1.34 \\
110700\end{array}$ & $\begin{array}{r}29316 \\
977 \\
1610 \\
553 \\
.63 \\
.70 \\
58150\end{array}$ & $\begin{array}{r}9967 \\
322 \\
874 \\
129 \\
.21 \\
.24 \\
19770\end{array}$ & $\begin{array}{r}4426 \\
143 \\
282 \\
101 \\
.09 \\
.11 \\
8780\end{array}$ & $\begin{array}{r}18268 \\
609 \\
1290 \\
157 \\
.39 \\
.44 \\
36230\end{array}$ \\
\hline $\begin{array}{l}\text { CAL YR } \\
\text { WTR YR }\end{array}$ & & $\begin{array}{ll}\text { TAL } & 54 \\
\text { TAL } & 24\end{array}$ & & $\begin{array}{r}1497 \\
683\end{array}$ & $\begin{array}{l}\text { MAX } \\
\text { MAX }\end{array}$ & $\begin{array}{l}00 \\
80\end{array}$ & $\begin{array}{rr}N & 103 \\
N & 67\end{array}$ & $\begin{array}{l}\text { CFSM } \\
\text { CFSM }\end{array}$ & $\begin{array}{l}\text { IN. } \\
\text { IN. }\end{array}$ & $\begin{array}{r}13.16 \\
5.99\end{array}$ & $\begin{array}{l}A C-F T \\
A C-F T\end{array}$ & $\begin{array}{r}1087000 \\
494400\end{array}$ \\
\hline
\end{tabular}


06606600 LITTLE SIOUX RIVER AT CORRECTIONVILLE, IA

LOCATION.--Lat $42^{\circ} 28^{\prime} 20^{\prime \prime}$, long $95^{\circ} 47^{\prime} 49^{\prime \prime}$, in NEl/4 NWl/4 sec.1, T.88 N., R.43 W., Woodbury County, Bydrologic Unit 10230003 on right bank $50 \mathrm{ft}$ upstream from bridge on state Bighway $31,0.3 \mathrm{mi}$ upstream from Bacon Creek, 0.5 $\mathrm{mi}$ west of Correctionville, $0.8 \mathrm{mi}$ downstream from Pierson Creek, and at mile 56.0 .

DRAINAGE AREA. $--2,500 \mathrm{mi}^{2}$.

PERIOD OF RECORD.--May 1918 to July 1925, October 1928 to July 1932, June 1936 to current year. Monthly discharge only for some periods, published in WSP 1310.

REVISED RECORDS.--WSP 856: 1919. WSP 1240: 1924-25, 1931, 1932 (M), 1937, 1945 (M), 1947 (M), 1949 (M). WSP 1440: Drainage area.

GAGE.--Water-stage recorder. Datum of gage is 1,096.49 ft above NGVD. May 28, 1918, to July 1, 1925 and Oct. 29, 1928 to July 15,1929 , nonrecording gage $0.2 \mathrm{mi}$ downstream at datum $1.25 \mathrm{ft} 10 \mathrm{wer}$. July 16 , 1929 , to July 2 , 1932, and June 15, 1936, to Nov. 7, 1938, nonrecording gage at present site and datum.

REMARKS.--Estimated daily discharges: Dec. 20-27, Dec. 29 to Mar. 3, Mar. 18-20, 22, Apr. 22-25, 29, 30, May 1, 18, 19, June 2-5, and Sept. 10. Records good except those for periods of estimated discharge, which are poor. U. S. Army Corps of Engineers rain-gage and gage-height satellite data collection platform at station.

AVERAGE DISCHARGE.--58 years (water years 1919-24, 1927-31, 1937-85), 807 ft/s, 4.38 in/yr, 584,700 acre-ft/yr, median of yearly mean discharge, $610 \mathrm{ft} / \mathrm{s}, 3.3 \mathrm{in} / \mathrm{yr}, 442,000 \mathrm{acre}-\mathrm{ft} / \mathrm{yr}$.

EXTREMES FOR PERIOD OF RECORD,--Maximum discharge, 29,800 ft3/s Apr. 7, 1965, gage height, 25.86 ft, minimum daily, $2.6 \mathrm{ft}^{3} / \mathrm{s}$ July $17,25,1936$, caused by construction dam above gage; minimum daily discharge excluding regulation, $4.0 \mathrm{ft}^{3} / \mathrm{s}$ oct. $9,12,1956$

EXTREMES OUTSIDE PERIOD OF RECORD.--Flood of June 23 or 24,1891 , reached a stage of 29.34 ft, present datum, from levels to floodmark by U. S. Soil Conservation Service (discharge not determined).

EXTREMES FOR CURRENT YEAR.--Peak discharges greater than base of 4,000 $\mathrm{ft}^{3} / \mathrm{s}$ and maximum (*):

\begin{tabular}{|c|c|c|c|c|c|c|c|c|}
\hline $\begin{array}{l}\text { Date } \\
\text { Mar. } \\
\text { Mar. }\end{array}$ & $\begin{array}{l}4 \\
9\end{array}$ & $\begin{array}{l}\text { Time } \\
0615 \\
0100\end{array}$ & $\begin{array}{c}\text { Di scharge } \\
\left.\text { (ft } t^{3} / \mathrm{s}\right) \\
4,970 \\
4,370\end{array}$ & $\begin{array}{c}\text { Gage height } \\
\text { (ft) } \\
14.08 \\
13.26\end{array}$ & $\begin{array}{l}\text { Date } \\
\text { Apr. } 25 \\
\text { Apr. } 28\end{array}$ & $\begin{array}{l}\text { Time } \\
0600 \\
1800\end{array}$ & $\begin{array}{c}\text { Di scharge } \\
\left(f t^{2} / \mathrm{s}\right) \\
* 9,640 \\
9,540\end{array}$ & $\begin{array}{c}\text { Gage height } \\
\text { (ft) } \\
\star 18.38 \\
18.28\end{array}$ \\
\hline
\end{tabular}

Minimum daily discharge, $220 \mathrm{ft}^{2} / \mathrm{s}$ Feb. 10-17.

DISCHARGE, IN CUBIC FEET PER SECOND, WATER YEAR OCTOBER 1984 TO SEPTEMBER 1985 MEAN VALUES

\begin{tabular}{|c|c|c|c|c|c|c|c|c|c|c|c|c|}
\hline DAY & OCT & NOV & DEC & JAN & FEB & MAR & APR & MAY & JUN & JUL & AUG & SEP \\
\hline $\begin{array}{l}1 \\
2 \\
3 \\
4 \\
5\end{array}$ & $\begin{array}{l}269 \\
267 \\
264 \\
262 \\
264\end{array}$ & $\begin{array}{l}564 \\
535 \\
529 \\
529 \\
513\end{array}$ & $\begin{array}{l}489 \\
476 \\
365 \\
354 \\
390\end{array}$ & $\begin{array}{r}1100 \\
900 \\
1200 \\
900 \\
800\end{array}$ & $\begin{array}{l}240 \\
240 \\
230 \\
230 \\
230\end{array}$ & $\begin{array}{r}400 \\
400 \\
1040 \\
3910 \\
2120\end{array}$ & $\begin{array}{l}1370 \\
1360 \\
1450 \\
1610 \\
1830\end{array}$ & $\begin{array}{l}7730 \\
6730 \\
5570 \\
4820 \\
4260\end{array}$ & $\begin{array}{l}2190 \\
2100 \\
2050 \\
2000 \\
1900\end{array}$ & $\begin{array}{l}1390 \\
1290 \\
1200 \\
1110 \\
1030\end{array}$ & $\begin{array}{l}332 \\
315 \\
315 \\
322 \\
319\end{array}$ & $\begin{array}{l}474 \\
437 \\
417 \\
405 \\
544\end{array}$ \\
\hline $\begin{array}{r}6 \\
7 \\
8 \\
9 \\
10\end{array}$ & $\begin{array}{l}288 \\
305 \\
317 \\
312 \\
305\end{array}$ & $\begin{array}{l}502 \\
497 \\
494 \\
530 \\
776\end{array}$ & $\begin{array}{l}387 \\
408 \\
423 \\
438 \\
430\end{array}$ & $\begin{array}{l}700 \\
680 \\
640 \\
620 \\
600\end{array}$ & $\begin{array}{l}230 \\
230 \\
230 \\
230 \\
220\end{array}$ & $\begin{array}{l}1760 \\
1760 \\
2620 \\
3750 \\
3000\end{array}$ & $\begin{array}{l}2100 \\
2310 \\
2490 \\
2530 \\
2400\end{array}$ & $\begin{array}{l}3800 \\
3390 \\
3000 \\
2680 \\
2490\end{array}$ & $\begin{array}{l}1740 \\
1670 \\
1600 \\
1510 \\
1440\end{array}$ & $\begin{array}{l}946 \\
871 \\
806 \\
764 \\
714\end{array}$ & $\begin{array}{l}317 \\
301 \\
295 \\
284 \\
291\end{array}$ & $\begin{array}{l}1120 \\
1340 \\
1670 \\
1820 \\
1710\end{array}$ \\
\hline $\begin{array}{l}11 \\
12 \\
13 \\
14 \\
15\end{array}$ & $\begin{array}{l}312 \\
339 \\
328 \\
311 \\
401\end{array}$ & $\begin{array}{l}767 \\
780 \\
769 \\
732 \\
696\end{array}$ & $\begin{array}{l}434 \\
440 \\
475 \\
397 \\
410\end{array}$ & $\begin{array}{l}600 \\
500 \\
450 \\
400 \\
390\end{array}$ & $\begin{array}{l}220 \\
220 \\
220 \\
220 \\
220\end{array}$ & $\begin{array}{l}2860 \\
3190 \\
3310 \\
3350 \\
3380\end{array}$ & $\begin{array}{l}2200 \\
2020 \\
1890 \\
1800 \\
1720\end{array}$ & $\begin{array}{l}2330 \\
2190 \\
2060 \\
2120 \\
2730\end{array}$ & $\begin{array}{l}1410 \\
1390 \\
1360 \\
1400 \\
1920\end{array}$ & $\begin{array}{l}666 \\
628 \\
601 \\
586 \\
557\end{array}$ & $\begin{array}{l}284 \\
293 \\
319 \\
351 \\
324\end{array}$ & $\begin{array}{l}1440 \\
1320 \\
1320 \\
1320 \\
1330\end{array}$ \\
\hline $\begin{array}{l}16 \\
17 \\
18 \\
19 \\
20\end{array}$ & $\begin{array}{l}467 \\
595 \\
661 \\
748 \\
822\end{array}$ & $\begin{array}{l}660 \\
651 \\
650 \\
602 \\
583\end{array}$ & $\begin{array}{l}1370 \\
2180 \\
1740 \\
1360 \\
1050\end{array}$ & $\begin{array}{l}380 \\
360 \\
350 \\
330 \\
310\end{array}$ & $\begin{array}{l}220 \\
220 \\
230 \\
230 \\
270\end{array}$ & $\begin{array}{l}3110 \\
2550 \\
2340 \\
2220 \\
2070\end{array}$ & $\begin{array}{l}1680 \\
1620 \\
1560 \\
1500 \\
1460\end{array}$ & $\begin{array}{l}3130 \\
3240 \\
3300 \\
3300 \\
3320\end{array}$ & $\begin{array}{l}1500 \\
1730 \\
1910 \\
1930 \\
1760\end{array}$ & $\begin{array}{l}531 \\
503 \\
481 \\
462 \\
443\end{array}$ & $\begin{array}{l}323 \\
325 \\
317 \\
301 \\
287\end{array}$ & $\begin{array}{l}1340 \\
1320 \\
1270 \\
1190 \\
1130\end{array}$ \\
\hline $\begin{array}{l}21 \\
22 \\
23 \\
24 \\
25\end{array}$ & $\begin{array}{l}826 \\
774 \\
729 \\
685 \\
655\end{array}$ & $\begin{array}{l}537 \\
566 \\
566 \\
551 \\
571\end{array}$ & $\begin{array}{l}1300 \\
1200 \\
1150 \\
1100 \\
1000\end{array}$ & $\begin{array}{l}290 \\
270 \\
260 \\
250 \\
240\end{array}$ & $\begin{array}{l}300 \\
320 \\
350 \\
350 \\
350\end{array}$ & $\begin{array}{l}1900 \\
1720 \\
1610 \\
1550 \\
1510\end{array}$ & $\begin{array}{l}2160 \\
2860 \\
6710 \\
8600 \\
9110\end{array}$ & $\begin{array}{l}3250 \\
3040 \\
2790 \\
2760 \\
2710\end{array}$ & $\begin{array}{l}1580 \\
1470 \\
1360 \\
1250 \\
1170\end{array}$ & $\begin{array}{l}430 \\
410 \\
395 \\
387 \\
390\end{array}$ & $\begin{array}{l}286 \\
282 \\
297 \\
311 \\
353\end{array}$ & $\begin{array}{l}1070 \\
1030 \\
1020 \\
1020 \\
1060\end{array}$ \\
\hline $\begin{array}{l}26 \\
27 \\
28 \\
29 \\
30 \\
31\end{array}$ & $\begin{array}{l}629 \\
611 \\
590 \\
566 \\
548 \\
539\end{array}$ & $\begin{array}{l}565 \\
548 \\
527 \\
520 \\
519 \\
---\end{array}$ & $\begin{array}{l}1000 \\
1000 \\
2200 \\
1500 \\
1300 \\
1200\end{array}$ & $\begin{array}{l}240 \\
240 \\
240 \\
240 \\
240 \\
240\end{array}$ & $\begin{array}{l}350 \\
360 \\
380 \\
-- \\
--- \\
--\end{array}$ & $\begin{array}{l}1490 \\
1500 \\
1490 \\
1440 \\
1450 \\
1440\end{array}$ & $\begin{array}{c}7150 \\
7560 \\
9060 \\
9240 \\
8560 \\
---\end{array}$ & $\begin{array}{l}2680 \\
2730 \\
2730 \\
2620 \\
2450 \\
2320\end{array}$ & $\begin{array}{l}1100 \\
1100 \\
1110 \\
1260 \\
1400 \\
-\end{array}$ & $\begin{array}{l}372 \\
363 \\
358 \\
356 \\
335 \\
332\end{array}$ & $\begin{array}{l}400 \\
378 \\
345 \\
868 \\
857 \\
551\end{array}$ & $\begin{array}{l}1110 \\
1150 \\
1150 \\
1170 \\
1240 \\
-\cdots\end{array}$ \\
\hline $\begin{array}{l}\text { TOTAL } \\
\text { MEAN } \\
\text { MAX } \\
\text { MIN } \\
\text { CESH } \\
\text { IN. } \\
\text { AC-FT }\end{array}$ & $\begin{array}{r}14989 \\
484 \\
826 \\
262 \\
.19 \\
.22 \\
29730\end{array}$ & $\begin{array}{r}17829 \\
594 \\
780 \\
494 \\
.24 \\
327 \\
35360\end{array}$ & $\begin{array}{r}27966 \\
902 \\
2200 \\
354 \\
.36 \\
.42 \\
55470\end{array}$ & $\begin{array}{r}14960 \\
483 \\
1200 \\
240 \\
.19 \\
.22 \\
29670\end{array}$ & $\begin{array}{r}7340 \\
262 \\
380 \\
220 \\
110 \\
14560\end{array}$ & $\begin{array}{r}66240 \\
2137 \\
3910 \\
400 \\
.85 \\
.99 \\
131400\end{array}$ & $\begin{array}{r}107910 \\
3597 \\
9240 \\
1360 \\
1.44 \\
1.61 \\
214000\end{array}$ & $\begin{array}{r}102270 \\
3299 \\
7730 \\
2060 \\
1.32 \\
1.52 \\
202900\end{array}$ & $\begin{array}{r}47310 \\
1577 \\
2190 \\
1100 \\
.63 \\
.70 \\
93840\end{array}$ & $\begin{array}{r}19707 \\
636 \\
1390 \\
332 \\
.25 \\
.29 \\
39090\end{array}$ & $\begin{array}{r}11143 \\
359 \\
868 \\
282 \\
.14 \\
117 \\
22100\end{array}$ & $\begin{array}{r}33937 \\
1131 \\
1820 \\
405 \\
.45 \\
.50 \\
67310\end{array}$ \\
\hline
\end{tabular}

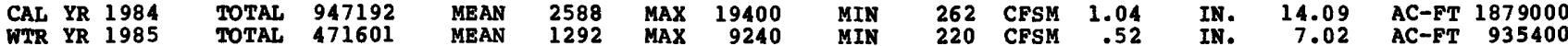




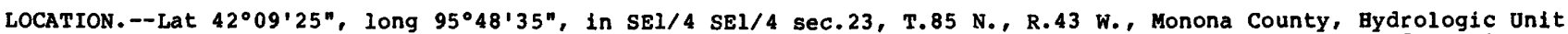
10230005 , on right bank at downstream side of bridge on state Highway 175, $1.0 \mathrm{mi}$ downstream from Simmons Creek, $1.1 \mathrm{mi}$ southwest of intersection of State 日ighways 175 and 141 in Mapleton, $2.1 \mathrm{mi}$ upstream from McCleery Creek, and $16.0 \mathrm{mi}$ upstream from mouth.

DRAINAGE AREA. $--669 \mathrm{mi}^{2}$.

PERIOD OF RECORD.--October 1941 to current year.

REVISED RECORDS.--WSP 1310: 1942 (M), 1946 (M), 1948 (M). WSP 1440: Drainage area.

GAGE. - Water-stage recorder. Datum of gage is $1,085.86 \mathrm{ft}$ above NGVD. See WSP 1730 for history of changes prior to Sept. 20, 1956 .

REMARRs.--Estimated daily discharges: oct. 25-28, 30, Dec. 5-11, 14, 15, 18-27 and Jan. 1 to Mar. 5, Mar. 13-27, 30,31 and Apr. 1, 2, 11-18. Records good except those for winter period, which are poor. U. S. Army Corps of Engineers rain-gage and gage-height satellite data collection platform at station.

AVERAGE DISCHARGE. -44 years, $261 \mathrm{ft} 3 / \mathrm{s}, 5.30 \mathrm{in} / \mathrm{yr}, 189,100$ acre-ft/yr.

EXTREMES FOR PERIOD OF RECORD.--Maximum discharge, $20,800 \mathrm{ft}^{3} / \mathrm{s} \mathrm{Sept.} \mathrm{12,} \mathrm{1978,} \mathrm{gage} \mathrm{height,} 16.74 \mathrm{ft}$; maximum gage height, $22.1 \mathrm{ft}$ June 12,1950 ; no flow Sept. 21, 22, 1945 caused by temporary dam above gage; minimum daily discharge excluding regulation, $2.5 \mathrm{ft} / \mathrm{s} \mathrm{Feb} .17-20,1959$.

EXTREMES FOR CURRENT YEAR.--Peak discharges greater than base of $4,000 \mathrm{ft} / \mathrm{s}$ and maximum $(*)$ :

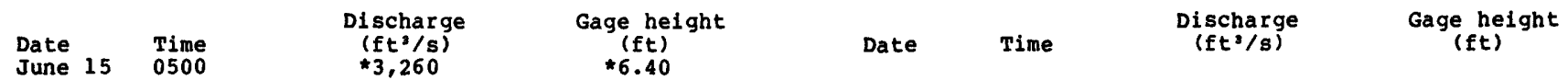

Minimum discharge, $71 \mathrm{ft}^{3} / \mathrm{s}$, Dec. 4 , result of freezeup.

DISCHARGE, IN CUBIC FEET PER SECOND, WATER YEAR OCTOBER 1984 TO SEPTEMBER 1985 MEAN VALUES

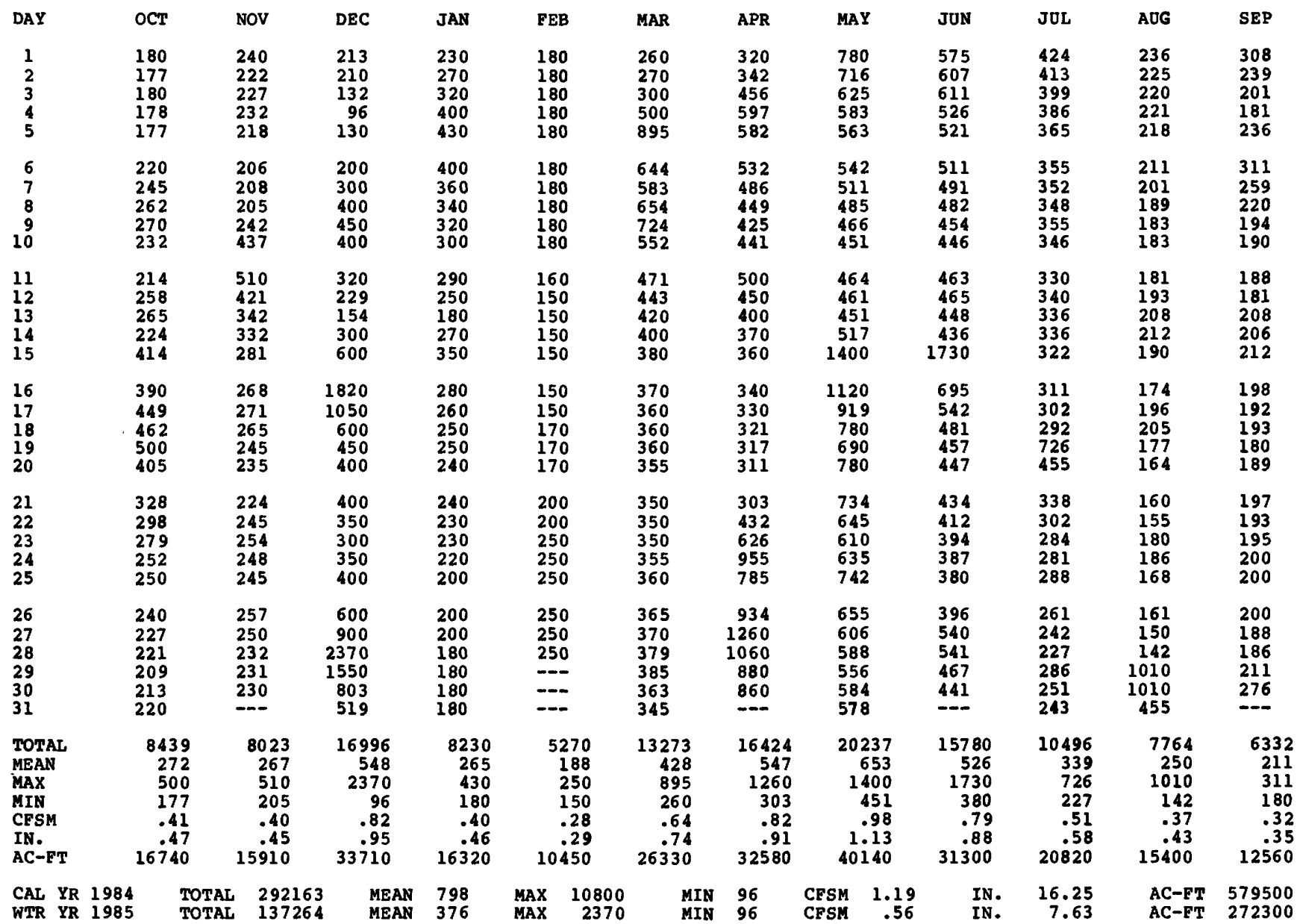


LOCATION.--Lat $41^{\circ} 57^{\prime} 52$, long $95^{\circ} 58^{\prime} 21^{\prime \prime}$, in NW1/4 NE1/4 sec.33, T.83 N., R.44 W., Monona County, Bydrologic Unit 10230003 , on left bank on downstream side of bridge on county highway E54, $1.0 \mathrm{mi}$ east of gaging station on Monona-Harrison ditch near Turin, $2.5 \mathrm{mi}$ downstream from Maple River, $3.8 \mathrm{mi}$ south of Turin, 6.2 mi northeast of Blencoe, and at mile 13.5 .

DRAINAGE AREA.--3,526 $\mathrm{mi}^{2}$. Prior to Jan. 15, 1958, 4,426 $\mathrm{mi}^{2}$, combined area above this station and MononaHarrison ditch station $1.0 \mathrm{mi}$ west.

PERIOD OF RECORD.--January 1958 to current year. April 1939 to May 1942 at site 4.7 mi downstream, published as "near Blencoe" June 1942 to January 1958 at site 1,200 ft east on old river channel; records not equivalent owing to diversion into Monona-Barrison ditch through equalizer ditch $1.5 \mathrm{mi}$ upstream.

GAGE.--Water-stage recorder. Datum of gage is 1,019.850 ft above NGVD (U. S. Army Corps of Engineers bench mark). Prior to July 15, 1958, nonrecording gages near present site at different datums. July 15 to Sept. 3 , 1958, nonrecording gage at present site and datum.

REMARKS.--Estimated daily discharges: Dec. 4-7, 14, 15, 18-27, Jan. 1 to Mar. 1 and April 24 to May 1. good except for winter period, which are poor. 0. S. Army Corps of Engineers rain-gage and gage-height satelife data collection platform at station.

AVRRAGE DISCHARGE.--27 years (water years 1959-85), $1,362 \mathrm{ft} / \mathrm{s}, 5.25 \mathrm{in} / \mathrm{yr}, 986,800 \mathrm{acre}-\mathrm{ft} / \mathrm{yr}$.

EXTREMES FOR PERIOD OF RECORD.--Maximum discharge, $31,200 \mathrm{ft} 2 / \mathrm{s}$ June 21,1983 gage height, $26.54 \mathrm{ft}$, maximum gage height, $27.44 \mathrm{ft}$ Feb. 19, 1971, backwater from ice; minimum daily discharge, $17 \mathrm{ft}^{3 / 8} \mathrm{Jan}$. 18-20, Jan. 28 to Feb. 1, 1977.

EXTREMES FOR CURRENT YEAR.--Peak discharges greater than base of $4,500 \mathrm{ft}^{2} / \mathrm{s}$ and maximum (*):

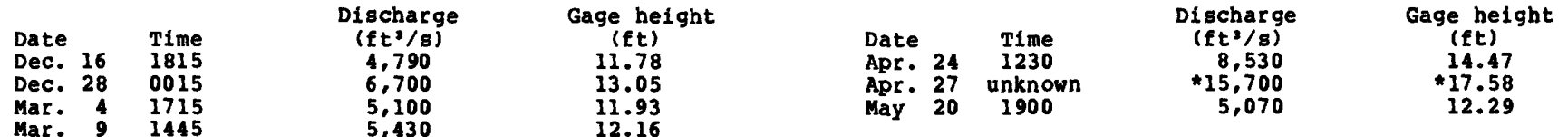

Minimum recorded discharge, $434 \mathrm{ft} / \mathrm{s}$ Aug 21, but may have been less during period of ice effect.

DISCHARGE, IN CUBIC FEET PER SECOND, WATER YEAR OCTOBER 1984 TO SEPTEMBER 1985 MEAN VALUES

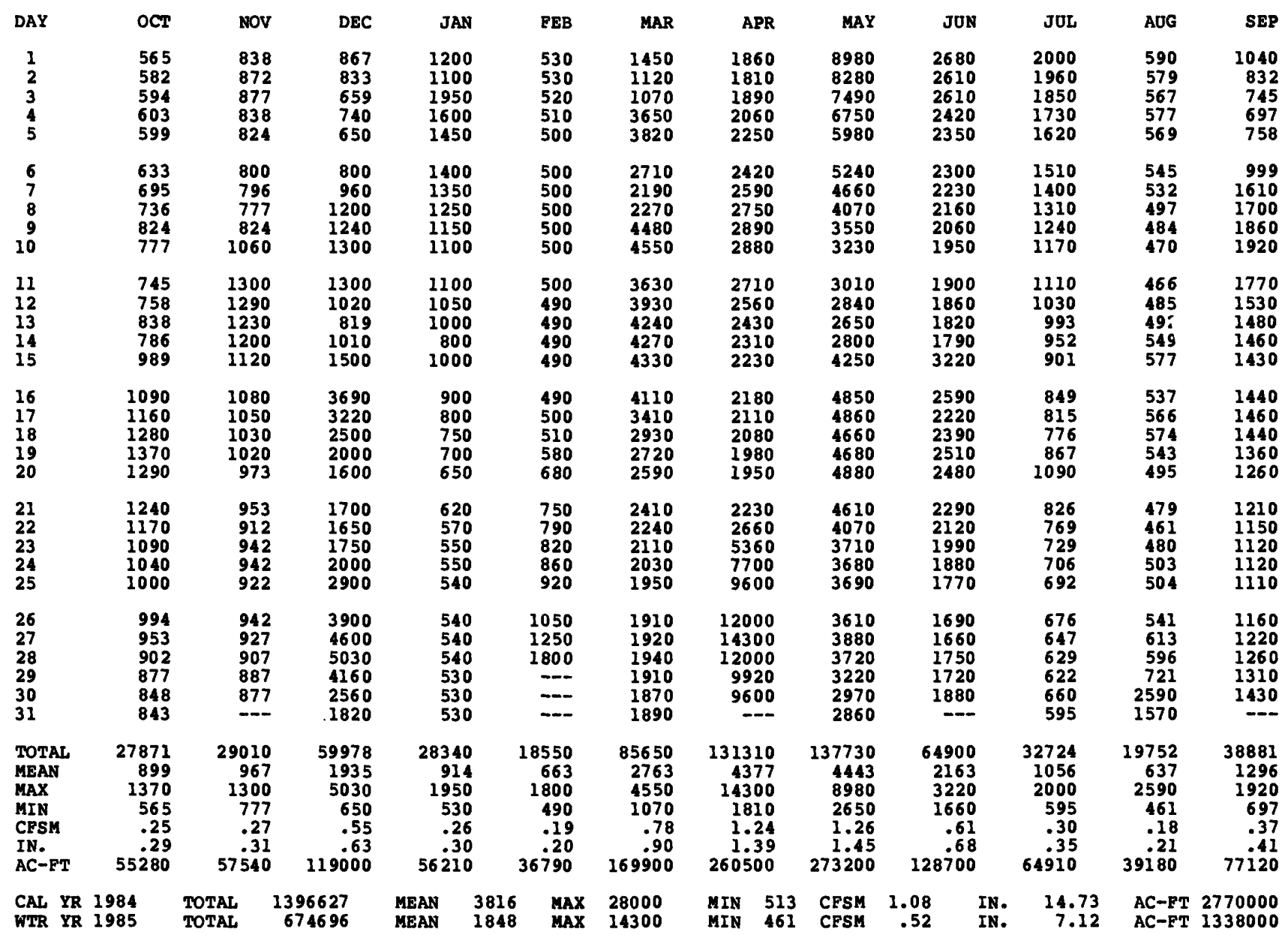


LOCATION.--Lat $41^{\circ} 49^{\prime} 50^{\prime \prime}$, long $95^{\circ} 55^{\prime} 54^{\prime \prime}$, in NWl/4 NEl/4 sec.14, T.81 N., R.44 W., Harrison County, Hydrologic Onit 10230001 , on right bank at downstream side of bridge on county highway F20, at west edge of Pisgah, 0.4 mi downstream from Cobb Creek, $0.5 \mathrm{mi}$ upstream from Mogger Ditch, and 13.1 mi upstream from mouth.

DRAINAGE AREA. $--407 \mathrm{mi}^{2}$.

PERIOD OF RECORD.--March 1940 to current year.

REVISED RECORDS.--WSP 956: 1940 (M). WSP 1240: 1940, 1941 (M), 1947. WSP 1440: Drainage area.

GAGE.--Water-stage recorder, Datum of gage is 1,036.53 ft above NGVD. Prior to Oct. 11, 1954 , nonrecording gage at same site and datum with supplementary water-stage recorder operating above $8.2 \mathrm{ft}$ gage height Mar. 2 , 1946 to Sept. 24, 1953. Prior to Feb. 1954, on left bank at downstream side of bridge.

REMARKS.--Estimated daily discharges: Dec. 4-16, 18-28 and Dec. 31 to Mar. 4. Records good except those for periods of estimated discharge, which are poor. o.s. Army Corps of Engineers rain-gage and gage-height satellite data collection platform at station.

AVERAGE DISCHARGE. -45 years, $131 \mathrm{ft} / \mathrm{s}, 4.37 \mathrm{in} / \mathrm{yr}, 94,910 \mathrm{acre}-\mathrm{ft} / \mathrm{yr}$.

EXTREMES FOR PERIOD OF RECORD.--Maximum discharge, 22,500 ft's June 12, 1950, gage height, 28.17 ft, minimum daily, $2.0 \mathrm{ft}^{3} / \mathrm{s}$ Jan. 2-10, 1945.

EXTREMES FOR CORRENT YEAR.--Peak discharges greater than base discharge of $5,000 \mathrm{ft} / \mathrm{s}$ and maximum ( $*$ )

\begin{tabular}{|c|c|c|c|c|c|c|}
\hline $\begin{array}{l}\text { Date } \\
\text { Dec. } 28\end{array}$ & Time & $\begin{array}{c}\text { Discharge } \\
\text { (ft } 3 / \mathrm{s}) \\
* 2,900\end{array}$ & $\begin{array}{c}\text { Gage height } \\
(f t) \\
a * 14.17\end{array}$ & Date & Time & $\begin{array}{c}\text { Gage height } \\
\text { (ft) }\end{array}$ \\
\hline
\end{tabular}

a ice jam

Minimum daily discharge, $73 \mathrm{ft} / \mathrm{s}$ sept. 9.

DISCHARGE, IN CUBIC FEET PER SECOND, WATER YEAR OCTOBER 1984 TO SEPTEMBER 1985 MEAN VALUES

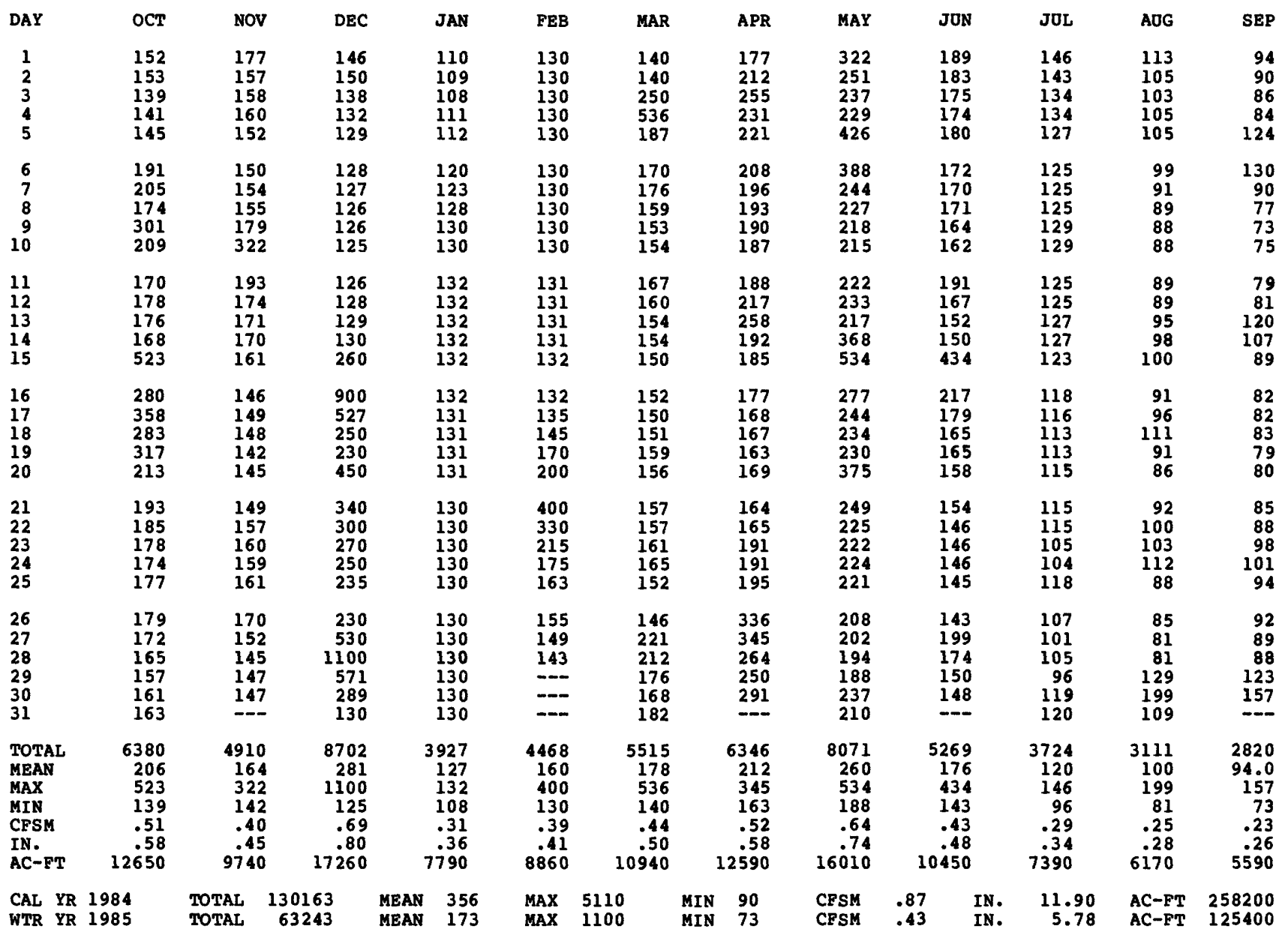


LOCATION.--Lat $41^{\circ} 38^{\prime} 33^{\prime \prime}$, Long $95^{\circ} 46^{\prime} 57^{\prime \prime}$, in SEl/4 Nol/4 sec.19, T.79 N., R.42 W., Harrison County, Hydrologic Unit 10230007 , on left bank $9 \mathrm{ft}$ downstream from Illinois Central Railroad bridge at Logan, 0.4 mi downstream from Elk Grove Creek, $10.5 \mathrm{mi}$ upstream from Willow Creek, and $15.8 \mathrm{mi}$ upstream from mouth.

DRAINAGE AREA. $--871 \mathrm{mi}^{2}$.

PERIOD OF RECORD.--May 1918 to July 1925, November 1937 to current year. Monthly discharge only for some periods, published in WSP 1310 .

REVISED RECORDS.--WSP 956: 1938-39. WSP 1240: 1918-19, 1920 (M), 1921, 1922 (M), 1924-25, 1938 (M), 1945. WSP 1440: Drainage area.

GAGE.--Water-stage recorder. Datum of gage is 1,009.38 ft above NGVD (Chicago and Northwestern Railway Company bench mark). See WSP 1918 for history of changes prior to Oct. 18, 1960 .

REMARRS.--Estimated daily discharges: Dec. 5-28, Dec. 31 to Feb. 21, and May 15-24. Records fair except for estimated daily discharges, which are poor. U.s. Army Corps of Engineers rain-gage and gage-height satellite data collection platform at station.

AVERAGE DISCHARGE.--53 years (water years 1919-24, 1939-85), $345 \mathrm{ft} / \mathrm{s}, 5.07$ in/yr, 235,400 acre-ft/yr, median of yearly mean discharge, $280 \mathrm{ft} / \mathrm{s}, 4.4 \mathrm{in} / \mathrm{yr}, 203,000 \mathrm{acre}-\mathrm{ft} / \mathrm{yr}^{3}$.

EXTREMES FOR PERIOD OF RECORD,--Maximum discharge, 25,000 ft's Feb. 19, 1971, gage height, 22.65 ft, from floodmark; maximum gage height, $25.22 \mathrm{ft}$ Mar. 1, 1965 , backwater from ices minimum dally discharge, l.5 ft/s July 16,1938 .

EXTREMES FOR CURRENT YEAR.--Peak discharges greater than base of $6,000 \mathrm{ft} / \mathrm{s}$ and maximum (*):

\begin{tabular}{|c|c|c|c|c|c|c|c|}
\hline $\begin{array}{l}\text { ate } \\
\text { eb. } 21\end{array}$ & Time & $\begin{array}{c}\text { Discharge } \\
\left(f t^{3} / g\right) \\
a * 8,600\end{array}$ & $\begin{array}{c}\text { Gage height } \\
\text { (ft) } \\
* 15.54\end{array}$ & Date & Time & $\begin{array}{c}\text { Discharge } \\
\left(\mathrm{ft}^{2} / \mathrm{s}\right)\end{array}$ & $\begin{array}{c}\text { Gage height } \\
(f t)\end{array}$ \\
\hline
\end{tabular}

a backwater from ice.

Minimum discharge, $113 \mathrm{ft} / \mathrm{s}$ Aug. 21.

DISCHARGE, IN CUBIC FEET PER SECOND, WATER YEAR OCTOBER 1984 TO SEPTEMBER I985 MEAN VALUES

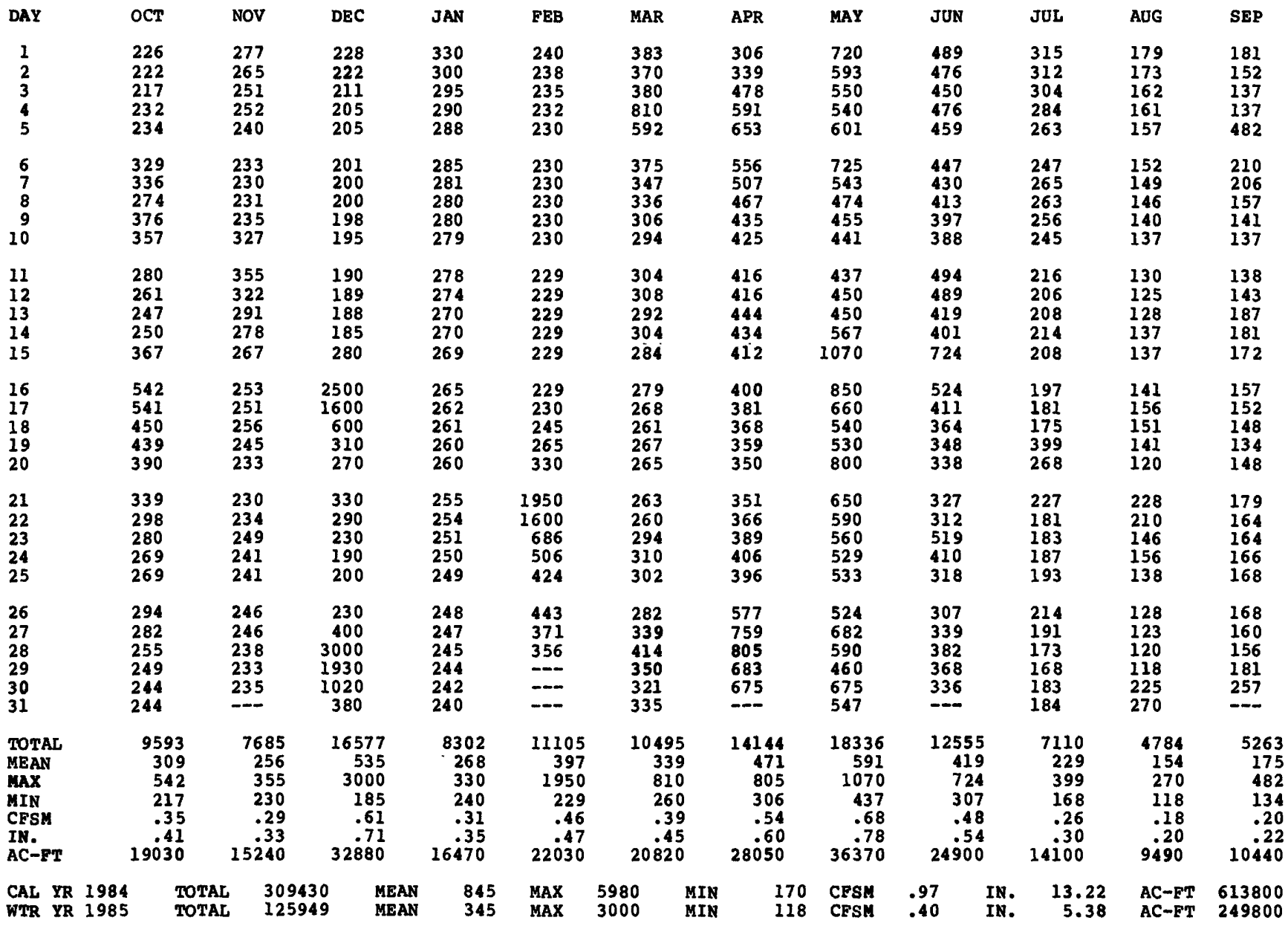




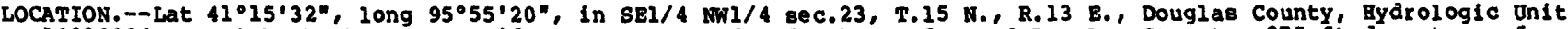
10230006 , on right bank on left side of concrete floodwall, at foot of Douglas street, 275 ft downstream from Interstate 480 Highway bridge in Omaha, and at mile 615.9 .

DRAINAGE AREA. $--322,800 \mathrm{mi}^{2}$, approximately.

\section{WATER-DISCEARGE RECORDS}

PERIOD OF RECORD.--September 1928 to current year. April 1872 to December 1899 (gage helghts only) in reports of the Hissouri River Commission and since January 1875 , (gage heights only) in reports of the 0.5 . Weather Bureau.

REVISED RECORDS.--WSP 761: Drainage area.

GAGE.--Water-stage recorder, Datum of gage is $948.24 \mathrm{ft}$ above NGVD. See wsP 1730 for history of changes prior to Sept. 30,1936 . Oct. 1, 1936 to sept. 30,1982 at datum $10.00 \mathrm{ft}$ hlgher.

REMARKS.--Estimated daily discharges: Dec. 7-10, Jan. 11-14, 20, 21, 23-27, and Feb. 1-3. Records good except estimated daily discharges, which are poor. Flow regulated by upstream main-stem reservoirs. 0. S. National Weather Service gage-height telemeter at station. U.s. Army Corps of Engineers rain-gage and gage-height satelilte data collection platform at station.

AVERAGE DISCHARGE. -57 years, 30,560 ft's/8, 22,141,000 acre-ft/yr.

EXTREMES FOR PERIOD OR RECORD,--Maximum discharge, $396,000 \mathrm{ft} / \mathrm{s}$ Apr. 18, 1952, gage height, $40.20 \mathrm{ft}$, present datum, minimum, about $2,200 \mathrm{ft} / \mathrm{s} \mathrm{Jan} .6,1937$, minimum gage height observed, $7.23 \mathrm{ft}$, present datum, Jan. 10 , 1957 , result of freezeup.

EXTREMES FOR CURRENT YEAR.--Maximum discharge, 70,700 ft'/8 April 24, gage height, 22.98 ft, minimum daily discharge, $20,800 \mathrm{ft} / \mathrm{s}$ Jan. 23, minimum gage height $10.00 \mathrm{ft} \mathrm{Jan} 23$.

DISCHARGE, IN CUBIC FEET PER SECOND, WATER YEAR OCTOBER 1984 TO SEPTEMBER 1985 MEAM VALUES

\begin{tabular}{|c|c|c|c|c|c|c|c|c|c|c|c|c|}
\hline DAY & OCT & Nov & DEC & JAN & FEB & MAR & APR & MAY & JUN & JUL & AUG & SEP \\
\hline $\begin{array}{l}1 \\
2 \\
3 \\
4 \\
5\end{array}$ & $\begin{array}{l}49600 \\
49700 \\
49000 \\
48500 \\
47800\end{array}$ & $\begin{array}{l}56600 \\
55600 \\
54300 \\
54300 \\
54100\end{array}$ & $\begin{array}{l}54000 \\
54200 \\
50900 \\
46100 \\
41700\end{array}$ & $\begin{array}{l}24300 \\
24700 \\
24300 \\
24900 \\
27300\end{array}$ & $\begin{array}{l}28500 \\
27000 \\
28000 \\
28000 \\
28000\end{array}$ & $\begin{array}{l}28100 \\
27500 \\
27800 \\
35000 \\
41400\end{array}$ & $\begin{array}{l}38400 \\
37100 \\
36400 \\
36800 \\
38100\end{array}$ & $\begin{array}{l}40100 \\
44900 \\
45500 \\
43000 \\
41600\end{array}$ & $\begin{array}{l}40900 \\
41200 \\
42600 \\
42600 \\
40900\end{array}$ & $\begin{array}{l}39000 \\
38900 \\
38900 \\
38500 \\
38100\end{array}$ & $\begin{array}{l}35900 \\
35600 \\
34800 \\
35000 \\
35500\end{array}$ & $\begin{array}{l}36300 \\
34200 \\
35600 \\
35900 \\
36300\end{array}$ \\
\hline $\begin{array}{r}6 \\
7 \\
8 \\
9 \\
10\end{array}$ & $\begin{array}{l}48300 \\
47700 \\
48800 \\
47500 \\
47500\end{array}$ & $\begin{array}{l}54600 \\
55400 \\
54600 \\
55100 \\
57400\end{array}$ & $\begin{array}{l}38300 \\
35800 \\
34000 \\
32000 \\
32200\end{array}$ & $\begin{array}{l}28300 \\
27200 \\
26400 \\
25800 \\
25100\end{array}$ & $\begin{array}{l}27400 \\
26600 \\
26000 \\
25800 \\
25300\end{array}$ & $\begin{array}{l}31600 \\
29700 \\
29800 \\
30500 \\
33300\end{array}$ & $\begin{array}{l}39100 \\
39600 \\
40000 \\
39800 \\
38500\end{array}$ & $\begin{array}{l}41500 \\
40100 \\
40200 \\
40700 \\
39800\end{array}$ & $\begin{array}{l}38300 \\
36900 \\
39200 \\
40700 \\
40000\end{array}$ & $\begin{array}{l}37500 \\
37100 \\
36800 \\
36800 \\
37000\end{array}$ & $\begin{array}{l}34800 \\
34400 \\
34500 \\
34600 \\
34500\end{array}$ & $\begin{array}{l}36500 \\
36400 \\
37500 \\
38700 \\
38400\end{array}$ \\
\hline $\begin{array}{l}11 \\
12 \\
13 \\
14 \\
15\end{array}$ & $\begin{array}{l}47800 \\
48600 \\
49100 \\
50100 \\
52200\end{array}$ & $\begin{array}{l}57200 \\
55200 \\
54600 \\
55900 \\
57100\end{array}$ & $\begin{array}{l}32600 \\
33400 \\
33500 \\
32300 \\
32100\end{array}$ & $\begin{array}{l}27500 \\
25000 \\
24500 \\
24400 \\
26000\end{array}$ & $\begin{array}{l}25400 \\
24900 \\
24100 \\
24200 \\
24600\end{array}$ & $\begin{array}{l}34200 \\
34500 \\
35600 \\
36700 \\
36900\end{array}$ & $\begin{array}{l}37700 \\
38200 \\
39800 \\
39100 \\
38100\end{array}$ & $\begin{array}{l}39100 \\
38100 \\
37800 \\
38100 \\
43500\end{array}$ & $\begin{array}{l}39400 \\
39100 \\
38500 \\
37400 \\
37200\end{array}$ & $\begin{array}{l}36800 \\
36500 \\
36300 \\
36300 \\
36000\end{array}$ & $\begin{array}{l}34500 \\
34500 \\
35200 \\
37200 \\
35600\end{array}$ & $\begin{array}{l}36900 \\
35500 \\
35100 \\
37400 \\
39100\end{array}$ \\
\hline $\begin{array}{l}16 \\
17 \\
18 \\
19 \\
20\end{array}$ & $\begin{array}{l}53800 \\
53300 \\
52700 \\
53300 \\
55400\end{array}$ & $\begin{array}{l}56500 \\
54400 \\
52900 \\
52500 \\
52800\end{array}$ & $\begin{array}{l}43000 \\
41700 \\
34500 \\
31100 \\
31200\end{array}$ & $\begin{array}{l}23400 \\
23600 \\
24800 \\
25200 \\
24500\end{array}$ & $\begin{array}{l}24500 \\
24900 \\
25200 \\
25600 \\
25700\end{array}$ & $\begin{array}{l}37800 \\
37600 \\
36600 \\
36300 \\
37300\end{array}$ & $\begin{array}{l}37000 \\
35700 \\
35900 \\
36500 \\
36200\end{array}$ & $\begin{array}{l}45300 \\
41600 \\
39000 \\
39100 \\
42400\end{array}$ & $\begin{array}{l}40800 \\
39600 \\
38500 \\
37000 \\
35900\end{array}$ & $\begin{array}{l}35700 \\
35500 \\
35700 \\
39300 \\
38800\end{array}$ & $\begin{array}{l}34400 \\
35200 \\
35200 \\
35200 \\
33800\end{array}$ & $\begin{array}{l}36800 \\
36700 \\
38000 \\
36800 \\
37000\end{array}$ \\
\hline $\begin{array}{l}21 \\
22 \\
23 \\
24 \\
25\end{array}$ & $\begin{array}{l}56100 \\
55700 \\
56300 \\
56700 \\
57700\end{array}$ & $\begin{array}{l}\mathbf{5 3 1 0 0} \\
\mathbf{5 2 3 0 0} \\
\mathbf{5 2 0 0 0} \\
\mathbf{5 3 3 0 0} \\
\mathbf{5 4 4 0 0}\end{array}$ & $\begin{array}{l}32800 \\
32800 \\
29500 \\
28000 \\
27300\end{array}$ & $\begin{array}{l}23500 \\
21000 \\
20800 \\
25300 \\
27500\end{array}$ & $\begin{array}{l}28800 \\
33300 \\
28800 \\
27200 \\
27000\end{array}$ & $\begin{array}{l}38000 \\
38000 \\
37600 \\
37400 \\
37100\end{array}$ & $\begin{array}{l}37000 \\
43500 \\
56100 \\
68800 \\
63200\end{array}$ & $\begin{array}{l}43800 \\
42200 \\
41200 \\
40700 \\
40900\end{array}$ & $\begin{array}{l}35800 \\
35500 \\
36300 \\
37500 \\
36000\end{array}$ & $\begin{array}{l}38900 \\
36500 \\
35100 \\
35200 \\
35800\end{array}$ & $\begin{array}{l}33400 \\
34400 \\
34300 \\
34100 \\
34200\end{array}$ & $\begin{array}{l}38400 \\
38600 \\
38700 \\
37900 \\
37100\end{array}$ \\
\hline $\begin{array}{l}26 \\
27 \\
28 \\
29 \\
30\end{array}$ & $\begin{array}{l}56800 \\
56900 \\
58900 \\
58000 \\
57400 \\
57100\end{array}$ & $\begin{array}{r}54700 \\
56200 \\
55400 \\
55000 \\
54300 \\
\end{array}$ & $\begin{array}{l}25000 \\
27000 \\
35000 \\
32000 \\
29400 \\
25200\end{array}$ & $\begin{array}{l}30000 \\
29500 \\
27100 \\
29000 \\
30200 \\
29700\end{array}$ & $\begin{array}{r}27200 \\
28400 \\
28800 \\
\ldots \\
\ldots\end{array}$ & $\begin{array}{l}37900 \\
39000 \\
40100 \\
39800 \\
38600 \\
38600\end{array}$ & $\begin{array}{c}50400 \\
48800 \\
51000 \\
45700 \\
41000 \\
\end{array}$ & $\begin{array}{l}41300 \\
42100 \\
42400 \\
41600 \\
40900 \\
41400\end{array}$ & $\begin{array}{c}36000 \\
38100 \\
44500 \\
43600 \\
39700 \\
-\end{array}$ & $\begin{array}{l}35900 \\
35700 \\
35100 \\
35400 \\
36600 \\
36500\end{array}$ & $\begin{array}{l}33700 \\
33500 \\
33200 \\
33200 \\
36200 \\
43500\end{array}$ & $\begin{array}{c}36700 \\
36500 \\
36000 \\
36600 \\
37600 \\
\end{array}$ \\
\hline $\begin{array}{l}\text { TOTAL } \\
\text { MEAN } \\
\text { MAX } \\
\text { MIN } \\
\text { AC-FT }\end{array}$ & $\begin{array}{r}1628300 \\
52530 \\
58900 \\
47500 \\
3230000\end{array}$ & $\begin{array}{r}1641800 \\
54730 \\
57400 \\
52000 \\
3257000\end{array}$ & $\begin{array}{r}1088600 \\
35120 \\
54200 \\
25000 \\
2159000\end{array}$ & $\begin{array}{r}800800 \\
25830 \\
30200 \\
20800 \\
1588000\end{array}$ & $\begin{array}{r}749200 \\
26760 \\
33300 \\
24100 \\
1486000\end{array}$ & $\begin{array}{r}1100300 \\
35490 \\
41400 \\
27500 \\
2182000\end{array}$ & $\begin{array}{r}1263500 \\
42120 \\
68800 \\
35700 \\
2506000\end{array}$ & $\begin{array}{r}1279900 \\
41290 \\
45500 \\
37800 \\
2539000\end{array}$ & $\begin{array}{r}1169700 \\
38990 \\
44500 \\
35500 \\
2320000\end{array}$ & $\begin{array}{r}1142200 \\
36850 \\
39300 \\
35100 \\
2266000\end{array}$ & $\begin{array}{r}1084100 \\
34970 \\
43500 \\
33200 \\
2150000\end{array}$ & $\begin{array}{r}1109200 \\
36970 \\
39100 \\
34200 \\
2200000\end{array}$ \\
\hline $\begin{array}{ll}\text { CAL } & \text { YR } \\
\text { WIR } & \text { YR }\end{array}$ & $\begin{array}{l}1984 \\
1985\end{array}$ & $\begin{array}{l}\text { TOTAL } \\
\text { TOTAL }\end{array}$ & $\begin{array}{l}17825200 \\
14057600\end{array}$ & $\begin{array}{l}\text { MEAN } \\
\text { MEAN }\end{array}$ & $\begin{array}{l}48700 \\
38510\end{array}$ & $\begin{array}{l}\operatorname{MAX} \\
\operatorname{MaX}\end{array}$ & $\begin{array}{r}114000 \\
68800\end{array}$ & $\begin{array}{l}\text { MIN } \\
\text { MIN }\end{array}$ & $\begin{array}{l}22200 \\
20800\end{array}$ & C-PT27 & $\begin{array}{l}000 \\
000\end{array}$ & \\
\hline
\end{tabular}


06610000 MISSOURI RIVER AT OMAHA, NE--Continued

(National stream-quality accounting network station)

WATER-QUALITY RECORDS

LOCATION.--Water quality samples were collected from Interstate 80 highway bridge 2.0 mi downstream from gaging station. Samples for particle-size distribution were collected from boat cross-section $3.6 \mathrm{mi}$ downstream from gaging station.

PERIOD OF RECORD.-Water years 1969-76, 1978 to current year. Daily sediment $10 a d s$ for April 1939 to September 1971 are in reports of Corps of Engineers.

PERIOD OF DAILY RECORD.--

CHEMICAL ANALYSES: JU1Y 1969 to June 1972.

SPECIFIC CONDUCTANCE: October 1972 to September 1976 , January 1978 to September 1981

WATER TEMPERATURES: October 1971 to September 1976, January 1978 to September 1981.

SUSPENDED-SEDIMENT DISCHARGE: October 1971 to September 1976.

EXTREMES FOR PERIOD OF DAILY RECORD.--

SPECIPIC CONDUCTANCE: Maximum daily, 950 microsiemens Dec. 4,5, 1980; minimum daily, 335 microsiemens Mar. 22, 1978.

GATER TEMPERATUREs: Maximum daily, $32.0^{\circ} \mathrm{C} J u l y ~ 24,1972$; minimum daily, $0.0^{\circ} \mathrm{C}$ on many days during winter period.

SEDIMENT CONCENTRATIONS: Maximum daily mean, 8,180 mg/L May 19, 1974, minimum daily mean, $165 \mathrm{mg} / \mathrm{L}$ Sept. 13, 1976.

SEDIMENT LOADS: Maximum daily, 1,060,000 tons May 19, 1974; minimum daily, 3,990 tons Jan. 14 , 1975.

WATER QUALITY DATA, WATER YEAR OCTOBER 1984 TO SEPTEMBER 1985

\begin{tabular}{|c|c|c|c|c|c|c|c|c|c|c|}
\hline TIME & $\begin{array}{l}\text { STREAM- } \\
\text { FLON, } \\
\text { INSTAN- } \\
\text { TANEOOS } \\
\text { (CFS) } \\
\text { (00061) }\end{array}$ & $\begin{array}{l}\text { SPE- } \\
\text { CIFIC } \\
\text { CON- } \\
\text { DUCT- } \\
\text { ANCE } \\
\text { (US/CH) } \\
(00095)\end{array}$ & $\begin{array}{c}\text { PH } \\
\text { (STAND- } \\
\text { ARD } \\
\text { UNITS) } \\
(00400)\end{array}$ & $\begin{array}{l}\text { TEMPER- } \\
\text { ATURE } \\
\text { (DEG C) } \\
(00010)\end{array}$ & $\begin{array}{c}\text { TUR- } \\
\text { BID- } \\
\text { ITY } \\
\text { (NTU) } \\
(00076)\end{array}$ & $\begin{array}{c}\text { OXYGEN, } \\
\text { DIS- } \\
\text { SOLVED } \\
(\text { MG/L) } \\
(00300)\end{array}$ & $\begin{array}{c}\text { OXYGEN, } \\
\text { DIS- } \\
\text { SOLVED } \\
\text { (PER- } \\
\text { CENT } \\
\text { SATUR- } \\
\text { ATION) } \\
\text { (00301) }\end{array}$ & $\begin{array}{l}\text { BARO- } \\
\text { METRIC } \\
\text { PRES- } \\
\text { SURE } \\
\text { (MM } \\
\text { OF } \\
\text { HG) } \\
(00025)\end{array}$ & $\begin{array}{l}\text { COLI- } \\
\text { FORH, } \\
\text { FECAL, } \\
0.7 \\
\text { UH-MF } \\
\text { (COLS.' } \\
\text { 100 ML) } \\
\text { (31625) }\end{array}$ & $\begin{array}{c}\text { STREP- } \\
\text { TOCOCCI } \\
\text { FECAL, } \\
\text { KF AGAR } \\
\text { (COLS. } \\
\text { PER } \\
100 \text { ML) } \\
(31673)\end{array}$ \\
\hline
\end{tabular}

Nov 1984

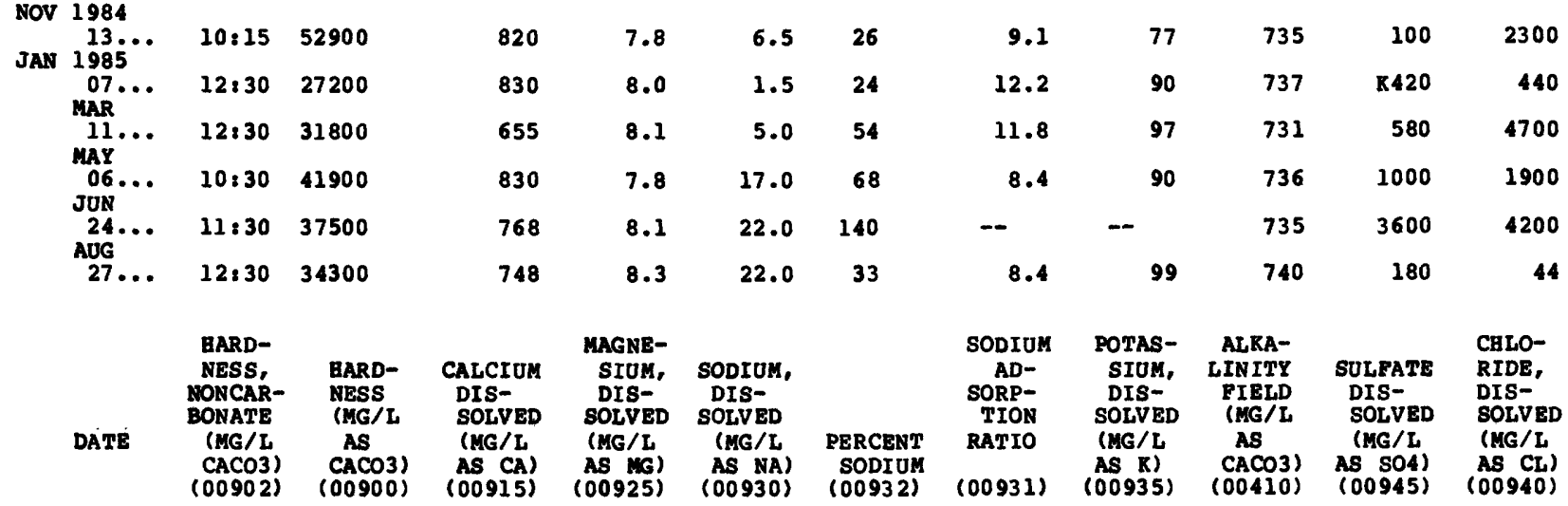

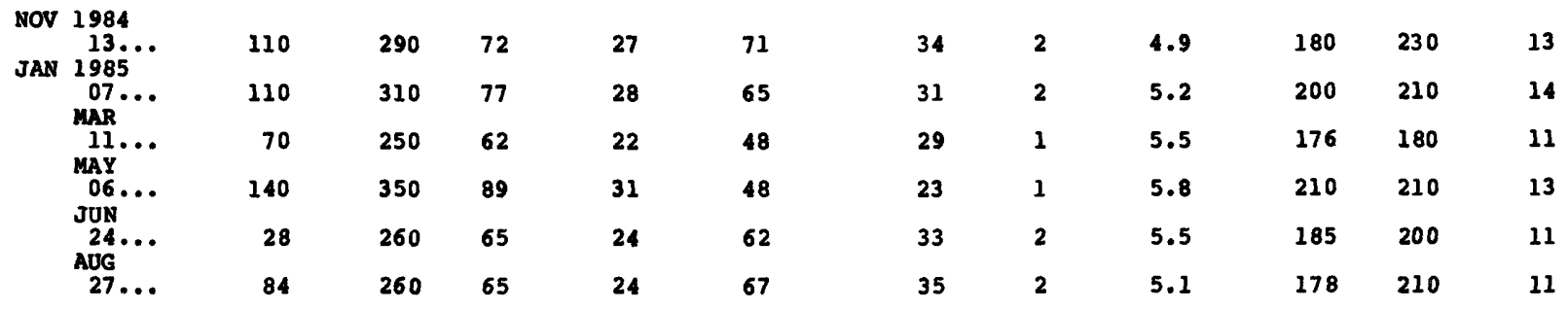

R Results based on colony count outside ideal range. 
WATER-QUAL ITY RECORDS

WATER QUALITY DATA, WATER YEAR OCTOBER 1984 TO SEPTEMBER 1985

\begin{tabular}{|c|c|c|c|c|c|c|c|c|c|c|c|}
\hline ATE & $\begin{array}{l}\text { FLUO- } \\
\text { RIDE, } \\
\text { DIS- } \\
\text { SOLVED } \\
\text { (HG/L } \\
\text { AS F) }\end{array}$ & $\begin{array}{l}\text { SILICA, } \\
\text { DIS- } \\
\text { SOLVED } \\
\text { (MG/L } \\
\text { AS } \\
\text { STO2) }\end{array}$ & $\begin{array}{c}\text { SOLIDS, } \\
\text { RESIDUE } \\
\text { AT } 180 \\
\text { DEG C } \\
\text { DIS- } \\
\text { SOLVED }\end{array}$ & $\begin{array}{c}\text { SOLIDS, } \\
\text { SUM OF } \\
\text { CONSTI- } \\
\text { TUENTS, } \\
\text { DIS- } \\
\text { SOLVED } \\
\text { (MG/T, }\end{array}$ & $\begin{array}{c}\text { SOLIDS, } \\
\text { DIS- } \\
\text { SOLVED } \\
\text { (TONS } \\
\text { PER } \\
\text { AC-FT) }\end{array}$ & $\begin{array}{c}\text { SOLIDS, } \\
\text { DIS- } \\
\text { SOLVED } \\
\text { (TONS } \\
\text { PER } \\
\text { DAY) }\end{array}$ & $\begin{array}{c}\text { NITRO- } \\
\text { GEN, } \\
\text { NO2+NO3 } \\
\text { DIS- } \\
\text { SOLVED } \\
\text { (MG/L }\end{array}$ & $\begin{array}{l}\text { NITRO- } \\
\text { GEN, } \\
\text { AMMONIA } \\
\text { DIS- } \\
\text { SOLVED } \\
\text { (MG/L }\end{array}$ & $\begin{array}{c}\text { NITRO- } \\
\text { GEN, } \\
\text { AMMONIA } \\
\text { DIS- } \\
\text { SOLVED } \\
\text { (MG/L } \\
\text { NS NH4) }\end{array}$ & $\begin{array}{l}\text { NITRO- } \\
\text { GEN, AM- } \\
\text { MONIA + } \\
\text { ORGANIC } \\
\text { TOTAL } \\
\text { (MG/L } \\
\text { AS N) }\end{array}$ & $\begin{array}{l}\text { PHOS- } \\
\text { PHORUS, } \\
\text { ORTHO, } \\
\text { DIS- } \\
\text { SOLVED } \\
\text { (MG/L } \\
\text { AS P) }\end{array}$ \\
\hline & $\begin{array}{c}\text { AS F) } \\
(00950)\end{array}$ & $\begin{array}{c}\text { SIO2) } \\
(00955)\end{array}$ & $\begin{array}{r}(M G / L) \\
(70300)\end{array}$ & $\begin{array}{r}(M G / L) \\
(70301)\end{array}$ & $\begin{array}{c}A C-F T) \\
(70303)\end{array}$ & $\begin{array}{c}\text { DAY }) \\
(70302)\end{array}$ & $\begin{array}{c}\text { AS N) } \\
(00631)\end{array}$ & $\begin{array}{c}\text { AS N) } \\
(00608)\end{array}$ & $\begin{array}{c}\text { AS NH4) } \\
(71846)\end{array}$ & $(00625)$ & $\begin{array}{l}\text { As P) } \\
(00671)\end{array}$ \\
\hline
\end{tabular}

Nov 2984

13 ..

$\begin{array}{lllll}13 \ldots & & & & \\ 134 & 0.5 & 7.8 & 536 & 540\end{array}$

$07 \ldots$

0.7376600

0.60

0.04

0.05

0.9

0.03

MAR

0.511

541

0.7439700

1.50

0.13

0.17

1.0

0.03

MAY

0.4

11

422

0.5736200

1.70

0.17

0.22

2.6

0.08

JUN

0.610

0.7663000

2.80

0.10

0.13

0.8

0.14

$24 \ldots$

0.4

7.7

495

0.6750100

1.20

0.06

0.08

1.5

0.06

27 ...

0.5

7.3

497

0.6846000

0.14

0.02

0.03

0.7

$<0.01$

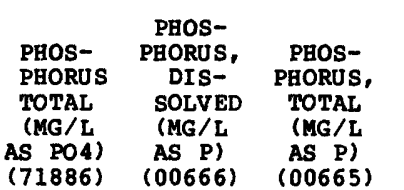

SEDI-
MENT,
SUS-
PENDED
(MG/L)
(80154)

SEDI- SED.

MENT, SUSP.

DIS- SIEVE

CHARGE, DIAM.

SUS- \& PINER

PENDED TINAN

$\begin{array}{ll}\text { PENDED } & \text { THAN } \\ \text { (T/DAY) } & .062\end{array}$

$\begin{array}{ll}(\mathrm{T} / \mathrm{DAY}) & .062 \mathrm{MH} \\ (80155) & (70331)\end{array}$

ARSEN IC

ALUM-

INUM, BARIUM,

BERYL-

DIS- DIS- DIS-

SOLVED

(DG/L

AS AS)
$(01000)$

SOLVED SOLVED

(UG/L) (UG/I

(UG/L

AS AL)
(01106)

(UG/L

AS BA)
$(01005)$

LIUM,

DIS-

SOLVED SOLVED

AS BE) AS CD)

NOV 1984

\begin{tabular}{|c|c|c|c|c|c|c|}
\hline 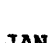 & $13 \ldots$ & -- & 0.02 & 0.09 & 450 & 643 \\
\hline 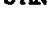 & $07 \ldots$ & - & 0.04 & 0.17 & 342 & 2510 \\
\hline & $\underset{\text { MAY }}{\operatorname{MAR}}$ & -- & 0.09 & 0.57 & 1160 & 996 \\
\hline & JUN & - & 0.48 & 0.16 & 894 & 101 \\
\hline & $\begin{array}{c}24 \ldots \\
\text { AUG } \\
27 . \ldots\end{array}$ & $\begin{array}{l}2.0 \\
0.12\end{array}$ & 0.16 & 0.66 & $\begin{array}{l}957 \\
401\end{array}$ & 96 \\
\hline
\end{tabular}

16
37
78
79
83
32


IUM
IS-
LVED
LIL
LI)
I30)

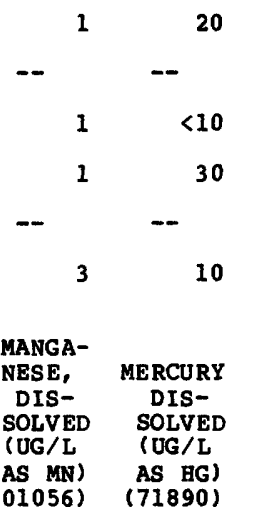

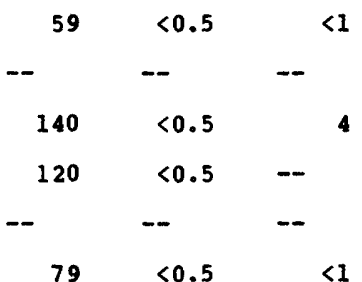

CHRO-

MIUM, COBALT,

DIS-

DIS-

COPPER,

$\begin{array}{ccc}\text { IRON, } & \text { LEAD, } & \text { LITH IUM } \\ \text { DIS- } & \text { DIS- } & \text { DIS- } \\ \text { SOLVED } & \text { SOLVED } & \text { SOLVED } \\ \text { (UG/L } & \text { (UG/L } & \text { (UG/L } \\ \text { AS FE) } & \text { AS PB) } & \text { AS LI) } \\ (01046) & (01049) & (01130)\end{array}$

$\begin{array}{cccccccccc}A S & & \end{array}$

MOLYB- $S E L E-$

DENUM, NICKEL, NIUM,

DIS- DIS- DIS-

SOLVED SOLVED SOLVED

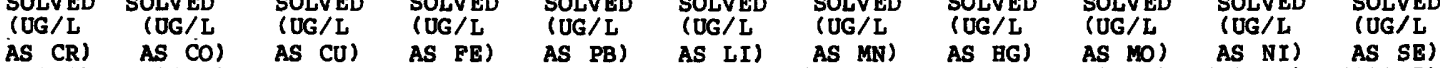

NOV 1984

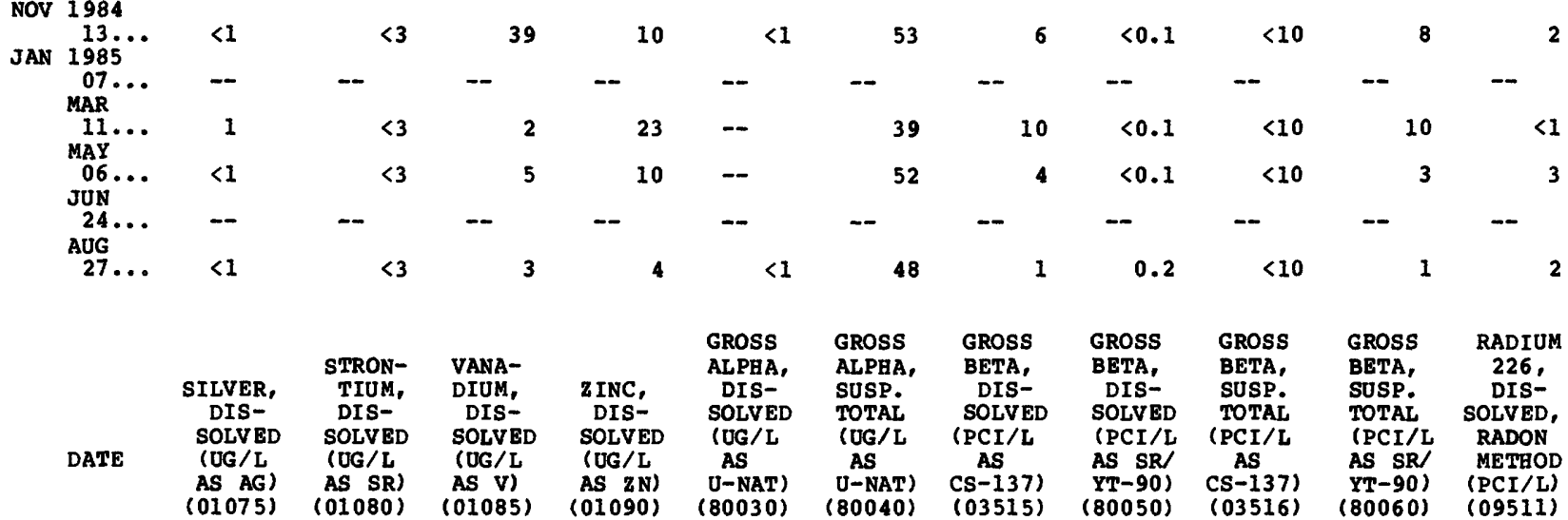

NOV 1984

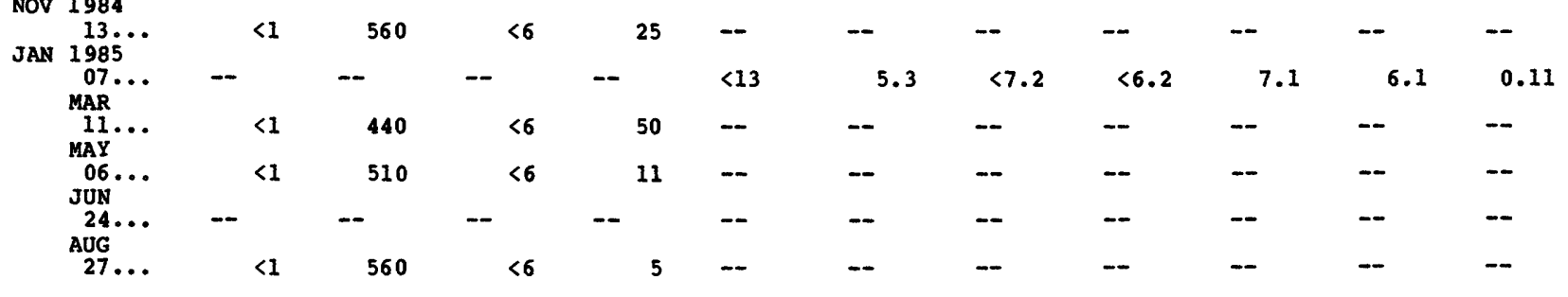


06610000 MISSOURI RIVER AT OMAHA, NE--Continued

WATER-QUALITY RECORDS

PARTICLE SIZE DISTRIBUTION OF SUSPENDED-SEDIMENT, WATER YEAR OCTOBER 1984 TO SEPTEMBER 1985

\begin{tabular}{|c|c|c|c|c|c|c|c|c|c|c|c|c|c|c|c|}
\hline DATE & TIME & $\begin{array}{l}\text { SAMPLE } \\
\text { LOC- } \\
\text { ATION, } \\
\text { CROSS } \\
\text { SECTION } \\
\text { (FT FM } \\
\text { L BANK) }\end{array}$ & $\begin{array}{l}\text { DEPTH } \\
\text { AT } \\
\text { SAMPLE } \\
\text { LOC- } \\
\text { ATION, } \\
\text { TOTAL } \\
\text { (EEET) }\end{array}$ & $\begin{array}{l}\text { SAM- } \\
\text { PLING } \\
\text { DEPTE } \\
\text { (FEET) }\end{array}$ & $\begin{array}{l}\text { STREAY } \\
\text { VELOC- } \\
\text { ITY, } \\
\text { POINT) } \\
\text { (FPS) }\end{array}$ & $\begin{array}{l}\text { SEDI- } \\
\text { MENT, } \\
\text { SUS- } \\
\text { PENDED } \\
\text { (MG/L) }\end{array}$ & .0 & $\begin{array}{l}\text { SED. } \\
\text { SUSP. } \\
\text { FALL } \\
\text { DIAM. } \\
\text { FINER } \\
\text { TEAN } \\
04 \text { MI }\end{array}$ & $\begin{array}{l}8 \\
.0\end{array}$ & $\begin{array}{l}\text { SED. } \\
\text { SUSP. } \\
\text { FALL } \\
\text { DIAM. } \\
\text { FINER } \\
\text { THAN } \\
62 \text { MH }\end{array}$ & 8 & $\begin{array}{l}\text { SED. } \\
\text { SUSP. } \\
\text { FALL } \\
\text { DIAY. } \\
\text { FINER } \\
\text { TRAN } \\
125 \text { MH }\end{array}$ & $\begin{array}{l}8 \\
.2\end{array}$ & $\begin{array}{l}\text { SED. } \\
\text { SUSP. } \\
\text { FALL } \\
\text { DIAM. } \\
\text { FINER } \\
\text { THAN } \\
250 \mathrm{ML}\end{array}$ & $\begin{array}{l}\text { SED. } \\
\text { SUSP. } \\
\text { FALL } \\
\text { DIAM. } \\
8 \text { FINER } \\
\text { THAN } \\
.500 \mathrm{MH}\end{array}$ \\
\hline
\end{tabular}

OCT 1984

03... WATER TEMPERATURE

03... $10: 30 \quad 180$

$03 \ldots . \quad 10: 35 \quad 180$

$03 \ldots 10: 40 \quad 180$

$03 \ldots 10: 45 \quad 180$

$03 \ldots 10: 50 \quad 180$

$03 \ldots \quad 11: 10 \quad 310$

$03 \ldots \quad 11: 15 \quad 310$

$03 \ldots . .11: 25 \quad 310$

$03 \ldots \ldots \quad 11: 29 \quad 310$

$\begin{array}{lll}03 \ldots \ldots & 11: 29 & 310 \\ 03 \ldots & 11: 30 & 410\end{array}$

$03 \ldots .11: 35 \quad 410$

$03 \ldots \quad 11: 40 \quad 410$

$03 \ldots . .11: 42$

$\begin{array}{ll}03 \ldots \ldots & 11: 45 \\ 03 \ldots \ldots & 11: 50\end{array}$

$\begin{array}{ll}03 \ldots & 11: 50 \\ 03 \ldots & 11: 55\end{array}$

$\begin{array}{lll}03 \ldots \ldots & 12: 00 & 510 \\ 03 \ldots & 12: 05 & 510\end{array}$

$03 \ldots \quad 12: 10 \quad 510$

$03 \ldots \ldots \quad 12: 15 \quad 510$

$03 \ldots . .12: 20 \quad 510$

$03 \ldots .6 \quad 12: 23 \quad 510$

$03 \ldots . .12: 30 \quad 590$

$03 \ldots 12.35$

$03 \ldots 12: 40$

$03 \ldots . .12: 45$

590

590
$\mathbf{5 9 0}$
$\mathbf{5 9 0}$

$13.0^{\circ} \mathrm{C}(1030-1300$ HOURS):

DISChARgE, $\quad 48,600 \mathrm{ft} / \mathrm{s}$

$\begin{array}{ccccc}12.0 & 2.80 & 4.37 & 280 & =- \\ -- & 6.00 & 3.72 & 805 & --\end{array}$

$\begin{array}{rcrrr}- & 6.00 & 3.72 & 805 & = \\ - & 8.60 & 2.98 & 615 & - \\ - & 10.0 & 3.24 & 1140 & - \\ 1 & 10.8 & 2.76 & 1450 & -\end{array}$

$12.4 \quad 2.90$

$\begin{array}{ll}12.4 & 2.90 \\ - & 6.20 \\ - & 8.90\end{array}$

6.32

\begin{tabular}{cc}
-- & 10.3 \\
15.8 & 11.2 \\
\hline & 3.70
\end{tabular}

$\begin{array}{lr}15.8 & 3.70 \\ -- & 7.90 \\ -- & 11.3\end{array}$

6.11

6.32

$03 \ldots \quad 12: 50$

590

$\begin{array}{ll}-- & 11.3 \\ -- & 13.2 \\ - & 14.2\end{array}$

$5.89 \quad 514 \quad--$

$5.59 \quad 701$--

6.24

$-$

$\begin{array}{ll}13.2 & 6.11 \\ 14.2 & 5.32 \\ 14.9 & 4.70\end{array}$

$\begin{array}{ll}17.0 & 3.90 \\ -0 & 8.50\end{array}$

-- 12.1

$\begin{array}{ll}- & 14.2 \\ - & 15.3\end{array}$

$\begin{array}{cc}-18.8 & 16.0 \\ 18 & 4.30\end{array}$

$\begin{array}{lc}18.8 & 4.30 \\ -- & 9.40 \\ -- & 13.4\end{array}$

$\begin{array}{ll}-- & 13.4 \\ -- & 15.7 \\ - & 16.9\end{array}$

5.89

4.70
7.20

7.20
6.99

6.54

6.28

6.11

5.80

5.11

5.67
5.32
5.45

5.45
4.98
4.07

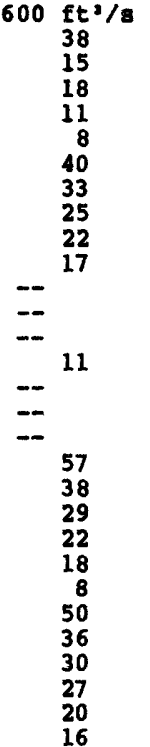

56

$\begin{array}{rr}98 & 100 \\ 65 & 100 \\ 69 & 100 \\ 68 & 100 \\ 62 & 100 \\ 96 & 100 \\ 97 & 100 \\ 97 & 100 \\ 94 & 100 \\ 91 & 100 \\ - & -- \\ - & -- \\ - & -- \\ - & - \\ - & - \\ - & - \\ - & - \\ - & -- \\ 100 & -- \\ 99 & 100 \\ 98 & 100 \\ 97 & 100 \\ 97 & 100 \\ 90 & 100 \\ 98 & 100 \\ 98 & 100 \\ 96 & 100 \\ 93 & 100 \\ 92 & 100 \\ 88 & 100\end{array}$

MAY 1985

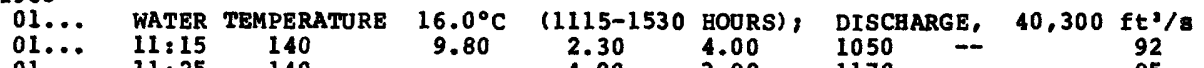

$01 \cdots \quad 11: 25$

$01 \ldots \quad 11: 35$

$01 \ldots . .21: 55$

$01 \ldots 12: 00$

$01 \ldots .12: 05$

$01 \ldots \quad 12: 10$

$01 \ldots 12: 20$

$01 \ldots \quad 12: 35$

$01 \ldots . . \quad 12: 45$

$01 \ldots . \quad 12: 50$

$01 \ldots \quad 12: 55$

$01 \ldots \quad 13: 05$

$\begin{array}{lll}01 \ldots & 13: 10 \\ 01 \ldots . . & 13: 15\end{array}$

$01 \ldots . \quad 13: 20$

$01 \ldots \quad 13: 30$

$01 \ldots \quad 13: 50$

$01 \ldots 13: 55$

$01 \ldots 14: 00$

$01 \ldots \quad 14: 05$

$01 \ldots \quad 14: 10$

$\begin{array}{lll}01 \ldots . & 14: 15 \\ 01 \ldots . & 14: 20\end{array}$

$\begin{array}{lll}01 \ldots . . & 14: 20 \\ 01 \ldots & 14: 25\end{array}$

140
140
140
140
140
265
265
265
265
265
390
390
390
390
390
390
390
490
490
490
490
490
490
590
590
590
590
590
590

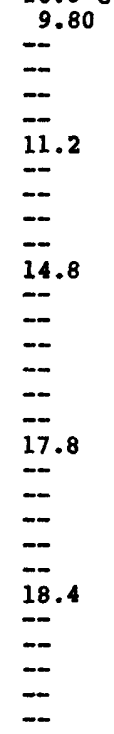

$-$

$300 \mathrm{ft}$
92
85
80
72
74
87
80
79
75
75
-

3.57

7.00

8.20

3.55

3.55
3.37

8.80

3.37
4.15

5.60

4.09

1170
1270

1400 -

1330
1160

$\begin{array}{ll}1160 & -- \\ 1290 & --\end{array}$

9.30

4.41
4.46

10.0

3.40
7.40

$\begin{array}{lll}4.46 & 1400 \\ 4.00 & 1390\end{array}$

4.00
3.94
4.11

$--$

10.6

3.

$\overline{-1}$

$\because \quad=$

13.3

13.9

3.87

1480

4.11

3.87

4.10
8.90

5.17

12.7

14.7

14.8
16.0

16.8

4.59

4.76

4.76
4.30

4.87
5.54

9.20

5.39

13.1

15.3

16.6

4.54

4.30
4.28

--

1450

1450

1450

1480 --

1620

1350 -

1180 -- 85

1170 - $\quad 85$

1630
1800

1790

61
59

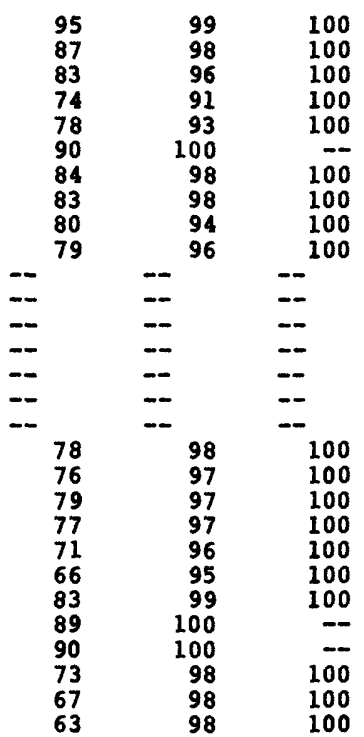


PARTICLE SIZE DISTRIBUTION OF SUSPENDED MATERIAL, WATER YEAR OCTOBER 1984 TO SEPTEMBER 1985

\begin{tabular}{|c|c|c|c|c|c|c|c|c|c|c|c|}
\hline$\Delta T$ & TIME & $\begin{array}{l}\text { SAMPLE } \\
\text { LOC- } \\
\text { ATION, } \\
\text { CROSS } \\
\text { SECTION } \\
\text { (FT FM } \\
\text { L BANK) }\end{array}$ & $\begin{array}{l}\text { DEPTH } \\
\text { AT } \\
\text { SAMPLE } \\
\text { LOC- } \\
\text { ATION, } \\
\text { TOTAL, } \\
\text { (FEET) }\end{array}$ & $\begin{array}{l}\text { SAM- } \\
\text { PLING } \\
\text { DEPTH } \\
\text { (FEET) }\end{array}$ & $\begin{array}{l}\text { STREAM } \\
\text { VELOC- } \\
\text { ITY, } \\
\text { POINT) } \\
\text { (FPS) }\end{array}$ & $\begin{array}{l}\text { SEDI- } \\
\text { MENT, } \\
\text { SUS- } \\
\text { PENDED } \\
\text { (MG/L) }\end{array}$ & $\begin{array}{l}\text { SED. } \\
\text { SUSP. } \\
\text { FALL } \\
\text { DIAM. } \\
\text { FINER } \\
\text { THAN } \\
.004 \text { MM }\end{array}$ & $\begin{array}{l}\text { SED. } \\
\text { SUSP. } \\
\text { FALL } \\
\text { DIAM. } \\
\text { FINER } \\
\text { THAN } \\
.062 \mathrm{MM}\end{array}$ & $\begin{array}{l}\text { SED. } \\
\text { SUSP. } \\
\text { FALL } \\
\text { DIAM. } \\
\text { FINER } \\
\text { FHAN } \\
\text { TIA MM }\end{array}$ & $\begin{array}{l}\text { SED. } \\
\text { SUSP. } \\
\text { FALL } \\
\text { DIAM. } \\
\text { PINER } \\
\text { FHAN } \\
.250 \text { MM }\end{array}$ & $\begin{array}{l}\text { SED. } \\
\text { SUSP. } \\
\text { FALL } \\
\text { DIAM. } \\
8 \text { FINER } \\
\text { THAN } \\
.500 \mathrm{MM}\end{array}$ \\
\hline
\end{tabular}

JUN 1985

\begin{tabular}{|c|c|c|c|c|c|}
\hline $\begin{array}{l}05 \ldots \\
05 \ldots \\
05 \ldots \\
05 \ldots \\
05 \ldots \\
05 \ldots \\
05 \ldots \\
05 \ldots \\
05 \ldots \\
05 \ldots \\
05 \ldots \\
05 \ldots\end{array}$ & $\begin{array}{l}\text { WATER } \\
10: 30 \\
10: 35 \\
10: 40 \\
10: 45 \\
10: 50 \\
11: 00 \\
11: 05 \\
11: 10 \\
11: 15 \\
11: 20 \\
11: 25 \\
11: 35 \\
11: 40 \\
11: 45 \\
11: 48 \\
11: 50 \\
11: 55 \\
12: 00 \\
12: 45 \\
12: 50 \\
12: 55 \\
13: 00 \\
13: 05 \\
13: 10 \\
13: 20 \\
13: 25 \\
13: 30 \\
13: 35 \\
13: 40 \\
13: 45 \\
13: 50\end{array}$ & $\begin{array}{c}\text { TEMPERATORE } \\
210 \\
210 \\
210 \\
210 \\
210 \\
340 \\
340 \\
340 \\
340 \\
340 \\
340 \\
470 \\
470 \\
470 \\
470 \\
470 \\
470 \\
470 \\
560 \\
560 \\
560 \\
560 \\
560 \\
560 \\
650 \\
650 \\
650 \\
650 \\
650 \\
650 \\
650\end{array}$ & 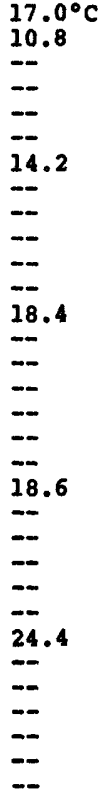 & $\begin{array}{c}1030-1430 \\
2.50 \\
5.40 \\
7.70 \\
9.00 \\
9.70 \\
3.30 \\
7.10 \\
10.1 \\
11.8 \\
12.8 \\
13.4 \\
4.30 \\
9.20 \\
13.1 \\
15.3 \\
15.3 \\
16.6 \\
17.3 \\
4.30 \\
9.30 \\
13.3 \\
15.5 \\
16.7 \\
17.5 \\
5.60 \\
12.2 \\
17.4 \\
20.3 \\
22.0 \\
23.0 \\
23.5\end{array}$ & $\begin{array}{c}\text { BOURS): } \\
4.02 \\
3.87 \\
3.37 \\
3.02 \\
2.65 \\
5.04 \\
4.65 \\
4.30 \\
4.33 \\
3.61 \\
3.37 \\
5.37 \\
5.02 \\
4.78 \\
-3.98 \\
3.98 \\
3.78 \\
3.37 \\
5.17 \\
5.22 \\
4.67 \\
4.63 \\
3.96 \\
4.54 \\
4.65 \\
4.00 \\
3.72 \\
3.68 \\
3.11 \\
2.85 \\
2.85\end{array}$ \\
\hline
\end{tabular}

\begin{tabular}{cc} 
DISCHARGE \\
448 \\
449 & \\
536 & \\
609 & \\
556 & \\
512 & \\
663 & \\
835 & \\
947 & \\
949 & \\
1110 & \\
- & \\
\hline & \\
\hline 799 & \\
799 & \\
\hline & \\
\hline & \\
\hline 441 & \\
536 & \\
593 & \\
728 & \\
921 & \\
772 & \\
403 & \\
415 & \\
453 & \\
474 & \\
641 & \\
735 & \\
1330 &
\end{tabular}

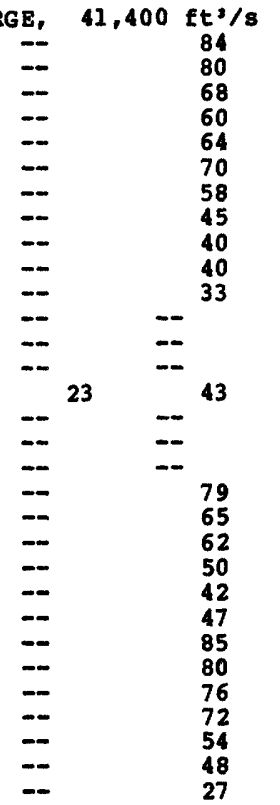

\begin{tabular}{r}
90 \\
85 \\
75 \\
68 \\
71 \\
79 \\
68 \\
54 \\
58 \\
48 \\
48 \\
40 \\
-- \\
-- \\
\hline- \\
\hline- \\
\hline- \\
- \\
- \\
85 \\
75 \\
72 \\
63 \\
52 \\
60 \\
92 \\
88 \\
81 \\
80 \\
60 \\
56 \\
32
\end{tabular}

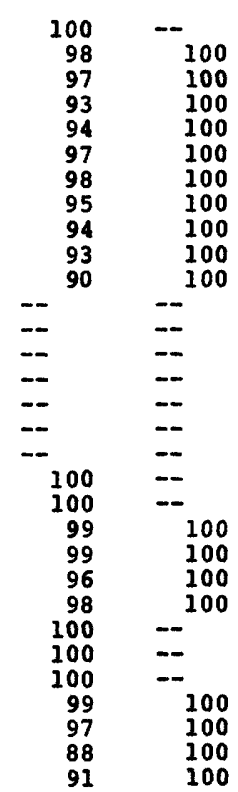

JUL 1985

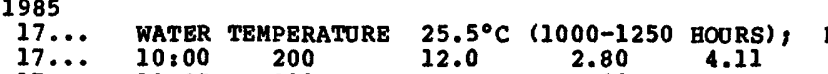

DISCHARGE

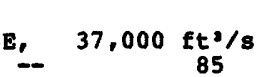

$17 \ldots 10: 05$

$17 \ldots \quad 10: 10$

$17 \ldots . .10: 15$

$17 \ldots . .210: 20$

$17 \ldots 10: 35$

$17 \ldots 10: 40$

$17 \ldots \quad 10: 45$

$17 \ldots .10: 50$

$17 \ldots . .210: 55$

$17 \ldots \quad 11: 00$

$17 \ldots \quad 11: 15$

$17 \ldots \quad 11: 20$

$17 \ldots . .11: 25$

$17 \ldots$ 11:28

$17 \ldots . .11: 30$

$17 \ldots \quad 11: 35$

$17 \ldots \quad 11: 40$

$17 \ldots \quad 11: 55$

$17 \ldots .011: 59$

$17 \ldots$ 12:03

$17 \ldots . . \quad 12: 07$

$17 \ldots .12: 11$

$17 \ldots . .12: 15$

$17 \ldots . \quad 12: 30$

$17 \ldots . .12: 33$

$17 \ldots .12: 36$

$17 \ldots . \quad 12: 39$

$\begin{array}{ll}17 \ldots . . & 12: 42 \\ 17 \ldots & 12: 45\end{array}$

200
200
200
200
300
300
300
300
300
300
420
420
420
420
420
420
420
520
520
520
520
520
520
595
595
595
595
595
595

$12.0 \quad 2.80$

$\begin{array}{lr}-- & 6.00 \\ - & 8.60\end{array}$

4.11

150 8.60

3.39

- $\quad 10.0 \quad 3.35$

$73.4 \quad 10.8$

$\begin{array}{lll}13.4 & 3.10 & 4.04 \\ -- & 6.60 & 3.76\end{array}$

3.35
3.22

199
286
316

- $\quad 9.40$

$=\quad 11.0$

3.35

3.00

$\begin{array}{lll}18.8 & 12.4 & 2.37\end{array}$

$18.8 \quad 4.30$

9.40
13.4

$\bar{z} \quad 13.4$

$=\quad 15.7$

$=\quad 16.9$

$\begin{array}{lr}\overline{17} .6 & 4.10 \\ -- & 8.80\end{array}$

12.6

15.8

16.6
4.60

4.60
10.0

10.0
14.3

16.7

18.0

325

257
352

352

430

460
634
633

63

4.35
3.85

3.20

$-2.57$

2.57
1.72

1.72

4.67
4.33

4.33
3.94

4.04

3.15

2.85

4.28
3.94

3.94
3.63

3.28

2.85

--

$-$

$\overline{--}$

348

284

302

423

513

199

289
346

353

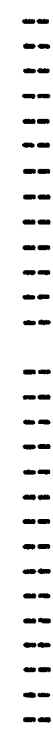

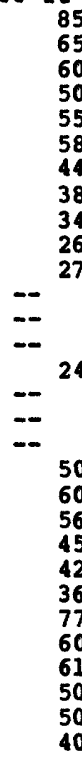

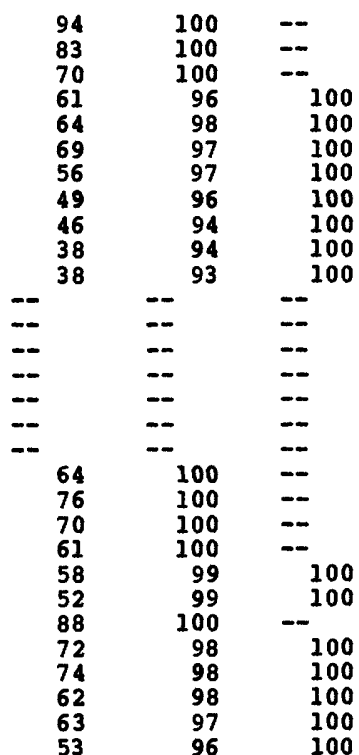


06610000 MISSOURI RIVER AT OMAHA, NE--Continued

WATER-QUALITY RECORDS

PARTICLE SIZE DISTRIBUTION OF SUSPENDED MATERIAL, WATER YEAR OCTOBER 1984 TO SEPTEMBER 1985

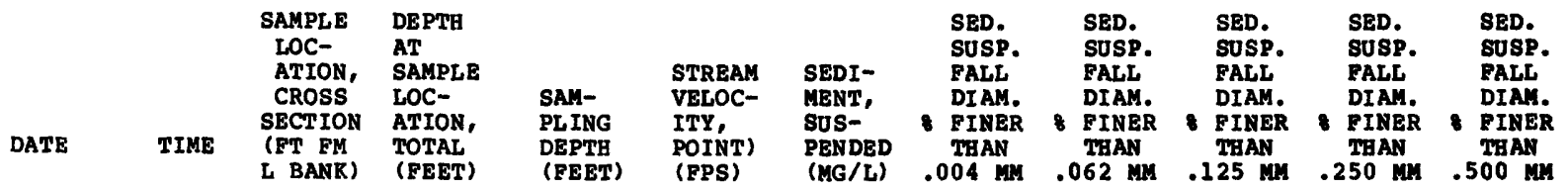

AUG 1985

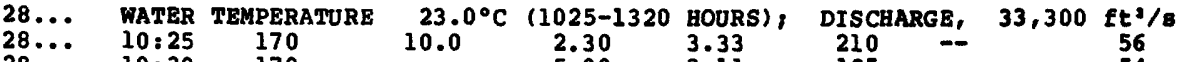

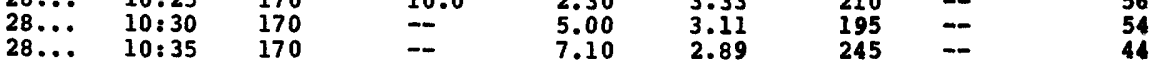

$28 \ldots 10.45 \quad 170$

28... 11:03 305

$28 \ldots 11: 06 \quad 305$

$-8.30$

9.00

10.42 .40

2.91

2.48

2.48
4.50

$28 \ldots . . \quad 11: 12 \quad 305$

$28 \ldots .11: 15 \quad 305$

$28 \ldots \quad 11: 30 \quad 425$

$28 \ldots . \quad 11: 35 \quad 425$

$\begin{array}{lll}28 \ldots & 11: 40 & 425 \\ 28 \ldots & 11: 42 & 425\end{array}$

$28 \ldots \quad 11: 45 \quad 425$

28... $11: 50 \quad 425$

$28 \ldots . \quad 11: 55 \quad 425$

$28 \ldots \quad 12: 05 \quad 505$

$28 \ldots . \quad 12: 10 \quad 505$

$28 \ldots . .12: 20 \quad 505$

$28 \ldots .12: 25 \quad 505$

$28 \ldots .12: 30 \quad 505$

$28 \ldots \quad 12: 45 \quad 605$

$28 \ldots \quad 12: 50 \quad 605$

$28 \ldots \quad 13: 05 \quad 605$

$28 \ldots . \quad 13: 10 \quad 605$

$\begin{array}{ll}- & 8.70 \\ \overline{15} & 9.40 \\ 15 & 3.50\end{array}$

5.20
7.40

4.37

324

$\begin{array}{ll}494 & - \\ 221 & - \\ 293 & -\end{array}$

$\begin{array}{ll}15.0 & 3.50 \\ -- & 7.50\end{array}$

-- 10.7

-- $\quad \overline{12.5}$

$-$

$18.6 \quad 14.1$

$\begin{array}{rr}18.6 & 4.30 \\ - & 9.20\end{array}$

- $\quad 13.1$

- 15.3

$=\quad 16.6$

$20.0 \quad 4.60$

$=10.0$

3.94

3.33

2.85

4.65

4.11

$-4.30$

4.00

4.00
3.72

3.76
4.70

4.70
4.15

3.96

3.72

3.55

3.18

4.85

4.54

$\begin{array}{ll}293 & - \\ 412 & - \\ 528 & -\end{array}$

$528=-$
$626 \quad-$

$-\infty$

$--$

$\begin{array}{ll}-- & 16.7 \\ - & 18.0\end{array}$

4.04

3.72
3.28

471

$-$

25

371

546

628 -

$145=$
201

20

206

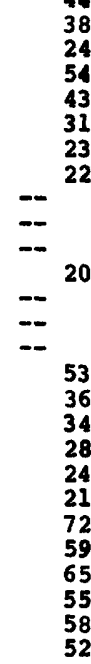

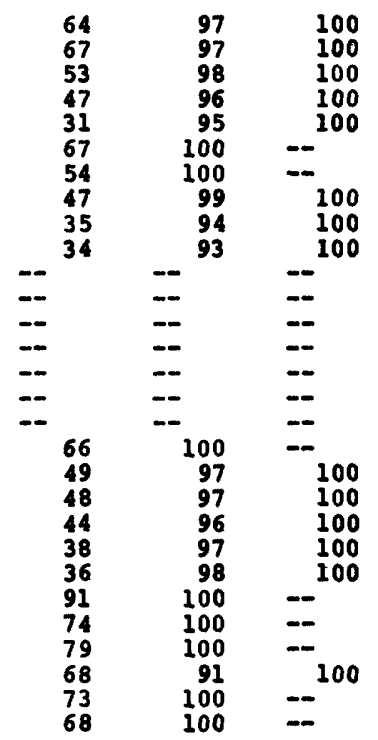

PARTICLE SIZE DISTRIBUTION OF BED MATERIAL, WATER YEAR OCTOBER 1984 TO SEPTEMBER 1985

\begin{tabular}{|c|c|c|c|c|c|c|c|c|c|}
\hline DATE & TIME & $\begin{array}{c}\text { NUMBER } \\
\text { OF } \\
\text { SAM- } \\
\text { PLING } \\
\text { POINTS }\end{array}$ & $\begin{array}{c}\text { BED } \\
\text { MAT. } \\
\text { SIEVE } \\
\text { DIAY. } \\
\text { FINER } \\
\text { THAN } \\
.062 \mathrm{MM}\end{array}$ & $\begin{array}{l}\text { BED } \\
\text { MAT. } \\
\text { SIEVE } \\
\text { DIAM. } \\
\text { FINER } \\
\text { THAN } \\
.125 \mathrm{MM}\end{array}$ & $\begin{array}{c}\text { BED } \\
\text { MAT. } \\
\text { SIEVE } \\
\text { DIAY. } \\
\text { FINER } \\
\text { THAN } \\
\text { THO MH }\end{array}$ & $\begin{array}{c}\text { BED } \\
\text { MAT. } \\
\text { SIEVE } \\
\text { DIAM. } \\
\text { FINER } \\
\text { THAN } \\
.500 \text { MM }\end{array}$ & $\begin{array}{c}\text { BED } \\
\text { MAT. } \\
\text { SIEVE } \\
\text { DIAM. } \\
\text { PINER } \\
\text { PHAN } \\
1.00 \text { GM }\end{array}$ & $\begin{array}{l}\text { BED } \\
\text { MAT. } \\
\text { SIEVE } \\
\text { DIAM. } \\
\text { PINER } \\
\text { THAN } \\
2.00 \text { MH }\end{array}$ & $\begin{array}{l}\text { BED } \\
\text { MAT. } \\
\text { SIEVE } \\
\text { DIAM. } \\
\text { FINER } \\
\text { THAN } \\
4.00 \mathrm{MH}\end{array}$ \\
\hline $\begin{array}{l}\text { OCT } \\
03 \ldots \\
\text { MAY }\end{array}$ & $13: 00$ & 5 & 0 & 1 & 29 & 98 & 100 & -- & - \\
\hline${ }_{\text {JUN }}^{01} \ldots$ & $15: 30$ & 4 & 0 & 1 & 28 & 99 & 100 & - & $-\infty$ \\
\hline $\begin{array}{l}05 . \cdots \\
\text { JUL }\end{array}$ & $14: 30$ & 5 & 0 & 1 & 21 & 99 & 100 & - & - \\
\hline$\underset{\text { AUG }}{17} \cdots$ & $12: 50$ & 5 & 0 & 1 & 23 & 99 & 100 & -- & -- \\
\hline $28 \ldots$ & $13: 20$ & 5 & 0 & 1 & 19 & 98 & 99 & 99 & 100 \\
\hline
\end{tabular}


LOCATION.--Lat $40^{\circ} 40^{\prime} 55^{\prime \prime}$, long $95^{\circ} 50^{\prime} 48^{\prime \prime}$, in Nwl/4 NEl/4 sec.9, T.8 N., R.14 E., Otoe County, Hydrologic Unit 10240001 , on right bank $0.7 \mathrm{mi}$ upstream from waubonsie Highway Bridge at Rebraska City, and at mile 562.6 .

DRAINAGE AREA . - 410,000 $\mathrm{mi}^{2}$, approximately. The 3,959 mi in Great Divide basin are not included.

PERIOD OF RECORD,--August 1929 to current year. Gage-height records collected in this vicinity from August 1878

to December 1899 are contained in reports of Missouri River Commission.

REVISED RECORDS.--WSP 761: Drainage area.

GAGE-Water-atage recorder. Datum of gage is $905.36 \mathrm{ft}$ above NGVD, supplementary adjustment of 1954 . See wSP 1918 or 1919 for history of changes prior to Apr. 1, 1963.

REMARRS.--Estimated daily discharges: Dec. 13-16, 19-22 and 26, 31. Records good except for estimated daily discharges, which are poor. Flow regulated by upstream main-stem reservoirs. U.S. National Weather Service gageheight telemeter at station. U.s. Army Corps of Engineers rain-gage and gage-height satellite data collection platform at station.

AVERAGE DISCHARGE. --56 years, 36,690 $\mathrm{ft}^{3} / 8,26,580,000$ acre-ft/yr.

EXTREMES FOR PERIOD OF RECORD.-Maximum discharge, $414,000 \mathrm{ft}^{2} / 8$ Apr. 19, 1952 , maximum gage height, $27.66 \mathrm{ft}$ Apr. 18, 1952, minimum discharge, 1,600 ft/s Dec. 31 , 1946 (discharge measurement), minimum gage height observed, $-0.28 \mathrm{ft}$ Dec. 24, 1960 , result of freezeup.

EXTREMES FOR CURRENT YEAR.--Maximum discharge, 83,900 ft/8 April 25, gage height, $17.55 \mathrm{ft}$, minimum daily, 21,800 $\mathrm{ft}^{3 / \mathrm{s}} \mathrm{Jan} 23$; minimum gage height, $5.41 \mathrm{ft}$ Jan. 23 .

DISCHARGE, IN CUBIC FEET PER SECOND, WATER YEAR OCTOBER 1984 TO SEPTEMBER 1985 MEAN VALUES

\begin{tabular}{|c|c|c|c|c|c|c|c|c|c|c|c|c|}
\hline DAY & OCT & NOV & DEC & JAN & FEB & MAR & APR & MAY & JUN & JUL & AUG & SEP \\
\hline $\begin{array}{l}1 \\
2 \\
3 \\
4 \\
5\end{array}$ & $\begin{array}{l}52900 \\
52100 \\
52700 \\
52400 \\
52000\end{array}$ & $\begin{array}{l}64700 \\
63500 \\
62000 \\
61700 \\
60700\end{array}$ & $\begin{array}{l}61700 \\
61700 \\
60200 \\
56300 \\
52200\end{array}$ & $\begin{array}{l}35900 \\
32500 \\
28500 \\
28500 \\
30300\end{array}$ & $\begin{array}{l}31000 \\
30000 \\
29000 \\
29200 \\
29600\end{array}$ & $\begin{array}{r}45200 \\
49200 \\
48400 \\
46700 \\
57700\end{array}$ & $\begin{array}{l}46700 \\
46300 \\
46100 \\
45900 \\
46200\end{array}$ & $\begin{array}{l}54900 \\
57500 \\
61700 \\
56400 \\
52000\end{array}$ & $\begin{array}{l}48600 \\
48300 \\
48800 \\
49800 \\
49000\end{array}$ & $\begin{array}{l}47900 \\
46600 \\
45600 \\
44500 \\
43100\end{array}$ & $\begin{array}{l}36700 \\
37300 \\
38300 \\
38600 \\
39700\end{array}$ & $\begin{array}{l}41100 \\
37700 \\
37900 \\
38200 \\
38100\end{array}$ \\
\hline $\begin{array}{r}6 \\
7 \\
8 \\
9 \\
10\end{array}$ & $\begin{array}{l}53400 \\
54000 \\
55100 \\
56300 \\
57200\end{array}$ & $\begin{array}{l}59500 \\
59400 \\
59300 \\
59800 \\
62300\end{array}$ & $\begin{array}{l}48200 \\
46100 \\
44400 \\
43000 \\
41400\end{array}$ & $\begin{array}{l}31900 \\
33200 \\
33900 \\
34800 \\
33400\end{array}$ & $\begin{array}{l}29000 \\
28700 \\
28400 \\
28300 \\
28600\end{array}$ & $\begin{array}{l}48700 \\
42400 \\
41700 \\
39700 \\
41300\end{array}$ & $\begin{array}{l}47400 \\
47000 \\
47400 \\
47400 \\
47500\end{array}$ & $\begin{array}{l}51200 \\
49200 \\
47600 \\
46800 \\
45700\end{array}$ & $\begin{array}{r}48100 \\
46100 \\
46000 \\
46700 \\
46500\end{array}$ & $\begin{array}{l}41500 \\
40600 \\
39200 \\
39000 \\
38300\end{array}$ & $\begin{array}{l}40100 \\
39100 \\
39000 \\
38600 \\
38800\end{array}$ & $\begin{array}{l}38800 \\
38300 \\
39000 \\
39800 \\
40500\end{array}$ \\
\hline $\begin{array}{l}11 \\
12 \\
13 \\
14 \\
15\end{array}$ & $\begin{array}{l}56700 \\
55900 \\
55600 \\
55600 \\
57300\end{array}$ & $\begin{array}{l}63600 \\
63700 \\
63200 \\
62400 \\
62500\end{array}$ & $\begin{array}{l}41500 \\
43000 \\
43400 \\
41200 \\
41400\end{array}$ & $\begin{array}{l}31400 \\
29500 \\
28300 \\
27400 \\
27700\end{array}$ & $\begin{array}{l}28800 \\
29100 \\
28400 \\
29000 \\
29500\end{array}$ & $\begin{array}{l}42900 \\
43300 \\
43900 \\
45400 \\
45400\end{array}$ & $\begin{array}{l}45900 \\
45000 \\
45600 \\
43600 \\
43400\end{array}$ & $\begin{array}{l}45300 \\
45700 \\
45900 \\
49200 \\
61100\end{array}$ & $\begin{array}{l}45500 \\
45200 \\
44100 \\
43100 \\
42200\end{array}$ & $\begin{array}{l}38100 \\
37600 \\
37300 \\
37100 \\
36500\end{array}$ & $\begin{array}{l}38700 \\
38000 \\
38000 \\
39200 \\
39800\end{array}$ & $\begin{array}{l}40100 \\
39500 \\
39500 \\
42000 \\
47700\end{array}$ \\
\hline $\begin{array}{l}16 \\
17 \\
18 \\
19 \\
20\end{array}$ & $\begin{array}{l}60700 \\
62900 \\
63400 \\
64800 \\
66200\end{array}$ & $\begin{array}{l}63300 \\
63000 \\
61400 \\
60700 \\
60600\end{array}$ & $\begin{array}{l}50800 \\
60600 \\
51000 \\
47100 \\
43600\end{array}$ & $\begin{array}{l}28800 \\
27600 \\
28300 \\
30400 \\
30500\end{array}$ & $\begin{array}{l}29600 \\
29900 \\
30700 \\
31600 \\
32100\end{array}$ & $\begin{array}{l}46100 \\
46800 \\
46300 \\
46400 \\
47000\end{array}$ & $\begin{array}{l}42200 \\
41200 \\
40900 \\
40900 \\
41500\end{array}$ & $\begin{array}{l}75700 \\
65100 \\
60400 \\
56600 \\
58000\end{array}$ & $\begin{array}{l}43600 \\
46000 \\
44600 \\
43900 \\
43200\end{array}$ & $\begin{array}{l}36100 \\
36300 \\
36400 \\
44700 \\
53700\end{array}$ & $\begin{array}{l}38600 \\
39300 \\
39600 \\
39800 \\
38600\end{array}$ & $\begin{array}{l}47300 \\
44200 \\
44100 \\
43500 \\
42800\end{array}$ \\
\hline $\begin{array}{l}21 \\
22 \\
23 \\
24\end{array}$ & $\begin{array}{l}65400 \\
65100 \\
64900 \\
63900 \\
63400\end{array}$ & $\begin{array}{l}61100 \\
60700 \\
61400 \\
60700 \\
60500\end{array}$ & $\begin{array}{l}42600 \\
42100 \\
39400 \\
37200 \\
35100\end{array}$ & $\begin{array}{l}27500 \\
24100 \\
21800 \\
25300 \\
30000\end{array}$ & $\begin{array}{l}35300 \\
43500 \\
39600 \\
37700 \\
38200\end{array}$ & $\begin{array}{l}46800 \\
46800 \\
46400 \\
46100 \\
45200\end{array}$ & $\begin{array}{l}41300 \\
44300 \\
51800 \\
71000 \\
79100\end{array}$ & $\begin{array}{l}58500 \\
55800 \\
52700 \\
51300 \\
49700\end{array}$ & $\begin{array}{l}42900 \\
42400 \\
42300 \\
45300 \\
45400\end{array}$ & $\begin{array}{l}44400 \\
42800 \\
39900 \\
39100 \\
38900\end{array}$ & $\begin{array}{l}38300 \\
38200 \\
38800 \\
38900 \\
39000\end{array}$ & $\begin{array}{l}43100 \\
43100 \\
43200 \\
42600 \\
41800\end{array}$ \\
\hline $\begin{array}{l}26 \\
27 \\
28 \\
29 \\
30\end{array}$ & $\begin{array}{l}63500 \\
63000 \\
64500 \\
64400 \\
64000 \\
63900\end{array}$ & $\begin{array}{r}61100 \\
61500 \\
62500 \\
62400 \\
62000 \\
-\end{array}$ & $\begin{array}{l}33900 \\
34400 \\
42600 \\
48100 \\
44600 \\
39700\end{array}$ & $\begin{array}{l}32000 \\
31400 \\
29500 \\
29600 \\
30900 \\
30800\end{array}$ & $\begin{array}{r}39200 \\
40400 \\
41400 \\
- \\
-\end{array}$ & $\begin{array}{l}45300 \\
46700 \\
46700 \\
47000 \\
46300 \\
46700\end{array}$ & $\begin{array}{r}67000 \\
66500 \\
77200 \\
67300 \\
57300 \\
--\end{array}$ & $\begin{array}{l}49200 \\
49500 \\
49700 \\
48800 \\
48000 \\
48100\end{array}$ & $\begin{array}{r}42600 \\
43000 \\
48600 \\
53200 \\
51700 \\
--\end{array}$ & $\begin{array}{l}38500 \\
37400 \\
36400 \\
35900 \\
36900 \\
37200\end{array}$ & $\begin{array}{l}38800 \\
38800 \\
38000 \\
37400 \\
37300 \\
41600\end{array}$ & $\begin{array}{r}41400 \\
41400 \\
41100 \\
40700 \\
41800 \\
-\end{array}$ \\
\hline $\begin{array}{l}\text { TOTAL } \\
\text { MEAN } \\
\text { MAX } \\
\text { MIN } \\
\text { AC-FT }\end{array}$ & $\begin{array}{r}1843200 \\
59460 \\
66200 \\
52000 \\
3656000\end{array}$ & $\begin{array}{r}1851200 \\
61710 \\
64700 \\
59300 \\
3672000\end{array}$ & $\begin{array}{r}1418500 \\
45760 \\
61700 \\
33900 \\
2814000\end{array}$ & $\begin{array}{r}925700 \\
29860 \\
35900 \\
21800 \\
1836000\end{array}$ & $\begin{array}{r}905800 \\
32350 \\
43500 \\
28300 \\
1797000\end{array}$ & $\begin{array}{r}1424500 \\
45950 \\
57700 \\
39700 \\
2825000\end{array}$ & $\begin{array}{r}1520900 \\
50700 \\
79100 \\
40900 \\
3017000\end{array}$ & $\begin{array}{r}1647300 \\
53140 \\
75700 \\
45300 \\
3267000\end{array}$ & $\begin{array}{r}1376700 \\
45890 \\
53200 \\
42200 \\
2731000\end{array}$ & $\begin{array}{r}1247500 \\
40240 \\
53700 \\
35900 \\
2474000\end{array}$ & $\begin{array}{r}1200900 \\
38740 \\
41600 \\
36700 \\
2382000\end{array}$ & $\begin{array}{r}1240300 \\
41340 \\
47700 \\
37700 \\
2460000\end{array}$ \\
\hline $\begin{array}{ll}\text { CAL } & \text { YR } \\
\text { WTR } & \text { YR }\end{array}$ & $\begin{array}{l}1984 \\
1985\end{array}$ & $\begin{array}{l}\text { TOTAL } \\
\text { TOTAL }\end{array}$ & $\begin{array}{l}716500 \\
602500\end{array}$ & $\begin{array}{l}\text { MEAN } \\
\text { MEAN }\end{array}$ & $\begin{array}{l}64800 \\
45490\end{array}$ & $\begin{array}{l}\text { MAX } \\
\text { MAX }\end{array}$ & $\begin{array}{r}180000 \\
79100\end{array}$ & $\begin{array}{l}\text { MIN } \\
\text { MIN }\end{array}$ & $\begin{array}{l}300 \\
300\end{array}$ & FT32S & 10 & \\
\hline
\end{tabular}


PERIOD OF RECORD.-- Lay 1951 to current year. Dally sediment loads August 1957 to September 1971 in reports of Corps of Engineers.

REMARKS.--Samples for particle size distribution were collected from boat cross-section 0.7 mi upstream from gage.

PERIOD OF DAILY RECORD, -

SPECIFIC CONDOCTANCE: May 1951 to September 1976.

TATER TENPERATURES: NaY 1951 to September 1976.

SEDIMENT DISCHARGE: October 1971 to September 1976.

EXTRENBS FOR PERIOD OF DAILY RBCORD...

SPECIFIC CONDUCTANCE: Maximum daily, 994 microsiemens Dec. 17, 1962; minimum daily, 273 microsiemens June 17, 1964. WATER TEMPERATURES: Maximum daily, $31^{\circ} \mathrm{C} J u l y ~ 26,1977$, minimum, $0.0^{\circ} \mathrm{C}$ on many days during winter periods.

SEDIMENT CONCENTRATIONs: Maximum daily mean, 8,220 mg/L Nay 19, 1974, minimum daily mean, 137 mg/L Jan. 14, 1975 .

SEDIMENT LOADS: Maximum daily, 1,590,000 tons May 19, 1974, minimum daily, 4,050 tons Jan. $17,1972$.

PARTICLE SIZE DISTRIBUTION OF SOSPENDED-SEDIMENT, WATER YEAR OCTOBER 1984 TO SEPTEMBER 1985

\begin{tabular}{|c|c|c|c|c|c|c|c|c|c|c|c|c|}
\hline & TIME & $\begin{array}{l}\text { SAYPLE } \\
\text { LOC- } \\
\text { ATION, } \\
\text { CROSS } \\
\text { SECTION } \\
\text { (FT PU } \\
\text { L BANK) }\end{array}$ & $\begin{array}{l}\text { DEPTH } \\
\text { AT } \\
\text { SAYPLE } \\
\text { LOC- } \\
\text { ATION, } \\
\text { TOTAL } \\
\text { (FEET) }\end{array}$ & $\begin{array}{l}\text { SAN- } \\
\text { PLINE } \\
\text { DEPTH } \\
\text { (FBET) }\end{array}$ & $\begin{array}{l}\text { STREAY } \\
\text { VELOC- } \\
\text { ITY, } \\
\text { POINT) } \\
\text { (FPS) }\end{array}$ & $\begin{array}{l}\text { SEDI- } \\
\text { MENT, } \\
\text { SUS- } \\
\text { PENDED } \\
\text { (MG/L) }\end{array}$ & $\begin{array}{l}\text { SED. } \\
\text { SUSP. } \\
\text { FALL } \\
\text { DIAM. } \\
\text { FINER } \\
\text { THAN } \\
.004 \text { MH }\end{array}$ & $\begin{array}{l}\text { SED. } \\
\text { SUSP. } \\
\text { FALI } \\
\text { DIAY. } \\
\text { FINER } \\
\text { THAN } \\
.062 \mathrm{MH}\end{array}$ & $\begin{array}{l}\text { SED. } \\
\text { SUSP. } \\
\text { FALL } \\
\text { DIAY. } \\
\text { FINBR } \\
\text { THAN } \\
\text { T25 MM }\end{array}$ & $\begin{array}{l}\text { SED. } \\
\text { SUSP. } \\
\text { FALL } \\
\text { DIAM. } \\
\text { FINER } \\
\text { THAN } \\
.250\end{array}$ & $\begin{array}{l}\text { SED. } \\
\text { SOSP. } \\
\text { FALI } \\
\text { DIAY, } \\
\text { FINER } \\
\text { THAN } \\
.500 \text { MU }\end{array}$ & $\begin{array}{l}\text { SED. } \\
\text { SOSP. } \\
\text { FALI. } \\
\text { DIAY. } \\
\text { FINER } \\
\text { THAN } \\
1.00 \mathrm{MM}\end{array}$ \\
\hline
\end{tabular}

OCT 1984

02... WATER TEMPERATURE, $13.0^{\circ} \mathrm{C}$ (1105-1330 BOORs), DISCHARGE, $51,900 \mathrm{ft}^{2} / 8$.

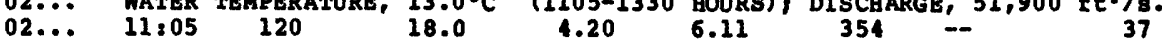

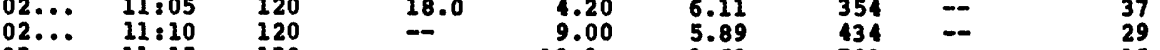

$02 \ldots 11: 20 \quad 120$

$02 \ldots 11: 25 \quad 120$

$02 \ldots 11: 30 \quad 120$

$02 \ldots .11: 35 \quad 220$

$02 \ldots 11: 40 \quad 220$

$02 \ldots . \quad 11: 45 \quad 220$

$02 \ldots 11: 50 \quad 220$

$02 \ldots 11: 55 \quad 220$

$02 \ldots \quad 12: 05 \quad 320$

$02 \ldots 12: 10 \quad 320$

$02 \ldots 12: 14 \quad 320$

$02 \ldots .12815 \quad 320$

$02 \ldots \quad 12: 20 \quad 320$

$02 \ldots 12: 25 \quad 320$

$02 \ldots 12: 30 \quad 420$

$02 \ldots .12: 35 \quad 420$

$02 \ldots \quad 12: 40 \quad 420$

$02 \ldots .12: 45 \quad 420$

$02 \ldots 12,50 \quad 420$

$02 \ldots 12: 55 \quad 420$

$02 \ldots .13: 00 \quad 550$

$02 \ldots \quad 13: 05 \quad 550$

$02 \ldots \quad 13: 10 \quad 550$

$02 \ldots 13: 15 \quad 550$

$02 \ldots 13: 20 \quad 550$

$02 \ldots .13: 25 \quad 550$
12.9

15.0

16.2

16.2

2.80

6.00

8.60

10.0

10.8

2.80

6.10

8.70

10.2

11.0
3.90

3.90
8.50

12.1

14.2

15.3

16.0

3.80

8.30

11.9

13.8

13.8

14.9
15.6

2.63
1.68

1.68

1.68

1. 76

8.08

7.86
6.98

6.85

6.32

6.32

7.86

7.

7.64

7.42

6.85

6.32
5.85

5.85

5.30

5.32

4.37

4.07

4.15

3. 50

3.07

2. 72
780
$1470=-$

1870 --

1640 -

$\begin{array}{ll}336 & = \\ 464 & =-\end{array}$

809

$-$

510

$-$

$-177$

230
488

488

665

1050

183

192

222

233
231

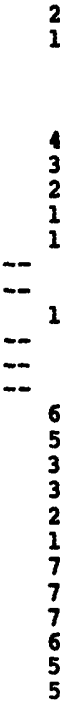

4
3
2
1
1
5
5
3
2
1
$-\quad$
-
-
-
-
-
7
7
7
5
5
3
3
8
8
7
73
66
6

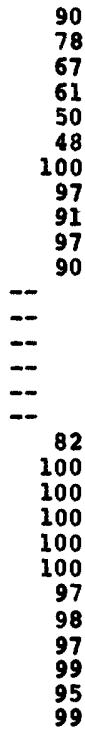

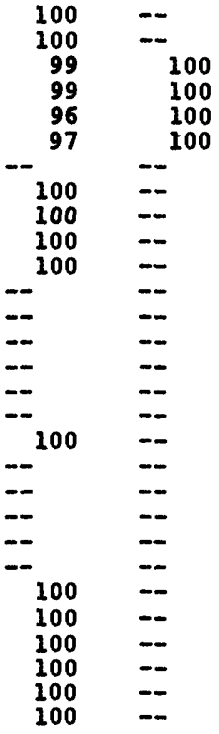


WATER-QUALITY RECORDS

PARTICLB SIZE DISTRIBUTION OF SUSPENDED-SEDIMENT, WATER YEAR OCTOBER 1984 TO SEPTEMBER 1985

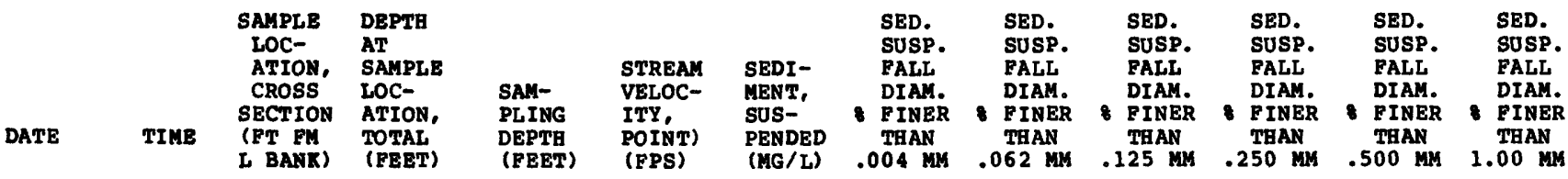

APR 1985

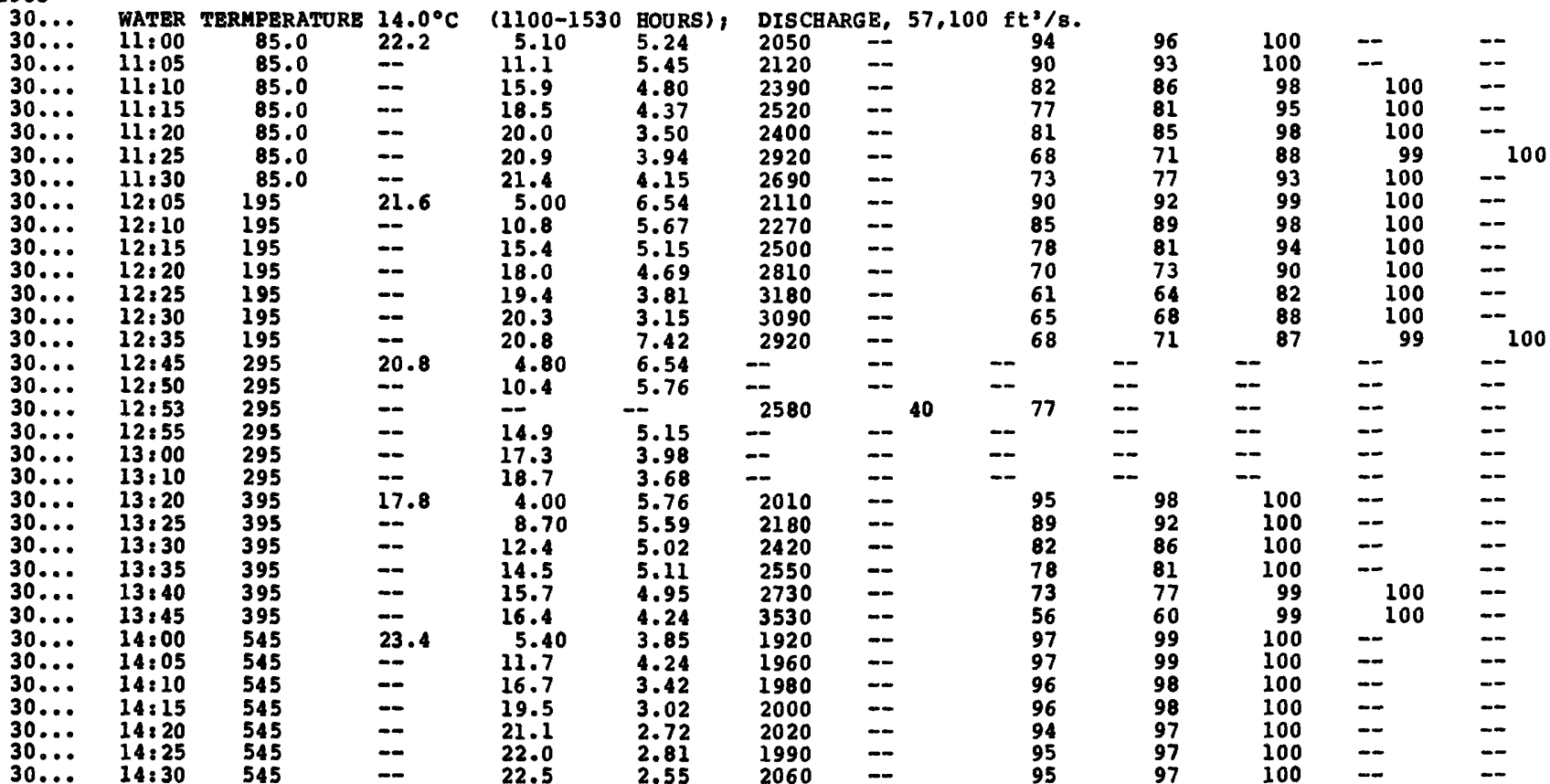

Jow 1985

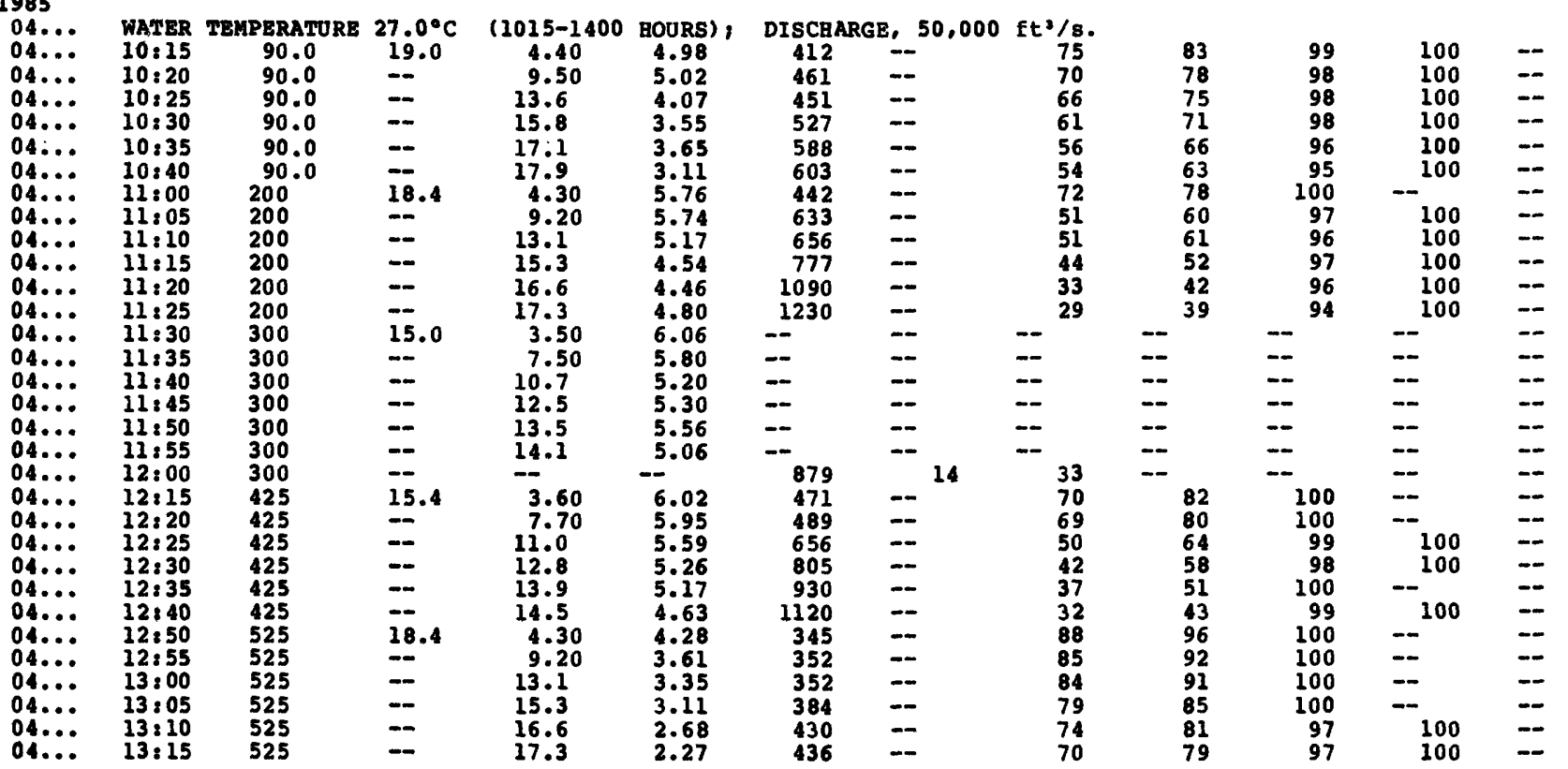


06807000 MISSOURI RIVER AT NEBRASKA CITY, NB--Continued

WATER-QUALITY RECORDS

PARTICLE SIZE DISTRIBUTION OF SUSPENDED-SEDIMENT, WATER YEAR OCTOBER 1984 TO SEPTEMBER I985

\begin{tabular}{|c|c|c|c|c|c|c|c|c|c|c|c|c|}
\hline & TIME & $\begin{array}{l}\text { SAMPLE } \\
\text { LOC- } \\
\text { ATION, } \\
\text { CROSS } \\
\text { SECTION } \\
\text { (FT FU } \\
\text { L BANK) }\end{array}$ & $\begin{array}{l}\text { DEPTH } \\
\text { AT } \\
\text { SAMPLE } \\
\text { LOC- } \\
\text { ATION, } \\
\text { TOTAL } \\
\text { (FEET) }\end{array}$ & $\begin{array}{l}\text { SAH- } \\
\text { PLING } \\
\text { DEPTH } \\
\text { (FEET) }\end{array}$ & $\begin{array}{l}\text { STREAY } \\
\text { VELOC- } \\
\text { ITY, } \\
\text { POINT) } \\
\text { (FPS) }\end{array}$ & $\begin{array}{l}\text { SEDI- } \\
\text { MENT, } \\
\text { SUS- } \\
\text { PENDED } \\
\text { (MG/L) }\end{array}$ & $\begin{array}{l}\text { SED. } \\
\text { SOSP. } \\
\text { FALL } \\
\text { DIAM. } \\
\text { FINER } \\
\text { THAN } \\
.004 \text { MM }\end{array}$ & $\begin{array}{l}\text { SED. } \\
\text { SUSP. } \\
\text { FALL } \\
\text { DIAY. } \\
\text { FINER } \\
\text { THAN } \\
.062 \mathrm{MH}\end{array}$ & $\begin{array}{l}\text { SED. } \\
\text { SUSP. } \\
\text { FALL } \\
\text { DIAM. } \\
\text { FINER } \\
\text { THAN } \\
.125 \mathrm{MM}\end{array}$ & $\begin{array}{l}\text { SED. } \\
\text { SUSP. } \\
\text { FALL } \\
\text { DIAM. } \\
\text { FINER } \\
\text { THAN } \\
.250 \mathrm{MH}\end{array}$ & $\begin{array}{l}\text { SED. } \\
\text { SUSP. } \\
\text { FALL } \\
\text { DIAM. } \\
\text { FINER } \\
\text { THAN } \\
.500 \mathrm{MM}\end{array}$ & $\begin{array}{l}\text { SED. } \\
\text { SUSP. } \\
\text { FALL } \\
\text { DIAM. } \\
\text { FINER } \\
\text { THAN } \\
1.00 \mathrm{MH}\end{array}$ \\
\hline
\end{tabular}

JUL 1985

16... WATER TEMPERATURE $27.5^{\circ} \mathrm{C}$ (1105-1540 HOURS); DISCHARGE, $36,000 \mathrm{ft} / \mathrm{s}$

$16 \ldots \quad 11: 05$

$16 \ldots . . \quad 11: 10$

$16 \ldots . . \quad 11: 15$

$16 \ldots . . \quad 11: 25$

$16 \ldots . \quad 11: 30$

$16 \ldots .11: 50$

$16 \ldots . \quad 11: 52$

$16 \ldots . \quad 11: 54$

$16 \ldots \quad 11: 56$

$16 \ldots \quad 11: 58$

$16 \ldots \quad 12: 00$

$16 \ldots .12: 50$

$16 \ldots .12: 53$

$16 \ldots \quad 12: 56$

$16 \ldots 12: 58$

$16 \ldots \ldots \quad 12: 59$

$16 \ldots \ldots \quad 13: 02$

$16 \ldots .13: 40$

$16 \ldots \quad 13: 43$

$16 \ldots \quad 13: 46$

$16 \ldots \quad 13: 49$

$16 \ldots .13: 52$

$16 \ldots . \quad 13: 55$

$16 \ldots 14: 3$

$16 \ldots .14: 35$

$16 \ldots$ 14:40

$16 \ldots .14: 45$

60.0
60.0
60.0
60.0
60.0
60.0
150
150
150
150
150
150
275
275
275
275
275
275
275
375
375
375
375
375
375
515

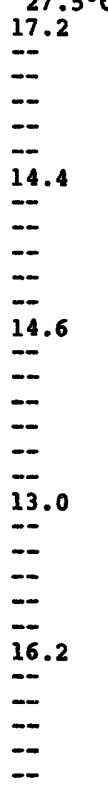

4.00

40 HOURS)
4.83
4.33

$\begin{array}{llll}209 & - & 83 & 92 \\ 316 & - & 58 & 65 \\ 323 & - & 57 & 67 \\ 337 & - & 53 & 61 \\ 433 & - & 40\end{array}$

$\begin{array}{ll}12.3 & 3.87 \\ 14.3 & 3.24\end{array}$

3.24

16.2

3.30

2.29

433

$\overline{-}$

7.10

5.67

10.1

5.11

304

12.8

4.72
4.67

433
617

$4.67 \quad 604$

13.4
3.30

3.30
7.20

3.50

740

10.3

5.80
5.45

12.0

4.85

12.0

3.98

13.0
13.6

3.00

3.20

2.96

6.40

4.80

10.7

4.33

11.5

12.0

4.11

3.70

3.70

3.65
4.22

8.10

4.22
3.57

11.6

13.5
14.6

3.44

15.2

2.98
3.24

817
110

$\because$

2.74

303
435
624
787
1100
1640
323
379
444
702
725
684
200
216
219
222
222
283

$\because$

$\equiv$

AUG 1985

27... WATER TEMPERATURE $23.0^{\circ} \mathrm{C}$ (1035-1130 HOORS);

$27 \ldots . .10: 40$

$27 \ldots \quad 10: 45$

$27 \ldots 10: 50$

27... 10:55

$27 \ldots .11: 00$

$27 \ldots \quad 11: 20$

$27 \ldots . . \quad 11: 25$

27... $11: 30$

$27 \ldots .11: 35$

$27 \ldots .11: 40$

$27 \ldots .11: 45$

$27 \ldots . . \quad 11: 50$

27... $11: 55$

27... 12:00

27... $12: 05$

$27 \ldots \quad 12: 10$

$27 \ldots 12: 15$

$27 \ldots \quad 12: 20$

$27 \ldots \quad 12: 30$

$27 \ldots .12: 35$

$27 \ldots .12: 40$

$27 \ldots .12: 45$

$27 \ldots 12: 50$

$27 \ldots \quad 13: 05$

27... 13:10

27... 13:15

$27 \ldots \quad 13: 20$

$27 \ldots 13: 25$

85.
85.0
85.0
85
85.
85.
160
160
160
160
160
160
285
285
285
285
285
285
285
410
410
410
410
410
525
525
525
525
525
525

15.2

3.50

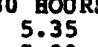

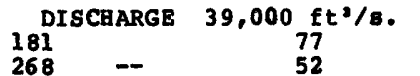

7.50

5.35
5.09

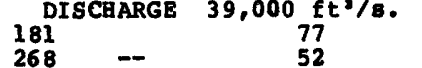

$-$

12.5

4.52
3.87

339

$=$

$\begin{array}{ll}-- & 13.5 \\ \overline{14.2} & 14.1\end{array}$

3.30
7.10

3.57

2.79

5.72

499
584
275
372

10.1

5.45

$\begin{array}{ll}-\infty & 10.1 \\ - & 11.8\end{array}$

4.98

$\begin{array}{ll}- & 12.8 \\ -\infty & 13.4\end{array}$

14.4

3.30

$\begin{array}{ll}-\infty & 3.30 \\ - & 7.20\end{array}$

- 10.3

- 12.0

12.0
13.0
13.6

$12.2 \quad 13.6$

$\begin{array}{ll}- & 6.10 \\ - & 8.70\end{array}$

4.26
4.24

4.17

5.56

4.91

4.41
4.07

3.61
3.00

5.09

4.80
4.59
4.37

11.0

4.37
4.15

$\overline{17.0}$

3.90
8.50

4.15

12.1

3.72

$\begin{array}{ll}- & 14.2 \\ - & 15.3 \\ - & 16.0\end{array}$

$\begin{array}{ll}- & 14.2 \\ - & 15.3 \\ - & 16.0\end{array}$

3.57
3.35

2.63
2.46

521
575

575

545

$-$

844
--

$\bar{z}=$

$\overline{-}$

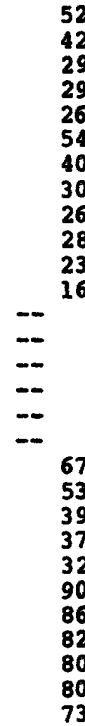

\begin{tabular}{r}
88 \\
62 \\
51 \\
37 \\
39 \\
36 \\
70 \\
54 \\
44 \\
39 \\
43 \\
36 \\
25 \\
-- \\
$-\quad$ \\
$-\quad$ \\
-- \\
\hline- \\
- \\
\hline \\
\\
\\
78 \\
62 \\
50 \\
46 \\
43 \\
98 \\
95 \\
94 \\
93 \\
90 \\
82
\end{tabular}

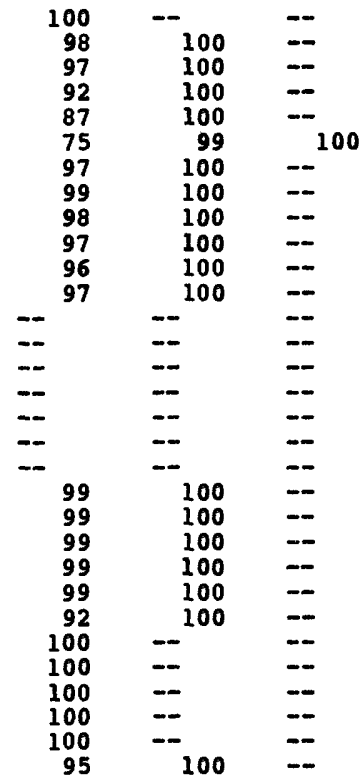

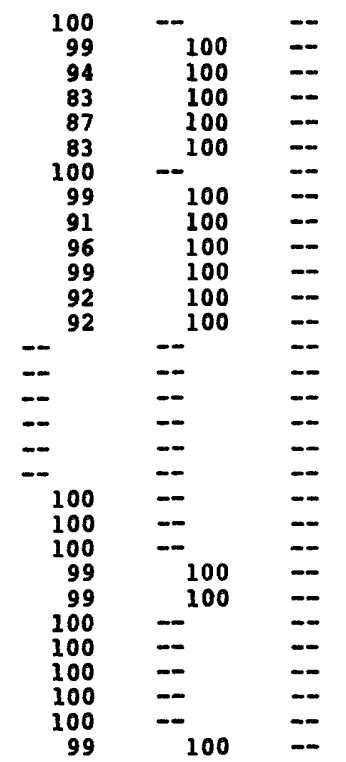


06807000 MISSOURI RIVER AT NEBRASRA CITY, NB--Continued

WATER-QUALITY RECORDS

PARTICLE SIZE DISTRIBUTION OR BED MATERIAL, WATER YEAR OCTOBER 1984 TO SEPTEMBER 1985

\begin{tabular}{|c|c|c|c|c|c|c|c|c|c|c|c|}
\hline DATE & TIME & $\begin{array}{c}\text { NUMBER } \\
\text { OF } \\
\text { SAM- } \\
\text { PLING } \\
\text { POINTS }\end{array}$ & $\begin{array}{c}\text { BED } \\
\text { MAT. } \\
\text { SIEVE } \\
\text { DIAM. } \\
8 \text { EINER } \\
\text { THAN } \\
.062 \mathrm{MM}\end{array}$ & $\begin{array}{c}\text { BED } \\
\text { MAT. } \\
\text { SIEVE } \\
\text { DIAN. } \\
\text { \& EINER } \\
\text { THAN } \\
.125 \mathrm{NM}\end{array}$ & $\begin{array}{c}\text { BED } \\
\text { MAT. } \\
\text { SIEVE } \\
\text { DIAM. } \\
8 \text { FINER } \\
\text { THAN } \\
.250 \mathrm{MM}\end{array}$ & $\begin{array}{c}\text { BED } \\
\text { MAT. } \\
\text { SIEVE } \\
\text { DIAM. } \\
8 \text { FINER } \\
\text { THAN } \\
.500 \mathrm{MM}\end{array}$ & $\begin{array}{c}\text { BED } \\
\text { MAT. } \\
\text { SIEVE } \\
\text { DIAN. } \\
8 \text { FINER } \\
\text { THAN } \\
1.00 \mathrm{MM}\end{array}$ & $\begin{array}{c}\text { BED } \\
\text { MAT. } \\
\text { SIEVE } \\
\text { DIAM. } \\
\text { 8 FINER } \\
\text { THAN } \\
2.00 \mathrm{MM}\end{array}$ & $\begin{array}{c}\text { BED } \\
\text { MAT. } \\
\text { SIEVE } \\
\text { DIAM. } \\
\text { \& EINER } \\
\text { THAN } \\
4.00 \mathrm{MM}\end{array}$ & $\begin{array}{c}\text { BED } \\
\text { MAT. } \\
\text { SIEVE } \\
\text { DIAM. } \\
\text { 8 FINER } \\
\text { THAN } \\
8.00 \mathrm{MM}\end{array}$ & $\begin{array}{c}\text { BED } \\
\text { MAT. } \\
\text { SIEVE } \\
\text { DIAM. } \\
\text { 8 FINER } \\
\text { THAN } \\
16.0 \mathrm{NM}\end{array}$ \\
\hline $\begin{array}{l}\text { OCT } \\
02 \ldots\end{array}$ & $13: 30$ & 5 & -- & 0 & 21 & 62 & 76 & 89 & 97 & 99 & 100 \\
\hline $\begin{array}{l}30 . . \\
\text { JUN }\end{array}$ & $15: 30$ & 5 & -- & 0 & 19 & 58 & 87 & 97 & 99 & 100 & -- \\
\hline $\begin{array}{l}04 . . \\
\text { JUL }\end{array}$ & $14: 0$ & 5 & 0 & 1 & 22 & 49 & 80 & 96 & 99 & 100 & -- \\
\hline $16 \ldots$ & $15: 40$ & 5 & 0 & 1 & 17 & 45 & 77 & 92 & 98 & 100 & -- \\
\hline 2 & $13: 35$ & 5 & - & 0 & 24 & 51 & 77 & 91 & 97 & 99 & 100 \\
\hline
\end{tabular}


06807410 WEST NISHNABOTNA RIVER AT HANCOCK, IA

LOCATION.--Lat $41^{\circ} 23^{\prime} 24^{\prime \prime}$, long $95^{\circ} 22^{\prime} 17^{\prime \prime}$, in Nw1/4 NEl/4 sec.18, T. 76 N., R.39 w., Pottawattamie County, Bydrologic Unit 10240002 , on right bank at upstream side of bridge on county highway G30, $0.6 \mathrm{mi}$ west of Bancock school, $3.0 \mathrm{ml}$ downstream from Jim Creek, $59.6 \mathrm{mi}$ upstream from confluence with East N1shnabotna River, and at mile $75.1 \mathrm{mi}$ upstream from mouth of Nishnabotna River.

DRAINAGE AREA. $--609 \mathrm{mi}^{2}$.

PERIOD OF RECORD,--October 1959 to current year.

GAGE.- Water-stage recorder. Datum of gage is 1,085.83 ft above NGVD. Prior to Sept. 15 , 1980 , on downstream end of right pier at same datum.

REMARRS.--Estimated daily discharge: Dec. 1-15, 19-27, Dec. 30 to Feb. 22 . Records good excepts for estimated daily discharges, which are poor. U.S. Army Corps of Engineers rain-gage and gage-height satellite data collection platform at station.

AVERAGE DISChARGE.--26 years, $286 \mathrm{ft} / \mathrm{s}, 6.38 \mathrm{in} / \mathrm{yr}, 207,200$ acre-ft/yr; median of yearly mean discharges, 240 $\mathrm{ft}^{3} / \mathrm{s}, 5.4 \mathrm{in} / \mathrm{yr}, 174,000$ acre-ft/yr.

EXTREMES FOR PERIOD OF RECORD.--Maximum discharge, 26,400 ft3/s Sept. 13, 1972, gage height, $22.12 \mathrm{ft}$; minimum daily, $2.2 \mathrm{ft}^{3} / \mathrm{s}$ Feb. 8, 9, 1971.

EXTREMES FOR CURRENT YEAR.--Peak discharges greater than base of 4,000 ft/s and maximum (*):

\begin{tabular}{|c|c|c|c|c|c|c|c|}
\hline $\begin{array}{l}\text { Date } \\
\text { Dec. } 16 \\
\text { Dec. } 28\end{array}$ & $\begin{array}{l}\text { Time } \\
1845 \\
0745\end{array}$ & $\begin{array}{c}\text { Discharge } \\
\left(f t^{3} / \mathrm{s}\right) \\
4,700 \\
* 5,610\end{array}$ & $\begin{array}{c}\text { Gage height } \\
(\mathrm{ft}) \\
8.62 \\
9.48\end{array}$ & $\begin{array}{l}\text { Date } \\
\text { Feb. } 21\end{array}$ & $\begin{array}{l}\text { Time } \\
1715\end{array}$ & $\begin{array}{c}\text { Discharge } \\
\left.\text { (ft } t^{3} / \mathrm{s}\right) \\
\text { ice jam }\end{array}$ & $\begin{array}{c}\text { Gage height } \\
\text { (ft) } \\
* 14.49\end{array}$ \\
\hline
\end{tabular}

Minimum discharge, $85 \mathrm{ft}^{3} / \mathrm{s}$ Sept. 19.

REVISIONS.--The peak discharge for June 13, 1984 has been revised to $5,700 \mathrm{ft} / \mathrm{s}$.

DISCHARGE, IN CUBIC FEET PER SECOND, WATER YEAR OCTOBER 1984 TO SEPTEMBER 1985 MEAN VALUES

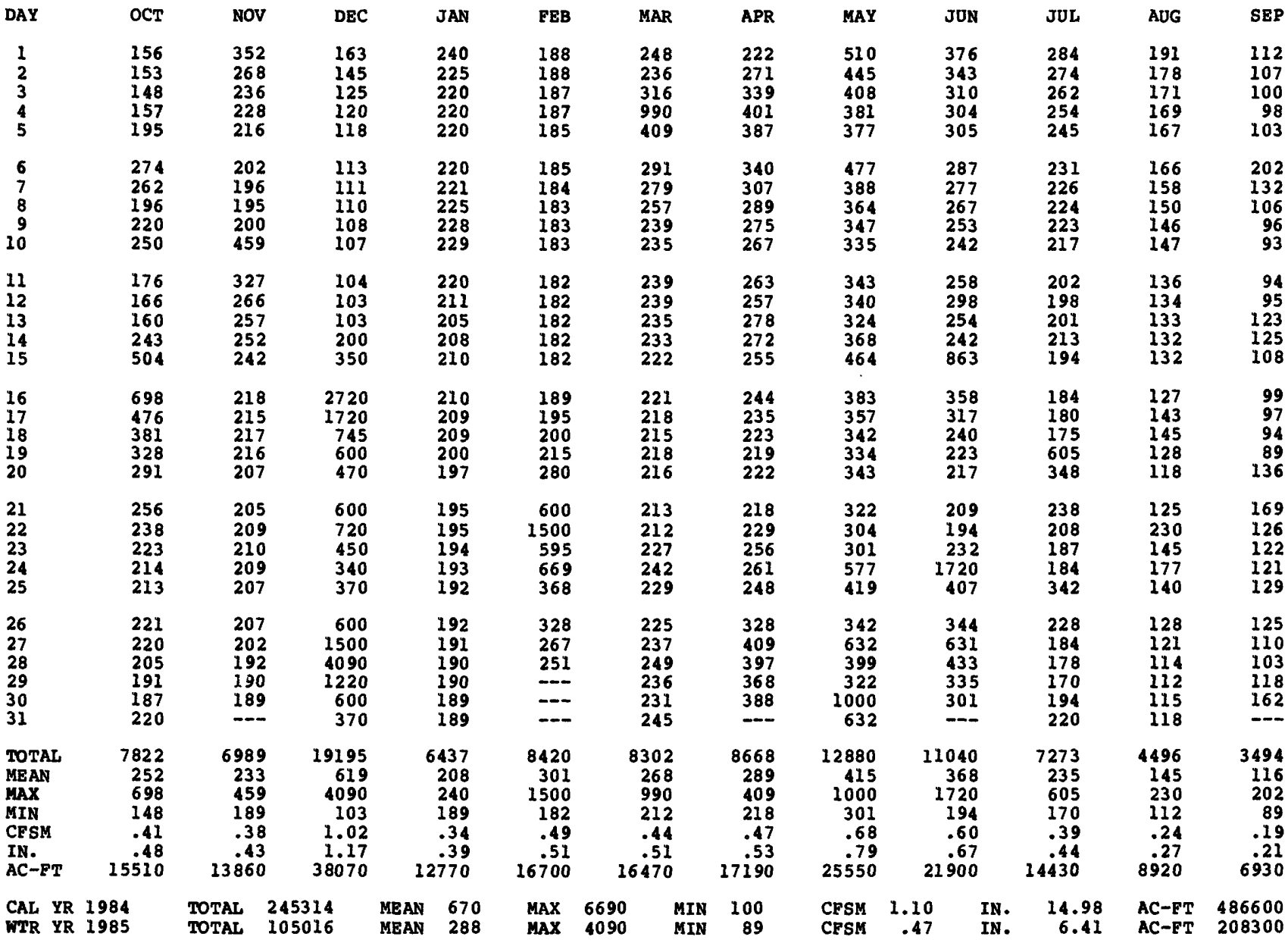


LOCATION, --Lat $40^{\circ} 52^{\prime} 23^{\prime \prime}$, long 95'34'48", in NEl/4 NEl/4 sec.17, T.70 N. R.41 w., Fremont County, Hydrologic Unit 10240002 , on right bank at upstream side of bridge on State Highway 184 , 0.3 mi downstream from Deer Creek, 0.5 $\mathrm{mi}$ west of Randolph, and $16.0 \mathrm{mi}$ upstream from confluence with East Nishnabotna River and at mile 31.5 upstream from mouth of Nishnabotna River.

DRAINAGE AREA. $--1,326 \mathrm{mi}^{2}$.

PERIOD OF RECORD.--June 1948 to current year.

REVISED RECORDS.--WSP 1440: Drainage area. WDR IA-74-1: 1973 (M). WDR IA-76-1: 1975 (P).

GAGE. - Water-stage recorder. Datum of gage is $932.99 \mathrm{ft}$ above NGVD, unadjusted. Prior to Aug. 26, 1955 , nonrecording gage with supplementary water-stage recorder operating above 8.4 ft June 30 , 1949 to Aug. 25 , 1955 at same site and datum.

REMARKS.--Estimated daily discharges: Dec. 7-13, 23-26 and Jan. 2 to Feb. 22 . Records good except those for estimated discharges, which are poor. National Weather Service gage-height telemeter at station.

AVERAGE DISCHARGE. -37 years, $572 \mathrm{ft} / \mathrm{s}, 5.86 \mathrm{in} / \mathrm{yr}, 414.100$ acre-ft/yr; median of yearly mean discharges, 500 ft'/s, $51 \mathrm{in} / \mathrm{yr}, 362,000$ acre-ft/yr.

EXTREMES FOR PERIOD OF RECORD,--Maximum discharge, 35,500 ft'/s June 21, 1967, gage height, $22.60 \mathrm{ft}$, maximum gage height, $24.8 \mathrm{ft}$ Mar. 5,1949 , from graph based on gage readings (backwater from ice), minimum daily discharge, $10 \mathrm{ft} / \mathrm{s}$ Dec. 17-2i, 1955 .

EXTREMES OUTSIDE PERIOD OF RECORD.--Flood in June 1947 reached a stage of about $24 \mathrm{ft}$, discharge not determined, from information by local residents.

EXTREMES FOR CURRENT YEAR.--Peak discharges greater than base of $6,500 \mathrm{ft} / \mathrm{s}$ and maximum (*):

\begin{tabular}{|c|c|c|c|}
\hline $\begin{array}{l}\text { Date } \\
\text { Feb. } 21\end{array}$ & Time & $\begin{array}{c}\text { Discharge } \\
\left(\mathrm{ft}^{*} / \mathrm{s}\right) \\
* 5,600\end{array}$ & $\begin{array}{c}\text { Gage height } \\
(\mathrm{ft}) \\
a * 17.57\end{array}$ \\
\hline
\end{tabular}

a Ice jam.

Minimum discharge, $195 \mathrm{ft} / \mathrm{s}$ Sept. 19, 20.

DISCHARGE, IN CUBIC FEET PER SECOND, WATER YEAR OCTOBER 1984 TO SEPTEMBER 1985 MEAN VALUES

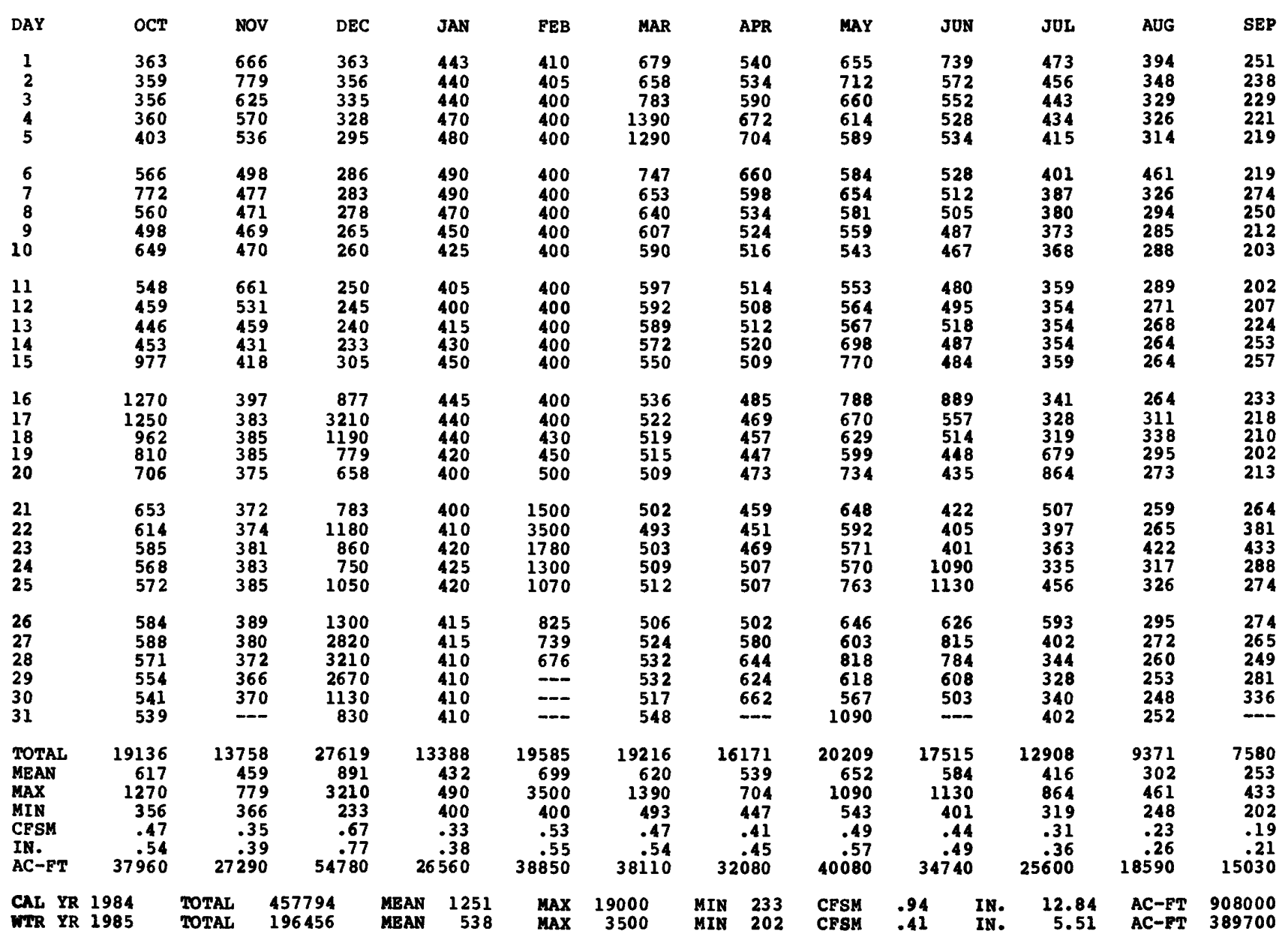


06809210 EAST NISBNABOTNA RIVER NEAR ATLANTIC, IA

LOCATION.--Lat $41^{\circ} 20^{\prime} 46^{\prime \prime}$, long $9^{\circ} 04^{\prime} 36^{\prime \prime}$, In WM1/4 N1/4 sec.35, T.76 N., R.37 w., Cass County, Bydrologic unit 10240003 , on left bank at downstream side of bridge on county highway, $1.6 \mathrm{mi}$ upstream from Turkey Creek, 5.2 $\mathrm{mi}$ southwest of junction of $\mathrm{U} . \mathrm{s}$. Bighway 6 and state Bighway 83 in At lantic, $69.1 \mathrm{mi}$ upstream from confluence with West Nishnabotna River, and at mile 84.6 above mouth of Nishnabotna River.

DRAINAGE AREA. $--436 \mathrm{mi}^{2}$.

PERIOD OF RECORD.--October 1960 to current year.

GAGE.--Water-stage recorder. Datum of gage is $1,105.83 \mathrm{ft}$ above NGVD. Prior to oct. 1, 1970, at site $2.2 \mathrm{mi}$ upstream at datum $5.00 \mathrm{ft}$ higher.

REMARKS.--Estimated daily discharges: Nov. 6 to Dec. 15, Dec. 19-27, Jan. 1 to Feb. 20, Feb. 24 and June 1-6, $10-15,18,19,21$, and 22. Records good except those for estimated daily discharges, which are poor. 0.5 Army Corps of Engineers rain-gage and gage-height satellite data collection platform at station.

AVERAGE DISCBARGE. - 25 years, $217 \mathrm{ft} / \mathrm{s}, 6.76 \mathrm{in} / \mathrm{yr}, 157,200$ acre-ft/yr; median of yearly mean discharges, 230 $\mathrm{ft}^{\prime} / \mathrm{s}, 7.2 \mathrm{in} / \mathrm{yr}, 167,000$ acre-ft/yr.

EXTREMES POR PERIOD OF RECORD,--Maximum discharge, $26,700 \mathrm{ft} / \mathrm{s}$ sept. 12, 1972, gage height, $22.81 \mathrm{ft}$, minimum daily, $2.5 \mathrm{ft} / \mathrm{s}$ July 10,1977 .

EXTREMES OUTSIDE PERIOD OF RECORD,--Flood of JU1Y 2, 1958 (corrected) reached a stage of $22.49 \mathrm{ft}$, from floodmark, discharge, $34,200 \mathrm{ft} \% / \mathrm{s}$.

EXTREMES POR CURRENT YEAR.--Peak discharges greater than base $3,000 \mathrm{ft}^{2} / \mathrm{s}$ and maximum $(*)$ :

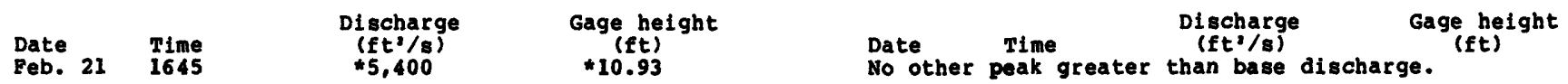

Minimum discharge, $28 \mathrm{ft}^{2} / \mathrm{s}$ Sept. 9 .

DISCHARGE, IN CUBIC FEET PER SECOND, WATER YEAR OCTOBER 1984 TO SEPTEMBER 1985 MEAN VALUES

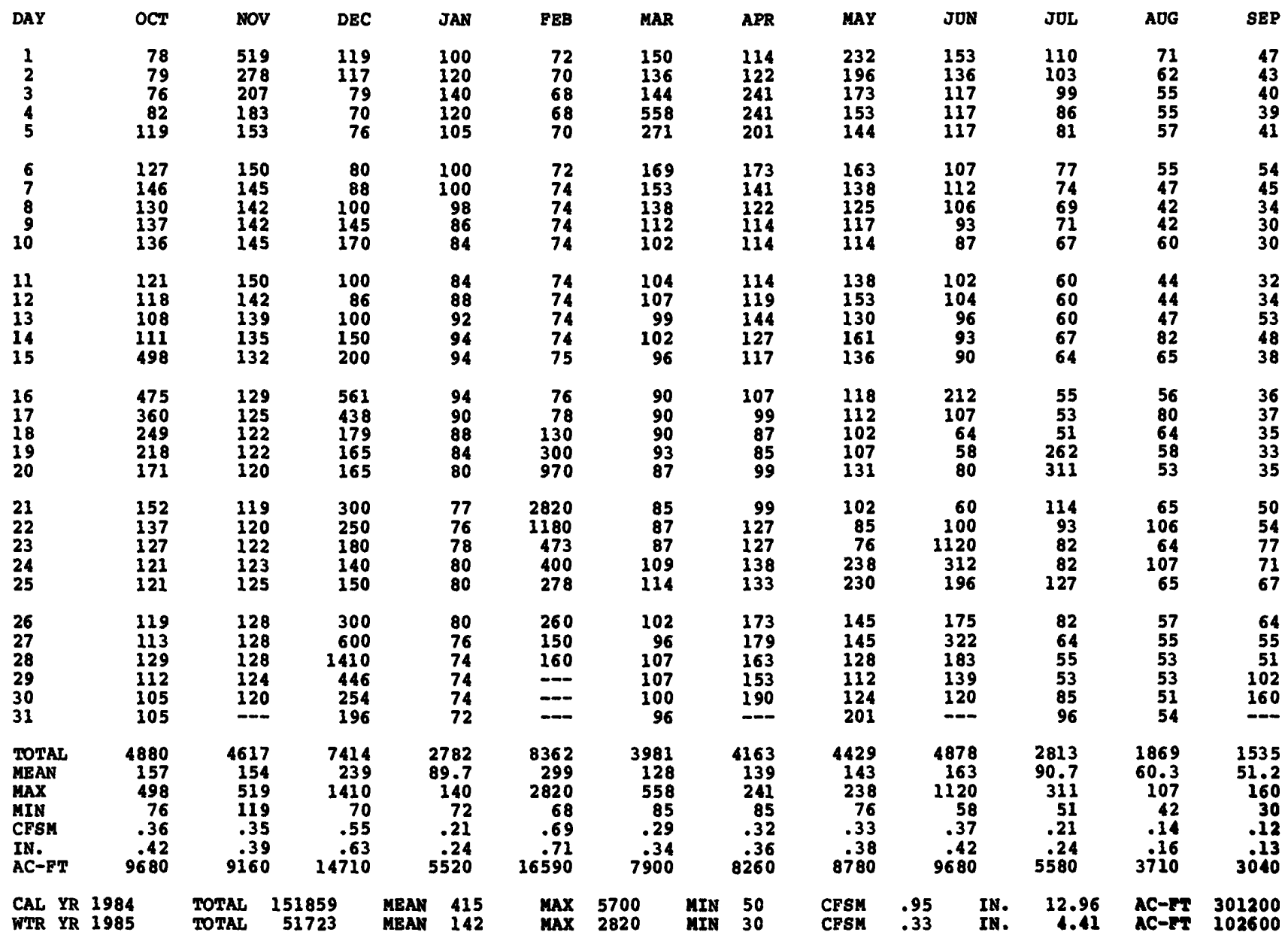




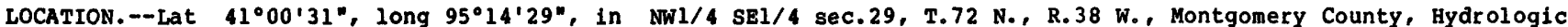
Unit 10240003, on left bank on downstream side of Coolbaugh street bridge in Red Oak, and 0.2 mi upstream from Red Oak Creek, $38.0 \mathrm{mi}$ upstream from confluence with West Nishnabotna River, and at mile 53.6 upstream from mouth of Nishnabotna River.

DRAINAGE AREA. $--894 \mathrm{mi}^{2}$.

PERIOD OF RECORD.--May 1918 to July 1925, May 1936 to current year. Monthly discharge only for some periods, pub11 shed in WSP 1310 .

REVISED RECORDS,--WSP 1240: 1921, 1922-23 (M), 1924, 1942 (M), 1944 (M), 1946. WSP 1440: Drainage area. WSP 1710: 1957 .

GAGE.--Water-stage recorder. Datum of gage is 1,005.45 ft above NGVD. Prior to July 5, 1925 , nonrecording gage at present site at datum $4.60 \mathrm{ft}$ higher. May 29, 1936, to Nov, 13, 1952, nonrecording gage with supplementary water-stage recorder in operation above $3.2 \mathrm{ft}$ gage height July 30 , 1939, to Nov. 13, 1952, and Nov. 14, 1952, to June 13, 1966, water-stage recorder, all at site $0.5 \mathrm{mi}$ upstream at datum $5.00 \mathrm{ft}$ higher. June 14 , 1966 , to Sept. 30,1969 , at present site at datum 5.00 ft higher.

REMARKS-Estimated daily discharges: Dec. 4-27, Dec. 31 to Feb. 21, Feb. 24, Aug. 18-28 and Sept. 6-10, 23, 28-30. Records good except those for estimated dally discharges, which are poor. U.S. National Weather Service gageheight telemeter at station.

AVERAGE DISCHARge.--55 years (water years 1919-24, 1937-85), 386 ft'/s, 5.86 in/yr, 279,700 acre-ft/yr.

EXTREMES FOR PERIOD OF RECORD.--Maximum discharge, 38,000 ft'/s sept. 13, 1972, gage height, 27.43 ft; maximum gage height, $28.23 \mathrm{ft} J u n e ~ 13,1947$, present datum; minimum daily discharge, $6 \mathrm{ft} / \mathrm{s}$ Aug. $18,1936$.

EXTREMES FOR CURRENT YEAR.--Peak discharges greater than base of 4,500 $\mathrm{ft}^{*} / \mathrm{s}$ and maximum (*):

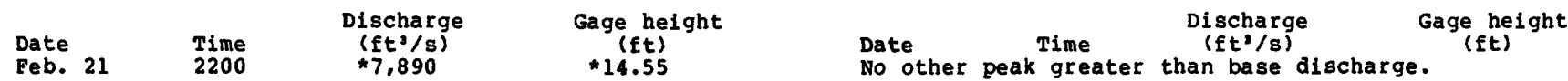

Minimum dally discharge, $88 \mathrm{ft} / \mathrm{s}$ Sept. 19.

DISCHARGE, IN CUBIC FEET PER SECOND, WATER YEAR OCTOBER 1984 TO SEPTEMBER 1985 MEAN VALUES

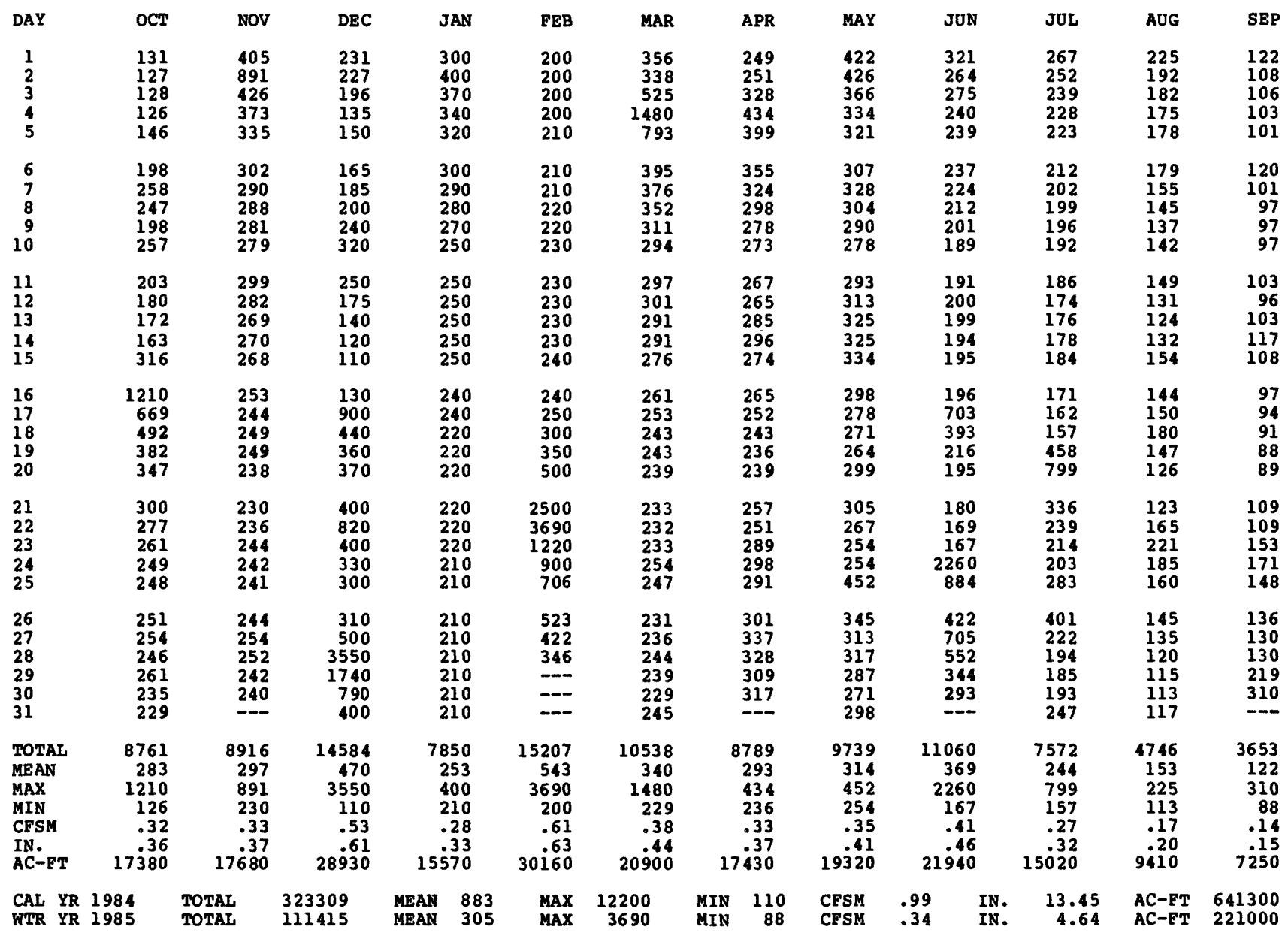


06810000 NISHNABOTNA RIVER ABOVE BAMBURG, IA

(National stream-quality accounting network station)

LOCATION.--Lat $40^{\circ} 37^{\prime} 57^{*}$, long $95^{\circ} 37^{\prime} 32^{\%}$, in SWl/4 SEl/4 sec.11, T.67 N., R.42 W., Fremont County, Bydrologic Unit 10240004 , on left bank $1.7 \mathrm{mi}$ downstream from confluence of East Nishnabotna and West Nishnabotna Rivers, 2 mi northeast of Hamburg, and at mile 13.8 .

DRAINAGE AREA. $--2,806 \mathrm{mi}^{2}$.

\section{WATER-DISCHARGE RECORDS}

PERIOD OF RECORD.--March 1922 to September 1923, October 1928 to current year. Monthly discharge only for some periods published in wSP 1310 .

REVISED RECORDS.-WSP 1240: 1923, 1929-37, 1938-40 (M), 1943 (M). WSP 1440: Drainage area. WDR IA-74-1: 1973.

GAGE.--Water-stage recorder. Datum of gage is $894.17 \mathrm{ft}$ above NGVD. See wsP 1730 for history of changes prior Nov. 16,1950 .

REMARKS.--Estimated daily discharges: Dec. 5-26,Jan. 1 to Feb. 22, April 3-6, Apr. 11 to May 2, May 8-21 and Sept. 13. Records good except those for estimated daily discharges, which are poor. U.S. Army Corps of Engineers rain-gage and gage-height satellite data collection platform at station.

AVERAGE DISChARGE--58 years (water years $1923,1929-85$ ), $1,082 \mathrm{ft}^{2} / \mathrm{s}, 5.24 \mathrm{in} / \mathrm{yr}$, 783,900 acre-ft/yr; median of yearly mean discharges, $940 \mathrm{ft} / \mathrm{s}, 4.6 \mathrm{in} / \mathrm{yr}^{3}, 681,000 \mathrm{acre}-\mathrm{ft} / \mathrm{yr}$.

EXTREMES FOR PERIOD OF RECORD.--Maximum discharge, 55,500 ft3/s June 24, 1947, gage height, 26.03. ft, from floodmark, present site and datum, maximum gage height, $27.46 \mathrm{ft}$ Mar. 7, 1979' (back-water from ice); minimum daily

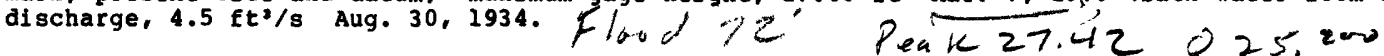

EXTREMES FOR CURRENT YEAR.--Peak discharges greater than base of $9,000 \mathrm{ft} / \mathrm{s}$ and maximum $(*)$ :

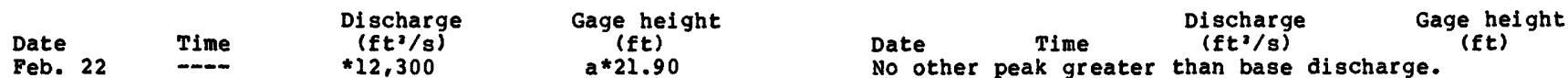

(a) Ice jam

Minimum daily discharge, $258 \mathrm{ft}^{2} / \mathrm{s}$ sept. 12.

DISCHARGE, IN CUBIC FEET PER SECOND, WATER YEAR OCTOBER 1984 TO SEPTEMBER 1985 MEAN VALUES

\begin{tabular}{|c|c|c|c|c|c|c|c|c|c|c|c|c|}
\hline DAY & OCT & NOV & DEC & JAN & FEB & MAR & $A P R$ & MAY & JUN & JUL & AUG & SEP \\
\hline $\begin{array}{l}1 \\
2 \\
3 \\
4 \\
5\end{array}$ & $\begin{array}{l}528 \\
524 \\
519 \\
515 \\
542\end{array}$ & $\begin{array}{l}1090 \\
1310 \\
1430 \\
1130 \\
1050\end{array}$ & $\begin{array}{l}772 \\
748 \\
701 \\
638 \\
590\end{array}$ & $\begin{array}{r}1000 \\
800 \\
800 \\
820 \\
830\end{array}$ & $\begin{array}{l}680 \\
680 \\
680 \\
680 \\
680\end{array}$ & $\begin{array}{l}1310 \\
1290 \\
1270 \\
2130 \\
2390\end{array}$ & $\begin{array}{r}905 \\
905 \\
950 \\
1100 \\
1200\end{array}$ & $\begin{array}{l}1200 \\
1300 \\
1080 \\
1100 \\
1090\end{array}$ & $\begin{array}{r}1290 \\
1000 \\
918 \\
921 \\
893\end{array}$ & $\begin{array}{l}933 \\
889 \\
846 \\
814 \\
778\end{array}$ & $\begin{array}{l}763 \\
705 \\
667 \\
662 \\
620\end{array}$ & $\begin{array}{l}331 \\
328 \\
317 \\
305 \\
297\end{array}$ \\
\hline $\begin{array}{r}6 \\
7 \\
8 \\
9 \\
10\end{array}$ & $\begin{array}{r}716 \\
920 \\
1000 \\
805 \\
864\end{array}$ & $\begin{array}{l}986 \\
935 \\
906 \\
907 \\
906\end{array}$ & $\begin{array}{l}560 \\
540 \\
570 \\
600 \\
630\end{array}$ & $\begin{array}{l}840 \\
830 \\
780 \\
750 \\
720\end{array}$ & $\begin{array}{l}680 \\
680 \\
680 \\
680 \\
680\end{array}$ & $\begin{array}{l}2050 \\
1420 \\
1260 \\
1190 \\
1130\end{array}$ & $\begin{array}{l}1200 \\
1100 \\
1080 \\
1040 \\
1000\end{array}$ & $\begin{array}{r}1090 \\
1080 \\
990 \\
900 \\
900\end{array}$ & $\begin{array}{l}887 \\
871 \\
851 \\
819 \\
791\end{array}$ & $\begin{array}{l}755 \\
728 \\
698 \\
684 \\
666\end{array}$ & $\begin{array}{r}1050 \\
750 \\
580 \\
539 \\
535\end{array}$ & $\begin{array}{l}286 \\
303 \\
362 \\
308 \\
284\end{array}$ \\
\hline $\begin{array}{l}11 \\
12 \\
13 \\
14 \\
15\end{array}$ & $\begin{array}{l}903 \\
749 \\
665 \\
662 \\
904\end{array}$ & $\begin{array}{r}1020 \\
1070 \\
972 \\
936 \\
908\end{array}$ & $\begin{array}{l}600 \\
560 \\
520 \\
500 \\
500\end{array}$ & $\begin{array}{l}730 \\
720 \\
740 \\
770 \\
800\end{array}$ & $\begin{array}{l}680 \\
680 \\
680 \\
680 \\
680\end{array}$ & $\begin{array}{l}1090 \\
1100 \\
1080 \\
1030 \\
1020\end{array}$ & $\begin{array}{l}980 \\
970 \\
960 \\
950 \\
930\end{array}$ & $\begin{array}{r}900 \\
1000 \\
1020 \\
1100 \\
1200\end{array}$ & $\begin{array}{l}789 \\
793 \\
820 \\
812 \\
798\end{array}$ & $\begin{array}{l}647 \\
633 \\
630 \\
625 \\
619\end{array}$ & $\begin{array}{l}533 \\
516 \\
487 \\
472 \\
477\end{array}$ & $\begin{array}{l}268 \\
258 \\
340 \\
361 \\
368\end{array}$ \\
\hline $\begin{array}{l}16 \\
17 \\
18 \\
19 \\
20\end{array}$ & $\begin{array}{l}1770 \\
2230 \\
1860 \\
1510 \\
1280\end{array}$ & $\begin{array}{l}881 \\
853 \\
851 \\
854 \\
836\end{array}$ & $\begin{array}{r}1210 \\
3320 \\
2730 \\
1900 \\
980\end{array}$ & $\begin{array}{l}810 \\
800 \\
790 \\
780 \\
750\end{array}$ & $\begin{array}{l}690 \\
690 \\
700 \\
780 \\
880\end{array}$ & $\begin{array}{l}978 \\
950 \\
931 \\
907 \\
875\end{array}$ & $\begin{array}{l}910 \\
890 \\
865 \\
830 \\
840\end{array}$ & $\begin{array}{r}1200 \\
1180 \\
1050 \\
960 \\
1000\end{array}$ & $\begin{array}{r}988 \\
990 \\
1190 \\
963 \\
790\end{array}$ & $\begin{array}{r}616 \\
584 \\
560 \\
869 \\
1450\end{array}$ & $\begin{array}{l}489 \\
543 \\
605 \\
560 \\
480\end{array}$ & $\begin{array}{l}328 \\
308 \\
292 \\
271 \\
265\end{array}$ \\
\hline $\begin{array}{l}21 \\
22 \\
23 \\
24 \\
25\end{array}$ & $\begin{array}{r}1180 \\
1090 \\
981 \\
914 \\
896\end{array}$ & $\begin{array}{l}817 \\
816 \\
821 \\
840 \\
830\end{array}$ & $\begin{array}{l}1500 \\
2100 \\
1900 \\
1600 \\
1200\end{array}$ & $\begin{array}{l}730 \\
720 \\
720 \\
720 \\
700\end{array}$ & $\begin{array}{l}2500 \\
7000 \\
4030 \\
4100 \\
2600\end{array}$ & $\begin{array}{l}836 \\
825 \\
833 \\
844 \\
855\end{array}$ & $\begin{array}{l}850 \\
850 \\
860 \\
860 \\
880\end{array}$ & $\begin{array}{r}1110 \\
1040 \\
953 \\
928 \\
994\end{array}$ & $\begin{array}{r}736 \\
709 \\
690 \\
879 \\
3070\end{array}$ & $\begin{array}{r}1490 \\
926 \\
743 \\
695 \\
982\end{array}$ & $\begin{array}{l}438 \\
419 \\
598 \\
701 \\
503\end{array}$ & $\begin{array}{l}354 \\
391 \\
731 \\
560 \\
461\end{array}$ \\
\hline $\begin{array}{l}26 \\
27 \\
28 \\
29 \\
30 \\
31\end{array}$ & $\begin{array}{l}913 \\
901 \\
887 \\
849 \\
830 \\
811\end{array}$ & $\begin{array}{l}827 \\
810 \\
798 \\
784 \\
776 \\
-\end{array}$ & $\begin{array}{l}1300 \\
1570 \\
4220 \\
4920 \\
2410 \\
1650\end{array}$ & $\begin{array}{l}700 \\
690 \\
680 \\
680 \\
680 \\
680\end{array}$ & $\begin{array}{r}1880 \\
1570 \\
1410 \\
- \\
- \\
-\end{array}$ & $\begin{array}{l}864 \\
855 \\
855 \\
855 \\
855 \\
875\end{array}$ & $\begin{array}{r}890 \\
1000 \\
1100 \\
1000 \\
980 \\
---\end{array}$ & $\begin{array}{r}1210 \\
1050 \\
1110 \\
1100 \\
971 \\
1100\end{array}$ & $\begin{array}{l}1450 \\
1510 \\
1500 \\
1330 \\
1030 \\
-\end{array}$ & $\begin{array}{r}1030 \\
1000 \\
701 \\
634 \\
651 \\
705\end{array}$ & $\begin{array}{l}542 \\
444 \\
404 \\
377 \\
361 \\
337\end{array}$ & $\begin{array}{l}424 \\
407 \\
381 \\
416 \\
576 \\
-\end{array}$ \\
\hline $\begin{array}{l}\text { TOTAL } \\
\text { MEAN } \\
\text { MAX } \\
\text { MIN } \\
\text { CFSM } \\
\text { IN. } \\
\text { AC-FT }\end{array}$ & $\begin{array}{r}29718 \\
959 \\
2230 \\
515 \\
.34 \\
.39 \\
58950\end{array}$ & $\begin{array}{r}27950 \\
932 \\
1430 \\
776 \\
.33 \\
537 \\
55440\end{array}$ & $\begin{array}{r}43539 \\
1404 \\
4920 \\
500 \\
.50 \\
.58 \\
86360\end{array}$ & $\begin{array}{r}23560 \\
760 \\
1000 \\
680 \\
.27 \\
46731\end{array}$ & $\begin{array}{r}39030 \\
1394 \\
7000 \\
680 \\
.50 \\
.52 \\
77420\end{array}$ & $\begin{array}{r}34753 \\
1121 \\
2390 \\
825 \\
.40 \\
.46 \\
68930\end{array}$ & $\begin{array}{r}28875 \\
963 \\
1200 \\
830 \\
.34 \\
.38 \\
57270\end{array}$ & $\begin{array}{r}32906 \\
1061 \\
1300 \\
900 \\
.38 \\
.44 \\
65270\end{array}$ & $\begin{array}{r}31078 \\
1036 \\
3070 \\
690 \\
.37 \\
.41 \\
61640\end{array}$ & $\begin{array}{r}24581 \\
793 \\
1490 \\
560 \\
.28 \\
.33 \\
48760\end{array}$ & $\begin{array}{r}17157 \\
553 \\
1050 \\
337 \\
.20 \\
3423 \\
34030\end{array}$ & $\begin{array}{r}10881 \\
363 \\
731 \\
258 \\
.13 \\
.14 \\
21580\end{array}$ \\
\hline
\end{tabular}

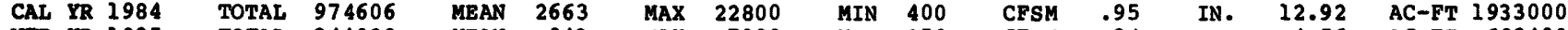
WIR YR 1985 TOTAL 344028 MEAN $943 \quad$ MAX 7000 MIN $258 \quad$ CFSM 
PERIOD OF RECORD.--April 1979 to current year.

PERIOD OF DAILY RECORD.--

SPECIFIC CONDUCTANCE: April 1979 to September 1981.

WATER TEMPERATURES: April 1979 to September 1981.

EXTREMES FOR PERIOD OF DAILY RECORD.--

SPECIFIC CONDUCTANCE: Maximum daily, 815 microsiemens Sept. 16,18, 19, 28,30, 1979, minimum daily, 155 micro-

siemens, July 20, 1981 .

WATER TEMPERATURES: Maximum daily, $32.0^{\circ} \mathrm{C}$ July 14,1980 ; minimum daily $0.0^{\circ} \mathrm{C}$, on many days during winter period.

WATER QUALITY DATA, WATER YEAR OCTOBER 1984 TO SEPTEMBER 1985

DATE TIME $\begin{gathered}\text { STREAM- } \\ \text { FLOW, } \\ \text { INSTAN- } \\ \text { TANEOUS } \\ (\text { CFS) } \\ (00061)\end{gathered}$

SPE-

CIFIC

CON- PH

DUCT- (STAND- TEMPER- TUR- OXYGEN,

ARD ATURE

$\begin{array}{lll}(\text { US/CM } & \text { UNITS) } & \text { (DEG C) } \\ (00095) & (00400) & (00010)\end{array}$
OXYGEN,

SOLVED METRI

(RER- SURE

CENT

SATUR-

ATION)

$(00301)$

(00025)

$\begin{array}{rrr}8.2 & 9.0 & 66 \\ 8.3 & 0.0 & 24 \\ 7.6 & 23.0 & 240 \\ 8.7 & 24.5 & 35\end{array}$

542

8.7

MAGNE-

SIUM, SODIUM,

DIS- DIS-

SOLVED SOLVED

(MG/L (MG/L

AS NG) AS NA

PERCENT
SODIUM
(00932)

\section{SODIUM}

AD-
SORP-
TION

RATIO

AS (MG/L

(00900) (00915)

Nov 1984

FEB 1985
$19 . \ldots$
MAY
$08 \ldots$
AUG
$23 \ldots$

SOLIDS, SOLIDS,

RESIDUE SUM OF

AT 180 CONSTI-

DEG. C TUENTS,

DIS- DIS-

SOLVED SOLVED

(MG/L) (MG/L)

(70300) (70301)

$\begin{array}{ll}22 & 11 \\ 21 & 12 \\ 22 & 10 \\ 24 & 14\end{array}$

(00931)

(00932)

DATE

$\begin{array}{ccc}\text { SOLIDS, } & \text { SOLIDS, } & \text { NITRO- } \\ \text { GEN, } \\ \text { DIS- } & \text { DIS- } & \text { NO2+NO3 } \\ \text { SOLVED } & \text { SOLVED } & \text { DIS- } \\ \text { (TONS } & \text { (TONS } & \text { SOLVED } \\ \text { PER } & \text { PER } & \text { (MG/L } \\ \text { AC-FT) } & \text { DAY) } & \text { AS N) }\end{array}$

NITRO-

GEN,

AMYON IA

DIS-

(MG/L

AS N)

(00608)

\begin{tabular}{|c|c|}
\hline 10.6 & 97 \\
\hline 10.5 & 75 \\
\hline 8.0 & 96 \\
\hline 10.8 & 134 \\
\hline $\begin{array}{l}\text { OTAS- } \\
\text { SIUM, } \\
\text { DIS- } \\
\text { OLVED } \\
\text { (MG/L } \\
\text { AS R) } \\
\text { (0935) }\end{array}$ & $\begin{array}{c}\text { ALKA- } \\
\text { LINITY } \\
\text { FIELD } \\
\text { (MG/L } \\
\text { AS } \\
\text { CACO3) } \\
(00410)\end{array}$ \\
\hline
\end{tabular}

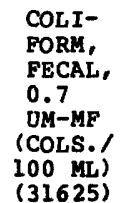

STREP-

TOCOCCI

FECAL,

(COLS. BONATE

PER (MG/L

$\begin{array}{ll}100 \mathrm{ML}) & \mathrm{CACO} 3) \\ (31673) & (00902)\end{array}$

$(00410)$

725
734
740
738

$\begin{array}{rrr}5400 & 1000 & 53 \\ 2500 & 3700 & 40 \\ 5600 & 3100 & 46 \\ 400 & 310 & 39\end{array}$

CHLO- FLUO- SILICA,

RIDE, RIDE, DIS-

DIS- DIS- SOLVED

DIS- DIS- DIS- SOLVED

SOLVED SOLVED SOLVED (MG/L

(MG/L (MG/L

(MG/L AS

$\begin{array}{cccc}\text { AS SO4) } & \text { AS CL) } & \text { AS F) } & \begin{array}{c}\text { SIO2) } \\ (00945)\end{array} \\ (00940) & (00950) & (00955)\end{array}$

$\begin{array}{lllll}0.3 & 3.3 & 220 & 36 & 15 \\ 0.3 & 3.0 & 217 & -- & - \\ 0.3 & 3.2 & 230 & 37 & 13 \\ 0.4 & 3.3 & 253 & 43 & 15\end{array}$

$\begin{array}{ll}0.4 & 17 \\ 0.3 & 16 \\ 0.5 & 14 \\ 0.4 & 11\end{array}$

Nov 1984

$14 . \ldots$

$\begin{array}{rr}328 & 310 \\ - & - \\ 360 & 310 \\ 334 & 340\end{array}$

$$
\begin{array}{rr}
0.45 & 870 \\
- & -- \\
0.49 & 1210 \\
0.45 & 490
\end{array}
$$

5.80

5.20

6.00

2.00

NITRO- NITRO- PHOS-

GEN, GEN, AM- PHORUS,

AMLONIA MONIA + ORTHO

DIS- ORGANIC

SOLVED TOTAL

(MG/L

AS NH4)

(71846)

(MG/L

DIS-

SOLVED

(MG/L
AS P)

$\begin{array}{ll}(00625) & (00671)\end{array}$

PHOS-
PHORUS
TOTAL
(MG/L
AS PO4)
(71886)

PHOS-

PHORUS,

DIS- $\quad$ PHOS-

DHORUS,

(MG/L TOTAL

AS P) (006)

$\begin{array}{ll}(00666) \quad(00665) & \end{array}$

0.04
0.36
0.11
0.02

0.05

1.5

0.14

$-$

0.15

0.15

0.42

0.46

1.1

0.24

$-$

0.19

0.29

0.14

1.1

0.03

0.03

1.3

0.33

0.62

0.41 
06810000 NISBNABOTNA RIVER ABOVE BAMBURG, IA--Continued

WATER-QUALITY RECORDS

WATER QUALITY DATA, WATER YEAR OCTOBER 1984 TO SEPTEMBER 1985

\begin{tabular}{|c|c|c|c|c|c|c|c|c|c|c|c|c|}
\hline DATE & $\begin{array}{l}\text { SEDI- } \\
\text { MENT, } \\
\text { SUS- } \\
\text { PENDED }\end{array}$ & $\begin{array}{c}\text { SEDI- } \\
\text { MENT, } \\
\text { DIS- } \\
\text { CHARGE, } \\
\text { SUS- } \\
\text { PENDED }\end{array}$ & $\begin{array}{l}\text { SED. } \\
\text { SUSP. } \\
\text { SIEVE } \\
\text { DIAM. } \\
\text { FINER } \\
\text { THAN }\end{array}$ & $\begin{array}{c}\text { ARSEN IC } \\
\text { DIS- } \\
\text { SOLVED } \\
\text { (UG/L }\end{array}$ & $\begin{array}{l}\text { ALUM- } \\
\text { INUM, } \\
\text { DIS- } \\
\text { SOLVED } \\
\text { (UG/L }\end{array}$ & $\begin{array}{l}\text { BARIUM, } \\
\text { DIS- } \\
\text { SOLVED } \\
\text { (UG/L }\end{array}$ & $\begin{array}{l}\text { BERYL- } \\
\text { LIUM, } \\
\text { DIS- } \\
\text { SOLVED } \\
\text { (UG/L }\end{array}$ & $\begin{array}{c}\text { CADMIUM } \\
\text { DIS- } \\
\text { SOLVED } \\
\text { (UG/L }\end{array}$ & $\begin{array}{l}\text { CHRO- } \\
\text { MIUM, } \\
\text { DIS- } \\
\text { SOLVED } \\
\text { (UG/L }\end{array}$ & $\begin{array}{l}\text { COBALT, } \\
\text { DIS- } \\
\text { SOLVED } \\
\text { (UG/L }\end{array}$ & $\begin{array}{l}\text { COPPER, } \\
\text { DIS- } \\
\text { SOLVED } \\
\text { (UG/L }\end{array}$ & $\begin{array}{l}\text { IRON, } \\
\text { DIS- } \\
\text { SOLVED } \\
\text { (UG/L }\end{array}$ \\
\hline & $\begin{array}{r}(\mathrm{MG} / L) \\
(80154)\end{array}$ & $\begin{array}{l}(\mathrm{T} / \mathrm{DAY}) \\
(80155)\end{array}$ & $.062 \mathrm{MM}$ & $\begin{array}{c}\text { AS AS }) \\
(01000)\end{array}$ & $\begin{array}{c}\text { As AL) } \\
(01106)\end{array}$ & $\begin{array}{c}\text { AS BA) } \\
(01005)\end{array}$ & $\begin{array}{l}\text { AS BE) } \\
(01010)\end{array}$ & $\begin{array}{c}\text { AS CD }) \\
(01025)\end{array}$ & $\begin{array}{r}\text { AS CR }) \\
(01030)\end{array}$ & $\begin{array}{r}\text { As CO) } \\
(01035)\end{array}$ & $\begin{array}{l}\text { AS CU) } \\
(01040)\end{array}$ & $\begin{array}{c}\text { AS FE) } \\
(01046)\end{array}$ \\
\hline
\end{tabular}

NOV 1984

$\begin{array}{crr}\begin{array}{c}1984 \\ 14 . \ldots\end{array} & 255 & 676 \\ 1985 & & \\ \text { MAY } \ldots & 105 & 219 \\ 08 \ldots & 963 & 3220 \\ \text { AUG } & & \\ 23 \ldots & 170 & 249\end{array}$

$\begin{array}{rrrrcrr}95 & 2 & 10 & 130 & 2 & <1 & <1 \\ 99 & <1 & 30 & 170 & 0.6 & - & - \\ 99 & 3 & 90 & 140 & 2 & 2 & 2 \\ 97 & 4 & 10 & 190 & <0.5 & <1 & <1\end{array}$

$\begin{array}{rrr}<3 & 3 & 11 \\ <3 & 5 & 12 \\ <3 & 7 & 470 \\ <3 & 4 & 5\end{array}$

$\begin{array}{ccc} & & \\ & \text { LEAD, } & \text { LITHIUM } \\ \text { DIS- } & \text { DIS- } \\ \text { SOLVED } & \text { SOLVED } \\ \text { DATE } & \text { (UG/L } & \text { (UG/L } \\ \text { AS PB) } & \text { AS LI) } \\ (01049) & (01130)\end{array}$

$\begin{array}{lc}\text { MANGA- } & \\ \text { NESE, } & \text { MERCURY } \\ \text { DIS- } & \text { DIS- } \\ \text { SOLVED } & \text { SOLVED } \\ \text { (UG/L } & \text { (UG/L } \\ \text { AS MN) } & \text { AS BG) } \\ \text { (0I056) } & (71890)\end{array}$

MOLYB-
DENUM,
DIS-
SOLVED
(UG/L
AS MO)
$(01060)$

NICKEL,
DIS-
SOLVED
(UG/L
AS NI)
(01065)

$\begin{array}{ccccc}\text { SELE- } & & \text { STRON- } & \text { VANA- } & \\ \text { NIUM, } & \text { SILVER, } & \text { TIUM, } & \text { DIUM, } & \text { ZINC, } \\ \text { DIS- } & \text { DIS- } & \text { DIS- } & \text { DIS- } & \text { DIS- } \\ \text { SOLVED } & \text { SOLVED } & \text { SOLVED } & \text { SOLVED } & \text { SOLVED } \\ \text { (UG/L } & (U G / L & \text { (UG/L } & \text { (UG/L } & (\text { UG/L } \\ \text { AS SE) } & \text { AS AG) } & \text { AS SR) } & \text { AS V) } & \text { AS ZN) } \\ (01145) & (01075) & (01080) & (01085) & (01090)\end{array}$

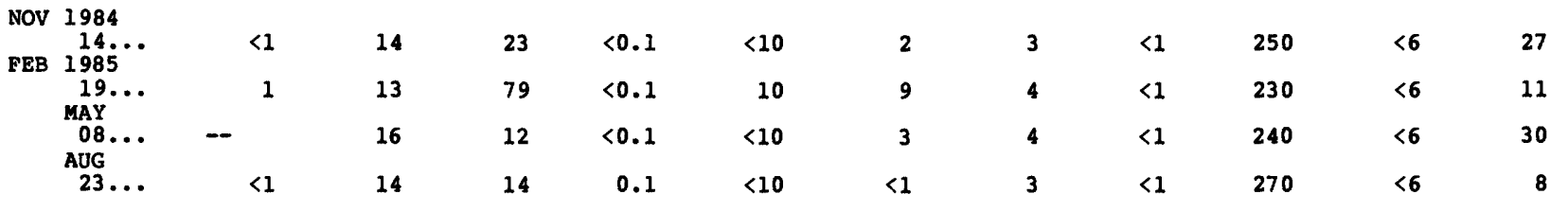

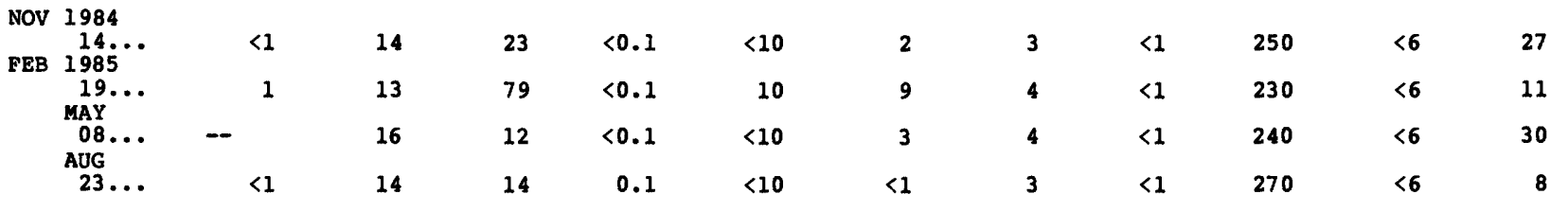

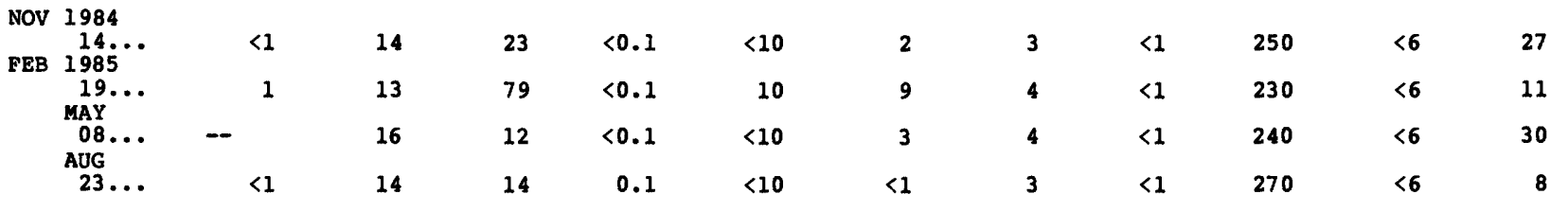

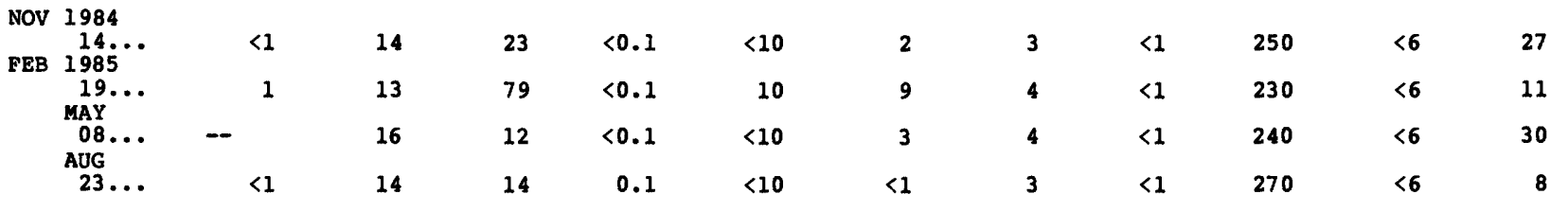

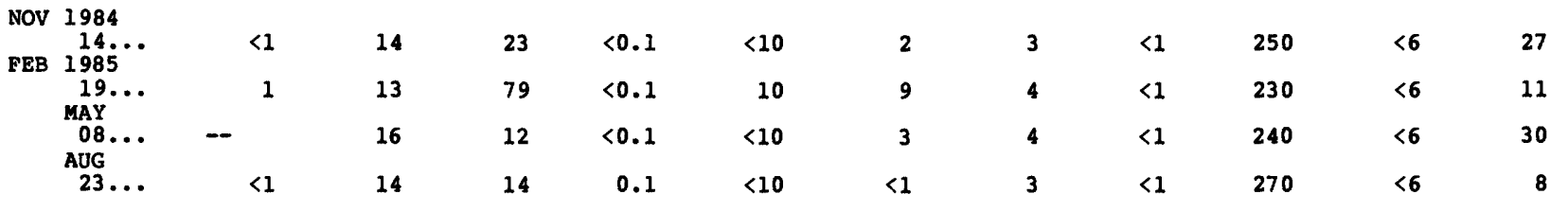

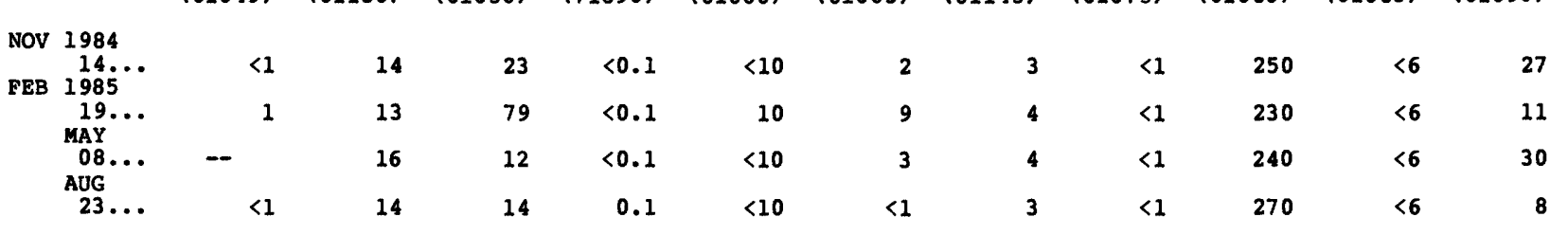

1080)

$(01085) \quad(01090)$ 


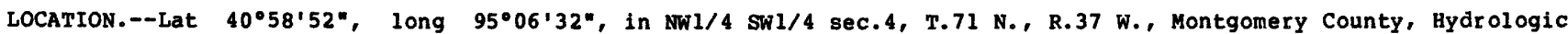
Unit 10240005, on right bank $10 \mathrm{ft}$ downstream from bridge on county highway $\mathrm{H} 42$, 0.1 mi downstream from Little

Tarkio Creek, and $0.5 \mathrm{mi}$ west of stanton.

DRAINAGE AREA. $--49.3 \mathrm{mi}^{2}$.

PERIOD OF RECORD.--October 1957 to current year. Annual maximum, water years $1952-57$.

REVISED RECORDS.--WSP 1919: 1960 (M).

GAGE.-Water-stage recorder and concrete control. Datum of gage is $1,104.67 \mathrm{ft}$ above NGVD.

REMARKs.--Estimated daily discharges: Dec. 4-14, 19-26, Dec. 29 to Feb. 22. and July 16-18. Records fair except those for estimated discharges, which are poor.

AVERAGE DISCHARGE.--28 years, $28.2 \mathrm{ft}^{3} / \mathrm{s}, 7.77 \mathrm{in} / \mathrm{yr}, 20,430$ acre-ft/yr; median of yearly mean discharge, 25 $\mathrm{ft}^{3} / \mathrm{s}, 6.9 \mathrm{in} / \mathrm{yr}, 18,100$ acre-ft/yr.

EXTREMES FOR PERIOD OF RECORD.--Maximum discharge, 22,500 ft3/s June 9, 1967, gage height, $28.56 \mathrm{ft}$, from rating curve extended above $1,600 \mathrm{ft}^{3 / \mathrm{s}}$ on basis of siope-area measurement of peak flow; no flow at times most years. EXTREMES FOR CURRENT YEAR.--Peak discharges greater than base of $1,500 \mathrm{ft} / \mathrm{s}$, and maximum (*):

\begin{tabular}{|c|c|c|c|c|c|c|}
\hline $\begin{array}{l}\text { Jate } \\
\text { lar. } 3\end{array}$ & $\begin{array}{l}\text { Time } \\
1400\end{array}$ & $\begin{array}{c}\text { Discharge } \\
\left(f t^{3} / \mathrm{s}\right) \\
* 765\end{array}$ & $\begin{array}{c}\text { Gage height } \\
\text { (ft) } \\
* 11.82\end{array}$ & Date & Time & $\begin{array}{l}\text { Gage height } \\
(f t)\end{array}$ \\
\hline
\end{tabular}

Minimum daily discharge, no flow oct. 1, 2, July 3-18, 22, 23, 28, 29, Aug. 3 and sept. 7, 10 .

DISCHARGE, IN CUBIC FEET PER SECOND, WATER YEAR OCTOBER 1984 TO SEPTEMBER 1985 MEAN VALUES

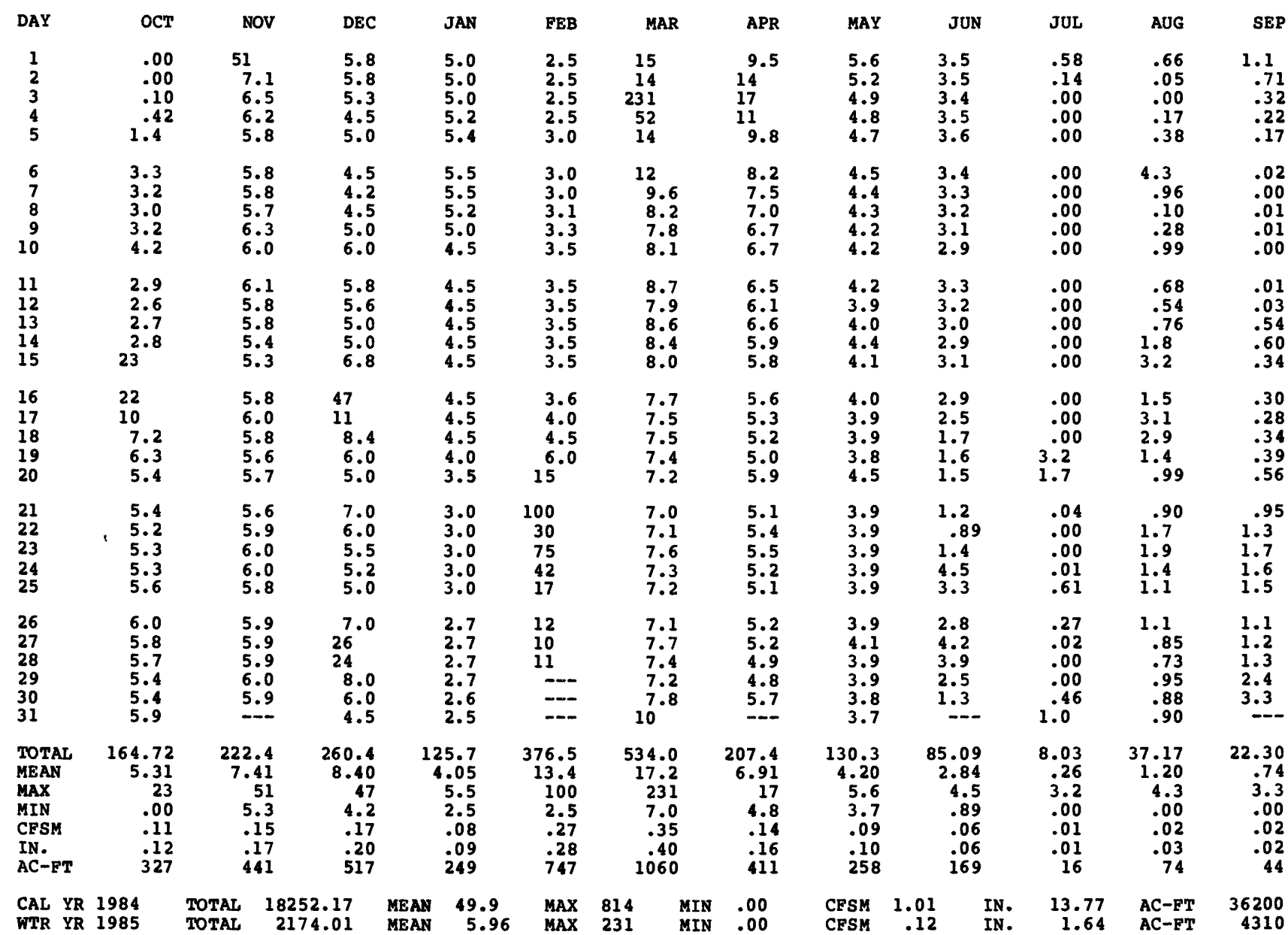


LOCATION.--Lat $40^{\circ} 03^{\prime} 13^{\circ}$, long $95^{\circ} 25^{\prime} 19^{\prime \prime}$, in Nw1/4 Nw1/4 sec.17, T.I N., R.18 E., Richardson County, Hydrologic Unit 10240005, on right bank at downstream side of bridge on U.s. Highway 159 at Rulo, 3.2 mi upstream from Big Nemaha River, and at mile 498.0 .

DRAINAGE AREA. $-414,900 \mathrm{mi}^{2}$, approximately. The $3,959 \mathrm{mi}^{2}$ in Great Divide basin are not included.

PERIOD OF RECORD,--October 1949 to current year in reports of Geological survey. Gage-height record collected at site 80 ft upstream January 1886 to December 1899 published in reports of Missouri River Commission September 1929 to September 1950 in files of Kansas City office of O.S. Army Corps of Engineers.

GAGE.--Water-stage recorder. Datum of gage is $837.23 \mathrm{ft}$ above NGVD. Oct. 1949 to Sept. 12 , 1950 , nonrecording gage at 81 te $80 \mathrm{ft}$ upstream and sept. 13, 1950 to Apr. 19, 1983, recording gage on downstream end of middle pier, all at same datum.

REMARKS.--Estimated daily discharges: Dec. 26 to Jan. 31. Records good except those for estimated daily discharges, which are poor. Flow regulated by upstream main-stem reservoirs. National Weather Service gageheight telemeter at station. U.s. Army Corps of Engineers gage-height satellite data collection platform at station.

AVERAGE DISCBARGE. --36 years, $41,100 \mathrm{ft} / 8,29,780,000$ acre-ft/yr.

EXTREMES FOR PERIOD OF RECORD. --Haximum discharge, 358,000 ft'/s Apr. 22, 1952, gage height, 25.60 ft; minimum daily, 4,420 ft'/s Jan. 13, 1957; minimum gage height, $0.65 \mathrm{ft} \mathrm{Jan.} \mathrm{7,} \mathrm{1971,} \mathrm{result} \mathrm{of} \mathrm{freezeup.}$

EXTREMES OUTSIDE PERIOD OF RECORD.--Flood in 1881 reached a stage of $22.9 \mathrm{ft}$, from floodmark, discharge not determined.

EXTREMES FOR CURRENT YEAR.--Maximum discharge, $88,800 \mathrm{ft} / \mathrm{s}$ April 25, gage height, $16.76 \mathrm{ft}$; minimum daily, $24,500 \mathrm{ft} / \mathrm{s}$ Jan. 23; minimum gage height not determined, occurred during period of no gage-height record Jan. 23,24 .

DISCHARGE, IN CUBIC FEET PER SECOND, WATER YEAR OCTOBER 1984 TO SEPTEMBER 1985 MEAN VALUES

\begin{tabular}{|c|c|c|c|c|c|c|c|c|c|c|c|c|}
\hline DAY & OCT & NOV & DEC & JAN & FEB & MAR & APR & MAY & JUN & JUL & AUG & SEP \\
\hline $\begin{array}{l}1 \\
2 \\
3 \\
4 \\
5\end{array}$ & $\begin{array}{l}53900 \\
53300 \\
53800 \\
53600 \\
52800\end{array}$ & $\begin{array}{l}66200 \\
65600 \\
64600 \\
63900 \\
62600\end{array}$ & $\begin{array}{l}64000 \\
63700 \\
63200 \\
59800 \\
55200\end{array}$ & $\begin{array}{l}36000 \\
32000 \\
29000 \\
31500 \\
31000\end{array}$ & $\begin{array}{l}32000 \\
31600 \\
30100 \\
29700 \\
30400\end{array}$ & $\begin{array}{l}44800 \\
50500 \\
51700 \\
49100 \\
55200\end{array}$ & $\begin{array}{r}47000 \\
46500 \\
46300 \\
46600 \\
47200\end{array}$ & $\begin{array}{l}59800 \\
58800 \\
62000 \\
61000 \\
55500\end{array}$ & $\begin{array}{l}50800 \\
50200 \\
50300 \\
50800 \\
51000\end{array}$ & $\begin{array}{l}48900 \\
46400 \\
45100 \\
44400 \\
43100\end{array}$ & $\begin{array}{l}38200 \\
38000 \\
39100 \\
42300 \\
41200\end{array}$ & $\begin{array}{l}44600 \\
39800 \\
37700 \\
38800 \\
38800\end{array}$ \\
\hline $\begin{array}{r}6 \\
7 \\
8 \\
9 \\
10\end{array}$ & $\begin{array}{l}53700 \\
55300 \\
55600 \\
57500 \\
58000\end{array}$ & $\begin{array}{l}61600 \\
61400 \\
61700 \\
61300 \\
62600\end{array}$ & $\begin{array}{l}49700 \\
46500 \\
44200 \\
42600 \\
41300\end{array}$ & $\begin{array}{l}32500 \\
33500 \\
34000 \\
34500 \\
35000\end{array}$ & $\begin{array}{l}30100 \\
29600 \\
29300 \\
29200 \\
29100\end{array}$ & $\begin{array}{l}59000 \\
45400 \\
43100 \\
42000 \\
40700\end{array}$ & $\begin{array}{l}48400 \\
49000 \\
48900 \\
48900 \\
48700\end{array}$ & $\begin{array}{l}52600 \\
52000 \\
49400 \\
47900 \\
48100\end{array}$ & $\begin{array}{l}49700 \\
48000 \\
46300 \\
47400 \\
47900\end{array}$ & $\begin{array}{l}41600 \\
40300 \\
39400 \\
38400 \\
38100\end{array}$ & $\begin{array}{l}43700 \\
43100 \\
40900 \\
40200 \\
42200\end{array}$ & $\begin{array}{l}39100 \\
39400 \\
39100 \\
40400 \\
41200\end{array}$ \\
\hline $\begin{array}{l}11 \\
12 \\
13 \\
14 \\
15\end{array}$ & $\begin{array}{l}58900 \\
57700 \\
57700 \\
56600 \\
57000\end{array}$ & $\begin{array}{l}64800 \\
65400 \\
64900 \\
63600 \\
62700\end{array}$ & $\begin{array}{l}40600 \\
41300 \\
42300 \\
41200 \\
38400\end{array}$ & $\begin{array}{l}33000 \\
31000 \\
28500 \\
28000 \\
28600\end{array}$ & $\begin{array}{l}29400 \\
29500 \\
29500 \\
29100 \\
29900\end{array}$ & $\begin{array}{l}42800 \\
43900 \\
44700 \\
45900 \\
47100\end{array}$ & $\begin{array}{r}47400 \\
45700 \\
46900 \\
46100 \\
45500\end{array}$ & $\begin{array}{l}47500 \\
48800 \\
49900 \\
53600 \\
61300\end{array}$ & $\begin{array}{l}47000 \\
46300 \\
46500 \\
45000 \\
44200\end{array}$ & $\begin{array}{l}37700 \\
37600 \\
37700 \\
37900 \\
38100\end{array}$ & $\begin{array}{l}42300 \\
40400 \\
39400 \\
40800 \\
44300\end{array}$ & $\begin{array}{l}40700 \\
39400 \\
40500 \\
47900 \\
46700\end{array}$ \\
\hline $\begin{array}{l}16 \\
17\end{array}$ & $\begin{array}{l}60700 \\
64300\end{array}$ & $\begin{array}{l}63900 \\
64500\end{array}$ & $\begin{array}{l}41400 \\
61400\end{array}$ & $\begin{array}{l}29700 \\
28500\end{array}$ & $\begin{array}{l}30200 \\
30500\end{array}$ & $\begin{array}{l}47000 \\
47400\end{array}$ & $\begin{array}{l}44600 \\
43700\end{array}$ & $\begin{array}{l}77700 \\
76200\end{array}$ & $\begin{array}{l}43900 \\
48900\end{array}$ & $\begin{array}{l}37500 \\
37300\end{array}$ & $\begin{array}{l}40900 \\
39400\end{array}$ & $\begin{array}{l}52200 \\
45100\end{array}$ \\
\hline $\begin{array}{l}18 \\
19 \\
20\end{array}$ & $\begin{array}{l}65200 \\
64900 \\
65400\end{array}$ & $\begin{array}{l}64100 \\
62700 \\
61800\end{array}$ & $\begin{array}{l}54400 \\
45600 \\
43000\end{array}$ & $\begin{array}{l}29200 \\
30800 \\
30500\end{array}$ & $\begin{array}{l}30900 \\
32100 \\
33400\end{array}$ & $\begin{array}{l}48300 \\
47700 \\
48400\end{array}$ & $\begin{array}{r}43000 \\
42900 \\
44000\end{array}$ & $\begin{array}{l}65300 \\
61200 \\
60700\end{array}$ & $\begin{array}{l}46500 \\
45100 \\
43700\end{array}$ & $\begin{array}{l}37200 \\
39300 \\
61300\end{array}$ & $\begin{array}{r}41500 \\
42300 \\
42100\end{array}$ & $\begin{array}{l}43800 \\
44000 \\
43000\end{array}$ \\
\hline $\begin{array}{l}21 \\
22 \\
23 \\
24 \\
25\end{array}$ & $\begin{array}{l}67000 \\
65700 \\
66000 \\
65400 \\
64400\end{array}$ & $\begin{array}{l}61700 \\
61700 \\
62000 \\
61200 \\
61100\end{array}$ & $\begin{array}{l}41700 \\
41800 \\
41000 \\
38400 \\
36400\end{array}$ & $\begin{array}{l}28500 \\
26000 \\
24500 \\
29000 \\
31500\end{array}$ & $\begin{array}{l}36500 \\
52700 \\
47300 \\
44000 \\
40900\end{array}$ & $\begin{array}{l}48000 \\
47900 \\
48000 \\
47600 \\
46800\end{array}$ & $\begin{array}{l}44200 \\
44900 \\
50600 \\
66800 \\
85600\end{array}$ & $\begin{array}{l}63000 \\
61400 \\
56500 \\
54600 \\
52000\end{array}$ & $\begin{array}{l}42800 \\
42400 \\
42100 \\
45100 \\
50400\end{array}$ & $\begin{array}{l}51900 \\
46400 \\
43000 \\
41000 \\
42500\end{array}$ & $\begin{array}{l}39700 \\
39100 \\
39100 \\
40000 \\
40100\end{array}$ & $\begin{array}{l}42500 \\
43800 \\
45200 \\
45300 \\
42900\end{array}$ \\
\hline $\begin{array}{l}26 \\
27 \\
28 \\
29 \\
30 \\
31\end{array}$ & $\begin{array}{l}65300 \\
64600 \\
64700 \\
65200 \\
65000 \\
65000\end{array}$ & $\begin{array}{r}61900 \\
61700 \\
63100 \\
64100 \\
64400 \\
-\end{array}$ & $\begin{array}{l}34700 \\
33000 \\
43000 \\
52000 \\
46000 \\
41000\end{array}$ & $\begin{array}{l}34900 \\
35200 \\
33000 \\
31500 \\
32500 \\
33000\end{array}$ & $\begin{array}{r}41300 \\
42000 \\
42700 \\
-- \\
--\end{array}$ & $\begin{array}{l}46400 \\
46800 \\
47700 \\
47200 \\
47000 \\
46700\end{array}$ & $\begin{array}{c}75700 \\
67100 \\
76100 \\
77900 \\
65300 \\
-\end{array}$ & $\begin{array}{l}\mathbf{5 1 5 0 0} \\
\mathbf{5 2 7 0 0} \\
\mathbf{5 2 3 0 0} \\
\mathbf{5 0 4 0 0} \\
\mathbf{5 0 4 0 0} \\
\mathbf{5 0 5 0 0}\end{array}$ & $\begin{array}{r}45700 \\
45600 \\
46900 \\
52300 \\
53300 \\
--\end{array}$ & $\begin{array}{l}41600 \\
39700 \\
38300 \\
37000 \\
37500 \\
38600\end{array}$ & $\begin{array}{l}39000 \\
38500 \\
38700 \\
38000 \\
37600 \\
39400\end{array}$ & $\begin{array}{r}42000 \\
41900 \\
41200 \\
42300 \\
48100 \\
-\end{array}$ \\
\hline $\begin{array}{l}\text { TOTAL } \\
\text { MEAN } \\
\text { MAX } \\
\text { MIN } \\
\text { AC-ET }\end{array}$ & $\begin{array}{r}1874200 \\
60460 \\
67000 \\
52800 \\
3717000\end{array}$ & $\begin{array}{r}1892800 \\
63090 \\
66200 \\
61100 \\
3754000\end{array}$ & $\begin{array}{r}1428800 \\
46090 \\
64000 \\
33000 \\
2834000\end{array}$ & $\begin{array}{r}966400 \\
31170 \\
36000 \\
24500 \\
1917000\end{array}$ & $\begin{array}{r}953000 \\
34040 \\
52700 \\
29100 \\
1890000\end{array}$ & $\begin{array}{r}1464800 \\
47250 \\
59000 \\
40700 \\
2905000\end{array}$ & $\begin{array}{r}1581500 \\
52720 \\
85600 \\
42900 \\
3137000\end{array}$ & $\begin{array}{r}1744600 \\
56280 \\
77700 \\
47500 \\
3460000\end{array}$ & $\begin{array}{r}1416100 \\
47200 \\
53300 \\
42100 \\
2809000\end{array}$ & $\begin{array}{r}1284800 \\
41450 \\
61300 \\
37000 \\
2548000\end{array}$ & $\begin{array}{r}1251500 \\
40370 \\
44300 \\
37600 \\
2482000\end{array}$ & $\begin{array}{r}1277400 \\
42580 \\
52200 \\
37700 \\
2534000\end{array}$ \\
\hline $\begin{array}{ll}\text { CAL } & \text { YR } \\
\text { WTR } & \text { IR }\end{array}$ & $\begin{array}{l}1984 \\
1985\end{array}$ & $\begin{array}{l}\text { TOTAL } \\
\text { TOTAL }\end{array}$ & $\begin{array}{l}25226900 \\
17135900\end{array}$ & $\begin{array}{l}\text { MEAN } \\
\text { MEAN }\end{array}$ & $\begin{array}{l}68930 \\
46950\end{array}$ & $\begin{array}{l}\text { MAX } \\
\text { MAX }\end{array}$ & $\begin{array}{r}216000 \\
85600\end{array}$ & $\begin{array}{l}\text { MIN } \\
\text { MIN }\end{array}$ & $\begin{array}{l}29800 \\
24500\end{array}$ & 3 & $\begin{array}{l}00 \\
00\end{array}$ & \\
\hline
\end{tabular}


LOCATION.--Lat $40^{\circ} 44^{\prime} 19^{\prime \prime}$, long $95^{\circ} 00^{\prime} 47^{\prime \prime}$, in SWl/4 NEl/4 sec.32, T.69 N., R.36 W., Page County, Hydrologic Unit 10240009 , near left abutment on downstream side of bridge on state Highway 2 (city route), 0.5 mi downstream from North Branch, $1.2 \mathrm{mi}$ east of city square of Clarinda, and $7.5 \mathrm{mi}$ upstream from East Nodaway River.

DRAINAGE AREA. $--762 \mathrm{mi}^{2}$.

WATER DISCHARGE RECORDS

PERIOD OF RECORD,--May 1918 to July 1925, May 1936 to current year. Monthly discharge only for some periods, published in WSP 1310 .

REV ISED RECORDS.--WSP 1240: 1918-20 (M), 1921, 1922-25 (M), 1936-38, 1942, 1943-45 (M), 1948. WSP 1440: Drainage area. WSP 1710: 1958, 1959 (P).

GAGE.- Water-stage recorder. Datum of gage is $960.36 \mathrm{ft}$ above NVGD. Prior to July 5, 1925 , and May 28 , 1936 , to Mar. 26, 1957 nonrecording gage at same site and datum.

REMARKS.--Estimated daily discharges: Dec. 5-15, 18-26, and Jan. 1 to Feb. 21. Records good except those for winter period, which are poor. Clarinda municipal water supply is taken from Nodaway River, 500 ft above station. Average daily pumpage was $1.40 \mathrm{ft}^{3} / \mathrm{s}$. U.S. National Weather Service gage-height telemeter at station.

COOPERATION.--Average pumpage furnished by City of Clarinda water works.

AVERAGE DISCHARGE.--55 years (1918-24, 1936-85), $342 \mathrm{ft} / \mathrm{s}, 6.09$ in/yr, 247,800 acre-ft/yr; median of yearly mean discharges, $260 \mathrm{ft}^{3}, 4.6 \mathrm{in} / \mathrm{yr}, 188,000$ acre-ft/yr.

EXTREMES FOR PERIOD OF RECORD.--Maximum discharge, $31,100 \mathrm{ft}^{3} / \mathrm{s}$ June 13,1947 , gage-height, $25.3 \mathrm{ft}$, from floodmark, from rating curve extended above $15,000 \mathrm{ft} / \mathrm{s}$ on basis of an overflow profile and extended channel rating; minimum daily, $1.0 \mathrm{ft} / \mathrm{s}$ Sept. 5, 9, 12, 1918, Dec. 9 27-31 1923. 27-31, 1923.

EXTREMES OUTSIDE PERIOD OF RECORD.--Flood in August 1903 reached a stage of $25.4 \mathrm{ft}$, from floodmarks, discharge not determined.

EXTREMES FOR CURRENT YEAR.--Peak discharges greater than base of 5,000 $\mathrm{ft}^{3} / \mathrm{s}$ and maximum (*):

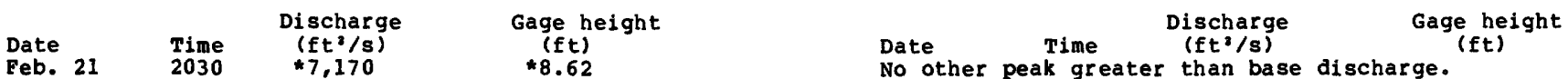

Minimum discharge, $16 \mathrm{ft}^{3} / \mathrm{s}$ July 19.

DISCHARGE, IN CUBIC FEET PER SECOND, WATER YEAR OCTOBER 1984 TO SEPTEMBER 1985*; MEAN VALUES

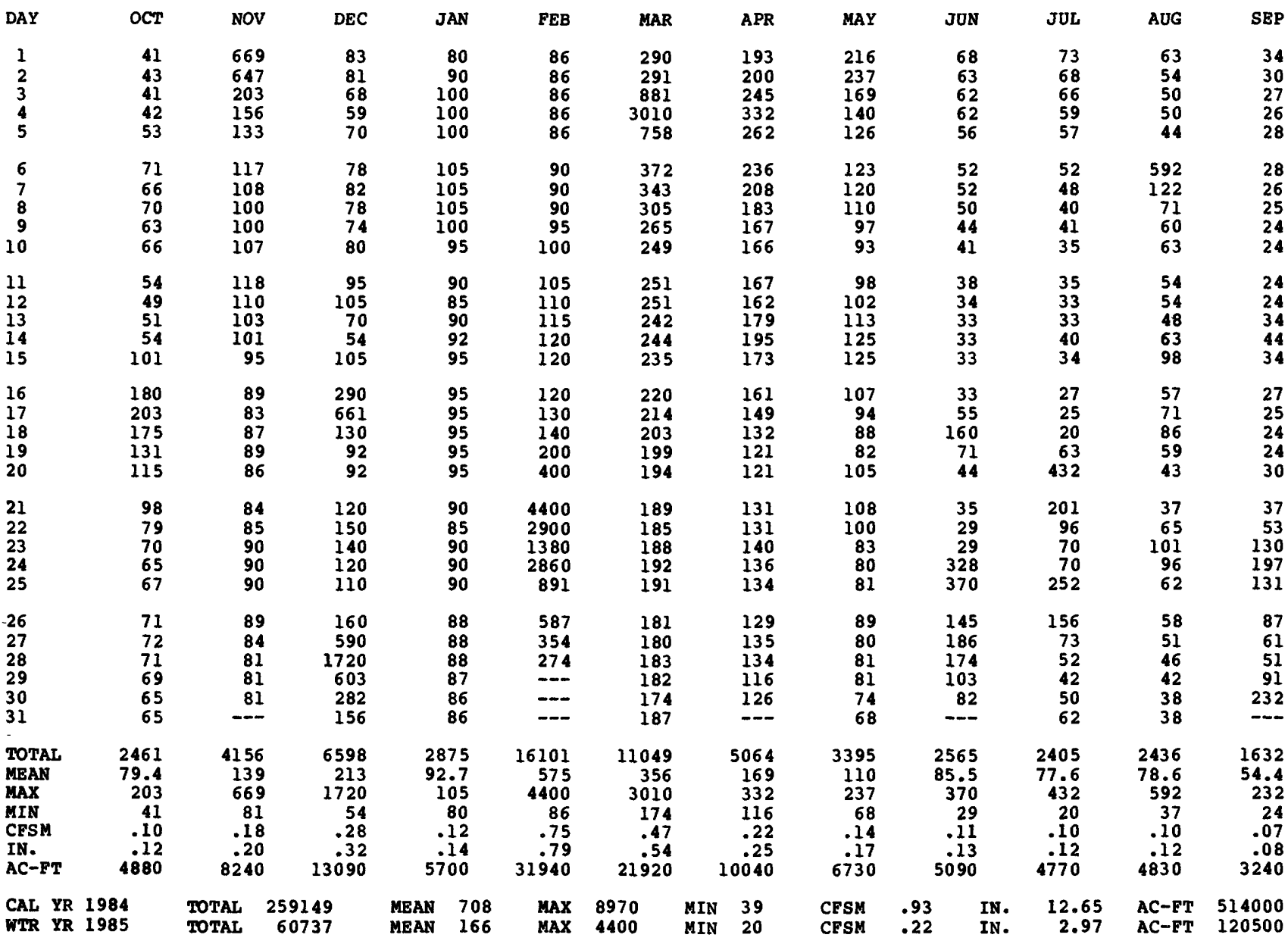


PERIOD OF RECORD.--October 1976 to current year.

PERIOD OF DAILY RECORD.--

SPECIFIC CONDUCTANCE: October 1975 to current year.

WATER TEMPERATURES: October 1975 to September 1978 , October 1979 to current year.

SUSPENDED-SEDIMENT DISCHARGE: October 1975 to current year.

REMARKS.--Records of specific conductance are obtained from suspended-sediment samples at time of analysis. Suspended-sediment samples at normal fiows and winter period are collected below dam 300 ft upstream from gage. Samples at higher stages are collected from bridge at gage. Random water temperatures are on file for the 1979 water year.

EXTREMES FOR PERTOD OF DAILY RECORD, -

SPECIFIC CONDUCTANCE: Maximum daily, 600 microsiemens Aug. 22, 1982; minimum daily, 130 microsiemens June 15, 1976 .

WATER TEMPERATUREs: Maximum daily, $30.5^{\circ} \mathrm{C}$ Aug. 23,1978 , minimum daily, $0.0^{\circ} \mathrm{C}$ on many days during winter period.

SEDIMENT CONCENTRATIONS: Maximum daily mean, 23,800 mg/L Apr. 17, 1978, minimum daily mean, 5 mg/L Dec. 14, 1977, Feb, 24, 1978 .

SEDIMENT LOADS: Maximum daily, 1,500,000 tons June 16, 1982, minimum daily, 0.23 ton Dec. $14,1977$.

EXTREWES FOR CURRENT YEAR.--

SPECIFIC CONDUCTANCE: Maximum daily, 530 microsiemens Dec, 7, 8; minimum daily, 180 microsiemens June 25, SEDIHENT CONCENTRATIONS: Maximum daily mean, 12,300 mg/L Mar. 4; minimum daily mean, 6 mg/L Nov. 18, Dec. 9, Peb. 14-16.

SEDIMENT LOADS: Maximum daily, 105,000 tons Mar. 4; minimum daily, 1.2 ton Dec.9.

SPECIFIC CONDUCTANCE (MICROSIEMENS/CM AT 25 DEG. C.), WATER YEAR OCTOBER 1984 TO SEPTEMBER 1985 RANDOM VALUES

\begin{tabular}{|c|c|c|c|c|c|c|c|c|c|c|c|}
\hline DAY & OCT & NOV & DEC & JAN & FEB & MAR & APR & MAY & JUN & JUL & AUG \\
\hline $\begin{array}{l}1 \\
2 \\
3 \\
4 \\
5\end{array}$ & $\begin{array}{l}-2- \\
400 \\
380 \\
380\end{array}$ & $\begin{array}{l}300 \\
280 \\
280 \\
320 \\
360\end{array}$ & $\begin{array}{l}430 \\
430 \\
440 \\
460 \\
460\end{array}$ & $\begin{array}{l}350 \\
370 \\
430 \\
430 \\
360\end{array}$ & $\begin{array}{l}--- \\
460 \\
430 \\
400\end{array}$ & $\begin{array}{l}330 \\
320 \\
320 \\
260 \\
250\end{array}$ & $\begin{array}{l}380 \\
380 \\
380 \\
360 \\
350\end{array}$ & $\begin{array}{l}360 \\
360 \\
365 \\
400 \\
---\end{array}$ & $\begin{array}{l}420 \\
410 \\
410 \\
410 \\
400\end{array}$ & $\begin{array}{l}390 \\
410 \\
410 \\
360 \\
380\end{array}$ & $\begin{array}{l}380 \\
390 \\
390 \\
380 \\
380\end{array}$ \\
\hline $\begin{array}{r}6 \\
7 \\
8 \\
9 \\
10\end{array}$ & $\begin{array}{l}360 \\
380 \\
400 \\
400 \\
400\end{array}$ & $\begin{array}{l}400 \\
410 \\
410 \\
400 \\
400\end{array}$ & $\begin{array}{l}460 \\
530 \\
530 \\
450 \\
430\end{array}$ & $\begin{array}{l}360 \\
370 \\
380 \\
380 \\
400\end{array}$ & $\begin{array}{l}440 \\
440 \\
440 \\
420 \\
430\end{array}$ & $\begin{array}{l}280 \\
320 \\
330 \\
340 \\
360\end{array}$ & $\begin{array}{l}360 \\
360 \\
380 \\
380 \\
400\end{array}$ & $\begin{array}{l}400 \\
405 \\
400 \\
410 \\
420\end{array}$ & $\begin{array}{l}410 \\
410 \\
420 \\
420 \\
420\end{array}$ & $\begin{array}{l}390 \\
380 \\
380 \\
400 \\
390\end{array}$ & $\begin{array}{l}310 \\
220 \\
300 \\
350 \\
360\end{array}$ \\
\hline $\begin{array}{l}11 \\
12 \\
13 \\
14 \\
15\end{array}$ & $\begin{array}{l}400 \\
410 \\
400 \\
410 \\
380\end{array}$ & $\begin{array}{l}400 \\
410 \\
400 \\
420 \\
420\end{array}$ & $\begin{array}{l}410 \\
400 \\
410 \\
420 \\
420\end{array}$ & $\begin{array}{l}400 \\
400 \\
420 \\
430 \\
420\end{array}$ & $\begin{array}{l}420 \\
420 \\
430 \\
440 \\
420\end{array}$ & $\begin{array}{l}360 \\
360 \\
370 \\
370 \\
380\end{array}$ & $\begin{array}{l}385 \\
385 \\
360 \\
370 \\
380\end{array}$ & $\begin{array}{l}400 \\
415 \\
405 \\
380 \\
390\end{array}$ & $\begin{array}{l}410 \\
400 \\
400 \\
400 \\
380\end{array}$ & $\begin{array}{l}400 \\
380 \\
380 \\
380 \\
370\end{array}$ & $\begin{array}{l}360 \\
380 \\
380 \\
360 \\
300\end{array}$ \\
\hline $\begin{array}{l}16 \\
17 \\
18 \\
19 \\
20\end{array}$ & $\begin{array}{l}365 \\
360 \\
370 \\
380 \\
400\end{array}$ & $\begin{array}{l}420 \\
420 \\
420 \\
430 \\
425\end{array}$ & \begin{tabular}{l}
360 \\
330 \\
\hdashline-0 \\
340
\end{tabular} & $\begin{array}{l}430 \\
420 \\
420 \\
410 \\
420\end{array}$ & $\begin{array}{l}420 \\
430 \\
380 \\
330 \\
280\end{array}$ & $\begin{array}{l}380 \\
390 \\
390 \\
390 \\
400\end{array}$ & $\begin{array}{l}380 \\
380 \\
390 \\
390 \\
390\end{array}$ & $\begin{array}{l}400 \\
400 \\
410 \\
410 \\
380\end{array}$ & $\begin{array}{l}380 \\
360 \\
220 \\
300 \\
340\end{array}$ & $\begin{array}{l}370 \\
340 \\
340 \\
280 \\
260\end{array}$ & $\begin{array}{l}340 \\
340 \\
350 \\
360 \\
390\end{array}$ \\
\hline $\begin{array}{l}21 \\
22 \\
23 \\
24 \\
25\end{array}$ & $\begin{array}{l}420 \\
430 \\
410 \\
410 \\
410\end{array}$ & $\begin{array}{l}425 \\
420 \\
420 \\
420 \\
420\end{array}$ & $\begin{array}{l}360 \\
380 \\
320 \\
300 \\
350\end{array}$ & $\begin{array}{l}460 \\
440 \\
400 \\
430 \\
410\end{array}$ & $\begin{array}{l}220 \\
210 \\
220 \\
240 \\
240\end{array}$ & $\begin{array}{l}--0 \\
400 \\
390 \\
390 \\
400\end{array}$ & $\begin{array}{l}380 \\
380 \\
380 \\
380 \\
385\end{array}$ & $\begin{array}{l}385 \\
400 \\
400 \\
405 \\
410\end{array}$ & $\begin{array}{l}360 \\
400 \\
400 \\
360 \\
180\end{array}$ & $\begin{array}{l}240 \\
300 \\
340 \\
360 \\
310\end{array}$ & $\begin{array}{l}380 \\
380 \\
310 \\
310 \\
350\end{array}$ \\
\hline $\begin{array}{l}26 \\
27 \\
28 \\
29 \\
30 \\
31\end{array}$ & $\begin{array}{l}410 \\
450 \\
450 \\
430 \\
440 \\
440\end{array}$ & $\begin{array}{l}420 \\
420 \\
420 \\
420 \\
420 \\
-\end{array}$ & $\begin{array}{l}360 \\
320 \\
350 \\
210 \\
270 \\
300\end{array}$ & $\begin{array}{l}440 \\
420 \\
360 \\
430 \\
430 \\
440\end{array}$ & $\begin{array}{l}270 \\
280 \\
300 \\
- \\
-\end{array}$ & $\begin{array}{l}400 \\
400 \\
390 \\
390 \\
390 \\
380\end{array}$ & $\begin{array}{l}380 \\
380 \\
380 \\
380 \\
380 \\
-\end{array}$ & $\begin{array}{l}410 \\
400 \\
400 \\
410 \\
410 \\
410\end{array}$ & $\begin{array}{l}240 \\
280 \\
240 \\
310 \\
320 \\
-\end{array}$ & $\begin{array}{l}260 \\
320 \\
370 \\
400 \\
380 \\
360\end{array}$ & $\begin{array}{l}370 \\
380 \\
370 \\
360 \\
360 \\
360\end{array}$ \\
\hline
\end{tabular}


WATER-OUALITY RECORDS

WATER YEAR OCTOBER 1984 TO SEPTEMBER 1985

\begin{tabular}{|c|c|c|c|c|c|c|c|c|c|c|c|c|}
\hline DAY & $\begin{array}{l}\text { MEAN } \\
\text { CONCEN- } \\
\text { TRATION } \\
(M G / L)\end{array}$ & $\begin{array}{l}\text { LOADS } \\
(\mathrm{T} / \mathrm{DAY})\end{array}$ & $\begin{array}{l}\text { MEAN } \\
\text { CONCEN- } \\
\text { TRATION } \\
\text { (MG/L) }\end{array}$ & $\begin{array}{l}\text { LOADS } \\
\text { ( } T / D A Y)\end{array}$ & $\begin{array}{l}\text { MEAN } \\
\text { CONCEN- } \\
\text { TRATION } \\
(M G / L)\end{array}$ & $\begin{array}{l}\text { LOADS } \\
\text { (T/DAY) }\end{array}$ & $\begin{array}{l}\text { MEAN } \\
\text { CONCEN- } \\
\text { TRATION } \\
\text { (MG/L) }\end{array}$ & $\begin{array}{l}\text { LOADS } \\
\text { (T/DAY) }\end{array}$ & $\begin{array}{l}\text { MEAN } \\
\text { CONCEN- } \\
\text { TRATION } \\
\text { (MG/L) }\end{array}$ & $\begin{array}{l}\text { LOADS } \\
\text { (T/DAY) }\end{array}$ & $\begin{array}{c}\text { MEAN } \\
\text { CONCEN - } \\
\text { TRATION } \\
\text { (MG/L) }\end{array}$ & $\begin{array}{l}\text { LOADS } \\
\text { (T/DAY) }\end{array}$ \\
\hline & \multicolumn{2}{|c|}{ OCTOBER } & \multicolumn{2}{|c|}{ NOVEMBER } & \multicolumn{2}{|c|}{ DECEMBER } & \multicolumn{2}{|c|}{ JANUARY } & \multicolumn{2}{|c|}{ FEBROARY } & \multicolumn{2}{|c|}{ MARCH } \\
\hline $\begin{array}{l}1 \\
2 \\
3 \\
4 \\
5\end{array}$ & $\begin{array}{l}14 \\
16 \\
16 \\
19 \\
33\end{array}$ & $\begin{array}{l}1.5 \\
1.9 \\
1.8 \\
2.2 \\
4.7\end{array}$ & $\begin{array}{r}2920 \\
3180 \\
850 \\
265 \\
145\end{array}$ & $\begin{array}{r}6630 \\
6440 \\
466 \\
112 \\
52\end{array}$ & $\begin{array}{l}12 \\
15 \\
10 \\
11 \\
12\end{array}$ & $\begin{array}{l}2.7 \\
3.3 \\
1.8 \\
1.8 \\
2.3\end{array}$ & $\begin{array}{r}101 \\
31 \\
80 \\
124 \\
160\end{array}$ & $\begin{array}{l}22 \\
7.5 \\
22 \\
33 \\
43\end{array}$ & $\begin{array}{l}16 \\
20 \\
10 \\
16 \\
10\end{array}$ & $\begin{array}{l}3.7 \\
4.6 \\
2.3 \\
3.7 \\
2.3\end{array}$ & $\begin{array}{r}650 \\
475 \\
2390 \\
12300 \\
5000\end{array}$ & $\begin{array}{r}509 \\
373 \\
5690 \\
105000 \\
12200\end{array}$ \\
\hline $\begin{array}{r}6 \\
7 \\
8 \\
9 \\
10\end{array}$ & $\begin{array}{l}19 \\
21 \\
27 \\
32 \\
34\end{array}$ & $\begin{array}{l}3.6 \\
3.7 \\
5.1 \\
5.4 \\
6.1\end{array}$ & $\begin{array}{l}97 \\
92 \\
89 \\
86 \\
89\end{array}$ & $\begin{array}{l}31 \\
27 \\
24 \\
23 \\
26\end{array}$ & $\begin{array}{r}13 \\
11 \\
7 \\
6 \\
10\end{array}$ & $\begin{array}{l}2.7 \\
2.4 \\
1.5 \\
1.2 \\
2.2\end{array}$ & $\begin{array}{r}129 \\
108 \\
91 \\
79 \\
53\end{array}$ & $\begin{array}{l}37 \\
31 \\
26 \\
21 \\
14\end{array}$ & $\begin{array}{r}8 \\
10 \\
8 \\
10 \\
9\end{array}$ & $\begin{array}{l}1.9 \\
2.4 \\
1.9 \\
2.6 \\
2.4\end{array}$ & $\begin{array}{r}1610 \\
1000 \\
620 \\
389 \\
317\end{array}$ & $\begin{array}{r}1620 \\
926 \\
511 \\
278 \\
213\end{array}$ \\
\hline $\begin{array}{l}11 \\
12 \\
13 \\
14 \\
15\end{array}$ & $\begin{array}{r}26 \\
26 \\
25 \\
23 \\
195\end{array}$ & $\begin{array}{r}3.8 \\
3.4 \\
3.4 \\
3.4 \\
53\end{array}$ & $\begin{array}{r}103 \\
79 \\
69 \\
76 \\
64\end{array}$ & $\begin{array}{l}33 \\
23 \\
19 \\
21 \\
16\end{array}$ & $\begin{array}{r}21 \\
32 \\
16 \\
9 \\
35\end{array}$ & $\begin{array}{l}5.4 \\
9.1 \\
3.0 \\
1.3 \\
9.9\end{array}$ & $\begin{array}{l}45 \\
27 \\
24 \\
24 \\
23\end{array}$ & $\begin{array}{r}11 \\
6.2 \\
5.8 \\
6.0 \\
5.9\end{array}$ & $\begin{array}{l}9 \\
9 \\
7 \\
6 \\
6\end{array}$ & $\begin{array}{l}2.6 \\
2.7 \\
2.2 \\
1.9 \\
1.9\end{array}$ & $\begin{array}{l}315 \\
314 \\
262 \\
246 \\
230\end{array}$ & $\begin{array}{l}213 \\
213 \\
171 \\
162 \\
146\end{array}$ \\
\hline $\begin{array}{l}16 \\
17 \\
18 \\
19 \\
20\end{array}$ & $\begin{array}{r}246 \\
288 \\
221 \\
146 \\
96\end{array}$ & $\begin{array}{r}120 \\
158 \\
104 \\
52 \\
30\end{array}$ & $\begin{array}{r}40 \\
21 \\
6 \\
24 \\
33\end{array}$ & $\begin{array}{l}9.6 \\
4.7 \\
1.4 \\
5.8 \\
7.7\end{array}$ & $\begin{array}{r}673 \\
2140 \\
500 \\
114 \\
90\end{array}$ & $\begin{array}{r}772 \\
40.20 \\
175 \\
28 \\
22\end{array}$ & $\begin{array}{l}21 \\
18 \\
18 \\
21 \\
24\end{array}$ & $\begin{array}{l}5.4 \\
4.6 \\
4.6 \\
5.4 \\
6.2\end{array}$ & $\begin{array}{r}6 \\
13 \\
49 \\
94 \\
178\end{array}$ & $\begin{array}{c}1.9 \\
4.6 \\
19 \\
51 \\
192\end{array}$ & $\begin{array}{l}200 \\
174 \\
160 \\
168 \\
158\end{array}$ & $\begin{array}{r}119 \\
101 \\
88 \\
90 \\
83\end{array}$ \\
\hline $\begin{array}{l}21 \\
22 \\
23 \\
24 \\
25\end{array}$ & $\begin{array}{l}75 \\
52 \\
43 \\
44 \\
47\end{array}$ & $\begin{array}{l}20 \\
11 \\
8.1 \\
7.7 \\
8.5\end{array}$ & $\begin{array}{l}29 \\
11 \\
24 \\
20 \\
24\end{array}$ & $\begin{array}{l}6.6 \\
2.5 \\
5.8 \\
4.9 \\
5.8\end{array}$ & $\begin{array}{l}105 \\
130 \\
211 \\
173 \\
129\end{array}$ & $\begin{array}{l}34 \\
53 \\
80 \\
56 \\
38\end{array}$ & $\begin{array}{l}16 \\
19 \\
21 \\
19 \\
25\end{array}$ & $\begin{array}{l}3.9 \\
4.4 \\
5.1 \\
4.6 \\
6.1\end{array}$ & $\begin{array}{l}8350 \\
6770 \\
3110 \\
6350 \\
2400\end{array}$ & $\begin{array}{r}99200 \\
63400 \\
13500 \\
53200 \\
5770\end{array}$ & $\begin{array}{l}139 \\
118 \\
115 \\
117 \\
106\end{array}$ & $\begin{array}{l}71 \\
59 \\
58 \\
61 \\
55\end{array}$ \\
\hline $\begin{array}{c}26 \\
27 \\
28 \\
29 \\
30 \\
31 \\
\text { TOTAL }\end{array}$ & $\begin{array}{r}49 \\
63 \\
28 \\
21 \\
26 \\
22 \\
---\end{array}$ & $\begin{array}{r}9.4 \\
12 \\
5.4 \\
3.9 \\
4.6 \\
3.9 \\
661.5\end{array}$ & $\begin{array}{r}29 \\
18 \\
14 \\
15 \\
12 \\
---\end{array}$ & $\begin{array}{r}7.0 \\
4.1 \\
3.1 \\
3.3 \\
2.6 \\
14017.9\end{array}$ & $\begin{array}{r}154 \\
1130 \\
3890 \\
2620 \\
800 \\
270 \\
--2\end{array}$ & $\begin{array}{r}67 \\
2990 \\
18400 \\
4640 \\
609 \\
114 \\
32148.6\end{array}$ & $\begin{array}{l}18 \\
15 \\
14 \\
14 \\
12 \\
11 \\
--\end{array}$ & $\begin{array}{r}4.3 \\
3.6 \\
3.3 \\
3.3 \\
2.8 \\
2.6 \\
361.6\end{array}$ & $\begin{array}{r}1250 \\
920 \\
675 \\
- \\
-- \\
- \\
--\end{array}$ & $\begin{array}{r}1980 \\
879 \\
499 \\
- \\
- \\
238735.6\end{array}$ & $\begin{array}{r}99 \\
92 \\
83 \\
79 \\
64 \\
88 \\
-\end{array}$ & $\begin{array}{r}48 \\
45 \\
41 \\
39 \\
30 \\
44 \\
129257\end{array}$ \\
\hline DAY & $\begin{array}{c}\text { MEAN } \\
\text { CONCEN- } \\
\text { TRATION } \\
\text { (MG/L) }\end{array}$ & $\begin{array}{l}\text { LOADS } \\
\text { (T/DAY) }\end{array}$ & $\begin{array}{c}\text { MEAN } \\
\text { CONCEN- } \\
\text { TRATION } \\
(\text { MG/L) }\end{array}$ & $\begin{array}{l}\text { LOADS } \\
\text { (T/DAY) }\end{array}$ & $\begin{array}{c}\text { MEAN } \\
\text { CONCEN- } \\
\text { TRATION } \\
(M G / L)\end{array}$ & $\begin{array}{l}\text { LOADS } \\
\text { (T/DAY) }\end{array}$ & $\begin{array}{l}\text { MEAN } \\
\text { CONCEN- } \\
\text { TRATION } \\
\text { (MG/ L) }\end{array}$ & $\begin{array}{l}\text { LOADS } \\
\text { (T/DAY) }\end{array}$ & $\begin{array}{l}\text { MEAN } \\
\text { CONCEN- } \\
\text { TRATION } \\
\text { (MG/L) }\end{array}$ & $\begin{array}{l}\text { LOADS } \\
\text { (T/DAY) }\end{array}$ & $\begin{array}{c}\text { MEAN } \\
\text { CONCEN- } \\
\text { TRATION } \\
\text { (MG/L) }\end{array}$ & $\begin{array}{l}\text { LOADS } \\
\text { (T/DAY) }\end{array}$ \\
\hline
\end{tabular}

APRIL

$\begin{array}{rrrr}82 & 43 & 154 & 90 \\ 92 & 50 & 237 & 152 \\ 230 & 152 & 110 & 50 \\ 975 & 874 & 89 & 34 \\ 525 & 371 & 88 & 30 \\ 282 & 180 & 91 & 30 \\ 187 & 105 & 121 & 39 \\ 142 & 70 & 88 & 26 \\ 108 & 49 & 63 & 16 \\ 101 & 45 & 74 & 19\end{array}$

$\begin{array}{rr}87 & 39 \\ 86 & 38 \\ 109 & 53 \\ 137 & 72 \\ 101 & 47\end{array}$

$\begin{array}{ll}74 & 32 \\ 70 & 28 \\ 52 & 19\end{array}$

$52 \quad 19$

$38 \quad 13$

$23 \quad 8.1$

$\begin{array}{lr}29 & 11 \\ 25 & 9.2 \\ 25 & 9.0\end{array}$

8.4
13
14
6.6
13
MAY

$\begin{array}{ll}62 & 16 \\ 54 & 15 \\ 48 & 15 \\ 64 & 22 \\ 50 & 17\end{array}$

$\begin{array}{ll}52 & 15 \\ 45 & 11 \\ 44 & 10 \\ 46 & 10 \\ 72 & 20\end{array}$

$\begin{array}{ll}61 & 18 \\ 56 & 15\end{array}$

72
51
45

11

$$
9.8
$$

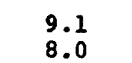

$$
\begin{array}{r}
9.0 \\
13
\end{array}
$$$$
13
$$

7.9 TONS. JONE

$\begin{array}{rrrr}55 & 10 & 192 & 38 \\ 65 & 11 & 109 & 20 \\ 59 & 9.9 & 88 & 16 \\ 45 & 7.5 & 89 & 14 \\ 40 & 6.0 & 80 & 12\end{array}$

$42 \quad 5.9 \quad 96$

$\begin{array}{rr}5.9 & 96 \\ 5.6 & 105 \\ 5.9 & 83\end{array}$

$\begin{array}{ll}5.2 & 100 \\ 4.8 & 104\end{array}$

$4.2 \quad 101$

$\begin{array}{rr}4.2 & 101 \\ 2.9 & 102 \\ 3.0 & 91\end{array}$

3.0
3.4

91
117
134

3.0

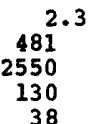

107
86
95
445
2100

38

245

145
108

2930

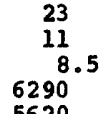

6290
5620

1010
1640
2020

1640
2020

949

$328 \quad 792$

31
TOTAL
FOR YEAR: 
NODAWAY RIVER BASIN

06817000 NODAWAY RIVER AT CLARINDA, IA--Continued

WATER-QUALITY RECORDS

WATER QUALITY DATA, WATER YEAR OCTOBER 1984 TO SEPTEMBER 1985

\begin{tabular}{|c|c|c|c|c|c|c|c|}
\hline DATE & TIME & $\begin{array}{l}\text { TEMPER- } \\
\text { ATURE } \\
\text { (DEG C) }\end{array}$ & $\begin{array}{l}\text { STREAM- } \\
\text { FLOW, } \\
\text { INSTAN- } \\
\text { TANEOUS } \\
\text { (CES) }\end{array}$ & $\begin{array}{l}\text { SEDI- } \\
\text { MENT, } \\
\text { SUS- } \\
\text { PENDED } \\
\text { (MG/L) }\end{array}$ & $\begin{array}{c}\text { SEDI- } \\
\text { MENT, } \\
\text { DIS- } \\
\text { CHARGE, } \\
\text { SUS- } \\
\text { PENDED } \\
\text { (T/DAY) }\end{array}$ & $\begin{array}{l}\text { SED. } \\
\text { SUSP. } \\
\text { FALL } \\
\text { DIAM. } \\
8 \text { FINER } \\
\text { THAN } \\
.002 \text { MM }\end{array}$ & $\begin{array}{l}\text { SED. } \\
\text { SUSP. } \\
\text { FALL } \\
\text { DIAM. } \\
\text { \& FINER } \\
\text { THAN } \\
.004 \mathrm{MM}\end{array}$ \\
\hline $\begin{array}{l}\text { NOV } \\
07 \ldots . . \\
\text { DEC }\end{array}$ & $09: 50$ & 10.0 & 105 & 131 & 37 & - & -- \\
\hline$\underset{\text { FEB }}{19} \ldots$ & $13: 41$ & 0.0 & 94 & 117 & 30 & 82 & 84 \\
\hline $\begin{array}{l}21 \ldots \\
22 \ldots \\
\text { MAR }\end{array}$ & $\begin{array}{l}07: 30 \\
14: 30\end{array}$ & -1.0 & $\begin{array}{l}2930 \\
2390\end{array}$ & $\begin{array}{l}5500 \\
5610\end{array}$ & $\begin{array}{l}43500 \\
36200\end{array}$ & $\begin{array}{l}36 \\
44\end{array}$ & $\begin{array}{l}39 \\
48\end{array}$ \\
\hline $\begin{array}{l}04 \ldots \\
14 \ldots \\
\text { APR }\end{array}$ & $\begin{array}{l}07: 30 \\
09: 38\end{array}$ & $-\overline{4.0}$ & $\begin{array}{r}2720 \\
245\end{array}$ & $\begin{array}{r}14900 \\
248\end{array}$ & $\begin{array}{r}109000 \\
164\end{array}$ & $-{ }^{38}$ & $-\quad 42$ \\
\hline & $09: 40$ & 18.0 & 130 & 60 & 21 & -- & -- \\
\hline$\underset{\text { JUN }}{29} \ldots$ & $11: 05$ & 20.0 & 82 & 79 & 17 & - & -- \\
\hline & $07: 30$ & $-\infty$ & 408 & 6200 & 6830 & 63 & 73 \\
\hline $\begin{array}{l}24 \ldots \\
\text { AUG }\end{array}$ & $09: 00$ & 24.5 & 57 & 95 & 15 & -- & -- \\
\hline $06 \ldots$ & $13: 15$ & 25.0 & 1290 & 6480 & 22600 & 56 & 65 \\
\hline DATE & $\begin{array}{l}\text { SED. } \\
\text { SUSP. } \\
\text { FALL } \\
\text { DIAM. } \\
\text { \& FINER } \\
\text { THAN } \\
.008 \mathrm{MM}\end{array}$ & $\begin{array}{l}\text { SED. } \\
\text { SUSP. } \\
\text { FALL } \\
\text { DIAM. } \\
\text { \&INER } \\
\text { THAN } \\
.016 \mathrm{MM}\end{array}$ & $\begin{array}{c}\text { SED. } \\
\text { SUSP. } \\
\text { FALL } \\
\text { DIAM. } \\
\text { FINER } \\
\text { THAN } \\
.062 \mathrm{MM}\end{array}$ & $\begin{array}{l}\text { SED. } \\
\text { SUSP. } \\
\text { FALL } \\
\text { DIAM. } \\
\text { FINER } \\
\text { THAN } \\
.125 \mathrm{MIM}\end{array}$ & $\begin{array}{c}\text { SED. } \\
\text { SUSP. } \\
\text { FALL } \\
\text { DIAM. } \\
\text { \&INER } \\
\text { THAN } \\
.250 \mathrm{MM}\end{array}$ & $\begin{array}{c}\text { SED. } \\
\text { SUSP. } \\
\text { FALL } \\
\text { DIAM. } \\
\text { FINER } \\
\text { THAN } \\
.500 \mathrm{MH}\end{array}$ & $\begin{array}{c}\text { SED. } \\
\text { SUSP. } \\
\text { SIEVE } \\
\text { DIAM. } \\
\text { FINER } \\
\text { THAN } \\
.062 \mathrm{MM}\end{array}$ \\
\hline NOV & & & & & & & \\
\hline $\begin{array}{l}\text { DEC } \\
19 \ldots \\
\text { FEB }\end{array}$ & 85 & 87 & 94 & 94 & 96 & 100 & - \\
\hline $\begin{array}{r}21 \ldots \\
22 \ldots \\
\text { MAR }\end{array}$ & $\begin{array}{l}41 \\
54\end{array}$ & $\begin{array}{l}54 \\
63\end{array}$ & $\begin{array}{l}91 \\
93\end{array}$ & $\begin{array}{l}96 \\
96\end{array}$ & $\begin{array}{l}100 \\
100\end{array}$ & - & - \\
\hline $\begin{array}{l}04 \ldots \\
14 \ldots \\
A P R\end{array}$ & $--\quad 48$ & $--^{59}$ & $-\quad 97$ & -99 & $--^{100}$ & - & -96 \\
\hline $\begin{array}{l}18 . \\
\text { MAY }\end{array}$ & -- & $-\infty$ & - & -- & - & $-\infty$ & 98 \\
\hline $\begin{array}{l}29 \\
\text { JUN } \\
25 \ldots\end{array}$ & -- & -- & -- & -- & -- & -- & 85 \\
\hline $\begin{array}{l}\text { JUL } \\
24 \ldots \\
\text { AUG } \\
06 . . .\end{array}$ & 76 & 86 & 94 & 95 & 96 & 100 & 93 \\
\hline
\end{tabular}


NODAWAY RIVER BASIN

06817000 NODAWAY RIVER AT CLARINDA, IA--Continued

WATER-QUALITY RECORDS

WATER QOALITY DATA, WATER YEAR OCTOBER 1984 TO SEPTEMBER 1985

\begin{tabular}{|c|c|c|c|c|c|c|c|}
\hline DATE & TIME & $\begin{array}{l}\text { STREAY- } \\
\text { FLOW, } \\
\text { INSTAN- } \\
\text { TANEOUS } \\
\text { (CFS) }\end{array}$ & $\begin{array}{c}\text { NOMBER } \\
\text { OF } \\
\text { SAM- } \\
\text { PLING } \\
\text { POINTS }\end{array}$ & $\begin{array}{c}\text { BED } \\
\text { MAT. } \\
\text { SIEVE } \\
\text { DIAH. } \\
\text { 8 FINER } \\
\text { THAN } \\
.062 \text { MM }\end{array}$ & $\begin{array}{c}\text { BED } \\
\text { MAT. } \\
\text { SIEVE } \\
\text { DIAH. } \\
\text { \& FINER } \\
\text { THAN } \\
.125 \mathrm{MM}\end{array}$ & $\begin{array}{c}\text { BED } \\
\text { MAT. } \\
\text { SIEVE } \\
\text { DIAM. } \\
\text { \& FINER } \\
\text { THAN } \\
.250 \mathrm{MM}\end{array}$ & $\begin{array}{c}\text { BED } \\
\text { MAT. } \\
\text { SIEVE } \\
\text { DIAM. } \\
\text { \& FINER } \\
\text { THAN } \\
.500 \mathrm{MM}\end{array}$ \\
\hline NOV & & & & & & & \\
\hline$\underset{\text { DEC }}{07} \ldots$ & $10: 00$ & 105 & 3 & 1 & 1 & 4 & 28 \\
\hline$\underset{\text { JAN }}{19} \ldots$ & $13: 41$ & 94 & 4 & 1 & 1 & 6 & 31 \\
\hline $\begin{array}{l}30 \ldots \\
M A R\end{array}$ & $11: 00$ & 86 & 2 & 5 & 10 & 22 & 43 \\
\hline$\underset{A P R}{14 \ldots}$ & $09: 45$ & 245 & 3 & 0 & 1 & 8 & 40 \\
\hline $\operatorname{MAY}_{18} \ldots$ & $09: 53$ & 130 & 3 & 0 & 1 & 3 & 14 \\
\hline$\underset{\text { JOL }}{29}$ & $11: 16$ & 82 & 3 & 1 & 1 & 6 & 31 \\
\hline$\underset{A O G}{24} \ldots$ & $09: 08$ & 57 & 3 & 1 & 1 & 7 & 42 \\
\hline $\begin{array}{l}06 \ldots \\
13 \ldots \\
\text { SEP }\end{array}$ & $\begin{array}{l}12: 29 \\
15: 13\end{array}$ & $\begin{array}{r}1290 \\
48\end{array}$ & $\begin{array}{l}3 \\
3\end{array}$ & $\begin{array}{l}0 \\
1\end{array}$ & $\begin{array}{l}1 \\
1\end{array}$ & $\begin{array}{l}10 \\
10\end{array}$ & $\begin{array}{l}67 \\
47\end{array}$ \\
\hline & $10: 45$ & 21 & 3 & 1 & 2 & 17 & 2 \\
\hline
\end{tabular}

\begin{tabular}{|c|c|c|c|c|c|c|}
\hline DATE & $\begin{array}{c}\text { BED } \\
\text { MAT. } \\
\text { SIEVE } \\
\text { DIAM. } \\
8 \text { FINER } \\
\text { THAN } \\
1.00 \mathrm{MM}\end{array}$ & $\begin{array}{l}\text { BED } \\
\text { MAT. } \\
\text { SIEVE } \\
\text { DIAM. } \\
\text { FINER } \\
\text { THAN } \\
2.00 \mathrm{MM}\end{array}$ & $\begin{array}{c}\text { BED } \\
\text { MAT. } \\
\text { SIEVE } \\
\text { DIAM. } \\
\text { 8 FINER } \\
\text { THAN } \\
\text { 4.00 MM }\end{array}$ & $\begin{array}{l}\text { BED } \\
\text { MAT. } \\
\text { SIEVE } \\
\text { DIAM. } \\
\text { \&INER } \\
\text { THAN } \\
8.00 \text { MM }\end{array}$ & $\begin{array}{c}\text { BED } \\
\text { MAT. } \\
\text { SIEVE } \\
\text { DIAM. } \\
8 \text { FINER } \\
\text { THAN } \\
16.0 \mathrm{MM}\end{array}$ & $\begin{array}{c}\text { BED } \\
\text { MAT. } \\
\text { SIEVE } \\
\text { DIAM. } \\
\text { FINER } \\
\text { THAN } \\
32.0 \mathrm{NM}\end{array}$ \\
\hline NOV & & & & & & \\
\hline $\begin{array}{l}07 \ldots \\
\text { DEC }\end{array}$ & 49 & 63 & 72 & 78 & 91 & 10 \\
\hline $\begin{array}{l}19 \ldots \\
\text { JAN }\end{array}$ & 44 & 53 & 61 & 70 & 88 & 10 \\
\hline $\begin{array}{l}30 \ldots \\
\text { MAR }\end{array}$ & 61 & 71 & 78 & 85 & 100 & - \\
\hline$\underset{A P R}{14 \ldots}$ & 54 & 60 & 66 & 74 & 90 & 10 \\
\hline $\begin{array}{l}18 \ldots \\
\text { MAY }\end{array}$ & 26 & 34 & 46 & 64 & 82 & 10 \\
\hline $\begin{array}{l}29 \\
\text { JOL }\end{array}$ & 50 & 58 & 65 & 75 & 91 & \\
\hline$\underset{A O G}{24} \cdots$ & 62 & 69 & 74 & 81 & 91 & 1 \\
\hline $\begin{array}{l}06 \ldots \\
13 \ldots\end{array}$ & $\begin{array}{l}89 \\
67\end{array}$ & $\begin{array}{l}96 \\
77\end{array}$ & $\begin{array}{l}99 \\
86\end{array}$ & $\begin{array}{r}100 \\
92\end{array}$ & -98 & --100 \\
\hline $\begin{array}{r}\text { SEP } \\
19\end{array}$ & 90 & 94 & 97 & 100 & - & $-\infty$ \\
\hline
\end{tabular}


LOCATION,--Lat $40^{\circ} 46^{\prime} 02^{\prime \prime}$, long $94^{\circ} 24^{\prime} 46^{\prime \prime}$, in NEl/4 NWl/4 sec.22, T.69 N., R.3l W., Ringgold County, Hydrologic Unit 10240012, on left bank at downstream side of bridge on county highway, 2.2 mi upstream from Turkey Creek, $4.6 \mathrm{mi}$ southwest of Diagonal, and $4.9 \mathrm{mi}$ downstream from Gard Creek.

DRAINAGE AREA. $--217 \mathrm{mi}^{2}$.

PERIOD OF RECORD.--April 1968 to current year.

REVISED RECORDS.- WSP 2119: 1969 (P).

GAGE.--Water-stage recorder. Datum of gage is $1,095.27 \mathrm{ft}$ above NGVD.

REMARKS.--Estimated daily discharges: Oct. 1 to Feb.20, Feb. 26,27, Mar.2 and Mar.4-9. Records good except those for estimated period, which are poor.

AVERAGE DISCHARGE.--17 years, $131 \mathrm{ft} / \mathrm{s}, 8.20 \mathrm{in} / \mathrm{yr}, 94,910$ acre-ft/yr; median of yearly mean discharges, 110 $\mathrm{ft}^{3} / \mathrm{s}, 6.9 \mathrm{in} / \mathrm{yr}, 79,700 \mathrm{acre}-\mathrm{ft} / \mathrm{yr}$.

EXTREMES FOR PERIOD OF RECORD.--Maximum discharge, $6,420 \mathrm{ft} / \mathrm{s}$ Oct. 12, 1973, gage height, 23.24 ft; minimum daily, 0.21 ft/s Jan. 14, 15, 1969.

EXTREMES OUTSIDE PERIOD OF RECORD.--Flood of June 1967 reached a stage of $23.16 \mathrm{ft}$, from floodmark by local resident, discharge, $6,360 \mathrm{ft}^{3} / \mathrm{s}$.

EXTREMES FOR CURRENT YEAR.--Peak discharge greater than base of $3,000 \mathrm{ft} \% \mathrm{~s}$ and maximum (*):

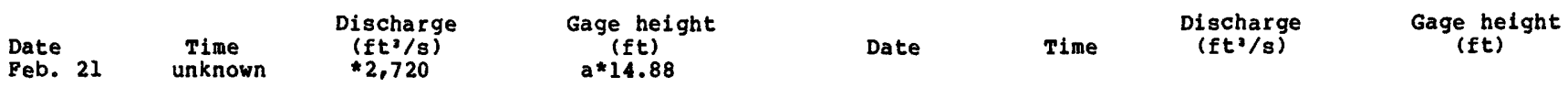

(a) from floodmark.

Minimum discharge, $1.8 \mathrm{ft} / \mathrm{s}$ Sept. 16,17 , but may have been less during period of backwater from beaver dam. DISCHARGE, IN CUBIC FEET PER SECOND, MATER YEAR OCTOBER 1984 TO SEPTEMBER 1985 MEAN VALUES

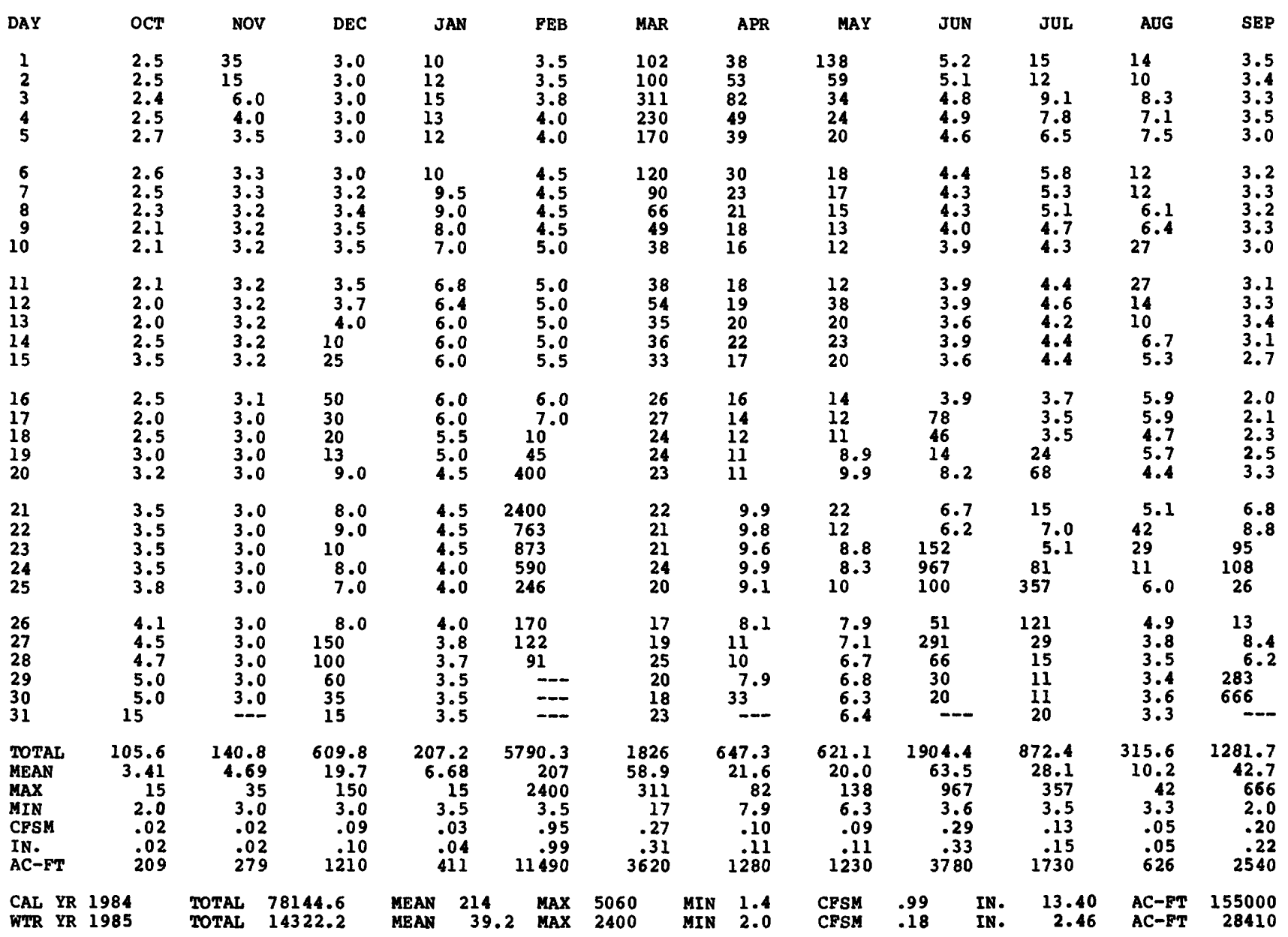


LOCATION.--Lat $40^{\circ} 39^{\prime} 38^{\prime \prime}$, long $94^{\circ} 42^{\prime} 59^{\prime \prime}$, in NEl/4 sec.35, T.68 N., R.34 W., Taylor County, Hydrologic Unit 10240013 , on left bank at downstream side of bridge of county highway N44, $0.1 \mathrm{mi}$ south of Bedford, 0.4 mi upstream from concrete stablization dam, and $3.0 \mathrm{mi}$ upstream from Daugherty creek.

DRAINAGE AREA. $--85.4 \mathrm{mi}^{2}$.

PERIOD OF RECORD.--October 1983 to current year.

GAGE.-Water-stage recorder. Datum of gage is 1,069.16 ft above NGVD.

REMARKS.--Estimated daily discharges: Dec. 31 to Mar. 13 and July 3-23. Records good except those for estimated daily discharges, which are poor. Slight regulation at low flow by low dam used for water supply in Bedford. National Weather Service gage-height telemeter at station.

EXTREMES FOR CURRENT YEAR.--Peak discharge greater than base 2,000 ft:/s and maximum (*):

$\begin{array}{lccccc}\text { Date } & \text { Time } & \begin{array}{c}\text { Discharge } \\ (\mathrm{ft} / \mathrm{s})\end{array} & \begin{array}{c}\text { Gage height } \\ (\mathrm{ft})\end{array} & \text { Date } & \begin{array}{c}\text { Gage height } \\ \text { (ft) }\end{array} \\ \text { July } 25 & 0345 & * 1,160 & * 15.96 & \text { Time }\end{array}$

Minimum discharge, $0.28 \mathrm{ft} / \mathrm{s}$ Oct. 17 .

DISCHARGE, IN CUBIC FEET PER SECOND, WATER YEAR OCTOBER 1984 TO SEPTEMBER 1985 MEAN VALUES

\begin{tabular}{|c|c|c|c|c|c|c|c|c|c|c|c|c|}
\hline DAY & OCT & NOV & DEC & JAN & FEB & MAR & APR & MAY & JUN & JUL & AUG & SEP \\
\hline $\begin{array}{l}1 \\
2 \\
3 \\
4 \\
5\end{array}$ & $\begin{array}{l}.40 \\
.39 \\
.38 \\
.39 \\
.44\end{array}$ & $\begin{array}{l}9.3 \\
5.4 \\
5.0 \\
3.7 \\
2.1\end{array}$ & $\begin{array}{l}.75 \\
.75 \\
.75 \\
.77 \\
.78\end{array}$ & $\begin{array}{l}.90 \\
.90 \\
.85 \\
.80 \\
.75\end{array}$ & $\begin{array}{l}.70 \\
.70 \\
.70 \\
.70 \\
.70\end{array}$ & $\begin{array}{r}43 \\
220 \\
156 \\
8.0 \\
4.5\end{array}$ & $\begin{array}{c}8.6 \\
9.5 \\
11 \\
7.1 \\
4.8\end{array}$ & $\begin{array}{l}54 \\
12 \\
4.4 \\
2.2 \\
1.6\end{array}$ & $\begin{array}{l}1.3 \\
1.2 \\
1.1 \\
1.3 \\
1.3\end{array}$ & $\begin{array}{l}2.0 \\
2.0 \\
1.9 \\
.70 \\
.58\end{array}$ & $\begin{array}{l}1.9 \\
1.4 \\
1.6 \\
1.3 \\
1.0\end{array}$ & $\begin{array}{l}.66 \\
.66 \\
.66 \\
.67 \\
.67\end{array}$ \\
\hline $\begin{array}{r}6 \\
7 \\
8 \\
9 \\
10\end{array}$ & $\begin{array}{r}.42 \\
.38 \\
.37 \\
.34 \\
.34\end{array}$ & $\begin{array}{r}1.4 \\
.88 \\
.87 \\
.87 \\
.86\end{array}$ & $\begin{array}{l}.79 \\
.80 \\
.81 \\
.82 \\
.83\end{array}$ & $\begin{array}{l}.70 \\
.70 \\
.90 \\
.90 \\
.90\end{array}$ & $\begin{array}{l}.70 \\
.70 \\
.70 \\
.70 \\
.70\end{array}$ & $\begin{array}{c}5.7 \\
6.2 \\
8.7 \\
10 \\
9.4\end{array}$ & $\begin{array}{l}4.0 \\
5.8 \\
3.4 \\
2.6 \\
2.4\end{array}$ & $\begin{array}{l}1.5 \\
1.4 \\
1.2 \\
1.0 \\
.94\end{array}$ & $\begin{array}{r}1.4 \\
1.3 \\
1.3 \\
.91 \\
.95\end{array}$ & $\begin{array}{l}.60 \\
.59 \\
.70 \\
.72 \\
.59\end{array}$ & $\begin{array}{c}5.8 \\
1.9 \\
.91 \\
18^{.89}\end{array}$ & $\begin{array}{l}.66 \\
.66 \\
.66 \\
.66 \\
.65\end{array}$ \\
\hline $\begin{array}{l}11 \\
12 \\
13 \\
14 \\
15\end{array}$ & $\begin{array}{r}.34 \\
.32 \\
.32 \\
.38 \\
.56\end{array}$ & $\begin{array}{l}.83 \\
.80 \\
.79 \\
.79 \\
.79\end{array}$ & $\begin{array}{l}.83 \\
.84 \\
.83 \\
1.2 \\
1.8\end{array}$ & $\begin{array}{l}.90 \\
.85 \\
.85 \\
.80 \\
.80\end{array}$ & $\begin{array}{l}.66 \\
.64 \\
.62 \\
.60 \\
.60\end{array}$ & $\begin{array}{l}8.7 \\
6.8 \\
6.2 \\
5.7 \\
4.3\end{array}$ & $\begin{array}{l}2.5 \\
2.5 \\
3.0 \\
3.2 \\
3.1\end{array}$ & $\begin{array}{r}2.1 \\
9.4 \\
6.0 \\
15 \\
5.8\end{array}$ & $\begin{array}{l}.88 \\
1.1 \\
1.1 \\
1.2 \\
1.1\end{array}$ & $\begin{array}{l}.63 \\
.63 \\
.70 \\
.86 \\
.81\end{array}$ & $\begin{array}{l}1.5 \\
1.4 \\
78^{.89} \\
17\end{array}$ & $\begin{array}{l}.65 \\
.65 \\
.66 \\
.66 \\
.65\end{array}$ \\
\hline $\begin{array}{l}16 \\
17 \\
18 \\
19 \\
20\end{array}$ & $\begin{array}{r}.37 \\
.29 \\
.38 \\
.50 \\
.53\end{array}$ & $\begin{array}{l}.78 \\
.77 \\
.77 \\
.76 \\
.76\end{array}$ & $\begin{array}{l}2.4 \\
1.2 \\
.92 \\
1.1 \\
1.1\end{array}$ & $\begin{array}{l}.80 \\
.80 \\
.80 \\
.80 \\
.80\end{array}$ & $\begin{array}{r}.60 \\
.70 \\
1.0 \\
3.0 \\
25\end{array}$ & $\begin{array}{l}4.1 \\
3.7 \\
3.7 \\
3.5 \\
3.2\end{array}$ & $\begin{array}{l}2.5 \\
2.1 \\
2.0 \\
1.9 \\
1.8\end{array}$ & $\begin{array}{l}3.0 \\
2.1 \\
1.4 \\
1.1 \\
4.3\end{array}$ & $\begin{array}{l}1.2 \\
1.2 \\
1.1 \\
1.1 \\
1.2\end{array}$ & $\begin{array}{l}.83 \\
.88 \\
9.4 \\
94 \\
11\end{array}$ & $\begin{array}{r}3.6 \\
2.4 \\
1.4 \\
1.1 \\
.82\end{array}$ & $\begin{array}{l}.65 \\
.65 \\
.65 \\
.64 \\
.65\end{array}$ \\
\hline $\begin{array}{l}21 \\
22 \\
23 \\
24 \\
25\end{array}$ & $\begin{array}{l}.56 \\
.57 \\
.57 \\
.56 \\
.62\end{array}$ & $\begin{array}{l}.76 \\
.75 \\
.75 \\
.75 \\
.75\end{array}$ & $\begin{array}{l}1.5 \\
1.2 \\
1.2 \\
1.1 \\
1.0\end{array}$ & $\begin{array}{l}.80 \\
.80 \\
.75 \\
.75 \\
.75\end{array}$ & $\begin{array}{r}100 \\
200 \\
350 \\
200 \\
40\end{array}$ & $\begin{array}{l}2.9 \\
2.7 \\
3.3 \\
3.7 \\
3.3\end{array}$ & $\begin{array}{l}1.6 \\
2.0 \\
1.8 \\
1.8 \\
1.7\end{array}$ & $\begin{array}{r}1.7 \\
1.3 \\
.92 \\
.88 \\
.88\end{array}$ & $\begin{array}{r}1.2 \\
1.3 \\
1.6 \\
214 \\
8.7\end{array}$ & $\begin{array}{r}2.9 \\
2.5 \\
1.2 \\
65 \\
557\end{array}$ & $\begin{array}{l}.78 \\
.74 \\
.70 \\
.70 \\
.68\end{array}$ & $\begin{array}{l}.66 \\
.67 \\
.83 \\
3.0 \\
8.4\end{array}$ \\
\hline $\begin{array}{l}26 \\
27 \\
28 \\
29 \\
30 \\
31\end{array}$ & $\begin{array}{l}.68 \\
.71 \\
.77 \\
.81 \\
.83 \\
2.0\end{array}$ & $\begin{array}{l}.75 \\
.76 \\
.76 \\
.76 \\
.75 \\
.--\end{array}$ & $\begin{array}{c}1.5 \\
3.0 \\
10 \\
3.9 \\
2.0 \\
1.2\end{array}$ & $\begin{array}{l}.75 \\
.75 \\
.75 \\
.75 \\
.70 \\
.70\end{array}$ & $\begin{array}{l}29 \\
27 \\
23 \\
- \\
-\end{array}$ & $\begin{array}{l}2.6 \\
3.6 \\
4.2 \\
3.6 \\
4.0 \\
8.2\end{array}$ & $\begin{array}{c}2.0 \\
2.0 \\
1.9 \\
1.7 \\
35 \\
-\end{array}$ & $\begin{array}{l}.88 \\
.88 \\
1.5 \\
1.4 \\
1.5 \\
1.3\end{array}$ & $\begin{array}{c}10 \\
.87 \\
6.8 \\
2.9 \\
1.6 \\
-\end{array}$ & $\begin{array}{l}50 \\
9.3 \\
3.1 \\
1.9 \\
2.7 \\
2.7\end{array}$ & $\begin{array}{l}.66 \\
.66 \\
.66 \\
.66 \\
.66 \\
.66\end{array}$ & $\begin{array}{r}3.6 \\
2.3 \\
2.2 \\
607 \\
503\end{array}$ \\
\hline $\begin{array}{l}\text { TOTAL } \\
\text { MEAN } \\
\text { MAX } \\
\text { MIN } \\
\text { CFSM } \\
\text { IN. } \\
\text { AC-FT }\end{array}$ & $\begin{array}{r}16.52 \\
.53 \\
2.0 \\
.29 \\
.01 \\
.01 \\
33\end{array}$ & $\begin{array}{r}45.76 \\
1.53 \\
9.3 \\
.75 \\
.02 \\
.02 \\
91\end{array}$ & $\begin{array}{r}47.67 \\
1.54 \\
10 \\
.75 \\
.02 \\
.02 \\
95\end{array}$ & $\begin{array}{r}24.75 \\
.80 \\
.90 \\
.70 \\
.01 \\
.01 \\
49\end{array}$ & $\begin{array}{r}1009.42 \\
36.1 \\
350 \\
.60 \\
.42 \\
.44 \\
2000\end{array}$ & $\begin{array}{r}563.5 \\
18.2 \\
220 \\
2.6 \\
.21 \\
1125\end{array}$ & $\begin{array}{r}135.3 \\
4.51 \\
35 \\
1.6 \\
.05 \\
.06 \\
268\end{array}$ & $\begin{array}{r}143.58 \\
4.63 \\
54 \\
.88 \\
.05 \\
.06 \\
285\end{array}$ & $\begin{array}{r}272.21 \\
9.07 \\
214 \\
.87 \\
.11 \\
.12 \\
540\end{array}$ & $\begin{array}{r}828.42 \\
26.7 \\
557 \\
.58 \\
.31 \\
.36 \\
1640\end{array}$ & $\begin{array}{r}150.37 \\
4.85 \\
78 \\
.66 \\
.06 \\
.07 \\
298\end{array}$ & $\begin{array}{r}1144.78 \\
38.2 \\
607 \\
.64 \\
.45 \\
.50 \\
2270\end{array}$ \\
\hline $\begin{array}{ll}\text { CAL } & \text { YR } \\
\text { WTR } & Y R\end{array}$ & $\begin{array}{l}1984 \\
1985\end{array}$ & :AL & $\begin{array}{l}50 \\
28\end{array}$ & $\begin{array}{ll}\text { AN } & 81 \\
\text { AN } & 12\end{array}$ & $\begin{array}{l}\text { MAX } \\
\text { MAX }\end{array}$ & $\begin{array}{r}2370 \\
607\end{array}$ & $\begin{array}{ll}\text { MIN } & .29 \\
\text { MIN } & .29\end{array}$ & $\begin{array}{l}\text { CFSM } \\
\text { CFSM }\end{array}$ & $\begin{array}{l}.95 \\
.14\end{array}$ & $\begin{array}{r}12.94 \\
1.91\end{array}$ & $\begin{array}{l}A C-F T \\
A C-F T\end{array}$ & $\begin{array}{r}58930 \\
8690\end{array}$ \\
\hline
\end{tabular}


LOCATION.--Lat $40^{\circ} 43^{\prime} 18^{\prime \prime}$, long $93^{\circ} 56^{\prime} 12^{\prime \prime}$, near SE corner sec.34, T.69 N., R.27 W., Decatur County, Hydrologic Unit 10280102 , at right downstream corner of bridge on county highway, 1,000 ft downstream from west Elk Creek, $5.2 \mathrm{mi}$ upstream from mouth, and $5.7 \mathrm{mi}$ southwest of Decatur City.

DRAINAGE AREA. $--52.5 \mathrm{mi}^{2}$.

WATER DISCHARGE RECORDS

PERIOD OF RECORD--October 1967 to current year.

GAGE.--Water-stage recorder. Datum of gage is $924.70 \mathrm{ft}$ above NGVD. Oct. 1, 1967, to Sept. 30, 1974, at datum $10.00 \mathrm{ft}$ higher.

REMARKS.--Estimated daily discharges during water year: oct. 1-6, 21-30, Nov, 2, 3, 5-21, Dec. 6 to April 1, May 29 to June 20, July 2-13 and Aug. 6, 18. Records fair except those for periods of estimated discharge, which are poor.

AVERAGE DISCHARGE.--18 years, $29.9 \mathrm{ft} / \mathrm{s}, 7.73 \mathrm{in} / \mathrm{yr}, 21,660$ acre-ft/yr, median of yearly mean discharges, 25 $\mathrm{ft}^{\prime} / \mathrm{s}, 6.5 \mathrm{in} / \mathrm{yr}, 18,100 \mathrm{acre}-\mathrm{ft} / \mathrm{yr}$.

EXTREMES FOR PERIOD OF RECORD.--Maximum discharge, 16,400 ft'/s June 2, 1980, gage height, $28.22 \mathrm{ft}$, from rating curve extended above $5,300 \mathrm{ft} / \mathrm{s}$ on basis of step-backwater computation; no flow at times most years.

EXTREMES OUTSIDE PERIOD OF RECORD.--Flood of June 14, 1967, reached a stage of $18.35 \mathrm{ft}$, datum in use prior to Oct. 1, 1974, discharge, $17,800 \mathrm{ft}^{2} / \mathrm{s}$, estimated from rating curve extended above $5,300 \mathrm{ft} / \mathrm{s}$ on basis of stepbackwater computation. Flood of Aug. 6, 1959 , reached a stage between 20.5 and 22.5 ft, datum in use prior to Oct. $1,1974,300 \mathrm{ft}$ downstream, from information by assistant county engineer, discharge not determined.

EXTREMES FOR CURRENT YEAR.--Peak discharges greater than base of $500 \mathrm{ft} / \mathrm{s}$ and maximum (*):

\begin{tabular}{|c|c|c|c|c|c|c|c|}
\hline $\begin{array}{l}\text { Date } \\
\text { Feb. } 21 \\
\text { Mar. } 3\end{array}$ & $\begin{array}{l}\text { Time } \\
1100\end{array}$ & $\begin{array}{c}\text { Discharge } \\
\left(f t^{3} / \mathrm{s}\right) \\
550 \\
1,250\end{array}$ & $\begin{array}{c}\text { Gage height } \\
\text { ( } f t) \\
\text { ice jam } \\
15.65\end{array}$ & $\begin{array}{l}\text { Date } \\
\text { Sept. } 29\end{array}$ & $\begin{array}{l}\text { Time } \\
2215\end{array}$ & $\begin{array}{c}\text { Discharge } \\
\left(f t^{2} / \mathrm{s}\right) \\
\star 1550\end{array}$ & $\begin{array}{c}\text { Gage height } \\
\text { (ft) } \\
* 16.23\end{array}$ \\
\hline
\end{tabular}

No flow Oct. 1-6, July 28,29 , Aug. 7,8 and Sept. 16, 18-20.

DISCHARGE, IN CUBIC FEET PER SECOND, WATER YEAR OCTOBER 1984 TO SEPTEMBER 1985 MEAN WATER YEAR

\begin{tabular}{|c|c|c|c|c|c|c|c|c|c|c|c|c|}
\hline DAY & OCT & NOV & DEC & JAN & FEB & MAR & APR & MAY & JUN & JUL & AUG & SEP \\
\hline $\begin{array}{l}1 \\
2 \\
3 \\
4 \\
5\end{array}$ & $\begin{array}{l}.00 \\
.00 \\
.00 \\
.00 \\
.00\end{array}$ & $\begin{array}{r}24 \\
8.0 \\
5.0 \\
1.4 \\
1.0\end{array}$ & $\begin{array}{r}1.6 \\
1.4 \\
.77 \\
.59 \\
.47\end{array}$ & $\begin{array}{l}.98 \\
.96 \\
.93 \\
.95 \\
1.0\end{array}$ & $\begin{array}{l}.77 \\
.76 \\
.74 \\
.74 \\
.73\end{array}$ & $\begin{array}{c}15 \\
6.7 \\
248 \\
183 \\
38\end{array}$ & $\begin{array}{l}23 \\
17 \\
14 \\
12 \\
10\end{array}$ & $\begin{array}{l}10 \\
9.7 \\
6.4 \\
6.0 \\
5.6\end{array}$ & $\begin{array}{r}1.1 \\
2.8 \\
1.5 \\
1.1 \\
.80\end{array}$ & $\begin{array}{l}.21 \\
.13 \\
.09 \\
.06 \\
.04\end{array}$ & $\begin{array}{l}.56 \\
.04 \\
.07 \\
.15 \\
.06\end{array}$ & $\begin{array}{r}1.1 \\
.78 \\
.41 \\
.34 \\
.36\end{array}$ \\
\hline $\begin{array}{r}6 \\
7 \\
8 \\
9 \\
10\end{array}$ & $\begin{array}{l}.00 \\
2.4 \\
3.0 \\
3.8 \\
3.0\end{array}$ & $\begin{array}{l}.86 \\
.75 \\
.62 \\
.54 \\
.72\end{array}$ & $\begin{array}{l}.43 \\
.39 \\
.44 \\
.50 \\
.58\end{array}$ & $\begin{array}{l}1.0 \\
1.0 \\
1.0 \\
1.0 \\
.98\end{array}$ & $\begin{array}{l}.71 \\
.71 \\
.71 \\
.70 \\
.70\end{array}$ & $\begin{array}{l}28 \\
27 \\
22 \\
19 \\
18\end{array}$ & $\begin{array}{r}11 \\
8.5 \\
7.6 \\
7.5 \\
7.8\end{array}$ & $\begin{array}{l}5.9 \\
8.5 \\
5.5 \\
4.0 \\
3.5\end{array}$ & $\begin{array}{l}.68 \\
.60 \\
.55 \\
.50 \\
.46\end{array}$ & $\begin{array}{l}.03 \\
.03 \\
.02 \\
.02 \\
.02\end{array}$ & $\begin{array}{l}.03 \\
.00 \\
.00 \\
.86 \\
5.6\end{array}$ & $\begin{array}{l}.66 \\
.26 \\
.37 \\
.50 \\
.25\end{array}$ \\
\hline $\begin{array}{l}11 \\
12 \\
13 \\
14 \\
15\end{array}$ & $\begin{array}{l}2.2 \\
1.9 \\
1.3 \\
1.1 \\
2.6\end{array}$ & $\begin{array}{l}2.2 \\
1.4 \\
1.0 \\
.83 \\
.70\end{array}$ & $\begin{array}{l}.78 \\
.66 \\
.70 \\
.76 \\
1.2\end{array}$ & $\begin{array}{l}1.1 \\
.93 \\
.98 \\
.94 \\
.98\end{array}$ & $\begin{array}{r}.70 \\
.70 \\
.70 \\
.72 \\
1.9\end{array}$ & $\begin{array}{l}18 \\
18 \\
17 \\
14 \\
12\end{array}$ & $\begin{array}{l}7.9 \\
7.2 \\
6.9 \\
6.9 \\
7.1\end{array}$ & $\begin{array}{l}3.1 \\
4.2 \\
2.4 \\
2.5 \\
2.2\end{array}$ & $\begin{array}{l}.44 \\
.47 \\
.50 \\
.52 \\
.57\end{array}$ & $\begin{array}{l}.02 \\
.02 \\
.02 \\
.06 \\
6.8\end{array}$ & $\begin{array}{r}2.2 \\
1.8 \\
2.5 \\
18 \\
2.4\end{array}$ & $\begin{array}{l}.21 \\
.08 \\
.10 \\
.12 \\
.03\end{array}$ \\
\hline $\begin{array}{l}16 \\
17 \\
18 \\
19 \\
20\end{array}$ & $\begin{array}{l}5.7 \\
1.3 \\
4.3 \\
6.2 \\
4.8\end{array}$ & $\begin{array}{l}.62 \\
.54 \\
.66 \\
1.4 \\
1.0\end{array}$ & $\begin{array}{l}1.9 \\
1.0 \\
.52 \\
.33 \\
.37\end{array}$ & $\begin{array}{l}.98 \\
.93 \\
.93 \\
.95 \\
.90\end{array}$ & $\begin{array}{l}5.4 \\
64 \\
86 \\
150 \\
470\end{array}$ & $\begin{array}{l}12 \\
10 \\
10 \\
10 \\
8.6\end{array}$ & $\begin{array}{l}6.3 \\
6.1 \\
5.9 \\
5.7 \\
5.4\end{array}$ & $\begin{array}{l}2.5 \\
2.0 \\
1.8 \\
1.3 \\
2.2\end{array}$ & $\begin{array}{l}.65 \\
.76 \\
.62 \\
.52 \\
.46\end{array}$ & $\begin{array}{l}.75 \\
.17 \\
.04 \\
6.7 \\
2.8\end{array}$ & $\begin{array}{l}1.1 \\
1.1 \\
1.3 \\
6.0 \\
1.8\end{array}$ & $\begin{array}{l}.00 \\
.01 \\
.00 \\
.00 \\
.00\end{array}$ \\
\hline $\begin{array}{l}21 \\
22 \\
23 \\
24 \\
25\end{array}$ & $\begin{array}{l}3.5 \\
2.1 \\
1.8 \\
1.5 \\
2.6\end{array}$ & $\begin{array}{r}.90 \\
.78 \\
.85 \\
1.1 \\
1.0\end{array}$ & $\begin{array}{l}.46 \\
.60 \\
.90 \\
.74 \\
.60\end{array}$ & $\begin{array}{l}.89 \\
.88 \\
.87 \\
.86 \\
.85\end{array}$ & $\begin{array}{r}530 \\
250 \\
130 \\
76 \\
31\end{array}$ & $\begin{array}{l}8.2 \\
8.2 \\
8.9 \\
8.2 \\
8.6\end{array}$ & $\begin{array}{l}5.1 \\
5.0 \\
5.8 \\
5.2 \\
4.6\end{array}$ & $\begin{array}{l}1.7 \\
.89 \\
.17 \\
.56 \\
.68\end{array}$ & $\begin{array}{r}.36 \\
.79 \\
32.5 \\
.91\end{array}$ & $\begin{array}{c}1.1 \\
.54 \\
.38 \\
15\end{array}$ & $\begin{array}{l}2.5 \\
46 \\
2.9 \\
1.2 \\
1.2\end{array}$ & $\begin{array}{c}1.67 \\
104 \\
15 \\
5.5\end{array}$ \\
\hline $\begin{array}{l}26 \\
27 \\
28 \\
29 \\
30 \\
31\end{array}$ & $\begin{array}{l}2.1 \\
1.8 \\
1.5 \\
1.3 \\
1.1 \\
12\end{array}$ & $\begin{array}{l}.89 \\
1.1 \\
1.2 \\
.80 \\
1.1 \\
-.-\end{array}$ & $\begin{array}{l}.64 \\
1.6 \\
3.0 \\
1.8 \\
1.3 \\
1.1\end{array}$ & $\begin{array}{l}.83 \\
.81 \\
.80 \\
.79 \\
.78 \\
.78\end{array}$ & $\begin{array}{c}15 \\
7.1 \\
6.4 \\
- \\
-.- \\
-.-\end{array}$ & $\begin{array}{c}7.3 \\
7.9 \\
10 \\
7.6 \\
8.9 \\
28\end{array}$ & $\begin{array}{l}4.8 \\
6.2 \\
5.1 \\
4.4 \\
22 \\
-.-\end{array}$ & $\begin{array}{l}.15 \\
.60 \\
.63 \\
.56 \\
.51 \\
.45\end{array}$ & $\begin{array}{l}1.1 \\
1.6 \\
1.3 \\
.95 \\
.37 \\
.--\end{array}$ & $\begin{array}{l}.99 \\
.18 \\
.00 \\
.00 \\
.40 \\
1.7\end{array}$ & $\begin{array}{l}.47 \\
.25 \\
.27 \\
.54 \\
.91 \\
.97\end{array}$ & $\begin{array}{r}7.4 \\
8.7 \\
9.9 \\
343 \\
306\end{array}$ \\
\hline $\begin{array}{l}\text { TOTAL } \\
\text { MEAN } \\
\text { MAX } \\
\text { MIN } \\
\text { CESM } \\
\text { IN. } \\
\text { AC-ET }\end{array}$ & $\begin{array}{r}74.90 \\
2.42 \\
12 \\
.00 \\
.05 \\
.05 \\
149\end{array}$ & $\begin{array}{r}62.96 \\
2.10 \\
24 \\
.54 \\
.04 \\
.04 \\
125\end{array}$ & $\begin{array}{r}28.13 \\
.91 \\
3.0 \\
.33 \\
.02 \\
.02 \\
56\end{array}$ & $\begin{array}{r}28.56 \\
.92 \\
1.1 \\
.78 \\
.02 \\
.02 \\
57\end{array}$ & $\begin{array}{r}1832.89 \\
65.5 \\
530 \\
.70 \\
1.25 \\
1.30 \\
3640\end{array}$ & $\begin{array}{r}846.1 \\
27.3 \\
248 \\
6.7 \\
.52 \\
.60 \\
1680\end{array}$ & $\begin{array}{r}252.0 \\
8.40 \\
23 \\
4.4 \\
.16 \\
.18 \\
500\end{array}$ & $\begin{array}{r}96.20 \\
3.10 \\
10 \\
.15 \\
.06 \\
.07 \\
191\end{array}$ & $\begin{array}{r}64.48 \\
2.15 \\
32 \\
.36 \\
.04 \\
.05 \\
128\end{array}$ & $\begin{array}{r}38.82 \\
1.25 \\
15 \\
.00 \\
.02 \\
.03 \\
77\end{array}$ & $\begin{array}{r}102.78 \\
3.32 \\
46 \\
.00 \\
.06 \\
.07 \\
204\end{array}$ & $\begin{array}{r}806.85 \\
26.9 \\
343 \\
.00 \\
.51 \\
.57 \\
1600\end{array}$ \\
\hline $\begin{array}{l}\text { CAL YF } \\
\text { WTR YF }\end{array}$ & $\begin{array}{l}984 \\
985\end{array}$ & $\begin{array}{l}\text { TOTAL } \\
\text { TOTAL }\end{array}$ & $\begin{array}{l}.21 \\
.67\end{array}$ & $\begin{array}{l}\text { MEAN } \\
\text { MEAN }\end{array}$ & $\begin{array}{l}\text { MAX } \\
\text { MAX }\end{array}$ & $\begin{array}{l}843 \\
530\end{array}$ & $\begin{array}{l}.00 \\
.00\end{array}$ & $\begin{array}{l}\text { CESM } \\
\text { CFSM }\end{array}$ & $\begin{array}{l}.64 \\
.22\end{array}$ & $\begin{array}{l}8.75 \\
3.00\end{array}$ & $\begin{array}{l}A C-F T \\
A C-F T\end{array}$ & $\begin{array}{r}24490 \\
8400\end{array}$ \\
\hline
\end{tabular}


WATER-QUALITY RECORDS

PERIOD OF RECORD.--Water years 1968 to current year.

REMARKS.--Miscellaneous biological data collected September 1970 to september 1972 are available in the District office.

WATER QUALITY DATA, WATER YEAR OCTOBER 1984 TO SEPTEMBER 1985

\begin{tabular}{|c|c|c|c|c|c|c|c|c|c|c|c|}
\hline ATE & TIME & $\begin{array}{l}\text { STREAM- } \\
\text { FLOW, } \\
\text { INSTAN- } \\
\text { TANEOUS } \\
\text { (CFS) } \\
(00061)\end{array}$ & $\begin{array}{l}\text { SPE- } \\
\text { CIFIC } \\
\text { CON- } \\
\text { DUCT- } \\
\text { ANCE } \\
\text { (US/CM) } \\
(00095)\end{array}$ & $\begin{array}{c}\text { PH } \\
\text { (STAND- } \\
\text { ARD } \\
\text { UN ITS) } \\
(00400)\end{array}$ & $\begin{array}{l}\text { TEMPER- } \\
\text { ATURE } \\
\text { (DEG C) } \\
(00010)\end{array}$ & $\begin{array}{c}\text { TUR- } \\
\text { BID- } \\
\text { ITY } \\
\text { (NTU) } \\
(00076)\end{array}$ & $\begin{array}{c}\text { OXYGEN, } \\
\text { DIS- } \\
\text { SOLVED } \\
\text { (MG/L) } \\
(00300)\end{array}$ & $\begin{array}{c}\text { OXYGEN, } \\
\text { DIS- } \\
\text { SOLVED } \\
\text { (PER- } \\
\text { CENT } \\
\text { SATUR- } \\
\text { ATION) } \\
\text { (0030I) }\end{array}$ & $\begin{array}{l}\text { BARO- } \\
\text { METRIC } \\
\text { PRES- } \\
\text { SURE } \\
\text { (MM } \\
\text { OF } \\
\text { HG) } \\
(00025)\end{array}$ & $\begin{array}{l}\text { COLI- } \\
\text { FORM, } \\
\text { FECAL, } \\
0.7 \\
\text { UM-MF } \\
\text { (COLS. } \\
100 \mathrm{ML}) \\
(31625)\end{array}$ & $\begin{array}{c}\text { STREP- } \\
\text { TOCOCCI } \\
\text { FECAL, } \\
\text { KF AGAR } \\
\text { (COLS. } \\
\text { PER } \\
100 \text { ML) } \\
(31673)\end{array}$ \\
\hline
\end{tabular}

NOV 198

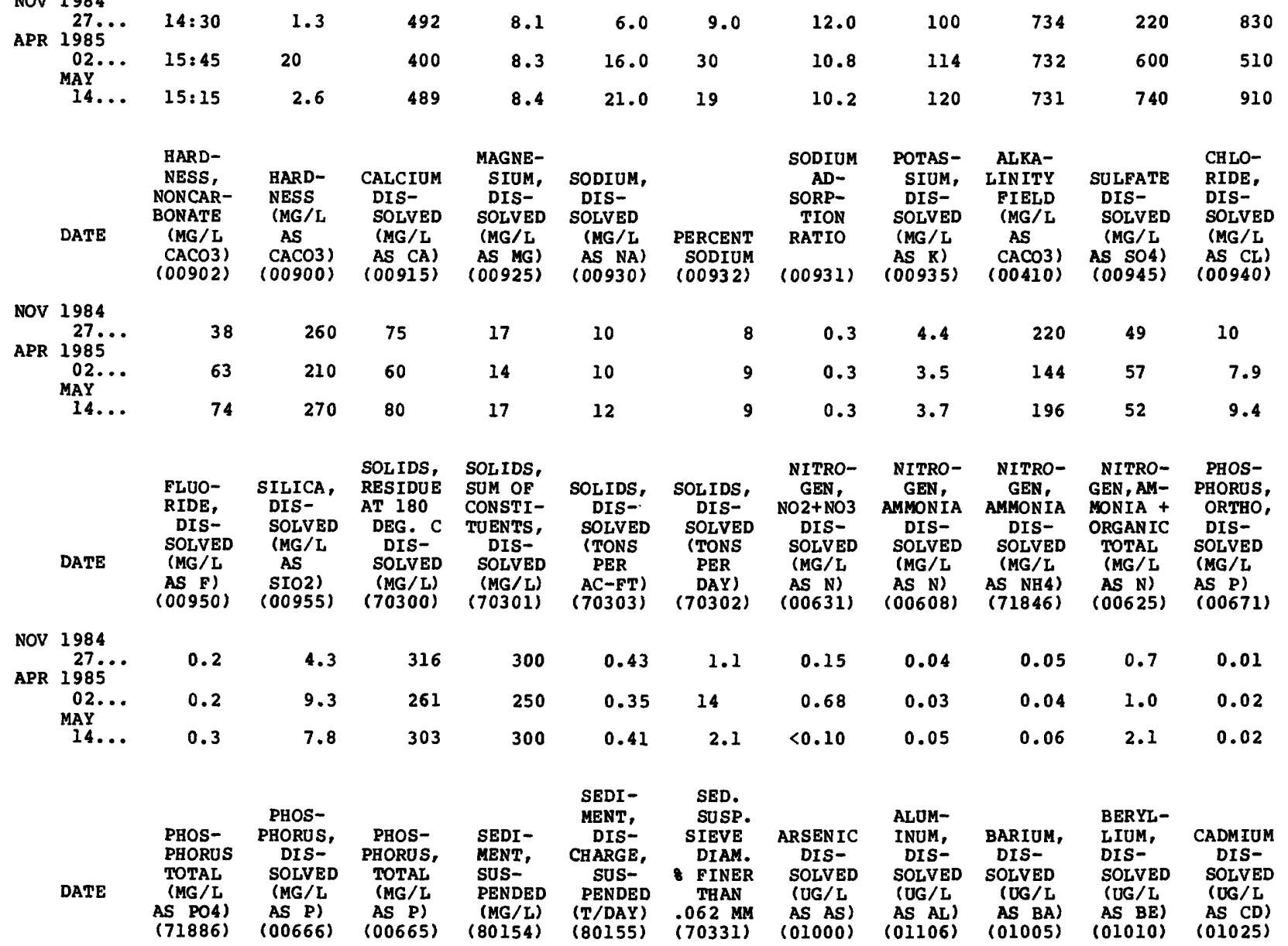

NOV 1984

\begin{tabular}{|c|c|c|c|c|c|c|c|c|c|c|c|}
\hline $27 \ldots$ & - & 0.03 & 0.07 & 39 & 0.14 & 92 & $<1$ & 10 & 110 & $<0.5$ & $<1$ \\
\hline & - & 0.03 & 0.10 & 72 & 3.9 & 99 & - & -- & - & - & - \\
\hline 14 & 0.28 & 0.05 & 0.09 & 62 & 0.44 & 97 & $<1$ & $<10$ & 110 & $<0.5$ & $<1$ \\
\hline
\end{tabular}


06897950 ELK CREEK NEAR DECATUR CITY, IA--Continued

WATER-QUALITY RECORDS

WATER QUALITY DATA, WATER YEAR OCTOBER 1984 TO SEPTEMBER 1985

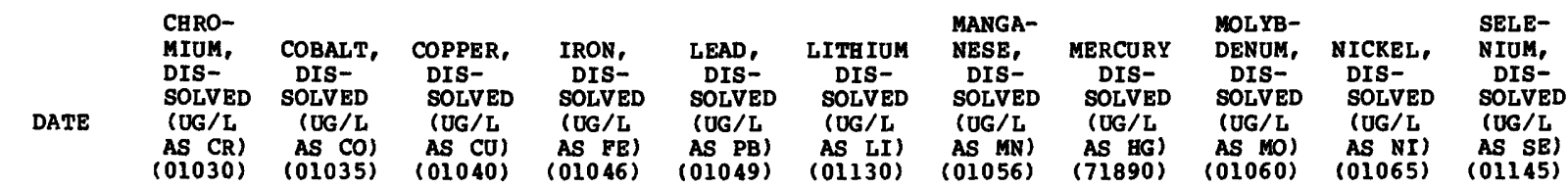

NOV 1984

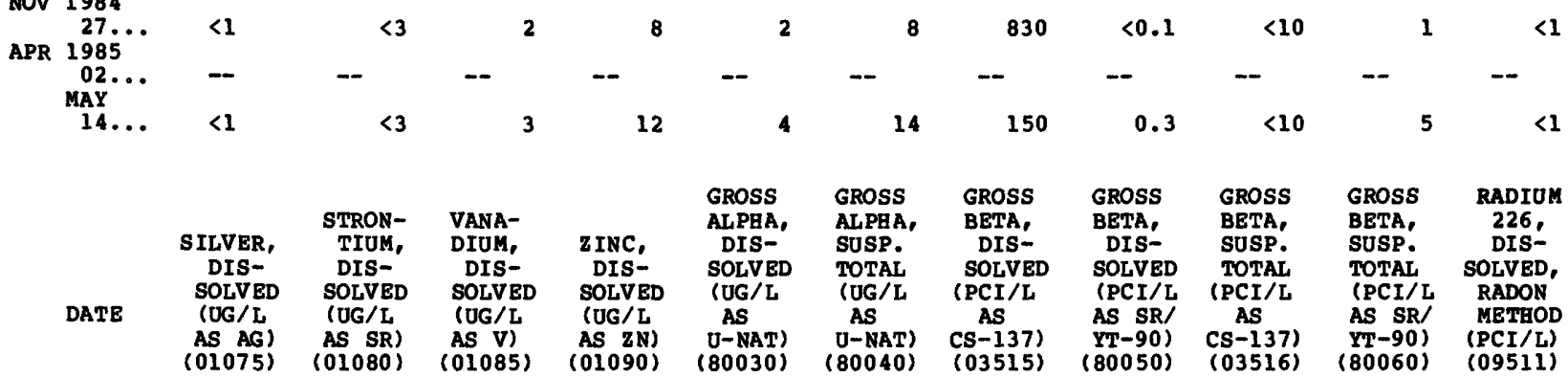

NOV 1984

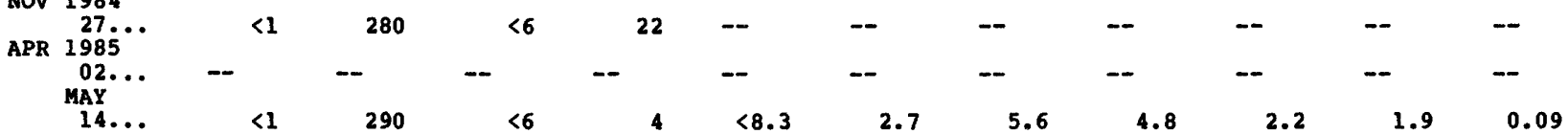


LOCATION.--Lat $40^{\circ} 38^{\prime} 25^{\prime \prime}$, long $93^{\circ} 48^{\prime} 29^{\prime \prime}$, in SEl/4 SE1/4 sec.35, T.68 N., R.26 w., Decatur County, Hydrologic Unit 10280102 , on right bank $15 \mathrm{ft}$ downstream from bridge on U.S. Highway 69 at Davis City, 2.6 mi upstream from Dickersons Branch, and $5.2 \mathrm{mi}$ upstream from Iowa-Missouri state line.

DRAINAGE AREA. $--701 \mathrm{mi}^{2}$.

PERIOD OF RECORD.--May 1918 to July 1925, July 1941 to current year. Monthly discharge only for some periods, published in WSP 1310. Prior to October 1918, published as "Grand River".

REVISED RECORDS.--WSP 1240: 1918, 1920-21 (M), 1922-24, 1925 (M), 1946-47 (M). WSP 1440: Drainage area. WSP 1710 : 1957

GAGE.-Water-stage recorder. Datum of gage is $874.04 \mathrm{ft}$ above NGvD. May 14, 1918, to July 2, 1925, July 14, 1941, to Feb. 24, 1942, nonrecording gage, and Feb. 25, 1942, to Feb. 8, 1967, water-stage recorder at same site at datum $2.00 \mathrm{ft}$ higher.

REMARKS.--Estimated daily discharges during water year: Dec 4. to Feb. 22 . Records good except those for periods of estimated discharges, which are fair. 0.S. National Weather Service gage-height telemeter at station.

AVERAGE DISCHARGE.--50 years (water years 1919-24,1942-85), 371 ft'/s, 7.19 in/yr, 268,800 acre-ft/yr; median of yearly mean discharges, $320 \mathrm{ft} / \mathrm{s}, 6.2 \mathrm{in} / \mathrm{yr} 232,000$ acre-ft/yr.

EXTREMES FOR PERIOD OF RECORD.--Maximum discharge, 24,300 ft'/s June 10, 1974, gage height, 19.43 ft, from rating curve extended above $17,000 \mathrm{ft} / \mathrm{s}$ on basis of velocity-area study; minimum daily, $0.1 \mathrm{ft} / \mathrm{s}$ June 25 , 1956 .

EXTREMES OUTSIDE PERIOD OF RECORD.--Flood of Aug. 8, 1885 , reached a stage of $22.8 \mathrm{ft}$, datum in use prior to Feb. 9, 1967, from floodmark, discharge, $30,000 \mathrm{ft} / \mathrm{s}$, from rating curve extended as explained above.

EXTREMES FOR CURRENT YEAR.--Peak discharges greater than base of 4,500 ft'/s and maximum (*):

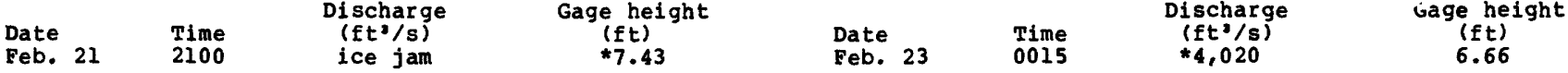

Minimum discharge, $4.0 \mathrm{ft}^{3} / \mathrm{s}$ Sept.18-20.

DISCHARGE, IN CUBIC FEET PER SECOND, WATER YEAR OCTOBER 1984 TO SEPTEMBER 1985 MEAN VALUES

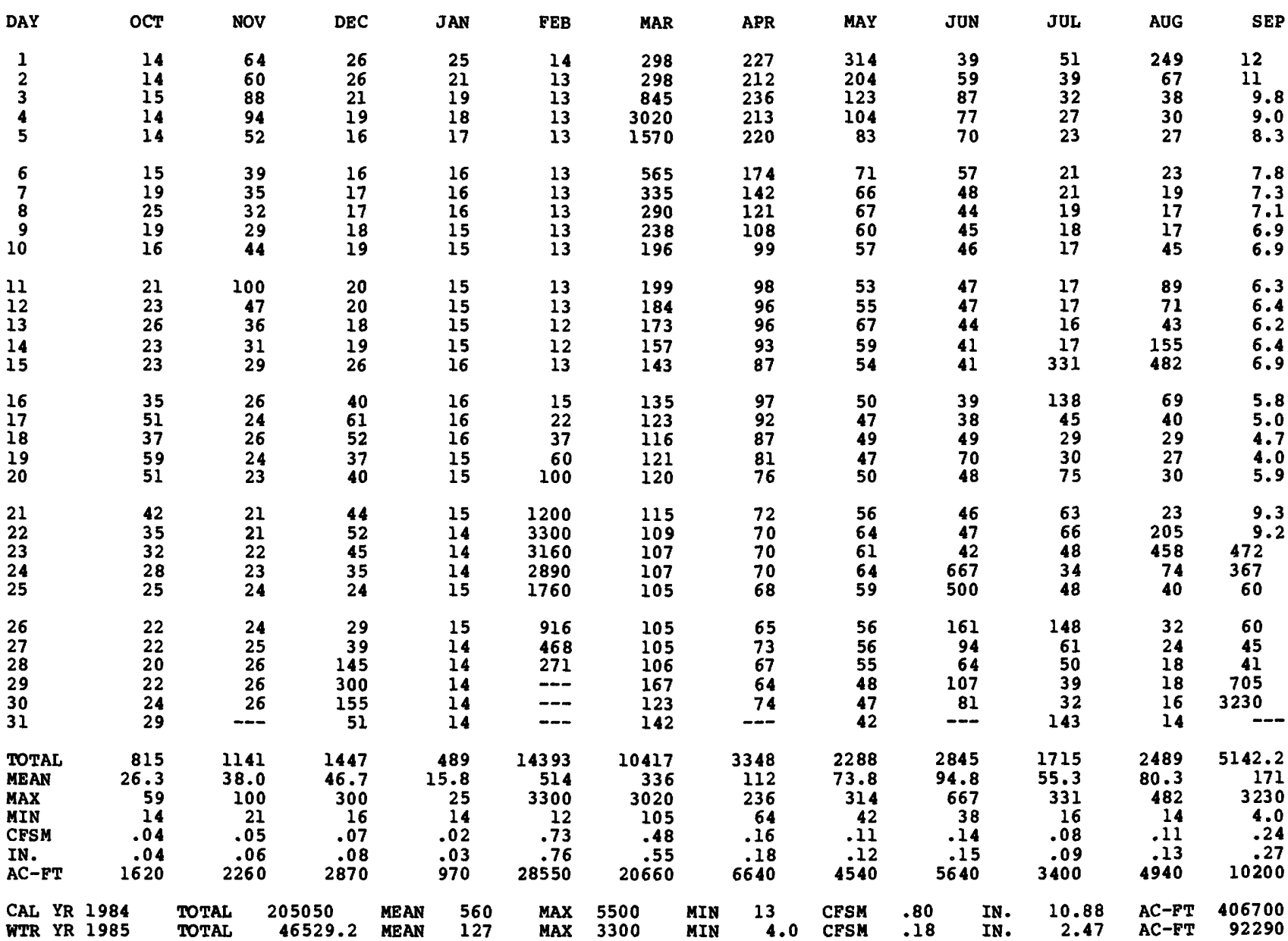


06898400 WELDON RIVER NEAR LEON, IA

LOCATION-Lat $40^{\circ} 41^{\prime} 45$, long $93^{\circ} 38^{\prime} 07^{\prime \prime}$, in NEl/4 NEl/4 sec.17, T.68 N., R. 24 W., Decatur County, Bydrologic Unit

10280102, on left bank $10 \mathrm{ft}$ downstream from bridge on county highway A, $200 \mathrm{ft}$ upstream from unnamed creek,

$1.3 \mathrm{mi}$ downstream from Brush Creek, and $6.5 \mathrm{mi}$ southeast of post office at Leon.

DRAINAGE AREA. $--104 \mathrm{mi}^{2}$.

PERIOD OF RECORD,--October 1958 to current year.

GAGE.--Water-8tage recorder. Datum of gage is $906.26 \mathrm{ft}$ above NGVD.

REMARKS.--Estimated daily discharge: Nov. 12-26 and Dec. 7 to April 1 . Records fair except those for periods of estimated record, which are poor.

AVERAGE DISCHARGE, - -27 years, $70.2 \mathrm{ft} / \mathrm{s}, 9.17$ in/yr, 50,860 acre-ft/yr; median of yearly mean discharges, 59 ft' $/ 8,7.7 \mathrm{in} / \mathrm{Yr}, 42,700$ acre-ft/yr.

EXTREMES FOR PERIOD OF RECORD.--Maximum discharge, 48,600 ft/s Aug. 6, 1959, gage height, 25.27 ft, from rating curve extended above $5,600 \mathrm{ft} / \mathrm{s}$ on basis of contracted-opening and flow-over-embankment measurement at gage height $25.27 \mathrm{ft}$; no flow at times.

EXTREMES OUTSIDE PERIOD OF RECORD,--stage and discharge of the flood of Aug. 6 , 1959 are the greatest since at least 1919 .

EXTREMES FOR CURRENT YEAR.--Peak discharges gtreater than base discharge of $4,500 \mathrm{ft} \% / 8$ and maximum (*):

$\begin{array}{lccc}\text { Date } & \text { Time } & \begin{array}{c}\text { Discharge } \\ (f t / 8)\end{array} & \text { Gage height } \\ \text { Sept. } 29 & 2000 & * 2,840 & * 12.28\end{array}$

Minimum daily discharge, .07 cfs sept. 10. No flow part of each day on many days.

DISCHARGE, IN CUBIC FEET PER SECOND, WATER YEAR OCTOBER 1984 TO SEPTEMBER 1985 MEAN VALUES

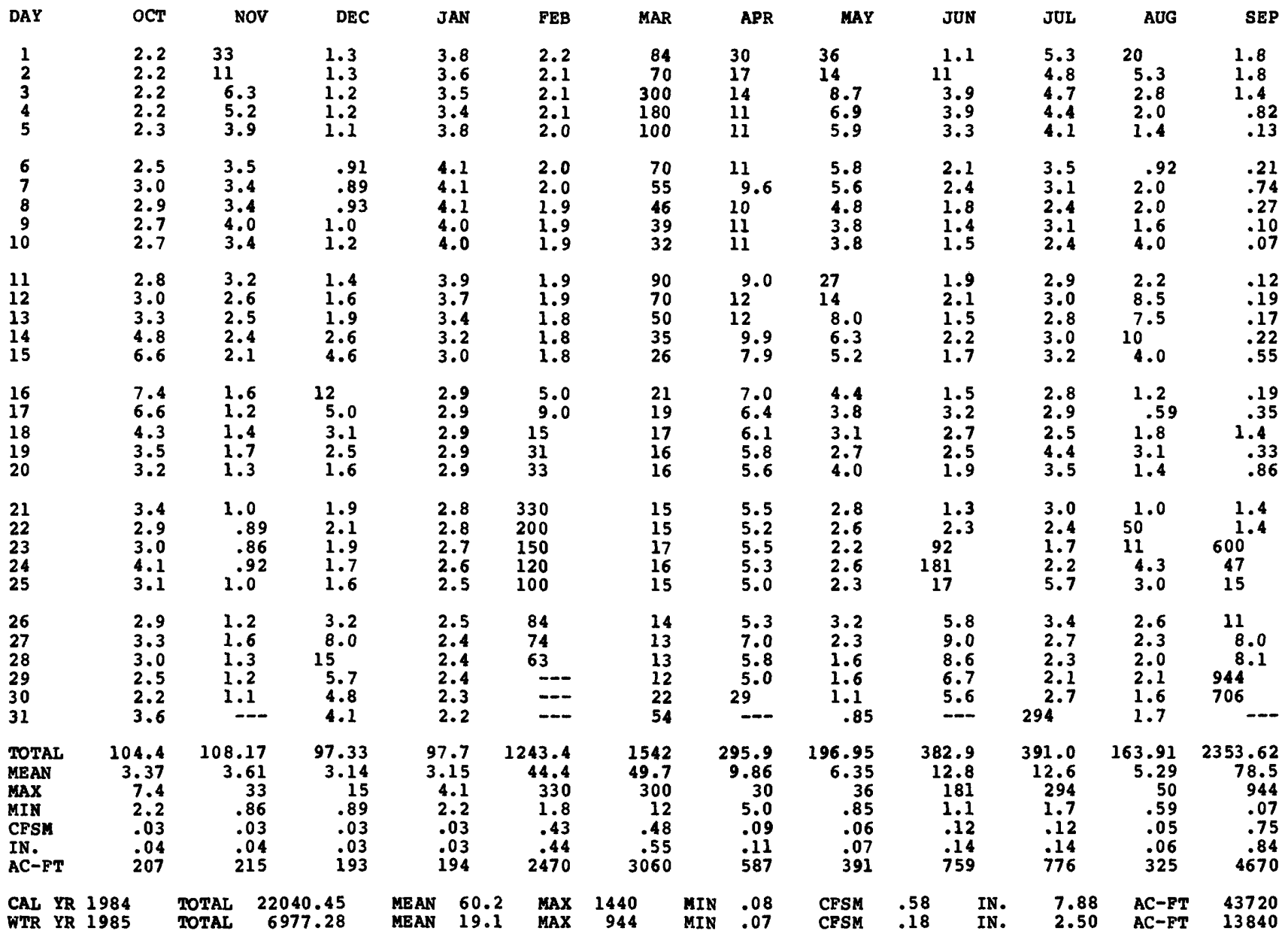




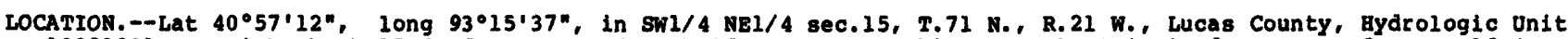
10280201 , on right bank $15 \mathrm{ft}$ downstream from bridge on county highway $\mathrm{s43}, 0.4 \mathrm{mi}$ downstream from wolf Creek and $5.0 \mathrm{mi}$ southeast of Chariton.

DRAINAGE AREA. $--182 \mathrm{~mL}^{2}$.

PERIOD OF RECORD.--October 1965 to current year. Occasional low-flow measurements, water years 1958-60, 1962, 1964 .

GAGE.--Water-stage recorder. Datum of gage is $917.90 \mathrm{ft}$ above NGVD (U.S. Army Corps of Engineers bench mark).

REMARRs.--Estimated daily discharges during water year: Oct. 1-4, 6-15, Nov. 8-10, 14-17, 22-25, Dec. 2 to March 1. March 22-27, May 28-31, and Sept. 7-16. Records fair except those for periods of estimated record, which are poor. U.S. Army Corps of Engineers data collection platform at the station.

AVERAGE DISCHARGE. - 20 years, $113 \mathrm{ft} / 8,8.43 \mathrm{in} / \mathrm{yr}, 81,870$ acre-ft/yr; median of yearly mean discharges, 92 $f t^{2} / 8,6.9$ in $/ y r, 66,700$ acre-ft/yr.

EXTREMES FOR PERIOD OF RECORD.--Maximum discharge, $16,600 \mathrm{ft} / \mathrm{s}$ July 4, 1981, gage height, $23.14 \mathrm{ft}$; no flow Aug. 1,1977 .

EXTREMES OUTSIDE PERIOD OF RECORD. --Flood in March 1960 reached a stage of about $23 \mathrm{ft}$, discharge, about 15,000 $\mathrm{ft}^{\prime} / \mathrm{s}$ and flood of June 5,1947 reached a stage of $21.65 \mathrm{ft}$, from floodmark, discharge, $11,000 \mathrm{ft} / \mathrm{s}$. A discharge of $0.08 \mathrm{ft}^{3} / \mathrm{s}$ was measured on Oct. $30,1963$.

EXTREMES FOR CURRENT YEAR.--Peak discharges greater than base of $1,600 \mathrm{ft} / \mathrm{s}$ and maximum $(*)$ :

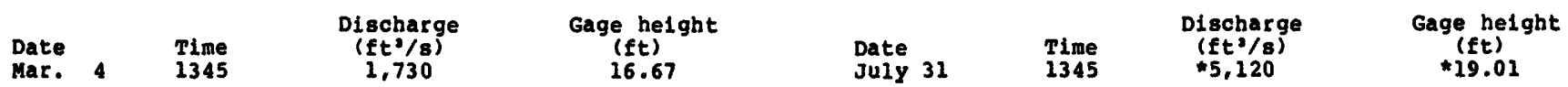

Minimum discharge, $0.42 \mathrm{ft} / \mathrm{s}$ July 29 , Sept.17.

DISCHARGE, IN CUBIC PEET PER SECOND, WATER YEAR OCTOBER 1984 TO SEPTEMBER 1985

\begin{tabular}{|c|c|c|c|c|c|c|c|c|c|c|c|c|}
\hline DAY & OCT & nov & DEC & JAN & FEB & MAR & APR & MAY & JUN & JUL & AUG & SEP \\
\hline $\begin{array}{l}1 \\
2 \\
3 \\
4 \\
5\end{array}$ & $\begin{array}{l}.85 \\
.83 \\
.76 \\
.74 \\
.72\end{array}$ & $\begin{array}{l}12 \\
17 \\
8.4 \\
8.2 \\
9.8\end{array}$ & $\begin{array}{l}.95 \\
.95 \\
.75 \\
.65 \\
.60\end{array}$ & $\begin{array}{l}15 \\
11 \\
7.7 \\
6.3 \\
6.5\end{array}$ & $\begin{array}{l}3.7 \\
3.3 \\
3.0 \\
2.9 \\
2.9\end{array}$ & $\begin{array}{r}110 \\
109 \\
307 \\
1570 \\
873\end{array}$ & $\begin{array}{l}65 \\
55 \\
45 \\
35 \\
28\end{array}$ & $\begin{array}{l}11 \\
8.0 \\
4.6 \\
3.4 \\
2.8\end{array}$ & $\begin{array}{r}.98 \\
.94 \\
.89 \\
.95 \\
1.1\end{array}$ & $\begin{array}{l}5.8 \\
3.6 \\
2.3 \\
2.0 \\
1.6\end{array}$ & $\begin{array}{r}1780 \\
1310 \\
761 \\
91 \\
37\end{array}$ & $\begin{array}{l}3.8 \\
3.1 \\
3.1 \\
2.4 \\
2.4\end{array}$ \\
\hline $\begin{array}{r}6 \\
7 \\
8 \\
9 \\
10\end{array}$ & $\begin{array}{l}.72 \\
.94 \\
1.3 \\
1.6 \\
1.3\end{array}$ & $\begin{array}{l}3.3 \\
1.0 \\
.66 \\
.70 \\
.80\end{array}$ & $\begin{array}{l}.56 \\
.54 \\
.60 \\
.56 \\
.74\end{array}$ & $\begin{array}{l}7.0 \\
7.1 \\
6.9 \\
7.2 \\
7.2\end{array}$ & $\begin{array}{l}2.9 \\
2.9 \\
2.8 \\
2.8 \\
2.8\end{array}$ & $\begin{array}{r}824 \\
204 \\
99 \\
73 \\
60\end{array}$ & $\begin{array}{l}24 \\
19 \\
15 \\
12 \\
11\end{array}$ & $\begin{array}{l}2.6 \\
2.8 \\
2.5 \\
2.0 \\
1.9\end{array}$ & $\begin{array}{l}1.4 \\
1.3 \\
1.3 \\
1.0 \\
.92\end{array}$ & $\begin{array}{l}1.1 \\
.96 \\
1.2 \\
1.5 \\
1.9\end{array}$ & $\begin{array}{l}22 \\
12 \\
7.0 \\
4.4 \\
5.6\end{array}$ & $\begin{array}{l}2.2 \\
1.7 \\
1.4 \\
1.2 \\
1.0\end{array}$ \\
\hline $\begin{array}{l}11 \\
12 \\
13 \\
14 \\
15\end{array}$ & $\begin{array}{l}2.3 \\
3.0 \\
3.4 \\
2.7 \\
1.8\end{array}$ & $\begin{array}{r}1.6 \\
2.3 \\
1.1 \\
.90 \\
.80\end{array}$ & $\begin{array}{l}.78 \\
1.0 \\
1.1 \\
1.5 \\
3.5\end{array}$ & $\begin{array}{l}7.3 \\
6.8 \\
6.8 \\
7.3 \\
6.8\end{array}$ & $\begin{array}{l}2.7 \\
2.7 \\
2.7 \\
2.6 \\
2.7\end{array}$ & $\begin{array}{l}62 \\
66 \\
59 \\
51 \\
39\end{array}$ & $\begin{array}{r}11 \\
9.8 \\
9.4 \\
9.2 \\
8.8\end{array}$ & $\begin{array}{c}3.0 \\
36 \\
8.9 \\
7.3 \\
6.8\end{array}$ & $\begin{array}{l}.91 \\
1.0 \\
.97 \\
3.3 \\
6.4\end{array}$ & $\begin{array}{l}1.9 \\
1.6 \\
1.1 \\
1.8 \\
2.4\end{array}$ & $\begin{array}{l}6.0 \\
28 \\
34 \\
36 \\
29\end{array}$ & $\begin{array}{l}.92 \\
.82 \\
.74 \\
.67 \\
.59\end{array}$ \\
\hline $\begin{array}{l}16 \\
17 \\
18 \\
19\end{array}$ & $\begin{array}{l}6.0 \\
6.9 \\
2.8 \\
5.0 \\
1.9\end{array}$ & $\begin{array}{r}.75 \\
.70 \\
.79 \\
1.7 \\
1.4\end{array}$ & $\begin{array}{l}19 \\
16 \\
14 \\
12 \\
7.3\end{array}$ & $\begin{array}{l}6.8 \\
6.8 \\
6.7 \\
6.3 \\
5.9\end{array}$ & $\begin{array}{l}6.6 \\
8.0 \\
12 \\
27 \\
45\end{array}$ & $\begin{array}{l}34 \\
30 \\
27 \\
24 \\
22\end{array}$ & $\begin{array}{l}7.1 \\
6.0 \\
5.3 \\
4.8 \\
4.2\end{array}$ & $\begin{array}{l}4.5 \\
4.6 \\
4.1 \\
3.4 \\
3.0\end{array}$ & $\begin{array}{l}4.4 \\
2.8 \\
1.6 \\
1.1 \\
.94\end{array}$ & $\begin{array}{l}1.8 \\
1.3 \\
1.0 \\
2.6 \\
4.3\end{array}$ & $\begin{array}{c}15 \\
7.3 \\
4.2 \\
3.2 \\
2.9\end{array}$ & $\begin{array}{r}.54 \\
.51 \\
.97 \\
1.1 \\
1.9\end{array}$ \\
\hline $\begin{array}{l}21 \\
22 \\
23 \\
24 \\
25\end{array}$ & $\begin{array}{r}.83 \\
.84 \\
1.6 \\
3.2 \\
3.1\end{array}$ & $\begin{array}{l}1.2 \\
1.1 \\
1.0 \\
.97 \\
1.0\end{array}$ & $\begin{array}{l}6.4 \\
6.2 \\
5.8 \\
5.3 \\
4.9\end{array}$ & $\begin{array}{l}5.5 \\
5.3 \\
5.2 \\
5.2 \\
5.0\end{array}$ & $\begin{array}{r}250 \\
1200 \\
990 \\
1100 \\
800\end{array}$ & $\begin{array}{l}20 \\
19 \\
19 \\
18 \\
18\end{array}$ & $\begin{array}{l}4.1 \\
3.9 \\
4.3 \\
4.0 \\
3.3\end{array}$ & $\begin{array}{l}3.1 \\
2.7 \\
2.4 \\
2.2 \\
1.9\end{array}$ & $\begin{array}{r}1.1 \\
3.6 \\
109 \\
971 \\
439\end{array}$ & $\begin{array}{l}2.5 \\
1.8 \\
1.1 \\
1.1 \\
3.9\end{array}$ & $\begin{array}{l}2.2 \\
151 \\
620 \\
226 \\
55\end{array}$ & $\begin{array}{r}3.2 \\
3.3 \\
588 \\
849 \\
658\end{array}$ \\
\hline $\begin{array}{l}26 \\
27 \\
28 \\
29 \\
30\end{array}$ & $\begin{array}{l}3.3 \\
3.3 \\
3.4 \\
3.8 \\
3.0 \\
2.3\end{array}$ & $\begin{array}{l}1.1 \\
1.3 \\
1.3 \\
1.3 \\
0.90 \\
--.\end{array}$ & $\begin{array}{l}5.6 \\
23 \\
33 \\
36 \\
28 \\
18\end{array}$ & $\begin{array}{l}5.0 \\
4.9 \\
4.7 \\
4.5 \\
4.2 \\
4.0\end{array}$ & $\begin{array}{l}320 \\
160 \\
105 \\
--- \\
---\end{array}$ & $\begin{array}{l}17 \\
17 \\
20 \\
18 \\
18 \\
59\end{array}$ & $\begin{array}{l}3.2 \\
3.2 \\
3.7 \\
3.7 \\
3.8 \\
--.\end{array}$ & $\begin{array}{l}1.2 \\
1.4 \\
1.3 \\
1.2 \\
1.1 \\
1.0\end{array}$ & $\begin{array}{r}95 \\
42 \\
22 \\
12 \\
8.1\end{array}$ & $\begin{array}{c}4.4 \\
1.8 \\
1.1 \\
2.80 \\
3090^{.8}\end{array}$ & $\begin{array}{l}29 \\
21 \\
15 \\
9.9 \\
6.6 \\
4.8\end{array}$ & $\begin{array}{r}282 \\
57 \\
29 \\
204 \\
1450\end{array}$ \\
\hline $\begin{array}{l}\text { TOTAL } \\
\text { MEAN } \\
\text { MAX } \\
\text { MIN } \\
\text { CFSM } \\
\text { IN. } \\
\text { AC-ET }\end{array}$ & $\begin{array}{r}74.23 \\
2.39 \\
6.99 \\
.72 \\
.01 \\
.02 \\
147\end{array}$ & $\begin{array}{r}85.07 \\
2.84 \\
17 \\
.66 \\
.02 \\
.02 \\
169\end{array}$ & $\begin{array}{r}255.28 \\
8.23 \\
36 \\
.54 \\
.05 \\
.05 \\
506\end{array}$ & $\begin{array}{r}202.9 \\
6.55 \\
15 \\
4.0 \\
.04 \\
.04 \\
402\end{array}$ & $\begin{array}{r}5067.0 \\
181 \\
1200 \\
2.6 \\
.99 \\
1.04 \\
10050\end{array}$ & $\begin{array}{r}4886 \\
158 \\
1570 \\
17 \\
.87 \\
.00 \\
9690\end{array}$ & $\begin{array}{r}421.8 \\
14.1 \\
65 \\
3.2 \\
.08 \\
.09 \\
837\end{array}$ & $\begin{array}{r}142.7 \\
4.60 \\
36 \\
1.0 \\
.03 \\
.03 \\
283\end{array}$ & $\begin{array}{r}1737.00 \\
57.9 \\
971 \\
.89 \\
.32 \\
.36 \\
3450\end{array}$ & $\begin{array}{r}3153.06 \\
102 \\
3090 \\
.80 \\
.56 \\
.64 \\
6250\end{array}$ & $\begin{array}{r}5336.1 \\
172 \\
1780 \\
2.2 \\
.95 \\
1.09 \\
10580\end{array}$ & $\begin{array}{r}4154.56 \\
138 \\
1450 \\
.51 \\
.76 \\
.85 \\
8240\end{array}$ \\
\hline $\mathbf{A L}$ & & AL & 70 & $\begin{array}{rr}127 \\
\text { AN }\end{array}$ & $\underset{\operatorname{MAX}}{\operatorname{MAX}}$ & $\begin{array}{l}1800 \\
3090\end{array}$ & $\begin{array}{l}.36 \\
.51\end{array}$ & $\begin{array}{l}\text { CFSH } \\
\text { CPSH }\end{array}$ & $\begin{array}{l}.70 \\
.38\end{array}$ & $\begin{array}{l}9.51 \\
5.22\end{array}$ & $\begin{array}{l}A C-P T \\
A C-F T\end{array}$ & $\begin{array}{l}92320 \\
50610\end{array}$ \\
\hline
\end{tabular}


06903700 SOUTH FORK CHARITON RIVER NEAR PROMISE CITY, IA

LOCATION.--Lat $40^{\circ} 48^{\prime} 02^{\prime \prime}$, long $93^{\circ} 11^{\prime} 32^{\prime \prime}$, in SW1/4 SW1/4 sec.5, T.69 N.., R.20 W., wayne County, Bydrologic Unit 10280201 , on right bank $20 \mathrm{ft}$ downstream from bridge on county highway $550,1.3$ mi downstream from Jordan Creek and $4.3 \mathrm{mi}$ northwest of Promise City.

DRAINAGE AREA. $-168 \mathrm{mi}^{2}$.

PERIOD OF RECORD.--October 1967 to current year. Occasional low-flow measurements, water years 1958-66, published as "near Bethlehem". Monthly discharge measurements for March 1965 to September 1967 available in files of Iowa City district office.

GAGE.--Water-stage recorder. Datum of gage is $913.70 \mathrm{ft}$ above NGVD (0.S. Army Corps of Engineers bench mark).

REMARKS.--Estimated daily discharges: Oct. 7, Nov. 30 to Feb. 24 and July 9-16, July 21 to Aug. 5 . Records good except those for periods of estimated record, which are poor. D.s. Army Corps of Engineers data collection platform at station.

AVERAGE DISCHARGE. - -18 years, $116 \mathrm{ft} / \mathrm{s}, 9.38 \mathrm{in} / \mathrm{yr}, 84,040$ acre-ft/yr; median of yearly mean discharges, 100 $\mathrm{ft}^{3} / 8,8.1 \mathrm{in} / \mathrm{yr}, 72,400$ acre-ft/yr.

EXTREMES FOR PERIOD OF RECORD.--Maximum discharge, $28,000 \mathrm{ft}^{3} / \mathrm{s}$ July 4, 1981, gage height, $29.95 \mathrm{ft}$; no flow July $6,7,21-24,28-31$, and Aug. 1, 1977 .

EXTREMES OUTSIDE PERIOD OF RECORD.--Plood of Sept. 21, 1965, reached a stage of 25.5 ft, from floodmarks, discharge, about $18,000 \mathrm{ft}^{3} / \mathrm{s}$.

EXTREMES FOR CURRENT YEAR.--Peak discharges greater than base of $2,000 \mathrm{ft} 3 / \mathrm{s}$ and maximum $(*)$ :

\begin{tabular}{|c|c|c|c|c|c|c|c|}
\hline $\begin{array}{l}\text { Date } \\
\text { Feb. 21 } \\
\text { Mar. }\end{array}$ & $\begin{array}{l}\text { Time } \\
2245 \\
0915\end{array}$ & $\begin{array}{l}\text { Discharge } \\
\left(\mathrm{ft} \mathrm{t}^{2 / 8)}\right. \\
\text { ice jam } \\
* 3,040\end{array}$ & $\begin{array}{c}\text { Gage height } \\
\text { (ft) } \\
\text { 18.06 } \\
16.36\end{array}$ & $\begin{array}{l}\text { Date } \\
\text { Sept. } 30\end{array}$ & $\begin{array}{l}\text { Time } \\
0330\end{array}$ & $\begin{array}{c}\text { Discharge } \\
(\mathrm{ft} 3 / \mathrm{s}) \\
2,490\end{array}$ & $\begin{array}{c}\text { Gage height } \\
(\mathrm{ft}) \\
14.86\end{array}$ \\
\hline
\end{tabular}

Minimum daily discharge, $0.72 \mathrm{ft}^{3} / \mathrm{s}$ June 10,11 .

DISCHARGE, IN CUBIC FEET PER SECOND, WATER YEAR OCTOBER 1984 TO SEPTEMBER 1985 MEAN VALUES

\begin{tabular}{|c|c|c|c|c|c|c|c|c|c|c|c|c|}
\hline DAY & OCT & Nov & DEC & JAN & PEB & MAR & APR & MAY & JON & JOL & AUG & SEP \\
\hline $\begin{array}{l}1 \\
2 \\
3 \\
4 \\
5\end{array}$ & $\begin{array}{l}2.9 \\
2.5 \\
2.1 \\
2.0 \\
1.9\end{array}$ & $\begin{array}{l}47 \\
42 \\
19 \\
9.1 \\
4.2\end{array}$ & $\begin{array}{l}1.8 \\
1.5 \\
1.3 \\
1.1 \\
1.1\end{array}$ & $\begin{array}{l}23 \\
21 \\
20 \\
20 \\
29\end{array}$ & $\begin{array}{l}11 \\
11 \\
11 \\
11 \\
10\end{array}$ & $\begin{array}{r}138 \\
132 \\
563 \\
2340 \\
314\end{array}$ & $\begin{array}{l}93 \\
51 \\
38 \\
30 \\
27\end{array}$ & $\begin{array}{l}90 \\
79 \\
27 \\
15 \\
10\end{array}$ & $\begin{array}{l}1.2 \\
1.2 \\
1.1 \\
1.1 \\
1.1\end{array}$ & $\begin{array}{l}3.4 \\
2.6 \\
2.5 \\
2.5 \\
1.8\end{array}$ & $\begin{array}{c}150 \\
35 \\
16 \\
10 \\
6.5\end{array}$ & $\begin{array}{l}4.7 \\
4.3 \\
3.9 \\
3.5 \\
3.1\end{array}$ \\
\hline $\begin{array}{r}6 \\
7 \\
8 \\
9 \\
10\end{array}$ & $\begin{array}{l}1.8 \\
1.8 \\
2.3 \\
2.9 \\
1.5\end{array}$ & $\begin{array}{l}3.8 \\
2.8 \\
2.3 \\
2.3 \\
2.1\end{array}$ & $\begin{array}{l}1.0 \\
1.0 \\
1.1 \\
1.1 \\
1.5\end{array}$ & $\begin{array}{l}22 \\
22 \\
21 \\
21 \\
20\end{array}$ & $\begin{array}{l}10 \\
10 \\
9.8 \\
9.6 \\
9.6\end{array}$ & $\begin{array}{r}127 \\
99 \\
83 \\
66 \\
60\end{array}$ & $\begin{array}{l}32 \\
28 \\
21 \\
17 \\
15\end{array}$ & $\begin{array}{l}8.5 \\
7.1 \\
5.7 \\
4.2 \\
3.1\end{array}$ & $\begin{array}{l}1.0 \\
.90 \\
.87 \\
.79 \\
.72\end{array}$ & $\begin{array}{l}1.4 \\
1.8 \\
2.0 \\
2.0 \\
2.0\end{array}$ & $\begin{array}{l}4.7 \\
3.1 \\
2.2 \\
1.9 \\
9.7\end{array}$ & $\begin{array}{l}2.6 \\
2.0 \\
1.5 \\
1.2 \\
1.1\end{array}$ \\
\hline $\begin{array}{l}11 \\
12 \\
13 \\
14 \\
15\end{array}$ & $\begin{array}{l}3.6 \\
4.6 \\
2.9 \\
2.2 \\
2.5\end{array}$ & $\begin{array}{l}8.0 \\
7.6 \\
4.9 \\
3.3 \\
2.4\end{array}$ & $\begin{array}{l}1.9 \\
2.5 \\
2.8 \\
14 \\
36\end{array}$ & $\begin{array}{l}19 \\
18 \\
17 \\
17 \\
16\end{array}$ & $\begin{array}{l}9.5 \\
9.5 \\
9.4 \\
9.3 \\
9.7\end{array}$ & $\begin{array}{r}157 \\
121 \\
75 \\
63 \\
55\end{array}$ & $\begin{array}{l}15 \\
15 \\
13 \\
13 \\
12\end{array}$ & $\begin{array}{r}118 \\
360 \\
61 \\
45 \\
34\end{array}$ & $\begin{array}{l}.72 \\
.83 \\
.77 \\
1.7 \\
1.9\end{array}$ & $\begin{array}{l}2.0 \\
1.8 \\
1.8 \\
1.6 \\
1.6\end{array}$ & $\begin{array}{c}9.5 \\
5.9 \\
11 \\
12 \\
5.8\end{array}$ & $\begin{array}{l}1.1 \\
.97 \\
.91 \\
.88 \\
.88\end{array}$ \\
\hline $\begin{array}{l}16 \\
17 \\
18 \\
19 \\
20\end{array}$ & $\begin{array}{l}3.4 \\
2.6 \\
40 \\
56 \\
12\end{array}$ & $\begin{array}{l}1.8 \\
1.6 \\
1.8 \\
2.2 \\
1.5\end{array}$ & $\begin{array}{c}62 \\
38 \\
26 \\
12 \\
9.4\end{array}$ & $\begin{array}{l}15 \\
14 \\
14 \\
14 \\
14\end{array}$ & $\begin{array}{l}13 \\
16 \\
20 \\
25 \\
39\end{array}$ & $\begin{array}{l}46 \\
43 \\
43 \\
12 \\
37\end{array}$ & $\begin{array}{c}12 \\
9.8 \\
9.6 \\
8.3 \\
7.1\end{array}$ & $\begin{array}{l}18 \\
14 \\
10 \\
7.0 \\
6.2\end{array}$ & $\begin{array}{c}1.1 \\
1.1 \\
.88 \\
.88 \\
1.1\end{array}$ & $\begin{array}{l}1.5 \\
1.8 \\
1.5 \\
3.2 \\
2.9\end{array}$ & $\begin{array}{l}2.9 \\
1.8 \\
1.3 \\
1.6 \\
4.6\end{array}$ & $\begin{array}{r}.88 \\
.88 \\
.88 \\
.89 \\
1.1\end{array}$ \\
\hline $\begin{array}{l}21 \\
22 \\
23 \\
24 \\
25\end{array}$ & $\begin{array}{l}8.3 \\
5.0 \\
2.9 \\
2.2 \\
2.6\end{array}$ & $\begin{array}{l}1.4 \\
1.4 \\
1.6 \\
1.8 \\
2.3\end{array}$ & $\begin{array}{l}11 \\
12 \\
11 \\
10 \\
9.2\end{array}$ & $\begin{array}{l}13 \\
13 \\
13 \\
13 \\
13\end{array}$ & $\begin{array}{r}110 \\
1300 \\
1100 \\
840 \\
743\end{array}$ & $\begin{array}{l}30 \\
28 \\
28 \\
30 \\
27\end{array}$ & $\begin{array}{l}6.6 \\
6.1 \\
6.6 \\
5.7 \\
4.9\end{array}$ & $\begin{array}{l}5.0 \\
3.8 \\
3.4 \\
3.2 \\
2.9\end{array}$ & $\begin{array}{c}1.6 \\
5.9 \\
73 \\
726 \\
85\end{array}$ & $\begin{array}{l}2.7 \\
2.0 \\
1.4 \\
1.2 \\
1.5\end{array}$ & $\begin{array}{c}7.8 \\
536 \\
517 \\
82 \\
44\end{array}$ & $\begin{array}{r}2.0 \\
3.0 \\
146 \\
118 \\
28\end{array}$ \\
\hline $\begin{array}{l}26 \\
27 \\
28 \\
29 \\
30 \\
31\end{array}$ & $\begin{array}{l}3.4 \\
6.2 \\
24 \\
12 \\
6.2 \\
4.1\end{array}$ & $\begin{array}{l}2.0 \\
3.1 \\
3.2 \\
2.8 \\
2.3 \\
-.-\end{array}$ & $\begin{array}{l}14 \\
52 \\
62 \\
58 \\
36 \\
26\end{array}$ & $\begin{array}{l}12 \\
12 \\
12 \\
12 \\
12 \\
12\end{array}$ & $\begin{array}{r}254 \\
137 \\
117 \\
-- \\
--\end{array}$ & $\begin{array}{l}26 \\
24 \\
25 \\
23 \\
23 \\
96\end{array}$ & $\begin{array}{l}4.5 \\
8.2 \\
15 \\
14 \\
18 \\
-\end{array}$ & $\begin{array}{r}2.5 \\
17 \\
7.8 \\
2.9 \\
2.3 \\
1.7\end{array}$ & $\begin{array}{c}25 \\
20 \\
7.4 \\
5.5 \\
3.9 \\
-\end{array}$ & $\begin{array}{r}1.5 \\
1.4 \\
1.4 \\
1.4 \\
2.7 \\
600\end{array}$ & $\begin{array}{l}25 \\
16 \\
10 \\
7.6 \\
6.1 \\
5.3\end{array}$ & $\begin{array}{r}33 \\
15 \\
9.4 \\
319 \\
1470\end{array}$ \\
\hline $\begin{array}{l}\text { TOTAL } \\
\text { MEAN } \\
\text { MAX } \\
\text { MIN } \\
\text { CFSM } \\
\text { IN. } \\
\text { AC-FT }\end{array}$ & $\begin{array}{r}228.4 \\
7.37 \\
56 \\
1.5 \\
.04 \\
.05 \\
453\end{array}$ & $\begin{array}{r}191.6 \\
6.39 \\
47 \\
1.4 \\
.04 \\
.04 \\
380\end{array}$ & $\begin{array}{r}518.6 \\
16.7 \\
62 \\
1.0 \\
.10 \\
111 \\
1030\end{array}$ & $\begin{array}{r}503 \\
16.2 \\
23 \\
11 \\
.10 \\
11 \\
998\end{array}$ & $\begin{array}{r}5164.4 \\
184 \\
1300 \\
9.3 \\
1.10 \\
1.14 \\
10240\end{array}$ & $\begin{array}{r}4964 \\
160 \\
2340 \\
23 \\
.95 \\
1.10 \\
9850\end{array}$ & $\begin{array}{r}556.4 \\
18.5 \\
93 \\
4.5 \\
.11 \\
.12 \\
1100\end{array}$ & $\begin{array}{r}975.3 \\
31.5 \\
360 \\
1.7 \\
.19 \\
122 \\
1930\end{array}$ & $\begin{array}{r}974.26 \\
32.5 \\
726 \\
.72 \\
.19 \\
.22 \\
1930\end{array}$ & $\begin{array}{r}658.9 \\
21.3 \\
600 \\
1.2 \\
.13 \\
.15 \\
1310\end{array}$ & $\begin{array}{r}1552.3 \\
50.1 \\
536 \\
1.3 \\
.30 \\
.34 \\
3080\end{array}$ & $\begin{array}{r}2180.67 \\
72.7 \\
1470 \\
.88 \\
.43 \\
.48 \\
4330\end{array}$ \\
\hline $\begin{array}{ll}A L & Y R \\
\text { TR } & Y{ }^{2}\end{array}$ & & $\begin{array}{l}3997 \\
1846\end{array}$ & & $\begin{array}{c}109 \\
50.6\end{array}$ & $\begin{array}{l}\operatorname{MAX} \\
\max \end{array}$ & $\begin{array}{l}3460 \\
2340\end{array}$ & $\begin{array}{l}.51 \\
.72\end{array}$ & $\begin{array}{l}\text { CFSM } \\
\text { CFSM }\end{array}$ & $\begin{array}{l}\text { IN. } \\
\text { IN. }\end{array}$ & $\begin{array}{l}8.85 \\
4.09\end{array}$ & $\begin{array}{l}A C-F T \\
A C-F T\end{array}$ & $\begin{array}{l}79290 \\
36630\end{array}$ \\
\hline
\end{tabular}


LOCATION.--Lat $40^{\circ} 49^{\prime} 30^{\prime}$, long $92^{\circ} 53^{\prime} 33^{\prime \prime}$, in NW1/4 NE1/4 sec.35, T.70 N., R.18 W. , Appanoose County, Hydrologic Unit 10280201 , at control tower of Rathbun Dam, $1.8 \mathrm{mi}$ north of Rathbun and $3.9 \mathrm{mi}$ upstream from Walnut Creek and at mile 142.3 .

DRAINAGE AREA. $--549 \mathrm{mi}^{2}$.

PERIOD OF RECORD.--October 1969 to current year.

GAGE.--Water-stage recorder. Datum of gage is at NGVD.

REMARKS.--Reservoir is formed by earthfill dam completed in 1969. Storage began in November 1969. Release is controlled by two hydraulically controlled slide gages, $6 \mathrm{ft}$ wide and $12 \mathrm{ft}$ high, into forechamber of an $11-\mathrm{ft}$ diameter horseshoe conduit through the dam. No dead storage. Maximum design discharge through gates is 5,000 $\mathrm{ft}^{3 / 8}$. Uncontrolled notch spillway is concrete overflow section $500 \mathrm{ft}$ in length, located about $3,000 \mathrm{ft}$ west of the right abutment of the dam and provides emergency discharge into the adjacent drainage area of Little Walnut creek. Uncontrolled notch spiliway is at elevation $926 \mathrm{ft}$, contents 545,621 acre-ft, surface area, 20,974 acres. Conservation pool level is at elevation $904.0 \mathrm{ft}$, contents 199,830 acre-ft, surface area, 10,989 acres. Reservoir is used for flood control, low-flow augumentation, conservation and recreation.

COOPERATION. - Records provided by U.S. Army Corps of Engineers.

EXTREMES FOR PERIOD OF RECORD.--Maximum daily contents, 514,000 acre-ft July 22, 23, 1982; maximum elevation, $924.46 \mathrm{ft}$ July 22, 1982 ; minimum daily contents, 100 acre-ft Oct. 1-15, Nov. 17-21, 1969; minimum elevation, 855.40 ft Oct. 6-10, 1969 .

EXTREMES FOR CURRENT YEAR.--Maximum daily contents, 212,000 acre-ft Sept. 30 ; maximum elevation 905.07 ft Sept. 30; minimum daily contents, 156,000 acre-ft Feb. 17-19; minimum elevation, 899.79 ft Feb. 17-19.

Capacity table (elevation, in feet, and contents, in acre-feet)

$\begin{array}{lrrrrr}860 & 150 & 880 & 31,900 & 905 & 211,000 \\ 862 & 226 & 885 & 52,700 & 910 & 272,600 \\ 865 & 950 & 890 & 80,300 & 915 & 345,000 \\ 870 & 5,870 & 895 & 115,600 & 920 & 428,900 \\ 875 & 17,000 & 900 & 158,800 & 925 & 524,900\end{array}$

RESERVOIR STORAGE (AC-FT), WATER YEAR OCTOBER 1984 TO SEPTEMBER 1985 INSTANTANEOUS OBSERVATIONS AT 0800

\begin{tabular}{|c|c|c|c|c|c|c|c|c|c|c|c|c|}
\hline DAY & $O C T$ & NOV & DEC & JAN & FEB & MAR & APR & MAY & JUN & JUL & AUG & SEP \\
\hline $\begin{array}{l}1 \\
2 \\
3 \\
4 \\
5\end{array}$ & $\begin{array}{l}188000 \\
188000 \\
187000 \\
187000 \\
187000\end{array}$ & $\begin{array}{l}183000 \\
182000 \\
182000 \\
181000 \\
181000\end{array}$ & $\begin{array}{l}1: 0000 \\
160000 \\
159000 \\
157000 \\
157000\end{array}$ & $\begin{array}{l}164000 \\
163000 \\
163000 \\
163000 \\
163000\end{array}$ & $\begin{array}{l}157000 \\
157000 \\
157000 \\
157000 \\
157000\end{array}$ & $\begin{array}{l}190000 \\
189000 \\
187000 \\
192000 \\
200000\end{array}$ & $\begin{array}{l}176000 \\
175000 \\
175000 \\
175000 \\
175000\end{array}$ & $\begin{array}{l}173000 \\
173000 \\
173000 \\
173000 \\
174000\end{array}$ & $\begin{array}{l}173000 \\
173000 \\
173000 \\
172000 \\
172000\end{array}$ & $\begin{array}{l}183000 \\
183000 \\
183000 \\
183000 \\
182000\end{array}$ & $\begin{array}{l}195000 \\
203000 \\
206000 \\
209000 \\
210000\end{array}$ & $\begin{array}{l}204000 \\
204000 \\
204000 \\
204000 \\
204000\end{array}$ \\
\hline $\begin{array}{r}6 \\
7 \\
8 \\
9 \\
10\end{array}$ & $\begin{array}{l}187000 \\
187000 \\
187000 \\
187000 \\
187000\end{array}$ & $\begin{array}{l}180000 \\
178000 \\
178000 \\
177000 \\
177000\end{array}$ & $\begin{array}{l}158000 \\
157000 \\
157000 \\
157000 \\
157000\end{array}$ & $\begin{array}{l}163000 \\
162000 \\
162000 \\
162000 \\
161000\end{array}$ & $\begin{array}{l}157000 \\
157000 \\
157000 \\
157000 \\
157000\end{array}$ & $\begin{array}{l}204000 \\
205000 \\
206000 \\
204000 \\
202000\end{array}$ & $\begin{array}{l}175000 \\
175000 \\
175000 \\
174000 \\
174000\end{array}$ & $\begin{array}{l}174000 \\
173000 \\
173000 \\
173000 \\
173000\end{array}$ & $\begin{array}{l}172000 \\
172000 \\
172000 \\
172000 \\
172000\end{array}$ & $\begin{array}{l}182000 \\
182000 \\
182000 \\
181000 \\
181000\end{array}$ & $\begin{array}{l}210000 \\
209000 \\
208000 \\
206000 \\
206000\end{array}$ & $\begin{array}{l}204000 \\
204000 \\
203000 \\
203000 \\
203000\end{array}$ \\
\hline $\begin{array}{l}11 \\
12 \\
13 \\
14 \\
15\end{array}$ & $\begin{array}{l}188000 \\
188000 \\
188000 \\
187000 \\
188000\end{array}$ & $\begin{array}{l}176000 \\
175000 \\
174000 \\
173000 \\
173000\end{array}$ & $\begin{array}{l}157000 \\
157000 \\
157000 \\
157000 \\
157000\end{array}$ & $\begin{array}{l}161000 \\
160000 \\
159000 \\
158000 \\
158000\end{array}$ & $\begin{array}{l}157000 \\
157000 \\
157000 \\
157000 \\
157000\end{array}$ & $\begin{array}{l}201000 \\
199000 \\
197000 \\
195000 \\
193000\end{array}$ & $\begin{array}{l}174000 \\
174000 \\
174000 \\
174000 \\
174000\end{array}$ & $\begin{array}{l}173000 \\
174000 \\
174000 \\
175000 \\
175000\end{array}$ & $\begin{array}{l}172000 \\
172000 \\
171000 \\
172000 \\
172000\end{array}$ & $\begin{array}{l}181000 \\
181000 \\
181000 \\
181000 \\
181000\end{array}$ & $\begin{array}{l}205000 \\
203000 \\
202000 \\
201000 \\
200000\end{array}$ & $\begin{array}{l}203000 \\
202000 \\
202000 \\
202000 \\
201000\end{array}$ \\
\hline $\begin{array}{l}16 \\
17 \\
18 \\
19 \\
20\end{array}$ & $\begin{array}{l}188000 \\
188000 \\
187000 \\
189000 \\
188000\end{array}$ & $\begin{array}{l}172000 \\
170000 \\
170000 \\
169000 \\
168000\end{array}$ & $\begin{array}{l}159000 \\
159000 \\
159000 \\
159000 \\
159000\end{array}$ & $\begin{array}{l}158000 \\
158000 \\
158000 \\
158000 \\
158000\end{array}$ & $\begin{array}{l}157000 \\
156000 \\
156000 \\
156000 \\
157000\end{array}$ & $\begin{array}{l}191000 \\
189000 \\
186000 \\
184000 \\
182000\end{array}$ & $\begin{array}{l}174000 \\
173000 \\
173000 \\
173000 \\
173000\end{array}$ & $\begin{array}{l}175000 \\
175000 \\
175000 \\
175000 \\
175000\end{array}$ & $\begin{array}{l}172000 \\
172000 \\
172000 \\
171000 \\
171000\end{array}$ & $\begin{array}{l}181000 \\
181000 \\
180000 \\
180000 \\
180000\end{array}$ & $\begin{array}{l}200000 \\
200000 \\
200000 \\
200000 \\
200000\end{array}$ & $\begin{array}{l}201000 \\
201000 \\
201000 \\
201000 \\
201000\end{array}$ \\
\hline $\begin{array}{l}21 \\
22 \\
23 \\
24 \\
25\end{array}$ & $\begin{array}{l}189000 \\
188000 \\
187000 \\
186000 \\
186000\end{array}$ & $\begin{array}{l}167000 \\
166000 \\
166000 \\
165000 \\
164000\end{array}$ & $\begin{array}{l}159000 \\
160000 \\
159000 \\
160000 \\
159000\end{array}$ & $\begin{array}{l}158000 \\
158000 \\
158000 \\
158000 \\
158000\end{array}$ & $\begin{array}{l}157000 \\
163000 \\
170000 \\
178000 \\
185000\end{array}$ & $\begin{array}{l}180000 \\
177000 \\
177000 \\
177000 \\
176000\end{array}$ & $\begin{array}{l}173000 \\
173000 \\
173000 \\
173000 \\
172000\end{array}$ & $\begin{array}{l}175000 \\
174000 \\
174000 \\
174000 \\
174000\end{array}$ & $\begin{array}{l}172000 \\
172000 \\
171000 \\
177000 \\
181000\end{array}$ & $\begin{array}{l}180000 \\
179000 \\
179000 \\
179000 \\
179000\end{array}$ & $\begin{array}{l}199000 \\
199000 \\
201000 \\
203000 \\
204000\end{array}$ & $\begin{array}{l}201000 \\
201000 \\
202000 \\
203000 \\
205000\end{array}$ \\
\hline $\begin{array}{l}26 \\
27 \\
28 \\
29 \\
30\end{array}$ & $\begin{array}{l}185000 \\
184000 \\
185000 \\
184000 \\
183000 \\
182000\end{array}$ & $\begin{array}{r}163000 \\
164000 \\
163000 \\
161000 \\
161000 \\
-\end{array}$ & $\begin{array}{l}159000 \\
160000 \\
160000 \\
162000 \\
162000 \\
163000\end{array}$ & $\begin{array}{l}158000 \\
158000 \\
158000 \\
158000 \\
158000 \\
158000\end{array}$ & $\begin{array}{r}190000 \\
192000 \\
191000 \\
0- \\
\ldots-\end{array}$ & $\begin{array}{l}176000 \\
176000 \\
176000 \\
176000 \\
175000 \\
176000\end{array}$ & $\begin{array}{r}172000 \\
172000 \\
172000 \\
172000 \\
172000 \\
=-\end{array}$ & $\begin{array}{l}174000 \\
174000 \\
174000 \\
173000 \\
173000 \\
173000\end{array}$ & $\begin{array}{c}182000 \\
184000 \\
184000 \\
184000 \\
183000 \\
---\end{array}$ & $\begin{array}{l}179000 \\
179000 \\
179000 \\
179000 \\
179000 \\
187000\end{array}$ & $\begin{array}{l}205000 \\
205000 \\
204000 \\
204000 \\
204000 \\
204000\end{array}$ & $\begin{array}{r}207000 \\
208000 \\
208000 \\
208000 \\
212000 \\
\end{array}$ \\
\hline $\begin{array}{l}\text { MEAN } \\
\text { MAX } \\
\text { MIN }\end{array}$ & $\begin{array}{l}187000 \\
189000 \\
182000\end{array}$ & $\begin{array}{l}172000 \\
183000 \\
161000\end{array}$ & $\begin{array}{l}159000 \\
163000 \\
157000\end{array}$ & $\begin{array}{l}160000 \\
164000 \\
158000\end{array}$ & $\begin{array}{l}163000 \\
192000 \\
156000\end{array}$ & $\begin{array}{l}188000 \\
206000 \\
175000\end{array}$ & $\begin{array}{l}174000 \\
176000 \\
172000\end{array}$ & $\begin{array}{l}174000 \\
175000 \\
173000\end{array}$ & $\begin{array}{l}174000 \\
184000 \\
171000\end{array}$ & $\begin{array}{l}181000 \\
187000 \\
179000\end{array}$ & $\begin{array}{l}203000 \\
210000 \\
195000\end{array}$ & $\begin{array}{l}204000 \\
212000 \\
201000\end{array}$ \\
\hline
\end{tabular}

$\begin{array}{lllllll}\text { CAL YR } 1984 & \text { MEAN } & 193000 & \text { MAX } & 265000 & \text { MIN } & 157000\end{array}$ WTR YR 1985 MEAN 178000 MAX 212000 MIN 156000 
06903900 CHARITON RIVER NEAR RATHBUN, IA

LOCATION,--Lat $40^{\circ} 49^{\prime} 22^{\prime \prime}$, long $92^{\circ} 53^{\prime} 22^{\prime \prime}$, in SEl/4 NEl/4 sec.35, T.70 N., R. 18 w., Appanoose County, Hydrologic Un1t 10280201 , on left bank $600 \mathrm{ft}$ downstream from outlet of Rathbun Dam, $1.8 \mathrm{mi}$ north of Rathbun and $3.7 \mathrm{mi}$ upstream from walnut Creek and at mile 142.1 .

DRAINAGE AREA. $--549 \mathrm{mi}^{2}$.

PERIOD OF RECORD.--October 1956 to current year. Monthly discharge only for some periods, published in wSP 1730.

REVISED RECORDS.--WSP 1560: Drainage area.

GAGE.--Water-stage recorder. Datum of gage is $847.92 \mathrm{ft}$ above NGVD. Prior to Nov. 16 , 1960 , nonrecording gage and Nov. 17, 1960, to Sept. 30, 1969, recording gage, at site 3.1 mi downstream at datum 4.65 ft lower.

REMARKS.--Estimated daily discharges during water year: Jan. 21 to Feb. 20, Feb. 22-25, June 24, July 31 and Aug. 1. Records good, except those for periods of estimated record, which are fair. Flow regulated by Rathbun Reservoir (station 06903880 ) since Nov. 21, 1969. Records of discharge include diversion of:

$\begin{array}{lc}\text { Date } & \begin{array}{c}\text { Discharge } \\ \text { (cfs) }\end{array} \\ \text { Oct. } 1-5 & 16 \\ \text { Oct. } 6,7 & 15 \\ \text { Oct. } 8,9 & 16 \\ \text { Oct. } 10-14 & 15 \\ \text { Oct. } 15-19 & 16 \\ \text { Oct. 20-22 } & 15\end{array}$

$\begin{array}{lc}\text { Date } & \begin{array}{c}\text { Discharge } \\ \text { (cfs) }\end{array} \\ \text { Oct. } 23 & 16 \\ \text { Oct. 24 } & 15 \\ \text { Oct. 25 } & 16 \\ \text { Oct. 26-28 } & 15 \\ \text { Oct. 29-Nov. 15 } & 16 \\ \text { Nov. } 16 & 13\end{array}$

$\begin{array}{lc}\text { Date } & \begin{array}{c}\text { Discharge } \\ \text { (cfs) }\end{array} \\ \text { Nov. 17-Dec. 28 } & 11 \\ \text { Dec. 29 } & 12 \\ \text { Dec. 30-Jan. 2 } & 13 \\ \text { Jan. 3-Aug. 9 } & 12 \\ \text { Aug. 10 } & 11 \\ \text { Aug. 11-Sept. 30 } & 13\end{array}$

The diversion goes from the reservoir through fish ponds on left bank downstream from dam. Diverted flow returns to stream $0.1 \mathrm{mi}$ downstream from gage. $0 . s$. Army Corps of Engineers gage-helght telemeter at station. Rathbun Regional Water Association permit No. 3663 allows withdrawal from Rathbun Dam discharge immediately downstream from gage for maximum rate of $4,200 \mathrm{gpm}\left(9.36 \mathrm{ft}^{3} / \mathrm{s}\right)$ and maximum guantity of 638

million gallons per year $(1,955$ acre-ft $)$.

AVERAGE DISCHARGE.--29 years, $338 \mathrm{ft} / \mathrm{s}, 8.36 \mathrm{in} / \mathrm{yr}$, (unadjusted) 244,900 acre- $\mathrm{ft} / \mathrm{yr}$; median of yearly mean discharges, $270 \mathrm{ft} / \mathrm{s}, 6.7 \mathrm{in} / \mathrm{yr}, 196,000$ acre-ft/yr.

EXTREMES FOR PERIOD OR RECORD,--Maximum discharge, 21,800 ft/s Mar. 31, 1960, gage height, 25.3 ft from floodmark, site and datum then in use; no flow Oct. 26, 1977.

EXTREMES FOR CURRENT YEAR.--Maximum discharge, $1,160 \mathrm{ft} / \mathrm{s}$ March 11 , gage height, $11.87 \mathrm{ft}$, minimum daily discharge, $13 \mathrm{ft} / \mathrm{s}$ Dec. 30.

DISCHARGE, IN CUBIC PEET PER SECOND, WATER YEAR OCTOBER 1984 TO SEPTEHBER 1985

\begin{tabular}{|c|c|c|c|c|c|c|c|c|c|c|c|c|}
\hline DAY & OCT & NOV & DEC & JAN & FEB & MAR & APR & MAY & JUN & JUL & AUG & SEP \\
\hline $\begin{array}{l}1 \\
2 \\
3 \\
4 \\
5\end{array}$ & $\begin{array}{l}27 \\
28 \\
28 \\
25 \\
24\end{array}$ & $\begin{array}{r}220 \\
32 \\
239 \\
398 \\
396\end{array}$ & $\begin{array}{r}378 \\
378 \\
377 \\
173 \\
26\end{array}$ & $\begin{array}{r}38 \\
35 \\
114 \\
188 \\
151\end{array}$ & $\begin{array}{l}30 \\
30 \\
29 \\
30 \\
30\end{array}$ & $\begin{array}{r}1100 \\
1070 \\
911 \\
573 \\
41\end{array}$ & $\begin{array}{l}194 \\
194 \\
194 \\
193 \\
193\end{array}$ & $\begin{array}{l}25 \\
25 \\
25 \\
24 \\
24\end{array}$ & $\begin{array}{l}20 \\
20 \\
20 \\
20 \\
20\end{array}$ & $\begin{array}{l}19 \\
20 \\
20 \\
19 \\
20\end{array}$ & $\begin{array}{r}23 \\
21 \\
21 \\
21 \\
257\end{array}$ & $\begin{array}{l}28 \\
28 \\
28 \\
28 \\
28\end{array}$ \\
\hline $\begin{array}{r}6 \\
7 \\
8 \\
9 \\
10\end{array}$ & $\begin{array}{l}28 \\
15 \\
16 \\
16 \\
15\end{array}$ & $\begin{array}{l}396 \\
397 \\
397 \\
396 \\
395\end{array}$ & $\begin{array}{l}27 \\
26 \\
25 \\
25 \\
25\end{array}$ & $\begin{array}{l}139 \\
137 \\
247 \\
388 \\
388\end{array}$ & $\begin{array}{l}30 \\
30 \\
30 \\
31 \\
31\end{array}$ & $\begin{array}{r}251 \\
752 \\
872 \\
1140 \\
1120\end{array}$ & $\begin{array}{r}193 \\
193 \\
129 \\
59 \\
59\end{array}$ & $\begin{array}{l}24 \\
24 \\
24 \\
24 \\
23\end{array}$ & $\begin{array}{l}20 \\
20 \\
19 \\
20 \\
20\end{array}$ & $\begin{array}{l}19 \\
19 \\
20 \\
19 \\
20\end{array}$ & $\begin{array}{l}586 \\
585 \\
585 \\
580 \\
433\end{array}$ & $\begin{array}{l}28 \\
28 \\
28 \\
28 \\
28\end{array}$ \\
\hline $\begin{array}{l}11 \\
12 \\
13 \\
14 \\
15\end{array}$ & $\begin{array}{l}25 \\
32 \\
29 \\
30 \\
30\end{array}$ & $\begin{array}{l}394 \\
393 \\
393 \\
393 \\
391\end{array}$ & $\begin{array}{l}25 \\
26 \\
26 \\
27 \\
27\end{array}$ & $\begin{array}{r}387 \\
386 \\
387 \\
187 \\
37\end{array}$ & $\begin{array}{l}30 \\
30 \\
29 \\
30 \\
30\end{array}$ & $\begin{array}{l}1130 \\
1120 \\
1080 \\
1060 \\
1040\end{array}$ & $\begin{array}{l}59 \\
59 \\
59 \\
59 \\
60\end{array}$ & $\begin{array}{l}22 \\
22 \\
23 \\
22 \\
21\end{array}$ & $\begin{array}{l}20 \\
20 \\
20 \\
20 \\
20\end{array}$ & $\begin{array}{l}20 \\
19 \\
20 \\
20 \\
20\end{array}$ & $\begin{array}{l}583 \\
584 \\
585 \\
582 \\
270\end{array}$ & $\begin{array}{l}28 \\
28 \\
28 \\
28 \\
28\end{array}$ \\
\hline $\begin{array}{l}16 \\
17 \\
18 \\
19 \\
20\end{array}$ & $\begin{array}{r}156 \\
642 \\
412 \\
34 \\
30\end{array}$ & $\begin{array}{l}388 \\
385 \\
384 \\
383 \\
383\end{array}$ & $\begin{array}{l}26 \\
26 \\
26 \\
25 \\
25\end{array}$ & $\begin{array}{l}37 \\
36 \\
36 \\
35 \\
34\end{array}$ & $\begin{array}{l}30 \\
30 \\
30 \\
30 \\
30\end{array}$ & $\begin{array}{l}1030 \\
1020 \\
1030 \\
1040 \\
1040\end{array}$ & $\begin{array}{l}60 \\
58 \\
59 \\
59 \\
59\end{array}$ & $\begin{array}{l}22 \\
23 \\
22 \\
22 \\
22\end{array}$ & $\begin{array}{l}20 \\
20 \\
21 \\
20 \\
20\end{array}$ & $\begin{array}{r}20 \\
233 \\
164 \\
61 \\
21\end{array}$ & $\begin{array}{l}28 \\
29 \\
28 \\
29 \\
29\end{array}$ & $\begin{array}{l}28 \\
28 \\
28 \\
28 \\
29\end{array}$ \\
\hline $\begin{array}{l}21 \\
22 \\
23 \\
24 \\
25\end{array}$ & $\begin{array}{l}135 \\
314 \\
394 \\
392 \\
394\end{array}$ & $\begin{array}{l}382 \\
382 \\
382 \\
381 \\
380\end{array}$ & $\begin{array}{l}26 \\
25 \\
26 \\
27 \\
30\end{array}$ & $\begin{array}{l}34 \\
32 \\
32 \\
31 \\
31\end{array}$ & $\begin{array}{l}30 \\
30 \\
29 \\
29 \\
29\end{array}$ & $\begin{array}{r}1030 \\
557 \\
202 \\
197 \\
197\end{array}$ & $\begin{array}{l}58 \\
50 \\
56 \\
56 \\
57\end{array}$ & $\begin{array}{l}22 \\
22 \\
21 \\
21 \\
21\end{array}$ & $\begin{array}{l}20 \\
20 \\
21 \\
22 \\
20\end{array}$ & $\begin{array}{l}21 \\
21 \\
21 \\
21 \\
22\end{array}$ & $\begin{array}{l}29 \\
29 \\
29 \\
28 \\
28\end{array}$ & $\begin{array}{l}29 \\
29 \\
31 \\
29 \\
29\end{array}$ \\
\hline $\begin{array}{l}26 \\
27 \\
28 \\
29 \\
30 \\
31\end{array}$ & $\begin{array}{l}391 \\
398 \\
398 \\
397 \\
397 \\
400\end{array}$ & $\begin{array}{l}379 \\
382 \\
380 \\
380 \\
379 \\
-\end{array}$ & $\begin{array}{l}26 \\
26 \\
23 \\
15 \\
13 \\
19\end{array}$ & $\begin{array}{l}30 \\
30 \\
29 \\
29 \\
30 \\
30\end{array}$ & $\begin{array}{l}177 \\
545 \\
907 \\
-\ldots \\
-\ldots \\
---\end{array}$ & $\begin{array}{l}193 \\
195 \\
195 \\
195 \\
194 \\
194\end{array}$ & $\begin{array}{r}57 \\
58 \\
59 \\
59 \\
38 \\
---\end{array}$ & $\begin{array}{l}21 \\
21 \\
21 \\
21 \\
21 \\
21\end{array}$ & $\begin{array}{r}20 \\
20 \\
20 \\
20 \\
20 \\
---\end{array}$ & $\begin{array}{l}21 \\
20 \\
21 \\
21 \\
22 \\
23\end{array}$ & $\begin{array}{l}28 \\
28 \\
28 \\
28 \\
28 \\
28\end{array}$ & $\begin{array}{r}29 \\
29 \\
29 \\
33 \\
32 \\
-\end{array}$ \\
\hline $\begin{array}{l}\text { TOTAL } \\
\text { MEAN } \\
\text { MAX } \\
\text { MIN } \\
\text { AC-ET }\end{array}$ & $\begin{array}{r}5652 \\
182 \\
642 \\
15 \\
11210\end{array}$ & $\begin{array}{r}10960 \\
365 \\
398 \\
32 \\
21740\end{array}$ & $\begin{array}{r}1975 \\
63.7 \\
378 \\
13 \\
3920\end{array}$ & $\begin{array}{r}3725 \\
120 \\
388 \\
29 \\
7390\end{array}$ & $\begin{array}{r}2376 \\
84.9 \\
907 \\
29 \\
4710\end{array}$ & $\begin{array}{r}21769 \\
702 \\
1140 \\
41 \\
43180\end{array}$ & $\begin{array}{r}2740 \\
91.3 \\
194 \\
38 \\
5430\end{array}$ & $\begin{array}{r}696 \\
22.5 \\
25 \\
21 \\
1380\end{array}$ & $\begin{array}{r}603 \\
20.1 \\
22 \\
19 \\
1200\end{array}$ & $\begin{array}{r}1027 \\
33.1 \\
233 \\
19 \\
2040\end{array}$ & $\begin{array}{r}6170 \\
199 \\
586 \\
21 \\
12240\end{array}$ & $\begin{array}{r}860 \\
28.7 \\
33 \\
28 \\
1710\end{array}$ \\
\hline $\begin{array}{l}\text { CAL YR } \\
\text { WTR YR }\end{array}$ & & $\begin{array}{l}\text { TOTAL } \\
\text { TOTAL }\end{array}$ & $\begin{array}{r}147634 \\
58553\end{array}$ & $\begin{array}{l}\text { MEAN } \\
\text { MEAN }\end{array}$ & $\begin{array}{l}403 \\
160\end{array}$ & $\begin{array}{l}\operatorname{MAX} \\
\text { MAX }\end{array}$ & $\begin{array}{l}1220 \\
1140\end{array}$ & $\begin{array}{l}\text { MIN } \\
\text { MIN }\end{array}$ & $\begin{array}{l}13 \\
13\end{array}$ & $\begin{array}{l}A C-E T \\
A C-E T\end{array}$ & $\begin{array}{l}292800 \\
116100\end{array}$ & \\
\hline
\end{tabular}


LOCATION,--Lat $40^{\circ} 41^{\prime} 30^{\prime \prime}$, Iong $92^{\circ} 46^{\prime} 15^{\prime \prime}$, in sEl/4 NEl/4 sec.14, T.68N., R.17w., Appanoose County, Hydrologic Unit 10280201 , on right bank $6 \mathrm{ft}$ downstream from bridge on county highway J45, $0.7 \mathrm{mi}$ downstream from Hickory Creek, $5.0 \mathrm{mi}$ west of Moulton, $8.0 \mathrm{mi}$ upstream from Iowa-Missouri border, $20.8 \mathrm{mi}$ downstream from Rathun dam, and at mile 121.5 .

DRAINAGE AREA. $--740 \mathrm{mi}^{2}$.

PERIOD OF RECORD--August 1979 to current year

GAGE-Water stage recorder. Datum of gage $18800.00 \mathrm{ft}$ above NGVD (U.S. Army Corps of Engineers bench mark).

REMARKS.--Estimated daily discharges during water year: Oct. 1-17 and Jan. 5 to Feb. 25 . Records good except for periods of estimated record, which are poor. Flow regulated by Rathbun Reservoir (8tation 06903880 ) $20.8 \mathrm{mi}$ upstream. U.s. Army Corps of Engineers rain-gage, gage-height telemeters and data collection platform at station.

AVERAGE DISCHARGE. - -6 years, $642 \mathrm{ft} / \mathrm{s}, 11.8 \mathrm{in} / \mathrm{yr}^{\prime}, 465,100 \mathrm{acre}-\mathrm{ft} / \mathrm{yr}$.

EXTREMES FOR PERIOD OF RECORD.--Maximum discharge, 11,200 ft/s July 16, 1982, gage height, 36.83 ft; minimum daily, $19 \mathrm{ft} / \mathrm{s}$ Oct. 26,1979 .

EXTREMES OUTSIDE PERIOD OF RECORD.--Flood in June 1947 reached a stage of about 45 ft, discharge unknown, from information by U.S. Army Corps of Engineers.

EXTREMES FOR CURRENT PERIOD,--Maximum discharge, 5,280 ft's March 4 , gage height, 32.79 ft, minimum daily discharge, $21 \mathrm{ft} / \mathrm{s}$ June $9-11,20$.

DISCHARGE, IN CUBIC FEET PER SECOND, WATER YEAR OCTOBER 1984 TO SEPTEMBER 1985

\begin{tabular}{|c|c|c|c|c|c|c|c|c|c|c|c|c|}
\hline DAY & OCT & NOV & DEC & JAN & EEB & MAR & APR & MAY & JUN & JUL & AUG & SEP \\
\hline $\begin{array}{l}1 \\
2 \\
3 \\
4 \\
5\end{array}$ & $\begin{array}{l}33 \\
33 \\
36 \\
38 \\
33\end{array}$ & $\begin{array}{r}2220 \\
719 \\
171 \\
405 \\
438\end{array}$ & $\begin{array}{l}417 \\
415 \\
410 \\
393 \\
126\end{array}$ & $\begin{array}{l}113 \\
163 \\
133 \\
153 \\
200\end{array}$ & $\begin{array}{l}45 \\
43 \\
42 \\
42 \\
41\end{array}$ & $\begin{array}{l}1270 \\
1370 \\
2050 \\
4660 \\
1810\end{array}$ & $\begin{array}{l}293 \\
255 \\
241 \\
227 \\
227\end{array}$ & $\begin{array}{r}86 \\
127 \\
85 \\
60 \\
49\end{array}$ & $\begin{array}{l}28 \\
28 \\
25 \\
24 \\
24\end{array}$ & $\begin{array}{l}31 \\
29 \\
29 \\
28 \\
27\end{array}$ & $\begin{array}{r}1390 \\
272 \\
85 \\
61 \\
52\end{array}$ & $\begin{array}{l}33 \\
33 \\
33 \\
33 \\
32\end{array}$ \\
\hline $\begin{array}{r}6 \\
7 \\
8 \\
9 \\
10\end{array}$ & $\begin{array}{l}31 \\
33 \\
40 \\
28 \\
22\end{array}$ & $\begin{array}{l}426 \\
422 \\
422 \\
423 \\
417\end{array}$ & $\begin{array}{l}63 \\
59 \\
53 \\
-22 \\
56\end{array}$ & $\begin{array}{l}160 \\
150 \\
150 \\
280 \\
450\end{array}$ & $\begin{array}{l}40 \\
39 \\
38 \\
38 \\
38\end{array}$ & $\begin{array}{r}321 \\
604 \\
771 \\
1090 \\
1200\end{array}$ & $\begin{array}{r}230 \\
223 \\
218 \\
124 \\
91\end{array}$ & $\begin{array}{l}46 \\
43 \\
42 \\
40 \\
38\end{array}$ & $\begin{array}{l}24 \\
24 \\
23 \\
21 \\
21\end{array}$ & $\begin{array}{l}27 \\
26 \\
25 \\
26 \\
25\end{array}$ & $\begin{array}{l}445 \\
613 \\
610 \\
608 \\
527\end{array}$ & $\begin{array}{l}32 \\
31 \\
31 \\
30 \\
29\end{array}$ \\
\hline $\begin{array}{l}11 \\
12 \\
13 \\
14 \\
15\end{array}$ & $\begin{array}{r}22 \\
54 \\
220 \\
370 \\
320\end{array}$ & $\begin{array}{l}414 \\
411 \\
412 \\
414 \\
414\end{array}$ & $\begin{array}{r}55 \\
61 \\
59 \\
271 \\
282\end{array}$ & $\begin{array}{l}450 \\
450 \\
450 \\
450 \\
120\end{array}$ & $\begin{array}{l}38 \\
37 \\
36 \\
36 \\
37\end{array}$ & $\begin{array}{l}1630 \\
1820 \\
1480 \\
1380 \\
1250\end{array}$ & $\begin{array}{l}89 \\
89 \\
85 \\
81 \\
81\end{array}$ & $\begin{array}{r}37 \\
38 \\
44 \\
131 \\
67\end{array}$ & $\begin{array}{l}21 \\
22 \\
22 \\
29 \\
33\end{array}$ & $\begin{array}{l}26 \\
25 \\
25 \\
27 \\
27\end{array}$ & $\begin{array}{l}568 \\
620 \\
623 \\
616 \\
583\end{array}$ & $\begin{array}{l}29 \\
30 \\
29 \\
28 \\
28\end{array}$ \\
\hline $\begin{array}{l}16 \\
17 \\
18 \\
19 \\
20\end{array}$ & $\begin{array}{r}370 \\
550 \\
1290 \\
1270 \\
178\end{array}$ & $\begin{array}{l}411 \\
412 \\
414 \\
413 \\
412\end{array}$ & $\begin{array}{r}287 \\
221 \\
130 \\
99 \\
79\end{array}$ & $\begin{array}{l}54 \\
52 \\
52 \\
52 \\
52\end{array}$ & $\begin{array}{l}38 \\
42 \\
47 \\
51 \\
58\end{array}$ & $\begin{array}{l}1230 \\
1220 \\
1220 \\
1220 \\
1220\end{array}$ & $\begin{array}{l}80 \\
78 \\
76 \\
75 \\
73\end{array}$ & $\begin{array}{l}47 \\
43 \\
40 \\
37 \\
35\end{array}$ & $\begin{array}{l}25 \\
23 \\
22 \\
22 \\
21\end{array}$ & $\begin{array}{r}26 \\
25 \\
243 \\
126 \\
59\end{array}$ & $\begin{array}{r}141 \\
42 \\
38 \\
43 \\
46\end{array}$ & $\begin{array}{l}27 \\
28 \\
28 \\
29 \\
28\end{array}$ \\
\hline $\begin{array}{l}21 \\
22 \\
23 \\
24 \\
25\end{array}$ & $\begin{array}{l}138 \\
258 \\
382 \\
394 \\
393\end{array}$ & $\begin{array}{l}414 \\
415 \\
416 \\
417 \\
417\end{array}$ & $\begin{array}{r}93 \\
112 \\
93 \\
89 \\
95\end{array}$ & $\begin{array}{l}53 \\
52 \\
51 \\
50 \\
50\end{array}$ & $\begin{array}{r}72 \\
270 \\
2700 \\
2300 \\
1800\end{array}$ & $\begin{array}{r}1220 \\
1140 \\
328 \\
242 \\
238\end{array}$ & $\begin{array}{l}72 \\
71 \\
64 \\
67 \\
66\end{array}$ & $\begin{array}{l}33 \\
31 \\
31 \\
31 \\
30\end{array}$ & $\begin{array}{r}23 \\
40 \\
80 \\
1430 \\
349\end{array}$ & $\begin{array}{l}30 \\
28 \\
27 \\
28 \\
46\end{array}$ & $\begin{array}{r}38 \\
43 \\
96 \\
132 \\
71\end{array}$ & $\begin{array}{r}37 \\
42 \\
137 \\
136 \\
81\end{array}$ \\
\hline $\begin{array}{l}26 \\
27 \\
28 \\
29 \\
30 \\
31\end{array}$ & $\begin{array}{l}398 \\
409 \\
512 \\
446 \\
416 \\
576\end{array}$ & $\begin{array}{l}422 \\
458 \\
462 \\
436 \\
425 \\
---\end{array}$ & $\begin{array}{l}101 \\
198 \\
311 \\
496 \\
357 \\
169\end{array}$ & $\begin{array}{l}49 \\
48 \\
47 \\
47 \\
46 \\
46\end{array}$ & $\begin{array}{l}586 \\
522 \\
868 \\
\ldots- \\
\ldots- \\
-\ldots\end{array}$ & $\begin{array}{l}242 \\
241 \\
240 \\
237 \\
236 \\
290\end{array}$ & $\begin{array}{r}66 \\
68 \\
73 \\
72 \\
75 \\
--\end{array}$ & $\begin{array}{l}30 \\
28 \\
29 \\
28 \\
28 \\
28\end{array}$ & $\begin{array}{r}78 \\
50 \\
40 \\
36 \\
33 \\
-\end{array}$ & $\begin{array}{r}39 \\
33 \\
31 \\
32 \\
45 \\
1610\end{array}$ & $\begin{array}{l}49 \\
42 \\
38 \\
36 \\
36 \\
35\end{array}$ & $\begin{array}{r}71 \\
55 \\
46 \\
59 \\
715 \\
-\end{array}$ \\
\hline $\begin{array}{l}\text { TOTAL } \\
\text { MEAN } \\
\text { MAX } \\
\text { MIN } \\
\text { AC-PT }\end{array}$ & $\begin{array}{r}9293 \\
300 \\
1290 \\
22 \\
18430\end{array}$ & $\begin{array}{r}14472 \\
482 \\
2220 \\
171 \\
28710\end{array}$ & $\begin{array}{r}5702 \\
184 \\
496 \\
52 \\
11310\end{array}$ & $\begin{array}{r}4673 \\
151 \\
450 \\
46 \\
9270\end{array}$ & $\begin{array}{r}9944 \\
355 \\
2700 \\
36 \\
19720\end{array}$ & $\begin{array}{r}33470 \\
1080 \\
4660 \\
236 \\
66390\end{array}$ & $\begin{array}{r}3630 \\
121 \\
293 \\
64 \\
7200\end{array}$ & $\begin{array}{r}1462 \\
47.2 \\
131 \\
28 \\
2900\end{array}$ & $\begin{array}{r}2641 \\
88.0 \\
1430 \\
21 \\
5240\end{array}$ & $\begin{array}{r}2831 \\
91.3 \\
1610 \\
25 \\
5620\end{array}$ & $\begin{array}{r}8599 \\
277 \\
1390 \\
35 \\
17060\end{array}$ & $\begin{array}{r}1980 \\
66.0 \\
715 \\
27 \\
3930\end{array}$ \\
\hline $\begin{array}{l}\text { CAL YR } \\
\text { WTR YE }\end{array}$ & $\begin{array}{l}984 \\
985\end{array}$ & $\begin{array}{l}\text { TOTAL } \\
\text { TOTAL }\end{array}$ & $\begin{array}{r}212119 \\
98697\end{array}$ & $\begin{array}{l}\text { MEAN } \\
\text { MEAN }\end{array}$ & $\begin{array}{l}580 \\
270\end{array}$ & $\begin{array}{l}\operatorname{MAX} \\
\text { MAX }\end{array}$ & $\begin{array}{l}4650 \\
4660\end{array}$ & & $\begin{array}{l}22 \\
21\end{array}$ & \multicolumn{2}{|c|}{$\begin{array}{r}420700 \\
\Gamma \quad 195800\end{array}$} & \\
\hline
\end{tabular}


Crest-stage partial-record stations

The following table contains annual maximum discharge for crest-stage stations. A crest-stage is a device which will register the peak stage occurring between inspections of the gage. for each gage is developed from discharge measurements made by indirect measurements of peak $f l o w$ or by current for each gage is developed from discharge measurements made by indirect measurements of peak $t$ iow or by current nearby continuous-record stations, weather records, or local inguiry. Only the maximum discharge for each water year is given. Information on some lower floods may have been obtained, but is not published herein. The years given in the period of record represent water years up to the current year for which the annual maximum has been determined.

Annual maximum discharge at crest-stage partial-record stations during water year 1985

$\begin{gathered}\text { Station } \\ \text { no. }\end{gathered}$
05387500 Upper Iowa River
at Decorah,
Iowa
05388400 Wexford Creek near
Barpers Ferry,
Ia.

\section{Paint Creek near Watervilie, Ia.
05388700 Little Paint Creek tributary near Watervilie, Ia.
05411530 North Branch Tur- key River near Cresco, Ia.
05411700 Crane Creek near Lourdes, Ia.

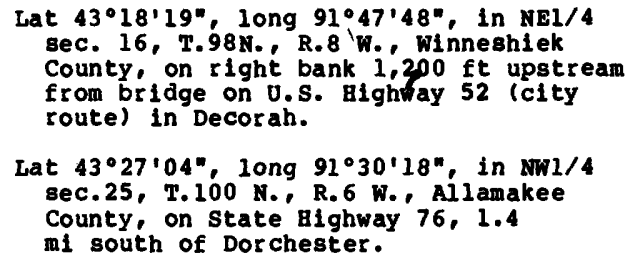

Lat $43^{\circ} 27^{\prime} 04^{\prime \prime}$, long $91^{\circ} 30^{\prime} 18^{\prime \prime}$, in $2 W 1 / 4$ 8ec.25, T. 100 N., R. 6 W., All amakee County, on state Highway $76,1.4$

mi south of Dorchester.

\section{Wexford Creek Basin}

Lat $4^{\circ} 16^{\prime} 22^{\circ}$, long $9^{\circ} 08^{\circ} 00^{\circ}$, in $\mathrm{SEl} / 4$ sec. 25, T.98 N., R.3 W., Al lamakee County, at bridge, $5 \mathrm{mi}$ north of Barpers Ferry on county highway $\times 52$.

Paint Creek Basin

Lat $43^{\circ} 10^{\prime} 24^{\prime \prime}$, long $91^{\circ} 15^{\prime} 42^{\prime \prime}$, near center sec.36, T.97 N., R.4 W., Allamakee County, at bridge on county highway, $3 \mathrm{mi}$ southeast of Watervilie.

Lat $43^{\circ} 14^{\prime} 23^{\prime \prime}$, long $91^{\circ} 15^{\prime} 07^{\prime \prime}$, in SEI/4 sec.1, T. 97 N., R.4 W., Allamakee County, at culvert on county highway, $3.5 \mathrm{mi}$ northeast of Waterville.

\section{Turkey River Basin}

Lat $43^{\circ} 22^{\prime} 15^{\prime \prime}$, long $92^{\circ} 12^{\prime} 49^{\prime \prime}$, in $N W 1 / 4$ sec.25, T.99 N.. R.12.W, Howard County, at bridge on state highway $9,5 \mathrm{mi}$ west of Cresco.

Lat $43^{\circ} 14^{\prime} 57^{\prime \prime}$, long $92^{\circ} 18^{\prime} 32^{\prime \prime}$, in SEL/ NW1/4 sec.6, T.97 N., R.12 \%., Howard County, at bridge on' state Bighway 272, 1 mi southwest of Lourdes.

\section{Little Maquoketa River Basin}

05414350 Little Magouketa River near Graf Ia.

Lat $42^{\circ} 30^{\prime} 09^{\prime \prime}$, long $90^{\circ} 51^{\prime} 50^{\prime \prime}$, in SEL/ sec.20, T.89 H.. R.1 E., Dubuque County, at bridge on county highway, $300 \mathrm{ft}$ downstream from Ilinois Central railroad bridge, $0.5 \mathrm{mi}$ northeast of Graf.

05414400 Middle Fork Iittle Maguoketa River near Rickardsville, Ia.

05414450 North Fork Little Maquoketa River near Rickardsville, Ia.

05414500 Little Maguoketa River near Durango, Ia.

05414600 Little Maquoketa River tributary at Dubuque, Ia.
Lat $42^{\circ} 33^{\prime} 38^{\prime \prime}$, long $90^{\circ} 51^{\prime} 35^{\prime \prime}$, in $8 E 1 / 4$ at bridge on county highway, 2 mi southeast of Rickardsvilie.

Lat $42^{\circ} 35^{\prime} 09^{\prime \prime}$, long 90'51'20", near NW corner sec.28, T.90 N., R.1'E., Dubuque County, at bridge on county high-

way, 1 mi northeast of Rickardsville.

Lat $42^{\circ} 33^{\prime} 18^{\prime \prime}$, long $90^{\circ} 44^{\prime} 46^{\prime \prime}$, In NW1/4

NE1/4 sec. 5, T.89 N., R.2 E.', Dubuque

county, on left bank io ft $\left(3^{\prime} \mathrm{m}\right)$ upstream

from bridge on county highway, $300 \mathrm{ft}(91 \mathrm{~m})$

upstream from Cloie Branch, $1.7 \mathrm{mi}(2.7 \mathrm{~km})$ east of Durango, $5.6 \mathrm{mi}(9.0 \mathrm{~km})$ northwest of court house at Dubuque and $6.4 \mathrm{mi}(10.3 \mathrm{~km})$ upstream from mouth.

Lat $42^{\circ} 32^{\prime} 33^{\prime \prime}$, long $90^{\circ} 41^{\prime} 38^{\prime \prime}$, near NW corner sec.11, T.89 N., R.2 E., Dubuque County at bridge on state Bighway 386 , near north city limits of Dubuque. sec. 32, T.90 N., R.I E., Dubugue County,

Drainage
area
$\begin{array}{lc}\text { area } & \text { of } \\ \text { (mi2) } & \text { record }\end{array}$ Annual maximum
Gage
helght
(feet)
charge
(ft/s)

$43.6 \quad 1966-\quad 02-23-85 \quad 699.08 \quad 1,050$

$11.9 \quad 1953-02-23-85 \quad 6.60 \quad 1.350$

$\begin{array}{lrrrr}56.0 & 1953- & 02-23-85 & 8.80 & 1,350 \\ 1.09 & 1953- & 02-23-85 & 2.45 & 155\end{array}$

$\begin{array}{lllll}19.5 & 1966- & 1985 & 87.33 & 78\end{array}$

$\begin{array}{llll}75.8 & 1951-09-30-85 & 7.49 & 580\end{array}$

$39.6 \quad 1951-02-23-85 \quad 9.59 \quad 2,180$

$30.2 \quad 1951-\quad 02-23-85 \quad 15.02 \quad 640$

$21.6 \quad 2951-\quad 02-23-85 \quad 8.09 \quad 1,320$

$1934-\quad 1985$ 
Annual maximum discharge at crest-stage partial-record stations during water year 1985--Continued

Station station name
no.

05417530 Plum Creek at Earlville, Ia.

05417590 Ritty Creek near Langworthy, Ia.

05420600 Little Wapsipinicon River tributary near Rice utary near
ville, Ia.

05420620 Little Wapsipinicon River near Acme, Ia.

05420640 Little Wapsipinicon River at Elma, Ia.

05420650 Little Wapsipinicon River near New Hampton, Ia.

05420690 East Fork Wapsipinicon River near New Hampton, Ia.

05420850 Little Wapsipinicon River near Oran, Ia.

05420855 Buck Creek near Oran, Ia.

05421100 Pine Creek tributary near Winthrop, Ia.

0541200 Pine Creek near Winthrop, Ia.

05421300 Pine Creek tributaxy No. 2 at winthrop, Ia.

05421550 Buffalo Creek above winthrop, Ia.

05421600 Buffalo Creek near winthrop, Ia.

05421890 Silver Creek at welton, Ia.
Maguoketa River Basin

Lat $42^{\circ} 28^{\prime} 13^{\prime \prime}$, long $91^{\circ} 14^{\prime} 53^{\prime \prime}$, in NEL/4 sec. I, T.88 N., R. 4 W.., Delaware County, at bridge on U.S. Highway $20,1.5 \mathrm{mi}$ southeast of Earivilie.

Lat $42^{\circ} 12^{\prime} 04^{\prime \prime}$, long $91^{\circ} 12^{\prime} 27^{\prime \prime}$, in NW1/4 sec.4, T.85 N., R. 3 W.. Jones County, at bridge on U.S. Highway 151, $1 \mathrm{mi}$ northeast of Langworthy.

Wapsipinicon River Basin

Lat $43^{\circ} 21^{\prime} 31^{\prime \prime}$, long $92^{\circ} 29^{\prime} 08^{\prime \prime}$, near $\mathrm{s} 1 / 4$ corner sec. 27 , T.99 N., R.14 W. Howard County, at culvert on county highway, $3.5 \mathrm{mi}$ east of Riceville.

Lat $43^{\circ} 19^{\prime} 37^{\prime \prime}$, long $92^{\circ} 29^{\prime} 07^{\prime \prime}$, near $\mathrm{N} 1 / 4$ corner sec.10, T.98 N.. R.14 W..

Howard County, at bridge on county highway, $1 \mathrm{mi}$ north of Acme.

Lat $43^{\circ} 14^{\prime} 30^{\prime \prime}$, long $92^{\circ} 27^{\prime} 04^{\prime \prime}$, in $\mathrm{Nw1/4}$ sec.12, T.97 N., R.14 W., Howard County, at bridge on county highway B17, near west city limits of Elma.

Lat $4^{\circ} 03^{\prime} 58^{\prime \prime}$, long $92^{\circ} 23^{\prime} 38^{\prime \prime}$, in NW1/4 sec.9, T.95 N., R. 13 W. Chickasaw County, at bridge on U.S. Highway $18,4 \mathrm{mi}$ west of New Hampton.

Lat $43^{\circ} 05^{\prime} 11^{\prime} \%$, long $92^{\circ} 18^{\prime} 22^{\prime} \%$, in $\mathrm{SEl} / 4$ sec.31, T.96 N., R.12 W., Chickasaw County, at bridge on $\mathrm{J} . \mathrm{S}$. Highway 63,2 mi north of New Hampton.

Lat $42^{\circ} 42^{\prime} 53^{\prime \prime}$, long $92^{\circ} 02^{\prime} 29^{\prime \prime}$, near $N$ W corner sec.9, T.91 N., R. 10 W.. Payette County at bridge on State Highway 3,2 mi northeast of oran.

Lat $42^{\circ} 42^{\prime} 53^{\prime \prime}$, long $92^{\circ} 07^{\prime} 33^{\prime \prime}$, in NEl/4 sec.10, T.91 N., R.11 W.., Bremer County. at bridge on state Highway $3,2.5 \mathrm{mi}$ northwest of Oran.

Lat $42^{\circ} 29^{\prime} 17^{n}$, long $91^{\circ} 47^{\prime} 10^{n}$, in $5 w 1 / 4$ sec.27, T. 89 N., R.8 W., Buchanan County. at culvert on county highway, $2.5 \mathrm{mi}$ nor thwest of winthrop.

Lat $42^{\circ} 28^{\prime} 11^{\prime \prime}$, long $91^{\circ} 47^{\circ} 01^{\prime \prime}$, in $5 w / 4$ sec.34, T.89 N., R.8 W., Buchanan County. at rail road bridge, $500^{\circ} \mathrm{ft}$ upstream from O.S. Highway 20 , and $2.5 \mathrm{mi}$ northwest of winthrop.

Lat $42^{\circ} 28^{\prime} 06^{\prime \prime}$, long $91^{\circ} 44^{\prime} 33^{\prime \prime}$, at $\mathrm{N} / \mathrm{4}$ corner sec. 2, T.88 N., R.8 W.., Buchanan County, at culvert on U.S. Bighway 20 , near west city 1 imits of winthrop.

Lat $42^{\circ} 29^{\prime} 51^{\prime \prime}$, long $91^{\circ} 43^{\prime} 42^{\prime \prime}$, near NE corner sec. 25 , T.89 N., R.8 W.., Buchanan County, at bridge on county highway $\$ 45$, $1.5 \mathrm{mi}$ nor theast of winthrop.

Lat $42^{\circ} 28^{\circ} 07^{n}$, long $91^{\circ} 43^{\prime} 04$ in NEI/4 sec.1, T.88 N., R. 8 W.., Buchanan County, at bridge on U.S. Highway 20 , $1 \mathrm{mi}$ east of winthrop.

Lat $41^{\circ} 54^{\prime} 54^{\prime \prime}$, long $90^{\circ} 36^{\prime} 00^{\prime \prime}$, in $\mathrm{NW1} / 4$ sec.15, T.82 N., R. 3 E., Clinton County, at bridge on U.S. Highway 61, at north edge of Welton.
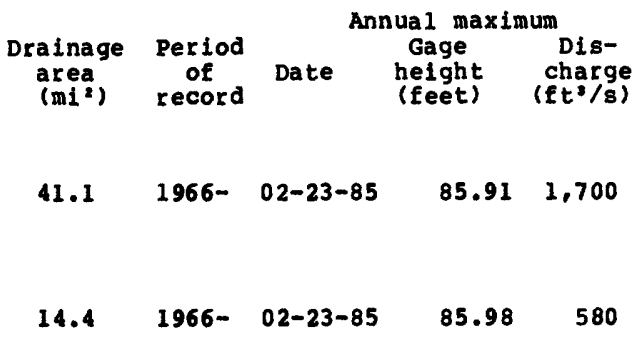
Annual maximum discharge at crest-stage partial-record stations during water year 1985--Continued

\begin{tabular}{|c|c|c|c|c|c|c|c|}
\hline \multirow[t]{2}{*}{$\begin{array}{c}\text { Station } \\
\text { no. }\end{array}$} & \multirow[t]{2}{*}{ station name } & \multirow{2}{*}{\multicolumn{2}{|c|}{ Location }} & \multirow[t]{2}{*}{$\begin{array}{l}\text { Period } \\
\text { of } \\
\text { record }\end{array}$} & Date & $\begin{array}{l}\text { nnual maxi } \\
\text { Gage } \\
\text { helght } \\
\text { (feet) }\end{array}$ & $\begin{array}{l}\text { Disum } \\
\text { Dis- } \\
\text { charge } \\
\left(\mathrm{ft}^{3} / \mathrm{s}\right)\end{array}$ \\
\hline & & & & & & & \\
\hline 05448400 & $\begin{array}{l}\text { Westmain arainage } \\
\text { ditch } 1 \text { near } \\
\text { Britt, Ia. }\end{array}$ & 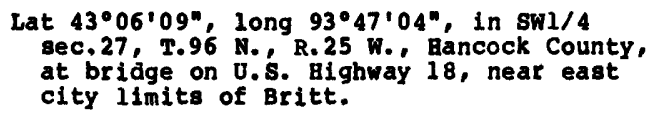 & 21.2 & 1966- & $09-06-85$ & 81.86 & 118 \\
\hline 05448600 & $\begin{array}{l}\text { East Branch Iowa } \\
\text { River above } \\
\text { Hayfield, Ia. }\end{array}$ & $\begin{array}{l}\text { Lat } 43^{\circ} 09^{\prime} 21^{\prime \prime}, \text { long } 93^{\circ} 41 \cdot 21^{\prime \prime} \text {, near } \mathrm{sl} / 4 \\
\text { corner sec.4, T. } 96 \mathrm{~N}, \mathrm{R} .24^{\circ} \mathrm{w} \text {. Bancock } \\
\text { County, at br ldge on county highway, } 1.5 \\
\text { mi southeast of Bayfleld. }\end{array}$ & 2.23 & 1953- & $09-06-85$ & 4.43 & $(+)$ \\
\hline 05448700 & $\begin{array}{l}\text { Bast Branch Iowa } \\
\text { RIver near } \\
\text { Hayfield, Ia. }\end{array}$ & 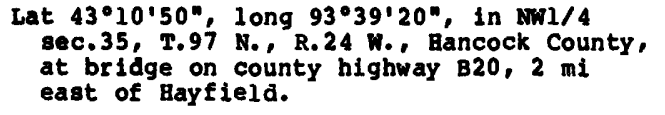 & 7.94 & 1952- & $09-06-85$ & 7.74 & 71 \\
\hline 05448800 & $\begin{array}{l}\text { East Branch Iowa } \\
\text { River near } \\
\text { Garner, Ia. }\end{array}$ & 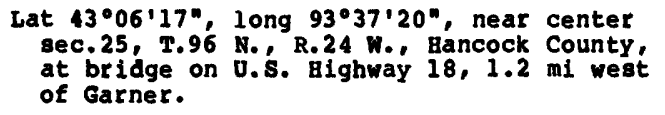 & 45.1 & $1952-$ & 1985 & (a) & $<29$ \\
\hline 05448900 & $\begin{array}{l}\text { East Branch Iowa } \\
\text { River tributary } \\
\text { near Garner, Ia. }\end{array}$ & 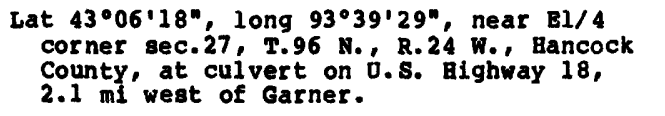 & 5.98 & $1952-$ & $09-06-85$ & 5.21 & 100 \\
\hline 05451955 & $\begin{array}{l}\text { stein creek near } \\
\text { clutier, Ia. }\end{array}$ & $\begin{array}{l}\text { Lat } 42^{\circ} 04^{\prime} 46^{\prime \prime}, \text { long } 92^{\circ} 18^{\prime} 00^{\prime \prime} \text {, in NE1/4 } \\
\text { sec. } 24 \text {, T. } 84 \text { N., R.13 W. Tama County, } \\
\text { at bridge on state Bighway } 318,5 \mathrm{mi} \\
\text { east of Clutier. }\end{array}$ & 23.4 & $1971-$ & $02-22-85$ & 73.85 & 1,550 \\
\hline 05453200 & $\begin{array}{l}\text { Price Creek at } \\
\text { Amana, Ia. }\end{array}$ & $\begin{array}{l}\text { Lat } 41^{\circ} 48^{\prime} 18^{\prime \prime}, \text { long } 91^{\circ} 52^{\prime} 23^{\prime \prime}, \text { in } \mathrm{SEl} / 4 \\
\text { sec. } 22^{\prime} \text {, T. } 81 \text { N., R.9 W. Iowa County, at } \\
\text { bridge on state gighway } 149 \text {, near north } \\
\text { edge of Amana. }\end{array}$ & 29.1 & 1966- & $10-18-84$ & 84.19 & 1,200 \\
\hline 05453600 & $\begin{array}{l}\text { Rapid Creek below } \\
\text { Morse, Ia. }\end{array}$ & $\begin{array}{l}\text { Lat } 41^{\circ} 43^{\prime} 45^{\prime \prime}, \text { long } 91^{\circ} 25^{\prime} 38^{\prime \prime} \text {, near NE } \\
\text { corner sec.21, T. } 80^{\prime} \text { N. R. }^{\prime} \text { W. Johnson } \\
\text { County, at bridge on county highway, } \\
1.5 \mathrm{mi} \text { southeast of Morse. }\end{array}$ & 8.12 & 1951- & $10-18-84$ & 19.58 & 550 \\
\hline 05453750 & $\begin{array}{l}\text { Rapid Creek south- } \\
\text { west of Morse, Ia. }\end{array}$ & $\begin{array}{l}\text { Lat } 41^{\circ} 43^{\prime} 23^{\prime \prime}, \text { long } 91^{\circ} 26^{\prime} 16^{\prime \prime} \text {, in w1/2 sec. } \\
21 \text {, T.80 N. R.5 w. Johnson County, at } \\
\text { bridge on county highway, } 2 \mathrm{mi} \text { southwest } \\
\text { of Morse. }\end{array}$ & 15.2 & 1951- & $02-22-85$ & 24.36 & 1,020 \\
\hline 05453850 & $\begin{array}{l}\text { Rapid Creek trib- } \\
\text { utary No. } 3 \text { near } \\
\text { Oasis, Ia. }\end{array}$ & $\begin{array}{l}\text { Lat } 41^{\circ} 42^{\prime} 33^{\prime \prime}, \text { long } 91^{\circ} 27^{\prime} 14^{\prime \prime} \text {, near center } \\
\text { sec. } 29, \mathrm{~T} .80 \mathrm{~N}, \mathrm{R} .5 \mathrm{~W} . \text { Johnson } \\
\text { County, at bridge on county highway, } 3.5 \\
\text { mi west of Oasis. }\end{array}$ & 1.62 & 1951- & $02-22-85$ & 18.65 & 91 \\
\hline 05453900 & $\begin{array}{l}\text { Rapid Creek trib- } \\
\text { utary near Oasis, } \\
\text { Ia. }\end{array}$ & $\begin{array}{l}\text { Lat } 41^{\circ} 41^{\prime} 14^{\prime \prime}, \text { long } 91^{\circ} 26^{\prime} 37^{\prime \prime}, \text { near SW } \\
\text { corner sec. } 33 \text {, T. } 80^{\prime} \mathrm{N}, \text { R. } 5^{\prime} \text { w. Johnson } \\
\text { County, at bridge on county highway X16, } \\
3 \text { mi southwest of Oasis. }\end{array}$ & 0.97 & 1951- & $10-18-84$ & 13.61 & 190 \\
\hline 05453950 & $\begin{array}{l}\text { Rapid Creek trib- } \\
\text { utary near Iowa } \\
\text { City. Ia. }\end{array}$ & 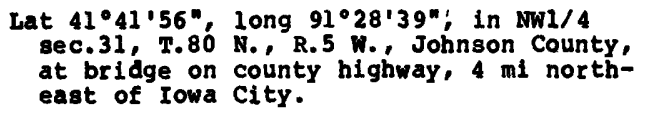 & 3.43 & $1951-$ & $02-22-85$ & 20.95 & 170 \\
\hline 05455100 & $\begin{array}{l}\text { Ol d Mans Creek } \\
\text { near Iowa City, } \\
\text { Ia. (Discontinued) }\end{array}$ & 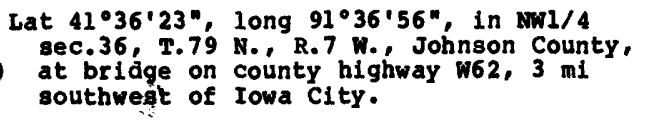 & 201 & $\begin{array}{l}1950-64 \\
1965-85\end{array}$ & $02-23-85$ & 12.22 & 2.870 \\
\hline 05455140 & $\begin{array}{l}\text { North Engliah Riv- } \\
\text { er near Montezuma, } \\
\text { Ia. }\end{array}$ & 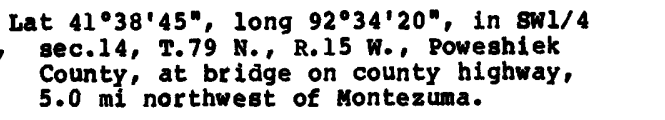 & 31.0 & $1972-$ & $02-22-85$ & 22.39 & 1,020 \\
\hline 05455200 & $\begin{array}{l}\text { North English Riv- } \\
\text { er near Guernsey, } \\
\text { Ia. }\end{array}$ & 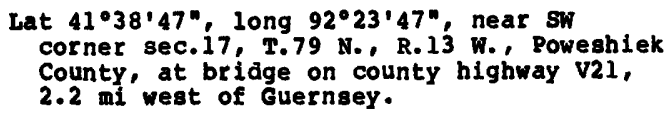 & 68.7 & 1953- & $02-22-85$ & 10.57 & 2,000 \\
\hline 05455210 & $\begin{array}{l}\text { North English Riv- } \\
\text { er at Guernsey. } \\
\text { Ia. }\end{array}$ & 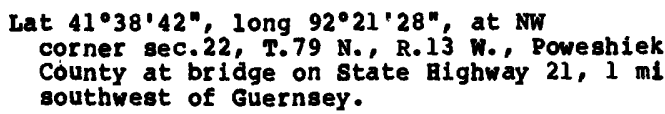 & $k^{81.5}$ & $\begin{array}{l}1960 \\
1966=\end{array}$ & $02-22-85$ & 82.69 & 2,200 \\
\hline
\end{tabular}


Station station name no.

Iowa River Basin--Continued
05455230 Deep River at Deep Lat $41^{\circ} 35^{\prime} 29^{\prime \prime}$, long $92^{\circ} 21^{\prime} 18^{\prime}$, in Swl/4 River, Ia.

05455300 South English River near Barnes City, Ia.

05455350 south English River tributary No. 2 near Montezuma Ia.

05455550 Bulgers run near Riverside, Ia.

05457440 Deer Creek near Carpenter, Ia.

05458560 Beaverdam Creek near sheffleld, Ia.

05459010 Elk Creek at Rensett, Ia.

05459490 spring Creek near Mason City, Ia.

05460100 n1110w Creek near Mason C1ty, Ia.

05462750 Beaver Creek tribIat $42^{\circ} 34^{\prime} 40^{\prime \prime}$, long $92^{\circ} 50^{\prime} 49^{\prime \prime}$, in $\mathrm{N} / 1 / 4$ utary near Apling- sec.27, T.90 N., R.17 W., Butler County, ton, Ia. at brlage on 0.S. Highway 20, 2 mi east of Aplington.

05463090 Black Hawk Creek at Grundy Center. Ia.

Lat $42^{\circ} 22^{\prime} 10^{\mathrm{m}}$, long $92^{\circ} 46^{\prime} 05^{\prime \prime}$, in $\mathrm{NWl} / 4$ sec. 7, T.87 N., R. 16 W., Grundy county. at bridge on state Highway 14 , at north edge of Grundy Center.

05464145 Twelve Mile Creek near Traer, Ia.

\section{0 pratt Creek near} Garrison, Ia. 05464318 East Blue Creek at
Center Point, Ia.

05464560 Prairie Creek at Blairstown, Ia.

05464880 otter Creek at uilton, Ia.

05465150 North Fork Long Creek at Alnsworth, Ia.
Sec.3, T. 78 N. R. R. 13 W.' Poweshiek 21 ,

$1 \mathrm{mi}$ northeast of Deep River.
County, at bridge on county highway, $1 \mathrm{mi}$

north of Barnes City.

Lat $41^{\circ} 34^{\prime} 02^{\prime \prime}$, long $92^{\circ} 27^{\prime} 01^{\prime \prime}$, near $\mathrm{SW}$

sec.11, T. 77 N., R.7 W., Washington

county, at bridge on state at bridge on state Highway 105, 1.5 mi east of Carpenter.

Lat $42^{\circ} 56^{\prime} 11^{\prime \prime}$, long $93^{\circ} 12^{\prime} 09^{\prime \prime}$, at NW corner sec.27, T.94 N., R.20 W., Cerro Gordo county, at bridge on $0 . S$. Highway $65,3 \mathrm{ml}$ north of sheffield.

Lat $43^{\circ} 22^{\prime} 18^{\prime \prime}$, long $93^{\circ} 12^{\prime} 37^{\prime \prime}$, in NEI/4 aec.28, T.99 N., R. 20 W., Worth County, of Rensett.

Lat $43^{\circ} 12^{\prime} 48^{\prime \prime}$, long $93^{\circ} 12^{\prime} 38^{\prime \prime}$, in $\mathrm{SEl} / 4$ sec.16, T.97 H., R. 20 W., Cerro Gordo county, at bridge on 0.5 . Highway 65,4 mi north of Mason City.

Lat $43^{\circ} 08^{\prime} 5^{\prime \prime}$, long $93^{\circ} 16^{\prime} 07^{\prime \prime}$, near center sec.12, T.96 N., R. 21 W., Cerro Gordo County, at bridge on 0.
mi west of Mason City.

Lat $42^{\circ} 13^{\prime} 50^{\prime \prime}$, long $92^{\circ} 27^{\prime} 56^{\prime \prime}$, in $\mathrm{sEl} / 4$ sec.27, T.86 N., R.14 W., Tama County, at bridge on U.S. Highway $63,2.5 \mathrm{mi}$ north of Traer.

Lat $42^{\circ} 10^{\prime} 53^{\prime \prime}$, long $92^{\circ} 11^{\prime} 10^{\prime \prime}$, in sEl/4 sec.12, T.85 N., R.12 W., Benton County, at bridge on 0.S. Bighway $218,3.5 \mathrm{mi}$ northwest of Garrison.

Lat $42^{\circ} 12^{\prime} 44^{\circ}$, long $91^{\circ} 47^{\prime} 21^{\prime \prime}$, in $5 W 1 / 4$ sec. 33, T.86 N., R. 8 \%., Inn County, at bridge on state Highway $150,1.5 \mathrm{mi}$ north of Center Point.

Lat $41^{\circ} 54^{\prime} 42^{\prime \prime}$, long $92^{\circ} 05^{\prime} 03^{\prime \prime}$, in $5 \times 1 / 4$ sec. 13, T. 82 N., R.11 W., Benton County, at bridge on state Highway 82 , at north edge of Blairstown.

Lat $41^{\circ} 36^{\prime} 17^{\prime \prime}$, long $91^{\circ} 02^{\prime} 08^{\prime \prime}$, in $\mathrm{NEl} / 4$ sec.35, T.79 N., R.2 W.. Cedar county at bridge on state Highway $38,1.5 \mathrm{mi}$ northwest of wilton.

Lat $41^{\circ} 16^{\prime} 51^{\prime \prime}$, long $91^{\circ} 32^{\prime} 16^{\prime \prime}$, in SW1/4 sec. 22 , T. 75 N., R. 6 W., Washington County, at bridge on U.S. Highway 218 ,

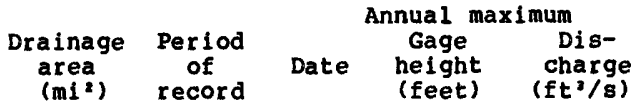

1960

1985

(a)

$<420$

$02-22-85$

10.80

410

corner sec.34, T.78 N., R.14 W., Poweshiek corner sec.11, T.78 N., R.14 W., Poweshiek county, at box culvert on county highway,

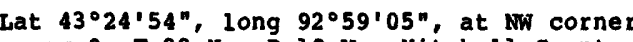
sec.9, T. 99 N., R. 18 W., Mitchell County, County, at bridge on U.S. Highway $18,3.5$ $1 \mathrm{ml}$ southeast of Ainsworth.
$0.523 \quad 1953-\quad 02-22-85 \quad 11.07 \quad 122$

$6.31 \quad 1965-\quad 03-03-85 \quad 85.30 \quad 820$

$91.6 \quad 1966-\quad 1985$

(a) $<1,450$

123

$1966-$

1985

(a)

$<610$

$58.1 \quad 1966-\quad 1985$

(a) $<200$

$29.3 \quad 1966-\quad 1985$

(a)

$<115$

78.6

$1966-$

$3-11-85$

90.01

595

$11.6 \quad 1966-\quad 1985$

(a) $<100$

$56.9 \quad 1966-\quad 1985$

(a)

$<40$

(a) $<460$

$23.4 \quad 1966-\quad 02-22-85 \quad 90.69 \quad 1,800$

17.6

$1966-$

$10-18-84$

80.53

950

$87.0 \quad 1966-\quad 1985$

(a) $<1,100$

1966

$02-23-8$

85.35

680

$30.2 \quad 1951, \quad 03-03-85 \quad 88.761,050$
$43.8 \quad 1966-\quad 1985$ 
Annual maximum discharge at crest-stage partial-record stations during water year 1985--Continued

Station station name
no.

05469860 Mud Lake drainage ditch 71 in Jewel1, ra.

05469990 Reigley Branch near story City, Ia.

05472090 North Skunk River near Baxter, Ia.

05472290 Sugar Creek near Sear sbor 0 , Ia.

05472390 Middle Creek near Lacey, Ia.

05472445 Rock Creek at Sigourney, Ia.

05473300 Cedar Creek near Batavia, Ia.
Location

\section{Skunk River Basin}

Lat $42^{\circ} 18^{\prime} 52^{\circ}$, long $93^{\circ} 38^{\prime} 23^{\circ}$, in $5 \times 1 / 4$ sec. 27, T.87 N., R.24 W.. Hamilton County, at bridge on U.S. Highway 69 , in Jewell.

lat $42^{\circ} 09^{\prime} 01^{\circ}$, long $93^{\circ} 37^{\prime} 13^{\prime \prime}$, in $\mathrm{NWl} / 4$ sec. 26, T. 85 N., R.24 W. story County, at bridge on 0.5 . Highway $69,3 \mathrm{mi}$ south of story City.

Lat $41^{\circ} 49^{\prime} 13^{\circ}$, long $93^{\circ} 03^{\prime} 41^{\prime}$, in $\mathrm{NEl} / 4$ sec. 21, T.81 N. R. 19 W. Jasper County, at bridge on state Highway $223,4.5 \mathrm{mi}$ east of Baxter.

Lat $41^{\circ} 34^{\prime} 26^{\prime \prime}$, long $92^{\circ} 44^{\prime} 20^{\prime \prime}$, at $\mathrm{E} 1 / 4$ corner sec.7, T.78 N., R. 16 W., Poweshiek County, at bridge on state Highway 225 , $1.8 \mathrm{mi}$ west of searsboro.

Lat $41^{\circ} 25^{\prime} 17^{\prime \prime}$, long $92^{\circ} 39^{\prime} 04^{\prime \prime}$, near N1/4 corner sec.1, T.76 N., R.16 W., Mahaska County, at bridge on v.s. Highway 63 , $1.5 \mathrm{mi}$ nor thwest of Lacey.

Lat $41^{\circ} 20^{\prime} 12^{\prime \prime}$, long $92^{\circ} 13^{\prime} 20^{\prime \prime}$, in $\mathrm{NEl} / 4$ sec.3, T. 75 N. , R.12 W., Reokuk County, at bridge on state Highway 92 , near west edge of Sigourney.

Lat $41^{\circ} 00^{\prime} 34^{\prime \prime}$, long $92^{\circ} 07^{\prime} 06^{\prime \prime}$, in $\mathrm{SW1} / 4$ sec. 27, T. 72 N. R. 11 W. Jefferson County, at bridge on U.S. Highway 34 , $2.5 \mathrm{mi}$ nor theast of Batavia.

Des Moines River Basin

05480930 White Fox Creek at clarion, ra.

Lat $42^{\circ} 43^{\prime} 55^{\prime \prime}$, long $93^{\circ} 42^{\prime} 26^{\prime \prime}$, in $\mathrm{Nw} 1 / 4$ sec.5, T.91 N., R. 24 W., Wright County, at bridge on state Highway $3,1.5 \mathrm{mi}$ east of Clarion.

05481510 Bluff Creek at Pi- Lat $42^{\circ} 09^{\prime} 59^{\prime \prime}$, long $94^{\circ} 01^{\prime} 15^{\prime \prime}$, in $\mathrm{MM} 1 / 4$ lot Mound, Ia. sec. 20 , T.85 N. R. 27 W.. Boone County. at bridge on state Highway 329 , at northwest edge of pilot Mound.

05481680 Beaver Creek at

Lat $42^{\circ} 02^{\prime} 04^{\circ}$, long $94^{\circ} 08^{\prime} 46^{\prime \prime}$, in $\mathrm{NE1} / 4$ sec.6, T.83 N., R. 28 W., Boone County, at bridge on 0.S. Highway 30 , at southwest edge of Beaver.

05481690 West Beaver Creek Lat $42^{\circ} 01 ' 56^{\prime \prime}$, long $94^{\circ} 12 \cdot 38^{\prime \prime}$, in NEI/4 at Grand Junction, sec.3, T.83 N., R.29 W., Greene County, Ia. at bridge on U.S. Highway 30 , near east edge of Grand Junction.

05482600 Bardin Creek at Farnhamville, Ia.

05482800 Happy Run at Churdan, Ia.

05482900 Hardin Creek near Farlin, ra.

Lat $42^{\circ} 16^{\prime} 01^{\prime \prime}$, long $94^{\circ} 25^{\prime} 10^{\prime \prime}$, near NE corner sec.14, T.86 N., R.31 W., Calhoun County, at bridge on state Highway 175, near west city limits of Farnhamville.

Lat $42^{\circ} 10^{\prime} 16^{\prime \prime}$, long $94^{\circ} 29^{\prime} 39^{\prime}$, in $5 \% 1 / 4$ sec.17, T.85 N., R.31 W.., Greene County, at bridge on county highway, $1 \mathrm{mi}$ northwest of Churdan.

Lat $42^{\circ} 05^{\prime} 34^{\prime \prime}$, long $94^{\circ} 25^{\prime} 39^{\prime \prime}$, near $N 1 / 4$ corner sec.14, T.84 N., R.31 W., Greene County, at bridge on county highway,

$1.5 \mathrm{mi}$ northeast of Farlin.

05483318 Brushy Fork Creek near Templeton. ra.

05483349 Middle Raccoon River tributary at Carroll, Ia

05487350 South Otter Creek tributary near Woodburn, Ia.

lat $41^{\circ} 56^{\prime} 45^{\prime \prime}$, Iong $94^{\circ} 52^{\prime} 45^{\prime \prime}$, in $\mathrm{Nw} 1 / 4$ sec.1, T.82 N., R. 35 W., Carroll County, at bridge on U.S. Highway $71,4 \mathrm{mi}$ nor theast of Templeton.

Lat $42^{\circ} 02^{\prime} 30^{\prime \prime}$, long $94^{\circ} 52^{\prime} 43^{\prime \prime}$, in $\mathrm{NW} 1 / 4$ sec.36, T. 84 N.. R. 35 W., Carroll County, at bridge on U.S. Highway 71 , $1.5 \mathrm{mi}$ south of Carroll.

Lat $41^{\circ} 02^{\prime} 48^{\prime \prime}$, long $93^{\circ} 35^{\prime} 26^{\prime \prime}$ near SW corner sec.11, T.72 N.. R. 24 W.. Clarke County, at bridge on county highway, 2

Dr

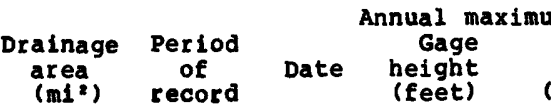
Dis

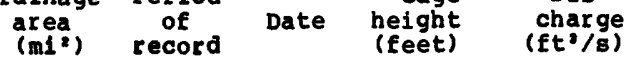

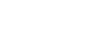
mi north of Hoodburn.
101

$1951-$

1985

(a)

$<580$

$45.0 \quad 1966-\quad 1985$

(a)

$6.58 \quad 1966-\quad 1985$

(a)

$0.71 \quad 1955-\quad 1985$ 
Annual maximum discharge at crest-stage partial-record stations during water year 1985--Continued

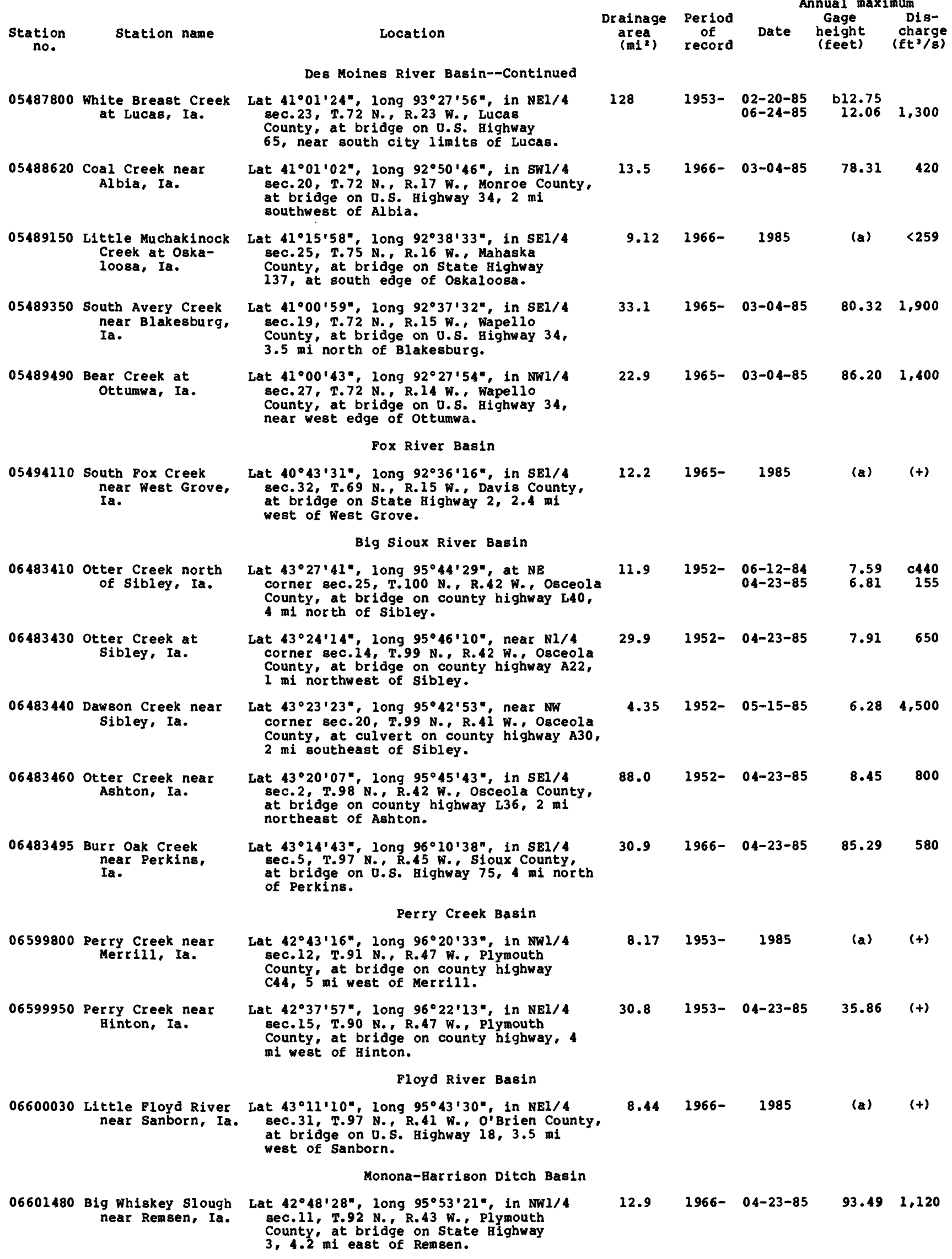


Annual maximum discharge at crest-stage partial-record stations during water year 1985--Continued

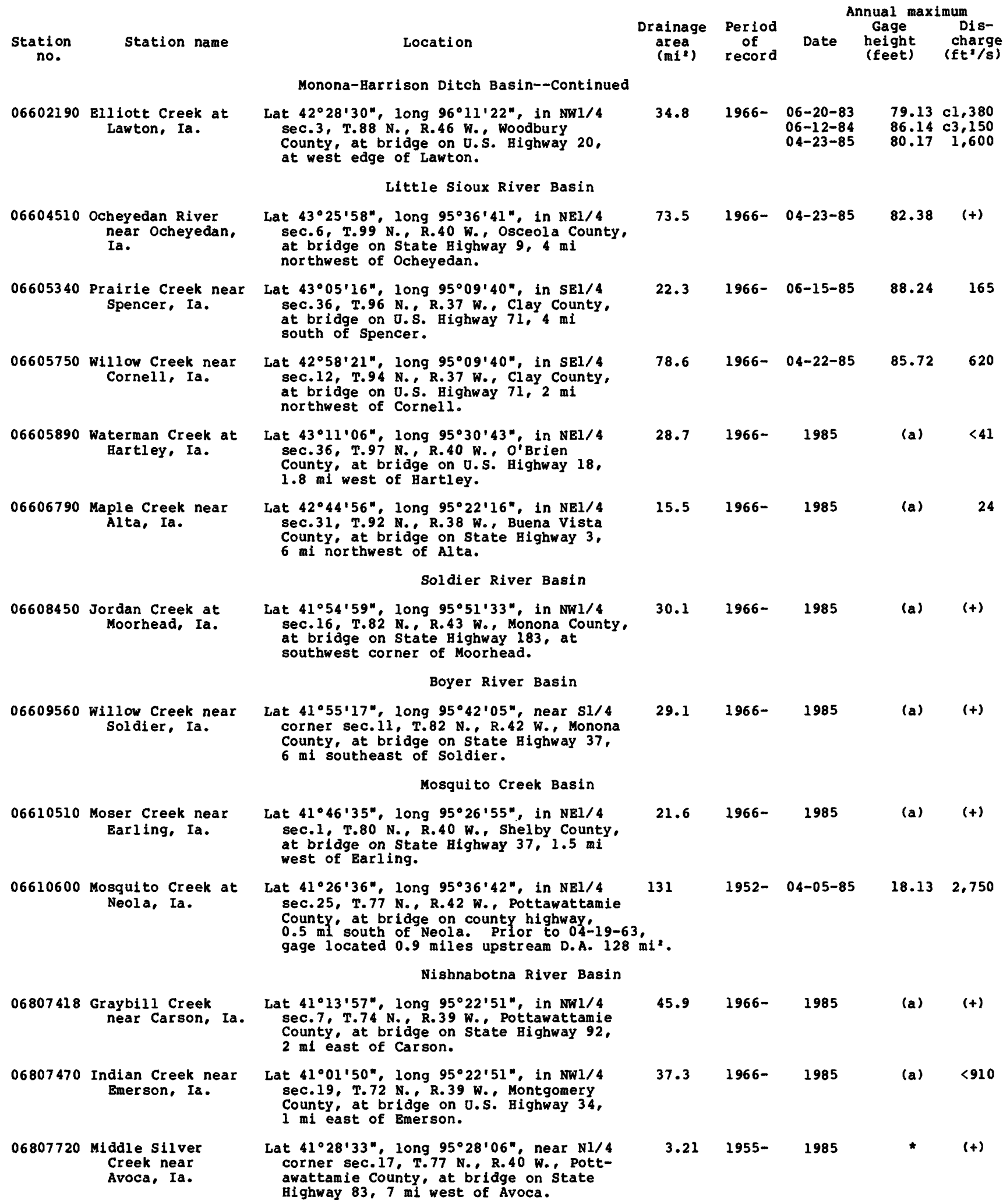


Annual maximum discharge at crest-stage partial-record stations during water year 1985--Continued

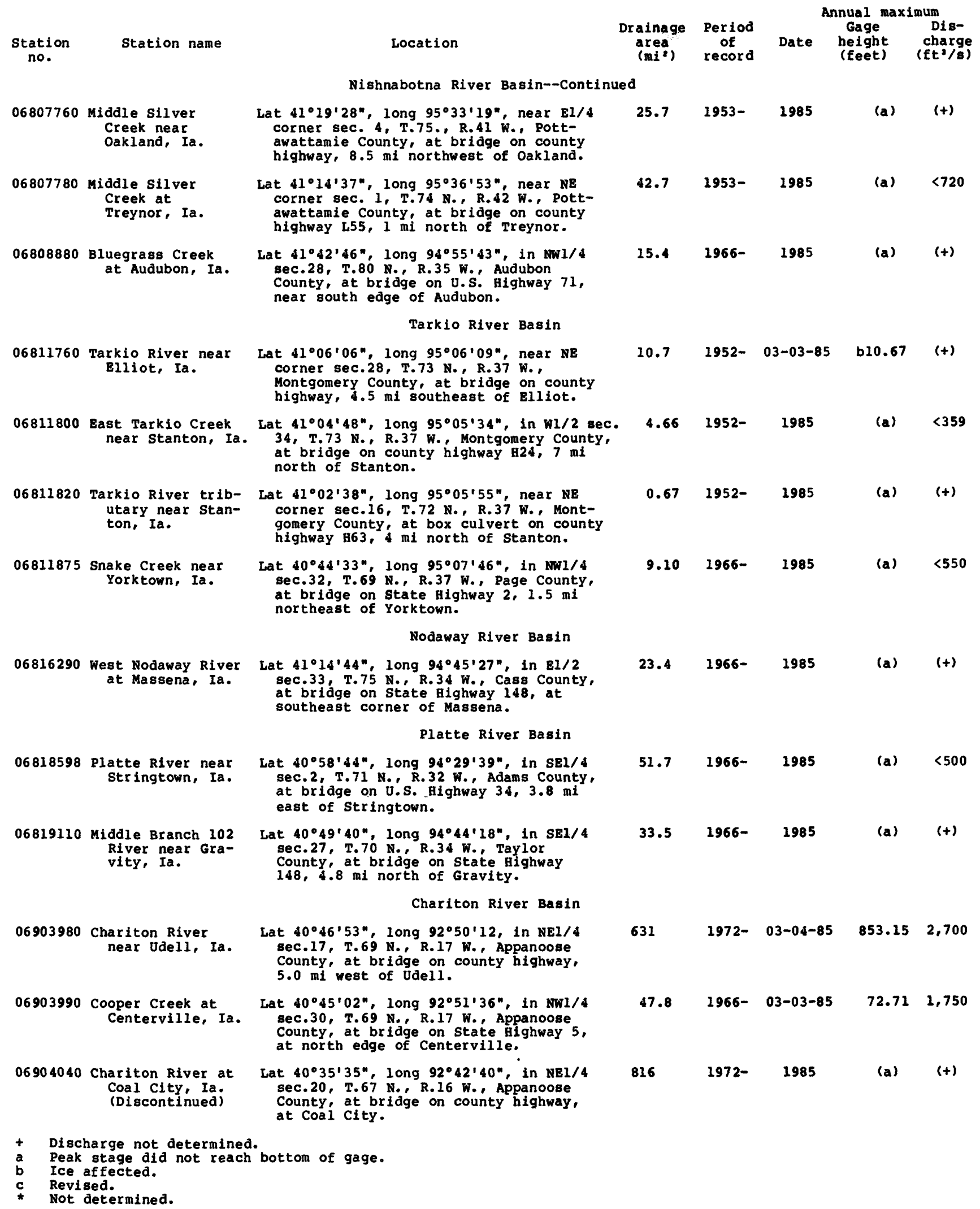




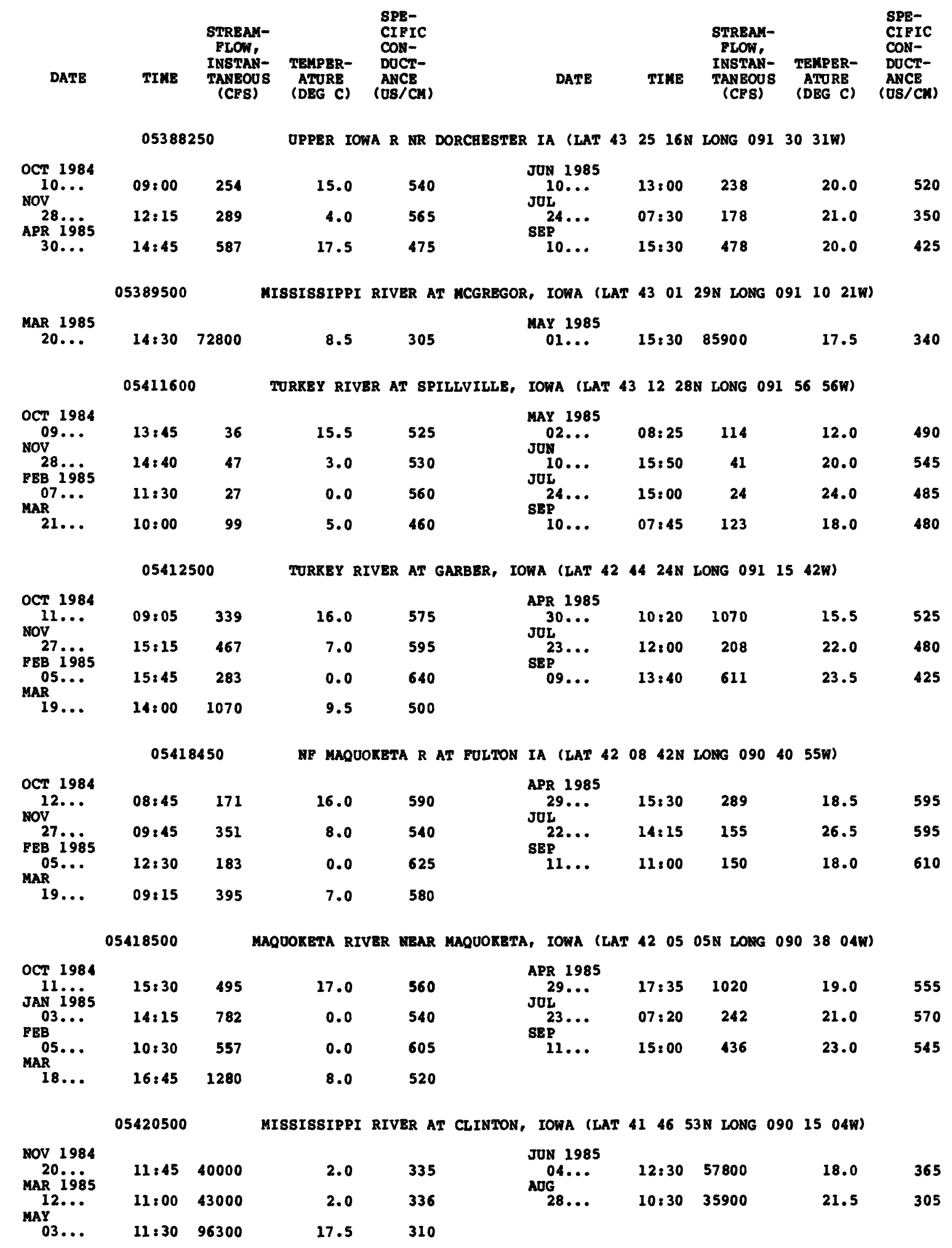




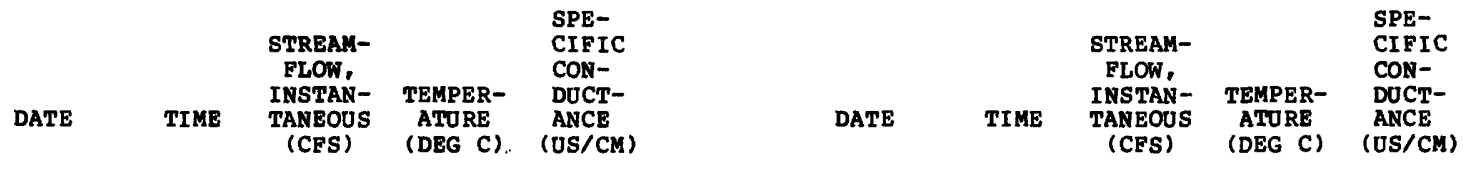

05420560 WAPSIPINICON RIVER NEAR ELMA, IOWA (LAT 4314 34N LONG 0923148 W)

\begin{tabular}{|c|c|c|c|c|c|c|c|c|c|}
\hline $\begin{array}{l}\text { OCT } 1984 \\
02 \ldots\end{array}$ & $17: 55$ & 8.0 & 13.0 & 520 & $\begin{array}{c}\text { APR } 1985 \\
30 \ldots\end{array}$ & $12: 40$ & 55 & 17.0 & 440 \\
\hline DEC $14 \ldots$ & $15: 30$ & 59 & 6.0 & 420 & ${ }_{J U L} 12 \ldots$ & $13: 10$ & 14 & 17.0 & 410 \\
\hline FEB 19385 & $15: 30$ & 18 & 0.5 & 470 & ${ }_{A U G} 24 \ldots$ & $12: 55$ & 5.0 & 25.0 & 570 \\
\hline MAR & $14: 15$ & 8.1 & 0.0 & 570 & $27 \ldots$ & $13: 35$ & 7.2 & 26.0 & 460 \\
\hline $19 \ldots$ & $10: 25$ & 48 & 7.0 & 450 & & & & & \\
\hline
\end{tabular}

05421000 WAPSIPINICON R AT INDEPENDENCE, IOWA (LAT 42 27 49N LONG 09153 42W)

\begin{tabular}{|c|c|c|c|c|c|c|c|c|c|}
\hline $\begin{array}{c}\text { OCT } 1984 \\
09 . .\end{array}$ & $10: 00$ & 89 & 17.0 & 420 & 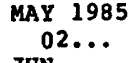 & $12: 30$ & 585 & 17.5 & 410 \\
\hline FEB $19 \ddot{985}$ & $12: 45$ & 192 & 3.5 & 480 & $\begin{array}{l}\text { JUN } \\
10 . . . \\
\text { JUL }\end{array}$ & 09:00 & 121 & 22.5 & 420 \\
\hline MAR & $11: 40$ & 89 & 0.0 & 560 & $\operatorname{SEP}^{25 \ldots}$ & $11: 20$ & 61 & 24.5 & 400 \\
\hline $21 \ldots$ & $13: 40$ & 667 & 8.0 & 350 & $09 .$. & $08: 45$ & 261 & 27.5 & 385 \\
\hline
\end{tabular}

05422000 WAPSIPINICON RIVER NEAR DE WITT, IOWA (LAT 4146 01N LONG 09032 05W)

\begin{tabular}{|c|c|c|c|c|c|c|c|c|c|}
\hline $\begin{array}{c}\text { OCT } 1984 \\
12 \ldots \\
\text { Nov }\end{array}$ & $11: 00$ & 314 & 17.0 & 425 & $\begin{array}{c}\text { APR } 1985 \\
29 . \ldots\end{array}$ & $12: 10$ & 1660 & 17.0 & 450 \\
\hline${ }_{M A R}^{26}$ i & $13: 40$ & 822 & 7.0 & 520 & $\begin{array}{l}22 \ldots \\
\text { SEP }\end{array}$ & $11: 45$ & 255 & 27.0 & 390 \\
\hline $18 \ldots$ & $13: 45$ & 4000 & 7.0 & 310 & $12 \ldots$ & $08: 40$ & 258 & 18.5 & 370 \\
\hline
\end{tabular}

05422470 CROW C AT BETTENDORF IA (LAT 4133 03N LONG 090 27 15W)

\begin{tabular}{|c|c|c|c|c|c|c|c|c|c|}
\hline $\begin{array}{l}\text { OCT } 1984 \\
12 \ldots \\
\text { NOV }\end{array}$ & $13: 15$ & 2.1 & 18.0 & 675 & $\begin{array}{c}\text { MAR } 1985 \\
18 \ldots \\
\text { APR }\end{array}$ & $10: 00$ & 20 & 5.0 & 665 \\
\hline JAN 19385 & $10: 20$ & 6.0 & 6.0 & 715 & $29 .$. & $09: 15$ & 8.1 & 13.0 & 635 \\
\hline$\underset{\text { FEB }}{04 \ldots}$ & $12: 45$ & 13 & 0.0 & 460 & $\begin{array}{l}22 \ldots \\
\text { SEP }\end{array}$ & $09: 15$ & 1.4 & 23.5 & 670 \\
\hline $04 \ldots$ & $10: 00$ & 5.4 & 0.0 & 790 & $12 \ldots$ & $11: 30$ & 0.1 & 19.0 & 620 \\
\hline
\end{tabular}

05449000 EAST BRANCH IOWA RIVER NEAR RLEMME, IOWA (LAT 43 O0 31 N LONG O93 3742 W)

\begin{tabular}{|c|c|c|c|c|c|c|c|c|c|}
\hline $\begin{array}{l}\text { NOV } 1984 \\
13 \ldots \\
\text { DEC }\end{array}$ & $13: 30$ & 6.8 & 7.0 & 800 & $\begin{array}{c}\text { APR } 1985 \\
29 \ldots \\
\text { JUN }\end{array}$ & $13: 20$ & 105 & 15.0 & 710 \\
\hline${ }_{\text {FEB }}^{18} i \ddot{g}_{5}$ & $13: 15$ & 41 & 0.0 & 740 & $10 \ldots$ & $15: 05$ & 13 & 17.0 & 660 \\
\hline MAR & $15: 50$ & 3.3 & 0.0 & 460 & $\begin{array}{l}23 \ldots \\
\text { SEP }\end{array}$ & $13: 20$ & 6.3 & 27.0 & 610 \\
\hline 19 & $12: 50$ & 35 & 10.0 & 550 & $12 \ldots$ & $11: 05$ & 83 & 17.0 & 850 \\
\hline
\end{tabular}

05449500 IOWA RIVER NEAR ROWAN, IOWA (LAT $424536 \mathrm{~N}$ LONG 0933723 )

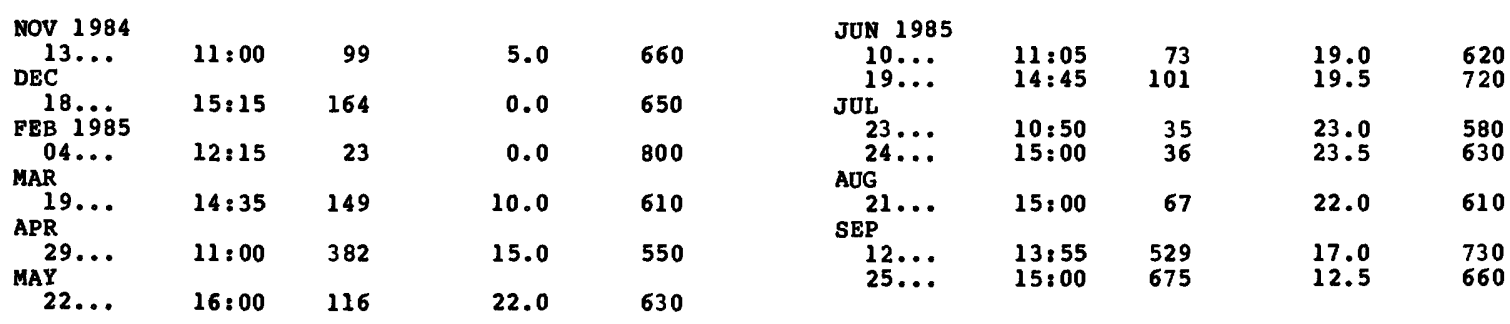




\begin{tabular}{|c|c|c|c|c|c|c|c|c|c|}
\hline DATE & TIME & $\begin{array}{l}\text { STREAM- } \\
\text { FLOW, } \\
\text { INSTAN- } \\
\text { TANEOUS } \\
\text { (CFS) }\end{array}$ & $\begin{array}{c}\text { TEMPER- } \\
\text { ATURE } \\
\text { (DEG C) }\end{array}$ & $\begin{array}{l}\text { SPE- } \\
\text { CIFIC } \\
\text { CON- } \\
\text { DUCT- } \\
\text { ANCE } \\
\text { (US/CY) }\end{array}$ & DATE & TIME & $\begin{array}{l}\text { STREAK- } \\
\text { FLOW, } \\
\text { INSTAN- } \\
\text { TANEOUS } \\
\text { (CFS) }\end{array}$ & $\begin{array}{c}\text { TEMPER- } \\
\text { ATURE } \\
\text { (DEG C) }\end{array}$ & $\begin{array}{l}\text { SPE- } \\
\text { CIFIC } \\
\text { CON- } \\
\text { DUCT- } \\
\text { ANCE } \\
\text { (US/CM) }\end{array}$ \\
\hline
\end{tabular}

05451500 IOWA RIVER AT MARSHALLTOWN, IOWA (LAT 4203 57N LONG 09254 27W)

\begin{tabular}{|c|c|c|c|c|c|c|c|c|c|}
\hline $\begin{array}{l}\text { OCT } 1984 \\
29 \ldots\end{array}$ & $16: 15$ & 250 & 9.0 & 635 & $\begin{array}{l}\text { JUN } 1985 \\
20 . \cdots\end{array}$ & $08: 45$ & 370 & 18.0 & 650 \\
\hline JAN 1985 & $11: 00$ & 305 & 1.0 & 667 & $\begin{array}{l}12 \ldots \\
25 \ldots\end{array}$ & $\begin{array}{l}11: 50 \\
09: 00\end{array}$ & $\begin{array}{l}161 \\
350\end{array}$ & $\begin{array}{l}23.0 \\
23.0\end{array}$ & $\begin{array}{l}549 \\
630\end{array}$ \\
\hline$\underset{A P R}{24 \ldots}$ & $09: 35$ & 222 & 0.0 & 650 & & $09: 00$ & 79 & 19.0 & 423 \\
\hline $\operatorname{MAY}^{17} \ldots$ & $12: 20$ & 709 & 15.5 & 618 & $\underset{\text { SEP }}{22} \cdots$ & $09: 15$ & 267 & 19.0 & 435 \\
\hline $\begin{array}{l}23 \ldots \\
30 \ldots\end{array}$ & $\begin{array}{l}08: 45 \\
12: 00\end{array}$ & $\begin{array}{l}395 \\
314\end{array}$ & $\begin{array}{l}18.0 \\
21.5\end{array}$ & $\begin{array}{l}680 \\
587\end{array}$ & $26 \ldots$ & $09: 15$ & 365 & 11.5 & 610 \\
\hline
\end{tabular}

05451700 TIMBER CREEK NEAR MARSHALLTOWN, IOWA (LAT 4200 25N LONG O92 51 15W)

\begin{tabular}{|c|c|c|c|c|c|c|c|c|c|}
\hline OCT 1984 & $09: 30$ & 25 & 9.0 & 592 & $\begin{array}{c}\text { APR } 1985 \\
17 \ldots\end{array}$ & $14: 20$ & 56 & 16.0 & 541 \\
\hline $\begin{array}{l}\text { DEC } \\
\text { JAN } 11985\end{array}$ & $13: 15$ & 25 & 0.0 & 581 & $\begin{array}{l}\text { MAY } \\
30 \ldots \\
\text { JUL }\end{array}$ & $14: 40$ & 25 & 24.5 & 603 \\
\hline $\operatorname{MAR}^{24 \cdots}$ & $11: 10$ & 40 & 0.0 & 575 & ${ }_{A U G}^{12 \ldots}$ & $13: 50$ & 14 & 22.0 & 582 \\
\hline $07 \ldots$ & $10: 45$ & 75 & 2.5 & 503 & $19 \ldots$ & $16: 45$ & 3.6 & 22.5 & 597 \\
\hline
\end{tabular}

05451900 RICHLAND CREEK NEAR HAVEN, IOWA (LAT 4153 58N LONG 0922827 W)

\begin{tabular}{|c|c|c|c|c|c|c|c|c|c|}
\hline $\begin{array}{c}\text { OCT } 1984 \\
30 \ldots\end{array}$ & $11: 30$ & 5.9 & 10.0 & 502 & $\begin{array}{c}\text { MAY } 1985 \\
28 \ldots\end{array}$ & $14: 20$ & 9.4 & 21.0 & 492 \\
\hline $\begin{array}{l}\mathrm{DEC} \\
12 \ldots{ }^{2}\end{array}$ & $12: 45$ & 6.5 & 0.0 & 454 & $\underset{\text { JUL }}{10 \ldots}$ & $15: 15$ & 3.9 & 25.0 & 449 \\
\hline $\begin{array}{l}06 \ldots \\
\text { APR } \\
18\end{array}$ & $15: 30$ & 45 & 3.0 & $\begin{array}{r}358 \\
454\end{array}$ & $19 \ldots$ & $13: 00$ & 2.6 & - & 483 \\
\hline
\end{tabular}

05452000 SALT CREEK NR ELBERON, IOWA (LAT 4157 51N LONG 0921847 )

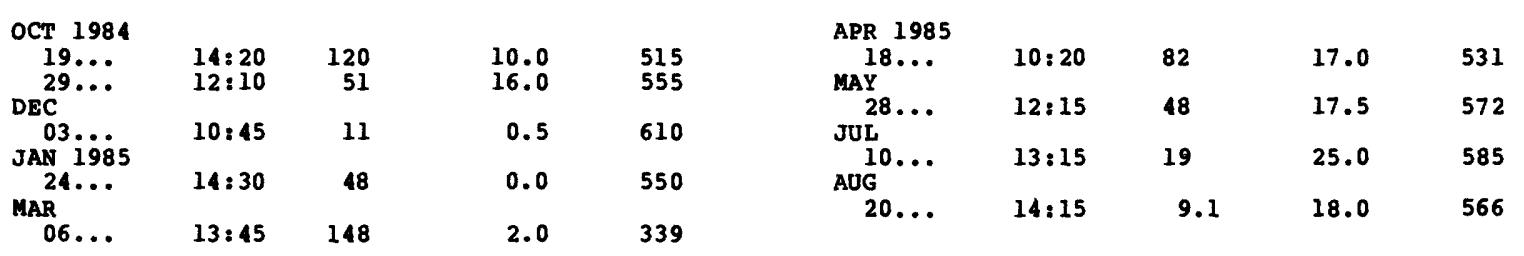

05452200 WALNUT CREEK NEAR HARTWICK, IOWA (LAT 4150 O6N LONG $0922310 \%$ )

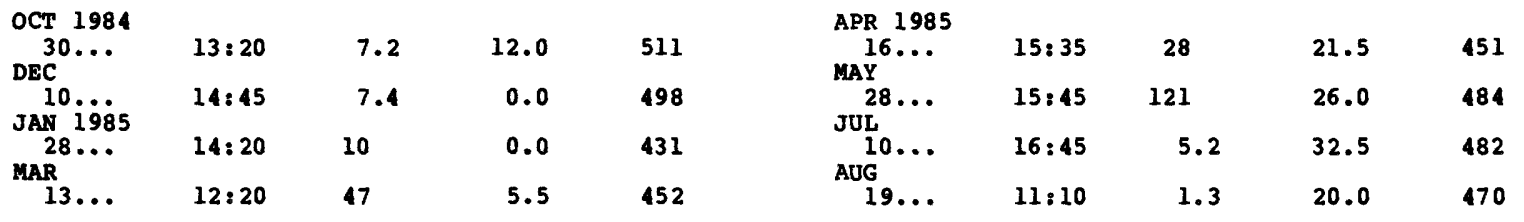




\begin{tabular}{|c|c|c|c|c|c|c|c|c|c|}
\hline DATE & TIME & $\begin{array}{c}\text { STREAM- } \\
\text { PLOW, } \\
\text { INSTAN- } \\
\text { TANEOUS } \\
\text { (CFS) }\end{array}$ & $\begin{array}{l}\text { TEMPER- } \\
\text { ATURE } \\
\text { (DEG C) }\end{array}$ & $\begin{array}{l}\text { SPE- } \\
\text { CIFIC } \\
\text { CON- } \\
\text { DUCT- } \\
\text { ANCE } \\
\text { (US/CM) }\end{array}$ & DATE & TIME & $\begin{array}{l}\text { STREAM- } \\
\text { FLOW, } \\
\text { INSTAN- } \\
\text { TANEOUS } \\
\text { (CFS) }\end{array}$ & $\begin{array}{l}\text { TEMPER- } \\
\text { ATURE } \\
\text { (DEG C) }\end{array}$ & $\begin{array}{l}\text { SPE- } \\
\text { CIFIC } \\
\text { CON- } \\
\text { DUCT- } \\
\text { ANCE } \\
\text { (US/CM) }\end{array}$ \\
\hline
\end{tabular}

05453000

$\begin{array}{lrr}\text { OCT } 1984 & & \\ 23 \ldots & 13: 30 & 34 \\ 30 \ldots & 15: 00 & 40 \\ \text { DEC } & & \\ 10 \\ \text { JAN } 1985 & 13: 05 & 39 \\ 28 \ldots & 16: 00 & 38 \\ \text { MAR } & & \\ 04 & 10: 30 & 4270\end{array}$

05453100

\begin{tabular}{|c|c|c|}
\hline-11908 & & \\
\hline $\begin{array}{l}22 \ldots \\
31 \ldots\end{array}$ & $\begin{array}{l}13: 00 \\
12: 00\end{array}$ & $\begin{array}{l}842 \\
575\end{array}$ \\
\hline $\begin{array}{l}\text { DEC } \\
10 \ldots \ldots \\
\text { JAN } 1985\end{array}$ & $11: 00$ & 867 \\
\hline MAR & $12: 00$ & 595 \\
\hline $\begin{array}{l}06 \\
\text { APR }\end{array}$ & $11: 30$ & 7860 \\
\hline
\end{tabular}

BIG BEAR CREEK AT LADORA, IOWA (LAT 4144 58N LONG 09210 55W)

$\begin{array}{lllll}\begin{array}{c}\text { APR } 1985 \\ 16 \ldots . .\end{array} & 13: 10 & 88 & 17.5 & 512 \\ \begin{array}{c}\text { MAY } \\ 29 \ldots\end{array} & 12: 40 & 38 & 18.5 & 575 \\ \begin{array}{c}\text { JUL } \\ \text { 08... }\end{array} & 13: 50 & 18 & 25.5 & 572 \\ \begin{array}{c}\text { AUG } \\ 21 \ldots\end{array} & 13: 30 & 6.3 & 23.0 & 673\end{array}$

IOWA RIVER NEAR MARENGO, IOWA (LAT $414841 \mathrm{~N}$ LONG 09203 42W)

$\begin{array}{rr}10.5 & 570 \\ 8.0 & 596 \\ 1.5 & 646 \\ 0.0 & 644 \\ 1.5 & 236 \\ 16.5 & 586\end{array}$

$\begin{array}{ccccc}\text { MAY } 1985 & & & & \\ 23 \ldots . . & 12: 00 & 746 & 21.0 & 580 \\ 29 \ldots & 10: 55 & 664 & 20.0 & 541 \\ \text { JUN } & 12: 00 & 780 & 21.0 & 620 \\ 20 \ldots & 12: 15 & 429 & 26.0 & 376 \\ \text { JUL } & 12: 00 & 217 & 25.0 & 430 \\ 08 \ldots . & 12.0 & 20.0 & 453 \\ 25 \ldots & 12: 00 & 168 & 20.0 & 430 \\ \text { AUG } & 12: 00 & 261 & & \\ 21 \ldots & 12: 00 & 1460 & 13.0 & 500 \\ 22 \ldots & & & & \end{array}$

05454000

RAPID CREEK NEAR IOWA CITY, IOWA (LAT 4141 19N LONG 09129 15W)

OCT 1984

\begin{tabular}{|c|c|c|c|c|}
\hline $\begin{array}{l}O 21 \\
02 \ldots\end{array}$ & $11: 10$ & 0.54 & 10.0 & 515 \\
\hline JAN 19385 & $11: 15$ & 10 & 0.0 & 660 \\
\hline 07 & $09: 00$ & 21 & 0.0 & \\
\hline
\end{tabular}

APR 1985

$\begin{array}{ccccc}\underset{29}{29} \ldots & 14: 20 & 9.0 & 20.0 & 555 \\ \begin{array}{c}\text { AUG } \\ \text { O2... }\end{array} & 11: 00 & 0.33 & 20.0 & 450 \\ \text { SEP } & 07: 45 & 0.02 & 21.0 & 530\end{array}$

05454300

CLeAR CREgk NR CORALVILLE, IOWA (LAT 4140 36N LONG 09135 55W)

OCT 1984

$\begin{array}{rrrrr}02 \ldots \ldots & 14: 15 & 5.4 & 16.0 & 585 \\ 30 \ldots & 12: 30 & 65 & 11.5 & 550 \\ \text { DEC } & & & & \\ 04 \ldots & 14: 15 & 57 & 0.0 & 620 \\ 12 \ldots & 15: 20 & 42 & 3.0 & 550 \\ \text { JAN } 1985 & & & & \\ 07 \ldots \ldots & 10: 45 & 71 & 0.0 & 525 \\ 31 \ldots \ldots & 11: 30 & 30 & 0.0 & 570 \\ \text { FEB } & & & & \\ 11 \ldots & 14: 00 & 27 & 0.0 & 570\end{array}$

$\begin{array}{ccccc}\begin{array}{c}\text { APR } 1985 \\ 03 \ldots . .\end{array} & 14: 15 & 112 & 14.0 & 515 \\ \begin{array}{c}\text { MAY } \\ 06 \ldots\end{array} & 14: 10 & 38 & 22.0 & 550 \\ \begin{array}{c}\text { JUN } \\ 03 \ldots\end{array} & 08: 15 & 18 & 15.0 & 590 \\ \begin{array}{c}\text { AUG } \\ 01 \ldots\end{array} & 11: 30 & 8.9 & 22.0 & 680 \\ \begin{array}{c}\text { SEP } \\ 04 \ldots\end{array} & 08: 30 & 2.8 & 22.0 & 740\end{array}$

05454500

IOWA RIVER AT IOWA CITY, IOWA (LAT $413924 \mathrm{~N}$ LONG 09132 27W)

OCT 1984

$\begin{array}{ccccc}\begin{array}{c}\text { OCF } \\ \text { NOF }\end{array} & 11: 15 & 410 & 16.0 & 490 \\ \begin{array}{c}\text { NOV } \ldots \\ \text { DEC }\end{array} & 11: 00 & 2120 & 10.0 & 470 \\ 05 \ldots & 17: 00 & 841 & 0.0 & 480 \\ \begin{array}{c}\text { JAN } 1985 \\ 04 \ldots\end{array} & 16: 35 & 588 & 0.0 & 700 \\ \begin{array}{c}\text { APR } \\ 05 \ldots\end{array} & 10: 15 & 2720 & 7.5 & 540 \\ \begin{array}{c}\text { MAY } \\ 09 \ldots\end{array} & 09: 30 & 665 & 20.5 & 590 \\ 23 \ldots & 14: 45 & 616 & 21.0 & 610\end{array}$

JUN 1985

$\begin{array}{ccccc}06 \ldots . . & 09: 00 & 660 & 21.0 & 540 \\ 20 \ldots & 14: 30 & 800 & 22.0 & 500 \\ \text { JUL } & & & & \\ 02 \ldots & 09: 30 & 639 & 25.0 & 480 \\ 26 \ldots & 09: 15 & 216 & 25.0 & 480 \\ \text { AUG } & & & & \\ 02 \ldots & 09: 15 & 228 & 23.5 & 490 \\ 23 \ldots & 09: 00 & 195 & 22.0 & 445 \\ \text { SEP } \ldots & & & & \\ \text { 03... } & 14: 15 & 196 & 26.5 & 470 \\ 26 \ldots & 14: 15 & 650 & 17.0 & 470\end{array}$




\begin{tabular}{|c|c|c|c|c|c|c|c|c|c|}
\hline AATE & TIME & $\begin{array}{c}\text { STREAM- } \\
\text { FLOW, } \\
\text { INSTAN- } \\
\text { TANEOUS } \\
\text { (CFS) }\end{array}$ & $\begin{array}{l}\text { TEMPER- } \\
\text { ATURE } \\
\text { (DEG C) }\end{array}$ & $\begin{array}{l}\text { SPE- } \\
\text { CIFIC } \\
\text { CON- } \\
\text { DUCT- } \\
\text { ANCE } \\
\text { (US/CM) }\end{array}$ & DATE & TIME & $\begin{array}{l}\text { STREAM- } \\
\text { FLOW, } \\
\text { INSTAN- } \\
\text { TANEOUS } \\
\text { (CFS) }\end{array}$ & $\begin{array}{l}\text { TEMPER- } \\
\text { ATURE } \\
\text { (DEG C) }\end{array}$ & $\begin{array}{l}\text { SPE- } \\
\text { CIFIC } \\
\text { CON- } \\
\text { DUCT- } \\
\text { ANCE } \\
\text { (US/CM) }\end{array}$ \\
\hline
\end{tabular}

05455000 RALSTON CREEK AT IOWA CITY, IOWA (LAT 4139 50N LONG 091 $3048 W$ )

\begin{tabular}{|c|c|c|c|c|c|c|c|c|c|}
\hline OCT 1984 & & & & & APR 1985 & & & & \\
\hline $\begin{array}{l}02 \ldots \\
31 \ldots \\
\text { DEC }\end{array}$ & $\begin{array}{l}15: 45 \\
16: 00\end{array}$ & $\begin{array}{l}0.04 \\
3.5\end{array}$ & $\begin{array}{l}12.0 \\
12.0\end{array}$ & $\begin{array}{l}580 \\
590\end{array}$ & $\begin{array}{l}03 \ldots \\
29 \ldots \\
\text { JUN }\end{array}$ & $\begin{array}{l}10: 20 \\
10: 30\end{array}$ & $\begin{array}{l}2.5 \\
0.59\end{array}$ & $\begin{array}{r}9.5 \\
13.0\end{array}$ & $\begin{array}{l}610 \\
760\end{array}$ \\
\hline JAN 1985 & $09: 15$ & 0.81 & 0.0 & 800 & AUG & $10: 45$ & 0.12 & 16.0 & 640 \\
\hline $\begin{array}{l}02 \ldots \\
29 \ldots\end{array}$ & $\begin{array}{l}10: 05 \\
15: 15\end{array}$ & $\begin{array}{l}3.2 \\
1.3\end{array}$ & $\begin{array}{l}0.0 \\
0.0\end{array}$ & $\begin{array}{l}715 \\
655\end{array}$ & SEP & $08: 45$ & 0.14 & 17.5 & 520 \\
\hline $\begin{array}{l}\text { MAR } \\
01 \ldots\end{array}$ & $14: 00$ & 3.9 & 8.0 & 555 & $03 \ldots$ & $09: 45$ & 0.02 & 22.0 & 570 \\
\hline
\end{tabular}

05455010 SOUTH BRANCH RALSTON CREER AT IOWA CITY, IOWA (LAT $413905 \mathrm{~N}$ LONG 091 $3027 \mathrm{~W}$

\begin{tabular}{|c|c|c|c|c|c|c|c|c|c|}
\hline $\begin{array}{c}\text { OCT } 1984 \\
02 \ldots \\
\text { DEC }\end{array}$ & $16: 10$ & 0.15 & 12.5 & 765 & $\begin{array}{c}\text { MAR } 1985 \\
01 \ldots \\
\text { APR }\end{array}$ & $14: 55$ & 4.0 & 9.0 & 625 \\
\hline JAN 04985 & $10: 00$ & 1.0 & 0.0 & 715 & $\underset{M A Y}{01} \ldots$ & $14: 15$ & 3.1 & 4.0 & 620 \\
\hline $\begin{array}{l}04 \ldots \\
30 \ldots \\
\text { FEB }\end{array}$ & $\begin{array}{l}12: 00 \\
15: 00\end{array}$ & $\begin{array}{l}3.9 \\
1.0\end{array}$ & $\begin{array}{l}0.0 \\
0.0\end{array}$ & $\begin{array}{l}695 \\
650\end{array}$ & $\begin{array}{l}02 \ldots \\
31 \ldots\end{array}$ & $\begin{array}{l}13: 50 \\
13: 50\end{array}$ & $\begin{array}{l}0.79 \\
0.33\end{array}$ & $\begin{array}{l}16.0 \\
20.0\end{array}$ & $\begin{array}{l}720 \\
670\end{array}$ \\
\hline $21 \ldots$ & $09: 40$ & 78 & 0.0 & 245 & $01 \ldots$ & $09: 00$ & 0.18 & 17.5 & 530 \\
\hline
\end{tabular}

05455100 OLD MANS CR NR IOWA CITY, IOWA (LAT 4136 25N LONG $0913640 \mathrm{~W}$ )

\begin{tabular}{|c|c|c|c|c|c|c|c|c|c|}
\hline $\begin{array}{c}\text { NOV } 1984 \\
05 \ldots\end{array}$ & $12: 00$ & 177 & 7.0 & 475 & $\begin{array}{c}\text { MAY } 1985 \\
02 \ldots\end{array}$ & $15: 50$ & 56 & 20.0 & 485 \\
\hline $\begin{array}{l}\text { DEC } \\
03 \ldots \ldots \\
\text { JAN } 1985\end{array}$ & $12: 45$ & 63 & 0.0 & 530 & $\begin{array}{l}\text { JUN } \\
03 \ldots \\
\text { AUG }\end{array}$ & $09: 55$ & 32 & 17.0 & 500 \\
\hline $\begin{array}{l}07 \ldots \\
29 \ldots\end{array}$ & $\begin{array}{l}12: 00 \\
11: 00\end{array}$ & $\begin{array}{r}129 \\
49\end{array}$ & $\begin{array}{l}0.0 \\
0.0\end{array}$ & $\begin{array}{l}490 \\
515\end{array}$ & $\begin{array}{l}01 \ldots \\
\text { SEP }\end{array}$ & $13: 15$ & 18 & 24.0 & 475 \\
\hline $\begin{array}{l}\text { APR } \\
\quad 03 \ldots\end{array}$ & $16: 00$ & 194 & $-\infty$ & 465 & $04 \ldots$ & $11: 15$ & 3.9 & 24.0 & 455 \\
\hline
\end{tabular}

05455500 ENGLISB RIVER AT KALONA, IOWA (LAT 4127 59N LONG 0914256 )

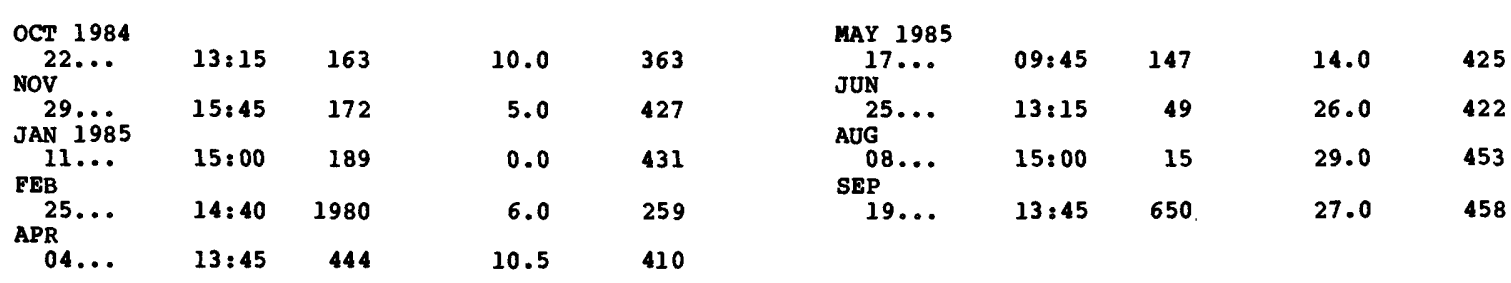

05455700 IOWA RIVER NEAR LONE TREE, IOWA (LAT 4125 15N LONG $0912825 W$ )

\begin{tabular}{|c|c|c|c|c|}
\hline CT 1984 & & & & \\
\hline nov $23 . .$. & $13: 45$ & 2440 & 13.0 & 452 \\
\hline $\begin{array}{l}30 \\
\text { FEB } 1985\end{array}$ & $13: 30$ & 1410 & 6.5 & 501 \\
\hline $\operatorname{MAY}^{25} \ldots$ & $12: 15$ & 12400 & 0.5 & 318 \\
\hline $\begin{array}{l}20 \ldots \\
24 \ldots\end{array}$ & $\begin{array}{l}13: 30 \\
08: 30\end{array}$ & $\begin{array}{l}1240 \\
1200\end{array}$ & $\begin{array}{l}22.5 \\
20.0\end{array}$ & $\begin{array}{l}580 \\
590\end{array}$ \\
\hline
\end{tabular}

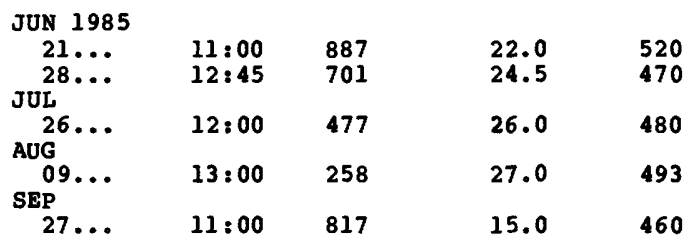




\begin{tabular}{|c|c|c|c|c|c|c|c|c|c|}
\hline TE & TIME & $\begin{array}{l}\text { STREAM- } \\
\text { FLOW, } \\
\text { INSTAN- } \\
\text { TANEOUS } \\
\text { (CFS) }\end{array}$ & $\begin{array}{l}\text { TEMPER- } \\
\text { ATURE } \\
\text { (DEG C) }\end{array}$ & $\begin{array}{l}\text { SPE- } \\
\text { CIFIC } \\
\text { CON- } \\
\text { DUCT- } \\
\text { ANCE } \\
\text { (US/CM) }\end{array}$ & DATE & TIME & $\begin{array}{l}\text { STREAM- } \\
\text { FLOW, } \\
\text { INSTAN- } \\
\text { TANEOUS } \\
\text { (CFS) }\end{array}$ & $\begin{array}{l}\text { TEMPER- } \\
\text { ATURE } \\
\text { (DEG C) }\end{array}$ & $\begin{array}{l}\text { SPE- } \\
\text { CIFIC } \\
\text { CON- } \\
\text { DUCT- } \\
\text { ANCE } \\
\text { (US/CM) }\end{array}$ \\
\hline
\end{tabular}

05457700

$\begin{array}{ccc}\text { OCT } 1984 & & \\ 03 \ldots & 09: 45 & 182 \\ \text { DEC } & & \\ 28 \ldots & 09: 15 & 668 \\ \text { FEB } 1985 & 10: 20 & 187 \\ 06 \ldots . . & 10: 20 & \\ \begin{array}{c}\text { APR } \\ 30 \ldots . . .\end{array} & 15: 15 & 749\end{array}$

05458000

OCT 1984

$\begin{array}{lrr}\begin{array}{l}\text { OCT } 1984 \\ 03 \ldots \ldots\end{array} & 11: 40 & 37 \\ \begin{array}{c}\text { NOV } \\ 15 \ldots .\end{array} & 13: 00 & 182 \\ \begin{array}{c}\text { DEC } \\ 28 \ldots . \ldots 5\end{array} & 10: 40 & 203 \\ \begin{array}{c}\text { FEB } 1985 \\ 06 \ldots .\end{array} & 12: 55 & 40 \\ \text { MAR } & & \end{array}$

$19 \ldots 12: 20 \quad 162$

05458500

Nov 1984

$19 \ldots$

JAN 1985

$23 \ldots \ldots \quad 14: 40 \quad 344$

$\underset{\text { MAR }}{11 \ldots} \quad 14: 20 \quad 290$

26... 10:20 903

CEDAR RIVER AT CHARLES CITY, IOWA (LAT $430345 \mathrm{~N}$ IONG $0924023 \mathrm{w}$ )

\begin{tabular}{|c|c|c|c|c|c|c|}
\hline 13.0 & 590 & $\begin{array}{c}\text { JUN } 1985 \\
12 \ldots\end{array}$ & $09: 40$ & 295 & 17.0 & 560 \\
\hline 3.0 & 540 & $\begin{array}{l}\text { JUL } \\
24 \ldots \\
\text { SEP }\end{array}$ & $19: 45$ & 154 & 26.0 & 645 \\
\hline 0.0 & 300 & $10 \ldots$ & $17: 40$ & 513 & 21.0 & 520 \\
\hline 17.0 & 600 & & & & & \\
\hline
\end{tabular}

LITTLE CEDAR RIVER NEAR IONIA, IOWA (LAT 4302 05N LONG 0923005 W)

\begin{tabular}{|c|c|c|c|c|c|c|}
\hline 13.0 & 560 & $\begin{array}{c}\operatorname{MAY} \\
01 \ldots 85 \\
\text { JUN }\end{array}$ & $09: 50$ & 182 & 15.0 & 490 \\
\hline 5.0 & 420 & $12 \ldots$ & $11: 20$ & 66 & 17.0 & 400 \\
\hline 1.0 & 340 & & $10: 55$ & 26 & 24.0 & 400 \\
\hline 0.0 & 550 & $10 \ldots$ & $15: 40$ & 152 & 22.0 & 460 \\
\hline 9.0 & 520 & & & & & \\
\hline
\end{tabular}

CEDAR RIVER AT JANESVILLE, IONA (LAT 4238 54N LONG $0922754 \mathrm{~W}$ )

05458900 WEST FORK CEDAR RIVER AT FINCHFORD, IOWA (LAT 423750 LONG O92 32 24W)

\begin{tabular}{|c|c|c|c|c|c|c|c|c|c|}
\hline NOV 1984 & $09: 45$ & 237 & 3.0 & 600 & $\begin{array}{c}\text { JUN } 1985 \\
17 \ldots\end{array}$ & $13: 20$ & 406 & 22.0 & 580 \\
\hline $\begin{array}{l}\text { JAN } 1983 \\
23 \ldots \\
\text { MAR }\end{array}$ & $12: 40$ & 118 & 0.0 & 600 & $\begin{array}{l}\text { JUL } \\
22 \ldots \\
\text { SEP }\end{array}$ & $15: 30$ & 135 & 28.0 & 440 \\
\hline $\begin{array}{l}25 \ldots \\
\text { APR } \\
30\end{array}$ & $\begin{array}{l}16: 45 \\
12: 20\end{array}$ & 497 & 6.0 & 615 & $10 \ldots$ & $10: 55$ & 590 & 22.0 & 600 \\
\hline
\end{tabular}

05459000

OCT 1984

\begin{tabular}{|c|c|c|c|c|}
\hline $\begin{array}{l}02 \ldots \\
23 \ldots\end{array}$ & $\begin{array}{l}15: 15 \\
13: 52\end{array}$ & $\begin{array}{r}13 \\
118\end{array}$ & $\begin{array}{r}14.0 \\
9.0\end{array}$ & $\begin{array}{l}540 \\
562\end{array}$ \\
\hline NOV & & & & \\
\hline $\begin{array}{l}14 \ldots \\
27 \ldots \\
\text { DEC }\end{array}$ & $\begin{array}{l}12: 30 \\
15: 00\end{array}$ & $\begin{array}{l}184 \\
127\end{array}$ & $\begin{array}{l}6.0 \\
4.0\end{array}$ & $\begin{array}{l}650 \\
579\end{array}$ \\
\hline $\begin{array}{r}26 \ldots \\
27 \ldots \ldots \\
\text { JAN } i 985\end{array}$ & $\begin{array}{l}15: 30 \\
13: 35\end{array}$ & $1 \overline{165}$ & $\begin{array}{l}2.0 \\
0.5\end{array}$ & $\begin{array}{l}695 \\
670\end{array}$ \\
\hline FEB $28 \ldots$ & $14: 30$ & 260 & 0.0 & 940 \\
\hline$\underset{M A R}{05} \cdots$ & $11: 30$ & 32 & 0.0 & 990 \\
\hline $\begin{array}{l}18 \ldots \\
25 \ldots\end{array}$ & $\begin{array}{l}13: 00 \\
11: 45\end{array}$ & $\begin{array}{l}370 \\
252\end{array}$ & $\begin{array}{l}6.0 \\
3.5\end{array}$ & $\begin{array}{l}710 \\
520\end{array}$ \\
\hline
\end{tabular}

$\begin{array}{crrrr}\text { APR } 1985 & & & \\ \text { 30... } & 09: 55 & 1300 & 18.0 & 500 \\ \begin{array}{c}\text { JUN } \\ 17 \ldots\end{array} & 17: 25 & 603 & 21.0 & 540 \\ \begin{array}{c}\text { JUL } \\ 23 \ldots\end{array} & 09: 05 & 252 & 21.0 & 450 \\ \begin{array}{c}\text { SEP } \\ 10 \ldots\end{array} & 09: 20 & 582 & 22.0 & 480\end{array}$

SHELL ROCK RIVER NEAR NORTEWOOD, IOWA (LAT $43 \quad 2451$ N LONG $093 \quad 1314$ W)

\begin{tabular}{|c|c|c|c|c|}
\hline $\begin{array}{l}24 \ldots \\
30 \ldots\end{array}$ & $\begin{array}{l}14: 00 \\
09: 40\end{array}$ & $\begin{array}{l}236 \\
202\end{array}$ & $\begin{array}{l}15.0 \\
16.0\end{array}$ & $\begin{array}{l}565 \\
520\end{array}$ \\
\hline $\begin{array}{l}\mathrm{MAY} \\
20 \ldots \\
\text { JUN }\end{array}$ & $12: 30$ & 110 & 19.0 & 600 \\
\hline $\begin{array}{l}11 \ldots \\
17 \ldots\end{array}$ & $\begin{array}{l}15: 35 \\
13: 15\end{array}$ & $\begin{array}{r}56 \\
100\end{array}$ & $\begin{array}{l}16.0 \\
21.5\end{array}$ & $\begin{array}{l}670 \\
610\end{array}$ \\
\hline $\begin{array}{l}\text { JUL } \\
22 \ldots \\
\text { AUG }\end{array}$ & $13: 45$ & 21 & 28.0 & 900 \\
\hline $\begin{array}{l}19 . \\
\text { SEP }\end{array}$ & $13: 15$ & 15 & 24.0 & 938 \\
\hline $\begin{array}{l}11 \ldots \\
23 \ldots\end{array}$ & $\begin{array}{l}11: 50 \\
12: 30\end{array}$ & $\begin{array}{r}101 \\
69\end{array}$ & $\begin{array}{l}19.0 \\
12.0\end{array}$ & $\begin{array}{l}700 \\
640\end{array}$ \\
\hline
\end{tabular}




\begin{tabular}{|c|c|c|c|c|c|c|c|c|c|}
\hline DATE & TIME & $\begin{array}{l}\text { STREAM- } \\
\text { FLOW, } \\
\text { INSTAN- } \\
\text { TANEOUS } \\
\text { (CES) }\end{array}$ & $\begin{array}{l}\text { TEMPER- } \\
\text { ATURE } \\
\text { (DEG C) }\end{array}$ & $\begin{array}{l}\text { SPE- } \\
\text { CIFIC } \\
\text { CON- } \\
\text { DUCT- } \\
\text { ANCE } \\
\text { (US/CM) }\end{array}$ & DATE & TIME & $\begin{array}{l}\text { STREAM- } \\
\text { FLOW, } \\
\text { INSTAN- } \\
\text { TANEOUS } \\
\text { (CFS) }\end{array}$ & $\begin{array}{l}\text { TEMPER- } \\
\text { ATURE } \\
\text { (DEG C) }\end{array}$ & $\begin{array}{l}\text { SPE- } \\
\text { CIFIC } \\
\text { CON- } \\
\text { DUCT- } \\
\text { ANCE } \\
\text { (US/CM) }\end{array}$ \\
\hline
\end{tabular}

05459500 WINNEBAGO RIVER AT MASON CITY, IOWA (LAT 4309 54N LONG 0931133 W)

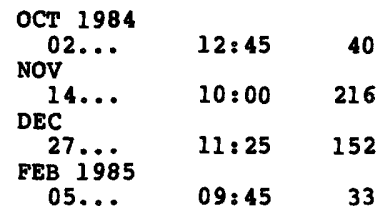

$\begin{array}{rr}21.0 & 690 \\ 5.0 & 780 \\ 2.0 & 750 \\ 0.0 & 800\end{array}$

\begin{tabular}{|c|c|c|}
\hline $\begin{array}{l}\operatorname{MaR} 1985 \\
18 \ldots\end{array}$ & $17: 40$ & 51 \\
\hline $29 . .$. & $16: 20$ & 30 \\
\hline & $16: 30$ & 3 \\
\hline
\end{tabular}

$\begin{array}{rl}9.0 & 680 \\ 17.0 & 700 \\ 25.0 & 625 \\ 24.0 & 810\end{array}$

05462000

SHELL ROCK RIVER AT SHELL ROCR, IOWA (LAT 4239 10N LONG 09235 46W)

\begin{tabular}{|c|c|c|}
\hline $\begin{array}{c}\text { Nov } 1984 \\
19 \ldots\end{array}$ & $14: 05$ & 602 \\
\hline $03 \ldots$ & $12: 40$ & 496 \\
\hline $11 \ldots$ & 12:05 & 250 \\
\hline & $14: 40$ & 989 \\
\hline
\end{tabular}

$\begin{array}{ll}3.0 & 650 \\ 0.0 & 500 \\ 0.0 & 690 \\ 7.0 & 610\end{array}$

$\begin{array}{crr}\text { APR } 1985 & & \\ 30 \ldots & 16: 30 & 1150 \\ \text { JUN } & & \\ 17 \ldots & 15: 35 & 922 \\ \text { JUL } & \\ 22 \ldots & 13: 45 & 260 \\ \begin{array}{c}\text { SEP } \\ 10 . . .\end{array} & 12: 45 & 754\end{array}$

$\begin{array}{ll}18.0 & 550 \\ 21.0 & 600 \\ 23.5 & 540 \\ 22.0 & 690\end{array}$

05463000

BEAVER CREER AT NEW HARTFORd, IOWA (LAT 4230 50N LONG 09237 55W)

Nov 1984

\begin{tabular}{|c|c|}
\hline 20 & $17: 20$ \\
\hline $03 \ldots$ & $15: 30$ \\
\hline $\begin{array}{l}\text { PEB } \\
12 \ldots \\
\operatorname{MAR}\end{array}$ & $16: 30$ \\
\hline 2 & $11: 30$ \\
\hline
\end{tabular}

$\begin{array}{ll}1.0 & 660 \\ 0.0 & 550 \\ 0.0 & 500 \\ 5.0 & 625\end{array}$

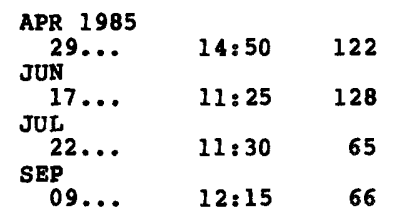

$20.0 \quad 550$

$19.0 \quad 610$

05463500

BLACK HAWK CREER AT hUDSON, IOWA (LAT 4224 28N LONG 09227 47w)

\begin{tabular}{|c|c|c|}
\hline $\begin{array}{l}\text { Nov } 1984 \\
20\end{array}$ & $15: 05$ & 77 \\
\hline $23 \ldots$ & $16: 10$ & 46 \\
\hline $\begin{array}{l}\text { PEB } \\
12 \ldots\end{array}$ & $11: 30$ & 33 \\
\hline $26 \ldots$ & $16: 45$ & 135 \\
\hline
\end{tabular}

\begin{tabular}{|c|c|c|}
\hline $\begin{array}{l}\text { Rov } 1984 \\
20\end{array}$ & $13: 30$ & 215 \\
\hline${ }_{M A R} 2 \ldots$ & $16: 00$ & 262 \\
\hline & 4 & \\
\hline
\end{tabular}

05464500

$\begin{array}{rr}1.0 & 620 \\ 0.0 & 650 \\ 0.0 & 220 \\ 10.0 & 650\end{array}$

$\begin{array}{crr}\text { APR } 1985 & & \\ 29 . . . & 12: 10 & 120 \\ \text { JUN } & & \\ \text { 18... } & 12: 35 & 101 \\ \text { JUL } 23 . . . & 14: 30 & 39 \\ \text { SEP } \\ 09 . . . & 15: 05 & 39\end{array}$

$17.0 \quad 550$

$17.0 \quad 590$

25.5610

CEDAR RIVER AT WATERLOO, IOWA (LAT 4229 44N LONG 09220 03W)

\begin{tabular}{|c|c|c|c|c|c|c|}
\hline 2.0 & 640 & $\begin{array}{c}\text { APR } 1985 \\
29 \ldots\end{array}$ & $19: 30$ & 4600 & 18.0 & 540 \\
\hline 0.0 & 500 & & $12: 30$ & 875 & 22.0 & 500 \\
\hline 9.0 & 620 & $09 \ldots$ & $15: 50$ & 3230 & 24.0 & 500 \\
\hline
\end{tabular}

CEDAR RIVER AT CEDAR RAPIDS, IOWA (LAT 4158 14N LONG 09140 O1W)

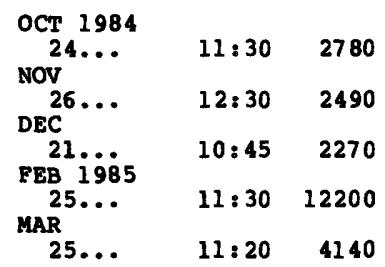

$\begin{array}{rr}10.0 & 531 \\ 7.0 & 578 \\ 0.0 & 939 \\ 1.0 & 340 \\ 7.0 & 514\end{array}$

\begin{tabular}{|c|c|c|}
\hline $\begin{array}{c}\text { APR } 1985 \\
24 \ldots\end{array}$ & $09: 45$ & 4300 \\
\hline $\begin{array}{l}\text { MAY } \\
24 \ldots \\
\text { JUN }\end{array}$ & $09: 50$ & 2230 \\
\hline JoL $10 \ldots$ & $11: 30$ & 1690 \\
\hline${ }_{A \cup G} 25 \ldots$ & $12: 30$ & 1160 \\
\hline 28 & $10: 15$ & 814 \\
\hline
\end{tabular}

$\begin{array}{ll}17.5 & 447 \\ 22.0 & 410 \\ 24.0 & 375 \\ 25.5 & 338 \\ 20.5 & 371\end{array}$




\begin{tabular}{|c|c|c|c|c|c|c|c|c|c|}
\hline DATE & TIME & $\begin{array}{l}\text { STREAM- } \\
\text { FLOW, } \\
\text { INSTAN- } \\
\text { TANEOUS } \\
\text { (CFS) }\end{array}$ & $\begin{array}{l}\text { TEMPER- } \\
\text { ATURE } \\
\text { (DEG C) }\end{array}$ & $\begin{array}{l}\text { SPE- } \\
\text { CIFIC } \\
\text { CON- } \\
\text { DUCT- } \\
\text { ANCE } \\
\text { (US/CM) }\end{array}$ & DATE & TIME & $\begin{array}{l}\text { STREAM- } \\
\text { FLOW, } \\
\text { INSTAN- } \\
\text { TANEOUS } \\
\text { (CFS) }\end{array}$ & $\begin{array}{l}\text { TEMPER- } \\
\text { ATURE } \\
\text { (DEG C) }\end{array}$ & $\begin{array}{l}\text { SPE- } \\
\text { CIFIC } \\
\text { CON- } \\
\text { DUCT- } \\
\text { ANCE } \\
\text { (US/CM) }\end{array}$ \\
\hline
\end{tabular}

05465000

$\begin{array}{lll}\text { OCT } 1984 & \\ 23 \ldots . & 11: 30 & 3230 \\ \text { NOV } & & \\ \text { 30..: } & 11: 15 & 2990 \\ \text { APR } 1985 & 11: 00 & 7850\end{array}$

05465500
05470000

$\begin{array}{ccc}\text { OCT } 1984 & \\ 03 \ldots \ldots & 14: 30 & 1980 \\ 30 \ldots \ldots & 10: 30 & 5640 \\ \text { DEC } & & \\ 11 \ldots . \ldots 5 & 10: 30 & 3650 \\ \text { MAR } 1985 & 12: 00 & 26300 \\ 01 \ldots \ldots & & \end{array}$

CEDAR RIVER NEAR CONESVILLE, IOWA (LAT $412436 \mathrm{~N}$ LONG $0911706 \mathrm{~W}$ )

\begin{tabular}{|c|c|c|c|c|c|}
\hline 11.0 & 525 & $\begin{array}{c}\text { MAY } 1985 \\
17 \ldots\end{array}$ & $13: 30$ & 3650 & 17.5 \\
\hline 5.0 & 587 & $28 \ldots$ & $10: 45$ & 2040 & 24.0 \\
\hline 7.0 & 525 & $\begin{array}{l}\text { AUG } \\
09 . . .\end{array}$ & $11: 00$ & 1150 & 25.0 \\
\hline
\end{tabular}

IOWA RIVER AT WAPELLO, IOWA (IAT 4110 48N LONG 09110 57W)

OCT 1984

OCT 1984

24... 11:20

$28 \ldots 10: 20 \quad 41$

$09 \ldots$.

$11: 30 \quad 50$

$04 \ldots \quad 12: 30 \quad 481$

05470500

OCT 1984

$24 \ldots$ 09:25

NOV 28

JAN $28 \dot{9} 5$

$09 . .$.

FEB

$20 \ldots \quad 15: 15 \quad 86$

$04 \ldots 09: 45 \quad 286$

05471050

OCT 1984

$31 \ldots$
MAR 1985
$13 \ldots$

APR

$18 \ldots \quad 11: 50 \quad 302$

$30 \ldots \quad 14: 50 \quad 161$

05471200

NOV 1984

MAR 1985

MAR 1985

APR

18 ...

$\begin{array}{rr}10: 20 & 317 \\ 08: 35 & 174 \\ 13: 10 & 91\end{array}$

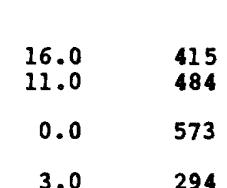
MAY 1985
01... 11:30 7410
$09 . . . \quad 11: 30 \quad 2510$
$27 \ldots 10: 30 \quad 1530$

$17.0 \quad 494$

$27.0 \quad 408$

$3.0 \quad 294$

21.0

483

SOUTH SKUNR RIVER NEAR AMES, IOWA (LAT $420405 \mathrm{~N}$ LONG $0933702 \mathrm{~W}$ )

$\begin{array}{ll}9.0 & 560 \\ 3.0 & 690 \\ 0.0 & 700 \\ 6.0 & 680\end{array}$

MAY 1985

\begin{tabular}{|c|c|c|c|c|}
\hline JUN $16 \ldots$ & $10: 45$ & 89 & 13.5 & 790 \\
\hline AUG $24 \ldots$ & $13: 15$ & 42 & 24.0 & 740 \\
\hline & $15: 35$ & 2.0 & 27.0 & 560 \\
\hline & $17: 30$ & 27 & 26.0 & 750 \\
\hline
\end{tabular}

SQUAW CREER AT AMES, IOWA (LAT $420121 \mathrm{~N}$ LONG $0933745 \mathrm{~W}$ )

$\begin{array}{ll}6.0 & 700 \\ 3.0 & 610 \\ 0.0 & 650 \\ 1.5 & 390 \\ 6.0 & 680\end{array}$

MAY 1985

$\begin{array}{ccccc}\begin{array}{c}\text { 16... } \\ \text { JUN }\end{array} & 09: 25 & 40 & 13.0 & 700 \\ \underset{24 \ldots}{\text { AUG }} & 19: 05 & 20 & 25.0 & 700 \\ \underset{06}{\text { SEP } \ldots} & 14: 30 & 2.5 & 24.0 & 760 \\ \underset{19}{19} & 18: 20 & 19 & 25.0 & 750\end{array}$

S SRUNR R AT COLFAX, IOWA (LAT 4140 55N LONG $0931447 \mathrm{~W}$ )

\begin{tabular}{|c|c|c|c|c|c|c|}
\hline 10.0 & 660 & $\begin{array}{c}\text { JUL } 1985 \\
11 \ldots\end{array}$ & $10: 25$ & 54 & 19.0 & 630 \\
\hline 4.0 & 540 & $\begin{array}{l}\text { AUG } \\
21 \ldots \\
\text { SEP }\end{array}$ & $13: 40$ & 17 & 20.0 & 630 \\
\hline 0.5 & 660 & $19 \ldots$ & $11: 20$ & 83 & 24.5 & 600 \\
\hline 6.0 & 680 & & & & & \\
\hline
\end{tabular}

INDIAN CREER NEAR MINGO, IOWA (LAT 4148 17N LONG $093 \quad 1826$ W)

\begin{tabular}{|c|c|c|c|c|c|c|}
\hline & & MAY 1985 & & & & \\
\hline 8.0 & 390 & $\mathrm{JUL}^{30 \ldots}$ & $16: 20$ & 24 & 27.0 & 650 \\
\hline 3.0 & 540 & ${ }_{A \cup G}^{11 \ldots}$ & $08: 05$ & 5.3 & 19.0 & 620 \\
\hline 21.5 & 620 & 21 & $14: 45$ & 1.8 & 23.0 & 580 \\
\hline
\end{tabular}




\begin{tabular}{|c|c|c|c|c|c|c|c|c|c|}
\hline DATE & TIME & $\begin{array}{l}\text { STREAY- } \\
\text { FLOW, } \\
\text { INSTAN- } \\
\text { TANEOUS } \\
\text { (CFS) }\end{array}$ & $\begin{array}{c}\text { TEMPER- } \\
\text { ATURE } \\
\text { (DEG C) }\end{array}$ & $\begin{array}{l}\text { SPE- } \\
\text { CIFIC } \\
\text { CON- } \\
\text { DUCT- } \\
\text { ANCE } \\
\text { (US/CM) }\end{array}$ & DATE & TIME & $\begin{array}{c}\text { STREAM- } \\
\text { FLOW. } \\
\text { INSTAN- } \\
\text { TANEOUS } \\
\text { (CFS) }\end{array}$ & $\begin{array}{c}\text { TEMPER- } \\
\text { ATORE } \\
\text { (DEG C) }\end{array}$ & $\begin{array}{l}\text { SPE- } \\
\text { CIFIC } \\
\text { CON- } \\
\text { DUCT- } \\
\text { ANCE } \\
\text { (OS/CH) }\end{array}$ \\
\hline
\end{tabular}

05471500 SOOTH SKONR RIVER NEAR OSKALOOSA, IOWA (LAT 4121 19N LONG 092 3931 W)

\begin{tabular}{|c|c|c|c|c|c|c|c|c|}
\hline OCT 1984 & $10: 45$ & 383 & 8.0 & 590 & APR 1985 & $10: 05$ & 724 & 17.5 \\
\hline JAN 12. & $09: 00$ & 596 & 0.0 & 550 & & $09: 55$ & 297 & 18.5 \\
\hline MAR & $10: 30$ & 272 & 0.0 & 580 & $\begin{array}{l}08 \ldots \\
00 G\end{array}$ & $10: 05$ & 148 & 26.0 \\
\hline $\begin{array}{l}04 \ldots \\
14 \ldots .\end{array}$ & $\begin{array}{l}12: 05 \\
10: 45\end{array}$ & $\begin{array}{l}8380 \\
1210\end{array}$ & $\begin{array}{l}3.0 \\
6.0\end{array}$ & $\begin{array}{l}260 \\
520\end{array}$ & $19 \ldots$ & $10: 00$ & 56 & 21.0 \\
\hline
\end{tabular}

05472500 NORTE SKONR RIVER NEAR SIGOORNEY, IOWA (LAT 4118 03N LONG $0921216 \mathrm{~W}$ )

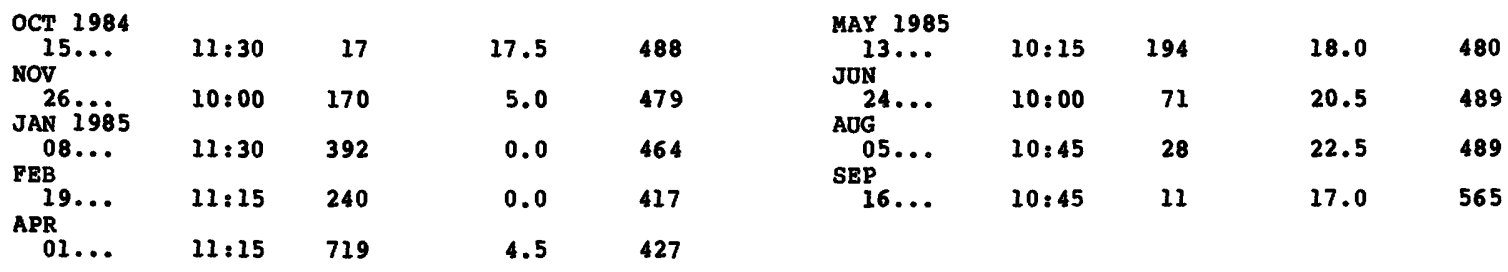

05473400 CEDAR CR NR OARLAND MILLS, IONA (LAT 4055 OON LONG O91 40 OOW)

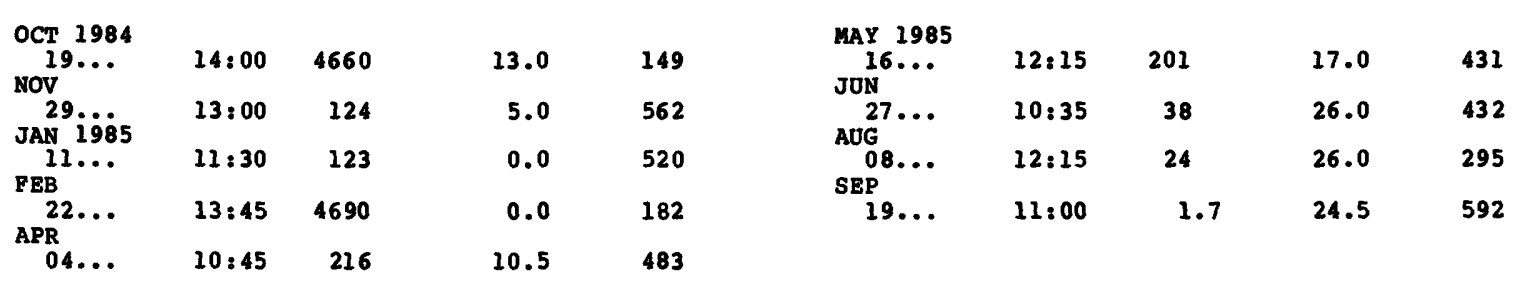

05474000 SKONK RIVER AT AOGOSTA, IOWA (LAT 4045 13N LONG $091 \quad 1640 \mathrm{~W}$ )

\begin{tabular}{|c|c|c|c|c|c|c|c|c|c|}
\hline OCT 1984 & & & & & FEB 1985 & & & & \\
\hline $\begin{array}{l}03 \cdots \\
26 \cdots \\
D E C\end{array}$ & $\begin{array}{l}11: 00 \\
12: 00\end{array}$ & $\begin{array}{r}302 \\
1620\end{array}$ & $\begin{array}{l}15.0 \\
12.0\end{array}$ & $\begin{array}{l}512 \\
466\end{array}$ & $\begin{array}{l}05 \ldots \\
27 \ldots \\
\text { MAY }\end{array}$ & $\begin{array}{l}12: 00 \\
14: 00\end{array}$ & $\begin{array}{r}611 \\
15100\end{array}$ & $\begin{array}{l}0.0 \\
1.5\end{array}$ & $\begin{array}{l}647 \\
238\end{array}$ \\
\hline 20 & $12: 30$ & 2180 & 0.0 & 442 & $\begin{array}{c}07 \ldots \\
\operatorname{SEP} \\
06 \ldots\end{array}$ & $\begin{array}{l}13: 00 \\
12: 00\end{array}$ & $\begin{array}{l}937 \\
431\end{array}$ & $\begin{array}{l}20.0 \\
27.0\end{array}$ & $\begin{array}{l}474 \\
514\end{array}$ \\
\hline
\end{tabular}

05476500 DES MOINES RIVER AT ESTHERVILLE, IOWA (LAT $432351 N$ LONG $0945038 \mathrm{~W}$ )

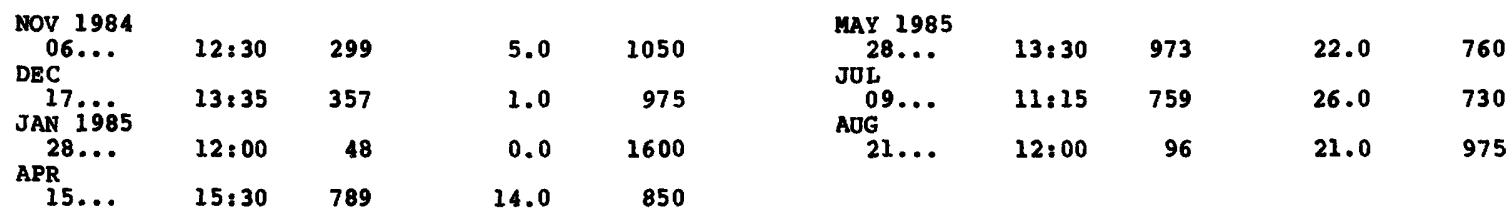

05476750 DES MOINES RIVER AT BOMBOLDT, IOWA (LAT 4243 12N LONG 0941306 W)

\begin{tabular}{|c|c|c|c|c|c|c|c|c|c|}
\hline $\begin{array}{c}\text { Nov } 1984 \\
07 \ldots\end{array}$ & $15: 30$ & 464 & 12.0 & 990 & $\begin{array}{c}\text { JoN } 1985 \\
25 \ldots\end{array}$ & $11: 20$ & 761 & 20.0 & 800 \\
\hline $\begin{array}{l}\text { DEC } \\
20 \\
\text { MAR } i 985\end{array}$ & $12: 35$ & 742 & 0.0 & 760 & $\underset{\text { AUG }}{\text { JUL }}$ & $11: 30$ & 826 & 25.0 & 720 \\
\hline $13 \ldots$ & $16: 35$ & 2730 & 3.0 & 800 & $19 \ldots$ & $13: 15$ & 212 & 24.5 & 620 \\
\hline
\end{tabular}




\begin{tabular}{|c|c|c|c|c|c|c|c|c|c|}
\hline ATE & TIME & $\begin{array}{l}\text { STREAM- } \\
\text { FLOW, } \\
\text { INSTAN- } \\
\text { TANEOUS } \\
\text { (CFS) }\end{array}$ & $\begin{array}{c}\text { TEMPER- } \\
\text { ATURE } \\
\text { (DEG C) }\end{array}$ & $\begin{array}{l}\text { SPE- } \\
\text { CIFIC } \\
\text { CON- } \\
\text { DUCT- } \\
\text { ANCE } \\
\text { (US/CM) }\end{array}$ & DATE & TIME & $\begin{array}{l}\text { STREAN- } \\
\text { FLOW, } \\
\text { INSTAN- } \\
\text { TANEOUS } \\
\text { (CFS) }\end{array}$ & $\begin{array}{l}\text { TEMPER- } \\
\text { ATURE } \\
\text { (DEG C) }\end{array}$ & $\begin{array}{l}\text { SPE- } \\
\text { CIFIC } \\
\text { CON- } \\
\text { DUCT- } \\
\text { ANCE } \\
\text { (US/CM) }\end{array}$ \\
\hline
\end{tabular}

05479000

$\begin{array}{lrr}\begin{array}{l}\text { NOV } 1984 \\ 07 \ldots . .\end{array} & 11: 00 & 132 \\ \text { DEC } & \\ 19 . . . & 16: 20 & 537 \\ \text { JAN } 1985 & 12: 55 & 72 \\ \quad 30 \ldots & 12: . . & \\ \begin{array}{l}\text { MAR } \\ 13 \ldots\end{array} & 14: 30 & 1260\end{array}$

05480500

\begin{tabular}{|c|c|}
\hline $\begin{array}{c}\text { OCT } 1984 \\
02 \ldots\end{array}$ & $14: 30$ \\
\hline JAN 1978 & $11: 45$ \\
\hline $21 \ldots$ & $16: 00$ \\
\hline
\end{tabular}

05481000

OCT 1984

\begin{tabular}{|c|c|}
\hline $19 .$. & $13: 15$ \\
\hline JAN 19685 & $12: 20$ \\
\hline $\begin{array}{c}09 . . . \\
\mathrm{FEB}\end{array}$ & $13: 55$ \\
\hline
\end{tabular}

05481300

OCT 1984

$\begin{array}{rrr}24 \\ \text { FEB } 1985 & 14: 20 \quad 909\end{array}$

$21 \ldots \quad 12: 15 \quad 619$

05481650

NOV 1984

$\begin{array}{lll}\text { NOV } 1984 & \\ 29 \\ \begin{array}{c}\text { JAN } 1985 \\ 08\end{array} & 12: 05 & 1090 \\ \text { APR } & 14: 15 & 1680\end{array}$

OCT 1984

\begin{tabular}{|c|c|}
\hline FEB 1985 & $14: 50$ \\
\hline$\underset{\text { MAR }}{20} \ldots$ & $09: 55$ \\
\hline
\end{tabular}

05482135

DEC 1984

\begin{tabular}{|c|c|}
\hline $04 \ldots$ & $13: 00$ \\
\hline $\begin{array}{l}\text { FEB } 1985 \\
25 \ldots \\
\text { MAR }\end{array}$ & $14: 45$ \\
\hline$\underset{A P R}{13} \ldots$ & $09: 45$ \\
\hline 16. & $14: 55$ \\
\hline
\end{tabular}

DES MOINES RIVER AT FORT DODGE, IOWA (LAT 4230 22N LONG 09412 04W)

\begin{tabular}{|c|c|c|c|c|}
\hline $\begin{array}{l}\text { APR } 1985 \\
18 \ldots\end{array}$ & $12: 30$ & 934 & 18.0 & 600 \\
\hline $31 \ldots$ & $11: 00$ & 465 & 20.5 & 650 \\
\hline AUG & $13: 30$ & 138 & 26.5 & 690 \\
\hline & $11: 30$ & 41 & 24.0 & 610 \\
\hline
\end{tabular}

$\begin{array}{ll}8.0 & 680 \\ 0.0 & 650 \\ 0.0 & 480 \\ 5.0 & 680\end{array}$

$\begin{array}{lrr}\text { MAR } 1985 & & \\ 19 . \ldots & 16: 00 & 4400 \\ \text { JUL } 15 \ldots & 12: 55 & 780 \\ \text { AUG } \ldots & 16: 00 & 25 \\ 19 . . & \end{array}$

$2.0 \quad 725$

$\begin{array}{rr}14.0 & 680 \\ 9.0 & 900 \\ 0.0 & 1200 \\ 0.0 & 750\end{array}$

$26.0 \quad 700$

BOONE RIVER NEAR WEBSTER CITY, IOWA (LAT 4226 O1N LONG 09348 12W)

$\begin{array}{rr}13.0 & 580 \\ 8.0 & 750 \\ 0.0 & 800 \\ 1.0 & 460\end{array}$

\begin{tabular}{|c|c|c|}
\hline $\begin{array}{c}\text { MAR } 1985 \\
04 \ldots\end{array}$ & $15: 30$ & 704 \\
\hline $15 \ldots$ & $15: 10$ & 326 \\
\hline 24 & $11: 15$ & 121 \\
\hline
\end{tabular}

$6.0 \quad 660$

$15.0 \quad 650$

1.0460

DES MOINES RIVER NR STRATFORD, IOWA (LAT 4215 O4N LONG 09359 52W)

\begin{tabular}{|c|c|c|c|c|c|c|}
\hline 10.0 & 800 & $\begin{array}{c}\text { MAR } 1985 \\
05 \ldots \\
\text { SEP }\end{array}$ & $11: 20$ & 4950 & 6.0 & 680 \\
\hline 1.5 & 540 & $26 \ldots$ & $13: 50$ & 2700 & 14.0 & 870 \\
\hline
\end{tabular}

DES MOINES RIVER NEAR SAYLORVILLE, IOWA (LAT 4140 50N LONG 09340 07W)

\begin{tabular}{|c|c|c|c|c|c|c|}
\hline 5.0 & 740 & ${ }^{25}{ }^{25}$ & $10: 05$ & 2000 & 26.0 & 590 \\
\hline 1.0 & 750 & $\operatorname{SEP}_{\text {SEP }}$ & $10: 15$ & 314 & 24.0 & 710 \\
\hline 7.0 & 700 & $17 \ldots$ & $12: 45$ & 2360 & 24.0 & 460 \\
\hline
\end{tabular}

BEAVER CREEK NEAR GRIMES, IOWA (LAT 4141 18N LONG 09344 08W)

\begin{tabular}{|c|c|c|c|c|c|c|}
\hline 12.0 & 750 & $\begin{array}{c}\text { APR } 1985 \\
14 \ldots \\
\text { JUN }\end{array}$ & $16: 55$ & 89 & 19.0 & 740 \\
\hline 0.5 & 550 & $25 \ldots$ & $13: 40$ & 36 & 26.0 & 740 \\
\hline 0 & 650 & & & & & \\
\hline
\end{tabular}

NORTH RACCOON RIVER NR NEWELL, IOWA (LAT 4236 16N LONG 09502 42W)

\begin{tabular}{|c|c|c|c|c|c|c|}
\hline 0.0 & 925 & $\begin{array}{c}\text { MAY } 1985 \\
29 \ldots\end{array}$ & $10: 50$ & 160 & 16.0 & 720 \\
\hline 0.0 & 950 & $10 \ldots$ & $11: 15$ & 41 & 22.5 & 680 \\
\hline 5.0 & 800 & $26 \ldots$ & $16: 15$ & 5.7 & 27.0 & 540 \\
\hline 18.0 & 710 & & & & & \\
\hline
\end{tabular}




\begin{tabular}{|c|c|c|c|c|c|c|c|c|c|}
\hline ATE & TIME & $\begin{array}{c}\text { STREAY- } \\
\text { FLON, } \\
\text { INSTAN- } \\
\text { TANEOOS } \\
\text { (CPS) }\end{array}$ & $\begin{array}{c}\text { TEMPER- } \\
\text { ATURE } \\
\text { (DEG C) }\end{array}$ & $\begin{array}{l}\text { SPE- } \\
\text { CIFIC } \\
\text { CON- } \\
\text { DUCT- } \\
\text { ANCE } \\
\text { (OS/CM) }\end{array}$ & DATE & TIME & $\begin{array}{l}\text { STREAM- } \\
\text { FLOW, } \\
\text { INSTAN- } \\
\text { TANEOUS } \\
\text { (CFS) }\end{array}$ & $\begin{array}{l}\text { TEMPER- } \\
\text { ATURE } \\
\text { (DEG C) }\end{array}$ & $\begin{array}{l}\text { SPE- } \\
\text { CIPIC } \\
\text { CON- } \\
\text { DUCT- } \\
\text { ANCE } \\
\text { (US/CM) }\end{array}$ \\
\hline
\end{tabular}

05482170

BIG CEDAR CREEk near VARINA, IOWA (LAT 4241 16N LONG 09447 52W)

\begin{tabular}{|c|c|c|c|c|c|c|c|c|c|}
\hline $\begin{array}{l}\text { OCT } 1984 \\
26 \ldots \\
\text { DEC }\end{array}$ & $15: 10$ & 1.2 & 11.0 & 690 & $\begin{array}{l}\text { MAY } 2985 \\
29 \ldots\end{array}$ & $13: 45$ & 50 & 28.0 & 700 \\
\hline $04 \ldots$ & $15: 30$ & 2.1 & 12.0 & 2600 & $10 \ldots$ & $09: 15$ & 10 & 21.0 & 790 \\
\hline $\begin{array}{l}25 . . \\
A P R\end{array}$ & $11: 35$ & 20 & 0.0 & 960 & $26 \ldots$ & $11: 10$ & 3.4 & 20.0 & 875 \\
\hline ... & $11: 30$ & 41 & 16.0 & 690 & & & & & \\
\hline
\end{tabular}

05482300 N RACCOON R NR SAC CITY IOWA (LAT $42 \quad 20$ 28N LONG 09459 05W)

\begin{tabular}{|c|c|c|c|c|c|c|c|c|c|}
\hline $\begin{array}{l}\text { OCT } 1984 \\
23 \ldots\end{array}$ & $16: 15$ & 74 & 15.0 & 680 & $\begin{array}{c}\text { APR } 1985 \\
16 \ldots\end{array}$ & $18: 00$ & 282 & 18.0 & 660 \\
\hline JAN 1985 & $10: 40$ & 44 & 0.0 & 850 & $\begin{array}{c}\text { MAY } \\
29 . . . \\
\text { JUL }\end{array}$ & $14: 00$ & 425 & 21.0 & 650 \\
\hline FEB & $11: 50$ & 96 & 0.0 & 960 & AUG $10 .$. & $13: 30$ & 112 & 24.5 & 660 \\
\hline $27 \ldots$ & $14: 05$ & 98 & 2.0 & 750 & $22 \ldots$ & $14: 30$ & 22 & 23.0 & 625 \\
\hline
\end{tabular}

05482500 NORTE RACCOON RIVER NEAR JEFFERSON, IOWA (LAT 4159 17N LONG $0942236 \mathrm{~W}$ )

\begin{tabular}{|c|c|c|c|c|c|c|c|c|c|}
\hline $\begin{array}{l}\text { OCT } 1984 \\
22 \ldots \\
\text { DEC }\end{array}$ & $18: 00$ & 258 & 12.5 & 690 & $\begin{array}{c}\text { APR } 1985 \\
17 \ldots \\
\operatorname{MAY}\end{array}$ & $11: 00$ & 602 & 18.0 & 690 \\
\hline FEB 1985 & $15: 25$ & 231 & 0.5 & 775 & $\begin{array}{l}30 \ldots \\
\text { JoL }\end{array}$ & $12: 15$ & 912 & 21.0 & 660 \\
\hline $\begin{array}{l}13 \ldots \\
27 \ldots\end{array}$ & $\begin{array}{l}12: 35 \\
11: 25\end{array}$ & $\begin{array}{r}90 \\
410\end{array}$ & $\begin{array}{l}0.0 \\
0.0\end{array}$ & $\begin{array}{l}750 \\
625\end{array}$ & $\begin{array}{l}10 \ldots \\
23 \ldots\end{array}$ & $\begin{array}{l}18: 45 \\
11: 00\end{array}$ & $\begin{array}{r}252 \\
75\end{array}$ & $\begin{array}{l}29.0 \\
22.0\end{array}$ & $\begin{array}{l}590 \\
510\end{array}$ \\
\hline
\end{tabular}

05483000 EAST FORK HARDIN CREER NR. CHURDAN, IOWA (LAT 4206 27N LONG 09422 12W)

\begin{tabular}{|c|c|c|c|c|c|c|c|c|c|}
\hline \multirow{4}{*}{$\begin{array}{c}\text { OCT } 1984 \\
22 \ldots \\
\text { DEC } \\
03 . . \\
\text { JAN } 1985 \\
17 \ldots \\
\text { PEB } \\
26 \ldots\end{array}$} & $13: 15$ & 0.3 & 12.0 & 710 & \multirow{4}{*}{$\begin{array}{c}\text { APR } 1985 \\
17 \ldots \\
\text { MAY } \\
30 \ldots \\
\text { JOL } \\
16 \ldots \\
\text { AOG } \ldots \\
23 \ldots\end{array}$} & $13: 50$ & 5.0 & 20.0 & 610 \\
\hline & $12: 25$ & 0.31 & 1.0 & 900 & & $09: 15$ & 6.6 & 19.0 & 620 \\
\hline & $14: 00$ & 1.8 & 0.0 & 1090 & & $15: 30$ & 1.0 & 29.0 & 650 \\
\hline & $13: 15$ & 2.7 & 0.0 & 690 & & $13: 00$ & 0.14 & 22.5 & 600 \\
\hline
\end{tabular}

05483450 M RACCOON R NR BAYARD, IOWA (LAT 4147 OON LONG 09430 OOW)

\begin{tabular}{|c|c|c|c|c|c|c|c|c|c|}
\hline $\begin{array}{l}\text { Nov } 1984 \\
26\end{array}$ & $11: 05$ & 99 & 7.0 & 700 & $\begin{array}{c}\text { MAY } 1985 \\
09 \ldots\end{array}$ & $15: 05$ & 211 & 22.0 & 600 \\
\hline PEB & $12: 00$ & 191 & 0.0 & 670 & AUG $20 .$. & $13: 45$ & 120 & 22.0 & 750 \\
\hline$\underset{\mathrm{APR}}{19 \ldots}$ & $12: 05$ & 112 & 0.0 & 450 & $\begin{array}{l}05 \ldots \\
\operatorname{SEP}\end{array}$ & $10: 45$ & 44 & 23.0 & $\begin{array}{l}700 \\
600\end{array}$ \\
\hline
\end{tabular}

05483600 MIDDLE RACCOON RIVER AT PANORA, IOWA (LAT 4141 14N LONG 09422 15W)

\begin{tabular}{|c|c|c|c|c|c|c|c|c|c|}
\hline $\begin{array}{c}\text { OCT } 1984 \\
31 \ldots \\
\end{array}$ & $15: 05$ & 81 & 11.0 & 590 & $\begin{array}{c}\text { JUN } 1985 \\
20 . .\end{array}$ & $11: 20$ & 128 & 20.0 & 620 \\
\hline $\begin{array}{l}26 \\
\text { APR } i 985\end{array}$ & $13: 20$ & 111 & 7.0 & 450 & SEP & $12: 35$ & 25 & 24.0 & 420 \\
\hline & $15: 15$ & 189 & 6.0 & 650 & & 24.30 & 28 & 230 & 620 \\
\hline
\end{tabular}




\begin{tabular}{|c|c|c|c|c|c|c|c|c|c|}
\hline ATE & TIME & $\begin{array}{l}\text { STREAM- } \\
\text { FLOH, } \\
\text { INSTAN- } \\
\text { TANEOUS } \\
\text { (CFS) }\end{array}$ & $\begin{array}{c}\text { TEMPER- } \\
\text { ATURE } \\
\text { (DEG C) }\end{array}$ & $\begin{array}{l}\text { SPE- } \\
\text { CIFIC } \\
\text { CON- } \\
\text { DUCT- } \\
\text { ANCE } \\
\text { (US/CM) }\end{array}$ & DATE & TIME & $\begin{array}{l}\text { STREA4- } \\
\text { FLOW, } \\
\text { INSTAN- } \\
\text { TANEOUS } \\
\text { (CES) }\end{array}$ & $\begin{array}{l}\text { TEMPER- } \\
\text { ATURE } \\
\text { (DEG C) }\end{array}$ & $\begin{array}{l}\text { SPE- } \\
\text { CIFIC } \\
\text { CON- } \\
\text { DUCT- } \\
\text { ANCE } \\
\text { (US/CM }\end{array}$ \\
\hline
\end{tabular}

05484000 SOUTH RACCOON RIVER AT REDFIELD, IOWA (LAT 4134 48N LONG 09410 58\%)

\begin{tabular}{|c|c|c|c|c|c|c|c|c|c|}
\hline $\begin{array}{l}\text { OCT } 1984 \\
22 . .\end{array}$ & $16: 15$ & 273 & 12.0 & 620 & $\begin{array}{c}\operatorname{MAY} 1985 \\
14 \ldots\end{array}$ & $14: 25$ & 331 & 19.0 & 590 \\
\hline $26 \ldots$ & $15: 15$ & 248 & 9.0 & 595 & $25 \ldots$ & $17: 25$ & 305 & 26.0 & 620 \\
\hline $\begin{array}{c}\text { AN } \\
07 . . . \\
\text { FEB }\end{array}$ & $16: 20$ & 470 & 0.0 & 560 & $05 . .$. & $14: 15$ & 90 & 24.0 & 600 \\
\hline $19 \ldots$ & $15: 30$ & 435 & 1.0 & 490 & & & & & \\
\hline
\end{tabular}

05484500 RACCOON RIVER AT VAN METER, IOWA (LAT 4132 02N LONG 09356 59W)

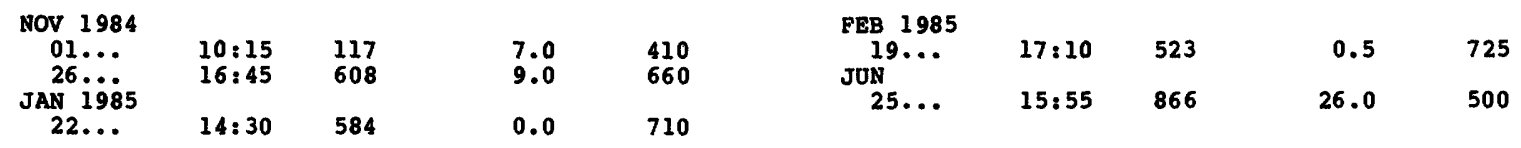

05484800 WALNUT CREEK AT DES MOINES, IOWA (LAT 4135 14N LONG 09342 11W)

\begin{tabular}{|c|c|c|c|}
\hline $\begin{array}{c}\mathrm{OCT} 1984 \\
30 \ldots\end{array}$ & $17: 05$ & 6.3 & 10.0 \\
\hline $13 \ldots$ & $16: 10$ & 13 & 0.5 \\
\hline $\begin{array}{l}\text { JAN } 1985 \\
23 \ldots \\
\text { MAR }\end{array}$ & $09: 00$ & 8.8 & 0.0 \\
\hline $\begin{array}{l}11 \ldots \\
\text { APR }\end{array}$ & $12: 50$ & 42 & 9.0 \\
\hline
\end{tabular}

\begin{tabular}{|c|c|c|c|c|}
\hline $\begin{array}{c}\text { MAY } 1985 \\
30 \ldots \\
\text { JUL }\end{array}$ & $08: 05$ & 22 & 19.5 & 555 \\
\hline $\begin{array}{r}10 \ldots \\
23 . . .\end{array}$ & $\begin{array}{l}07: 40 \\
10: 25\end{array}$ & $\begin{array}{l}1.5 \\
0.35\end{array}$ & $\begin{array}{l}20.5 \\
20.0\end{array}$ & $\begin{array}{l}690 \\
620\end{array}$ \\
\hline 20 & $15: 25$ & 0.13 & 23.0 & 730 \\
\hline
\end{tabular}

05484900

OCT 1984

$31 \ldots$

MAR 1985

$12 . .$.

17 ...

$16: 40$

05485500

OCT 1984

$03 \ldots 8 \quad 13: 10 \quad 543$

05485640

OCT 1984

\begin{tabular}{|c|c|}
\hline $31 \ldots$ & $12: 15$ \\
\hline 14 & $09: 10$ \\
\hline $23 . \cdots$ & $11: 35$ \\
\hline & $14: 15$ \\
\hline & $09: 40$ \\
\hline
\end{tabular}

05486000

\begin{tabular}{|c|c|}
\hline $\begin{array}{c}\text { CT } 1984 \\
30 \ldots\end{array}$ & $14: 55$ \\
\hline $13 \ldots 0$ & $12: 45$ \\
\hline $\begin{array}{c}22 \ldots \\
\text { MAR } \\
07 \ldots \ldots\end{array}$ & $\begin{array}{l}15: 45 \\
12: 35\end{array}$ \\
\hline
\end{tabular}

RACCOON RIVER AT FLEUR DRIVE, DES MOINES, IOWA (LAT 4134 58N LONG $0933830 \mathrm{~W}$

$\begin{array}{rrr}476 & 8.0 & 650 \\ 1440 & 5.0 & 540 \\ 1370 & 19.0 & 600\end{array}$

$\begin{array}{lrr}\text { MAY } 1985 & & \\ 29 \ldots & 15: 45 & 1820 \\ \text { JUL } & & \\ 10 \ldots & 09: 00 & 464 \\ \text { AUG } & & \\ 20 . . & 14: 10 & 108\end{array}$

22.0

630

DES MOINES R. BL RACCOON R. AT DES MOINES, IOWA (LAT 4134 30N LONG 0933548

543

$17.5 \quad 600$

AUG 1985

$21 . . \quad 08: 40 \quad 344$

21.5

590

FOURMILE CREER AT DES MOINES, IOWA (LAT 4136 50N LONG 09332 43W)

$\begin{array}{rrr}3 & 8.0 & 850 \\ 2 & 0.0 & 920 \\ 2 & 0.0 & 980 \\ 70 & 6.0 & 690 \\ 37 & 18.0 & 730\end{array}$

$\begin{array}{ccccr}\text { MAY } 1985 & & & & \\ 30 \ldots & 10: 10 & 18 & 21.0 & 770 \\ \text { JUL } \ldots & 10: 35 & 2.0 & 23.0 & 1280 \\ 10 \ldots & 10: 35 & 0.65 & 19.5 & 1280 \\ 23 \ldots & 09: 10 & & & \\ \text { AUG } & & & & \\ 21 \ldots & 09: 50 & 0.8 & 18.5 & 1700\end{array}$

NORTE RIVER NEAR NORWALK, IOWA (LAT 41 27 25N LONG 09339 10W)

$\begin{array}{rr}10.0 & 480 \\ 0.0 & 430 \\ 0.0 & 560 \\ 3.5 & 405\end{array}$

$13: 30 \quad 69$

$13: 10 \quad 21$

14:00 $\quad 12$

$12: 50 \quad 2.1$

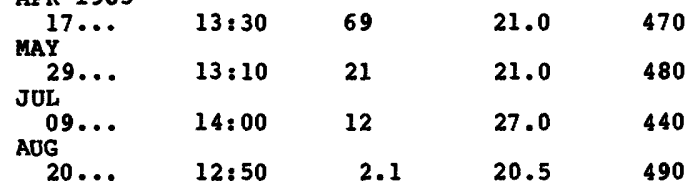




\begin{tabular}{|c|c|c|c|c|c|c|c|c|c|}
\hline ATE & TIME & $\begin{array}{l}\text { STREAY- } \\
\text { FLOW, } \\
\text { INSTAN- } \\
\text { TANEOUS } \\
\text { (CFS) }\end{array}$ & $\begin{array}{c}\text { TEMPER- } \\
\text { ATURE } \\
\text { (DEG C) }\end{array}$ & $\begin{array}{l}\text { SPE- } \\
\text { CIFIC } \\
\text { CON- } \\
\text { DUCT- } \\
\text { ANCE } \\
\text { (US/CM) }\end{array}$ & DATE & TIME & $\begin{array}{c}\text { STREAM- } \\
\text { FLOW, } \\
\text { INSTAN- } \\
\text { TANEOOS } \\
\text { (CFS) }\end{array}$ & $\begin{array}{l}\text { TEMPER- } \\
\text { ATURE } \\
\text { (DEG C) }\end{array}$ & $\begin{array}{l}\text { SPE- } \\
\text { CIFIC } \\
\text { CON- } \\
\text { DUCT- } \\
\text { ANCE } \\
\text { (US/CM) }\end{array}$ \\
\hline
\end{tabular}

05486490

$\begin{array}{lll}\text { OCT } 1984 & & \\ 30 \ldots \ldots & 13: 00 & 36 \\ \text { DEC } & & \\ 13 \ldots & 11: 15 & 31 \\ \text { JAN } 1985 & 14: 05 & 44 \\ 22 \ldots \ldots & 14: 05 & \\ \begin{array}{l}\text { MAR } \\ 07\end{array} & 10: 30 & 290\end{array}$

05487470

$\begin{array}{lll}\text { OCT } 1984 & & \\ 30 \ldots & 10: 25 & 10 \\ \text { DEC } & & \\ 13 \ldots & 09: 30 & 14 \\ \text { JAN } 1985 & & \\ 22 \ldots & 11: 35 & 17 \\ \begin{array}{c}\text { MAR } \\ 07 \ldots\end{array} & 08: 35 & 297\end{array}$

MIDDLE RIVER NEAR INDIANOLA, IOWA (LAT $412527 N$ LONG 09335 O9W)

\section{0}

OCT 1984

$\begin{array}{ccccc}\text { OCT } 1984 & & & \\ 30 \ldots . . & 08: 30 & 7.6 & 10.0 & 470 \\ \begin{array}{c}\text { DEC } \\ 12 \ldots\end{array} & 15: 00 & 21 & 0.0 & 510 \\ \begin{array}{c}\text { JAN } 1985 \\ 22 \ldots . .\end{array} & 09: 25 & 9.2 & 0.0 & 660 \\ \begin{array}{c}\text { MAR } \\ \text { 06... }\end{array} & 16: 00 & 318 & 1.5 & 350\end{array}$

05488200

$\begin{array}{lll}\text { OCT } 1984 & & \\ 29 \ldots . . & 16: 15 & 1.7 \\ \text { DEC } & & \\ 12 \ldots & 16: 10 & 6.0 \\ \begin{array}{c}\text { MAR } 1985 \\ \text { O6 ... }\end{array} & 13: 50 & 54 \\ \begin{array}{c}\text { ARR } \\ 16 \ldots . .\end{array} & 15: 40 & 14\end{array}$

05488500

$\begin{array}{lll}\text { OCT } 1984 & & \\ 29 \ldots \ldots & 13: 15 & 2530 \\ \text { DEC } & & \\ 12 \ldots . . & 11: 15 & 3580 \\ \text { JAN } 1985 & 13: 10 & 5130 \\ \quad 21 \ldots \ldots & 10: 15 & 5020 \\ \begin{array}{c}\text { MAR } \\ \text { O6 ... }\end{array} & 10\end{array}$

05489000

$\begin{array}{lrr}\text { OCT } 1984 & & \\ 29 & 15: 05 & 96 \\ \text { DEC } & 12 \ldots & 52 \\ \text { JAN } 1985 & 13: 10 & 51 \\ 21 \cdots & 15: 00 & 31 \\ \underset{M A R}{M} & 12: 10 & 414\end{array}$

05489500

$\begin{array}{lll}\text { OCT } 1984 & & \\ 15 \ldots \ldots & 16: 45 & 2510 \\ \text { NOV } & & \\ 26 \ldots 385 & 13: 00 & 2420 \\ \text { MAR } 1985 & 12: 30 & 9090 \\ 11 \ldots \ldots & 12: 30 & \\ \text { APR } \\ 01 \ldots . . & 15: 00 & 6260\end{array}$

$\begin{array}{rrr}.7 & 8.5 & 750 \\ 6.0 & 0.5 & 630 \\ & 1.5 & 395 \\ & 17.0 & 570\end{array}$

$\begin{array}{rr}10.0 & 520 \\ 0.0 & 310 \\ 0.0 & 580 \\ 3.5 & 365\end{array}$

APR 1985

$\begin{array}{lll}\begin{array}{l}17 \ldots \\ \text { MAY }\end{array} & 13: 05 & 107 \\ 29 \ldots & 11: 20 & 52 \\ \text { JUL } & & \\ \text { O9... } & 12: 30 & 37 \\ \text { AUG } & 11: 35 & 15\end{array}$

107
52
37
15

$\begin{array}{ll}20.0 & 450 \\ 19.0 & 500 \\ 29.0 & 410 \\ 19.0 & 520\end{array}$

SOUTH RIVER NEAR ACKWORTH, IOWA (LAT 4120 14N LONG 09329 10W)

$\begin{array}{rr}10.0 & 480 \\ 0.0 & 550 \\ 0.0 & 520 \\ 3.0 & 370\end{array}$

$10: 20 \quad 63$

$09: 55 \quad 17$

$10: 25 \quad 18$ $\begin{array}{lllll}\text { AUG } & & & & \\ 20 . & 09: 55 & 8.9 & 19.0 & 400\end{array}$

$17.0 \quad 470$

$18.5 \quad 500$

$26.0 \quad 460$

WHITE BREAST CREEK NEAR DALLAS, IOWA (LAT $411441 \mathrm{~N}$ LONG 09316 08W)

$\begin{array}{ccccc}\begin{array}{c}\text { APR } 1985 \\ 17 \ldots .\end{array} & 08: 20 & 48 & 15.5 & 520 \\ \begin{array}{c}\text { MAY } \\ 29 \ldots\end{array} & 08: 05 & 8.7 & 17.5 & 520 \\ \begin{array}{c}\text { JUL } \\ \text { O9... }\end{array} & 08: 20 & 3.9 & 24.5 & 440 \\ \begin{array}{c}\text { AUG } \\ 20 \ldots\end{array} & 08: 20 & 8.3 & 18.0 & 300\end{array}$

ENGLISE CR NR KNOXVILLE, IOWA (LAT 4116 OON LONG 09305 OOW)

$\begin{array}{ll}\text { MAY } 1985 & \\ 28 \ldots & 15: 20 \\ \text { JUL } & \\ \text { O8... } & 15: 50 \\ \text { AUG } & \\ 19 \ldots & 15: 15\end{array}$

2.020 .0

630

0.427 .0

570

$0.29 \quad 24.0 \quad 400$

DES MOINES RIVER NEAR TRACY, IOWA (LAT $41 \quad 16$ 53N LONG 0925134 )

\begin{tabular}{|c|c|c|c|c|c|c|}
\hline 10.5 & 610 & $\begin{array}{c}\text { APR } 1985 \\
16 \ldots \\
M A Y\end{array}$ & $12: 25$ & 6810 & 14.5 & 580 \\
\hline 1.0 & 640 & JUL $28 \ldots$ & $12: 10$ & 6250 & 21.0 & 680 \\
\hline 0.0 & 570 & AOG & $12: 20$ & 2710 & 26.0 & 590 \\
\hline 0.5 & 470 & $19 \ldots$ & $12: 15$ & 508 & 24.0 & 600 \\
\hline
\end{tabular}

CEDAR CREER NEAR BUSSEY, IOWA (LAT 4113 O9N LONG $0925438 \%$ )

\begin{tabular}{|c|c|c|c|c|c|c|}
\hline 11.0 & 350 & $\begin{array}{c}\text { APR } 1985 \\
16 \ldots \\
M A Y\end{array}$ & $14: 30$ & 72 & 17.5 & 620 \\
\hline 0.5 & 700 & ${ }_{\text {JUL }}^{28 \ldots}$ & $14: 00$ & 26 & 21.0 & 680 \\
\hline 0.0 & 675 & AUG & $14: 45$ & 7.7 & 28.0 & 470 \\
\hline 1.5 & 370 & $19 \ldots$ & $14: 10$ & 6.1 & 24.0 & 530 \\
\hline
\end{tabular}

DES MOINES RIVER AT OTTUWWA, IOWA (LAT $410039 \mathrm{~N}$ LONG $092 \quad 2440 \%)$

\begin{tabular}{|c|c|c|c|c|c|c|}
\hline 18.0 & 644 & $\begin{array}{c}\text { MAY } 1985 \\
13 \ldots\end{array}$ & $13: 45$ & 7820 & 19.0 & 625 \\
\hline 6.0 & 638 & $24 \ldots$ & $13: 30$ & 3920 & 22.0 & 654 \\
\hline 5.0 & 445 & $\begin{array}{l}05 \ldots \\
\text { SEP }\end{array}$ & $14: 15$ & 1210 & 26.0 & 650 \\
\hline 7.0 & 495 & $16 \ldots$ & $15: 00$ & 2390 & 21.0 & 6411 \\
\hline
\end{tabular}




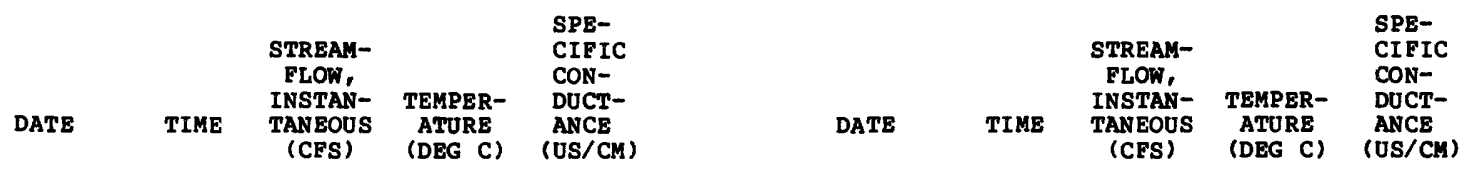

05490500 DES MOINES RIVER AT KEOSAUQUA, IOWA (LAT 404340 LONG $0915734 W$ )

\begin{tabular}{|c|c|c|c|c|c|c|c|c|}
\hline OCT 1984 & $11: 15$ & 10500 & 12.0 & 319 & $\begin{array}{c}\operatorname{MAY} 1985 \\
16 \ldots\end{array}$ & $10: 30$ & 6590 & 17.0 \\
\hline MAR 1985 & $10: 45$ & 3500 & 5.0 & 653 & $\begin{array}{l}\text { AUG } \\
08 \ldots .\end{array}$ & $10: 15$ & 770 & 23.5 \\
\hline $06 \ldots$ & $14: 30$ & 8150 & 3.0 & 371 & & & & \\
\hline
\end{tabular}

06483500 ROCK RIVER NEAR ROCK VALLEY, IOWA (LAT 4312 52N LONG 096 $1739 \mathrm{~W}$ )

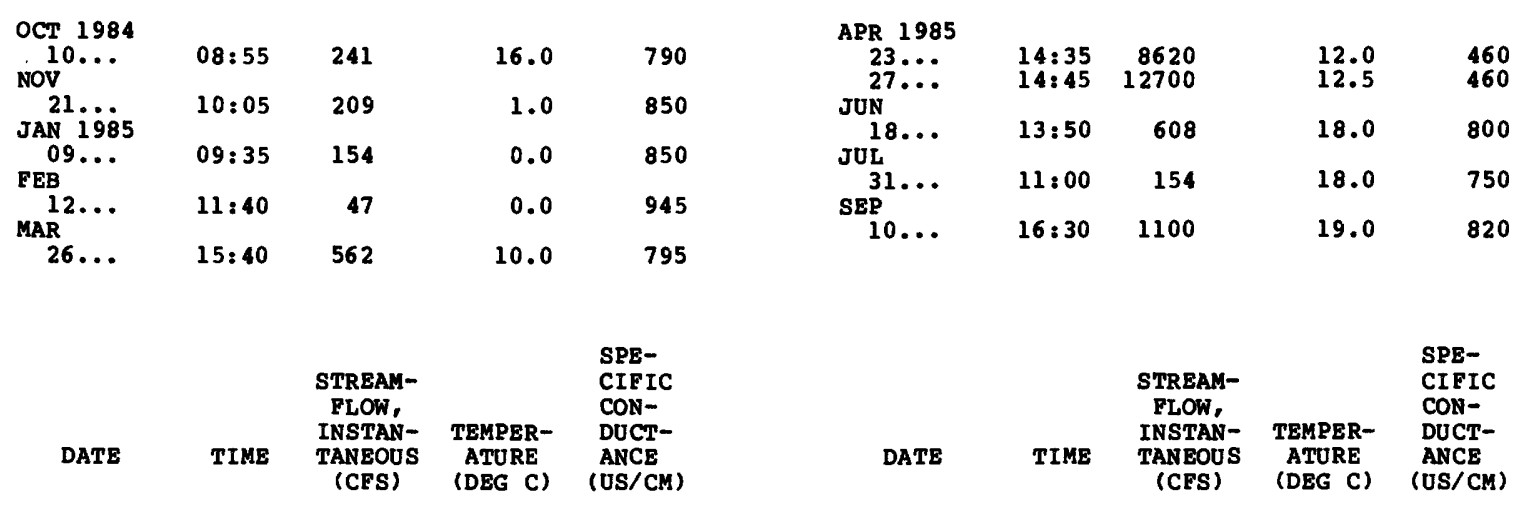

06486000

OCT 1984

\begin{tabular}{|c|c|c|}
\hline $\begin{array}{l}05 \ldots \\
11 \ldots \\
15 \ldots \\
18 \ldots \\
22 \ldots \\
25 \ldots \\
29 \ldots\end{array}$ & $\begin{array}{l}10: 10 \\
11: 00 \\
14: 40 \\
11: 00 \\
11: 00 \\
10: 30 \\
12: 15\end{array}$ & $\begin{array}{l}46000 \\
45000 \\
47400 \\
47100 \\
50200 \\
50200 \\
50300\end{array}$ \\
\hline \multicolumn{3}{|l|}{ NOV } \\
\hline $\begin{array}{l}01 \ldots \\
05 \ldots \\
07 \ldots \\
15 \ldots \\
21 \ldots \\
25 \ldots \\
30 \ldots \\
C C\end{array}$ & $\begin{array}{l}11: 30 \\
10: 45 \\
10: 20 \\
13: 00 \\
13: 10 \\
10: 30 \\
12: 35\end{array}$ & $\begin{array}{l}19300 \\
47700 \\
48600 \\
46100 \\
48200 \\
47500 \\
48200\end{array}$ \\
\hline $\begin{array}{r}05 \ldots \\
12 \ldots \\
28 \ldots \\
\text { JAN } 1985\end{array}$ & $\begin{array}{l}13: 25 \\
13: 25 \\
12: 50\end{array}$ & $\begin{array}{l}34000 \\
25900 \\
22700\end{array}$ \\
\hline $\begin{array}{l}08 \ldots \\
23 \ldots \\
29 \ldots\end{array}$ & $\begin{array}{l}12: 30 \\
17: 15 \\
11: 50\end{array}$ & $\begin{array}{r}21300 \\
22100 \\
225000\end{array}$ \\
\hline \multicolumn{3}{|l|}{ FEB } \\
\hline $\begin{array}{r}22 \\
26 \\
\text { MAR }\end{array}$ & $\begin{array}{l}12: 10 \\
10: 30\end{array}$ & $\begin{array}{l}22000 \\
23200\end{array}$ \\
\hline $\begin{array}{l}06 . \\
12 . \\
19 . \\
26 .\end{array}$ & $\begin{array}{l}11: 20 \\
12: 00 \\
14: 00 \\
11: 30\end{array}$ & $\begin{array}{l}22600 \\
28900 \\
32900 \\
33200\end{array}$ \\
\hline \multicolumn{3}{|l|}{ APR } \\
\hline $\begin{array}{l}01 \ldots \\
04 \ldots \\
11 \ldots \\
15 \ldots \\
18 \ldots \\
22 \ldots \\
25 \ldots \\
29 \ldots \\
\text { MAY }\end{array}$ & $\begin{array}{l}12: 45 \\
13: 00 \\
10: 40 \\
12: 40 \\
13: 25 \\
10: 50 \\
11: 20 \\
11: 45\end{array}$ & $\begin{array}{l}31900 \\
34200 \\
31700 \\
30900 \\
30400 \\
39700 \\
30100 \\
27400\end{array}$ \\
\hline 0 & $\begin{array}{l}09: 50 \\
13: 00 \\
11: 25\end{array}$ & $\begin{array}{l}31700 \\
30900 \\
31200\end{array}$ \\
\hline
\end{tabular}

MISSOURI RIVER AT SIOUX CITY, IOWA (LAT 4229 ION LONG 0962447 )

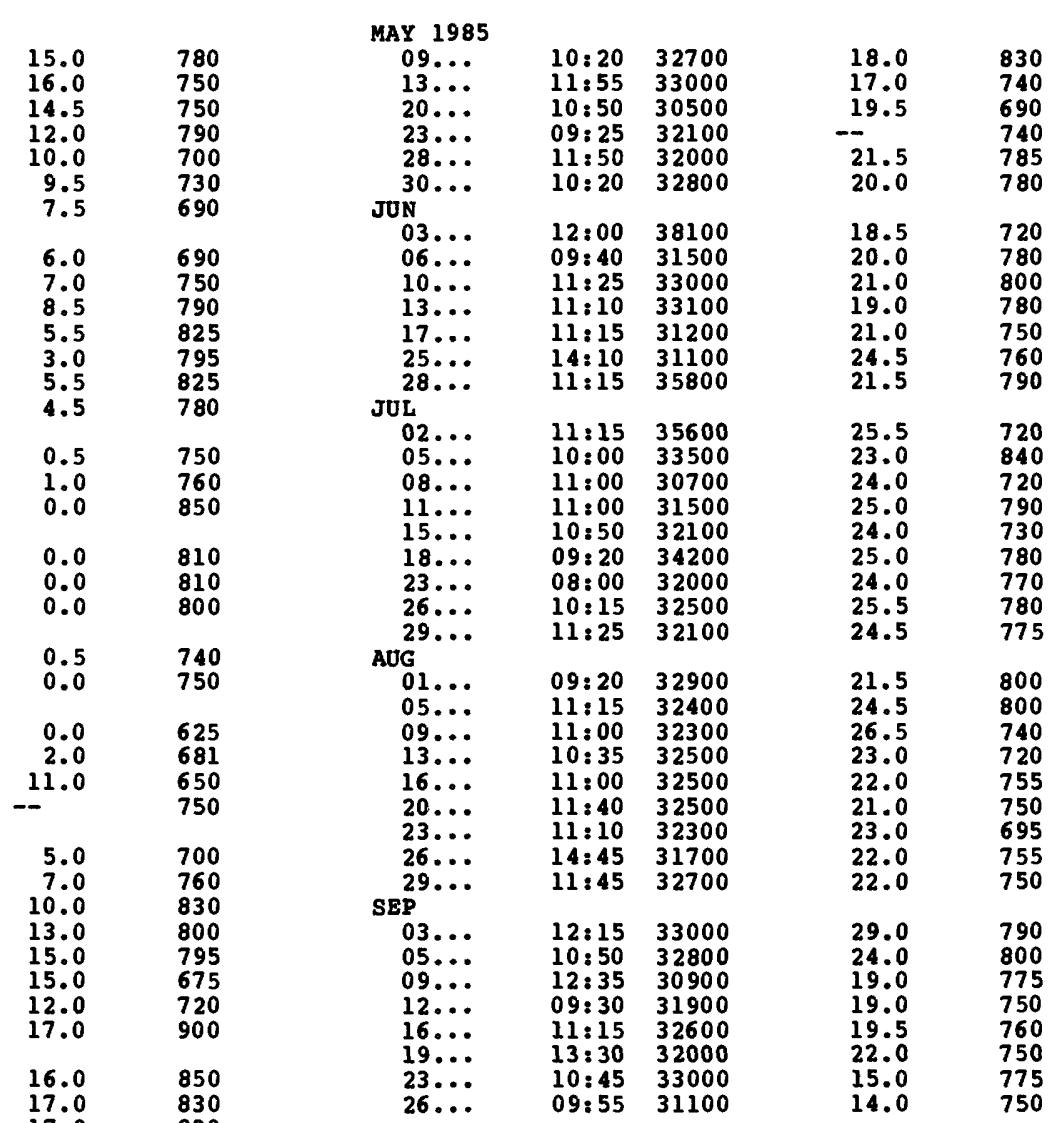




\begin{tabular}{|c|c|c|c|c|c|c|c|c|c|}
\hline DATE & TIME & $\begin{array}{l}\text { STREAM- } \\
\text { FLOW, } \\
\text { INSTAN- } \\
\text { TANEOUS } \\
\text { (CFS) }\end{array}$ & $\begin{array}{l}\text { TEMPER- } \\
\text { ATURE } \\
\text { (DEG C) }\end{array}$ & $\begin{array}{l}\text { SPE- } \\
\text { CIFIC } \\
\text { CON- } \\
\text { DOCT- } \\
\text { ANCE } \\
\text { (US/CM) }\end{array}$ & DATE & TIME & $\begin{array}{l}\text { STREAM- } \\
\text { FLON, } \\
\text { INSTAN- } \\
\text { TANEOUS } \\
\text { (CFS) }\end{array}$ & $\begin{array}{l}\text { TEMPER- } \\
\text { ATORE } \\
\text { (DEG C) }\end{array}$ & $\begin{array}{l}\text { SPE- } \\
\text { CIFIC } \\
\text { CON- } \\
\text { DUCT- } \\
\text { ANCE } \\
\text { (US/CM) }\end{array}$ \\
\hline
\end{tabular}

06600000 PERRY CREEK AT 38TE STREET, SIOUX CITY, IOWA (LAT 4232 05N LONG 09624 35W)

\begin{tabular}{|c|c|c|c|c|c|c|c|c|c|}
\hline $\begin{array}{c}\text { OCT } 1984 \\
18 \ldots \\
\text { NOV }\end{array}$ & $13: 00$ & 28 & 10.0 & 790 & $\begin{array}{c}\text { MAY } 1985 \\
06 \ldots\end{array}$ & $16: 30$ & 33 & 15.0 & 830 \\
\hline 19 JAN 1985 & $13: 40$ & 17 & 2.0 & 750 & $17 \ldots$ & $14: 20$ & 23 & 20.5 & 750 \\
\hline$\underset{\text { FEB }}{08 \ldots}$ & $15: 30$ & 12 & 0.0 & 850 & SEP $29 .$. & $19: 10$ & 11 & 22.0 & 700 \\
\hline $\begin{array}{l}13 \ldots \\
25 \ldots\end{array}$ & $\begin{array}{l}14: 00 \\
15: 10\end{array}$ & $\begin{array}{l}10 \\
17\end{array}$ & $\begin{array}{l}0.0 \\
7.0\end{array}$ & $\begin{array}{l}800 \\
795\end{array}$ & $09 \ldots$ & $15: 30$ & 15 & 18.0 & 775 \\
\hline
\end{tabular}

06600100 FLOYD RIVER AT ALTON, IOWA (LAT 4258 55N LONG 09600 03W)

\begin{tabular}{|c|c|c|c|c|c|c|c|c|c|}
\hline $\begin{array}{c}\text { OCT } 1984 \\
10 \ldots\end{array}$ & $15: 30$ & 37 & 17.0 & 945 & $\begin{array}{c}\text { MAR } 1985 \\
27 \ldots\end{array}$ & $09: 45$ & 69 & 11.0 & 860 \\
\hline${ }_{\text {JAN }}^{\text {NOV }} \ddot{1985}$ & $14: 40$ & 53 & 1.5 & 675 & $\begin{array}{c}\text { MAY } \\
08 \ldots\end{array}$ & $14: 15$ & 214 & 17.0 & 870 \\
\hline $10 \ldots$ & $12: 20$ & 34 & 0.0 & 950 & SEP & $16: 40$ & 26 & 20.0 & 850 \\
\hline $11 \ldots$ & $14: 30$ & 6.1 & 0.0 & 1200 & $11 \ldots$ & $12: 15$ & 88 & 19.0 & 940 \\
\hline
\end{tabular}

06600300 WEST BRANCB FLOYD RIVER NEAR STROBLE, IOWA (LAT 4255 15N LONG 096 10 30W)

\begin{tabular}{|c|c|c|c|c|c|c|c|c|c|}
\hline $\begin{array}{c}\text { OCT } 1984 \\
15 \ldots \\
\text { NOV }\end{array}$ & $15: 35$ & 31 & 16.0 & 1050 & $\begin{array}{c}\text { JUN } 1985 \\
18 \ldots \\
\text { JUL }\end{array}$ & $09: 50$ & 52 & 15.5 & 1000 \\
\hline${ }_{\text {FEB }}^{21} 1985$ & $13: 20$ & 25 & 3.0 & 950 & $\begin{array}{l}30 \ldots \\
\text { SEP }\end{array}$ & $14: 35$ & 32 & 19.0 & 900 \\
\hline & $15: 10$ & 9.9 & 0.0 & 1100 & $10 \ldots$ & $13: 00$ & 71 & 18.5 & 990 \\
\hline $26 \ldots$ & $11: 10$ & 37 & 12.0 & 1150 & & & & & \\
\hline
\end{tabular}

06600500 FLOYD RIVER AT JAMES, IOWA (LAT 4234 36N LONG 09618 43W)

\begin{tabular}{|c|c|c|c|c|c|c|c|c|c|}
\hline $\begin{array}{l}\text { OCT } 1984 \\
09 . .\end{array}$ & $13: 10$ & 205 & 17.0 & 890 & $\begin{array}{c}\text { MAY } 1985 \\
06 \ldots\end{array}$ & $14: 00$ & 1060 & 17.0 & 900 \\
\hline JAN 1985 & $11: 25$ & 261 & 0.5 & 675 & $17 \ldots$ & $16: 55$ & 415 & 22.0 & 920 \\
\hline $\begin{array}{l}09 . . \\
\text { MAR }\end{array}$ & $11: 25$ & 127 & 0.0 & 1150 & $\begin{array}{l}31 \ldots \\
\text { SEP }\end{array}$ & $11: 05$ & 150 & 20.0 & 850 \\
\hline $25 \ldots$ & $12: 45$ & 240 & 8.0 & 850 & $10 \ldots$ & $10: 30$ & 388 & 18.5 & 910 \\
\hline
\end{tabular}

06601200 - MISSOURI RIVER AT DECATUR, NEBR. (LAT 420026 LONG 0961429 )

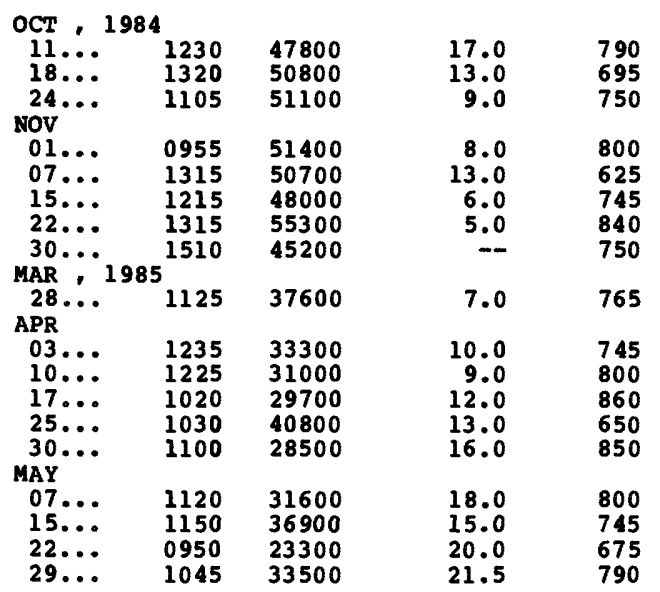

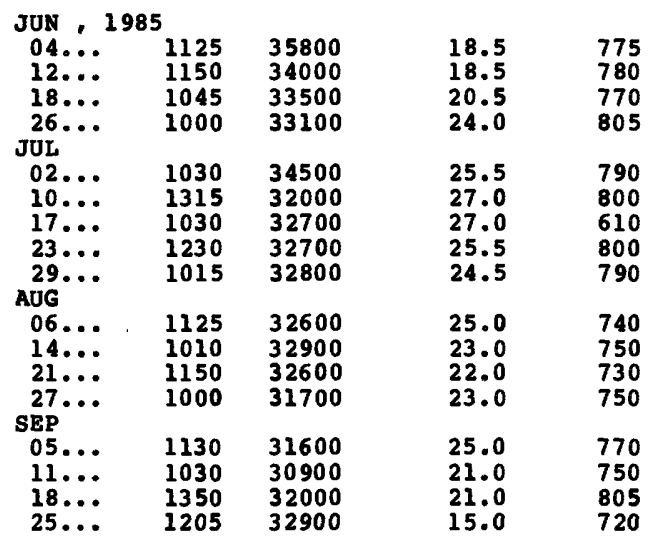




\begin{tabular}{|c|c|c|c|c|c|c|c|c|c|}
\hline ATE & TIME & $\begin{array}{c}\text { STREAM- } \\
\text { FLOW, } \\
\text { INSTAN- } \\
\text { TANEOUS } \\
\text { (CFS) }\end{array}$ & $\begin{array}{l}\text { TEMPER- } \\
\text { ATURE } \\
\text { (DEG C) }\end{array}$ & $\begin{array}{l}\text { SPE- } \\
\text { CIFIC } \\
\text { CON- } \\
\text { DUCT- } \\
\text { ANCE } \\
\text { (US/CM) }\end{array}$ & DATE & TIME & $\begin{array}{c}\text { STREAM- } \\
\text { FLOW, } \\
\text { INSTAN- } \\
\text { TANEOUS } \\
\text { (CFS) }\end{array}$ & $\begin{array}{l}\text { TEMPER- } \\
\text { ATURE } \\
\text { (DEG C) }\end{array}$ & $\begin{array}{l}\text { SPE- } \\
\text { CIFIC } \\
\text { CON- } \\
\text { DUCT- } \\
\text { ANCE } \\
\text { (US/CM) }\end{array}$ \\
\hline
\end{tabular}

06602020 WEST FORK DITCH AT HORNICK, IOWA (LAT $421337 \mathrm{~N}$ LONG $0960440 \mathrm{~W}$ )

$\begin{array}{lrrrr}\text { OCT } 1984 & & & \\ 30 \ldots . . & 11: 35 & 119 & 7.5 & 675 \\ \text { DEC } & 11 \ldots .20 & 133 & 0.5 & 675 \\ \begin{array}{l}\text { JAN } 1985 \\ 22 \ldots \ldots\end{array} & 15: 30 & 72 & 0.0 & 590 \\ \begin{array}{c}\text { MAR } \\ 05 \ldots . .\end{array} & 12: 00 & 730 & 0.0 & 265\end{array}$

\begin{tabular}{|c|c|c|c|c|}
\hline $\begin{array}{r}\text { APR } 1985 \\
10 \ldots \\
23 \ldots\end{array}$ & $\begin{array}{l}15: 00 \\
15: 15\end{array}$ & $\begin{array}{r}778 \\
3960\end{array}$ & $\begin{array}{l}15.5 \\
12.0\end{array}$ & $\begin{array}{l}800 \\
740\end{array}$ \\
\hline $20 \ldots$ & $14: 40$ & 596 & 18.0 & 420 \\
\hline $\begin{array}{l}01 . . . \\
\text { AUG }\end{array}$ & $10: 15$ & 174 & 25.0 & 5 \\
\hline & $12: 10$ & 76 & 22.0 & \\
\hline
\end{tabular}

06602400 MONONA-HARRISON DITCH NEAR TURIN, IOWA (LAT 4157 52N LONG 095 59 30W)

\begin{tabular}{|c|c|c|c|c|c|c|c|c|}
\hline $\begin{array}{c}\text { OCT } 1984 \\
31 \not \dddot{1} \\
\text { JAN } 1985\end{array}$ & $10: 30$ & 211 & 7.5 & 710 & $\begin{array}{c}\text { MAY } 1985 \\
22 \ldots \\
\text { JUL }\end{array}$ & $14: 25$ & 679 & 21.0 \\
\hline MAR $24 \ldots$ & $12: 20$ & 153 & 0.5 & 870 & $\begin{array}{l}02 \ldots \\
31 \ldots\end{array}$ & $\begin{array}{l}13: 00 \\
13: 10\end{array}$ & $\begin{array}{l}294 \\
166\end{array}$ & $\begin{array}{l}28.0 \\
20.5\end{array}$ \\
\hline${ }_{A P R}^{12} \cdots$ & $14: 10$ & 271 & 6.0 & 600 & $\begin{array}{l}\text { AUG } \\
19 \ldots\end{array}$ & $16: 30$ & 152 & 26.5 \\
\hline $\begin{array}{l}09 \ldots \\
24 \ldots \\
29 \ldots\end{array}$ & $\begin{array}{l}15: 20 \\
11: 35 \\
13: 15\end{array}$ & $\begin{array}{r}299 \\
5480 \\
1310\end{array}$ & $\begin{array}{l}10.0 \\
12.0 \\
17.0\end{array}$ & $\begin{array}{l}840 \\
280 \\
675\end{array}$ & & & & \\
\hline
\end{tabular}

06605000

NOV 1984

$\begin{array}{crrrr}\begin{array}{c}\text { NOV } 1984 \\ 05 \ldots . .\end{array} & 16: 30 & 62 & 5.0 & 690 \\ \begin{array}{c}\text { DEC } \\ 18 \ldots . \ldots\end{array} & 11: 50 & 83 & 0.0 & 285 \\ \begin{array}{c}\text { JAN } 1985 \\ 29 \ldots\end{array} & 10: 00 & 17 & 0.0 & 900 \\ \begin{array}{c}\text { MAR } \\ 11 \ldots\end{array} & 17: 00 & 1390 & 3.0 & 760\end{array}$

06605850

$\begin{array}{crrrr}\text { NOV } 1984 & & & & \\ 05 \ldots & 13: 20 & 200 & 5.0 & 680 \\ \text { JAN } 1985 & & & & \\ 16 \ldots . . & 16: 10 & 121 & 0.0 & 700 \\ 24 \ldots & 13: 40 & 79 & 0.0 & 1000 \\ \begin{array}{c}\text { MAR } \\ \quad 11 \ldots\end{array} & 12: 10 & 2820 & 3.0 & 1180 \\ \begin{array}{c}\text { APR } \\ 16 \ldots\end{array} & 11: 00 & 1090 & 12.0 & 700\end{array}$

OCHEYEDAN R NR SPENCER, IOWA (LAT $430744 \mathrm{~N}$ LONG $0951237 \mathrm{~W}$ )

$\begin{array}{lrrrr}\begin{array}{l}\text { APR } 1985 \\ 15 \ldots . .\end{array} & 19: 15 & 267 & 14.0 & 670 \\ \begin{array}{c}\text { MAY } \\ 28 \ldots . .\end{array} & 18: 15 & 361 & 21.0 & 660 \\ \begin{array}{c}\text { JUN } \\ \text { O9... }\end{array} & 15: 15 & 118 & 28.0 & 700 \\ \begin{array}{c}\text { AUG } \\ 21 \ldots . .\end{array} & 18: 40 & 26 & 21.0 & 650\end{array}$

06606600 LITTLE SIOUX RIVER AT CORRECTIONVILLE, IOWA (LAT $422820 \mathrm{~N}$ LONG O95 $4749 \mathrm{~W}$ )

$\begin{array}{ccccc}\text { DEC 1984 } & & & & \\ 111 . \ldots 5 & 15: 45 & 422 & 1.0 & 750 \\ \begin{array}{c}\text { JAN } 1985 \\ 23 \ldots\end{array} & 09: 55 & 260 & 0.0 & 620 \\ \begin{array}{c}\text { MAR } \\ 27 \ldots\end{array} & 14: 45 & 1510 & 11.0 & 580 \\ \text { APR } & & & & \\ 23 \ldots & 18: 30 & 7570 & 12.0 & 360 \\ 24 \ldots & 11: 00 & 8500 & 13.0 & 380\end{array}$

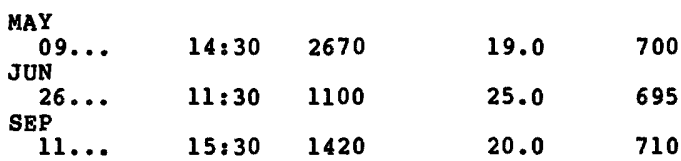

MAPLE RIVER AT MAPLETON, IOWA (LAT 4209 28N LONG 09548 27W)

\begin{tabular}{|c|c|c|c|c|c|}
\hline 7.0 & 690 & $\begin{array}{c}\text { APR } 1985 \\
10 \ldots \\
\text { MAY }\end{array}$ & $12: 20$ & 439 & 13.5 \\
\hline & 580 & ${ }_{\text {JUL }}^{21}$ & $09: 30$ & 737 & 19.0 \\
\hline 0.0 & 420 & $01 \ldots$ & $14: 25$ & 497 & 28.0 \\
\hline 0.0 & 295 & & & & \\
\hline
\end{tabular}

06607500

OCT 1984

\begin{tabular}{|c|c|c|}
\hline $31 \ldots$ & $13: 45$ & 838 \\
\hline MAR & $12: 30$ & 568 \\
\hline $\mathrm{PR}^{12 \ldots}$ & $12: 15$ & 3870 \\
\hline $09 \ldots$ & $\begin{array}{l}12: 30 \\
15: 30 \\
13: 50 \\
10: 30\end{array}$ & $\begin{array}{r}27900 \\
5500 \\
7940 \\
10400\end{array}$ \\
\hline
\end{tabular}

LITTLE SIOUX RIVER NR. TURIN, IOWA (LAT $415752 \mathrm{~N}$ LONG $0955821 \mathrm{~W}$ )

$\begin{array}{crrrr}\text { MAY } 1985 & & & & \\ 22 \ldots \ldots & 10: 50 & 3930 & 19.0 & 650 \\ \text { JUL } & & & & \\ 02 \ldots . & 09: 10 & 1980 & 28.0 & 630 \\ \text { 31... } & 10: 35 & 599 & 20.0 & 690 \\ \text { AUG } & 13: 00 & 521 & 24.5 & 700 \\ 19 \ldots & 13: 00 & & \end{array}$




\begin{tabular}{|c|c|c|c|c|c|c|c|c|c|}
\hline ATE & TIME & $\begin{array}{c}\text { STREAM- } \\
\text { FLOW, } \\
\text { INSTAN- } \\
\text { TANEOUS } \\
\text { (CFS) }\end{array}$ & $\begin{array}{c}\text { TEMPER- } \\
\text { ATURE } \\
\text { (DEG C) }\end{array}$ & $\begin{array}{l}\text { SPE- } \\
\text { CIFIC } \\
\text { CON- } \\
\text { DUCT- } \\
\text { ANCE } \\
\text { (US/CM) }\end{array}$ & DATE & TIME & $\begin{array}{l}\text { STREAM- } \\
\text { FLOW, } \\
\text { INSTAN- } \\
\text { TANEOUS } \\
\text { (CFS) }\end{array}$ & $\begin{array}{c}\text { TEMPER- } \\
\text { ATURE } \\
\text { (DEG C) }\end{array}$ & $\begin{array}{l}\text { SPE- } \\
\text { CIFIC } \\
\text { CON- } \\
\text { DUCT- } \\
\text { ANCE } \\
\text { (US/CM) }\end{array}$ \\
\hline
\end{tabular}

06608500

\begin{tabular}{|c|c|}
\hline $\begin{array}{c}\mathrm{OCT} 1984 \\
11 . \ldots\end{array}$ & $16: 30$ \\
\hline $13 \ldots$ & $11: 45$ \\
\hline & $11: 50$ \\
\hline & $10: 30$ \\
\hline & $14: 20$ \\
\hline
\end{tabular}

\section{0}

$\begin{array}{lrr}\text { NOV } 1984 & \\ 14 \\ \begin{array}{lr}\text { MAR } 1985 \\ 20\end{array} & 14: 00 & 17 \\ \text { APR } & 11: 30 & 149 \\ 30 & 11: 30 & 506\end{array}$

06609500

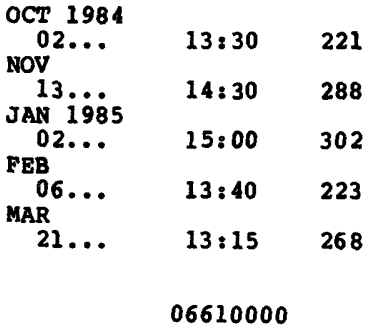

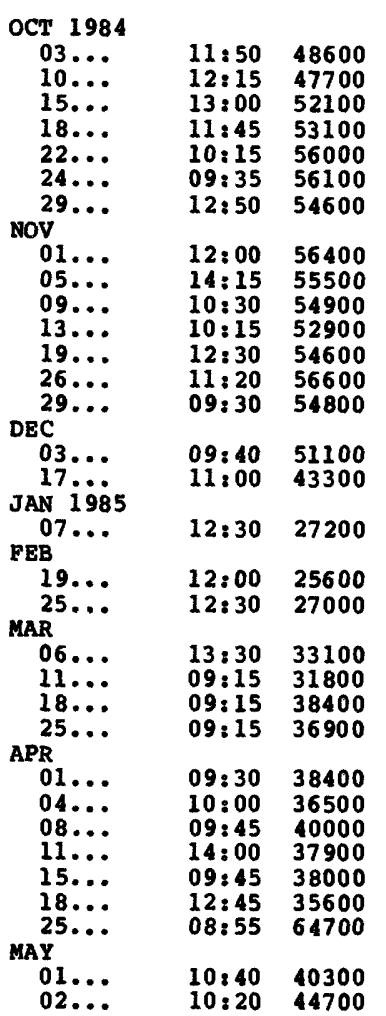

SOLDIER RIVER AT PISGAH, IOWA (LAT 4149 52N LONG 09555 50W)

\begin{tabular}{|c|c|c|c|c|c|c|}
\hline 17.0 & 740 & $\begin{array}{c}\text { APR } 1985 \\
08 \ldots \\
\text { MAY }\end{array}$ & $12: 20$ & 189 & 8.0 & 665 \\
\hline 5.5 & 710 & $21 \ldots$ & $15: 30$ & 245 & 20.0 & 640 \\
\hline 0.0 & 600 & AUG $23 \ldots$ & $11: 45$ & 109 & 24.5 & 640 \\
\hline 0.0 & 750 & $20 \ldots$ & $10: 45$ & 89 & 21.0 & 660 \\
\hline 1.0 & 510 & & & & & \\
\hline
\end{tabular}

BOYER R NR DENISON, IOWA (LAT 4200 OON LONG 09523 OOW)

\begin{tabular}{|c|c|c|c|c|c|c|}
\hline & & JUN 1985 & & & & \\
\hline 12.0 & 700 & ${ }_{\text {JUL }}^{11 \ldots}$ & $14: 00$ & 306 & 17.0 & 530 \\
\hline 11.0 & 840 & & $16: 20$ & 111 & 29.0 & 660 \\
\hline 16. & 700 & 03. & $12: 45$ & 86 & 28.0 & 840 \\
\hline
\end{tabular}

BOYER RIVER AT LOGAN, IOWA (LAT 4138 33N LONG 09546 57w)

$\begin{array}{rr}14.0 & 740 \\ 12.0 & 600 \\ 0.0 & 650 \\ 0.0 & 850 \\ 13.0 & 700\end{array}$

$\begin{array}{ccccc}\text { ARR } 1985 & & & \\ 29 \ldots & 11: 10 & 702 & 16.0 & 700 \\ \begin{array}{c}\text { JUN } \\ 12 \ldots\end{array} & 15: 30 & 472 & 19.5 & 620 \\ \begin{array}{c}\text { JUL } \\ 24 \ldots\end{array} & 15: 25 & 195 & 30.0 & 635 \\ \begin{array}{c}\text { AUG } \\ 20 \ldots\end{array} & 13: 00 & 115 & 24.5 & 700\end{array}$

MISSOURI RIVER AT OMABA, NEBRASKA (LAT $41 \quad 1532 \mathrm{~N}$ LONG 0955520 )

\begin{tabular}{|c|c|}
\hline $\begin{array}{l}13.0 \\
16.0 \\
17.0 \\
13.0 \\
10.0 \\
10.0 \\
15.0\end{array}$ & $\begin{array}{l}780 \\
740 \\
775 \\
750 \\
780 \\
800 \\
750\end{array}$ \\
\hline $\begin{array}{r}9.5 \\
14.0 \\
10.0 \\
6.5 \\
6.0 \\
9.0 \\
6.0\end{array}$ & $\begin{array}{l}850 \\
750 \\
805 \\
820 \\
850 \\
810 \\
710\end{array}$ \\
\hline $\begin{array}{l}3.0 \\
1.5\end{array}$ & $\begin{array}{l}750 \\
460\end{array}$ \\
\hline 1.5 & 830 \\
\hline 3.0 & $\begin{array}{l}700 \\
800\end{array}$ \\
\hline $\begin{array}{l}3.0 \\
5.0 \\
6.0 \\
7.5\end{array}$ & $\begin{array}{l}610 \\
655 \\
650 \\
655\end{array}$ \\
\hline $\begin{array}{r}7.0 \\
9.0 \\
8.0 \\
13.0 \\
9.0 \\
17.0 \\
14.0\end{array}$ & $\begin{array}{r}660 \\
675 \\
790 \\
760 \\
1000 \\
875 \\
990\end{array}$ \\
\hline $\begin{array}{l}16.0 \\
18.0\end{array}$ & $\begin{array}{l}760 \\
800\end{array}$ \\
\hline
\end{tabular}

\begin{tabular}{|c|c|c|c|c|}
\hline $\begin{array}{l}06 \ldots \\
10 \ldots \\
13 \ldots \\
16 \ldots \\
20 \ldots \\
23 \ldots\end{array}$ & $\begin{array}{l}10: 30 \\
10: 00 \\
08: 35 \\
09: 00 \\
10: 00 \\
13: 25\end{array}$ & $\begin{array}{l}41900 \\
39000 \\
38100 \\
46700 \\
42200 \\
41400\end{array}$ & $\begin{array}{l}17.0 \\
20.0 \\
15.0 \\
15.0 \\
18.0 \\
-\end{array}$ & $\begin{array}{l}830 \\
780 \\
800 \\
680 \\
790 \\
760\end{array}$ \\
\hline JUN & & & & \\
\hline $\begin{array}{l}05 \ldots \\
10 \ldots \\
13 \ldots \\
17 \ldots \\
20 \ldots \\
24 \ldots \\
27 \ldots \\
\text { JuL }\end{array}$ & $\begin{array}{l}10: 05 \\
12: 40 \\
10: 00 \\
09: 45 \\
09: 30 \\
11: 30 \\
10: 50\end{array}$ & $\begin{array}{l}41100 \\
39900 \\
38500 \\
39500 \\
35700 \\
37500 \\
37400\end{array}$ & $\begin{array}{l}17.0 \\
22.5 \\
18.5 \\
22.0 \\
21.0 \\
22.0 \\
26.0\end{array}$ & $\begin{array}{l}690 \\
725 \\
760 \\
780 \\
770 \\
768 \\
780\end{array}$ \\
\hline $\begin{array}{l}03 \ldots \\
08 \ldots \\
11 \ldots \\
17 \ldots \\
22 \ldots \\
25 \ldots \\
29 \ldots \\
\text { Aug }\end{array}$ & $\begin{array}{l}09: 30 \\
09: 40 \\
10: 35 \\
11: 20 \\
09: 30 \\
10: 15 \\
09: 10\end{array}$ & $\begin{array}{l}38400 \\
36800 \\
36600 \\
37000 \\
36800 \\
36000 \\
35000\end{array}$ & $\begin{array}{l}27.5 \\
25.0 \\
26.0 \\
25.5 \\
25.5 \\
26.5 \\
26.0\end{array}$ & $\begin{array}{l}800 \\
775 \\
770 \\
770 \\
575 \\
760 \\
700\end{array}$ \\
\hline $\begin{array}{l}01 \ldots \\
05 \ldots \\
08 \ldots \\
12 \ldots \\
15 \ldots \\
19 \ldots \\
22 \ldots \\
27 \ldots \\
28 \ldots \\
\text { SEP }\end{array}$ & $\begin{array}{l}09: 15 \\
10: 15 \\
09: 50 \\
10: 50 \\
11: 35 \\
09: 40 \\
10: 45 \\
12: 30 \\
11: 30\end{array}$ & $\begin{array}{l}35900 \\
35400 \\
34400 \\
34600 \\
35600 \\
35300 \\
35000 \\
34300 \\
33300\end{array}$ & $\begin{array}{l}23.5 \\
24.5 \\
26.0 \\
23.5 \\
23.5 \\
24.0 \\
23.0 \\
22.0 \\
23.5\end{array}$ & $\begin{array}{l}800 \\
760 \\
700 \\
810 \\
775 \\
790 \\
780 \\
748 \\
790\end{array}$ \\
\hline $\begin{array}{l}03 \ldots \\
12 \ldots \\
16 \ldots \\
19 \ldots \\
23 \ldots \\
26 \ldots \\
30 \ldots\end{array}$ & $\begin{array}{l}10: 25 \\
14: 00 \\
14: 30 \\
10: 00 \\
11: 10 \\
11: 05 \\
11: 30\end{array}$ & $\begin{array}{l}35500 \\
35600 \\
36900 \\
35500 \\
38700 \\
36500 \\
37600\end{array}$ & $\begin{array}{l}25.0 \\
20.5 \\
18.5 \\
22.0 \\
17.0 \\
15.0 \\
-\end{array}$ & $\begin{array}{l}775 \\
775 \\
755 \\
800 \\
720 \\
775 \\
780\end{array}$ \\
\hline
\end{tabular}




\begin{tabular}{|c|c|c|c|c|c|c|c|c|c|}
\hline TE & TIME & $\begin{array}{l}\text { STREAM- } \\
\text { FLOW, } \\
\text { INSTAN- } \\
\text { TANEOUS } \\
\text { (CFS) }\end{array}$ & $\begin{array}{l}\text { TEMPER- } \\
\text { ATURE } \\
\text { (DEG C) }\end{array}$ & $\begin{array}{l}\text { SPE- } \\
\text { CIFIC } \\
\text { CON- } \\
\text { DUCT- } \\
\text { ANCE } \\
\text { (US/CM) }\end{array}$ & DATE & TIME & $\begin{array}{c}\text { STREAM- } \\
\text { FLOW, } \\
\text { INSTAN- } \\
\text { TANEOUS } \\
\text { (CFS) }\end{array}$ & $\begin{array}{l}\text { TEMPER- } \\
\text { ATURE } \\
\text { (DEG C) }\end{array}$ & $\begin{array}{l}\text { SPE- } \\
\text { CIFIC } \\
\text { CON- } \\
\text { DUCT- } \\
\text { ANCE } \\
\text { (US/CM) }\end{array}$ \\
\hline
\end{tabular}

06807000 MISSOURI RIVER AT NEBRASKA CITY, NEBR. (LAT 4040 55N LONG 09550 48W)

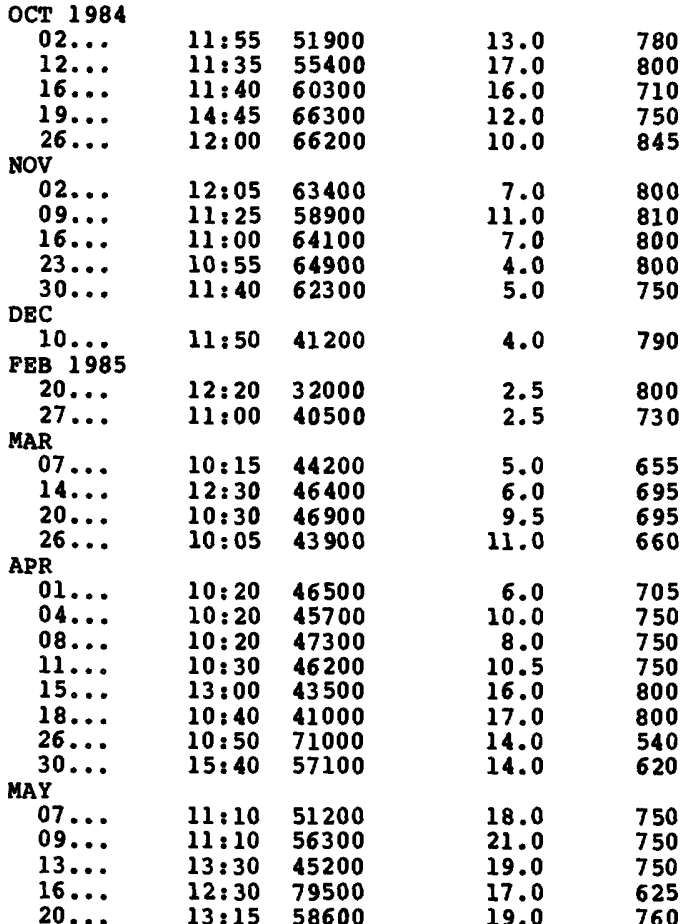

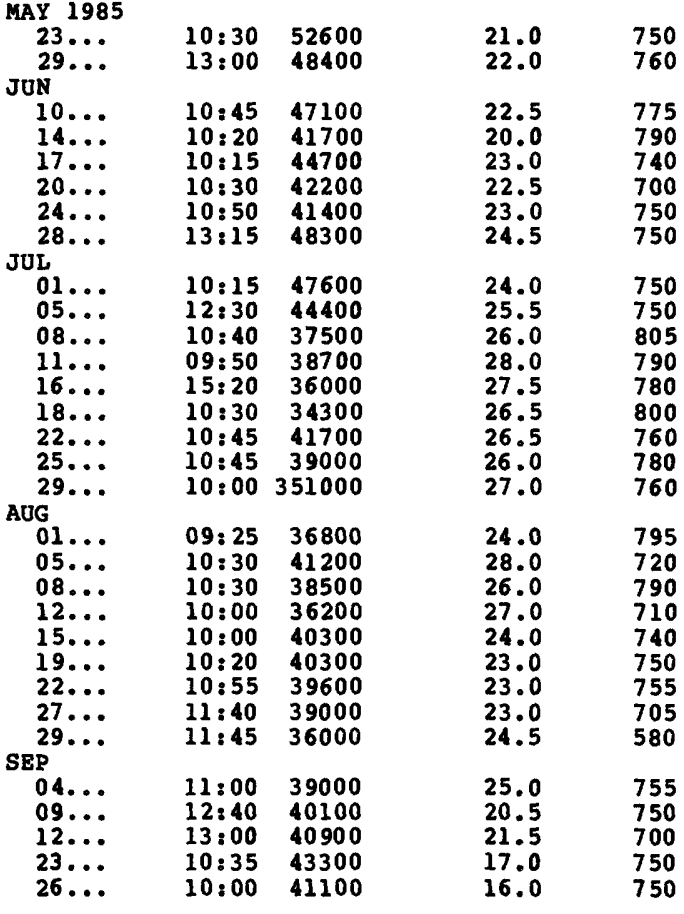

06807410 WEST NISHNABOTNA RIVER AT BANCOCK, IOWA (LAT 4123 24N LONG 09522 17W)

\begin{tabular}{|c|c|c|c|c|c|c|c|c|c|}
\hline $\begin{array}{c}\text { OCT } 1984 \\
23 \ldots\end{array}$ & $11: 35$ & 220 & 9.0 & 610 & $\begin{array}{c}\operatorname{MAY} 1985 \\
14 \ldots\end{array}$ & $11: 00$ & 377 & 16.0 & 560 \\
\hline $\begin{array}{l}\mathrm{DEC} \\
03 \\
\mathrm{JAN}\end{array} \ddot{1985}$ & $13: 20$ & 124 & 0.0 & 610 & $\begin{array}{c}\text { JUN } \\
24 \ldots\end{array}$ & $13: 00$ & 865 & 22.5 & 260 \\
\hline FEB & $13: 30$ & 185 & 0.0 & 365 & $18 \ldots$ & $10: 40$ & 122 & 18.5 & 650 \\
\hline$\underset{A P R}{26} \cdots$ & $11: 50$ & 304 & 4.0 & 525 & $10 \ldots$ & $10: 40$ & 97 & 19.5 & 645 \\
\hline $02 \ldots$ & $16: 35$ & 290 & 14.0 & 540 & & & & & \\
\hline
\end{tabular}

06808500 WEST NISHNABOTNA RIVER AT RANDOLPH, IOWA (LAT 4052 23N LONG 09534 48W)

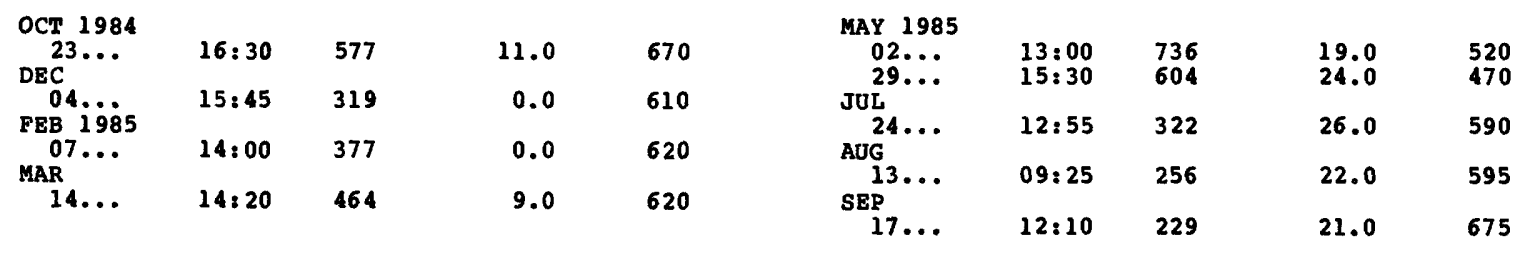

06809210 EAST NISBNABOTNA RIVER NEAR ATLANTIC, IOWA (LAT 4120 47N LONG 09504 31W)

$\begin{array}{crrrr}\text { OCT 1984 } & & & & \\ 31 \ldots .0 & 12: 45 & 104 & 8.5 & 575 \\ \text { FEB } 1985 & 13: 15 & 74 & 0.0 & 560 \\ 07 \ldots & 14: 20 & 248 & 4.0 & 360\end{array}$

\begin{tabular}{|c|c|c|c|c|}
\hline $\begin{array}{r}02 \ldots \\
14 \ldots \\
A U G\end{array}$ & $\begin{array}{l}12: 30 \\
14: 00\end{array}$ & $\begin{array}{l}151 \\
158\end{array}$ & $\begin{array}{l}11.0 \\
18.5\end{array}$ & $\begin{array}{l}520 \\
560\end{array}$ \\
\hline & $08: 10$ & 60 & 18.0 & \\
\hline 1 & $13: 10$ & 40 & 20.0 & 520 \\
\hline
\end{tabular}

06809500

EAST NISHNABOTNA RIVER NEAR RED OAK, IOWA (LAT $410041 \mathrm{~N}$ LONG 09514 07W)

\begin{tabular}{|c|c|c|c|c|c|c|c|c|c|}
\hline $\begin{array}{c}\text { OCT } 1984 \\
24 \ldots\end{array}$ & $12: 35$ & 259 & 8.0 & 570 & $\begin{array}{c}\text { APR } 1985 \\
05 \ldots\end{array}$ & $12: 50$ & 404 & 9.0 & 455 \\
\hline JAN 19085 & $11: 15$ & 136 & 0.0 & 480 & $\underset{S E P}{12} \ldots$ & $14: 05$ & 127 & 26.0 & 500 \\
\hline $28 \ldots$ & $12: 10$ & 206 & 0.0 & 540 & $17 \ldots$ & $10: 35$ & 91 & 20.0 & 510 \\
\hline & $13: 30$ & 330 & 6.0 & 400 & & & & & \\
\hline
\end{tabular}




\begin{tabular}{|c|c|c|c|c|c|c|c|c|c|}
\hline DATE & TIHE & $\begin{array}{c}\text { STREAM- } \\
\text { FLOW, } \\
\text { INSTAN- } \\
\text { TANEOUS } \\
\text { (CFS) }\end{array}$ & $\begin{array}{c}\text { TEMPER- } \\
\text { ATURE } \\
\text { (DEG C) }\end{array}$ & $\begin{array}{l}\text { SPE- } \\
\text { CIFIC } \\
\text { CON- } \\
\text { DUCT- } \\
\text { ANCE } \\
\text { (US/CM) }\end{array}$ & DATE & TIME & $\begin{array}{l}\text { STREAM- } \\
\text { FLOW, } \\
\text { INSTAN- } \\
\text { TANEOOS } \\
\text { (CES) }\end{array}$ & $\begin{array}{l}\text { TEMPER- } \\
\text { ATURE } \\
\text { (DEG C) }\end{array}$ & $\begin{array}{l}\text { SPE- } \\
\text { CIFIC } \\
\text { CON- } \\
\text { DUCT- } \\
\text { ANCE } \\
\text { (US/CM) }\end{array}$ \\
\hline
\end{tabular}

06810000 NISHNABOTNA RIVER ABOVE HAMBURG, IOWA (LAT 4037 57N LONG $0953732 \mathrm{~W}$ )

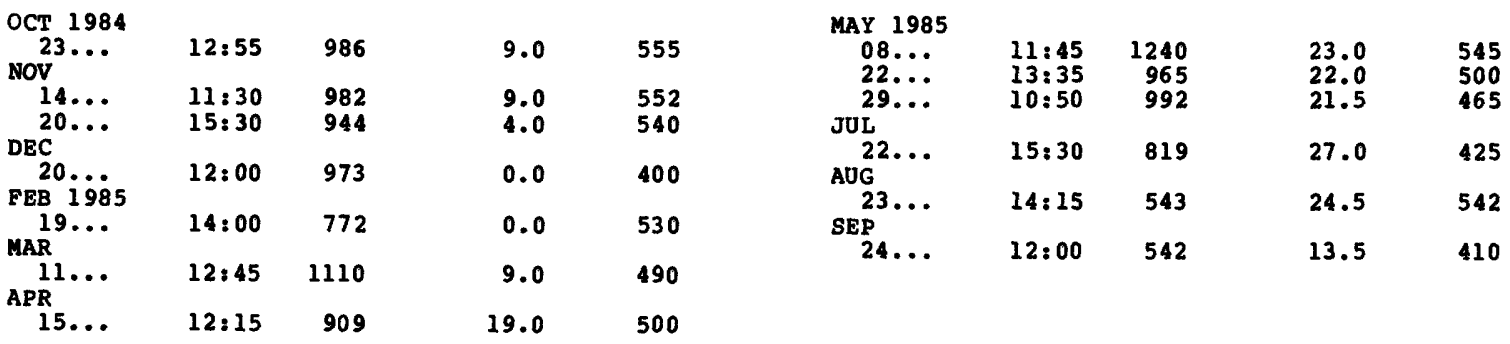

06811840 TARKIO RIVER AT STANTON, IOWA (LAT 4058 52N LONG $0950632 W$ )

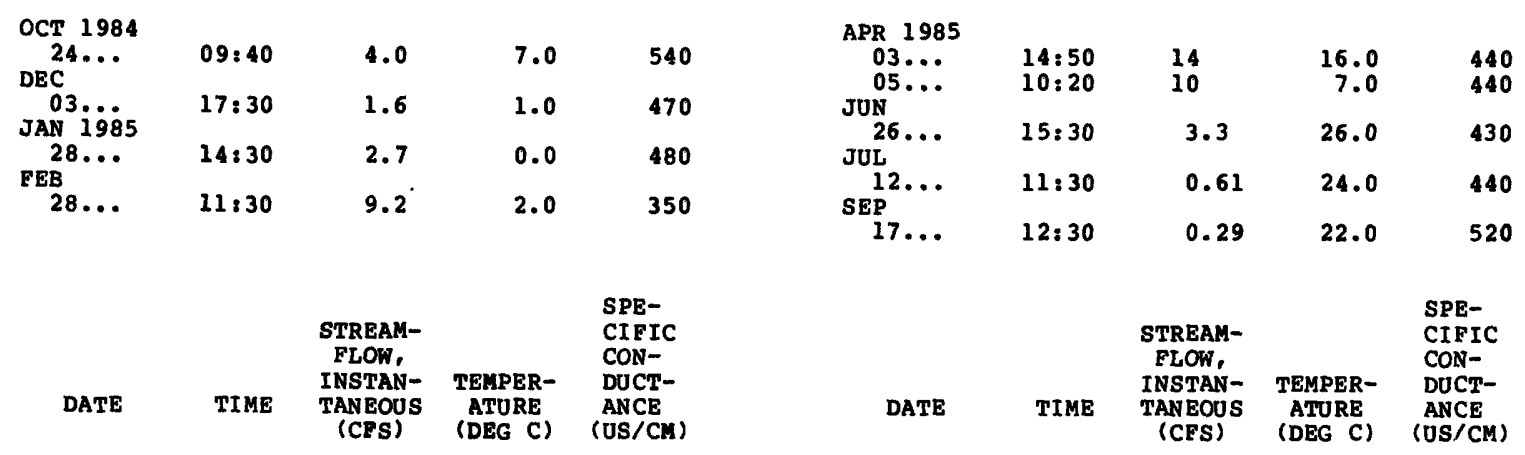

06813500 MISSOURI RIVER AT RULO, NEBRASKA (LAT 4003 14N LONG 095 25 $12 \%$ )

\begin{tabular}{|c|c|c|}
\hline 1 & & \\
\hline $\begin{array}{l}05 \ldots \\
10 \ldots \\
18 \ldots \\
23 \ldots \\
31 \ldots\end{array}$ & $\begin{array}{l}13: 45 \\
11: 45 \\
13: 30 \\
11: 10 \\
14: 45\end{array}$ & $\begin{array}{l}51400 \\
58000 \\
65800 \\
66800 \\
66700\end{array}$ \\
\hline nov & & \\
\hline 08 & $\begin{array}{l}12: 35 \\
14: 30\end{array}$ & $\begin{array}{l}61300 \\
61200\end{array}$ \\
\hline DEC & $14: 25$ & 640 \\
\hline FEB 11985 & $14: 30$ & 41100 \\
\hline $\begin{array}{l}19 . \\
25 .\end{array}$ & $\begin{array}{l}11: 45 \\
11: 45\end{array}$ & $\begin{array}{l}32000 \\
40600\end{array}$ \\
\hline MAR & & \\
\hline $27 \ldots$ & $\begin{array}{l}13: 50 \\
11: 45 \\
11: 30 \\
10: 50\end{array}$ & $\begin{array}{l}50600 \\
43600 \\
45000 \\
47200\end{array}$ \\
\hline APR & & \\
\hline 02 . & $\begin{array}{l}13: 40 \\
12: 25 \\
13: 20 \\
10: 45\end{array}$ & $\begin{array}{l}46900 \\
49000 \\
44300 \\
65900\end{array}$ \\
\hline
\end{tabular}

06817000

NOV 1984

$07 \ldots \ldots 90105$

DEC $19 . .985$

$\begin{array}{ccc}\text { JAN } 1985 & 11: 55 & 94 \\ 30 \ldots & 10: 00 & 86\end{array}$

$\begin{array}{lll}\text { FEB } & \\ 22 \ldots & 14: 30 \quad 2390\end{array}$

MAR $14 \ldots \quad 09: 25 \quad 245$

18... $09: 30 \quad 130$

$\begin{array}{rr}15.0 & 800 \\ 17.0 & 720 \\ 15.0 & 760 \\ 10.5 & 800 \\ - & 725 \\ 9.0 & 840 \\ 0.0 & 900 \\ 6.0 & 760 \\ 3.0 & 880 \\ 2.5 & 845 \\ 2.5 & 700 \\ 4.0 & 615 \\ 6.0 & 600 \\ 8.0 & 700 \\ 11.0 & 700 \\ 8.0 & 690 \\ 8.0 & 675 \\ 15.0 & 780 \\ 18.0 & 700\end{array}$

$\begin{array}{ccccc}\text { MAY } 1985 & & & & \\ 02 \ldots & 12: 00 & 59900 & 16.0 & 650 \\ 09 \ldots & 10: 50 & 48500 & 20.0 & 695 \\ 14 \ldots & 12: 15 & 54000 & 20.0 & 720 \\ 21 \ldots & 13: 30 & 62300 & 19.5 & 720 \\ \text { JUN } & & & & \\ 03 \ldots & 12: 50 & 48300 & 20.5 & 750 \\ 10 \ldots & 16: 15 & 47000 & 23.0 & 755 \\ 18 \ldots & 10: 30 & 41100 & 23.0 & 690 \\ 26 \ldots & 11: 30 & 44900 & 26.0 & 700 \\ \text { JUL } \ldots & & & \\ 01 \ldots & 11: 45 & 49000 & 25.0 & 735 \\ 09 \ldots & 11: 45 & 38200 & 28.0 & 750 \\ 17 \ldots . & 11: 30 & 37500 & 28.5 & 760 \\ 29 \ldots & 12: 05 & 41000 & 26.0 & 750 \\ 30 \ldots & 11: 15 & 37600 & 27.0 & 780 \\ \text { AUG } \ldots & & & & \\ 07 \ldots . & 12: 15 & 42700 & 26.0 & 705 \\ 13 \ldots & 10: 45 & 39200 & 25.5 & 740 \\ 19 \ldots & 10: 45 & 41600 & 23.0 & 700 \\ 27 \ldots & 11: 45 & 34700 & 24.0 & 750 \\ \text { SEP } \ldots & & & & \\ 05 \ldots . & 11: 35 & 38700 & 27.0 & 640 \\ 10 \ldots & 13: 10 & 38000 & 25.5 & 700 \\ 17 \ldots & 10: 15 & 44600 & 20.0 & 720 \\ 24 \ldots & 12: 00 & 45300 & 17.5 & 750\end{array}$

NODAWAY RIVER AT CLARINDA, IOWA (LAT 4044 19N LONG 09500 47w)

$\begin{array}{rr}10.0 & 410 \\ 0.0 & 355 \\ 0.0 & 405 \\ 1.0 & 209 \\ 4.0 & 400 \\ 18.0 & 400\end{array}$

MAY 1985

$\begin{array}{lrrrr}29 \ldots . & 10: 55 & 82 & 20.0 & 380 \\ \text { JUL } & & & & \\ 24 \ldots & 09: 00 & 57 & 24.5 & 360 \\ \begin{array}{c}\text { AUG } \\ \text { O6... }\end{array} & 13: 15 & 1290 & 27.0 & 182 \\ \underset{13}{13} \ldots & 14: 55 & 48 & 28.0 & 395 \\ \begin{array}{c}\text { SEP } \\ 19 \ldots\end{array} & 10: 45 & 21 & 24.0 & 350\end{array}$




\begin{tabular}{|c|c|c|c|c|c|c|c|c|c|}
\hline ATE & TIME & $\begin{array}{c}\text { STREAY- } \\
\text { ELON, } \\
\text { INSTAN- } \\
\text { TANEOUS } \\
\text { (CES) }\end{array}$ & $\begin{array}{c}\text { TEMPER- } \\
\text { ATURE } \\
\text { (DBG C) }\end{array}$ & $\begin{array}{l}\text { SPE- } \\
\text { CIFIC } \\
\text { CON- } \\
\text { DUCT- } \\
\text { ANCE } \\
\text { (US/CH) }\end{array}$ & DATE & TIME & $\begin{array}{c}\text { STREAN- } \\
\text { ELON, } \\
\text { INSTAN- } \\
\text { TANBOUS } \\
\text { (CES) }\end{array}$ & $\begin{array}{l}\text { TRMPER- } \\
\text { ATURE } \\
\text { (DEG C) }\end{array}$ & $\begin{array}{l}\text { SPE- } \\
\text { CIFIC } \\
\text { CON- } \\
\text { DUCT- } \\
\text { ANCE } \\
\text { (US/CH) }\end{array}$ \\
\hline
\end{tabular}

06818750 PLATTE RIVER NEAR DIAGONAL, IOWA (LAT 4046 O2N LONG 09424 46W)

\begin{tabular}{|c|c|c|c|c|c|c|c|c|c|}
\hline $\begin{array}{c}\text { Nov } 1984 \\
06 \ldots\end{array}$ & $13: 00$ & 3.3 & 10.0 & 410 & 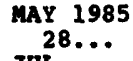 & $12: 45$ & 7.1 & 24.5 & 470 \\
\hline JAN 19885 & $13: 40$ & 19 & -- & 325 & $\begin{array}{c}23 \\
A U G\end{array}$ & $10: 50$ & 5.4 & 24.0 & 420 \\
\hline MAR 29 & $10: 30$ & 3.8 & 0.0 & 640 & $\operatorname{sep}^{14} \ldots$ & $12: 05$ & 7.0 & 22.0 & 360 \\
\hline${ }_{A P R}^{13} \cdots$ & $13: 30$ & 34 & 5.0 & 375 & $18 \ldots$ & $13: 30$ & 2.2 & 25.0 & 530 \\
\hline 17 & $12: 00$ & 14 & 21.0 & 100 & & & & & \\
\hline
\end{tabular}

06819185

EAST EORK 102 RIVER AT BEDFORD, IOWA (LAT 4039 10N LONG 09442 58W)

\begin{tabular}{|c|c|c|c|c|c|c|c|c|c|}
\hline \multirow[t]{5}{*}{1984} & $15: 50$ & 1.5 & 10.0 & 495 & \multirow{5}{*}{$\begin{array}{c}\text { MAY } 1985 \\
28 \ldots \\
\text { JUL } \\
28 \ldots \\
\text { AUG } \\
14 \ldots \\
\begin{array}{l}148 \\
18 \ldots\end{array} \\
18 . \ldots\end{array}$} & $16: 35$ & 1.0 & 27.0 & 455 \\
\hline & $16: 55$ & 1.1 & - & 170 & & $14: 00$ & 1.6 & 31.0 & 460 \\
\hline & $13: 00$ & 0.62 & 0.0 & 625 & & $09: 50$ & 74 & 27.0 & 205 \\
\hline & $16: 35$ & 6.1 & 7.0 & 415 & & $16: 25$ & 0.65 & 25.0 & 365 \\
\hline & $16: 15$ & 2.0 & 20.0 & 485 & & & & & \\
\hline
\end{tabular}

06897950 ELK CREEK NEAR DECATUR CITY, IOWA (LAT 4043 18N LONG 09356 19W)

\begin{tabular}{|c|c|c|c|c|c|c|c|c|c|}
\hline $\begin{array}{c}\text { OCT } 1984 \\
17 \ldots \\
\text { nOV }^{-\cdots}\end{array}$ & $09: 45$ & 1.3 & 8.0 & 310 & $\begin{array}{l}\text { APR } 1985 \\
02 \ldots\end{array}$ & $15: 45$ & 20 & 16.0 & 400 \\
\hline 27 J̈̈85 & $14: 30$ & 1.3 & 6.0 & 492 & $14 \ldots$ & $15: 15$ & 2.6 & 21.0 & 489 \\
\hline $10 \ldots$ & $09: 30$ & 0.93 & 0.0 & 681 & $26 \ldots$ & $09: 30$ & 1.0 & 24.5 & 389 \\
\hline $21 \ldots$ & $09: 45$ & 522 & 0.0 & 170 & & & & & \\
\hline
\end{tabular}

06898000 THOMPSON RIVER AT DAVIS CITY, IOWA (LAT 4038 25N LONG 09348 29W)

\begin{tabular}{|c|c|c|c|c|c|c|c|c|c|}
\hline OCT 1984 & $14: 45$ & 49 & 12.0 & 378 & $\begin{array}{c}\text { MAY } 1985 \\
14 \ldots\end{array}$ & $12: 15$ & 54 & 18.0 & 480 \\
\hline 27 ํㅕㄴ & $12: 00$ & 24 & 5.0 & 482 & $25 \ldots$ & $16: 00$ & 474 & 24.0 & 209 \\
\hline PEB & $16: 00$ & 15 & 0.0 & 482 & SEP & $17: 00$ & 21 & 24.0 & 336 \\
\hline $20 \ldots$ & $16: 45$ & 101 & 0.0 & 375 & $17 \ldots$ & $14: 30$ & 4.5 & 23.0 & 500 \\
\hline & $13: 15$ & 216 & 8.5 & 398 & & & & & \\
\hline
\end{tabular}

06898400 WELDON RIVER NEAR LEON, IOWA (LAT 4041 45N LONG 09338 07W)

\begin{tabular}{|c|c|c|c|c|c|c|c|c|c|}
\hline \multirow{5}{*}{ 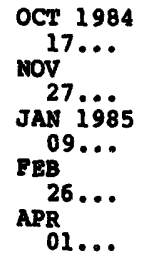 } & $15: 30$ & 5.7 & 14.0 & 371 & \multirow{5}{*}{$\begin{array}{c}\text { MAY } 1985 \\
14 \ldots \\
\text { JUR } \\
25 \ldots \\
\text { AUG } \\
06 \ldots \\
\text { SEP } \\
17 \ldots\end{array}$} & $10: 15$ & 6.5 & 18.0 & 473 \\
\hline & $10: 05$ & 1.5 & 5.0 & 433 & & $13: 30$ & 15 & 29.0 & 268 \\
\hline & $13: 45$ & 4.0 & 0.0 & 649 & & $13: 00$ & 0.98 & 25.0 & 381 \\
\hline & $12: 45$ & 33 & 0.0 & 340 & & $13: 15$ & 0.33 & 24.0 & 462 \\
\hline & $11: 30$ & 21 & 8.5 & 450 & & & & & \\
\hline
\end{tabular}

06903400

CHARITON RIVER NEAR CBARITON, IOWA (LAT 4057 12N LONG 093 15 37w)

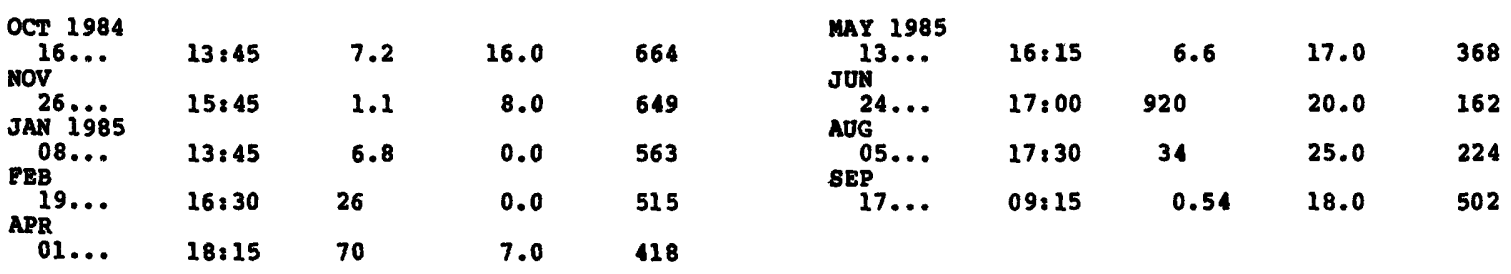




\begin{tabular}{|c|c|c|c|c|c|c|c|c|c|}
\hline ATE & TIME & $\begin{array}{l}\text { STREAM- } \\
\text { ELOW, } \\
\text { INSTAN- } \\
\text { TANEOUS } \\
\text { (CFS) }\end{array}$ & $\begin{array}{l}\text { TEMPER- } \\
\text { ATURE } \\
\text { (DEG C) }\end{array}$ & $\begin{array}{l}\text { SPE- } \\
\text { CIFIC } \\
\text { CON- } \\
\text { DUCT- } \\
\text { ANCE } \\
\text { (US/CM) }\end{array}$ & DATE & TIME & $\begin{array}{l}\text { STREAM- } \\
\text { FLOW, } \\
\text { INSTAN- } \\
\text { TANEOUS } \\
\text { (CFS) }\end{array}$ & $\begin{array}{l}\text { TEMPER- } \\
\text { ATURE } \\
\text { (DEG C) }\end{array}$ & $\begin{array}{l}\text { SPE- } \\
\text { CIFIC } \\
\text { CON- } \\
\text { DUCT- } \\
\text { ANCE } \\
\text { (US/CM) }\end{array}$ \\
\hline
\end{tabular}

06903700 OCT 1984 $16 \ldots$

$28 \ldots$

JAN 1985 09. .

FEB

$20 \ldots$

$03 \ldots \quad 10: 15 \quad 38$

06903900

NOV 1984

28 .

$10 \ldots \quad 15: 15 \quad 373$

$21 \ldots 18: 45 \quad 18$

$\begin{array}{lll}\text { APR } & \\ 03 \ldots & 13: 00 & 172\end{array}$

06904010

OCT 1984

18 ...

$28 \ldots \quad 14: 00 \quad 460$

APR 1985

$03 \ldots$

$15: 45 \quad 244$

$15 \ldots .64$

$\begin{array}{rrr}4.0 & 14.0 & 412 \\ 3.0 & 2.5 & 511 \\ 20 & 0.0 & 533 \\ 39 & 0.0 & 447 \\ 38 & 9.5 & 439\end{array}$

CHARITON RIVER NEAR RATHBUN, IOWA (LAT 4049 22N LONG 09253 22W)

$\begin{array}{rr}6.5 & 266 \\ 1.0 & 234 \\ 4.0 & 366 \\ 10.0 & 258\end{array}$

MAY 1985

$15 \ldots$ 15:30

9.0

18.0

259

$26 \ldots 16: 45$

8.0

24.5

276

AUG $07 \ldots \quad 16: 30 \quad 559$

$25.0 \quad 272$

$18 \ldots 14: 15 \quad 14$

19.0

290

CHARITON R NR MOULTON, IOWA (LAT $404130 N$ LONG 09246 15W)

$\begin{array}{rr}15.0 & 256 \\ 6.0 & 337 \\ 11.0 & 339 \\ 18.0 & 447\end{array}$

$\begin{array}{lrrrr}\text { JUN } 1985 & & & \\ 25 \ldots & 14: 45 & 70 & 27.0 & 288 \\ \text { AUG } & 14: 00 & 615 & 25.0 & 282 \\ \text { SEP } \ldots & 14: 0 & 28.0 & 327\end{array}$


420319N091540102. Local number, 84-9-28 DBCC2.

LOCATION.--Lat $42^{\circ} 03^{\prime} 19^{\prime \prime}$, long $91^{\circ} 54^{\prime} 01^{\prime \prime}$, Hydrologic Unit 07080205 , approximately $3 \mathrm{mi}$ south and $1.5 \mathrm{mi}$ west of the Town of Shellsburg. Owner: Iowa Geological Survey and U.S. Geological Survey.

AQUIFER.--Silurian-Devonian: in limestone of Devonian age and dolomite of Silurian age.

WELL CHARACrERISTICS.--Drilled observation artersian water well, diameter 6 in. to 171.7 ft, 4 in. to $260 \mathrm{ft}$, depth $590 \mathrm{ft}$, cased to $260 \mathrm{ft}$, open hole 265 to $590 \mathrm{ft}$.

INSTRUMENTATION.--Quarterly measurement with chalked tape by USGS personnel.

DATUM.--Elevation of land-surface is $915 \mathrm{ft}$ above National Geodetic Vertical Datum of 1929 , from topographic map. Measuring point: Top of 4 in. casing, $1.10 \mathrm{ft}$ above land-surface datum.

REMARKS.--Parker's Grove cemetary well. Cement plug 260 to $265 \mathrm{ft}$. $59.7 \mathrm{ft}$ of open Devonian rock rock reported to yield little, if any, water.

PERIOD OF RBCORD.--April 1975 to current year.

EXTREMES FOR PERIOD OF RECORD.--Highest water level measured, 150.73 ft below land-surface datum, Apr

14, 1975; lowest measured, 166.92 ft below land-surfae datum, Aug. 9, 1977.

WATER LEVEL, IN FEET BELOW LAND-SUREACE DATUM, WATER YEAR OCTOBER 1974 TO SEPTEMBER 1975

$\begin{array}{lllll}\text { DATE } & \begin{array}{l}\text { WATER } \\ \text { LEVEL }\end{array} & \text { DATE } & \begin{array}{l}\text { WATER } \\ \text { LEVEL }\end{array} \\ \text { APR } & 14 & 150.73 & \text { JON } 24 & 158.30\end{array}$

WATER LEVEL, IN FEET BELOW LAND-SURFACE DATUM, WATER YEAR OCTOBER 1975 TO SEPTEMBER 1976

$\begin{array}{llllllll}\text { DATE } & \begin{array}{l}\text { WATER } \\ \text { LEVEL }\end{array} & \text { DATE } & \begin{array}{l}\text { WATER } \\ \text { LEVEL }\end{array} & \text { DATE } & \begin{array}{l}\text { WATER } \\ \text { LEVEL }\end{array} \\ \text { OCT } 2 & 160.78 & \text { MAR } 30 & 160.00 & \text { JUL } 12 & 154.00\end{array}$

WATER LEVEL, IN FEET BELOW LAND-SURFACE DATUM, WATER YEAR OCTOBER 1976 TO SEPTEMBER 1977

\begin{tabular}{|c|c|c|c|c|c|c|c|c|c|c|c|}
\hline DATE & & $\begin{array}{l}\text { WATER } \\
\text { LEVEL }\end{array}$ & DATE & & $\begin{array}{l}\text { WATER } \\
\text { LEVEL }\end{array}$ & DATE & & $\begin{array}{l}\text { WATER } \\
\text { LEVEL }\end{array}$ & DATE & & $\begin{array}{l}\text { WATER } \\
\text { LEVEL }\end{array}$ \\
\hline $\begin{array}{l}\text { FEB } \\
\text { JUN }\end{array}$ & $\begin{array}{r}11 \\
9\end{array}$ & $\begin{array}{l}166.41 \\
166.01\end{array}$ & JUN & 21 & 166.59 & JUL & 6 & 166.48 & AUG & 9 & 166.92 \\
\hline
\end{tabular}

WATER LEVEL, IN FEET BELOW LAND-SURFACE DATUM, WATER YEAR OCTOBER 1977 TO SEPTEMBER 1978

\begin{tabular}{|c|c|c|c|c|c|c|c|c|c|c|c|}
\hline \multicolumn{2}{|c|}{ DATE } & $\begin{array}{l}\text { WATER } \\
\text { LEVEL }\end{array}$ & \multicolumn{2}{|c|}{ DATE } & $\begin{array}{l}\text { WATER } \\
\text { LEVEL }\end{array}$ & \multicolumn{2}{|c|}{ DATE } & $\begin{array}{l}\text { WATER } \\
\text { LEVEL }\end{array}$ & \multicolumn{2}{|c|}{ DATE } & $\begin{array}{l}\text { WATER } \\
\text { LEVEL }\end{array}$ \\
\hline $\begin{array}{l}\text { OCT } \\
\text { NOV } \\
\text { DEC }\end{array}$ & $\begin{array}{r}21 \\
4 \\
16\end{array}$ & $\begin{array}{l}161.60 \\
160.27 \\
158.96\end{array}$ & $\begin{array}{l}\text { JAN } \\
\text { HAR } \\
\text { MAY }\end{array}$ & $\begin{array}{r}11 \\
22 \\
2\end{array}$ & $\begin{array}{l}160.20 \\
160.57 \\
158.33\end{array}$ & $\begin{array}{l}\text { MAY } \\
\text { JUL } \\
\text { AUG }\end{array}$ & $\begin{array}{l}30 \\
18 \\
17\end{array}$ & $\begin{array}{l}157.44 \\
158.01 \\
158.24\end{array}$ & SEP & 12 & 158.83 \\
\hline
\end{tabular}

WATER LEVEL, IN FEET BELOW LAND-SURFACE DATUM, WATER YEAR OCTOBER 1978 TO SEPTEMBER 1979

\begin{tabular}{|c|c|c|c|c|c|c|c|c|c|c|c|}
\hline \multicolumn{2}{|l|}{ DATE } & $\begin{array}{l}\text { WATER } \\
\text { LEVEL }\end{array}$ & \multicolumn{2}{|c|}{ DATE } & $\begin{array}{l}\text { WATER } \\
\text { LEVEL }\end{array}$ & \multicolumn{2}{|c|}{ DATE } & $\begin{array}{l}\text { WATER } \\
\text { LEVEL }\end{array}$ & \multicolumn{2}{|c|}{ DATE } & $\begin{array}{l}\text { WATER } \\
\text { LEVEL }\end{array}$ \\
\hline $\begin{array}{l}\text { OCT } \\
\text { NOV } \\
\text { DEC }\end{array}$ & $\begin{array}{r}11 \\
9 \\
7\end{array}$ & $\begin{array}{l}158.88 \\
159.27 \\
157.41\end{array}$ & $\begin{array}{l}\text { MAR } \\
\text { APR } \\
\text { MAY }\end{array}$ & $\begin{array}{r}13 \\
3 \\
9\end{array}$ & $\begin{array}{l}157.90 \\
158.39 \\
156.45\end{array}$ & $\begin{array}{l}\text { JUN } \\
\text { JUL } \\
\text { AUG }\end{array}$ & $\begin{array}{l}5 \\
9 \\
8\end{array}$ & $\begin{array}{l}156.48 \\
157.57 \\
158.43\end{array}$ & SEP & 13 & 157.98 \\
\hline
\end{tabular}

WATER LEVEL, IN FEET BELOW LAND-SURFACE DATUM, WATER YEAR OCTOBER 1979 TO SEPTEMBER 1980

\begin{tabular}{|c|c|c|c|c|c|c|c|c|c|c|c|}
\hline DATE & & $\begin{array}{l}\text { WATER } \\
\text { LEVEL }\end{array}$ & DATE & & $\begin{array}{l}\text { WATER } \\
\text { LEVEL }\end{array}$ & DAT & & $\begin{array}{l}\text { WATER } \\
\text { LEVEL }\end{array}$ & DATE & & $\begin{array}{l}\text { WATER } \\
\text { LEVEL }\end{array}$ \\
\hline $\begin{array}{l}\text { OCT } \\
\text { NOV } \\
\text { DEC }\end{array}$ & $\begin{array}{r}10 \\
6 \\
7\end{array}$ & $\begin{array}{l}158.16 \\
159.25 \\
159.33\end{array}$ & $\begin{array}{l}\text { JAN } \\
\text { FEB }\end{array}$ & $\begin{array}{l}8 \\
4\end{array}$ & $\begin{array}{l}160.92 \\
161.24\end{array}$ & $\begin{array}{l}\text { MAR } \\
\text { MAY }\end{array}$ & $\begin{array}{r}5 \\
21\end{array}$ & $\begin{array}{l}160.24 \\
161.23\end{array}$ & $\begin{array}{l}\text { JUL } \\
\text { SEP }\end{array}$ & $\begin{array}{l}18 \\
17\end{array}$ & $\begin{array}{l}162.59 \\
163.18\end{array}$ \\
\hline
\end{tabular}

WATER LEVEL, IN FEET BELOW LAND-SURFACE DATUM, WATER YEAR OCTOBER 1980 TO SEPTEMBER 1981

\begin{tabular}{|c|c|c|c|c|c|c|c|c|c|c|}
\hline DATE & & $\begin{array}{l}\text { WATER } \\
\text { LEVEL }\end{array}$ & DATE & & $\begin{array}{l}\text { WATER } \\
\text { LEVEL }\end{array}$ & DATE & $\begin{array}{l}\text { WATER } \\
\text { LEVEL }\end{array}$ & DATE & & $\begin{array}{l}\text { WATER } \\
\text { LEVEL }\end{array}$ \\
\hline NOV & 18 & 164.24 & FEB & 3 & 164.67 & MAR 18 & 164.15 & SEP & 8 & 164.56 \\
\hline
\end{tabular}

WATER LEVEL, IN FEET BELOW LAND-SURFACE DATUM, WATER YEAR OCTOBER 1981 TO SEPTEMBER 1982

$\begin{array}{lll}\text { DATE } & \begin{array}{l}\text { WATER } \\ \text { LEVEL }\end{array} \\ \text { SEP } \quad 27 & 159.98\end{array}$

WATER LEVEL, IN FEET BELOW LAND-SURFACE DATUM, WATER YEAR OCTOBER 1982 TO SEPTEMBER 1983

$\begin{array}{lllll}\text { DATE } & \begin{array}{l}\text { WATER } \\ \text { LEVEL }\end{array} & \text { DATE } & \begin{array}{l}\text { WATER } \\ \text { LEVEL }\end{array} \\ \text { MAR } 17 & 156.94 & \text { AUG } 24 & 158.71\end{array}$

WATER LEVEL, IN FEET BELOW LAND-SURFACE DATUM, WATER YEAR OCTOBER 1983 TO SEPTEMBER 1984

\begin{tabular}{|c|c|c|c|c|c|c|c|c|c|}
\hline DATE & & $\begin{array}{l}\text { WATER } \\
\text { LEVEL }\end{array}$ & DATE & $\begin{array}{l}\text { WATER } \\
\text { LEVEL }\end{array}$ & DATE & & $\begin{array}{l}\text { WATER } \\
\text { LEVEL }\end{array}$ & DATE & $\begin{array}{l}\text { WATER } \\
\text { LEVEL }\end{array}$ \\
\hline OCT & 5 & 159.58 & APR 17 & 159.02 & AUG & 7 & 156.62 & SEP 11 & 157.85 \\
\hline
\end{tabular}




\section{BENTON COUNTY}

420319N091540102. Local number, 84-9-28 DBCC2.--continued.

WATER LEVEL, IN FEET BELOW LAND-SURFACE DATUM, WATER YEAR OCTOBER 1984 TO SEPTEMBER 1985

\begin{tabular}{|c|c|c|c|c|c|c|c|c|c|c|}
\hline DATE & $\begin{array}{l}\text { WATER } \\
\text { LEVEL }\end{array}$ & DATE & & $\begin{array}{l}\text { WATER } \\
\text { LEVEL }\end{array}$ & DATE & & $\begin{array}{l}\text { WATER } \\
\text { LEVEL }\end{array}$ & DATE & & $\begin{array}{l}\text { WATER } \\
\text { LEVEL }\end{array}$ \\
\hline v & 158.91 & MAR & 5 & 159.32 & MAY & 2 & 157.68 & AUG & 21 & 161.03 \\
\hline
\end{tabular}

420731 N092083801. Local number, 85-11-33 CCBC1.

LOCATION.--Lat 42.07'31", long $92^{\circ} 08^{\prime} 38^{\prime \prime}$, Hydrologic Unit 07080205, approximately $1 \mathrm{mi}$ south of the of Garrison, just east of County Road V-56. Owner: Iowa Geological survey and U.s. Geological Survey.

AQUIFER.--Cedar Valley: in limestone of Devonian age.

WELL CBARACTERISTICS. --Drilled observation artesian water we11, diameter $0.75 \mathrm{in.}$, depth $237 \mathrm{ft}$, cased $170 \mathrm{ft}$, slotted below cement plug, open hole 170 to $237 \mathrm{ft}$.

INSTRUMENTATION. --Quarterly measurement with chalked tape by USGS personnel.

DATUM.--Elevation of land-surface datum is $912 \mathrm{ft}$ above National Geodetic Vertical Datum of 1929, from topographic map. Measuring point: Top of 6 in. casing, $2.20 \mathrm{ft}$ above 1 and-surface datum.

REMARRs.--Garrison 170 well. $3 \mathrm{ft}$ cement plugs from 97 to $100 \mathrm{ft}$ and 237 to $240 \mathrm{ft}$.

PERIOD OF RECORD.--June 1977 to current year.

EXTREMES FOR PERIOD OF RECORD.--Highest water level measured, $60.18 \mathrm{ft}$ below land-surface datum, Apr. 19, 1983; lowest measured, $64.80 \mathrm{ft}$ below land-surface datum, Jan. 29, 1977.

WATER LEVEL, IN FEET BELOW LAND-SURFACE DATUM, WATER YEAR OCTOBER 1976 TO SEPTEMBER 1977

$\begin{array}{lllll}\text { DATE } & \begin{array}{c}\text { WATER } \\ \text { LEVEL }\end{array} & \text { DATE } & & \begin{array}{c}\text { WATER } \\ \text { LEVEL }\end{array} \\ \text { JUN } 29 & 64.80 & \text { AUG } & 9 & 63.53\end{array}$

WATER LEVEL, IN FEET BELOW LAND-SURFACE DATUM, WATER YEAR OCTOBER 1977 TO SETEMBER 1978

\begin{tabular}{|c|c|c|c|c|c|c|c|c|c|c|}
\hline DATE & $\begin{array}{l}\text { WATER } \\
\text { LEVEL }\end{array}$ & DATE & & $\begin{array}{l}\text { WATER } \\
\text { LEVEL }\end{array}$ & DATE & & $\begin{array}{l}\text { WATER } \\
\text { LEVEL }\end{array}$ & DATE & & $\begin{array}{l}\text { WATER } \\
\text { LEVEL }\end{array}$ \\
\hline $\begin{array}{lr}\text { NOV } & 4 \\
\text { JAN } & 21\end{array}$ & $\begin{array}{l}61.55 \\
62.48\end{array}$ & $\begin{array}{l}\text { MAR } \\
\text { MAY }\end{array}$ & $\begin{array}{r}24 \\
2\end{array}$ & $\begin{array}{l}61.68 \\
61.72\end{array}$ & $\begin{array}{l}\text { MAY } \\
\text { JUL }\end{array}$ & $\begin{array}{l}30 \\
18\end{array}$ & $\begin{array}{l}62.20 \\
61.76\end{array}$ & $\begin{array}{l}\text { AUG } \\
\text { SEP }\end{array}$ & $\begin{array}{l}22 \\
14\end{array}$ & $\begin{array}{l}63.08 \\
62.90\end{array}$ \\
\hline
\end{tabular}

WATER LEVEL, IN FEET BELOW LAND-SURFACE DATUM, WATER YEAR OCTOBER 1978 TO SEPTEMBER 1979

\begin{tabular}{|c|c|c|c|c|c|c|c|c|c|c|c|}
\hline DATE & & $\begin{array}{l}\text { WATER } \\
\text { LEVEL }\end{array}$ & DATE & & $\begin{array}{l}\text { WATER } \\
\text { LEVEL }\end{array}$ & DATE & & $\begin{array}{l}\text { WATER } \\
\text { LEVEL }\end{array}$ & DATE & & $\begin{array}{l}\text { WATER } \\
\text { LEVEL }\end{array}$ \\
\hline $\begin{array}{l}\text { OCT } \\
\text { NOV } \\
\text { DEC }\end{array}$ & $\begin{array}{r}12 \\
9 \\
7\end{array}$ & $\begin{array}{l}62.36 \\
63.03 \\
62.44\end{array}$ & $\begin{array}{l}\text { MAR } \\
\text { APR } \\
\text { MAY }\end{array}$ & $\begin{array}{r}23 \\
3 \\
8\end{array}$ & $\begin{array}{l}60.56 \\
60.84 \\
61.44\end{array}$ & $\begin{array}{l}\text { JUN } \\
\text { JUL } \\
\text { AUG }\end{array}$ & $\begin{array}{l}5 \\
9 \\
8\end{array}$ & $\begin{array}{l}62.12 \\
62.47 \\
62.81\end{array}$ & SEP & 13 & 62.59 \\
\hline
\end{tabular}

WATER LEVEL, IN FEET BELOW LAND-SURFACE DATUM, WATER YEAR OCTOBER 1979 TO SEPTEMBER 1980

\begin{tabular}{|c|c|c|c|c|c|c|c|c|c|c|c|}
\hline DATE & & $\begin{array}{l}\text { WATER } \\
\text { LEVEL }\end{array}$ & DATE & & $\begin{array}{l}\text { WATER } \\
\text { LEVEL }\end{array}$ & DATE & & $\begin{array}{l}\text { WATER } \\
\text { LEVEL }\end{array}$ & DATE & & $\begin{array}{l}\text { WATER } \\
\text { LEVEL }\end{array}$ \\
\hline $\begin{array}{l}\text { OCT } \\
\text { NOV } \\
\text { DEC }\end{array}$ & $\begin{array}{r}10 \\
5 \\
7\end{array}$ & $\begin{array}{l}62.78 \\
63.03 \\
62.85\end{array}$ & $\begin{array}{l}\text { JAN } \\
\text { FEB }\end{array}$ & $\begin{array}{l}8 \\
4\end{array}$ & $\begin{array}{l}63.02 \\
62.78\end{array}$ & $\begin{array}{l}\text { MAR } \\
\text { MAY }\end{array}$ & $\begin{array}{r}5 \\
21\end{array}$ & $\begin{array}{l}63.44 \\
62.41\end{array}$ & $\begin{array}{l}\text { JUL } \\
\text { SEP }\end{array}$ & $\begin{array}{l}18 \\
17\end{array}$ & $\begin{array}{l}63.41 \\
63.06\end{array}$ \\
\hline
\end{tabular}

WATER LEVEL, IN FEET BELOW LAND-SURFACE DATUM, WATER YEAR OCTOBER 1980 TO SEPTEMBER 1981

$\begin{array}{lllllll}\text { DATE } & \begin{array}{l}\text { WATER } \\ \text { LEVEL }\end{array} & \text { DATE } & & \begin{array}{l}\text { WATER } \\ \text { LEVEL }\end{array} & \text { DATE } & \text { WATER } \\ & & & & & \text { LEVEL } \\ \text { NOV } 18 & 63.22 & \text { FEB } & 3 & 63.39 & \text { MAR } 18 & 63.41\end{array}$

WATER LEVEL, IN FEET BELOW LAND-SURFACE DATUM, WATER YEAR OCTOBER 1982 TO SEPTEMBER 1983

$\begin{array}{lllllll}\text { DATE } & \begin{array}{l}\text { WATER } \\ \text { LEVEL }\end{array} & \text { DATE } & \begin{array}{l}\text { WATER } \\ \text { LEVEL }\end{array} & \text { DATE } & \text { WATER } \\ \text { LEVEL }\end{array}$

WATER LEVEL, IN FEET BELOW LAND-SURFACE DATUM, WATER YEAR OCTOBER 1983 TO SEPTEMBER 1984

$\begin{array}{lllllllll}\text { DATE } & \begin{array}{l}\text { WATER } \\ \text { LEVEL }\end{array} & \text { DATE } & \begin{array}{l}\text { WATER } \\ \text { LEVEL }\end{array} & \text { DATE } & \begin{array}{l}\text { WATER } \\ \text { LEVEL }\end{array} & \text { DATE } & \begin{array}{l}\text { WATER } \\ \text { LEVEL }\end{array} \\ \text { OCT } & 5 & 62.93 & \text { APR } 17 & 62.34 & \text { AUG } 7 & 62.83 & \text { SEP } 11 & 62.63\end{array}$

WATER LEVEL, IN FEET BELOW LAND-SURFACE DATUM, WATER YEAR OCTOBER 1984 TO SEPTEMBER 1985

\begin{tabular}{|c|c|c|c|c|c|c|c|c|c|c|c|}
\hline DATE & & $\begin{array}{l}\text { WATER } \\
\text { LEVELL }\end{array}$ & DATE & & $\begin{array}{l}\text { WATER } \\
\text { LEVEL }\end{array}$ & DATE & & $\begin{array}{l}\text { WATER } \\
\text { LEVEL }\end{array}$ & DATE & & $\begin{array}{l}\text { WATER } \\
\text { LEVEL }\end{array}$ \\
\hline Nov & 8 & 62.33 & MAR & 7 & 62.32 & MAY & 2 & 62.38 & AUG & 21 & 63.88 \\
\hline
\end{tabular}


420731N092083802. Local number, 85-11-33 CCBC2.

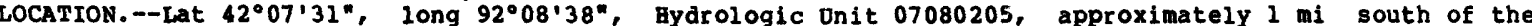
Town of Garrison, just east of County Road v-56. Owner: Iowa Geological Survey and 0.S. Geological Survey.

AQUIFER.--Silurian-Devonian: in limestone of Devonian age and dolomite of silurian age.

WELL CHARACTERISTICS.--Drilied observation artesian water well, diameter 0.75 in., depth 538 ft, cased to $340 \mathrm{ft}$, open hole 340 to $538 \mathrm{ft}$.

INSTRUMENTATION.--Quarterly measurement with chalked tape by osGS personnel.

DATUX.--Elevation of land-surface datum is $912 \mathrm{ft}$ above National Geodetic vertical Datum of 1929 , from topographic map. Measuring point: Top of 6 in. casing, $2.20 \mathrm{ft}$ above land-surface datum.

REMARRs.--Garrison 340 well. $106 \mathrm{ft}$ of open Devonian rock reported to yield little, if any, water. 3 ft cement plug 237 to $240 \mathrm{ft}$.

RERIOD OF RECORD,--October 1975, June 1977 to current year.

EXTREMES FOR PERIOD OF RECORD. --Highest water level measured, e88.00 ft below land-surface datum, Oct. 17, 1975, lowest measured, $104.94 \mathrm{ft}$ below land-surface datum, Aug. 21, 1985 .

WATER LEVEL, IN FEET BELOW LAND-SORFACE DATUK, WATER YEAR OCTOBER 1975 TO SEPTEMBER 1976

$\begin{array}{ll}\text { DATE } & \begin{array}{l}\text { WATER } \\ \text { LEVEL }\end{array} \\ \text { OCT } \quad 17 & \text { e88.00 }\end{array}$

WATER LEVEL, IN FEET BELOW LAND-SURFACE DATUK, WATER YEAR OCTOBER 1976 TO SEPTEMBER 1977

$\begin{array}{lllll}\text { DATE } & \begin{array}{l}\text { WATER } \\ \text { LEVEL }\end{array} & \text { DATE } & & \begin{array}{l}\text { FATER } \\ \text { LEVEL }\end{array} \\ \text { JUN } 29 & 95.93 & \text { AUG } & 9 & 98.45\end{array}$

WATER LEVEL, IN FEET BELON LAND-SURFACE DATUM, WATER YEAR OCTOBER 1977 TO SEPTELBER 1978

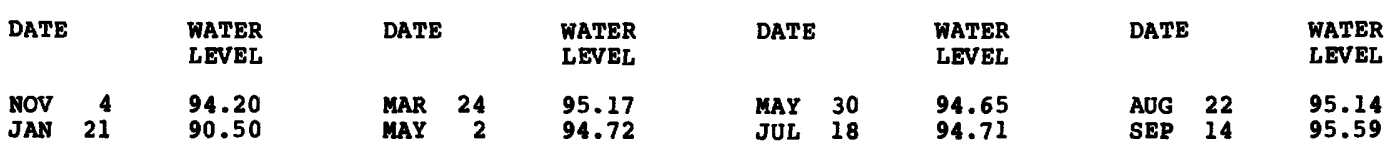

WATER LEVEL, IN FEET BELON LAND-SUREACE DATUK, WATER YBAR OCTOBER 1978 TO SEPTEMBER 1979

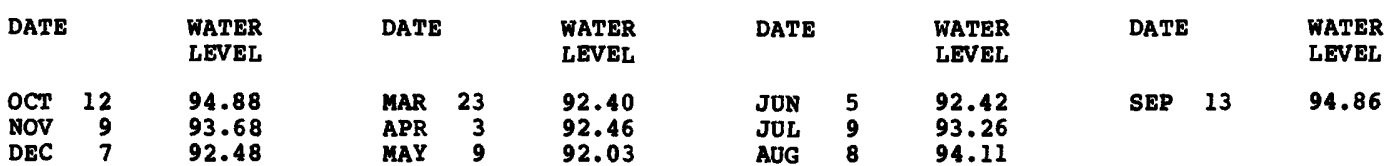

WATER LEVEL, IN FEET BELOW LAND-SURFACE DATUK, WATER YEAR OCTOBER 1979 TO SEPTEMBER 1980

\begin{tabular}{|c|c|c|c|c|c|c|c|c|c|c|}
\hline DATE & $\begin{array}{l}\text { WATER } \\
\text { LEVEL }\end{array}$ & DATE & & $\begin{array}{l}\text { WATER } \\
\text { LEVEL }\end{array}$ & DAT & & $\begin{array}{l}\text { WATER } \\
\text { LEVEL }\end{array}$ & DATE & & $\begin{array}{l}\text { WATER } \\
\text { LEVEL }\end{array}$ \\
\hline $\begin{array}{lr}\text { OCT } & 10 \\
\text { NOV } & 6\end{array}$ & $\begin{array}{l}94.86 \\
93.21\end{array}$ & $\begin{array}{l}\text { DEC } \\
\text { FEB }\end{array}$ & $\begin{array}{l}7 \\
4\end{array}$ & $\begin{array}{l}92.86 \\
93.14\end{array}$ & $\begin{array}{l}\text { MAR } \\
\text { MAY }\end{array}$ & $\begin{array}{r}5 \\
21\end{array}$ & $\begin{array}{l}88.26 \\
91.16\end{array}$ & $\begin{array}{l}\text { JUL } \\
\text { SEP }\end{array}$ & $\begin{array}{l}18 \\
17\end{array}$ & $\begin{array}{l}96.60 \\
93.03\end{array}$ \\
\hline
\end{tabular}

WATER LEVEL, IN FEET BELOW LAND-SURFACE DATUM, WATER YEAR OCTOBER 1980 TO SEPTEMBER 1981

$\begin{array}{lllllll}\text { DATE } & \begin{array}{l}\text { WATER } \\ \text { LEVEL }\end{array} & \text { DATE } & & \begin{array}{l}\text { WATER } \\ \text { LEVEL }\end{array} & \text { DATE } & \begin{array}{l}\text { WATER } \\ \text { LEVEL }\end{array} \\ \text { NOV } 18 & 92.71 & \text { FEB } 3 & 95.20 & \text { MAR } 18 & 95.37\end{array}$

WATER LEVEL, IN FEET BELOW LAND-SURFACE DATUM, WATER YEAR OCTOBER 1982 TO SEPTEMBER 1983

$\begin{array}{llllll}\text { DATE } & \begin{array}{l}\text { WATER } \\ \text { LEVEL }\end{array} & \text { DATE } & \begin{array}{l}\text { WATER } \\ \text { LEVEL }\end{array} & \text { DATE } & \begin{array}{l}\text { WATER } \\ \text { LEVEL }\end{array} \\ \text { NOV } 18 & 94.23 & \text { APR } 19 & 90.27 & \text { AUG } 24 & 94.18\end{array}$

WATER LEVEL, IN FEET BELOW LAND-SURFACE DATUM, WATER YEAR OCTOBER 1983 TO SEPTEMBER 1984

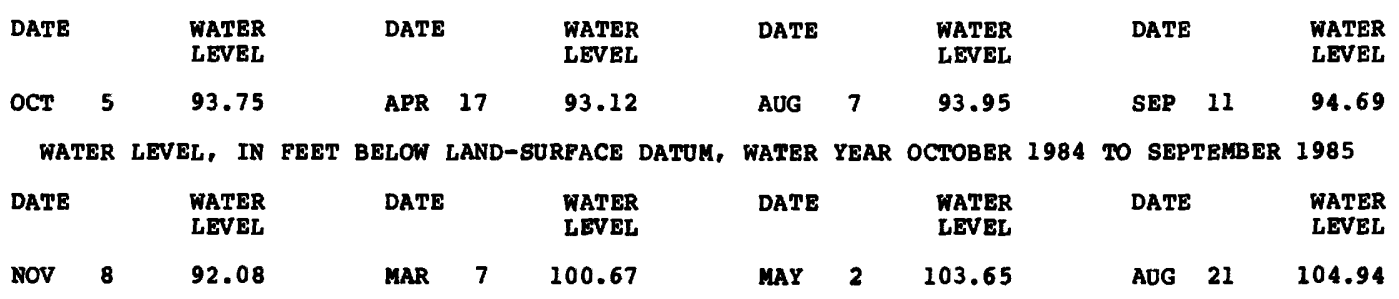

e Estimated 
BENTON COUNTY

420731N092083803. Local number, 85-11-33 CCBC3.

LOCATION.--Lat 42.07'31", long $92^{\circ} 08^{\prime} 38^{\prime \prime}$, Hydrologic Unit 07080205 , approximately 1 mi south of the Town of Garrison, just east of County Road V-56. Owner: Iowa Geological Survey and U.S. Geological Survey.

AQUIFER.--Cedar Valley: in limestone of Devonian age.

WELL CHARACTERISTICS.--Drilled observation artesian water well, diameter 6 in., depth 97 ft, cased to $90 \mathrm{ft}$, open hole 90 to $97 \mathrm{ft}$.

INSTRUMENTATION.--Quarterly measurement with chalked tape by uSGS personnel.

DATUM.--Elevation of land-surface is $912 \mathrm{ft}$ above National Geodetic Vertical Datum of 1929 , from topographic map. Measuring point: Top of 6 in. casing, $2.20 \mathrm{ft}$ above land-surface datum.

REMARKS.--Garrison 109 weli. $3 \mathrm{ft}$ cement plug 97 to $100 \mathrm{ft}$.

PERIOD OF RECORD.--June 1977 to current year.

EXTREMES FOR PERIOD OF RECORD,--Highest water level measured, 60.63 ft below land-surface datum, Mar. 23, 1979; lowest measured, $64.86 \mathrm{ft}$ below land-surface datum, Jun. 29, 1977.

WATER LEVEL, IN FEET BELOW LAND-SURFACE DATUM, WATER YEAR OCTOBER 1976 TO SEPTEMBER 1977

$\begin{array}{lll}\text { DATE } & \begin{array}{l}\text { WATER } \\ \text { LEVEL }\end{array} \\ \text { JUN } \quad 29 & 64.86\end{array}$

WATER LEVEL, IN FEET BELOW LAND-SURFACE DATUM, WATER YEAR OCTOBER 1977 TO SEPTEMBER 1978

$\begin{array}{lllll}\text { DATE } & \begin{array}{l}\text { KATER } \\ \text { LEVEL }\end{array} & \text { DATE } & \begin{array}{l}\text { WATER } \\ \text { LEVEL }\end{array} \\ \text { JUL } 18 & 62.82 & \text { SEP } 14 & 62.90\end{array}$

WATER LEVEL, IN FEET BELOW LAND-SURFACE DATUM, WATER YEAR OCTOBER 1978 TO SEPTEMBER 1979

\begin{tabular}{|c|c|c|c|c|c|c|c|c|c|c|}
\hline DATE & $\begin{array}{l}\text { WATER } \\
\text { LEVEL }\end{array}$ & DATE & & $\begin{array}{l}\text { TATER } \\
\text { LEVEL }\end{array}$ & DAT & & $\begin{array}{l}\text { MATER } \\
\text { LEVEL }\end{array}$ & DATE & & $\begin{array}{l}\text { WATER } \\
\text { LEVEL }\end{array}$ \\
\hline $\begin{array}{ll}\text { NOT } & 1 \\
\text { NOV } & \end{array}$ & $\begin{array}{l}62.22 \\
63.11\end{array}$ & $\begin{array}{l}\text { DEC } \\
\text { MAR }\end{array}$ & $\begin{array}{r}7 \\
23\end{array}$ & $\begin{array}{l}62.46 \\
60.63\end{array}$ & APR & 13 & 60.92 & SEP & 13 & 62.59 \\
\hline
\end{tabular}

WATER LEVEL, IN FEET BELOW LAND-SURFACE DATUM, KATER YEAR OCTOBER 1979 TO SEPTEMBER 1980

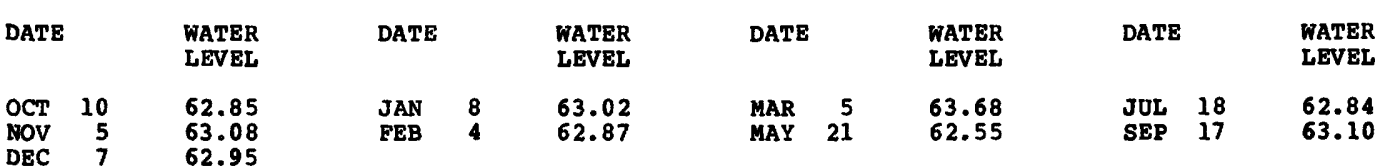

WATER LEVEL, IN FEET BELOW LAND-SURFACE DATUM, KATER YEAR OCTOBER 1980 TO SEPTEMBER 1981

$\begin{array}{llllllll}\text { DATE } & \begin{array}{l}\text { WATER } \\ \text { LEVEL }\end{array} & \text { DATE } & \begin{array}{l}\text { WATER } \\ \text { LEVEL }\end{array} & \text { DATE } & \begin{array}{l}\text { WATER } \\ \text { LEVEL }\end{array} \\ \text { NOV } 18 & 63.26 & \text { FEB } 3 & 63.40 & \text { MAR } 18 & 63.15\end{array}$

WATER LEVEL, IN FEET BELOW LAND-SUREACE DATUM, WATER YEAR OCTOBER 1982 TO SEPTEMBER 1983

\begin{tabular}{|c|c|c|c|c|c|c|}
\hline DATE & & $\begin{array}{l}\text { WATER } \\
\text { LEVEL }\end{array}$ & DATE & $\begin{array}{l}\text { WATER } \\
\text { LEVÉL }\end{array}$ & DATE & $\begin{array}{l}\text { WATER } \\
\text { LEVEL }\end{array}$ \\
\hline NOV & 18 & 61.46 & APR & 60.85 & AUG & 62.49 \\
\hline
\end{tabular}

WATER LEVEL, IN FEET BELOW LAND-SURFACE DATUM, WATER YEAR,OCTOBER 1983 TO SEPTEMBER 1984

\begin{tabular}{|c|c|c|c|c|c|c|c|c|c|c|}
\hline DATE & & $\begin{array}{l}\text { WATER } \\
\text { LEVEL }\end{array}$ & DATE & $\begin{array}{l}\text { WATER } \\
\text { LEVEL }\end{array}$ & DATE & & $\begin{array}{l}\text { WATER } \\
\text { LEVEL }\end{array}$ & DATE & & $\begin{array}{l}\text { WATER } \\
\text { LEVEL }\end{array}$ \\
\hline $\mathrm{Cr}$ & 5 & 62.97 & APR $\quad 17$ & 62.39 & ADG & 7 & 62.94 & SEP & 11 & 62.70 \\
\hline
\end{tabular}

WATER LEVEL, IN FEET BELOW LAND-SURFACE DATUM, WATER YEAR OCTOBER 1984 TO SEPTEMBER 1985

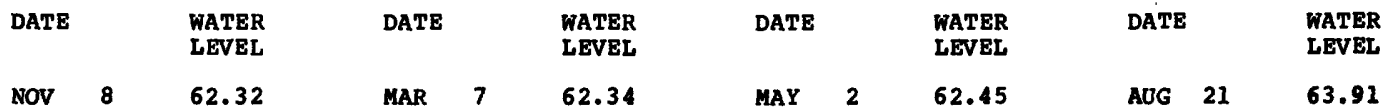


421326N091522701. Local number, 86-9-34 AAAD1.

LOCATION. - Lat $42^{\circ} 13^{\prime} 29^{\prime \prime}$, long $91^{\circ} 52^{\prime} 19^{\prime \prime}$, Hydrologic Unit 07080205, next to the water tower in the Town of Urbana. Owner: Town of Urbana.

AQUIFER.--Silurian-Devonian and ordovician: open from limestone of Devonian age into limestone and dolomite of the Platteville formation of ordovician age.

WELL CBARACTERISTICS.--Drilled unused artesian water well, diameter $8 \mathrm{in.,}$ depth 1,033 ft, cased to 142 $\mathrm{ft}$, open hole 142 to $1,033 \mathrm{ft}$.

INSTRUMENTATION.--Monthly measurement with chalked tape by USGS personnel.

DATUM.--Elevation of land-surface is $940 \mathrm{ft}$ above National Geodetic Vertical Datum of 1929, from topographic map. Measuring point: Nipple on plate welded to casing, $3.15 \mathrm{ft}$ above land-surface datum.

REMARRS. - - None

EXTREMES FOR PERIOD OF RECORD.--Highest water level measured, $142.00 \mathrm{ft}$ below land-surface datum, Dec.

11, 1984; lowest measured, $148.25 \mathrm{ft}$ below land-surface datum, Sep. 23, 1985.

WATER LEVEL, IN FEET BELOW LAND-SURFACE DATUM, WATER YEAR OCTOBER 1983 TO SEPTEMBER 1984

$\begin{array}{lrrrrr}\text { DATE } & \begin{array}{r}\text { WATER } \\ \text { LEVEL }\end{array} & \text { DATE } & \begin{array}{r}\text { WATER } \\ \text { LEVEL }\end{array} \\ \text { SEP } 10 & 142.05 & \text { SEP } 18 & 143.40\end{array}$

WATER LEVEL, IN FEET BELOW LAND-SURFACE DATUM, WATER YEAR OCTOBER 1984 TO SEPTEMBER 1985

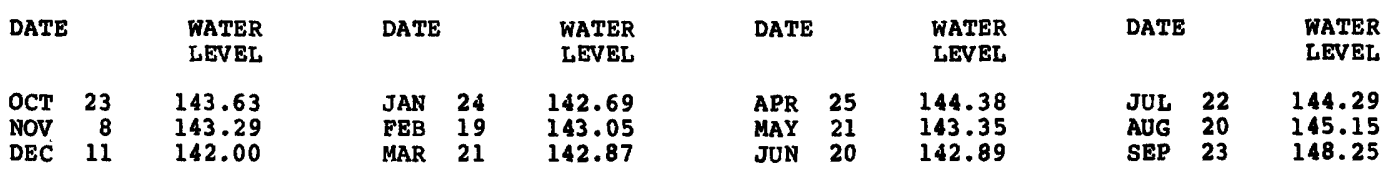

BUENA VISTA COUNTY

423646N095020101. Local number, 90-36-13 ADDA1.

LOCATION. - Lat $42^{\circ} 36^{\prime} 46^{n}$, long $95^{\circ} 02^{\prime} 01^{n}$, Hydrologic Unit 07100006 , north of the Illinois Central

Guif Rallroad tracks, approximately $\mathrm{I}^{\prime} \mathrm{mi}$ west and $0.5 \mathrm{mi}$ north of the Town of Newell. Owner: Iowa Geological Survey and 0. S. Geological survey.

AQUIFER.-Mississippian: in limestone of Mississippian age.

WELL CHARACTERISTICS.--Drilled observation artesian water well, diameter 2 in., depth $338 \mathrm{ft}$, cased to $338 \mathrm{ft}$, perforated 323 to $338 \mathrm{ft}$.

INSTRUMENTATION. --Quarterly measurement with chalked tape by USGS personnel.

DATUM. --Elevation of land-surface datum is $1,281 \mathrm{ft}$ above National Geodetic vertical Datum of 1929 , from topographic map. Measuring point: Top of casing, $3.30 \mathrm{ft}$ above land-surface datum.

REMARKS.--Well D-26. 8.5 ft of casing perforated in Pleistocene glacial drift.

PERIOD OP RECORD. - - May 1979 to current year.

EXTREMES FOR PERIOD OF RECORD.--Highest water level measured, $99.34 \mathrm{ft}$ below land-surface datum, May

13, 1985; lowest measured, $101.82 \mathrm{ft}$ below land-surface datum, Aug. $5,1980$.

WATER LEVEL, IN FEET BELOW LAND-SURFACE DATUM, WATER YEAR OCTOBER 1984 TO SEPTEMBER 1985

$\begin{array}{lllllllll}\text { DATE } & \begin{array}{l}\text { WATER } \\ \text { LEVEL }\end{array} & \text { DATE } & \begin{array}{l}\text { WATER } \\ \text { LEVEL }\end{array} & \text { DATE } & \begin{array}{c}\text { WATER } \\ \text { LEVEL }\end{array} & \text { DATE } & \begin{array}{l}\text { WATER } \\ \text { LEVEL }\end{array} \\ \text { DEC } 19 & 99.48 & \text { MAR } 13 & 99.34 & \text { MAY } 29 & 99.44 & \text { AUG } & 6 & 96.93\end{array}$

423618N095194511. Local number, 90-38-16 DDDD11.

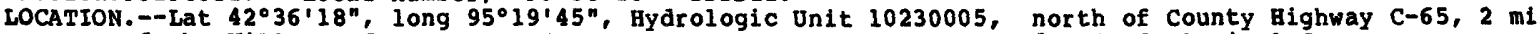
east of the Village of Hanover. Owner: Iowa Geological Burvey and U.S. Geological Survey.

AQUIFER.--Dakota: in sandstone of Early Cretaceous age.

WELI CHARACTERISTICS.--Drilled observation artesian water well, diameter 2 in., depth $497 \mathrm{ft}$, cased to $497 \mathrm{ft}$, perforated 346.5 to $349.5 \mathrm{ft}$.

INSTRUMENTATION. --Quarterly measurement with chalked tape by USGS personnel.

DATUM.--Elevation of land-surface datum is $1,365 \mathrm{ft}$ above Naitonal Geodetic Vetical Datum of 1929 , from topographic map. Measuring point: Top of casing, $3.50 \mathrm{ft}$ above land-surface datum. REMARRS. - - WEII D-25.

PERIOD OP RECORD. - April 1980 to current year.

EXTREMES FOR PERIOD OF RECORD. - Highest water level measured, $187.54 \mathrm{ft}$ below land-surface datum, Mar.

12, 1985; lowest measured, $189.53 \mathrm{ft}$ below land-surface datum, Dec. $6,1983$.

WATER LEVEL, IN FEET BELOW LAND-SURFACE DATUM, WATER YEAR OCTOBER 1984 TO SEPTEMBER 1985

$\begin{array}{lrrrrrrr}\text { DATE } & \begin{array}{r}\text { WATER } \\ \text { LEVEL }\end{array} & \text { DATE } & \begin{array}{r}\text { WATER } \\ \text { LEVEL }\end{array} & \text { DATE } & \begin{array}{r}\text { WATER } \\ \text { LEVEL }\end{array} & \text { DATE } & \begin{array}{r}\text { WATER } \\ \text { LEVEL }\end{array} \\ \text { DEC } \quad 19 & 187.67 & \text { MAR } 12 & 187.54 & \text { MAY } 23 & 187.57 & \text { AUG } 22 & 187.69\end{array}$


424023N095571401. Local number, 91-35-26 BCCCl.

LOCATION.--Lat $42^{\circ} 40^{\prime} 23^{\circ}$, Iong $95^{\circ} 57^{\prime} 14^{\prime}$, Hydrologic unit 07100006 , approximately $2.7 \mathrm{mi}$ west and 0.5 mi north of the Village of varina. Owner: Iowa Geological Survey and U.S. Geological Survey. AQUIFER. --Dakota: in sandstone of Early Cretaceous age.

WELL CHARACTERIsTrCS.--Drilled observation artesian water well, diameter 2 in., depth 357 ft, cased to $357 \mathrm{ft}$, perforated 338 to $347 \mathrm{ft}$.

INSTRUMENTATION.--Quarterly measurement with chalked tape by uSGS personnel.

DATOM.--Elevation of land-surface datum is 1,291 ft above National Geodetic vertical Datum of 1929 , from topographic map. Measuring point: Top of casing, $2.00 \mathrm{ft}$ above land-surface datum.

REMARRS. - Well D-24. Paleozolc rock at $347 \mathrm{ft}$.

PERIOD OF RECORD.--December 1979 to current year.

EXTREMES FOR PERIOD OF RECORD.--Highest water level measured, 18.40 ft below land-surface datum, Jan.

7. 1980 ; lowest measured, $45.07 \mathrm{ft}$ below land-surface datum, Aug. 26, 1985.

WATER LEVEL, IN FEET BELOW LAND-SURFACE DATUM, WATER YEAR OCTOBER 1984 TO SEPTEMBER 1985

\begin{tabular}{|c|c|c|c|c|c|c|c|c|c|c|c|}
\hline DATE & & $\begin{array}{l}\text { WATER } \\
\text { LEVEL }\end{array}$ & DATE & & $\begin{array}{l}\text { WATER } \\
\text { LEVEL }\end{array}$ & DATE & & $\begin{array}{l}\text { WATER } \\
\text { LEVEL }\end{array}$ & DATE & & $\begin{array}{l}\text { WATER } \\
\text { LEVEL }\end{array}$ \\
\hline DEC & 19 & 42.64 & MAR & 11 & 43.46 & MAY & 29 & 44.25 & AUG & 26 & 45.07 \\
\hline
\end{tabular}

425233N094545001. Local number, 93-35-13 ADAAI.

LOCATION.--Lat $42^{\circ} 52^{\prime} 33^{\prime}$, long $94^{\circ} 54^{\prime} 50^{\circ}$, Hydrologic unit 07100006, south of the Chicago, Rock

Island and Pacific Railroad track, approximately $3.5 \mathrm{mi}$ east and $0.75 \mathrm{mi}$ north of the Town of Marathon. Owner: Iowa Geological Survey and U.S. Geological Survey.

AQUIFER.--Dakota: in sandstone of Early Cretaceous age.

WELL CHARACTERISTICS,--Drilled observation artesian water well, diameter 1.50 in., depth 381 ft, cased to $381 \mathrm{Et}$, perforated 350 to $360 \mathrm{ft}$.

INSTRUMENTATION.--Quarterly measurement with chalked tape by USGS personnel.

DATUM.--Elevation of land-surface datum is 1,330 ft above National Geodetic Vetrical Datum of 1929 , from topographic map. Measuring point: Top of casing, $3.00 \mathrm{ft}$ above land-surface datum. REMARKS. - Weil D-36.

PERIOD OF RECORD. - February 1980 to current year.

EXTREMES FOR PERIOD OF RECORD,--Highest water level measured, 131.65 ft below land-surface datum, May 6. 1985; lowest measured, $133.67 \mathrm{ft}$ below land-surface datum, Sept. 11, 1981.

WATER LEVEL, IN FEET BELOW LAND-SURFACE DATOM, WATER YEAR OCTOBER 1984 TO SEPTEMBER 1985

\begin{tabular}{|c|c|c|c|c|c|c|c|c|c|c|}
\hline DATE & $\begin{array}{l}\text { WATER } \\
\text { LEVEL }\end{array}$ & DATE & & $\begin{array}{l}\text { WATER } \\
\text { LEVEL }\end{array}$ & DATE & & $\begin{array}{l}\text { WATER } \\
\text { LEVEL }\end{array}$ & DATE & & $\begin{array}{l}\text { WATER } \\
\text { LEVEL }\end{array}$ \\
\hline EC & 131.76 & MAR & 12 & 131.72 & MAY & 6 & 131.65 & JUL & 25 & 132.02 \\
\hline
\end{tabular}

CALHOUN COUNTY

422846N094375601. Local number, 89-32-33 CABCl.

LOCATION.--Lat $42^{\circ} 28^{\prime} 46^{\prime}$, long $94^{\circ} 37^{\prime} 56^{\prime}$, Hydrologic Unit 07100006 , west edge of the picnic area on the east side of North Twin Lake, approximately $5 \mathrm{mi}$ north of Rockwell City. Owner: Iowa State Conservation Comission.

AQUIFER.--Glacial drift: in material of Pleistocene age.

WELL CHARACTERISTICS.--Drilled unused water-table well, diameter. 8 in., depth $53 \mathrm{ft}$, $1 \mathrm{ined}$ with tile. INSTRUMENTATION.--Quarterly measurement with chalked tape by usGs personnel.

DATUM.--Elevation of land-gurface datum 18 1,222 ft above National Geodetic Vertical Datum of 1929 , from topographic map. Measuring point: Hole in concrete platform, 0.50 ft above land-8urface datum. REMARRS - - 1948 to 1955 records published in Geological Survey Water-Supply Papers. Well 33 Fl. A public-supply well prior to 1978 .

PERIOD OF RECORD.--October 1948 to June 1959, December 1961 to August 1966, July 1968 to November 1971. October 1973 to current year.

EXTREMES FOR PERIOD OF RECORD.--Highest water level measured, 3.82 ft below land-surface datum, May 9. 1984; lowest measured, $32.12 \mathrm{ft}$ below land-surface datum, Aug. 8, 1977.

WATER LEVEL, IN FEET BELOW LAND-SURFACE DATUM, WATER YEAR OCTOBER 1984 TO SEPTEMBER 1985

\begin{tabular}{|c|c|c|c|c|c|c|c|c|c|c|}
\hline DATE & $\begin{array}{l}\text { WATER } \\
\text { LEVEL }\end{array}$ & DATE & & $\begin{array}{l}\text { WATER } \\
\text { LEVEL }\end{array}$ & DATE & & $\begin{array}{l}\text { WATER } \\
\text { LEVEL }\end{array}$ & DATE & & $\begin{array}{l}\text { WATER } \\
\text { LEVEL }\end{array}$ \\
\hline 13 & 24.10 & MAR & 13 & 21.00 & MAY & 28 & 21.50 & AUG & 21 & 31.70 \\
\hline
\end{tabular}


420335N094521501. Local number, 84-35-25 BDADl.

LOCATION, - Lat $42^{\circ} 03^{\prime} 35^{\prime \prime}$, long $94^{\circ} 52^{\prime} 15^{\circ}$, Aydrologic unit 07100007 , near the city water plant, Carroll. Owner: City of Carroll.

AgOIFER.--Dakota: in sandstone of Early Cretaceous age.

WELL CHARACTERISTICS.--Drilled unused artesian water well, diameter 8 in.. depth 120 ft, cased to 100 $f t$, open hole 100 to $120 \mathrm{ft}$.

INSTROMENTATION.--Intermittent measurement reported by personnel from the City of Carroll.

DATUM.--Elevation of land-8urface datum is $1,275 \mathrm{ft}$ above National Geodetic Vetrical Datum of 1929 , from topographic map. Measuring point: Top of casing, $4.00 \mathrm{ft}$ above land-surface datum.

REMARRS.--City test No. 1.

PERIOD OF RECORD.--September 1939 to December 1949 , May 1952 to current year.

EXTREMES FOR PERIOD OF RECORD. - Highest water level measured, 34.55 ft below land-surface datum, Sept. 8, 1945, lowest measured, $85.50 \mathrm{ft}$ below land-surface datum, Jul. 15, 1981.

WATER LEVEL, IN FEET BELOW LAND-SURFACE DATUM, WATER YEAR OCTOBER 1984 TO SEPTEMBER 1985

\begin{tabular}{|c|c|c|c|c|c|c|c|c|c|c|c|}
\hline \multicolumn{2}{|c|}{ DATE } & $\begin{array}{l}\text { WATER } \\
\text { LEVEL }\end{array}$ & \multicolumn{2}{|c|}{ DATE } & $\begin{array}{l}\text { WATER } \\
\text { LEVEL }\end{array}$ & \multicolumn{2}{|c|}{ DATE } & $\begin{array}{l}\text { WATER } \\
\text { LEVEL }\end{array}$ & \multicolumn{2}{|c|}{ DATE } & $\begin{array}{l}\text { WATER } \\
\text { LEVEL }\end{array}$ \\
\hline $\begin{array}{l}\text { DEC } \\
\text { JAN } \\
\text { FEB }\end{array}$ & $\begin{array}{r}10 \\
8 \\
14 \\
26 \\
10 \\
6 \\
18\end{array}$ & $\begin{array}{l}61.19 \\
59.13 \\
60.91 \\
57.25 \\
58.66 \\
57.52 \\
59.57\end{array}$ & $\begin{array}{l}\text { MAR } \\
\text { APR } \\
\text { MAY }\end{array}$ & $\begin{array}{r}21 \\
8 \\
15 \\
1 \\
13 \\
17 \\
22\end{array}$ & $\begin{array}{l}60.88 \\
59.42 \\
60.62 \\
60.74 \\
61.22 \\
60.78 \\
63.80\end{array}$ & $\begin{array}{l}\text { JUN } \\
\text { JUL } \\
\text { AUG }\end{array}$ & $\begin{array}{l}12 \\
20 \\
28 \\
17 \\
22 \\
30 \\
13\end{array}$ & $\begin{array}{l}60.30 \\
61.80 \\
64.35 \\
72.00 \\
67.30 \\
66.00 \\
62.60\end{array}$ & $\begin{array}{l}\text { AUG } \\
\text { SEP }\end{array}$ & $\begin{array}{r}19 \\
27 \\
4 \\
9 \\
17 \\
27\end{array}$ & $\begin{array}{l}63.20 \\
64.75 \\
63.60 \\
62.95 \\
63.50 \\
61.64\end{array}$ \\
\hline
\end{tabular}

421058N094582701. Local number, 85-35-7 ccccl.

LOCATION.--Lat $42^{\circ} 10^{\prime} 58^{\prime \prime}$, long $94^{\circ} 58^{\prime} 27^{\prime \prime}$, Hydrologic unit 07100006 , approximately 1 block north of Iowa Highway 217, next to the town maintenance building, Breda. Owner: Town of Breda.

AQUIFER.--Dakota: in sandstone of Early Cretaceous age.

WELL CHARACTERISTICS.--Drilled municipal artesian water well, diameter 10 in., depth 340 ft, cased to $320 \mathrm{ft}$, screen 320 to $340 \mathrm{ft}$.

INSTROMENTATION.--Quarterly measurement with chalked taped by uSGS personnel.

DATUM.-Altitude of land-surface datum is $1,362 \mathrm{ft}$ above National Geodetic vertical Datum of 1929 , from topographic map. Measuring point: Vent pipe, $1.60 \mathrm{ft}$ above land-surface datum.

REMARRs.--Town weli No. 3. Water levels affected by pumping. Original depth 349 ft. 1942 to 1955 Records published in Geological survey Water-supply Papers.

PERIOD OF RBCORD, - March 1942 to August 1966, March 1968 to November 1971 , June 1975 to current year.

EXTREMES FOR PERIOD OF RECORD, - - Highest water level measured, 187.70 ft below land-surface datum, Mar.

25, 1948, lowest measured, $250.40 \mathrm{ft}$ below land-surface datum, May $24,1977$.

WATER LEVEL, IN FEET BELOW LAND-SURFACE DATUM, WATER YEAR OCTOBER 1984 TO SEPTEMBER 1985

\begin{tabular}{|c|c|c|c|c|c|c|c|c|}
\hline DATE & $\begin{array}{l}\text { WATER } \\
\text { LEVEL }\end{array}$ & DATE & $\begin{array}{l}\text { WATER } \\
\text { LEVEL }\end{array}$ & DATE & $\begin{array}{l}\text { WATER } \\
\text { LEVEL }\end{array}$ & DATE & & $\begin{array}{l}\text { WATER } \\
\text { LEVEL }\end{array}$ \\
\hline $\mathrm{EC}$ & 199.42 & FEB & 199.37 & MAY & 202.94 & AUG & 22 & 199.48 \\
\hline
\end{tabular}

CERRO GORDO COUNTY

430806 N093164501. Local number, 96-21-13 BCCB1.

LOCATION. --Lat $43^{\circ} 08^{\prime} 06^{\mathrm{N}}$, Iong $93^{\circ} 16^{\prime} 45^{\mathrm{m}}$, Hydrologic Unit 07080203, south of the County Home, just north of Iowa Bighway' 106 , east of the'City of Ciear Lake. Owner: Mason City and Clear Lake Railroad.

AQUIFER.--Cedar Valley: in limestone of Devonian age.

WELL CBARACTERISTICS.--Drilled unused artesian water well, diameter 5 in., depth $198 \mathrm{ft}$.

INSTRUNENTATION. - - Quarterly measurement with chalked tape by uSGS personnel.

DATUM.--Elevation of land-surface datum 18 1,165 ft above National Geodetic vertical Datun of 1929 , from topographic map. Measuring point: Top of well curb, $1.30 \mathrm{ft}$ above land-surface datum.

REMARRS.--Casing information not available.

PERIOD OF RECORD.--November 1940 to August 1971, March 1973 to current year.

EXTREMES FOR PERIOD OF RECORD.--Highest water level measured, 1.73 ft below land-surface datum, Jan.

28, 1951; lowest measured, $17.26 \mathrm{ft}$ below 1and-surface datum, Nov. 18, 1955.

WATER LEVEL, IN FEET BELOW LAND-SURFACE DATUM, WATER YEAR OCTOBER 1984 TO SEPTEMBER 1985

$\begin{array}{rrrrrrr}\text { DATE } & \begin{array}{r}\text { WATER } \\ \text { LEVEL }\end{array} & \text { DATE } & \begin{array}{r}\text { WATER } \\ \text { LEVEL }\end{array} & \text { DATE } & \begin{array}{r}\text { WATER } \\ \text { LEVEL }\end{array} \\ \text { DEC } 28 & 6.04 & \text { MAR } 18 & 6.24 & \text { JUL } 10 & 5.77\end{array}$


430658N093281001. Local number, 96-22-20 CADCl.

LOCATION. - Lat $43^{\circ} 06^{\prime} 58^{\prime \prime}$, long $93^{\circ} 28^{\prime} 10^{\prime \prime}$, Bydrologic Unit 07080203 , east of County Road s-14 in Ventura Heights. Owner: W. Baine and H. Elder.

AQUIFER.--Glacial drift: in material of pleistocene age.

WELL CHARACTERISTICS.--Drilled unused water-table well, diameter 5 in., depth $126 \mathrm{ft}$.

INSTRUMENTATION. --Quarterly measurement with chalked tape by usGs personnel.

DATUM.--Elevation of land-8urface datum is $1,249 \mathrm{ft}$ above National Geodetic vertical Datum of 1929. from topgraphic map. Measuring point: Hole in side of casing, 0.87 ft above land-surface datum. REMARRS. --Casing information not available. Formerly Boy Scouts of America.

PERIOD OF RECORD.--July 1940 to August 1971, March 1973 to current year.

EXTREMES FOR PERIOD OF RECORD.--Highest water level measured, 29.65 ft below land-8urface datum, Mar.

25, 1942; lowest measured, $51.37 \mathrm{ft}$ below land-8urface datum, Aug. 4, 1977.

WATER LEVEL, IN EEET BELON LAND-SURFACE DATUM, WATER YEAR OCTOBER 1984 TO SEPTEKBER 1985

$\begin{array}{llllllll}\text { DATE } & \begin{array}{r}\text { WATER } \\ \text { LEVEL }\end{array} & \text { DATE } & \begin{array}{c}\text { WATER } \\ \text { LEVEL }\end{array} & \text { DATE } & \begin{array}{c}\text { WATER } \\ \text { LEVEL }\end{array} \\ \text { DEC } 28 & 43.63 & \text { MAR } 18 & 44.21 & \text { JUL } 10 & 44.82\end{array}$

CHEROKEE COUNTY

423833N095365701. Local number, 90-40-6 BDCD1.

LOCATION. --Lat $42^{\circ} 38^{\prime} 33^{\prime \prime}$, long $95^{\circ} 36^{\prime} 57^{\prime \prime}$, Hydrologic unit 10230003 , approximately 3.1 mi east of 0.5 .

Highway 59 and $0.55 \mathrm{mi}$ north of lowa Highway 31 along the Illinols Central Rallroad track. Owner: Iowa Geological Survey and U.S. Geological survey.

AQUIFER. --Dakota: in sandstone of Early Cretaceous age.

WELL CHARACTERISTICS.--Drilled observation artesian water well, diameter 1.25 in., depth 253 ft, cased to $252 \mathrm{ft}$, sandpoint 252 to $253 \mathrm{ft}$.

INSTRUMENTATION.--Quarterly measurements with chalked tape by USGS personnel.

DATUM.--Elevation of land-surface datum is 1,182 ft above National Geodetic vertical Datum of 1929 , from topographic map. Measuring point: Top of casing, 4.00 ft above land-surface datum.

REMARKS. - We II D-6.

PERIOD OF RECORD. --December 1978 to current year.

EXTREMES FOR PERIOD OF RECORD. - - Highest water level measured, 28.38 ft below land-8urface datum, Aug.

27, 1983; lowest measured, $37.22 \mathrm{ft}$ below land-8urface datum, Sept. 10, 1981.

WATER LEVEL, IN FEET BELOW LAND-SURFACE DATUM, WATER YEAR OCTOBER 1984 TO SEPTEMBER 1985

\begin{tabular}{|c|c|c|c|c|c|c|c|c|c|c|c|}
\hline DATE & & $\begin{array}{l}\text { WATER } \\
\text { LEVEL }\end{array}$ & DATE & & $\begin{array}{l}\text { WATER } \\
\text { LEVEL }\end{array}$ & DATE & & $\begin{array}{l}\text { MATER } \\
\text { LEVEL }\end{array}$ & DATE & & $\begin{array}{l}\text { WATER } \\
\text { LEVEL }\end{array}$ \\
\hline OCT & 17 & 32.18 & JAN & 8 & 32.43 & APR & 2 & 32.60 & JUL & $\mathbf{y}$ & 31.67 \\
\hline
\end{tabular}

424348N095231601. Local number, 91-39-1 ADADl.

LOCATION.--Lat $42^{\circ} 43^{\prime} 48^{\prime \prime}$, long $95^{\circ} 23^{\prime} 16^{\prime}$, Hydrologic Unit 10230005 , approximately $2 \mathrm{mi}$ east and $0.5 \mathrm{mi}$ north of the Town of Aurelia at the Larson Lake County Park. Owner: Iowa Geological Survey and U.S. Geological Survey.

AQUIFER.--Cambrian-Ordovician: in dolomite of Ordovician age and sandstone of Cambrian age.

WELL CHARACTERISITICS.--Drilled observation artesian water well, diameter 6 in. to 236 ft, 5 in. to $486 \mathrm{ft}, 2 \mathrm{in}$. to $1,545 \mathrm{ft}$, depth $1,545 \mathrm{ft}$, cased to $1,126 \mathrm{ft}$, open hole $1,126 \mathrm{fo} 1,545 \mathrm{ft}$.

INSTRUMENTATION.--Quarterly measurement with chalked tape or electric ilne by usGs personnel.

DATUM.--Elevation of land-surface datum is $1,370 \mathrm{ft}$ above National Geodetic Vertical Datum of 1929 , from topographic map. Measuring point: Top of casing, $3.20 \mathrm{ft}$ above land-surface datum. REMARKS. - WeII D-28.

PERIOD OF RECORD.--September 1979 to current year.

EXTREMES FOR PERIOD OF RECORD,--Highest water level measured, 190.70 ft below land-surface datum, Dec. 6, 1984; lowest measured, $194.47 \mathrm{ft}$ below land-8urface datum, May $5,1982$.

WATER LEVEL, IN PEET BELON LAND-SURFACE DATUM, NATER YEAR OCTOBER 1984 TO SEPTEMBER 1985

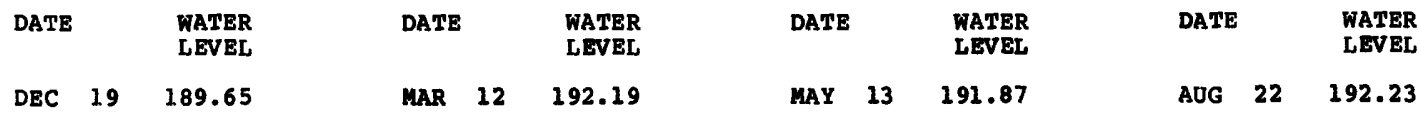


424348N095231602. Local number, 91-39-1 ADAD2.

LOCATION.--Lat $42^{\circ} 43^{\prime} 48^{\prime \prime}$, Iong $95^{\circ} 23^{\prime} 16^{\prime \prime}$, Hydrologic Unit 10230005 , approximately $2 \mathrm{ml}$ east and $0.5 \mathrm{ml}$ north of the Town of Aurelia at the Larson Lake County Park. Owner: Iowa Geological Survey and U.S. Geological Survey.

AQUIFER. --Dakota: in sandstone of Early Cretaceous age.

WELL CHARACTERISTICS.--Dr1lled observation artesian water well, diameter 4 in., depth 340 ft, cased to $340 \mathrm{ft}$, perforated 235 to $240 \mathrm{ft}$.

INSTRUMENTATION.--Quarterly measurement with chalked tape or electric line by usgs personnel.

DATUM.--Elevation of land-surface datum is 1,370 ft above National Geodetic Vertical Datum of 1929 , from topographic map. Measuring point: Top of casing, $3.30 \mathrm{ft}$ above land-surface datum. REMARKS. - Well D-29.

PERIOD OF RECORD.--September 1979 to current year.

EXTREMES FOR PERIOD OF RECORD.--Highest water level measured, 189.15 ft below land-surface datum, May 13, 1985; lowest measured, $194.15 \mathrm{ft}$ below land-surface datum, Aug. $24,1982$.

WATER LEVEL, IN FEET BELOW LAND-SURFACE DATUM, WATER YEAR OCTOBER 1984 TO SEPTEMBER 1985

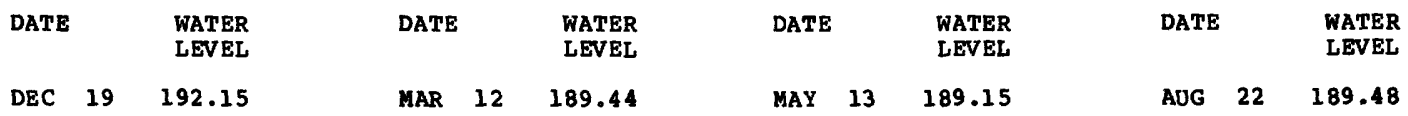

424132N095480211. Local number, 91-42-16 DDDD11.

LOCATION.--Lat $42^{\circ} 41^{\prime} 32^{\prime \prime}$, long $95^{\circ} 48^{\prime} 02^{\prime \prime}$, Hydrologic Unit 10230004 , approximately $2 \mathrm{ml}$ north of the Village of Flelding at the junction of County Roads L-36 and C-44. Owner: Iowa Geological Survey and U.S. Geological Survey.

AQUIFER.--Dakota: in sandstone of Early Cretaceous age.

WELL CHARACTERISTICS.--Drilled observation artesian water well, diameter 2 in., depth 390 ft, cased to 390 perforated 386 to $390 \mathrm{ft}$.

INSTRUMENTATION.--Quarterly measurement with chalked tape by usgs personnel.

DATUM.--Elevation of land-surface datum is $1,320 \mathrm{ft}$ above National Geodetic vertical Datum of 1929 , from topographlc map. Measuring point: Top of casing, $1.50 \mathrm{ft}$ above land-surface datum.

REMARKS. - - Well D-11.

PERIOD OF RECORD.--March 1980 to current year.

EXTREMES FOR PERIOD OF RECORD.--Highest water level measured, 152.75 ft below land-surface datum, June 27, 1984; lowest measured, 155.50 ft below land-surface datum, Dec. 15,1980 .

WATER LEVEL IN FEET BELOW LAND-SURFACE DATUM, WATER YEAR OCTOBER 1984 TO SEPTEMBER 1985

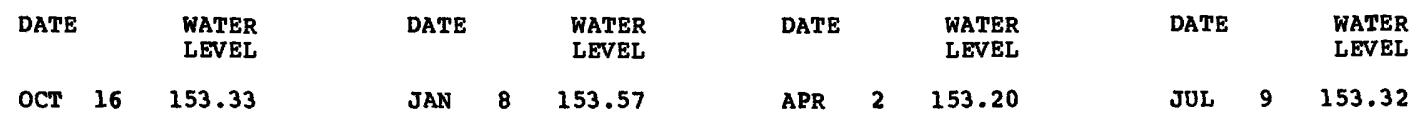

424802N095331201. Local number, 92-40-10 BDDDl.

LOCATION, - Lat $42^{\circ} 48^{\prime} 02^{\prime \prime}$, long $95^{\circ} 33^{\prime} 12^{\prime \prime}$, Hydrologic Unit 10230003, along 0.S. Highway 59, approximately

$2.5 \mathrm{mi}$ north of the City of Cherokee. Owner: Iowa Geological Survey and 0.5 . Geological Survey.

AQUIFER.--Dakota: in sandstone of Early Cretaceous age.

WELL CHARACTERISTICS.--Drilled observation artesian water well, diameter 2.501 in., depth 300 ft, cased to $300 \mathrm{ft}$, perforated 114 to $118 \mathrm{ft}$.

INSTRUMENTATION. --Quarterly measurement with chalked tape by usGs personnel.

DATUM.--Elevation of land-surface datum is $1,210 \mathrm{ft}$ above National Geodet1c Vert1cal Datum of 1929 , from topographic map. Measuring polnt: Top of casing, $0.30 \mathrm{ft}$ above land-surface datum.

REMARRS. - Well D-5.

PERIOD OF RECORD.-Apr11 1980 to October 1980, May 1982 to current year.

EXTREMES FOR PERIOD OF RECORD. - Highest water level measured, 26.05 ft bel ow land-surface datum, June 27, 1984; lowest measured, $29.19 \mathrm{ft}$ below land-surface datum, May $5,1982$.

WATER LEVEL, IN FEET BELOW LAND-SURFACE DATUM, WATER YEAR OCTOBER 1984 TO SEPTEMBER 1985

\begin{tabular}{|c|c|c|c|c|c|c|c|c|c|c|c|}
\hline DATE & & $\begin{array}{l}\text { WATER } \\
\text { LEVEL }\end{array}$ & DATE & & $\begin{array}{l}\text { WATER } \\
\text { LEVEL }\end{array}$ & DATE & & $\begin{array}{l}\text { WATER } \\
\text { LEVEL }\end{array}$ & DATE & & $\begin{array}{l}\text { WATER } \\
\text { LEVEL }\end{array}$ \\
\hline OCT & 16 & 27.06 & JAN & 8 & 26.95 & APR & 1 & 26.89 & JUL & 9 & 27.09 \\
\hline
\end{tabular}


CLAYTON COUNTY

424023N091291201. Local number, 91-5-30 BBBB1.

LOCATION.--Lat 42.40'23", long 91.29'12". Bydrologic Unit 07060006, 5 mi northwest of the City of Edgewood, or $2 \mathrm{mi}$ northwest of the junction of rowa Bighways 3 and 13 east of strawberry Point. Owner: Barold knight.

AQUIFER.--Glacial drift: in material of Pleistocene age.

WELL CHARACTERISTICS.--Dug unused water-table well, diameter 36 in., depth $36 \mathrm{ft}$.

INSTRUMENTATION.--Intermittent measurement with chalked tape by USGS personnel.

DATUM. --Elevation of land-surface datum is 1,233 ft above National Geodetic Vertical Datum of 1929 , from topographic map. Measuring point: Bole in pump base at land-surface datum.

REMARKS. - Casing information not available.

PERIOD OF RECORD. --June 1957 to current year.

EXTREMES FOR PERIOD OF RECORD.--Highest water level measured, $15.10 \mathrm{ft}$ below land-surface datum, Apr.

5, 1983; lowest measured, $30.68 \mathrm{ft}$ below land-surface datum, Jan. 12, 1959.

WATER LEVEL, IN FEET BELOW LAND-SURFACE DATUM, WATER YEAR OCTOBER 1984 TO SEPTEMBER 1985

$\begin{array}{llllllllll}\text { DATE } & \begin{array}{l}\text { WATER } \\ \text { LEVEL }\end{array} & \text { DATE } & \begin{array}{l}\text { WATER } \\ \text { LEVEL }\end{array} & \text { DATE } & \begin{array}{l}\text { WATER } \\ \text { LEVEL }\end{array} & \text { DATE } & \text { WATER } \\ \text { LEVEL }\end{array}$

424057N091320001. Local number, 91-6-22 ACACl.

LOCATION. - Lat 42.40'57", long $91^{\circ} 32^{\prime} 00^{\prime \prime}$, Bydrologic Unit 07060006 , southeast corner of the junction of lowa Bighways 3 and 13 , Strawberry Point. Owner: City of Strawberry Point.

AQUIFER.--Silurian-Devonian and Ordovician: in dolomite of Silurian age and Upper Ordovician age.

WELL CBARACTERISTICS. --Drilled unused artesian water well, diameter 16 in. $0-130 \mathrm{ft}, 12$ in. 130-161

$\mathrm{ft}$, depth $492 \mathrm{ft}$, cased to $161 \mathrm{ft}$ with a $10 \mathrm{in}$. liner 229-370 ft, open hole 161 to $229 \mathrm{ft}$ and 370 to $492 \mathrm{ft}$.

INSTRUMENTATION. --Water-level recorder.

DATUM.--Elevation of land-surface datum is 1,219 ft above National Geodetic Vertical datum of 1929, from topographic map. Measuring point: Top of recorder platform, $2.10 \mathrm{ft}$ above land-surface datum. REMARKS. - City well No. 2

PERIOD OF RECORD. - March 1963 to current year.

REVISED RECORDS. --WDR IA-84-1.

EXTREMES FOR PERIOD OF RECORD.---Bighest water level recorded, $114.38 \mathrm{ft}$ below land-surface datum, May

9, 1973; lowest recorded, $133.18 \mathrm{ft}$ below land-surface datum, Feb. 4, 1968.

WATER LEVEL, IN FEET, BELOW LAND-SURFACE DATUM, WATER YEAR OCTOBER 1984 TO SEPTEMBER 1985 NOON VALUES

\begin{tabular}{|c|c|c|c|c|c|c|c|c|c|c|c|c|}
\hline DAY & OCT & Nov & DEC & JAN & FEB & MAR & APR & MAY & JUN & JUL & AUG & SEP \\
\hline $\begin{array}{r}5 \\
10 \\
15 \\
20 \\
25 \\
\text { EOM }\end{array}$ & $\begin{array}{r}123.13 \\
123.55 \\
123.01 \\
\mathrm{e} 123.50 \\
123.63 \\
123.60\end{array}$ & $\begin{array}{c}---- \\
--- \\
-- \\
123.85 \\
124.00\end{array}$ & $\begin{array}{c}124.25 \\
124.45 \\
124.72 \\
124.40 \\
124.25\end{array}$ & $\begin{array}{l}124.24 \\
124.57 \\
124.69 \\
124.90 \\
125.20 \\
125.30\end{array}$ & $\begin{array}{l}125.12 \\
125.46 \\
125.38 \\
125.48 \\
125.00 \\
124.62\end{array}$ & $\begin{array}{l}124.84 \\
123.85 \\
123.79 \\
123.78 \\
123.85 \\
122.50\end{array}$ & $\begin{array}{l}122.30 \\
122.03 \\
122.01 \\
122.45 \\
122.98 \\
123.26\end{array}$ & $\begin{array}{l}123.30 \\
123.45 \\
123.73 \\
124.17 \\
124.22 \\
124.38\end{array}$ & $\begin{array}{l}125.00 \\
125.33 \\
125.16 \\
125.42 \\
125.63 \\
126.05\end{array}$ & $\begin{array}{l}125.88 \\
126.30 \\
126.47 \\
126.67 \\
126.55 \\
126.78\end{array}$ & $\begin{array}{l}126.63 \\
127.20 \\
127.12 \\
127.35 \\
127.28 \\
127.17\end{array}$ & $\begin{array}{l}127.17 \\
127.68 \\
127.62 \\
127.80 \\
127.53 \\
127.57\end{array}$ \\
\hline & & & & 97 & 10, & 1985 & LOWEST & 128.06 & SEP & 3, 1985 & & \\
\hline
\end{tabular}

e Estimated.

430156N091182901. Local number, 95-4-22 BCBD1.

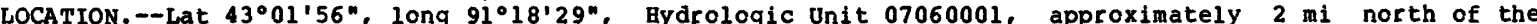
junction of U.S. Bighway 18 and U.S. Highway 52-Iowa Bighway 13, near Spook Cave. Owner: Gerald Mielke.

AQUIFER.--St. Peter: in sandstone of Middle Ordovician age.

WELL CHARACTER ISTICS. --Drilled unused artesian water well, diameter 6 in., depth $49 \mathrm{ft}$.

INSTRUMENTATION.--Quarterly measurement with chalked tape by USGS personnel.

DATUM. --Elevation of land-surface datum is $940 \mathrm{ft}$ above National Geodetic Vertical Datum of 1929 , from topographic map. Measuring point: Top of casing, $1.00 \mathrm{ft}$ above land-surface datum.

REMARKS.--Casing information not available. Water level for Mar. 3, 1984, $22.51 \mathrm{ft}$.

PER IOD OF RECORD. --October 1957 to current year.

EXTREMES FOR PERIOD OF RECORD.--Bighest water level measured, $13.98 \mathrm{ft}$ below land-surface datum, Dec.

7, 1983; lowest measured, $27.88 \mathrm{ft}$ below land-surface datum, Mar. 4, 1968.

WATER LEVEL, IN FEET BELOW LAND-SURFACE DATUM, WATER YEAR OCTOBER 1984 TO SEPTEMBER 1985

$\begin{array}{llllllll}\text { DATE } & \begin{array}{l}\text { WATER } \\ \text { LEVEL }\end{array} & \text { DATE } & \begin{array}{c}\text { WATER } \\ \text { LEVEL }\end{array} & \text { DATE } & & \begin{array}{c}\text { WATER } \\ \text { LEVEL }\end{array} \\ \text { NOV } 28 & 23.35 & \text { FEB } & 6 & 23.55 & \text { MAY } & 1 & 22.95\end{array}$


425940N091194701. Local number, 95-4-32 DDDDl.

LOCATION.--Lat $42^{\circ} 59^{\prime} 40^{\prime \prime}$, long 91\%19'47", Hydrologic Unit 07060004, 1 mi west of the junction of U. S. Highway 52 and Iowa Highway 13 , or northeast of the Town of Farmersburg. owner: Milton and wili is Meier.

AQUIFER.--St. Peter: in sandstone of Middle Ordovician age.

WELL CHARACTERISTICS.--Drilled stock artesian water well, diameter 6 in., depth $380 \mathrm{ft}$ (reported).

INSTRUMENTATION.--Quarterly measurement with chalked tape by USGS personnel.

DATUM.--Elevation of land-surface datum is $1,090 \mathrm{ft}$ above National Geodetic vertical datum of 1929 , from topographic map. Measuring point: Plug in pump base, $1.00 \mathrm{ft}$ above land-surface datum.

REMARKS. --Casing information not available. Water level form Mar. 7, 1984, 78.10 ft.

PERIOD OF RECORD.--October 1957 to current year.

EXTREMES FOR PERIOD OF RECORD.--Highest water level measured, 74.08 ft below land-surface datum, July

10, 1984; lowest measured, 126.56 ft below land-surface datum, Jan. 13, 1969 .

WATER LEVEL, IN FEET BELOW LAND-SURFACE DATUM, WATER YEAR OCTOBER 1984 TO SEPTEMBER 1985

$\begin{array}{lllllllll}\text { DATE } & \begin{array}{l}\text { WATER } \\ \text { LEVEL }\end{array} & \text { DATE } & & \begin{array}{l}\text { WATER } \\ \text { LEVEL }\end{array} & & \text { DATE } & \begin{array}{c}\text { WATER } \\ \text { LEVEL }\end{array} \\ \text { NOV } 28 & \mathbf{7 9 . 5 0} & \text { FEB } & 6 & \mathbf{8 1 . 9 4} & \text { MAY } & \mathbf{1} & \mathbf{8 3 . 7 5}\end{array}$

CRAWFORD COUNTY

421031N095225611. Local number, 85-39-16 ADDD11.

LOCATION. - Lat 42.10'31", long $95^{\circ} 22^{\prime} 56^{\prime \prime}$, Hydrologic Unit 10230007 , approximately $2.5 \mathrm{mi}$ east and $0.5 \mathrm{mi}$ north of the Town of Schleswig. Owner: Iowa Geological Survey and U.S. Geological Survey.

AQUIFER.--Mississippian: in limestone of Mississippian age.

WELL CHARACTERISTICS.--Drilled observation artesian water well, diameter 2 in., depth 561 ft, cased to $561 \mathrm{ft}$, perforated 543 to $561 \mathrm{ft}$.

INSTRUMENTATION.--Quarterly measurement with chalked tape or electric line by osGS personnel.

DATUM.--Elevation of land-surface datum is $1,370 \mathrm{ft}$ above National Geodetic Vertical Datum of 1929 , from topographic map. Measuring point: Top of casing, 3.14 ft above land-surface datum.

REMARKS. - Well WC-7B.

PERIOD OF RECORD.--June 1981 to current year.

EXTREMES FOR PERIOD OF RECORD,--Highest water level measured, $305.58 \mathrm{ft}$ below land-surface datum, Feb.

8, 1983; lowest measured, $307.64 \mathrm{ft}$ below land-surface datum, Oct. 4, 1983.

WATER LEVEL, IN FEET BELOW LAND-SURFACE DATUM, WATER YEAR OCTOBER 1984 TO SEPTEMBER 1985

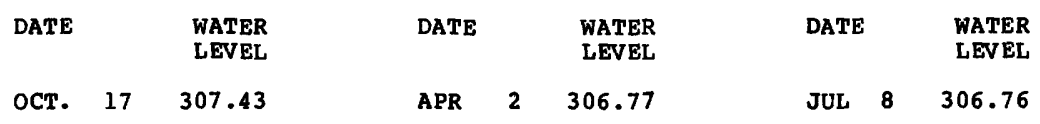

DELAWARE COUNTY

422029N091144302. Local number, 87-3-18 CBCD2.

LOCATION, - Lat $42^{\circ} 20^{\prime} 37^{\prime \prime}$, long $91^{\circ} 14^{\prime} 47^{\prime \prime}$, Hydrologic Unit 07060006 , behind the municipal utilities building in downtown Hopkinton. Owner: Town of Hopkinton.

AQUIFER.--Silurian-Devonian: in dolomite of Silurian age.

WELL CHARACTERISTICS.-Drilled unused artesian water well, diameter 8 in., depth $86 \mathrm{ft}$.

INSTRUMENTATION.--Intermittent measurement with chalked tape by uSGs personnel.

DATUM.--Elevation of land-surface is $863 \mathrm{ft}$ above National Geodetic vertical Datum of 1929 , from topographic map. Measuring point: Top of recorder platform, $2.25 \mathrm{ft}$ above land-surface datum.

REMARKS.--Casing information not available. Water levels affected by pumping of a nearby well.

PERIOD OF RECORD. --December 1984 to current year.

EXTREMES FOR PERIOD OF RECORD.-- Bighest water level measured, 21.10 ft below land-surface datum, Jan. 18, 1985; lowest measured, 22.29 ft below land-surface datum, Aug. 13, 1985.

WATER LEVEL, IN FEET BELOW LAND-SURFACE DATUM, WATER YEAR OCTOBER 1984 TO SEPTEMBER 1985

\begin{tabular}{|c|c|c|c|c|c|c|c|c|c|c|}
\hline DATE & & $\begin{array}{l}\text { WATER } \\
\text { LEVEL }\end{array}$ & DATE & $\begin{array}{l}\text { WATER } \\
\text { LEVEL }\end{array}$ & DATE & & $\begin{array}{l}\text { WATER } \\
\text { LEVEL }\end{array}$ & DATE & & $\begin{array}{l}\text { WATER } \\
\text { LEVEL }\end{array}$ \\
\hline DEC & $\begin{array}{l}11 \\
18\end{array}$ & $\begin{array}{l}21 \cdot 15 \\
21 \cdot 30\end{array}$ & $\begin{array}{lr}\text { JAN } & 18 \\
\text { AUG } & 5\end{array}$ & $\begin{array}{l}21.10 \\
21.78\end{array}$ & AUG & 9 & 21.91 & AUG & 13 & 22.29 \\
\hline
\end{tabular}


404844N091142701. Local number, 69-3-6 AABAl.

LOCATION.--Lat $40^{\circ} 48^{\prime} 44^{\prime}$, long $91^{\circ} 14^{\prime} 27^{\prime}$, Bydrologic onit 07080104 , at the Iowa Army Ammunition Plant, near the Town of Middieton. Owner: Iowa Ordnance Plant.

AQUIFER.--St. Peter: in sandstone of Middle Ordovician age.
VELL CHARACTERISTICS. - Drilled unused artesian water well, diameter 16 in., depth 1,209 ft, cased to $855 \mathrm{ft}$, open hole 855 to $1,209 \mathrm{ft}$.

INSTRUMBNTATION.-- Intermittent measurement with chalked tape by observer.

DATUM.--Elevation of land-surface datum is $717 \mathrm{ft}$ above National Geodetic Vertical of 1929 , from topographic map. Measuring point: Top of plateorm, $1.61 \mathrm{ft}$ above land-surface datum.

REMARKS.--Plant well No. 3 .

PERIOD OF RECORD.--March 1950 to current year.

EXTREHES FOR PERIOD OF RECORD, - - Bighest water level measured, $108.35 \mathrm{ft}$ below 1 and-surface datum, Mar. 91985 ; lowest measured, $201.75 \mathrm{ft}$ below land-surface datum, Aug. 15, 1978.

WATER LEVEL, IN FEET BELOW LAND-SURFACE DATUK, WATER YEAR OCTOBER 1984 TO SBPTEMBER 1985

\begin{tabular}{|c|c|c|c|c|c|c|c|c|c|c|}
\hline DATE & & $\begin{array}{l}\text { WATER } \\
\text { LEVEL. }\end{array}$ & DATE & & $\begin{array}{l}\text { MATER } \\
\text { LEVEL }\end{array}$ & DATE & & $\begin{array}{l}\text { WATER } \\
\text { LEVEL }\end{array}$ & DATE & \\
\hline $\begin{array}{l}\text { NOV } \\
\text { FEB }\end{array}$ & $\begin{array}{l}24 \\
10\end{array}$ & $\begin{array}{l}115.39 \\
114.39\end{array}$ & $\begin{array}{l}\text { MAR } \\
\text { JOL }\end{array}$ & $\begin{array}{l}9 \\
6\end{array}$ & $\begin{array}{l}108.35 \\
109.69\end{array}$ & ADG & 3 & 109.97 & SEP & 7 \\
\hline
\end{tabular}

404753N091142501. Local number, 69-3-6 DDCDI.

LOCATION.--Lat $40^{\circ} 47^{\prime} 53^{\circ}$, long $91^{\circ} 14^{\prime} 25^{\prime}$, Hydrologic Unit 07080204 , at the Iowa Army Ammunition Plant, near the Town of Hiddleton. Owner: Iowa Ordnance Plant.

AQUIFER.--Cedar Valley and Mississippian: in limestone of Devonian and Mississippian age.

WELL CHARACTERISTICS.--Drilled unused artesian water well, diameter 19 in., depth $675 \mathrm{ft}$, cased to 75 $f t$, open hole 75 to $675 \mathrm{ft}$.

INSTRUMENTATION. --Intermittent measurement with chaiked tape by observer.

DATUM.--Elevation of land-gurface datum is $699 \mathrm{ft}$ above National Geodetic vertical Datum of 1929 , from topographic map. Measuring point: Top of platform, $1.91 \mathrm{ft}$ above land-surface datum. RELARRS.--Plant well No. 2.

PERIOD OF RECORD.-March 1950 to current year.

EXTREMES FOR PERIOD OF RECORD. - Highest water level measured, 74.46 ft below 1 and-surface datum, Apr. 18,1975 , lowest measured, $83.19 \mathrm{ft}$ below land-surface datum, Apr. 26, 1950 .

WATER LEVEL, IN FEET BELOW LAND-SURFACE DATUM, WATER YEAR OCTOBER 1984 TO SEPTEMBER 1985

\begin{tabular}{|c|c|c|c|c|c|c|c|c|c|c|c|}
\hline DATE & & $\begin{array}{l}\text { WATER } \\
\text { LEVEL }\end{array}$ & DATE & & $\begin{array}{l}\text { MATER } \\
\text { LEVEL }\end{array}$ & DATE & & $\begin{array}{l}\text { WATER } \\
\text { LEVEL }\end{array}$ & DATE & & $\begin{array}{l}\text { WATER } \\
\text { LEVEL }\end{array}$ \\
\hline $\begin{array}{l}\text { NOV } \\
\text { FEB }\end{array}$ & $\begin{array}{l}24 \\
10\end{array}$ & $\begin{array}{l}80.37 \\
80.09\end{array}$ & $\begin{array}{c}\text { MAR } \\
\text { JOL }\end{array}$ & $\begin{array}{l}9 \\
6\end{array}$ & $\begin{array}{l}80.19 \\
79.63\end{array}$ & AOG & 5 & 97 & IP & 1 & 4 \\
\hline
\end{tabular}

BMABT COONTY

432927N094345501. Local number, 100-32-11 DDDD1.

LOCATION.--Lat $43^{\circ} 29^{\prime} 27^{\prime \prime}$, Iong $94^{\circ} 34^{\prime} 55^{\%}$, Hydrologic Unit 07100003 , at Okamanpedan Lake Reserve State Park, north of the Town of Dolliver. Owner: state of Iowa.

AQUIFER.--Dakota: in sandstone of Barly Cretaceous age.

MELL CHARACTERISTICS.-Drilled public-supply artesian water well, diameter 6 in., depth 277 ft.

INSTRUMENTATION. - Quarterly mesurenent with chalked tape by osGs personnel.

DATOM.--glevation of land-gurface datum is 1,233 ft above National Geodetic vertical Datum of 1929 , from topographic map. Measuring point: Plug in pump base, 0.61 ft above land-surface datum.

REMARKS.--Casing information not available.

PERIOD OF RECORD. - November 1939 to current year.

EXTREMES FOR PERIOD OF RECORD,--Bighest water level measured, 59.60 ft below land-surface datum, Dec.

19, 1946, lowest measured, $77.86 \mathrm{ft}$ below land-surface datum, Aug. 27, 1979 .

WATER LEVEL, IN FEET BELOW LAND-SURPACE DATUK, WATER YEAR OCTOBER 1984 TO SEPTEMBER 1985

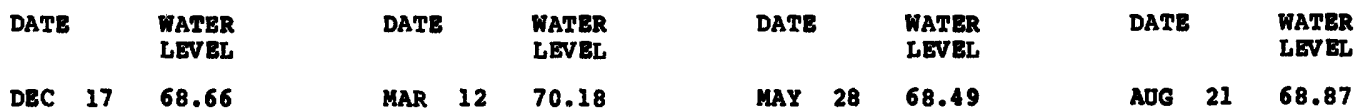


415449N094161501. Local number, 82-29-18 CAAAl.

LOCATION. --Lat 41.54'49", long $94^{\circ} 16^{\prime} 15^{\prime \prime}$, Hydrologic Unit 07100006 , approximately $0.5 \mathrm{mi}$ south and $4 \mathrm{mi}$ east of the village of Cooper and just south of County Road E-57. Owner: Iowa Geological Survey and U.S. Geological Survey.

AQUIFER.--Pennsylvanian: in sandstone of Pennsylvanian age.

WELL CHARACTERISTICS. --Drilled observation artesian water well, diameter 2 in., depth $101 \mathrm{ft}$, cased to $100 \mathrm{ft}$, perforated 89 to $100 \mathrm{ft}$, open hole 100 to $101 \mathrm{ft}$.

INSTRUMENTATION. --Quarterly measurement with chalked tape by uSGS personnel.

DATUM.--Elevation of land-surface datum is $960 \mathrm{ft}$ above National Geodetic vertical Datum of 1929 , from topographic map. Measuring point: Top of casing, $2.00 \mathrm{ft}$ above land-surface datum. REMARKS. - Well WC-116.

PERIOD OP RECORD. - - September 1982 to current year.

EXTREMES FOR PERIOD OF RECORD. - - Highest water level measured, $0.41 \mathrm{ft}$ above land-surface datum, Jul. 5, 1983; lowest measured, $4.52 \mathrm{ft}$ below land-surface datum, Nov. 5,1982 .

WATER LEVEL, IN FEET BELOW LAND-SURFACE DATUM, WATER YEAR OCTOBER 1984 TO SEPTMEBER 1985

$\begin{array}{lrrrrr}\text { DATE } & \begin{array}{r}\text { WATER } \\ \text { LEVEL }\end{array} & \text { DATE } & & \begin{array}{r}\text { WATER } \\ \text { LEVEL }\end{array} \\ \text { OCT } \quad 17 & 3.89 & \text { APR } & 2 & 3.35\end{array}$

415449N094173201. Local number, 82-30-13 CABAl.

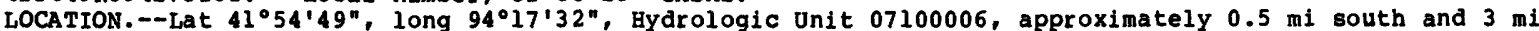
east of the Village of Cooper and just south of County Road E-57. Owner: Iowa Geological Survey and U.S. Geological Survey.

AQUIFER.--Pennsylvanian and Mississippian: in sandstone of Pennsylvanian age and limestone of Mississippian age.

WELL CHARACTERISTICS.--Drilled observation artesian water well, diameter 2 in., depth $230 \mathrm{ft}$, cased to $230 \mathrm{ft}$, perforated 209 to $230 \mathrm{ft}$.

INSTRUMENTATION. --Quarterly measurement with chalked tape by uSGs personnel.

DATUM.--Elevation of land-surface datum is 1,035 ft above National Geodetic Vertical Datum of 1929 , from topographic map. Measuring point: Top of casing, $1.45 \mathrm{ft}$ above land-surface datum.

REMARKS. - Well WC-118. Original depth $245 \mathrm{ft}$, casing plugged at $230 \mathrm{ft}$

PERIOD OF RECORD. --September 1982 to current year.

EXTREMES FOR PERIOD OF RECORD,--Highest water level measured, $66.79 \mathrm{ft}$ below land-surface datum, Jul. 5, 1983; lowest measured, 71.48 bel ow land-surface datum, Sep. 2, 1982 .

WATER LEVEL, IN FEET BELOW LAND-SURFACE DATUM, WATER YEAR OCTOBER 1984 TO SEPTEMBER 2985

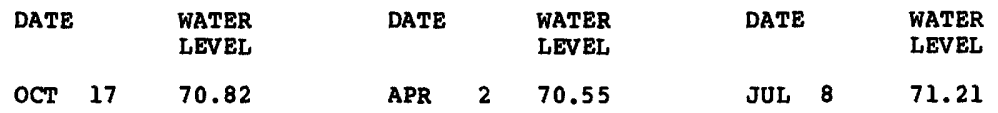

\section{GRONDY COUNTY}

422605N092560001. Local number, 88-18-15 DBBB1.

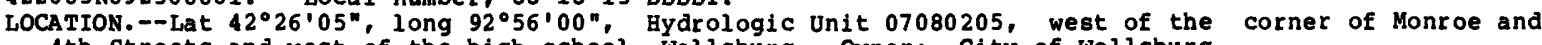
4 th Streets and west of the high school, Wellsburg. Owner: City of Wellsburg.

AQUIFER. - Yellow Springs Group: in limestone and dolomite of upper Devonian age.

WELL CHARACTERISTICS.--Drilled public-emergency-supply artesian water well, diameter 12 in., depth 280 $\mathrm{ft}$, cased to $128 \mathrm{ft}$, open hole 128 to $280 \mathrm{ft}$.

INSTRUMENTATION. --Quarterly measurement with chalked tape by uSGS personnel.

DATUM.--Elevation of land-surface datum is 1,060 ft above National Geodetic Vertical Datum of 1929 , $\mathrm{ft}$, topographic map. Measuring point: Edge of vent pipe, $1.25 \mathrm{ft}$ above land-surface datum. REMARKS. - None.

PERIOD OF RECORD.--September 1960 to August 1971, May 1973 to current year.

EXTREMES FOR PERIOD OF RECORD. - - Highest water level measured, $34.45 \mathrm{ft}$ below land-surface datum, Feb. 22, 1983, lowest measured, $96.81 \mathrm{ft}$ below land-surface datum, Sep. 27, 1960.

WATER LEVEL, IN FEET BELOW LAND-SURFACE DATUM, WATER YEAR OCTOBER 1984 TO SEPTEMBER 1985

$\begin{array}{llllllll}\text { DATE } & \begin{array}{r}\text { WATER } \\ \text { LEVEL }\end{array} & \text { DATE } & \begin{array}{c}\text { WATER } \\ \text { LEVEL }\end{array} & \text { DATE } & \begin{array}{c}\text { WATER } \\ \text { LEVEL }\end{array} \\ \text { JAN } 2 & 35.34 & \text { MAR } 26 & 34.49 & \text { JUN } 26 & 34.92\end{array}$


413838N095462001. Local number, 79-42-19 AADBI.

LOCATION. - Lat $41^{\circ} 38^{\prime} 38^{\prime \prime}$, Long $95^{\circ} 46^{\prime} 20^{\prime}$, Hyarologic Unit 10230007 , approximately $0.5 \mathrm{mi}$ east of 22 , 22, 1983; Town of Logan, near U.S. Highway 30. Owner: Lowa Geological Survey and D.s. Geological

Survey.
AQUIFER.--Mississippian: in dolomite of Mississippian age.

WELL CHARACTERISTICS. --Drilled observation artesian water well, diameter 2 in., depth $628 \mathrm{ft}$, cased to $628 \mathrm{ft}$, perforated 588 to $628 \mathrm{ft}$.

INSTRUMENTATION. - Intermittent measurement with chalked tape by USGS personnel.

DATUM.--Elevation of land-surface datum is 1,045 $\mathrm{ft}$ above National Geodetic Vertical Datum of 1929 , from topogarphic map. Measuring point: Top of casing, $4.40 \mathrm{ft}$ above 2 and-surface datum.

REMARKS. --We11 WC-22.

PERIOD OP RECORD. --November 1981 to current year.

EXTREMES FOR PERIOD OF RECORD. --Highest water level measured, $4.70 \mathrm{ft}$ below land-surface datum, Mar. 20, 1985; lowest measured, 16.37 ft below land-surface datum, Jun. 3, 1982 .

WATER LEVEL, IN FEET BELOW LAND-SURFACE DATUM, WATER YEAR OCTOBER 1984 TO SEPTEMBER 2985

\begin{tabular}{|c|c|c|c|c|c|c|c|c|c|c|}
\hline DATE & $\begin{array}{l}\text { WATER } \\
\text { LEVEL }\end{array}$ & DATE & & $\begin{array}{l}\text { WATER } \\
\text { LEVEL }\end{array}$ & DATE & & $\begin{array}{l}\text { WATER } \\
\text { LEVEL }\end{array}$ & DATE & & $\begin{array}{l}\text { WATER } \\
\text { LEVEL }\end{array}$ \\
\hline $\begin{array}{ll}\text { CT } \\
\text { Hov } & 24 \\
\text { OEC } & 27\end{array}$ & $\begin{array}{l}9.77 \\
8.95 \\
6.49\end{array}$ & $\begin{array}{l}\text { PEB } \\
\text { MAR }\end{array}$ & $20^{4}$ & $\begin{array}{l}6.10 \\
4.70\end{array}$ & $\begin{array}{l}\text { MAY } \\
\text { JUN }\end{array}$ & 12 & $\begin{array}{l}4.90 \\
4.78\end{array}$ & $\begin{array}{l}\text { JUL } \\
\text { SEP }\end{array}$ & $\begin{array}{r}24 \\
3\end{array}$ & $\begin{array}{l}5.23 \\
5.31\end{array}$ \\
\hline
\end{tabular}

414955N096000601. Local number, 81-44-18 AADAl.

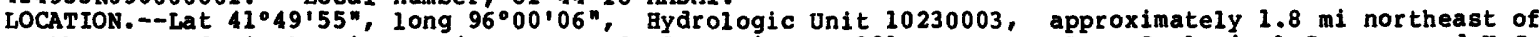
the Town of Little Sioux, just west of Iowa Highway 301. Owner: Iowa Geological Survey and U.S. Geologi cal survey.

AQUIFER. --Pennsylvanian: in sandstone of Pennsylvania age.

WELL CBARACTERISTICS.--Drilled observation artesian water well, diameter 2 in., depth $126 \mathrm{ft}$, cased to $126 \mathrm{ft}$, perforated 108 to $26 \mathrm{ft}$.

INSTROMENTATION. --Quarterly measurement with chalked tape by USGS personnel.

DATUM.--Elevation of land-surface datum is 1,075 ft above National Geodetic Vertical Datum of 1929 , from topographic map. Measuring point: Top of casing, $2.80 \mathrm{ft}$ above land-surface datum.

REMARKS. - Well WC-23. Original depth $209 \mathrm{ft}$, casing plugged $126 \mathrm{ft}$.

PERIOD OF RECORD. --January 1982 to current year.

EXTREMES FOR PERIOD OF RECORD. -- Highest water level measured, $52.33 \mathrm{ft}$ below land-surface datum, Jul.

12, 1984; lowest measured, $64.07 \mathrm{ft}$ below land-surface datum, Jan. 15, 1982 .

WATER LEVEL, IN FEET BELOW LAND-SURFACE DATUM, WATER YEAR OCTOBER 1984 TO SEPTEMBER 1985

\begin{tabular}{|c|c|c|c|c|c|c|c|c|c|c|}
\hline DATE & $\begin{array}{l}\text { WATER } \\
\text { LEVEL }\end{array}$ & DATE & & $\begin{array}{l}\text { WATER } \\
\text { LEVEL }\end{array}$ & DATE & & $\begin{array}{l}\text { WATER } \\
\text { LEVEL }\end{array}$ & DATI & & $\begin{array}{l}\text { WATER } \\
\text { LEVEL }\end{array}$ \\
\hline CT 15 & 59.60 & JAN & 7 & 60.43 & APR & 1 & 62.05 & JUL & 11 & 60.89 \\
\hline
\end{tabular}

HENRY COUNTY

405810N091330502. Local number, 71-6-9 ABAC2.

LOCATION. --Lat $40^{\circ} 58^{\prime} 10^{\prime \prime}$, long $9 i^{\circ} 33^{\prime} 5^{\prime \prime}$, Hydrologic Unit 07080107 , in the city water plant on Adams

Street, Mount Pleasant. Owner: City of Mount Pleasant.

AQUIFER. --Jordan: in strata of Cambrian and Ordovician age.

WELL CBARACTERISTICS. - Drilled municipal artesian water well, diameter 20 to 19 in., depth $1,860 \mathrm{ft}$, cased to $623 \mathrm{ft}$, open hole 623 to $1,860 \mathrm{ft}$.

INSTRUMENTATION.--Quarterly measurement with airline by USGS personnel.

DATUM.--Elevation of land-surface datum is $725 \mathrm{ft}$ above National Geodetic Vertical Datum of 1929 , from topographic map. Measuring point: Hole in pump base, $2.25 \mathrm{ft}$ above land-surface datum.

REMARKS.--City well No. 4 . Water $l$ evel s af fected by pumping.

PERIOD OF RECORD.--April i 946 to December 1950, January 1953 to November 1955, December 1962 to current year.

EXTREMES FOR PERIOD OF RECORD.-- Highest water level measured, $132.00 \mathrm{ft}$ below land-surface datum, May 5, 1946; lowest measured, nonpumping, $198.75 \mathrm{ft}$ below land-surface datum, Jan. 7,1978 .

WATER LEVEL, IN FEET BELOW LAND-SURFACE DATUM, WATER YEAR OCTOBER 1984 TO SEPTEMBER 1985

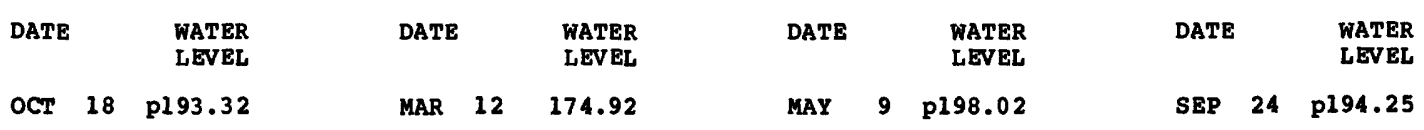

p Well being pumped. 
410852N091394301. Local number, 73-7-9 AABD1.

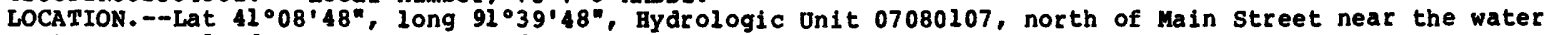
tower, Wayland. Owner: Town of wayland.

AQUIFER.--Glacial drift: in material of Pleistocene age.

WELL CHARACTERISTICS.--Dug unused water-table well, diameter $4 \mathrm{ft}$, depth $52 \mathrm{ft}$.

INSTRUMENTATION.--Quarterly measurement with chalked tape by USGS perBonnel.

DATUM.--Elevation of land-surface datum $1 \mathrm{~s} 735 \mathrm{ft}$ above National Geodetic Vertical Datum of 1929 , from topographic map. Measuring point: Top of cement cover, 0.21 ft above land-gurface datum. REMARKS.--Casing information not available.

PERIOD OF RECORD. - September 1960 to current year.

EXTREMES FOR PERIOD OF RECORD,--Highest water level measured, 2.30 ft below land-surface datum, Sep.

1, 1965 ; lowest measured, $14.69 \mathrm{ft}$ below land-surface datum, Feb. 2, 1977.

WATER LEVEL, IN FEET BELOW LAND-SURFACE DATUM, WATER YEAR OCTOBER 1984 TO SEPTMEBER 1985

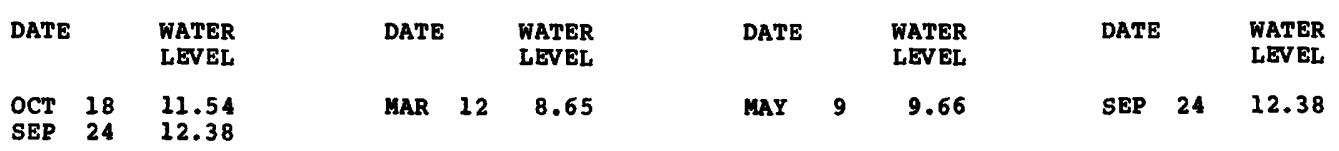

IDA COUNTY

422215N095390811. Local number, 87-41-5 cccc11.

LOCATION. - Iat $42^{\circ} 22^{\prime} 15^{\circ}$, long $95^{\circ} 39^{\prime} 08^{\prime \prime}$. Hydrologic onit 10230005 , approximately $0.75 \mathrm{mi}$ east and 6.5 mi south of the village of Cushing. Owner: Iowa Geological survey and $0 . s$. Geological Survey. AQUIFER.--Dakota: in sandstone of Early Cretaceous age.

WELL CHARACTERISTICS.--Drilled observation artesian water well, diameter 2 in., depth 490 ft, cased to $490 \mathrm{ft}$, perforated 301 to $305 \mathrm{ft}$.

INSTROMENTATION.--Quarterly measurement with chalked tape by USGS personnel.

DATUM.--Elevation of land-surface datum is $1,344 \mathrm{ft}$ above National Geodetic vertical Datum of 1929 , from topographic map. Measuring point: Top of casing, 2.72 ft above land-surface datum.

REMARKS. - Well D-10. Original depth, $510 \mathrm{ft}$, cemented back to $490 \mathrm{ft}$.

PERIOD OF RECORD. - June 1980 to current year.

EXTREMES FOR PERIOD OF RECORD,--Highest water level measured, 202.55 ft below land-surface datum, Jun. 4, 1980; lowest measured, $206.50 \mathrm{ft}$ below land-surface datum, May 7, 1982.

WATER LEVEL, IN FEET BELOW LAND-SURFACE DATUM, WATER YERA OCTOBER 1984 TO SEPTEMBER 1985

\begin{tabular}{|c|c|c|c|c|c|c|c|c|c|c|c|}
\hline DATE & & $\begin{array}{l}\text { WATER } \\
\text { LEVEL }\end{array}$ & DATE & & $\begin{array}{l}\text { WATER } \\
\text { LEVEL }\end{array}$ & DATE & & $\begin{array}{l}\text { WATER } \\
\text { LEVEL }\end{array}$ & DATE & & $\begin{array}{l}\text { WATER } \\
\text { LEVEL }\end{array}$ \\
\hline OCT & 17 & 203.50 & JAN & 8 & 203.52 & APR & 2 & 203.96 & JUL & 10 & 203.97 \\
\hline
\end{tabular}

423107N095383201. Local number, 89-41-13 ccccl.

LOCATION.--Lat 42.31'07\%, long 95.38'32\%, Hydrologic Unit 10230003, at a roadside park on County Road D-15, approximately $1^{\prime} .5 \mathrm{mi}$ east and $3.5 \mathrm{mi}$ north of the V1llage of Cushing. Owner: Iowa Geological Survey and 0. S. Geological survey.

AQUIFER.--Mississippian: in limestone of Mississippian age.

WELL CHARACTERISTICS.--Drilled obsezvation artesian water well, diameter 2 in., depth 469 ft, cased to $468 \mathrm{ft}$, sand point 465 to $468 \mathrm{ft}$, open hole 468 to $469 \mathrm{ft}$.

INSTRUMENTATION. --Quarterly measurement with chalked tape by usgs personnel.

DATUK.--Elevation of land-surface datum is 1,320 ft above National Geodetic vertical Datum of 1929 , from topographic map. Measuring point: Top of casing, $1.50 \mathrm{ft}$ above land-surface datum.

REMARKS, - WeII D-9.

PERIOD OF RECORD.--December 1978 to current year.

EXTREMES FOR PERIOD OF RECORD.- Highest water level measured, 186.45 ft below land-surface datum, Jul. 27. 1983 ; lowest measured, $207.14 \mathrm{ft}$ below land-surface datum, Apr. 8, 1980.

WATER LEVEL, IN FEET BELON LAND-SURFACE DATUM, WATER YEAR OCTOBER 1984 TO SEPTEMBER 1985

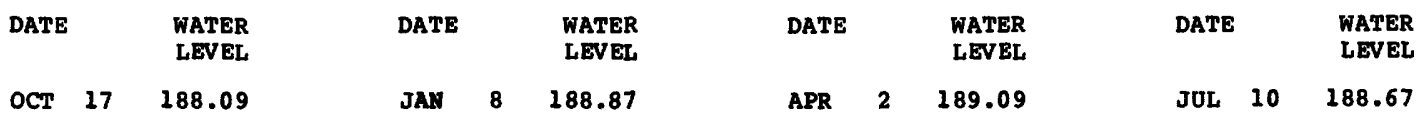


420842N090165701. Local number, 85-6E-29 ACADl.

LOCATION.--Lat $42^{\circ} 08^{\prime} 42 \%$, Iong $90^{\circ} 16^{\prime} 57 \%$, Hydrologic Unit 07060005,1 mi east of 0.5 . Highway 52 , 2 mi southeast of the Village of Green Island beside the Chicago, Milwaukee, St. Paul and Pacific Railroad tracks in the Upper Mississippi River Wildlife and Fish Refuge. Owner: U.S. Geological Survey. AQUIFER. - Mt. Simon: in sandstone of Early Cambrian age.

WELL CHARACTERISTICS.--Drilled observation artesian water well, diameter 2 in. depth 1,804 ft, cased to $1,725 \mathrm{ft}$, screened 1,705 to $1,725 \mathrm{ft}$, open hole 1,725 to $1,804 \mathrm{ft}$.

INSTROWENTATION. --Monthly measurement with engineers rule by uSGS personnel.

DATUM.--Elevation of land-surface datum is $610 \mathrm{ft}$ above National Geodetic Vertical Datum of 1929 , from topographic map. Measuring point: Mark on angle iron attached to wel1 house, $6.05 \mathrm{ft}$ above 1 andsurf ace datum.

REMARKS. - None.

PERIOD OF RECORD. - May 1983 to current year.

EXTREMES FOR PERIOD OF RECORD.--Highest water level measured, 9.41 ft above land-surface datum, Apr.

12. 1984 ; lowest measured, $7.67 \mathrm{ft}$ above land-surface datum, Sept. 6, 1984 .

WATER LEVEL, IN FEET BELOW LAND-SURFACE DATUM, WATER YEAR OCTOBER 1984 TO SEPTEMBER 1985

\begin{tabular}{|c|c|c|c|c|c|c|c|c|c|c|c|}
\hline DATE & & $\begin{array}{l}\text { WATER } \\
\text { LEVEL }\end{array}$ & DATE & & $\begin{array}{l}\text { WATER } \\
\text { LEVEL }\end{array}$ & DATE & & $\begin{array}{l}\text { WATER } \\
\text { LEVEL }\end{array}$ & DATE & & $\begin{array}{l}\text { WATER } \\
\text { LEVEL }\end{array}$ \\
\hline $\begin{array}{l}\text { OCT } \\
\text { NOV } \\
\text { DEC }\end{array}$ & $\begin{array}{l}5 \\
6 \\
4\end{array}$ & $\begin{array}{l}+7.85 \\
+8.23 \\
+7.92\end{array}$ & $\begin{array}{l}\text { FEB } \\
\text { MAR } \\
\text { APR }\end{array}$ & $\begin{array}{l}21 \\
14 \\
16\end{array}$ & $\begin{array}{r}+8.87 \\
+8.76 \\
+8.77\end{array}$ & $\begin{array}{l}\text { MAY } \\
\text { JUN } \\
\text { JUL }\end{array}$ & $\begin{array}{l}20 \\
12 \\
23\end{array}$ & $\begin{array}{l}+8.87 \\
+8.58 \\
+8.55\end{array}$ & $\begin{array}{l}\text { AUG } \\
\text { SEP }\end{array}$ & $\begin{array}{l}19 \\
11\end{array}$ & $\begin{array}{l}+8.61 \\
+8.36\end{array}$ \\
\hline
\end{tabular}

420842N090165703. Local number, 85-6E-29 ACAD3.

LOCATION. --Lat $42^{\circ} 08^{\prime} 42^{\prime \prime}$, Iong $90^{\circ} 16^{\prime} 57^{\circ}$, Hydrologic Unit 07060005,1 mi east of U.S. Highway 52 , 2 mi

southeast of the Village of Green Island beside the Chicago, Milwaukee, St. Paul and Pacific Rail-

road tracks in the Upper Mississippi River Wildlife and Fish Refuge. Owner: U.S. Geological Survey. AQUIFER. - St. Peter and Prairie du Chien: in sandstone and dolomite of Middle and Early Ordovician age. WELL CBARACTERISTICS.--Drilled observation artesian water well, diameter 2 in. depth 910 ft, cased to $624.2 \mathrm{ft}$, screened 604.2 to $624.2 \mathrm{ft}$, open hole 624.2 to $910 \mathrm{ft}$.

INSTRUMENTATION.--Monthly measurement with chalked tape by uSGS personnel.

DATUM.--Elevation of land-surface datum is $610 \mathrm{ft}$ above National Geodetic Vertical Datum of 1929 , from

topographic map. Measuring point: Top of casing, 2.00 ft above land-surface datum.

REMARKS. --None.

PERIOD OF RECORD. - MaY 1982 to current year.

EXTREMES FOR PERIOD OF RECORD,--Highest water level measured, 6.25 ft below land-surface datum, Apr.

16. 1985; lowest measured $9.90 \mathrm{ft}$ below land-surface datum, Aug. 31, 1983.

WATER LEVEL, IN FEET BELOW LAND-SURFACE DATUM, WATER YEAR OCTOBER 1984 TO SEPTEMBER 1985

\begin{tabular}{|c|c|c|c|c|c|c|c|c|c|c|c|}
\hline DATE & & $\begin{array}{l}\text { WATER } \\
\text { LEVEL }\end{array}$ & DATE & & $\begin{array}{l}\text { WATER } \\
\text { LEVEL }\end{array}$ & DATE & & $\begin{array}{l}\text { WATER } \\
\text { LEVEL }\end{array}$ & DATE & & $\begin{array}{l}\text { WATER } \\
\text { LEVEL }\end{array}$ \\
\hline $\begin{array}{l}\text { OCT } \\
\text { NOV } \\
\text { DEC }\end{array}$ & $\begin{array}{l}5 \\
6 \\
4\end{array}$ & $\begin{array}{l}8.15 \\
8.68 \\
7.92\end{array}$ & $\begin{array}{l}\text { JAN } \\
\text { FEB } \\
\text { MAR }\end{array}$ & $\begin{array}{l}29 \\
21 \\
14\end{array}$ & $\begin{array}{l}6.97 \\
6.75 \\
6.44\end{array}$ & $\begin{array}{l}\text { APR } \\
\text { MAY } \\
\text { JUN }\end{array}$ & $\begin{array}{l}16 \\
20 \\
12\end{array}$ & $\begin{array}{l}6.25 \\
6.34 \\
6.77\end{array}$ & $\begin{array}{l}\text { JUL } \\
\text { AUG } \\
\text { SEP }\end{array}$ & $\begin{array}{l}23 \\
19 \\
11\end{array}$ & $\begin{array}{l}7.32 \\
7.64 \\
7.97\end{array}$ \\
\hline
\end{tabular}

420842N090165704. LOCAL NUMBER, 85-6E-29 ACAD4.

LOCATION. - Lat $42^{\circ} 08^{\prime} 42^{\prime \prime}$, long $90^{\circ} 16^{\prime} 57^{\prime \prime}$, Hydrologic Unit 07060005,1 mi east of 0.5 . Highway 52, 2 mi southeast of the Village of Green Island beside the Chicago, Milwaukee, St. Paul and Pacific Railroad tracks in the Upper Mississippi River Wildlife and Fish Refuge. Owner: U.S. Geological Survey. AQUIFER.--Galena: in dolomite of Ordovician age.

WELL CHARACTERISTICS.--Drilled observation artesian water well, diameter 2 in., depth 400 ft, cased to $319.6 \mathrm{ft}$, screened 299.6 to $319.6 \mathrm{ft}$, open hole 319.6 to $400 \mathrm{ft}$.

INSTROMENTATION.--Monthly measurements with chalked tape by uSGS personnel.

DATUM.--Elevation of land-surface datum is $610 \mathrm{ft}$ above National Geodetic Vertical Datum of 1929 , from topographic map. Measuring point: Top of casing, $2.00 \mathrm{ft}$ above land-surface datum.

REMARKS. --None.

PERIOD OF RECORD.--MaY 1982 to current year.

EXTREMES FOR PERIOD OF RECORD, - - Bighest water level measured, 12.22 ft below land-surface datum Apr. 22. 1983; lowest measured, $17.30 \mathrm{ft}$ below land-surface datum, Sept. $6,1984$.

WATER LEVEL, IN FEET BELON LAND-SURFACE DATUM, WATER YEAR OCTOBER 1984 TO SEPTEMBER 1985

\begin{tabular}{|c|c|c|c|c|c|c|c|c|c|c|c|}
\hline DATE & & $\begin{array}{l}\text { WATER } \\
\text { LEVEL }\end{array}$ & DATE & & $\begin{array}{l}\text { WATER } \\
\text { LEVEL }\end{array}$ & DATE & & $\begin{array}{l}\text { WATER } \\
\text { LEVEL }\end{array}$ & DATE & & $\begin{array}{l}\text { WATER } \\
\text { LEVEL }\end{array}$ \\
\hline $\begin{array}{l}\text { OCT } \\
\text { NOV } \\
\text { DEC }\end{array}$ & $\begin{array}{l}5 \\
6 \\
4\end{array}$ & $\begin{array}{l}17.17 \\
14.59 \\
15.97\end{array}$ & $\begin{array}{l}\text { JAN } \\
\text { FEB } \\
\text { MAR }\end{array}$ & $\begin{array}{l}29 \\
21 \\
14\end{array}$ & $\begin{array}{l}15.66 \\
16.03 \\
13.69\end{array}$ & $\begin{array}{l}\text { APR } \\
\text { MAY } \\
\text { JUN }\end{array}$ & $\begin{array}{l}16 \\
20 \\
12\end{array}$ & $\begin{array}{l}12.73 \\
13.88 \\
15.37\end{array}$ & $\begin{array}{l}\text { JUL } \\
\text { AUG } \\
\text { SEP }\end{array}$ & $\begin{array}{l}23 \\
19 \\
11\end{array}$ & $\begin{array}{l}16.98 \\
16.85 \\
17.05\end{array}$ \\
\hline
\end{tabular}


414205N092592001. Local number, 80-18-31 ABBB1.

LOCATION.--Lat 41.42'05", long 92.59'20\%, Hydrologic Unit 07080105 , approximately $3 \mathrm{mi}$ east of the City of Newton just south of U.S. Highway 6. Owner: P.W. Beukema.

AQUIFER.--Glacial drift: in materials of pleistocene age.

WELL CHARACTERISTICS.--Dug stock water-table well, diameter 36 in., depth 37 ft, cribbed with brick.

INSTRUMENTATION.--Quarterly measurement with chalked tape by USGS personnel.

DATUM.--Elevation of land-surface datum is $940 \mathrm{ft}$ above National Geodetic Vertical Datum of 1929 , from topographic map. Measuring point: Top of cement platform, 0.70 ft land-surface datum.

REMARKS. - None.

PERIOD OF RECORD.--February 1940 to current year.

EXTREMES FOR PERIOD OF RECORD.--Highest water level measured, 2.67 ft below land-surface datum, Jun.

10, 1947; lowest measured, $27.15 \mathrm{ft}$ below land-surface datum, Dec. 18, 1948.

WATER LEVEL, IN FEET BELOW LAND-SURFACE DATUM, WATER YEAR OCTOBER 1984 TO SEPTEMBER 1985

\begin{tabular}{|c|c|c|c|c|c|c|c|c|c|c|c|}
\hline DATE & & $\begin{array}{l}\text { WATER } \\
\text { LEVEL }\end{array}$ & DATE & & $\begin{array}{l}\text { WATER } \\
\text { LEVEL }\end{array}$ & DATE & & $\begin{array}{l}\text { WATER } \\
\text { LEVEL }\end{array}$ & DATE & & $\begin{array}{l}\text { WATER } \\
\text { LEVEL }\end{array}$ \\
\hline NOV & 1 & 6.53 & JAN & 23 & 8.44 & APR & 18 & 6.86 & JUL & 10 & 13.61 \\
\hline
\end{tabular}

414147N093035401. Local number, 80-19-33 ACACl.

LOCATION.--Lat 41.41'47", long 93०03'54", Hydrologic Unit 07080105, 231 West 10th Street, Newton. Owner: John Coppess.

AQUIFER.--Jordan: in strata of Cambrian and Ordovician age.

WELL CHARACTERISTICS.--Drilled unused private artesian water well, diameter 12 to 6 in., depth 2,567 $\mathrm{ft}$, cased to $1,750 \mathrm{ft}$, open hole 1,750 to $2,567 \mathrm{ft}$.

INSTRUMENTATION.--Quarterly measurement with chalked tape by usgs personnel.

DATUM. --Elevation of land-surface datum is $915 \mathrm{ft}$ above National Geodetic vertical Datum of 1929 , from topographic map. Measuring point: Plug in cement well cover, 0.50 ft above land-surface datum.

REMARXS.--461 ft of the Prairie du Chien formation of Ordovician age, $262 \mathrm{ft}$ of the St. Lawrence formation of Cambrian age, and $94 \mathrm{ft}$ of Franconia sandstone of Cambrian age open.

PERIOD OF RECORD.--September 1963 to current year.

EXTREMES FOR PERIOD OF RECORD.--Highest water level measured, 98.43 ft below land-surface datum, Jun. 14, 1966 ; lowest measured, $266.10 \mathrm{ft}$ below land-surface datum, Jan. $27,1982$.

WATER LEVEL, IN FEET BELOW LAND-SURFACE DATUM, WATER YEAR OCTOBER 1984 TO SEPTEMBER 1985

\begin{tabular}{|c|c|c|c|c|c|c|c|}
\hline DATE & $\begin{array}{l}\text { WATER } \\
\text { LEVEL }\end{array}$ & DATE & $\begin{array}{l}\text { WATER } \\
\text { LEVEL }\end{array}$ & DATE & $\begin{array}{l}\text { WATER } \\
\text { LEVEL }\end{array}$ & DATE & \\
\hline Nov & 246.80 & JAN & 234.10 & APR & 251.52 & JUL & 10 \\
\hline
\end{tabular}

\section{JOHNSON COUNTY}

414107 N091322901. Local number, 79-6-4 AAAAl.

LOCATION.--Lat 41.41.07\%, long 91.32'29\%, Hydrologic unit 07080209, at Forest view Trailer Court, northern edge of Iowa City. Owner: Forest View Trailer court.

AQUIFER.--Silurian-Devonian: in limestone of Silurian age.

WELL CHARACTERISTICS.--Drilled unused artesian water well, diameter 6 in., depth 280 ft, cased to 96 $f t$, open hole 96 to $280 \mathrm{ft}$.

INSTRUMENTATION.--Water-level recorder.

DATUM.--Elevation of land-surface datum is $735 \mathrm{ft}$ above National Geodetic Vertical Datum of 1929 , from topographic map. Measuring point: Top of casing, $1.00 \mathrm{ft}$ above land-surface datum.

REMARKS.--Water levels affected by wells in the area pumping in late spring, summer, and early fall. PERIOD OF RECORD. - May 1971 to current year.

REVISED RECORDS - - WDR IA-84-1.

EXTREMES FOR PERIOD OF RECORD.--Highest water level recorded, 96.93 ft below land-surface datum, Mar. 23, 1979; lowest recorded, $146.01 \mathrm{ft}$ below land-surface datum, Jul. 17, 1971 .

WATER LEVEL, IN FEET BELOW LAND-SURFACE DATUM, WATER YEAR OCTOBER 1984 TO SEPTEMBER 1985 NOON VALUES

\begin{tabular}{|c|c|c|c|c|c|c|c|c|c|c|c|c|}
\hline DAY & OCT & nov & DEC & JAN & FEB & MAR & APR & MAY & JUN & JUL & AUG & SEP \\
\hline $\begin{array}{r}5 \\
10 \\
15 \\
20 \\
25 \\
\text { EOM }\end{array}$ & $\begin{array}{l}123.04 \\
123.55 \\
123.04 \\
121.94 \\
116.02 \\
113.64\end{array}$ & $\begin{array}{l}112.05 \\
108.76 \\
106.83 \\
106.05 \\
104.17 \\
103.31\end{array}$ & $\begin{array}{l}103.11 \\
102.44 \\
102.13 \\
101.86 \\
102.46 \\
101.97\end{array}$ & $\begin{array}{l}101.60 \\
101.34 \\
101.24 \\
101.09 \\
100.98 \\
100.78\end{array}$ & $\begin{array}{l}100.55 \\
100.54 \\
100.48 \\
100.33 \\
100.32 \\
100.27\end{array}$ & $\begin{array}{r}100.36 \\
99.71 \\
99.89 \\
99.55 \\
99.66 \\
98.82\end{array}$ & $\begin{array}{r}98.97 \\
99.58 \\
100.83 \\
106.05 \\
111.17 \\
114.57\end{array}$ & $\begin{array}{c}116.83 \\
119.89 \\
120.53 \\
121.82 \\
122.73 \\
\end{array}$ & $\begin{array}{l}--- \\
123.48 \\
124.22 \\
124.85 \\
127.22 \\
127.75\end{array}$ & $\begin{array}{l}128.25 \\
130.11 \\
130.11 \\
129.64 \\
129.92 \\
129.50\end{array}$ & $\begin{array}{r}129.62 \\
\text { el } 29.65 \\
\text { el } 28.30 \\
=127.50 \\
128.40\end{array}$ & $\begin{array}{l}129.05 \\
130.37 \\
131.20 \\
131.95 \\
131.59 \\
129.48\end{array}$ \\
\hline
\end{tabular}

WTR YEAR 1985 HIGHEST 98.71 MAR 28, 1985 LOWEST 132.12 SEP 24, 1985

e Estimated. 
413925N091324001. Local number, 79-6-9 DDBC1.

LOCATION. --Lat $41^{\circ} 39^{\prime} 34^{\prime \prime}$, long 91.32'42", Hydrologic Onit 07080209, at the Quadrangle Dormitory, University of Iowa, Iowa City, Owner: Oniversity of Iowa.

AQDIFER.--Silurian-Devonian: in dolomite of Silurian age, diameter $12 \mathrm{in}$, depth $430.5 \mathrm{ft}$, cased to 225 $f t$, open hole 225 to $430.5 \mathrm{ft}$.

INSTROMENTATION.--Monthly measurement with chalked tape by uSGS personnel.

DATUM.--Elevation of land-gurface datum is $714 \mathrm{ft}$ above National Geodetic Vertical Datum of 1929 , from topographic map. Measuring polnt: Hole in well cap, 1. $50 \mathrm{ft}$ above land-8urface datum.

REMARRs.-- Water levels affected by nearby wells pumping in late spring, summer and early fall.

PERIOD OF RECORD.--April 1975 to current year.

REVISED RECORDS. - -WDR IA-84-1.

EXTREMES FOR PERIOD OP RECORD. --Bighest water level measured, $75.02 \mathrm{ft}$ below land-surface datum, Mar. 15, 1979, lowest measured, $165.93 \mathrm{ft}$ below land-8urface datum, Jul. 13, 1977 .

WATER LEVEL, IN FEET BELOW LAND-SORFACE DATOM, WATER YEAR OCTOBER 1984 TO SEPTEMBER 1985

\begin{tabular}{|c|c|c|c|c|c|c|c|c|c|c|c|}
\hline DATE & & $\begin{array}{l}\text { WATER } \\
\text { LEVEL }\end{array}$ & DATE & & $\begin{array}{l}\text { WATER } \\
\text { LEVEL }\end{array}$ & DATE & & $\begin{array}{l}\text { WATER } \\
\text { LEVEL }\end{array}$ & DATE & & $\begin{array}{l}\text { WATER } \\
\text { LEVEL }\end{array}$ \\
\hline $\begin{array}{l}\text { OCT } \\
\text { NOV } \\
\text { DEC }\end{array}$ & $\begin{array}{l}25 \\
29 \\
27\end{array}$ & $\begin{array}{r}101.91 \\
84.14 \\
90.52\end{array}$ & $\begin{array}{l}\text { JAN } \\
\text { FEB } \\
\text { MAR }\end{array}$ & $\begin{array}{l}31 \\
26 \\
19\end{array}$ & $\begin{array}{l}84.75 \\
87.61 \\
85.34\end{array}$ & $\begin{array}{l}\text { APR } \\
\text { MAY } \\
\text { JON }\end{array}$ & $\begin{array}{r}18 \\
13 \\
7\end{array}$ & $\begin{array}{l}103.69 \\
133.56 \\
135.16\end{array}$ & $\begin{array}{l}\text { JUL } \\
\text { AUG } \\
\text { SEP }\end{array}$ & $\begin{array}{l}8 \\
8 \\
9\end{array}$ & $\begin{array}{l}153.11 \\
152.46 \\
151.38\end{array}$ \\
\hline
\end{tabular}

413955N091320303. Local number, 79-6-10 BDBC3.

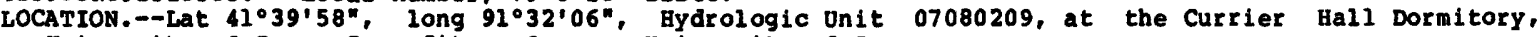
Oniversity of Iowa, Iowa City. Owner: University of Iowa.

AOUIFER.--silurian-Devonian: in dolomite of silurian age.

WELL CHARACTERISTICS.--Drilled unused artesian water weli, diameter 12 in., depth $425 \mathrm{ft}$, cased to 160 ft, Open hole 160 to $425 \mathrm{ft}$.

INSTRUEENTATION. - Monthly measurement with chalked tape by usGs personnel.

DATUM.--Elevation of land-gurface datum is $707 \mathrm{ft}$ above vational Geodetic Vertical Datum of 1929 , from from topographic map. Measuring point: Nipple welded to plate on top of casing, 7.94 ft below landgurface datum.

REMARRs.--Water levels affected by nearby wells pumping in late spring, summer, and early fall. Thirtyfive $f t$ of Devonian open.

PERIOD OR RECORD.--October 1971 to current year.

EXTREMES EOR PERIOD OF RECORD.--Highest water level measured, 62.12 ft below land-surface datum, Apr.

23, 1973, lowest measured, $163.16 \mathrm{ft}$ below land-gurface datum, Jul. $14,1978$.

WATER LEVEL, IN FEET BELOW LAND-SORFACE DATOM, WATER YEAR OCTOBER 1984 TO SEPTEMBER 1985

\begin{tabular}{|c|c|c|c|c|c|c|c|c|c|c|c|}
\hline DATE & & $\begin{array}{l}\text { WATER } \\
\text { EEVEL }\end{array}$ & DATE & & $\begin{array}{l}\text { WATER } \\
\text { LEVEL }\end{array}$ & DATE & & $\begin{array}{l}\text { WATER } \\
\text { LEVEL }\end{array}$ & DATE & & $\begin{array}{l}\text { WATER } \\
\text { LEVEL }\end{array}$ \\
\hline $\begin{array}{l}\text { OCT } \\
\text { NOV } \\
\text { JAN }\end{array}$ & $\begin{array}{l}25 \\
29 \\
31\end{array}$ & $\begin{array}{l}91.17 \\
72.43 \\
69.27\end{array}$ & $\begin{array}{l}\text { PEB } \\
\text { MAR } \\
\text { APR }\end{array}$ & $\begin{array}{l}26 \\
19 \\
18\end{array}$ & $\begin{array}{r}69.86 \\
68.83 \\
118.78\end{array}$ & $\begin{array}{l}\text { MAY } \\
\text { JUN } \\
\text { JUN }\end{array}$ & $\begin{array}{r}13 \\
7 \\
26\end{array}$ & $\begin{array}{l}143.19 \\
127.34 \\
154.83\end{array}$ & $\begin{array}{l}\text { JOL } \\
\text { AUG } \\
\text { SEP }\end{array}$ & $\begin{array}{l}8 \\
8 \\
9\end{array}$ & $\begin{array}{l}156.23 \\
157.72 \\
159.03\end{array}$ \\
\hline
\end{tabular}

413844N091323201. Local number, 79-6-16 DDAD1.

LOCATION,--Lat $41^{\circ} 38^{\prime} 44^{\prime \prime}$, long $91^{\circ} 32^{\prime} 32^{\prime \prime}$, Hydrologic Onit 07080209, 1223 South River81de Drive, Iowa

City. Owner: Iowa city Community school District.

AQOIFBR.--Silurian-Devonian: in limestone and dolomite of Devonian age and dolomite of silurian age.

WELL CBARACTERISTICS.--Drilied observation artesian water well, diameter 6 in., depth $363 \mathrm{ft}$, cased to $66.5 \mathrm{ft}$, open hole 66.5 to $363 \mathrm{ft}$.

INSTRUHENTATION.--Monthly measurement with chalked tape by osGs personnel.

DATUK.--Elevation of land-gurface datum is $652 \mathrm{ft}$ above National Geodetic Vertical Datum of 1929 , from topographic map. Measuring point: Nipple welded to plate on top of casing, $2.12 \mathrm{ft}$ above 1 andgurface datum.

REMARKS.--U.S.G.8.- I.G.S. warehouse well. water levels affected by wells in the area pumping in 1 ate apring, aummer, and early fall.

PERIOD OF RECORD.--April 1974 to current year.

REVISED RECORDS, - WDR IA-84-1.

EXTREYES FOR PERIOD OF RECORD,--Highegt water level measured, 9.96 ft below land-gurface datum, Apr 11. 1979, lowest measured, $32.94 \mathrm{ft}$ below land-surface datum, Jul. 15, 1977.

WATER LEVEL, IN PEET BELON LAND SUREACE DATUM, WATER YEAR OCTOBER 1984 TO SEPTEMBER 1985

\begin{tabular}{|c|c|c|c|c|c|c|c|c|c|c|c|}
\hline DATE & & $\begin{array}{l}\text { WATER } \\
\text { LEVEL }\end{array}$ & DATE & & $\begin{array}{l}\text { WATER } \\
\text { LEVEL }\end{array}$ & DATE & & $\begin{array}{l}\text { WATER } \\
\text { LEVEL }\end{array}$ & DATE & & $\begin{array}{l}\text { WATER } \\
\text { LEVEL }\end{array}$ \\
\hline $\begin{array}{l}\text { OCT } \\
\text { NOV } \\
\text { DEC }\end{array}$ & $\begin{array}{l}25 \\
29 \\
27\end{array}$ & $\begin{array}{l}23.72 \\
15.17 \\
13.55\end{array}$ & $\begin{array}{l}\text { JAN } \\
\text { EEB } \\
\text { MAR }\end{array}$ & $\begin{array}{l}31 \\
26 \\
19\end{array}$ & $\begin{array}{l}13.28 \\
12.83 \\
11.93\end{array}$ & $\begin{array}{l}\text { APR } \\
\text { MAY } \\
\text { JUN }\end{array}$ & $\begin{array}{r}18 \\
13 \\
7\end{array}$ & $\begin{array}{l}11.81 \\
21.22 \\
23.49\end{array}$ & $\begin{array}{l}\text { JOL } \\
\text { ADG } \\
\text { SEP }\end{array}$ & $\begin{array}{l}8 \\
8 \\
9\end{array}$ & $\begin{array}{l}28.72 \\
28.91\end{array}$ \\
\hline
\end{tabular}


414315N091252001. Local number, 80-5-22 CBCB1.

LOCATION, - Lat $41^{\circ} 43^{\prime} 15^{\prime \prime}$, long $91^{\circ} 25^{\prime} 20^{\prime}$, Hydrologic Unit 07080209, along the Chicago, Rock Island and

Pacific Railroad track, southeast of the overpass on Rapid Creek Road over the track, approximately $5.50 \mathrm{mi}$ northeast of the junction of Interstate 80 and Iowa Highway 1 . Owner: Chicago, Rock Island and Pacific Railroad Co.

AQUIFER.--Glacial drift: in material of Pleistocene age.

WELL CHARACTERISTICS.--Drilled unused water-table well, diameter 1.25 in., depth $20 \mathrm{ft}$, cased to $18 \mathrm{ft}$, screened 18 to $20 \mathrm{ft}$.

INSTRUMENTATION.--Monthly measurement with chalked tape by uSGS personnel.

DATUM.--Elevation of land-surface datum is $753 \mathrm{ft}$ above National Geodetic vertical Datum of 1929 , from topographic map. Measuring point: Top of casing, $4.20 \mathrm{ft}$ above land-surface datum.

REMARRS. - At the site of the former Elmira depot.

PERIOD OF RECORD.--October 1941 to September 1956, January 1958 to current year.

EXTREMES FOR PERIOD OF RECORD.--Highest water level measured, 5.78 ft below land-surface datum, Sep.

20, 1977, lowest measured, dry, Dec. 2-31, 1955 and Nov. 8 - Dec. 31, 1964.

WATER LEVEL, IN FEET BELOW LAND-SURFACE DATUM, WATER YEAR OCTOBER 1984 TO SEPTEMBER 1985

$\begin{array}{llllllllll}\text { DATE } & \begin{array}{l}\text { WATER } \\ \text { LEVEL }\end{array} & \text { DATE } & & \begin{array}{l}\text { WATER } \\ \text { LEVEL }\end{array} & \text { DATE } & \text { WATER } & & \text { DATE } & \text { WATER } \\ \text { LEVEL }\end{array}$

414315N091252002. Local number, 80-5-22 CBCB2.

LOCATION.--Lat 41.43'15", long 91०25'20". Hydrologic Unt 07080209 , along the Chicago, Rock Island and

Pacific Railroad track, southeast of the overpass on Rapid Creek Road over the track, approximately

$5.50 \mathrm{mi}$ northeast of the junction of Interstate 80 and Iowa Highway 1 . Owner: Chicago, Rock Island and Pacific Rall road Co.

AQUIFER.--Cedar Valley: in limestone of Devonian age.

WELL CHARACTERISTICS.-Drilled unused artesian water well, diameter 5 in., depth $82 \mathrm{ft}$

INSTRUMENTATION.--Monthly measurement with chalked tape by usGs personnel.

DATUM.--Elevation of land-surface datum is $753 \mathrm{ft}$ above National Geodetic Vertical Datum of 1929 , from

topographic map. Measuring point: Top of casing, $2.50 \mathrm{ft}$ above land-surface datum.

REMARKS.--Casing information not available. At the site of the former Elmira depot.

PERIOD OF RECORD.--December 1941 to current year.

EXTREMES FOR PERIOD OF RECORD.-- Highest water level measured, 8.15 ft below land-surface datum, Apr.

21, 1952; lowest measured, $21.05 \mathrm{ft}$ below land-surface datum, Sep. $26,1957$.

WATER LEVEL, IN FEET BELOW LAND-SURFACE DATUM, WATER YEAR OCTOBER 1984 TO SEPTEMBER 1985

\begin{tabular}{|c|c|c|c|c|c|c|c|c|c|c|c|}
\hline DATE & & $\begin{array}{l}\text { WATER } \\
\text { LEVEL }\end{array}$ & DATE & & $\begin{array}{l}\text { WATER } \\
\text { LEVEL }\end{array}$ & DATE & & $\begin{array}{l}\text { WATER } \\
\text { LEVEL }\end{array}$ & DATE & & $\begin{array}{l}\text { WATER } \\
\text { LEVEL }\end{array}$ \\
\hline $\begin{array}{l}\text { OCT } \\
\text { NOV } \\
\text { DEC }\end{array}$ & $\begin{array}{l}23 \\
20 \\
20\end{array}$ & $\begin{array}{l}15.92 \\
15.66 \\
15.49\end{array}$ & $\begin{array}{l}\text { JAN } \\
\text { PEB } \\
\text { MAR }\end{array}$ & $\begin{array}{l}24 \\
19 \\
21\end{array}$ & $\begin{array}{l}15.57 \\
15.92 \\
15.11\end{array}$ & $\begin{array}{l}\text { APR } \\
\text { MAY } \\
\text { JUN }\end{array}$ & $\begin{array}{l}25 \\
21 \\
20\end{array}$ & $\begin{array}{l}15.47 \\
16.15 \\
16.80\end{array}$ & $\begin{array}{l}\text { JUL } \\
\text { AUG } \\
\text { SEP }\end{array}$ & $\begin{array}{l}22 \\
20 \\
23\end{array}$ & $\begin{array}{l}17.62 \\
18.42 \\
18.76\end{array}$ \\
\hline
\end{tabular}

414853N091425101. Local number, 81-7-19 BCBBl.

LOCATION.--Lat $41^{\circ} 48^{\prime} 53^{\circ}$, long $91^{\circ} 42^{\prime} 51^{\circ}$, Hydrologic Unit 07080208 , approximately 0.75 mi west and 2.25

mi south of the Town of Swisher. Owner: Iowa Geological Survey and v.s. Geological survey.

AQUIFER.--Silurian-Devonian: in dolomite of Silurian age and limestone of Devonian age.

WELL CHARACTERISTICs.--Drilled observation artesian water well, diameter 6 in.. depth 535 ft, cased to $130 \mathrm{ft}$, open hole 130 to $535 \mathrm{ft}$.

INSTRUMENTATION.--Water-level recorder.

DATUM.--Elevation of land-surface datum is $745 \mathrm{ft}$ above National Geodetic vertical Datum of 1929 , from topographic map. Measuring point: Top of casing, $3.50 \mathrm{ft}$ above land-surface datum.

REMARKS.--U.S.G.S.-I.G.S. PI um Creek weIl.

PERIOD OF RECORD.--November 1976 to current year.

EXTREMES FOR PERIOD OF RECORD.--Highest water level recorded, 64.46 ft below land-surface datum, May

31, 1983, lowest recorded, $74.60 \mathrm{ft}$ below land-surface datum, Sept. 13 and 14, 1985 .

WATER LEVEL, IN FEET BELOW LAND-SURFACE DATUM, WATER YEAR OCTOBER 1984 TO SEPTEMBER 1985 NOON VÁUUBS

\begin{tabular}{|c|c|c|c|c|c|c|c|c|c|c|c|c|}
\hline DAY & OCT & NOV & DEC & JAN & FEB & MAR & APR & MAY & JUN & JUL & AUG & SEP \\
\hline $\begin{array}{r}5 \\
10 \\
15 \\
20 \\
25 \\
\text { EOM }\end{array}$ & $\begin{array}{l}69.88 \\
70.02 \\
69.36 \\
69.90 \\
69.89 \\
69.95\end{array}$ & $\begin{array}{l}69.97 \\
69.72 \\
69.86 \\
70.38 \\
69.71 \\
69.59\end{array}$ & \begin{tabular}{l}
69.75 \\
69.63 \\
69.56 \\
0 \\
\hdashline
\end{tabular} & $\begin{array}{l}- \\
68.98 \\
\ldots .97\end{array}$ & $\begin{array}{l}68.66 \\
68.80 \\
68.74 \\
68.68 \\
68.60 \\
68.27\end{array}$ & $\begin{array}{l}68.59 \\
68.27 \\
68.64 \\
68.66 \\
68.70 \\
67.76\end{array}$ & $\begin{array}{l}67.94 \\
68.29 \\
68.13 \\
68.10 \\
68.47\end{array}$ & $\begin{array}{l}68.47 \\
68.71 \\
68.69 \\
68.72 \\
68.87 \\
68.86\end{array}$ & $\begin{array}{r}69.42 \\
69.79 \\
e 69.88 \\
70.38 \\
70.74\end{array}$ & $\begin{array}{l}70.59 \\
71.16 \\
71.49 \\
71.69 \\
71.85 \\
72.24\end{array}$ & $\begin{array}{l}72.36 \\
72.84 \\
73.15 \\
73.52 \\
73.73\end{array}$ & $\begin{array}{l}73.71 \\
74.17 \\
74.46 \\
74.46 \\
74.48 \\
74.44\end{array}$ \\
\hline
\end{tabular}

WTR YEAR HIGHEST 67.76 MAR 31, 1985 LOWEST 74.60 SEP 13 and 14, 1985

e Estimated 
415808N091160501. Local number, 83-4-25 CBBBl.

LOCATION. --Lat 4i.58'08", long $91^{\circ} 16^{\prime} 05^{\prime \prime}$, Bydrologic unit $07080103,4 \mathrm{mi}$ north of the Town of Mechanicsville and $1 \mathrm{mi}$ west of County Road $\mathrm{x}-40$. Owner: Iowa Geological Survey and U.S. Geological Survey.

AQUIFER.--Silurian-Devonian: in dolomite of silurian age.

WELL CBARACTERISTICS. - Drilled observation artesian water well, diameter $6 \mathrm{in}$. to $41 \mathrm{ft}$, $5 \mathrm{in}$. to 517 $\mathrm{ft}$, depth $517 \mathrm{ft}$, cased to $41 \mathrm{ft}$, open hole 41 to $517 \mathrm{ft}$.

INSTRUMENTATION. --Ouarterly measurement with chalked tape by USGS personnel.

DATUM.--Elevation of land-surface datum is $807 \mathrm{ft}$ above National Geodetic vertical Datum of 1929 , from topographic map. Measuring point: Top of casing, $1.00 \mathrm{ft}$ above land-surface datum.

REMARKS. - White Oak creek well.

PERIOD OF RECORD.--July 1976 to current year.

EXTREMES FOR PERIOD OF RECORD. - - Highest water level measured, $1.24 \mathrm{ft}$ below land-surface datum, Apr. 3 , 1979, lowest measured, $5.49 \mathrm{ft}$ below land-surface datum, Jun. 29, 1977.

WATER LEVEL, IN FEET BELOW LAND-SURFACE DATUM, WATER YEAR OCTOBER 1984 TO SEPTEMBER 1985

$\begin{array}{lrrrrrrr}\text { DATE } & \begin{array}{r}\text { WATER } \\ \text { LEVEL }\end{array} & \text { DATE } & \begin{array}{r}\text { WATER } \\ \text { LEVEL }\end{array} & \text { DATE } & \begin{array}{r}\text { WATER } \\ \text { LEVEL }\end{array} & \text { DATE } & \begin{array}{r}\text { WATER } \\ \text { LEVEL }\end{array} \\ \text { NOV } 13 & 2.30 & \text { MAR } 19 & 2.29 & \text { MAY } 21 & 3.23 & \text { AUG } 21 & 4.85\end{array}$

LINN COUNTY

415422N091422601. Local number, 82-7-18 CDCDl.

LOCATION. --Lat 41.54'22", Iong 91.42'26", Hydrologic Unit 07080205, on 76th Avenue sw, approximately

$1.5 \mathrm{mi}$ west of U.S. Highway 218 , Cedar Rapids. Owner: Lester Petrak.

AQUIFER. --Glacial drift: in material of Pleistocene age.

WELL CHARACTERISTICS.--Dug unused water-table well, diameter $4 \mathrm{ft}$, depth $14 \mathrm{ft}$, cribbed with brick. INSTRUMENTATION. - -Water-level recorder.

DATOM.--Elevation of land-surface datum is $835 \mathrm{ft}$ above National Geodetic Vertical Datum of 1929 , from

topographic map. Measuring point: Base of recorder shelter, $0.25 \mathrm{ft}$ above land-surface datum.

REMARKS. - -None.

PERIOD OF RECORD.--July 1959 to current year.

REVISED RECORDS. - WDR IA-84-1.

EXTREMES FOR PERIOD OF RECORD.-- Highest water level recorded, $1.09 \mathrm{ft}$ below land-surface datum, Aug.

4, 1968; lowest recorded, ell, $75 \mathrm{ft}$ below land-surface datum, Feb. 8, 1977.

WATER LEVEL, IN FEET BELOW LAND-SURFACE DATUM, WATER YEAR OCTOBER 1984 TO SEPTEMBER 1985 NOON VALUES

\begin{tabular}{|c|c|c|c|c|c|c|c|c|c|c|c|c|}
\hline DAY & OCT & NOV & DEC & JAN & FEB & MAR & APR & MAY & JUN & JUL & AUG & SEP \\
\hline $\begin{array}{r}5 \\
10 \\
15 \\
20 \\
25 \\
\text { EOM }\end{array}$ & $\begin{array}{l}9.08 \\
9.21 \\
8.58 \\
4.99 \\
5.00 \\
4.46\end{array}$ & $\begin{array}{l}4.25 \\
3.34 \\
4.22 \\
4.68 \\
4.87 \\
5.05\end{array}$ & $\begin{array}{r}e 5.24 \\
5.45 \\
5.69 \\
4.61 \\
4.82 \\
4.06\end{array}$ & $\begin{array}{r}e 4.55 \\
e 4.90 \\
e 5.10 \\
\text { e5.25 } \\
5.44 \\
5.76\end{array}$ & $\begin{array}{l}5.99 \\
6.24 \\
6.59 \\
6.19 \\
4.25 \\
4.55\end{array}$ & $\begin{array}{l}3.79 \\
4.52 \\
4.65 \\
4.80 \\
4.94 \\
4.73\end{array}$ & $\begin{array}{l}4.51 \\
4.81 \\
4.95 \\
5.09 \\
5.13 \\
5.26\end{array}$ & $\begin{array}{l}5.35 \\
5.58 \\
5.48 \\
5.78 \\
6.13 \\
6.48\end{array}$ & $\begin{array}{l}6.85 \\
7.16 \\
7.25 \\
7.53 \\
7.68 \\
7.99\end{array}$ & $\begin{array}{l}8.28 \\
8.60 \\
8.85 \\
9.10 \\
9.30 \\
9.51\end{array}$ & $\begin{array}{r}9.68 \\
9.85 \\
10.01 \\
10.17 \\
10.08 \\
10.25\end{array}$ & $\begin{array}{r}10.39 \\
10.54 \\
10.69 \\
10.84 \\
10.29 \\
9.53\end{array}$ \\
\hline
\end{tabular}

WTR YEAR 1985 HIGEEST 3.28 NOV 10, 1984 LOWEST 10.85 SEP 21, 1985

e Estimated.

415509N091461801. LOCal number, 82-8-20 ACBBl.

LOCATION. --Lat 41.55'09", Iong 91.46'18", Bydrologic Unit 070802005, approximately $1.5 \mathrm{mi}$ southwest of the Town of Fairfax, just northwest of Iowa Highway 149. Owner: Iowa Geological Survey and U.S. Geological Survey.

AQUIFER.--Silurian-Devonian: in limestone of Devonian age and dolomite of silurian age.

WELL CHARACTERISTICS. --Drilled observation artesian water well, diameter 5 in., depth $569 \mathrm{ft}$, cased to $100.5 \mathrm{ft}$, open hole 100.5 to $569 \mathrm{ft}$.

INSTROMENTATION.--Quarterly measurement with chalked tape by USGS personnel.

DATUM.--Elevation of land-surface datum is $842 \mathrm{ft}$ above National Geodetic Vertical Datum of 1929, from topogarphic map. Measuring point: Top of casing, $0.88 \mathrm{ft}$ above land-surface datum.

REMARKS.--Rock Pile well.

PERIOD OF RECORD. - March 1974 to current year.

REVISED RECORDS. --WDR IA-84-1.

EXTREMES FOR PERIOD OF RECORD. -- Highest water level measured, $96.70 \mathrm{ft}$ below land-surface datum, Jun. 21, 1974; lowest measured, $108.37 \mathrm{ft}$ below land-surface datum, Jul. 22 and 23, 1977.

WATER LEVEL, IN FEET BELOW LAND-SURFACE DATUM, WATER YEAR OCTOBER 1984 TO SEPTEMBER 1985

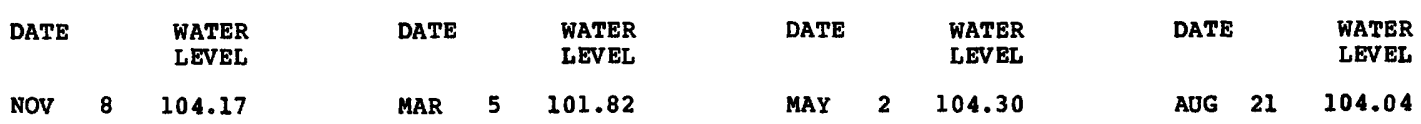


415816N091393401. Local number, 83-7-28 ADDAl.

LOCATION,--Lat $41^{\circ} 58^{\prime} 16^{\circ}$, long $91^{\circ} 39^{\prime} 34^{\circ}$, Hydrologic Unit 07080205, 320 11th Avenue SE, Cedar Rapids. Owner: Robert Chadima.

AOUIFER.--Silurian-Devonian: in limestone of silurian age.

WELL CHARACTERISTICS.--Drilied unused artesian water weil, diameter 10 in., depth $420 \mathrm{ft}$, cased to 75 $f t$, open hole 75 to $420 \mathrm{ft}$.

INSTRUMENTATION.--Water-level recorder.

DATUM.--Elevation of land-surface datum is $735 \mathrm{ft}$ above National Geodetic Vertical Datum of 1929 , from

topographic map. Measuring point: Top of recorder platform, 2.95 ft below land-surface datum.

REMARKS. --Formerly The Racena Co.. Inc.

PERIOD OF RECORD.--January 1962 to current year.

REVISED RECORDS. - WDR IA-84-1.

EXTREMES FOR PERIOD OF RECORD, - - Highest water level recorded, 51.10 ft below land-surface datum, Feb.

25, 1963; lowest recorded, $101.40 \mathrm{ft}$ below land-surface datum, Jul. $27,1981$.

WATER LEVEL, IN FEET BELON LAND-SURFACE DATUM, WATER YEAR OCTOBER 1984 TO SEPTELBER 1985 NOON VALUES

\begin{tabular}{|c|c|c|c|c|c|c|c|c|c|c|c|c|}
\hline DAY & OCT & Nov & DEC & JAN & FEB & MAR & APR & MAY & JUN & JUL & AUG & SEP \\
\hline $\begin{array}{r}5 \\
10 \\
15 \\
20 \\
25 \\
\text { EOM }\end{array}$ & $\begin{array}{l}95.60 \\
95.76 \\
94.77 \\
95.13 \\
95.00 \\
94.55\end{array}$ & $\begin{array}{l}94.33 \\
93.87 \\
93.72 \\
94.16 \\
93.23 \\
93.26\end{array}$ & $\begin{array}{l}93.47 \\
93.35 \\
93.50 \\
93.47 \\
93.66 \\
93.25\end{array}$ & $\begin{array}{l}93.24 \\
93.37 \\
93.26 \\
93.25 \\
93.23 \\
93.31\end{array}$ & $\begin{array}{l}92.88 \\
93.02 \\
93.13 \\
93.10 \\
93.18 \\
93.15\end{array}$ & $\begin{array}{l}93.57 \\
93.17 \\
93.62 \\
93.51 \\
93.61 \\
-\end{array}$ & 94.29 & $\begin{array}{l}94.58 \\
94.82 \\
94.98 \\
95.49 \\
95.26 \\
95.10\end{array}$ & e95.20 & $\begin{array}{l}95.05 \\
95.29 \\
95.44 \\
95.71 \\
95.63 \\
96.04\end{array}$ & $\begin{array}{l}96.01 \\
96.48 \\
96.63 \\
97.00 \\
96.90 \\
97.10\end{array}$ & $\begin{array}{r}97.00 \\
97.59 \\
97.88 \\
97.89 \\
e 97.50 \\
\end{array}$ \\
\hline
\end{tabular}

WTR YEAR 1985 HIGHEST 92.26 MAR 4,1985 LOWEST $98.16 \quad$ SEP 13,1985

e Estimated.

415725N091410101. Local number, 83-7-32 ACDCl.

LOCATION,--Lat $41^{\circ} 57^{\prime} 25^{\circ}$, long 91.41.01\%, Hydrologic Unit 07080205 , northwest corner of 22 nd Avenue sW

and lith Street Sw, Cedar Rapids. Owner: Floyd Fetter.

AQUIFER.--Silurian-Devonian: in limestone of silurian age.

WELL CHARACTERISTICS.--Drilied unused artesian water well, diameter 5 in., depth $282 \mathrm{ft}$.

INSTRUMENTATION. - Monthly measurement with chalked tape by uSGS personnel.

DATOM.--Elevation of land-surface datum is $805 \mathrm{ft}$ above National Geodetic Vertical Datum of 1929 , from

topographic map. Measuring point: Plug in well cover at land-gurface datum.

REMARKS --Casing information not available.

PERIOD OF RECORD.--July 1940 to current year.

EXTREMES FOR PERIOD OF RECORD.--Highest water level measured, 75.80 ft below land-surface datum, Jan.

26, 1942; lowest measured, $107.00 \mathrm{ft}$ below land-surface datum, Sept. 16, 1976.

WATER LEVEL, IN FEET BELON LAND-SURFACE DATUM, WATER YEAR OCTOBER 1984 TO SEPTEMBER 1985

\begin{tabular}{|c|c|c|c|c|c|c|c|c|c|c|c|}
\hline \multirow[t]{2}{*}{ DATE } & & WATER & \multirow{2}{*}{\multicolumn{2}{|c|}{ DATE }} & WATER & \multirow{2}{*}{\multicolumn{2}{|c|}{ DATE }} & WATER & \multicolumn{2}{|c|}{ DATE } & WATER \\
\hline & & LEVEL & & & L EVEL & & & LEVEL & & & LEVEL \\
\hline $\begin{array}{l}\text { OCT } \\
\text { NOV } \\
\text { DEC }\end{array}$ & $\begin{array}{l}23 \\
20 \\
20\end{array}$ & $\begin{array}{l}89.24 \\
90.98 \\
92.98\end{array}$ & $\begin{array}{l}\text { JAN } \\
\text { FEB } \\
\text { MAR }\end{array}$ & $\begin{array}{l}24 \\
19 \\
21\end{array}$ & $\begin{array}{l}92.74 \\
92.66 \\
91.98\end{array}$ & $\begin{array}{l}\text { APR } \\
\text { MAY } \\
\text { JUN }\end{array}$ & $\begin{array}{l}25 \\
21 \\
20\end{array}$ & $\begin{array}{l}93.79 \\
94.53 \\
95.16\end{array}$ & $\begin{array}{l}\text { JUL } \\
\text { AUG } \\
\text { SEP }\end{array}$ & $\begin{array}{l}22 \\
20 \\
23\end{array}$ & $\begin{array}{l}96.11 \\
97.52 \\
97.44\end{array}$ \\
\hline
\end{tabular}

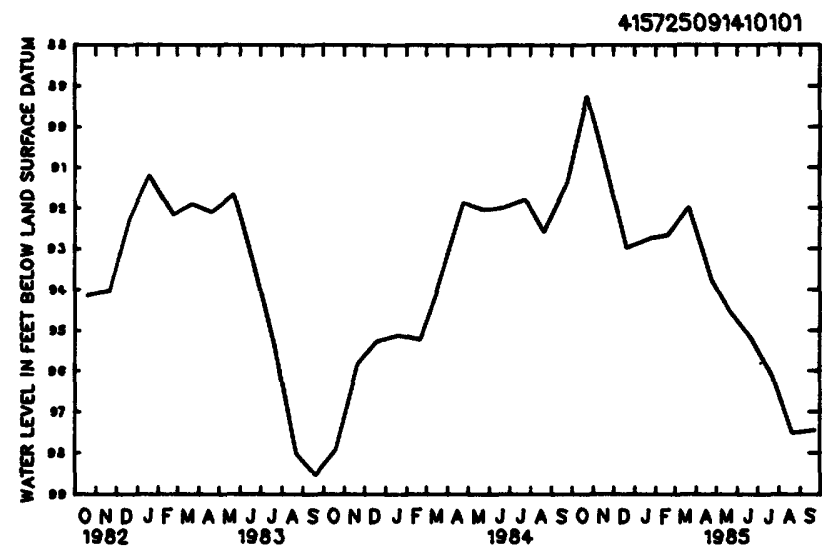




\section{LINN COUNTY}

420526N091370701. Local number, 84-7-13 BCBB1.

LOCATION.--Lat 42.05'26", long 91.37'07", Bydrologic Unit 07080206, approximately $0.25 \mathrm{mi}$ south of the junction of County Roads $W-58$ and E-34, or approximately $3.75 \mathrm{mi}$ north of the City of Marion. Owner: 0.S. Geological survey.

AQUIFER. --Glacial drift: in material of Pleistocene age.

WELL CHARACTERISTICS.--Drilled observation water-table well, diameter 1.25 in., depth $17 \mathrm{ft}$, cased to $15 \mathrm{ft}$, screened 15 to $17 \mathrm{ft}$.

INSTRUMENTATION. - Monthly measurement with chalked tape by OSGS personnel.

DATUM.--Elevation of land-surface datum is $882 \mathrm{ft}$ above National Geodetic Vertical Datum of 1929 , from topographic map. Measuring point: Top of casing, $0.75 \mathrm{ft}$ above land-surface datum.

REMARRS.--None.

PERIOD OF RECORD.--September 1948 to current year.

EXTREMES FOR PERIOD OF RECORD. -- Highest water level measured, $0.93 \mathrm{ft}$ below land-surface datum, May 18 , 1982; lowest measured, $12.90 \mathrm{ft}$ bel ow land-surface datum, Dec. 3, 1956.

WATER LEVEL, IN FEET BELOW LAND-SURFACE DATUM, WATER YEAR OCTOBER 1984 TO SEPTEMBER 1985

\begin{tabular}{|c|c|c|c|c|c|c|c|c|c|c|c|}
\hline DATE & & $\begin{array}{l}\text { WATER } \\
\text { LEVEL }\end{array}$ & DATE & & $\begin{array}{l}\text { WATER } \\
\text { LEVEL }\end{array}$ & DATE & & $\begin{array}{l}\text { WATER } \\
\text { LEVEL }\end{array}$ & DATE & & $\begin{array}{l}\text { WATER } \\
\text { LEVEL }\end{array}$ \\
\hline $\begin{array}{l}\text { OCT } \\
\text { NOV } \\
\text { DEC }\end{array}$ & $\begin{array}{l}23 \\
20 \\
20\end{array}$ & $\begin{array}{l}4.71 \\
4.24 \\
3.36\end{array}$ & $\begin{array}{l}\text { JAN } \\
\text { FEB } \\
\text { MAR }\end{array}$ & $\begin{array}{l}24 \\
19 \\
21\end{array}$ & $\begin{array}{l}3.99 \\
4.52 \\
2.18\end{array}$ & $\begin{array}{l}\text { APR } \\
\text { MAY } \\
\text { JUN }\end{array}$ & $\begin{array}{l}25 \\
21 \\
20\end{array}$ & $\begin{array}{l}2.06 \\
3.75 \\
5.59\end{array}$ & $\begin{array}{l}\text { JUL } \\
\text { AUG } \\
\text { SEP }\end{array}$ & $\begin{array}{l}22 \\
20 \\
23\end{array}$ & $\begin{array}{l}5.00 \\
8.02 \\
8.72\end{array}$ \\
\hline
\end{tabular}

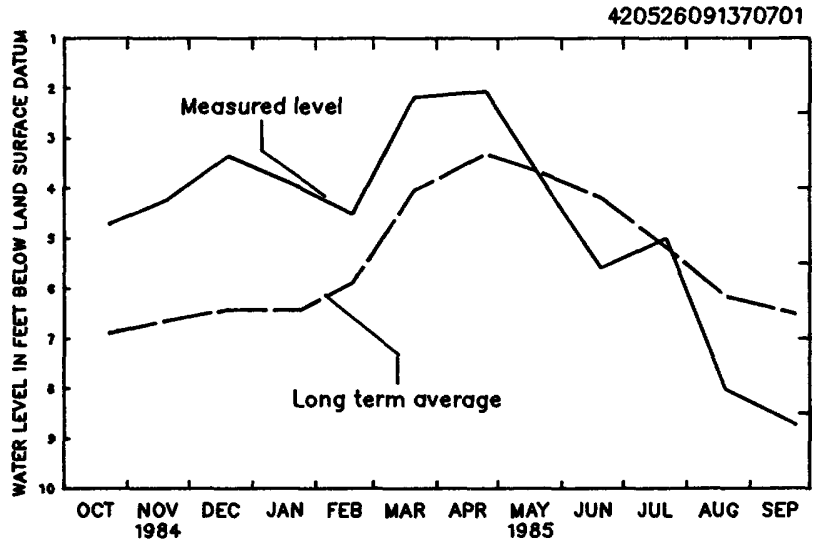

421149N091403301. Local number, 85-7-4 CCCCl.

LOCATION.--Lat $42^{\circ} 11^{149 "}$, long $91^{\circ} 40^{\prime} 33^{\prime \prime}$, Bydrologic Unit 07080205, approximately $5 \mathrm{mi}$ east of the Town of Center Point, north side of 'County Road E-16. Owner: Iowa Geological Survey and o.S. Geological Survey.

AQDIFER.--Silurian-Devonian: in dolomite of Silurian age and limestone of Devonian age.

WELL CHARACTERISTICS.--Drilled observation artesian water well, diameter 6 in., cased to $41 \mathrm{ft}, 5$ in. liner 129 to $147 \mathrm{ft}$, depth $435 \mathrm{ft}$, open hole 41 to $129 \mathrm{ft}$ and 147 to $435 \mathrm{ft}$.

INSTROMENTATION. --Quarterly measurement with chalked tape by uSGS personnel.

DATUM. - - Elevation of land-surface datum is $912 \mathrm{ft}$ above National Geodetic vertical Datum of 1929, from topographic map. Measuring point: Top of casing at land-surface datum.

REMARKS. --Alice well.

PERIOD OF RECORD.--July 1973 to current year.

REV ISED RECORDS. - WDR IA-84-1.

EXTREMES FOR PERIOD OF RECORD.--Highest water level measured, $17.06 \mathrm{ft}$ below land-surface datum, Jun.

10,1974 , lowest measured, $32.87 \mathrm{ft}$ below land-surface datum, Mar. 23, 1977 .

WATER LEVEL, IN FEET BELOW LAND-SURFACE DATUM, WATER YEAR OCTOBER 1984 TO SEPTEMBER 1985

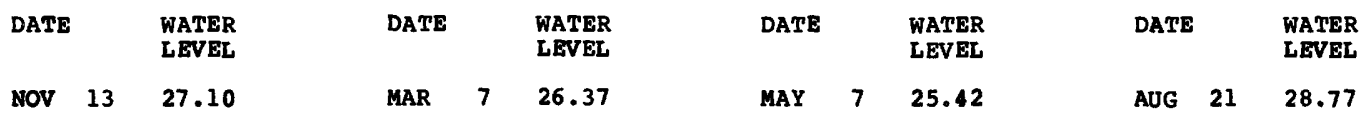


431812N096302701. Local number, 98-48-16 DDADI.

LOCATION. --Lat $43^{\circ} 18^{\prime} 12^{\prime \prime}$, long $96^{\circ} 30^{\prime} 27^{\prime \prime}$, Hydrologic Unit 10170203 , approximately $3.5 \mathrm{mi}$ east of the City of Canton, S.D., south of U.S. Highway 18. Owner: Iowa Geological Survey and 0.S. Geological Survey.

AQUIFER.--Dakota: in sandstone of Early Cretaceous age.

WELL CHARACTER ISTICS.--Drilled observation artesian water well, diameter 2 in., depth $358 \mathrm{ft}$, cased to $358 \mathrm{ft}$, perforated 335 to $355 \mathrm{ft}$.

INSTRUMENTATION. --Quarterly measurement with chalked tape by OSGS personel.

DATUM.--Elevation of land-surface datum is $1,268 \mathrm{ft}$ above National Geodetic Vertical Datum of 1929 ,

from topogarphic map. Measuring point: Top of casing, $2.00 \mathrm{ft}$ above land-surface datum.

REMARKS. - Well D-20. Sioux quartzite from 353 to $358 \mathrm{ft}$.

PERIOD OF RECORD. --December 1978 to December 1980 , May 1982 to current year.

EXTREMES FOR PERIOD OF RECORD.--Highest water level measured, $93.40 \mathrm{ft}$ below land-surface datum, Mar.

28, 1980 and May 6, 1980; lowest measured, $97.56 \mathrm{ft}$ below land-surface datum, Dec. 9, 1982.

WATER LEVEL, IN FEET BELOW LAND-SURFACE DATUM, WATER YEAR OCTOBER 1984 TO SEPTEMBER 1985

\begin{tabular}{|c|c|c|c|c|c|c|c|c|c|c|}
\hline DATE & $\begin{array}{l}\text { WATER } \\
\text { LEVEL }\end{array}$ & DATE & & $\begin{array}{l}\text { WATER } \\
\text { LEVEL }\end{array}$ & DATE & & $\begin{array}{l}\text { WATER } \\
\text { LEVEL }\end{array}$ & DATE & & $\begin{array}{l}\text { WATER } \\
\text { LEVEL }\end{array}$ \\
\hline CT 15 & 96.08 & JAN & 8 & 96.57 & APR & 2 & 95.95 & JUL & 8 & 96.00 \\
\hline
\end{tabular}

432140N095595301. Local number, 99-44-26 DDDD1.

LOCATION.--Lat $43^{\circ} 21^{\prime} 40^{\prime}$, long $95^{\circ} 59^{\prime} 53^{\circ}$, Hydrologic onit 10170204, 1 mi north of the City of George, west of Iowa Highway 339. Owner: State of Iowa.

AQUIFER.--Glacial drift: in material of pleistocene age.

WELL CHARACTERISTICS.--Drilled unused water-table well, diameter 20 in., depth $38 \mathrm{ft}$, 1 ined with tile. INSTROMENTATION.--Quarterly measurement with chalked tape by USGS personnel.

DATUM.--Elevation of land-surface datum is 1,400 ft above National Geodetic Vertical Datum of 1929. from topographic map. Measuring point: plug in well cover, 2.01 ft above land-surface datum. REMARKS. - None.

PERIOD OF RECORD.--October 1940 to June 1943, May 1947 to current year.

EXTREMES FOR PERIOD OF RECORD. - - Highest water level measured, 0.24 ft above land-surface datum, Apr. 24, 1984; 10west measured, $9.47 \mathrm{ft}$ below land-surface datum, Oct. 24, 1940.

WATER LEVEL, IN FEET BELOW LAND-SURFACE DATUM, WATER YEAR OCTOBER 1984 TO SEPTEMBER 1985

$\begin{array}{lrrrrrrrr}\text { DATE } & \begin{array}{r}\text { WATER } \\ \text { LEVEL }\end{array} & \text { DATE } & \begin{array}{r}\text { WATER } \\ \text { LEVEL }\end{array} & \text { DATE } & \text { WATER } \\ \text { LEVEL }\end{array}$

432553 N096105701. Local number, 99-45-5 ABACl.

LOCATION.--Lat $43^{\circ} 25^{\prime} 53^{\prime \prime}$, long $96^{\circ} 10^{\prime} 55^{\prime \prime}$, Hydrologic Unit 10170204, 0.05 mi south of Iowa Highway 9 on 2nd street, Rock Rapids. Owner: City of Rock Rapids.

AQUIFER.--Dakota: in sandstone of Early Cretaceous age.

WELL CHARACTERISTICS.--Drilled unused artesian water well, diameter 10 in., depth 375 ft, cased to 296 ft, open hole 296 to $375 \mathrm{ft}$.

INSTRUMENTATION.--Intermittent measurement with chalked tape by oSGS personnel.

DATUM.--Elevation of land-surface datum is $1,368 \mathrm{ft}$ above National Geodetic vertical Datum of 1929, from topographic map. Measuring point: Plug in cover over casing, 1.00 ft above land-surface datum. REMARKS.--City test well No. 3.

PERIOD OF RECORD.--August 1960 to current year.

EXTREMES FOR PERIOD OF RECORD.--Highest water level measured, 100.08 ft below land-surface datum, Jul.

27, 1964; lowest measured, $114.60 \mathrm{ft}$ below land-surface datum, May 7, 1985.

WATER LEVEL, IN FEET BELOW LAND-SURFACE DATUM, WATER YEAR OCTOBER 1984 TO SEPTEMBER 1985

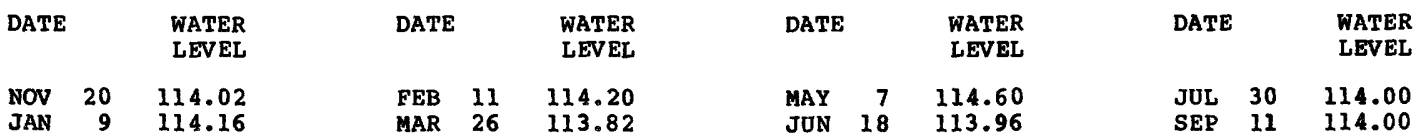

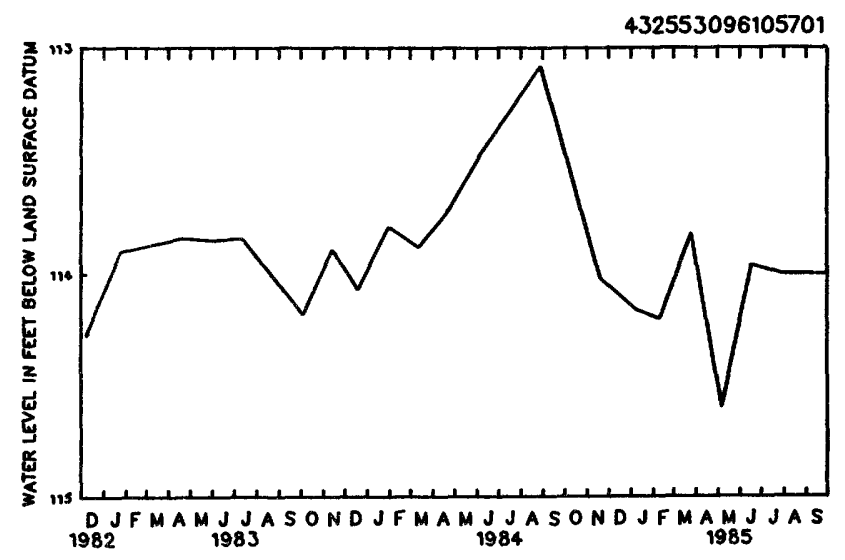


LYON COUNTY

432601N096335511. Local number, 100-48-31 cccc11.

LOCATION. - Lat $43^{\circ} 26^{\prime} 01^{\prime \prime}$, long $96^{\circ} 33^{\prime} 55^{\prime \prime}$, Hydrologic unit 10170203, $0.5 \mathrm{ml}$ west and $2.5 \mathrm{ml}$ south of the village of Granite. Owner: Iowa Geological Survey and U.S. Geological Survey.

AQUIFER.--Dakota: In sandstone of Early Cretaceous age.

WELL CHARACTERISTICS. --Drilled obse rvation artesian water well, dlameter 2 in., depth $657 \mathrm{ft}$, cased to $657 \mathrm{ft}$, perforated 450 to $455 \mathrm{ft}$ and 630 to $650 \mathrm{ft}$.

INSTRUMENTATION. --Quarterly measurement with chalked tape by USGS personnel.

DATUK.--Elevation of land-surface datum is 1,417 ft above National Geodetic Vertical Datum of 1929 , from topographic map. Measuring point: Top of casing at land-surface datum.

REMARRS. --Well D-19.

PERIOD OF RECORD.--December 1978 to December 1980, May 1982 to current year.

EXTREMES FOR PERIOD OF RECORD. - - Highest water level measured, $152.57 \mathrm{ft}$ below land-surface datum, June

5. 1984; lowest measured, $157.53 \mathrm{ft}$ below land-surface datum, Aug. 12, 1982 .

WATER LEVEL, IN FEET BELOW LAND-SUREACE DATUM, WATER YEAR OCTOBER 1984 TO SEPTEKBER 1985

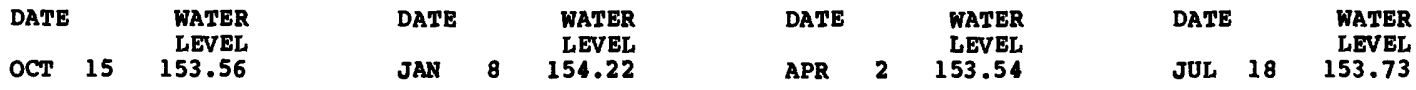

MADISON COUNTY

411727N093483001. Local number, 75-26-23 AAACl.

LOCATION. -Lat 41.17'27", long 93048'30", Hydrologic Unit 07100008, near the shelter house in the city park, St. Charles. Owner: City of St. Charles

AQUIFER.--Mississippian: in limestone of Mississippian age.

WELL CHARACTERISTICS. --Drilled unused artesian water well, diameter $10 \mathrm{in.,}$ depth 1,058 ft, cased to $657 \mathrm{ft}$, open hole 657 to $1,058 \mathrm{ft}$.

INSTRUMENTATION. --Biannual measurement with chalked tape by USGS personnel.

DATUM. - Elevation of land-surface datum is 1,067 ft above National Geodetic vertical Datum of 1929 , $657 \mathrm{ft}$, topographic map. Measuring point: Plug in well cover, $1.20 \mathrm{ft}$ above land-surface datum.

REMARRS.--City well No. 1 .

PERIOD OF RECORD. --November 1962 to current year.

EXTREMES FOR PERIOD OF RECORD.--Highest water level measured, $261.62 \mathrm{ft}$ below land-surface datum, Nov.

20. 1962; lowest measured, 271.94 ft below land-surface datum, Oct. 30,1984 .

WATER LEVEL, IN FEET BELOW LAND-SURFACE DATOM, WATER YEAR OCTOBER 1984 TO SEPTEMBER 1985

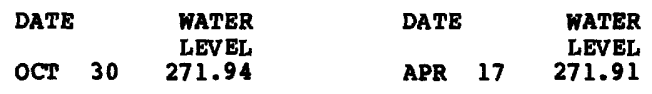

MARION COUNTY

411323N093142601. Local number, 74-21-11 BBCD1.

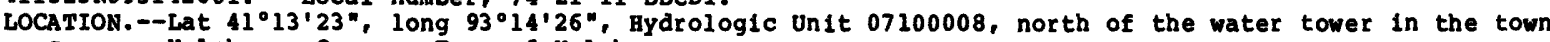
square, Melcher. Owner: Town of Melcher.

AQUIFER.--Glacial drift: in material of Pleistocene age.

WELL CHARACTERISTICS.--Drilled unused water-table well, diameter $18 \mathrm{in.,} \mathrm{depth} 12.2 \mathrm{ft}$, 1 ined with tile. INSTRUMENTATION. - Twice a month measurement with chalked tape by observer.

DATUM.--Elevation of land-surface datum is $948 \mathrm{ft}$ above Naitonal Geodetic Vertical Datum of 1929 , from topographic map. Measuring point: Top of well cover, $0.75 \mathrm{ft}$ above land-surface datum.

REMARKS. - Town well No. 2. Depth formerly $25 \mathrm{ft}$, re-measured in 1981.

PERIOD OF RECORD. --March 1950 to current year.

EXTREMES FOR PERIOD OF RECORD.-- Highest water level measured, $0.12 \mathrm{ft}$ below land-surface datum, Apr. 24 1976, lowest measured, $16.27 \mathrm{ft}$ below land-surface datum, oct. 22, 1953.

WATER LEVEL, IN FEET BELOW LAND-SURFACE DATUM, WATER YEAR OCTOBER 1984 TO SEPTEMBER 1985

\begin{tabular}{|c|c|c|c|c|c|c|c|c|c|c|c|}
\hline DATE & & $\begin{array}{l}\text { WATER } \\
\text { LEVEL }\end{array}$ & DATE & & $\begin{array}{l}\text { WATER } \\
\text { LEVEL }\end{array}$ & DATE & & $\begin{array}{l}\text { WATER } \\
\text { LEVEL }\end{array}$ & DATE & & $\begin{array}{l}\text { WATER } \\
\text { LEVEL }\end{array}$ \\
\hline $\begin{array}{l}\text { OCT } \\
\text { OCT } \\
\text { NOV } \\
\text { NOV } \\
\text { DEC } \\
\text { DEC }\end{array}$ & $\begin{array}{r}12 \\
24 \\
9 \\
23 \\
10 \\
27\end{array}$ & $\begin{array}{l}6.55 \\
5.31 \\
4.72 \\
4.97 \\
5.33 \\
3.45\end{array}$ & $\begin{array}{l}\text { JAN } \\
\text { JAN } \\
\text { FEB } \\
\text { FEB } \\
\text { MAR } \\
\text { MAR }\end{array}$ & $\begin{array}{l}10 \\
23 \\
10 \\
22 \\
10 \\
23\end{array}$ & $\begin{array}{l}5.02 \\
4.93 \\
4.84 \\
3.35 \\
3.55 \\
3.90\end{array}$ & $\begin{array}{l}\text { APR } \\
\text { APR } \\
\text { MAY } \\
\text { MAY } \\
\text { JUN } \\
\text { JUN }\end{array}$ & $\begin{array}{l}10 \\
23 \\
10 \\
22 \\
15 \\
25\end{array}$ & $\begin{array}{l}4.15 \\
4.40 \\
5.05 \\
5.05 \\
5.25 \\
4.65\end{array}$ & $\begin{array}{l}\text { JUL } \\
\text { JUL } \\
\text { AUG } \\
\text { AUG } \\
\text { SEP } \\
\text { SEP }\end{array}$ & $\begin{array}{r}8 \\
22 \\
15 \\
24 \\
11 \\
23\end{array}$ & $\begin{array}{l}5.55 \\
5.82 \\
5.22 \\
4.80 \\
5.01 \\
5.23\end{array}$ \\
\hline
\end{tabular}

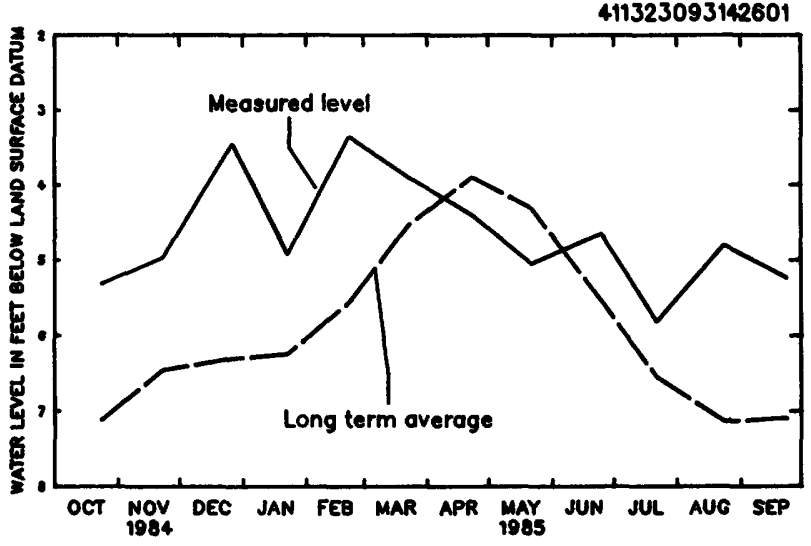


420355N092534701. Local number, 84-18-24 CDCAI.

LOCATION.--Lat $42^{\circ} 03^{\prime} 55^{\circ}$, long $92^{\circ} 53^{\prime} 47^{\prime}$, Hydrologic Unit 07080208 , east of Riverview Park and south of the sewage treatment plant, Marshalltown. Owner: City of Marshalltown.

AQUIFER.--Giacial sand and gravel: in material of Pleistocene age.

WELL CBARACTERISTICS.--Drilied unused artesian water well, diameter 8 in., depth 200 ft, cased to 190 $f t$, screened 190 to $200 \mathrm{ft}$.

INSTRUMENTATION. - Quarterly measurement with chalked tape by usGs personnel.

DATUM.--Elevation of land-surface datum is $871 \mathrm{ft}$ above National Geodetic Vertical Datum of 1929 , from topographic map. Measuring point: Top of casing at land-surface datum.

REMARKS. - -None.

PERIOD OF RECORD,--May 1949 to August 1971, March 1973 to current year.

EXTREMES FOR PERIOD OR RECORD.--Highest water level measured, 4.92 ft below land-surface datum, Jul. 13, 1951 , lowest measured, $54.95 \mathrm{ft}$ below land-surface datum, May 8, 1981 .

WATER LEVEL, IN EEET BELON LAND-SURFACE DATUM, WATER YEAR OCTOBER 1984 TO SEPTEMBER 1985

$\begin{array}{llllllll}\text { DATE } & \begin{array}{c}\text { WATER } \\ \text { LEVEL }\end{array} & \text { DATE } & \begin{array}{c}\text { WATER } \\ \text { LEVEL }\end{array} & \text { DATE } & \begin{array}{r}\text { WATER } \\ \text { LEVEL }\end{array} \\ \text { JAN } 29 & \mathbf{4 0 . 6 3} & \text { APR } 17 & 37.22 & \text { JUL } 12 & \mathbf{4 6 . 9 5}\end{array}$

\section{MONTGOMERY COUNTY}

405841 N095012701. Local number, 71-36-6 DADAl.

LOCATION.--Lat $40^{\circ} 58^{\prime} 41^{\prime \prime}$, long $95^{\circ} 01^{\prime} 27^{\prime \prime}$, Hydrologic Unit 10240009 , east of viking Lake in viking Lake State Park, or approximately 4 mi east of the town of stanton and $0.25 \mathrm{mi}$ south of $\mathrm{U}$. S. Highway 34 , Owner: State of Iowa.

AQUIFER.--Glacial drift: in material of Pleistocene age.

WELL CHARACTERISTICS.--Drilled observation water-table well, diameter 1.25 in., depth 38 ft, cased to $36 \mathrm{ft}$, screened 36 to $38 \mathrm{ft}$.

INSTRUMENTATION.--Twice a month measurement with chalked tape by usgs personnel or observer.

DATUM.--Elevation of land-surface datum is 1,081 ft above National Geodetic vertical Datum of 1929 , from topographic map. Measuring point: Top of casing, 2.95 ft above land-surface datum.

REMARRS.--Measuring point changed October 11 , 1983.

PERIOD OF RECORD.--April 1950 to current year.

EXTREMES FOR PERIOD OR RECORD.--Highest water level measured, 2.52 ft below land-surface datum, May 31 ,

1951, lowest measured, $30.99 \mathrm{ft}$ below land-surface datum, Apr. 26, 1950.

WATER LEVEL, IN FEET BELON LAND-SURFACE DATUM, WATER YEAR OCTOBER 1984 TO SEPTEMBER 1985

\begin{tabular}{|c|c|c|c|c|c|c|c|c|c|c|c|}
\hline \multicolumn{2}{|c|}{ DATE } & $\begin{array}{l}\text { WATER } \\
\text { LEVEL }\end{array}$ & \multicolumn{2}{|c|}{ DATE } & $\begin{array}{l}\text { WATER } \\
\text { LEVEL }\end{array}$ & \multicolumn{2}{|c|}{ DATE } & $\begin{array}{l}\text { WATER } \\
\text { LEVEL }\end{array}$ & \multicolumn{2}{|c|}{ DATE } & $\begin{array}{l}\text { WATER } \\
\text { LEVEL }\end{array}$ \\
\hline $\begin{array}{l}\text { OCT } \\
\text { NOV } \\
\text { DEC } \\
\text { JAN }\end{array}$ & $\begin{array}{l}22 \\
24 \\
23 \\
20 \\
21\end{array}$ & $\begin{array}{l}15.00 \\
15.03 \\
15.15 \\
15.25 \\
15.26\end{array}$ & $\begin{array}{l}\text { JAN } \\
\text { EEB } \\
\text { MAR } \\
\text { APR }\end{array}$ & $\begin{array}{r}28 \\
20 \\
22 \\
5 \\
22\end{array}$ & $\begin{array}{l}15.30 \\
15.35 \\
15.00 \\
14.86 \\
14.93\end{array}$ & $\begin{array}{l}\text { MAY } \\
\text { JUN } \\
\text { JUL } \\
\text { AUG }\end{array}$ & $\begin{array}{r}22 \\
25 \\
3 \\
20 \\
12\end{array}$ & $\begin{array}{l}14.84 \\
15.15 \\
18.94 \\
15.49 \\
15.54\end{array}$ & $\begin{array}{l}\text { AUG } \\
\text { SEP }\end{array}$ & $\begin{array}{l}18 \\
28\end{array}$ & $\begin{array}{l}15.60 \\
15.85 \\
15.69\end{array}$ \\
\hline
\end{tabular}

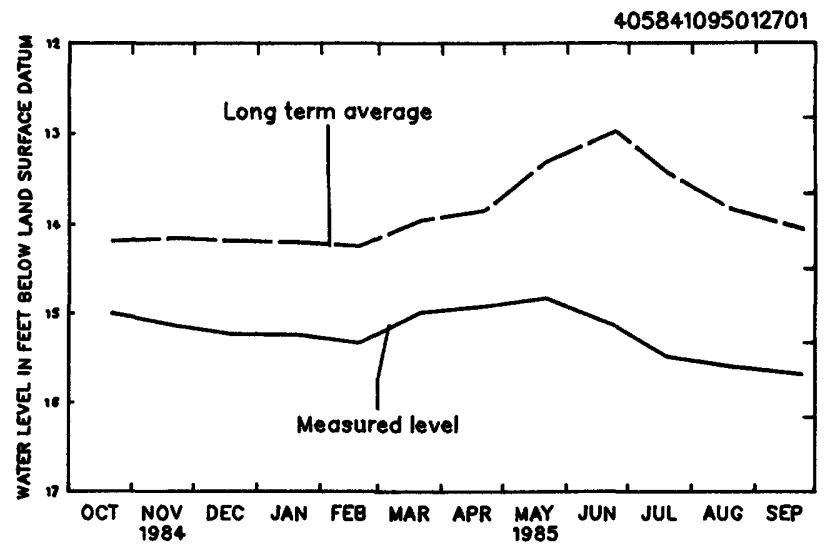


MUSCATINE COUNTY

412120N091080401. Local number, 76-2-30 CBAAl.

LOCATION.--Lat $41^{\circ} 21^{\prime} 20^{\prime \prime}$, long $91^{\circ} 08^{\prime} 04^{\prime \prime}$, Hydrologic Unit 07080101 , west of the Town of Fruitland on an Iowa State University Agricultural Experiment Farm. Owner: U.S. Geological Survey.

AQUIFER.--Alluvial sand and gravel: in material of Holocene age.

WELL CHARACTERISTICS.--Drilled observation water-table well, diameter 6 in., depth $27 \mathrm{ft}$, cased to 24 ft, screened 24 to $27 \mathrm{ft}$.

INSTRUMENTATION. --Water-level recorder.

DATUM.--Elevation of land-surface datum is $546 \mathrm{ft}$ above National Geodetic Vertical Datum of 1929 , from topographic map. Measuring point: Base of recorder shelter, 3.70 ft above land-surface datum.

REMARKS.--Site identification number corrected 1983.

PERIOD OF RECORD.--May 1966 to current year.

REVISED RECORDS. - -WDR IA-84-1.

EXTREMES FOR PERIOD OF RECORD,--Highest water level recorded, 8.51 ft below land-surface datum, May 16, 1973; lowest recorded, $15.76 \mathrm{ft}$ below land-surface datum, sept. 30, 1985.

WATER LEVEL, IN FEET BELOW LAND-SURFACE DATUM, WATER YEAR OCTOBER 1984 TO SEPTEMBER 1985 NOON VALUES

\begin{tabular}{|c|c|c|c|c|c|c|c|c|c|c|c|c|}
\hline DAY & OCT & NOV & DEC & JAN & FEB & MAR & APR & MAY & JUN & JUL & AUG & SEP \\
\hline $\begin{array}{r}5 \\
10 \\
15 \\
20 \\
25 \\
\text { EOM }\end{array}$ & $\begin{array}{l}14.68 \\
14.76 \\
14.78 \\
14.60 \\
14.28 \\
14.19\end{array}$ & $\begin{array}{l}13.82 \\
13.55 \\
13.48 \\
13.53 \\
13.58 \\
13.65\end{array}$ & $\begin{array}{l}13.73 \\
13.79 \\
13.83 \\
13.87 \\
13.88 \\
13.86\end{array}$ & $\begin{array}{l}13.81 \\
13.74 \\
13.68 \\
13.65 \\
13.63 \\
13.68\end{array}$ & $\begin{array}{l}13.73 \\
13.77 \\
13.80 \\
13.84 \\
13.63 \\
13.46\end{array}$ & $\begin{array}{l}13.25 \\
12.82 \\
12.63 \\
12.56 \\
12.57 \\
12.56\end{array}$ & $\begin{array}{l}12.64 \\
12.73 \\
12.80 \\
12.87 \\
12.97 \\
13.08\end{array}$ & $\begin{array}{l}13.16 \\
13.28 \\
13.30 \\
13.29 \\
13.30 \\
13.40\end{array}$ & $\begin{array}{l}13.49 \\
13.65 \\
13.74 \\
13.83 \\
13.90 \\
14.09\end{array}$ & $\begin{array}{l}14.27 \\
14.44 \\
14.55 \\
14.73 \\
14.91 \\
15.07\end{array}$ & $\begin{array}{l}15.08 \\
15.23 \\
15.20 \\
15.27 \\
15.37 \\
15.46\end{array}$ & $\begin{array}{l}15.51 \\
15.60 \\
15.68 \\
15.73 \\
15.74 \\
15.76\end{array}$ \\
\hline
\end{tabular}

WTR YEAR 1985 HIGHEST 12.53 MAR 24, 1985 LONEST 15.76 SEP 30,1985

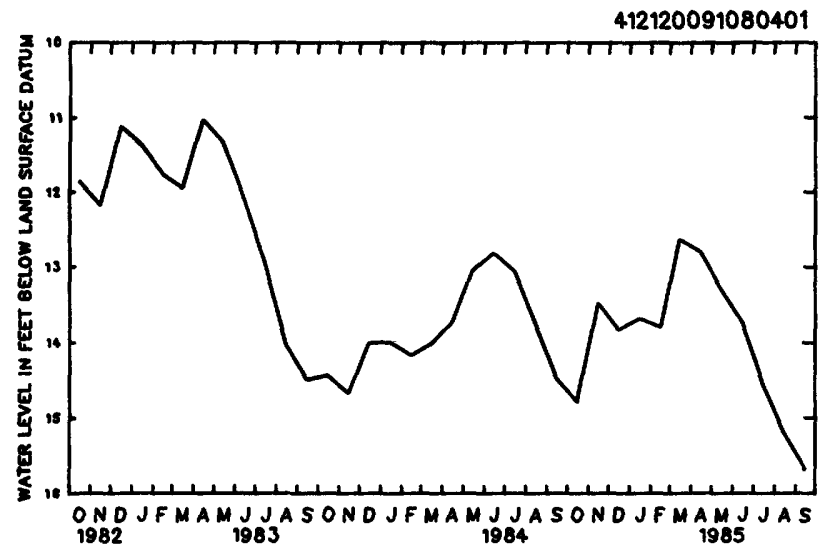

O'BRIEN COUNTY

425610N095250611. Local number, 94-39-26 BADB11.

LOCATION.--Lat $42^{\circ} 56^{\prime} 10^{\prime \prime}$, long $95^{\circ} 25^{\prime} 06^{\prime \prime}$, Hydrologic Unit 10230003 , near a dead-end road just south of

the little Sioux River, $0.9 \mathrm{mi}$ north of Iowa Highway 10, approximately $5 \mathrm{mi}$ southeast of the Town of

Sutherland. Owner: Iowa Geological Survey and U. S. Geological survey.

AQUIFER.--Dakota: in sandstone of Early Cretaceous age.

WELL CHARACTERISTICS.--Drilled observation artesian water well, diameter 2.50 in., depth 329 ft, cased to $329 \mathrm{ft}$, perforated 291 to $295 \mathrm{ft}$.

INSTRUMBNTATION.--Quarterly measurement with chalked tape or electric 1 ine by usGs personnel.

DATUM.--Elevation of land-surface datum is $1,212 \mathrm{ft}$ above National Geodetic Vertical Datum of 1929.

from topographic map. Measuring point: Top of casing at land-surface datum.

REMARKS. - We11 D-3.

PERIOD OF RECORD.--April 1980 to current year.

EXTREMES FOR PERIOD OF RECORD.--Highest water level measured, 35.38 ft below land-surface datum, Dec.

18, 1984 and Mar. 1, 1984; lowest mesured, $36.85 \mathrm{ft}$ below land-surface datum, Dec. 15, 1980.

WATER LEVEL, IN FEET BELOW LAND-SURFACE DATUM, WATER YEAR OCTOBER 1984 TO SEPTEMBER 1985

\begin{tabular}{|c|c|c|c|c|c|c|c|c|c|c|c|}
\hline DATE & & $\begin{array}{l}\text { WATER } \\
\text { LEVEL }\end{array}$ & DATE & & $\begin{array}{l}\text { WATER } \\
\text { LEVEL }\end{array}$ & DAT & & $\begin{array}{l}\text { WATER } \\
\text { LEVEL }\end{array}$ & DAT & & $\begin{array}{l}\text { WATER } \\
\text { LEVEL }\end{array}$ \\
\hline DEC & 18 & 35.38 & MAR & 11 & 35.61 & MAX & 29 & 35.93 & AUG & 22 & 35.47 \\
\hline
\end{tabular}




\section{O'BRIEN COUNTY}

425808N095480311. Local number, 94-42-9 DDDDll.

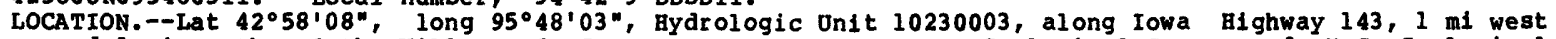
and $l \mathrm{mi}$ north of the Village of Germantown. Owner: Iowa Geological survey and u.s. Geological Survey.

AQOIFER.-Dakota: in sandstone of Early Cretaceous age.

WELL CHARACTERISTICS.--Drilled observation artesian water well, diameter 2 in., depth 638 ft, cased to $638 \mathrm{ft}$, perforated 516 to $536 \mathrm{ft}$.

INSTROMENTATION.--Quarterly measurement with chalked tape by osgs personnel.

DATOK,--Elevation of land-surface is $1,440 \mathrm{ft}$ above National Geodetic Vertical Datum of 1929 , from topographic map. Measuring point: Top of casing, $4.00 \mathrm{ft}$ above land-surface datum. REMARKS. - Wel1 D -42 .

PER IOD OF RECORD.--July 1980 to current year.

EXTREMES FOR PERIOD OF RECORD.--Highest water level measured, 215.09 ft below land-surface datum, May 6. 1982 , lowest measured, $260.64 \mathrm{ft}$ below land-surface datum, July $10,1980$.

WATER LEVEL, IN FEET BELON LAND-SURFACE DATUM, WATER YEAR OCTOBER 1984 TO SEPTMEBER 1985

\begin{tabular}{|c|c|c|c|c|c|c|c|c|c|c|}
\hline DATE & & $\begin{array}{l}\text { WATER } \\
\text { LEVEL }\end{array}$ & DATE & & $\begin{array}{l}\text { WATER } \\
\text { LEVEL }\end{array}$ & DATE & & $\begin{array}{l}\text { WATER } \\
\text { LEVEL }\end{array}$ & DATE & $\begin{array}{l}\text { WATER } \\
\text { LEVEL }\end{array}$ \\
\hline OCT & 15 & 229.43 & JAN & 8 & 230.35 & APR & 2 & 230.68 & JUL 19 & 231.10 \\
\hline
\end{tabular}

430930N095350401. Local number, 96-40-5 DDDAl.

LOCATION.--Lat $43^{\circ} 09^{\prime} 30^{n}$, long $95^{\circ} 35^{\prime} 04^{n}$, Hydrologic Unit 10230003 , approximately $3 \mathrm{mi}$ east of the Town of Sanborn and $2 \mathrm{mi}$ south of U.s. Highway 18. Owner: Iowa Geological survey and 0.s. Geological Survey.

AQUIFER.--Dakota and Ordovician: in sandstone of Early Cretaceous age and sandy shale of Ordovician age. WELL CHARACTERISTICS. --Drilled observation artesian water well, diameter 2 in., depth 701 ft, cased to $701 \mathrm{ft}$, perforated 661 to $701 \mathrm{ft}$.

INSTRUMENTATION.--Quarterly measurement with chalked tape by osgs personnel.

DATUM.--Elevation of land-surface datum is $1,560 \mathrm{ft}$ above vational Geodetic vertical Datum of 1929 , from topogarphic map. Measuring point: Top of casing, $4.00 \mathrm{ft}$ above land-surface datum.

REMARKS. - Wel1 D-4i.

PERIOD OF RECORD.--June 1980 to current year.

EXTREWES FOR PERIOD OF RECORD.--Highest water level measured, 359.14 ft below land-surface datum, Oct. 18. 1984; lowest measured, $361.40 \mathrm{ft}$ below land-surface datum, Jul. 16, 1980 .

WATER LEVEL, IN FEET BELON LAND-SURFACE DATUM, WATER YEAR OCTOBER 1984 TO SEPTEMBER 1985

\begin{tabular}{|c|c|c|c|c|c|c|c|c|c|c|c|}
\hline DATE & & $\begin{array}{l}\text { WATER } \\
\text { LEVEL }\end{array}$ & DATE & & $\begin{array}{l}\text { WATER } \\
\text { LEVEL }\end{array}$ & DATE & & $\begin{array}{l}\text { WATER } \\
\text { LEVEL }\end{array}$ & DATE & & $\begin{array}{l}\text { WATER } \\
\text { LEVEL }\end{array}$ \\
\hline OCT & 18 & 359.14 & JAN & 8 & 359.64 & APR & 2 & 359.33 & JUL & 9 & 359.59 \\
\hline
\end{tabular}

\section{OSCEOLA COUNTY}

431620N095250501. Local number, 98-39-26 CDADl.

LOCATION.-Lat $43^{\circ} 16^{\prime} 20^{\circ}$, long $95^{\circ} 25^{\prime} 05^{\prime}$, Hydrologic unit $10230003,3.5 \mathrm{mi}$ south and $2.5 \mathrm{mi}$ east of the Village of May City. Owner: Iowa Geological Survey and 0.s. Geological Survey.

AQUIFER.--st. Peter: in sandstone of middle Ordovician age.

WELL CHARACTERISTICS.--Drilled observation artesian water well, diameter 2 in.. depth 662 ft, cased to $662 \mathrm{ft}$, perforated 622 to $662 \mathrm{ft}$.

INSTRUMENTATION.--Quarterly measurement with chalked tape or electric line by usgs personnel or observer.

DATUM.--Elevation of land-surface datum is $1,402 \mathrm{ft}$ above National Geodetic Vertical Datum of 1929 , from topographic map. Measuring point: Top of low pipe, 1.47 ft above land-surface datum.

REMARKS. - Wel 1 D-38 Deep Hibbing.

PERIOD OF RECORD.--June 1980 to current year. 8, $1984 ;$ lowest measured, $199.52 \mathrm{ft}$ below land-surface datum, Aug. 5,1980 .

WATER LEVEL, IN FEET BELON LAND-SURFACE DATUM, WATER YEAR OCTOBER 1984 TO SEPTEMBER 1985

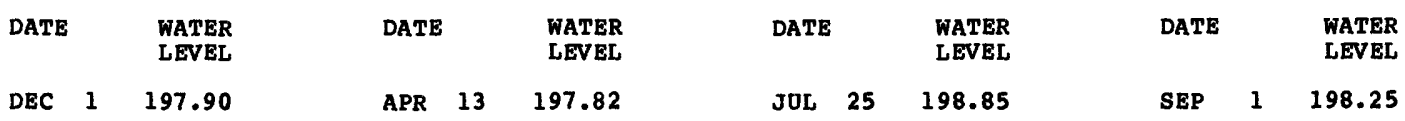


431620N095250511. Local number, 98-39-26 CDAD11.

LOCATION. --Lat $43^{\circ} 16^{\prime} 20^{\prime \prime}$, long $95^{\circ} 25^{\prime} 05^{\prime \prime}$. Hydrologic Unit $10230003,3.5 \mathrm{mi}$ south and $2.5 \mathrm{mi}$ east of the Village of May City. Owner: Iowa Geological Survey and U.S. Geological Survey.

AQUIFER. --Dakota: in sandstone of Early Cretaceous age.

WELL CHARACTERISTICS. - Drilled observation artesian water well, diameter 2 in., depth 345 ft, cased to $345 \mathrm{ft}$, perforated 335 to $345 \mathrm{ft}$.

INSTRUMENTATION.--Quarterly measurement with chalked tape or electric line by usGs personnel or observer.

DATUM.--Elevation of land-surface datum is $1,402 \mathrm{ft}$ above National Geodetic Vertical Datum of 1929 , from topographic map. Measuring point: Top of high pipe, $2.60 \mathrm{ft}$ above land-surface datum.

REMARRS. - Well D-38 shall ow Hibbing.

PERIOD OF RECORD. --June 1980 to current year.

EXTREMES FOR PERIOD OF RECORD. --Highest water level measured, $192.20 \mathrm{ft}$ below land-surface datum, Sep. 10, 1981; lowest measured, $194.11 \mathrm{ft}$ below land-surface datum, Jul. 25, 1982 .

WATER LEVEL, IN FEET BELOW LAND-SURFACE DATUM, WATER YEAR OCTOBER 1984 TO SEPTEMBER 1985

\begin{tabular}{|c|c|c|c|c|c|c|c|c|c|c|}
\hline DATE & $\begin{array}{l}\text { WATER } \\
\text { LEVEL }\end{array}$ & DATE & & $\begin{array}{l}\text { WATER } \\
\text { LEVEL }\end{array}$ & DATE & & $\begin{array}{l}\text { WATER } \\
\text { LEVEL }\end{array}$ & DATE & & $\begin{array}{l}\text { WATER } \\
\text { LEVEL }\end{array}$ \\
\hline & 193.40 & APR & 13 & 193.56 & JUL & 25 & 193.49 & SEP & 1 & 193.69 \\
\hline
\end{tabular}

431613N095251801. Local number, 98-39-26 CDCC1.

LOCATION.--Lat $43^{\circ} 16^{\prime} 13^{\prime \prime}$, long $95^{\circ} 25^{\prime} 18^{\prime \prime}$, Hydrologic unit $10230003,3.5 \mathrm{mi}$ south and $2.5 \mathrm{mi}$ east of the Village of May City. Owner: Iowa Geological Survey and U.s. Geological Survey.

AQUIFER. --Dakota: in sandstone of Early Cretaceous age.

WELL CHARACTERISTICS.--Drilled observation artesian water well, diameter 2 in., depth $500 \mathrm{ft}$, cased to $500 \mathrm{ft}$, perforated 490 to $500 \mathrm{ft}$.

INSTRUMENTATION.--Quarterly measurement with chalked tape or electric line by usGs personnel or observer.

DATUM.--Elevation of land-surface datum is 1,398 ft above National Geodetic vertical Datum of 1929 , from topographic map. Measuring point: Top of casing, $2.70 \mathrm{ft}$ above land-surface datum.

REMARRS. - -Well D-39.

PERIOD OF RECORD. --June 1980 to current year.

EXTREMES FOR PERIOD OF RECORD.--Highest water level measured, $189.99 \mathrm{ft}$ below land-surface datum, Jun.

17, 1980 ; lowest measured, $196.85 \mathrm{ft}$ (nearby well pumping) below land-surface datum, Sept. 6, 1984.

WATER LEVEL, IN FEET BELOW LAND-SURFACE DATUM, WATER YEAR OCTOBER 1984 TO SEPTEMBER 1985

\begin{tabular}{|c|c|c|c|c|c|c|c|c|c|}
\hline DATE & $\begin{array}{l}\text { WATER } \\
\text { LEVEL }\end{array}$ & DATE & & $\begin{array}{l}\text { WATER } \\
\text { LEVEL }\end{array}$ & DATE & & $\begin{array}{l}\text { WATER } \\
\text { LEVEL }\end{array}$ & DATE & $\begin{array}{l}\text { WATER } \\
\text { LEVEL }\end{array}$ \\
\hline $\mathrm{c}$ & 191.18 & APR & 13 & 191.10 & JUL & 25 & 192.39 & SEP & 191.46 \\
\hline
\end{tabular}

431620N095482402. Local number, 98-42-33 AABB2.

LOCATION.--Lat $43^{\circ} 16^{\prime} 20^{\prime \prime}$, long $95^{\circ} 48^{\prime} 24^{\prime \prime}$, Hydrologic Unit 10170204, approximately $2.75 \mathrm{mi}$ south of the Town of Ashton, west of Iowa Highway 60 , near the Chicago and Northwestern Railroad tracks. Owner: Iowa Geological Survey and U.S. Geological Survey.

AQUIFER.--Dakota: in sandstone of Early Cretaceous age.

WELL CHARACTERISTICS. --Drilled observation artesian water well, diameter 2 in., depth $400 \mathrm{ft}$, cased to $400 \mathrm{ft}$, perforated 385 to $395 \mathrm{ft}$.

INSTRUMENTATION.--Quarterly measurement with chalked tape by uSGS personel.

DATUM.--Elevation of land-surface datum is $1,440 \mathrm{ft}$ above National Geodetic Vertical Datum of 1929 , topographic map. Measuring point: Top of casing, $2.80 \mathrm{ft}$ above land-surface datum. REMARRS. - Well D-40.

PERIOD OF RECORD. --May 1982 to current year.

EXTREMES FOR PERIOD OF RECORD.--Highest water level measured, $195.87 \mathrm{ft}$ below land-surface datum, June 1. 1983; lowest measured, $206.48 \mathrm{ft}$ bel ow land-surface datum, May 6, 1982 .

WATER LEVEL, IN FEET BELOW LAND-SURFACE DATUM, WATER YEAR OCTOBER 1984 TO SEPTEMBER 1985

$\begin{array}{lrrrrrrr}\text { DATE } & \begin{array}{r}\text { WATER } \\ \text { LEVEL }\end{array} & \text { DATE } & \begin{array}{r}\text { WATER } \\ \text { LEVEL }\end{array} & \text { DATE } & & \begin{array}{r}\text { WATER } \\ \text { LEVEL }\end{array} \\ \text { JAN } 8 & 203.65 & \text { APR } & 2 & 206.20 & \text { JUL } & 9 & 204.40\end{array}$

432828N095283611. LoCal number, 100-39-17 DCCB11.

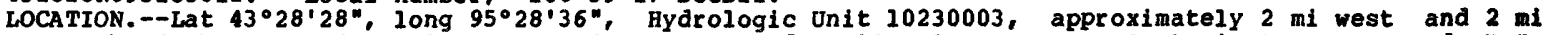
north of the Town of Harris, east of County Road M-12. Owner: Iowa Geological survey and U.s. Geological Survey.

AQUIFER. --Dakota: in sandstone of Early Cretaceous age.

WELL CHARACTERISTICS. - Drilled observation artesian water well, diameter 5 in. to $461 \mathrm{ft}$, 4 in. to 760 $\mathrm{ft}$, depth $760 \mathrm{ft}$, cased to $760 \mathrm{ft}$, perforated 680 to $700 \mathrm{ft}$.

INSTRURRNTATION.--Quarterly measurement with electric line by USGS personnel.

from topographic map. Measuring point: Top of casing, $3.00 \mathrm{ft}$ above land-surface datum.

REMARRS. - WeII D-13.

PERIOD OF RECORD. --July 1980 to current year.

EXTREMES FOR PERIOD OF RECORD.--Highest water level measured, $341.80 \mathrm{ft}$ below land-surface datum, Aug.

5, 1980; lowest measured, $343.70 \mathrm{ft}$ below land-surface datum, Aug. 21, 1985 .

WATER LEVEL, IN FEET BELOW LAND-SURFACE DATUM, WATER YEAR OCTOBER 1984 TO SEPTEMBER 1985

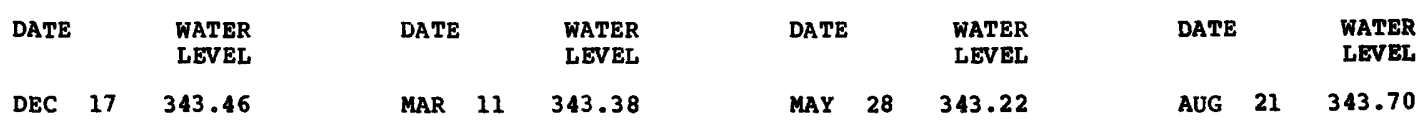


404257 N095150801. Local number, 68-38-7 CCAA1

LOCATION.--Lat 40.42'57", long 95'15'08", Hydrologic Unit 10240005, approximately 2 mi south of the Village of Norwich and $1.5 \mathrm{mi}$ west of County Road M-48. Owner: William Brayman. AQUIFER.--Glacial drift: in material of Pleistocene age.

WELL CHARACTERISTICS.--Drilled unused water-table well, diameter 12 in., depth 44 ft, 1 ined with tile. INSTRUMENTATION.--Intermittent measurement with chalked tape by uSGs personnel.

DATUM.--Elevation of land-surface datum is $1,087 \mathrm{ft}$ above National Geodetic vertical Datum of 1929.

topogarphic map. Measuring point: Top of pipe inserted through board cover, 1.00 ft above landsurface datum.

REMARKS.-Measuring point changed september 1983. Site identification number corrected 1983.

PERIOD OF RECORD.--May 1934 to current year.

EXTREMES FOR PERIOD OF RECORD.--Highest water level measured, $1.44 \mathrm{ft}$ below land-surface datum, Jun.

23, 1947, lowest measured, $20.96 \mathrm{ft}$ below land-surface datum, Nov. 24, 1958 .

WATER LEVEL, IN FEET BELOW LAND-SURFACE DATUM, WATER YEAR OCTOBER 1984 TO SEPTEMBER 1985

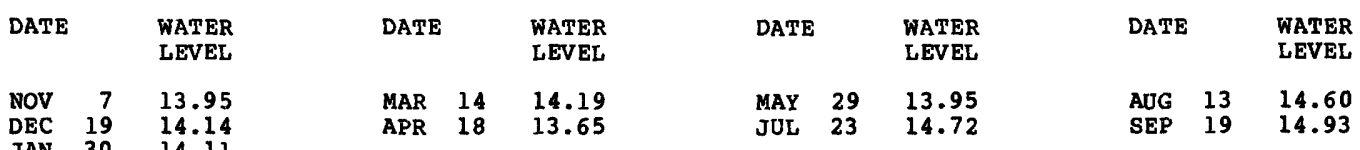

\section{PLYMOUTH COUNTY}

424850 N096074801. Local number, 92-45-2 CBCB1.

LOCATION.--Lat $42^{\circ} 48^{\prime} 50^{\prime \prime}$, long $96^{\circ} 07^{\prime} 48^{\prime \prime}$, Bydrologic unit 10230002, approximately $3.8 \mathrm{mi}$ west and $0.6 \mathrm{mi}$ south of the Village of Oyens. Owner: Iowa Geological Survey and U.s. Geological Survey.

AQUIFER.--Cambrian-Ordovician: in dolomite of Ordovician age and Cambrian age.

WELL CHARACTERISTICS.--Drilled observation artesian water well, diameter 5 in. to $161 \mathrm{ft}$, 4 in. to 598 2 in. to $1,340 \mathrm{ft}$, depth $1,340 \mathrm{ft}$, cased to $598 \mathrm{ft}$, open hole 598 to $1,340 \mathrm{ft}$.

INSTRUMENTATION.--Quarterly measurement with chalked tape by usGs personnel.

DATUM.--Elevation of land-surface datum is $1,245 \mathrm{ft}$ above National Geodetic vertical Datum of 1929 , from topographic map. Measuring point: Top of casing, $2.80 \mathrm{ft}$ above land-surface datum.

REMARRs. - Well D-21. Well deepened from 1,089 to 1,340 ft, May 1984 . Penetrates the Precanbrian. Measuring point changed, Oct. 1984 .

PERIOD OF RECORD.--May 1979 to January 1981, May 1982 to current year.

EXTREMES FOR PERIOD OF RECOPD.--Highest water level measured, 87.97 ft below land-surface datum, Mar. 13, 1984; lowest measured. $102.10 \mathrm{ft}$ below land-surface datum, Aug. 6, 1980.

WATER LEVEL, IN FEET BELOW LAND-SURFACE DATOM, WATER YEAR OCTOBER 1984 TO SEPTEMBER 1985

$\begin{array}{lllllllll}\text { DATE } & \begin{array}{r}\text { WATER } \\ \text { LEVEL }\end{array} & \text { DATE } & & \begin{array}{l}\text { WATER } \\ \text { LEVEL }\end{array} & \text { DATE } & \text { WATER } \\ \text { LEVEL }\end{array}$

424850N096074802. Local number, 92-45-2 CBCB2.

LOCATION.--Lat $42^{\circ} 48^{\prime} 50^{\prime \prime}$, long $96^{\circ} 07^{\prime} 48^{\prime \prime}$, Hydrologic Unit 10230002 , approximately 3.8 mi west and 0.6 mi south of the Village of Oyens. Owner: Iowa Geological Survey and U.s. Geological Survey. AQUIFER.--Dakota: in sandstone of Early Cretaceous age

WELL CHARACTERISTICS.--Drilled observation artesian water well, diameter 4 in. to 155 ft, 2 in. to 365 $\mathrm{ft}$, depth $365 \mathrm{ft}$, cased to $365 \mathrm{ft}$, perforated 347 to $365 \mathrm{ft}$.

INSTRUMENTATION.--Quarterly measurement with chalked tape by usGs personnel.

DATUM.--Elevation of land-surface datum is $1,245 \mathrm{ft}$ above National Geodetic Vertical Datum of 1929 , from topographic map. Measuring point: Wood cover over well, $2.80 \mathrm{ft}$ above land-surface datum.

REMARRS. - Well D-22. Measuring point changed, Oct. 1984.

PERIOD OF RECORD.--April 1979 to January 1981 , May 1982 to current year.

EXTREMES FOR PERIOD OF RECORD.-- Highest water level measured, 93.59 ft below land-surface datum, Jan. 8 , 1985: lowest measured, $106.56 \mathrm{ft}$ below land-surface datum, sept. 4, 1980.

WATER LEVEL, IN FEET BELOW LAND-SURFACE DATUM, WATER YEAR OCTOBER 1984 TO SEPTEMBER 1985

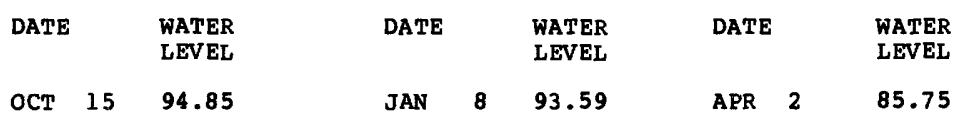


424833N096324701. Local number, 92-48-6 DDDAl.

LOCATION.--Lat $42^{\circ} 48^{\prime} 33^{\circ}$, Iong $96^{\circ} 32^{\prime} 47^{\circ}$, Eydrologic Unit 10170203, just south of the curve on Iowa Highway 3, $1 \mathrm{mi}$ south of the Town of Akron. Owners Iowa Geological survey and o.s. Geological Survey.

AQUIFER.-Dakota: in sandstone of Early Cretaceous age.

WELL CHARACTERISTICs.--Drilled observation artesian water well, diameter 4 in. to $184 \mathrm{ft}$, 2 in. to 581 $\mathrm{ft}$, depth $581 \mathrm{ft}$, cased to $576 \mathrm{ft}$, perforated 430 to $434 \mathrm{ft}$ and 510 to $515 \mathrm{ft}$, open hole $576 \mathrm{to} 581$ ft.

INSTRUMENTATION.--Quarterly measurement with chalked tape by usGs personnel.

DATUH.--Elevation of land-8urface datum is $1,282 \mathrm{ft}$ above National Geodetic vertical Datum of 1929 , from topographic map. Measuring point: Top of casing, $4.80 \mathrm{ft}$ above land-surface datum.

REMARKs.--Well D-35, 5 feet of Paleozoic rock open 576 to $581 \mathrm{ft}$.

PERIOD OF RECORD.--December 1979 to December 1980 , May 1982 to current year.

EXTREMES FOR PERIOD OF RECORD.--Highest water level measured, 139.12 ft below land-8urface datum, July 18,1985 , lowest measured, 159.82 ft below land-surface datum, Aug. 6,1980 .

WATER LEVEL, IN FEET BELON LAND-SURPACE DATUM, WATER YEAR OCTOBER 1984 TO 8 EPTEMBER 1985

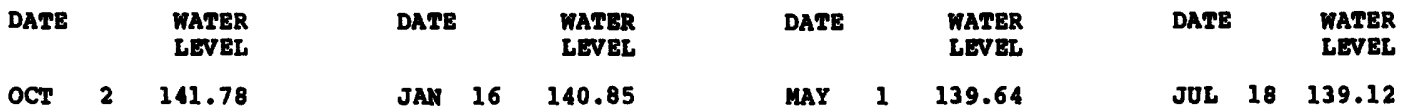

425249N096125001. Local number, 93-46-12 DDDD1.

LOCATION.--Lat $42^{\circ} 52^{\prime} 49^{\circ}$, long $96^{\circ} 12^{\prime} 50^{\circ}$, Bydrologic Unit 10230002 , 1 mi west and 1 mi south of the village of struble. Owner: Iowa Geological survey and 0.8. Geological survey.

AOUIPER.--Dakota: in sandstone of Early Cretaceous age.

WELI CGARACTERISTICs.--Drilled observation artesian water well, diameter 2.50 in., depth 570 ft, cased to $570 \mathrm{ft}$, perfor ated 356 to $360 \mathrm{ft}$.

INSTRUMENTATION.--Quarterly measurement with chalked tape by usGs personnel.

DATUM.--Elevation of land-surface datum is 1,280 ft above National Geodetic Vertical Datum of 1929 , from topographic map. Measuring point: Top of coupling, $4.80 \mathrm{ft}$ above land-surface datum. REMAR Ks - - Well D-2.

PERIOD OF RECORD.--March 1980 to December 1980, May 1982 to current year.

EXTREMBS POR PERIOD OF RECORD, --Bighest water level measured, 117.78 ft below land-surface datum, Apr. 9, 1980, lowest measured, $122.00 \mathrm{ft}$ below land-8urface datum, Mar. 27, 1980.

MATER LEVEL, IN FEET BELOM LAND-SUREACE DATUM, MATER YEAR OCTOBER 1984 TO SEPTEMBER 1985

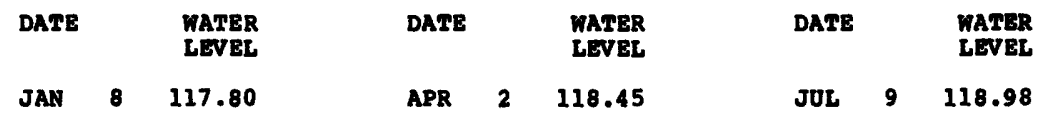

SAC COUNTY

422500N095084801. Local number, 88-37-22 CCCC1.

LOCATION.--Lat $42^{\circ} 25^{\prime} 00^{\circ}$, long $95^{\circ} 08^{\prime} 48^{\circ}$, Hydrologic Unit 10230007 , approximately $3 \mathrm{mi}$ south of the Town of Early or $0.5 \mathrm{mi}$ south of the junction of 0.8 . Bighways 20 and 71 . Owner: Iowa Geological survey and 0.8 . Geological survey.

AQUIFER.--Dakota and Pennsylvanian: in sandstone of Barly Cretaceous age and limestone of Pennsylvanian age.

MELI CHARACTERIsTICs.--Drilled observation artesian water well, diameter 2 in., depth 435 ft, cased to $435 \mathrm{ft}$, perforated 417 to $435 \mathrm{Et}$.

INSTRUNBNTATION. - Quarterly measurement with chalked tape by usgs personnel.

DATUH.--Elevation of land-8urface datum is $1,320 \mathrm{ft}$ above National Geodetic vertical Datum of 1929 , from topographic map. Measuring point: Top of casing, $2.50 \mathrm{ft}$ above land-8urface datum. REMARKS - - VIe11 D-16.

PERIOD OF RECORD.--December 1978 to current year.

EXTREMES FOR PERIOD OF RECORD.--Bighest water level measured, 163.93 ft below land-surface datum, May

12, 1984 , lowest measured, $165.40 \mathrm{ft}$ below land-8urface datum, Dec. 16, 1980.

MATER LEVEE, IN PEET BELON LAND-EURPACE DATUH, MATER YEAR OCTOBER 1984 TO 8EPTEMBER 1985

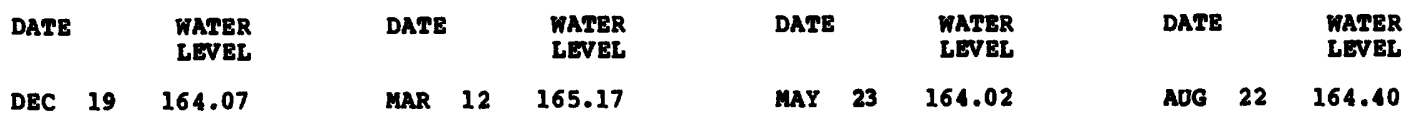

423013H095175301. Local number, 89-38-26 ABAAl.

LOCATION, - Iat $42^{\circ} 30^{\prime} 13^{\circ}$, long $95^{\circ} 17^{\prime} 53^{\prime \prime}$, Bydrologic unit 10230005, northern part of the Town of schaller. Owner: Town of schaller.

AQUIFER.--Dakota: in sandstone of Early Cretaceous age.

WEL CHARACTERISTICS.--Drilled public-emergency-supply artesian water well, diameter 10 to 8 in., depth $352 \mathrm{ft}$, cased to $352 \mathrm{ft}$, perforated 304 to $352 \mathrm{Et}$.

INSTRUMEATATION.--Quarterly measuerment with chalked tape by usGs personnel.

DATum.--Elevation of land-surface datum is $1,376 \mathrm{ft}$ above National Geodetic Vertical Datum of 1929 , from topographic map. Measuring point: Edge of pump breather pipe, 1.80 ft above land-surface datum. REMARKs.--Rone.

PERIOD OF RECORD.--October 1940 to current year.

EXTREMES POR PERIOD OF RECORD.-Bighest water level measured, 210.04 ft below land-8urface datum, Mar. 25, 1948; lowest non-pumping measured, $240.10 \mathrm{ft}$ below land-surface datum, May $24,1977$.

WATER LEVEL, IN FEET BBLON LAND-SURFACE DATUM, WATER YEAR OCTOBER 1984 TO SEPTELBER 1985

\begin{tabular}{|c|c|c|c|c|c|c|c|c|c|c|c|}
\hline DATE & & $\begin{array}{l}\text { WATER } \\
\text { LEVEL }\end{array}$ & DATE & & $\begin{array}{l}\text { TAMER } \\
\text { TEVEL }\end{array}$ & DATE & & $\begin{array}{l}\text { WATER } \\
\text { LEVET }\end{array}$ & DATE & & $\begin{array}{l}\text { RAIER } \\
\text { LEVEL }\end{array}$ \\
\hline 1EC & 19 & 230.43 & MAR & 12 & 231.52 & MAY & 23 & 231.86 & ADG & 22 & 230.84 \\
\hline
\end{tabular}


422850N095171501. Local number, 89-38-36 CBCCl.

LOCATION. - Lat $42^{\circ} 28^{\prime} 50^{\prime}$, Iong $95^{\circ} 17^{\prime} 15^{\prime \prime}$, Hydrologic Unit 10230005 , just east of Iowa Highway 110 , 0.75 mi south of the Town of Schaller and $0.25 \mathrm{mi}$ north of U.S. Highway 20. Owner: Iowa Geological Survey and U.S. Geological Survey.

AQUIFER.--Dakota: sandstone of Early Cretaceous age.

WELL CHARACTERISTICS.--Drilled observation artesian water well, diameter 2 in., depth 521 ft, cased to $512 \mathrm{ft}$, perforated 410 to $430 \mathrm{ft}$, open hole 512 to $521 \mathrm{ft}$.

INSTROMENTATION. - Quarterly measurement with chalked tape or electric line by usGs personnel.

DATUM.--Elevation of land-surface datum is $1,445 \mathrm{ft}$ above National Geodetic Vertical Datum of 1929 , $512 \mathrm{ft}$, topographic map. Measuring point: Top of casing, $4.00 \mathrm{ft}$ above land-surface datum.

REMARKS. - Weli $\mathrm{D}-17$. $9 \mathrm{ft}$ of Paleozoic rock open.

PERIOD OR RECORD.--December 1978 to current year.

EXTREMES POR PERIOD OF RECORD,--kighest water level measured, 288.05 ft below land-surface datum, Jun.

2. 1980 ; lowest measured, $291.50 \mathrm{ft}$ below land-surface datum, Apr. 8, 1980.

WATER LEVEL, IN FEET BELOW LAND-SURFACE DATUM, WATER YEAR OCTOBER 1984 TO SEPTEMBER 1985

\begin{tabular}{|c|c|c|c|c|c|c|c|c|}
\hline DATE & $\begin{array}{l}\text { WATER } \\
\text { LEVEL }\end{array}$ & DATE & $\begin{array}{l}\text { NATER } \\
\text { LEVEL }\end{array}$ & DATE & $\begin{array}{l}\text { WATER } \\
\text { LEVEL }\end{array}$ & DATE & & $\begin{array}{l}\text { WATER } \\
\text { LEVEL }\end{array}$ \\
\hline & 291.48 & MAR 12 & 291.31 & MAY & 291.27 & AUG & 22 & 291. \\
\hline
\end{tabular}

SCOTT COUNTY

413544N090212901. Local number, 78-5E-3 AADAl.

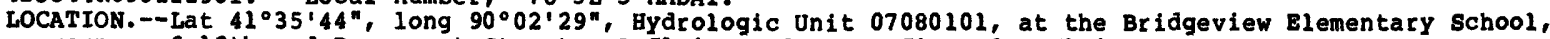
corner of 12 th and Davenport Streets, Leclaire. Owner: City of Leclaire.

AQUIFER.--Jordan: in strata of Cambrian and Ordovician age.

WELL CHARACTERISTICS.--Drilled unused municipal artesian water well, diameter 16 to 12 in., depth 1,607 $\mathrm{ft}$, cased to $1,128 \mathrm{ft}$, open hole 1,128 to $1,607 \mathrm{ft}$.

INSTRUMENTATION.--Water-level recorder and monthly measurement with chalked tape by usGs personnel.

DATUM.--Elevation of land-surface datum is $703 \mathrm{ft}$ above National Geodetic Vertical Datum of 1929 , from topographic map. Measuring point: Nipple on plate welded to casing, 2.11 ft above surface datum.

REMARKs.-Water-level recorder removed Dec. 4, 1984 . Oct. and Nov, readings are noon values from recorder, the rest are chalked tape measurements.

PERIOD OF RECORD. - -July 1975 to current year.

REVISED RECORDS. - WDR IA-84-1.

EXTREMES FOR PERIOD OF RECORD.--Highest water level recorded, 247.46 ft below land-surface datum, Jul. 8, 1975, lowest recorded, 271.77 ft below land-surface datum, May $15,1984$.

WATER LEVEL, IN FEET BELOW LAND-SURFACE DATUM, WATER YEAR OCTOBER 1984 TO SEPTEMBER 1985

\begin{tabular}{|c|c|c|c|c|c|c|c|c|c|c|c|}
\hline DATE & & $\begin{array}{l}\text { WATER } \\
\text { LEVEL }\end{array}$ & DATE & & $\begin{array}{l}\text { WATER } \\
\text { LEVEL }\end{array}$ & DATE & & $\begin{array}{l}\text { WATER } \\
\text { LEVEL }\end{array}$ & DATE & & $\begin{array}{l}\text { WATER } \\
\text { LEVEL }\end{array}$ \\
\hline OCT & $\begin{array}{r}5 \\
10 \\
15 \\
20 \\
25 \\
31\end{array}$ & $\begin{array}{l}270.63 \\
270.58 \\
269.82 \\
270.21 \\
270.29 \\
270.27\end{array}$ & Nov & $\begin{array}{l}5 \\
10 \\
15 \\
20 \\
25 \\
30\end{array}$ & $\begin{array}{l}270.22 \\
269.67 \\
269.70 \\
270.20 \\
269.41 \\
269.11\end{array}$ & $\begin{array}{l}\text { DEC } \\
\text { JAN } \\
\text { FEB } \\
\text { MAR } \\
\text { APR } \\
\text { MAY }\end{array}$ & $\begin{array}{l}4 \\
29 \\
21 \\
14 \\
16 \\
20\end{array}$ & $\begin{array}{l}269.73 \\
269.64 \\
268.84 \\
270.60 \\
271.26 \\
269.19\end{array}$ & $\begin{array}{l}\text { JUN } \\
\text { JUL } \\
\text { AUG } \\
\text { SEP }\end{array}$ & $\begin{array}{l}13 \\
23 \\
19 \\
12\end{array}$ & $\begin{array}{l}268.80 \\
266.37 \\
264.58 \\
264.11\end{array}$ \\
\hline
\end{tabular}

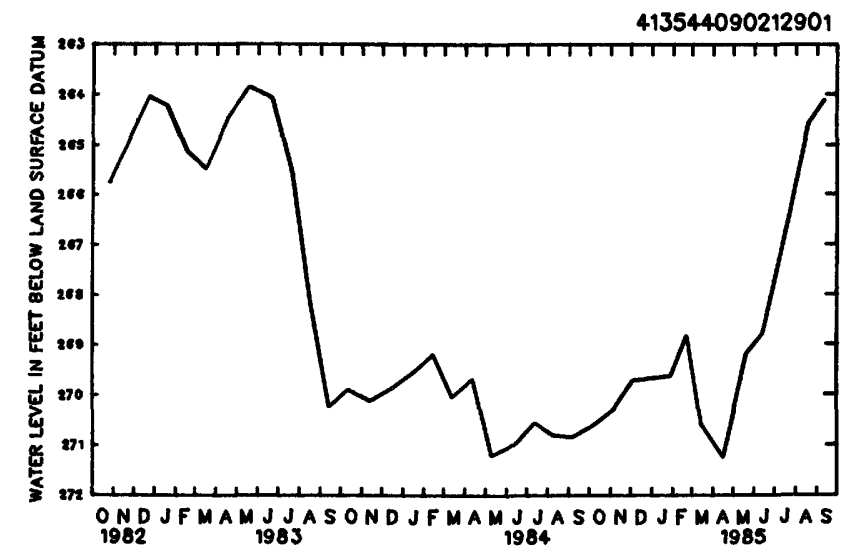


430140N095573101. Local number, 95-43-7 AAAAl.

LOCATION.--Lat $43^{\circ} 04^{\prime} 10^{\prime \prime}$, long $95^{\circ} 57^{\prime} 32^{\prime \prime}$, Bydrologic Unit 10230002, just south of County Road B-40, $1 \mathrm{mi}$ east of the village of Newkirk. Owner: Iowa Geological Survey and U.S. Geological Survey. AQUIFER.--Dakota: in sandstone of Early Cretaceous age.

WELL CBARACTERISTICS.--Drilled observation artesian water well, diameter 2 in., depth $681 \mathrm{ft}$, cased to $681 \mathrm{ft}$, perforated 641 to $681 \mathrm{ft}$.

INSTRUKENTATION.--Quarterly measurement with chalked tape by USGS personnel.

DATUM.--Elevation of land-surface datum is 1,390 ft above National Geodetic Vertical Datum of 1929 , from topographic map. Measuring point: Top of casing, $3.70 \mathrm{ft}$ above land-surface datum.

REMARKS. - Well D-43. Paleozoic rock from 674 to $681 \mathrm{ft}$.

PERIOD OF RECORD.--JULY 1980 to December 1980 , May 1982 to current year.

EXTREMES POR PERIOD OF RECORD.---Bighest water level measured, $215.13 \mathrm{ft}$ below land-surface datum, June 5, 1984, lowest measured, 217.23 ft bel ow land-surface datum, July 9, 1985.

WATER LEVEL, IN FEET BELOW LAND-SURFACE DATUM, WATER YEAR OCTOBER 1984 TO SEPTEMBER 1985

$\begin{array}{lrrrrrrr}\text { DATE } & \begin{array}{r}\text { WATER } \\ \text { LEVEL }\end{array} & \text { DATE } & \begin{array}{r}\text { WATER } \\ \text { LEVEL }\end{array} & \text { DATE } & & \begin{array}{r}\text { WATER } \\ \text { LEVEL }\end{array} \\ \text { JAN } 8 & 216.57 & \text { APR } & 2 & 215.55 & \text { JUL } & 9 & 217.23\end{array}$

430913N096033201. Local number, 96-44-8 ADAAl.

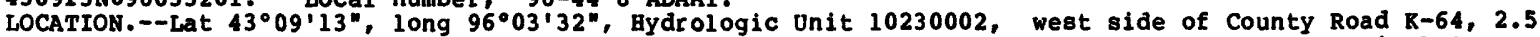
$\mathrm{mi}$ west of the Town of Boyden and $2.2 \mathrm{mi}$ south of $\mathrm{U} . \mathrm{s}$. Highway 18. Owner: Iowa Geological survey and U.S. Geological Survey.

AQUIFER.--Dakota: in sandstone of Early Cretaceous age.

FELL CBARACTERISTICS.--Drilled observation artesian water well, diameter 2 in., depth $682 \mathrm{ft}$, cased to $682 \mathrm{ft}$, perforated 647 to $667 \mathrm{ft}$.

INSTRUMENTATION. --Quarterly measurement with chalked tape by uSGS personnel.

DATUM. --Elevation of land-surface datum is 1,373 ft above National Geodetic vertical Datum of 1929 , from topographic map. Measuring point: Top of casing, $3.70 \mathrm{ft}$ above land-surface datum.

REMARRS.--Well D-44. One $\mathrm{ft}$ of Paleozoic rock penetrated.

PERIOD OF RECORD. --August 1980 to December 1980 , May 1982 to current year.

EXTREMES POR PERIOD OF RECORD. -- Highest water level measured, $187.85 \mathrm{ft}$ below land-surface datum, Oct. 16, 1984, lowest measured, $193.95 \mathrm{ft}$ below land-surface datum, Dec. 8, 1982.

WATER LEVEL, IN FEET BELOW LAND-SURFACE DATUM, WATER YEAR OCTOBER 1984 TO SEPTEKBER 1985

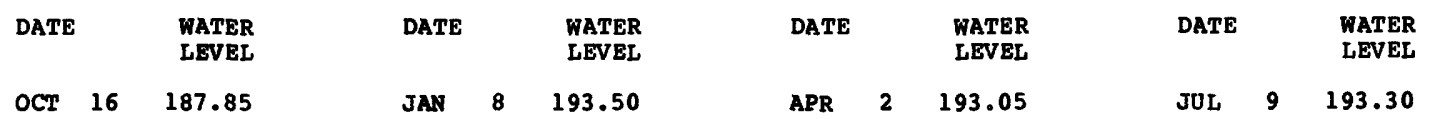

\section{WASHINGTON COUNTY}

421829N091304701. Local number, 75-6-14 ABBB1.

LOCATION.--Lat $42^{\circ} 18^{\prime} 29^{\prime \prime}$, long $91^{\circ} 30^{\prime} 47^{\prime \prime}$, Bydrologic unit $07080209,1 \mathrm{mi}$ north and $1.5 \mathrm{mi}$ east of the junction of U.s. Bighway 218 and Iowa Bighway 92. Owner: Mrs. David Armstrong. AQUIPER.--Glacial Drift: in material of Pleistocene age.

WELL CHARACTERISTICs.--Bored unused water-table well, diameter $12 \mathrm{in.}$, depth $45 \mathrm{ft}$, lined with tile. INSTRUMENTATION:--Monthly measurement with chalked tape by uSGS personnel.

DATUM.--Elevation of land-surface is $745 \mathrm{ft}$ above National Geodetic Vertical Datum of 1929, from topographic map. Measuring point: Nipple welded to barrel, $3.33 \mathrm{ft}$ above land-surface datum. REMARRS. - -NONe.

PERIOD OR RECORD. - -December 1983 to current year.

EXTREMES POR PERIOD OF RECORD, -- Highest water level measured, $1.53 \mathrm{ft}$ below land-surface datum, May 23 , 1984; lowest measured, $9.21 \mathrm{ft}$ below land-surface datum, Sep. 5, 1985 .

WATER LEVEL, IN FEET BELOW LAND-SURFACE DATUM, WATER YEAR OCTOBER 1983 TO SEPTEMBER 1984

\begin{tabular}{|c|c|c|c|c|c|c|c|c|c|c|}
\hline DATE & $\begin{array}{l}\text { WATER } \\
\text { LEVEL }\end{array}$ & DATE & & $\begin{array}{l}\text { WATER } \\
\text { LEVEL }\end{array}$ & DATE & & $\begin{array}{l}\text { WATER } \\
\text { LEVEL }\end{array}$ & DATE & & $\begin{array}{l}\text { WATER } \\
\text { LEVEL }\end{array}$ \\
\hline $\begin{array}{ll}\text { DEC } & 1 \\
& 13 \\
\text { JAN } & 26\end{array}$ & $\begin{array}{l}2.62 \\
2.00 \\
3.83\end{array}$ & $\begin{array}{l}\text { FEB } \\
\text { MAR } \\
\text { APR }\end{array}$ & $\begin{array}{l}28 \\
27 \\
26\end{array}$ & $\begin{array}{l}2.83 \\
1.86 \\
2.47\end{array}$ & $\begin{array}{l}\text { MAY } \\
\text { JUN } \\
\text { JUL }\end{array}$ & $\begin{array}{l}23 \\
19 \\
19\end{array}$ & $\begin{array}{l}1.53 \\
3.71 \\
3.77\end{array}$ & $\begin{array}{l}\text { AUG } \\
\text { SEP }\end{array}$ & $\begin{array}{l}21 \\
20\end{array}$ & $\begin{array}{l}5.81 \\
8.17\end{array}$ \\
\hline
\end{tabular}

WATER LEVEL, IN FEET BELOW LAND-SURFACE DATUM, WATER YEAR OCTOBER 1984 TO SEPTEMBER 1985

\begin{tabular}{|c|c|c|c|c|c|c|c|c|c|c|c|}
\hline DATE & & $\begin{array}{l}\text { WATER } \\
\text { LEVEL }\end{array}$ & DATE & & $\begin{array}{l}\text { WATER } \\
\text { LEVEL }\end{array}$ & DATE & & $\begin{array}{l}\text { WATER } \\
\text { LEVEL }\end{array}$ & DATE & & $\begin{array}{l}\text { WATER } \\
\text { LEVEL }\end{array}$ \\
\hline $\begin{array}{l}\text { OCT } \\
\text { NOV } \\
\text { DEC } \\
\text { JAN }\end{array}$ & $\begin{array}{l}18 \\
15 \\
13 \\
15\end{array}$ & $\begin{array}{l}6.67 \\
3.49 \\
4.24 \\
3.77\end{array}$ & $\begin{array}{l}\text { FEB } \\
\text { MAR } \\
\text { APR }\end{array}$ & $\begin{array}{l}12 \\
12 \\
11\end{array}$ & $\begin{array}{l}4.72 \\
2.20 \\
3.62\end{array}$ & $\begin{array}{l}\text { MAY } \\
\text { JUN } \\
\text { JUL }\end{array}$ & $\begin{array}{l}9 \\
6 \\
3\end{array}$ & $\begin{array}{l}4.71 \\
5.20 \\
5.72\end{array}$ & $\begin{array}{l}\text { AUG } \\
\text { SEP }\end{array}$ & $\begin{array}{r}5 \\
5 \\
24\end{array}$ & $\begin{array}{l}6.81 \\
9.21 \\
8.61\end{array}$ \\
\hline
\end{tabular}


412037N091564701. Local number, 76-9-31 CBBCl.

LOCATION.--Lat 41.20'37\%, long $91^{\circ} 56^{\prime} 47^{\circ}$, Hydrologic Unit 07080107, at Pepper Quarry on County Road V-15 V-15, $1 \mathrm{mi}$ south of the City of Reota. Owner: River Products Co.

AQUIFER.-Mississippian and Devonian: in limestone of Mississippian age and sandstone of Devonian age.

WELL CHARACTERISTICs.--Drilled observation artesian water well, diameter 5 in., depth 136 ft, cased to $19 \mathrm{ft}$, open hole 19 to $136 \mathrm{ft}$.

INSTRUMENTATION.--Water-level recorder.

DATUM.--Elevation of land-surface datum is $745 \mathrm{ft}$ above National Geodetic Vertical Datum of 1929 . from topographic map. Measuring point: Top of casing, $2.88 \mathrm{ft}$ above land-surface datum.

REMARRS. - Water levels af fected by quarrying operations.

PERIOD OF RECORD.--August 1979 to current year.

REVI8ED RECORDS, - -WDR IA-84-1.

EXTREMES FOR PERIOD OF RECORD.--Highest water level recorded, 9.38 ft below land-surface datum, Mar. 4 , 1985; lowest recorded, $24.06 \mathrm{ft}$ below land-surface datum, sept. 18, 1983.

WATER LEVEL, IN FEET BELON LAND-SURFACE DATOM, WATER YEAR OCTOBER 1984 TO SEPTEMBER 1985 NOON VALUES

\begin{tabular}{|c|c|c|c|c|c|c|c|c|c|c|c|c|}
\hline DAY & OCT & MOV & DEC & JAN & FEB & MAR & APR & MAY & JUN & JUL & AUG & SEP \\
\hline $\begin{array}{r}5 \\
10 \\
15 \\
20 \\
25 \\
\text { EOM }\end{array}$ & 20.86 & $\begin{array}{l}17.19 \\
17.49 \\
18.70 \\
18.80 \\
19.14\end{array}$ & $\begin{array}{l}19.68 \\
19.87 \\
19.26 \\
18.68 \\
18.72 \\
16.69\end{array}$ & $\begin{array}{r}16.50 \\
16.85 \\
17.46 \\
17.06 \\
e 17.25\end{array}$ & $\begin{array}{r}\text { e17.25 } \\
\text { e17.05 } \\
17.28 \\
15.95 \\
11.35 \\
12.10\end{array}$ & $\begin{array}{l}10.58 \\
12.22 \\
12.58 \\
13.24 \\
13.86 \\
12.08\end{array}$ & $\begin{array}{l}13.13 \\
13.79 \\
14.13 \\
14.78 \\
15.39 \\
15.73\end{array}$ & $\begin{array}{l}15.73 \\
16.21 \\
16.03 \\
16.42 \\
16.74 \\
17.08\end{array}$ & $\begin{array}{r}17.75 \\
18.18 \\
18.41 \\
e 18.77 \\
19.16 \\
\mathrm{e}\end{array}$ & $\begin{array}{l}19.74 \\
20.25 \\
18.76 \\
19.66 \\
20.07 \\
20.40\end{array}$ & $\begin{array}{l}20.74 \\
16.25 \\
17.52 \\
18.48 \\
19.17 \\
19.86\end{array}$ & $\begin{array}{l}20.15 \\
20.40 \\
20.28 \\
20.18 \\
17.53 \\
16.48\end{array}$ \\
\hline
\end{tabular}

WTR YEAR 1985 HIGHEST 9.38 MAR $4,1985 \quad$ LONEST 22.85 OCT 18,1984

e Estimated.

412750N091495201. Local number, 77-9-24 AADA1.

LOCATION.--Lat $41^{\circ} 27^{\prime} 54^{\circ}$, long $91^{\circ} 49^{\prime} 47^{\circ}$, Hydrologic Unit 07080209 , north of the city sewage treatment plant and west of First Avenue 8B, Meliman. Owner: City of Weliman.

AQUIFER.--Dolomite of Mississippian age and dolomite of Devonian age.

WELL CaARACTERIsTICs.--Drilled unused artesian water well, diameter 8 in., depth $110 \mathrm{ft}$, cased to $47 \mathrm{ft}$, open hole 47 to $110 \mathrm{ft}$.

INSTRUMENTATION.--Monthly mesurement wtih chalked tape by usGs personnel.

DATUM.--Elevation of land-surface datum is $695 \mathrm{ft}$ above vational Geodetic Vertical Datum of 1929 , from topographic map. Measuring point: Top of casing, $1.35 \mathrm{ft}$ above land-surface datum.

REMARKS. - - City test well Ho. 1 .

PERIOD OF RECORD. - May 1963 to October 1971, May 1973 to current year.

REVI8ED RECORDS.- -WDR IA-84-1.

EXTREMES FOR PERIOD OF RBCORD.-- Highest water level measured, 1.35 ft above land-surface datum, Nov. 3 , 1977, Mar. 28, 1979, and Apr. 13, 1983, lowest measured, 6.92 ft below land-surface datum, Nov. 1 , 1964.

WATER LEVEL, IN FEET BELON LAND SURFACB- DATUM, WATER YEAR OCTOBER 1984 TO SEPTEMBER 1985

\begin{tabular}{|c|c|c|c|c|c|c|c|c|c|c|c|}
\hline DATE & & $\begin{array}{l}\text { WATER } \\
\text { LEVEL }\end{array}$ & DATE & & $\begin{array}{l}\text { KATER } \\
\text { LEVEL }\end{array}$ & DATE & & $\begin{array}{l}\text { WATER } \\
\text { LEVEL }\end{array}$ & DATE & & $\begin{array}{l}\text { WATER } \\
\text { LEVEL }\end{array}$ \\
\hline $\begin{array}{l}\text { OCT } \\
\text { NOV } \\
\text { DEC }\end{array}$ & $\begin{array}{l}18 \\
15 \\
13\end{array}$ & $\begin{array}{l}4.16 \\
2.26 \\
3.38\end{array}$ & $\begin{array}{l}\text { FEB } \\
\text { MAR } \\
\text { APR }\end{array}$ & $\begin{array}{l}12 \\
12 \\
11\end{array}$ & $\begin{array}{l}3.15 \\
0.24 \\
0.72\end{array}$ & $\begin{array}{l}\text { MAY } \\
\text { JUN } \\
\text { JUL. }\end{array}$ & $\begin{array}{l}9 \\
6 \\
3\end{array}$ & $\begin{array}{l}1.93 \\
3.29 \\
4.09\end{array}$ & $\begin{array}{l}\text { ADG } \\
\text { SEP }\end{array}$ & $\begin{array}{r}5 \\
5 \\
24\end{array}$ & $\begin{array}{l}5.02 \\
5.70 \\
5.21\end{array}$ \\
\hline
\end{tabular}

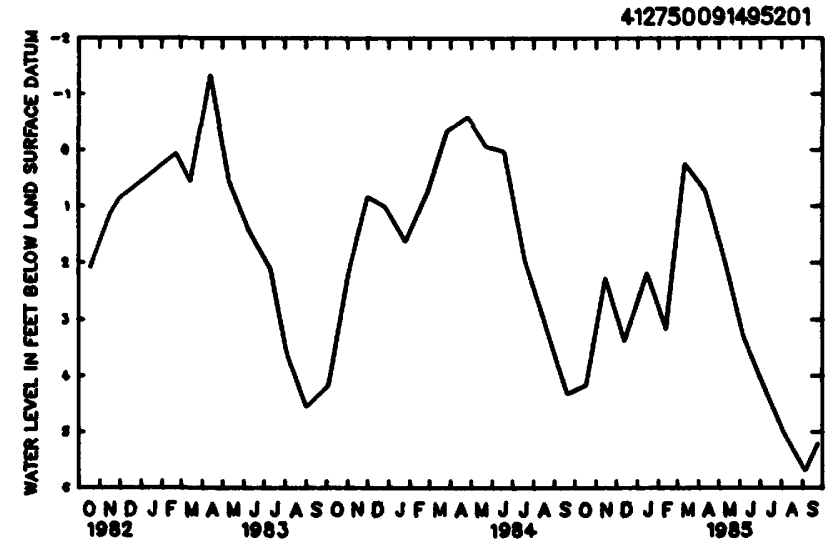


421550N094041001. Local number, 86-28-14 ADABI.

LOCATION.--Lat $42^{\circ} 15^{\prime} 50^{\prime \prime}$, long $94^{\circ} 04^{\prime} 10^{\prime \prime}$, Hydrologic unit 07100004, in the town water plant, next to the water tower, Dayton. Owner: Town of Dayton.

AQUIFER.--Devonian and Mississippian: in limestone of Devonian age and Mississippian age.

WELL CHARACTERISTICS.--Drilled municipal artesian water well, diameter 13 to 10 in.' depth $1,240 \mathrm{ft}$, cased to $505 \mathrm{ft}, 8$ in. Iiner 770 to $966 \mathrm{ft}$, open hole 505 to $770 \mathrm{ft}$ and 966 to $1,240 \mathrm{ft}$.

INSTRUMENTATION. --Quarterly measurement with air line by USGS personnel.

DATUM.--Elevation of land-surface datum is 1,121 ft above National Geodetic Vertical Datum of 1929 , from topographic map. Measuring point: Pump base, $1.30 \mathrm{ft}$ above land-surface datum.

REMARKS. --Town weli No. 2. Water levels affected by pumping.

PERIOD OF RECORD. --September 1942 to December 1948, January 1952 to November 1971, March 1974 to current year.

REVISIONS. --WTR YEAR 1984 WATER LEVEL 145.20 JUL $23,1984$.

EXTREMES FOR PERIOD OF RECORD. --Highest water level measured, $69.93 \mathrm{ft}$ below land-surface datum, Nov. 17, 1942; lowest measured, $145.20 \mathrm{ft}$ below land-surface datum, Jul. 23, 1984 .

WATER LEVEL, IN FEET BELOW LAND-SURFACE DATUM, WATER YEAR OCTOBER 1984 TO SEPTEMBER 1985

$\begin{array}{lrrrrrrr}\text { DATE } & \begin{array}{r}\text { WATER } \\ \text { LEVEL }\end{array} & \text { DATE } & \begin{array}{r}\text { WATER } \\ \text { LEVEL }\end{array} & \text { DATE } & \begin{array}{r}\text { WATER } \\ \text { LEVEL }\end{array} \\ \text { JAN } 4 & \mathbf{1 4 4 . 2 0} & \text { MAR } 12 & 136.20 & \text { JUN } 27 & 139.20\end{array}$

421837N094083601. Local number, 87-28-29 CCCD1.

LOCATION.--Lat $42^{\circ} 18 \cdot 37^{\%}$, long $94^{\circ} 08 \cdot 36^{\%}$, Hydrologic Unit 07100006 , $3 \mathrm{mi}$ north and $2 \mathrm{mi}$ east of the Town of Hancourt. Owner: Ransom Helms.

AQUIFER.--Glacial drift: in material of pleistocene age.

WELL CHARACTERISTICS.--Drilled unused water-table weli, diameter 12 in., depth $42 \mathrm{ft}$, 1 ined with tile. INSTRUMENTATION. --Monthly measurement with chalked tape by USGS personnel.

DATOM.--Elevation of land-surface datum is $1,165 \mathrm{ft}$ above National Geodetic vertical Datum of 1929 , from topographic map. Measuring point: Top of casing, 0.75 ft above land-surface datum.

REMARKS. - None.

PERIOD OF RECORD,--October 1942 to June 1956, March 1958 to current year.

EXTREMES FOR PERIOD OF RECORD.--Highest water level measured, 0.05 ft below land-surface datum, Aug. 1 , 1972; lowest measured, $13.62 \mathrm{ft}$ below land-surface datum, Mar. 12, 1956.

WATER LEVEL, IN FEET BELOW LAND-SURFACE DATUM, WATER YEAR OCTOBER 1984 TO SEPTEMBER 1985

\begin{tabular}{|c|c|c|c|c|c|c|c|c|c|c|c|}
\hline DATE & & $\begin{array}{l}\text { WATER } \\
\text { LEVEL }\end{array}$ & DATE & & $\begin{array}{l}\text { WATER } \\
\text { LEVEL }\end{array}$ & DATE & & $\begin{array}{l}\text { WATER } \\
\text { LEVEL }\end{array}$ & DATE & & $\begin{array}{l}\text { WATER } \\
\text { LEVEL }\end{array}$ \\
\hline $\begin{array}{l}\text { OCT } \\
\text { NOV } \\
\text { DEC }\end{array}$ & $\begin{array}{l}19 \\
20 \\
20\end{array}$ & $\begin{array}{l}5.24 \\
4.63 \\
3.64\end{array}$ & $\begin{array}{l}\text { JAN } \\
\text { FEB } \\
\text { MAR }\end{array}$ & $\begin{array}{l}21 \\
20 \\
20\end{array}$ & $\begin{array}{l}4.53 \\
3.15 \\
2.88\end{array}$ & $\begin{array}{l}\text { APR } \\
\text { MAY } \\
\text { JUN }\end{array}$ & $\begin{array}{l}19 \\
20 \\
20\end{array}$ & $\begin{array}{l}3.48 \\
3.69 \\
4.48\end{array}$ & $\begin{array}{l}\text { JUL } \\
\text { AUG } \\
\text { SEP }\end{array}$ & $\begin{array}{l}22 \\
20 \\
23\end{array}$ & $\begin{array}{l}5.33 \\
5.03 \\
3.73\end{array}$ \\
\hline
\end{tabular}

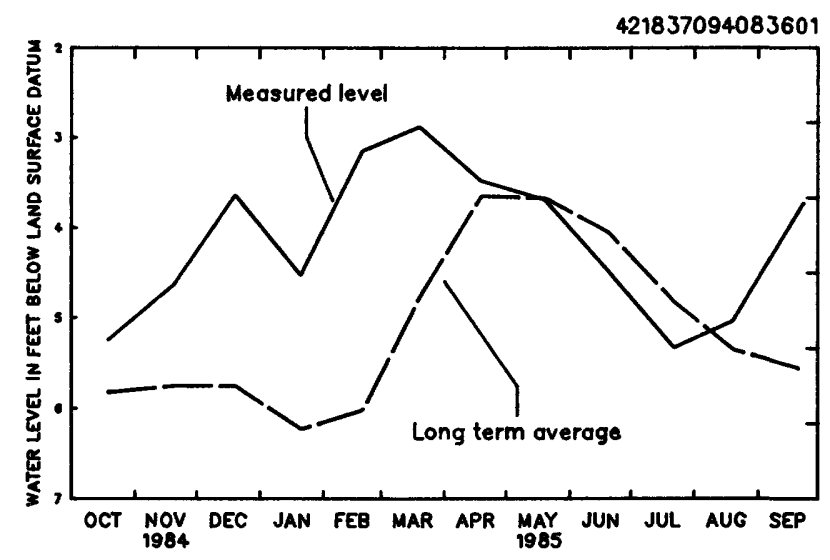


423018N094214701. Local number, 89-30-23 CCBBI.

LOCATION, --Lat 42.30'18\%, Iong 94\%21'47\%, Hydrologic Unit 07100004, 75 ft west of the new school addition, Barnum. Owner: Johnson Township Consolidated School.

AQUIFER.--Dakota: in sandstone of Early Cretaceous age.

WELL CHARACTERISTICS.--Drilled unused artesian water well, diameter 4 in., reported depth $208 \mathrm{ft}$, cased to $208 \mathrm{ft}$, perforated 203-208 $\mathrm{ft}$.

INSTRUMENTATION.--Quarterly measurement with chalked tape by uSGS personnel.

DATUK.--Elevation of land-surface datum is $1,174 \mathrm{ft}$ above National Geodetic Vertical Datum of 1929 ,

from topogarphic map. Measuring point: Top of casing at land-surface datum.

REMARRS. - -Site identification number corrected 1983.

PERIOD OF RECORD.--October 1942 to September 1945, May 1947 to current year.

EXTREMES FOR PERIOD OF RECORD. - - Highest water level measured, 30.86 ft below land-surface datum, July

2. 1945 ; lowest measured, $52.60 \mathrm{ft}$ below land-surface datum, Feb. 26, 1980.

WATER LEVEL, IN FEET BELOW LAND-SURFACE DATUM, WATER YEAR OCTOBER 1984 TO SEPTEMBER 1985

$\begin{array}{lllllllll}\text { DATE } & \begin{array}{l}\text { WATER } \\ \text { LEVEL }\end{array} & \text { DATE } & \begin{array}{l}\text { WATER } \\ \text { LEVEL }\end{array} & \text { DATE } & \text { WATER } & \text { WATE } & \begin{array}{l}\text { WATER } \\ \text { LEVEL }\end{array} \\ \text { DEC } 13 & 42.88 & \text { MAR } 13 & 42.70 & \text { MAY } 28 & 43.14 & \text { AUG } & 21 & 43.58\end{array}$

WOODBURY COUNTY

422058N095573701. Local number, 87-44-15 CBBBl.

LOCATION. - Lat $42^{\circ} 20^{\prime} 58^{\prime \prime}$, long $95^{\circ} 57^{\prime} 37^{\prime \prime}$. Bydrologic Unit 10230003 , approximately $3.5 \mathrm{mi}$ west and $5.5 \mathrm{mi}$ north of the Village ot Oto. Owner: Iowa Geological Survey and U.S. Geological Survey.

AQUIFER.--Dakota: in sandstone of Early Cretaceous age.

WELL CHARACTERISTICS.--Drilled observation artesian water well, diameter 2 in., depth 197 ft, cased to $197 \mathrm{ft}$, perforated 185 to $189 \mathrm{ft}$.

INSTRUMENTATION.--Quarterly measurement with chalked tape by usgs personnel.

DATUM.--Elevation of land-surface datum is $1,165 \mathrm{ft}$ above National Geodetic vertical Datum of 1929 , from topographic map. Measuring point: Top of casing, $1.50 \mathrm{ft}$ above land-surface datum.

REMARKS. - Well D-34.

PERIOD OF RECORD.--April 1980 to December 1980, May 1982 to current year.

EXTREMES FOR PERIOD OF RECORD.--Highest water level measured, 54.74 ft below 1 and-surface datum, Oct. 15, 1984; lowest measured, $63.56 \mathrm{ft}$ below land-surface datum, Nov. 2, 1982 .

WATER LEVEL, IN FEET BELOW LAND-SURFACE DATUM, WATER YEAR OCTOBER 1984 TO SEPTEMBER 1985

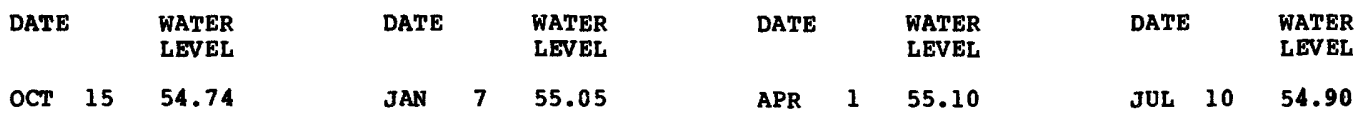

422830N096000511. Local number, 88-44-6 BAABll.

LOCATION.--Lat $42^{\circ} 28^{\prime} 30^{\circ}$, long $96^{\circ} 00^{\prime} 05^{\circ}$, Eydrologic unit 10230004 , approximately 3 mi east and 0.5 mi south of the Town of Moville. Owner: Iowa Geological Survey and u. S. Geological Survey.

AQUIFER.--Dakota: in sandstone of Early cretaceous age.

WELL CHARACTERISTICS.--Drilled observation artesian water well, diameter 2 in., depth 337 ft, cased to $337 \mathrm{ft}$, perforated 332 to $337 \mathrm{ft}$.

INSTRUMENTATION.--Quarterly measurement with chalked tape by usGs personnel.

DATUM.--Elevation of land-surface datum is $1,340 \mathrm{ft}$ above National Geodetic vertical Datum of 1929 , from topographic map. Measuring point: Top of casing, $3.50 \mathrm{ft}$ above land-surface datum.

REMARRS - Well D-33.

PERIOD OF RECORD.--October 1979 to December 1980, May 1982 to current year.

EXTREMES FOR PERIOD OF RECORD.--Highest water level measured, 199.33 ft below land-surface datum, Oct.

15. 1984; lowest measured, $202.90 \mathrm{ft}$ below land-surface datum, Oct. 17, 1979.

WATER LEVEL, IN FEET BELOW LAND-SURFACE DATUM, WATER YEAR OCTOBER 1984 TO SEPTEMBER 1985

\begin{tabular}{|c|c|c|c|c|c|c|c|c|c|c|c|}
\hline DATE & & $\begin{array}{l}\text { WATER } \\
\text { LEVEL }\end{array}$ & DATE & & $\begin{array}{l}\text { WATER } \\
\text { LEVEL }\end{array}$ & DATE & & $\begin{array}{l}\text { WATER } \\
\text { LEVEL }\end{array}$ & DATE & & $\begin{array}{l}\text { WATER } \\
\text { LEVEL }\end{array}$ \\
\hline DCT & 15 & 199.33 & JAN & 7 & 199.67 & APR & 1 & 199.45 & JUL & 10 & 199.41 \\
\hline
\end{tabular}

423015N096034601. Local number, 89-44-20 DCDCl.

LOCATION.--Lat $42^{\circ} 30^{\prime} 15^{\circ}$, long $96^{\circ} 03^{\prime} 46^{\circ}$, Bydrologic Unit 10230004, east of Iowa Highway 140, approximately $1 \mathrm{mi}$ north of the Town of Moville. Owner: Iowa Geological Survey and U.S. Geological Survey.

AQUIFER.--Dakota: in sandstone of Early Cretaceous age.

WELL CHARACTERISTICS.--Drilled observation artesian water well, diameter 2 in., depth 221 ft, cased to $221 \mathrm{ft}$, perforated 206 to $221 \mathrm{ft}$.

INSTRUMENTATION.--Quarterly measurement with chalked tape by usgs personnel.

DATUM.--Elevation of land-surface datum is 1,160 ft above National Geodetic Vertical Datum of 1929 , from topographic map. Measuring point: Top of casing, $4.00 \mathrm{ft}$ above land-surface datum.

REMARRS - - Well D-32.

PERIOD OF RECORD.--October 1979 to December 1980 , May 1982 to current year.

EXTREMES FOR PERIOD OF RECORD,--Highest water level measured, $22.64 \mathrm{ft}$ below 1 and-surface datum, Aug.

8. 1984; lowest measured, $26.65 \mathrm{ft}$ below land-surface datum, Dec. 11, 1980.

WATER LEVEL, IN FEET BELOW LAND-SURFACE DATUM, WATER YEAR OCTOBER 1984 TO SEPTEMBER 1985

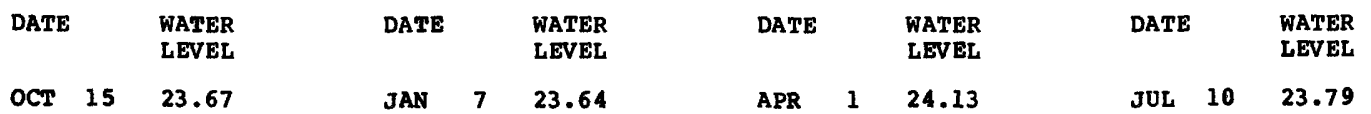


WOODBURY COUNTY

422910N096135811. Local number, 89-46-36 BBDC11.

LOCATION.--Lat $42^{\circ} 29^{\prime} 10^{\prime \prime}$, long $96^{\circ} 13^{\prime} 58^{\prime \prime}$, Hydrologic Unit 10230004 , approximately 0.75 mi northeast of the Eberly Cemetary or $2.5 \mathrm{mi}$ west and $0.75 \mathrm{mi}$ north of the Village of Lawton. Owner: Iowa Geological survey and U.S. Geological survey.

AOUIFER.--Dakota: in sandstone of Early Cretaceous age.

WELL CHARACTERISTICS.--Drilled observation artesian water well, diameter 2 in., depth 500 ft, cased to $500 \mathrm{ft}$, perforated 358 to $362 \mathrm{ft}$.

INSTRUMENTATION.--Quarterly measurement with chalked tape by usGs personnel.

DATUM.--Elevation of land-surface datum is $1,268 \mathrm{ft}$ above National Geodetic vertical Datum of 1929 , Geological topographic map. Measuring point: Top of casing, 3.00 ft above land-surface datum.

REMARKS. - Well D-30.

PERIOD OF RECORD.--April 1980 to December 1980, May 1982 to current year.

EXTREMES FOR PERIOD OF RECORD. --Bighest water level measured, 128.50 ft below land-surface datum, Aug. 8, 1984 ; lowest measured, $135.35 \mathrm{ft}$ below land-surface datum, Nov. $2,1982$.

WATER LEVEL, IN FEET BELOW LAND-SURFACE DATUM, WATER YEAR OCTOBER 1984 TO SEPTEMBER 1985

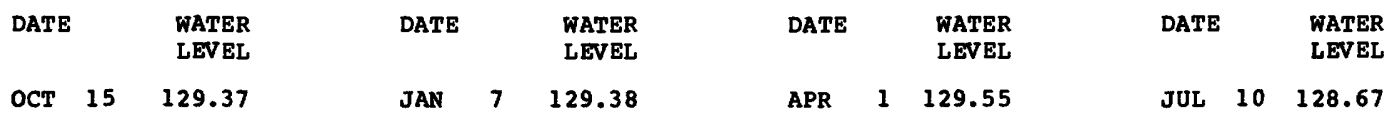


STATION NUMBER

405631094560802D07135W20AACA 41353709453270107835 W0 4BCBD $41323409455240107835 \mathrm{Wl}$ 9BCDB $41374309504140107936 \mathrm{~W} 29 \mathrm{BBCA}$ 41433009452480108035 W23 ADDD

$41424509452490108035 W 26$ AAD 41595009151250108309 W1 4DBD 42003009205300108311 W1 IDCD $41595509212070108312 \mathrm{Wl} 3 \mathrm{CBBB}$ 42052009152470108409 W15ACC

42101609201590108510 W17DBDC $42132609152530108609 \mathrm{W3} 4 \mathrm{ABB}$ 42280109215280108812 W0 BBBC 42280509216590108812 W06ACAA 42311209221390108913 WI SDABB

$42281809221280108913 \omega 34 D D A$ $42313909226140108914 \mathrm{Wl} 2 \mathrm{DDCD}$ 42505809231560109314 W2 OCC 42190009200200108710 W27CB 42283309143170108908 W36DCAA

42371009154000109009 W10CBA 42383709513500209037 W0 5ADAA 42351209252100109017 W29AAAA $42423909235000109115 \mathrm{~W} 11$ ACBB $42470409240080309215 W 18 B C A A$

42462709254230209217 Wl $8 \mathrm{CCCC}$ 42452409247460109217 W25ABDA 42445509258180109218 W28DBDD 42535509247580109317 WO1ACCC $42161409432510108632 W 11$ CCAA

41514709440350108233 W34DCCC $41543009504160108236 \mathrm{Wl} 7 \mathrm{CCCA}$ 42002409457590108335 Wl 8BAAD 41163709452020107535 W22CAC 41242909459430107636 W04CAD

41271409446070107735 W21 BDDD $43075609326320109622 \mathrm{Wl}$ 6DABC $43142609307330109719 \% 06 \mathrm{DD}$ 43092309511450109637 W03DDCC 43092209519350109638 W03CCDD

42402609132150209106 W22CDDA $42465309106080109202 W 17 \mathrm{CADA}$ $42513809123490109305 \mathrm{W23ABBB}$ $41492109045040108102 \mathrm{E} 17 \mathrm{ACC}$ 41465209015320108106 E33ADA

41565009527560208240 WO2ABDD 42013109522110108339 W03DCAC 42032809512240108437 W30CBBB 42055109518580108438 \%07CDBA 42041509535220108441 W23CACC

42112509519310108539 W12ADDB $42100409527270108540 \mathrm{Wl} 3 \mathrm{CCCC}$ 42073609534240108541 w36CCBC 41351709411410107829 W0 4BDDD $41363809353090107926 \mathrm{W3} 3 \mathrm{BAC}$

42205909129140108706 W13DBA $42270509056120108801 \mathrm{WI} 1 \mathrm{CABB}$ 42291009107270108902 W30DCCC 42313609038350108903 E1 8AADC 42313409038340108903 E18AADD

$42173109101150108602 W 01 \mathrm{ABCC}$ $42503609148010109308 W 28 B B D D$ 42560609156550109409 W30ABAA 43032909202090109510 W09CABD 43091909235180109615 W11 BBA
STATION NAME

1976 NODAWAY NO 3

1969EXIRA NO 11

1976 BRAYTON

1966KIMBALLTON NO 6 AUDUBON NO 2

1977AUDUBON 14

$\begin{array}{ll}18068 & \text { ATRINS TOWN NO2 } \\ 07384 & \text { VAN HORNE CITY2 } \\ & \text { KEYSTONE CITY } \\ 00001 & \text { SHELLSBURG 1 }\end{array}$

1973VINTON NO 4

$\begin{array}{ll}11586 & \text { URBANA TONN } 2 \\ 12372 & \text { ELR RUN HTS } 1\end{array}$

100391958 EVANSDALE NO

1937 WATERLOO NO 10

07482

WATERLOO 15

CEDAR FALLS 2

11138 PLAINFIELD 1

03894 BRANDON IOWA 2

25801 1980WINTHROP NO 3

06208 BAZELTON IOWA 1 1967STORH LARE CITY NO 6 1962APLINGTON TOWN 2 1941 SAELL ROCR TOWN NO 1 1981CLARKSVILLE 3

20256 1967BRISTOW TOWN WELL 1899ALLISON TOWN NO 1 1925DUMONT TOWN

1948GREENE TOWN NO

1978 LOHRVILLE 4

1955COON RAPIDS 5

1958 MANNING 6

1936 HALBUR 1

129691961 CUMBERLAND NO 3

1945ATLANTIC NO 2

1960ANITA NO 3

255381977 VENTURA WELL NO 1

1925PLYMOUTH TOWN I

1971 SPENCER NO 3

1976 EVERLY TOWN NO 3

085831957 STRANBERRY PT TWN 6

006661937 GUTTENBERG CITY 2

184201965 ELRADER CITY WELL 5

00549 CALAYUS IOWA $\$ 2$

CAMANCHE CITY 2

1925ARION TOWN NO 1

1976DENISON NO 7

1960VAIL NO 2

1969DELOIT NO 4

1950 CHARTER OAR NO 3

1937KIRON NO 4

1917 SCHLESWIG NO 3-WEST

1931 RICRETTS NO 2 (MAIN)

197 9REDEIELD 3

174251965 WAUREE NO 3

\begin{tabular}{|c|c|c|}
\hline 02242 & $\begin{array}{l}\text { RYAN CITY } 3 \\
\text { 1979EPWORTH } 3 \\
\text { 1959DYERSVILLE NO } 1 \\
\text { 1956DUBUQUE NO } 3 \\
\text { 1956DUBUQUE NO } 4\end{array}$ & $\begin{array}{l}\text { DELAWARE } \\
\text { DUBUQUE } \\
\text { DUBUQUE } \\
\text { DUBUQUE } \\
\text { DUBUQUE }\end{array}$ \\
\hline $\begin{array}{l}03479 \\
25513\end{array}$ & 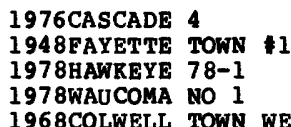 & $\begin{array}{l}\text { DUBUQUE } \\
\text { FAYETTE } \\
\text { FAYETTE } \\
\text { FAYETTE }\end{array}$ \\
\hline
\end{tabular}

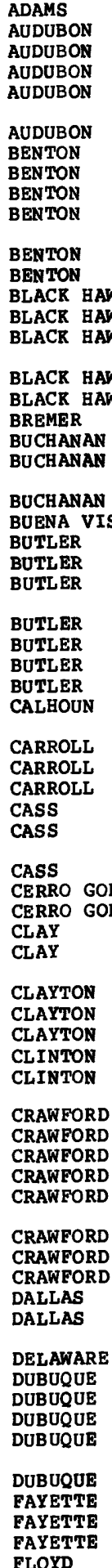

GEO-
LOGIC
UNIT

DEPT

$\mathrm{OF}$

TOLLP

(FEET)

(72008)

38.00

60.00

40.00

37.00

34.00

35.00

485.00

$\begin{array}{lllr}07-03-85 & 14: 15 & 350 \text { SLRN } & 485.00 \\ 09-25-85 & 11: 15 & 371 \text { JRDN } & 1870.00 \\ 09-25-85 & 13: 00 & \text { 364STRR } & 1360.00 \\ 07-03-85 & 12: 35 & \text { 371TMPL } & 1615.00\end{array}$

$\begin{array}{llll}09-25-85 & 11: 15 & 371 \text { JRDN } & 1870.00 \\ 09-25-85 & 13: 00 & 364 \text { STPR } & 1360.00 \\ 07-03-85 & 12: 35 & \text { 371TMPL } & 1615.00\end{array}$

$\begin{array}{llll}09-25-85 & 11: 15 & 371 \text { JRDN } & 1870.00 \\ 09-25-85 & 13: 00 & 364 \text { STPR } & 1360.00 \\ 07-03-85 & 12: 35 & \text { 371TMPL } & 1615.00\end{array}$

06-25-85 11:45 112PLSC 90.00

$\begin{array}{llll}07-03-85 & 10: 15 & 350 \text { SLRN } & 560.00\end{array}$

07-31-85 10:00 344CDVL 125.00

$07-31-85 \quad 11: 15$ 344WPPC 145.00

08-15-85 12:00 111ALVM $\quad 76.00$

08-15-85 10:30 344CDVL 206.00

08-15-85 15:00 344CDVL 125.00

07-30-85 12:00 344DVNNM 150.00

08-09-85 09:45 350SLRN 405.00

08-09-85 $13: 45$ 340DVSL $\quad 180.00$

08-09-85 $11: 15$ 350SLRN 65.00

05-23-85 10:15 110QRNR 110.00

07-08-85 11:00 341 LMCK 118.00

07-08-85 16:00 344CDVL 156.00

07-08-85 14:30 340DVNN 240.00

07-09-85 13:30 344CDVL 180.00

07-08-85 13:15 344CDVL 283.00

07-09-85 12:10 340DVNN 185.00

07-09-85 $15: 00 \quad 344$ CDVL $\quad 120.00$

08-13-85 13:30 330MSSP 900.00

05-22-85 12:00 217DROT 130.00

05-22-85 11:25 111ALVM 50.00

05-22-85 12:00 111ALVM 23.00

08-22-85 13:50 217DROT 257.00

08-22-85 10:30 217DROT 81.50

08-15-85 11:30 217DROT 237.00

06-18-85 11:05 340DVNN 500.00

06-18-85 12:45 344CDVL 268.00

12-04-84 12:00 112PLSC 38.00

12-04-84 14:05 111ALVM 16.00

05-09-85 16:15 358ALXD 240.00

06-24-85 $12: 30$ 371TMPL 435.00

05-09-85 12:00 364STPR 225.00

12-20-84 11:30 350SLRN 278.00

01-08-85 11:00 112PLSC 60.00

06-17-85 11:35 111ALVM 55.00

06-17-85 11:35 111ALVM 87.00

06-18-85 10:05 111BRRV 40.00

06-12-85 14:00 111ALVM 54.00

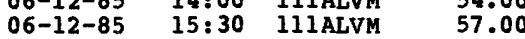

06-12-85 09:55 111ALVM 26.00

06-12-85 14:00 111ALVM 30.00

06-17-85 14:30 111SDRV 28.00

08-20-85 09:45 112PLSC 50.00

08-20-85 12:15 371JRDN 2737.00

06-25-85 14:30 350SLRN 420.00

06-24-85 15:45 350SLRN 200.00

06-24-85 14:15 350SLRN 120.00

06-25-85 09:30 111ALVM 200.00

06-25-85 10:30 111ALVM 190.00

06-24-85 09:30 350SLRN 240.00

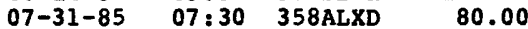

07-30-85 16:00 112PLSC 85.00

07-30-85 14:00 364STPR 682.00

08-27-85 11:00 344CDVL 286.00 


\begin{tabular}{|c|c|c|c|c|c|c|c|c|}
\hline STATION NUMBER & DATE & $\begin{array}{c}\text { FLOW } \\
\text { RATE } \\
(\text { GPM }) \\
(00058)\end{array}$ & $\begin{array}{c}\text { PUMP } \\
\text { OR FLOW } \\
\text { PERIOD } \\
\text { PRIOR } \\
\text { TO SAM- } \\
\text { PLING } \\
\text { (MIN) } \\
\text { (72004) }\end{array}$ & $\begin{array}{l}\text { SPE- } \\
\text { CIFIC } \\
\text { CON- } \\
\text { DUCT- } \\
\text { ANCE } \\
\text { (US/CM) } \\
(00095)\end{array}$ & $\begin{array}{c}\text { PH } \\
\text { (STAND- } \\
\text { ARD } \\
\text { UN ITS) } \\
(00400)\end{array}$ & $\begin{array}{l}\text { HARD- } \\
\text { NESS } \\
\text { (MG/L } \\
\text { AS } \\
\text { CACO3) } \\
(00900)\end{array}$ & $\begin{array}{l}\text { CALCIUM } \\
\text { DIS- } \\
\text { SOLVED } \\
\text { (MG/L } \\
\text { AS CA) } \\
(00915)\end{array}$ & $\begin{array}{l}\text { MAGN } \\
\text { SIUR } \\
\text { DIS } \\
\text { SOLVI } \\
\text { (MG/I } \\
\text { AS MC } \\
(0092\end{array}$ \\
\hline $\begin{array}{l}405631094560802 \\
413537094532701 \\
413234094552401 \\
413743095041401 \\
414330094524801\end{array}$ & $\begin{array}{l}08-20-85 \\
06-10-85 \\
06-10-85 \\
06-11-85 \\
06-11-85\end{array}$ & $\begin{array}{r}25 \\
150 \\
35 \\
38 \\
32\end{array}$ & $\begin{array}{r}60 \\
60 \\
30 \\
180 \\
60\end{array}$ & $\begin{array}{l}590 \\
600 \\
850 \\
740 \\
620\end{array}$ & $\begin{array}{l}6.8 \\
7.4 \\
7.0 \\
7.3 \\
7.1\end{array}$ & $\begin{array}{l}270 \\
320 \\
420 \\
350 \\
340\end{array}$ & $\begin{array}{r}71 \\
94 \\
110 \\
100 \\
100\end{array}$ & $\begin{array}{l}22 \\
21 \\
35 \\
25 \\
23\end{array}$ \\
\hline $\begin{array}{l}414245094524901 \\
415950091512501 \\
420030092053001 \\
415955092120701 \\
420520091524701\end{array}$ & $\begin{array}{l}06-11-85 \\
07-03-85 \\
09-25-85 \\
09-25-85 \\
07-03-85\end{array}$ & $\begin{array}{r}60 \\
60 \\
160 \\
120 \\
170\end{array}$ & $\begin{array}{l}60 \\
30 \\
25 \\
30 \\
30\end{array}$ & $\begin{array}{r}670 \\
730 \\
1160 \\
1700 \\
635\end{array}$ & $\begin{array}{l}6.9 \\
7.3 \\
7.6 \\
7.1 \\
7.4\end{array}$ & $\begin{array}{l}340 \\
250 \\
420 \\
700 \\
290\end{array}$ & $\begin{array}{r}100 \\
60 \\
93 \\
160 \\
63\end{array}$ & $\begin{array}{l}23 \\
24 \\
45 \\
74 \\
32\end{array}$ \\
\hline $\begin{array}{l}421016092015901 \\
421326091525301 \\
422801092152801 \\
422805092165901 \\
423112092213901\end{array}$ & $\begin{array}{l}06-25-85 \\
07-03-85 \\
07-31-85 \\
07-31-85 \\
08-15-85\end{array}$ & $\begin{array}{r}600 \\
70 \\
370 \\
450 \\
2000\end{array}$ & $\begin{array}{r}60 \\
30 \\
30 \\
30 \\
240\end{array}$ & $\begin{array}{l}595 \\
505 \\
510 \\
625 \\
530\end{array}$ & $\begin{array}{l}7.4 \\
7.4 \\
7.5 \\
7.2 \\
7.7\end{array}$ & $\begin{array}{l}310 \\
220 \\
260 \\
290 \\
270\end{array}$ & $\begin{array}{l}81 \\
47 \\
71 \\
82 \\
72\end{array}$ & $\begin{array}{l}26 \\
26 \\
20 \\
21 \\
22\end{array}$ \\
\hline $\begin{array}{l}422818092212801 \\
423139092261401 \\
425058092315601 \\
421900092002001 \\
422833091431701\end{array}$ & $\begin{array}{l}08-15-85 \\
08-15-85 \\
07-30-85 \\
08-09-85 \\
08-09-85\end{array}$ & $\begin{array}{r}1900 \\
2300 \\
175 \\
280 \\
300\end{array}$ & $\begin{array}{r}240 \\
45 \\
30 \\
30 \\
30\end{array}$ & $\begin{array}{l}645 \\
525 \\
450 \\
635 \\
710\end{array}$ & $\begin{array}{l}7.1 \\
7.6 \\
7.6 \\
7.2 \\
7.4\end{array}$ & $\begin{array}{l}330 \\
250 \\
240 \\
320 \\
320\end{array}$ & $\begin{array}{l}93 \\
70 \\
69 \\
82 \\
70\end{array}$ & $\begin{array}{l}23 \\
19 \\
17 \\
29 \\
35\end{array}$ \\
\hline $\begin{array}{l}423710091540001 \\
423837095135002 \\
423512092521001 \\
424239092350001 \\
424704092400803\end{array}$ & $\begin{array}{l}08-09-85 \\
05-23-85 \\
07-08-85 \\
07-08-85 \\
07-08-85\end{array}$ & $\begin{array}{r}120 \\
500 \\
-- \\
200 \\
300\end{array}$ & $\begin{array}{l}30 \\
90 \\
20 \\
60\end{array}$ & $\begin{array}{l}520 \\
800 \\
670 \\
470 \\
520\end{array}$ & $\begin{array}{l}7.3 \\
7.3 \\
7.2 \\
7.5 \\
7.6\end{array}$ & $\begin{array}{l}260 \\
430 \\
300 \\
230 \\
230\end{array}$ & $\begin{array}{r}66 \\
110 \\
67 \\
65 \\
64\end{array}$ & $\begin{array}{l}24 \\
37 \\
32 \\
17 \\
16\end{array}$ \\
\hline $\begin{array}{l}424627092542302 \\
424524092474601 \\
424455092581801 \\
425355092475801 \\
421614094325101\end{array}$ & $\begin{array}{l}07-09-85 \\
07-08-85 \\
07-09-85 \\
07-09-85 \\
08-13-85\end{array}$ & $\begin{array}{r}70 \\
150 \\
130 \\
215 \\
130\end{array}$ & $\begin{array}{r}60 \\
90 \\
20 \\
40 \\
120\end{array}$ & $\begin{array}{r}620 \\
420 \\
680 \\
440 \\
1500\end{array}$ & $\begin{array}{l}7.6 \\
7.6 \\
7.6 \\
7.2 \\
7.1\end{array}$ & $\begin{array}{l}270 \\
220 \\
310 \\
230 \\
750\end{array}$ & $\begin{array}{r}70 \\
60 \\
83 \\
68 \\
190\end{array}$ & $\begin{array}{l}23 \\
17 \\
25 \\
15 \\
66\end{array}$ \\
\hline $\begin{array}{l}415147094403501 \\
415430095041601 \\
420024094575901 \\
411637094520201 \\
412429094594301\end{array}$ & $\begin{array}{l}05-22-85 \\
05-22-85 \\
05-22-85 \\
08-22-85 \\
08-22-85\end{array}$ & $\begin{array}{r}120 \\
85 \\
10 \\
25 \\
140\end{array}$ & $\begin{array}{r}40 \\
120 \\
40 \\
60 \\
60\end{array}$ & $\begin{array}{r}420 \\
1010 \\
860 \\
380 \\
540\end{array}$ & $\begin{array}{l}7.2 \\
7.3 \\
7.2 \\
7.3 \\
6.4\end{array}$ & $\begin{array}{l}210 \\
500 \\
400 \\
170 \\
220\end{array}$ & $\begin{array}{r}58 \\
140 \\
110 \\
49 \\
60\end{array}$ & $\begin{array}{l}16 \\
37 \\
31 \\
12 \\
18\end{array}$ \\
\hline $\begin{array}{l}412714094460701 \\
430756093263201 \\
431426093073301 \\
430923095114501 \\
430922095193501\end{array}$ & $\begin{array}{l}08-15-85 \\
06-18-85 \\
06-18-85 \\
12-04-84 \\
12-04-84\end{array}$ & $\begin{array}{l}100 \\
320 \\
150 \\
280 \\
230\end{array}$ & $\begin{array}{r}60 \\
20 \\
20 \\
2160 \\
30\end{array}$ & $\begin{array}{l}650 \\
610 \\
620 \\
570 \\
620\end{array}$ & $\begin{array}{l}7.7 \\
7.0 \\
7.5 \\
8.2 \\
7.1\end{array}$ & $\begin{array}{l}280 \\
310 \\
320 \\
300 \\
440\end{array}$ & $\begin{array}{r}79 \\
81 \\
81 \\
84 \\
120\end{array}$ & $\begin{array}{l}20 \\
25 \\
28 \\
23 \\
34\end{array}$ \\
\hline $\begin{array}{l}424026091321502 \\
424653091060801 \\
425138091234901 \\
414921090450401 \\
414652090153201\end{array}$ & $\begin{array}{l}05-09-85 \\
06-24-85 \\
05-09-85 \\
12-20-84 \\
01-08-85\end{array}$ & $\begin{array}{l}240 \\
290 \\
280 \\
135 \\
210\end{array}$ & $\begin{array}{l}20 \\
30 \\
20 \\
20 \\
15\end{array}$ & $\begin{array}{l}401 \\
670 \\
552 \\
417 \\
406\end{array}$ & $\begin{array}{l}7.4 \\
7.1 \\
7.0 \\
7.6 \\
7.5\end{array}$ & $\begin{array}{l}210 \\
340 \\
290 \\
230 \\
200\end{array}$ & $\begin{array}{l}51 \\
77 \\
68 \\
58 \\
49\end{array}$ & $\begin{array}{l}19 \\
36 \\
29 \\
20 \\
18\end{array}$ \\
\hline $\begin{array}{l}415650095275602 \\
420131095221101 \\
420328095122401 \\
420551095185801 \\
420415095352201\end{array}$ & $\begin{array}{l}06-17-85 \\
06-17-85 \\
06-18-85 \\
06-12-85 \\
06-12-85\end{array}$ & $\begin{array}{r}600 \\
80 \\
200 \\
43\end{array}$ & $\begin{array}{l}60 \\
60 \\
60 \\
60 \\
30\end{array}$ & $\begin{array}{r}1400 \\
790 \\
770 \\
720 \\
1100\end{array}$ & $\begin{array}{l}7.5 \\
7.0 \\
7.0 \\
8.0 \\
7.1\end{array}$ & $\begin{array}{l}720 \\
370 \\
410 \\
350 \\
540\end{array}$ & $\begin{array}{l}190 \\
110 \\
110 \\
100 \\
150\end{array}$ & $\begin{array}{l}59 \\
24 \\
34 \\
24 \\
41\end{array}$ \\
\hline $\begin{array}{l}421125095193101 \\
421004095272701 \\
420736095342401 \\
413517094114101 \\
413638093530901\end{array}$ & $\begin{array}{l}06-12-85 \\
06-12-85 \\
06-17-85 \\
08-20-85 \\
08-20-85\end{array}$ & $\begin{array}{r}-7 \\
100 \\
120 \\
240\end{array}$ & $\begin{array}{r}60 \\
30 \\
60 \\
120 \\
180\end{array}$ & $\begin{array}{r}580 \\
830 \\
860 \\
750 \\
2200\end{array}$ & $\begin{array}{l}7.6 \\
6.9 \\
7.2 \\
7.1 \\
7.4\end{array}$ & $\begin{array}{l}280 \\
410 \\
470 \\
400 \\
520\end{array}$ & $\begin{array}{r}83 \\
120 \\
120 \\
110 \\
130\end{array}$ & $\begin{array}{l}18 \\
26 \\
42 \\
31 \\
48\end{array}$ \\
\hline $\begin{array}{l}422059091291401 \\
422705090561201 \\
422910091072701 \\
423136090383501 \\
423134090383401\end{array}$ & $\begin{array}{l}06-25-85 \\
06-24-85 \\
06-24-85 \\
06-25-85 \\
06-25-85\end{array}$ & $\begin{array}{r}40 \\
180 \\
500 \\
2100 \\
2500\end{array}$ & $\begin{array}{l}60 \\
30 \\
30 \\
30 \\
30\end{array}$ & $\begin{array}{l}610 \\
845 \\
855 \\
450 \\
390\end{array}$ & $\begin{array}{l}7.3 \\
7.3 \\
7.0 \\
7.4 \\
7.6\end{array}$ & $\begin{array}{l}280 \\
410 \\
420 \\
240 \\
180\end{array}$ & $\begin{array}{r}66 \\
100 \\
95 \\
58 \\
44\end{array}$ & $\begin{array}{l}28 \\
40 \\
44 \\
23 \\
17\end{array}$ \\
\hline $\begin{array}{l}421731091011501 \\
425036091480101 \\
425606091565501 \\
430329092020901 \\
430919092351801\end{array}$ & $\begin{array}{l}06-24-85 \\
07-31-85 \\
07-30-85 \\
07-30-85 \\
08-27-85\end{array}$ & $\begin{array}{r}360 \\
190 \\
90 \\
125 \\
50\end{array}$ & $\begin{array}{l}30 \\
30 \\
30 \\
45 \\
60\end{array}$ & $\begin{array}{l}670 \\
555 \\
600 \\
745 \\
640\end{array}$ & $\begin{array}{l}7.0 \\
7.3 \\
7.1 \\
7.1 \\
7.2\end{array}$ & $\begin{array}{l}380 \\
290 \\
350 \\
360 \\
240\end{array}$ & $\begin{array}{r}87 \\
78 \\
110 \\
80 \\
61\end{array}$ & $\begin{array}{l}39 \\
22 \\
18 \\
39 \\
21\end{array}$ \\
\hline
\end{tabular}




\begin{tabular}{|c|c|c|c|c|c|c|c|c|}
\hline RATION NUMBER & DATE & $\begin{array}{l}\text { DIS- } \\
\text { SOLVED } \\
\text { (MG/L } \\
\text { AS NA) } \\
(00930)\end{array}$ & $\begin{array}{l}\text { DIS- } \\
\text { SOLVED } \\
\text { (MG/L } \\
\text { AS R) } \\
(00935)\end{array}$ & $\begin{array}{c}\text { LAB } \\
\text { (MG/L } \\
\text { AS } \\
\text { CACO3) } \\
(90410)\end{array}$ & $\begin{array}{l}\text { DIS- } \\
\text { SOLVED } \\
\text { (MG/L } \\
\text { AS CL) } \\
(00940)\end{array}$ & $\begin{array}{l}\text { DIS- } \\
\text { SOLVED } \\
(M G / L \\
\text { AS SO4) } \\
(00945)\end{array}$ & $\begin{array}{l}\text { DIS- } \\
\text { SOLVED } \\
\text { (MG/L } \\
\text { AS F) } \\
(00950)\end{array}$ & $\begin{array}{l}\text { SOLVED } \\
\text { (MG/L } \\
\text { AS } \\
\text { SIO2) } \\
(00955)\end{array}$ \\
\hline $\begin{array}{l}405631094560802 \\
413537094532701 \\
413234094552401 \\
413743095041401 \\
414330094524801\end{array}$ & $\begin{array}{l}08-20-85 \\
06-10-85 \\
06-10-85 \\
06-11-85 \\
06-11-85\end{array}$ & $\begin{array}{l}10 \\
13 \\
26 \\
16 \\
7.5\end{array}$ & $\begin{array}{l}1.0 \\
3.2 \\
0.9 \\
1.6 \\
2.0\end{array}$ & $\begin{array}{l}157 \\
215 \\
305 \\
241 \\
278\end{array}$ & $\begin{array}{r}18 \\
24 \\
52 \\
76 \\
4.0\end{array}$ & $\begin{array}{r}120 \\
81 \\
120 \\
52 \\
64\end{array}$ & $\begin{array}{l}0.2 \\
0.25 \\
0.25 \\
0.2 \\
0.2\end{array}$ & $\begin{array}{l}19 \\
15 \\
18 \\
31 \\
23\end{array}$ \\
\hline $\begin{array}{l}414245094524901 \\
415950091512501 \\
420030092053001 \\
415955092120701 \\
420520091524701\end{array}$ & $\begin{array}{l}06-11-85 \\
07-03-85 \\
09-25-85 \\
09-25-85 \\
07-03-85\end{array}$ & $\begin{array}{l}7.8 \\
62 \\
100 \\
160 \\
26\end{array}$ & $\begin{array}{l}0.7 \\
5.3 \\
14 \\
10 \\
5.5\end{array}$ & $\begin{array}{l}211 \\
392 \\
293 \\
289 \\
313\end{array}$ & $\begin{array}{r}15 \\
2.5 \\
12 \\
3.5 \\
1.5\end{array}$ & $\begin{array}{r}140 \\
21 \\
320 \\
680 \\
26\end{array}$ & $\begin{array}{l}0.15 \\
0.45 \\
1.2 \\
1.6 \\
0.8\end{array}$ & $\begin{array}{r}24 \\
7.6 \\
7.6 \\
7.8 \\
6.9\end{array}$ \\
\hline $\begin{array}{l}421016092015901 \\
421326091525301 \\
422801092152801 \\
422805092165901 \\
423112092213901\end{array}$ & $\begin{array}{l}06-25-85 \\
07-03-85 \\
07-31-85 \\
07-31-85 \\
08-15-85\end{array}$ & $\begin{array}{l}20 \\
27 \\
13 \\
15 \\
7.9\end{array}$ & $\begin{array}{l}2.3 \\
4.5 \\
2.2 \\
1.5 \\
1.3\end{array}$ & $\begin{array}{l}279 \\
241 \\
196 \\
223 \\
210\end{array}$ & $\begin{array}{l}2.0 \\
3.5 \\
24 \\
29 \\
16\end{array}$ & $\begin{array}{l}73 \\
32 \\
52 \\
72 \\
27\end{array}$ & $\begin{array}{l}0.4 \\
0.7 \\
0.15 \\
0.4 \\
0.2\end{array}$ & $\begin{array}{r}17 \\
6.9 \\
180 \\
12 \\
15\end{array}$ \\
\hline $\begin{array}{l}422818092212801 \\
423139092261401 \\
425058092315601 \\
421900092002001 \\
422833091431701\end{array}$ & $\begin{array}{l}08-15-85 \\
08-15-85 \\
07-30-85 \\
08-09-85 \\
08-09-85\end{array}$ & $\begin{array}{l}9.6 \\
6.4 \\
8.3 \\
17 \\
31\end{array}$ & $\begin{array}{l}1.9 \\
1.1 \\
1.2 \\
3.7 \\
3.8\end{array}$ & $\begin{array}{l}216 \\
203 \\
181 \\
295 \\
312\end{array}$ & $\begin{array}{r}12 \\
9.5 \\
14 \\
4.5 \\
<0.5\end{array}$ & $\begin{array}{l}86 \\
31 \\
28 \\
24 \\
81\end{array}$ & $\begin{array}{l}0.5 \\
0.2 \\
0.15 \\
0.75 \\
0.35\end{array}$ & $\begin{array}{l}15 \\
16 \\
12 \\
8.2 \\
13\end{array}$ \\
\hline $\begin{array}{l}423710091540001 \\
423837095135002 \\
423512092521001 \\
424239092350001 \\
424704092400803\end{array}$ & $\begin{array}{l}08-09-85 \\
05-23-85 \\
07-08-85 \\
07-08-85 \\
07-08-85\end{array}$ & $\begin{array}{l}5.6 \\
24 \\
30 \\
4.1 \\
3.3\end{array}$ & $\begin{array}{l}2.0 \\
4.4 \\
4.6 \\
1.5 \\
1.2\end{array}$ & $\begin{array}{l}194 \\
300 \\
289 \\
198 \\
186\end{array}$ & $\begin{array}{r}12 \\
34 \\
1.0 \\
5.5 \\
7.0\end{array}$ & $\begin{array}{r}24 \\
150 \\
69 \\
23 \\
36\end{array}$ & $\begin{array}{l}0.1 \\
0.3 \\
0.45 \\
0.3 \\
0.35\end{array}$ & $\begin{array}{l}15 \\
15 \\
14 \\
14 \\
12\end{array}$ \\
\hline $\begin{array}{l}424627092542302 \\
424524092474601 \\
424455092581801 \\
425355092475801 \\
421614094325101\end{array}$ & $\begin{array}{l}07-09-85 \\
07-08-85 \\
07-09-85 \\
07-09-85 \\
08-13-85\end{array}$ & $\begin{array}{r}4.5 \\
7.0 \\
7.9 \\
2.0 \\
58\end{array}$ & $\begin{array}{l}1.3 \\
1.2 \\
1.3 \\
0.8 \\
5.2\end{array}$ & $\begin{array}{l}222 \\
219 \\
239 \\
212 \\
411\end{array}$ & $\begin{array}{l}11 \\
<0.5 \\
<0.5 \\
1.0 \\
0.5\end{array}$ & $\begin{array}{r}32 \\
8.2 \\
79 \\
18 \\
430\end{array}$ & $\begin{array}{l}0.15 \\
0.5 \\
0.75 \\
0.25 \\
0.45\end{array}$ & $\begin{array}{l}12 \\
13 \\
13 \\
12 \\
27\end{array}$ \\
\hline $\begin{array}{l}415147094403501 \\
415430095041601 \\
420024094575901 \\
411637094520201 \\
412429094594301\end{array}$ & $\begin{array}{l}05-22-85 \\
05-22-85 \\
05-22-85 \\
08-22-85 \\
08-22-85\end{array}$ & $\begin{array}{l}6.0 \\
24 \\
17 \\
10 \\
13\end{array}$ & $\begin{array}{l}0.8 \\
1.7 \\
0.6 \\
1.5 \\
1.6\end{array}$ & $\begin{array}{l}183 \\
337 \\
262 \\
182 \\
127\end{array}$ & $\begin{array}{l}2.0 \\
47 \\
34 \\
0.5 \\
26\end{array}$ & $\begin{array}{r}28 \\
130 \\
100 \\
16 \\
69\end{array}$ & $\begin{array}{l}0.3 \\
0.25 \\
0.35 \\
0.3 \\
0.25\end{array}$ & $\begin{array}{l}9.6 \\
10 \\
8.3 \\
21 \\
20\end{array}$ \\
\hline $\begin{array}{l}412714094460701 \\
430756093263201 \\
431426093073301 \\
430923095114501 \\
430922095193501\end{array}$ & $\begin{array}{l}08-15-85 \\
06-18-85 \\
06-18-85 \\
12-04-84 \\
12-04-84\end{array}$ & $\begin{array}{l}26 \\
10 \\
9 \cdot 2 \\
3 \cdot 3 \\
13\end{array}$ & $\begin{array}{l}3.0 \\
2.2 \\
3.3 \\
2.4 \\
3.7\end{array}$ & $\begin{array}{l}255 \\
328 \\
325 \\
219 \\
287\end{array}$ & $\begin{array}{r}0.5 \\
<0.5 \\
<0.5 \\
5.5 \\
54\end{array}$ & $\begin{array}{l}81 \\
5.8 \\
17 \\
66 \\
56\end{array}$ & $\begin{array}{l}0.45 \\
0.3 \\
0.35 \\
0.1 \\
0.2\end{array}$ & $\begin{array}{l}22 \\
18 \\
12 \\
27 \\
27\end{array}$ \\
\hline $\begin{array}{l}424026091321502 \\
424653091060801 \\
425138091234901 \\
414921090450401 \\
414652090153201\end{array}$ & $\begin{array}{l}05-09-85 \\
06-24-85 \\
05-09-85 \\
12-20-84 \\
01-08-85\end{array}$ & $\begin{array}{l}2.4 \\
16 \\
4.6 \\
6.9 \\
11\end{array}$ & $\begin{array}{l}0.6 \\
1.9 \\
4.8 \\
1.3 \\
2.2\end{array}$ & $\begin{array}{l}159 \\
298 \\
241 \\
228 \\
123\end{array}$ & $\begin{array}{l}5.5 \\
16 \\
2.0 \\
1.0 \\
22\end{array}$ & $\begin{array}{l}18 \\
38 \\
56 \\
2.0 \\
27\end{array}$ & $\begin{array}{l}0.2 \\
0.15 \\
0.65 \\
0.15 \\
<0.1\end{array}$ & $\begin{array}{l}12 \\
11 \\
8.2 \\
18 \\
23\end{array}$ \\
\hline $\begin{array}{l}415650095275602 \\
420131095221101 \\
420328095122401 \\
420551095185801 \\
420415095352201\end{array}$ & $\begin{array}{l}06-17-85 \\
06-17-85 \\
06-18-85 \\
06-12-85 \\
06-12-85\end{array}$ & $\begin{array}{l}38 \\
11 \\
12 \\
12 \\
14\end{array}$ & $\begin{array}{l}3.8 \\
1.9 \\
1.5 \\
2.1 \\
2.8\end{array}$ & $\begin{array}{l}406 \\
297 \\
276 \\
281 \\
350\end{array}$ & $\begin{array}{l}86 \\
22 \\
22 \\
15 \\
58\end{array}$ & $\begin{array}{r}210 \\
77 \\
88 \\
71 \\
140\end{array}$ & $\begin{array}{l}0.3 \\
0.2 \\
0.3 \\
0.25 \\
0.2\end{array}$ & $\begin{array}{l}25 \\
26 \\
19 \\
22 \\
22\end{array}$ \\
\hline $\begin{array}{l}421125095193101 \\
421004095272701 \\
420736095342401 \\
413517094114101 \\
413638093530901\end{array}$ & $\begin{array}{l}06-12-85 \\
06-12-85 \\
06-17-85 \\
08-20-85 \\
08-20-85\end{array}$ & $\begin{array}{l}9.0 \\
16 \\
12 \\
12 \\
280\end{array}$ & $\begin{array}{l}0.6 \\
16 \\
3.1 \\
2.1 \\
22\end{array}$ & $\begin{array}{l}207 \\
313 \\
312 \\
279 \\
222\end{array}$ & $\begin{array}{r}14 \\
17 \\
43 \\
22 \\
110\end{array}$ & $\begin{array}{r}88 \\
62 \\
92 \\
89 \\
730\end{array}$ & $\begin{array}{l}0.3 \\
0.3 \\
0.4 \\
0.25 \\
2.9\end{array}$ & $\begin{array}{l}21 \\
21 \\
21 \\
25 \\
13\end{array}$ \\
\hline $\begin{array}{l}422059091291401 \\
422705090561201 \\
422910091072701 \\
423136090383501 \\
423134090383401\end{array}$ & $\begin{array}{l}06-25-85 \\
06-24-85 \\
06-24-85 \\
06-25-85 \\
06-25-85\end{array}$ & $\begin{array}{r}18 \\
16 \\
22 \\
8.1 \\
7.3\end{array}$ & $\begin{array}{l}3.0 \\
3.4 \\
3.4 \\
1.5 \\
1.2\end{array}$ & $\begin{array}{l}292 \\
277 \\
261 \\
221 \\
161\end{array}$ & $\begin{array}{l}<0.5 \\
37 \\
54 \\
12 \\
10\end{array}$ & $\begin{array}{l}41 \\
81 \\
72 \\
43 \\
24\end{array}$ & $\begin{array}{l}0.35 \\
0.1 \\
<0.1 \\
0.1 \\
0.15\end{array}$ & $\begin{array}{l}8.3 \\
16 \\
13 \\
19 \\
18\end{array}$ \\
\hline $\begin{array}{l}421731091011501 \\
425036091480101 \\
425606091565501 \\
430329092020901 \\
430919092351801\end{array}$ & $\begin{array}{l}06-24-85 \\
07-31-85 \\
07-30-85 \\
07-30-85 \\
08-27-85\end{array}$ & $\begin{array}{l}7.8 \\
12 \\
13 \\
26 \\
32\end{array}$ & $\begin{array}{l}0.6 \\
5.5 \\
0.8 \\
2.6 \\
3.5\end{array}$ & $\begin{array}{l}323 \\
248 \\
247 \\
284 \\
313\end{array}$ & $\begin{array}{l}18 \\
13 \\
25 \\
1.0 \\
0.5\end{array}$ & $\begin{array}{r}38 \\
40 \\
84 \\
150 \\
11\end{array}$ & $\begin{array}{l}0.15 \\
0.25 \\
0.25 \\
2.2 \\
1.7\end{array}$ & $\begin{array}{r}17 \\
12 \\
12 \\
6.6 \\
9.5\end{array}$ \\
\hline
\end{tabular}




\begin{tabular}{|c|c|c|c|c|c|c|c|c|}
\hline RATION NUMBER & DATE & $\begin{array}{l}\text { SOLIDS, } \\
\text { RESIDUE } \\
\text { AT 105 } \\
\text { DEG. C, } \\
\text { DIS- } \\
\text { SOLVED } \\
\text { (MG/L) } \\
(00515)\end{array}$ & $\begin{array}{c}\text { NITRO- } \\
\text { GEN, } \\
\text { NO2+NO3 } \\
\text { DIS- } \\
\text { SOLVED } \\
\text { (MG/L } \\
\text { AS N) } \\
(00631)\end{array}$ & $\begin{array}{c}\text { NITRO- } \\
\text { GEN, } \\
\text { AMMONIA } \\
\text { DIS- } \\
\text { SOLVED } \\
\text { (MG/L } \\
\text { AS N) } \\
(00608)\end{array}$ & $\begin{array}{l}\text { PHOS- } \\
\text { PHORUS, } \\
\text { ORTHO, } \\
\text { DIS- } \\
\text { SOLVED } \\
\text { (MG/L } \\
\text { AS P) } \\
(00671)\end{array}$ & $\begin{array}{l}\text { IRON, } \\
\text { DIS- } \\
\text { SOLVED } \\
(\text { UG/L } \\
\text { AS FE) } \\
(01046)\end{array}$ & $\begin{array}{l}\text { MANGA- } \\
\text { NESE, } \\
\text { DIS- } \\
\text { SOLVED } \\
\text { (UG/L } \\
\text { AS MN) } \\
(01056)\end{array}$ & $\begin{array}{c}\text { ARSEN IC } \\
\text { DIS- } \\
\text { SOLVED } \\
(U G / L \\
\text { AS AS) } \\
(01000)\end{array}$ \\
\hline $\begin{array}{l}405631094560802 \\
413537094532701 \\
413234094552401 \\
413743095041401 \\
414330094524801\end{array}$ & $\begin{array}{l}08-20-85 \\
06-10-85 \\
06-10-85 \\
06-11-85 \\
06-11-85\end{array}$ & $\begin{array}{l}384 \\
386 \\
583 \\
447 \\
402\end{array}$ & $\begin{array}{r}0.31 \\
5.77 \\
0.04 \\
<0.02 \\
2.89\end{array}$ & $\begin{array}{l}-- \\
0.08 \\
0.15 \\
0.46 \\
0.02\end{array}$ & $\begin{array}{l}-- \\
0.07 \\
0.17 \\
0.41 \\
0.13\end{array}$ & $\begin{array}{r}1400 \\
500 \\
8200 \\
15000 \\
10\end{array}$ & $\begin{array}{r}110 \\
960 \\
1100 \\
1700 \\
10\end{array}$ & $\begin{array}{l}<10 \\
<10 \\
<10 \\
<10 \\
<10\end{array}$ \\
\hline $\begin{array}{l}414245094524901 \\
415950091512501 \\
420030092053001 \\
415955092120701 \\
420520091524701\end{array}$ & $\begin{array}{l}06-11-85 \\
07-03-85 \\
09-25-85 \\
09-25-85 \\
07-03-85\end{array}$ & $\begin{array}{r}478 \\
407 \\
783 \\
1300 \\
351\end{array}$ & $\begin{array}{r}<0.02 \\
0.11 \\
<0.02 \\
<0.02 \\
0.16\end{array}$ & $\begin{array}{l}0.13 \\
-- \\
-- \\
--\end{array}$ & $\begin{array}{l}0.18 \\
-- \\
-- \\
--\end{array}$ & $\begin{array}{r}1300 \\
1100 \\
1600 \\
710 \\
740\end{array}$ & $\begin{array}{r}1500 \\
<10 \\
20 \\
<10 \\
20\end{array}$ & $\begin{array}{l}<10 \\
<10 \\
<10 \\
<10 \\
<10\end{array}$ \\
\hline $\begin{array}{l}421016092015901 \\
421326091525301 \\
422801092152801 \\
422805092165901 \\
423112092213901\end{array}$ & $\begin{array}{l}06-25-85 \\
07-03-85 \\
07-31-85 \\
07-31-85 \\
08-15-85\end{array}$ & $\begin{array}{l}382 \\
286 \\
315 \\
374 \\
311\end{array}$ & $\begin{array}{l}0.09 \\
0.09 \\
3.60 \\
0.11 \\
3.55\end{array}$ & $\begin{array}{l}-- \\
-- \\
-- \\
--\end{array}$ & $\begin{array}{l}-- \\
-- \\
-- \\
--\end{array}$ & $\begin{array}{r}2600 \\
40 \\
20 \\
1200 \\
10\end{array}$ & $\begin{array}{r}190 \\
<10 \\
20 \\
60 \\
10\end{array}$ & $\begin{array}{l}<10 \\
<10 \\
<10 \\
<10 \\
<10\end{array}$ \\
\hline $\begin{array}{l}422818092212801 \\
423139092261401 \\
425058092315601 \\
421900092002001 \\
422833091431701\end{array}$ & $\begin{array}{l}08-15-85 \\
08-15-85 \\
07-30-85 \\
08-09-85 \\
08-09-85\end{array}$ & $\begin{array}{l}412 \\
307 \\
259 \\
313 \\
379\end{array}$ & $\begin{array}{l}0.40 \\
6.44 \\
6.20 \\
2.66 \\
0.55\end{array}$ & $\begin{array}{l}-- \\
-- \\
-- \\
--\end{array}$ & $\begin{array}{l}-- \\
-- \\
-- \\
--\end{array}$ & $\begin{array}{r}10 \\
<10 \\
<10 \\
50 \\
1200\end{array}$ & $\begin{array}{r}60 \\
<10 \\
<10 \\
<10 \\
50\end{array}$ & $\begin{array}{l}<10 \\
<10 \\
<10 \\
<10 \\
<10\end{array}$ \\
\hline $\begin{array}{l}423710091540001 \\
423837095135002 \\
423512092521001 \\
424239092350001 \\
424704092400803\end{array}$ & $\begin{array}{l}08-09-85 \\
05-23-85 \\
07-08-85 \\
07-08-85 \\
07-08-85\end{array}$ & $\begin{array}{l}252 \\
642 \\
401 \\
272 \\
278\end{array}$ & $\begin{array}{r}8.44 \\
<0.02 \\
0.09 \\
3.11 \\
2.89\end{array}$ & $\begin{array}{l}-- \\
1.60 \\
\overline{-0.01} \\
--\end{array}$ & $\begin{array}{l}-- \\
0.44 \\
-- \\
0.05\end{array}$ & $\begin{array}{r}20 \\
2800 \\
830 \\
10 \\
10\end{array}$ & $\begin{array}{l}<10 \\
160 \\
<10 \\
<10 \\
10\end{array}$ & $\begin{array}{l}<10 \\
<10 \\
<10 \\
<10 \\
<10\end{array}$ \\
\hline $\begin{array}{l}424627092542302 \\
424524092474601 \\
424455092581801 \\
425355092475801 \\
421614094325101\end{array}$ & $\begin{array}{l}07-09-85 \\
07-08-85 \\
07-09-85 \\
07-09-85 \\
08-13-85\end{array}$ & $\begin{array}{r}316 \\
245 \\
377 \\
251 \\
1090\end{array}$ & $\begin{array}{r}4.00 \\
0.13 \\
0.09 \\
0.11 \\
<0.02\end{array}$ & $\begin{array}{l}0.01 \\
-- \\
-- \\
-- \\
1.10\end{array}$ & $\begin{array}{l}0.02 \\
-- \\
-- \\
-- \\
0.07\end{array}$ & $\begin{array}{r}<10 \\
390 \\
800 \\
260 \\
2200\end{array}$ & $\begin{array}{r}<10 \\
20 \\
30 \\
20 \\
240\end{array}$ & $\begin{array}{l}<10 \\
<10 \\
<10 \\
<10 \\
<10\end{array}$ \\
\hline $\begin{array}{l}415147094403501 \\
415430095041601 \\
420024094575901 \\
411637094520201 \\
412429094594301\end{array}$ & $\begin{array}{l}05-22-85 \\
05-22-85 \\
05-22-85 \\
08-22-85 \\
08-22-85\end{array}$ & $\begin{array}{l}300 \\
681 \\
559 \\
212 \\
313\end{array}$ & $\begin{array}{l}2.44 \\
5.32 \\
8.90 \\
0.33 \\
4.66\end{array}$ & $\begin{array}{l}0.01 \\
0.21 \\
0.01 \\
-- \\
0.01\end{array}$ & $\begin{array}{l}0.02 \\
0.04 \\
0.05 \\
-- \\
0.04\end{array}$ & $\begin{array}{r}70 \\
230 \\
10 \\
270 \\
<10\end{array}$ & $\begin{array}{r}50 \\
190 \\
10 \\
50 \\
90\end{array}$ & $\begin{array}{l}<10 \\
<10 \\
<10 \\
<10 \\
<10\end{array}$ \\
\hline $\begin{array}{l}412714094460701 \\
430756093263201 \\
431426093073301 \\
430923095114501 \\
430922095193501\end{array}$ & $\begin{array}{l}08-15-85 \\
06-18-85 \\
06-18-85 \\
12-04-84 \\
12-04-84\end{array}$ & $\begin{array}{l}384 \\
329 \\
332 \\
337 \\
530\end{array}$ & $\begin{array}{l}<0.02 \\
0.07 \\
0.07 \\
1.30 \\
10.2\end{array}$ & $\begin{array}{l}=- \\
=- \\
=-\end{array}$ & $\begin{array}{l}\overline{-} \\
\overline{z-} \\
--\end{array}$ & $\begin{array}{l}<10 \\
690 \\
670 \\
900 \\
<10\end{array}$ & $\begin{array}{r}430 \\
10 \\
10 \\
330 \\
<10\end{array}$ & $\begin{array}{l}<10 \\
<10 \\
<10 \\
<10 \\
<10\end{array}$ \\
\hline $\begin{array}{l}424026091321502 \\
424653091060801 \\
425138091234901 \\
414921090450401 \\
414652090153201\end{array}$ & $\begin{array}{l}05-09-85 \\
06-24-85 \\
05-09-85 \\
12-20-84 \\
01-08-85\end{array}$ & $\begin{array}{l}229 \\
382 \\
327 \\
223 \\
247\end{array}$ & $\begin{array}{r}27.0 \\
1.15 \\
0.11 \\
<0.02 \\
5.60\end{array}$ & $\begin{array}{l}<0.01 \\
-- \\
-- \\
--\end{array}$ & $\begin{array}{l}<0.01 \\
-- \\
-- \\
--\end{array}$ & $\begin{array}{r}<10 \\
20 \\
<10 \\
1000 \\
<10\end{array}$ & $\begin{array}{r}<10 \\
80 \\
<10 \\
40 \\
<10\end{array}$ & $\begin{array}{l}<10 \\
<10 \\
<10 \\
<10 \\
<10\end{array}$ \\
\hline $\begin{array}{l}415650095275602 \\
420131095221101 \\
420328095122401 \\
420551095185801 \\
420415095352201\end{array}$ & $\begin{array}{l}06-17-85 \\
06-17-85 \\
06-18-85 \\
06-12-85 \\
06-12-85\end{array}$ & $\begin{array}{l}987 \\
475 \\
514 \\
436 \\
701\end{array}$ & $\begin{array}{l}11.8 \\
3.11 \\
6.22 \\
3.11 \\
1.73\end{array}$ & $\begin{array}{r}0.03 \\
0.06 \\
-- \\
<0.01 \\
0.18\end{array}$ & $\begin{array}{l}0.09 \\
0.09 \\
-- \\
0.07 \\
0.01\end{array}$ & $\begin{array}{r}30 \\
120 \\
20 \\
90 \\
1400\end{array}$ & $\begin{array}{r}310 \\
290 \\
230 \\
110 \\
1400\end{array}$ & $\begin{array}{l}<10 \\
<10 \\
<10 \\
<10 \\
<10\end{array}$ \\
\hline $\begin{array}{l}421125095193101 \\
421004095272701 \\
420736095342401 \\
413517094114101 \\
413638093530901\end{array}$ & $\begin{array}{l}06-12-85 \\
06-12-85 \\
06-17-85 \\
08-20-85 \\
08-20-85\end{array}$ & $\begin{array}{r}412 \\
504 \\
566 \\
510 \\
1500\end{array}$ & $\begin{array}{r}0.36 \\
6.66 \\
1.98 \\
<0.02 \\
<0.02\end{array}$ & $\begin{array}{l}-- \\
0.03 \\
-- \\
--\end{array}$ & $\begin{array}{l}-- \\
0.05 \\
-- \\
--\end{array}$ & $\begin{array}{r}<10 \\
10 \\
660 \\
1600 \\
410\end{array}$ & $\begin{array}{r}1600 \\
90 \\
470 \\
310 \\
<10\end{array}$ & $\begin{array}{l}<10 \\
<10 \\
<10 \\
<10 \\
<10\end{array}$ \\
\hline $\begin{array}{l}422059091291401 \\
422705090561201 \\
422910091072701 \\
423136090383501 \\
423134090383401\end{array}$ & $\begin{array}{l}06-25-85 \\
06-24-85 \\
06-24-85 \\
06-25-85 \\
06-25-85\end{array}$ & $\begin{array}{l}336 \\
508 \\
515 \\
289 \\
228\end{array}$ & $\begin{array}{c}0.16 \\
8.21 \\
12.0 \\
0.16 \\
0.09\end{array}$ & $\begin{array}{l}-- \\
-- \\
\overline{1.00} \\
--\end{array}$ & $\begin{array}{l}-- \\
-- \\
-- \\
--\end{array}$ & $\begin{array}{r}160 \\
10 \\
<10 \\
1400 \\
420\end{array}$ & $\begin{array}{r}20 \\
10 \\
<10 \\
2400 \\
2000\end{array}$ & $\begin{array}{l}<10 \\
<10 \\
<10 \\
<10 \\
<10\end{array}$ \\
\hline $\begin{array}{l}421731091011501 \\
425036091480101 \\
425606091565501 \\
430329092020901 \\
430919092351801\end{array}$ & $\begin{array}{l}06-24-85 \\
07-31-85 \\
07-30-85 \\
07-30-85 \\
08-27-85\end{array}$ & $\begin{array}{l}423 \\
350 \\
421 \\
489 \\
319\end{array}$ & $\begin{array}{r}3.77 \\
3.33 \\
0.53 \\
0.09 \\
<0.02\end{array}$ & $\begin{array}{l}-- \\
=- \\
=- \\
--\end{array}$ & $\begin{array}{l}-- \\
-- \\
-- \\
--\end{array}$ & $\begin{array}{l}10 \\
<10 \\
690 \\
860 \\
420\end{array}$ & $\begin{array}{r}10 \\
20 \\
320 \\
10 \\
10\end{array}$ & $\begin{array}{l}<10 \\
<10 \\
<10 \\
<10 \\
<10\end{array}$ \\
\hline
\end{tabular}




\begin{tabular}{|c|c|c|c|c|c|c|c|c|}
\hline TATION NUMBER & DATE & $\begin{array}{l}\text { BARIUM, } \\
\text { DIS- } \\
\text { SOLVED } \\
\text { (UG/L } \\
\text { AS BA) } \\
(01005)\end{array}$ & $\begin{array}{c}\text { CADM IUM } \\
\text { DIS- } \\
\text { SOLVED } \\
\text { (UG/L } \\
\text { AS CD) } \\
(01025)\end{array}$ & $\begin{array}{l}\text { CHRO- } \\
\text { MIUM, } \\
\text { DIS- } \\
\text { SOLVED } \\
\text { (UG/L } \\
\text { AS CR) } \\
(01030)\end{array}$ & $\begin{array}{l}\text { COPPER, } \\
\text { DIS- } \\
\text { SOLVED } \\
(U G / L \\
\text { AS CU) } \\
(01040)\end{array}$ & $\begin{array}{l}\text { LEAD, } \\
\text { DIS- } \\
\text { SOLVED } \\
\text { (UG/L } \\
\text { AS PB) } \\
(01049)\end{array}$ & $\begin{array}{c}\text { MERCURY } \\
\text { DIS- } \\
\text { SOLVED } \\
\text { (UG/L } \\
\text { AS HG) } \\
(71890)\end{array}$ & $\begin{array}{l}\text { SELE- } \\
\text { NIUM, } \\
\text { DIS- } \\
\text { SOLVED } \\
\text { (UG/L } \\
\text { AS SE) } \\
(01145)\end{array}$ \\
\hline $\begin{array}{l}405631094560802 \\
413537094532701 \\
413234094552401 \\
413743095041401 \\
414330094524801\end{array}$ & $\begin{array}{l}08-20-85 \\
06-10-85 \\
06-10-85 \\
06-11-85 \\
06-11-85\end{array}$ & $\begin{array}{l}200 \\
300 \\
500 \\
500 \\
200\end{array}$ & $\begin{array}{l}<1 \\
<1 \\
<1 \\
<1 \\
<1\end{array}$ & $\begin{array}{l}<10 \\
<10 \\
<10 \\
<10 \\
<10\end{array}$ & $\begin{array}{r}10 \\
20 \\
20 \\
40 \\
<10\end{array}$ & $\begin{array}{l}<10 \\
<10 \\
<10 \\
<10 \\
<10\end{array}$ & $\begin{array}{l}<1.0 \\
<1.0 \\
<1.0 \\
<1.0 \\
<1.0\end{array}$ & $\begin{array}{l}<10 \\
<10 \\
<10 \\
<10 \\
<10\end{array}$ \\
\hline $\begin{array}{l}414245094524901 \\
415950091512501 \\
420030092053001 \\
415955092120701 \\
420520091524701\end{array}$ & $\begin{array}{l}06-11-85 \\
07-03-85 \\
09-25-85 \\
09-25-85 \\
07-03-85\end{array}$ & $\begin{array}{r}<100 \\
300 \\
<100 \\
<100 \\
<100\end{array}$ & $\begin{array}{l}<1 \\
<1 \\
<1 \\
<1 \\
<1\end{array}$ & $\begin{array}{l}<10 \\
<10 \\
<10 \\
<10 \\
<10\end{array}$ & $\begin{array}{l}<10 \\
<10 \\
<10 \\
<10 \\
<10\end{array}$ & $\begin{array}{l}<10 \\
<10 \\
<10 \\
<10 \\
<10\end{array}$ & $\begin{array}{l}<1.0 \\
<1.0 \\
<1.0 \\
<1.0 \\
<1.0\end{array}$ & $\begin{array}{l}<10 \\
<10 \\
<10 \\
<10 \\
<10\end{array}$ \\
\hline $\begin{array}{l}421016092015901 \\
421326091525301 \\
422801092152801 \\
422805092165901 \\
423112092213901\end{array}$ & $\begin{array}{l}06-25-85 \\
07-03-85 \\
07-31-85 \\
07-31-85 \\
08-15-85\end{array}$ & $\begin{array}{r}300 \\
<100 \\
300 \\
200 \\
300\end{array}$ & $\begin{array}{l}<1 \\
<1 \\
<1 \\
<1 \\
<1\end{array}$ & $\begin{array}{l}<10 \\
<10 \\
<10 \\
<10 \\
<10\end{array}$ & $\begin{array}{r}<10 \\
10 \\
<10 \\
<10 \\
20\end{array}$ & $\begin{array}{l}<10 \\
<10 \\
<10 \\
<10 \\
<10\end{array}$ & $\begin{array}{l}<1.0 \\
<1.0 \\
<1.0 \\
<1.0 \\
<1.0\end{array}$ & $\begin{array}{l}<10 \\
<10 \\
<10 \\
<10 \\
<10\end{array}$ \\
\hline $\begin{array}{l}422818092212801 \\
423139092261401 \\
425058092315601 \\
421900092002001 \\
422833091431701\end{array}$ & $\begin{array}{l}08-15-85 \\
08-15-85 \\
07-30-85 \\
08-09-85 \\
08-09-85\end{array}$ & $\begin{array}{r}<100 \\
<100 \\
200 \\
200 \\
100\end{array}$ & $\begin{array}{l}<1 \\
<1 \\
<1 \\
<1 \\
<1\end{array}$ & $\begin{array}{l}<10 \\
<10 \\
<10 \\
<10 \\
<10\end{array}$ & $\begin{array}{l}<10 \\
<10 \\
<10 \\
<10 \\
10\end{array}$ & $\begin{array}{l}<10 \\
<10 \\
<10 \\
<10 \\
<10\end{array}$ & $\begin{array}{l}<1.0 \\
<1.0 \\
<1.0 \\
<1.0 \\
<1.0\end{array}$ & $\begin{array}{l}<10 \\
<10 \\
<10 \\
<10 \\
<10\end{array}$ \\
\hline $\begin{array}{l}423710091540001 \\
423837095135002 \\
423512092521001 \\
424239092350001 \\
424704092400803\end{array}$ & $\begin{array}{l}08-09-85 \\
05-23-85 \\
07-08-85 \\
07-08-85 \\
07-08-85\end{array}$ & $\begin{array}{r}100 \\
<100 \\
<100 \\
200 \\
200\end{array}$ & $\begin{array}{l}<1 \\
<1 \\
<1 \\
<1 \\
<1\end{array}$ & $\begin{array}{l}<10 \\
<10 \\
<10 \\
<10 \\
<10\end{array}$ & $\begin{array}{r}10 \\
<10 \\
20 \\
10 \\
<10\end{array}$ & $\begin{array}{l}<10 \\
<10 \\
<10 \\
<10 \\
<10\end{array}$ & $\begin{array}{l}<1.0 \\
<1.0 \\
<1.0 \\
<1.0 \\
<1.0\end{array}$ & $\begin{array}{l}<10 \\
<10 \\
<10 \\
<10 \\
<10\end{array}$ \\
\hline $\begin{array}{l}424627092542302 \\
424524092474601 \\
424455092581801 \\
42535509475801 \\
421614094325101\end{array}$ & $\begin{array}{l}07-09-85 \\
07-08-85 \\
07-09-85 \\
07-09-85 \\
08-13-85\end{array}$ & $\begin{array}{l}200 \\
200 \\
200 \\
300 \\
100\end{array}$ & $\begin{array}{l}<1 \\
<1 \\
<1 \\
<1 \\
<1\end{array}$ & $\begin{array}{l}<10 \\
<10 \\
<10 \\
<10 \\
<10\end{array}$ & $\begin{array}{l}30 \\
20 \\
20 \\
20 \\
10\end{array}$ & $\begin{array}{l}<10 \\
<10 \\
<10 \\
<10 \\
<10\end{array}$ & $\begin{array}{l}<1.0 \\
<1.0 \\
<1.0 \\
<1.0 \\
<1.0\end{array}$ & $\begin{array}{l}<10 \\
<10 \\
<10 \\
<10 \\
<10\end{array}$ \\
\hline $\begin{array}{l}415147094403501 \\
415430095041601 \\
420024094575901 \\
41163709450201 \\
412429094594301\end{array}$ & $\begin{array}{l}05-22-85 \\
05-22-85 \\
05-22-85 \\
08-22-85 \\
08-22-85\end{array}$ & $\begin{array}{r}200 \\
100 \\
100 \\
<100 \\
<100\end{array}$ & $\begin{array}{l}<1 \\
<1 \\
<1 \\
<1 \\
<1\end{array}$ & $\begin{array}{l}<10 \\
<10 \\
<10 \\
<10 \\
<10\end{array}$ & $\begin{array}{r}20 \\
<10 \\
<10 \\
10 \\
<10\end{array}$ & $\begin{array}{l}<10 \\
<10 \\
<10 \\
<10 \\
<10\end{array}$ & $\begin{array}{l}<1.0 \\
<1.0 \\
<1.0 \\
<1.0 \\
<1.0\end{array}$ & $\begin{array}{l}<10 \\
<10 \\
<10 \\
<10 \\
<10\end{array}$ \\
\hline $\begin{array}{l}412714094460701 \\
430756093263201 \\
431426093073301 \\
430923095114501 \\
430922095193501\end{array}$ & $\begin{array}{l}08-15-85 \\
06-18-85 \\
06-18-85 \\
12-04-84 \\
12-04-84\end{array}$ & $\begin{array}{r}<100 \\
300 \\
200 \\
300 \\
200\end{array}$ & $\begin{array}{l}<1 \\
<1 \\
<1 \\
<1 \\
<1\end{array}$ & $\begin{array}{l}<10 \\
<10 \\
<10 \\
<10 \\
<10\end{array}$ & $\begin{array}{r}10 \\
10 \\
<10 \\
<10 \\
30\end{array}$ & $\begin{array}{l}<10 \\
<10 \\
<10 \\
<10 \\
<10\end{array}$ & $\begin{array}{l}<1.0 \\
<1.0 \\
<1.0 \\
<1.0 \\
<1.0\end{array}$ & $\begin{array}{l}<10 \\
<10 \\
<10 \\
<10 \\
<10\end{array}$ \\
\hline $\begin{array}{l}424026091321502 \\
424653091060801 \\
425138091234901 \\
414921090450401 \\
414652090153201\end{array}$ & $\begin{array}{l}05-09-85 \\
06-24-85 \\
05-09-85 \\
12-20-84 \\
01-08-85\end{array}$ & $\begin{array}{r}<100 \\
<100 \\
100 \\
200 \\
100\end{array}$ & $\begin{array}{l}<1 \\
<1 \\
<1 \\
<1 \\
<1\end{array}$ & $\begin{array}{l}<10 \\
<10 \\
<10 \\
<10 \\
<10\end{array}$ & $\begin{array}{r}30 \\
10 \\
30 \\
<10 \\
<10\end{array}$ & $\begin{array}{l}<10 \\
<10 \\
<10 \\
<10 \\
<10\end{array}$ & $\begin{array}{l}<1.0 \\
<1.0 \\
<1.0 \\
<1.0 \\
<1.0\end{array}$ & $\begin{array}{l}<10 \\
<10 \\
<10 \\
<10 \\
<10\end{array}$ \\
\hline $\begin{array}{l}415650095275602 \\
420131095221101 \\
420328095122401 \\
420551095185801 \\
420415095352201\end{array}$ & $\begin{array}{l}06-17-85 \\
06-17-85 \\
06-18-85 \\
06-12-85 \\
06-12-85\end{array}$ & $\begin{array}{r}<100 \\
300 \\
200 \\
100 \\
400\end{array}$ & $\begin{array}{l}<1 \\
<1 \\
<1 \\
<1 \\
<1\end{array}$ & $\begin{array}{l}<10 \\
<10 \\
<10 \\
<10 \\
<10\end{array}$ & $\begin{array}{l}60 \\
20 \\
30 \\
10 \\
30\end{array}$ & $\begin{array}{l}<10 \\
<10 \\
<10 \\
<10 \\
<10\end{array}$ & $\begin{array}{l}<1.0 \\
<1.0 \\
<1.0 \\
<1.0 \\
<1.0\end{array}$ & $\begin{array}{l}<10 \\
<10 \\
<10 \\
<10 \\
<10\end{array}$ \\
\hline $\begin{array}{l}421125095193101 \\
421004095272701 \\
420736095342401 \\
413517094114101 \\
413638093530901\end{array}$ & $\begin{array}{l}06-12-85 \\
06-12-85 \\
06-17-85 \\
08-20-85 \\
08-20-85\end{array}$ & $\begin{array}{r}200 \\
<100 \\
200 \\
300 \\
<100\end{array}$ & $\begin{array}{l}<1 \\
<1 \\
<1 \\
<1 \\
<1\end{array}$ & $\begin{array}{l}<10 \\
<10 \\
<10 \\
<10 \\
<10\end{array}$ & $\begin{array}{r}20 \\
<10 \\
20 \\
10 \\
50\end{array}$ & $\begin{array}{l}<10 \\
<10 \\
<10 \\
<10 \\
<10\end{array}$ & $\begin{array}{l}<1.0 \\
<1.0 \\
<1.0 \\
<1.0 \\
<1.0\end{array}$ & $\begin{array}{l}<10 \\
<10 \\
<10 \\
<10 \\
<10\end{array}$ \\
\hline $\begin{array}{l}422059091291401 \\
422705090561201 \\
422910091072701 \\
423136090383501 \\
423134090383401\end{array}$ & $\begin{array}{l}06-25-85 \\
06-24-85 \\
06-24-85 \\
06-25-85 \\
06-25-85\end{array}$ & $\begin{array}{r}<100 \\
<100 \\
100 \\
200 \\
100\end{array}$ & $\begin{array}{l}<1 \\
<1 \\
<1 \\
<1 \\
<1\end{array}$ & $\begin{array}{l}<10 \\
<10 \\
<10 \\
<10 \\
<10\end{array}$ & $\begin{array}{r}10 \\
30 \\
30 \\
<10 \\
10\end{array}$ & $\begin{array}{l}<10 \\
<10 \\
<10 \\
<10 \\
<10\end{array}$ & $\begin{array}{l}<1.0 \\
<1.0 \\
<1.0 \\
<1.0 \\
<1.0\end{array}$ & $\begin{array}{l}<10 \\
<10 \\
<10 \\
<10 \\
<10\end{array}$ \\
\hline $\begin{array}{l}421731091011501 \\
425036091480101 \\
425606091565501 \\
430329092020901 \\
430919092351801\end{array}$ & $\begin{array}{l}06-24-85 \\
07-31-85 \\
07-30-85 \\
07-30-85 \\
08-27-85\end{array}$ & $\begin{array}{r}<100 \\
<100 \\
200 \\
<100 \\
200\end{array}$ & $\begin{array}{l}<1 \\
<1 \\
<1 \\
<1 \\
<1\end{array}$ & $\begin{array}{l}<10 \\
<10 \\
<10 \\
<10 \\
<10\end{array}$ & $\begin{array}{r}20 \\
<10 \\
<10 \\
<10 \\
<10\end{array}$ & $\begin{array}{l}<10 \\
<10 \\
<10 \\
<10 \\
<10\end{array}$ & $\begin{array}{l}<1.0 \\
<1.0 \\
<1.0 \\
<1.0 \\
<1.0\end{array}$ & $\begin{array}{l}<10 \\
<10 \\
<10 \\
<10 \\
<10\end{array}$ \\
\hline
\end{tabular}


STATION NUMBER DATE

$405631094560802 \quad 08-20-85$ $41353709453270106-10-85$ $41323409455240106-10-85$ $413743095041401 \quad 06-11-85$ 414330094524801 06-11-85

414245094524901 06-11-85 $415950091512501 \quad 07-03-85$ 420030092053001 09-25-85 $415955092120701 \quad 09-25-85$ 420520091524701 07-03-85

421016092015901 06-25-85 $421326091525301 \quad 07-03-85$ $422801092152801 \quad 07-31-85$ $422805092165901 \quad 07-31-85$ 423112092213901 08-15-85

422818092212801 08-15-85 $423139092261401 \quad 08-15-85$ $425058092315601 \quad 07-30-85$ $421900092002001 \quad 08-09-85$ 422833091431701 08-09-85

423710091540001 08-09-85 $423837095135002 \quad 05-23-85$ $423512092521001 \quad 07-08-85$ $424239092350001 \quad 07-08-85$ 424704092400803 07-08-85

424627092542302 07-09-85 $424524092474601 \quad 07-08-85$ $424455092581801 \quad 07-09-85$ $425355092475801 \quad 07-09-85$ $421614094325101 \quad 08-13-85$

$415147094403501 \quad 05-22-85$ $415430095041601 \quad 05-22-85$ $420024094575901 \quad 05-22-85$ $411637094520201 \quad 08-22-85$ 412429094594301 08-22-85

$41271409446070108-15-85$ $430756093263201 \quad 06-18-85$ $431426093073301 \quad 06-18-85$ 430923095114501 12-04-84 $430922095193501 \quad 12-04-84$

424026091321502 05-09-85 $424653091060801 \quad 06-24-85$ 425138091234901 05-09-85 414921090450401 12-20-84 414652090153201 01-08-85

415650095275602 06-17-85 $420131095221101 \quad 06-17-85$ $420328095122401 \quad 06-18-85$ $420551095185801 \quad 06-12-85$ 420415095352201 06-12-85

421125095193101 06-12-85 $421004095272701 \quad 06-12-85$ $420736095342401 \quad 06-17-85$ $413517094114101 \quad 08-20-85$ 413638093530901 08-20-85

422059091291401 06-25-85 $422705090561201 \quad 06-24-85$ $422910091072701 \quad 06-24-85$ $423136090383501 \quad 06-25-85$ 423134090383401 06-25-85

$42173109101150106-24-85$ $425036091480101 \quad 07-31-85$ $425606091565501 \quad 07-30-85$ $430329092020901 \quad 07-30-85$ $430919092351801 \quad 08-27-85$

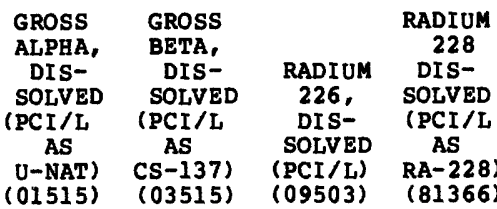

$<10<10$

1.3
3.2
7.4
1.0
0.3

2.0

1.0

3.0

2.0

1.2

$<10$

$<10$

$<10$

$<10$

$<10$

$<10$

$<10$

$<10$

$<10$

$<10$

$<10$

$<10$

$<10$

$<10$

$<10$

$<10$

$<10$

$<10$

$<10$

$<10$

$<10$

$<10$

$<10$

$<10$

$<10$

$<10$

$<10$

$<10$

$<10$

$<10$

$<10$

$<10$

$<10$

$<10$

$<10$

$<10$

$<10$

$<10$

$<10$

$<10$

$<10$

$<10$

$<10$

$<10$

$<10$

$<10$

$<10$

$<10$

$<10$

$<10$

$<10$

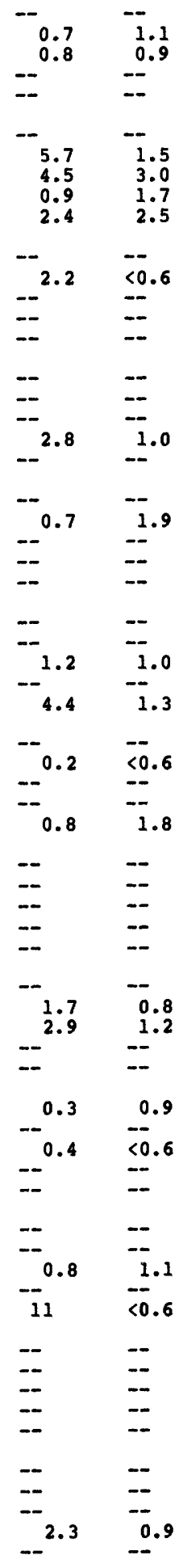


STATION NUMBER DATE

$405631094560802 \quad 08-20-85$ $413537094532701 \quad 06-10-85$ $41323409455240106-10-85$ 413743095041401 06-11-85 414330094524801 06-11-85

414245094524901 06-11-85 $415950091512501 \quad 07-03-85$ 420030092053001 09-25-85 $415955092120701 \quad 09-25-85$ 420520091524701 07-03-85

421016092015901 06-25-85 $421326091525301 \quad 07-03-85$ $422801092152801 \quad 07-31-85$ $422805092165901 \quad 07-31-85$ $42311209221390108-15-85$

422818092212801 08-15-85 423139092261401 08-15-85 $425058092315601 \quad 07-30-85$ $421900092002001 \quad 08-09-85$ 422833091431701 08-09-85

423710091540001 08-09-85 $423837095135002 \quad 05-23-85$ $423512092521001 \quad 07-08-85$ $424239092350001 \quad 07-08-85$ 424704092400803 07-08-85

$424627092542302 \quad 07-09-85$ $424524092474601 \quad 07-08-85$ 424455092581801 07-09-85 $425355092475801 \quad 07-09-85$ $42161409432510108-13-85$

415147094403501 05-22-85 $415430095041601 \quad 05-22-85$ $420024094575901 \quad 05-22-85$ $411637094520201 \quad 08-22-85$ 412429094594301 08-22-85

$412714094460701 \quad 08-15-85$ $430756093263201 \quad 06-18-85$ $431426093073301 \quad 06-18-85$ 430923095114501 12-04-84 430922095193501 12-04-84

424026091321502 05-09-85 $424653091060801 \quad 06-24-85$ $425138091234901 \quad 05-09-85$

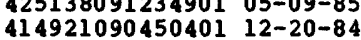
$41465209015320101-08-85$

$415650095275602 \quad 06-17-85$ $420131095221101 \quad 06-17-85$ 420328095122401 06-18-85 420551095185801 06-12-85 420415095352201 06-12-85

$421125095193101 \quad 06-12-85$ $\begin{array}{lll}421004095272701 & 06-12-85 \\ 420736095342401 & 06-17-85\end{array}$

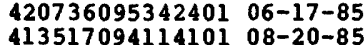
413638093530901 08-20-85

422059091291401 06-25-85 $422705090561201 \quad 06-24-85$ 422910091072701 06-24-85 $423136090383501 \quad 06-25-85$ 423134090383401 06-25-85

$421731091011501 \quad 06-24-85$ $425036091480101 \quad 07-31-85$ $425606091565501 \quad 07-30-85$ $430329092020901 \quad 07-30-85$ $430919092351801 \quad 08-27-85$ BUZIN IN

WHOLE

WATER

(UG/L)

(81408)

$<0.05$

$<0.1$

$<0.1$

0.49

1.6

0.13
$<0.05$

$<0.05$

$<0.05$

$<0.1<0.1$

$<0.05$

$<0.1$

$<0.1$

$\begin{array}{ll}-- & -- \\ -- & -\end{array}$

$-$

$\overline{--}$

$<0.1$

$-$

$-$

$<0.1$

$<0.1$

0.37

$<0.1$

$<0.05$

$\overline{<0.05}$

ALA-
CHLOR
TOTAL
RECOVER
(UG/L)
(77825)

METOLA-

CBLOR TRI-

IN

WHOLE

WATER

(UG/L)

(39356)

$\begin{array}{ccc}<0.1 & <0.1 & <0.05 \\ 0.18 & 0.71 & <0.05 \\ <0.1 & <0.1 & <0.05 \\ <0.1 & <0.1 & <0.05 \\ <0.1 & <0.1 & <0.05\end{array}$

$<0.1<0.1<0.05$

$\overline{--}$

$<0.05$

$=-=$

$<0.1$

$<0.1<0.05$

$<0.1<\overline{0.1}<\overline{0.05}$

$<0.05$

\begin{tabular}{|c|c|c|c|c|c|}
\hline -- & -. & -- & -- & -- & -. \\
\hline-- & -- & -- & -- & -- & 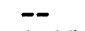 \\
\hline$<0.1$ & $<0.1$ & $<0.05$ & $<0.1$ & $<0.1$ & $<0.05$ \\
\hline-- & -- & -- & -- & - & - \\
\hline-- & -- & -- & -- & - & - \\
\hline$<0.1$ & $<0.1$ & $<0.05$ & $<0.1$ & $<0.1$ & $<0.05$ \\
\hline-- & - & & -- & -- & -- \\
\hline$<0.1$ & $<0.1$ & $<0.05$ & $<0.1$ & $<0.1$ & $<0.05$ \\
\hline- & -- & -- & -- & - & -- \\
\hline & -- & - & -- & - & - \\
\hline- & - & -- & -- & -- & -- \\
\hline & -- & - & - & - & \\
\hline & - & - & -- & $=$ & -- \\
\hline & -- & - & -- & - & - \\
\hline-- & -- & $\ldots$ & -- & -- & -- \\
\hline .1 & $<0.1$ & $<0.05$ & $<0.1$ & $<0.1$ & $<0.05$ \\
\hline & - & -- & -- & -- & - \\
\hline & - & - & -- & .. & -- \\
\hline & & & & & \\
\hline & -- & - & -- & - & - \\
\hline & -- & -- & $=$ & - & \\
\hline & -- & -- & -- & - & - \\
\hline & -- & $\cdots$ & -- & - & -- \\
\hline- & -- & - & -- & -- & -- \\
\hline & - & - & - & & \\
\hline & - & - & -- & - & \\
\hline & - & -- & -- & - & -- \\
\hline
\end{tabular}

$<0.1<0.1$

$<0.1<0.1$

$<0.05$

$<0.05$

$<0.05$

$<0.05$

$<0.1$

$<0.1$

$<0.1<0.1$

$<0.1$

$<0.1$

$<0.1$

$<0.05$

$<0.05$

$<0.05$

$<0.1<0.1 \quad<0.05$

$<0.1$

$<0.1$

$<0.05$

$<0.05$

$0.31<0.1$

$<0.1$

$<0.1$

$<0.1<0.1$

$<0.1<0.1$

$<0.1$

$<0.1$

$<0.05$

$<0.05$

$<0.05$

$<0.1<0.1$

$\begin{array}{lll}-- & -- & -\end{array}$

$\overline{0.37}<\overline{<0} \quad \overline{<0.05}$

$<\overline{0.1}<\overline{0.1} \quad \overline{0.05}$

$--$

$<0.1$

$\overline{0.25}<\overline{0}$

$0.27<0.1$

$--$
$<0.05$

$<0.05$

--
$<0$.

$<0.1$
$<0.05$

$<0.05$

$<0.05$

$-$

$<\overline{0.05}$

$<0.05$

$-$

$<0.05$

$<0.05$ 


\begin{tabular}{|c|c|c|c|c|c|c|c|}
\hline TATION NUMBER & DATE & $\begin{array}{c}\text { DICAMBA } \\
\text { (MED- } \\
\text { IBEN) } \\
\text { (BAN- } \\
\text { VEL D) } \\
\text { TOTAL } \\
\text { (UG/L) } \\
(82052)\end{array}$ & $\begin{array}{l}2,4-D, \\
\text { TOTAL } \\
(U G / L) \\
(39730)\end{array}$ & $\begin{array}{c}\text { SILVEX, } \\
\text { TOTAL } \\
\text { (UG/L) } \\
(39760)\end{array}$ & $\begin{array}{l}\text { DYFO- } \\
\text { NATE } \\
\text { (UG/L) } \\
(81294)\end{array}$ & $\begin{array}{c}\text { TERBU- } \\
\text { FOS } \\
(\text { UG/L) } \\
(82088)\end{array}$ & $\begin{array}{l}\text { PHORATE } \\
\text { OTAL } \\
\text { (UG/L) } \\
(39023)\end{array}$ \\
\hline $\begin{array}{l}405631094560802 \\
413537094532701 \\
413234094552401 \\
413743095041401 \\
414330094524801\end{array}$ & $\begin{array}{l}08-20-85 \\
06-10-85 \\
06-10-85 \\
06-11-85 \\
06-11-85\end{array}$ & $\begin{array}{l}<0.07 \\
<0.07 \\
<0.07 \\
<0.07 \\
<0.07\end{array}$ & $\begin{array}{l}<0.07 \\
<0.07 \\
<0.07 \\
<0.07 \\
<0.07\end{array}$ & $\begin{array}{l}<0.05 \\
<0.05 \\
<0.05 \\
<0.05 \\
<0.05\end{array}$ & $\begin{array}{l}<0.1 \\
<0.1 \\
<0.1 \\
<0.1 \\
<0.1\end{array}$ & $\begin{array}{l}-- \\
=- \\
--\end{array}$ & $\begin{array}{l}<0.1 \\
<0.1 \\
<0.1 \\
<0.1 \\
<0.1\end{array}$ \\
\hline $\begin{array}{l}414245094524901 \\
415950091512501 \\
420030092053001 \\
415955092120701 \\
420520091524701\end{array}$ & $\begin{array}{l}06-11-85 \\
07-03-85 \\
09-25-85 \\
09-25-85 \\
07-03-85\end{array}$ & $\begin{array}{l}<0.07 \\
-- \\
-- \\
-- \\
--\end{array}$ & $\begin{array}{l}<0.07 \\
-- \\
-- \\
--\end{array}$ & $\begin{array}{l}<0.05 \\
=- \\
=- \\
--\end{array}$ & $\begin{array}{l}<0.1 \\
=- \\
=- \\
=-\end{array}$ & $\begin{array}{l}-- \\
\overline{--} \\
--\end{array}$ & $\begin{array}{l}<0.1 \\
-- \\
-- \\
--\end{array}$ \\
\hline $\begin{array}{l}421016092015901 \\
421326091525301 \\
422801092152801 \\
422805092165901 \\
423112092213901\end{array}$ & $\begin{array}{l}06-25-85 \\
07-03-85 \\
07-31-85 \\
07-31-85 \\
08-15-85\end{array}$ & $\begin{array}{l}<0.07 \\
<\overline{0.07} \\
<\overline{0.07}\end{array}$ & $\begin{array}{l}<0.07 \\
-\therefore<0 \\
<0.07 \\
<0.07\end{array}$ & $\begin{array}{l}<0.05 \\
-- \\
<0.05 \\
-- \\
<0.05\end{array}$ & $\begin{array}{l}<0.1 \\
<- \\
<0.1 \\
--0.1\end{array}$ & $\begin{array}{l}-- \\
\overline{<0.1} \\
--\end{array}$ & $\begin{array}{l}<0.1 \\
<0.1 \\
<0.1\end{array}$ \\
\hline $\begin{array}{l}422818092212801 \\
42313909261401 \\
425058092315601 \\
421900092002001 \\
422833091431701\end{array}$ & $\begin{array}{l}08-15-85 \\
08-15-85 \\
07-30-85 \\
08-09-85 \\
08-09-85\end{array}$ & $\begin{array}{l}-- \\
\overline{0}-07 \\
--\end{array}$ & $\begin{array}{l}-- \\
\overline{-0} \\
-- \\
--\end{array}$ & $\begin{array}{l}-- \\
\overline{<0.05} \\
\overline{--}\end{array}$ & $\begin{array}{l}-- \\
-\overline{<0} \\
-- \\
--\end{array}$ & $\begin{array}{l}-- \\
\ddot{<0} \\
-- \\
--\end{array}$ & $\begin{array}{l}-- \\
\overline{<0.1} \\
--\end{array}$ \\
\hline $\begin{array}{l}423710091540001 \\
423837095135002 \\
423512092521001 \\
424239092350001 \\
424704092400803\end{array}$ & $\begin{array}{l}08-09-85 \\
05-23-85 \\
07-08-85 \\
07-08-85 \\
07-08-85\end{array}$ & $\begin{array}{c}<0.07 \\
<0.07 \\
--\end{array}$ & $\begin{array}{l}<0.07 \\
<0.07 \\
--\end{array}$ & $\begin{array}{l}<0.05 \\
-- \\
<0.05 \\
--\end{array}$ & $\begin{array}{l}<0.1 \\
<0.1 \\
-- \\
--\end{array}$ & $\begin{array}{l}-- \\
=- \\
=-\end{array}$ & $\begin{array}{l}<0.1 \\
-- \\
<0.1 \\
--\end{array}$ \\
\hline $\begin{array}{l}424627092542302 \\
424524092474601 \\
424455092581801 \\
425355092475801 \\
421614094325101\end{array}$ & $\begin{array}{l}07-09-85 \\
07-08-85 \\
07-09-85 \\
07-09-85 \\
08-13-85\end{array}$ & $\begin{array}{l}\overline{-} \\
\overline{-} \\
\overline{-}\end{array}$ & $\begin{array}{l}-- \\
=- \\
=-\end{array}$ & $\begin{array}{l}=- \\
=- \\
=-\end{array}$ & $\begin{array}{l}-- \\
=- \\
--\end{array}$ & $\begin{array}{l}= \\
= \\
=\end{array}$ & $\begin{array}{l}=- \\
\overline{-} \\
=-\end{array}$ \\
\hline $\begin{array}{l}415147094403501 \\
415430095041601 \\
420024094575901 \\
411637094520201 \\
412429094594301\end{array}$ & $\begin{array}{l}05-22-85 \\
05-22-85 \\
05-22-85 \\
08-22-85 \\
08-22-85\end{array}$ & $\begin{array}{l}-\overline{0.07} \\
\overline{-} \\
\overline{-}\end{array}$ & $\begin{array}{l}-\overline{00} \\
-- \\
=\end{array}$ & $\begin{array}{l}-\overline{<0.05} \\
=- \\
=-\end{array}$ & $\begin{array}{l}-\overline{<0.1} \\
-- \\
--\end{array}$ & $\begin{array}{l}-\overline{<0.1} \\
-- \\
--\end{array}$ & $\begin{array}{l}-\overline{<0.1} \\
\overline{-} \\
=-\end{array}$ \\
\hline $\begin{array}{l}412714094460701 \\
430756093263201 \\
431426093073301 \\
430923095114501 \\
430922095193501\end{array}$ & $\begin{array}{l}08-15-85 \\
06-18-85 \\
06-18-85 \\
12-04-84 \\
12-04-84\end{array}$ & $\begin{array}{l}=- \\
=- \\
=\end{array}$ & $\begin{array}{l}=- \\
=- \\
=\end{array}$ & $\begin{array}{l}-- \\
-- \\
--\end{array}$ & $=$ & $\overline{-}=$ & $\begin{array}{l}=- \\
=- \\
=-\end{array}$ \\
\hline $\begin{array}{l}424026091321502 \\
424653091060801 \\
425138091234901 \\
414921090450401 \\
414652090153201\end{array}$ & $\begin{array}{l}05-09-85 \\
06-24-85 \\
05-09-85 \\
12-20-84 \\
01-08-85\end{array}$ & $\begin{array}{l}=- \\
\overline{--} \\
=-\end{array}$ & $\begin{array}{l}=- \\
\overline{--} \\
--\end{array}$ & $\begin{array}{l}= \\
=- \\
=-\end{array}$ & $\begin{array}{l}=- \\
\overline{--} \\
=-\end{array}$ & $\overline{-}$ & $\begin{array}{l}=- \\
=- \\
--\end{array}$ \\
\hline $\begin{array}{l}415650095275602 \\
420131095221101 \\
420328095122401 \\
420551095185801 \\
420415095352201\end{array}$ & $\begin{array}{l}06-17-85 \\
06-17-85 \\
06-18-85 \\
06-12-85 \\
06-12-85\end{array}$ & $\begin{array}{l}<0.07 \\
<0.07 \\
<0.07 \\
<0.07 \\
<0.07\end{array}$ & $\begin{array}{l}<0.07 \\
<0.07 \\
<0.07 \\
<0.07 \\
<0.07\end{array}$ & $\begin{array}{l}<0.05 \\
<0.05 \\
<0.05 \\
<0.05 \\
<0.05\end{array}$ & $\begin{array}{l}<0.1 \\
<0.1 \\
<0.1 \\
<0.1 \\
<0.1\end{array}$ & $\begin{array}{l}-- \\
<0.1 \\
--\end{array}$ & $\begin{array}{l}<0.1 \\
<0.1 \\
<0.1 \\
<0.1 \\
<0.1\end{array}$ \\
\hline $\begin{array}{l}421125095193101 \\
421004095272701 \\
420736095342401 \\
413517094114101 \\
413638093530901\end{array}$ & $\begin{array}{l}06-12-85 \\
06-12-85 \\
06-17-85 \\
08-20-85 \\
08-20-85\end{array}$ & $\begin{array}{l}<0.07 \\
<0.07 \\
<0.07 \\
<0.07 \\
--\end{array}$ & $\begin{array}{l}<0.07 \\
<0.07 \\
<0.07 \\
<0.07 \\
--\end{array}$ & $\begin{array}{l}<0.05 \\
<0.05 \\
<0.05 \\
<0.05 \\
--\end{array}$ & $\begin{array}{l}<0.1 \\
<0.1 \\
<0.1 \\
<0.1 \\
--\end{array}$ & $\begin{array}{l}-- \\
\overline{<0.1} \\
--\end{array}$ & $\begin{array}{l}<0.1 \\
<0.1 \\
<0.1 \\
<0.1 \\
--\end{array}$ \\
\hline $\begin{array}{l}422059091291401 \\
422705090561201 \\
422910091072701 \\
423136090383501 \\
423134090383401\end{array}$ & $\begin{array}{l}06-25-85 \\
06-24-85 \\
06-24-85 \\
06-25-85 \\
06-25-85\end{array}$ & $\begin{array}{c}\overline{-} \\
<\overline{0.07} \\
\overline{0.07}\end{array}$ & $\begin{array}{l}\overline{-} \\
\overline{<0.07} \\
\overline{<0.07}\end{array}$ & $\begin{array}{l}\overline{--} \\
\overline{<0.05} \\
\overline{<0.05}\end{array}$ & $\begin{array}{l}-- \\
\overline{<0.1} \\
\overline{<0.1}\end{array}$ & $\begin{array}{l}-- \\
-- \\
--\end{array}$ & $\begin{array}{l}-- \\
<0.1 \\
<0.1\end{array}$ \\
\hline $\begin{array}{l}421731091011501 \\
425036091480101 \\
425606091565501 \\
430329092020901 \\
430919092351801\end{array}$ & $\begin{array}{l}06-24-85 \\
07-31-85 \\
07-30-85 \\
07-30-85 \\
08-27-85\end{array}$ & $\begin{array}{l}-- \\
<0.07 \\
<0.07 \\
-- \\
--\end{array}$ & $\begin{array}{l}-\overline{<} \\
<0.07 \\
<0.07 \\
--\end{array}$ & $\begin{array}{l}-- \\
<0.05 \\
<0.05 \\
-- \\
--\end{array}$ & $\begin{array}{l}-- \\
<0.1 \\
<0.1 \\
-- \\
--\end{array}$ & $\begin{array}{l}=- \\
=- \\
=-\end{array}$ & $\begin{array}{l}-- \\
<0.1 \\
<0.1 \\
-- \\
--\end{array}$ \\
\hline
\end{tabular}


STATION NUMBER

$43074109254060109617 W 18 \mathrm{CCAD}$ $43083609300170109618 W 07$ DDAD 42431209313210109120 W05DADD 42453709322050209221 W1 9DCCD 42534209313370109320 W0 5DDBB

40360409539440106742 W21DDCA 40522509533500106841 W1 $4 \mathrm{CDBB}$ 40422409531060106841 W1 4CDBB $41552709411490108229 \mathrm{W1} 1 \mathrm{CDB}$ 4200470942239010833 OW07DADA

$42010409432430108332 \mathrm{Wl} 1 \mathrm{BDBD}$ $42133609252440108617 W 30 \mathrm{CDDB}$ 42185609235510108715 W28DBDD $42132709249220108617 \mathrm{W3} 4 \mathrm{BB}$ 41403509430250107931 W06CDBC

41403509430250207931 W06CDBC 41462409421120108030 W0 4 BBAD 41503409425480108131 W11 BDCA 42141709336070108624 W26AAAD 42172409347410108625 W0 5 BCCB

$42182809338150108724 \mathrm{~W} 34 \mathrm{BBCC}$ 42290409332420108923 W27DCDB $42552809336450109423 \% 30 C C D A$ 42593609357240109426 W06ABAA 43001509336050109523 W31 ACA

$43062709336130109623 W 30 A B D$ 43053909348220109625 W3 3 BAAC $42145509303460108619 W 21 A D B D$ 42165809310110108620 W03CDC 42154409300220108619 W13ACAA

42245309303500108819 W21DDC 42332309303470108919 W02BB $41500309555240108144 W 13 \mathrm{BBB}$ 40581009133051107106 W09ABAC 41074009126000107305 W1 6AA

$41074909132400107306 \mathrm{Wl}$ 5BBB $41074909132410107306 \mathrm{Wl}$ 15BBC 41085109139440107307 W0 9AABD 43225709206570109911 W23 BCBB 43265009217020110012 W29DBDC

43292309221250110013 W1ODDAB 42430809413260109129 W01CCAC 42391109423340209130 W3 3 ACCC 42483609403010109227 W05DAAD 42454809417190109229 W2ODDB

42201809520510108739 W23 ABDD $42210609528020108740 \mathrm{Wl} 4 \mathrm{ACBB}$ 42190809535370108741 W26CBBB 42303309525050108939 W23CADA $42043209040120108402 \mathrm{E} 24 \mathrm{AAB}$

41425109254170108018W26AADC $42000909108490108303 \mathrm{Wl} 3 \mathrm{BA}$ 42010209121410108304 W07B 42063109117200108404 W03DDD 42074709110580108503 W34ACC

$42142009114200108603 W 21 C D$ 41280909214200107712 W1 5CCBC 42542609405030109327 W06 BABB 43034009425270209530 W0 8BBCD 43115409413070109729 W24CDCD

$43173709412560109829 W 24 A C B C$ 40380409117400106704 WO2BBDC 40374809117430106704 W02CBBA 41055709102370107302 W25BBCC 41105609111150107403 W2 7BDDD
STATION NAME

COUNTY

1916 RUDD TOWN WELL NO 1 FLOYD 1958 NORA SPRINGS NO 1 FLOYD 1975 HAMPTON NO 6 FRANKLIN 1951 LATIMER IOWA NO 2 FRANKLIN 1977 SHEFF IELD 3

FRANKLIN

1973 HAMBURG 5

1966 RANDOLPH 3

1973RIVERTON 2

REMONT

FREMONT

GRE ENE

1953 JEFEERSON TOWN NO 4 GREENE

1977 SCRANTON TOWN NO 4 CONRAD 4

1978REINBECK 3

1978BEAMAN 2

1929GUTHRIE CENTER NO 1

1941GUTHRIE CENTER NO 2

13717 1962YALE NO 1

1898 TOWN OF BAGLEY

066221954 RANDALL NO 1

1973 STANHOPE NO 5

1932JEWELL NO 1

186401965 WILLIAMS TOWN NO 3

168491964 GOODELL TOWN

048641950 CORWITH TOWN

111681959 KLEMME TOWN $\$ 2$

00134 1932GARNER TOWN \#1

00554 1937BRITT IOWA \$2

202601967 UNION NO 3

023641946 NEW PROVIDENCE CITY $1955 \mathrm{WH}$ ITTEN 1

051881951 STEAMBOAT ROCK

015761942 ACKLEY NO 3 1929 PISGAH NO

$019681946 \mathrm{MT}$ PLEASANT NO 4 001191915 WINFIELD CITY WELL

$1827619650 L D S$ TOWN WELL NO I $2435619770 L D S$ TOWN WELL NO 4 252741951 TOWN OF WAYLAND NO 2 170751965 CRESCO CITY 3 018361944 LIMES PRINGS

1898 CHESTER NO

1973 HUMBOLDT TOWN WELL

1968 PIONEER IOWA NO 1

1966 HARDY TOWN NO 1

03374 1948RU TLAND IOWA

1923ARTHUR TOWN NO 1

1965 IDA GROVE NO 4

1972 BATTLE CREEK NO 3

1957 GALVA TOWN NO 2

MAQUOKETA 3

1939KELLOGG NO

217921969 MARTELLE TOWN $\# 2$

07306 ANAMOSA IOWA 2

03334 AMBER IOWA

07032 MONTICELLO

$080001957 \mathrm{KESWICK}$ NO

1967 LUVERNE NO 2

1958 WHITTEMORE NO 2

1965BURT NO 3

122771960 BANCROFT IA $\# 3$ 1979 FORT MADISON NO 2 1967 FORT MADISON NO 1 19730AKVILLE NO 1 1976 WAPELLO NO 2
GREENE

GRUNDY

GRUNDY

GRUNDY

GUTHRIE

GUTHRIE

GUTHR IE

HAMILTON

HAM ILTON

HAM ILTON

HANCOCK

HANCOCK

HANCOCK

HANCOCK

BANCOCK

HARDIN

HARDIN

HARDIN

HARDIN

HARDIN

HARRISON

HENRY

HENRY

HENRY

HENRY

HENRY

HOWARD

HOWARD

HOW ARD

HUMBOL DT

HUMBOLDT

HUMBOLDT

HUMBOLDT

IDA

IDA

IDA

IDA

JACKSON

JASPER

JONES

JONES

JONES

JONES

JONES

KEOKUK

KOSSUTH

KOSSUTH

KOSSUTH

KOSSU TH

LEE

LEE

LOU ISA

LOU ISA
HAM ILTON

GEO-
LOGIC
UNIT

DEPTH

OE

WELL,

(FEET)

(72008)

08-06-85

10:00 344CDVL

200.00

289.00

44.00

170.00

27.00

$07-10-85 \quad 13: 30$ 330MSSP

07-10-85 12:10 IIIALVM

75.00

08-14-85 10:00 111ALVM

08-14-85 10:15 111ALVM

08-21-85 12:00 IIIALVM

08-13-85 09:00 112RCLC

08-13-85 11:00 112 HCKC

53.00

57.00

135.00

146.00

08-13-85 12:00 112PLSC

11-13-85 08:20 330MSSP

$11-13-85 \quad 13: 25$ 344CDVL

$11-13-85 \quad 09: 30$ 330MSSP

13:05 112PLSC

212.00

130.00

420.00

125.00

60.00

05-21-85 0 : $112 \mathrm{PLSC}$

05-21-85 07:00 112PLSC

05-21-85 12:00 112RLCL

06-04-85 12:15 339KDRK

06-04-85

$13: 15$

33 OMSSP

06-04-85 11:00 112PLSC

06-04-85 09:15 330MSSP

06-04-85 10:00 339HMPN

$06-04-85 \quad 14: 45 \quad 339$ HMPN

06-04-85 11:15 340DVNN

06-04-85 12:30 344CDVL

06-04-85 13:40 344CDVL

06-27-85 10:10 339HMPN

$13.45 \quad 330$ MSSP

11-13-85 10:35 330MSSP

06-26-85 12:30 339HMPN

07-09-85 09:05 339KDRK

02-08-85 10:45 111SDRV

$07-11-85 \quad 09: 30 \quad 3600 \mathrm{VCB}$

$06-27-85$

12:15 3600VCB

06-27-85 09:30 330MSSP

$10: 30 \quad 3600 \mathrm{VCB}$

06-28-85 09:00 3600VCB

$08-07$

$08-07-85$

09:45 371TMPL

11:05 364GLEN

62.00

82.00

96.00

347.00

585.00

68.00

425.00

190.00

120.00

185.00

225.00

197.00

195.00

485.00

188.00

110.00

140.00

102.00

1809.00

1260.00

274.00

1910.00

1900.00

1145.00

358.00

176.00

08-07-85 12:30 340DVNN

$13: 15$ 330MSSP

13:15 330MSSP

09:00 112PLSC

05-30-85

$05-30-85$ 


\begin{tabular}{|c|c|c|c|c|c|c|c|c|}
\hline STATION NUMBER & DATE & $\begin{array}{c}\text { FLOW } \\
\text { RATE } \\
(\text { GPM }) \\
(00058)\end{array}$ & $\begin{array}{c}\text { PUMP } \\
\text { OR FLOW } \\
\text { PERIOD } \\
\text { PRIOR } \\
\text { TO SAM- } \\
\text { PLING } \\
\text { (MIN) } \\
(72004)\end{array}$ & $\begin{array}{l}\text { SPE- } \\
\text { CIFIC } \\
\text { CON- } \\
\text { DOCT- } \\
\text { ANCE } \\
\text { (US/CM) } \\
(00095)\end{array}$ & $\begin{array}{c}\text { PH } \\
\text { (STAND- } \\
\text { ARD } \\
\text { UNITS) } \\
(00400)\end{array}$ & $\begin{array}{l}\text { HARD- } \\
\text { NESS } \\
\text { (MG/L } \\
\text { AS } \\
\text { CACO3) } \\
(00900)\end{array}$ & $\begin{array}{l}\text { CALCIUM } \\
\text { DIS- } \\
\text { SOLVED } \\
\text { (MG/L } \\
\text { AS CA) } \\
(00915)\end{array}$ & $\begin{array}{c}\text { MAGNE- } \\
\text { SIUM, } \\
\text { DIS- } \\
\text { SOLVED } \\
\text { (MG/L } \\
\text { AS MG) } \\
(00925)\end{array}$ \\
\hline $\begin{array}{l}430741092540601 \\
430836093001701 \\
424312093132101 \\
424537093220502 \\
425342093133701\end{array}$ & $\begin{array}{l}08-06-85 \\
08-06-85 \\
07-09-85 \\
07-10-85 \\
07-10-85\end{array}$ & $\begin{array}{r}50 \\
200 \\
300 \\
120 \\
60\end{array}$ & $\begin{array}{r}20 \\
1440 \\
120 \\
30 \\
30\end{array}$ & $\begin{array}{l}580 \\
690 \\
795 \\
770 \\
490\end{array}$ & $\begin{array}{l}7.6 \\
7.8 \\
7.2 \\
7.1 \\
7.6\end{array}$ & $\begin{array}{l}270 \\
350 \\
400 \\
350 \\
240\end{array}$ & $\begin{array}{r}72 \\
92 \\
100 \\
92 \\
60\end{array}$ & $\begin{array}{l}21 \\
30 \\
35 \\
29 \\
21\end{array}$ \\
\hline $\begin{array}{l}403604095394401 \\
405225095335001 \\
404224095310601 \\
415527094114901 \\
420047094223901\end{array}$ & $\begin{array}{l}08-14-85 \\
08-14-85 \\
08-21-85 \\
08-13-85 \\
08-13-85\end{array}$ & $\begin{array}{l}170 \\
110 \\
100 \\
300\end{array}$ & $\begin{array}{l}60 \\
60 \\
60 \\
30 \\
30\end{array}$ & $\begin{array}{l}800 \\
810 \\
660 \\
770 \\
940\end{array}$ & $\begin{array}{l}7.3 \\
7.8 \\
7.3 \\
7.2 \\
7.3\end{array}$ & $\begin{array}{l}390 \\
400 \\
310 \\
380 \\
430\end{array}$ & $\begin{array}{r}100 \\
99 \\
86 \\
100 \\
120\end{array}$ & $\begin{array}{l}35 \\
36 \\
23 \\
32 \\
32\end{array}$ \\
\hline $\begin{array}{l}420104094324301 \\
421336092524401 \\
421856092355101 \\
421327092492201 \\
414035094302501\end{array}$ & $\begin{array}{l}08-13-85 \\
11-13-85 \\
11-13-85 \\
11-13-85 \\
05-21-85\end{array}$ & $\begin{array}{l}200 \\
165 \\
280 \\
1 \overline{120}\end{array}$ & $\begin{array}{l}90 \\
30 \\
90 \\
40 \\
40\end{array}$ & $\begin{array}{l}660 \\
596 \\
944 \\
740 \\
625\end{array}$ & $\begin{array}{l}7.3 \\
7.4 \\
7.3 \\
7.5 \\
6.9\end{array}$ & $\begin{array}{l}310 \\
310 \\
520 \\
390 \\
270\end{array}$ & $\begin{array}{r}77 \\
86 \\
130 \\
90 \\
74\end{array}$ & $\begin{array}{l}29 \\
24 \\
48 \\
39 \\
20\end{array}$ \\
\hline $\begin{array}{l}414035094302502 \\
414624094211201 \\
415034094254801 \\
421417093360701 \\
421724093474101\end{array}$ & $\begin{array}{l}05-21-85 \\
05-21-85 \\
05-21-85 \\
06-04-85 \\
06-04-85\end{array}$ & $\begin{array}{r}90 \\
100 \\
70 \\
45 \\
90\end{array}$ & $\begin{array}{l}40 \\
40 \\
40 \\
30 \\
30\end{array}$ & $\begin{array}{r}640 \\
580 \\
630 \\
640 \\
1100\end{array}$ & $\begin{array}{l}7.1 \\
7.1 \\
7.3 \\
7.1 \\
7.2\end{array}$ & $\begin{array}{l}300 \\
330 \\
320 \\
330 \\
490\end{array}$ & $\begin{array}{l}85 \\
84 \\
87 \\
71 \\
99\end{array}$ & $\begin{array}{l}21 \\
28 \\
25 \\
37 \\
60\end{array}$ \\
\hline $\begin{array}{l}421828093381501 \\
422904093324201 \\
425528093364501 \\
425936093572401 \\
430015093360501\end{array}$ & $\begin{array}{l}06-04-85 \\
06-04-85 \\
06-04-85 \\
06-04-85 \\
06-04-85\end{array}$ & $\begin{array}{l}180 \\
135 \\
120 \\
130 \\
100\end{array}$ & $\begin{array}{l}60 \\
60 \\
20\end{array}$ & $\begin{array}{r}780 \\
650 \\
750 \\
1060 \\
960\end{array}$ & $\begin{array}{l}7.1 \\
7.2 \\
7.5 \\
7.4 \\
7.4\end{array}$ & $\begin{array}{l}410 \\
360 \\
340 \\
370 \\
410\end{array}$ & $\begin{array}{r}110 \\
73 \\
84 \\
97 \\
100\end{array}$ & $\begin{array}{l}34 \\
43 \\
32 \\
32 \\
38\end{array}$ \\
\hline $\begin{array}{l}430627093361301 \\
430539093482201 \\
421455093034601 \\
421658093101101 \\
421544093002201\end{array}$ & $\begin{array}{l}06-04-85 \\
06-04-85 \\
06-27-85 \\
06-26-85 \\
11-13-85\end{array}$ & $\begin{array}{r}170 \\
400 \\
110 \\
65 \\
50\end{array}$ & $\begin{array}{r}180 \\
15 \\
30 \\
15 \\
30\end{array}$ & $\begin{array}{l}780 \\
620 \\
765 \\
400 \\
635\end{array}$ & $\begin{array}{l}7.1 \\
7.3 \\
7.2 \\
7.8 \\
7.2\end{array}$ & $\begin{array}{l}370 \\
310 \\
350 \\
100 \\
340\end{array}$ & $\begin{array}{l}86 \\
79 \\
95 \\
22 \\
84\end{array}$ & $\begin{array}{l}37 \\
27 \\
28 \\
11 \\
31\end{array}$ \\
\hline $\begin{array}{l}422453093035001 \\
423323093034701 \\
41500309552401 \\
405810091330511 \\
410740091260001\end{array}$ & $\begin{array}{l}06-26-85 \\
07-09-85 \\
02-08-85 \\
07-11-85 \\
06-27-85\end{array}$ & $\begin{array}{r}65 \\
150 \\
150 \\
950 \\
120\end{array}$ & $\begin{array}{l}30 \\
30 \\
30 \\
90 \\
40\end{array}$ & $\begin{array}{r}810 \\
1100 \\
689 \\
1900 \\
1600\end{array}$ & $\begin{array}{l}7.3 \\
7.0 \\
7.3 \\
7.1 \\
7.8\end{array}$ & $\begin{array}{l}370 \\
480 \\
360 \\
420 \\
230\end{array}$ & $\begin{array}{r}92 \\
140 \\
90 \\
99 \\
49\end{array}$ & $\begin{array}{l}34 \\
31 \\
33 \\
43 \\
25\end{array}$ \\
\hline $\begin{array}{l}410749091324001 \\
410749091324101 \\
410851091394401 \\
432257092065701 \\
432650092170201\end{array}$ & $\begin{array}{l}06-27-85 \\
06-27-85 \\
06-28-85 \\
08-07-85 \\
08-07-85\end{array}$ & $\begin{array}{r}6 \\
60 \\
250 \\
600 \\
240\end{array}$ & $\begin{array}{l}40 \\
30 \\
30 \\
20 \\
20\end{array}$ & $\begin{array}{r}832 \\
1600 \\
1630 \\
550 \\
460\end{array}$ & $\begin{array}{l}7.7 \\
7.2 \\
7.4 \\
7.5 \\
7.4\end{array}$ & $\begin{array}{l}120 \\
430 \\
450 \\
250 \\
220\end{array}$ & $\begin{array}{r}23 \\
100 \\
99 \\
66 \\
60\end{array}$ & $\begin{array}{l}15 \\
44 \\
49 \\
21 \\
17\end{array}$ \\
\hline $\begin{array}{l}432923092212501 \\
42430809432601 \\
423911094233402 \\
424836094030101 \\
424548094171901\end{array}$ & $\begin{array}{l}08-07-85 \\
05-30-85 \\
05-30-85 \\
05-30-85 \\
05-30-85\end{array}$ & $\begin{array}{r}250 \\
1000 \\
12 \\
-- \\
--\end{array}$ & $\begin{array}{r}20 \\
360 \\
20\end{array}$ & $\begin{array}{r}600 \\
670 \\
1250 \\
650 \\
680\end{array}$ & $\begin{array}{l}7.2 \\
6.9 \\
7.2 \\
7.5 \\
7.4\end{array}$ & $\begin{array}{l}300 \\
360 \\
560 \\
460 \\
380\end{array}$ & $\begin{array}{r}82 \\
98 \\
140 \\
120 \\
99\end{array}$ & $\begin{array}{l}22 \\
28 \\
51 \\
38 \\
31\end{array}$ \\
\hline $\begin{array}{l}422018095205101 \\
422106095280201 \\
421908095353701 \\
423033095250501 \\
420432090401201\end{array}$ & $\begin{array}{l}12-05-84 \\
12-05-84 \\
12-05-84 \\
05-23-85 \\
12-20-84\end{array}$ & $\begin{array}{r}100 \\
500 \\
250 \\
75 \\
550\end{array}$ & $\begin{array}{r}20 \\
30 \\
30 \\
1440 \\
15\end{array}$ & $\begin{array}{l}590 \\
960 \\
625 \\
900 \\
762\end{array}$ & $\begin{array}{l}7.5 \\
7.6 \\
7.7 \\
7.2 \\
7.1\end{array}$ & $\begin{array}{l}350 \\
460 \\
380 \\
480 \\
400\end{array}$ & $\begin{array}{r}98 \\
140 \\
100 \\
140 \\
96\end{array}$ & $\begin{array}{l}25 \\
27 \\
31 \\
32 \\
38\end{array}$ \\
\hline $\begin{array}{l}414251092541701 \\
420009091084901 \\
420102091214101 \\
420631091172001 \\
420747091105801\end{array}$ & $\begin{array}{l}09-24-85 \\
07-19-85 \\
07-18-85 \\
07-17-85 \\
07-17-85\end{array}$ & $\begin{array}{r}40 \\
200 \\
100 \\
190 \\
20\end{array}$ & $\begin{array}{l}10 \\
30 \\
30 \\
30 \\
40\end{array}$ & $\begin{array}{r}1050 \\
540 \\
360 \\
950 \\
640\end{array}$ & $\begin{array}{l}6.8 \\
7.4 \\
7.3 \\
7.3 \\
7.2\end{array}$ & $\begin{array}{l}410 \\
280 \\
180 \\
410 \\
310\end{array}$ & $\begin{array}{r}120 \\
64 \\
47 \\
100 \\
72\end{array}$ & $\begin{array}{l}28 \\
29 \\
15 \\
40 \\
32\end{array}$ \\
\hline $\begin{array}{l}421420091142001 \\
412809092142001 \\
425426094050301 \\
430340094252702 \\
431154094130701\end{array}$ & $\begin{array}{l}07-17-85 \\
12-18-84 \\
05-31-85 \\
05-31-85 \\
05-31-85\end{array}$ & $\begin{array}{r}445 \\
40 \\
195 \\
120 \\
350\end{array}$ & $\begin{array}{l}30 \\
30 \\
20 \\
30 \\
30\end{array}$ & $\begin{array}{r}620 \\
605 \\
760 \\
1250 \\
900\end{array}$ & $\begin{array}{l}7.4 \\
7.2 \\
7.2 \\
7.3 \\
7.3\end{array}$ & $\begin{array}{l}310 \\
310 \\
390 \\
580 \\
390\end{array}$ & $\begin{array}{r}78 \\
80 \\
100 \\
150 \\
100\end{array}$ & $\begin{array}{l}29 \\
26 \\
33 \\
50 \\
35\end{array}$ \\
\hline $\begin{array}{l}431737094125601 \\
403804091174001 \\
403748091174301 \\
410557091023701 \\
411056091111501\end{array}$ & $\begin{array}{l}05-31-85 \\
05-21-85 \\
05-21-85 \\
07-09-85 \\
04-10-85\end{array}$ & $\begin{array}{r}180 \\
350 \\
450 \\
\overline{210}\end{array}$ & $\begin{array}{r}30 \\
60 \\
60 \\
30 \\
150\end{array}$ & $\begin{array}{r}1300 \\
470 \\
650 \\
431 \\
350\end{array}$ & $\begin{array}{l}7.1 \\
7.3 \\
7.1 \\
7.5 \\
7.5\end{array}$ & $\begin{array}{l}680 \\
220 \\
330 \\
200 \\
190\end{array}$ & $\begin{array}{r}180 \\
57 \\
89 \\
54 \\
55\end{array}$ & $\begin{array}{l}57 \\
18 \\
26 \\
15 \\
12\end{array}$ \\
\hline
\end{tabular}


STATION NUMBER DATE

430741092540601 08-06-85 430836093001701 08-06-85 424312093132101 07-09-85 $424537093220502 \quad 07-10-85$ 425342093133701 07-10-85

403604095394401 08-14-85 $405225095335001 \quad 08-14-85$ $404224095310601 \quad 08-21-85$ 415527094114901 08-13-85 420047094223901 08-13-85

420104094324301 08-13-85 421336092524401 11-13-85 $421856092355101 \quad 11-13-85$ 421327092492201 11-13-85 414035094302501 05-21-85

$414035094302502 \quad 05-21-85$ $47462409421120105-21-85$ 415034094254801 05-21-85 421417093360701 06-04-85 421724093474101 06-04-85

421828093381501 06-04-85 422904093324201 06-04-85 425528093364501 06-04-85 425936093572401 06-04-85 430015093360501 06-04-85

$430627093361301 \quad 06-04-85$ $430539093482201 \quad 06-04-85$ 421455093034601 06-27-85 $421658093101101 \quad 06-26-85$ 421544093002201 11-13-85

$422453093035001 \quad 06-26-85$ 423323093034701 07-09-85 415003095552401 02-08-85 $405810091330511 \quad 07-11-85$ 410740091260001 06-27-85

$410749091324001 \quad 06-27-85$ $410749091324101 \quad 06-27-85$ 410851091394401 06-28-85 $432257092065701 \quad 08-07-85$ 432650092170201 08-07-85

$432923092212501 \quad 08-07-85$ 424308094132601 05-30-85 423911094233402 05-30-85 $424836094030101 \quad 05-30-85$ 424548094171901 05-30-85

422018095205101 12-05-84 $422106095280201 \quad 12-05-84$ $421908095353701 \quad 12-05-84$ $423033095250501 \quad 05-23-85$ $420432090401201 \quad 12-20-84$

$414251092541701 \quad 09-24-85$ 420009091084901 07-19-85 $420102091214101 \quad 07-18-85$ $420631091172001 \quad 07-17-85$ 420747091105801 07-17-85

421420091142001 07-17-85 $412809092142001 \quad 12-18-84$ $425426094050301 \quad 05-31-85$ $430340094252702 \quad 05-31-85$ 431154094130701 05-31-85

$431737094125601 \quad 05-31-85$ $403804091174001 \quad 05-21-85$ $403748091174301 \quad 05-21-85$ $410557091023701 \quad 07-09-85$ $\begin{array}{lll}410557091023701 & 07-09-85 \\ 411056091111501 & 04-10-85\end{array}$

\begin{tabular}{|c|c|c|}
\hline $\begin{array}{l}\text { SODIUM, } \\
\text { DIS- } \\
\text { SOLVED } \\
\text { (MG/L } \\
\text { AS NA) } \\
(00930)\end{array}$ & $\begin{array}{c}\text { POTAS- } \\
\text { SIUM, } \\
\text { DIS- } \\
\text { SOLVED } \\
\text { (MG/L } \\
\text { AS K) } \\
(00935)\end{array}$ & $\begin{array}{c}\text { ALRA- } \\
\text { LIN ITY } \\
\text { LAB } \\
\text { (MG/L } \\
\text { AS } \\
\text { CACO3) } \\
(90410)\end{array}$ \\
\hline
\end{tabular}

$\begin{array}{lc}\text { CHLO- } & \\ \text { RIDE, } & \text { SULEATE } \\ \text { DIS- } & \text { DIS- } \\ \text { SOLVED } & \text { SOLVED } \\ \text { (MG/L } & (\text { MG/L } \\ \text { AS CL) } & \text { AS SO4) } \\ (00940) & (00945)\end{array}$

RIDE, DIS-

DIS- SOLVED

SOLVED (MG/L

(MG/L AS

AS F) SIO2)

$\begin{array}{llllll} & (00930)(00935) \quad(90410) & (00940) \quad(00945)\end{array}$

(00950) (00955)

$\begin{array}{ccc}7.2 & 1.6 & 188 \\ 10 & 3.3 & 318 \\ 5.6 & 2.5 & 304 \\ 14 & 1.3 & 368 \\ 6.6 & 1.5 & 209 \\ 16 & 5.3 & 354\end{array}$

9.5
11.5
9.5
0.5
9.0
16

48
35
68
3.1
21

$0.3 \quad 13$

$\begin{array}{ll}0.9 & 12 \\ 0.2 & 28\end{array}$

$0.4 \quad 21$

$0.15 \quad 21$

$16 \quad 5.3 \quad 354$

$3.3 \quad 320$

$4.6 \quad 433$

2.5338

$3.5 \quad 347$

1.1267

3.8216

$3.3 \quad 343$

$4 \quad 136$

$\begin{array}{lll}5.7 & 2.4 & 136\end{array}$

$\begin{array}{ll}1.9 & 314 \\ 2.5 & 300\end{array}$

$\begin{array}{rrr}7.3 & 2.5 & 300 \\ 2 & 3.2 & 345\end{array}$

$54 \quad 15^{.2} 335$

$12 \quad 5.4 \quad 370$

$3.3 \quad 419$

$\begin{array}{ll}3.3 & 419 \\ 1.4 & 348\end{array}$

$4.4 \quad 411$

16
32

4.0

86.5

51

0.4529

0.4

$0.4 \quad 24$

$0.5 \quad 29$

$<0.5 \quad 14$

$9.0 \quad 38$

$1.0 \quad 330$

$\begin{array}{lr}8.5 & 50 \\ 15 & 130\end{array}$

$18 \quad 140$

$2.0 \quad 10$

$\begin{array}{ll}5.0 & 22 \\ 1.0 & 1.1\end{array}$

6.5290

10

2.5

52

$5.0 \quad 11$

$\begin{array}{ll}2.0 & 160 \\ 5.5 & 140\end{array}$

0.418

$0.35 \quad 17$

$1.5 \quad 12$

$\begin{array}{ll}0.45 & 12 \\ 0.2 & 9.0\end{array}$

0.28 .6

0.457 .2

$0.3 \quad 5.8$

$\begin{array}{ll}2.2 & 11 \\ 2.5 & 7.4\end{array}$

$0.25 \quad 35$

$1.4 \quad 11$

$\begin{array}{ll}0.3 & 31 \\ 0.4 & 24\end{array}$

$0.85 \quad 9.2$

$\begin{array}{llll}2.0 & 8.7 & 0.7 & 18\end{array}$

2.5227

18

2.

261

$3.3 \quad 397$

1.4316

1.4351

$4.7 \quad 363$

$5.8 \quad 362$

$4.0 \quad 313$

160

190
220

21

19235

$1.5 \quad 0.9 \quad 232$

$4.3 \quad 1.7 \quad 206$

$11 \quad 2.6 \quad 275$

$\begin{array}{ccc}6.1 & 3.4 & 263 \\ 73 & 2.9 & 433\end{array}$

$18, \quad 5.1 \quad 378$

$11 \quad 0.6 \quad 254$

$30 \quad 2.4 \quad 302$

$21.5 \quad 2.4 \quad 306$

$17 \quad 1.8 \quad 304$

3322.3205

$\begin{array}{lll}8.8 & 1.0 & 277\end{array}$

$\begin{array}{rll}4.7 & 0.2 & 189\end{array}$

$\begin{array}{lll}24 & 2.7 & 331 \\ 17 & 2.9 & 315\end{array}$

$4.4 \quad 0.5 \quad 265$

$\begin{array}{lll}15 & 2.3 & 262\end{array}$

$3.7 \quad 357$

$\begin{array}{lll}76 & 4.9 & 353 \\ 40 & 7.2 & 368\end{array}$

$\begin{array}{lll}70 & 6.7 & 311\end{array}$

$\begin{array}{rrr}8.0 & 3.0 & 226 \\ 11 & 2.4 & 347\end{array}$

$\begin{array}{rrr}11 & 2.4 & 347 \\ 8.1 & 1.1 & 219\end{array}$

$\begin{array}{lll}8.1 & 1.1 & 219 \\ 5.6 & 1.6 & 152\end{array}$
12

50

$130^{\circ}$

22

29

68

63

1.0

2.0

16

$\begin{array}{rr}16 & 61 \\ 18 & 320\end{array}$

$3.5 \quad 46$

16

80

6.0

28

36

36
40.5
34

34.5

$<0.5$

6.5
9.0

1.0

2.5
2.0

5.0

3.5

3.0

0.5
3.5
$0.3 \quad 27$

$0.15 \quad 18$

0.218

0.216

0.3

1.5

$\begin{array}{ll}0.5 & 10 \\ 0.6 & 7.3\end{array}$

1.47 .4

0.9510

$1.4 \quad 11$

$0.5 \quad 11$

$0.8 \quad 13$

$0.35 \quad 22$

$\begin{array}{ll}0.4 & 23 \\ 0.3 & 30\end{array}$

0.2524

$0.5 \quad 19$

$\begin{array}{ll}4.6 & 28 \\ 0.3 & 27\end{array}$

$0.3 \quad 8.9$

0.323

$<0.2 \quad 22$

$0.25 \quad 15$

0.2514

0.214

$0.1 \quad 14$

$0.35 \quad 23$

$0.65 \quad 7.3$

0.5511

0.211

$\begin{array}{ll}1.5 & 18 \\ 0.1 & 22\end{array}$
0.413

0.215 


\begin{tabular}{|c|c|c|c|c|c|c|c|c|}
\hline TATION NUMBER & DATE & $\begin{array}{l}\text { SOLIDS, } \\
\text { RESIDUE } \\
\text { AT } 105 \\
\text { DEG. C, } \\
\text { DIS- } \\
\text { SOLVED } \\
\text { (MG/L) } \\
(00515)\end{array}$ & $\begin{array}{c}\text { NITRO- } \\
\text { GEN, } \\
\text { NO2+NO3 } \\
\text { DIS- } \\
\text { SOLVED } \\
\text { (MG/L } \\
\text { AS N) } \\
(00631)\end{array}$ & $\begin{array}{c}\text { NITRO- } \\
\text { GEN, } \\
\text { AMMONIA } \\
\text { DIS- } \\
\text { SOLVED } \\
\text { (MG/L } \\
\text { AS N) } \\
(00608)\end{array}$ & $\begin{array}{l}\text { PHOS- } \\
\text { PHORUS, } \\
\text { ORTHO, } \\
\text { DIS- } \\
\text { SOLVED } \\
\text { (MG/L } \\
\text { AS P) } \\
(00671)\end{array}$ & $\begin{array}{c}\text { IRON, } \\
\text { DIS- } \\
\text { SOLVED } \\
\text { (UG/L } \\
\text { AS FE) } \\
\text { (01046) }\end{array}$ & $\begin{array}{l}\text { MANGA- } \\
\text { NESE, } \\
\text { DIS- } \\
\text { SOLVED } \\
\text { (UG/L } \\
\text { AS MN) } \\
(01056)\end{array}$ & $\begin{array}{c}\text { ARSENIC } \\
\text { DIS- } \\
\text { SOLVED } \\
\text { (DG/L } \\
\text { AS AS) } \\
(01000)\end{array}$ \\
\hline $\begin{array}{l}430741092540601 \\
430836093001701 \\
424312093132101 \\
424537093220502 \\
425342093133701\end{array}$ & $\begin{array}{l}08-06-85 \\
08-06-85 \\
07-09-85 \\
07-10-85 \\
07-10-85\end{array}$ & $\begin{array}{l}289 \\
352 \\
445 \\
378 \\
291\end{array}$ & $\begin{array}{l}0.09 \\
0.09 \\
0.09 \\
0.09 \\
1.82\end{array}$ & $\begin{array}{c}<0.01 \\
0.16 \\
-- \\
--\end{array}$ & $\begin{array}{l}0.02 \\
0.02 \\
-- \\
--\end{array}$ & $\begin{array}{r}190 \\
630 \\
1100 \\
2000 \\
10\end{array}$ & $\begin{array}{l}<10 \\
<10 \\
430 \\
120 \\
110\end{array}$ & $\begin{array}{l}<10 \\
<10 \\
<10 \\
<10 \\
<10\end{array}$ \\
\hline $\begin{array}{l}403604095394401 \\
405225095335001 \\
404224095310601 \\
415527094114901 \\
420047094223901\end{array}$ & $\begin{array}{l}08-14-85 \\
08-14-85 \\
08-21-85 \\
08-13-85 \\
08-13-85\end{array}$ & $\begin{array}{l}483 \\
503 \\
380 \\
434 \\
557\end{array}$ & $\begin{aligned}<0.02 \\
0.47 \\
<0.02 \\
<0.02 \\
<0.02\end{aligned}$ & $\begin{array}{l}=- \\
=- \\
=\end{array}$ & $\begin{array}{l}=- \\
=- \\
=-\end{array}$ & $\begin{array}{r}6900 \\
1200 \\
750 \\
2600 \\
6400\end{array}$ & $\begin{array}{l}470 \\
220 \\
270 \\
400 \\
100\end{array}$ & $\begin{array}{l}<10 \\
<10 \\
<10 \\
<10 \\
<10\end{array}$ \\
\hline $\begin{array}{l}420104094324301 \\
421336092524401 \\
421856092355101 \\
421327092492201 \\
414035094302501\end{array}$ & $\begin{array}{l}08-13-85 \\
11-13-85 \\
11-13-85 \\
11-13-85 \\
05-21-85\end{array}$ & $\begin{array}{l}376 \\
365 \\
700 \\
396 \\
373\end{array}$ & $\begin{array}{r}<0.02 \\
5.77 \\
<0.02 \\
0.20 \\
6.88\end{array}$ & $\begin{array}{l}-- \\
\overline{-} \\
\overline{0} \\
<0.01\end{array}$ & $\begin{array}{l}-- \\
\overline{-} \\
\overline{0.09}\end{array}$ & $\begin{array}{r}3700 \\
<10 \\
530 \\
280 \\
70\end{array}$ & $\begin{array}{r}150 \\
<10 \\
40 \\
250 \\
290\end{array}$ & $\begin{array}{l}<10 \\
<10 \\
<10 \\
<10 \\
<10\end{array}$ \\
\hline $\begin{array}{l}414035094302502 \\
414624094211201 \\
415034094254801 \\
421417093360701 \\
421724093474101\end{array}$ & $\begin{array}{l}05-21-85 \\
05-21-85 \\
05-21-85 \\
06-04-85 \\
06-04-85\end{array}$ & $\begin{array}{l}401 \\
260 \\
284 \\
344 \\
718\end{array}$ & $\begin{array}{l}9.32 \\
1.55 \\
2.22 \\
0.04 \\
0.04\end{array}$ & $\begin{array}{l}0.03 \\
0.04 \\
0.16 \\
0.23 \\
1.30\end{array}$ & $\begin{array}{r}0.08 \\
0.05 \\
0.02 \\
<0.01 \\
0.01\end{array}$ & $\begin{array}{r}80 \\
210 \\
80 \\
80 \\
490\end{array}$ & $\begin{array}{r}240 \\
800 \\
1400 \\
<10 \\
<10\end{array}$ & $\begin{array}{l}<10 \\
<10 \\
<10 \\
<10 \\
<10\end{array}$ \\
\hline $\begin{array}{l}421828093381501 \\
422904093324201 \\
425528093364501 \\
425936093572401 \\
430015093360501\end{array}$ & $\begin{array}{l}06-04-85 \\
06-04-85 \\
06-04-85 \\
06-04-85 \\
06-04-85\end{array}$ & $\begin{array}{l}486 \\
416 \\
378 \\
654 \\
532\end{array}$ & $\begin{array}{l}<0.02 \\
0.04 \\
0.04 \\
0.07 \\
0.04\end{array}$ & $\begin{array}{l}0.58 \\
0.44 \\
1.10 \\
0.57 \\
0.77\end{array}$ & $\begin{array}{l}0.10 \\
0.01 \\
0.05 \\
0.04 \\
0.01\end{array}$ & $\begin{array}{r}4800 \\
90 \\
2400 \\
1500 \\
1800\end{array}$ & $\begin{array}{r}170 \\
<10 \\
<10 \\
140 \\
60\end{array}$ & $\begin{array}{r}<10 \\
<10 \\
10 \\
<10 \\
<10\end{array}$ \\
\hline $\begin{array}{l}430627093361301 \\
430539093482201 \\
421455093034601 \\
421658093101101 \\
421544093002201\end{array}$ & $\begin{array}{l}06-04-85 \\
06-04-85 \\
06-27-85 \\
06-26-85 \\
11-13-85\end{array}$ & $\begin{array}{l}373 \\
366 \\
436 \\
220 \\
384\end{array}$ & $\begin{array}{r}0.04 \\
0.04 \\
7.77 \\
0.11 \\
<0.02\end{array}$ & $\begin{array}{l}0.22 \\
0.34 \\
=- \\
--\end{array}$ & $\begin{array}{l}0.01 \\
0.05 \\
-- \\
--\end{array}$ & $\begin{array}{r}110 \\
1100 \\
20 \\
360 \\
570\end{array}$ & $\begin{array}{r}30 \\
160 \\
10 \\
<10 \\
140\end{array}$ & $\begin{array}{l}<10 \\
<10 \\
<10 \\
<10 \\
<10\end{array}$ \\
\hline $\begin{array}{l}422453093035001 \\
423323093034701 \\
415003095552401 \\
405810091330511 \\
410740091260001\end{array}$ & $\begin{array}{l}06-26-85 \\
07-09-85 \\
02-08-85 \\
07-11-85 \\
06-27-85\end{array}$ & $\begin{array}{r}430 \\
674 \\
391 \\
1280 \\
661\end{array}$ & $\begin{array}{l}2.11 \\
0.11 \\
0.22 \\
0.09 \\
0.20\end{array}$ & $\begin{array}{l}=- \\
\overline{--} \\
\overline{1.30}\end{array}$ & $\begin{array}{c}-- \\
\overline{-} \\
<0.01\end{array}$ & $\begin{array}{r}30 \\
4000 \\
<10 \\
190 \\
960\end{array}$ & $\begin{array}{r}10 \\
610 \\
<10 \\
<10 \\
20\end{array}$ & $\begin{array}{l}<10 \\
<10 \\
<10 \\
<10 \\
<10\end{array}$ \\
\hline $\begin{array}{l}410749091324001 \\
410749091324101 \\
410851091394401 \\
432257092065701 \\
432650092170201\end{array}$ & $\begin{array}{l}06-27-85 \\
06-27-85 \\
06-28-85 \\
08-07-85 \\
08-07-85\end{array}$ & $\begin{array}{r}530 \\
1150 \\
1160 \\
236 \\
206\end{array}$ & $\begin{array}{l}0.36 \\
0.16 \\
0.22 \\
0.02 \\
0.30\end{array}$ & $\begin{array}{c}-- \\
-- \\
\angle 0.01 \\
0.27\end{array}$ & $\begin{array}{l}-- \\
-- \\
0.01 \\
0.01\end{array}$ & $\begin{array}{r}<10 \\
3600 \\
1900 \\
190 \\
40\end{array}$ & $\begin{array}{r}10 \\
60 \\
20 \\
<10 \\
30\end{array}$ & $\begin{array}{l}<10 \\
<10 \\
<10 \\
<10 \\
<10\end{array}$ \\
\hline $\begin{array}{l}432923092212501 \\
424308094132601 \\
423911094233402 \\
424836094030101 \\
424548094171901\end{array}$ & $\begin{array}{l}08-07-85 \\
05-30-85 \\
05-30-85 \\
05-30-85 \\
05-30-85\end{array}$ & $\begin{array}{l}289 \\
410 \\
901 \\
492 \\
397\end{array}$ & $\begin{array}{l}0.09 \\
4.66 \\
0.09 \\
0.11 \\
0.82\end{array}$ & $\begin{array}{r}1.10 \\
<0.01 \\
0.94 \\
0.75 \\
<0.01\end{array}$ & $\begin{array}{l}0.04 \\
0.06 \\
0.08 \\
0.05 \\
0.04\end{array}$ & $\begin{array}{r}1400 \\
<10 \\
2300 \\
1200 \\
<10\end{array}$ & $\begin{array}{l}<10 \\
<10 \\
570 \\
150 \\
200\end{array}$ & $\begin{array}{l}<10 \\
<10 \\
<10 \\
<10 \\
<10\end{array}$ \\
\hline $\begin{array}{l}422018095205101 \\
422106095280201 \\
421908095353701 \\
423033095250501 \\
420432090401201\end{array}$ & $\begin{array}{l}12-05-84 \\
12-05-84 \\
12-05-84 \\
05-23-85 \\
12-20-84\end{array}$ & $\begin{array}{l}396 \\
644 \\
416 \\
649 \\
447\end{array}$ & $\begin{array}{l}4.90 \\
5.80 \\
9.50 \\
9.00 \\
1.29\end{array}$ & $\begin{array}{l}0.02 \\
-- \\
0.265 \\
--\end{array}$ & $\begin{array}{l}0.07 \\
-- \\
-0.02 \\
--\end{array}$ & $\begin{array}{r}<10 \\
10 \\
10 \\
<10 \\
70\end{array}$ & $\begin{array}{r}10 \\
<10 \\
<10 \\
80 \\
<10\end{array}$ & $\begin{array}{l}<10 \\
<10 \\
<10 \\
<10 \\
<10\end{array}$ \\
\hline $\begin{array}{l}414251092541701 \\
420009091084901 \\
420102091214101 \\
420631091172001 \\
420747091105801\end{array}$ & $\begin{array}{l}09-24-85 \\
07-19-85 \\
07-18-85 \\
07-17-85 \\
07-17-85\end{array}$ & $\begin{array}{l}594 \\
294 \\
179 \\
535 \\
342\end{array}$ & $\begin{array}{l}6.80 \\
0.07 \\
0.05 \\
4.22 \\
0.04\end{array}$ & $\begin{array}{l}0.06 \\
0.06 \\
0.06 \\
0.25\end{array}$ & $\begin{array}{c}0.05 \\
-- \\
0.04 \\
<0.01 \\
--\end{array}$ & $\begin{array}{r}230 \\
140 \\
740 \\
<10 \\
1100\end{array}$ & $\begin{array}{r}140 \\
90 \\
<10 \\
<10 \\
<10\end{array}$ & $\begin{array}{l}<10 \\
<10 \\
<10 \\
<10 \\
<10\end{array}$ \\
\hline $\begin{array}{l}421420091142001 \\
412809092142001 \\
425426094050301 \\
430340094252702 \\
431154094130701\end{array}$ & $\begin{array}{l}07-17-85 \\
12-18-84 \\
05-31-85 \\
05-31-85 \\
05-31-85\end{array}$ & $\begin{array}{l}318 \\
359 \\
421 \\
933 \\
536\end{array}$ & $\begin{array}{l}1.69 \\
0.04 \\
0.24 \\
0.04 \\
0.04\end{array}$ & $\begin{array}{l}-- \\
-- \\
0.27 \\
0.87 \\
0.86\end{array}$ & $\begin{array}{l}-- \\
\overline{0.07} \\
0.07 \\
0.06\end{array}$ & $\begin{array}{r}<10 \\
2400 \\
20 \\
1800 \\
850\end{array}$ & $\begin{array}{r}<10 \\
160 \\
220 \\
80 \\
20\end{array}$ & $\begin{array}{l}<10 \\
<10 \\
<10 \\
<10 \\
<10\end{array}$ \\
\hline $\begin{array}{l}431737094125601 \\
403804091174001 \\
403748091174301 \\
410557091023701 \\
411056091111501\end{array}$ & $\begin{array}{l}05-31-85 \\
05-21-85 \\
05-21-85 \\
07-09-85 \\
04-10-85\end{array}$ & $\begin{array}{l}305 \\
401 \\
234 \\
191\end{array}$ & $\begin{array}{l}0.04 \\
0.11 \\
0.09 \\
0.07 \\
<0.02\end{array}$ & $\begin{array}{l}0.99 \\
2.00 \\
1.20 \\
-.18 \\
0.18\end{array}$ & $\begin{array}{l}0.07 \\
0.85 \\
0.14 \\
-- \\
0.01\end{array}$ & $\begin{array}{r}890 \\
5700 \\
4 \\
2100 \\
1200\end{array}$ & $\begin{array}{r}20 \\
1700 \\
350 \\
160 \\
200\end{array}$ & $\begin{array}{l}<10 \\
<10 \\
<10 \\
<10 \\
<10\end{array}$ \\
\hline
\end{tabular}




\begin{tabular}{|c|c|c|c|c|c|c|c|c|}
\hline STATION NUMBER & DATE & $\begin{array}{l}\text { BARIUM, } \\
\text { DIS- } \\
\text { SOLVED } \\
\text { (UG/L } \\
\text { AS BA) } \\
(01005)\end{array}$ & $\begin{array}{c}\text { CADMIUM } \\
\text { DIS- } \\
\text { SOLVED } \\
\text { (UG/L } \\
\text { AS CD) } \\
\text { (01025) }\end{array}$ & $\begin{array}{l}\text { CHRO- } \\
\text { MIUM, } \\
\text { DIS- } \\
\text { SOLVED } \\
\text { (UG/L } \\
\text { AS CR) } \\
(01030)\end{array}$ & $\begin{array}{l}\text { COPPER, } \\
\text { DIS- } \\
\text { SOLVED } \\
\text { (UG/L } \\
\text { AS CU) } \\
(01040)\end{array}$ & $\begin{array}{l}\text { LEAD, } \\
\text { DIS- } \\
\text { SOLVED } \\
\text { (UG/L } \\
\text { AS PB) } \\
\text { (01049) }\end{array}$ & $\begin{array}{c}\text { MERCURY } \\
\text { DIS- } \\
\text { SOLVED } \\
\text { (UG/L } \\
\text { AS HG) } \\
(71890)\end{array}$ & $\begin{array}{l}\text { SELE- } \\
\text { NIUM, } \\
\text { DIS- } \\
\text { SOLVED } \\
\text { (UG/L } \\
\text { AS SE) } \\
\text { (01145) }\end{array}$ \\
\hline $\begin{array}{l}430741092540601 \\
430836093001701 \\
424312093132101 \\
424537093220502 \\
425342093133701\end{array}$ & $\begin{array}{l}08-06-85 \\
08-06-85 \\
07-09-85 \\
07-10-85 \\
07-10-85\end{array}$ & $\begin{array}{r}300 \\
300 \\
300 \\
400 \\
<100\end{array}$ & $\begin{array}{l}<1 \\
<1 \\
<1 \\
<1\end{array}$ & $\begin{array}{l}<10 \\
<10 \\
<10 \\
<10 \\
<10\end{array}$ & $\begin{array}{r}20 \\
<10 \\
40 \\
10 \\
20\end{array}$ & $\begin{array}{l}<10 \\
<10 \\
<10 \\
<10 \\
<10\end{array}$ & $\begin{array}{l}<1.0 \\
<1.0 \\
<1.0 \\
<1.0 \\
<1.0\end{array}$ & $\begin{array}{l}<10 \\
<10 \\
<10 \\
<10 \\
<10\end{array}$ \\
\hline $\begin{array}{l}403604095394401 \\
40522509535001 \\
404224095310601 \\
415527094114901 \\
420047094223901\end{array}$ & $\begin{array}{l}08-14-85 \\
08-14-85 \\
08-21-85 \\
08-13-85 \\
08-13-85\end{array}$ & $\begin{array}{l}300 \\
200 \\
100 \\
500 \\
500\end{array}$ & $\begin{array}{l}<1 \\
<1 \\
<1 \\
<1 \\
<1\end{array}$ & $\begin{array}{l}<10 \\
<10 \\
<10 \\
<10 \\
<10\end{array}$ & $\begin{array}{r}20 \\
20 \\
<10 \\
<10 \\
30\end{array}$ & $\begin{array}{l}<10 \\
<10 \\
<10 \\
<10 \\
<10\end{array}$ & $\begin{array}{l}<1.0 \\
<1.0 \\
<1.0 \\
<1.0 \\
<1.0\end{array}$ & $\begin{array}{l}<10 \\
<10 \\
<10 \\
<10 \\
<10\end{array}$ \\
\hline $\begin{array}{l}420104094324301 \\
421336092524401 \\
421856092355101 \\
421327092492201 \\
414035094302501\end{array}$ & $\begin{array}{l}08-13-85 \\
11-13-85 \\
11-13-85 \\
11-13-85 \\
05-21-85\end{array}$ & $\begin{array}{r}300 \\
200 \\
<100 \\
200 \\
100\end{array}$ & $\begin{array}{l}<1 \\
<1 \\
<1 \\
<1 \\
<1\end{array}$ & $\begin{array}{l}<10 \\
<10 \\
<10 \\
<10 \\
<10\end{array}$ & $\begin{array}{l}10 \\
10 \\
20 \\
10 \\
10\end{array}$ & $\begin{array}{l}<10 \\
<10 \\
<10 \\
<10 \\
<10\end{array}$ & $\begin{array}{l}<1.0 \\
<1.0 \\
<1.0 \\
<1.0 \\
<1.0\end{array}$ & $\begin{array}{l}<10 \\
<10 \\
<10 \\
<10 \\
<10\end{array}$ \\
\hline $\begin{array}{l}414035094302502 \\
414624094211201 \\
415034094254801 \\
421417093360701 \\
421724093474101\end{array}$ & $\begin{array}{l}05-21-85 \\
05-21-85 \\
05-21-85 \\
06-04-85 \\
06-04-85\end{array}$ & $\begin{array}{r}<100 \\
600 \\
200 \\
1600 \\
100\end{array}$ & $\begin{array}{l}<1 \\
<1 \\
<1 \\
<1 \\
<1\end{array}$ & $\begin{array}{l}<10 \\
<10 \\
<10 \\
<10 \\
<10\end{array}$ & $\begin{array}{l}30 \\
10 \\
20 \\
10 \\
10\end{array}$ & $\begin{array}{l}<10 \\
<10 \\
<10 \\
<10 \\
<10\end{array}$ & $\begin{array}{l}<1.0 \\
<1.0 \\
<1.0 \\
<1.0 \\
<1.0\end{array}$ & $\begin{array}{l}<10 \\
<10 \\
<10 \\
<10 \\
<10\end{array}$ \\
\hline $\begin{array}{l}421828093381501 \\
422904093324201 \\
425528093364501 \\
425936093572401 \\
430015093360501\end{array}$ & $\begin{array}{l}06-04-85 \\
06-04-85 \\
06-04-85 \\
06-04-85 \\
06-04-85\end{array}$ & $\begin{array}{r}400 \\
200 \\
300 \\
<100 \\
<100\end{array}$ & $\begin{array}{l}<1 \\
<1 \\
<1 \\
<1 \\
<1\end{array}$ & $\begin{array}{l}<10 \\
<10 \\
<10 \\
<10 \\
<10\end{array}$ & $\begin{array}{l}10 \\
10 \\
10 \\
10 \\
10\end{array}$ & $\begin{array}{l}<10 \\
<10 \\
<10 \\
<10 \\
<10\end{array}$ & $\begin{array}{l}<1.0 \\
<1.0 \\
<1.0 \\
<1.0 \\
<1.0\end{array}$ & $\begin{array}{l}<10 \\
<10 \\
<10 \\
<10 \\
<10\end{array}$ \\
\hline $\begin{array}{l}430627093361301 \\
430539093482201 \\
421455093034601 \\
421658093101101 \\
421544093002201\end{array}$ & $\begin{array}{l}06-04-85 \\
06-04-85 \\
06-27-85 \\
06-26-8 ! \\
11-13-8 !\end{array}$ & $\begin{array}{r}200 \\
100 \\
<100 \\
300 \\
<100\end{array}$ & $\begin{array}{l}<1 \\
<1 \\
<1 \\
<1 \\
<1\end{array}$ & $\begin{array}{l}<10 \\
<10 \\
<10 \\
<10 \\
<10\end{array}$ & $\begin{aligned} & 10 \\
&<10 \\
&<10 \\
&<10 \\
&<10\end{aligned}$ & $\begin{array}{l}<10 \\
<10 \\
<10 \\
<10 \\
<10\end{array}$ & $\begin{array}{l}<1.0 \\
<1.0 \\
<1.0 \\
<1.0 \\
<1.0\end{array}$ & $\begin{array}{l}<10 \\
<10 \\
<10 \\
<10 \\
<10\end{array}$ \\
\hline $\begin{array}{l}422453093035001 \\
423323093034701 \\
415003095552401 \\
405810091330511 \\
410740091260001\end{array}$ & $\begin{array}{l}06-26-85 \\
07-09-85 \\
02-08-85 \\
07-11-85 \\
06-27-85\end{array}$ & $\begin{array}{r}<100 \\
100 \\
200 \\
400 \\
100\end{array}$ & $\begin{array}{r}<1 \\
<1 \\
2 \\
<1 \\
<1\end{array}$ & $\begin{array}{l}<10 \\
<10 \\
<10 \\
<10 \\
<10\end{array}$ & $\begin{array}{r}<10 \\
60 \\
20 \\
20 \\
<10\end{array}$ & $\begin{array}{l}<10 \\
<10 \\
<10 \\
<10 \\
<10\end{array}$ & $\begin{array}{l}<1.0 \\
<1.0 \\
<1.0 \\
<1.0 \\
<1.0\end{array}$ & $\begin{array}{l}<10 \\
<10 \\
<10 \\
<10 \\
<10\end{array}$ \\
\hline $\begin{array}{l}410749091324001 \\
410749091324101 \\
410851091394401 \\
432257092065701 \\
432650092170201\end{array}$ & $\begin{array}{l}06-27-85 \\
06-27-85 \\
06-28-85 \\
08-07-85 \\
08-07-85\end{array}$ & $\begin{array}{r}<100 \\
<100 \\
<100 \\
<100 \\
100\end{array}$ & $\begin{array}{l}<1 \\
<1 \\
<1 \\
<1 \\
<1\end{array}$ & $\begin{array}{l}<10 \\
<10 \\
<10 \\
<10 \\
<10\end{array}$ & $\begin{aligned} & 20 \\
&<10 \\
&<10 \\
&<10 \\
&<10\end{aligned}$ & $\begin{array}{l}<10 \\
<10 \\
<10 \\
<10 \\
<10\end{array}$ & $\begin{array}{l}<1.0 \\
<1.0 \\
<1.0 \\
<1.0 \\
<1.0\end{array}$ & $\begin{array}{r}10 \\
<10 \\
<10 \\
<10 \\
<10\end{array}$ \\
\hline $\begin{array}{l}432923092212501 \\
424308094132601 \\
423911094233402 \\
424836094030101 \\
424548094171901\end{array}$ & $\begin{array}{l}08-07-95 \\
05-30-85 \\
05-30-85 \\
05-30-85 \\
05-30-85\end{array}$ & $\begin{array}{r}200 \\
200 \\
<100 \\
100 \\
200\end{array}$ & $\begin{array}{l}<1 \\
<1 \\
<1 \\
<1 \\
<1\end{array}$ & $\begin{array}{l}<10 \\
<10 \\
<10 \\
<10 \\
<10\end{array}$ & $\begin{array}{r}<10 \\
40 \\
20 \\
20 \\
20\end{array}$ & $\begin{array}{l}<10 \\
<10 \\
<10 \\
<10 \\
<10\end{array}$ & $\begin{array}{l}<1.0 \\
<1.0 \\
<1.0 \\
<1.0 \\
<1.0\end{array}$ & $\begin{array}{l}<10 \\
<10 \\
<10 \\
<10 \\
<10\end{array}$ \\
\hline $\begin{array}{l}422018095205101 \\
422106095280201 \\
421908095353701 \\
423033095250501 \\
420432090401201\end{array}$ & $\begin{array}{l}12-05-84 \\
12-05-84 \\
12-05-84 \\
05-23-85 \\
12-20-84\end{array}$ & $\begin{array}{l}200 \\
300 \\
400 \\
100 \\
200\end{array}$ & $\begin{array}{l}<1 \\
<1 \\
<1 \\
<1\end{array}$ & $\begin{array}{l}<10 \\
<10 \\
<10 \\
<10 \\
<10\end{array}$ & $\begin{array}{r}20 \\
60 \\
20 \\
<10 \\
10\end{array}$ & $\begin{array}{l}<10 \\
<10 \\
<10 \\
<10 \\
<10\end{array}$ & $\begin{array}{l}<1.0 \\
<1.0 \\
<1.0 \\
<1.0 \\
<1.0\end{array}$ & $\begin{array}{l}<10 \\
<10 \\
<10 \\
<10 \\
<10\end{array}$ \\
\hline $\begin{array}{l}414251092541701 \\
420009091084901 \\
420102091214101 \\
420631091172001 \\
420747091105801\end{array}$ & $\begin{array}{l}09-24-85 \\
07-19-85 \\
07-18-85 \\
07-17-85 \\
07-17-85\end{array}$ & $\begin{array}{r}<100 \\
200 \\
<100 \\
<100 \\
<100\end{array}$ & $\begin{array}{l}<1 \\
<1 \\
<1 \\
<1 \\
<1\end{array}$ & $\begin{array}{l}<10 \\
<10 \\
<10 \\
<10 \\
<10\end{array}$ & $\begin{array}{l}<10 \\
<10 \\
<10 \\
<10 \\
<10\end{array}$ & $\begin{array}{l}<10 \\
<10 \\
<10 \\
<10 \\
<10\end{array}$ & $\begin{array}{l}<1.0 \\
<1.0 \\
<1.0 \\
<1.0 \\
<1.0\end{array}$ & $\begin{array}{l}<10 \\
<10 \\
<10 \\
<10 \\
<10\end{array}$ \\
\hline $\begin{array}{l}421420091142001 \\
412809092142001 \\
425426094050301 \\
430340094252702 \\
431154094130701\end{array}$ & $\begin{array}{l}07-17-85 \\
12-18-84 \\
05-31-85 \\
05-31-85 \\
05-31-85\end{array}$ & $\begin{array}{r}200 \\
100 \\
<100 \\
<100 \\
<100\end{array}$ & $\begin{array}{l}<1 \\
<1 \\
<1 \\
<1 \\
<1\end{array}$ & $\begin{array}{l}<10 \\
<10 \\
<10 \\
<10 \\
<10\end{array}$ & $\begin{array}{r}<10 \\
<10 \\
20 \\
30 \\
30\end{array}$ & $\begin{array}{l}<10 \\
<10 \\
<10 \\
<10 \\
<10\end{array}$ & $\begin{array}{l}<1.0 \\
<1.0 \\
<1.0 \\
<1.0 \\
<1.0\end{array}$ & $\begin{array}{l}<10 \\
<10 \\
<10 \\
<10 \\
<10\end{array}$ \\
\hline $\begin{array}{l}431737094125601 \\
403804091174001 \\
403748091174301 \\
410557091023701 \\
411056091111501\end{array}$ & $\begin{array}{l}05-31-85 \\
05-21-85 \\
05-21-85 \\
07-09-85 \\
04-10-85\end{array}$ & $\begin{array}{r}<100 \\
300 \\
400 \\
<100 \\
100\end{array}$ & $\begin{array}{l}<1 \\
<1 \\
<1 \\
<1 \\
<1\end{array}$ & $\begin{array}{l}<10 \\
<10 \\
<10 \\
<10 \\
<10\end{array}$ & $\begin{array}{r}20 \\
<10 \\
<10 \\
60 \\
10\end{array}$ & $\begin{array}{l}<10 \\
<10 \\
<10 \\
<10 \\
<10\end{array}$ & $\begin{array}{l}<1.0 \\
<1.0 \\
<1.0 \\
<1.0 \\
<1.0\end{array}$ & $\begin{array}{l}<10 \\
<10 \\
<10 \\
<10 \\
<10\end{array}$ \\
\hline
\end{tabular}


STATION NUMBER DATE

430741092540601 08-06-85 $430836093001701 \quad 08-06-85$ $424312093132101 \quad 07-09-85$ $424537093220502 \quad 07-10-85$ $425342093133701 \quad 07-10-85$

403604095394401 08-14-85 $405225095335001 \quad 08-14-85$ $404224095310601 \quad 08-21-85$ $415527094114901 \quad 08-13-85$ 420047094223901 08-13-85

420104094324301 08-13-85 $421336092524401 \quad 11-13-85$ 421856092355101
421327092492201
$11-13-85$ 414035094302501 05-21-85

414035094302502 05-21-85 $414624094211201 \quad 05-21-85$ 415034094254801 05-21-85 $421417093360701 \quad 06-04-85$ 421724093474101 06-04-85

421828093381501 06-04-85 $42290409332420106-04-85$ 425528093364501 06-04-85 $425936093572401 \quad 06-04-85$ 430015093360501 06-04-85

430627093361301 06-04-85 $430539093482201 \quad 06-04-85$ 421455093034601 06-27-85 $421658093101101 \quad 06-26-85$ 421544093002201 11-13-85

$42245309303500106-26-85$ $423323093034701 \quad 07-09-85$ $415003095552401 \quad 02-08-85$ $405810091330511 \quad 07-11-85$ $410740091260001 \quad 06-27-85$

410749091324001 06-27-85 $410749091324101 \quad 06-27-85$ $410851091394401 \quad 06-28-85$ $432257092065701 \quad 08-07-85$ 432650092170201 08-07-85

432923092212501 08-07-85 $424308094132601 \quad 05-30-85$ 423911094233402 05-30-85 424836094030101 05-30-85 424548094171901 05-30-85

422018095205101 12-05-84 $422106095280201 \quad 12-05-84$ $421908095353701 \quad 12-05-84$ 423033095250501 05-23-85 420432090401201 12-20-84

$414251092541701 \quad 09-24-85$ $420009091084901 \quad 07-19-85$ $420102091214101 \quad 07-18-85$ $42010209121410107-18-85$ $\begin{array}{lll}420631091172001 & 07-17-85 \\ 420747091105801 & 07-17-85\end{array}$

421420091142001 07-17-85 $412809092142001 \quad 12-18-84$

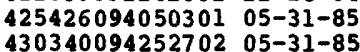
431154094130701 05-31-85

$431737094125601 \quad 05-31-85$ $403804091174001 \quad 05-21-85$ $403748091174301 \quad 05-21-85$ $410557091023701 \quad 07-09-85$ $41105609111150104-10-85$
GROS

GROSS

BETA,

DIS-

DIS-

SOLVED

( $\mathrm{PCI} / \mathrm{L}$

DIS-

DOLVED

DIS-

SOLVED

U-NAT)

(01515)

(PCI/L

AS

$C s-137)$
$(03515)$

$(01090)$

1.2
0.5
1.3
6.1
0.9$$
\begin{array}{lll}
3.0 & -- & -- \\
2.0 & -- & - \\
2.0 & -- & - \\
5.0 & 3.6 & 0.8 \\
3.0 & -- & -- \\
4.0 & - & -- \\
3.0 & 0.8 & <0.6 \\
4.0 & - & -- \\
9.0 & 4.0 & 1.3 \\
1.0 & 3.4 & 1.5
\end{array}
$$

$<10<10$

$<10$

$<10$

$<10$

$<10$

$<10$

$<10$

$<10$

$<10$

$<10$

$<10$

$<10$

$<10$

$<10$

$<10$

$<10$

$<10$

$<10$

$<10$

$<10$

$<10$

$<10$

$<10$

$<10$

$<10$
$<10$
$<10$

$<10$

$<10$

$<10$

$<10$

$<10$

$<10$

$<10$

$<10$

$<10$

$<10$

$<10$
$<10$

$<10$
10
$<10$

$<10$

$<10$

$<10$

10
20

20
$<10$

$<10$

$<10$

$<10$

$<10$

$<10$

0.4
8.4
0.4
4.6
4.2

7.2

$<0.2$

10.

2.0

4.4

1.6

4.7

9.6
2.4

11.

7.0
4.0
8.0
4.0

4.0

2.0
6.0

6.0
4.0

8.0

30

$<0.2$

4.0
1.5

1.5
3.5

3.5

7.0

2.0
$<0.5$

3.0

$<0.2$

20

$<0.2$

1.0

3.1

1.2

$<0.2$

0.6

29
4.7

II

4.0

$<0.5$

5.0

1

1.0 -- --

$<0.5 \quad=-$

$<10$

130

$<10$

$<10$

$<10$
$<10$

64.

22

0.7

3.9

27

$\begin{array}{cc}4.7 & 1.9 \\ -- & = \\ -3.4 & 0.7\end{array}$

0.61 .1

$4.0 \quad 0.7$

$6.0 \quad 1.0$

-- $\quad-$

$2.5<0.6$

$1.2<0.6$

$\begin{array}{ll}-- & =- \\ -- & = \\ -- & = \\ -- & =- \\ -- & =- \\ 15 & 1\end{array}$

$32.0 \quad-3.1 \quad--$

$22 \quad 12.1 \quad 2.5$

$\begin{array}{lll}1.0 & -- & -- \\ 2.0 & 1.0 & <0.6\end{array}$

$<10$

1.7

2.1

13

5.0 --

$3.0 \quad 1.0<0.6$

$8.0 \quad--$

30
$<10$

$<10$

2.3

1.9

2.1

$<10$

$<10$
10

$<0.2$

$<10<10$

$<10 \quad 10$

$<10$

1.7

2.1

1.6

3.6

3.0

0.9

$<0.6$

4.0 -- --

$6.0 \quad--$

$\begin{array}{lll}1.0 & - & - \\ 1.0 & <0.1 & 0.9\end{array}$

5.0 -- -.

$<0.6 \quad-=$

$<0.6 \quad-\quad--$

$\begin{array}{rrr}<0.6 & 0.7 & <0.6 \\ 1.0 & 1.3 & 1.2\end{array}$

$<10<10$

$<10 \quad 20$

$<10<10$

$<10 \quad<10$

1.0

$0.1 \quad--\quad-$

$\begin{array}{lll}4.0 & - & - \\ 9.0 & 2.3 & 0.9\end{array}$

4.2

3.5
8.3

7.0

$\begin{array}{ll}1.4 & 2.0 \\ 3.2 & 1.8\end{array}$

$<10$

$<10<10$

$<10$

$<10$

$<30$
$<0.6$

5.0

$1.8 \quad 2$.

$\begin{array}{ll}1.3 & 2.0 \\ 1.3 & 1.6\end{array}$ 
STATION NUMBER DATE

$430741092540601 \quad 08-06-85$ $430836093001701 \quad 08-06-85$ $424312093132101 \quad 07-09-85$ 424537093220502 07-10-85 425342093133701 07-10-85

403604095394401 08-14-85 405225095335001 08-14-85 $404224095310601 \quad 08-21-85$ $41552709411490108-13-85$ 420047094223901 08-13-85

420104094324301 08-13-85 421336092524401 11-13-85 421856092355101 11-13-85 421327092492201 11-13-85 414035094302501 05-21-85

414035094302502 05-21-85 414624094211201 05-21-85 415034094254801 05-21-85 $421417093360701 \quad 06-04-85$ 421724093474101 06-04-85

421828093381501 06-04-85 422904093324201 06-04-85 425528093364501 06-04-85 425936093572401 06-04-85 430015093360501 06-04-85

430627093361301 06-04-85 430539093482201 06-04-85 $421455093034601 \quad 06-27-85$ 421658093101101 06-26-85 421544093002201 11-13-85

422453093035001 06-26-85 $423323093034701 \quad 07-09-85$ $415003095552401 \quad 02-08-85$ $40581009133051107-11-85$ $41074009126000106-27-85$

$410749091324001 \quad 06-27-85$ $410749091324101 \quad 06-27-85$ 410851091394401 06-28-85 $432257092065701 \quad 08-07-85$ 432650092170201 08-07-85

$432923092212501 \quad 08-07-85$ $424308094132601 \quad 05-30-85$ 423911094233402 05-30-85

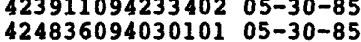
424548094171901 05-30-85

$422018095205101 \quad 12-05-84$ $422106095280201 \quad 12-05-84$ 421908095353701 12-05-84 423033095250501 05-23-85 420432090401201 12-20-84

$414251092541701 \quad 09-24-85$

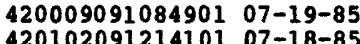
$420102091214101 \quad 07-18-85$
420631091172001
$07-17-85$

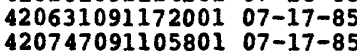

$421420091142001 \quad 07-17-85$

412809092142001 12-18-84

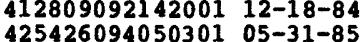

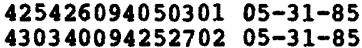
$43115409413070105-31-85$

$431737094125601 \quad 05-31-85$ $403804091174001 \quad 05-21-85$ 403748091174301 05-21-85 410557091023701 07-09-85 411056091111501 04-10-85
METRIBUZ IN

INE, AZINE

TOTAL TOTAL

(UG/L) (UG/L)

(39630) (81757)

IN

WHOLE

WATER

(UG/L)

(81408)
$-$

$-\bar{x}-\overline{0}$

$<0.1$

0.18

$<0.1$

$<0.1$

$<0.1$

$<0.1$

$<0.1$

$<0.1$

$<0.1$

$-\infty$

$<0.1$

$-<\quad<0.1$

$-$

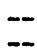

$\overline{--}$

$<0$.

$-$

$<0$

$<0.1$

$-$

$\overline{-}$

$\bar{z}$

$<0$.

0.12

$\overline{--}$

$-$

$-$

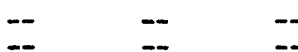

$\because \quad \bar{z} \quad \bar{z}$

$<0$.

$<0.1$

$<0.1$

$<0.1$

$<0.1$

$<0.1$

$<0.1$

$<0.1$

$<0.1$

$-$

$\overline{<0.05}$

$<0.05$

$<0.05$

$<0.05$

$<0.05$

$<0.05$

$<0.05$

$<0.1<0.05$

$--$

$--$

$<0.05$

$--$

$=$

$\overline{-}$

$-$

$<0.1$

$-$

$<0.1$

$-$

$-$

$<0.05$

$--$

$<0.05$

$-$

$-$

$\overline{-\infty}$

$-$

$\overline{-}$

$=$

$<0.1$

$<0.1$

$<0.1$

$<0.1$

$<0.1$

$<0.05$

$<0.05$

$--$

$-$

$\bar{z}$

$<0.05$

$<0.05$

$<0.05$

$<0.05$

$<0.05$

$\because$

$<0.01$

$<0.05$

$=$
$-$

ALA-
CHLOR
TOTAL
RECOVER
(UG/L)
$(77825)$

METOLA-

CHLOR FRI-

WHOLE

(UATER

(39356)

LIN

TOTAL

RECOVER

(UG/L)

-

$<0.1$

$<0.1$

$\overline{<0.1} \quad \overline{0} \quad \overline{0.05}$

$<0.1$

$<0.1$

$<0.1$

$\begin{array}{lll}<0.1 & <0.1 & <0.05 \\ <0.1 & <0.1 & <0.05\end{array}$

$<0.1<0.05$

$<0.1$

0.05

$<0.1<0.05$

$<0.1 \quad<0.05$

$<0.1<0.1<0.05$

$-$

$<0.1$

$=--$

$<0.1<0.0$

$=\quad--\quad=$

$--$

$-$

$<0.1$

$--$

$<0.1$

$\overline{-} \quad-$

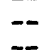

$\overline{--}$

$<0.1<0.05$

$--$

$\therefore \quad--$

$<0.1<0.05$

$\begin{array}{lll}-2 & -2 & -\end{array}$

$<0.1$

$<0.1$

$\because$

$<0.1<0.05$

$<0.1<0.05$

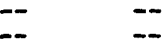

- $=$

$=\quad=\quad=$

$\because \quad=\quad \because$

$<0.1<0.1<0.05$

$<0.1<0.1<0.05$

$<0.1<0.1<0.05$

$<0.1 \quad<0.1 \quad<0.05$

$<0.1<0.1<0.05$

$=--$

$-\infty \quad \cdots$

$-$

$\overline{<0.08}$

$\overline{--}$

$=$

$<\overline{0.02}$

$<0.1$

$<0.1<0.05$

$\because \quad=$

$\because$

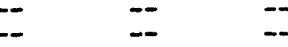

$=\quad--\quad=$

$\overline{-}$

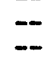

$\because$

$\overline{--}$

$--$

$=$

$\overline{<0.1}$

$<0.1$

$<0.1$

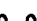

$\begin{array}{lll}<0.1 & <0.1 & <0.05\end{array}$

$<0.1 \quad<0.1 \quad<0.05$

$<0.1$

$<0.05$

$<0.05$ 


\begin{tabular}{|c|c|c|c|c|c|c|c|}
\hline STATION NUMBER & DATE & $\begin{array}{c}\text { DICAMBA } \\
\text { (MED- } \\
\text { IBEN) } \\
\text { (BAN- } \\
\text { VEL D) } \\
\text { TOTAL } \\
\text { (UG/L) } \\
(82052)\end{array}$ & $\begin{array}{c}2,4-D, \\
\text { TOTAL } \\
(U G / L) \\
(39730)\end{array}$ & $\begin{array}{c}\text { SILVEX, } \\
\text { TOTAL } \\
\text { (UG/L) } \\
(39760)\end{array}$ & $\begin{array}{l}\text { DYFO- } \\
\text { NATE } \\
\text { (UG/L) } \\
(81294)\end{array}$ & $\begin{array}{c}\text { TERBU- } \\
\text { FOS } \\
(\mathrm{UG} / \mathrm{L}) \\
(\mathbf{8 2 0 8 8 )}\end{array}$ & $\begin{array}{l}\text { PHORATE } \\
\text { OTAL } \\
(\text { UG/L) } \\
(39023)\end{array}$ \\
\hline $\begin{array}{l}430741092540601 \\
430836093001701 \\
424312093132101 \\
424537093220502 \\
425342093133701\end{array}$ & $\begin{array}{l}08-06-85 \\
08-06-85 \\
07-09-85 \\
07-10-85 \\
07-10-85\end{array}$ & $\begin{array}{l}-- \\
<0.07 \\
<0.07\end{array}$ & $\begin{array}{l}-- \\
<0.07 \\
-\overline{<0.07}\end{array}$ & $\begin{array}{l}-- \\
\overline{<0.05} \\
\overline{<0.05}\end{array}$ & $\begin{array}{l}-\bar{x} \\
\overline{<0.1} \\
\overline{<0.1}\end{array}$ & $\begin{array}{l}-- \\
\ddot{--} \\
--\end{array}$ & $\begin{array}{l}-\overline{-} \\
<0.1 \\
\overline{<0} .1\end{array}$ \\
\hline $\begin{array}{l}403604095394401 \\
405225095335001 \\
404224095310601 \\
415527094114901 \\
420047094223901\end{array}$ & $\begin{array}{l}08-14-85 \\
08-14-85 \\
08-21-85 \\
08-13-85 \\
08-13-85\end{array}$ & $\begin{array}{l}<0.07 \\
<0.07 \\
<0.07 \\
<0.07 \\
<0.07\end{array}$ & $\begin{array}{l}<0.07 \\
<0.07 \\
<0.07 \\
<0.07 \\
<0.07\end{array}$ & $\begin{array}{l}<0.05 \\
<0.05 \\
<0.05 \\
<0.05 \\
<0.05\end{array}$ & $\begin{array}{l}<0.1 \\
<0.1 \\
<0.1 \\
<0.1 \\
<0.1\end{array}$ & $\begin{array}{l}-- \\
\overline{--} \\
--\end{array}$ & $\begin{array}{l}<0.1 \\
<0.1 \\
<0.1 \\
<0.1 \\
<0.1\end{array}$ \\
\hline $\begin{array}{l}420104094324301 \\
421336092524401 \\
421856092355101 \\
421327092492201 \\
414035094302501\end{array}$ & $\begin{array}{l}08-13-85 \\
11-13-85 \\
11-13-85 \\
11-13-85 \\
05-21-85\end{array}$ & $\begin{array}{l}<0.07 \\
-- \\
-\overline{0} \\
--\end{array}$ & $\begin{array}{l}<0.07 \\
-- \\
=- \\
<0.07\end{array}$ & $\begin{array}{l}<0.05 \\
=- \\
=- \\
--\end{array}$ & $\begin{array}{l}<0.1 \\
-- \\
-\overline{<0.1} \\
--\end{array}$ & $\begin{array}{l}<0.1 \\
-- \\
-- \\
--\end{array}$ & $\begin{array}{l}<0.1 \\
=- \\
=- \\
--\end{array}$ \\
\hline $\begin{array}{l}414035094302502 \\
414624094211201 \\
415034094254801 \\
421417093360701 \\
421724093474101\end{array}$ & $\begin{array}{l}05-21-85 \\
05-21-85 \\
05-21-85 \\
06-04-85 \\
06-04-85\end{array}$ & $\begin{array}{l}-- \\
\overline{-} \\
--\end{array}$ & $\begin{array}{l}=- \\
\overline{z-} \\
=-\end{array}$ & $\begin{array}{l}-- \\
\overline{--} \\
--\end{array}$ & $\begin{array}{l}=- \\
=- \\
=-\end{array}$ & $\begin{array}{l}-- \\
=- \\
--\end{array}$ & $\begin{array}{l}-- \\
=- \\
--\end{array}$ \\
\hline $\begin{array}{l}421828093381501 \\
422904093324201 \\
425528093364501 \\
425936093572401 \\
430015093360501\end{array}$ & $\begin{array}{l}06-04-85 \\
06-04-85 \\
06-04-85 \\
06-04-85 \\
06-04-85\end{array}$ & $\begin{array}{l}<0.07 \\
\ddot{-} \\
\angle 0.07 \\
--\end{array}$ & $\begin{array}{l}<0.07 \\
-- \\
-- \\
-\infty\end{array}$ & $\begin{array}{l}<0.05 \\
-- \\
-- \\
--\end{array}$ & $\begin{array}{l}<0.1 \\
-- \\
-- \\
-\infty\end{array}$ & $\begin{array}{l}-- \\
\overline{--} \\
--\end{array}$ & $\begin{array}{l}<0.1 \\
-- \\
-\infty \\
--\end{array}$ \\
\hline $\begin{array}{l}430627093361301 \\
430539093482201 \\
421455093034601 \\
421658093101101 \\
421544093002201\end{array}$ & $\begin{array}{l}06-04-85 \\
06-04-85 \\
06-27-85 \\
06-26-85 \\
11-13-85\end{array}$ & $\begin{array}{l}=- \\
=- \\
=\end{array}$ & $\begin{array}{l}=- \\
=- \\
=-\end{array}$ & $\begin{array}{l}=- \\
=- \\
=\end{array}$ & $\begin{array}{l}=- \\
=- \\
=-\end{array}$ & $\begin{array}{l}-- \\
=- \\
--\end{array}$ & $\begin{array}{l}=- \\
\overline{--} \\
--\end{array}$ \\
\hline $\begin{array}{l}422453093035001 \\
423323093034701 \\
415003095552401 \\
405810091330511 \\
410740091260001\end{array}$ & $\begin{array}{l}06-26-85 \\
07-09-85 \\
02-08-85 \\
07-11-85 \\
06-27-85\end{array}$ & $\begin{array}{l}<0.07 \\
<0.07 \\
-- \\
--\end{array}$ & $\begin{array}{l}<0.07 \\
<0.07 \\
=- \\
=-\end{array}$ & $\begin{array}{l}<0.05 \\
<0.05 \\
-- \\
--\end{array}$ & $\begin{array}{l}<0.1 \\
<0.1 \\
-- \\
--\end{array}$ & $\begin{array}{l}-- \\
\overline{--} \\
=-\end{array}$ & $\begin{array}{l}<0.1 \\
<0.1 \\
\therefore- \\
-\end{array}$ \\
\hline $\begin{array}{l}410749091324001 \\
410749091324101 \\
410851091394401 \\
432257092065701 \\
432650092170201\end{array}$ & $\begin{array}{l}06-27-85 \\
06-27-85 \\
06-28-85 \\
08-07-85 \\
08-07-85\end{array}$ & $\begin{array}{l}-- \\
\overline{--} \\
--\end{array}$ & $\begin{array}{l}-- \\
\overline{--} \\
--\end{array}$ & $\begin{array}{l}=- \\
\overline{--} \\
--\end{array}$ & $\begin{array}{l}-- \\
-- \\
--\end{array}$ & $\begin{array}{l}-- \\
\overline{-} \\
--\end{array}$ & $\begin{array}{l}-- \\
\overline{--} \\
--\end{array}$ \\
\hline $\begin{array}{l}432923092212501 \\
424308094132601 \\
423911094233402 \\
424836094030101 \\
424548094171901\end{array}$ & $\begin{array}{l}08-07-85 \\
05-30-85 \\
05-30-85 \\
05-30-85 \\
05-30-85\end{array}$ & $\begin{array}{l}<0.07 \\
<0.07 \\
<0.07 \\
<0.07 \\
<0.07\end{array}$ & $\begin{array}{l}<0.07 \\
<0.07 \\
<0.07 \\
<0.07 \\
<0.07\end{array}$ & $\begin{array}{l}<0.05 \\
<0.05 \\
<0.05 \\
<0.05 \\
<0.05\end{array}$ & $\begin{array}{l}<0.1 \\
<0.1 \\
<0.1 \\
<0.1 \\
<0.1\end{array}$ & $\begin{array}{l}-- \\
-- \\
<0.1 \\
<0.1 \\
<0.1\end{array}$ & $\begin{array}{l}<0.1 \\
<0.1 \\
<0.1 \\
<0.1 \\
<0.1\end{array}$ \\
\hline $\begin{array}{l}422018095205101 \\
422106095280201 \\
421908095353701 \\
423033095250501 \\
420432090401201\end{array}$ & $\begin{array}{l}12-05-84 \\
12-05-84 \\
12-05-84 \\
05-23-85 \\
12-20-84\end{array}$ & $\begin{array}{l}-- \\
-- \\
\angle 0.07\end{array}$ & $\begin{array}{l}=- \\
=- \\
=- \\
<0.07\end{array}$ & $\begin{array}{l}-- \\
-- \\
-\overline{<0} \\
<0.05\end{array}$ & $\begin{array}{l}-- \\
\overline{-} \\
\overline{-0}\end{array}$ & $\begin{array}{l}-- \\
-- \\
\overline{-} \\
<0.1\end{array}$ & $\begin{array}{l}- \\
- \\
\overline{<} \\
<0.1\end{array}$ \\
\hline $\begin{array}{l}414251092541701 \\
420009091084901 \\
420102091214101 \\
420631091172001 \\
420747091105801\end{array}$ & $\begin{array}{l}09-24-85 \\
07-19-85 \\
07-18-85 \\
07-17-85 \\
07-17-85\end{array}$ & $\begin{array}{l}<0.07 \\
=- \\
=-\end{array}$ & $\begin{array}{l}<0.07 \\
=- \\
=-\end{array}$ & $\begin{array}{l}<0.05 \\
=- \\
=- \\
=-\end{array}$ & $\begin{array}{l}<0.1 \\
=- \\
=- \\
=\end{array}$ & $\begin{array}{l}=- \\
=- \\
=-\end{array}$ & $\begin{array}{l}<0.1 \\
-- \\
= \\
--\end{array}$ \\
\hline $\begin{array}{l}421420091142001 \\
412809092142001 \\
425426094050301 \\
430340094252702 \\
431154094130701\end{array}$ & $\begin{array}{l}07-17-85 \\
12-18-84 \\
05-31-85 \\
05-31-85 \\
05-31-85\end{array}$ & $\begin{array}{l}=- \\
\bar{z} \\
=\end{array}$ & $\begin{array}{l}=- \\
\bar{z} \\
=-\end{array}$ & $\begin{array}{l}=- \\
=- \\
=-\end{array}$ & $\begin{array}{l}-- \\
-- \\
--\end{array}$ & $\begin{array}{l}=- \\
=- \\
=-\end{array}$ & $=$ \\
\hline $\begin{array}{l}431737094125601 \\
403804091174001 \\
403748091174301 \\
410557091023701 \\
411056091111501\end{array}$ & $\begin{array}{l}05-31-85 \\
05-21-85 \\
05-21-85 \\
07-09-85 \\
04-10-85\end{array}$ & $\begin{array}{l}<-- \\
<0.07 \\
<0.07 \\
<0.07\end{array}$ & $\begin{array}{l}-- \\
<0.07 \\
<0.07 \\
<0.07 \\
--\end{array}$ & $\begin{array}{l}-- \\
<0.05 \\
<0.05 \\
<0.05 \\
--\end{array}$ & $\begin{array}{l}-- \\
<0.1 \\
<0.1 \\
<0.1 \\
--\end{array}$ & $\begin{array}{l}-- \\
\ddot{--} \\
--\end{array}$ & $\begin{array}{l}-- \\
<0.1 \\
<0.1 \\
<0.1 \\
--\end{array}$ \\
\hline
\end{tabular}


41164409111070107503 22DCBD $41165209121380107504 \mathrm{Wl}$ 9CDA 41153909122150107505 W3 6 AAD $43184409626350109847 \mathrm{Wl}$ 8BDB $41121309253150107418 \mathrm{~W} 13 \mathrm{CCCC}$

$41231009316060107621 W 1$ 5BCDC 41553409311150108220 0 9 CADC 41011409530000106841 W1 4CDBB 41011609546410107243 W22CACA 43133709246190109716 W07DDDD

40555909459150107136 W21DDAB $41021609511340107238 \mathrm{Wl} 4 \mathrm{CBBB}$ $41232109103480107602 W 15 A A C B$ 41232909104130107602 W1 5BAAA 41221309106360107602 W20CAAA

41342809109460107803 W1 1DBBB 42585909540320109441 W03CDDC 43104509541380109741 W33 BDDD 43170309527240109839 228ABBB 43231409532000109940 W1 4DCCC

43264609526020110039 2727DCDB 40451709524530106940 OW26 BAD 42573509427020109431 W1 $3 A C$

$42353609558350109043 \mathrm{Wl}$ 9CCBB $42430609614570109146 \mathrm{WI} 1 \mathrm{BBDC}$

42491609558120109243 \%06 BABD $42483809616100109246 \mathrm{W0} C \mathrm{CCAB}$ 42452809636200109249 W27DAAA 42494809633290109348 W31 BDDC $41341809343240307825 W 1$ OCD

41405109319090207921 W05CAAA 41440909324100108022 W1 5CBCD 41120109525280107440 W2 2AADC 41135609536080107441 W07ABBA 41183809525280107540 W1 ODAAB

41232709521540107639 W0 8CCCC 41265409537120107742 W24DCCD 41344909222390107813 W0 8AACA 41342909242040107816 W09ADDD $41393309035130107903 \mathrm{E} 11 \mathrm{CBC}$

41343709503440107837 WI IAAAB 41304809526070107840 W3 4BDCD $41384209518420107938 W 19 A B A B$ $41381009518540107938 \mathrm{Wl}$ 9 BDDB $41434009516030108038 W 21$ ADAA

41462209525010108039 W0 5ACAA $41440709528410108040 \mathrm{Wl} 4 \mathrm{CCBD}$ 41472909512400108138 W36AAAB 41493209520190208139 W13CACB 42590409552280109443 W01CDBC

42574909610420109445 W17AACD 42582009618460109446 W07 DAD 43010809609380109545 W2 8DBAA 43113309607590209745 W26CBAA 41540309318100108221 W21BDCA

41530709323470108222 W27 BDD 42014109336570108324 W02CBAA 42014109336360108324 WO 2DBBB $41353509101300107802 W 01 D C D$ 41550209224010508213 W1 8AAC

$41593509235180108315 \mathrm{Wl}$ 5CCDC $41574909234530108315 \% 34 \mathrm{ABBB}$ 41585209242490108316 W21DCAB $42053309240380208416 \mathrm{Wl} 4 \mathrm{ABA}$ 42112209243110208516 W09ACC
1879

02977

19170

GRANDVIEW NORTH

COLUMBUS JCT 2

01344 1940

230621972 BUSSEY NO 3

190671967 PLEASANTVILLE 1

05760 1952RHODES NO 1

1965 BASTINGS

1972GLENWOOD 3

11450 19590RCHARD TOWN

1974VILLISCA 7-3

07047 1955RED OAK NO 4 MUSCATINE 5 MUSCATINE 19

1981 MUSCATINE 26

00856 ATALISSA IOWA 1

1955 PAULLINA NO 4

1969 SANBORN NO 4

1973 MELVIN NO 2 OCHEYEDAN 1

12508 1960HARRIS TOWN WELL 1975 SHENODOAH 21

107121959 WEST BEND CITY WELL 1979KINGSLEY NO 2 1959MERRILL NO 2

1968REMSEN NO 5

1970BRUNSVILLE CITY

1965 WESTFIELD NO 1

1959AKRON NO 4

088891956 WEST DES MOINES 6

09808 1958MITCHELLVILLE NO 2

1981 BONDURANT 4

1962 MACE DONIA 1

1980 TREYNOR NO 3

$19790 A K L A N D$

1978 HANCOCK 6

1978 NEOLA

1940DEEP RIVER NO I

085511955 SEARSBORO NO

07460 ELDRIDGE IOWA 3

1967 ELK HORN NO 9

1954 SHELBY NO 3

1978 HARLAN 20

1978HARLAN 27

1972KIRKMAN TOWN NO 1

1968 EARL ING NO 1

1967 PANAMA NO 1

1946 TOWN OF IRWIN NO 2 DEFIANCE PUMPHOUSE 4

1959GRANVILLE NO 2

148601962 TOWN OF MAURICE NO 3 143101946 IRETON TOWN WELL
1970 ORANGE CITY NO 2

104341959 HULL CITY WELL NO 4

246221977 COLLINS NO 3

03694 1946MAXWELL 2

196 BAMES NO 12

188021966 AMES NO 9

1981 WILTON 3

CHELSEA IOWA

245281977 TOLEDO JORDAN NO 2

1966 TAMA NO 4

1972 MONTOUR 2

GARWIN 1

06209 GLADBROOK 3
LOU IS

LOU ISA

LOUISA

LYON

MARION

MARION

MARSHALL

MILLS

MILIS

MITCHELL

MONTGOMERY

MONTGOMERY

MUSCATINE

MUSCATINE

MUSCATINE

MUSCATINE

O'BRIEN

O'BRIEN

OSCEOLA

OSCEOLA

OSCEOLA

PAGE

PALO ALTO

PALO ALTO

PLYMOU TH

PLYMOU TH

PL YMOU TE

PLYMOU TH

PLYMOU TE

POLK

POLR

POLK

POTTAWATTaMIE

POTTAWATTAMIE

POTTAKATTAMIE

POTTANATTAMIE

PotTakattamie

POWESHIEK

POWESHIEK

SCOTI

SHELBY

SHELBY

SHELBY

SHELBY

SHELBY

SHELBY

SHELBY

SHELBY

SHELBY

SIOUX

SIOUX

SIOUX

SIOUX

SIOUX

STORY

STORY

STORY

STORY

TAMA

TAMA

TAMA

TAMA

TAMA

TAMA

04-10-85 10:30 112AFN

05-01-85 15:00 112PLSC

04-25-85 15:00 112AFNN

12-03-84 13:15 217DKOT

09-26-85 15:00 3600VCB

04-30-85 13:50 3600VCB

09-24-85 12:00 112PLSC

08-08-85 13:00 111ALVM

08-08-85 10:15 111ALVM

08-06-85 13:00 344RPID

08-07-85

08-07-85

04-26-85

$04-26-85$

$04-26-85$

04-26-85

12-05-84

$12-05-84$

$12-04-$

$12-04-84$

12-04-84

$08-21-85$

08-19-85

09-18-85

$09-16-85$

10.20

$12: 00$

$08: 45$

$09: 30$

10:00 IIIALVM

$14: 30$ 350 SL RN

14:00 112 PLSC

$10: 55$ 112PLSC

$14: 45$ 110QRNR

$11: 55$ 110QRNR

$10: 25 \quad 112$ PLSC

$08: 45$ 111ALVM

$11: 00$ 3600VCB

09:00 111ALVH

15:30 IIIALVM

09-17-85 12:30 111ALVM

09-17-85 10:00 111ALVM

09-04-85 15:00 IIIALVM

09-04-85 11:45 112PLSC

09-26-85 11:00 111ALVM

09-11-85 10:30 111ALVM

09-11-85 11:45 111ALVM

08-06-85 13:40 IIIALVM

08-06-85 15:10 112PLSC

08-07-85 15:10 IIIALVM

08-06-85 11:30 111ALVM

08-06-85

$07-29-85$

07-29-85

$01-08-85$

$09: 15$

$15: 00$ IIIALVM

$13: 45$ 338KKUK

09:05 355NIGR

$06-11-85$

$06-13-85$

$06-13-85$

$06-13-85$

$06-19-85$

$11: 30$

$111 \mathrm{ALVM}$

09:30 111ALVM

12:50 IIIALVM

$13: 00$ 111 ALVM

$11: 45$ 111 ALVM

06-13-85 10:15 111ALVM

06-19-85 09:30 IllALVM

06-19-85 12:45 IIIALVM

06-12-85 10:00 111ALVM

12-06-84 09:15 112PLSC

$12-11-84$

$12-11-84$

$12-05-84$

$12-03-84$

07-25-85

07-25-85

$08-28-85$

$08-28-85$

$04-26-85$

07-29-85

$06-26-85$

$06-26-85$ 


\begin{tabular}{|c|c|c|c|c|c|c|c|c|}
\hline STATION NUMBER & DATE & $\begin{array}{c}\text { FLOW } \\
\text { RATE } \\
\text { (GPM) } \\
(00058)\end{array}$ & $\begin{array}{c}\text { PUMP } \\
\text { OR FLOW } \\
\text { PERIOD } \\
\text { PRIOR } \\
\text { TO SAM- } \\
\text { PLING } \\
\text { (MIN) } \\
(72004)\end{array}$ & $\begin{array}{l}\text { SPE- } \\
\text { CIFIC } \\
\text { CON- } \\
\text { DUCT- } \\
\text { ANCE } \\
\text { (US/CM) } \\
(00095)\end{array}$ & $\begin{array}{c}\text { PH } \\
\text { (STAND- } \\
\text { ARD } \\
\text { UNITS) } \\
(00400)\end{array}$ & $\begin{array}{l}\text { HARD- } \\
\text { NESS } \\
\text { (MG/L } \\
\text { AS } \\
\text { CACO3) } \\
(00900)\end{array}$ & $\begin{array}{l}\text { CALCIUM } \\
\text { DIS- } \\
\text { SOLVED } \\
\text { (MG/L } \\
\text { AS CA) } \\
(00915)\end{array}$ & $\begin{array}{c}\text { MAGNE- } \\
\text { SIUM, } \\
\text { DIS- } \\
\text { SOLVED } \\
\text { (MG/L } \\
\text { AS MG) } \\
(00925)\end{array}$ \\
\hline $\begin{array}{l}411644091110701 \\
411652091213801 \\
411539091221501 \\
431844096263501 \\
411213092531501\end{array}$ & $\begin{array}{l}04-10-85 \\
05-01-85 \\
04-25-85 \\
12-03-84 \\
09-26-85\end{array}$ & $\begin{array}{r}-- \\
70 \\
10 \\
11 \\
100\end{array}$ & $\begin{array}{l}60 \\
30 \\
60\end{array}$ & $\begin{array}{r}465 \\
639 \\
714 \\
1400 \\
1350\end{array}$ & $\begin{array}{l}7.3 \\
7.5 \\
7.2 \\
7.0 \\
7.7\end{array}$ & $\begin{array}{l}240 \\
320 \\
340 \\
630 \\
330\end{array}$ & $\begin{array}{r}67 \\
85 \\
82 \\
160 \\
80\end{array}$ & $\begin{array}{l}17 \\
26 \\
33 \\
56 \\
31\end{array}$ \\
\hline $\begin{array}{l}412310093160601 \\
415534093111501 \\
410114095300001 \\
410116095464101 \\
431337092461901\end{array}$ & $\begin{array}{l}04-30-85 \\
09-24-85 \\
08-08-85 \\
08-08-85 \\
08-06-85\end{array}$ & $\begin{array}{r}250 \\
42 \\
-- \\
150 \\
--\end{array}$ & $\begin{array}{l}30 \\
10 \\
60 \\
60 \\
20\end{array}$ & $\begin{array}{r}1010 \\
760 \\
680 \\
870 \\
600\end{array}$ & $\begin{array}{l}7.1 \\
7.6 \\
7.5 \\
7.5 \\
8.0\end{array}$ & $\begin{array}{l}280 \\
580 \\
320 \\
440 \\
290\end{array}$ & $\begin{array}{r}68 \\
140 \\
85 \\
120 \\
84\end{array}$ & $\begin{array}{l}27 \\
56 \\
25 \\
34 \\
19\end{array}$ \\
\hline $\begin{array}{l}405559094591501 \\
410216095113401 \\
412321091034801 \\
412329091041301 \\
412213091063601\end{array}$ & $\begin{array}{l}08-07-85 \\
08-07-85 \\
04-26-85 \\
04-26-85 \\
04-26-85\end{array}$ & $\begin{array}{r}80 \\
320 \\
600 \\
800 \\
1500\end{array}$ & $\begin{array}{r}60 \\
60 \\
1440 \\
1440 \\
24\end{array}$ & $\begin{array}{l}680 \\
400 \\
544 \\
322 \\
268\end{array}$ & $\begin{array}{r}- \\
7.5 \\
7.4 \\
7.5 \\
7.8\end{array}$ & $\begin{array}{l}210 \\
190 \\
280 \\
180 \\
140\end{array}$ & $\begin{array}{l}58 \\
54 \\
76 \\
47 \\
40\end{array}$ & $\begin{array}{l}17 \\
14 \\
23 \\
15 \\
8.6\end{array}$ \\
\hline $\begin{array}{l}413428091094601 \\
425859095403201 \\
431045095413801 \\
431703095272401 \\
432314095320001\end{array}$ & $\begin{array}{l}04-26-85 \\
12-05-84 \\
12-05-84 \\
12-04-84 \\
12-04-84\end{array}$ & $\begin{array}{r}52 \\
1250 \\
375 \\
40 \\
70\end{array}$ & $\begin{array}{r}10 \\
30 \\
120 \\
30 \\
30\end{array}$ & $\begin{array}{l}681 \\
815 \\
832 \\
726 \\
532\end{array}$ & $\begin{array}{l}6.9 \\
7.2 \\
7.0 \\
7.4 \\
7.5\end{array}$ & $\begin{array}{l}370 \\
440 \\
480 \\
360 \\
260\end{array}$ & $\begin{array}{r}90 \\
120 \\
130 \\
95 \\
65\end{array}$ & $\begin{array}{l}35 \\
35 \\
38 \\
29 \\
23\end{array}$ \\
\hline $\begin{array}{l}432646095260201 \\
404517095245301 \\
425735094270201 \\
42353609583501 \\
424306096145701\end{array}$ & $\begin{array}{l}12-04-84 \\
08-21-85 \\
08-19-85 \\
09-18-85 \\
09-16-85\end{array}$ & $\begin{array}{r}30 \\
100 \\
180 \\
180 \\
220\end{array}$ & $\begin{array}{r}45 \\
60 \\
60 \\
180 \\
360\end{array}$ & $\begin{array}{r}2300 \\
440 \\
1850 \\
850 \\
830\end{array}$ & $\begin{array}{l}7.2 \\
6.9 \\
7.2 \\
7.5 \\
6.9\end{array}$ & $\begin{array}{r}1400 \\
190 \\
870 \\
430 \\
440\end{array}$ & $\begin{array}{r}380 \\
52 \\
230 \\
120 \\
110\end{array}$ & $\begin{array}{r}120 \\
14 \\
71 \\
32 \\
39\end{array}$ \\
\hline $\begin{array}{l}424916095581201 \\
424838096161001 \\
424528096362001 \\
424948096332901 \\
413418093432403\end{array}$ & $\begin{array}{l}09-17-85 \\
09-17-85 \\
09-04-85 \\
09-04-85 \\
09-26-85\end{array}$ & $\begin{array}{r}90 \\
110 \\
82 \\
230 \\
175\end{array}$ & $\begin{array}{r}180 \\
40 \\
30 \\
30\end{array}$ & $\begin{array}{r}930 \\
1020 \\
1120 \\
1030 \\
1040\end{array}$ & $\begin{array}{l}7.5 \\
7.5 \\
7.5 \\
8.0 \\
7.2\end{array}$ & $\begin{array}{l}470 \\
490 \\
540 \\
520 \\
430\end{array}$ & $\begin{array}{l}130 \\
140 \\
150 \\
150 \\
120\end{array}$ & $\begin{array}{l}35 \\
34 \\
40 \\
35 \\
32\end{array}$ \\
\hline $\begin{array}{l}414051093190902 \\
414409093241001 \\
411201095252801 \\
411356095360801 \\
411838095252801\end{array}$ & $\begin{array}{l}09-11-85 \\
09-11-85 \\
08-06-85 \\
08-06-85 \\
08-07-85\end{array}$ & $\begin{array}{r}250 \\
350 \\
100 \\
125 \\
75\end{array}$ & $\begin{array}{r}20 \\
150 \\
60 \\
60\end{array}$ & $\begin{array}{l}640 \\
627 \\
640 \\
940 \\
515\end{array}$ & $\begin{array}{l}7.2 \\
7.9 \\
7.3 \\
7.8 \\
7.7\end{array}$ & $\begin{array}{l}320 \\
330 \\
350 \\
370 \\
250\end{array}$ & $\begin{array}{r}87 \\
90 \\
96 \\
100 \\
69\end{array}$ & $\begin{array}{l}26 \\
26 \\
27 \\
29 \\
20\end{array}$ \\
\hline $\begin{array}{l}412327095215401 \\
412654095371201 \\
413449092223901 \\
413429092420401 \\
413933090351301\end{array}$ & $\begin{array}{l}08-06-85 \\
08-06-85 \\
07-29-85 \\
07-29-85 \\
01-08-85\end{array}$ & $\begin{array}{r}30 \\
110 \\
36 \\
50 \\
435\end{array}$ & $\begin{array}{l}60 \\
60 \\
30 \\
10 \\
20\end{array}$ & $\begin{array}{r}870 \\
980 \\
1090 \\
1960 \\
398\end{array}$ & $\begin{array}{l}7.3 \\
7.7 \\
7.1 \\
7.2 \\
7.3\end{array}$ & $\begin{array}{l}400 \\
470 \\
580 \\
850 \\
210\end{array}$ & $\begin{array}{r}110 \\
130 \\
160 \\
200 \\
40\end{array}$ & $\begin{array}{l}30 \\
35 \\
44 \\
86 \\
26\end{array}$ \\
\hline $\begin{array}{l}413437095034401 \\
413048095260701 \\
413842095184201 \\
413810095185401 \\
414340095160301\end{array}$ & $\begin{array}{l}06-11-85 \\
06-13-85 \\
06-13-85 \\
06-13-85 \\
06-19-85\end{array}$ & $\begin{array}{r}18 \\
50 \\
70 \\
70 \\
4\end{array}$ & $\begin{array}{r}60 \\
30 \\
60 \\
60 \\
150\end{array}$ & $\begin{array}{r}580 \\
640 \\
1200 \\
780 \\
740\end{array}$ & $\begin{array}{l}7.3 \\
6.8 \\
6.8 \\
6.8 \\
7.4\end{array}$ & $\begin{array}{l}300 \\
340 \\
620 \\
400 \\
390\end{array}$ & $\begin{array}{r}84 \\
94 \\
180 \\
120 \\
95\end{array}$ & $\begin{array}{l}23 \\
25 \\
42 \\
24 \\
36\end{array}$ \\
\hline $\begin{array}{l}414622095250101 \\
414407095284101 \\
414729095124001 \\
414932095201902 \\
425904095522801\end{array}$ & $\begin{array}{l}06-13-85 \\
06-19-85 \\
06-19-85 \\
06-12-85 \\
12-06-84\end{array}$ & $\begin{array}{l}18 \\
20 \\
70 \\
21 \\
65\end{array}$ & $\begin{array}{l}60 \\
60 \\
60 \\
60 \\
30\end{array}$ & $\begin{array}{r}720 \\
960 \\
810 \\
930 \\
2490\end{array}$ & $\begin{array}{l}7.2 \\
7.2 \\
7.3 \\
7.3 \\
7.0\end{array}$ & $\begin{array}{r}350 \\
510 \\
400 \\
500 \\
1200\end{array}$ & $\begin{array}{r}97 \\
140 \\
110 \\
130 \\
320\end{array}$ & $\begin{array}{r}25 \\
40 \\
31 \\
42 \\
100\end{array}$ \\
\hline $\begin{array}{l}425749096104201 \\
425820096184601 \\
430108096093801 \\
431133096075902 \\
415403093181001\end{array}$ & $\begin{array}{l}12-11-84 \\
12-11-84 \\
12-05-84 \\
12-03-84 \\
07-25-85\end{array}$ & $\begin{array}{l}155 \\
125 \\
220 \\
270 \\
--\end{array}$ & $\begin{array}{l}30 \\
30 \\
30 \\
45 \\
20\end{array}$ & $\begin{array}{r}2750 \\
1500 \\
960 \\
2800 \\
975\end{array}$ & $\begin{array}{l}7.2 \\
7.2 \\
7.5 \\
7.3 \\
7.0\end{array}$ & $\begin{array}{r}1200 \\
730 \\
490 \\
1200 \\
320\end{array}$ & $\begin{array}{r}310 \\
180 \\
130 \\
300 \\
75\end{array}$ & $\begin{array}{r}100 \\
67 \\
39 \\
110 \\
33\end{array}$ \\
\hline $\begin{array}{l}415307093234701 \\
420141093365701 \\
420141093363601 \\
413535091013001 \\
415502092240105\end{array}$ & $\begin{array}{l}07-25-85 \\
08-28-85 \\
08-28-85 \\
04-26-85 \\
07-29-85\end{array}$ & $\begin{array}{l}200 \\
324 \\
840 \\
300 \\
100\end{array}$ & $\begin{array}{r}20 \\
1440 \\
4320 \\
30 \\
60\end{array}$ & $\begin{array}{l}755 \\
850 \\
970 \\
521 \\
460\end{array}$ & $\begin{array}{l}7.3 \\
7.1 \\
7.2 \\
7.5 \\
7.4\end{array}$ & $\begin{array}{l}340 \\
360 \\
470 \\
270 \\
230\end{array}$ & $\begin{array}{r}90 \\
92 \\
130 \\
72 \\
65\end{array}$ & $\begin{array}{l}28 \\
32 \\
35 \\
22 \\
17\end{array}$ \\
\hline $\begin{array}{l}415935092351801 \\
415749092345301 \\
415852092424901 \\
420533092403802 \\
421122092431102\end{array}$ & $\begin{array}{l}06-26-85 \\
06-26-85 \\
06-26-85 \\
07-29-85 \\
06-27-85\end{array}$ & $\begin{array}{r}500 \\
170 \\
60 \\
100 \\
180\end{array}$ & $\begin{array}{r}30 \\
40 \\
120 \\
60\end{array}$ & $\begin{array}{r}960 \\
705 \\
645 \\
1650 \\
660\end{array}$ & $\begin{array}{l}7.1 \\
7.1 \\
7.0 \\
7.4 \\
6.9\end{array}$ & $\begin{array}{l}410 \\
350 \\
340 \\
630 \\
340\end{array}$ & $\begin{array}{r}91 \\
90 \\
97 \\
130 \\
100\end{array}$ & $\begin{array}{l}45 \\
30 \\
24 \\
74 \\
22\end{array}$ \\
\hline
\end{tabular}




\begin{tabular}{|c|c|c|c|c|c|c|c|c|}
\hline TATION NUMBER & DATE & $\begin{array}{c}\text { SODIUM, } \\
\text { DIS- } \\
\text { SOLVED } \\
(M G / L \\
\text { AS NA) } \\
(00930)\end{array}$ & $\begin{array}{l}\text { POTAS- } \\
\text { SIUM, } \\
\text { DIS- } \\
\text { SOLVED } \\
\text { (MG/L) } \\
\text { AS R) } \\
(00935)\end{array}$ & $\begin{array}{c}\text { ALKA- } \\
\text { LINITY } \\
\text { LAB } \\
\text { (MG/L } \\
\text { AS } \\
\text { CACO3) } \\
(90410)\end{array}$ & $\begin{array}{l}\text { CHLO- } \\
\text { RIDE, } \\
\text { DIS- } \\
\text { SOLVED } \\
\text { (MG/L } \\
\text { AS CL) } \\
(00940)\end{array}$ & $\begin{array}{c}\text { SULFATE } \\
\text { DIS- } \\
\text { SOLVED } \\
\text { (MG/L } \\
\text { AS SO4) } \\
(00945)\end{array}$ & $\begin{array}{l}\text { FLUO- } \\
\text { RIDE, } \\
\text { DIS- } \\
\text { SOLVED } \\
\text { (MG/L } \\
\text { AS F) } \\
(00950)\end{array}$ & $\begin{array}{l}\text { SILICA, } \\
\text { DIS- } \\
\text { SOLVED } \\
\text { (MG/L } \\
\text { AS } \\
\text { SIO2) } \\
(00955)\end{array}$ \\
\hline $\begin{array}{l}411644091110701 \\
411652091213801 \\
411539091221501 \\
431844096263501 \\
411213092531501\end{array}$ & $\begin{array}{l}04-10-85 \\
05-01-85 \\
04-25-85 \\
12-03-84 \\
09-26-85\end{array}$ & $\begin{array}{l}8.3 \\
28 \\
38 \\
74 \\
200\end{array}$ & $\begin{array}{l}1.8 \\
3.1 \\
2.6 \\
16 \\
19\end{array}$ & $\begin{array}{l}258 \\
337 \\
416 \\
272 \\
264\end{array}$ & $\begin{array}{r}<0.5 \\
6.0 \\
1.0 \\
6.5 \\
66\end{array}$ & $\begin{array}{l}4.2 \\
24 \\
3.8 \\
480 \\
370\end{array}$ & $\begin{array}{l}0.25 \\
0.3 \\
0.45 \\
0.8 \\
1.3\end{array}$ & $\begin{array}{l}24 \\
18 \\
21 \\
11 \\
10\end{array}$ \\
\hline $\begin{array}{l}412310093160601 \\
415534093111501 \\
410114095300001 \\
410116095464101 \\
431337092461901\end{array}$ & $\begin{array}{l}04-30-85 \\
09-24-85 \\
08-08-85 \\
08-08-85 \\
08-06-85\end{array}$ & $\begin{array}{r}130 \\
140 \\
22 \\
14 \\
7.6\end{array}$ & $\begin{array}{l}16 \\
6.5 \\
2.5 \\
5.0 \\
1.3\end{array}$ & $\begin{array}{l}257 \\
300 \\
228 \\
392 \\
235\end{array}$ & $\begin{array}{l}34 \\
1.0 \\
24 \\
12 \\
19\end{array}$ & $\begin{array}{r}240 \\
550 \\
54 \\
47 \\
32\end{array}$ & $\begin{array}{l}1.7 \\
0.5 \\
0.3 \\
0.3 \\
0.25\end{array}$ & $\begin{array}{l}11 \\
13 \\
20 \\
27 \\
14\end{array}$ \\
\hline $\begin{array}{l}405559094591501 \\
410216095113401 \\
412321091034801 \\
412329091041301 \\
412213091063601\end{array}$ & $\begin{array}{l}08-07-85 \\
08-07-85 \\
04-26-85 \\
04-26-85 \\
04-26-85\end{array}$ & $\begin{array}{l}18 \\
11 \\
12 \\
3.5 \\
2.7\end{array}$ & $\begin{array}{l}2.0 \\
1.3 \\
2.6 \\
0.9 \\
0.7\end{array}$ & $\begin{array}{r}182 \\
202 \\
131 \\
78\end{array}$ & $\begin{array}{l}110 \\
2.5 \\
13 \\
7.5 \\
5.5\end{array}$ & $\begin{array}{r}120 \\
17 \\
81 \\
23 \\
23\end{array}$ & $\begin{array}{l}0.4 \\
0.25 \\
0.1 \\
0.1 \\
0.1\end{array}$ & $\begin{array}{l}19 \\
21 \\
16 \\
15 \\
12\end{array}$ \\
\hline $\begin{array}{l}413428091094601 \\
425859095403201 \\
431045095413801 \\
431703095272401 \\
432314095320001\end{array}$ & $\begin{array}{l}04-26-85 \\
12-05-84 \\
12-05-84 \\
12-04-84 \\
12-04-84\end{array}$ & $\begin{array}{l}11 \\
9.6 \\
15 \\
5.2 \\
7.5\end{array}$ & $\begin{array}{l}2.3 \\
2.2 \\
3.5 \\
1.9 \\
2.5\end{array}$ & $\begin{array}{l}378 \\
297 \\
359 \\
236 \\
194\end{array}$ & $\begin{array}{l}<0.5 \\
11 \\
10 \\
10 \\
12\end{array}$ & $\begin{array}{r}10 \\
89 \\
120 \\
95 \\
69\end{array}$ & $\begin{array}{l}0.25 \\
0.4 \\
0.5 \\
0.3 \\
0.2\end{array}$ & $\begin{array}{l}16 \\
28 \\
29 \\
29 \\
24\end{array}$ \\
\hline $\begin{array}{l}432646095260201 \\
404517095245301 \\
425735094270201 \\
42353609583501 \\
424306096145701\end{array}$ & $\begin{array}{l}12-04-84 \\
08-21-85 \\
08-19-85 \\
09-18-85 \\
09-16-85\end{array}$ & $\begin{array}{r}46 \\
11 \\
130 \\
12 \\
17\end{array}$ & $\begin{array}{r}12 \\
2.3 \\
22 \\
2.5 \\
3.8\end{array}$ & $\begin{array}{l}333 \\
128 \\
329 \\
302 \\
341\end{array}$ & $\begin{array}{l}0.5 \\
7.0 \\
20 \\
19 \\
20\end{array}$ & $\begin{array}{r}1200 \\
70 \\
760 \\
60 \\
50\end{array}$ & $\begin{array}{l}0.3 \\
0.25 \\
1.1 \\
0.4 \\
0.4\end{array}$ & $\begin{array}{l}32 \\
20 \\
7.8 \\
28 \\
24\end{array}$ \\
\hline $\begin{array}{l}424916095581201 \\
424838096161001 \\
42452809632001 \\
424948096332901 \\
413418093432403\end{array}$ & $\begin{array}{l}09-17-85 \\
09-17-85 \\
09-04-85 \\
09-04-85 \\
09-26-85\end{array}$ & $\begin{array}{l}18 \\
22 \\
23 \\
18 \\
68\end{array}$ & $\begin{array}{l}2.0 \\
2.1 \\
7.3 \\
6.8 \\
4.0\end{array}$ & $\begin{array}{l}276 \\
343 \\
338 \\
319 \\
306\end{array}$ & $\begin{array}{r}24 \\
20 \\
17 \\
28 \\
120\end{array}$ & $\begin{array}{r}160 \\
190 \\
200 \\
190 \\
76\end{array}$ & $\begin{array}{l}0.35 \\
0.5 \\
0.25 \\
0.15 \\
0.35\end{array}$ & $\begin{array}{l}22 \\
22 \\
25 \\
25 \\
22\end{array}$ \\
\hline $\begin{array}{l}414051093190902 \\
414409093241001 \\
411201095252801 \\
411356095360801 \\
411838095252801\end{array}$ & $\begin{array}{l}09-11-85 \\
09-11-85 \\
08-06-85 \\
08-06-85 \\
08-07-85\end{array}$ & $\begin{array}{l}8.8 \\
7.9 \\
10 \\
73 \\
10\end{array}$ & $\begin{array}{l}0.8 \\
1.4 \\
0.9 \\
3.8 \\
1.6\end{array}$ & $\begin{array}{l}285 \\
269 \\
258 \\
384 \\
248\end{array}$ & $\begin{array}{l}16 \\
17 \\
5.5 \\
3.5 \\
5.0\end{array}$ & $\begin{array}{r}35 \\
23 \\
96 \\
140 \\
25\end{array}$ & $\begin{array}{l}0.2 \\
0.3 \\
0.45 \\
0.3 \\
0.3\end{array}$ & $\begin{array}{l}22 \\
18 \\
20 \\
29 \\
19\end{array}$ \\
\hline $\begin{array}{l}412327095215401 \\
412654095371201 \\
413449092223901 \\
413429092420401 \\
413933090351301\end{array}$ & $\begin{array}{l}08-06-85 \\
08-06-85 \\
07-29-85 \\
07-29-85 \\
01-08-85\end{array}$ & $\begin{array}{r}25 \\
23 \\
18 \\
140 \\
12\end{array}$ & $\begin{array}{l}1.7 \\
3.4 \\
2.9 \\
8.2 \\
0.6\end{array}$ & $\begin{array}{l}291 \\
355 \\
301 \\
154 \\
220\end{array}$ & $\begin{array}{c}38 \\
36 \\
14 \\
14 \\
1.0\end{array}$ & $\begin{array}{r}95 \\
93 \\
300 \\
900 \\
1.0\end{array}$ & $\begin{array}{l}0.35 \\
0.3 \\
0.25 \\
0.75 \\
0.5\end{array}$ & $\begin{array}{l}20 \\
30 \\
23 \\
6.6 \\
17\end{array}$ \\
\hline $\begin{array}{l}413437095034401 \\
413048095260701 \\
413842095184201 \\
413810095185401 \\
414340095160301\end{array}$ & $\begin{array}{l}06-11-85 \\
06-13-85 \\
06-13-85 \\
06-13-85 \\
06-19-85\end{array}$ & $\begin{array}{l}9.8 \\
14 \\
24 \\
10 \\
9.7\end{array}$ & $\begin{array}{l}3.1 \\
3.7 \\
5.8 \\
2.4 \\
3.1\end{array}$ & $\begin{array}{l}269 \\
301 \\
473 \\
293 \\
342\end{array}$ & $\begin{array}{l}10 \\
11 \\
55 \\
16 \\
12\end{array}$ & $\begin{array}{r}44 \\
40 \\
120 \\
110 \\
32\end{array}$ & $\begin{array}{l}0.25 \\
0.3 \\
0.15 \\
0.25 \\
0.3\end{array}$ & $\begin{array}{l}37 \\
31 \\
20 \\
17 \\
24\end{array}$ \\
\hline $\begin{array}{l}414622095250101 \\
414407095284101 \\
414729095124001 \\
414932095201902 \\
425904095522801\end{array}$ & $\begin{array}{l}06-13-85 \\
06-19-85 \\
06-19-85 \\
06-12-85 \\
12-06-84\end{array}$ & $\begin{array}{l}12 \\
9.3 \\
15 \\
11 \\
240\end{array}$ & $\begin{array}{l}3.0 \\
4.4 \\
1.6 \\
3.7 \\
15\end{array}$ & $\begin{array}{l}267 \\
390 \\
312 \\
373 \\
342\end{array}$ & $\begin{array}{l}26 \\
10 \\
26 \\
19 \\
22\end{array}$ & $\begin{array}{r}80 \\
130 \\
72 \\
130 \\
1300\end{array}$ & $\begin{array}{l}0.4 \\
0.3 \\
0.25 \\
0.25 \\
1.0\end{array}$ & $\begin{array}{l}29 \\
44 \\
22 \\
27 \\
14\end{array}$ \\
\hline $\begin{array}{l}425749096104201 \\
425820096184601 \\
430108096093801 \\
431133096075902 \\
415403093181001\end{array}$ & $\begin{array}{l}12-11-84 \\
12-11-84 \\
12-05-84 \\
12-03-84 \\
07-25-85\end{array}$ & $\begin{array}{r}250 \\
69 \\
26 \\
190 \\
83\end{array}$ & $\begin{array}{l}20 \\
12 \\
39 \\
18 \\
16\end{array}$ & $\begin{array}{l}317 \\
319 \\
298 \\
316 \\
285\end{array}$ & $\begin{array}{l}26 \\
7.5 \\
34 \\
22 \\
14\end{array}$ & $\begin{array}{r}1300 \\
550 \\
150 \\
1200 \\
220\end{array}$ & $\begin{array}{l}1.5 \\
0.5 \\
0.5 \\
0.5 \\
1.4\end{array}$ & $\begin{array}{l}10 \\
29 \\
27 \\
12 \\
10\end{array}$ \\
\hline $\begin{array}{l}415307093234701 \\
420141093365701 \\
420141093363601 \\
413535091013001 \\
415502092240105\end{array}$ & $\begin{array}{l}07-25-85 \\
08-28-85 \\
08-28-85 \\
04-26-85 \\
07-29-85\end{array}$ & $\begin{array}{l}21 \\
14 \\
17 \\
11 \\
4.0\end{array}$ & $\begin{array}{l}3.9 \\
3.1 \\
2.6 \\
0.8 \\
0.4\end{array}$ & $\begin{array}{l}337 \\
272 \\
280 \\
264 \\
184\end{array}$ & $\begin{array}{l}12 \\
30 \\
45 \\
4.5 \\
7.0\end{array}$ & $\begin{array}{r}44 \\
85 \\
150 \\
16 \\
60\end{array}$ & $\begin{array}{l}0.55 \\
0.45 \\
0.3 \\
0.25 \\
0.2\end{array}$ & $\begin{array}{l}15 \\
24 \\
27 \\
22 \\
19\end{array}$ \\
\hline $\begin{array}{l}415935092351801 \\
415749092345301 \\
415852092424901 \\
420533092403802 \\
421122092431102\end{array}$ & $\begin{array}{l}06-26-85 \\
06-26-85 \\
06-26-85 \\
07-29-85 \\
06-27-85\end{array}$ & $\begin{array}{r}70 \\
33 \\
17 \\
180 \\
12\end{array}$ & $\begin{array}{r}16 \\
2.6 \\
2.1 \\
8.4 \\
2.2\end{array}$ & $\begin{array}{l}305 \\
269 \\
230 \\
186 \\
247\end{array}$ & $\begin{array}{l}9.5 \\
14 \\
26 \\
4.5 \\
31\end{array}$ & $\begin{array}{r}250 \\
120 \\
75 \\
800 \\
71\end{array}$ & $\begin{array}{l}1.2 \\
0.3 \\
0.2 \\
0.8 \\
0.1\end{array}$ & $\begin{array}{l}7.4 \\
25 \\
17 \\
6.6 \\
16\end{array}$ \\
\hline
\end{tabular}




\begin{tabular}{|c|c|c|c|c|c|c|c|c|}
\hline ATION NOMBER & DATE & $\begin{array}{l}\text { SOLIDS, } \\
\text { RESIDUE } \\
\text { AT 105 } \\
\text { DEG. C, } \\
\text { DIS- } \\
\text { SOLVED } \\
\text { (MG/L) } \\
(00515)\end{array}$ & $\begin{array}{c}\text { NITRO- } \\
\text { GEN, } \\
\text { NO2+NO3 } \\
\text { DIS- } \\
\text { SOLVED } \\
\text { (MG/L } \\
\text { AS N) } \\
(00631)\end{array}$ & $\begin{array}{c}\text { NITRO- } \\
\text { GEN, } \\
\text { AMMONIA } \\
\text { DIS- } \\
\text { SOLVED } \\
\text { (MG/L } \\
\text { AS N) } \\
(00608)\end{array}$ & $\begin{array}{l}\text { PHOS- } \\
\text { PHORUS, } \\
\text { ORTHO, } \\
\text { DIS- } \\
\text { SOLVED } \\
\text { (MG/L } \\
\text { AS P) } \\
(00671)\end{array}$ & $\begin{array}{c}\text { IRON, } \\
\text { DIS- } \\
\text { SOLVED } \\
\text { (OG/L } \\
\text { AS FE) } \\
(01046)\end{array}$ & $\begin{array}{l}\text { MANGA- } \\
\text { NESE, } \\
\text { DIS- } \\
\text { SOLVED } \\
\text { (UG/L } \\
\text { AS MN) } \\
(01056)\end{array}$ & $\begin{array}{c}\text { ARSEN IC } \\
\text { DIS- } \\
\text { SOLVED } \\
(U G / L \\
\text { AS AS) } \\
(01000)\end{array}$ \\
\hline $\begin{array}{l}411644091110701 \\
411652091213801 \\
411539091221501 \\
431844096263501 \\
411213092531501\end{array}$ & $\begin{array}{l}04-10-85 \\
05-01-85 \\
04-25-85 \\
12-03-84 \\
09-26-85\end{array}$ & $\begin{array}{r}225 \\
369 \\
398 \\
1000 \\
941\end{array}$ & $\begin{array}{r}<0.02 \\
0.60 \\
<0.02 \\
<0.02 \\
<0.02\end{array}$ & $\begin{array}{l}=- \\
=- \\
=-\end{array}$ & $\begin{array}{l}=- \\
=- \\
=-\end{array}$ & $\begin{array}{r}1800 \\
3100 \\
1900 \\
1100 \\
360\end{array}$ & $\begin{array}{l}60 \\
60 \\
40 \\
90 \\
50\end{array}$ & $\begin{array}{l}<10 \\
<10 \\
<10 \\
<10 \\
<10\end{array}$ \\
\hline $\begin{array}{l}412310093160601 \\
415534093111501 \\
41011409500001 \\
410116095464101 \\
431337092461901\end{array}$ & $\begin{array}{l}04-30-85 \\
09-24-85 \\
08-08-85 \\
08-08-85 \\
08-06-85\end{array}$ & $\begin{array}{r}638 \\
1070 \\
408 \\
540 \\
294\end{array}$ & $\begin{array}{r}<0.02 \\
<0.02 \\
5.55 \\
<0.02 \\
2.66\end{array}$ & $\begin{array}{l}\overline{-} \\
\overline{-} \\
<0.01\end{array}$ & $\begin{array}{l}=- \\
=- \\
\overline{0.03}\end{array}$ & $\begin{array}{r}1200 \\
2100 \\
<10 \\
1400 \\
<10\end{array}$ & $\begin{array}{r}10 \\
40 \\
<10 \\
960 \\
10\end{array}$ & $\begin{array}{l}<10 \\
<10 \\
<10 \\
<10 \\
<10\end{array}$ \\
\hline $\begin{array}{l}405559094591501 \\
41021609113401 \\
41232109103481 \\
412329091041301 \\
412213091063601\end{array}$ & $\begin{array}{l}08-07-85 \\
08-07-85 \\
04-26-85 \\
04-26-85 \\
04-26-85\end{array}$ & $\begin{array}{l}526 \\
225 \\
352 \\
184 \\
156\end{array}$ & $\begin{array}{r}<0.02 \\
2.89 \\
0.49 \\
1.64 \\
5.99\end{array}$ & $\begin{array}{l}-- \\
\overline{-} \\
-\end{array}$ & $\begin{array}{l}-- \\
=- \\
=-\end{array}$ & $\begin{array}{r}4000 \\
<10 \\
80 \\
100 \\
110\end{array}$ & $\begin{array}{r}2000 \\
<10 \\
80 \\
40 \\
140\end{array}$ & $\begin{array}{r}20 \\
<10 \\
<10 \\
<10 \\
<10\end{array}$ \\
\hline $\begin{array}{l}413428091094601 \\
425859095403201 \\
431045095413801 \\
431703095272401 \\
432314095320001\end{array}$ & $\begin{array}{l}04-26-85 \\
12-05-84 \\
12-05-84 \\
12-04-84 \\
12-04-84\end{array}$ & $\begin{array}{l}373 \\
493 \\
568 \\
442 \\
308\end{array}$ & $\begin{array}{r}<0.02 \\
6.20 \\
0.09 \\
<0.02 \\
1.80\end{array}$ & $\begin{array}{l}=- \\
=- \\
--\end{array}$ & $\begin{array}{l}= \\
= \\
=\end{array}$ & $\begin{array}{r}70 \\
50 \\
150 \\
1300 \\
<10\end{array}$ & $\begin{array}{r}10 \\
330 \\
330 \\
530 \\
80\end{array}$ & $\begin{array}{l}<10 \\
<10 \\
<10 \\
<10 \\
<10\end{array}$ \\
\hline $\begin{array}{l}432646095260201 \\
404517095245301 \\
425735094270201 \\
423536095583501 \\
424306096145701\end{array}$ & $\begin{array}{l}12-04-84 \\
08-21-85 \\
08-19-85 \\
09-18-85 \\
09-16-85\end{array}$ & $\begin{array}{r}2000 \\
248 \\
1500 \\
508 \\
508\end{array}$ & $\begin{array}{r}<0.02 \\
2.44 \\
<0.02 \\
14.7 \\
9.10\end{array}$ & $\begin{array}{l}-- \\
=- \\
=\end{array}$ & $=$ & $\begin{array}{r}5400 \\
130 \\
1800 \\
<10 \\
<10\end{array}$ & $\begin{array}{r}880 \\
30 \\
70 \\
<10 \\
10\end{array}$ & $\begin{aligned} & 20 \\
&<10 \\
&<10 \\
&<10 \\
&<10\end{aligned}$ \\
\hline $\begin{array}{l}424916095581201 \\
424838096161001 \\
42452809636001 \\
424948096332901 \\
413418093432403\end{array}$ & $\begin{array}{l}09-17-85 \\
09-17-85 \\
09-04-85 \\
09-04-85 \\
09-26-85\end{array}$ & $\begin{array}{l}606 \\
687 \\
707 \\
689 \\
662\end{array}$ & $\begin{array}{r}6.66 \\
0.42 \\
14.0 \\
9.99 \\
0.82\end{array}$ & $\begin{array}{l}-- \\
= \\
=\end{array}$ & $\begin{array}{l}-- \\
-- \\
--\end{array}$ & $\begin{array}{r}<10 \\
360 \\
20 \\
20 \\
390\end{array}$ & $\begin{array}{r}70 \\
360 \\
60 \\
50 \\
180\end{array}$ & $\begin{array}{l}<10 \\
<10 \\
<10 \\
<10 \\
<10\end{array}$ \\
\hline $\begin{array}{l}414051093190902 \\
414409093241001 \\
411201095252801 \\
411356095360801 \\
411838095252801\end{array}$ & $\begin{array}{l}09-11-85 \\
09-11-85 \\
08-06-85 \\
08-06-85 \\
08-07-85\end{array}$ & $\begin{array}{l}397 \\
383 \\
397 \\
566 \\
302\end{array}$ & $\begin{array}{l}18.0 \\
7.30 \\
2.66 \\
0.18 \\
0.33\end{array}$ & $\begin{array}{l}-- \\
<0.01 \\
1.80 \\
--\end{array}$ & $\begin{array}{l}-- \\
\overline{0.09} \\
0.09 \\
--\end{array}$ & $\begin{array}{r}680 \\
40 \\
10 \\
360 \\
600\end{array}$ & $\begin{array}{l}330 \\
160 \\
<10 \\
200 \\
160\end{array}$ & $\begin{array}{l}<10 \\
<10 \\
<10 \\
<10 \\
<10\end{array}$ \\
\hline $\begin{array}{l}412327095215401 \\
412654095371201 \\
413449092223901 \\
413429092420401 \\
413933090351301\end{array}$ & $\begin{array}{l}08-06-85 \\
08-06-85 \\
07-29-85 \\
07-29-85 \\
01-08-85\end{array}$ & $\begin{array}{r}510 \\
629 \\
757 \\
1610 \\
210\end{array}$ & $\begin{array}{r}1.86 \\
4.88 \\
0.07 \\
0.42 \\
<0.02\end{array}$ & $\begin{array}{l}-- \\
=- \\
=-\end{array}$ & $\begin{array}{l}-- \\
\overline{--} \\
--\end{array}$ & $\begin{array}{r}20 \\
<10 \\
3200 \\
10 \\
1700\end{array}$ & $\begin{array}{r}420 \\
610 \\
160 \\
170 \\
20\end{array}$ & $\begin{array}{r}<10 \\
<10 \\
<10 \\
<10 \\
20\end{array}$ \\
\hline $\begin{array}{l}413437095034401 \\
413048095260701 \\
413842095184201 \\
413810095185401 \\
414340095160301\end{array}$ & $\begin{array}{l}06-11-85 \\
06-13-85 \\
06-13-85 \\
06-13-85 \\
06-19-85\end{array}$ & $\begin{array}{l}396 \\
419 \\
791 \\
492 \\
470\end{array}$ & $\begin{array}{r}<0.02 \\
1.99 \\
<0.02 \\
<0.02 \\
1.69\end{array}$ & $\begin{array}{l}1.40 \\
0.60 \\
1.10 \\
0.50 \\
-.\end{array}$ & $\begin{array}{l}1.00 \\
0.05 \\
0.59 \\
0.40 \\
--\end{array}$ & $\begin{array}{r}16000 \\
1500 \\
15000 \\
10000 \\
50\end{array}$ & $\begin{array}{r}580 \\
470 \\
8800 \\
1800 \\
220\end{array}$ & $\begin{aligned} & 20 \\
&<10 \\
&<10 \\
&<10 \\
&<10\end{aligned}$ \\
\hline $\begin{array}{l}414622095250101 \\
414407095284101 \\
414729095124001 \\
414932095201902 \\
42590409552801\end{array}$ & $\begin{array}{l}06-13-85 \\
06-19-85 \\
06-19-85 \\
06-12-85 \\
12-06-84\end{array}$ & $\begin{array}{r}456 \\
674 \\
527 \\
609 \\
2230\end{array}$ & $\begin{array}{r}0.07 \\
<0.02 \\
3.55 \\
0.09 \\
<0.02\end{array}$ & $\begin{array}{l}0.88 \\
1.70 \\
0.04 \\
0.54 \\
--\end{array}$ & $\begin{array}{l}0.47 \\
1.20 \\
0.04 \\
0.15 \\
--.\end{array}$ & $\begin{array}{r}7000 \\
11000 \\
20 \\
1700 \\
1300\end{array}$ & $\begin{array}{r}1400 \\
1000 \\
260 \\
580 \\
290\end{array}$ & $\begin{array}{l}<10 \\
<10 \\
<10 \\
<10 \\
<10\end{array}$ \\
\hline $\begin{array}{l}425749096104201 \\
425820096184601 \\
430108096093801 \\
431133096075902 \\
415403093181001\end{array}$ & $\begin{array}{l}12-11-84 \\
12-11-84 \\
12-05-84 \\
12-03-84 \\
07-25-85\end{array}$ & $\begin{array}{r}2350 \\
1090 \\
587 \\
2370 \\
596\end{array}$ & $\begin{array}{r}<0.02 \\
0.09 \\
0.02 \\
-0.02\end{array}$ & $\begin{array}{l}1.90 \\
2.20 \\
5.00 \\
=- \\
=-\end{array}$ & $\begin{array}{l}0.05 \\
0.05 \\
-- \\
--\end{array}$ & $\begin{array}{l}1800 \\
150 \\
2700 \\
1200 \\
2500\end{array}$ & $\begin{array}{r}80 \\
180 \\
1000 \\
160 \\
20\end{array}$ & $\begin{array}{l}<10 \\
<10 \\
<10 \\
<10 \\
<10\end{array}$ \\
\hline $\begin{array}{l}415307093234701 \\
420141093365701 \\
420141093363601 \\
413535091013001 \\
415502092240105\end{array}$ & $\begin{array}{l}07-25-85 \\
08-28-85 \\
08-28-85 \\
04-26-85 \\
07-29-85\end{array}$ & $\begin{array}{l}403 \\
448 \\
595 \\
293 \\
306\end{array}$ & $\begin{array}{r}0.02 \\
<0.02 \\
<0.02 \\
<0.02 \\
0.64\end{array}$ & $\begin{array}{l}= \\
\bar{z} \\
=\end{array}$ & $\begin{array}{l}= \\
\overline{-} \\
\overline{-} \\
-\end{array}$ & $\begin{array}{l}1800 \\
3400 \\
8600 \\
2800 \\
4300\end{array}$ & $\begin{array}{r}60 \\
240 \\
400 \\
70 \\
1100\end{array}$ & $\begin{array}{l}<10 \\
<10 \\
<10 \\
<10 \\
<10\end{array}$ \\
\hline $\begin{array}{l}415935092351801 \\
415749092345301 \\
415852092424901 \\
420533092403802 \\
421122092431102\end{array}$ & $\begin{array}{l}06-26-85 \\
06-26-85 \\
06-26-85 \\
07-29-85 \\
06-27-85\end{array}$ & $\begin{array}{r}690 \\
504 \\
433 \\
1290 \\
461\end{array}$ & $\begin{array}{l}0.09 \\
1.80 \\
7.55 \\
0.02 \\
4.22\end{array}$ & $\begin{array}{l}=- \\
=- \\
=-\end{array}$ & $\begin{array}{l}-- \\
\overline{--} \\
--\end{array}$ & $\begin{array}{r}310 \\
30 \\
20 \\
60 \\
170\end{array}$ & $\begin{array}{r}20 \\
1000 \\
20 \\
<10 \\
200\end{array}$ & $\begin{array}{l}<10 \\
<10 \\
<10 \\
<10 \\
<10\end{array}$ \\
\hline
\end{tabular}




\begin{tabular}{|c|c|c|c|c|c|c|c|c|}
\hline STATION NUMBER & DATE & $\begin{array}{l}\text { BARIUM, } \\
\text { DIS- } \\
\text { SOLVED } \\
\text { (UG/L } \\
\text { AS BA) } \\
(01005)\end{array}$ & $\begin{array}{l}\text { CADMIUM } \\
\text { DIS- } \\
\text { SOLVED } \\
\text { (UG/L } \\
\text { AS CD) } \\
(01025)\end{array}$ & $\begin{array}{l}\text { CHRO- } \\
\text { MIUM, } \\
\text { DIS- } \\
\text { SOLVED } \\
\text { (UG/L } \\
\text { AS CR) } \\
(01030)\end{array}$ & $\begin{array}{l}\text { COPPER, } \\
\text { DIS- } \\
\text { SOLVED } \\
\text { (UG/L } \\
\text { AS CU) } \\
(01040)\end{array}$ & $\begin{array}{l}\text { LEAD, } \\
\text { DIS- } \\
\text { SOLVED } \\
\text { (UG/L } \\
\text { AS PB) } \\
(01049)\end{array}$ & $\begin{array}{l}\text { MERCURY } \\
\text { DIS- } \\
\text { SOLVED } \\
\text { (UG/L } \\
\text { AS HG) } \\
(71890)\end{array}$ & $\begin{array}{c}\text { SELE- } \\
\text { NIUM, } \\
\text { DIS- } \\
\text { SOLVED } \\
\text { (UG/L } \\
\text { AS SE) } \\
\text { (01145) }\end{array}$ \\
\hline $\begin{array}{l}411644091110701 \\
411652091213801 \\
411539091221501 \\
431844096263501 \\
411213092531501\end{array}$ & $\begin{array}{l}04-10-85 \\
05-01-85 \\
04-25-85 \\
12-03-84 \\
09-26-85\end{array}$ & $\begin{array}{r}100 \\
200 \\
400 \\
<100 \\
<100\end{array}$ & $\begin{array}{l}<1 \\
<1 \\
<1 \\
<1 \\
<1\end{array}$ & $\begin{array}{l}<10 \\
<10 \\
<10 \\
<10 \\
<10\end{array}$ & $\begin{array}{r}10 \\
10 \\
<10 \\
10 \\
<10\end{array}$ & $\begin{array}{l}<10 \\
<10 \\
<10 \\
<10 \\
<10\end{array}$ & $\begin{array}{l}<1.0 \\
<1.0 \\
<1.0 \\
<1.0 \\
<1.0\end{array}$ & $\begin{array}{l}<10 \\
<10 \\
<10 \\
<10 \\
<10\end{array}$ \\
\hline $\begin{array}{l}412310093160601 \\
415534093111501 \\
410114095300001 \\
410116095464101 \\
431337092461901\end{array}$ & $\begin{array}{l}04-30-85 \\
09-24-85 \\
08-08-85 \\
08-08-85 \\
08-06-85\end{array}$ & $\begin{array}{r}<100 \\
<100 \\
200 \\
500 \\
100\end{array}$ & $\begin{array}{l}<1 \\
<1 \\
<1 \\
<1 \\
<1\end{array}$ & $\begin{array}{l}<10 \\
<10 \\
<10 \\
<10 \\
<10\end{array}$ & $\begin{array}{r}30 \\
<10 \\
30 \\
10 \\
<10\end{array}$ & $\begin{array}{l}<10 \\
<10 \\
<10 \\
<10 \\
<10\end{array}$ & $\begin{array}{l}<1.0 \\
<1.0 \\
<1.0 \\
<1.0 \\
<1.0\end{array}$ & $\begin{array}{l}<10 \\
<10 \\
<10 \\
<10 \\
<10\end{array}$ \\
\hline $\begin{array}{l}405559094591501 \\
410216095113401 \\
412321091034801 \\
412329091041301 \\
412213091063601\end{array}$ & $\begin{array}{l}08-07-85 \\
08-07-85 \\
04-26-85 \\
04-26-85 \\
04-26-85\end{array}$ & $\begin{array}{l}<100 \\
<100 \\
100 \\
100 \\
<100\end{array}$ & $\begin{array}{l}<1 \\
<1 \\
<1 \\
<1 \\
<1\end{array}$ & $\begin{array}{l}<10 \\
<10 \\
<10 \\
<10 \\
<10\end{array}$ & $\begin{array}{r}60 \\
<10 \\
<10 \\
<10 \\
<10\end{array}$ & $\begin{array}{l}<10 \\
<10 \\
<10 \\
<10 \\
<10\end{array}$ & $\begin{array}{l}<1.0 \\
<1.0 \\
<1.0 \\
<1.0 \\
<1.0\end{array}$ & $\begin{array}{l}<10 \\
<10 \\
<10 \\
<10 \\
<10\end{array}$ \\
\hline $\begin{array}{l}413428091094601 \\
425859095403201 \\
431045095413801 \\
431703095272401 \\
432314095320001\end{array}$ & $\begin{array}{l}04-26-85 \\
12-05-84 \\
12-05-84 \\
12-04-84 \\
12-04-84\end{array}$ & $\begin{array}{l}400 \\
200 \\
100 \\
100 \\
100\end{array}$ & $\begin{array}{l}<1 \\
<1 \\
<1 \\
<1 \\
<1\end{array}$ & $\begin{array}{l}<10 \\
<10 \\
<10 \\
<10 \\
<10\end{array}$ & $\begin{array}{l}<10 \\
<10 \\
<10 \\
<10 \\
<10\end{array}$ & $\begin{array}{l}<10 \\
<10 \\
<10 \\
<10 \\
<10\end{array}$ & $\begin{array}{l}<1.0 \\
<1.0 \\
<1.0 \\
<1.0 \\
<1.0\end{array}$ & $\begin{array}{l}<10 \\
<10 \\
<10 \\
<10 \\
<10\end{array}$ \\
\hline $\begin{array}{l}432646095260201 \\
404517095245301 \\
425735094270201 \\
423536095583501 \\
424306096145701\end{array}$ & $\begin{array}{l}12-04-84 \\
08-21-85 \\
08-19-85 \\
09-18-85 \\
09-16-85\end{array}$ & $\begin{array}{r}100 \\
100 \\
<100 \\
300 \\
200\end{array}$ & $\begin{array}{l}<1 \\
<1 \\
<1 \\
<1 \\
<1\end{array}$ & $\begin{array}{l}<10 \\
<10 \\
<10 \\
<10 \\
<10\end{array}$ & $\begin{array}{r}10 \\
<10 \\
10 \\
<10 \\
40\end{array}$ & $\begin{array}{l}<10 \\
<10 \\
<10 \\
<10 \\
<10\end{array}$ & $\begin{array}{l}<1.0 \\
<1.0 \\
<1.0 \\
<1.0 \\
<1.0\end{array}$ & $\begin{array}{l}<10 \\
<10 \\
<10 \\
<10 \\
<10\end{array}$ \\
\hline $\begin{array}{l}424916095581201 \\
424838096161001 \\
424528096362001 \\
424948096332901 \\
413418093432403\end{array}$ & $\begin{array}{l}09-17-85 \\
09-17-85 \\
09-04-85 \\
09-04-85 \\
09-26-85\end{array}$ & $\begin{array}{r}<100 \\
<100 \\
100 \\
200 \\
300\end{array}$ & $\begin{array}{l}<1 \\
<1 \\
<1 \\
<1 \\
<1\end{array}$ & $\begin{array}{l}<10 \\
<10 \\
<10 \\
<10 \\
<10\end{array}$ & $\begin{array}{r}<10 \\
10 \\
20 \\
20 \\
<10\end{array}$ & $\begin{array}{l}<10 \\
<10 \\
<10 \\
<10 \\
<10\end{array}$ & $\begin{array}{l}<1.0 \\
<1.0 \\
<1.0 \\
<1.0 \\
<1.0\end{array}$ & $\begin{array}{l}<10 \\
<10 \\
<10 \\
<10 \\
<10\end{array}$ \\
\hline $\begin{array}{l}414051093190902 \\
414409093241001 \\
411201095252801 \\
411356095360801 \\
411838095252801\end{array}$ & $\begin{array}{l}09-11-85 \\
09-11-85 \\
08-06-85 \\
08-06-85 \\
08-07-85\end{array}$ & $\begin{array}{r}100 \\
100 \\
<100 \\
<100 \\
100\end{array}$ & $\begin{array}{l}<1 \\
<1 \\
<1 \\
<1 \\
<1\end{array}$ & $\begin{array}{l}<10 \\
<10 \\
<10 \\
<10 \\
<10\end{array}$ & $\begin{array}{r}20 \\
10 \\
<10 \\
<10 \\
10\end{array}$ & $\begin{array}{l}<10 \\
<10 \\
<10 \\
<10 \\
<10\end{array}$ & $\begin{array}{l}<1.0 \\
<1.0 \\
<1.0 \\
<1.0 \\
<1.0\end{array}$ & $\begin{array}{l}<10 \\
<10 \\
<10 \\
<10 \\
<10\end{array}$ \\
\hline $\begin{array}{l}412327095215401 \\
412654095371201 \\
413449092223901 \\
413429092420401 \\
413933090351301\end{array}$ & $\begin{array}{l}08-06-85 \\
08-06-85 \\
07-29-85 \\
07-29-85 \\
01-08-85\end{array}$ & $\begin{array}{r}100 \\
200 \\
200 \\
<100 \\
400\end{array}$ & $\begin{array}{l}<1 \\
<1 \\
<1 \\
<1 \\
<1\end{array}$ & $\begin{array}{l}<10 \\
<10 \\
<10 \\
<10 \\
<10\end{array}$ & $\begin{array}{r}<10 \\
10 \\
30 \\
20 \\
<10\end{array}$ & $\begin{array}{l}<10 \\
<10 \\
<10 \\
<10 \\
<10\end{array}$ & $\begin{array}{l}<1.0 \\
<1.0 \\
<1.0 \\
<1.0 \\
<1.0\end{array}$ & $\begin{array}{l}<10 \\
<10 \\
<10 \\
<10 \\
<10\end{array}$ \\
\hline $\begin{array}{l}413437095034401 \\
413048095260701 \\
413842095184201 \\
413810095185401 \\
414340095160301\end{array}$ & $\begin{array}{l}06-11-85 \\
06-13-85 \\
06-13-85 \\
06-13-85 \\
06-19-85\end{array}$ & $\begin{array}{l}400 \\
500 \\
600 \\
200 \\
200\end{array}$ & $\begin{array}{l}<1 \\
<1 \\
<1 \\
<1 \\
<1\end{array}$ & $\begin{array}{l}<10 \\
<10 \\
<10 \\
<10 \\
<10\end{array}$ & $\begin{array}{l}<10 \\
10 \\
20 \\
10 \\
40\end{array}$ & $\begin{array}{l}<10 \\
<10 \\
<10 \\
<10 \\
<10\end{array}$ & $\begin{array}{l}<1.0 \\
<1.0 \\
<1.0 \\
<1.0 \\
<1.0\end{array}$ & $\begin{array}{l}<10 \\
<10 \\
<10 \\
<10 \\
<10\end{array}$ \\
\hline $\begin{array}{l}414622095250101 \\
414407095284101 \\
414729095124001 \\
414932095201902 \\
425904095522801\end{array}$ & $\begin{array}{l}06-13-85 \\
06-19-85 \\
06-19-85 \\
06-12-85 \\
12-06-84\end{array}$ & $\begin{array}{r}500 \\
700 \\
400 \\
300 \\
<100\end{array}$ & $\begin{array}{l}<1 \\
<1 \\
<1 \\
<1 \\
<1\end{array}$ & $\begin{array}{l}<10 \\
<10 \\
<10 \\
<10 \\
<10\end{array}$ & $\begin{array}{r}10 \\
10 \\
30 \\
<10 \\
10\end{array}$ & $\begin{array}{l}<10 \\
<10 \\
<10 \\
<10 \\
<10\end{array}$ & $\begin{array}{l}<1.0 \\
<1.0 \\
<1.0 \\
<1.0 \\
<1.0\end{array}$ & $\begin{array}{l}<10 \\
<10 \\
<10 \\
<10 \\
<10\end{array}$ \\
\hline $\begin{array}{l}425749096104201 \\
425820096184601 \\
430108096093801 \\
431133096075902 \\
415403093181001\end{array}$ & $\begin{array}{l}12-11-84 \\
12-11-84 \\
12-05-84 \\
12-03-84 \\
07-25-85\end{array}$ & $\begin{array}{l}100 \\
100 \\
200 \\
100 \\
<100\end{array}$ & $\begin{array}{l}<1 \\
<1 \\
<1 \\
<1 \\
<1\end{array}$ & $\begin{array}{l}<10 \\
<10 \\
<10 \\
<10 \\
<10\end{array}$ & $\begin{array}{r}10 \\
<10 \\
<10 \\
20 \\
30\end{array}$ & $\begin{array}{l}<10 \\
<10 \\
<10 \\
<10 \\
<10\end{array}$ & $\begin{array}{l}<1.0 \\
<1.0 \\
<1.0 \\
<1.0 \\
<1.0\end{array}$ & $\begin{array}{l}<10 \\
<10 \\
<10 \\
<10 \\
<10\end{array}$ \\
\hline $\begin{array}{l}415307093234701 \\
420141093365701 \\
420141093363601 \\
413535091013001 \\
415502092240105\end{array}$ & $\begin{array}{l}07-25-85 \\
08-28-85 \\
08-28-85 \\
04-26-85 \\
07-29-85\end{array}$ & $\begin{array}{r}200 \\
300 \\
300 \\
400 \\
<100\end{array}$ & $\begin{array}{l}<1 \\
<1 \\
<1 \\
<1 \\
<1\end{array}$ & $\begin{array}{l}<10 \\
<10 \\
<10 \\
<10 \\
<10\end{array}$ & $\begin{array}{r}20 \\
20 \\
<10 \\
<10 \\
20\end{array}$ & $\begin{array}{l}<10 \\
<10 \\
<10 \\
<10 \\
<10\end{array}$ & $\begin{array}{l}<1.0 \\
<1.0 \\
<1.0 \\
<1.0 \\
<1.0\end{array}$ & $\begin{array}{l}<10 \\
<10 \\
<10 \\
<10 \\
<10\end{array}$ \\
\hline $\begin{array}{l}415935092351801 \\
415749092345301 \\
415852092424901 \\
420533092403802 \\
421122092431102\end{array}$ & $\begin{array}{l}06-26-85 \\
06-26-85 \\
06-26-85 \\
07-29-85 \\
06-27-85\end{array}$ & $\begin{array}{r}<100 \\
200 \\
200 \\
<100 \\
<100\end{array}$ & $\begin{array}{l}<1 \\
<1 \\
<1 \\
<1 \\
<1\end{array}$ & $\begin{array}{l}<10 \\
<10 \\
<10 \\
<10 \\
<10\end{array}$ & $\begin{array}{r}<10 \\
10 \\
<10 \\
<10 \\
20\end{array}$ & $\begin{array}{l}<10 \\
<10 \\
<10 \\
<10 \\
<10\end{array}$ & $\begin{array}{r}<1.0 \\
<1.0 \\
<1.0 \\
<1.0 \\
2.0\end{array}$ & $\begin{array}{l}<10 \\
<10 \\
<10 \\
<10 \\
<10\end{array}$ \\
\hline
\end{tabular}


STATION NUMBER DATE

411644091110701 04-10-85 $411652091213801 \quad 05-01-85$ 411539091221501 04-25-85 431844096263501 12-03-84 411213092531501 09-26-85

$412310093160601 \quad 04-30-85$ $415534093111501 \quad 09-24-85$ $410114095300001 \quad 08-08-85$ $410116095464101 \quad 08-08-85$ $43133709246190108-06-85$

405559094591501 08-07-85 $410216095113401 \quad 08-07-85$ $412321091034801 \quad 04-26-85$ $412329091041301 \quad 04-26-85$ 412213091063601 04-26-85

413428091094601 04-26-85 $425859095403201 \quad 12-05-84$ $431045095413801 \quad 12-05-84$ 431703095272401 12-04-84 432314095320001 12-04-84

$432646095260201 \quad 32-04-84$ 404517095245301 08-21-85

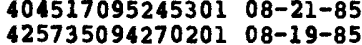
423536095583501 09-18-85 424306096145701 09-16-85

424916095581201 09-17-85 $424838096161001 \quad 09-17-85$ $424528096362001 \quad 09-04-85$ $424948096332901 \quad 09-04-85$ 413418093432403 09-26-85

414051093190902 09-11-85 $414409093241001 \quad 09-11-85$ 111201095252801 08-06-85 $411356095360801 \quad 08-05-85$ $411838095252801 \quad 08-07-85$

$412327095215401 \quad 08-06-85$ $412654095371201 \quad 08-06-85$ $413449092223901 \quad 07-29-85$ $413429092420401 \quad 07-29-85$ 413933090351301 01-08-85

$413437095034401 \quad 06-11-85$ $413048095260701 \quad 06-13-85$ $413842095184201 \quad 06-13-85$ $413810095185401 \quad 06-13-85$ 414340095160301 06-19-85

414622095250101 06-13-85 $414407095284101 \quad 06-19-85$ 414729095124001 06-19-85 414932095201902 06-12-85 425904095522801 12-06-84

425749096104201 12-11-84 $425820096184601 \quad 12-11-84$ 430108096093801 12-05-84 $43113309607590212-03-8$ 415403093181001 07-25-85

$415307093234701 \quad 07-25-85$ $420141093365701 \quad 08-28-85$ 420141093363602 08-28-85 413535091013001 04-26-85 415502092240105 07-29-85

$415935092351801 \quad 06-26-85$ $415749092345301 \quad 06-26-85$ 415852092424901 06-26-85 $\$ 20533092403802$ 07-29-85 $421122092431102 \quad 06-27-85$

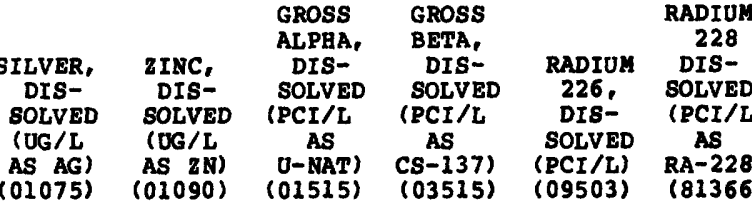

$\begin{array}{ll}<10 & <10 \\ <10 & <10 \\ <10 & <10 \\ <10 & <10 \\ <10 & <10 \\ <10 & <10 \\ <10 & <10 \\ <10 & <10 \\ <10 & <10 \\ <10 & <10 \\ <10 & 30 \\ <10 & <10 \\ <10 & <10 \\ <10 & <10 \\ <10 & <10 \\ <10 & <10 \\ <10 & <10 \\ <10 & <10 \\ <10 & 20 \\ <10 & <10\end{array}$

\section{$<0.3$}

0.8

$<0.2$

19.1

14

6.0

4.0

1.6

0.4

1.8

$<0.2$

0.6
0.8

$\begin{array}{ccc}2.0 & -- & 3.0 \\ 4.0 & -- & -- \\ 3.0 & - & - \\ 39 & 15 & 2.0\end{array}$

2.0

5.9

3.8

2.7
0.8

$<10 \quad 10 \quad 2$

2.9
1.5

32.

6.5

$<10 \quad 10$

$<10$

$<10$

$<10$

$<10$

12

20
$<10$

$<10$

$<10$

$<10<10$

$<10 \quad<10$

$<10$

$<10$

$<10<10$

$<10 \quad<10$

$<10$

$<10<10$

$<10 \quad 20$

$<10$

$<10$

$<10$

$<10$

10

$<10$

$<10$

$<10$
$<10$

$<10$

3.1

16

3.9

5.0

3.2
2.8

3.2

7.0

6.0

7.0

0.3

1.4

2.3

1.6

0.8

0.1

0.9

5.0

0.5
7.0

$<10<10$

24.2

0.3
4.7

$<10$

$<10$

$<0$
20

11

$<10<10 \quad 3.9$

$<10 \quad<0.2$

3.2
3.0

3.0
1.9

0.7

7.9

2.9
2.8

$<0.3$

2.4
$37.10 \quad 1.7$

$\begin{array}{rrr}3.0 & 1.3 & 0.2 \\ 0.5 & 0.6\end{array}$

$\begin{array}{lll}10 & 1.1 \quad 1.6\end{array}$

$4.0 \quad--\quad=$

$2.0 \quad=-$

$\begin{array}{lll}2.0 & -- & -\end{array}$

$\begin{array}{lll}5.0 & -0.5 & 0.6\end{array}$

$2.0 \quad=-.5$

$1.0 \quad=-$

$\begin{array}{lll}9.0 & -- & -- \\ 1.0 & -- & --\end{array}$

27

9.0

$0.3 \quad 1.1$

4.0

9.0

15

13

3.0

3.0
4.0

4.0
$<0.5$

1.0

$<0.7$

25

25.0
1.0

0.20 .9

$\begin{array}{ll}0.5 & 1.0 \\ 0.4 & <0.7\end{array}$

$--$

$<0$.

$0.7<0.7$

$\begin{array}{ll}0.3 & 1.4 \\ 0.9 & 3.5\end{array}$

$0.3 \quad 0.9$

4.0

$\begin{array}{lr}0.5 & 2.5 \\ 0.8 & 1.7 \\ 2.6 & <0.6 \\ 3.0 & 0.6\end{array}$

$3.0 \quad 0.6$

0.4 --

$\begin{array}{lll}4.0 & -- & =\end{array}$

$100 \quad=-$

$\begin{array}{lll}8.0 & - & - \\ 3.0 & 0.4 & <0.6\end{array}$

5.0

$\therefore$

$\begin{array}{lll}5.0 & 0.3 & 0.6\end{array}$

$\begin{array}{ccc}8.0 & - & -1.6\end{array}$

$21 \quad--3 \quad=$

30.0

30
12

$\begin{array}{rr}-1.3 & <0.4 \\ -3.1 & 1.3 \\ 1.5 & 8.6\end{array}$

$\begin{array}{lll}4.0 & 1.2 & 0.7\end{array}$

$\begin{array}{lll}6.0 & - & - \\ 4.0 & 1.3 & 0.7\end{array}$

.2

.7

6

.

9

.0

.4

(n)

.6

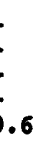

.6

4

.6

${ }_{2.0}=\quad=$

$\begin{array}{ccc}15 & 6.8 & 2.5 \\ 2.0 & = & = \\ 3.0 & = & = \\ 10 & = & = \\ 1.0 & - & \end{array}$ 


\begin{tabular}{|c|c|c|c|c|c|c|c|}
\hline TATION NUMBER & DATE & $\begin{array}{l}\text { ATRA- } \\
\text { Z INE, } \\
\text { TOTAL } \\
\text { (UG/L) } \\
(39630)\end{array}$ & $\begin{array}{l}\text { CYAN- } \\
\text { AZINE } \\
\text { TOTAL } \\
(U G / L) \\
(81757)\end{array}$ & $\begin{array}{l}\text { METRI- } \\
\text { BUZ IN } \\
\text { IN } \\
\text { WHOLE } \\
\text { WATER } \\
\text { (UG/L) } \\
(81408)\end{array}$ & $\begin{array}{c}\text { ALA- } \\
\text { CHLOR } \\
\text { TOTAL } \\
\text { RECOVER } \\
\text { (OG/L) } \\
(77825)\end{array}$ & $\begin{array}{l}\text { METOLA- } \\
\text { CHLOR } \\
\text { IN } \\
\text { WHOLE } \\
\text { WATER } \\
\text { (UG/L) } \\
(39356)\end{array}$ & $\begin{array}{l}\text { TRI- } \\
\text { FLURA- } \\
\text { LIN } \\
\text { TOTAL } \\
\text { RECOVER } \\
(\text { OG/L) } \\
(39030)\end{array}$ \\
\hline $\begin{array}{l}411644091110701 \\
411652091213801 \\
411539091221501 \\
431844096263501 \\
111213092531501\end{array}$ & $\begin{array}{l}04-10-85 \\
05-01-85 \\
04-25-85 \\
12-03-84 \\
09-26-85\end{array}$ & $\begin{array}{l}<0.1 \\
<0.1 \\
<0.1 \\
--\end{array}$ & $\begin{array}{l}<0.1 \\
<0.1 \\
<0.1 \\
--\end{array}$ & $\begin{array}{l}<0.05 \\
<0.05 \\
<0.05 \\
\therefore-\end{array}$ & $\begin{array}{l}<0.1 \\
<0.1 \\
<0.1 \\
-\therefore\end{array}$ & $\begin{array}{l}<0.1 \\
<0.1 \\
<0.1 \\
--\end{array}$ & $\begin{array}{l}<0.05 \\
<0.05 \\
<0.05 \\
--\end{array}$ \\
\hline $\begin{array}{l}412310093160601 \\
41553409311501 \\
410114095300001 \\
410116095461101 \\
431337092461901\end{array}$ & $\begin{array}{l}04-30-85 \\
09-24-85 \\
08-08-85 \\
08-08-85 \\
08-06-85\end{array}$ & $\begin{array}{l}-- \\
<0.1 \\
<0.1\end{array}$ & $\begin{array}{l}-- \\
\overline{<0.1} \\
<0.1 \\
--\end{array}$ & $\begin{array}{l}=- \\
<0.05 \\
<0.05\end{array}$ & $\begin{array}{l}-\overline{-} \\
<0.1 \\
<0.1\end{array}$ & $\begin{array}{l}-- \\
<0.1 \\
<0.1 \\
--\end{array}$ & $\begin{array}{l}-- \\
<0.05 \\
<0.05\end{array}$ \\
\hline $\begin{array}{l}405559094591501 \\
410216095113401 \\
112321091034801 \\
112329091041301 \\
412213091063601\end{array}$ & $\begin{array}{l}08-07-85 \\
08-07-85 \\
04-26-85 \\
04-26-85 \\
04-26-85\end{array}$ & $\begin{array}{l}<0.1 \\
-0.36 \\
<0.1 \\
<0.1\end{array}$ & $\begin{array}{l}<0.1 \\
-- \\
<0.1 \\
<0.1 \\
<0.1\end{array}$ & $\begin{array}{l}<0.05 \\
<0.05 \\
<0.05 \\
<0.05\end{array}$ & $\begin{array}{l}<0.1 \\
<0.1 \\
<0.1 \\
<0.1 \\
<0.1\end{array}$ & $\begin{array}{l}<0.1 \\
<0.1 \\
<0.1 \\
<0.1\end{array}$ & $\begin{array}{l}<0.05 \\
<- \\
<0.05 \\
<0.05 \\
<0.05\end{array}$ \\
\hline $\begin{array}{l}413428091094601 \\
125859095403201 \\
431045095413801 \\
431703095272401 \\
432314095320001\end{array}$ & $\begin{array}{l}04-26-85 \\
12-05-84 \\
12-05-84 \\
12-04-84 \\
12-04-84\end{array}$ & $\begin{array}{l}= \\
\overline{-} \\
\bar{m}\end{array}$ & $\begin{array}{l}=- \\
=- \\
=\end{array}$ & $\begin{array}{l}= \\
= \\
=\end{array}$ & $\begin{array}{l}=- \\
=- \\
=- \\
--\end{array}$ & $\begin{array}{l}= \\
= \\
=\end{array}$ & $\begin{array}{l}= \\
= \\
=\end{array}$ \\
\hline $\begin{array}{l}132646095260201 \\
404517095245301 \\
125735094270201 \\
12353609583501 \\
424306096145701\end{array}$ & $\begin{array}{l}12-04-84 \\
08-21-85 \\
08-19-85 \\
09-18-85 \\
09-16-85\end{array}$ & $\begin{array}{l}-\overline{<0.1} \\
\overline{-} \\
\overline{1.9}\end{array}$ & $\begin{array}{l}-\overline{<0.1} \\
-\overline{-} \\
<0.1\end{array}$ & $\begin{array}{l}-\overline{<0} \\
=-05 \\
\overline{<0}\end{array}$ & $\begin{array}{l}-\overline{<0.1} \\
-\overline{<0} \\
\overline{<0.1}\end{array}$ & $\begin{array}{l}-\overline{<0.1} \\
\overline{-} \\
\overline{<0.1}\end{array}$ & $\begin{array}{l}<-\overline{005} \\
\overline{--} \\
<\overline{0.05}\end{array}$ \\
\hline $\begin{array}{l}424916095581201 \\
424838096161001 \\
124528096362001 \\
424948096332901 \\
113418093432403\end{array}$ & $\begin{array}{l}09-17-85 \\
09-17-85 \\
09-04-85 \\
09-04-85 \\
09-26-85\end{array}$ & $\begin{array}{l}-- \\
<0.1 \\
<0.1 \\
<0.1 \\
0.87\end{array}$ & $\begin{array}{l}-- \\
<0.1 \\
<0.1 \\
<0.1 \\
<0.1\end{array}$ & $\begin{array}{l}-- \\
<0.05 \\
<0.05 \\
<0.05 \\
<0.05\end{array}$ & $\begin{array}{l}- \\
<0.1 \\
<0.1 \\
<0.1 \\
<0.1\end{array}$ & $\begin{array}{l}-- \\
<0.1 \\
<0.1 \\
<0.1 \\
<0.1\end{array}$ & $\begin{array}{l}<- \\
<0.05 \\
<0.05 \\
<0.05 \\
<0.05\end{array}$ \\
\hline $\begin{array}{l}114051093190902 \\
414409093241001 \\
11120109525801 \\
41135609560801 \\
111838095252801\end{array}$ & $\begin{array}{l}09-11-85 \\
09-11-85 \\
08-06-85 \\
08-06-85 \\
08-07-85\end{array}$ & $\begin{array}{l}<0.1 \\
<0.1 \\
0.24 \\
<0.1 \\
-\infty\end{array}$ & $\begin{array}{l}<0.1 \\
<0.1 \\
<0.1 \\
<0.1\end{array}$ & $\begin{array}{l}<0.05 \\
<0.05 \\
<0.05 \\
<0.05 \\
--\end{array}$ & $\begin{array}{l}<0.1 \\
<0.1 \\
<0.1 \\
<0.1 \\
--\end{array}$ & $\begin{array}{l}<0.1 \\
<0.1 \\
<0.1 \\
<0.1 \\
--\end{array}$ & $\begin{array}{l}<0.05 \\
<0.05 \\
<0.05 \\
<0.05\end{array}$ \\
\hline $\begin{array}{l}412327095215401 \\
41265409531201 \\
41344902223901 \\
413429092420401 \\
413933090351301\end{array}$ & $\begin{array}{l}08-06-85 \\
08-06-85 \\
07-29-85 \\
07-29-85 \\
01-08-85\end{array}$ & $\begin{array}{l}<0.1 \\
<0.1 \\
-- \\
-\end{array}$ & $\begin{array}{l}<0.1 \\
\therefore<.1 \\
\therefore \\
-\infty\end{array}$ & $\begin{array}{l}<0.05 \\
-- \\
<0.05 \\
-\infty\end{array}$ & $\begin{array}{l}<0.1 \\
-- \\
<0.1 \\
=-\end{array}$ & $\begin{array}{l}<0.1 \\
-- \\
<0.1 \\
--\end{array}$ & $\begin{array}{l}<0.05 \\
<0.05 \\
--\end{array}$ \\
\hline $\begin{array}{l}413437095034401 \\
413048095260701 \\
413842095184201 \\
413810095185401 \\
414340095160301\end{array}$ & $\begin{array}{l}06-11-85 \\
06-13-85 \\
06-13-85 \\
06-13-85 \\
06-19-85\end{array}$ & $\begin{array}{l}<0.1 \\
<0.1 \\
<0.1 \\
0.27 \\
<0.1\end{array}$ & $\begin{array}{l}<0.1 \\
<0.1 \\
<0.1 \\
<0.1 \\
<0.1\end{array}$ & $\begin{array}{l}<0.05 \\
<0.05 \\
<0.05 \\
<0.05 \\
<0.05\end{array}$ & $\begin{array}{l}<0.1 \\
0.19 \\
<0.1 \\
<0.1 \\
<0.1\end{array}$ & $\begin{array}{l}<0.1 \\
<0.1 \\
<0.1 \\
<0.1 \\
<0.1\end{array}$ & $\begin{array}{l}<0.05 \\
<0.05 \\
<0.05 \\
<0.05 \\
<0.05\end{array}$ \\
\hline $\begin{array}{l}414622095250101 \\
414407095284101 \\
414729095124001 \\
414932095201902 \\
425904095522801\end{array}$ & $\begin{array}{l}06-13-85 \\
06-19-85 \\
06-19-85 \\
06-12-85 \\
12-06-84\end{array}$ & $\begin{array}{l}<0.1 \\
<0.1 \\
<0.1 \\
<0.1\end{array}$ & $\begin{array}{l}<0.1 \\
-<0.1 \\
<0.1 \\
<0.08\end{array}$ & $\begin{array}{l}<0.05 \\
>0.05 \\
<0.05 \\
<0.01\end{array}$ & $\begin{array}{l}<0.1 \\
-- \\
<0.1 \\
<0.1 \\
<0.08\end{array}$ & $\begin{array}{l}<0.1 \\
<0.1 \\
<0.1 \\
<0.1\end{array}$ & $\begin{array}{l}<0.05 \\
<0.05 \\
<0.05 \\
<0.05\end{array}$ \\
\hline $\begin{array}{l}425749096104201 \\
425820096184601 \\
43010809609801 \\
431133096075902 \\
415403093181001\end{array}$ & $\begin{array}{l}12-11-84 \\
12-11-84 \\
12-05-84 \\
12-03-84 \\
07-25-85\end{array}$ & $\begin{array}{l}= \\
=- \\
=\end{array}$ & $\begin{array}{l}= \\
=- \\
=\end{array}$ & $\begin{array}{l}=- \\
=- \\
=-\end{array}$ & $\begin{array}{l}= \\
= \\
-\end{array}$ & $\begin{array}{l}=- \\
=- \\
=-\end{array}$ & $=$ \\
\hline $\begin{array}{l}415307093234701 \\
420141093365701 \\
420141093363601 \\
413535091013001 \\
415502092240105\end{array}$ & $\begin{array}{l}07-25-85 \\
08-28-85 \\
08-28-85 \\
04-26-85 \\
07-29-85\end{array}$ & $\begin{array}{l}<0.1 \\
<0.1 \\
<0.1 \\
<0.1\end{array}$ & $\begin{array}{l}<0.1 \\
<0.1 \\
<0.1 \\
<0.1\end{array}$ & $\begin{array}{l}<0.05 \\
<0.05 \\
<0.05 \\
<0.05\end{array}$ & $\begin{array}{l}<0.1 \\
<0.1 \\
<0.1 \\
<0.1\end{array}$ & $\begin{array}{l}<0.1 \\
<0.1 \\
<0.1 \\
<0.1\end{array}$ & $\begin{array}{l}<0.05 \\
<0.05 \\
<0.05 \\
<0.05\end{array}$ \\
\hline $\begin{array}{l}\$ 15935092351801 \\
415749092345301 \\
415852092424901 \\
420533092403802 \\
421122092431102\end{array}$ & $\begin{array}{l}06-26-85 \\
06-26-85 \\
06-26-85 \\
07-29-85 \\
06-27-85\end{array}$ & $\begin{array}{l}-\overline{<0.1} \\
<0.1 \\
-0.59\end{array}$ & $\begin{array}{l}<0.1 \\
<0.1 \\
<0.2\end{array}$ & $\begin{array}{l}<0.05 \\
<0.05 \\
-0.36\end{array}$ & \begin{tabular}{l}
$-\ddot{<0}$ \\
$<0.1$ \\
$<0.1$ \\
\hdashline 0.53
\end{tabular} & $\begin{array}{l}-\overline{<} \\
<0.1 \\
<0.1 \\
-\overline{0.31}\end{array}$ & $\begin{array}{l}<- \\
<0.05 \\
<0.05 \\
<0.05\end{array}$ \\
\hline
\end{tabular}




\begin{tabular}{|c|c|c|c|c|c|c|c|}
\hline TATION NUMBER & DATE & $\begin{array}{c}\text { DICAMBA } \\
\text { (MED- } \\
\text { IBEN) } \\
\text { (BAN- } \\
\text { VEL D) } \\
\text { TOTAL } \\
\text { (UG/L) } \\
\text { (82052) }\end{array}$ & $\begin{array}{c}2,4-D \\
\text { TOTAL } \\
\text { (UG/L) } \\
(39730)\end{array}$ & $\begin{array}{l}\text { SILVEX, } \\
\text { TOTAL } \\
\text { (UG/L) } \\
(39760)\end{array}$ & $\begin{array}{l}\text { DYFO- } \\
\text { NATE } \\
\text { (UG/L) } \\
(81294)\end{array}$ & $\begin{array}{l}\text { TERBU- } \\
\text { FOS } \\
\text { (UG/L) } \\
(82088)\end{array}$ & $\begin{array}{l}\text { PHORATE } \\
\text { OTAL } \\
\text { (UG/L) } \\
(39023)\end{array}$ \\
\hline $\begin{array}{l}411644091110701 \\
411652091213801 \\
411539091221501 \\
431844096263501 \\
411213092531501\end{array}$ & $\begin{array}{l}04-10-85 \\
05-01-85 \\
04-25-85 \\
12-03-84 \\
09-26-85\end{array}$ & $\begin{array}{l}<0.07 \\
<0.07 \\
<0.07 \\
-- \\
--\end{array}$ & $\begin{array}{l}<0.07 \\
<0.07 \\
<0.07 \\
-- \\
--\end{array}$ & $\begin{array}{l}<0.05 \\
<0.05 \\
<0.05 \\
-- \\
--\end{array}$ & $\begin{array}{l}<0.1 \\
<0.1 \\
<0.1 \\
-- \\
--\end{array}$ & $\begin{array}{l}<0.1 \\
<0.1 \\
<0.1 \\
-- \\
--\end{array}$ & $\begin{array}{l}<0.1 \\
<0.1 \\
<0.1 \\
-- \\
--\end{array}$ \\
\hline $\begin{array}{l}412310093160601 \\
415534093111501 \\
41011409500001 \\
410116095464101 \\
431337092461901\end{array}$ & $\begin{array}{l}04-30-85 \\
09-24-85 \\
08-08-85 \\
08-08-85 \\
08-06-85\end{array}$ & $\begin{array}{l}-- \\
<0.07 \\
<0.07\end{array}$ & $\begin{array}{l}-- \\
-\overline{<0.07} \\
<0.07 \\
--\end{array}$ & $\begin{array}{l}-- \\
-\overline{<} \\
<0.05 \\
--\end{array}$ & $\begin{array}{l}-- \\
-\overline{<0.1} \\
<0.1 \\
--\end{array}$ & $\begin{array}{l}-- \\
=- \\
=- \\
--\end{array}$ & $\begin{array}{l}-- \\
-\overline{<0.1} \\
<0.1 \\
--\end{array}$ \\
\hline $\begin{array}{l}405559094591501 \\
410216095113401 \\
412321091034801 \\
412329091041301 \\
412213091063601\end{array}$ & $\begin{array}{l}08-07-85 \\
08-07-85 \\
04-26-85 \\
04-26-85 \\
04-26-85\end{array}$ & $\begin{array}{l}<0.07 \\
-- \\
<0.07 \\
<0.07 \\
<0.07\end{array}$ & $\begin{array}{l}<0.07 \\
-- \\
<0.07 \\
<0.07 \\
<0.07\end{array}$ & $\begin{array}{l}<0.05 \\
-- \\
<0.05 \\
<0.05 \\
<0.05\end{array}$ & $\begin{array}{l}<0.1 \\
-- \\
<0.1 \\
<0.1 \\
<0.1\end{array}$ & $\begin{array}{l}-- \\
=- \\
\overline{<0.1} \\
--\end{array}$ & $\begin{array}{l}<0.1 \\
-- \\
<0.1 \\
<0.1 \\
<0.1\end{array}$ \\
\hline $\begin{array}{l}413428091094601 \\
425859095403201 \\
431045095413801 \\
431703095272401 \\
432314095320001\end{array}$ & $\begin{array}{l}04-26-85 \\
12-05-84 \\
12-05-84 \\
12-04-84 \\
12-04-84\end{array}$ & $\begin{array}{l}=- \\
=- \\
=\end{array}$ & $\begin{array}{l}=- \\
=- \\
=- \\
--\end{array}$ & $\begin{array}{l}-- \\
=- \\
-- \\
--\end{array}$ & $\begin{array}{l}-- \\
=- \\
-- \\
--\end{array}$ & $\begin{array}{l}-- \\
=- \\
z-\end{array}$ & $\begin{array}{l}-- \\
-- \\
-- \\
--\end{array}$ \\
\hline $\begin{array}{l}432646095260201 \\
404517095245301 \\
425735094270201 \\
42353609558501 \\
424306096145701\end{array}$ & $\begin{array}{l}12-04-84 \\
08-21-85 \\
08-19-85 \\
09-18-85 \\
09-16-85\end{array}$ & $\begin{array}{c}\ddot{0.07} \\
\ddot{-} \\
<0.07\end{array}$ & $\begin{array}{l}-- \\
<0.07 \\
\overline{-} \\
<0.07\end{array}$ & $\begin{array}{l}-\overline{<0} \\
\overline{-} .05 \\
\overline{<}\end{array}$ & $\begin{array}{l}-\overline{<0} \\
-\overline{0} \\
\overline{-} \\
<0.1\end{array}$ & $\begin{array}{l}=- \\
=- \\
=-\end{array}$ & $\begin{array}{l}-\overline{<0.1} \\
-\overline{0} \\
\overline{<0.1}\end{array}$ \\
\hline $\begin{array}{l}424916095581201 \\
424838096161001 \\
424528096362001 \\
424948096332901 \\
413418093432403\end{array}$ & $\begin{array}{l}09-17-85 \\
09-17-85 \\
09-04-85 \\
09-04-85 \\
09-26-85\end{array}$ & $\begin{array}{l}<- \\
<0.07 \\
<0.07 \\
<0.07 \\
<0.07\end{array}$ & $\begin{array}{l}-- \\
<0.07 \\
<0.07 \\
<0.07 \\
<0.07\end{array}$ & $\begin{array}{l}<- \\
<0.05 \\
<0.05 \\
<0.05 \\
<0.05\end{array}$ & $\begin{array}{l}-- \\
<0.1 \\
<0.1 \\
<0.1 \\
<0.1\end{array}$ & $\begin{array}{l}=- \\
\overline{-} \\
\overline{<0} .1\end{array}$ & $\begin{array}{l}-- \\
<0.1 \\
<0.1 \\
<0.1 \\
<0.1\end{array}$ \\
\hline $\begin{array}{l}414051093190902 \\
414409093241001 \\
411201095252801 \\
411356095360801 \\
411838095252801\end{array}$ & $\begin{array}{l}09-11-85 \\
09-11-85 \\
08-06-85 \\
08-06-85 \\
08-07-85\end{array}$ & $\begin{array}{l}<0.07 \\
<0.07 \\
<0.07 \\
<0.07 \\
--\end{array}$ & $\begin{array}{l}<0.07 \\
<0.07 \\
<0.07 \\
<0.07 \\
--\end{array}$ & $\begin{array}{l}<0.05 \\
<0.05 \\
<0.05 \\
<0.05 \\
--\end{array}$ & $\begin{array}{l}<0.1 \\
<0.1 \\
<0.1 \\
<0.1 \\
--\end{array}$ & $\begin{array}{l}<0.1 \\
=- \\
=- \\
=-\end{array}$ & $\begin{array}{l}<0.1 \\
<0.1 \\
<0.1 \\
<0.1 \\
-\infty\end{array}$ \\
\hline $\begin{array}{l}412327095215401 \\
412654095371201 \\
413449092223901 \\
413429092420401 \\
413933090351301\end{array}$ & $\begin{array}{l}08-06-85 \\
08-06-85 \\
07-29-85 \\
07-29-85 \\
01-08-85\end{array}$ & $\begin{array}{l}<0.07 \\
-- \\
<0.07 \\
--\end{array}$ & $\begin{array}{l}<0.07 \\
-- \\
<0.07 \\
--\end{array}$ & $\begin{array}{l}<0.05 \\
-- \\
<0.05 \\
=-\end{array}$ & $\begin{array}{l}<0.1 \\
-\infty \\
<0.1 \\
--\end{array}$ & $\begin{array}{l}-- \\
=- \\
--\end{array}$ & $\begin{array}{l}<0.1 \\
<- \\
<0.1 \\
--\end{array}$ \\
\hline $\begin{array}{l}413437095034401 \\
413048095260701 \\
413842095184201 \\
413810095185401 \\
414340095160301\end{array}$ & $\begin{array}{l}06-11-85 \\
06-13-85 \\
06-13-85 \\
06-13-85 \\
06-19-85\end{array}$ & $\begin{array}{l}<0.07 \\
<0.07 \\
<0.07 \\
<0.07 \\
<0.07\end{array}$ & $\begin{array}{l}<0.07 \\
<0.07 \\
<0.07 \\
<0.07 \\
<0.07\end{array}$ & $\begin{array}{l}<0.05 \\
<0.05 \\
<0.05 \\
<0.05 \\
<0.05\end{array}$ & $\begin{array}{l}<0.1 \\
<0.1 \\
<0.1 \\
<0.1 \\
<0.1\end{array}$ & $\begin{array}{l}-- \\
-- \\
--\end{array}$ & $\begin{array}{l}<0.1 \\
<0.1 \\
<0.1 \\
<0.1 \\
<0.1\end{array}$ \\
\hline $\begin{array}{l}414622095250101 \\
414407095284101 \\
414729095124001 \\
414932095201902 \\
425904095522801\end{array}$ & $\begin{array}{l}06-13-85 \\
06-19-85 \\
06-19-85 \\
06-12-85 \\
12-06-84\end{array}$ & $\begin{array}{l}<0.07 \\
<- \\
<0.07 \\
<0.07 \\
<0.07\end{array}$ & $\begin{array}{l}<0.07 \\
-<0.07 \\
<0.07 \\
<0.07\end{array}$ & $\begin{array}{l}<0.05 \\
-- \\
<0.05 \\
<0.05 \\
<0.05\end{array}$ & $\begin{array}{l}<0.1 \\
-- \\
<0.1 \\
<0.1 \\
<0.1\end{array}$ & $\begin{array}{l}=- \\
=- \\
--\end{array}$ & $\begin{array}{l}<0.1 \\
-<0.1 \\
<0.1 \\
<0.1\end{array}$ \\
\hline $\begin{array}{l}425749096104201 \\
425820096184601 \\
430108096093801 \\
431133096075902 \\
415403093181001\end{array}$ & $\begin{array}{l}12-11-84 \\
12-11-84 \\
12-05-84 \\
12-03-84 \\
07-25-85\end{array}$ & $\begin{array}{l}=- \\
=- \\
=\end{array}$ & $\begin{array}{l}= \\
=- \\
=\end{array}$ & $\begin{array}{l}=- \\
=- \\
z\end{array}$ & $\begin{array}{l}=- \\
-- \\
--\end{array}$ & $\begin{array}{l}-- \\
-- \\
--\end{array}$ & $\begin{array}{l}= \\
\bar{z} \\
=\end{array}$ \\
\hline $\begin{array}{l}415307093234701 \\
420141093365701 \\
420141093363601 \\
413535091013001 \\
415502092240105\end{array}$ & $\begin{array}{l}07-25-85 \\
08-28-85 \\
08-28-85 \\
04-26-85 \\
07-29-85\end{array}$ & $\begin{array}{l}<0.07 \\
<0.07 \\
<0.07 \\
-0 \\
<0.07\end{array}$ & $\begin{array}{l}<0.07 \\
<0.07 \\
<0.07 \\
-<0.07\end{array}$ & $\begin{array}{l}<0.05 \\
<0.05 \\
<0.05 \\
-- \\
<0.05\end{array}$ & $\begin{array}{l}<0.1 \\
<0.1 \\
<0.1 \\
-\infty 0.1\end{array}$ & $\begin{array}{l}<0.1 \\
-- \\
=- \\
--\end{array}$ & $\begin{array}{l}<0.1 \\
<0.1 \\
<0.1 \\
-\overline{<0.1}\end{array}$ \\
\hline $\begin{array}{l}415935092351801 \\
415749092345301 \\
415852092424901 \\
420533092403802 \\
421122092431102\end{array}$ & $\begin{array}{l}06-26-85 \\
06-26-85 \\
06-26-85 \\
07-29-85 \\
06-27-85\end{array}$ & $\begin{array}{l}<- \\
<0.07 \\
<0.07 \\
\ddot{2.3}\end{array}$ & $\begin{array}{l}-- \\
<0.07 \\
<0.07 \\
-0.07\end{array}$ & $\begin{array}{l}-- \\
<0.05 \\
<0.05 \\
\overline{<0.05}\end{array}$ & $\begin{array}{l}-- \\
<0.1 \\
<0.1 \\
<0.1\end{array}$ & $\begin{array}{l}\overline{-} \\
-- \\
\overline{-} \\
<0.1\end{array}$ & $\begin{array}{l}-\overline{<0.1} \\
<0.1 \\
-\overline{<0.1}\end{array}$ \\
\hline
\end{tabular}


STATION NUMBER

$40365909428530106732 \mathrm{Wl}$ 2CAAD $41273609324130107722 \mathrm{~W} 21 \mathrm{BCBD}$ 41303709329030107823 W34DDCA 42155209410370208629 W13BACC 42252109409090208828 W1 9ACBA

$42301909421430108930 \mathrm{~W} 23 \mathrm{CBC}$ 43161609338350109824 W26DCDC 43155609337540109824 W26DDCC 43232309357160109926 W1 8DACD $42140609613450108646 \mathrm{~W} 29 \mathrm{CBAB}$

$42283309546330108942 W 34 C D C$ $42292409604180108944 \mathrm{~W} 29 \mathrm{CCDD}$ 42284809621070108947 W3 5DADD 43171309312140209820 W21DDAA 43210909312450109920 W3 BDAB

42413509336280109123 W18DBCA $42392309330070109123 \mathrm{~W} 36 \mathrm{AAC}$ $42395409353580109126 \mathrm{~W} 27 \mathrm{DB}$ 42442209332400109223 W34ACC
STATION NAME COUNTY

1960BLOCKTON NO 1

247691978 HARTFORD NO 1971CARL ISLE NO 4

07307 1955HARCOURT TOWN NO 2 19780 THO NO 3

14551 1964BARNUM TOWN WELL 1 1973FOREST CITY NO 3

003041934 FOREST CITY 2

16406 1964BUFFALO CENTER 1980 SLOAN NO 3 -NEW WELL

088541957 CORRECT IONVILLE NO 2 1934 MOVILLE NO 2 1956SIOUX CITY 1-SP PARR 1920 MANLY NO 2 EAST

19172 1966KENSETT NO 2

1945GALT 1

03121 1948DOWS IOWA \#1

1952EAGLE GROVE

02929 1947ROWAN TWN 1

COUNTY
TAYLOR
WARREN
WARREN
WEBSTER
WEBSTER
WEBSTER
WINNEBAGO
WINNEBAGO
WINNEBAGO
WOODBURY
WOODBURY
WOODBURY
WOODBURY
WORTE
WORTH
WRIGHT
WRIGHT
WRIGHT
WRIGH

WRIGH'

\begin{tabular}{|c|c|c|c|}
\hline DATE & TIME & $\begin{array}{l}\text { GEO- } \\
\text { LOGIC } \\
\text { UNIT }\end{array}$ & $\begin{array}{l}\text { DEPTH } \\
\text { OF } \\
\text { WELL, } \\
\text { TOTAL } \\
\text { (FEET) } \\
\text { (72008) }\end{array}$ \\
\hline $\begin{array}{l}08-20-85 \\
09-11-85 \\
09-11-85 \\
08-06-85 \\
09-06-85\end{array}$ & $\begin{array}{l}13: 15 \\
15: 15 \\
14: 00 \\
12: 45 \\
10: 15\end{array}$ & $\begin{array}{l}112 \mathrm{PLSC} \\
367 \mathrm{PRDC} \\
111 \mathrm{ALVM} \\
340 \mathrm{DVNN} \\
340 \mathrm{DVNN}\end{array}$ & $\begin{array}{r}271.00 \\
2120.00 \\
50.00 \\
1249.00 \\
1050.00\end{array}$ \\
\hline $\begin{array}{l}08-22-85 \\
06-17-85 \\
06-17-85 \\
06-17-85 \\
09-05-85\end{array}$ & $\begin{array}{l}11: 15 \\
12: 35 \\
12: 00 \\
10: 30 \\
09: 00\end{array}$ & $\begin{array}{l}341 \mathrm{LMCK} \\
3600 \mathrm{ODC} \\
344 \mathrm{CDVL} \\
364 \mathrm{GLEN} \\
111 \mathrm{ALVM}\end{array}$ & $\begin{array}{l}850.00 \\
305.00 \\
142.00 \\
465.00 \\
104.00\end{array}$ \\
\hline $\begin{array}{l}09-18-85 \\
09-17-85 \\
09-04-85 \\
06-17-85 \\
06-17-85\end{array}$ & $\begin{array}{l}11: 45 \\
16: 00 \\
08: 00 \\
13: 55 \\
14: 05\end{array}$ & $\begin{array}{l}111 \mathrm{ALVM} \\
111 \mathrm{ALVM} \\
217 \mathrm{DKOT} \\
344 \mathrm{CDVL} \\
344 \mathrm{CDVL}\end{array}$ & $\begin{array}{r}50.00 \\
49.00 \\
390.00 \\
439.00 \\
303.00\end{array}$ \\
\hline $\begin{array}{l}06-11-85 \\
06-07-85 \\
06-07-85 \\
06-07-85\end{array}$ & $\begin{array}{l}12: 00 \\
13: 30 \\
09: 35 \\
12: 00\end{array}$ & $\begin{array}{l}330 \mathrm{MSSP} \\
344 \mathrm{CDVL} \\
112 \mathrm{PLSC} \\
339 \mathrm{KDRK}\end{array}$ & $\begin{array}{r}155.00 \\
752.00 \\
70.00 \\
225.00\end{array}$ \\
\hline
\end{tabular}

\begin{tabular}{|c|c|c|c|c|c|c|c|c|}
\hline STATION NUMBER & DATE & $\begin{array}{c}\text { FLOW } \\
\text { RATE } \\
\text { (GPM) } \\
(00058)\end{array}$ & $\begin{array}{c}\text { PUMP } \\
\text { OR FLOW } \\
\text { PERIOD } \\
\text { PRIOR } \\
\text { TO SAM- } \\
\text { PLING } \\
\text { (MIN) } \\
(72004)\end{array}$ & $\begin{array}{l}\text { SPE- } \\
\text { CIFIC } \\
\text { CON- } \\
\text { DUCT- } \\
\text { ANCE } \\
\text { (US/CM) } \\
(00095)\end{array}$ & $\begin{array}{c}\text { PH } \\
\text { (STAND- } \\
\text { ARD } \\
\text { UN ITS) } \\
(00400)\end{array}$ & $\begin{array}{l}\text { HARD- } \\
\text { NESS } \\
\text { (MG/L } \\
\text { AS } \\
\text { CACO3) } \\
(00900)\end{array}$ & $\begin{array}{l}\text { CALCIUM } \\
\text { DIS- } \\
\text { SOLVED } \\
\text { (MG/L } \\
\text { AS CA) } \\
(00915)\end{array}$ & $\begin{array}{c}\text { MAGNE- } \\
\text { SIUM, } \\
\text { DIS- } \\
\text { SOLVED } \\
\text { (MG/L } \\
\text { AS MG) } \\
(00925 \text { ) }\end{array}$ \\
\hline $\begin{array}{l}403659094285301 \\
412736093241301 \\
413037093290301 \\
421552094103702 \\
422521094090902\end{array}$ & $\begin{array}{l}08-20-85 \\
09-11-85 \\
09-11-85 \\
08-06-85 \\
09-06-85\end{array}$ & $\begin{array}{r}50 \\
300 \\
375 \\
60 \\
197\end{array}$ & $\begin{array}{r}60 \\
20 \\
120 \\
20 \\
20\end{array}$ & $\begin{array}{r}1750 \\
861 \\
548 \\
1290 \\
1040\end{array}$ & $\begin{array}{l}7.8 \\
7.4 \\
7.3 \\
7.5 \\
7.3\end{array}$ & $\begin{array}{l}130 \\
240 \\
280 \\
600 \\
490\end{array}$ & $\begin{array}{r}36 \\
58 \\
77 \\
130 \\
100\end{array}$ & $\begin{array}{l}9.8 \\
23 \\
22 \\
66 \\
58\end{array}$ \\
\hline $\begin{array}{l}423019094214301 \\
431616093383501 \\
431556093375401 \\
432323093571601 \\
421406096134501\end{array}$ & $\begin{array}{l}08-22-85 \\
06-17-85 \\
06-17-85 \\
06-17-85 \\
09-05-85\end{array}$ & $\begin{array}{r}45 \\
1100 \\
1450 \\
250 \\
300\end{array}$ & $\begin{array}{l}20 \\
20 \\
20 \\
30\end{array}$ & $\begin{array}{r}1120 \\
760 \\
740 \\
830 \\
1180\end{array}$ & $\begin{array}{l}7.2 \\
6.9 \\
6.9 \\
7.1 \\
7.3\end{array}$ & $\begin{array}{l}580 \\
370 \\
360 \\
320 \\
490\end{array}$ & $\begin{array}{r}140 \\
93 \\
92 \\
91 \\
120\end{array}$ & $\begin{array}{l}56 \\
33 \\
31 \\
23 \\
45\end{array}$ \\
\hline $\begin{array}{l}422833095463301 \\
422924096041801 \\
422848096210701 \\
431713093121402 \\
432109093124501\end{array}$ & $\begin{array}{l}09-18-85 \\
09-17-85 \\
09-04-85 \\
06-17-85 \\
06-17-85\end{array}$ & $\begin{array}{r}170 \\
120 \\
1000 \\
170 \\
350\end{array}$ & $\begin{array}{r}240 \\
180 \\
30 \\
30 \\
20\end{array}$ & $\begin{array}{l}820 \\
670 \\
650 \\
720\end{array}$ & $\begin{array}{l}7.3 \\
7.5 \\
7.2 \\
7.1 \\
7.2\end{array}$ & $\begin{array}{l}430 \\
320 \\
310 \\
350 \\
230\end{array}$ & $\begin{array}{r}120 \\
89 \\
89 \\
97 \\
62\end{array}$ & $\begin{array}{l}31 \\
24 \\
22 \\
27 \\
18\end{array}$ \\
\hline $\begin{array}{l}424135093362801 \\
423923093300701 \\
423954093535801 \\
424422093324001\end{array}$ & $\begin{array}{l}06-11-85 \\
06-07-85 \\
06-07-85 \\
06-07-85\end{array}$ & $\begin{array}{r}65 \\
140 \\
350 \\
90\end{array}$ & $\begin{array}{l}20 \\
20 \\
20\end{array}$ & $\begin{array}{l}680 \\
650 \\
710 \\
680\end{array}$ & $\begin{array}{l}7.1 \\
7.2 \\
7.1 \\
7.2\end{array}$ & $\begin{array}{l}350 \\
320 \\
350 \\
350\end{array}$ & $\begin{array}{l}98 \\
68 \\
93 \\
95\end{array}$ & $\begin{array}{l}25 \\
36 \\
28 \\
27\end{array}$ \\
\hline
\end{tabular}




\begin{tabular}{|c|c|c|c|c|c|c|c|c|}
\hline TATION NUMBER & DATE & $\begin{array}{l}\text { SODIUM, } \\
\text { DIS- } \\
\text { SOLVED } \\
\text { (MG/L } \\
\text { AS NA) } \\
(00930)\end{array}$ & $\begin{array}{c}\text { POTAS- } \\
\text { SIUM, } \\
\text { DIS- } \\
\text { SOLVED } \\
\text { (MG/L } \\
\text { AS R) } \\
(00935)\end{array}$ & $\begin{array}{c}\text { ALRA- } \\
\text { LINITY } \\
\text { LAE } \\
\text { (MG/L } \\
\text { AS } \\
\text { CACO3) } \\
(90410)\end{array}$ & $\begin{array}{l}\text { CHLO- } \\
\text { RIDE, } \\
\text { DIS- } \\
\text { SOLVED } \\
\text { (MG/L } \\
\text { AS CL) } \\
(00940)\end{array}$ & $\begin{array}{l}\text { SULFATE } \\
\text { DIS- } \\
\text { SOLVED } \\
\text { (MG/L } \\
\text { AS SO4) } \\
(00945)\end{array}$ & $\begin{array}{l}\text { FLUO- } \\
\text { RIDE, } \\
\text { DIS- } \\
\text { SOLVED } \\
\text { (MG/L } \\
\text { AS F) } \\
(00950)\end{array}$ & $\begin{array}{l}\text { SILICA, } \\
\text { DIS- } \\
\text { SOLVED } \\
\text { (MG/L } \\
\text { AS } \\
\text { SIO2) } \\
(00955)\end{array}$ \\
\hline $\begin{array}{l}403659094285301 \\
412736093241301 \\
413037093290301 \\
421552094103702 \\
422521094090902\end{array}$ & $\begin{array}{l}08-20-85 \\
09-11-85 \\
09-11-85 \\
08-06-85 \\
09-06-85\end{array}$ & $\begin{array}{c}330 \\
79 \\
8.2 \\
54 \\
41\end{array}$ & $\begin{array}{l}2.8 \\
15 \\
17.7 \\
17 \\
12\end{array}$ & $\begin{array}{l}422 \\
256 \\
199 \\
305 \\
337\end{array}$ & $\begin{array}{r}110 \\
27 \\
13 \\
8.5 \\
6.5\end{array}$ & $\begin{array}{r}240 \\
150 \\
94 \\
380 \\
230\end{array}$ & $\begin{array}{l}0.8 \\
1.7 \\
0.15 \\
2.4 \\
2.3\end{array}$ & $\begin{array}{r}12 \\
10 \\
24 \\
8.0 \\
8.0\end{array}$ \\
\hline $\begin{array}{l}423019094214301 \\
431616093383501 \\
431556093375401 \\
432323093571601 \\
421406096134501\end{array}$ & $\begin{array}{l}08-22-85 \\
06-17-85 \\
06-17-85 \\
06-17-85 \\
09-05-85\end{array}$ & $\begin{array}{l}65 \\
19 \\
17 \\
67 \\
48\end{array}$ & $\begin{array}{r}5.9 \\
2.9 \\
28 \\
3.7 \\
9.3\end{array}$ & $\begin{array}{l}393 \\
369 \\
371 \\
406 \\
457\end{array}$ & $\begin{array}{r}3.0 \\
<0.5 \\
0.5 \\
0.5 \\
77\end{array}$ & $\begin{array}{r}320 \\
48 \\
32 \\
52 \\
50\end{array}$ & $\begin{array}{l}0.7 \\
0.3 \\
0.3 \\
0.3 \\
0.4\end{array}$ & $\begin{array}{l}9.8 \\
22 \\
20 \\
24 \\
34\end{array}$ \\
\hline $\begin{array}{l}422833095463301 \\
422924096041801 \\
422848096210701 \\
431713093121402 \\
432109093124501\end{array}$ & $\begin{array}{l}09-18-85 \\
09-17-85 \\
09-04-85 \\
06-17-85 \\
06-17-85\end{array}$ & $\begin{array}{l}17 \\
15 \\
10 \\
12 \\
5.2\end{array}$ & $\begin{array}{l}2.2 \\
3.3 \\
5.7 \\
2.6 \\
0.4\end{array}$ & $\begin{array}{l}281 \\
269 \\
323 \\
324 \\
237\end{array}$ & $\begin{array}{l}26 \\
13 \\
1.5 \\
11 \\
3.0\end{array}$ & $\begin{array}{r}110 \\
38 \\
20 \\
55 \\
20\end{array}$ & $\begin{array}{l}0.2 \\
0.25 \\
0.4 \\
0.3 \\
0.2\end{array}$ & $\begin{array}{l}21 \\
24 \\
14 \\
12 \\
19\end{array}$ \\
\hline $\begin{array}{l}424135093362801 \\
423923093300701 \\
423954093535801 \\
424422093324001\end{array}$ & $\begin{array}{l}06-11-85 \\
06-07-85 \\
06-07-85 \\
06-07-85\end{array}$ & $\begin{array}{l}7.7 \\
18 \\
13 \\
16\end{array}$ & $\begin{array}{l}3.8 \\
13 \\
3.1 \\
1.6\end{array}$ & $\begin{array}{l}358 \\
319 \\
371 \\
365\end{array}$ & $\begin{array}{l}1.5 \\
4.5 \\
0.5 \\
3.0\end{array}$ & $\begin{array}{l}14 \\
41 \\
24 \\
7.0\end{array}$ & $\begin{array}{l}0.3 \\
2.3 \\
0.35 \\
0.4\end{array}$ & $\begin{array}{l}26 \\
91 \\
21\end{array}$ \\
\hline STATION NUMBER & DATE & $\begin{array}{l}\text { SOLIDS, } \\
\text { RESIDUE } \\
\text { AT } 105 \\
\text { DEG. C, } \\
\text { DIS- } \\
\text { SOLVED } \\
\text { (MG/L) } \\
(00515)\end{array}$ & $\begin{array}{c}\text { NITRO- } \\
\text { GEN, } \\
\text { NO2+NO3 } \\
\text { DIS- } \\
\text { SOLVED } \\
\text { (MG/L } \\
\text { AS N) } \\
(00631)\end{array}$ & $\begin{array}{c}\text { NITRO- } \\
\text { GEN, } \\
\text { AMMONIA } \\
\text { DIS- } \\
\text { SOLVED } \\
\text { (MG/L } \\
\text { AS N) } \\
(00608)\end{array}$ & $\begin{array}{l}\text { PHOS- } \\
\text { PHORUS, } \\
\text { ORTHO, } \\
\text { DIS- } \\
\text { SOLVED } \\
\text { (MG/L } \\
\text { AS P) } \\
(00671)\end{array}$ & $\begin{array}{l}\text { IRON, } \\
\text { DIS- } \\
\text { SOLVED } \\
\text { (UG/L } \\
\text { AS FE) } \\
(01046)\end{array}$ & $\begin{array}{l}\text { MANGA- } \\
\text { NESE, } \\
\text { DIS- } \\
\text { SOLVED } \\
\text { (UG/L } \\
\text { AS MN) } \\
(01056)\end{array}$ & $\begin{array}{l}\text { ARSENIC } \\
\text { DIS- } \\
\text { SOLVED } \\
\text { (UG/L } \\
\text { AS AS) } \\
(01000)\end{array}$ \\
\hline $\begin{array}{l}403659094285301 \\
412736093241301 \\
413037093290301 \\
421552094103702 \\
422521094090902\end{array}$ & $\begin{array}{l}08-20-85 \\
09-11-85 \\
09-11-85 \\
08-06-85 \\
09-06-85\end{array}$ & $\begin{array}{r}1080 \\
519 \\
339 \\
868 \\
651\end{array}$ & $\begin{array}{r}<0.02 \\
<0.02 \\
0.53 \\
0.07 \\
0.30\end{array}$ & $\begin{array}{l}-- \\
-- \\
--\end{array}$ & $\begin{array}{l}-- \\
-- \\
--\end{array}$ & $\begin{array}{r}650 \\
1900 \\
750 \\
1400 \\
320\end{array}$ & $\begin{array}{r}40 \\
40 \\
430 \\
<10 \\
<10\end{array}$ & $\begin{array}{l}<10 \\
<10 \\
<10 \\
<10 \\
<10\end{array}$ \\
\hline $\begin{array}{l}423019094214301 \\
431616093383501 \\
431556093375401 \\
432323093571601 \\
421406096134501\end{array}$ & $\begin{array}{l}08-22-85 \\
06-17-85 \\
06-17-85 \\
06-17-85 \\
09-05-85\end{array}$ & $\begin{array}{l}866 \\
438 \\
427 \\
490 \\
656\end{array}$ & $\begin{array}{r}<0.02 \\
0.07 \\
0.07 \\
0.07 \\
<0.02\end{array}$ & $\begin{array}{l}-- \\
0.72 \\
1.10 \\
--\end{array}$ & $\begin{array}{l}-- \\
0.14 \\
0.13 \\
-.\end{array}$ & $\begin{array}{l}1300 \\
1600 \\
1500 \\
1200 \\
6900\end{array}$ & $\begin{array}{r}20 \\
40 \\
50 \\
40 \\
340\end{array}$ & $\begin{array}{l}<10 \\
<10 \\
<10 \\
<10 \\
<10\end{array}$ \\
\hline $\begin{array}{l}422833095463301 \\
422924096041801 \\
422848096210701 \\
431713093121402 \\
432109093124501\end{array}$ & $\begin{array}{l}09-18-85 \\
09-17-85 \\
09-04-85 \\
06-17-85 \\
06-17-85\end{array}$ & $\begin{array}{l}531 \\
400 \\
337 \\
408 \\
272\end{array}$ & $\begin{array}{r}0.02 \\
6.22 \\
<0.02 \\
0.09 \\
0.07\end{array}$ & $\begin{array}{l}-- \\
0.16 \\
0.44 \\
0.27\end{array}$ & $\begin{array}{l}-- \\
<0.01 \\
0.10 \\
0.12\end{array}$ & $\begin{array}{r}1700 \\
<10 \\
730 \\
880 \\
1200\end{array}$ & $\begin{array}{r}250 \\
<10 \\
210 \\
120 \\
60\end{array}$ & $\begin{array}{l}<10 \\
<10 \\
<10 \\
<10 \\
<10\end{array}$ \\
\hline $\begin{array}{l}424135093362801 \\
423923093300701 \\
423954093535801 \\
424422093324001\end{array}$ & $\begin{array}{l}06-11-85 \\
06-07-85 \\
06-07-85 \\
06-07-85\end{array}$ & $\begin{array}{l}397 \\
370 \\
402 \\
385\end{array}$ & $\begin{array}{l}0.44 \\
0.04 \\
0.02 \\
0.04\end{array}$ & $\begin{array}{l}0.35 \\
0.80 \\
0.71 \\
0.78\end{array}$ & $\begin{array}{l}0.27 \\
0.26 \\
0.30 \\
0.07\end{array}$ & $\begin{array}{r}840 \\
140 \\
3400 \\
60\end{array}$ & $\begin{array}{r}170 \\
<10 \\
220 \\
50\end{array}$ & $\begin{array}{l}<10 \\
<10 \\
<10 \\
<10\end{array}$ \\
\hline
\end{tabular}




\begin{tabular}{|c|c|c|c|c|c|c|c|c|}
\hline AATION NUMBER & DATE & $\begin{array}{l}\text { BARIUH, } \\
\text { DIS- } \\
\text { SOLVED } \\
\text { (UG/L } \\
\text { AS BA) } \\
(01005)\end{array}$ & $\begin{array}{l}\text { CADMIOU } \\
\text { DIS- } \\
\text { SOLVED } \\
\text { (UG/L } \\
\text { AS CD) } \\
\text { (01025) }\end{array}$ & $\begin{array}{l}\text { CBRO- } \\
\text { MIUM, } \\
\text { DIS- } \\
\text { SOLVED } \\
\text { (UG/L } \\
\text { AS CR) } \\
\text { (01030) }\end{array}$ & $\begin{array}{l}\text { COPPER, } \\
\text { DIS- } \\
\text { SOLVED } \\
\text { (UG/L } \\
\text { AS CU) } \\
(01040)\end{array}$ & $\begin{array}{l}\text { LEAD, } \\
\text { DIS- } \\
\text { SOLVED } \\
\text { (OG/L } \\
\text { AS PB) } \\
(01049)\end{array}$ & $\begin{array}{c}\text { MERCURY } \\
\text { DIS- } \\
\text { SOLVED } \\
\text { (UG/L } \\
\text { AS HG) } \\
\text { (71890) }\end{array}$ & $\begin{array}{c}\text { SELE- } \\
\text { NIUH, } \\
\text { DIS- } \\
\text { SOLVED } \\
\text { (UG/L } \\
\text { AS SE) } \\
\text { (01145) }\end{array}$ \\
\hline $\begin{array}{l}403659094285301 \\
412736093241301 \\
413037093290301 \\
421552094103702 \\
422521094090902\end{array}$ & $\begin{array}{l}08-20-85 \\
09-11-85 \\
09-11-85 \\
08-06-85 \\
09-06-85\end{array}$ & $\begin{array}{r}200 \\
100 \\
100 \\
<100 \\
<100\end{array}$ & $\begin{array}{l}<1 \\
<1 \\
<I \\
<I \\
<I\end{array}$ & $\begin{array}{l}<10 \\
<10 \\
<10 \\
<10 \\
<10\end{array}$ & $\begin{array}{l}<10 \\
10 \\
<10 \\
<10 \\
<10\end{array}$ & $\begin{array}{l}<10 \\
<10 \\
<10 \\
<10 \\
<10\end{array}$ & $\begin{array}{l}<1.0 \\
<1.0 \\
<1.0 \\
<1.0 \\
<1.0\end{array}$ & $\begin{array}{l}<10 \\
<10 \\
<10 \\
<10 \\
<10\end{array}$ \\
\hline $\begin{array}{l}423019094214301 \\
431616093383501 \\
431556093375401 \\
432323093571601 \\
421406096134501\end{array}$ & $\begin{array}{l}08-22-85 \\
06-17-85 \\
06-17-85 \\
06-17-85 \\
09-05-85\end{array}$ & $\begin{array}{r}<100 \\
300 \\
100 \\
100 \\
200\end{array}$ & $\begin{array}{l}<1 \\
<1 \\
<1 \\
<1\end{array}$ & $\begin{array}{l}<10 \\
<10 \\
<10 \\
<10 \\
<10\end{array}$ & $\begin{array}{r}20 \\
<10 \\
<10 \\
10 \\
50\end{array}$ & $\begin{array}{l}<10 \\
<10 \\
<10 \\
<10 \\
<10\end{array}$ & $\begin{array}{l}-- \\
<1.0 \\
<1.0 \\
<1.0 \\
<1.0\end{array}$ & $\begin{array}{l}<10 \\
<10 \\
<10 \\
<10 \\
<10\end{array}$ \\
\hline $\begin{array}{l}422833095463301 \\
422924096041801 \\
422848096210701 \\
431713093121402 \\
432109093124501\end{array}$ & $\begin{array}{l}09-18-85 \\
09-17-85 \\
09-04-85 \\
06-17-85 \\
06-17-85\end{array}$ & $\begin{array}{l}200 \\
200 \\
200 \\
200 \\
100\end{array}$ & $\begin{array}{l}<1 \\
<1 \\
<1 \\
<1 \\
<1\end{array}$ & $\begin{array}{l}<10 \\
<10 \\
<10 \\
<10 \\
<10\end{array}$ & $\begin{aligned}<10 \\
<10 \\
<10 \\
10 \\
<10\end{aligned}$ & $\begin{array}{l}<10 \\
<10 \\
<10 \\
<10 \\
<10\end{array}$ & $\begin{array}{l}<1.0 \\
<1.0 \\
<1.0 \\
<1.0 \\
<1.0\end{array}$ & $\begin{aligned}<10 \\
<10 \\
<10 \\
<10 \\
<10\end{aligned}$ \\
\hline $\begin{array}{l}424135093362801 \\
423923093300701 \\
423954093535801 \\
424422093324001\end{array}$ & $\begin{array}{l}06-11-85 \\
06-07-85 \\
06-07-85 \\
06-07-85\end{array}$ & $\begin{array}{l}300 \\
200 \\
200 \\
300\end{array}$ & $\begin{array}{l}<1 \\
<1 \\
<1 \\
<1\end{array}$ & $\begin{array}{l}<10 \\
<10 \\
<10 \\
<10\end{array}$ & $\begin{array}{l}10 \\
20 \\
10 \\
30\end{array}$ & $\begin{array}{l}<10 \\
<10 \\
<10 \\
<10\end{array}$ & $\begin{array}{l}<1.0 \\
<1.0 \\
<1.0 \\
<1.0\end{array}$ & $\begin{array}{l}<10 \\
<10 \\
<10 \\
<10\end{array}$ \\
\hline
\end{tabular}

STATION NOMBER DATE

403659094285301 08-20-85 412736093241301 09-11-85 113037093290301 09-11-85 421552094103702 08-06-85 422521094090902 09-06-85

423019094214301 08-22-85 431616093383501 06-17-85 431556093375401 06-17-85 $432323093571601 \quad 06-17-85$ 421406096134501 09-05-85

122833095463301 09-18-85 $422924096041801 \quad 09-17-85$ 422848096210701 09-04-85 $43171309312140206-17-85$ 432109093124501 06-17-85

124135093362801 06-11-85 423923093300701 06-07-85 $23954093535801 \quad 06-07-85$
4 424422093324001 06-07-85

\begin{tabular}{|c|c|c|c|c|c|}
\hline $\begin{array}{c}\text { SILVER, } \\
\text { DIS- } \\
\text { SOLVED } \\
\text { (UG/L } \\
\text { AS AG) } \\
\text { (01075) }\end{array}$ & $\begin{array}{c}\text { ZIMC, } \\
\text { DIS- } \\
\text { SOLVED } \\
\text { (UG/L } \\
\text { AS ZN) } \\
(01090)\end{array}$ & $\begin{array}{c}\text { GROSS } \\
\text { ALPHA, } \\
\text { DIS- } \\
\text { SOLVED } \\
\text { (PCI/L } \\
\text { AS } \\
\text { U-NAT) } \\
\text { (01515) }\end{array}$ & $\begin{array}{c}\text { GROSS } \\
\text { BETA, } \\
\text { DIS- } \\
\text { SOLVED } \\
\text { (PCI/L } \\
\text { AS } \\
\text { C8-137) } \\
(03515)\end{array}$ & $\begin{array}{c}\text { RADIUA } \\
226, \\
\text { DIS- } \\
\text { SOLVED } \\
\text { (PCI/L) } \\
\text { (09503) }\end{array}$ & $\begin{array}{c}\text { RADIUH } \\
228 \\
\text { DIS- } \\
\text { SOLVED } \\
\text { (PCI/L } \\
\text { AS } \\
\text { RA-228) } \\
(81366)\end{array}$ \\
\hline $\begin{array}{l}<10 \\
<10 \\
<10 \\
<10 \\
<10\end{array}$ & $\begin{array}{r}10 \\
<10 \\
<10 \\
<10 \\
<10\end{array}$ & $\begin{array}{l}<0.2 \\
11 \\
1.0 \\
12.0 \\
4.9\end{array}$ & $\begin{array}{l}2.0 \\
18 \\
<0.2 \\
25 \\
12\end{array}$ & $\begin{array}{r}-7.0 \\
-7.6 \\
4.3\end{array}$ & $\begin{array}{l}-\overline{<0.7} \\
-6.3 \\
3.0\end{array}$ \\
\hline $\begin{array}{l}<10 \\
<10 \\
<10 \\
<10 \\
<10\end{array}$ & $\begin{array}{l}<10 \\
<10 \\
<10 \\
<10 \\
<10\end{array}$ & $\begin{array}{l}8.7 \\
6.4 \\
6.3 \\
1.7 \\
3.2\end{array}$ & $\begin{array}{r}5.0 \\
<0.6 \\
4.0 \\
3.0 \\
9.0\end{array}$ & $\begin{array}{r}1.8 \\
7.9 \\
6.7 \\
-\quad 1.5\end{array}$ & $\begin{array}{l}1.1 \\
<0.6 \\
<0.6 \\
-0.0 \\
2.0\end{array}$ \\
\hline $\begin{array}{l}<10 \\
<10 \\
<10 \\
<10 \\
<10\end{array}$ & $\begin{array}{r}<10 \\
20 \\
<10 \\
20 \\
<10\end{array}$ & $\begin{array}{l}1.8 \\
3.2 \\
3.0 \\
1.7 \\
0.4\end{array}$ & $\begin{array}{r}<0.7 \\
3.0 \\
12 \\
6.0 \\
1.0\end{array}$ & $\begin{array}{l}-- \\
0.4 \\
-- \\
--\end{array}$ & $\begin{array}{l}-- \\
0.8 \\
2.1 \\
--\end{array}$ \\
\hline $\begin{array}{l}<10 \\
<10 \\
<10\end{array}$ & $\begin{array}{r}30 \\
<10 \\
<10 \\
<10\end{array}$ & $\begin{array}{c}16 \\
8.1 \\
0.8 \\
1.7\end{array}$ & $\begin{array}{c}4.0 \\
12 \\
4.0\end{array}$ & $\begin{array}{l}12 \\
-1.4 \\
=-\end{array}$ & $\begin{array}{l}1.4 \\
<0.6 \\
\therefore-\end{array}$ \\
\hline
\end{tabular}




\begin{tabular}{|c|c|c|c|c|c|c|c|}
\hline STATION NUMBER & DATE & $\begin{array}{l}\text { ATRA- } \\
\text { Z INE, } \\
\text { TOTAL } \\
\text { (UG/L) } \\
(39630)\end{array}$ & $\begin{array}{l}\text { CYAN- } \\
\text { AZINE } \\
\text { TOTAL } \\
\text { (UG/L) } \\
(81757)\end{array}$ & $\begin{array}{l}\text { METRI- } \\
\text { BUZ IN } \\
\text { IN } \\
\text { WHOLE } \\
\text { WATER } \\
\text { (UG/L) } \\
(81408)\end{array}$ & $\begin{array}{c}\text { ALA- } \\
\text { CELOR } \\
\text { TOTAL } \\
\text { RECOVER } \\
\text { (UG/L) } \\
(77825)\end{array}$ & $\begin{array}{l}\text { METOLA- } \\
\text { CELOR } \\
\text { IN } \\
\text { WHOLE } \\
\text { WATER } \\
\text { (UG/L) } \\
(39356)\end{array}$ & $\begin{array}{l}\text { TRI- } \\
\text { FLURA- } \\
\text { LIN } \\
\text { TOTAL } \\
\text { RECOVER } \\
(U G / L) \\
(39030)\end{array}$ \\
\hline $\begin{array}{l}403659094285301 \\
412736093241301 \\
413037093290301 \\
421552094103702 \\
422521094090902\end{array}$ & $\begin{array}{l}08-20-85 \\
09-11-85 \\
09-11-85 \\
08-06-85 \\
09-06-85\end{array}$ & $\begin{array}{l}<0.1 \\
<0.1 \\
<0.1 \\
=-\end{array}$ & $\begin{array}{l}<0.1 \\
<0.1 \\
<0.1 \\
-- \\
--\end{array}$ & $\begin{array}{l}<0.05 \\
<0.05 \\
<0.05 \\
--\end{array}$ & $\begin{array}{l}<0.1 \\
<0.1 \\
<0.1 \\
\therefore-\end{array}$ & $\begin{array}{l}<0.1 \\
<0.1 \\
<0.1 \\
--\end{array}$ & $\begin{array}{l}<0.05 \\
<0.05 \\
<0.05 \\
\therefore-\end{array}$ \\
\hline $\begin{array}{l}423019094214301 \\
431616093383501 \\
43155609375401 \\
43232309357601 \\
421406096134501\end{array}$ & $\begin{array}{l}08-22-85 \\
06-17-85 \\
06-17-85 \\
06-17-85 \\
09-05-85\end{array}$ & $\begin{array}{l}-\overline{0} \\
<0.1 \\
<0.1\end{array}$ & $\begin{array}{l}-- \\
\overline{<0.1} \\
<0.1\end{array}$ & $\begin{array}{l}-\overline{-} \\
<0.05 \\
\overline{<0}\end{array}$ & $\begin{array}{l}-- \\
\overline{<0.1} \\
\overline{<0.1}\end{array}$ & $\begin{array}{l}-\overline{-} \\
<0.1 \\
-\infty \\
<0.1\end{array}$ & $<\overline{<0.05}$ \\
\hline $\begin{array}{l}422833095463301 \\
422924096041801 \\
422848096210701 \\
431713093121402 \\
432109093124501\end{array}$ & $\begin{array}{l}09-18-85 \\
09-17-85 \\
09-04-85 \\
06-17-85 \\
06-17-85\end{array}$ & $\begin{array}{l}<0.1 \\
= \\
=\end{array}$ & $\begin{array}{l}<0.1 \\
-- \\
=- \\
--\end{array}$ & $\begin{array}{l}<0.05 \\
=- \\
= \\
-\end{array}$ & $\begin{array}{l}<0.1 \\
-- \\
=- \\
--\end{array}$ & $\begin{array}{l}<0.1 \\
=- \\
= \\
=\end{array}$ & $\begin{array}{l}<0.05 \\
=- \\
\overline{-} \\
=\end{array}$ \\
\hline $\begin{array}{l}424135093362801 \\
423923093300701 \\
423954093535801 \\
424422093324001\end{array}$ & $\begin{array}{l}06-11-85 \\
06-07-85 \\
06-07-85 \\
06-07-85\end{array}$ & $\begin{array}{l}<0.1 \\
-\infty \\
-\infty\end{array}$ & $\begin{array}{l}<0.1 \\
-\infty \\
--\end{array}$ & $\begin{array}{l}<0.05 \\
-- \\
<0.05\end{array}$ & $\begin{array}{l}<0.1 \\
<0.1 \\
--\end{array}$ & $\begin{array}{l}<0.1 \\
-\infty \\
-\infty\end{array}$ & $\begin{array}{l}<0.05 \\
<0.05\end{array}$ \\
\hline
\end{tabular}

\begin{tabular}{|c|c|c|c|c|c|c|c|}
\hline ATION NUMBER & DATE & $\begin{array}{c}\text { DICAMBA } \\
\text { (MED- } \\
\text { IBEN) } \\
\text { (BAN- } \\
\text { VEL D) } \\
\text { TOTAL } \\
\text { (UG/L) } \\
(82052)\end{array}$ & $\begin{array}{l}2,4-D, \\
\text { TOTAL } \\
(\text { UG/L) } \\
(39730)\end{array}$ & $\begin{array}{c}\text { SILVEX, } \\
\text { TOTALL } \\
\text { (GGL) } \\
(39760)\end{array}$ & $\begin{array}{l}\text { DYFO- } \\
\text { NATE } \\
\text { (UG/L) } \\
(81294)\end{array}$ & $\begin{array}{l}\text { TERBD- } \\
\text { FOS } \\
(\mathrm{OG} / \mathrm{L}) \\
(82088)\end{array}$ & $\begin{array}{l}\text { PBORATE } \\
\text { OTAL } \\
(\text { OG/L) } \\
(39023)\end{array}$ \\
\hline $\begin{array}{l}403659094285301 \\
412736093241301 \\
413037093290301 \\
421552094103702 \\
422521094090902\end{array}$ & $\begin{array}{l}08-20-85 \\
09-11-85 \\
09-11-85 \\
08-06-85 \\
09-06-85\end{array}$ & $\begin{array}{l}<0.07 \\
<0.07 \\
<0.07 \\
-\therefore \\
--\end{array}$ & $\begin{array}{l}<0.07 \\
<0.07 \\
<0.07 \\
--\end{array}$ & \begin{tabular}{l}
$<0.05$ \\
$<0.05$ \\
$<0.05$ \\
\hdashline-
\end{tabular} & $\begin{array}{l}<0.1 \\
<0.1 \\
<0.1 \\
\square-\end{array}$ & $\begin{array}{l}-- \\
<0.1 \\
<0.1 \\
--\end{array}$ & $\begin{array}{l}<0.1 \\
<0.1 \\
<0.1 \\
=-\end{array}$ \\
\hline $\begin{array}{l}423019094214301 \\
431616093383501 \\
431556093375401 \\
432323093571601 \\
421406096134501\end{array}$ & $\begin{array}{l}08-22-85 \\
06-17-85 \\
06-17-85 \\
06-17-85 \\
09-05-85\end{array}$ & $\begin{array}{c}-- \\
<0.07 \\
<-0.07\end{array}$ & $\begin{array}{l}=- \\
<0.07 \\
<0.07\end{array}$ & $\begin{array}{l}-- \\
\overline{<0.05} \\
<0.05\end{array}$ & $\begin{array}{l}=- \\
\overline{<0.1} \\
\overline{<0.1}\end{array}$ & $\begin{array}{l}=- \\
=- \\
=\end{array}$ & $\begin{array}{l}\overline{-} \\
<0.1 \\
<0.1\end{array}$ \\
\hline $\begin{array}{l}422833095463301 \\
422924096041801 \\
422848096210701 \\
431713093121402 \\
432109093124501\end{array}$ & $\begin{array}{l}09-18-85 \\
09-17-85 \\
09-04-85 \\
06-17-85 \\
06-17-85\end{array}$ & $\begin{array}{l}<0.07 \\
=- \\
= \\
=\end{array}$ & $\begin{array}{l}<0.0 \\
=- \\
= \\
=\end{array}$ & $\begin{array}{l}<0.0 \\
=- \\
=- \\
=-\end{array}$ & $\begin{array}{l}<0.1 \\
=- \\
=- \\
=\end{array}$ & $\begin{array}{l}= \\
=- \\
= \\
=\end{array}$ & $\begin{array}{l}<0.1 \\
\because- \\
=\end{array}$ \\
\hline $\begin{array}{l}424135093362801 \\
423923093300701 \\
423954093535801 \\
424422093324001\end{array}$ & $\begin{array}{l}06-11-85 \\
06-07-85 \\
06-07-85 \\
06-07-85\end{array}$ & $\begin{array}{l}<0.07 \\
<0.07\end{array}$ & $\begin{array}{l}<0.07 \\
<0.07\end{array}$ & $\begin{array}{l}<0.05 \\
<0.05\end{array}$ & $\begin{array}{l}<0.1 \\
<0.1 \\
--\end{array}$ & $\begin{array}{l}<0.1 \\
<0.1 \\
--\end{array}$ & $\begin{array}{l}<0.1 \\
\leq 0.1 \\
--\end{array}$ \\
\hline
\end{tabular}


LOCATION,--Lat $42^{\circ} 54^{\prime} 35^{\prime \prime}$, long $91^{\circ} 28^{\prime} 11^{\prime \prime}$, in SEl/4 sEl/4 sec. 31, T.94 N., R.5 W., Clayton County, Hydrologic Unit $07060004,3.0 \mathrm{mi}$ north and $2.8 \mathrm{mi}$ west of Elkader, Iowa.

OWNER.--U.S. Geological survey.

PERIOD OF RECORD.--August 1984 to current year.

INSTRUMENTATION.--Wet/dry precipitation collector, weighing-bucket type recording rain gage with alter wind shield and event recorder and National Weather Service standard 8-inch rain and snow gage (back-up only).

EXTREMES FOR PERIOD OF RECORD,--Maximum field pH, 6.66, June 25 to July 2, 1985; minimum field pH, 3.83, July 30 to August 6,1985 .

EXTREMES FOR CURRENT YEAR.--Maximum field pH, 6.66, June 25 to July 2, 1985, minimum field pH, 3.83, July 30 to August 6, 1985 .

WET DEPOSITION DATA

CALCIUM

DON- DIS-

SOLVED

ANCE

AS CA) AS

UNITS) (US/CM) AS CA

(00925)

\begin{tabular}{|c|c|c|c|c|}
\hline $\begin{array}{l}\text { MAGNE- } \\
\text { SIUM, } \\
\text { DIS- } \\
\text { SOLVED } \\
\text { (MG/L } \\
\text { AS MG) }\end{array}$ & $\begin{array}{l}\text { POTAS- } \\
\text { SIUM, } \\
\text { DIS- } \\
\text { SOLVED } \\
\text { (MG/L } \\
\text { AS R) }\end{array}$ & $\begin{array}{l}\text { SODIOM, } \\
\text { DIS- } \\
\text { SOLVED } \\
\text { (MG/L } \\
\text { AS NA) }\end{array}$ & $\begin{array}{l}\text { NITRO- } \\
\text { GEN, } \\
\text { AMYNIA } \\
\text { DIS- } \\
\text { SOLVED } \\
\text { (MG/L } \\
\text { AS N) }\end{array}$ & $\begin{array}{c}\text { NITRO- } \\
\text { GEN, } \\
\text { NITRATE } \\
\text { DIS- } \\
\text { SOLVED } \\
\text { (MG/L } \\
\text { AS N) }\end{array}$ \\
\hline
\end{tabular}
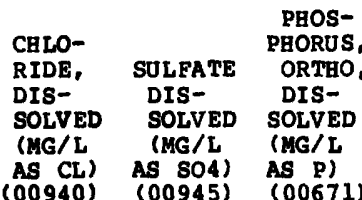

OCT 1984

\begin{tabular}{|c|c|c|c|c|c|c|c|c|c|c|c|}
\hline $02-09$ & 5.2 & 17 & 0.4 & 0.12 & 0.04 & 0.05 & 0.895 & 0.404 & 0.09 & 3.0 & $<0.001$ \\
\hline 09-16 & 4.2 & 30 & 0.34 & 0.15 & 0.15 & 0.06 & 0.529 & 0.511 & 0.23 & 4.4 & 0.003 \\
\hline $16-23$ & 4.4 & 15 & 0.14 & 0.03 & 0.03 & 0.05 & 0.124 & 0.171 & 0.1 & 2.0 & $<0.001$ \\
\hline $30-30$ & 4.5 & 23 & 1.4 & 0.62 & 0.87 & 0.06 & 0.062 & 0.009 & 1.2 & 2.7 & 0.202 \\
\hline $\begin{array}{l}\text { lov } 06 \\
\text { Nov }\end{array}$ & 4.6 & 15 & 0.05 & 0.01 & 0.01 & 0.04 & 0.288 & 0.191 & 0.15 & 1.4 & $<0.001$ \\
\hline $\begin{array}{l}06-13 \\
\text { NOV }\end{array}$ & 5.0 & 23 & 0.79 & 0.13 & 0.05 & 0.2 & 0.941 & 0.619 & 0.29 & 3.5 & 0.002 \\
\hline $\begin{array}{l}13-20 \\
\text { NOV }\end{array}$ & -- & -- & -- & -- & -- & -- & -- & -- & - & -- & -- \\
\hline VV $27-20-27$ & 5.8 & 8 & 0.26 & 0.05 & 0.01 & 0.04 & 0.42 & 0.20 & 0.04 & 1.0 & 0.002 \\
\hline $\begin{array}{r}\text { DEC } 04 \\
\text { DEC }\end{array}$ & 5.2 & 30 & 1.7 & 0.3 & 0.11 & 0.24 & 2.16 & 1.83 & 0.32 & 4.9 & $<0.001$ \\
\hline $\begin{array}{l}04-11 \\
\text { DEC }\end{array}$ & - & -- & -- & -- & -- & - & -- & -- & - & -- & -- \\
\hline${ }_{\mathrm{DEC}}^{11-18}$ & -- & - & 0.45 & 0.1 & 0.14 & 0.25 & 0.832 & 0.375 & 0.43 & 3.9 & 0.003 \\
\hline c $26-$ & - & -- & 0.06 & 0.02 & 0.01 & 0.03 & 0.124 & 0.118 & $<0.02$ & 1.9 & $<0.001$ \\
\hline $\begin{array}{l}A N 02 \\
N \cdot 1985\end{array}$ & -- & -- & 0.35 & 0.06 & 0.12 & 0.27 & 1.71 & 0.986 & 0.46 & 5.5 & $<0.001$ \\
\hline $\begin{array}{l}02-08 \\
\text { JAN }\end{array}$ & -- & - & 0.55 & 0.2 & 0.13 & 0.64 & $<0.28$ & 0.446 & 0.55 & 7.8 & 0.018 \\
\hline $\begin{array}{l}08-15 \\
\text { JAN }\end{array}$ & 4.9 & 10 & 0.58 & 0.17 & 0.07 & 0.24 & $<0.016$ & 0.291 & 0.25 & 0.5 & 0.003 \\
\hline $\begin{array}{l}22-29 \\
\text { N } 29-\end{array}$ & $\because$ & -- & 0.52 & 0.1 & 0.15 & 0.12 & $<0.016$ & 0.01 & 0.21 & 0.6 & $<0.001$ \\
\hline $\begin{array}{r}\text { EB } 05 \\
\text { FEB }\end{array}$ & 5.5 & 12 & 0.64 & 0.15 & 0.02 & 0.1 & 0.405 & 0.67 & 0.16 & 0.9 & $<0.001$ \\
\hline $\begin{array}{l}05-12 \\
\text { FEB }\end{array}$ & -- & -- & -- & -- & - & $\infty$ & -- & -- & -- & -- & -- \\
\hline FEB & -- & -- & 0.82 & 0.15 & 0.07 & 0.54 & 0.397 & 0.686 & 0.77 & 2.7 & 0.008 \\
\hline $\begin{array}{l}19-26 \\
\text { B } 26-\end{array}$ & -- & - & 0.08 & 0.01 & 0.03 & 0.07 & 0.397 & 0.269 & 0.12 & 1.9 & $<0.001$ \\
\hline $\begin{array}{l}\text { IAR } 05 \\
\text { MAR }\end{array}$ & 4.5 & 13 & 0.32 & 0.05 & 0.02 & 0.04 & 0.218 & 0.258 & 0.14 & 1.7 & $<0.001$ \\
\hline $\begin{array}{l}05-12 \\
\text { MAR }\end{array}$ & 4.6 & 20 & 0.31 & 0.06 & 0.04 & 0.07 & 1.01 & 0.38 & 0.14 & 3.1 & 0.003 \\
\hline $\begin{array}{l}12-19 \\
\text { MAR }\end{array}$ & 5.4 & 7 & 0.2 & 0.04 & 0.02 & 0.04 & 0.296 & 0.215 & 0.08 & 0.8 & $<0.001$ \\
\hline $19-26$ & 4.0 & 47 & 0.32 & 0.05 & 0.03 & 0.04 & 0.864 & 1.09 & 0.16 & 3.6 & $<0.001$ \\
\hline
\end{tabular}


BIG SPRINGS PISH HATCGERY NEAR ELKADER, IOWA WET DEPOSITION DATA

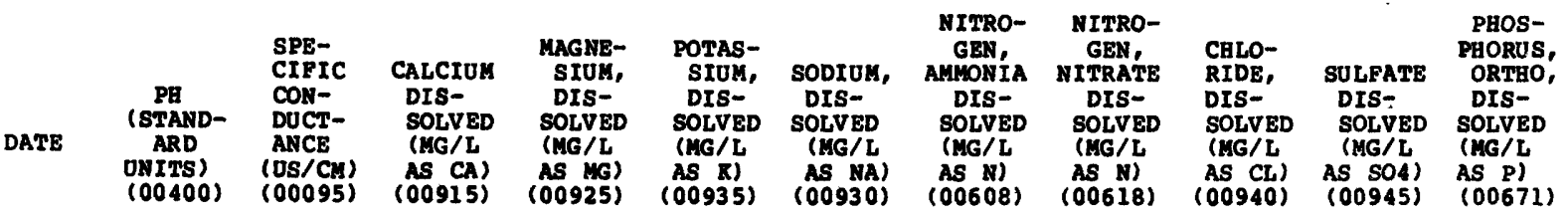

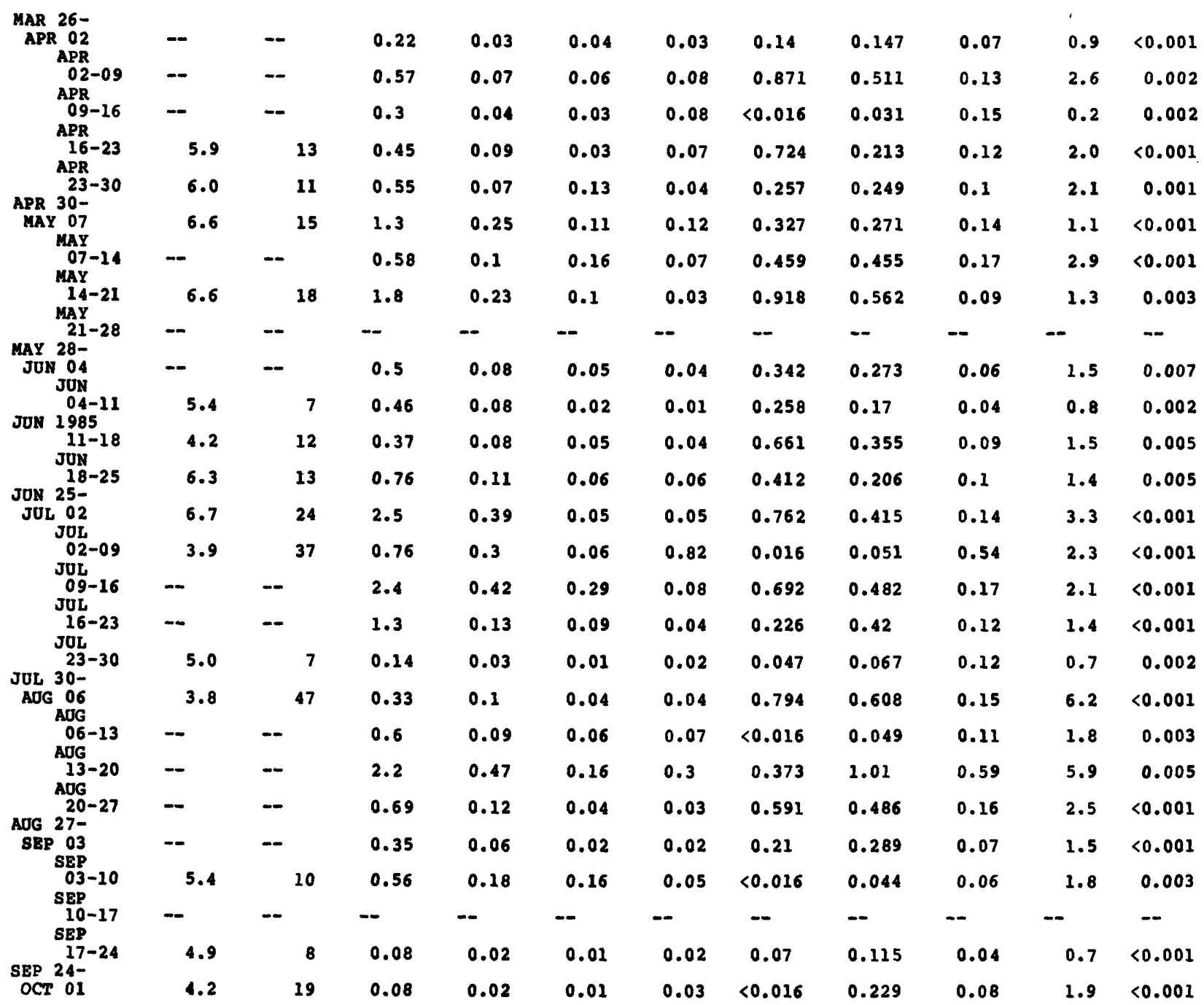


LOCATION.--Lat $40^{\circ} 57^{\prime} 47^{\prime \prime}$, long $93^{\circ} 23^{\prime} 32^{\prime \prime}$, in SWl/4 NEl/4 sec. 9, T.71 N., R.23 W., Lucas County, Hydrologic Unit $10280201 \mathrm{~m} 3.1 \mathrm{mi}$ east and $2.0 \mathrm{mi}$ north of Derby, Iowa, $3.4 \mathrm{mi}$ west and $2.8 \mathrm{mi}$ south of Chariton, Iowa.

OWNER.--U.S. Geological survey.

PERIOD OE RECORD.--September 1984 to current year.

INSTRUMENTATION.--Wet/dry precipitation collector, weighing-bucket type recording rain gage with alter wind shield and event recorder. National Weather Service standard 8-inch rain and snow gage (back-up only).

EXTREMES FOR PERIOD OF RECORD.--Maximum fiela pH, 5.78, May 21 to May 28, 1985, minimum field pH, 3.84, February 12 to February $19,1985$.

EXTREMES FOR CURRENT YEAR.--Maximum fleld pH, 5.78, May 21 to May 28, 1985; minimum field pH, 3.84, February 12 to February 19, 1985.

WET DEPOSITION DATA

$\begin{array}{cl} & \text { SPE- } \\ \text { PH } & \text { CIFIC } \\ \text { (STAND- } & \text { DUCT- } \\ \text { ARD } & \text { ANCE } \\ \text { UNITS) } & (\text { US } / C H) \\ (00400) & (00095)\end{array}$

$\begin{array}{cc} & \text { MAGNE- } \\ \text { CALCIUM } & \text { SIUH, } \\ \text { DIS- } & \text { DIS- } \\ \text { SOLVED } & \text { SOLVED } \\ \text { (MG/L } & \text { (MG/L } \\ \text { AS CA) } & \text { AS MG) } \\ (00915) & (00925)\end{array}$

POTAS-
SIUA,
DIS-
SOLVED
$($ NG/L
AS R)
$(00935)$

SODIUM,
DIS-
SOLVED
(NG/L
AS NA)
$(00930)$

$\begin{array}{cc}\text { NITRO- } & \text { NITRO- } \\ \text { GEN, } & \text { GEN, } \\ \text { AMNONIA } & \text { NITRATE } \\ \text { DIS- } & \text { DIS- } \\ \text { SOLVED } & \text { SOLVED } \\ \text { (MG/L } & \text { (MG/L } \\ \text { AS N) } & \text { AS N) } \\ (00608) & (00618)\end{array}$
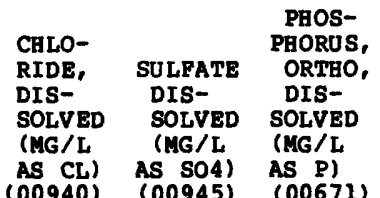

OCT 1984

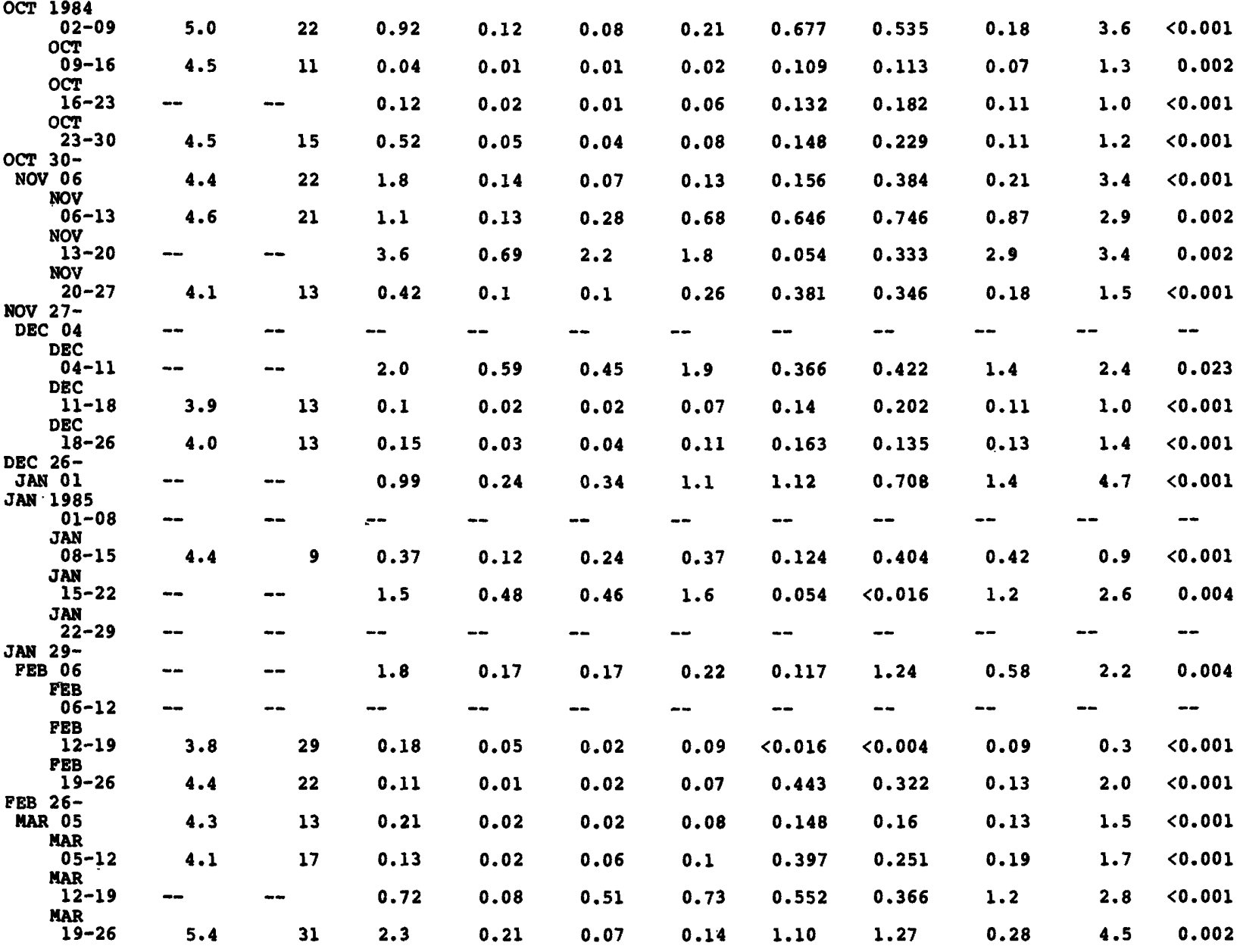


WET DEPOSITION DATA

\begin{tabular}{|c|c|c|c|c|c|c|c|c|c|c|}
\hline $\begin{array}{c}\text { PH } \\
\text { (STAND- } \\
\text { ARD }\end{array}$ & $\begin{array}{l}\text { SPE- } \\
\text { CrFIC } \\
\text { CON- } \\
\text { DUCT- } \\
\text { ANCE }\end{array}$ & $\begin{array}{l}\text { CALCIUM } \\
\text { DIS- } \\
\text { SOLVED } \\
\text { (HG/L }\end{array}$ & $\begin{array}{c}\text { MAGNE- } \\
\text { SIUM, } \\
\text { DIS- } \\
\text { SOLVED } \\
\text { (MG/L }\end{array}$ & $\begin{array}{l}\text { POTAS- } \\
\text { SrUM, } \\
\text { DIS- } \\
\text { SOLVED } \\
\text { (HG/L }\end{array}$ & $\begin{array}{l}\text { SODIUM, } \\
\text { DIS- } \\
\text { SOLVED } \\
\text { (MG/L }\end{array}$ & $\begin{array}{l}\text { NITRO- } \\
\text { GEN, } \\
\text { AMMONIA } \\
\text { DIS- } \\
\text { SOLVED } \\
\text { (MG/L }\end{array}$ & $\begin{array}{l}\text { NITRO- } \\
\text { GEN, } \\
\text { MITRATE } \\
\text { DIS- } \\
\text { SOLVED } \\
\text { (MG/L }\end{array}$ & $\begin{array}{l}\text { CHLO- } \\
\text { RIDE, } \\
\text { DIS- } \\
\text { SOLVED } \\
\text { (MG/L }\end{array}$ & $\begin{array}{l}\text { SUL } \\
\text { DI } \\
\text { SO } \\
\text { (H }\end{array}$ & $\begin{array}{l}\text { PHOS- } \\
\text { PHORUS, } \\
\text { ORTHO, } \\
\text { DIS- } \\
\text { SOLVED } \\
\text { MGGL }\end{array}$ \\
\hline $\begin{array}{l}\text { UNITS) } \\
(00400)\end{array}$ & $\begin{array}{l}\text { CX) } \\
\text { 95) }\end{array}$ & 1009 & $\begin{array}{l}\mathrm{AS} \\
\mathrm{COO}\end{array}$ & As & $\begin{array}{l}\text { AS } \\
100\end{array}$ & $\begin{array}{c}\text { As N) } \\
(00608)\end{array}$ & $\begin{array}{c}\text { As Ni) } \\
(00618)\end{array}$ & & & $\begin{array}{c}\text { AS } \\
10\end{array}$ \\
\hline
\end{tabular}

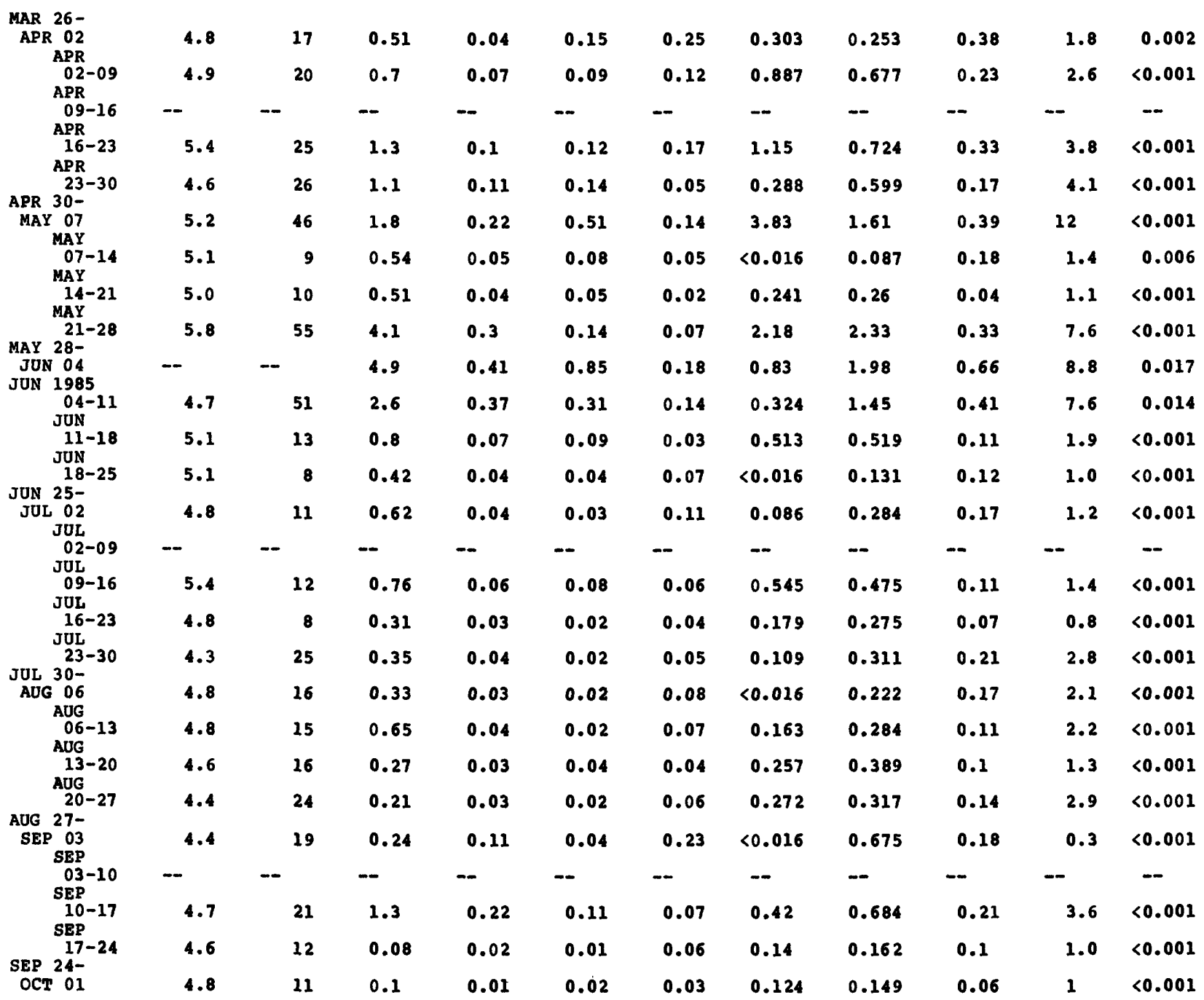


Acre-foot, definition of....................

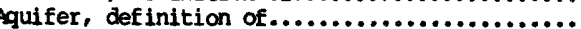
Artesian, definition of........................

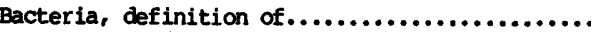
Beaver Creek (tributary to Iowa River) at

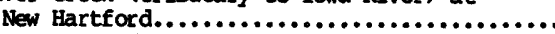

Beaver Creek (tributary to Des Noines River)

near Grimes.............................

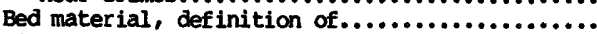

Big Bear Creek at Ladora.......................

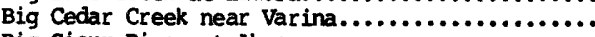

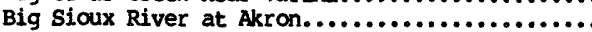

Big Sioux River basin, crest-stage partialrecord stations in.....................

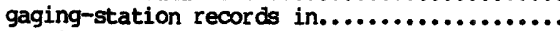

Big Springs Fish Hatchery near Elkader. Precipitation Water Quality, data for.....

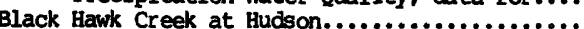

Blackhawk Lake at Lake View.

Boone River near Webster City...

Bottom material, definition of.................

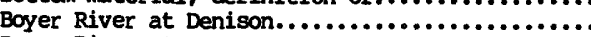

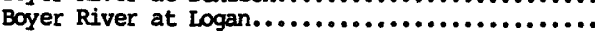

Boyer River basin, crest-stage partialrecord stations in.....................

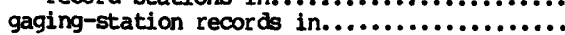

Cedar Creek (tributary to Des Moines River)

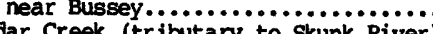

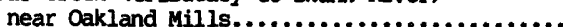

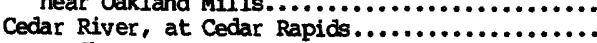
at Charles City............................

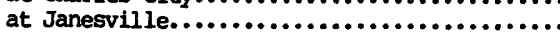

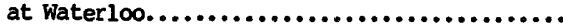

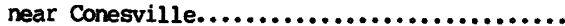
West Fork, at Finchford.....................

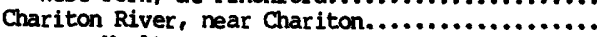
near Moulton.............................

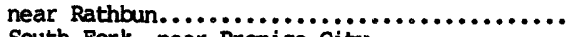

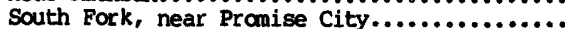

Chariton River basin, crest-stage partialrecord stations in.....................

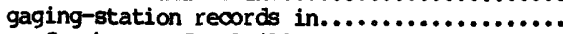

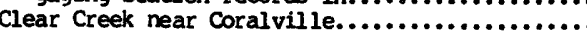
Clear Lake at Clear Lake...................... Contents, definition of . . . . . . . . . . . . . . . . .

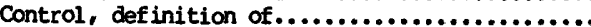

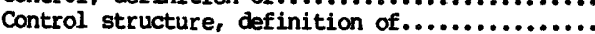

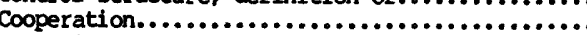
Coralville Lake near Coralvil le................. Crest-stage stations, maximum stage and

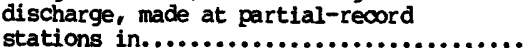

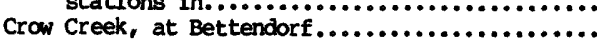
Cubic feet per second per square mile, definition of ...........................

Cubic foot per second, definition of.............

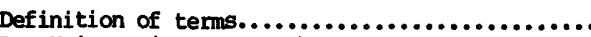

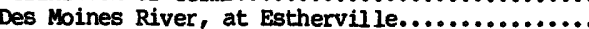
at Fort Dodge........................... at Humboldt. ............................

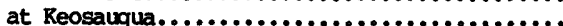

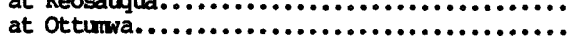

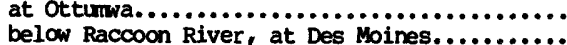

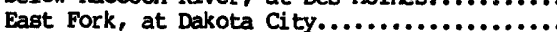

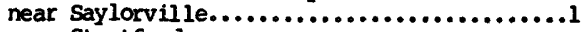
near Stratford............................

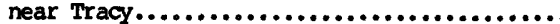

Des Moines River basin, crest-stage partialrecord stations in..................... gaging-station records in.................. Discharge, definition of .......................

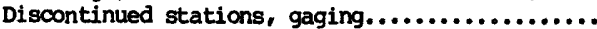
water-quality............................

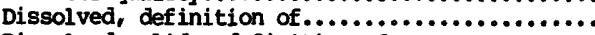

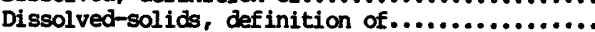
Downstream order system.......................

Drainage area, definition of East Nishnabotra River, at Red OaR.

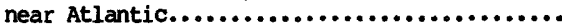

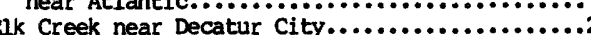

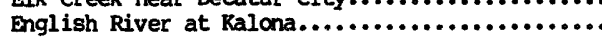

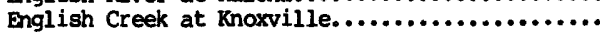
Example of site numbers for wells...............

107,247

142, 250

$81, \quad 244$

144,251

175

238

174-175

326-327

108,247

146

134,250

44
257

195, 257

171, 253

120, 249

110,247

99, 246

101,246

109,247

111,248

102, 246

228 , 260

232, 261

231,261

229, 261

240

228-232

85, 244

105

44

44

83

233-240

73,242

43-53

130,249

133,250

131, 249

173,254

172,253

163,252

132,250

$7-141,250$

135,250

170,253

237-238

130-173

44

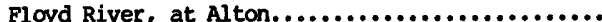

at James...............................

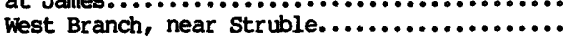
Floyd River basin, crest-stage partial-

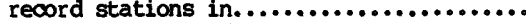

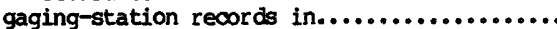
Foumile Creek (tributary to Des Moines River)

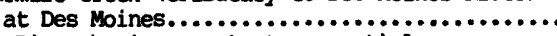
Fox River basin, crest-stage partial-

record stations in.....................

Gage height (G.H.), definition of...............

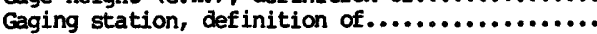
Grand River Basin

gaging-station records in................

Ground-water, by county, level data..............

Ground-water, by county, quality data............

Ground-water levels, records of.................

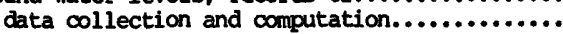

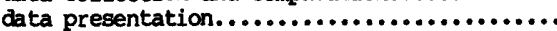

Ground-water quality, records of.................

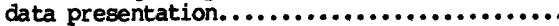
explanation of descriptive headings........... Hardin Creek, East Fork, near Churdan.............

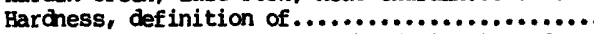
Hydrologic bench-mark network, definition of....

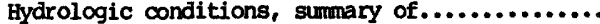
graphs of . ........................... ground-water...........................

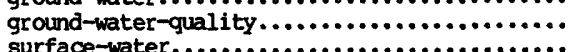
surface-water.......................... surface-water-quality......................

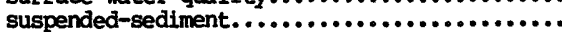

Hydrologic unit, definition of..................

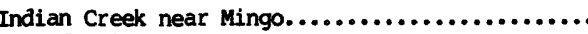

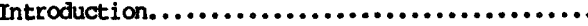

Iowa River, at Iowa City...................... at Marengo............................. at Marshalltown..........................

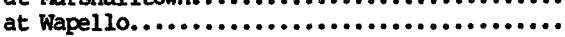
East Branch, near klemme...................

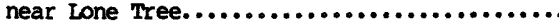

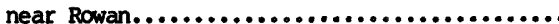

Iowa River basin, crest-stage partial-

record stations in.....................

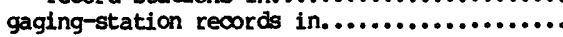

Land-surface datum............................. Lake Panorama at Panora......................... Lake Red Rock near Pella...................... Lakes and Reservoirs:

Blackhawk Lake near Lake View................ Clear Lake at Clear Lake..................... Coralvil le Lake near Coralville............... Panorana, Lake, at Panora.................. Rathbun Lake near Rathbun...................

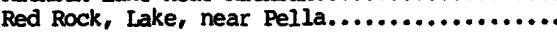
Saylorville Lake near Saylorville............ West Okoboji Lake at Lakeside Iaboraory near Milford. latitude-longitude system..................... Little Cedar River near Ionia................
Little Maquoketa River basin, crest-stage partial-record stations in..............

Little Sioux River, at Correctionville........... at Linn Grove...............................

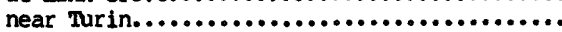
Little Sioux River basin, crest-stage

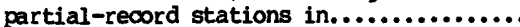
gaging-station records in..................
210,258

209,258 $3-225,260$

97. 245 253

183,255

185,255

184,255

238

183-185

164, 252

223-227 262-297

298-325

33-35

33
$34-35$

36-38

37

148,251

45
45

75, 242

235-236

74-115

46

154

169

146
105

105

83
154

230

169

136

188

00,246

191 233

190,256

193,256

239

188-193 


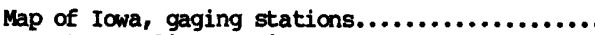

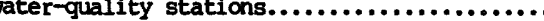
ground water observation wells................

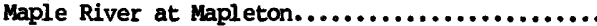

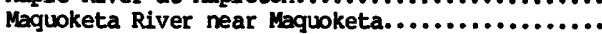
Maquoketa River basin, crest-stage

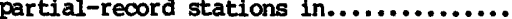

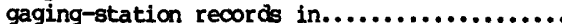

Mcklay Research Station near Chariton, precipitation water-quality, data for.....

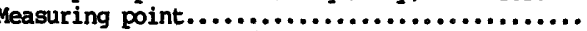

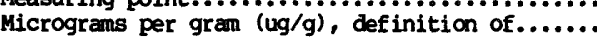
Micrograms per liter $(\omega \mathrm{G} / \mathrm{L}, u \mathrm{ug} / \mathrm{L})$

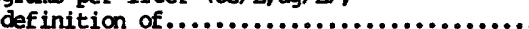

Middle Racooon River, at Panora................155-159, 251 near Bayard..............................149-153, 251 Middle River near Indianola................... 166, 253 Milligrams per liter (MG/L, mg/i) definition of........................ 46

Mississippi River, at Clinton...............666-69, 241 at Reokuk............................ 127-129 at MoGregor........................... 58-61, 241

Missouri River, at Decatur, Nebraska........... 255 at Nebraska City, Nebraska..................202-206, 258 at Omaha, Nebraska......................196-201, 257 at Rulo, Nebraska...................... 215, 259

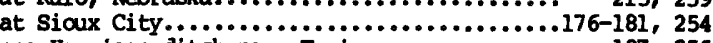

Monona-Harrison ditch near Turin.............. 187, 256

Monona-Harrison ditch basin, crest-stage partial-record stations in.............. 238-239

gaging-station records in.................... 186-187

Mosquito Creek basin, crest-stage partialrecord stations in......................

National geodetic vertical datum (NGVD),

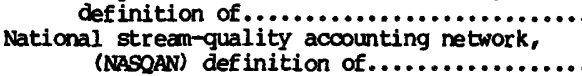

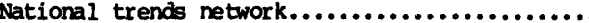

Nishnabotna River above Hamburg..............211-213, 259

Nishnabotna River basin, crest-stage partial-record stations in............. 239-240 gaging-station records in................ 207-213

Nodaway River at Clarinda.....................216-220, 259

Nodaway River basin, crest-stage partialrecord stations in......................

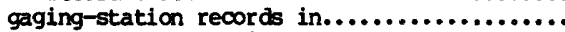

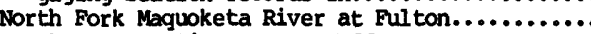
North Raccoon River, near Jefferson..............

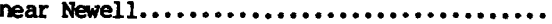

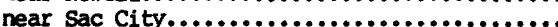

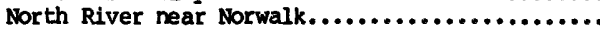

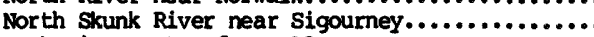

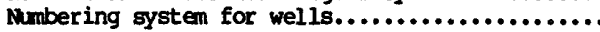

Ocheyedan River near Spencer

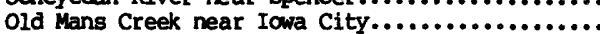
One Hundred and Two River, East Fork, near Bedford.

Paint Creek basin, crest-stage partial-

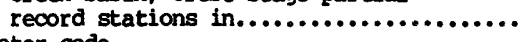

Parameter code................................

Partial-record station, definition of............

Partial-record station and miscellaneous

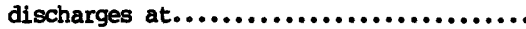

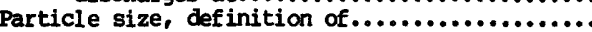
Particle size classification, definition of...... Perry Creek at 38th Street, Sioux City...........

Perry Creek basin, crest-stage partial-

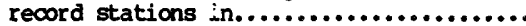

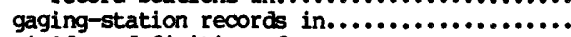

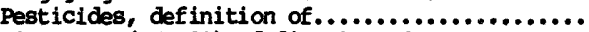

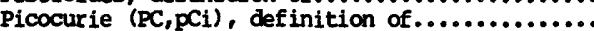

Platte River near Diagonal....................

platte River basin, crest-stage partial-

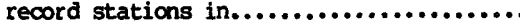

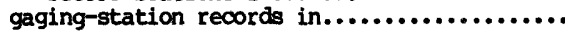
Precipitation water-quality data................ Publications on techniques of water-resources investigations........................

$326-329$

54

Radiochemical program, explanation of............ Raccoon River at Fluer Drive Des Moines........... Raccoon River at Van Meter.................... Ralston Creek, at Iowa City.................... South Branch, at Iowa City................... Rapid Creek near Iowa City $\ldots . . \ldots \ldots \ldots \ldots \ldots \ldots \ldots$ Rathbun Lake near Rathbun....................

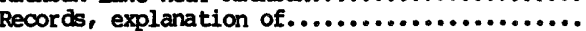
Recoverable from bottom material............... Reservoirs (See lakes and reservoirs)

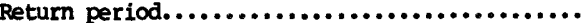

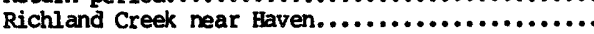

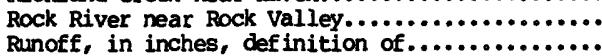

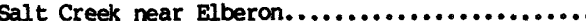
Saylorville Lake near Saylorville..............

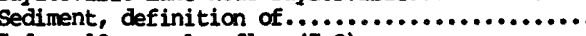

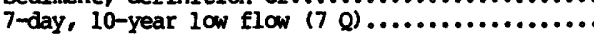

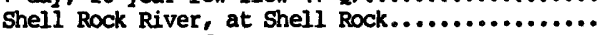

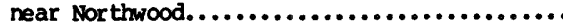
Skunk River at Augusta......................121-126, 249 Skunk River basin, crest-stage partialrecord stations in......................

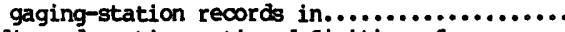
Sodium adsorption ratio, definition of............

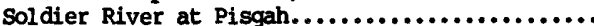
Soldier River basin, crest-stage partial-

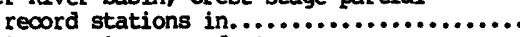

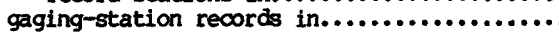
Solute, definition of......................... South Raccoon River at Redfield.................

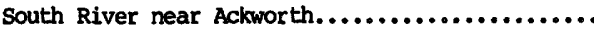
South Skunk River, near Ames...................

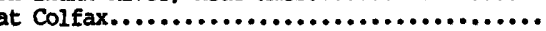
near Oskaloosa..........................

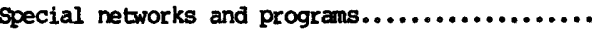
Bydrologic Benchmark Network................. National Stream Quality Accounting Network... National Trends Network....................

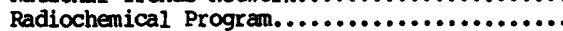
Tritium Network...........................

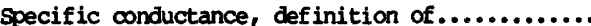

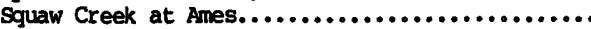
Stage-discharge relation, definition of.......... Stage and water-discharge, records of............. accuracy of the records...................... data collection and computation............... data presentation......................... identifying estimated daily discharge.........

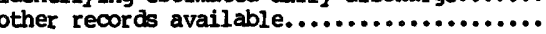

189,256 96,245

222,260

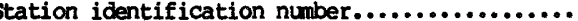
Streamflow, definition of .....................

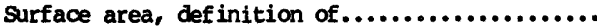

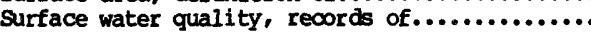
arrangement of records.....................

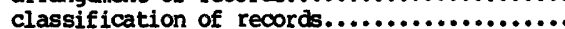

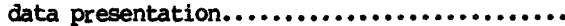

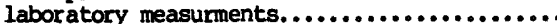
on site measurenents and sample collection... remarks codes...............................

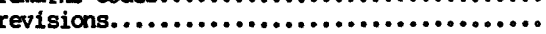
sediment. ............................. water temperature and specific conductance... Surficial bed material, definition of............ suspended, definition of....................... Suspended recoverable......................... Suspended total...............................
48

161,252

$91-94,245$

95,245

84, 244

230

15
48

49

78,243

174,254

79,243

136

49

106,247

103,246

237

116-126

$194, \quad 257$

239

194
50

160,252

167,253

116,248

118, 248

249

14

14

14

14

117,248

50
$18-25$

24-25

$18-20$

20-24 
PAGE

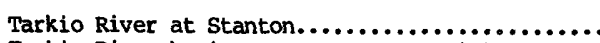

Tarkio River basin, crest-stage partialrecord stations in.....................

gaging-station records in.................

Terms, definition of ......................

Thermograph, def inition of $\ldots \ldots \ldots \ldots \ldots \ldots \ldots \ldots \ldots$

Thompson River at Davis City ...................

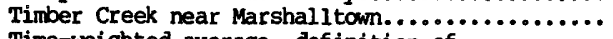

Time-weighted average, definition of .............

Tons per acre-foot, definition of ...............

Tons per day, definition of ...................

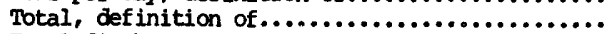

Total discharge...........................

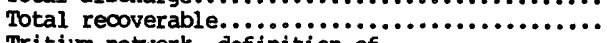

Tritium network, definition of ................

Turkey River, at Garber......................

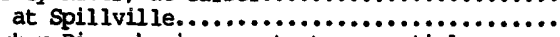

Turkey River basin, crest-stage partial-

reoord stations in.....................

gaging-station records in.................

Upper Iowa River, near Dorchester..............

Upper Iowa River basin, crest-stage

partial-record stations in . . . . . . . . . . .

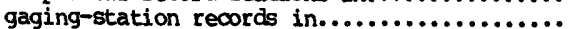

Walnut Creek at Des Moines................... Walnut Creek near Hartwick.....................

Wapsipinicon River, at Independence.............

near De Witt...........................

near Elma..............................

Wapsipinicon River basin, crest-stage

partial records in.

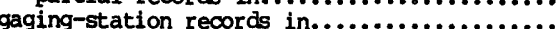

Water-quality, miscellaneous analyses............

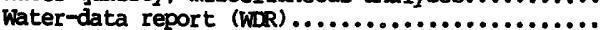

Water-supply papers (WSP), def inition of.........

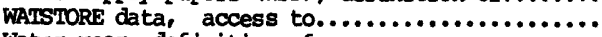

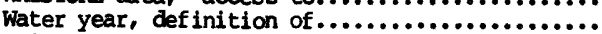

Weighted average, definition of .................

Weldon River near leon. .....................

Wells, ground water, levels and quality

of water data, by county:

Adams county......................

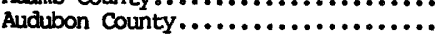

Benton County .....................

Black Hawk county $\ldots \ldots \ldots \ldots \ldots \ldots \ldots \ldots$

Bremer County $. . . . . . \ldots \ldots \ldots \ldots \ldots \ldots . . . .$.

Buchanan County $\ldots \ldots \ldots \ldots \ldots \ldots \ldots \ldots$

Buena vista County $. . . \ldots \ldots \ldots \ldots \ldots . .$.

Butler County ......................

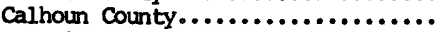

Carroll county....................

Cass county ......................

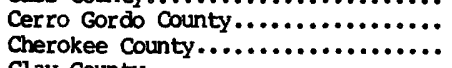

Clay County .......................

Clayton County...................

Clinton county....................

Crawford county ....................

Dallas County.....................

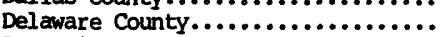

Des Moines County.................
214, 259

240

214

43-53

226,260

77,243

63,241

62,241

233

62-63

57,241

233
57

162,252

80,243

71,242

72,242

70,242

234
$70-72$

241-261

53

53

39
53

53

227,260

298-305

298-305

$262-266,298-305$

298-305

$298-305$
$298-305$

298-305

298-305

267, 298-305

$268,298-305$ 298-305

268-269, 298-305 269-270 298-305

271-272, 298-305

298-305

272, 298-305

298-305

$272, \quad 298-305$
$266-267,298-305$
Dubuque county $. . . \ldots . . . . . . . . .$.

Emmett County.......................

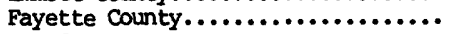

Floyd County.....................

Franklin county..................

Fremont county $\ldots \ldots \ldots \ldots \ldots \ldots \ldots \ldots \ldots$

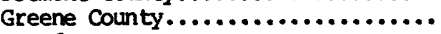

Grundy county...................

Guthrie County.....................

Hamilton County..................

Hancock county $. . . \ldots \ldots \ldots \ldots . . . . . .$.

Hardin county....................

Harrison County...................

Henry County....

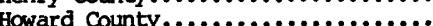

Humboldt coun

Ida County $\ldots \ldots \ldots \ldots \ldots \ldots \ldots \ldots \ldots \ldots$

Ida County $\ldots \ldots \ldots \ldots \ldots \ldots \ldots \ldots \ldots \ldots \ldots$

Jasper County......................

Johnson County ....................

Jones County.....................

Keokuk County ....................

Rossuth County ....................

Lee County .....................

Louisa County.....................

Linn County.......................

Iyon county.

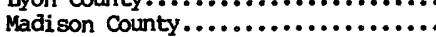

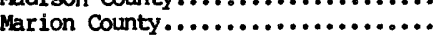

Marshall county...................

Mills County......................

Mitchell county...................

Montgomery County ..................

Muscatine county ...................

O'Brien County .....................

osceola county....................

Page County......................

Palo Alto county $. . . \ldots \ldots \ldots \ldots \ldots \ldots . . . .$.

Plymouth County $\ldots \ldots \ldots \ldots \ldots \ldots \ldots \ldots$

Polk County ........................

Poweshiek County...................

Sac county.......................

scott county $\ldots \ldots \ldots \ldots \ldots \ldots \ldots \ldots \ldots$

Shelby County ....................

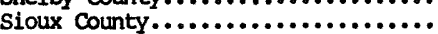

Story County .....................

Tama County.....................

Taylor County $\ldots \ldots \ldots \ldots \ldots \ldots \ldots \ldots \ldots$

Taylor County $\ldots \ldots \ldots \ldots \ldots \ldots \ldots \ldots \ldots$

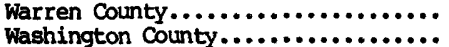

Webster county $\ldots \ldots \ldots \ldots \ldots \ldots \ldots \ldots \ldots . . \ldots \ldots$

Winnebago County...................

Woodbury County ...................

Wor th County.......................

Wright county.....................

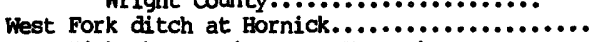

West Nishnabotna River, at Hancock..............

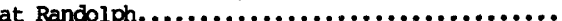

West Okoboji Lake at Lakeside

Laboratory near Milford........

Wexford Creek basin, crest-stage

partial-record stations in.

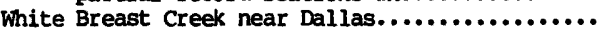

Winnebago River at Mason City..................
PAGE

298-305

273

298-305

$298-313$

306-313

306-313

274, 306-313

$274,306-313$

306-313

$306-313$

306-313

306-313

275, 306-313

306-313

306-313

276, 306-313

277, 306-313

278, 306-313

278-280

$281,306-313$

306-313

306-313

306-313

306-321

281-283

284-285, 314-321

285, 314-321

286 , 314-321

314-321

314-321

$286,314-321$

287, 314-321

287-288, 314-321

$290,314-321$

314-321

$90-291, \quad \begin{aligned} & 314-321 \\ & 314-321\end{aligned}$

314-321

314-321

291-292

292, 314-321

314-321

293, 314-321

$314-321$

$322-325$

$322-325$
$293-294$

95-296, 322-325

322-325

322-325

322-325

322-325

186,256

207,258

208,258

188

233

168,253

104,247 


\section{FACTORS FOR CONVERTING INCH-POUND UNITS TO INTERNATIONAL SYSTEM UNITS (SI)}

The following factors may be used to convert the inch-pound units published herein to the International System of Units (SI). This report contains both the inch-pound and SI unit equivalents in the station manuscript descriptions.

Multiply inch-pound units

By

\section{Length}

inches (in)

feet (ft)

miles (mi)

acres

gallons (gal)

million gallons

cubic feet $\left(\mathrm{ft}^{3}\right)$

acre-feet (acre-ft)

$2.54 \times 10^{1}$

Area square miles $\left(\mathrm{mi}^{2}\right)$

$2.54 \times 10^{-2}$

$3.048 \times 10^{-1}$

$1.609 \times 10^{0}$

$4.047 \times 10^{3}$

$4.047 \times 10^{-1}$

$4.047 \times 10^{-3}$

$2.590 \times 10^{0}$

\section{Volume}

$3.785 \times 10^{0}$

$3.785 \times 10^{0}$

$3.785 \times 10^{-3}$

$3.785 \times 10^{3}$

$3.785 \times 10^{-3}$

$2.832 \times 10^{1}$

$2.832 \times 10^{-2}$

$1.233 \times 10^{3}$

$1.233 \times 10^{-3}$

$1.233 \times 10^{-6}$

Flow

cubic feet per second $\left(\mathrm{ft}^{3} / \mathrm{s}\right)$

gallons per minute (gal/min)

million gallons per day

tons (short)
$2.832 \times 10^{1}$

$2.832 \times 10^{1}$

$2.832 \times 10^{-2}$

$6.309 \times 10^{-2}$

$6.309 \times 10^{-2}$

$6.309 \times 10^{-5}$

$4.381 \times 10^{1}$

$4.381 \times 10^{-2}$

Mass

$9.072 \times 10^{-1}$
To obtain SI units

millimeters (mm)

meters $(\mathrm{m})$

meters (m)

kilometers $(\mathrm{km})$

square meters $\left(\mathrm{m}^{2}\right)$

square hectometers $\left(\mathrm{hm}^{2}\right)$

square kilometers $\left(\mathrm{km}^{2}\right)$

square kilometers $\left(\mathrm{km}^{2}\right)$

\section{liters (L)}

cubic decimeters $\left(\mathrm{dm}^{3}\right)$

cubic meters $\left(\mathrm{m}^{3}\right)$

cubic meters $\left(\mathrm{m}^{3}\right)$

cubic hectometers $\left(\mathrm{hm}^{3}\right)$

cubic decimeters $\left(\mathrm{dm}^{3}\right)$

cubic meters $\left(\mathrm{m}^{3}\right)$

cubic meters $\left(\mathrm{m}^{3}\right)$

cubic hectometers $\left(\mathrm{hm}^{3}\right)$

cubic kilometers $\left(\mathrm{km}^{3}\right)$

\section{liters per second $(\mathrm{L} / \mathrm{s})$}

cubic decimeters per second $\left(\mathrm{dm}^{3} / \mathrm{s}\right)$

cubic meters per second $\left(\mathrm{m}^{3} / \mathrm{s}\right)$

liters per second $(\mathrm{L} / \mathrm{s})$

cubic decimeters per second $\left(\mathrm{dm}^{3} / \mathrm{s}\right)$

cubic meters per second $\left(\mathrm{m}^{3} / \mathrm{s}\right)$

cubic decimeters per second $\left(\mathrm{dm}^{3} / \mathrm{s}\right)$

cubic meters per second $\left(\mathrm{m}^{3} / \mathrm{s}\right)$

megagrams $(\mathrm{Mg})$ or metric tons 
US. DEPARTMENT OF THE INTERIOR

Geological Survey

P.O. Box 1230

lowa City, IA 52244

OFFICIAL BUSINESS

PENALTY FOR PRIVATE USE $\$ 300$

SPECIAL 4TH CLASS BOOK RATE

POSTACE AND FEF

U.S. DEPARTNIENT OF THE INTERIO INT 413
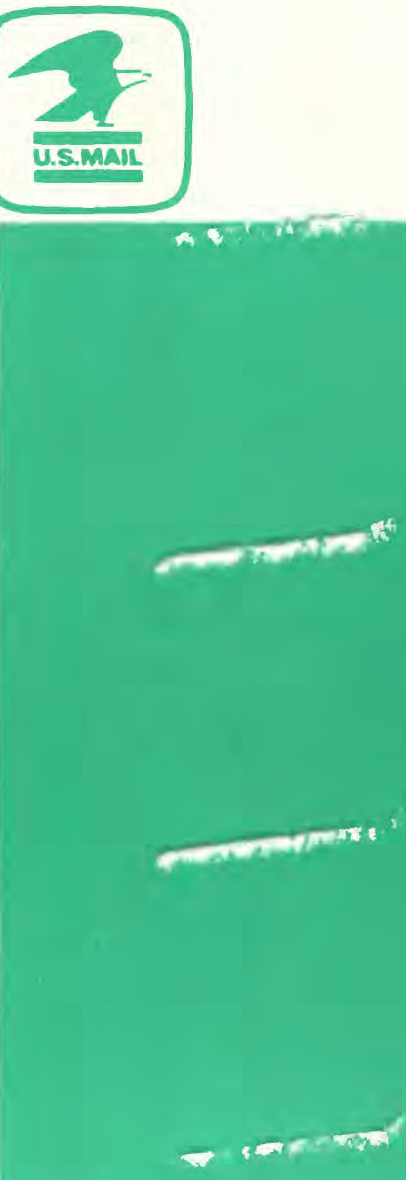

$+\ldots=\mathrm{ne}:$ 